\title{
ห)
}

\section{The Routledge Companion to Free Will}

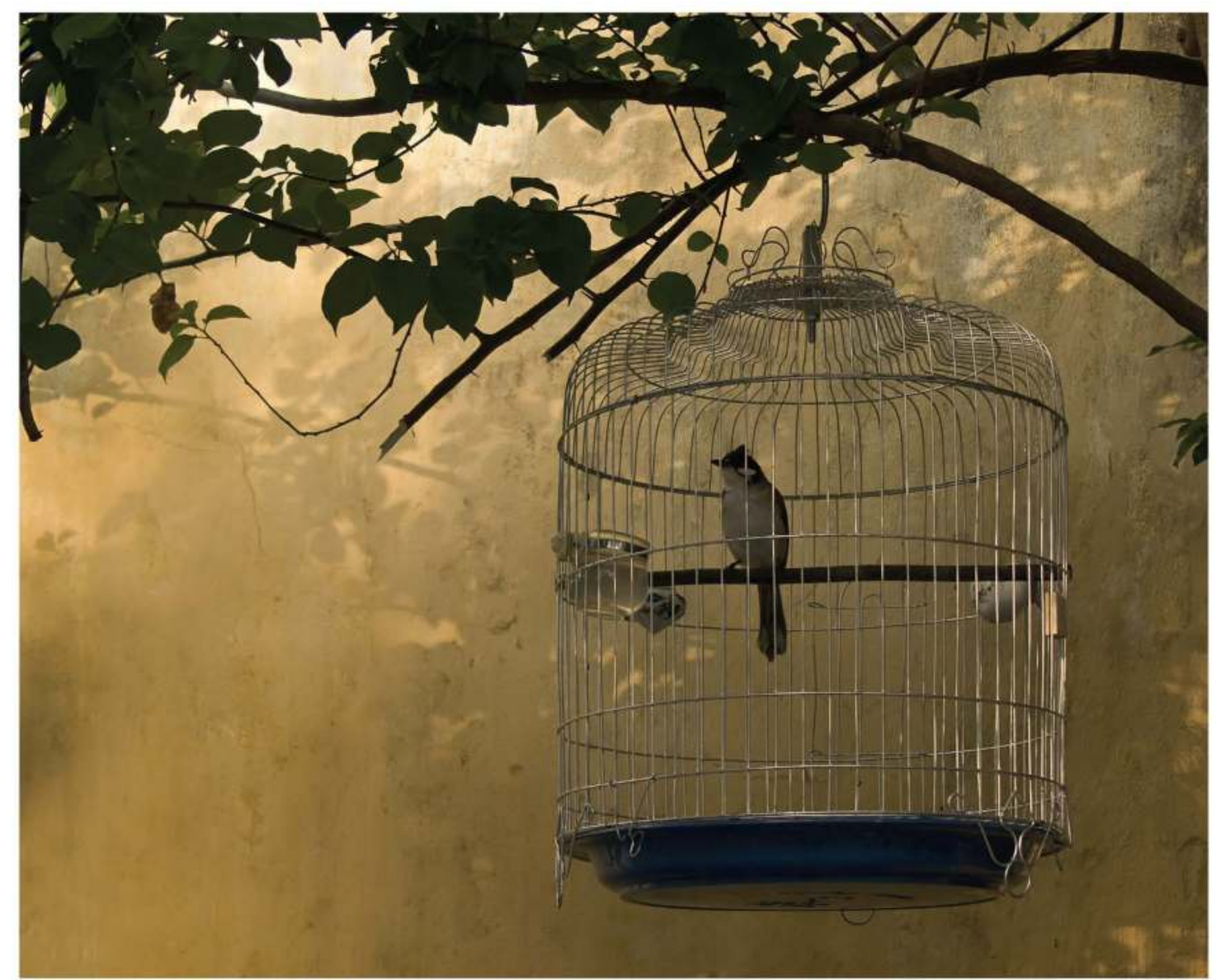

Edited by Kevin Timpe, Meghan Griffith, and Neil Levy 


\section{THE ROUTLEDGE COMPANION TO FREE WILL}

Questions concerning free will are intertwined with issues in almost every area of philosophy, from metaphysics to mind to moral philosophy, and are also informed by work in different areas of science (principally physics, neuroscience and social psychology). Free will is also a perennial concern of serious thinkers, in theology and in non-western traditions as much as in contemporary academic philosophy. Because free will can be approached from so many different perspectives and has implications for so many debates, a comprehensive survey needs to encompass an enormous range of approaches. This book is the first to draw together leading experts on every aspect of the debate, from those who are central to the current philosophical debate, to non-western perspectives, scientific contributions, and the rich history of the debate. Its 61 chapters, commissioned especially for this volume from the world's leading researchers, are framed by a General Introduction and brief section introductions for each of the six sections. A list of References, an annotated Further Reading list, and a short list of Related Topics are included at the end of each chapter.

Kevin Timpe holds the W. H. Jellema Chair in Christian Philosophy at Calvin College. He has published a number of books on free will, including Free Will: Sourcehood and Its Alternatives, Second Edition (2012), Free Will in Philosophical Theology (2013), and Free Will and Theism: Connections, Contingencies, and Concerns (2016).

Meghan Griffith is Associate Professor of Philosophy at Davidson College. She is the author of Free Will: The Basics (2013) and a number of articles centering on human agency.

Neil Levy is Professor of Philosophy at Macquarie University, Sydney, and a senior researcher at the Uehiro Centre for Practical Ethics, University of Oxford. He is the author of seven books, including, most recently, Consciousness and Moral Responsibility (2014). He has published very widely on free will, moral responsibility, philosophy of mind, applied ethics and other topics. 


\section{Routledge Philosophy Companions}

Routledge Philosophy Companions offer thorough, high quality surveys and assessments of the major topics and periods in philosophy. Covering key problems, themes and thinkers, all entries are specially commissioned for each volume and written by leading scholars in the field. Clear, accessible and carefully edited and organised, Routledge Philosophy Companions are indispensable for anyone coming to a major topic or period in philosophy, as well as for the more advanced reader.

The Routledge Companion to Aesthetics, Third Edition

Edited by Berys Gaut and Dominic Lopes

The Routledge Companion to Philosophy of Religion, Second Edition

Edited by Chad Meister and Paul Copan

The Routledge Companion to Philosophy of Science, Second Edition

Edited by Martin Curd and Stathis Psillos

The Routledge Companion to Twentieth Century Philosophy

Edited by Dermot Moran

The Routledge Companion to Philosophy and Film

Edited by Paisley Livingston and Carl Plantinga

The Routledge Companion to Metaphysics

Edited by Robin Le Poidevin, Peter Simons, Andrew McGonigal, and Ross Cameron

The Routledge Companion to Nineteenth Century Philosophy

Edited by Dean Moyar

The Routledge Companion to Ethics

Edited by John Skorupski

The Routledge Companion to Epistemology

Edited by Sven Bernecker and Duncan Pritchard

The Routledge Companion to Philosophy and Music

Edited by Theodore Gracyk and Andrew Kania

The Routledge Companion to Phenomenology

Edited by Søren Overgaard and Sebastian Luft

The Routledge Companion to Philosophy of Language

Edited by Gillian Russell and Delia Graff Fara

The Routledge Companion to Philosophy of Law

Edited by Andrei Marmor

The Routledge Companion to Social and Political Philosophy

Edited by Gerald Gaus and Fred D'Agostino

The Routledge Companion to Ancient Philosophy

Edited by Frisbee Sheffield and James Warren

The Routledge Companion to Eighteenth Century Philosophy

Edited by Aaron Garrett

The Routledge Companion to Hermeneutics

Edited by Jeff Malpas and Hans-Helmuth Gander 
The Routledge Companion to Bioethics

Edited by John Arras, Rebecca Kukla, and Elizabeth Fenton

The Routledge Companion to Virtue Ethics

Edited by Lorraine Besser-Jones and Michael Slote

The Routledge Companion to Islamic Philosophy

Edited by Richard C. Taylor and Luis Xavier López-Farjeat

The Routledge Companion to Philosophy of Literature

Edited by Noël Carroll and John Gibson

For a full list of published Routledge Philosophy Companions, please visit https://www.routledge. com/series/PHILCOMP

\section{Forthcoming:}

The Routledge Companion to Seventeenth Century Philosophy

Edited by Dan Kaufman

The Routledge Companion to Sixteenth Century Philosophy

Edited by Benjamin Hill and Henrik Lagerlund

The Routledge Companion to Thought Experiments

Edited by James Robert Brown; Yiftach Fehige; and Michael T. Stuart

The Routledge Companion to Medieval Philosophy

Edited by Richard Cross and JT Paasch

The Routledge Companion to Philosophy of Race

Edited by Paul C. Taylor, Linda Martín Alcoff, and Luvell Anderson

The Routledge Companion to Environmental Ethics

Edited by Benjamin Hale and Andrew Light

The Routledge Companion to Free Will

Edited by Meghan Griffith, Neil Levy, and Kevin Timpe

The Routledge Companion to Philosophy of Technology

Edited by Joseph Pitt and Ashley Shew Helfin

The Routledge Companion to Feminist Philosophy

Edited by Ann Garry, Serene J. Khader, and Alison Stone

The Routledge Companion to Philosophy of Medicine

Edited by Miriam Solomon, Jeremy R. Simon, and Harold Kincaid

The Routledge Companion to Philosophy of Psychology, Second Edition

Edited by Sarah Robins, John Symons, and Paco Calvo

The Routledge Companion to Shakespeare and Philosophy

Edited by Craig Bourne and Emily Caddick Bourne

The Routledge Companion to the Frankfurt School

Edited by Axel Honneth, Espen Hammer, and Peter Gordon

The Routledge Companion to Philosophy of Social Science

Edited by Lee McIntyre and Alex Rosenberg

The Routledge Companion to Philosophy of Physics

Edited by Eleanor Knox and Alastair Wilson 


\section{PRAISE FOR THE SERIES}

\section{The Routledge Companion to Aesthetics}

'This is an immensely useful book that belongs in every college library and on the bookshelves of all serious students of aesthetics.'-Journal of Aesthetics and Art

\section{Criticism}

'The succinctness and clarity of the essays will make this a source that individuals not familiar with aesthetics will find extremely helpful.' - The Philosophical Quarterly

'An outstanding resource in aesthetics . . . this text will not only serve as a handy reference source for students and faculty alike, but it could also be used as a text for a course in the philosophy of art.'-Australasian Journal of Philosophy

'Attests to the richness of modern aesthetics . . . the essays in central topics - many of which are written by well-known figures - succeed in being informative, balanced and intelligent without being too difficult.'-British Journal of Aesthetics

'This handsome reference volume . . . belongs in every library.'-CHOICE

'The Routledge Companions to Philosophy have proved to be a useful series of high quality surveys of major philosophical topics and this volume is worthy enough to sit with the others on a reference library shelf.'-Philosophy and Religion

\section{The Routledge Companion to Philosophy of Religion}

'. . . a very valuable resource for libraries and serious scholars.'-CHOICE

'The work is sure to be an academic standard for years to come . . . I shall heartily recommend The Routledge Companion to Philosophy of Religion to my students and colleagues and hope that libraries around the country add it to their collections.' -Philosophia Christi

\section{The Routledge Companion to Philosophy of Science}

\section{A CHOICE Outstanding Academic Title 2008}

'With a distinguished list of internationally renowned contributors, an excellent choice of topics in the field, and well-written, well-edited essays throughout, this compendium is an excellent resource. Highly recommended.'-CHOICE

'Highly recommended for history of science and philosophy collections.'-Library Journal

'This well conceived companion, which brings together an impressive collection of distinguished authors, will be invaluable to novices and experienced readers alike.' -Metascience

\section{The Routledge Companion to Twentieth Century Philosophy}

'To describe this volume as ambitious would be a serious understatement. . . full of scholarly rigor, including detailed notes and bibliographies of interest to professional philosophers. ... Summing up: Essential.'-CHOICE 


\section{The Routledge Companion to Philosophy and Film}

'A fascinating, rich volume offering dazzling insights and incisive commentary on every page ... Every serious student of film will want this book ... Summing Up: Highly recommended.'-CHOICE

\section{The Routledge Companion to Philosophy of Psychology}

'This work should serve as the standard reference for those interested in gaining a reliable overview of the burgeoning field of philosophical psychology. Summing Up: Essential.'-CHOICE

\section{The Routledge Companion to Metaphysics}

'The Routledge Philosophy Companions series has a deserved reputation for impressive scope and scholarly value. This volume is no exception ... Summing Up: Highly recommended.'-CHOICE

\section{The Routledge Companion to Nineteenth Century Philosophy}

\section{A CHOICE Outstanding Academic Title 2010}

'This is a crucial resource for advanced undergraduates and faculty of any discipline who are interested in the 19th-century roots of contemporary philosophical problems. Summing Up: Essential.'-CHOICE

\section{The Routledge Companion to Ethics}

'This fine collection merits a place in every university, college, and high school library for its invaluable articles covering a very broad range of topics in ethics[.] ... With its remarkable clarity of writing and its very highly qualified contributors, this volume is must reading for anyone interested in the latest developments in these important areas of thought and practice. Summing Up: Highly recommended.'-CHOICE

\section{The Routledge Companion to Philosophy and Music}

'Comprehensive and authoritative ... readers will discover many excellent articles in this well-organized addition to a growing interdisciplinary field. Summing Up: Highly recommended.'-CHOICE

'... succeeds well in catching the wide-ranging strands of musical theorising and thinking, and performance, and an understanding of the various contexts in which all this takes place.'-Reference Reviews

\section{The Routledge Companion to Phenomenology}

'Sebastian Luft and Søren Overgaard, with the help of over sixty contributors, have captured the excitement of this evolving patchwork named 'phenomenology'. The Routledge Companion to Phenomenology will serve as an invaluable reference volume for students, teachers, and scholars of phenomenology, as well as an accessible introduction to phenomenology for philosophers from other specialties or scholars from other disciplines.'-International Journal of Philosophical Studies

\section{The Routledge Companion to Epistemology}

A CHOICE Outstanding Academic Title 2011. 
'As a series, the Routledge Philosophy Companions has met with near universal acclaim. The expansive volume not only continues the trend but quite possibly sets a new standard. . . . Indeed, this is a definitive resource that will continue to prove its value for a long time to come. Summing Up: Essential.'-CHOICE

\section{The Routledge Companion to Philosophy of Language}

'This collection presents more than 65 new essays by prominent contemporary figures working in the philosophy of language. Collectively, they represent the cutting edge of philosophical research into issues surrounding the use, understanding, and study of language. ... the book constitutes an invaluable current resource for students and scholars alike. It will appeal to anyone interested in the current state-of-play within this important area of philosophical research. Summing Up: Highly recommended.'

\section{- $\mathrm{CHOICE}$}

\section{The Routledge Companion to Social and Political Philosophy}

'This 15th book in the "Routledge Philosophy Companions" series is also the most comprehensive, both chronologically and conceptually. ... . The polish and high quality of the essays provide a multifaceted mirror of the passions and interests of contemporary academic Anglophone philosophy. Summing Up: Highly recommended.'-CHOICE

\section{The Routledge Companion to Ancient Philosophy}

'This excellent reference will be useful to faculty and students alike. . . The essays are of uniformly high quality.'-CHOICE 


\title{
THE ROUTLEDGE COMPANION TO FREE WILL
}

\author{
Edited by Kevin Timpe, \\ Meghan Griffith, \\ and Neil Levy
}


First published 2017

by Routledge

711 Third Avenue, New York, NY 10017

and by Routledge

2 Park Square, Milton Park, Abingdon, Oxon, OX14 4RN

Routledge is an imprint of the Taylor $\mathcal{E}$ Francis Group, an informa business

(C) 2017 Taylor \& Francis

The right of the editors to be identified as the authors of the editorial material, and of the authors for their individual chapters, has been asserted in accordance with sections 77 and 78 of the Copyright, Designs and Patents Act 1988.

With the exception of Chapter 38, no part of this book may be reprinted or reproduced or utilised in any form or by any electronic, mechanical, or other means, now known or hereafter invented, including photocopying and recording, or in any information storage or retrieval system, without permission in writing from the publishers.

Chapter 38 of this book is available for free in PDF format as Open Access from the individual product page at www.routledge.com. It has been made available under a Creative Commons Attribution-Non Commercial-No Derivatives 4.0 license.

Trademark notice: Product or corporate names may be trademarks or registered trademarks, and are used only for identification and explanation without intent to infringe.

Library of Congress Cataloging in Publication Data

A catalog record for this book has been requested

ISBN: 978-1-138-79581-5 (hbk)

ISBN: 978-1-315-75820-6 (ebk)

Typeset in Goudy Oldstyle Std

by Sunrise Setting Ltd, Brixham, UK 


\section{CONTENTS}

List of Contributors $\quad$ xiv

Introduction $\quad \mathrm{xxi}$

\section{SECTION I}

Major Positions in the Free Will Debate 1

1 Semicompatibilism 5

JOHN MARTIN FISCHER

2 Identificationist Views $\quad 15$

AGNIESZKA JAWORSKA

3 Reasons-Responsive Theories of Freedom 27

MICHAEL MCKENNA

4 Classical Compatibilism $\quad 41$

BERNARD BEROFSKY

5 Dispositional Compatibilism $\quad 52$

KADRI VIHVELIN

6 Event-Causal Libertarianism $\quad 62$

LAURA W. EKSTROM

7 Agent Causation $\quad 72$

MEGHAN GRIFFITH

8 Non-Causal Libertarianism $\quad 86$

HUGH J. MCCANN

9 Free Will and Moral Sentiments: Strawsonian Theories 96 PAUL RUSSELL

$\begin{array}{ll}10 \text { Revisionism } & 109\end{array}$

KELLY MCCORMICK

11 Skeptical Views about Free Will

DERK PEREBOOM 
12 Nonstandard Views

SAUL SMILANSKY

SECTION II

Major Arguments

13 The Consequence Argument JOE CAMPBELL

14 The Manipulation Argument KRISTIN MICKELSON

15 Frankfurt-Style Examples

CAROLINA SARTORIO

16 Logical Fatalism

ALICIA FINCH

17 The Luck and Mind Arguments

CHRISTOPHER EVAN FRANKLIN

18 Leeway vs. Sourcehood Conceptions of Free Will

KEVIN TIMPE

\section{SECTION III}

Historical Figures

19 Aristotle

KAREN MARGRETHE NIELSEN

20 The Stoics on Fate and Freedom

TIM O'KEEFE

21 Augustine of Hippo JESSE COUENHOVEN

22 Anselm of Canterbury

SANDRA VISSER

23 Thomas Aquinas

HARM GORIS

24 John Duns Scotus

THOMAS WILLIAMS

25 René Descartes

C. P. RAGLAND 
26 Gottfried Leibniz

JULIA JORÁTI

27 Thomas Hobbes and John Bramhall

A. P. MARTINICH

28 John Locke

ANTONIA LOLORDO

29 David Hume

JOHN BRICKE

30 Thomas Reid

TERENCE CUNEO AND RANDALL HARP

31 Immanuel Kant

BENJAMIN VILHAUER

32 Georg Wilhelm Friedrich Hegel

CHRISTOPHER YEOMANS

33 Friedrich Nietzsche

MATTIA RICCARDI

KAI MARCHAL AND CHRISTIAN HELMUT WENZEL

35 Free Will and Freedom in Indian Philosophies ARINDAM CHAKRABARTI

\section{SECTION IV}

Empirical and Scientific Work

36 Situationism, Social Psychology, and Free Will

CHRISTIAN B. MILLER

37 Neuroscientific Threats to Free Will JOSHUA SHEPHERD

38 Empirical Perspectives on Consciousness and its Relationship to Free Will and Moral Responsibility

NEIL LEVY

39 Willpower, Freedom, and Responsibility 
41 Folk Intuitions

ADAM FELTZ

42 Born Free? Children's Intuitions about Choice

ADAM BEAR AND PAUL BLOOM

\section{SECTION V}

Free Will and Theology

43 Free Will and the Problem of Evil DANIEL SPEAK

44 Free Will and Theological Fatalism

45 Free Will and Theological Determinism LEIGH VICENS

46 Free Will and Substance Dualism STEWART GOETZ

47 Free Will and Grace

TIMOTHY PAWL

48 Free Will and Providence KEN PERSZYK

49 Divine Free Will

T. J. MAWSON

\section{SECTION VI}

Special Topics

50 Self-Control and Akrasia

51 Free Will and Criminal Law

ERIN KELLY

52 Deliberation

E. J. COFFMAN

53 Blame

600

DANA KAY NELKIN

54 The Relationship between Moral Responsibility and Freedom BENJAMIN ROSSI AND TED A. WARFIELD 
55 A Feminist Approach to Moral Responsibility MARINA OSHANA

56 Free Will and the Phenomenology of Agency

TIM BAYNE

57 Mental Causation

REBEKAH L. H. RICE

58 Marginal Agents and Responsibility Pluralism DAVID SHOEMAKER

59 Determinism

CHARLOTTE WERNDL

60 Free Will and Time Travel

NEAL A. TOGNAZZINI

Index

691 


\section{CONTRIBUTORS}

Tim Bayne, a native of New Zealand, did his undergraduate degree at the University of Otago and a doctorate in philosophy at the University of Arizona. He is the author of The Unity of Consciousness (2012) and A Very Short Introduction to Thought (2013). He is currently an ARC Future Fellow at Monash University in Melbourne.

Adam Bear is a third-year Ph.D. student in Psychology at Yale University. His main research explores the interplay between unconscious, intuitive mental processes and conscious, deliberative processes across a variety of domains, including cooperation, choice, and visual perception. His current work considers not only how the mind makes use of both kinds of cognition, but also why we would evolve to do so in the first place.

Bernard Berofsky is Professor Emeritus at Columbia University. He is the author of Nature's Challenge to Free Will (2012), Liberation from Self (1995), and other books and articles on the subject of free will. He has also taught at the University of Michigan, Vassar College, and the Hebrew University of Jerusalem.

Paul Bloom is the Brooks and Suzanne Regan Professor of Psychology and Cognitive Science at Yale University. His interests include questions about morality and how it develops; intuitions about personal identity, free will, and the self; the origin of religious belief; and the strange pleasure we get from fiction and art.

John Bricke, Professor Emeritus of Philosophy, University of Kansas, is the author of two book-length studies of Hume: Hume's Philosophy of Mind (1980) and Mind and Morality: An Examination of Hume's Moral Psychology (1996).

Joe Campbell has published in Philosophical Studies, Analysis, and International Journal for the Study of Skepticism. He is Metaphysics Editor of the Internet Encyclopedia of Philosophy, a co-founder of the Inland Northwest Philosophy Conference, and is working on his ninth edited book volume.

Arindam Chakrabarti obtained a D.Phil, in 1982, supervised by Peter Strawson and Michael Dummett at Oxford, subsequently receiving training in Sanskrit Nyaya Logic and Epistemology. Since 1997, he has been Professor of Philosophy at the University of Hawaii Manoa, where he currently directs the program on Eastern Philosophy of Consciousness and the Humanities (EPOCH).

E. J. Coffman is Associate Professor of Philosophy at the University of Tennessee -Knoxville, USA. He works in epistemology and philosophy of action. His 


\section{CONTRIBUTORS}

publications in these areas include several papers as well as Luck: Its Nature and Significance for Human Knowledge and Agency (2015).

Jesse Couenhoven is Associate Professor of Moral Theology in the Department of Humanities and Augustinian Traditions at Villanova University. He is currently finishing an introduction to the doctrine of predestination and the ideas of free will historically associated with it.

Terence Cuneo is Marsh Professor of Intellectual and Moral Philosophy at the University of Vermont. He is the author of The Normative Web (2007), Speech and Morality (2015), and Ritualized Faith (2016).

Laura W. Ekstrom is Class of 2016 Professor of Philosophy at the College of William \& Mary. She is the author of Free Will: A Philosophical Study, editor of Agency and Responsibility, and has published articles on autonomy, free agency, moral responsibility, and the problem of evil.

Adam Feltz is an Assistant Professor of Psychology and Applied Ethics at Michigan Technological University. He directs the Ethical Decision-making and Ethical Naturalism lab and is co-founder and co-managing director of RiskLiteracy.org.

Alicia Finch is Associate Professor of Philosophy at Northern Illinois University. Her research is focused on the metaphysics of free will and moral responsibility, moral psychology, and philosophy of religion.

John Martin Fischer is Distinguished Professor of Philosophy at the University of California, Riverside, where he has held a University of California President's Chair. He is past president of the American Philosophical Association, Pacific Division, and he was Project Leader, the Immortality Project (John Templeton Foundation).

Christopher Evan Franklin is an Assistant Professor of Philosophy at Grove City College. His research focuses on issues in ethics, metaphysics and philosophy of action. His publications have appeared in Australasian Journal of Philosophy, Mind, Pacific Philosophical Quarterly, and Philosophical Studies, among other venues.

Stewart Goetz is Professor of Philosophy at Ursinus College. His books include Freedom, Teleology, and Evil, The Purpose of Life, A Brief History of the Soul (co-written with Charles Taliaferro), and The Soul Hypothesis (co-edited with Mark Baker).

Harm Goris teaches systematic theology at the School of Catholic Theology of Tilburg University, the Netherlands and is a member of the Thomas Institute at Utrecht, the Netherlands. He specializes in the thought of Thomas Aquinas.

Meghan Griffith is Associate Professor of Philosophy at Davidson College. She is the author of Free Will: The Basics (2013) and a number of articles centering on human agency.

Randall Harp is Assistant Professor of Philosophy at the University of Vermont. His research interests include the philosophy of action, moral psychology, social ontology, and philosophy of social science. 


\section{CONTRIBUTORS}

David P. Hunt is Professor of Philosophy at Whittier College, adjunct professor at Talbot School of Theology, and two-time fellow at Notre Dame's Center for Philosophy of Religion. His fifty scholarly articles cover the theistic concept of God, the metaphysics of agency, ancient philosophy, and (of course) The Matrix.

Agnieszka Jaworska is Associate Professor of Philosophy at University of California, Riverside. Her research on the nature of the specifically human agency focuses on individuals whose status as persons seems compromised, such as Alzheimer's patients, addicts, psychopaths, and young children.

Julia Joráti is Assistant Professor of Philosophy at the Ohio State University and works mainly on the history of early modern philosophy. She has authored several articles about Leibniz and recently completed a book manuscript on Leibniz's philosophy of action.

Erin Kelly is Associate Professor of Philosophy at Tufts University, where she teaches ethics, political philosophy, and the philosophy of law. Her research focuses on questions about justice, the nature of moral reasons, moral responsibility and desert, and theories of punishment.

Neil Levy is Professor of Philosophy at Macquarie University, and at the Oxford Centre for Neuroethics. He has published seven books and more than 150 papers on free will and moral responsibility, philosophy of mind, applied ethics and other topics. His most recent book is Consciousness and Moral Responsibility (2014).

Antonia LoLordo is Professor of Philosophy at the University of Virginia. She is the author of Locke's Moral Man (2012) and Pierre Gassendi and the Birth of Early Modern Philosophy (2007), as well as the co-editor of Debates in Modern Philosophy (Routledge, 2013). She has published articles on Descartes, Edwards, Gassendi, Hume, Locke, and Malebranche, and is a section editor for Ergo.

Hugh J. McCann was Professor of Philosophy at Texas A\&M University. He was the author of The Works of Agency, and Creation and the Sovereignty of God, as well as numerous papers in the areas of action theory, philosophy of religion, and related topics in ethics and metaphysics.

Kelly McCormick is Assistant Professor of Philosophy at Texas Christian University. Her work lies at the intersection of metaphysics and ethics, focusing primarily on issues surrounding revisionism, basic desert, moral blame, and the proper role of intuition in responsibility theorizing.

Michael McKenna is Professor of Philosophy and the Keith Lehrer Chair in the Department of Philosophy and the Center for the Philosophy of Freedom. He is the author of Conversation and Responsibility (2012) and numerous articles on free will and moral responsibility.

Kai Marchal studied sinology and philosophy in Heidelberg, Paris, and Beijing and received his Ph.D. from the University of Munich in 2006. He is Associate 


\section{CONTRIBUTORS}

Professor in the Department of Philosophy at Soochow University, Taipei. He is working at the intersections of ethics, political philosophy, and traditional Chinese philosophy.

A. P. Martinich is Roy Allison Vaughan Centennial Professor in Philosophy and Professor of History and Government at the University of Texas at Austin, He is the author of The Two Gods of Leviathan (1992), Hobbes: A Biography (1999), and Hobbes (Routledge, 2005), and co-editor with Kinch Hoekstra of The Oxford Handbook of Hobbes (2016).

T. J. Mawson's university education was at Oxford and he has stayed there since; he is currently Edgar Jones Fellow in Philosophy at St Peter's College. He tries to keep up-to-date the list of his publications that is available on his Faculty webpage.

Kristin Mickelson is currently a postdoctoral fellow with the Gothenburg Responsibility Project and Department of Philosophy, Linguistics, and Theory of Science at the University of Gothenburg; she otherwise serves as a Visiting Assistant Professor at the University of Minnesota, Morris. She is primarily interested in the metaphysics of autonomy, broadly construed to include free will, mental causation, and personal identity. Her work appears in Australasian Journal Philosophy, Philosophical Studies, and Canadian Journal of Philosophy.

Christian B. Miller is Professor of Philosophy at Wake Forest University and Director of the Character Project (www.thecharacterproject.com). He is the author of over 75 papers as well as two books, Moral Character: An Empirical Theory (2013) and Character and Moral Psychology (2014).

Dana Kay Nelkin is Professor of Philosophy at the University of California, San Diego. She is the author of Making Sense of Freedom and Responsibility, and a number of articles on a variety of topics, including free will, moral principles, self-deception, and rationality.

Karen Margrethe Nielsen is Associate Professor in the Faculty of Philosophy at the University of Oxford and a Fellow of Somerville College. Her papers have appeared in The Philosophical Review, Classical Quarterly, Phronesis, and Antiquorum Philosophia, in addition to a number of edited volumes.

T. J. O’Keefe is Associate Professor of Philosophy at Georgia State University. He has published two books (Epicurus on Freedom and Epicureanism) and papers on the Epicureans, the Pyrrhonian skeptics, the Cyrenaics, Aristotle's cosmology, and the spurious Platonic dialogue the Axiochus.

Marina Oshana is Professor of Philosophy at the University of California, Davis. Professor Oshana's research focuses on issues in personal autonomy, responsible agency, and self-identity. She teaches classes in normative ethics, moral psychology, philosophy of law, and feminism. Her publications include Personal Autonomy in Society (Ashgate 2006) and The Importance of How We See 
Ourselves: Self-Identity and Responsible Agency (Rowman and Littlefield 2010). She is editor of Personal Autonomy and Social Oppression: Philosophical Perspectives (Routledge 2014).

Timothy Pawl is Associate Professor in the Department of Philosophy at the University of St. Thomas. He works on metaphysics and philosophical theology. Some places where his work has appeared include: The Australasian Journal of Philosophy, Faith and Philosophy, and Oxford Studies in Philosophy of Religion.

Derk Pereboom (Ph.D. UCLA) is the Susan Linn Sage Professor of Philosophy and Ethics at Cornell University. His areas of research include free will and moral responsibility, philosophy of mind, eighteenth century philosophy, and philosophy of religion. He is the author of Living without Free Will (2001), Consciousness and the Prospects of Physicalism (2011), and Free Will, Agency, and Meaning in Life (2014). He has published articles on free will and moral responsibility, philosophy of mind, Kant, and the problem of evil.

Ken Perszyk is Associate Professor at the University of Waikato, and Academic Director of the Tauranga CBD Campus Development. He is the editor of Molinism: The Contemporary Debate (2011) and is currently writing a book with John Bishop on the 'euteleological' conception of God.

Hanna Pickard is Reader in Philosophy at the University of Birmingham and a Fellow of All Souls College. She has also worked for many years in an NHS Therapeutic Community for people with personality disorder and complex needs.

C. P. Ragland is Associate Professor of Philosophy at Saint Louis University. His research focuses on the history of modern philosophy and the philosophy of religion. He is the co-editor of What is Philosophy? (2001) and author of The Will to Reason: Theodicy and Freedom in Descartes (2016).

Mattia Riccardi (Ph.D. Humboldt University, Berlin) is assistant professor at Bonn University. He works in the history of modern philosophy, in particular Kant and Nietzsche, and in the philosophy of mind.

Rebekah L. H. Rice is Associate Professor of Philosophy at Seattle Pacific University. She holds a Ph.D. from Brown University and works primarily in action theory, metaphysics, and the philosophy of mind.

Benjamin Rossi is a Ph.D. candidate at the University of Notre Dame where he is completing a dissertation on internal and external practical reasons. His main interests are in metaethics and philosophy of action and he has published papers on philosophy of action and moral responsibility.

Paul Russell is Professor of Philosophy at the University of British Columbia and the University of Gothenburg, where he is also Director of the Gothenburg Responsibility Project. He is the author of a number of books and articles including The Limits of Free Will: Selected Papers, forthcoming in 2016. 


\section{CONTRIBUTORS}

Carolina Sartorio received her Ph.D. in Philosophy from the Massachusetts Institute of Technology in 2003, and is currently Associate Professor of Philosophy at the University of Arizona. She is the author of Causation and Free Will (2016).

Joshua Shepherd is a Wellcome Trust Research Fellow at the University of Oxford, a Junior Research Fellow of Jesus College, and a James Martin Fellow at the Oxford Martin School. He works on issues in the philosophy of mind, action, cognitive science, and moral psychology.

David Shoemaker is Professor in the Department of Philosophy \& Murphy Institute at Tulane University. He works on agency, responsibility, moral psychology, and personal identity and ethics. His book Responsibility from the Margins was published in 2015 by Oxford University Press, and he edits Oxford Studies in Agency and Responsibility.

Saul Smilansky is Professor and Chair of the Department of Philosophy, University of Haifa, Israel. He is the author of Free Will and Illusion (2000), 10 Moral Paradoxes (2007), and numerous papers in philosophical journals.

Daniel Speak is Professor of Philosophy at Loyola Marymount University. He continues to think and write about free will, God, and the problems of evil (among other things).

Chandra Sripada is Associate Professor of Philosophy and Psychiatry at the University of Michigan and works on issues of agency, responsibility, and self-control from cross-disciplinary perspectives.

Christine Tappolet is Professor of Philosophy at the Universite de Montréal. Her research interests lie mainly in meta-ethics, moral psychology, and emotion theory. She has edited a number of volumes, including, with Sarah Stroud, Weakness of Will and Practical Irrationality (2003), and with Luc Faucher, The Modularity of Emotions (2008, Canadian Journal of Philosophy, supp. Vol. 32). She is the author of Émotions et valeurs (2000) and Emotions, Values, and Agency (2016).

Kevin Timpe holds the W. H. Jellema Chair in Christian Philosophy at Calvin College. He has published a number of books on free will, including Free Will: Sourcehood and Its Alternatives, Second Edition (2012) and Free Will in Philosophical Theology (2013).

Neal A. Tognazzini is an Assistant Professor of Philosophy at Western Washington University. He works at the intersection of metaphysics and ethics on issues of human agency. He is co-editor of Blame: Its Nature and Norms (2014).

Leigh Vicens is Assistant Professor of Philosophy at Augustana University in Sioux Falls, SD. Her areas of specialization include philosophy of religion, mind, and action.

Kadri Vihvelin is Professor of Philosophy at the University of Southern California. Her research interests include free will, determinism, causation, counterfactuals, and 


\section{CONTRIBUTORS}

time travel. Her book, Causes, Laws, and Free Will: Why Determinism Doesn't Matter, was published in 2013 by Oxford University Press.

Benjamin Vilhauer is Associate Professor and Chair at the City College of New York. He works on Kant's theory of free will and on contemporary free will skepticism.

Sandra Visser is Professor of Philosophy at Valparaiso University. She is co-author with Thomas Williams of Anselm (2009) and the author of several articles on Anselm and free will.

Ted A. Warfield is Professor of Philosophy at the University of Notre Dame. His teaching and research range widely over the problem areas of contemporary philosophy with special attention to epistemology and philosophy of action.

Christian Helmut Wenzel studied mathematics and philosophy in the USA and in Germany. He received a Ph.D. in both, on algebraic geometry 1990, and on Kant's aesthetics 1999. He is Distinguished Professor at National Taiwan University, working on Kant, philosophy of language, aesthetics, and free will.

Charlotte Werndl is Professor of Logic and Philosophy of Science at the Department of Philosophy at the University of Salzburg, and a Visiting Professor at the London School of Economics. Previously, she was an Associate Professor at the London School of Economics, before that a research fellow at the University of Oxford, and she completed her Ph.D. at the University of Cambridge.

Thomas Williams is Professor of Philosophy at the University of South Florida. He is editor of The Cambridge Companion to Duns Scotus (2002), co-editor of Philosophy in the Middle Ages, Third Edition (2010) and co-author (with Sandra Visser) of Anselm (2009).

Christopher Yeomans is Professor of Philosophy at Purdue University, and the author of Freedom and Reflection: Hegel and the Logic of Agency (2011) and The Expansion of Autonomy: Hegel's Pluralistic Philosophy of Action (2015). He works on German philosophy, philosophy of action, and critical theory. 


\section{INTRODUCTION}

The free will debate is sometimes regarded as a debate within metaphysics, and sometimes as a debate within ethics; occasionally, it is even categorized as a debate within philosophy of mind. Which kind of debate is it? It's probably best not to think of it as a debate, but as a cluster of debates, the exact boundaries of which are themselves debated. For many of the most active participants, however, it is best seen as a sub-field of philosophy in its own right; one which is so exciting and vibrant because it draws upon and helps in turn to illuminate issues in so many different areas of philosophy. The debates are broad, inasmuch as they draw on expertise across philosophy and beyond.

Moreover, free will matters; it is this fact that explains why so many people are drawn to it. Many philosophers believe that we can deserve to be praised, blamed, or punished only if we have free will: the legitimacy of our criminal justice might therefore depend (in part) on whether we are free. It is also plausible to think that other great goods depend in part on free will; deliberation, love, friendship, our conception of ourselves as rational agents, pride in our achievements, and shame or guilt at our failings might all stand or fall with free will. The connections between free will and these goods are intuitively grasped by nearly everyone; for that reason, free will debates are of enormous interest to people outside philosophy, including scientists and the general public. The breadth of the field, its vibrancy, and its philosophical and quotidian significance amply justify a volume devoted to surveying its most important topics, the major arguments and positions, the historical figures that have helped shape it, and its connections to other related issues in philosophy, theology, and various sciences. This volume aims to accomplish all that and more.

In putting together this collection, we have attempted to treat the breadth and importance of the central questions in the free will debate with the seriousness they deserve. The volume is broken down into six sections, although there are significant interactions across each section. Each chapter is new, but intentionally draws on the existing literature to be a conduit through which the reader can access other scholarship. The authors aim to map the landscape of current debates and enable readers to understand the contemporary state of play. But the authors have also been encouraged to pursue their themes in new directions, seeking unexplored connections and laying out proposals for future research and new arguments. Each chapter ends with suggestions for further reading as well as a list of the other chapters in the present volume that will likely be of greatest interest to the reader. The volume thus serves both as an advanced introduction and as a guide for specialists who want to continue to contribute to the free will debates.

We would like to express our gratitude to the staff at Routledge for their support and patience in putting together this volume and seeing it through to completion. In particular, we would like to thank Andy Beck for trusting us with a project of this 


\section{INTRODUCTION}

magnitude and Elizabeth Vogt for her help in seeing the manuscript through to completion. We would also like to express our gratitude to the contributors-without whom, of course, this collection wouldn't exist—and our universities for their support of our scholarly endeavors.

K.T.

M.G.

N.L. 


\section{Section I}

\section{MAJOR POSITIONS IN THE FREE WILL DEBATE}

To the uninitiated, it might seem puzzling to see so many chapters on major positions in the free will debate. After all, shouldn't there only be two positions? We have free will, or we do not. But as with most philosophical puzzles, matters are not so simple. While many philosophers working on the problem of free will are motivated by the 'do we' or 'don't we' question, they also recognize that we cannot answer whether we have free will if we are not clear on what it is, what its conditions are, and how it might work. Thus, the major positions in the free will debate also involve careful attempts to answer these sorts of questions.

One vital question is whether free will is compatible with determinism. If determinism turns out to be true- that is, if the laws of nature and history of the world dictate exactly what will occur, including all events associated with our actions-then we might wonder whether free will is possible. Incompatibilists believe that determinism would rule out free will. Compatibilists think that it would not. Although there are a number of important arguments on the compatibility question, we can save discussion of these for the next section. Here the focus is on laying out the details of various positions. What kinds of conditions are central such that determinism is or is not a threat? How do such conditions map onto the intuitions and practices surrounding free will? How ought we to understand the concept of free will?

Some compatibilists argue that free will centrally involves an ability to do what one wants, free of external obstacles. 'Classical compatibilists' (e.g., Hobbes, Locke, Mill, Hume, early twentieth-century thinkers such as G.E. Moore) seemed to "agree that freedom is at least partly constituted by a disposition to will or act on one's own desires rather than forces external to us" (Berofsky, this volume, page 43). Even if determinism is true, it seems undeniable that we often do what we want. Although some of those adopting this dispositional view (e.g., Hobbes) do not think free will requires an ability to do otherwise, others use the dispositional account to preserve the purportedly common-sense notion of alternative possibilities. On contemporary dispositional views, for example, free will is understood in terms of causal powers, "which differ in complexity but not in kind from dispositions like fragility, elasticity, and flammability" (Vihvelin, this volume, page 56). As Vihvelin argues, dispositions exist even when not manifested. So even if determinism is true, an agent does not "lose her power to decide to do one thing just because she makes another decision instead" (Vihvelin, this volume, page 56). 
Other compatibilists, however, focus their accounts on internal motivational structures. As Agniezska Jaworska suggests, if the classical compatibilist can be seen as claiming that one is free so long as one is doing what one wants, the identificationist modifies this approach to account for troublesome internal obstacles (e.g., addictive, obsessive, or phobic desires (Jaworska, this volume, page 15)). According to the identificationist, "one is free to the extent that one is able to do what one truly wants to do, where true wants are understood as desires with which the agent identifies" (15). Notice that identification with a desire does not appear to conflict with determinism.

Incompatibilists who believe we have free will are called 'libertarians.' Various libertarian theories have been offered, differing in their characterizations of the causes of free activity. Event-causal libertarians argue that free acts or decisions are caused but that such causation is not deterministic. On these views, there must be indeterminism in the process at some specific point along the way (particular event-causal views differ about where this must occur). Agent-causal views (which are usually but not always libertarian), argue that the free decision or action must be caused by the agent as a substance rather than in virtue of events inside of him. Noncausal views argue that free will is a truly spontaneous activity, although not an activity without explanation or control. Free will skeptics are often incompatibilists who think we do not have free will. Frequently the skepticism arises, not just as a result of concerns about determinism turning out to be true, but as a result of concerns that genuine agency is implausible or even impossible regardless of the status of determinism.

In many instances, concerns about moral responsibility play a vital role in the development and defense of the major positions. We want to know whether we are morally responsible for our choices and actions, and moral responsibility seems to require free will (among other things). Does determinism rule out the kind of power or control we would need to have in order to be responsible? Reasons-responsive compatibilist views, for example, suggest that it does not. On this view, moral responsibility requires that agents are appropriately sensitive to reasons when they act. This sensitivity appears to be compatible with determinism. Strawsonian theories make our natural 'reactive attitudes' central to responsibility and argue that determinism does not threaten them. Some free will skeptics such as Derk Pereboom, on the other hand, argue that because free will is implausible, no one is morally responsible in a 'basic desert sense.' And the revisionist argues that, although there are implausible elements in our concept of moral responsibility (freedom-related components in particular), this means that we ought to revise our concept rather than dismissing it altogether or concluding that moral responsibility cannot be preserved.

Although moral responsibility is quite central, it is important to note that the compatibility of moral responsibility and determinism may not be the same as the compatibility of freedom and determinism. On John Fischer's important 'semicompatibilist' view, for example, moral responsibility and determinism are held to be compatible but it is left open whether free will (in the sense of being able to do otherwise) is compatible or incompatible with determinism. This is because moral responsibility, on Fischer's view, does not require freedom to do otherwise, (though it does require freedom to guide one's own behavior). Also, it is worth pointing out that some free will skeptics, like Pereboom, still allow for moral responsibility of a forward-looking sort.

At this point, one might suppose the possible positions on free will have been exhausted. Not so! As Saul Smilansky offers, there are a number of interesting nonstandard positions. Smilansky characterizes standard views as 
those that are (i) distinctly libertarian, compatibilist, or hard determinist (or otherwise free-will-denying) positions, (ii) more or less within the paradigmatic view that takes free will to be a condition for moral responsibility, which is, in turn, a condition for desert, blame, and praise and other related beliefs, attitudes, and practices (Smilansky, this volume, pages 136-7).

He then discusses a number of views, including his 'illusionist' position, that differ along various dimensions from these standard positions.

So one can see by looking through this section of our volume that there are far more than two positions one might take on the problem of free will. In fact, although we have aimed to represent the major positions, both standard and nonstandard, there are still other possibilities. Perhaps some of these possibilities have not even been canvassed yet and will, in future generations, come to constitute new facets of an already multifaceted (and fascinating) debate.

M.G. 
$\because$ Taylor \& Francis Taylor \& Francis Group http://taylorandfrancis.com 


\section{1 \\ SEMICOMPATIBILISM John Martin Fischer}

Semicompatibilism is a claim about the relationship between various different doctrines, including God's foreknowledge of human behavior and causal determinism, on the one hand, and moral responsibility, on the other. As regards God's foreknowledge, semicompatibilism is the view that God's foreknowledge is compatible with moral responsibility, quite apart from whether God's foreknowledge rules out freedom to do otherwise. Although semicompatibilism does not take a stand on whether God's foreknowledge rules out human freedom to do otherwise, it follows from semicompatibilism that God's foreknowledge would be compatible with moral responsibility, even if it did rule out human freedom to do otherwise. Similarly, as regards causal determinism, semicompatibilism is the view that causal determinism is compatible with moral responsibility, quite apart from whether causal determinism rules out freedom to do otherwise. Again, semicompatibilism does not take a stand on whether causal determinism rules out freedom to do otherwise; it is thus consistent with both classical compatibilism (which, I take it, holds that causal determinism is compatible with freedom to do otherwise) and the rejection of classical compatiblism. A crucial element of the doctrine of semicompatibilism is that the compatibility of causal determinism and moral responsibility does not hinge on the compatibility of causal determinism and freedom to do otherwise. More specifically, the semicompatibilist holds that causal determinism would be compatible with moral responsibility, even if causal determinism were to rule out freedom to do otherwise.

Here my primary focus will be on the doctrine of semicompatibilism as it applies to causal determinism. What is the attraction of semicompatibilism? First, compatiblism in general (including classical compatibilism) is attractive because it would allow us to continue believing that we are morally responsible, even if in the future we were to be convinced that causal determinism is true. Our status as morally responsible agents would thus not 'hang on a thread' in this sense: it would not depend on whether or not causal determinism is true, that is, whether the laws of nature have attached to them 100 percent objective probabilities or (say) 90 percent objective probabilities. We typically make distinctions in the law and in morality between individuals who have been coerced and those who have not. Indeed, we distinguish between agents who have been manipulated (in certain ways), brainwashed, deceived, subject to clandestine subliminal advertising, and so forth, and those who are morally responsible. If causal determinism were true along with incompatibilism about causal determinism and moral 
responsibility, we would not be able to maintain these sorts of distinctions; no one would be morally responsible.

I think there is considerable appeal in protecting our status as morally responsible agents from the issue of whether the laws of nature are deterministic or probabilistic. But whereas compatibilism in general secures the protection in question, I believe that semicompatibilism is more attractive than classical compatibilism. Whereas classical compatibilism has to argue that causal determinism is consistent with freedom to do otherwise, semicompatibilism need not. I believe that this is a significant advantage of semicompatibilism, because I believe that there is strong reason to hold that causal determinism rules out freedom to do otherwise (in the sense relevant to moral responsibility). Of course, it could turn out that causal determinism is incompatible with moral responsibility for some reason other than the fact (if it is a fact) that it rules out freedom to do otherwise. But I contend that the argument for the incompatibility of causal determinism and freedom to do otherwise is considerably stronger than the argument for the contention that causal determinism is incompatible with moral responsibility for some other reason, that is, apart from issues pertaining to access to alternative possibilities.

Semicompatibilism thus shifts the focus from more incompatibilist-friendly to more compatibilist-friendly terrain. This is a big deal, especially because philosophers have been debating about the relationship between causal determinism and freedom to do otherwise for centuries. (Similarly, philosophers and theologians have been debating about the relationship between God's foreknowledge and human freedom to do otherwise for millennia.)

There is a powerful argument for the incompatibility of causal determinism and freedom to do otherwise. Peter van Inwagen dubbed this argument, "the Consequence Argument," because it proceeds from the fact that under causal determinism, all our behavior is a consequence of the past and laws of nature (van Inwagen 1983). I will now give a sketch of the argument. Suppose that causal determinism is true and I raise my coffee cup at $t 2$. It follows from the fact that causal determinism obtains that conditions of the universe at a prior time, $t 1$, together with the laws of nature, entail that I raise my coffee cup at $t 2$. So if I were to refrain from raising my coffee cup at $t 2$, either the past would have been different from what it actually was or the laws of nature would be different from what they are. But I cannot ever so act that the past would have been different from what it was: the past is in this sense 'fixed' and out of my control. And I cannot so act that the natural laws would be different from what they are: the natural laws are fixed and out of my control. Thus, it is not in my power just prior to $t 2$ (or at $t 2$ ) to do otherwise, that is, to refrain from picking up my coffee cup at $t 2$. And it is obvious that this argument generalizes to any action, under the assumption of causal determinism.

The fundamental drivers of the Consequence Argument are the intuitive ideas of the fixity of the past and the fixity of the laws of nature. There is an argument for theological incompatibilism that is similar insofar as it also is driven by the idea of the fixity of the past. I believe that the Consequence Argument provides strong reason to conclude that causal determinism is incompatible with freedom to do otherwise (that is, with genuine access to alternative possibilities). This challenge to the compatibility of causal determinism and freedom to do otherwise can be side-stepped by the semicompatibilist, insofar as she holds that moral responsibility does not require freedom to do otherwise. Again, this is a big advantage of semicompatibilism, and one of its big attractions. 
I myself am inclined to accept the Consequence Argument as sound, but I concede that reasonable (and very smart) people can and do disagree. And acceptance of the Consequence Argument is no part of semicompatibilism. The semicompatibilist need not conclude that if causal determinism is true, we do not have freedom to do otherwise; this is left open by the doctrine. What is crucial to the semicompatibilist is that causal determinism is compatible with moral responsibility (quite apart from the relationship between causal determinism and freedom to do otherwise).

But how does semicompatibilism motivate the contention that moral responsibility does not require freedom to do otherwise? That is, how does the proponent of semicompatibilism get the benefit of sidestepping the perennial disputes about the relationship between causal determinism and freedom to do otherwise? There are, in fact, various ways of getting to the conclusion that moral responsibility does not require freedom to do otherwise (alternative possibilities). One salient approach starts with what has come to be called a 'Frankfurt-Style Case':

Black is a stalwart defender of the Democratic party, despite some disappointments about Obama. He has secretly inserted a chip in Jones's brain which enables Black to monitor and control Jones's activities. Black can exercise this control through a sophisticated computer that he has programmed so that, among other things, it monitors Jones's voting behavior. If Jones were to show any inclination to vote for anyone other than the Democrat, then the computer, through the chip in Jones's brain, would intervene to assure that he actually decides to vote for the Democrat and does so vote. But if Jones decides on his own to vote for the Democrat (as Black, the old progressive would prefer), the computer does nothing but continue to monitor-without affecting-the goings-on in Jones's head.

Now suppose that Jones decides to vote for the Democrat on his own, just as he would have if Black had not inserted the chip in his head. It seems, upon first thinking about this case, that Jones can be held morally responsible for this choice and act of voting for the Democrat, although he could not have chosen otherwise and he could not have done otherwise.

(Frankfurt 1969; Fischer 1982, 1994)

This sort of case has a signature structure involving pre-emptive overdetermination. Similar examples were presented by Chrysippus (the example of a man running with a dog on a long leash) and John Locke (the example of a man who voluntarily stays in a room which is, unbeknownst to him, locked). Although the proper analysis of these cases is highly contentious, I believe that they render plausible the claim that an individual can be morally responsible for her behavior, even though she could not have done otherwise. I have argued that even if the examples have residual alternative possibilities, these exiguous alternatives are not sufficiently robust to play the role of grounding moral responsibility: they are mere flickers of freedom. So even if the Frankfurt Cases fall short of providing examples in which it is uncontentious that the agent is morally responsible for her behavior and she has absolutely no alternative possibilities, they strongly suggest that it is not in virtue of the presence of alternative possibilities that agents are morally responsible for their behavior. (Frankfurt 2003; Fischer 2013) 


\section{JOHN MARTIN FISCHER}

I contend that the Frankfurt Cases provide a prima facie case that if causal determinism rules out moral responsibility, this is not in virtue of ruling out alternative possibilities. Someone might however concede that it is not the mere fact that causal determinism expunges alternative possibilities that underwrites causal determinism's threat to moral responsibility; rather, the worry might be about the way in which causal determinism rules out alternative possibilities. After all, Black is a mere 'counterfactual intervener,' whereas causal determination flows right through the actual sequence issuing in the choice and action. It is thus not straightforward to extrapolate from the role of the counterfactual intervener in Frankfurt Cases to causal determinism; causal determinism rules out alternative possibilities in a crucially different way than Black or even God's foreknowledge insofar as it plays a causal role in the actual sequence. (Fischer 1982; Clarke 2010)

Although this is a nice point, I believe that the semicompatibilist has an answer. It seems to me that the Frankfurt Cases show (or at least provide strong reason to suppose) that the mere lack of alternative possibilities does not in itself rule out moral responsibility. How then could it be that a certain way of ruling out alternative possibilities would threaten moral responsibility? If the fact of one's lacking alternative possibilities does not itself remove moral responsibility, why would a certain way of eliminating alternative possibilities threaten moral responsibility? If (and it is admittedly not a small 'if') you are willing to grant that in the Frankfurt cases an agent is morally responsible for his behavior although he lacks alternative possibilities, why would it matter that causal determinism rules out alternative possibilities in a certain way?

I think that these questions point to the irrelevance of alternative possibilities to moral responsibility for action. But the worry about extrapolation from Frankfurt Cases to causal determinism still has force. The worry requires us to focus with greater care directly on the actual sequence. That is, even though causal determinism does not rule out moral responsibility by eliminating alternative possibilities (or by the way in which it does so), it might still rule out moral responsibility directly (i.e., in virtue of its specific role in the actual sequence). I will now turn to a discussion of various factors that have been invoked to seek to show that causal determinism removes moral responsibility directly.

Someone might contend that if causal determinism is true, this would imply that the agent is not 'creative' in the way required for moral responsibility; a related worry is that the agent would not 'initiate' his action in the right way. But I do not agree that the kind of creativity required for moral responsibility implies a metaphysical doctrine of causal indeterminism. It seems to me that the ordinary idea of creativity is essentially epistemic rather than metaphysical, as it were. A creative person combines ingredients in 'new' ways in the sense that those ways were not envisaged by others. Bach, Picasso, Miles Davis, Philip Glass - they are profoundly creative. And I do not think we would withdraw this judgment, if we were to be convinced by scientists that causal determinism is true. Their creativity is a matter of how they developed new 'forms' - put together elements of their respective disciplines in new ways-ways not anticipated fully by previous figures. It has nothing to do with causal indeterminism.

Similarly, the ordinary idea of initiation has nothing to do with causal indeterminism. Suppose a boy lights a match and throws it on some dry leaves. We would say that he started or 'initiated' the fire. If there were a legal trial, the judge (or jury) might well come to the conclusion that the boy started the fire. It would be rather ludicrous for the boy's attorney to argue as follows. "We do not know that causal determinism is false, so, out of fairness and an abundance of caution, we must assume that it is true. And if it is 
true, then my client did not in fact start or initiate the fire. After all, given causal determinism, there were antecedent conditions - and we can even trace such conditions all the way into the past prior even to the boy's birth-that causally necessitated the boy's choice to light the match, and so forth. Although it might appear this way, upon more careful reflection, you will see that, strictly speaking, my client did not start the fire (on the assumption of causal determinism)."

Of course, this argument would be laughed out of court. But a philosopher might insist that, nevertheless, there is a kernel of truth to it. She might distinguish an 'ordinary' or 'commonsense' notion of initiation from a 'rigorous' notion of initiation. She will concede that the boy starts the fire in the ordinary sense. But she will also go on to contend that, under the assumption of causal determinism, the boy does not initiate or start the fire, in the rigorous sense.

I think this is all fine and good. But now the important question is whether moral responsibility requires initiation only in the ordinary sense or also in the rigorous sense. I do not think that moral responsibility requires initiation in the rigorous sense. More carefully, I do not see an argument that it does, and I do not have the intuition that it does. When we suppose that moral responsibility requires initiation, it seems to me that this claim gains plausibility from an implicit employment of the ordinary, commonsense notion of initiation. If we plug in the rigorous notion, the claim becomes much more contentious-it loses its general appeal. That is, the idea that moral responsibility requires initiation is plausible only insofar as we do not build strong conditions, not licensed by commonsense, into the notion of initiation; once we do build such conditions into initiation, the intuitive plausibility disappears.

Consider, similarly, the notion of 'sourcehood.' It is often claimed that in order for an agent to be morally responsible for an action, she must be the source of it; alternatively, the claim is that the source of the behavior must be internal to the agent. An incompatibilist about causal determinism and moral responsibility might argue that causal determination implies that the source of the relevant behavior is not internal to the agent. This is a version of direct incompatibilism; the claim is that causal determination implies that the source of the action cannot be internal to the agent, and that this rules out moral responsibility, quite apart from considerations pertaining to freedom to do otherwise (and alternative possibilities).

But, again, there is a perfectly reasonable notion of 'sourcehood,' according to which the source's being internal to the agent is compatible with causal determination. The President of the United States might wonder who is the source of a leak of sensitive information to the press. Ascertaining who the source is does not require a presupposition of causal indeterminism! A plumber might wonder what the source of the leak is in the watering system. Clearly, identifying the source here does not require assuming that causal indeterminism obtains. Discovering the sources of leaks in information or water, or for that matter, the sources of good ideas, is not a matter of fundamental metaphysics; it does not require the assumption of causal indeterminism.

Again, an incompatibilist might insist that we make a distinction between sourcehood in an ordinary sense and sourcehood in a rigorous sense. In the ordinary sense, it will be admitted that causal determination is compatible with the source of an action's being internal to an agent. But an incompatibilist might insist that causal determination rules out the internality of sourcehood in the rigorous sense, and, further, that moral responsibility requires sourcehood in the rigorous sense. Robert Kane calls this rigorous notion of sourcehood "ultimate sourcehood" (Kane 1996). 
I think it is reasonable to distinguish an ordinary from a rigorous notion of sourcehood. But, as above, this raises the question of whether moral responsibility requires only sourcehood in the ordinary sense, or also in the rigorous sense. Once again, it seems to me that the plausibility and general appeal of the contention that moral responsibility requires sourcehood derives from employment of the ordinary, commonsense notion of sourcehood. If we plug in the more rigorous notion of sourcehood, we lose the broad and uncontroversial appeal of the principle, and we are left with something highly contentious.

A pattern is emerging. One might contend that notions such as creativity, initiation, sourcehood, and related phenomena, are both ruled out by causal determination and required for moral responsibility. But there is an ordinary and a more rigorous version of each of these notions. The notion, interpreted in an ordinary way, is required for moral responsibility but entirely compatible with causal determination. The notion, interpreted in a rigorous way, is incompatible with causal determination, but it is (at best) controversial whether the notion is required for moral responsibility. I do not think there is a widespread intuition that the rigorous notions are required for moral responsibility, and I do not see how to argue for this claim. I conclude that the argument for the incompatibility of causal determinism and freedom to do otherwise is considerably stronger than the direct argument for the incompatibility of causal determinism and moral responsibility. This is the reason why I hold that semicompatibilism takes us to a more compatibilist-friendly dialectical niche than classical compatiblism.

Robert Kane has emphasized that human beings care about the "objective worth" of our achievements, and not just the subjective satisfaction associated with them (Kane 1996). He further contends that our concern for "ultimate sourcehood" is of a piece with the value we place on objective worth. He writes:

Both ultimate responsibility and objective worth require us to stand back and take an objective view of the universe and our place in it. We imagine our deeds as having worth 'from the point of view of the universe,' and we imagine ourselves as buck-stopping originators of those deeds from the point of view of the universe. Both require an objective point of view.

(Kane 1996: 98)

I agree that objective worth requires an objective perspective, although I do not think it is obvious that this is the "point of view of the universe"-it could simply be a perspective that takes into account the "reflective equilibrium" (or intersubjective agreement) of the relevant community. But in my view it is important that taking a more objective perspective to generate objective worth does not require us to suppose that a rigorous notion of sourcehood is required for moral responsibility. I do not see how the need to take an objective viewpoint to generate objective worth has anything to do with the issue of whether moral responsibility requires the rigorous notion of sourcehood, rather than merely the ordinary notion. Certainly, the idea that we need some sort of objective perspective in both contexts-the context of generating objective worth and the context of assessing the etiology of our behavior-does not entail that, having taken the objective perspective in the latter case, we will find that we must suppose that causal indeterminism is true in order to sustain our moral responsibility.

Source incompatibilism contends that causal determinism rules out moral responsibility, quite apart from whether it eliminates freedom to do otherwise (alternative 
possibilities). Derk Pereboom has defended source incompatibilism (Pereboom 2001, 2014). He contends that when there is causal determination of an agent's action by factors external to the agent and beyond his control, this is sufficient to make it the case that the agent is not morally responsible for that action. Interpreted in an admittedly uncharitable way, this contention would seem to be question-begging (or at least dialectically unhelpful). After all, the issue under discussion is whether causal determination is compatible with moral responsibility. One could not expect to make dialectical progress simply by asserting that when an action is causally determined by factors beyond one's control, this suffices for non-responsibility. This is simply to assert incompatibilism —or something quite close to it. If one's interlocutor is unsure whether moral responsibility is compatible with causal determinism, simply asserting that causal determination by factors beyond the agent's control is sufficient for nonresponsibility will not be helpful.

We can give a more charitable interpretation of source incompatibilism. The source incompatibilist is presumably first contending that there is some sense of 'internal sourcehood,' which we can all identify as being required for moral responsibility. The source incompatibilist will then contend that causal determination eliminates this feature that is uncontroversially deemed necessary for moral responsibility. This is not question-begging or dialectically problematic, insofar as it starts with the claim that everyone-compatibilists and incompatibilists—agree that a certain sort of internal sourcehood is required for moral responsibility.

But what is this kind of internal sourcehood that we can all recognize as necessary for moral responsibility and ruled out by causal determinism? We might get at it by specifying a sufficient condition for its absence: when factors entirely outside an agent's control are sufficient for a given action, then the source of the action is external to her. The notion of sufficiency here should be understood as 'logical sufficiency' or perhaps 'logical sufficiency given background conditions.' This is a plausible and apparently nonquestion-begging way of articulating a constraint on the required kind of sourcehood, and causal determination would then imply that the source of an action is external to the agent.

Derk Pereboom has defended a version of the Frankfurt Cases in which he claims that the agent is morally responsible for an action, although she could not have done otherwise (Pereboom 2001, 2014). But he nevertheless embraces source incompatibilism; the idea is that, although the Frankfurt Cases help with the worry about lack of access to alternative possibilities, they do not help with the worry about sourcehood. But I now wish to point out that this is (arguably, at least) incorrect.

Let us simply stipulate here that a version of the Frankfurt Cases can be given in which the agent cannot do otherwise and is nevertheless morally responsible. Also, let us agree with Pereboom in supposing that there can be versions of the Frankfurt Cases in which indeterminism obtains (in a relevant way). Note now that the existence of the counterfactual intervener (such as Black in the Frankfurt Case described above [or a similar counterfactual intervener in a more sophisticated version of the Frankfurt Cases]), disposed as he is and with his 'technology,' is sufficient for the action of the relevant agent (say, Jones). That is, a condition entirely outside of the agent's control is sufficient for his action; thus, on the proposed understanding of sourcehood, the source of the agent's behavior would be external. But we have stipulated (and Pereboom agrees) that in the relevant version of the Frankfurt Cases, the agent is indeed morally responsible for her action. It is interesting that the Frankfurt Cases thus may address the 
sourcehood worry, as well as the alternative-possibilities worry, of the incompatibilist. They appear to show that the proposed interpretation of sourcehood is too strong.

Exactly the same point emerges from a consideration of God's foreknowledge. Suppose that God knew prior to Jones's birth that he would vote for the democrat on a particular occasion. Arguably, at least, God's foreknowledge (like Black's existence and technology) renders Jones unable to do otherwise, and yet it plays no role in the actual causal sequence leading to Jones's act of voting for the democrat. Insofar as God's prior belief played no causal role in the actual sequence leading to Jones's voting behavior, it would appear to be irrelevant to his act of voting for the democrat. And if this is correct, there would be no bar to concluding that Jones is morally responsible for his democratic vote, despite that fact that God believed prior to his birth that he would vote for the democrat. Of course, given God's essential omniscience, God's prior belief that Jones would vote for the democrat is sufficient for Jones's voting for the democrat. As with Black, God's prior belief would constitute a condition beyond Jones's control which is sufficient for Jones's action. It would follow from the proposed interpretation of internal sourcehood that the source of Jones's action is external. But, as with the Frankfurt Cases, this collides with the view that Jones is morally responsible, and it apparently shows that the interpretation of sourcehood under consideration is too strong.

Perhaps a source incompatibilist, such as Pereboom, would agree with me that the proposed interpretation of internal sourcehood needs to be sharpened in light of these problems. One approach to sharpening the account begins by noting that neither Black nor God's prior belief explains Jones's act of voting for the democrat. So the interpretation of internal sourcehood must be adjusted to reflect this fact. Maybe the following would do the trick (again, as a constraint on any adequate account of internal sourcehood): when a factor entirely out of an agent's control is explanatorily sufficient for her action, then the source of her action is external to her. It would appear that the causal determination of an action would imply that the source of it is not internal to the agent (on this understanding of internal sourcehood).

I think that the newly adjusted interpretation needs further sharpening. First, we should keep in mind that it is unclear that there is some 'objective and purpose-invariant' notion of explanation. Typically, we conceptualize explanation as purpose-relative and context-dependent. But put this set of worries aside for now. I would dispute the contention that whenever some factor beyond an agent's control both explains the behavior in question and is sufficient for it, the source of the agent's action is external to her and thus she is not morally responsible for so acting. It is just not at all obvious to me that this claim is correct; certainly, it is much more controversial than the ingredients that go into the Consequence Argument (in virtue of which it follows that causal determinism rules out freedom to do otherwise).

How would one establish that the newly adjusted interpretation of sourcehood yields a truth to the effect that whenever the source of an agent's action is external, then the agent is thereby not morally responsible for the action? I do not think that such an argumentative project would be straightforward or easy. One might think that consideration of a range of cases would help the incompatibilist here. And this is precisely the way in which Pereboom seeks to establish his version of the sourcehood requirement. (I'll assume for the sake of the rest of this discussion that Pereboom would accept the adjustment I have proposed to the interpretation of sourcehood.) He contends that the sourcehood requirement best explains our intuitions in a range of cases, some of which involve direct manipulation of the agent's brain. This is part of Pereboom's famous 
"Four-Stage Argument," in which he begins by imagining that an agent is thoroughly manipulated, and then proceeds via a set of three other cases to a case of "mere" causal determination (Pereboom 2001, 2014). At each point, Pereboom argues that there is no relevant difference as regards the agent's moral responsibility. Given that he started with a case in which we would (putatively) deem the agent not responsible, he concludes that the agent would not be responsible under causal determinism. He further holds that the sourcehood requirement is the best explanation of our pattern of intuitions about such cases (and others).

But I would dispute Pereboom's "inference to the best explanation” here. I do not believe that we need anything so strong as the sourcehood requirement, even on the adjusted interpretation under consideration here, in order to explain our intuitions about the cases involved in Pereboom's argument and related cases. When manipulation elicits the intuition that the agent is not morally responsible, it is not simply by indicating that there is an explanation of an agent's behavior by reference to conditions that are both out of the agent's control and sufficient for it. My contention is that manipulation elicits the no-responsibility intuition insofar as it points to a special kind of explanation of an agent's behavior. Now there are various ways of specifying the 'special' kind of explanation that rules out moral responsibility. I cannot develop my approach in any detail here (but see Fischer 2014). It must suffice to note that a compatibilist will point out that sometimes invocation of certain factors can explain behavior only by also explaining that the behavior was caused by the agent's motivational states in a certain distinctive way; we might say that this way involves going through the agent's normative structures and capacities, rather than bypassing them. (Fischer 2002 and forthcoming) A compatibilist will insist that it is only when the relevant sort of explanation indicates that the behavior in question was not caused in this sort of way that it shows that the agent is not morally responsible.

Again, my point is not that it is obvious that source incompatibilism is to be rejected. Rather, I claim that the issues here are nuanced; obviously, I have provided only the barest sketch of the compatibilist reply to the adjusted interpretation of internal sourcehood. I believe that it not at all clear that causal determination implies that the source of an individual's action is external. As I wrote above, semicompatibilism thus shifts the debate to terrain more hospitable to compatibilism, and our status as morally responsible agents need not hang on a thread or be held hostage to the arcane deliverances of the cosmologists and theoretical physicists. Semicompatibilism helps us to be at home in the world of morality and practical agency. It aids us in sleeping at night, metaphysically speaking.

\section{Acknowledgments}

Thanks to Meghan Griffith for helpful comments.

\section{Bibliography}

Clarke, R. (2010) "Determinism and Our Self-Conception," Philosophy and Phenomenological Research 1: $242-50$.

Fischer, J. (1982) "Responsibility and Control," Journal of Philosophy 89: 24-40.

Fischer, J. (1994) The Metaphysics of Free Will: An Essay on Control. Oxford: Blackwell Publishers.

Fischer, J. (2002) "Frankfurt-Style Compatibilism," in S. Buss and L. Overton (eds), Contours of Agency: Essays on Themes from Harry Frankfurt. Cambridge: MIT Press, pp. 1-26. 


\title{
JOHN MARTIN FISCHER
}

Fischer, J. (2013) "The Frankfurt-Style Cases: Philosophical Lightning Rods," in I. Haji and J. Caouhette (eds), Free Will and Moral Responsibility. Newcastle-upon-Tyne: Cambridge Scholars Press.

Fischer, J. (2014) "Review of Free Will, Agency, and Meaning in Life, by Derk Pereboom," Science, Religion, and Culture 1: 202-8.

Fischer, J. (forthcoming) "Responsibility and the Actual Sequence," in D. Shoemaker (ed.), Oxford Studies in Agency and Responsibility, Vol. 3.

Frankfurt, H. (1969) "Alternate Possibilities and Moral Responsibility," Journal of Philosophy 66: 829-39.

Frankfurt, H. (1971) "Freedom of the Will and the Concept of a Person," Journal of Philosophy 68: 5-20.

Frankfurt, H. (2003) "Some Thoughts Concerning PAP," in D. Widerker and M. McKenna (eds), Moral Responsibility and Alternative Possibilities. Aldershot: Ashgate, pp. 329-46.

Kane, R. (1996) The Significance of Free Will. New York: Oxford University Press.

Pereboom, D. (2001) Living without Free Will. Cambridge: Cambridge University Press.

Pereboom, D. (2014) Free Will, Agency, and Meaning in Life. New York: Oxford University Press.

van Inwagen, P. (1983) An Essay on Free Will. Oxford: Clarendon Press.

\section{Further Reading}

Peter Strawson is an influential semicompatibilist: Strawson, P. (1962) "Freedom and Resentment," Proceedings of the British Academy 48: 1-25. Jay Wallace follows Strawson's lead in developing a systematic Strawsonian semicompatibilism in: Wallace, R.J. (1994) Responsibility and the Moral Sentiments. Cambridge: Harvard University Press. For a comparison of Strawsonian and Fischer/Ravizza-type semicompatibilism see: Fischer, J. (2014) "Peter Strawson and the Facts of Agency," in D. Shoemaker (ed.) Oxford Studies in Agency and Responsibility Volume 2. New York: Oxford University Press, pp. 93-116. Other prominent developments of versions of semicompatibilism can be found in: Dennett, D. (1984) Elbow Room: The Varieties of Free Will Worth Wanting. Cambridge: MIT Press; Dennett, D. (2003) Freedom Evolves. New York: Viking Press; Haji, I. (1998) Moral Appraisability. New York: Oxford University Press; and McKenna, M. (2008) "Frankfurt's Argument Against Alternative Possibilities," Noûs 42: 770-93.

\section{Related Topics}

\author{
Identificationist Views \\ Reasons-Responsive Theories of Freedom \\ Classical Compatibilism \\ The Consequence Argument \\ Frankfurt-Style Examples \\ Leeway vs. Sourcehood Conceptions of Free Will \\ The Relationship between Moral Responsibility and Freedom \\ Determinism
}




\section{2 \\ IDENTIFICATIONIST VIEWS \\ Agnieszka Jaworska}

Identificationist views trace the capacity for freedom of the will to the differentiation in the agent's psychology such that the agent can fully identify with some of his desires, or more broadly, motivating attitudes, to make them deeply his own and internal. This approach to understanding freedom of the will was first put forth by Harry Frankfurt (1971), and in this original version, Frankfurt coupled it with his well-known "hierarchy of desire" account of what one's identification with a desire consists in. Since then, many different accounts of what it takes for an agent to be identified with a motivating attitude have been proposed, and these presumably would correspond to different versions of an identificationist view of free will. However, some authors who offer accounts of identification do not tie their accounts to an identificationist view of free will.

According to a line of thought in the classical compatibilist theory of freedom, one is free to the extent that one is able to do what one wants to do (e.g., Hobbes 1997: 108; I label this view "classical compatibilism"-compare the entry on "Classical Compatibilism" in this volume). Identificationist views developed in response to a crucial objection to this simple compatibilist view. The problem with the classical view is that it does not allow for obstacles to freedom that arise internally, from the agent's own motivational structure. The agent's wants or desires, no matter how problematic, are treated as given, and the impediments to freedom can only come from the circumstances in which the agent is acting. Agents enacting their addictive, obsessive, or phobic desires count as free: they are doing what they want to do, so, trivially, they are able to do that. Likewise, animals count as free so long as they enact their desires. Identificationist views modify the classical approach to avoid this sort of objection. They claim that one is free to the extent that one is able to do what one truly wants to do, where true wants are understood as desires with which the agent identifies.

\section{Identificationism and the Ability to Do Otherwise}

Classical compatibilism can bypass any concern with whether the agent is able to act otherwise under the circumstances: since what one wants leads to action unless there are external impediments, what is relevant to the freedom to do what one in fact wants to do is whether the circumstances permit the wanted action and not whether one is able to undertake a different action under these circumstances. (Some classical 
compatibilists did in fact see the ability to act otherwise as important and added it as a requirement of responsibility-see the entry on "Classical Compatibilism" for detailsbut the point here is that their approach can avoid this 'add-on,' as illustrated by the views of Hobbes.) The modification introduced by the identificationist views may appear not to touch this feature of classical compatibilism-we simply substitute 'true wants' for 'wants' and leave the rest of the view intact. However, this appearance is misleading. Two types of identificationist views are possible and they differ on the issue whether the ability to act otherwise is relevant to freedom. Authors are not always clear which version they have in mind, and even those explicitly advocating one version slip into formulations suggesting the other version.

\section{Broad Identificationist Approach}

First consider what I will call broad identificationism. If the identificationist simply substitutes 'true wants' for 'wants' in classical compatibilism, free will becomes the ability or the capacity to act on a motivation with which one is identified (hence broad identificationism could be called the 'capacity' model—see Nelkin 2011: 17, note 19). This capacity may be present in two, importantly distinct, conditions. In the easy case, an agent clearly has this capacity when his action is in fact governed by a motivating attitude with which he is identified. In Frankfurt's terminology, the agent wills to perform an action freely or acts "of his own free will" in such cases (Frankfurt 1971: 24). However, an agent might also have the relevant capacity even if he does not in fact exercise it: this agent is able to govern his action by a motivating attitude with which he is identified, but he does not do so. This agent also possesses free will, but here free will requires the agent's ability to do something other than what he did. Thus, the broad version of the identificationist approach cannot escape an appeal to the ability to do otherwise and the accompanying worries about how this ability should be conceptualized. Indeed, when theorists explicitly advocate identificationist views of this type, they tend to leave it obscure what the ability to do otherwise amounts to (see Frankfurt 1971: 24 or Watson 1975: 27). Notice that the ability to do otherwise cannot mean here (along the lines borrowed from those classical compatibilists who did analyze this notion) that, depending on which of the agent's motivations wins out (that is, depending on which of his desires is most effective), he is able to follow his identification or not. This is because on this way of understanding the ability to do otherwise, even an addict who does not identify with his addictive desire but loses his struggle against it, would qualify as having free will: he does not in fact follow his identification (he is an unwilling addict), but he would be able to if his addictive desire were not so strong and effective. Since the point of the identificationist views is to be able to account for such a case, they need a different interpretation of the ability to do otherwise.

Since both classical compatibilism and the broad identificationist modification refer to the agent's ability rather than to what the agent does, it might be unclear why the former account of freedom need not involve the ability to act otherwise, but the latter has to. Here is why this crucial difference emerges. In classical compatibilism, since the focus is on an agent's ability to do what he wants to do, what the agent wants to do is held constant and taken for granted. Moreover, what the agent wants is understood to be what effectively moves the agent to undertake the corresponding intentional action, absent any external impediments. So, holding the agent's wants fixed, only the circumstances in which the agent acts (the constraints on his action coming from outside his 


\section{IDENTIFICATIONIST VIEWS}

motivational makeup) affect what the person can do. His own ability to do otherwise under the circumstances is not relevant, since to exercise this ability he would first need to be able to want to do otherwise, but we are holding what he wants constant; the ability at issue is relative to what he wants. However, once the broad identificationist modification is introduced, the focus is on an agent's ability to do what he truly wants to do, so now only what the agent truly wants to do is held constant and taken for granted; the ability at issue is relative to what he truly wants. Crucially, though, what effectively moves an agent, and so what he in fact intentionally does when externally unimpeded, can come apart from what the agent truly wants to do. In such cases, the agent's ability to do otherwise than what he did is not only relevant, but central to his ability to do what he truly wants to do. So, it is the possible gap between what one truly wants and what effectively moves one, where there is no gap between what one wants and what effectively moves one, that makes the ability to do otherwise indispensable to the broad identificationist approach.

\section{Narrow Identificationist Approach}

Since classical compatibilism promises to be able to escape any worry about the agent's ability to do otherwise and since the identificationist modification appears to be a rather small tweak of the classical view, identificationist views are often developed or interpreted in a way different from what we have discussed so far, one that does indeed bypass any worries about the ability to do otherwise. To understand this version of the identificationist approach, which I will call the narrow version, it will help to first introduce Frankfurt's distinction between acting of one's own free will and having freedom of the will.

As we have seen, one acts of one's own free will (or freely), according to Frankfurt, when one's action is governed by a motivating attitude with which one is identified. By contrast, freedom of the will is the freedom to govern one's action by a motivating attitude with which one is identified; here one can govern one's action in the required way or not, but it is possible for the action to be governed otherwise than the way it was in fact governed.

One can act freely while lacking freedom of the will: in such a case one's action is governed by a desire with which one identifies, but one has no ability to do otherwise. Frankfurt's example here is the willing addict who fully embraces and identifies with his addictive impulse, even though he has no possibility of resisting his addiction. It also seems possible to have freedom of the will, but not act freely. An example of this would be a type of weak-willed action in which one betrays what one identifies with while being fully capable of avoiding this betrayal. At least on some interpretations of identification (particularly, as we will see shortly, on what I call robust interpretations of identification), garden variety laziness or procrastination appears to often fit this description: the person simply gives in to the pleasure of the moment against what matters to her much more deeply.

Having made this distinction, Frankfurt at times suggests that acting of one's own free will is the only freedom relevant for moral responsibility. While the question whether we have freedom of the will may be relevant for some purposes, acting of one's own free will is all we need to focus on if we are interested in freedom presupposed in responsibility assessments (Frankfurt 1971: 24, lines 10, 11; by contrast, elsewhere in Frankfurt [1971], and even in Frankfurt [1969], whose point is that the ability to act 
otherwise is not necessary for responsibility, the view seems to be more aligned, or at least compatible, with broad identificationism). The narrow versions of the identificationist approach follow this suggestion of Frankfurt. They zero in on freedom understood as acting on a motivation with which one is identified. In Nelkin's (2011: 17, note 19) terminology, they adopt the 'flow' model: an action is free if, and only if, it flows from one's identification. They may acknowledge that there are other notions of freedom, but they take this one to be at the center of the free will debate: this is the sort of freedom those who see freedom of the will as a precondition of moral responsibility should really be concerned with. It is important to note that the difference between the broad and narrow approach is not about how freedom of the will should be interpreted, but rather about which notion of freedom is relevant for responsibility assessments.

It is easy to see the attraction of the narrow identificationist approach. It promises to preserve the key strength of classical compatibilism: assessments of freedom and moral responsibility can bypass any concern with whether the agent was able to do otherwise. What matters is the action the agent did in fact perform and whether it was governed by a motivation with which the agent identifies. (For a pure version of a view of this sort, see Shoemaker 2003: 106ff. As I read them, the views of Velleman [1992] and Arpaly and Schroeder [1999] also fall in this category, and possibly Smith [2004] as well.)

\section{The Promise of Broad Identificationism}

By contrast, according to broad identificationism, the ability to act in accordance with one's identification is the notion of freedom relevant to moral responsibility. Broad identificationism cannot avoid an appeal to the ability to act otherwise, and needs to be supplemented with an explanation of what this ability involves. Nonetheless, although the broad type of identificationism is incomplete, it aspires to deliver important results. Broad identificationism can be formulated as a disjunctive view: what is necessary and sufficient for freedom relevant to moral responsibility is either (1) having one's action governed by one's identification or (2) being free to have one's action governed by one's identification. (Crucially, then, even though broad identificationism requires appeal to the ability to act otherwise in disjunct (2), this ability is not required for responsibilitythanks to disjunct (1) — contrary to the principle of alternative possibilities.) There is uncertainty about how to interpret disjunct (2), but there are some cases, including cases of addiction and phobia as these are standardly understood, in which the agent's lack of ability to do otherwise can be assumed. In these cases, disjunct (2) is false and thus only disjunct (1) determines whether the agent has the relevant freedom. In these cases, broad identificationism can yield firm answers and, if these answers are plausible, it can make significant contributions to the free will debate.

First, according to broad identificationism, a wanton agent, that is, an agent who altogether does not identify one way or another with his motivating attitudes, lacks freedom relevant for moral responsibility. In this way, broad identificationism promises to provide an interesting and plausible explanation of the common belief that non-human animals lack free will.

Second, in cases such as the willing addict, where the agent can be assumed to be unable to do otherwise but he nonetheless identifies with the desire that governs his action, broad identificationism renders the reasonable verdict that the agent has all the freedom relevant for moral responsibility. Of course, one may worry that it matters to responsibility how this identification came about - if it was caused by hypnosis or brain 
manipulation, for example, this may appear to rob the agent of freedom relevant for responsibility. Some identificationists bite the bullet in response to this objection and insist that the causal route to identification does not matter, regardless of whether the cause is the usual one, such as one's upbringing and cultural influences, or unusual one, such as in the manipulation cases (cf. Frankfurt 2002: 27-31). It is also possible that a specific view of what is required for identification will preclude identification caused by hypnosis or brain manipulation (cf. Smith 2005: 261, 262). Both these responses preserve the idea that identification with the governing desire does all the work of explaining responsibility. But identificationists may instead add some further conditions to the identificationist approach to address the cases of manipulation, and then identification would not do all the work.

Third, in cases such as the unwilling addict, where again the agent can be assumed to be unable to do otherwise but this time he does not identify with and perhaps even rejects the desire that governs his action, broad identificationism renders the verdict that the agent lacks the freedom relevant for moral responsibility, which also appears plausible. This would be the case of lack of freedom coming from the agent's internal constitution that classical compatibilism was missing. (It should be noted, though, that this agent may nonetheless be responsible for the ensuing action because he may be responsible for his current lack of freedom: he may have freely and culpably done something earlier that has resulted in his current lack of freedom-he freely and culpably got himself addicted. In other words, we can 'trace'- the literature owes this term to Fischer and Ravizza (1998) - his current lack of freedom to a prior free action. This does not change the assessment that he currently lacks the freedom relevant to moral responsibility. So having the relevant sort of freedom at the time of action is not a necessary condition of responsibility. It is nonetheless the freedom relevant for moral responsibility presumably because it is necessarily present somewhere in the causal pathway leading to the action.)

Of course, since disjunct (1) of broad identificationism has the same content as narrow identificationism, the above three cases (in which disjunct [2] is false) are also cases in which both broad and narrow identificationism give the same answers about freedom. This does not mean that narrow and broad identificationism account for all these cases in the same way. Although they give the same yes/no verdicts, and also the same explanations for these verdicts in the first two cases, broad identificationism gives a different explanation for why the unwilling addict lacks the relevant freedom: both his lack of identification with the desire governing his action and his inability to do otherwise are relevant. For narrow identificationism, only the lack of identification with the governing desire is relevant. (This is why, as we will see below, narrow identificationism, when it is coupled with a 'robust' interpretation of identification, cannot properly distinguish between the unwilling addict and the ordinary weak-willed agent.)

\section{Competing Accounts of Identification}

Broad and narrow identificationism admit of different sub-types depending on their interpretation of what it takes for an agent to be identified with a motivating attitude. There is a lively debate in the literature concerning this question. This debate has largely been guided by testing theories against intuitions about when it appears to us that we fully own our motivations and when we seem to be alienated from them. One can theorize about identification in this way without connecting the resulting theory to an identificationist view of free will, and at least part of the debate has proceeded in this way. 
In Frankfurt's original "hierarchy of desire" proposal, an agent's identification with a desire was understood in terms of having a further desire concerning that desire, that is, wanting that desire to move one to action (Frankfurt called this further desire a secondorder volition). Gary Watson (1975) famously objected that wanting a specific desire to move one to action is itself a mere desire, on a par with any other desire, with no special claim to represent where the agent truly stands. What distinguishes this desire is its peculiar second-order content, referring to another desire, but this, by itself, does not shield the second-order volition from alienation. A Frankfurtian type of theory could attempt to rule out alienation by appeal to a desire of a yet higher order, a desire that the second-order volition be effective, but this would not help, since this third-order volition is still a mere desire, allowing for the possibility that the agent could be alienated from it as well. This approach therefore simply threatens an infinite regress. Frankfurt attempted various solutions to this problem. In one (Frankfurt 1987), he aligned identification with a decision to commit to a second- or higher order volition. In another (Frankfurt 1992), he supplemented the hierarchy of desire model of identification with the idea of satisfaction: one is identified with a motivation so long as it is supported by the highest order volition and at the highest level of the desire hierarchy there is no conflict or opposition to the endorsing desire.

Watson (1975) proposed an alternative account of identification meant to avoid the problems with the hierarchical model. In his view, roughly, one identifies with a motivation when it is backed by or stems from one's evaluative judgment about how to live one's life. Watson (1987) later found this account problematic, recognizing that it does not allow for "perverse cases" in which the agent fully stands behind and identifies with choices and motivations that go against his better judgment, such as a wholehearted thrill-seeker fully prepared to admit that what he goes for in life is not the best.

David Velleman (1992) questioned all accounts of identification that equate the standpoint of the agent with a nexus of attitudes of a certain type- be it second-order volitions, decisions, or evaluations-attitudes that the agent himself can criticize or revise. The problem, as Velleman sees it, is that the criticism or revision is clearly done by the agent and must reflect the standpoint of the agent, so how does the agent maintain his standpoint in order to be the author of the revision and simultaneously revise an attitude that constitutes this standpoint? Besides, it does not seem that alienation from these attitudes can be avoided: for any of them, we can find examples where the agent is simply stuck with that particular attitude, alienated from it, or perhaps even unaware that he has it. What is needed for identification, according to Velleman, is backing by an attitude with a specific content, an attitude that plays the role of the agent in virtue of its content. One can only be alienated from such an attitude on pain of ceasing to be an agent at all. According to Velleman, it is the desire to act on reasons that plays this role. Thus, one is identified with a specific motivation to the extent that it is backed by one's desire to act on reasons.

Of the accounts canvassed so far, only Frankfurt's satisfaction-based account does not come into the purview of Velleman's objection (since, presumably, once an attitude comes up for revision, the agent is not satisfied with it). Nonetheless, this account faces similar difficulties. As Michael Bratman (1996) noted, satisfaction can be a result of unfinished reflection: one can be satisfied with one's current second-order volition simply because one is too tired or too depressed to examine the situation any further. In such cases, the second-order volition does not seem to represent the agent's true stance. Bratman (2000) has proposed an alternative account of identification with a desire, 
meant to avoid the difficulties with both Frankfurt's and Watson's approaches. It casts policies to treat the desire in question as reason-giving in motivationally effective deliberation as playing the role of the agent: one identifies with a desire to the extent that it is supported by such 'self-governing' policies (subject to a further condition of satisfaction).

Jeffrey Seidman (2009) has pointed out that, in some cases, we find out or discover what we identify with and so identification cannot rest on decision or intention. Since Bratman conceives of a self-governing policy as a species of intention, his proposal cannot account for the possibility of discovering one's identification. Seidman, relying partly on my own work (Jaworska 2007), has proposed that the attitude of caring is sufficient for identification. David Shoemaker (2003) has also argued that the solution to well-known problems with Frankfurt's and Watson's accounts is to see the source of authority for identification as stemming from what one cares about. These authors conceptualize caring in somewhat different ways, but agree on a key feature of caring: a thoroughgoing emotional attunement and vulnerability to how the object of care is faring. Arpaly and Schroeder (1999) have proposed a different solution, aligning the degree of identification with an attitude to the degree of its integration into the agent's entire psychological makeup. Angela Smith (2004) has emphasized problems with all "volitional" accounts of identification (like Frankfurt's and Velleman's), which split up the psyche into attitudes that "carry out" the identification and attitudes that are only thereby rendered one's own; her alternative view avoids such a split since identification is a matter of whether an attitude essentially involves the exercise of one's evaluative capacities and even non-volitional attitudes such as the emotions essentially involve evaluation.

The debate about the nature of identification is ongoing, but it is important to flag that the arguments and counterexamples offered do not always answer to the same concept of identification. Several concepts of identification are at play here, but it matters most for our purposes to distinguish the weakest one from those that are stronger. In the weakest, bare-bones sense, you identify with a motivation when acting on it is undeniably a product of your agency: the motivation is not merely visiting, not a mere happening in your psychology that you may discover to your surprise or merely observe and have to contend with; rather, you are the author of this motivation and of the resulting action. In the stronger, more robust senses, you identify with a motivation (i) when it is a deep and inextricable part of the subjective lens through which you currently interpret the world and the range of possibilities for action, or (ii) when you fully stand behind it and embrace it as part of your authentic self. (There may be additional robust concepts I am overlooking.) These concepts are easily confused with one another, especially because they can all be described using the same language of ownership, lack of alienation, self-governance, etc. Ordinary cases of weak-willed action bring out the difference between the bare-bones and the robust concepts of identification: the weakwilled agent giving in to temptation is nonetheless the author of his action (i.e., he identifies with the action in the bare-bones sense), and yet this agent can distance himself from the tempting desire either in the sense that he is capable of viewing the possibilities for action independently of this desire or in that he repudiates the desire and the resulting action (i.e., he may well not identify with the action in the robust senses).

Frankfurt, Watson, and Bratman at times suggest that their aim is to specify the barebones concept of identification. That is, they seem to see themselves as providing a theory of identification general enough to cover all cases when the agent fully authors 
an action. However, their proposals, as well as Seidman's and Arpaly and Schroeder's, in fact answer to more robust, narrower concepts of identification that leave out some instances of genuine agency. This is easy to see because it is possible to exercise one's own agency weak-willedly in betraying, respectively, one's wholehearted highest-order volitions, decisions, evaluations, self-governing policies, as well as cares and wellintegrated whole selves. Interestingly, objections to Frankfurt's original account apply regardless of whether this account is taken to specify the bare-bones or the more robust concepts of identification. By contrast, Velleman's account clearly pertains to the barebones concept: he explicitly tests his proposal against the desideratum that the relevant attitude must be able to play the functional role of the agent, so that the support by this attitude would be equivalent to an exercise of agency. Moreover, Velleman is at pains to show that even the motive of a weak-willed agent is backed by the agent's desire to act on reasons, that is, that even the weak-willed agent identifies with his motive in the sense that Velleman specifies (for his explanation of why this is so, too complex to be summarized here, see Velleman 2000: 28, note 34). While Velleman's talk of "fullblooded" action or "action par excellence" may seem to undercut my interpretation, I take these terms to merely distinguish human authorship of an action from animal agency that is never authored, and from those actions of humans that merely happen without the human agent's proper participation. (Admittedly, Velleman sometimes slips into a more robust concept of identification in his criticisms of rival views. For instance, he uses recoiling from one's materialism as an example of alienation from one's values [Velleman 1992: 134], but it seems clear that if a person acted on his materialism in such a case, he would be the author of his action.) Although she is critical of Velleman, Smith also takes herself to be working with the bare-bones concept of identification, since she aims at specifying the "authorial relation" we can bear to our attitudes and conduct (2004: 333). And, presumably, on her view, even a weak-willed agent identifies with his motive as a weak-willed agent acts intentionally and intention is among the attitudes that essentially involve the exercise of one's evaluative capacities.

\section{Is Identificationism Compatible with Both the Bare-Bones and Robust Concepts of Identification?}

Given the distinction between the bare-bones and the robust concepts of identification, it is important to determine if identificationism can be plausibly combined with either type of concept, as the literature suggests.

As it turns out, narrow identificationism is subject to a fatal objection unless the range of interpretations of the concept of identification with which it is coupled is somewhat restricted. (For a version of this point, which influenced my framing of the discussion below, see Fischer [2012].) Frankfurt's important contribution is to emphasize that acting of one's own free will is sufficient for moral responsibility; freedom of the will is not necessary in such cases. The willing addict is fully responsible for his actions: he identifies with what he does and it does not matter that he could not have done otherwise. Moreover, this claim is on solid ground regardless of which interpretation of the concept of identification we employ. The willing addict is responsible if he is fully the author of his action. And the willing addict is responsible if he identifies with his addictive desire in a robust sense such that this desire is an inextricable part of how he currently views his options for action or such that he fully stands behind this desire and 
owns it. But matters are different when we consider narrow identificationism as a necessary condition of responsibility. Suppose we interpret the concept of identification in such a way that it is possible to act weak-willedly with respect to it: that is, it is possible to betray what one identifies with through procrastination, indulging a temptation, and the like. Now, unless we want to radically revise ordinary judgments, acting freely in Frankfurt's sense cannot be necessary for moral responsibility. We judge a weak-willed person, such as the procrastinator, to be responsible for her action, and yet she acts against what she identifies with, and so does not act freely in Frankfurt's sense. Moreover, it will not help to trace the weak-willed person's current lack of freedom to some free action that deprived him of that freedom. There is no reason to believe that the garden variety weak-willed person would only be responsible if he had done something else that brought it about that he is now acting against his identification and he identified with the desire that governed this prior action. (It is worth noting that classical compatibilism is altogether immune to this line of difficulty because, while weakness of will with respect to what one truly wants might be possible-depending on how 'true want' is interpreted-weakness of will with respect to what one merely wants is not. Thus, although we might need to worry about the responsibility of an agent who betrays what he truly wants, there is no parallel worry about responsibility in a condition in which an agent betrays what he wants, since no such condition arises.)

Narrow identificationism can escape this fatal problem if identification is interpreted in a way that blocks the possibility of acting weak-willedly against one's identification. And such an interpretation is indeed available: as we have seen, the possibility of being weak-willed with respect to identification is what distinguishes the robust interpretations of identification from the bare-bones one. If what it means to identify with a motivation is that acting on it is undeniably a product of your agency (bare-bones identification), then it is not possible to go against your identification and still exercise your own agency: when you betray your identification, you are not strictly speaking acting; desire-governed action is merely happening. It appears that narrow identificationism can preserve plausibility only if it interprets identification in this bare-bones way.

Granted, narrow identificationism can evade this restriction if it is reformulated as providing only a sufficient condition of freedom. The weakness of will cases are no longer counterexamples then, since these are simply cases in which the proposed sufficient condition is not met. This view still allows us to set aside the concern with the possibility of doing otherwise, while retaining the plausible claim that the willing addict has all the freedom needed for moral responsibility. However, the critical flaw of this version of identificationism is that it cannot help with the original objection to classical compatibilism focused on internal obstacles to freedom, as a sufficient condition of freedom can never explain lack of freedom (in addiction, phobias, etc.).

Broad identificationism escapes the above line of objection, because, being a disjunctive view, it can account for responsibility in weakness of will cases by appeal to the claim that the weak-willed agent is nonetheless able to act in accordance with his identification. But can an analogous objection be mounted even in cases in which the agent can be assumed to be unable to act otherwise?

Notice that the distinction between the bare-bones and robust concepts of identification allows us to recognize the possibility of an addict (assumed incapable of doing otherwise) who is the author of his action (identifies with the action in the bare-bones sense) even though the addictive desire that motivates his action is not an inextricable part of how he views the world and he repudiates acting on it (he does not identify with 
it in the robust senses). Intuitively, it seems that this addict, who is not a passive bystander vis-à-vis his motivation but rather an author of his action, would have the freedom relevant for moral responsibility. (Note that this parallels our claim at the beginning of this section that the bare-bones identification is sufficient to deem a willing addict responsible for his action. Similarly, one could reasonably think that the responsibility of a weak-willed agent stems from his authorship of his action, not from his ability to do otherwise.) However, if narrow identificationism is coupled with a robust interpretation of identification, this addict fails to meet a necessary condition of freedom (his action does not flow from his robust identification) and he will not be considered responsible, contrary to the intuitive assessment. But note that this objection is not one that broad identificationism can escape by relying on the disjunct it adds to narrow identificationism's necessary condition of freedom. If broad identificationism is coupled with a robust interpretation of identification the added disjunct stays inert in this case since, by hypothesis, the addict is incapable of acting otherwise and so incapable of making his action flow from his robust identification. The addict thus fails to meet broad identificationism's disjunctive necessary condition of freedom, and the same counterintuitive assessment of his responsibility results. Therefore, both narrow and broad identificationism give plausible answers here only if they employ the bare-bones interpretation of identification. As we have seen, it is a key aspiration of identificationism to correctly delineate and account for the unwilling addict. If the bare-bones interpretation of identification is necessary for this-necessary to distinguish the above addict (who seems responsible) from the unwilling one (who is not) - this is the interpretation that even broad identificationism would have to employ.

\section{The Choice Between Broad and Narrow Identificationism}

Suppose we accept that identificationism must be coupled with the bare-bones interpretation of identification. What is at stake now in the choice between broad and narrow identificationism? Of course, narrow identificationism has the advantage of altogether bypassing any concern with the possibility of doing otherwise. But what are the drawbacks of narrow identificationism?

When identification is interpreted in a robust way, the difference in how broad versus narrow identificationism handle cases is rather significant since narrow identificationism seems to render garden variety weak-willed agents not responsible, while broad identificationism can secure the intuitively correct result here. However, once we couple identificationism with the bare-bones interpretation of identification, the difference in how the two versions handle cases is much smaller: it only occurs in cases in which a person does not exercise his agency (allowing a wayward desire to govern behavior), although he is perfectly able to exercise his agency and do otherwise than he did. If such cases of a person abdicating his agency are possible, it seems that we should hold the person responsible for the behavior. Broad identificationism renders this intuitively plausible answer here, while narrow identificationism deems this agent not responsible and cannot distinguish him from the type of unwilling addict who loses his agency to addiction. Thus, the choice between broad and narrow identificationism appears to rest in large part on whether this kind of case is possible.

However, cases of this kind, if any, would be rare, and for the vast majority of cases, we would not have to worry about the difference between narrow and broad identificationism, nor about the agent's ability to do otherwise. Overall then, this investigation 


\section{IDENTIFICATIONIST VIEWS}

upholds the merits of using the identificationist framework to understand freedom. Nonetheless, we have seen that the identificationists have gone astray in switching from the bare-bones to the robust concepts of identification. Velleman's and Smith's versions of identificationism, as the only ones that employ the bare-bones concept, are on the most promising track, but they have not received sufficient attention and vetting. Thus, much of the task of developing a proper specification of bare-bones identification, which would be a foundation of a promising version of identificationism, remains.

Since broad identificationism leaves the relevant sense of the possibility of doing otherwise vague, the reader may wonder what happens if the relevant sense cannot be specified, or if it turns out that human beings are not in fact capable of doing otherwise in the relevant sense. Broad identificationism would then collapse into narrow identificationism and all we have said about narrow identificationism would still hold.

\section{Acknowledgments}

Special thanks to John Martin Fischer, Meghan Griffith, and Dana Nelkin for very helpful comments on earlier drafts of this entry, and to David Beglin for all-around invaluable assistance.

\section{References}

Arpaly, N. and Schroeder, T. (1999) "Praise, Blame and the Whole Self," Philosophical Studies 93: 161-88. Bratman, M. (1996) "Identification, Decision, and Treating as a Reason," Philosophical Topics 24: 1-18.

Bratman, M. (2000) "Reflection, Planning, and Temporally Extended Agency," The Philosophical Review 109: 35-61.

Fischer, J.M. (2012) "Mission Creep: Responsibility and Autonomy," Philosophical Issues 22: 165-84.

Fischer, J.M. and Ravizza, M. (1998) Responsibility and Control. Cambridge: Cambridge University Press.

Frankfurt, H. (1969) "Alternative Possibilities and Moral Responsibility," Reprinted in Frankfurt, H. (1988) The Importance of What We Care About. Cambridge: Cambridge University Press, pp. 1-10.

Frankfurt, H. (1971) "Freedom of the Will and the Concept of a Person," Reprinted in Frankfurt, H. (1988) The Importance of What We Care About. Cambridge: Cambridge University Press, pp. 11-25.

Frankfurt, H. (1987) "Identification and Wholeheartedness," Reprinted in Frankfurt, H. (1988) The Importance of What We Care About. Cambridge: Cambridge University Press, pp. 159-76.

Frankfurt, H. (1992) "The Faintest Passion," Reprinted in Frankfurt, H. (1999) Necessity, Volition, and Love. Cambridge: Cambridge University Press, pp. 95-107.

Frankfurt, H. (2002) "Reply to John Martin Fischer," in The Contours of Agency: Essays on Themes from Harry Frankfurt, S. Buss and L. Overton (eds). Cambridge: MIT Press, pp. 27-31.

Hobbes, T. (1997) Leviathan, R.E. Flatman and D. Johnston (eds). New York: W.W. Norton \& Co.

Jaworska, A. (2007) "Caring and Internality," Philosophy and Phenomenological Research 74: 529-68.

Nelkin, D.K. (2011) Making Sense of Freedom and Responsibility. Oxford: Oxford University Press.

Seidman, J. (2009) "Valuing and Caring," Theoria 75: 272-303.

Shoemaker, D. (2003) "Caring, Identification, and Agency," Ethics 114: 88-118.

Smith, A. (2004) "Conflicting Attitudes, Moral Agency, and Conceptions of the Self," Philosophical Topics $32: 331-52$.

Smith, A. (2005) "Responsibility for Attitudes: Activity and Passivity in Mental Life," Ethics 115: 236-71.

Velleman, J.D. (1992) "What Happens When Someone Acts?" Reprinted in Velleman, J.D. (2000) The Possibility of Practical Reason. Oxford: Oxford University Press, pp. 123-43.

Velleman, J.D. (2000) The Possibility of Practical Reason. Oxford: Oxford University Press.

Watson, G. (1975) "Free Agency," Reprinted in Watson, G. (2004) Agency and Answerability: Selected Essays. Oxford: Oxford University Press, pp. 13-32.

Watson, G. (1987) "Free Action and Free Will," Reprinted in Watson, G. (2004) Agency and Answerability: Selected Essays. Oxford: Oxford University Press, pp. 161-96. 


\section{Further Reading}

Frankfurt, H. (1971) "Freedom of the Will and the Concept of a Person," Reprinted in Frankfurt, H. (1988) The Importance of What We Care About. Cambridge: Cambridge University Press, pp. 11-25. (In this seminal paper, Frankfurt first puts forth his "hierarchy of desire" view, according to which one acts freely just in case one acts on a second-order volition-a second-order desire that one's first-order desire move one to act.)

Frankfurt, H. (1987) "Identification and Wholeheartedness," Reprinted in Frankfurt, H. (1988) The Importance of What We Care About. Cambridge: Cambridge University Press, pp. 159-76. (Frankfurt supplements his "hierarchy of desire" view, aligning one's identification with one's decision to act on a second-order volition.)

Frankfurt, H. (1992) “The Faintest Passion," Reprinted in Frankfurt, H. (1999) Necessity, Volition, and Love. Cambridge: Cambridge University Press, pp. 95-107. (Frankfurt introduces the notion of satisfaction: one is identified with a desire that moves one to action insofar as one has a highest-order volition concerning that desire and there is no conflict at the highest-order level about endorsing that desire.)

Velleman, J. D. (1992) "What Happens When Someone Acts?" Velleman, J.D. (2000) The Possibility of Practical Reason. Oxford: Oxford University Press, pp. 123-43. (Velleman criticizes views, such as Frankfurt's or Watson's, that equate the standpoint of the agent with a nexus of attitudes, and he argues that the standpoint of the agent must be represented by an attitude with specific content, from which an agent cannot become alienated without ceasing to be an agent-Velleman suggests this is the desire to act for reasons.)

Watson, G. (1975) "Free Agency," Reprinted in Watson, G. (2004) Agency and Answerability: Selected Essays. Oxford: Oxford University Press, pp. 13-32. (Watson here criticizes Frankfurt's "hierarchy of desire" view on the grounds that it is unclear why second-order volitions, which are just another sort of desire, should have special authority to represent the agent, and he suggests that one acts freely insofar as one's motivation for acting is backed by one's evaluative judgment about how to live one's life.)

Watson, G. (1987) "Free Action and Free Will," Reprinted in Watson, G. (2004) Agency and Answerability: Selected Essays. Oxford: Oxford University Press, pp. 161-96. (In this paper, Watson introduces a worry for his own (1975) view, suggesting that he cannot account for "perverse" cases of action, cases in which an agent stands fully behind and identifies with choices or motivations that go against her better judgment.)

\section{Related Topics}

Reasons-Responsive Theories of Freedom

Classical Compatibilism

Willpower, Freedom, and Responsibility

Addiction

Self-Control and Akrasia

The Relationship Between Moral Responsibility and Freedom 


\section{3 \\ REASONS-RESPONSIVE
THEORIES OF FREEDOM \\ Michael McKenna}

Reasons-responsive theories of freedom explain free agency in terms of an agent's sensitivity to reasons. An agent who acts freely is responsive to variation in a suitable spectrum of reasons. Because many theorists understand free will in terms of the control condition(s) necessary for moral responsibility, reasons-responsive theories are also frequently cast in terms of theories of the control condition for moral responsibility.

\section{Reasons-Responsiveness: An Initial Characterization}

Consider a familiar case of unfree action: an agent, Handy, washes his hands from an extreme compulsive hand-washing disorder. Suppose Handy gets his hands dirty one day and washes them. It might be tempting to think that in washing his hands, he does so freely and that this consists in his responding appropriately to a good reason to wash his hands. But as it happens, Handy would have washed his hands at the time whether they were dirty or not in response to any number of whacky reasons. He would have washed them if they were clean and he just saw a garbage truck down the street, if someone within earshot had whispered the word 'germ,' or even if, when his hands were truly dirty, doing so would result in his being seriously injured (suppose for some reason that in the circumstances the only way for him to wash his hands requires breathing poisonous gas). What this suggests is that, in this situation, when Handy washes his hands when they are dirty, it is fortuitous that he does so in response to a good reason. The role of good reasons is not properly integrated with what leads him to action. This in turn suggests that Handy is not in control of his hand washing in a stable way. So he does not wash his hands freely.

Contrast Handy with Dandy. Dandy is a bit of a 'dandy.' He enjoys fancy dress and a very clean, well-groomed appearance. As such, Dandy might have an idiosyncratic commitment to keep his hands (and the rest of him) super clean-far more so than most normal people with good hygiene. Thus, he finds lots of good reasons for washing his hands and few good reasons not to, but his hand-washing is still well-integrated with the full range of reasons animating how he acts. Dandy, for instance, would not risk serious harm to himself just to wash his hands, and while he does find lots of good reasons to wash them, as in keeping with his dandy ways, these many reasons are still related to his overall goals and projects as a sane person. He does not wash them, for instance, just because the very mention of germs causes him to think horrible dirty 
thoughts. Suppose, like Handy, Dandy dirties his hands in a situation much like the one Handy was in and so Dandy washes his hands. It seems that while Handy does not wash his hands freely, Dandy does.

The cases of Handy and Dandy suggest two related features of a credible reasonsresponsive theory. First, to understand freedom in terms of reasons-responsiveness involves an agent's control in relation to a spectrum of potential but non-actual reasons, and this spectrum comes in degrees. Second, the actual causal processes issuing in free action must involve the agent's reasons-responsive resources.

To explain, consider first the matter of degree. Note that Handy would be regarded as unfree in his hand washing even if there was some sliver of reasons that would get him not to wash his hands compulsively in some situations. If, for instance, a murderer was threatening to kill Handy's child if Handy washed his hands, or if Handy's house was on fire and he were about to be incinerated, he would forgo washing his hands. It is just that the range of reasons to which Handy would be responsive is too limited to be the basis for his being free in any credible sense that would bear on free will and moral responsibility. Now consider Dandy. Suppose that there is some range of reasons to which Dandy would not be responsive but should be, even by his own lights. While he often would wash his hands in response to good reasons, there are a few occasions where even he is a bit reckless and does not wash them. For instance, perhaps he should wash them just before tending to his toddler's breakfast, but when in a hurry he fails to do so. In this way, he is not perfectly reasons-responsive. Still he is reasons-responsive enough to model his freedom on the spectrum of reasons to which he is responsive.

Now consider the matter of the actual causal process. When Dandy washes his hands because they are dirty, we have reason to think that the reasons for hand-washing are related to his rational abilities as an agent and that these abilities function well in playing a proper role in his act of hand washing. This is in part because his adequate degree of reasons-sensitivity is good evidence that Dandy is 'wired' in the right way. Handy, by contrast, appears to be driven largely by his compulsion, at least in this sphere of his life. When he washes his dirty hands, there is reason to think that his dirty hands do not even play the right sort of role as a reason for him that is part of the etiology leading to his act of hand washing. To the extent that his dirty plans are part of the actual cause of his hand washing, it is by way of a deviant causal process that is not an appropriately rational one, and so is in this way not freedom-conferring. It is likely to be a fluke or an unreliable occasion for him to give expression to his compulsion. (The issue of deviant as opposed to non-deviant causal processes in the production of action is familiar to those who work on the theory of action. To illustrate, consider a famous case due to Donald Davidson [1963] of a climber who realizes that to survive he must let go of a rope. The thought so unnerves him that he does so, but in a way that was not intentional. Here, he does respond to reasons, but not through a causal process that involves his controlling his action. As readers might suspect, it is extremely diffcult in these contexts to nail down in just what non-deviant as opposed to deviant causal processes consist.)

\section{Reasons-Responsiveness and the Compatibilism vs. Incompatibilism Debate}

In recent times, reasons-responsive theories are advanced mostly by compatibilists (about both free will and moral responsibility). But the appeal of a reasons-responsive 
theory is not limited to compatibilists; its merits extend beyond any having to do with the metaphysical problems associated with worries about determinism or indeterminism. Some (e.g., Irwin 1980) contend that Aristotle advanced a reasons-responsive theory as a way of explaining how man is a rational animal. And it is plausible to think that Kant required something like reasons-responsiveness-being able to track reasons in support of duty - as a condition for morality actually applying to persons. Historical origins aside, the contemporary appeal of a reasons-responsive theory is in part a matter of accounting for freedom in terms of features of agency that are distinctive of persons. Lots of agents with the capacity for sophisticated goal-directed activity, such as titmice or coyotes, are uncontroversially able to exercise a considerable amount of control over their environments. As such, there is a clear sense in which they possess a certain kind of freedom. But if one seeks a theory of freedom that explains what is distinctive about the freedom available to persons (skeptical worries aside), then it is plausible that this can be found in rational capacities unique to persons.

(I take it to be an open question which creatures—actual and possible-are persons. I assume the fictional non-human character Data from Star Trek is a person, as are the Replicants in the film Bladerunner. Moreover, it is not incredible that many actually existing non-human primates and other mammals are persons. Naturally, this turns on the philosophical question of what a person is as well as empirical questions about animal cognition.)

What of the appeal for compatibilists? Why have so many contemporary compatibilists opted for a reasons-responsive theory? (See, for example, Dennett 1984, 2003; Wolf 1990; Fischer and Ravizza 1998; Haji 1998; Nelkin 2011; Brink and Nelkin 2013; McKenna 2013; Vihvelin 2013; Sartorio, forthcoming) Here are two reasons:

First, an agent's reasons-responsiveness is established in terms of the range of reasons to which she would be responsive at the time in which she acts. This in turn can be explained (even if not reduced to) a set of counterfactuals about how an agent would have acted had certain reasons been salient that were not salient in her actual context of action. These propositions are not in any way inconsistent with the assumption that at the time an agent acted she was determined. Why? Determinism is a thesis about what is physically possible for an agent given her exact actual past and the totality of the laws of nature. Determinism is silent as regards truths about how an agent would act were her past (or the laws) just a bit different than they were. Counterfactuals that postulate non-actual but possible reasons involve antecedents that presuppose, relative to the actual world, that the past is a bit different.

Second, as noted when reflecting on the cases of Dandy and Handy, reasons-responsive theories help to show how it is that, when an agent is reasons-responsive, the actions she freely preforms are caused in the right way by resources that are distinctive of persons. One of the major burdens of any theory of freedom-compatibilist or incompatibilistis a matter of showing that an agent is the right kind of source of her actions. Many appeal to restrictive views about the metaphysics involved, which along with a requirement of indeterminism might include the notion of agent-causation. This is especially so for incompatibilists. Reasons-responsive compatibilist theories, however, are seemingly able to draw just upon far more mundane resources. Nevertheless, these resources assign a special role to the agent qua rational being as the source of her action. Moreover, by doing so, reasons-responsive theorists develop a familiar compatibilist strategy of distinguishing between kinds of causes of actions, some of which are freedom-defeating 
and others that are not. In a wide range of conditions in which the causes of an agent's actions are freedom-defeating (compulsion, psychosis, phobia, coercion, delusion, and so on) the agent is not reasons-responsive.

So as to avoid any misimpressions, and in keeping with my earlier remarks about the general appeal of reasons-responsive theories, it should be emphasized that it is open to incompatibilists seeking to develop a libertarian theory of freedom to adopt a reasonsresponsive view. They might, for instance, take on the major elements in a compatibilist's proposal and then simply add a further requirement of indeterminism (suitably located) to cement a libertarian thesis (e.g., see Ginet 2006). The point of this section was simply to showcase the simple features that make reasons-responsive theories appealing to compatibilists. These features aid the compatibilists, but they do not entail a compatibilist conclusion.

\section{Reasons-Responsiveness and Frankfurt's Attack on the Freedom to Do Otherwise}

One important detail about reasons-responsive theories is that they pose special puzzles for compatibilists who also defend Harry Frankfurt's (1969) thesis that the freedom that is required for moral responsibility does not include the ability (and so freedom) to do otherwise. Frankfurt's argument for this conclusion, if sound, would be of considerable benefit to compatibilists, since it would allow them to sidestep a powerful incompatibilist argument for the conclusion that if determinism is true, no agent has the ability to do otherwise. This incompatibilist argument, the Consequence Argument (Ginet 1966; Wiggins, 1973; van Inwagen 1975, 1983), has it that, under the assumption of determinism, a person is able to do otherwise only if she is able to alter the past or violate a law of nature, neither of which, it seems, an ordinary human person can do. While many able compatibilists have attempted to refute the Consequence Argument (e.g., Lewis 1981; Horgan 1985, 2015; Campbell 1997; Kapitan 2002; Vihvelin 2004, 2013; Berofsky 2012), others have instead seen that with Frankfurt's argument, they can grant the soundness of the Consequence Argument - perhaps just for the sake of argument-but then advance Frankfurt's argument to show that the freedom to do otherwise is not the sort that matters for moral responsibility. What of the freedom that is required for moral responsibility? That freedom, it can be argued, is compatible with determinism even if the freedom to do otherwise is not. John Martin Fischer (1994) calls this thesis semicompatibilism, and along with his coauthor Mark Ravizza, has offered the most sustained defense of it (1998). (Other compatibilists advancing a source compatibilist thesis include Frankfurt [1971], McKenna [2013] and Sartorio [forthcoming].) In this chapter, let us call this sort of compatibilism source compatibilism and the sort that requires the freedom to do otherwise leeway compatibilism. And call the two sorts of freedom source freedom and leeway freedom.

To appreciate why it is that reasons-responsive theorists have trouble accepting Frankfurt's argument consider the examples motivating that argument. Here is a simple one, Shoot Smith, truncated just for the purposes of our present discussion:

Jones seeks to shoot Smith, which he does on his own. As it happens, unknown to Jones, Black wants Jones to shoot Smith and would prefer that Jones do so on his own. But Black arranges things so that, if there is any reason to think that Jones would not shoot Smith, Black would cause Jones (maybe by direct 
manipulation of his brain) to shoot Smith. Since Jones acts on his own, Black never intervenes. He thus remains only a counterfactual intervener.

In the example Shoot Smith, Jones exercises source freedom, yet due to Black's presence, he lacks leeway freedom. So, granting that he is morally responsible, it appears that leeway freedom is not required for moral responsibility. For ease of discussion in what follows, let us refer to Black (or anything playing Black's role in a Frankfurt example) as a counterfactual intervener.

Frankfurt's argument and the examples he used to advance it, like Shoot Smith, are regarded as highly controversial. Some reasons-responsive compatibilists reject it and instead build a reasons-responsive theory of leeway freedom (e.g., Nelkin 2011; Vihvelin 2013). But other reasons-responsive compatibilists take advantage of the dialectical benefits noted above, and so endorse Frankfurt's argument. These source compatibilists face a striking problem. It looks on its face as if, whatever sort of freedom an agent does possess in a Frankfurt example, it cannot be accounted for in terms of reasons-responsiveness. Why? It seems that an agent in a Frankfurt example is not reasons-responsive. If she were given different reasons to do otherwise, she would not respond otherwise by acting otherwise. The counterfactual intervener would see to that by causing her to act as she does when she acts on her own for the reasons she actually has. Hence, a reasons-responsive theory of freedom appears ill-suited for the freedom found in a (successful) Frankfurt example. Does this mean reasons-responsive compatibilists are forced to defend a leeway theory?

Fischer and Ravizza (1998) attempt to get around this problem for source compatibilists by distinguishing between an agent's reasons-responsiveness and instead an agent's own actually-operative reasons-responsive mechanism of action. That is, they distinguish between an agent-based and a mechanism-based reasons-responsive theory. According to Fischer and Ravizza, an agent in a Frankfurt example is not reasonsresponsive because she would not respond otherwise to different reasons by acting otherwise, given the presence of the counterfactual intervener. But now consider the actual causal process that led to the agent acting as she did when she acted on her own. Just call that causal process, or at least the internal states of the agent in that process, the agent's mechanism of action. If we focus upon just this mechanism and then ask if it is reasons-responsive, we will have to test that by considering whether it would respond differently to reasons. But we can only run this test by considering possible situations in which it is allowed to function unimpeded in the presence of different reasons. This, however, requires that we 'factor out' the presence of the counterfactual intervener. Then we can determine how the agent would act by way of her mechanism of action were her mechanism left to function on its own. Thus, Fischer and Ravizza advance compatibilism by way of a mechanism-based reasons-responsive theory of source freedom.

While Fischer and Ravizza's mechanism-based proposal offers an ingenious way to join a reasons-responsive theory to source compatibilism, it comes at a cost. Explaining reasons-responsiveness in terms of mechanisms rather than agents gives rise to a range of objections. Some contend that it is counterintuitive and it is better to theorize in terms of agents responding to reasons rather than in terms of mechanisms (Wallace 1997). Some object that it is just not clear what a mechanism is supposed to be (Watson 2001). Others claim that the postulation of mechanisms does not do any work in the theory (Ginet 2006). Finally, others raise more specific worries about how to identify and individuate mechanisms one from the other (McKenna 2001). Can we be 
confident when we hold fixed an agent's mechanism of action, as Fischer and Ravizza require $(1998: 39,40)$, and consider the influence of different reasons that it is the same mechanism we are assessing? (For Fischer's replies, see his [2004: 166-71] reply to McKenna; his [2004: 169-71] reply to Watson; his [2006: 333, 334] reply to Ginet; and his [2012: 144-62] reply to Wallace.)

More recently, building on a point made by Carl Ginet (2006), I have argued that any mechanism-based view risks hamstringing an agent's responsiveness in a way incompatible with her freedom (McKenna 2013). For instance, in Ginet's example, an agent freely drives her car down a highway from a mechanism of unreflective habit. But if conditions were different (a closed road and no other routes she is familiar with), she would be given reason to deliberate about what other exit she should take. Her reasons-sensitivity should make room for that. However, if as Fischer and Ravizza would have it, we hold fixed the mechanism of unreflective habit, then we cannot assess how she would respond to reasons in deliberation, since this would not be unreflective habit. As I have argued, Ginet's example reveals a general, structural problem with mechanism-based views. Any sophisticated system with subsystems will be designed so that the system as a whole — in this case the entire person as a practical agent-will be able to allow some subsystems (mechanisms) to run uninhibited unless there is occasion for 'switching' to other subsystems that can then take over. The flexibility of the system is thus designed to be greater than the flexibility of the subsystems composing it. The problem for any mechanism-based account of freedom is that it will always risk limiting the freedom-conferring responsiveness of the agent to the responsiveness of the mechanism (subsystem) by which the agent acts. But our standards for assessing an agent's freedom in terms of responsiveness to reasons should surely be standards of the reasons for agents to act - not parts of agents. If I am correct, then reasons-responsive theories should be developed in agent-based terms rather than mechanism-based resources. (See Fischer [forthcoming] for the reply.) This, however, leads back to the problem for source compatibilists faced earlier: agent-based reasons-responsive views appear to require leeway freedom.

Can a source compatibilist overcome the apparent conflict with constraints on an agent-based reasons-responsive approach? The crucial question is this: is there a way for a source compatibilist to claim that an agent in a Frankfurt example is reasons-responsive even if, were different reasons put to the agent, the agent would not respond to those reasons by acting differently than she does when the counterfactual intervener remains dormant? I have argued (McKenna 2013) that we can make sense of an agent's responsiveness even in a Frankfurt example as follows: while in the presence of different reasons, an agent would not act differently (the counterfactual intervener would see to that), but the agent would not act as she does for her own reasons. As such, in contexts in which the intervener takes over, she would be reacting differently than she did when she produced her actions as a result of her own reasons. In this way, an agent even in a Frankfurt example is responsive to different reasons, even if her responsiveness would not manifest itself in her acting any differently.

Yet a different way to advance an agent-based reasons-responsive approach has been developed by Carolina Sartorio (forthcoming). Sartorio turns to the metaphysics of causation and relies upon the thesis that absences can be causes (or instead quasi-causes). If so, then the absence of certain reasons can be part of the actual cause for an agent's acting as she does. To explain, suppose Jones is not in a Frankfurt example when he decides to shoot Smith and that he is suitably reasons-responsive. Among the reasons 
to which he would react differently and not shoot Smith is the reason that Smith's child happens to be with him at the time. (In the actual situation, Smith's child was not present.) Thus, it is true in this case- because there is no counterfactual intervenerthat if Smith's child were with him, Jones would not shoot Smith. Now add the presence of the counterfactual intervener, Black. This renders the preceding counterfactual false. But granting Sartorio's thesis about absence causation, this remains true: In the actual scenario in which Jones acts— when Black remains dormant - the absence of a reason not to shoot Smith (a reason that involves the presence of Smith's child) is one of the actual causes of Jones's shooting Smith. Were that absence not part of the causal mix, Jones would not have shot Smith on his own. In this way, in acting as he does, Smith is responsive to a range of reasons that include not shooting Smith if his child is with him. This is an elegant proposal.

To summarize the results of this section, there are three positions reasons-responsive compatibilists might adopt when faced with Frankfurt's argument. One strategy is to adopt a leeway compatibilist thesis and reject the contention that a free agent in a Frankfurt example is unable to do otherwise (e.g., Nelkin 2011; Vihvelin 2013). Nelkin (2011) and Vihvelin (2004, 2013), for instance, argue that in a Frankfurt example, an agent retains the uninterfered-with ability to do otherwise when she is left to act on her own. A second strategy is to accept the lessons of Frankfurt's argument, embrace source compatibilism and opt for a mechanism-based theory (e.g., Fischer and Ravizza 1998). Yet a third also involves a commitment to source compatibilism, but seeks to explain reasons-responsiveness even in the context of a Frankfurt example by way of agentbased resources (e.g., McKenna 2013; Sartorio, forthcoming).

\section{Getting Down to the Nitty-Gritty Details: Capturing the Spectrum of Responsiveness}

Some reasons-responsive theorists only gesture in the direction of what is involved in suitable responsiveness to reasons as would be required for a theory of free will and moral responsibility (e.g., Dennett 1984). But most work out in some detail what responsiveness consists in and how to test for an adequate degree of sensitivity.

One way to clarify responsiveness is in terms of the content of the reasons that matter for the ability to act freely. Of course, a well-known historical version of this is Kant's, with his requirement that rational beings be able to grasp the Categorical Imperative and act from duty. But in recent times, Susan Wolf (1990) proposed such a compatibilist view, which she called the Reason View, in terms of reasons in support of, as she put it, the True and the Good. The capital letters indicate the metaethical commitments Wolf intended. Even more recently, Dana Nelkin (2011) advances a compatibilist view like Wolf's in terms of the ability to act for good reasons. Lest one think that Nelkin's understanding of good reasons is meant to be neutral regarding any metaethical commitments, note that on her view, when one does wrong and is blameworthy, she does not act for good reasons. Her blameworthiness is thus dependent on her ability to act for good reasons when she fails to do so.

The Wolf-Nelkin reasons-responsive view gives rise to a much-discussed asymmetry thesis: praiseworthiness does not require leeway freedom but blameworthiness does. If an agent acts in a morally exemplary way for the right reasons and is praiseworthy for it, she does not need leeway freedom, since in acting as she did, she clearly was responsive to good reasons-she actually acted on them. When, on the other 
hand, an agent does wrong and is a candidate for blameworthiness, her being blameworthy turns on whether she was able to respond to good reasons. Thus, Wolf and Nelkin are source compatibilists about praiseworthiness and leeway compatibilists about blameworthiness.

While the Wolf-Nelkin view is intuitive in certain ways-freedom is about the ability to act for good reasons-it makes room for an unusual result. Suppose that determinism is incompatible with leeway freedom but is not incompatible with source freedom. Then praiseworthiness would be compatible with determinism but blameworthiness would not. Naturally, Wolf and Nelkin resist this result by defending compatibilism about a reasons-responsive ability to do otherwise. But other reasons-responsive theorists (e.g., Fischer and Ravizza 1998) resist. In their view, Frankfurt's argument refutes the Wolf-Nelkin asymmetry thesis since it can be used to show that blameworthiness does not require leeway freedom any more than praiseworthiness does. The dispute remains highly contested. (See Nelkin's reply [2011].) I'll not pursue it further here.

A different strategy for developing a reasons-responsive theory involves explaining the spectrum of responsiveness to show the way reasons hang together and as well what counts as a sufficient pattern of responsiveness (recall our discussion of the cases of Handy and Dandy). (This distinct strategy is not in competition with one that specifies the content of the reasons to which one should be responsive in order to count as suitably free. For an example of a view that joins the two approaches, see Brink and Nelkin [2013].) In a highly influential paper, Bernard Gert and Timothy Duggan (1979) explained reasons-responsiveness in terms of patterns of threats and incentives that would be sufficient for an agent to act other than as she does. If, for instance, $\$ 100$ would not be sufficient to convince me to lie to my boss but $\$ 1,000$ would, then my sane response to such incentives should pass a plausible test that like-reasons falling on a scale of descending and ascending strength should also fail to move me or instead move me. So, if $\$ 100$ would not move me, then neither should $\$ 99, \$ 98$, and so on. Likewise, if $\$ 1,000$ would move me, then so should $\$ 1,001$, $\$ 1,002$, and so on.

While Gert and Duggan's suggestion showed promise, it was Fischer and Ravizza (1998) who demonstrated just how sophisticated this strategy could be. In what follows, I will examine Fischer and Ravizza's proposal in some detail. As explained in the preceding section, they account for reasons-responsiveness in terms of the sensitivity of mechanisms of action. In this section, I will forgo qualifying each point in terms of a mechanism's sensitivity and instead just write in terms of agents. This is adequate for present purposes.

The problem with Gert and Duggan's original proposal according to Fischer and Ravizza $(1998: 67,68)$ is that the patterns identified as sufficient for reasons-responsiveness might permit such a strange collection of preferences that it would be consistent with an agent who is not sane, and so not sufficiently free. Suppose as in the example above that I would not for some reasons and would for others be moved to lie to my boss in the ways specified (would not for incentives of $\$ 100$ and under and would for incentives of $\$ 1,000$ and over). But suppose also I would be moved to lie if my pea soup told me to do so, or if a Springsteen song was playing on the radio, which I would take as a secret message from Martians, and so on. The problem for the Gert and Duggan proposal, as Fischer and Ravizza put it, is that it relied exclusively on a quantitative assessment of the spectrum of responsiveness required for freedom. So, according to Fischer and 
Ravizza (1998: 71-3), what is also needed beyond an adequate quantity of reasonssensitivity is a sanity constraint, which they propose in terms of a hypothetical thirdparty interviewer seeking to establish whether the agent has a coherent understanding of the world that is grounded in reality. To this they also add a requirement that an agent be able to grasp moral reasons (1998: 77-81). They do not commit as Wolf and Nelkin do to more substantive metaethical views about morality and reasons. All they require is that an agent be able to understand moral reasons as providing sufficient conditions for action.

To develop their reasons-responsive theory, which they call Moderate ReasonsResponsiveness (MRR), Fischer and Ravizza distinguish between two different aspects of reasons-responsiveness: reasons-receptivity and reasons-reactivity. Reasons-receptivity is a matter of recognizing and assessing the reasons an agent takes to be sufficient to act otherwise or instead to persist in acting as she does. Reasons-reactivity is a matter of choosing and acting in accord with the reasons one takes to be sufficient for acting. The distinction appears to be implicit in Kant's conception of moral freedom. Susan Wolf draws a similar distinction in developing her view (1990), and other reasons-responsive theorists (e.g., Brink and Nelkin 2013; McKenna 2013; Kozuch and McKenna 2016); have also relied upon this distinction, drawing mostly from Fischer and Ravizza's illuminating development of it.

According to Fischer and Ravizza, the spectrum of sensitivity to reasons is asymmetric between the receptivity and the reactivity components. Whereas the degree of receptivity has to be fairly robust, as is in keeping with the conditions specified in the previous paragraph, the degree of an agent's reactivity need not. How so? An agent like Dandy must be receptive to a considerable range of sufficient reasons to do otherwise (as well as reasons to persist in acting as he does), yet he need only be reactive to a very limited range of reasons. Thus, as Fischer and Ravizza put it, MRR requires moderate receptivity but only weak reactivity.

Why the asymmetry? One reason is to make room for a familiar sort of blameworthy conduct. Sometimes an agent freely does what she knows to be morally wrong in the face of reasons she herself takes to be good reasons not to act as she does. She might act recklessly or succumb to temptation. In such cases, she is receptive to good reasons to act otherwise, but in fact she does not react to them. If a requirement of reasonsresponsiveness for free and responsible action is that an agent is just as reactive to the spectrum of reasons to which she is receptive, then when she fails to react as she knows she should, the theory would have it that she acts unfreely and so is not morally responsible and blameworthy for what she does. That would count strongly against the theory. It is for this reason that a reasons-responsive theory needs to allow for an asymmetry.

Granting that some sort of asymmetry should be accommodated, is it correct that mere weak reactivity is sufficient for acting freely? All that Fischer and Ravizza require for weak reactivity is that there is some reason to which an agent is receptive that is such that, if it were present, the agent would react to it and act otherwise. They contend that this is enough to establish that an agent is able to react otherwise to any of the reasons to which she is receptive. That is, according to Fischer and Ravizza, reacting otherwise to one good reason to do so proves a general ability (of an agent's mechanism) to react otherwise to any good reasons to do otherwise. But now recall the case of Handy, who suffered from a compulsive handwashing disorder and so was unfree when he washed his hands. Handy was reactive to some reasons to do otherwise. Recall he 
would not wash his hands if someone threatened to kill his child should he wash his hands. Still, he was not reactive to a large range of good reasons not to do so-including being exposed to poisonous gas. As such, his freedom was impaired. Handy is a counterexample to Fischer and Ravizza's requirement of weak receptivity. (This criticism is developed by McKenna [2005] and Mele [2006]. In reply to Mele, Fischer [2012: 190] grants the point and has revised his view so that what is required is stronger than mere weak reactivity.)

As an amendment to Fischer and Ravizza's theory, I propose a requirement of moderate reasons-receptivity and a degree of moderate reasons-reactivity that may be but need not be weaker than the receptivity component. Regardless, the reactivity component must be moderate enough to display a stable, sane way of relating to a sufficiently robust spectrum of reasons. Why weaker? Recall, as explained two paragraphs back, we want to leave open the possibility of an agent who is receptive to a reason to which, as a matter of fact, she would not be reactive and, as upshot be blameworthy for so acting. (I am indebted to David Brink and Dana Nelkin for an especially fruitful conversation regarding how to clarify the reactivity component. Brink and Nelkin helped me to see that it was too restrictive to require that the receptivity component be weaker. That's right. Still, it is important that it may be weaker.)

It is worth asking why Fischer and Ravizza opted for such a striking asymmetry thesis when a mild proposal like the one I offer here seems an obvious contender. One reason has to do with the battle between compatibilists and incompatibilists. Fischer and Ravizza wanted to establish that reactivity to one reason to do otherwise is sufficient to establish an agent's ability to react to any reason to do otherwise (from the same mechanism). They thus contended that "reactivity is all of a piece" (1998: 73). Call this thesis RIP. If RIP fails, then the ability to react to good reasons to do otherwise, as in the case of Handy, is selective; an agent might be able to react to some good reasons to do otherwise but not others. This provides an opening for an incompatibilist attack. How so? Consider an agent who is blameworthy and does not react to the good reasons to do otherwise that morality counsels. Suppose furthermore that she is receptive to these good reasons. In this case, the actual good reasons to do otherwise are reasons to which, as a matter of fact, she did not react. The worry is this: what if she is not able to react to these reasons? If so, then when she acts for bad reasons rather than the good ones, isn't she unfree?

If in response the reasons-responsive theorist attempts to establish an agent's ability to react otherwise to the very reasons present that an agent did not react to, it appears we are back to requiring leeway freedom. So the source compatibilist element of Fischer and Ravizza's view is threatened. Finally, the incompatibilist critic might then note that under the assumption of determinism, holding fixed the past and the laws, in the nearest possible world where the agent faces these actual reasons- the actual world-the agent does not react otherwise by acting for the morally good reasons. This then suggests, the incompatibilist might continue, drawing upon the Consequence Argument, that she is not able to react to those good reasons in that context, at least not without the ability to alter the past or the laws.

In my estimation, reasons-responsive source compatibilists have the resources to answer these incompatibilist charges. They can do this while rejecting RIP and embracing a version of MRR that requires only a modest reasons-reactivity thesis. (Elsewhere [2005], I have taken up this issue and defended Fischer and Ravizza against these incompatibilist charges.) But I will not pursue that topic here. My only goal in this section was 
to set out the skeleton of a carefully worked out reasons-responsive theory and then just show where and how an incompatibilist might resist it.

\section{Conclusion}

In closing, it is worth reflecting upon reasons-responsive compatibilist theories in relation to their closest compatibilist competitors, which are mesh theories of freedom, such as Harry Frankfurt's (1971) and Gary Watson's (1975). Mesh theories account for freedom in terms of the internal psychological architecture of a person qua practical agent. When an agent's action-generating subsystems mesh in a harmonious way, then she acts freely. But when her actions arise from a deviant or unharmonious mesh, then the agent's freedom is compromised. On Frankfurt's (1971) view, for instance, the different systems are cast in terms of orders of desires. When an agent's higher-order desires about which desires she wants to move her to action are misaligned with which first-order desires do lead her to action, then she is unfree. But when all goes smoothly, she instead acts freely. Watson (1975) instead works from distinct systems playing different roles in the exercise of free agency. An agent's motivational system aids in moving her about and gives rise to various kinds of desires. An agent's evaluative system provides resources for assessing what an agent values and takes to be worthy of pursuing. When an agent acts in such a way that her motivational system is out of whack with her evaluative system, she acts unfreely. She acts freely when the elements mesh harmoniously.

Note that one advantage that reasons-responsive theories appear to have over mesh theories is that they seem to be able to account much more easily for such phenomena as weakness of will. On a view like Frankfurt's, for instance, when an agent acts from desires that she does not want to move her, she is simply unfree. And this gets things right in certain cases, such as action from strong addictive desires. But in some such cases, it seems more plausible to say that the agent freely acts from desires that at a higher order she prefers not to act from. A mesh view like Frankfurt's has a difficult time explaining this (McKenna 2011). Reasons-responsive theories, by contrast are able to explain rather easily the difference between unfree actions from addictive desire as in contrast with free, weak-willed actions. In the former, the agent is responsive to a narrower class of reasons than in the latter.

While this shows that reasons-responsive theories have an advantage over mesh theories, there are also points at which it seems mesh theories are preferable. For instance, reasons-responsive theories do not offer resources to capture a unique fact about how our freedom as human agents can be compromised. Sometimes our struggles are internal to our own psychology, as in the case of the addict who struggles with cravings that she feels plague her in some way. Mesh theories offer the resources to identify how an agent's own psychological architecture can be a source of trouble for her freedom and responsibility. One interesting possibility worth exploring is a hybrid view that joins the resources of reasons-responsive and mesh theories (see McKenna and Van Schoelandt, forthcoming).

\section{Acknowledgments}

For helpful comments, I am indebted to Terry Horgan, Carolina Sartorio, and Mark Timmons. I am especially grateful to Meghan Griffith for an extremely insightful and thorough set of detailed comments on an earlier draft of this chapter. I would like to 
thank Meghan along with Neil Levy and Kevin Timpe for inviting me to contribute to this volume. Finally, I am grateful to the John Templeton Foundation for resources that helped support this project.

\section{References}

Berofsky, B. (2012) Nature's Challenge to Free Will. Oxford: Oxford University Press.

Brink, D. and Nelkin, D. (2013) "Fairness and the Architecture of Responsibility," in D. Shoemaker (ed.), Oxford Studies in Agency and Responsibility, Vol. 1. New York: Oxford University Press, pp. 284-313.

Campbell, J. (1997) "A Compatibilist Theory of Alternative Possibilities," Philosophical Studies 88: 319-30.

Davidson, D. (1963) “Actions, Reasons and Causes," Journal of Philosophy 60: 685-700.

Dennett, D. (1984) Elbow Room: Varieties of Free Will Worth Wanting. Cambridge: MIT Press.

Dennett, D. (2003) Freedom Evolves. London: Penguin Books.

Fischer, J. (1994) The Metaphysics of Free Will. Oxford: Blackwell Publishers.

Fischer, J. (2004) "Responsibility and Manipulation," Journal of Ethics 8: 145-77.

Fischer, J. (2006) "The Free Will Revolution (Continued)," Journal of Ethics 10: 315-45.

Fischer, J. (2012) Deep Control: Essays on Free Will and Value. New York: Oxford University Press.

Fischer, J. (forthcoming) "The Freedom Required for Moral Responsibility," in D. Brink, S. Meyer, and C. Shields (eds), Virtue, Happiness, and Knowledge: Essays for Gail Fine and Terence Irwin. Oxford: Clarendon Press.

Fischer, J. and Ravizza, M. (1998) Responsibility and Control: An Essay on Moral Responsibility. Cambridge: Cambridge University Press.

Frankfurt, H. (1969) "Alternate Possibilities and Moral Responsibility," Journal of Philosophy 66: 829-39.

Frankfurt, H. (1971) "Freedom of the Will and the Concept of a Person," Journal of Philosophy 68: 5-20.

Gert, B., and Duggan, T. (1979) "Free Will as the Ability to Will," Noûs, 13: 197-217.

Ginet, C. (1966) "Might We Have No Choice?" in K. Lehrer (ed.), Freedom and Determinism. New York: Random House, pp. 87-104.

Ginet, C. (2006) "Working with Fischer and Ravizza's Account of Moral Responsibility," Journal of Ethics, 10: 229-53.

Haji, I. (1998) Moral Appraisability. New York: Oxford University Press.

Horgan, T. (1985) "Compatibilism and the Consequence Argument," Philosophical Studies 47: 339-56.

Horgan, T. (2015) "Injecting the Phenomenology of Agency into the Free Will Debate," in D. Shoemaker (ed.), Oxford Studies in Agency and Responsibility, Vol. 3. Oxford: Oxford University Press, pp 34-61.

Irwin, T.H. (1980) "Reason and Responsibility in Aristotle," in A.O. Rorty (ed.), Essays on Aristotle's Ethics. Berkeley: University of California Press, pp. 117-55.

Kapitan, T. (2002) “A Master Argument for Incompatibilism?" in R. Kane (ed.), The Oxford Handbook of Free Will. New York: Oxford University Press, pp. 127-57.

Kozuch, B. and McKenna, M. (2016) "Free Will, Moral Responsibility, and Mental Illness," D. Moseley and G. Gala (eds), Philosophy and Psychiatry. New York: Routledge Press, pp. 89-113.

Lewis, D. (1981) "Are We Free to Break the Laws?" Theoria 47: 113-21.

McKenna, M. (2001) "Review of John Martin Fischer and Mark Ravizza's Responsibility \& Control," Journal of Philosophy XCVIII: 93-100.

McKenna, M. (2005) "Reasons Reactivity and Incompatibilist Intuitions," Philosophical Explorations 8: $131-43$.

McKenna, M. (2011) "Contemporary Compatibilism: Mesh Theories and Reasons-Responsive Theories," in R. Kane (ed.), Oxford Handbook of Free Will, 2nd ed. New York: Oxford University Press, pp. 175-98.

McKenna, M. (2013) "Reasons-Responsiveness, Agents, and Mechanisms," in D. Shoemaker (ed.), Oxford Studies in Agency and Responsibility, Vol. 1. New York: Oxford University Press, pp. 151-84.

McKenna, M. and Van Schoelandt, C.V. (forthcoming) "Crossing a Mesh Theory with a ReasonsResponsive Theory," in A. Buckareff, C. Moya, and S. Rosell (eds), Agency and Responsibility. Basingstoke: Palgrave Macmillan.

Mele, A. (2006) "Fischer and Ravizza on Moral Responsibility," Journal of Ethics 10: 283-94.

Nelkin, D. (2011) Making Sense of Freedom and Responsibility. Oxford: Oxford University Press.

Sartorio, C. (forthcoming) Causation and Free Will. Oxford: Oxford University Press.

van Inwagen, P. (1975) "The Incompatibility of Free Will and Determinism," Philosophical Studies 27: 185-99.

van Inwagen, P. (1983) An Essay on Free Will. Oxford: Clarendon Press. 


\section{REASONS-RESPONSIVE THEORIES OF FREEDOM}

Vihvelin, K. (2004) “Free Will Demystified: A Dispositional Account," Philosophical Topics 32: 427-50.

Vihvelin, K. (2013) Causes, Laws, and Free Will: Why Determinism Doesn't Matter. New York: Oxford University Press.

Wallace, R. Jay. (1997) "Review of John Martin Fischer's The Metaphysics of Free Will," Journal of Philosophy 94: 156-9.

Watson, G. (1975) "Free Agency," Journal of Philosophy 72: 205-20.

Watson, G. (2001) "Reason and Responsibility," Ethics 111: 374-94.

Wiggins, D. (1973) "Towards a Reasonable Libertarianism," in T. Honderich (ed.), Essays on Freedom of Action. London: Routledge and Kegan Paul, pp. 31-62.

Wolf, S. (1990) Freedom within Reason. Oxford: Oxford University Press.

\section{Further Reading}

Brink, D. and Nelkin, D. (2013) "Fairness and the Architecture of Responsibility," in D. Shoemaker (ed.), Oxford Studies in Agency and Responsibility, Vol. 1. New York: Oxford University Press, pp. 284-313. (In this paper, Brink and Nelkin defend a leeway view of freedom. In doing so, they couple an account of responsiveness to good reasons with a fair-opportunity account of freedom.)

Fischer, J. (2012) Deep Control: Essays on Free Will and Value. New York: Oxford University Press. (In this book, Fischer offers a comprehensive defense of his theory of free will developed with Mark Ravizza [1998], and responds to numerous critics. It is an excellent follow-up to his earlier work and reads as a natural extension of Fischer and Ravizza (1998).)

Fischer, J., and Ravizza, M. (1998) Responsibility and Control: An Essay on Moral Responsibility. Cambridge: Cambridge University Press. (Fischer and Ravizza's [1998] is perhaps the most through development of a compatibilist reasons-responsive theory, especially in developing an account of the proper spectrum of responsiveness and in applying the view to the full scope of the various items for which an agent can be morally responsible, including acts, omissions, and consequences of acts and omissions.)

Gert, B. and Duggan, T. (1979) "Free Will as the Ability to Will," Noûs 13: 197-217. (In this ground breaking paper, Gert and Duggan propose a way to theorize about freedom and responsiveness in terms of a suitable spectrum of reasons. This paper served as the basis for the view Fischer and Ravizza [1998] developed.)

Kozuch, B. and McKenna, M. (2016) "Free Will, Moral Responsibility, and Mental Illness," D. Moseley and G. Gala (eds), Philosophy and Psychiatry. New York: Routledge Press, pp. 89-113. (In this paper, Kozuch and McKenna apply a reasons-responsive theory of freedom to questions of psychiatric disorder and in doing so offer an account of how an agent might still be free and responsible even if sometimes her conduct is causally influenced by mental illness.)

McKenna, M. (2011) "Contemporary Compatibilism: Mesh Theories and Reasons-Responsive Theories," in R. Kane (ed.), Oxford Handbook of Free Will, 2nd ed. New York: Oxford University Press, pp. 175-98. (In this paper, McKenna surveys recent reasons-responsive theories and assesses them along with a competitor identificationist (or mesh-theory) approach of the sort advanced by Harry Frankfurt or Gary Watson.)

McKenna, M. and Van Schoelandt, C.V. (forthcoming) "Crossing a Mesh Theory with a Reasons-Responsive Theory," in A. Buckareff, C. Moya, and S. Rosell (eds), Agency and Responsibility. Basingstoke: Palgrave Macmillan. (In this paper, McKenna and Van Schoelandt propose a theory of freedom that couples the best elements of a reasons-responsive view with the best elements of a mesh theory.)

Nelkin, D. (2011) Making Sense of Freedom and Responsibility. Oxford: Oxford University Press. (In this book, Nelkin defends an agent-based leeway account of freedom in terms of reasons-responsiveness. Nelkin's book offers an advancement on the basic idea developed by Wolf [1990] and in doing so, Nelkin argues against source theoretical reasons-responsive approaches like Fischer and Ravizza's [1998].)

Sartorio, C. (forthcoming) Causation and Free Will. Oxford: Oxford University Press. (In this book, Sartorio develops a source compatibilist account of freedom in terms of reasons-responsiveness. Unlike Fischer and Ravizza's approach mechanism-based approach, she argues for an agent-based approach. She argues that the problems forcing Fischer and Ravizza away from an agent-based view and to a mechanism-based view can be avoided by attending to the metaphysics of causation.)

Wolf, S. (1990) Freedom within Reason. Oxford: Oxford University Press. (Wolf's highly influential compatibilist theory of freedom relies on the elegant idea that freedom is a matter of responsiveness to reasons that track what is good and true. In this respect, Wolf establishes a substantive constraint on the content of what kinds of reasons an agent needs to be responsive to in order to be adequately free.) 


\section{Related Topics}

Semicompatibilism

Identificationist Views

Dispositional Compatibilism

Frankfurt-Style Examples

Aristotle

Immanuel Kant

Determinism 


\section{4 \\ CLASSICAL \\ COMPATIBILISM \\ Bernard Berofsky}

The term 'compatibilism' in the free will/determinism controversy has a long and established history, meaning obviously that free will is compatible with determinism. (It is not obvious and indeed a subject of much dispute what the expressions 'free will' and 'determinism' mean. Also, some philosophers use the term 'compatibilism' to refer to the view that determinism is compatible with moral responsibility or with free will understood in a sense according to which free will is necessary for moral responsibility.) There is, however, no commonly accepted definition of 'classical compatibilism.' Thus, for one charged with assigning 'classical compatibilism' a meaning, it is more fruitful and avoids arbitrariness to begin by recognizing the central presupposition of the existence of this concept. The term originated in order to highlight the striking convergence of compatibilist views found within British philosophy from Thomas Hobbes in the mid-seventeenth century to twentieth-century figures such as G. E. Moore and A. J. Ayer. This pantheon includes seminal figures such as John Locke, David Hume, and John Stuart Mill. With notable exceptions, such as Thomas Reid, Richard Price, and F. H. Bradley, compatibilism prevailed within the Anglo-American tradition until the mid-twentieth century, when it confronted stiff resistance from British incompatibilists such as C. A. Campbell and J. L. Austin and American thinkers such as Roderick Chisholm. Shortly thereafter, two internal revolts, one led by P. F. Strawson and the other by Harry Frankfurt, produced very different forms of compatibilism, so that we may now block out that 300-year-old tradition that terminates around the beginning of the final third of the twentieth century - the period preceding Strawson and Frankfurt-as the 'classical' period. As some compatibilists continue to hold beliefs quite similar to the compatibilists of the classical period, they must now explain why they are not enamored of the newer versions advanced by thinkers like Strawson and Frankfurt.

\section{The Dispositional Analysis of Free Will}

Although modern (pre-twentieth century) British compatibilists share fundamentally similar views about the nature of free will, we do find significant differences in matters of detail. Consider first the similarities in the definitions each offers of liberty (used then as a synonym of freedom): 
Hobbes: A free agent is he that can do if he will and forbear if he will ("Of Liberty and Necessity" in Chappell 1999: 39).

Locke: $\quad$ Liberty . . . consists in a power to do, or not to do . . . as we will (1690/1959: 352).

Hume: By liberty, then, we can only mean a power of acting or not acting, according to the determinations of the will (1748/1955: 104).

Mill: $\quad$ The feeling of (moral) freedom is just the knowledge that one can alter one's will if one wishes (1874: 550).

The most striking similarity among these definitions is their conditional character. The dependence of our actions on our wills_or, in Mill's case, our wills on our wishes-is captured by these conditional formulations. This characterization of freedom persists in their twentieth-century successors (see Moore 1912; Schlick 1939; Ayer 1954; NowellSmith 1954; Smith 2003; Vihvelin 2004; Fara 2008). For many people, classical compatibilism is dispositionalism, that is, an agent is free if and only if he acted in the way that he did because he wanted (or chose) to do so and would have acted otherwise if he had wanted (chosen) to. Since twentieth-century critics such as J. L Austin (1961), Roderick Chisholm (1964), and Keith Lehrer (1968) identified key difficulties in these analyses, most philosophers have concluded that dispositionalism fails and classical compatibilism fails with it. If so, the question then for compatibilists is: can we retain the fundamental idea that freedom is acting out of desires from within the self rather than forces outside the self by aligning ourselves with one of the new forms of compatibilism (Strawson 1962; Frankfurt 1971) or can we salvage another version of a nondispositional form of compatibilism?

Dispositionalism, with its emphasis on acting from one's own choice or desire, implicitly captures the classical compatibilist emphasis upon the absence of external constraints, a condition that permits one's actions to conform with one's own will rather than an outside force. Thus, Hobbes adds immediately to the aforementioned quotation: "Liberty is the absence of external impediments."

Hobbes' and the classical empiricist thinkers' emphasis on external circumstances as impediments is regarded by many twentieth-century compatibilists as overly narrow. The latter would cite internal compulsions, phobias, mental illness, and perhaps other elements, such as undue stress, as additional internal impediments to action. Of course, this newer position imposes an additional burden on these thinkers, as one must find a way to distinguish those internal causes that inhibit freedom from the normal desires, beliefs, and values that cause decision or action. For all compatibilists allow that sufficient causation of will or action does not automatically preclude freedom. The compatibilist mantra that not all causation is compulsion requires an account that would enable us to distinguish one from the other. We thus find a twentieth-century literature, including important works by Robert Nozick (1969) and Harry Frankfurt (1973), which attempt to understand notions such as compulsion, coercion, manipulation, and threats and to distinguish them from causal accounts of decision making and action that are compatible with freedom.

Although, on the whole, classical compatibilists emphasized freedom of action rather than freedom of will, there are differences of detail. Hobbes entirely rejects the will for it had been characterized by many as a faculty of the soul and Hobbes, the materialist, would have none of that. So, for him, action is caused by the prevailing desire directly, without the intermediary of willing or intention formation. But Mill, who thinks of the 
will in purely naturalistic terms, is comfortable with freedom of will. Both Locke and Hume also allow acts of will.

Whether we are talking about freedom of action or freedom of will and whether or not we adopt an expansive account of impediments-an expansive account would permit as impediments internal compulsions, phobias, excessive stress, etc.—classical compatibilists agree that freedom is at least partly constituted by a disposition to will or act on one's own desires rather than forces external to us.

\section{Counterfactual Power and Free Will}

Beyond the adoption of a conditional account of freedom by twentieth-century compatibilists is another important common feature, to wit, the emphasis upon counterfactual power. It has often been said that the hallmark of a free agent is the fact that, whatever decision is in fact made, the agent could have decided (or acted) otherwise. Those who conceive of free will in this way are often said to hold a forking paths model of freedom, which can be interpreted in a weak or strong way. Leeway compatibilism is the weak view that freedom is constituted by the presence of these multiple opportunities for action and determinism would certainly seem to be compatible with freedom in this sense. But the more interesting position is the stronger claim that freedom is constituted by the power to take advantage of these opportunities. For example, providing me with a magnificent tennis racket, tennis shorts, and a tennis date with Roger Federer provides me with an opportunity to beat him, but hardly the power to do so. Since, obviously, the agent has the power to act as he does, the crucial component of freedom is the power to act otherwise, so-called counterfactual power. PAP, or the Principle of Alternate Possibilities, originally presented as the claim that counterfactual power is essential to moral responsibility, is the same claim advanced by twentieth century compatibilists once "moral responsibility" is replaced by "freedom of will," (Frankfurt 1969) although these compatibilists would generally be sympathetic with the original PAP as well. The demand for counterfactual power is often associated with the dispositional analysis of freedom; but they should in fact be distinguished for the following reason.

The dispositional analysis suffers from difficulties many regard as fatal. One of these was cited by Keith Lehrer (1968). Suppose that I want (desire) to do A and because of that, I do A. It is, of course, also true that, if I had wanted to do B, then I would have done B. Now, on the dispositional analysis, it follows from the latter that I could have done B. But that cannot be right because it is possible that I cannot do B at all. Why? The reason is that it is logically possible that the very desire to do A renders it impossible to do B. If the dispositional analysis were correct, it should be logically impossible that I cannot do B (for "I would do B if I wanted to" is true and means "I can do B"). The dispositional analysis, therefore, fails. But the recognition of the failure of the conditional analysis does not falsify the view that free will requires counterfactual power. One may still believe that, for free will, however one acts, one could have done otherwise. One will then have to produce a better, nondispositional or categorical analysis of power, to be sure. Thus, if one regards counterfactual power as a component of free will, one's position is not automatically refuted by the failure of the dispositional analysis.

The modern philosophers take differing positions on the importance of counterfactual power. Locke explicitly affirms the existence of counterfactual power in his discussion of freedom: "The power of moving my hand is not at all impaired by the determination of my will, which at present orders rest" (1690/1959: 369). So I retain 
the power to do otherwise (move) even when I will otherwise (rest). Locke goes on to identify that power to do either as liberty.

In a familiar passage, Locke denies that an agent is free to leave a room just because he stays in the room because he wants to; the room may be locked, in which case he is not free to leave, whether or not he knows the door to be locked. As his loss of freedom is based on the fact that he would not leave if he wanted to, his unfreedom can be explained in terms of the failure of the conditional analysis alone and is not, therefore, as clear a statement of the importance of counterfactual power found in the above quoted passage. Since the agent is staying in the room because he wants to, his action may be said to be voluntary; but for Locke, voluntariness is not sufficient for freedom.

In this regard, Locke's view is different from that of Hobbes. Hobbes explicitly affirms that voluntariness is necessary and sufficient for freedom. Counterfactual power is neither present nor essential. He says: "There is no such thing as an agent which, when all things requisite to action are present, can nevertheless forbear to produce it ... There is no such thing as freedom from necessity" (Chappell 1999: 41). Moreover, unlike Hume, Hobbes does not soften the necessity of causes by adopting a theory of causation according to which there is no objective necessary connection between cause and effect. So in spite of the fact that my action is necessary, that I cannot act otherwise, that the origin of the prevailing desire is irrelevant (and may, therefore, be the product of manipulation, threat, or hypnosis), I remain free. Hobbes would find few contemporary philosophers in sympathy with a view as extreme as this one. Hobbes' views ought, therefore, to be set apart from those of Locke, Hume, and Mill, who form the foundation of twentieth-century compatibilism.

Where, then, do Hume and Mill stand on the relation of counterfactual power to freedom or liberty? Mill appears to take Locke's side. He says "A person feels morally free who feels that his habits or his temptations are not his masters, but he theirs; who even in yielding to them knows that he can resist" (1874: 550; italics mine).

Mill's views are very similar to Hume's, including views about the nature of necessity, power, and causation. But there is no quotation in Hume that, like Mill's, enables us to identify Hume as a defender of the view that liberty requires counterfactual power. We know, of course, that Hume rejects the objective character of both power and necessity, reducing both to the constant conjunctions of events discovered through experience. We know, as well, that Hume does not object to providing truth conditions for statements of power and necessity; and in the case at hand, he does so in terms of conditionals. Though I did B, I could have done A because I would have done A had I wanted. But what would he have said if he became convinced that the conditional analysis is faulty? Is there a categorical sense he would be prepared to ascribe to counterfactual power? For Hume to deny counterfactual power in this case, he would have to think that the desire to do $B$ (that is followed by the doing of $B$ ) renders me impotent to do A. The problem is that two readings can be given to "if I want to and do B, I am impotent to do A." Just as we allow that the billiard ball, when struck by the 8 ball cannot burrow into the table, so can we allow that I cannot do A when I want to do B (in a deterministic world). Yet, on another reading, there is nothing literally, objectively, barring me from doing A. If the world is, in itself, just a sequence of distinct events that happens to fall under regularities, there is nothing in the world that denies me the power to do A (especially if I would do A if I tried to do so).

Although Hume's position may not be as straightforward as that of Locke and Mill, the idea that free will requires both a dispositional analysis and counterfactual power 
becomes locked in at the beginning of the twentieth century among most Englishspeaking philosophers. The philosopher most responsible for this development is G. E. Moore. Shortly after the turn of the twentieth century, Moore wrote:

We certainly have not got Free Will, in the ordinary sense of the word, if we never really could, in any sense at all, have done anything else than what we did do ... But ... the mere fact ... that we sometimes can, in one sense, do what we don't do, does not necessarily entitle us to say that we have Free Will.

(Moore 1912: 87)

So counterfactual power is a necessary, but not sufficient condition of free will. Now, Moore concedes that there are several senses of "can" and "could" and it is even true that, in one sense, "if everything is caused, it must be true, in some sense, that we never could have done, what we did not do" (1912: 90); but he denies that this is the sense of "can" that is relevant to free will. What, then, is the relevant sense of "can?"

When we say we could have done a thing which we did not do, we often mean merely that we should have done it, if we had chosen ... this fact is in no way inconsistent with the principle that everything has a cause ... It has been sometimes held that this (BB: We should have done it, if we had chosen) is what we mean (BB: when we assert that we have Free Will) and I cannot find any conclusive argument to the contrary. And if it is what we mean, then it absolutely follows that we really have Free Will.

(Moore 1912: 93)

So free will is constituted by counterfactual power together with a conditional analysis of that power, an analysis that establishes compatibilism in virtue of its consistency with determinism. This basic position was adopted by many Anglo-American philosophers who followed, thereby continuing the tradition that was begun in some ways by Thomas Hobbes, but more precisely by the British empiricists.

\section{Self-Determinism and Free Will}

The compatibilist identification of freedom with acting out of one's own desires rather than being coerced is designed to capture to some extent what it is to be self-governed. Yet it is evident for many reasons that these simple accounts do not do justice to a fully satisfactory account of self-governance. Indeed, the reason that many contemporary compatibilist thinkers felt it crucial to add certain conditions that behave as motivators, for example, phobias, as inimical to freedom is that such conditions, though internal, appear to undermine rather than express our true selves. Upon reflection, we would prefer not to be motivated by them; they appear as intruders into our system of values and reasons. So there is an internal bifurcation between elements that belong to the self and those that are external to the self.

It is true that the classical compatibilists did not, in general, take seriously the particular charge that we must look deeper into the nature and source of the desire or will that proximately causes action; nor did they worry that determinism, a doctrine to which they all subscribed, undermined the possibility of genuine self-determination. 
The burden on compatibilists, then, is to formulate a conception of self-determination that is more sophisticated than the one we find in the writings of the classical compatibilists, yet, of course, one that can exist in a deterministic world. A familiar effort along these lines may be found in the writings of Harry Frankfurt, a nonclassical compatibilist, who believes that it is sufficient for free will to add to the requirement that the agent be acting because of his desires the further requirement that self-reflection reveals no qualms about his being the sort of agent who acts from such desires (1999). The most important condition that renders Frankfurt's position nonclassical is his repudiation of the counterfactual power requirement in favor of an ancient view, found in the writings of the Stoic philosophers according to which internal harmony is the central component of freedom.

If, however, a compatibilist prefers to be true to the classical empiricist tradition, thereby rejecting the identification of self-origination with internal harmony, he must find within the resources of this tradition a way to add to voluntariness to reach genuine self-origination. Hobbes provides a partial response by insisting that an agent under nonphysical coercion, for example, being threatened, is acting voluntarily or freely, for, in submitting to the threat, the 'compulsion' is working through and, therefore, depends on the deliberative mechanism. As reflective of the agent's deeper desires, the submission displays his freedom. Locke disagrees, adopting the view closer to common sense according to which the will can be coerced (1690/1959: 354). Views similar to Hobbes' may be found in both F. H. Bradley (1927) and, much earlier, St. Augustine (387/1993). They both insist that the will cannot be coerced.

Bradley is a source incompatibilist, contending that determinism is incompatible with self-origination. Under determinism, the ultimate source of our actions lies outside the self. The self is constructed from materials that are not part of the self-genes or their antecedents. I do not mind the thought that my actions spring from my character; but I do mind that my character/self is formed from without.

Source incompatibilism aside, the classical compatibilist account of freedom as doing something because one wants to clearly needs supplementation. I may be doing something because I want to do it when I have been manipulated or indoctrinated, when I am suffering from addiction, when I am emotionally unstable, when I repudiate the desire that is motivating me, or when I am acting under extreme, debilitating fear. (It must be noted that some of these incompatibilist complaints would be undermined by an acceptance of the Augustine-Hobbes-Bradley idea that the will cannot be compelled.) In any case, it appears that classical compatibilism alone does not have the resources to provide the elements for genuine self-determination.

\section{Liberty of Indifference and Luck}

Since, in general, the classical compatibilists believed that a free agent is one who is acting from his own desires and values, unmanipulated and uncoerced-the freedom of spontaneity as it is sometimes called - they did not accept as a requirement on freedom that agents possess what is known as the liberty of indifference. Fearful of any internal causes, even one's own desires-after all, they may derive from sources beyond the person-defenders of the liberty of indifference sought freedom in the absence of determining causes. But as Locke says (1690/1959: 368), how is such a defender to locate the indifference? It would be absurd to think that freedom requires that an agent's judgment fails to determine the will and equally absurd to believe that it is to be found in an 
indetermination of judgment following upon deliberation. Hume conceded (1748/1955: 103) that, in performing an action, we sometimes feel a looseness between our deliberations and our will, as if the will depends on nothing. It is accompanied by the feeling that, since nothing determines the will, the latter can go either way. But, Hume concludes, this feeling is an illusion.

These questions of the classical compatibilists put the incompatibilist in a quandary. An agent in an indeterministic world who acts from no source, out of the blue, reflecting neither his desires nor his values nor his character, is not the paradigm of a free agent. So self-determinism must be distinguished from indeterminism. What sort of features, then, must an undetermined event have to count as self-determination? It is no boon to free will to find indetermination only in the distant past, long before the birth of the person in question. That sort of indetermination does not enhance my freedom now. But if we find indetermination at some stage in the deliberative process antecedent to a decision, what is to prevent us from regarding that event just as a matter of chance or randomness rather than self-determination? If, after a deliberation in which all considerations incline me to choose A and I then indeterministically choose B, can I be said to have chosen B freely?

Defenders of event-causal libertarianism, such as Robert Kane, offer a reply to this argument (1996). The defense includes an appeal to the distinction between determinism and causation. That is, Kane argues, that an agent can act on or because of her desires and, thus, be in some sense self-determined, without supposing that this causal relation presupposes the existence of a determining cause of the action. Others turn to the theory of agency. That is, agents, as undetermined causes, have the power to break into the causal order and directly cause an intention or an action without there being an event or state, such as a desire or reason, that is really doing the causing, as in conventional causal relations. Agent theorists must then explain how it is that, without a causal explanation of the agent's activity, agent causation constitutes a response to the original charge of randomness or nonrationality. Defenses of agent causation against these charges are proffered both by believers in agent causation and also by those, like Randolph Clarke (2003) and Derk Pereboom (2001), who believe that the theory is essential for freedom, but are dubious that this type of causation really exists in our world. Roderick Chisholm, in an extreme version of this doctrine, finds this agent causation in all human acts. "At least one of the events that is involved in any act is caused, not by any other event, but by the agent, by the man" (Chisholm 1966: 29).

The classical compatibilist rejection of the liberty of indifference is accompanied by a strengthening of the compatibilist doctrine. Locke suggests that freedom actually requires some sort of causation for nowhere in the chain of events that lead to a decision will indetermination actually enhance freedom. This thought is to be expressed by Hume, too, in the second part of his chapter on liberty and necessity in the Inquiry (1748/1955: 107), except that he makes the point in terms of moral responsibility rather than free will. He observes that one can only judge a man when his actions proceed from some cause in his character and disposition. An action can be bad, but its agent is accountable only if it derives from some durable component of his nature.

This thought, that determinism is actually not detrimental, but rather essential, to free will became a cornerstone of twentieth-century compatibilism. The thesis was presented in dramatic form in an influential article by R. E. Hobart (1934) and was defended in one form or another by many compatibilists of that century (Schlick 1939; Ayer 1954; Nowell-Smith 1954: 281-3). 
One way of expressing this compatibilist thesis is to claim that a decision that is genuinely undetermined, that proceeds from nothing, that is genuinely a 'product' of chance, may rightly be called a matter of luck. If the agent happens to act in a fortuitous way, the luck is good, otherwise bad. If a person does A, but his exact duplicate in another possible world with the exact same history and laws acts differently, the difference can only be 'explained' by luck. Thus, contemporary versions of this debate have revolved around the status of this 'argument from luck.' Alfred Mele (2006, 2013,2014 ) argues that the libertarian can acknowledge luck, while retaining the belief that this sort of luck is compatible with freedom and moral responsibility. Bernard Berofsky (2012) also rejects the appeal to luck against the incompatibilist by denying that an undetermined act (i) must be thought of as emanating from nothing and (ii) cannot be construed as under the control of the agent where self-control is the essence of free will.

\section{Application of Hume's Regularity Theory Against Incompatibilism}

Hume, the most influential of the classical compatibilists, advanced a distinctive critique of incompatibilism based on his theory of necessity. Noting that many thinkers confound the connection between cause and effect, for example, between the will and action, with "force, and violence, and constraint" (1748/1955: 369), it is easy to understand why someone would deny that a causally necessitated action is free. But on Hume's theory of necessity, the only objective relation we find is constant conjunction or regularity, the consistency of same cause accompanied by same effect. Thus, it has been argued (Berofsky 2012), that Hume's theory of necessity may subvert the incompatibilist position by removing the confusion that has led some to view determinism as implying that human actions are performed under compulsion or constraint. If one can advance a sophisticated regularity theory of causation, free of the difficulties that plague many traditional accounts, it will be clear that causation does not automatically yield compulsion.

Many compatibilists insist on a distinction between the necessity of laws (nomic necessity) and compulsion. On a Humean denial of nomic necessity, one must still characterize the difference between ordinary subsumption under law and compulsion or coercion. Views differ on the definition of the latter concepts when no appeal to necessity is allowed. One possibility involves a resuscitation of dispositionalism just for this narrow purpose. One may simply note the difference between the results of serious efforts. I am not compelled by my noncompulsive desires for I would act differently if I tried to do so; whereas I am compelled to drop the 300-pound weight for I would drop it no matter how hard I tried not to. (This appeal to counterfactuals does not reintroduce necessity for there are clearly nonnecessary subjunctive conditionals, for example, as a committed truth teller, if $\mathrm{P}$ were false, I would not tell you that it is true.)

Paul Russell (2014) rejects this Hume-based compatibilist argument on the grounds that compatibilists locate freedom in the nature of the cause (ordinary desires or values) rather than the nature of the causal relation. Hence, differing views on the nature of that relation are irrelevant.

It is true that our desires cause our actions regardless of which theory of causation is correct. Thus, I disagree with Russell that only causal necessity will provide us with (i) a connection between will and action that is essential to the freedom that confers moral responsibility and (ii) power over our actions and the world. 
Russell's position makes sense only if he is interpreting Hume as a causal eliminativist. To be sure, the defender of Hume must make good on his claim that Hume was basically right about causation. He must argue that all this talk of connection that Russell regards as intrinsic to causation can ultimately be replaced by a modern version of the regularity theory of causation. Whether or not this is true, a compatibilist would be advised to treat the regularity theory, not as a proposal to eliminate causation, but rather as a statement of the nature of causation, as did all who attempted to defend improved versions of Hume's position (Mill 1874; Braithwaite 1957; Nagel 1961; Ramsey 1978; Lewis 1994).

It is also true that the power required for freedom incorporates counterfactual power and, as we saw earlier, a dispositional analysis of counterfactual power is seriously problematic. Thus, devotees of the classical compatibilist tradition are required to produce a satisfactory nondispositional analysis.

\section{Moral Responsibility}

Classical compatibilists share yet another position that has influenced twentieth-century adherents. Hobbes observes that, even if the necessity of an action results from election by God, "I deny that it makes consultations to be in vain" (Chappell 1999: 25). Determinism or necessity, a doctrine that is different from fatalism, clearly allows that the addition of a new causal component may alter the effect. Thus, we may, in a deterministic world, influence others. Hume observes that the influence exerted by rewards and punishments is both genuine and desirable as a matter of social utility (1748/1955: 371).

In the twentieth century, Humean Moritz Schlick (1939) placed this idea at the center of his theory of moral responsibility, arguing in favor of a utilitarian conception according to which the moral responsibility of an agent is grounded in the possibility of the efficacy of rewards or punishments. This view was contrasted by Schlick with a desert- or retaliation-based conception, which Schlick viewed as "barbarous" (1939: 152). Nowell-Smith also defends utilitarianism as a doctrine about the purposes of laws, to wit, that their adoption is based upon the belief that they "promote the ends of the members of that society" (1954: 239). Retributivists argue that such views do not adequately account for the deeply held belief that individuals often deserve to be blamed whether or not doing so will have desirable consequences such as reform and deterrence.

\section{Bibliography}

Augustine, St. (387/1993) On Free Choice of the Will, trans. T. Williams. Indianapolis: Hackett Publishing Company.

Austin, J.L. (1961) "Ifs and Cans," in J.O. Urmson and G. Warnock (eds), Philosophical Papers. Oxford: Clarendon Press, pp. 153-80.

Ayer, A.J. (1954) "Freedom and Necessity," in S.M. Cahn (ed.), Philosophical Essays. New York: St. Martin's Press, pp. 271-84.

Berofsky, B. (2012) Nature's Challenge to Free Will. Oxford: Oxford University Press.

Bradley, F.H. (1927) "The Vulgar Notion of Responsibility in Connexion with the Theories of Free Will and Necessity," in F.H. Bradley (ed.), Ethical Studies. Oxford: Clarendon Press, pp. 3-57.

Braithwaite, R.B. (1957) Scientific Explanation. Cambridge: Cambridge University Press.

Chappell, V. (ed.) (1999) Hobbes and Bramhall on Liberty and Necessity. Cambridge: Cambridge University Press.

Chisholm, R. (1964) “J. L. Austin's philosophical papers," Mind 73: 20-5. 


\section{BERNARD BEROFSKY}

Chisholm, R. (1966) "Freedom and Action," in K. Lehrer (ed.), Freedom and Determinism. New York: Random House, pp. 20-35.

Clarke, R. (2003) Libertarian Accounts of Free Will. Oxford: Oxford University Press.

Fara, M. (2008) "Masked Abilities and Compatibilism," Mind 117: 843-65.

Frankfurt, H. (1969) "Alternate Possibilities and Moral Responsibility," Journal of Philosophy 66: 829-39.

Frankfurt, H. (1971) "Freedom of the Will and the Concept of a Person," Journal of Philosophy 68: 5-20.

Frankfurt, H. (1973/1988). "Coercion and Moral Responsibility," in H. Frankfurt (ed.), The Importance of What We Care About. New York: Cambridge University Press. First published in Essays on Freedom of Action, T. Honderich (ed.). London: Routledge \& Kegan Paul, pp. 65-86.

Frankfurt, H. (1999) "The Faintest Passion," in H. Frankfurt (ed.), Necessity, Volition, and Love. Cambridge: Cambridge University Press, pp. 95-107.

Hobart, R.E. (1934) "Free Will as Involving Determinism and Inconceivable Without It," Mind 43: 1-27.

Hobbes (1654) Of Liberty and Necessity. London: John Davies.

Hobbes (1656) The Questions Concerning Liberty, Necessity, and Chance. London: Printed for Andrew Crook.

Hume, D. (1739/1961). A Treatise of Human Nature. Garden City: Doubleday.

Hume, D. (1748/1955). An Inquiry Concerning Human Understanding. New York: Library of Liberal Arts.

Kane, R. (1996) The Significance of Free Will. New York: Oxford University Press.

Lehrer, K. (1968) "Cans Without Ifs," Analysis 29: 29-32.

Lewis, D. (1994) "Humean Supervenience Debugged," Mind 103: 473-89.

Locke, J. (1690/1959). An Essay Concerning Human Understanding, Vol. 1. New York: Dover.

Mele, A. (2006) Free Will and Luck. New York: Oxford University Press.

Mele, A. (2013) "Moral Responsibility and the Continuation Problem," Philosophical Studies, 162: 237-55.

Mele, A. (2014) "Luck and Free Will," Metaphilosophy 45: 543-57.

Mill, J.S. (1874) A System of Logic. Book 3, ch. 4. London: John W. Parker.

Moore, G.E. (1912) Ethics. New York: Oxford University Press.

Nagel, E. (1961) The Structure of Science. New York: Harcourt Brace.

Nielsen, K. (2002) "The Compatibility of Freedom and Determinism," in R. Kane (ed.), Free Will. Malden: Blackwell, pp. 39-46.

Nowell-Smith, P.H. (1954) "Freedom and Responsibility," in P.H. Nowell-Smith (ed.), Ethics. Harmondsworth: Penguin, pp. 285-90.

Nozick, R. (1969) "Coercion," in S. Morgenbesser, P. Suppes, and M. White (eds), Philosophy, Science, and Method: Essays in Honor of Ernest Nagel. New York: St. Martin's Press, pp. 440-72.

Pereboom, D. (2001) Living Without Free Will. Cambridge: Cambridge University Press.

Ramsey, F.P. (1978) Universals of Law and of Fact. London: Routledge and Kegan Paul.

Russell, P. (2014) "Hume on Free Will," in E. Zalta (ed.), The Stanford Encyclopedia of Philosophy (Fall 2008 Edition), available from: http://plato.stanford.edu/archives/fall2008/entries/hume-freewill/ (accessed 22 June 2016).

Schlick, M. (1939) "When Is a Man Responsible?" in M. Schlick (ed.), Problems of Ethics. Englewood Cliffs: Prentice-Hall, pp. 143-58.

Smith, M. (2003) "Rational Capacities, or: How to Distinguish Recklessness, Weakness, and Compulsion," in S. Stroud and C. Tappolet (eds), Weakness of Will and Practical Irrationality. Oxford: Clarendon Press, pp. $17-38$.

Strawson, P.F. (1962) "Freedom and Resentment," Proceedings of the British Academy 48: 1-25.

Vihvelin, K. (2004) "Free Will Demystified: A Dispositional Account," Philosophical Topics 32: 427-50.

\section{Further Reading}

Since contemporary classical compatibilism builds on the work of the British empiricists, those with historical interests can consult Free Will and Four English Philosophers (2006) by Joseph Rickaby [Lenox: Hard Press Publishing; originally published in 1906], or one can read the essays in this volume on the individual philosophers. The philosopher who served as a bridge between those thinkers and philosophers whose views were to dominate thinking about free will for most of the twentieth century was G. E. Moore (Moore, G.E. [1912] Ethics. New York: Oxford University Press). One of the few contemporary philosophers to hold a position close to classical compatibilism is Kadri Vihvelin (Vihvelin, K. [2012] Causes, Laws, and Free Will: Why Determinism Doesn't Matter. Oxford: Oxford University Press). For a review of the difficulties 


\section{CLASSICAL COMPATIBILISM}

confronted by classical compatibilists, see Bernard Berofsky (2011) "Compatibilism without Frankfurt: Dispositional Analyses of Free Will," in R. Kane (ed.), The Oxford Handbook of Free Will, 2nd ed. Oxford: Oxford University Press.

\section{Related Topics}

Identificationist Views

Dispositional Compatibilism

Event-Causal Libertarianism

Agent Causation

Free Will and Moral Sentiments: Strawsonian Theories

The Luck and Mind Arguments

Leeway vs. Sourcehood Conceptions of Free will

Thomas Hobbes and John Bramhall

John Locke

David Hume 


\section{5 \\ DISPOSITIONAL \\ COMPATIBILISM \\ Kadri Vihvelin}

We believe that we have free will, and this belief plays a central role in how we think about ourselves and about our lives. Free will matters to us, and not just because we think that having free will is a necessary condition of being morally responsible. Free will matters to us because having some say in the overall shape of our lives matters to us. We want to develop our skills and talents as best we can, make the most of our opportunities, and live the best lives it is in our power to live.

We know that there are severe limits to the control that we have over our lives. What we are able to achieve depends not only on us, but on our surroundings. We know that luck plays an enormous role, and we know that the playing field is not level. And even if we are fortunate in our starting point-in our native endowments, our parents, social class, and so on-we know that unforeseen events and the actions of other people can frustrate our plans and thwart our hopes. Knowing this, we might wonder how far our abilities extend, how much we are truly able to do. We might wonder whether we are really able to do, or even try to do, all the things we think we can do. We might worry that our powers of imagination are too limited, preventing us from even considering some of the things we might otherwise be able to choose and do. And so on.

But we don't doubt that we have free will. What we do is not the only thing we can do. The choices we make are not the only choices in our power to make. We are able to think for ourselves, whether or not we actually do so. We are able to try to do lots of things, whether or not we actually do try. We have abilities we don't exercise, perhaps some abilities we never exercise. We don't have to do what we do. We are able to do otherwise. Or so we believe. We also believe that we often use or exercise our free willwe take a moment to think before we act; we decide what to do, and then we act. (Note that this assumes that there is a difference between having and exercising free will. If you stumble and fall, you haven't thereby lost your free will. But your falling, unlike the falling of an actor in a play, is not an exercise of your free will.) And while we know that we sometimes make a choice while being mistaken about what our options are, we do not believe that this is always or usually the case. Ordinarily, when we make a choice we really do have the choice we think we have. You are, right now, able to continue reading this chapter, and you are also, right now, able to stop reading. Take a moment to consider these options. Then decide. Welcome back!

There is more to our view of ourselves as free agents than the belief that we have real choices and genuine alternatives, but this belief is at the core of our commonsense view 
of ourselves as individuals with free will. If we were somehow convinced that we never really have a choice about what we do, we would conclude that our belief that we have free will is either outright false, or, at best, that we are radically mistaken about the nature of our free will.

We can agree about this while leaving other questions up for grabs. Do we have a choice only on those occasions when we deliberate, weigh our reasons, make a decision, and then act, or do we also have a choice when we act spontaneously, or on the basis of a hunch, or on the basis of what feels right or seems obvious? Do we have a choice in cases of coercion, and other cases when we have "no real choice" or "no reasonable choice?" What about cases where making a particular choice would go so deeply against our values that it is, in some sense, unthinkable for us? These are questions about which reasonable people may disagree.

We can also leave open questions about the exact relationship between choice and moral responsibility. We can all agree that moral responsibility does not require having a choice at the time of action - we blame a drunk driver for the accident she causes, even if she was not able, at the time of the accident, to do otherwise. But does it require having a choice, at some earlier time, between sets of reasonably foreseeable outcomes of one's action? Or is it enough, so far as moral responsibility is concerned, that a person had a choice, at some time in the past, about the actions which led, eventually, to the formation of her present character? Again, these are questions about which reasonable people may disagree.

The answers to these questions are important, but irrelevant so far as the problem of free will and determinism is concerned. For determinism appears to have the consequence that it is never true that anyone has a choice of any kind-big or small, important or trivial. If we choose to lie, we could not have chosen to tell the truth. If we choose the scenic mountain road, we could not have chosen the freeway. If we choose the apple, we could not have chosen the orange.

\section{Determinism, the Free Will/Determinism Problem, and Some Responses}

Roughly stated, determinism is the conjunction of two claims: (i) that we are no exception to the laws of nature that govern everything else in the universe; and (ii) that these laws state sufficient (as opposed to merely necessary or probabilistic) conditions for the occurrence of every event, including those events that we think are our free choices and actions.

More precisely, determinism is the thesis that the universe is governed by laws of nature which are such that any two possible worlds with our laws that are exactly alike at any time are also exactly alike at every future time (Lewis 1973). If determinism is true, then, for every time $t$, there is no possible world that is exactly like our world at $t$ and which has exactly our laws, where the future relative to $t$ is different from our future (van Inwagen 1983). If determinism is true, then it seems that it is possible, at least in principle, to predict your entire future on the basis of information about the distant past and the laws of nature (LaPlace 2010).

Determinism is not part of our commonsense view. But as soon as we understand what the thesis of determinism says (and why it is a live possibility that determinism, or something close enough, is true), we see the problem. For if determinism is true, it seems that whatever happens must happen. And if that is true, then it seems that it must also 
be true, on each and every occasion, that what we do is the only thing we can do. We are never able to do otherwise, or even choose or try otherwise. And if that's so, then our belief that we have free will is an illusion.

The free will/determinism problem is the problem of deciding whether this apparent bad consequence of determinism really is a consequence. Suppose that scientists announce that they have discovered irrefutable evidence that the thesis of determinism is true. Would this mean that our belief that we have free will is false?

The commonsense compatibilist says "no."

(Warning: not all philosophers who call themselves compatibilists are commonsense compatibilists. Many—perhaps most—are moral compatibilists; the thesis they defend is that moral responsibility is compatible with determinism. Some are "semi-compatibilists," arguing that even if determinism is incompatible with free will, it is compatible with moral responsibility because moral responsibility does not require the ability to do otherwise [Fischer and Ravizza 1998]. In this chapter, I will be concerned only with commonsense compatibilism; to keep things simple, I will use 'compatibilist' to refer to the commonsense compatibilist.)

The incompatibilist says "yes."

The difference between the compatibilist and the incompatibilist is a philosophical difference. The compatibilist believes that the truth of determinism is compatible with the truth of our commonsense belief that we have free will; she believes that it is possible both that determinism is true and that we have free will. The incompatibilist believes that the relation between determinism and free will is like the relation between being a cube and being a sphere. There are things that are cubes and there are things that are spheres, but there is nothing that is both a cube and a sphere; being one precludes being the other. Determinism is not a simple property of an object, like being a cube or a sphere, but the same point holds. The incompatibilist believes that the truth of determinism is incompatible with the truth of our belief that we have free will. It's possible that determinism is true and it is possible that we have free will, but it is not possible that determinism is true and we have free will; the truth of the first precludes the truth of the second (Vihvelin 2008).

There are different kinds of incompatibilists. All incompatibilists accept the incompatibility thesis - the claim that the truth of determinism is incompatible with the existence of free will. But incompatibilists disagree about whether determinism is actually true, and therefore, disagree about an existential claim—that free will exists; more specifically, that we have free will. Some incompatibilists are hard determinists; they believe that determinism (or something close enough) is true, and therefore we should accept the "hard" consequence- that we have no free will. Other incompatibilists are libertarians; they believe that our free will belief is true and the thesis of determinism is false.

Suppose that you think that our commonsense beliefs about free will are true. Which of the two competing views-compatibilism or libertarianism-should you accept?

Note that the two views are not on a par. Both accept the existential claim - that we have free will. But the compatibilist says that the truth of determinism is compatible with the truth of the existential claim, while the libertarian denies this. The compatibilist says this because the compatibilist believes that the facts in virtue of which we have free will do not include the fact that determinism is false. The libertarian, by contrast, believes that the facts which make it true that we have free will include the fact that determinism is false in a very specific way; it must be true that at least some of our decisions or choices lack earlier nomologically sufficient conditions. 


\section{DISPOSITIONAL COMPATIBILISM}

Some libertarians also believe that we have free will only if we have some special power of agent-causation that is unique to rational beings (O'Connor 2000). We can sum this up by saying that compatibilism is an empirically (and perhaps also metaphysically) less risky hypothesis about free will than libertarianism.

This does not mean that you should accept compatibilism. You should accept compatibilism only if you have good reason to reject the incompatibility thesis and to accept the compatibility thesis. How do you decide this?

It's often thought that since the incompatibilist starts off with an intuitive advantage, the burden of proof is on the compatibilist, and this burden can be discharged only by providing an analysis of 'S has free will' or 'S acts freely.' I think this a mistake for two reasons.

First, I don't think that intuitions about the implications of determinism count for much. Intuitions have evidential weight only insofar as we have reason to believe they are reliable guides to the truth. We have no reason to believe that intuitions about an unfamiliar and complicated term such as 'determinism' are reliable guides to the truth.

Second, there are disagreements about what it takes to have or act with free will that are independent of the incompatibilist/compatibilist divide. The debate between the incompatibilist and the compatibilist is a debate about whether determinism has the consequence that no one ever has a choice of any kind, in any situation.

Neither side has the burden of proof; both sides must defend their claim by argument. But the kind of argument they can offer is different.

The compatibilist asserts a claim about possibility - that there are possible worlds (perhaps our own) where determinism is true and we have the free will we think we actually have; more specifically, we sometimes deliberate, decide, and act on the basis of our decision, and we are able to decide and act otherwise. The only way to offer a positive defense of a possibility claim is by providing a description with enough detail to make it plausible that what has been described is really possible. So far as the defense of compatibilism goes, this means that the compatibilist needs only to describe, in suffcient detail to make it clear that the description does not entail the falsity of determinism, an uncontroversial case of a person who has free will and who is in a situation where she is able to decide and act otherwise.

The incompatibilist, on the other hand, asserts a claim about impossibility-that there is no possible world where determinism is true and we have free will. This impossibility claim must be defended by an argument for the claim that any description of a possible world where determinism is true and we have free will either conceals some hidden contradiction or commits us to some logical or metaphysical impossibility. Once the incompatibilist has produced such an argument, the onus is on the compatibilist to show that the argument fails.

To sum up: If you believe that we have free will, then you should be a libertarian, rather than a compatibilist, only if you are convinced that there is no way to tell a consistent story about a possible world where determinism is true and we have the free will we think we actually have. There is a famous argument in the literature that no such story can be told; it is the Consequence Argument (van Inwagen 1983). I believe, and have argued, that the Consequence Argument fails (Vihvelin 2013), but this (and, more generally, criticism of arguments for incompatibilism) is not my assigned topic.

My topic is Dispositional Compatibilism. The dispositional compatibilist offers a certain kind of positive argument for the compatibilist's possibility claim. The dispositional compatibilist says that our commonsense beliefs about free will can be understood in a 
way that is consistent with our other beliefs about the natural world and our place in it, and which is neutral with respect to the truth or falsity of determinism.

There are different ways of being a dispositional compatibilist (Moore 1912; Hobart 1934; Graham 1972; Smith 1997, 2004; Vihvelin 2004, 2011, 2013; Fara 2008) but what all varieties have in common is that they claim that the most fundamental free will facts are facts about our causal powers (for instance, our power to decide on the basis of deliberation) and that our causal powers differ in complexity but not in kind from dispositions like fragility, elasticity, and flammability. In the older literature a distinction was sometimes drawn between "active" and "passive" powers- the active power "exerted" by the rock when it breaks a window, the passive power "manifested" by the window when it is broken. The contemporary literature does not recognize this distinction, and neither does dispositional compatibilism (DC). The claim is that all dispositions - of natural objects, artifacts, and human beings - are causal powers with the same kind of causal structure. How exactly that structure should be understood is the subject of much metaphysical debate. But the main point, so far as DC is concerned, is simple. Determinism seems to be incompatible with free will because determinism seems to have the consequence that we have no power over anything, not even our own choices. But if our causal powers are dispositions, this is not true. For dispositions are uncontroversially compatible with determinism. And dispositions are real properties of their bearers; they do not cease to exist simply because they are not being manifested. A rock does not lose its window-breaking power just because it is not currently breaking windows. A person does not lose her decision-making power just because she is not currently making a decision. Nor does she lose her power to decide to do one thing just because she makes another decision instead.

If the most fundamental free will facts are facts about our causal powers, and if these causal powers are dispositions, the free will/determinism problem has a compatibilist solution. Determinism does not entail that we are never able to choose or do otherwise. Can the solution to the free will/determinism problem really be so simple? Let us take a closer look.

\section{Dispositions and Abilities}

Let's begin by considering some features of dispositions.

When we attribute a disposition to an object, we do so on the basis of a counterfactual property that we associate with objects which have that disposition. For instance, the counterfactual property that we associate with fragile objects is the property of being such that if the object were dropped or struck, it would break. But an object might have the counterfactual property associated with a disposition without having the disposition. A sturdy concrete block on the edge of the roof of a 20-story building has the property of being such that if it were dropped, it would break. But the concrete block is not fragile. And an object may have a disposition without having the counterfactual property that we associate with that disposition. A crystal glass does not cease to be fragile when it is carefully wrapped in Styrofoam, but once it is thus protected, it no longer has the property of being such that if it were dropped, it would break.

Why do we say that the protected glass is fragile but the precariously perched concrete block is not?

First approximation. Because the glass is the kind of thing that breaks easily, in a wide range of circumstances; the concrete block is not. A bit more precisely, the glass 


\section{DISPOSITIONAL COMPATIBILISM}

shares some intrinsic property with other fragile objects (glasses not wrapped in Styrofoam), many of which have the counterfactual property. By contrast, the concrete block's possession of the counterfactual property is a highly extrinsic property; if the block is moved closer to the ground it loses this property.

It turns out to be surprisingly difficult to make these intuitive ideas more precise, but here is a rough characterization of what it is for something to be fragile. An object is fragile just in case it has some intrinsic property or set of properties $P$ such that if the object were dropped while in the right surroundings (those surroundings that count as providing a test for the disposition: no protective packing, from a moderate height, onto a hard surface, and so on), its being dropped and its having $P$ would together cause (or, perhaps, increase the chance of) its breaking. Because this intrinsic property figures in this way in the manifestation of the disposition, we call it the causal basis of the disposition.

More generally, an object has a disposition by having a certain kind of causal power and by having some intrinsic property that serves as the causal basis of the disposition.

The key claim of DC is that our abilities, including the abilities in virtue of which we have free will, are dispositions with the same kind of causal structure.

But before we get to free will, let's take a look at some less controversial examples of human abilities: the ability to walk, to walk a straight line, to play piano, to fall asleep as soon as your head hits the pillow. Let's call these 'ordinary abilities;' think of them as abilities to move your body in certain kinds of ways or abilities to cause certain kinds of changes in your body. These abilities are structurally like dispositions in the following ways: We have them by having certain intrinsic properties that are the causal basis of the ability (e.g., we have the ability to walk by having unbroken legs and certain other properties of our brain and nervous system) and we do not lose them simply because our surroundings have changed. (You might object that the shackled prisoner is no longer able to walk, and there is a sense in which this is true. But the sense in which it is true is the sense in which the Styrofoam-packed glass is no longer able to break.) Finally, while our abilities are relatively stable properties, they can be lost (and sometimes regained) in the same way that an object can lose (and sometimes regain) a disposition. A wet match is no longer flammable; a melted glass is no longer fragile. You lose your ability to walk when you break your legs, your ability to walk a straight line when you drink too much, and your ability to fall asleep as soon as your head hits the pillow when you drink a cup of coffee just before going to bed.

Some philosophers think that our causal powers and abilities are fundamentally different from dispositions and capacities because they think that the manifestations of dispositions and capacities are caused "willy-nilly" by environmental stimuli, whereas it is up to us whether we exercise our abilities/powers (van Inwagen 1983: 11). There is some truth to this, but we need to be careful. First, note that one of the abilities I listedthe ability to fall asleep as soon as your head hits the pillow-is exactly like the dispositions I've discussed insofar as its manifestation is caused "willy-nilly" by the environmental stimuli of your head being on the pillow. Despite this, we call it an ability, and it's a valuable ability to have. Second, it isn't true that the manifestations of dispositions are always caused by environmental stimuli. An animal's disposition to search for food is manifested in response to the internal stimulus of the animal's hunger. The ability to play piano is an ability that we exercise in response to the internal stimulus of trying to play. And other abilities have other kinds of internal stimuli. The ability to fall asleep by doing long division with your eyes closed is an ability you exercise in response to the internal stimulus of doing long division with your eyes closed. 
To sum up: our ordinary abilities are dispositions and they are intrinsic in the same way that dispositions are intrinsic. To have one of these abilities is to have some intrinsic property that is the causal basis of the ability; so long as you retain the property, you retain the ability. Sometimes our surroundings prevent us from exercising one of our abilities in the way that Styrofoam packing prevents a fragile glass from breaking. But this is not always or even typically the case.

\section{Dispositional Compatibilism}

Dispositional compatibilism is the name for a family of views. I will give a brief sketch of how I understand the view.

The most fundamental free will facts are facts about some bundle of abilities in virtue of which we think and deliberate and make decisions and choices and form intentions about what to do. Let's call this bundle of abilities 'the core free will bundle.' So long as we retain this core bundle, we retain free will, even if we are prevented, by unfortunate surroundings or loss of ordinary abilities, from moving our bodies in the ways we try to move them. The shackled prisoner has lost freedom of action, but not free will.

There is lots of room for argument about what abilities are required in order to have the core free will bundle, but the following are relatively uncontroversial parts of the package: the ability to form and revise beliefs on the basis of evidence and argument; the ability to deliberate for the purpose of deciding what to do in response to one's intention to so deliberate; and the ability to decide what to do in response to one's trying, by deliberating, to do so. More controversial candidates include the ability to control one's first order motivation by one's higher order volitions (Frankfurt 1971) and the ability to recognize good values as opposed to bad ones (Wolf 1990).

On my view, the abilities that are part of this bundle are all dispositions.

In addition to the abilities that constitute the core free will bundle, we have various other abilities, including the abilities in virtue of which we enjoy freedom of actionfor instance, the ability to act on the basis of our decisions and the ability to act on the basis of intentions which are simply acquired, without being the product of any prior mental action. While these other abilities are not essential to free will, they are nevertheless an important part of the free will we think we (most of us, most of the time) actually have.

These abilities are also dispositions.

We have the free will we think we have, including the freedom of action we think we have, by having some bundle of abilities and being in the right kind of surroundingsthe surroundings that are test cases for the relevant dispositions.

For instance, while typing this paragraph, I considered whether to stop and go to the kitchen for a cup of coffee. After thinking about it briefly, I decided not to, and went back to typing. Suppose that this is the kind of normal case where I really did have the choice I thought I had. (I wasn't a victim of a nefarious neurosurgeon or subject to a post-hypnotic command nor was there any sinister figure lurking in the background ready to manipulate my brain and body if I made the "wrong" decision.) I was free to decide and act as I did and also to decide and act otherwise. It was up to me what I did.

On my view, these commonsense beliefs are true in virtue of facts about my abilities (dispositions) and my surroundings. I was free to decide otherwise because I had and exercised the ability to decide, on the basis of deliberation, whether to get the coffee or continue typing. I was free to act otherwise - to get the coffee-because I had the ability 


\section{DISPOSITIONAL COMPATIBILISM}

to walk and because my surroundings were favorable. (I was not shackled, the door was not locked, there was nobody there to stop me, there really was coffee in the kitchen, and so on.)

Having some such bundle of dispositions, together with suitably friendly surroundings, suffices for our having the free will we think we have. Perhaps something else might also suffice-some power of agent-causation that is not a disposition. But such agent-causal powers, if they exist, are not needed for free will. And the falsity of determinism is also not needed, for it is no part of this story.

Could it be argued that if determinism is true, then our surroundings are always unfavorable, robbing us of the opportunity to exercise any unexercised ability? I don't think so. While it is theoretically possible that a person is always in surroundings that prevent her from exercising one or more of her abilities in the way that the Styrofoam prevents the fragile glass from breaking, determinism does not have this consequence. What determinism does entail is that if we don't exercise one of our abilities there is always some earlier nomologically sufficient condition of our not doing so. For instance, I didn't exercise my ability to walk to the kitchen for coffee because the upshot of my brief deliberation - it's late afternoon, another cup will keep me awake at night — was that I lost my desire for coffee. If determinism is true, there are facts about my brain (the neural realizers of my changed desire), and these facts, together with other facts, are nomologically sufficient for my continuing to type. But this change in my brain state doesn't rob me of the opportunity to get the coffee; it just means that I no longer want to take advantage of my opportunity.

The libertarian might object that what we would say is beside the point; what matters is that if determinism is true there is some metaphysically deep sense in which our surroundings are always unfriendly and we never have the genuine opportunity to choose or do anything other than what we actually do. But in saying this, the libertarian is simply assuming the truth of something that needs to be defended by argument: the claim that free will is incompatible with determinism.

\section{Objections}

In this section I will respond to three objections to DC.

First objection. Having free will cannot be a matter of having any disposition(s). Even if there is a sense in which a lump of sugar is able to dissolve, it is not up to the sugar whether it dissolves. Nor is it up to a car whether it starts or up to a computer whether it runs one program or another.

Reply. Having a mind is a necessary condition of having free will. Lumps of sugar, cars, and computers do not have minds.

Second objection. A dog has a mind and has dispositions, not only to behave in various ways, but also to make certain kinds of choices. But a dog does not have free will.

Reply. The case of dogs is less clear than it seems. If we deny free will to dogs, we must also deny it to babies and young children, and commonsense is conflicted on this point. But I am inclined to agree that dogs and babies lack free will. DC has the resources to say the right thing, which is that we acquire free will gradually as we acquire more sophisticated abilities, including abilities to make increasingly complex choices. We learn to do things with our bodies before learning to do things with our minds, and we acquire the abilities that ground our freedom of action before we acquire the abilities that ground our free will. 


\section{KADRI VIHVELIN}

The third objection is one that was widely accepted as a refutation of an older dispositional account-the Conditional Analysis (Moore 1912; Hobart 1934; Graham 1972). According to the Conditional Analysis, a person is able to do $X$ just in case it is true that if she tried (chose, decided, etc.) to do X, she would. Here's an example of the kind of case that, everyone agreed, was a decisive counterexample to the Conditional Analysis (Berofsky 2002).

Clea is an excellent cyclist, but she had a bad accident and now has a pathological fear of bike-riding, so she is not able to try to ride her bike. But since she is in perfect physical condition she would succeed in riding if she tried. (Or so it is claimed.) We are supposed to agree that Clea is not able to ride her bike. But the Conditional Analysis says that she can, so the Conditional Analysis is false.

Does this case refute DC?

I don't think so. The case is underdescribed, but on two plausible versions of the story, DC can say the right thing.

First version. Clea's phobia is so extreme that she won't calm down even if she somehow manages to get on her bike (perhaps with a little help from her friends). She'll panic and lose control of the bike. In this case, she lacks two different abilities-a volitional ability and also an ordinary ability. She lacks the ability to try to ride and she also lacks the ability to ride. It is not $u p$ to her whether she rides. (On this version of the case, the Conditional Analysis gives the right answer since if Clea tried to ride, she would fail.)

Second version. Clea's accident left her with a phobia that is purely volitional in this sense- she is not able to try to ride. But if she somehow did try - if she found herself in the saddle with her legs making, or beginning to make, the first bike-pedaling motions, her fears would melt away and she would be her old bike-riding self again.

In this case, we should say that she has the kind of ability to ride that a puppy has to chase its tail and a baby has to crawl in the direction of a bright and shiny object. She has the ordinary ability to ride, but she lacks the second order ability-also a disposition, or bundle of dispositions - to cause herself to exercise this ability (by reminding herself of her resolution to overcome her fears, taking a deep breath to calm herself, and so on). She can't make herself ride; it is not up to her whether she rides.

\section{Conclusion}

We have the free will we think we have, including real choices and genuine alternatives, by having a certain bundle of abilities (dispositions) while being reasonably fortunate with respect to our surroundings. We may continue to have free will despite losing many abilities and despite being very unfortunate in our surroundings. But determinism robs us neither of free will nor freedom of action.

\section{Bibliography}

Berofsky, B. (2002) "Ifs, Cans, and Free Will: The Issues," in R. Kane (ed.), The Oxford Handbook of Free Will. Oxford: Oxford University Press, pp. 181-201.

Davidson, D. (1973) "Freedom to Act," in T. Honderich (ed.), Essays on Freedom of Action, London: Routledge, pp. $137-56$.

Fara, M. (2008) "Masked Abilities and Compatibilism," Mind 117: 843-65.

Fischer, J. and Ravizza, M. (1998) Responsibility and Control: A Theory of Moral Responsibility. New York: Cambridge University Press. 


\section{DISPOSITIONAL COMPATIBILISM}

Frankfurt, H. (1971) "Freedom of the Will and the Concept of a Person," Journal of Philosophy, 68: 5-20.

Graham, K. (1972) "Ifs, Cans, and Dispositions," Mind 14: 186-99.

Hobart, R.E. (1934) "Free Will as Involving Determination and Inconceivable Without It," Mind 63: 1-27.

Lewis, D. (1973) "Causation," Journal of Philosophy 70: 556-67.

LaPlace, P. (2010) A Philosophical Essay on Probabilities. Charleston: Nabu Press.

Moore, G.E. (1912) “Free Will,” in G.E. Moore, Ethics. Oxford: Oxford University Press, pp. 84-95.

O'Connor, T. (2000) Persons and Causes: The Metaphysics of Free Will. New York: Oxford University Press.

Smith, M. (1997) "A Theory of Freedom and Responsibility," in G. Cullity (ed.), Ethics and Practical Reason. New York: Clarendon Press, pp. 293-319.

Smith, M. (2004) "Rational Capacities," in M. Smith, Ethics and the A Priori: Selected Essays on Moral Psychology and Meta-Ethics. New York: Cambridge University Press, pp. 114-35.

van Inwagen, P. (1983) An Essay on Free Will. Oxford: Clarendon Press.

Vihvelin, K. (2004) "Free Will Demystified: A Dispositional Account," Philosophical Topics 32: 427-50.

Vihvelin, K. (2008) "Compatibilism, Incompatibilism, and Impossibilism," in T. Sider, J. Hawthorne, and

D. Zimmerman (eds), Contemporary Debates in Metaphysics. Malden: Blackwell Publishing, pp. 303-18.

Vihvelin, K. (2011) "How to Think about the Free Will/Determinism Problem," in J. Campbell, M. O'Rourke, and M.H. Slater (eds), Carving Nature at its Joints. Cambridge: MIT Press, pp. 313-40.

Vihvelin, K. (2013) Causes, Laws, and Free Will: Why Determinism Doesn't Matter. New York: Oxford University Press.

Wolf, S. (1990) Freedom Within Reason. New York: Oxford University Press.

\section{Further Reading}

Lewis, D. (1997) "Finkish Dispositions," Philosophical Quarterly 47: 143-58. (Lewis proposes and defends an analysis of what it is for an object to have a disposition.)

Manley, D. and Wasserman, R. (2008) "On Linking Dispositions and Conditionals," Mind 117: 59-84. (Manley and Wasserman propose and defend a different analysis of what it is for an object to have a disposition.)

\section{Related Topics}

Classical Compatibilism

Event-Causal Libertarianism

Agent Causation

The Consequence Argument

The Relationship between Moral Responsibility and Freedom

Determinism 


\section{6 \\ EVENT-CAUSAL LIBERTARIANISM \\ Laura W. Ekstrom}

Theories concerning the nature of free action fall into different groups. Among these is a group of theories that, in common, take our having the power to act freely to be inconsistent with the truth of causal determinism and that, in common as well, do not require either that free acts be uncaused or that they be caused by agents as substances. In other words, on this collection of theories, we cannot act freely if every event is causally necessitated by the past and the laws of nature; and, in order to act freely, it need not be the case that our acts have no causal antecedents whatsoever nor need it be the case that agents cause actions in some way that is irreducible to event-causal terms. So, for instance, if you raise your glass to make a toast, this cannot be a free action if it is true that, at every moment, there is exactly one physically possible future. Furthermore, this action's counting as a free act of yours does not require that the act had no causes at all, and it does not require that you, as a substance, brought it about. Instead, according to these theories, your act of raising your glass, if free, had events that led up to it and brought it about. Particular accounts within this group differ over which sorts of events precede free actions and over where, in the causal history of the free act, there must be causation that is indeterministic in nature.

We might best call this group of theories 'event-causal indeterminist accounts' of free action. Traditionally the term 'libertarian' in the context of the free will debate has been taken to refer to those who maintain that our having free will- the power to act freely - is incompatible with the thesis of causal determinism and who assert, as well, that we do, in fact, have free will, so that causal determinism is, in fact, false. Some theorists, however, have developed accounts of what a free act would look like that fit the depiction in the previous paragraph, but without making the further claim that in fact we sometimes do act freely. These theorists, then, do not count as libertarians in the traditional sense, in that they do not make a particular empirical claim: namely, that causal determinism is false since we sometimes act freely. I will include the accounts of such theorists in this chapter's discussion of event-causal libertarianism, nonetheless, since the accounts share the conceptual approach to characterizing free action taken by traditional libertarians of the event-causal sort. Among 'event-causal libertarian theories' of free action, then, I include accounts developed by philosophers who are not committed to the actual realization of the proposed conditions. These theorists share a vision of what an act would need to be like in order to be free. 


\section{Why Libertarianism?}

Typically, free actions have been conceived roughly as those acts that both derive from the self and that are chosen from among alternatives. Arguably, compatibilist and incompatibilist accounts of free action through the history of the philosophical literature on the topic have aimed to capture these two conditions (Watson 1987; Ekstrom 2011), although in recent work, a number of theorists have emphasized one or the other. Compatibilists maintain that the self-derivation of an act is consistent with causal determinism. Compatibilists who agree that the ability to do otherwise is required for freedom generally hold that a free act could have been otherwise roughly in the sense that the act would have been otherwise had the agent chosen otherwise (or had she desired to do otherwise or had she judged it best to do otherwise). Libertarian conceptions of free action, by contrast, take one or the other or both of these two conditions to require the falsity of causal determinism. One might think that an act cannot truly derive from the self if the self is of causal necessity just as it is. And one might think that an act cannot truly be chosen from among alternatives if there is at every moment exactly one physically possible future.

Why might one think that an act cannot truly derive from the self if the self is of causal necessity just as it is? The thought is this: if one's genetics and formative experiences, occurring as they did in one's particular environment through time, lead to causal necessity to what one did at a specific time, then the action at that time was only the inevitable outcome of that particular combination of genetics, environment, and experiences and is not attributable to or truly derivative from the self. One might infer from this thought that, if an act is to be free, then it must derive from a self that somehow transcends the realm of causation among events; a free act, one might infer, must be agent caused, brought about by an agent in a way that cannot be captured in eventcausal terms and without the agent's being causally determined by any prior events to cause what it does. This is the route taken by agent-causal libertarianism. The eventcausal libertarian, by contrast, does not think that characterizing free action requires appeal to a kind of causation by an agent as an enduring entity, a sort of causation that is irreducible to causation among events. An event-causal libertarian might think that it is only if the self is in some sense of one's own making-where this is understood to require some appropriate causal indeterminism in the history of the self-that an act can count as truly deriving from the self or as deriving from the true self. The idea here is that it is important that it was not rigged from the start who we turned out to be: our actions should flow from our characters in order to be self-determined, and we should have a chance to be other than the sorts of people we are, rather than the past and natural laws leading of causal necessity to our being exactly as we are. Alternatively, an event-causal libertarian might think that the self-derivation condition of free action does not require causal indeterminism at all. She might think that the requirement of the falsity of causal determinism is generated, instead, by the other condition for freedom: the availability of alternative possibilities for action.

Why might one think that an act cannot truly be chosen from among alternatives if there is at every moment exactly one physically possible future? The idea is that if, at each moment, there is exactly one thing that can happen next, holding fixed the past and the laws of nature, then any feeling a person might have of having chosen from among available alternative options is illusory. It might seem as if we sometimes choose among various options, any one of which we could have brought about-such as 
choosing to wear the blue shirt rather than the red one or the white one- but if causal determinism is true, then the past and the natural laws entail a unique outcome. There is, in that case, exactly one thing we could have done in the strictest or categorical sense of 'could have done.' The libertarian rejects compatibilist conditional analyses of the could-have-done-otherwise component of free action on the grounds that, while it is true that the obtaining of causal determinism is consistent with the truth of the claim that the agent would have done otherwise if she had chosen (or desired or judged it best) to do otherwise, and while the claim that an agent would have done otherwise if she had chosen (or desired or judged it best) to do otherwise, may be grounded in the fact that the process leading to her act was appropriately responsive to reasons for doing otherwise, or in the fact that she possessed at the time of action the requisite skills and capacities for doing otherwise, nonetheless, neither the issuance of the act from a reasons-sensitive process, nor the possession of the skills and capacities for doing otherwise, is sufficient for a genuine ability to do otherwise in the circumstances in question. This is the case because the ability to do otherwise at a time requires the opportunity to exercise the relevant skills and capacities for doing otherwise, and this opportunity is ruled out if causal determinism is true, since, on the thesis of causal determinism, the future possibilities for action are narrowed to one.

\section{Why Not Agent-Causal Libertarianism?}

Why do event-causal libertarians reject the agent-causal libertarian's appeal to causation of a free act by the agent as a substance? Notice that event-causal libertarians can believe that agents cause their free acts, but they take such instances of causation to be reducible to event-causal terms. For instance, we commonly say such things as, "George freely flipped on the light switch." Event-causal libertarians can maintain that we are perfectly sensible in making such claims, but they also maintain that in such cases we are speaking in shorthand: what we really believe or ought to believe is that certain events involving George (events of which George is the subject) brought about the switch flipping. These events include, for instance, George's coming to desire light in the room and his forming the intention to flip the switch. What is wrong with maintaining that George-as-a-substance brought about the light switch flip?

It is natural to think of causation as a matter of something happening, making something else happen-in other words, as an event's occurring, bringing about another event. How would an enduring substance, which does not happen at a time, initiate a causal sequence? Suppose, for instance, we say that George freely brought about the light switch flip by exercising his agent-causal power to form the intention to flip the switch, an intention which then brought about by way of muscle movements the switch flip. The exercise of an agent-causal power is something that happens at a time-it is an event. If one were to say that a substance brings about an event simply by existing, without undergoing any change or exercising any power, then it seems inexplicable why the event occurs when it does and not at a previous time or a later time at which the substance also exists.

The agent-causal libertarian might say what explains the free choice happening when it does is the agent's coming to possess certain reasons in favor of making that choice then. But in that case, one wonders why it is not more sensible to say that the event of the occurrence of the reasons causes the choice rather than inserting an agent-as-substance into the causal story. If the reasons are said to be necessary but not 
sufficient causes of the free choice, then it is hard to see that we can have a reasonsexplanation of the choice.

The bottom line for event-causal libertarians regarding agent-causal libertarianism is that it is simply implausible to think that substances, in and of themselves, make a contribution to the causation of events that is additional to, and separate from, the contribution made by events involving the substance. Consider a vase, which sits on a table. How could the vase, as a substance, cause anything, without this being reducible to event-causal terms? If one knocks the vase with one's arm, so that it falls off the table, making a dent in the wood floor below, how could the vase itself make some causal contribution to the appearance on the dent in the floor that is additional to the falling of the vase (an event) and its hitting the floor with a certain force at a certain angle (another event)? By the same token, how can an agent make a causal contribution to the occurrence of one decision rather than another that is additional to the agent-involving events, such as her considering various reasons, giving rise to the decision? If we can account for free decisions without making an appeal to causation by agents as enduring entities or as uncaused causes or as "prime movers unmoved" (Chisholm 1964), then according to the event-causal libertarian it is most reasonable to do so.

\section{Location of Causal Indeterminism}

Event-causal indeterminist accounts of free action vary in their particular features. Variable factors include which events theorists take to precede free actions and where in the causal history of the act the indeterministic causal connections are conceived as best located.

On the model of free action Daniel Dennett (1981) sketched as the best available to a libertarian (albeit a model he himself, as a compatibilist, does not endorse), in the case of a free action it is causally undetermined which particular considerations occur to an agent as she is deliberating over what to do. His example is of a job candidate weighing two competing offers. When choosing option A, Dennett suggests, on the best libertarian model of the freedom of this choice, it is undetermined whether considerations $\mathrm{X}, \mathrm{Y}$, and Z come to mind, supporting option A, or instead considerations R, S, and $\mathrm{T}$ come to mind, supporting option B. Once the considerations occur and the last of them has occurred in practical deliberation, although, on the account Dennett sketches, there is a deterministic causal relation between the particular pattern of considerations that has happened to occur and the outcome of the deliberative process. This account is similar to Alfred Mele's model of modest libertarianism (Mele 1995, 2006). On Mele's modest libertarian view, it is causally undetermined which of an agent's non-occurrent beliefs will become occurrent and function in his deliberation. The beliefs that occur happen to occur when they do, and they are caused to occur by prior events, but they might not have occurred in the circumstances, holding fixed the past and the natural laws. The beliefs that do occur and operate in the agent's deliberation deterministically cause his considered best judgment concerning what to do, which, in turn, deterministically causes his free decision.

On the view defended by Laura Ekstrom (Ekstrom 2000, 2003), one acts freely in acting by way of a normal causal process from a preference, rather than a judgment. In particular, this preference must be non-coercively formed or maintained, and it must have an indeterministic causal history, such that its non-necessitating causes are various 
considerations that occur to a person as she is contemplating the question of what she prefers to do. A preference, as the term is used on this account, is a desire that has survived scrutiny with respect to an agent's conception of the good. This stipulated notion of preference results from a discussion of problems with Harry Frankfurt's hierarchical model of free action (Frankfurt 1971). Frankfurt highlights the fact that not all of our desires represent what we really want, and he proposes that free acts are acts that we want to do and that we want to want to do. The second-level desires-desires concerning other desires-Frankfurt takes to be internal to the self. The problem is that, in Frankfurt's model, these second-level desires can be formed and maintained on any basis whatsoever and even on no basis, and, furthermore, Frankfurt allows that they can be coercively imposed while still being the source of free action. Ekstrom aims to capture the idea that free acts derive from ourselves, and she argues that preferences in the stipulated sense are better suited to being key components in the identity of the self (Ekstrom 1993, 2005). Contrary to Frankfurt, she argues that there are certain requirements on the causal history of the preferences preceding free action. The model, then, requires non-coercion and certain non-necessitating causes in the construction of the self, while allowing (non-deviant) causally deterministic connections between the attitudes that comprise the self and the agent's free actions.

In a simpler model, which on Randolph Clarke's classification of libertarian theories would count as "an unadorned event-causal libertarian account" a decision or other act is free just in case it is caused non-deviantly and indeterministically by any attitudes of the agent's and other reasonable compatibilist conditions on free action are met (Clarke 2003; Ekstrom n.d.). On this type of account, in a case of directly free action (an action the freedom of which does not derive from an earlier free action), the act is caused non-deviantly and indeterministically by certain agentinvolving events - attitudes of hers, such as preferences, convictions, desires, values, and beliefs, which provide a reasons explanation of the act-and the act is not the result of compulsion, manipulation, or coercion for which the agent herself has not freely arranged. The directly free act, so conceived, counts as self-governed in virtue of its being caused by the agent's reasons, which on this model include any of the agent's psychological or motivational attitudes, not only certain ones, such as preferences; and it counts as meeting the alternative possibilities condition of freedom in virtue of the fact that, at the time the agent performed the act, she could have done otherwise in a categorical sense. Mele's "daring libertarian" proposal is also a view of this sort, on which the causal indeterminism required for "basically*" free acts is between one's considered best judgment concerning what to do and one's decision to act (Mele 2006).

Robert Kane's event-causal libertarian view contains a number of intriguing details, including a focus on competing efforts of will, which he argues helps to address various problems facing libertarian theories (Kane 1996, 2011a). Kane speculates on how causal indeterminacy might work in the human decision-making process. Concerning instances when there are powerful competing motivations, Kane writes,

there is tension and uncertainty in our minds about what to do, I suggest, that is reflected in appropriate regions of our brains by movement away from thermodynamic equilibrium - in short, a kind of stirring up of chaos in the brain that makes it sensitive to micro-indeterminacies at the neuronal level.

(Kane 2011b: 387) 
The efforts of will — conceived as being made in opposing directions at once in cases of basically free actions-are important, Kane thinks, so that, either way things turn out, the act is one that the agent was trying to do, making it voluntary and rational rather than accidental; and the agent could have done otherwise, and if she had done so, that other act, too, would have been voluntary and rational and non-accidental, since she was trying also to perform it. An objection to Kane's account is that it requires of an agent in performing basically free actions the deep irrationality of simultaneous efforts to decide in competing, incompatible ways (Clarke 2003; Ekstrom 2003; Mele 2006).

In any of the event-causal libertarian theories discussed thus far, free decisions may be made in light of rules of rational reflection and, indeed, may be guided by and governed by them. In any of the above event-causal libertarian theories, as well, free decisions may be governed by natural laws, so long as those laws are not deterministic ones, and the processes that lead to our free decisions may, as well, be law-governed and rule-governed.

David Hodgson's event-causal libertarian account departs from these views. His emphasis is on the notion of a conscious gestalt experience. Hodgson suggests that, in making decisions, persons "respond appositely" to gestalt experiences "that are too feature-rich to engage as wholes with laws of nature and generally do not engage with computational rules, so that the response is not determined by laws or rules of any kind" (2012: 153). Hodgson maintains that the subject of the experiences can also as a whole contribute to the response (2012: 153). Although this may sound like an appeal to irreducible agent-causation, Hodgson emphasizes that he does not intend to make appeal to causation of action by a substance:

I say that agents do cause free decisions, because they cause one thing rather than another to happen... However, I do not see that any contribution to this process by the agent is additional to the contribution by events involving the agent.

(2012: 164)

The view is a bit opaque, however, as Hodgson suggests that the law-governed physical realm leaves room for an agent to "steer" among a spectra of alternatives as she responds to non-law-governed and non-rule-governed conscious experiences (2012: 157). Hodgson's contention that conscious experiences could not be law-governed seems problematic given his view that "that there is no experiential change without a corresponding physical change" and that "there is accordingly a sense in which any information contained in our experiences must be contained or encoded in those physical processes" of our brains (2012: 98). Nonetheless, he writes:

The picture I am suggesting is of rational decision-making by conscious subjects (persons), which cannot be broken down into component parts, but which occurs within constraints prescribed by the combination of the physical aspect, considered in isolation, and the laws of nature.

The idea seems to be to appeal to emergent wholes that transcend the laws of nature. There is no need to posit such things, however, in order to account for free will, given the availability of the alternative event-causal libertarian accounts described above, and doing so seems to generate more questions than answers. 


\section{Objections to Event-Causal Libertarianism}

Some philosophers maintain that there are no such things as events. Such philosophers will not be attracted to event-causal libertarianism (or to event-causal compatibilism, for that matter). The strength of this ground for the rejection of event-causal libertarianism depends on the case for rejection of the existence of events. Other philosophers admit that events occur, but see it as problematic to posit non-necessitating causal relations among them, as event-causal libertarians do. The case for probabilistic causation, however, is widely endorsed (Anscombe 1981; Hitchcock 1999).

A more common concern with event-causal libertarianism is that the postulation of causal indeterminism in the history of an allegedly free act makes that act merely random or accidental or chancy or something that occurs as a matter of luck. Another allegation is that, in the picture of free action offered by event-causal libertarians, the agent 'disappears.' Arguably, event-causal libertarians can give successful responses to these problems concerning luck, randomness, disappearing agents, and chance (Balauger 2009; Ekstrom 2003, 2011, n.d.; Franklin 2013; Kane 1996; Mele 2006; Pereboom 2014a). First, a free act as the event-causal libertarian depicts it is not random, since it is caused and justified by reasons. And, second, a free act is not accidental, since it is done on purpose. But are event-causal libertarian free acts merely instances of luck? Consider a decision concerning whether or not to accept an invitation to speak at a conference. Suppose in our case that this is not merely a practical decision but is a morally laden one, since accepting the invitation will require missing a performance of one's children about which the children care very much. For simplicity's sake, let us call the reasons to accept the invitation the basically self-interested reasons and those favoring declining the invitation the parental-love-and-duty reasons. Now suppose that the agent decides to act for the self-interested reasons, having to do with enjoyment of the company of professional philosophers, advancement of one's career, and so on. In supposing that the various reasons the agent has for accepting the invitation cause the decision indeterministically rather than deterministically, have we turned the decision into a lucky event?

That depends on what luck is. There is quite a bit of literature on the nature of luck; what is most relevant to our discussion is this aspect: a lucky event, on many conceptions of it, is, in some sense, uncontrolled by the agent with respect to whom it is lucky (Levy 2011). The sense in which it is 'uncontrolled' is controversial. An incompatibilist may say that an event's being non-lucky with respect to an agent requires that she have something like 'full control' over it, which may be understood as her being at the time both able to make the event occur voluntarily and rationally and able to prevent it voluntarily and rationally and the opportunity for each of these abilities to be exercised, given past events and the laws of nature. The incompatibilist thus may view some causally determined compatibilist-free decisions as decisions that are lucky: in a case in which the determined compatibilist-free agent decides to do the right thing, she is lucky that the past and the natural laws led to her deciding in that way. From this perspective, the control that an agent with event-causal-libertarian freedom has is enhanced over that had by an agent with compatibilist freedom in that it is only the first who has full control over her free decisions.

But now the critic might allege this: the event-causal-libertarian free agent cannot select which of the potential decision outcomes is the actual outcome of her deliberation over what to do. If some of her reasons incline toward one decision outcome and 
others incline toward a different decision outcome (or toward not making a decision in the circumstances), then which way it turns out is not up to her or is not under her full control and so (if it meets other conditions on luck) is lucky. Consider our case about deciding whether or not to accept the invitation to a conference. Suppose that the agent is in motivational equipoise. We could now ask: with this motivational equipoise in place, what is it that settles whether the self-interested outcome occurs or the parental-love-based outcome subsequently occurs? (Pereboom 2001, 2014a, 2014b). It may seem that the event-causal libertarian can only say that when one of the outcomes occurs, it does so without anything about the agent saying that it did, since the extent to which the agent is involved is, at this point, exhausted by the preceding considerations, which by hypothesis are in equipoise. One might doubt that this picture allows sufficient agential control. Here, one might suggest, the agent-causalist has an apparent advantage, since she can say that the agent, as substance, settles which outcome occurs.

If 'settles' here means 'causally determines,' then, yes indeed, nothing settles which outcome occurs in the event-causal libertarian model. If the allegation is that it takes causal determination of a choice in order for that choice to be free, then the eventcausal libertarian simply denies the allegation. Notice that indeterministic causes bring about their effects. The causal events-in this case, the occurrence of the agent's considerations-do not simply sit there, inert, waiting for someone to give them causal force. The event-causal libertarian maintains that, when the agent makes the free decision, it is a decision she made for reasons that cause and justify it, and at the time of making it she had the power to do otherwise (by making a different decision or not deciding) for reasons that would have caused and justified that outcome, and so the decision she made was up to her. Thus, it is something about the agent that settles which decision occurs: the agent exercises her will in making a decision for reasons. Arguably, it is not the agent-causalist who has an advantage in saying that the agent, as substance, settles which decision occurs, for that requires a substance to stand in a causal relation with an event. The event-causal libertarian has the advantage in being able to say that events- the occurrence of certain of an agent's attitudes, considerations relevant to the decision - cause the event of the decision; that is, what it is for an agent, who is indeed present, to exercise her ability to make a decision for reasons.

The critic may ask: but what explains or accounts for or caused the fact or state of affairs that there was the particular decision outcome there was, rather than a different outcome? The event-causal libertarian, the critic may charge, cannot offer an explanation of or an account for (or name the cause of) this fact of A rather than B. If the answer is simply, "that is the way the indeterministic deliberative or decision process happened to turn out," then does this not show that, on the event-causal libertarian model, the agent's decisions are uncontrolled? Notice that, when the agent freely decides to do $\mathrm{A}$, she thereby decides to do $\mathrm{A}$ rather than $\mathrm{B}$, and her decision to do so is under her full control. If she had freely decided to do $B$, then she would have thereby decided to do $B$ rather than $A$, and her decision to do so would be under her full control. In making a decision concerning which alternative to pursue, she has thereby selected which alternative to pursue. In neither case of decision-making is she passive and in neither case is the decision uncaused or rationally inexplicable or random or uncontrolled. Arguably, then, there is no lack of the presence of an agent on plausible eventcausal libertarian accounts of freedom and no unsolved problem of luck for such accounts either. 


\section{Bibliography}

Anscombe, E. (1981) "Causality and Determination," in E. Anscombe, The Collected Philosophical Papers of G.E.M. Anscombe, Vol. 2. Minneapolis: University of Minnesota Press, pp. 133-47.

Balauger, M. (2009) Free Will as an Open Scientific Problem. Cambridge: MIT Press.

Chisholm, R. (1964) "Human Freedom and the Self," The Lindley Lecture, University of Kansas. Reprinted in Watson G. (ed.) (1982) Free Will. Oxford: Oxford University Press.

Clarke, R. (2003) Libertarian Accounts of Free Will. Oxford: Oxford University Press.

Dennett, D. (1981) "On Giving Libertarians What They Say They Want," in D. Dennett, Brainstorms: Philosophical Essays on Mind and Psychology. Cambridge: MIT Press, pp. 286-99.

Ekstrom, L. (1993) “A Coherence Theory of Autonomy," Philosophy and Phenomenological Research 53: 599-616.

Ekstrom, L. (1998) "Protecting Incompatibilist Freedom," American Philosophical Quarterly 35: 333-54.

Ekstrom, L. (2000) Free Will: A Philosophical Study. Boulder: Westview Press.

Ekstrom, L. (2002) "Libertarianism and Frankfurt-Style Cases," in R. Kane (ed.), The Oxford Handbook of Free Will, 1st edn. Oxford: Oxford University Press, pp. 309-22.

Ekstrom, L. (2003) "Free Will, Chance, and Mystery," Philosophical Studies 113: 153-80.

Ekstrom, L. (2005) "Alienation, Autonomy, and the Self," Midwest Studies in Philosophy 29: 45-67.

Ekstrom, L. (2008) "Review of Free Will and Luck, by Alfred Mele," Philosophical Books 491: 71-3.

Ekstrom, L. (2010) "Volition and the Will," in T. O'Connor and C. Sandis (eds), The Blackwell Companion to the Philosophy of Action. Oxford: Wiley-Blackwell, pp. 99-107.

Ekstrom, L. (2011) "Free Will Is Not a Mystery," in R. Kane (ed.), The Oxford Handbook of Free Will, 2nd edn. Oxford: Oxford University Press, pp. 366-80.

Ekstrom, L. (2013) "Rational Abilities and Responsibility," Philosophy and Phenomenological Research 86: 459-66.

Ekstrom, L. (forthcoming) "Conscious Gestalts, Apposite Responses and Libertarian Freedom," in M. Sevel and A. McCay (eds), Libertarian Free Will and The Law: New Essays. Aldershot: Ashgate.

Ekstrom, L. (n.d.) "Hope for Free Will Libertarianism?" presented at The Queen's College, Oxford University, Freedom, Determinism and Responsibility Conference, March 7, 2014.

Frankfurt, H. (1971) "Freedom of the Will and the Concept of a Person," Journal of Philosophy 68: 5-20.

Franklin, C. (2013) "How Should Libertarians Conceive of the Location and Role of Indeterminism?" Philosophical Explorations 16: 44-58.

Hitchcock, C. (1999) "Contrastive Explanation and the Demons of Determinism," The British Journal for the Philosophy of Science 50: 585-612.

Hodgson, D. (2005) “A Plain Person's Free Will,” Journal of Consciousness Studies 12: 3-19.

Hodgson, D. (2012) Rationality + Consciousness = Free Will. Oxford: Oxford University Press.

Kane, R. (1996) The Significance of Free Will. Oxford: Oxford University Press.

Kane, R. (ed.) (2002) The Oxford Handbook of Free Will, 1st edn. Oxford: Oxford University Press.

Kane, R. (ed.) (2011a) The Oxford Handbook of Free Will, 2nd edn. Oxford: Oxford University Press.

Kane, R. (2011b) "Rethinking Free Will: New Perspectives on an Ancient Problem," in R. Kane (ed.), The Oxford Handbook of Free Will, 2nd edn. Oxford: Oxford University Press, pp. 381-404.

Levy, N. (2011) Hard Luck: How Luck Undermines Free Will and Responsibility. Oxford: Oxford University Press.

Mele, A. (1995) Autonomous Agents: From Self-Control to Autonomy. Oxford: Oxford University Press.

Mele, A. (2006) Free Will and Luck. New York: Oxford University Press.

Nelkin, D. (2011) Making Sense of Freedom and Responsibility. Oxford: Oxford University Press.

Pereboom, D. (2001) Living Without Free Will. New York: Cambridge University Press.

Pereboom, D. (2014a) "The Disappearing Agent Objection to Event-Causal Libertarianism," Philosophical Studies 169: 59-69.

Pereboom, D. (2014b) Free Will, Agency, and Meaning in Life. Oxford: Oxford University Press.

van Inwagen, P. (1983) An Essay on Free Will. Oxford: Oxford University Press.

van Inwagen, P. (2002) "Free Will Remains a Mystery," The Oxford Handbook of Free Will, 1st edn. Oxford: Oxford University Press, pp. 158-79.

Watson, G. (1987) "Free Action and Free Will," Mind 46: 145-72.

\section{Further Reading}

Clarke, R. (2003) Libertarian Accounts of Free Will. Oxford: Oxford University Press. (Clark offers detailed analysis of a variety of libertarian accounts of free agency.) 


\section{EVENT-CAUSAL LIBERTARIANISM}

Ekstrom, L. (2000) Free Will: A Philosophical Study. Boulder: Westview Press. (Ekstrom develops a positive event-causal indeterminist account of free action and critiques compatibilism.)

Fischer, J., Kane, R., Pereboom, D., and Vargas, M. (2007) Four Views on Free Will. Malden: Blackwell Publishing. (This volume sets libertarianism in conversation with the competing views of revisionism, compatibilism, and free will skepticism.)

Hodgson, D. (2012) Rationality + Consciousness = Free Will. Oxford: Oxford University Press. (Hodgson argues that we have libertarian free will by appeal to undetermined responses to conscious gestalt experiences.)

Kane, R. (1996) The Significance of Free Will. Oxford: Oxford University Press. (This is the central source developing Kane's event-causal libertarian view, which is refined in subsequent articles.)

van Inwagen, P. (1983) An Essay on Free Will. Oxford: Oxford University Press. (In this modern classic, van Inwagen articulates arguments for incompatibilism concerning free will and determinism.)

\section{Related Topics}

Agent Causation

Non-Causal Libertarianism

The Luck and Mind Arguments

Deliberation

The Relationship between Moral Responsibility and Freedom 


\section{7 \\ AGENT CAUSATION \\ Meghan Griffith}

Suppose that a human person, Agnes, performs an action, such as turning on the light. Has Agnes done any causing? If it's an ordinary scenario, it seems that Agnes has caused a number of things: the movement of the light switch, the illumination of the room, maybe the startling of an intruder (to modify a famous example from Davidson 1963: 686). She has caused the movement of her body, as well as the movement of air particles (see Chisholm 1982). Maybe she has even caused her own volition or decision to flip the switch.

Most philosophers believe there are human agents, and that these agents cause things (for a similar claim see Clarke 2013: 218). But relatively few philosophers call themselves 'agent-causalists' or say that they believe in 'agent causation.' Most, in fact, espouse what we might call 'event-causal' rather than 'agent-causal' views. And yet, they do not deny human agency. For example, Laura Ekstrom notes that "event-causal libertarians can believe that agents cause their free acts" (Ekstrom: this volume, page 64). As she puts it:

For instance, we commonly say such things as, "George freely flipped on the light switch." Event-causal libertarians can maintain that we are perfectly sensible in making such claims, but they also maintain that in such cases we are speaking in shorthand: what we really believe or ought to believe is that certain events involving George (events of which George is the subject) brought about the switch flipping. These events include, for instance, George's coming to desire light in the room and his forming the intention to flip the switch.

(Ekstrom: this volume, page 64)

The same reasoning can be extended to nonlibertarian (compatibilist) versions of event-causalism. Thus, the term 'agent causation' (or 'agent-causalism') is typically used more narrowly to designate a view with controversial metaphysical commitments. It is a theory about the metaphysical nature of agency, but it is most often discussed within the context of free will and responsibility. Its proponents typically characterize it as a view, which, if true, would allow us to have the kind of free and responsible agency that we think we have.

In this chapter, I provide a sketch of agent causation. First I discuss what I take to be agent causation's defining characteristics. Then I discuss some of the ways in which agentcausal theories can vary. In the final two sections, I discuss motivations for agent-causalism 
and some objections. Overall, I hope to clear up common misconceptions and to present the view as a worthwhile contender among metaphysical theories of agency.

\section{Essential Features}

\section{Irreducible Substance Causation}

Agent causation is irreducible substance causation. The agent, the person, is a metaphysical substance whose causal activity grounds autonomous agency (and responsibility). According to the agent-causalist, exercises of free will require something other than the usual causal story about actions flowing from mental states or events. (My discussion centers on ontologically irreducible agent causation. For a discussion of the view that agent causation is merely conceptually irreducible, see Clarke 2013.)

As an illustration, take Agnes (or recall Ekstrom's George, above). The typical nonagent-causal story goes like this: to say that Agnes caused the light to go on, or caused herself to turn it on, is really to say that there was a sequence of mental states and events inside of (or involving) Agnes that causally led to this result. Perhaps Agnes' desire to see, coupled with her belief that turning on the light would allow her to see, caused a decision to flip the switch, which caused her muscles to contract, and so on (for an influential account of reasons as desire-belief pairs that cause action, see Davidson 1963).

This process could be deterministic or indeterministic. In contrast to the standard theory, agent causation does not allow reduction to these kinds of processes. The agent-causalist says that at some suitable point it must be the case that Agnes, the substance, the person - rather than merely her mental states (or events occurring inside of her) — causes some appropriate element of her own behavior.

Thus, the first essential feature of agent causation is irreducible substance causation. The agent is herself an irreducible cause. Exactly what this 'causing' looks like varies according to the particular theory. E. J. Lowe points out that the 'classical' agent-causal view "holds that when an agent causes an event, it is just the agent qua agent that causes the event, not the agent by acting in some manner" (Lowe 2008: 6). But Lowe himself dismisses the classical version, arguing instead that agents cause by acting (i.e., by willing). On a view like Lowe's, the agent does not, strictly speaking, cause her action (raising her arm). Instead, she causes an action-result (the event of the arm's rising) (Lowe 2008: 148. See also Steward 2012). Similarly, according to Timothy O'Connor's view, the agent's action is the causing event rather than the event that is caused (by the agent) (see Clarke 2003: 25, 138, for a helpful discussion of the difference between so-called 'component' views versus 'product' views.). According to O'Connor, the agent's "activity par excellence" is his causing of "the coming-to-be of a state of intention" that goes on to cause the action (see O'Connor 2000: $72 \mathrm{fn} 11,75$ ).

\section{Realism About Causation}

Another central feature of agent causation is realism about causation. As Randolph Clarke suggests, the agent-causalist cannot plausibly adopt a reductive view of causation. He says:

The most familiar accounts of event causation are reductionist, aiming to analyze causation in terms of such noncausal and nonnomological features as 
constant conjunction or counterfactual dependence, or in terms of the modalities of necessity and sufficiency. Certainly, if any of this type of account of event causation is correct, then agent causation cannot be the same relation as event causation. For agent causation plainly cannot be either the constant conjunction of an agent and an action type or the counterfactual dependence of an action on an agent, nor can it consist in an agent's being a necessary or sufficient condition for the performance of a particular action.

(Clarke 1993: 197, his footnote omitted)

When an agent agent-causes, there is a real bringing about of a genuine exercise of causal power. Agent causation, then, is nonreductive in more ways than one. There is no reduction to event-causation and no reduction to noncausal processes.

\section{Variations}

\section{Immanent Causation}

Roderick Chisholm, a famous proponent of agent causation, uses the term 'immanent causation' to refer to what I am here calling agent causation, and uses 'transeunt causation' to refer to event causation (Chisholm 1982). But in the interest of clarifying the agentcausal view, it may be helpful to consider some ways of understanding immanent causation and whether any of these are essential to agent causation. One way of understanding immanent causation would be to say that the substance, as a whole, causes changes in its parts (Steward 2012: 224). This would be to say that, for example, Agnes, the person, causes changes in her brain, her arm, and her finger, when she turns on the light. But is immanent causation, understood in this way, essential to agent-causalism? As Helen Steward points out, it is not that substance causation automatically suggests this wholepart version of immanent causation. She claims that it is instead something about agent causation that requires it (2012:224). But while it could turn out that the most plausible version of agent causation does in fact require this, whole-part immanent causation does not seem to be a conceptual requirement for agent causation in general. To take just one example, a substance dualist with an agent-causal position would not regard the relation between the agent and what she causes as a relation between a whole and its parts.

We might consider a broader notion of immanent causation here-that is, one that does not refer to wholes and parts. So perhaps immanent causation is the idea that a substance causes changes to itself. But even here, it is not clear that immanent causation is required. Presumably a divine agent could be an agent-causer and not cause any such changes (because on standard views of God's nature, not only does God not have parts, but God does not change). Thus, immanent causation seems not to be an essential feature of agent causation, though some version of it may be required for human agents, given particular facts about human nature.

\section{Mind and Body}

It is often supposed that the agent-causalist is forced to subscribe to Cartesian dualism or perhaps to idealism. (It may be worth noting that some philosophers characterize Berkeley and Kant as agent-causalists. Regarding Berkeley, see Clarke and Capes (2015). Regarding Kant, see Nelkin (2011), Watkins (2013), and Pereboom (2014). Although the 
assumption that agent causation requires Cartesian dualism or idealism is unwarranted, as I argue below, it is understandable. If my actions or movements cannot be caused solely by my internal states, but must be caused by me, then it would seem that I must be something other than these states. To put it in the words of Descartes himself, "what then am I?"

But while Cartesian dualism (and idealism) are both consistent with agent-causalism, so are a number of other positions. Again, the key component of agent-causalism is irreducible substance causation. Thus, one need only make room for agents as substances and allow for such substances to do real, irreducible, causal work. There is no need to posit Cartesian immaterial minds. According to agent-causalism, I am not just a bundle of internal states, but this does not automatically entail that I am wholly nonphysical. An agent-causalist could hold, for example, that agents are psychological substances with both mental and physical properties (see Lowe 2008). I argue that even a constitution view can be made consistent with agent-causalism, so long as substances are understood in a way consistent with constitution (Griffith, unpublished). The constitution view is meant to be a version of materialism - a person is constituted by a body though not identical to it (just as a statue is constituted by, but not identical to, a lump of marble). Constituted objects (e.g., persons, statues) have causal powers that are not possessed by the things that constitute them (e.g., bodies, lumps of marble) (see Baker 2000; note that Baker does not, to my knowledge, adopt an agent-causal view). Thus, a person can have the causal powers of agency as understood by the agentcausalist while still being fully constituted by the physical. Similarly, Timpe and Jacobs (2015) defend a naturalistic account of agent causation. (Interestingly, Pereboom claims that deterministic agent causation can be reconciled with physicalism, but that libertarian agent causation requires some kind of dualism. Personal correspondence; see also Pereboom 2015.)

\section{Reasons and Reasons-Explanations}

Another important variation among agent-causal positions involves reasons and reasons-explanations. The kind of action that concerns us in discussions of free will and responsibility is intentional action-action that is explicable in terms of the agent's reasons for acting. But if the substance causation at work in agent causation is not reducible to states or events within the agent, how should we understand the role of reasons? As noted above, the standard picture of action is a causal story whereby reasons (often thought of as pairs of desires and beliefs) cause what we do. But if I cause my behavior, what role do my reasons play? Some agent-causal accounts, such as the one offered (but ultimately abandoned on other grounds) by Randolph Clarke, leave room for reasons to play a causal role. Reasons are presented as partial causes (see, for example, Clarke 1993). Other views attribute explanatory work to reasons without giving reasons status as efficient causes. Timothy O'Connor, for example, appeals to Fred Dretske's distinction between structuring and triggering causes to suggest that reasons structure the probabilities of ensuing actions but do not act as action triggers (O'Connor 2009; discussed in Pereboom 2014: 60, 61). Others, like Lowe, argue that reasons are not states of the agent—such as internal desires or beliefs - that cause action. Instead, reasons are understood as external. They are states of affairs involving the agent's circumstances (Lowe 2008: 180, 181). Lowe goes on to say that reasons for action, unlike reasons for belief, are 'objective needs' rather than facts. What reasons the agent has for acting, then, will be constituted by the agent's 'objective needs' given the circumstances. In the realm of action, goodness plays the role that 
truth plays in the realm of belief-that is, "just as a true belief is one which corresponds to fact, so a good action is one which corresponds to need" (Lowe 2008: 209). When they act freely, agents are thus not caused to act by internal psychological forces, but can act for the reasons that they freely choose (Lowe 2008: 183).

\section{Exceptionality}

Another variation among agent-causal views is the way such positions treat agentcauses in comparison to other causes. It is often assumed that the agent-causal view posits a causal role for us that is metaphysically quite exceptional such that the way we cause is unlike anything else in the natural world. But while most agent-causalists (and many event-causalists) agree that human agency is exceptional in a number of ways, the agent-causal position does not entail such a stark difference between human agency and other causes. Some agent-causalists do indeed posit such a difference (e.g., Chisholm) but others do not. Thomas Reid argues that only beings with minds can have real causal powers. Thus, for Reid, ordinary physical causation is ultimately attributable to an agent (i.e., God). There are no genuine event-causes to contrast with the agent-causes and so human agency is not exceptional among the world's causes. Of course, by requiring mentality and requiring God as the source of physical causation, Reid's view will not appeal to those who want a more naturalistic explanation. But for those latter philosophers, there are other options. Some important current positions support the idea that all causation is substance causation, but without requiring mentality in all cases. The basic intuition is that substances, rather than events, are more appropriately endowed with causal power (Harré 2001; Lowe 2008; Timpe and Jacobs 2015; Griffith, unpublished). A different way to avoid exceptionality can be found in Helen Steward's recently developed naturalistic view (Steward 2012). She defends a pluralistic account of causation. On her view, "causation is best thought of as a category: a large and ontologically flexible umbrella concept under which we bring a wide diversity of ontologically various relations and relationships" (2012: 210). Substances are not the only causes in her account, but substance causes exist throughout the natural world and not just within the realm of human agency.

\section{Compatibilism and Incompatibilism}

The final variation I will note concerns incompatibilism and compatibilism. Most agent-causalists are libertarians - that is, they believe we have a kind of free will that is incompatible with determinism. And these agent-causalists may in fact be drawn to the view in virtue of their libertarianism (that is, because they think agent-causalism saves libertarianism from particular difficulties, as I discuss in the next section). But it is not at all clear that one must start from a libertarian standpoint. At its core, agent-causalism is a position about irreducibility and the relation between an agent and her behavior. Thus, it does not require an initial commitment to libertarianism and some agent-causalists are compatibilists (Markosian 1999, 2012; Nelkin 2011).

\section{Motivations}

Although agent causation is often subject to harsh criticism, it has attracted the serious attention of philosophers throughout history and continues to play an important role in 
the free will debate. In fact, the view seems to be attracting more proponents in recent years. What motivates the agent-causal view?

\section{Determinism and Luck}

Probably the most familiar and prominent motivation is the one expressed by Chisholm (1982). Chisholm worries about finding a place for responsible agency in light of threats from determinism on the one hand, and luck or chanciness on the other. How can we be free and responsible if our choices are determined by a prior chain of causes? On the other hand, how can we be in control of what we do if our choices are not determined by anything, not even our own desires, beliefs, reasons, and so on (see Levy 2011; Franklin: Chapter 17, this volume)? Agent causation is supposed to solve the problem. Our choices do not come from a chain of previous causes, nor do they happen by chance. We determine our choices. We are, in this sense, prime movers unmoved (Chisholm 1982). Agent causation is, in this way, often regarded as a way of rescuing agential control from the so-called 'luck objection' while simultaneously avoiding the concerns about determinism.

An important variation on the luck objection is Derk Pereboom's "disappearing agent objection." This objection is similar to the luck objection because it raises a problem of control for libertarian views utilizing indeterministic event-causes (but see Franklin: this volume, pages 205-6, for a distinction between Pereboom's argument and the luck objection). So while Pereboom does not ultimately adopt a libertarian agentcausal position, the objection can serve as further reason to embrace agent causation if one is inclined towards libertarianism. The objection spells out what is seen as a deficiency in non-agent-causal libertarian views. Take "event-causal libertarianism." Such a view might, for example, hold that a free decision involves competing sets of motivations or reasons for performing the act and reasons for refraining or performing an alternative. Whichever decision is made, the event-causal libertarian will say that it was indeterministically caused by the appropriate set of motivations. We can suppose for the sake of argument that the motivations for performing the act give it a 50 percent chance of occurring (Pereboom 2014: 32). Pereboom argues that:

Because [on event-causal libertarian views] no occurrence of antecedent events settles whether the decision will occur, and only antecedent events are causally relevant, nothing settles whether the decision will occur. Thus it can't be that the agent or anything about the agent settles whether the decision will occur, and she therefore will lack the control required for basic desert moral responsibility for it.

(Pereboom 2014: 32)

Thus, the agent is essentially missing from her own action. Pereboom indicates that agent causation could resolve the problem, although he rejects the existence of libertarian agent causation on other grounds (see also Griffith 2010).

It is worth noting that some important arguments have been made to the effect that agent-causalism, even if true, would not eradicate the luck associated with indeterminism because it would still be inexplicable why the agent chose to do A rather than doing something else that she could have done (see Mele 2006; Haji 2004; van Inwagen 2000. Pereboom 2014 and Clarke and Capes 2015 also discuss these arguments). The agent-causalist can push back by emphasizing the distinction between lack of control 
and lack of contrastive explanation (Clarke 2005: 416; O'Connor 2007). To see this, suppose that God is an agent-causer, capable of choosing between equally weighted options (setting aside concerns about whether God needs sufficient reason in order to be able to choose at all). There seems to be no conceptual difficulty with imagining God as able to control such a choice, even though there will be no contrastive explanation (Griffith 2010: 48).

So a major theme in discussing agent-causalism is whether the view can mitigate worries about determinism, on the one hand, and luck on the other. But the prominence of this theme may also be partly responsible for the unfortunate caricature of agent-causalism as a view that all too conveniently manages to provide exactly what is needed, almost as if agent-causal power were stipulated or wished into existence from an ethereal armchair. I do not think this caricature is fair, particularly if we keep in mind some other motivations for the view.

\section{Reduction}

Another important motivation, distinct from the problem of determinism/luck is a worry about reduction. This worry finds eloquent and forceful expression in the work of David Velleman, who argues that the "standard story" of action leaves the agent out of the picture (although Velleman does not ultimately adopt a nonreductive or agentcausal view). As Velleman argues:

In this story, reasons cause an intention, and an intention causes bodily movements, but nobody - that is, no person-does anything. Psychological and physiological events take place inside a person, but the person serves merely as the arena for these events: he takes no active part.

(Velleman 1992: 461, footnotes omitted)

Velleman's argument can be seen as an important precursor to Pereboom's disappearing agent objection, but it differs in its scope. Velleman's focus is on what he calls "fullblooded agency," whereas Pereboom is concerned more specifically with basic desert moral responsibility (Pereboom 2014: 32 fn1). Furthermore, Pereboom's argument zeros in on the diminished control associated with event-causal libertarianism (see Franklin 2014) whereas Velleman raises issues for the standard view in general. As Christopher Franklin argues, if the kinds of concerns Velleman raises are well-founded, they need to be addressed by those on all sides of the debate, not just libertarians (Franklin, forthcoming).

Thus, some argue that agent causation should be motivated by concerns about reduction rather than as a means of rescuing libertarianism (see Franklin, forthcoming and Griffith 2016). But of course, this motivation is undermined if there are reductive views that can adequately respond to Velleman's concerns. Velleman and others do offer such attempts, but it remains to be seen whether these attempts are sufficient (for arguments against the success of reductive attempts see Franklin 2015 and Griffith 2016).

\section{Metaphysics and Epistemology}

Finally, let us not overlook motivations that stem from more fundamental metaphysical or epistemological theorizing. For example, there may be good metaphysical 
reasons-reasons apart from concerns about agency-to think that substances have nonreductive causal powers. Rom Harré, for example, advocates an ontology of "causally active substances" or "powerful particulars" (Harré 2001). He argues that substance causation has both ontological and explanatory priority over event causation. He appeals, in part, to science and to general scientific practice to argue for the explanatory power of substance causes over event causes (human agents being only one kind of substance cause). He argues, for instance, that when regularities are observed between supposed cause-events and effect-events, scientists look for the "ontological tie" or "enduring mechanism" to explain the sequence of events (Harré 2001: 99, 100). Similarly, Lowe argues that events are not appropriately understood to be causers (strictly speaking) because to cause is to do. Events happen. They cannot do anything (Lowe 2008: 4). And Thomas Reid looks to observations regarding the origins of our concept of causality. Reid argues that we only understand causation based on our experience as causers:

In certain motions of my body, and directions of my thought, I know, not only that there must be a cause that has power to produce these effects, but that I am that cause; and I am conscious of what I do in order to the production of them.

From the consciousness of our own activity, seems to be derived, not only the clearest, but the only conception we can form of activity, or the exertion of active power.

If it be so that the conception of an efficient cause enters into the mind, only from the early conviction we have that we are the efficients of our own voluntary actions, which I think is most probable, the notion of efficiency will be reduced to this, that it is a relation between the cause and the effect, similar to that which is between us and our voluntary actions. This is surely the most distinct notion, and, I think, the only notion we can form of real efficiency.

(Reid 1788/1998: 226)

Reid argues from here that we therefore have no good reason to think that anything inanimate (and in fact, anything without a mind) can act as a genuine cause (Ibid. 226, 227). So while Reid's view is clearly tied to agency, the argument in this case is not that we should believe in agent causation because it is our only hope for responsible agency. Instead, Reid starts from the claim that we should believe in agent causation because agential causing constitutes our concept of causation. According to Reid, we have no good evidence to suggest that our concept needs to be revised.

\section{Objections and Replies}

Many kinds of objections have been leveled against agent causation. Some claim that the view is empty. Others claim that it is incoherent. In some literature, agent causation is defended as coherent but then rejected as implausible (e.g., Pereboom 2001) or as (probably) impossible (Clarke 2003) (though in more recent work, Pereboom expresses some misgivings about the coherence of libertarian agent-causalism. See Pereboom 2014). There are a number of objections, each of which raises complex metaphysical issues of its own. Thus, I cannot attempt to do justice to the objections here. Instead, I will highlight a few and briefly discuss potential responses or indicate what the agent-causalist might do in future work to respond. I divide these into two categories. 
The first category centers on what I will call the sufficiency of the theory. Is the view sufficient to tackle the problems it is meant to tackle? The second category involves plausibility and possibility.

\section{Sufficiency}

The first category involves how well the agent-causal view can account for free and responsible agency. In particular, can the view sufficiently account for agential control and action explanation? According to these objectors, agent causation falls short in its promise to grant control and/or explanation to agent-caused behavior.

\section{Timing}

One infamous objection to agent-causalism regards the timing of actions (this objection is a version of C. D. Broad's famous objection. See Clarke 2003: 198). It appears that an agent-cause would be unable to explain the timing of the effect. Why did the agent act as he did just when he did? Though some argue that the objection is unfounded (see Pereboom 2014: 63-4), others attempt to resolve it by appeal to reasons as partial causes of action (see Clarke 1993: 194). The timing of the action is thereby explained by the timing of the reasons that partly cause it: Agnes turns on the light when she does, because the reasons that partly cause her to do so occur at that time. But not all agent-causalists want to take this route, because they do not want to hold that reasons are partial causes of action. How, then, are they to solve the timing problem? I think it is useful to think in terms of properties. If substances cause, they presumably do so in virtue of their properties. If a rock causes a window to break, it is in virtue of its size, hardness, velocity, and so on. Substances have different properties at different times, and so the timing of causal behavior is explicable. It is in virtue of Agnes' properties at the time in question that she causes the flipping of the switch. One might worry, of course, as Clarke does, that this kind of reasoning collapses the distinction between agent causation and event causation. Citing properties as explanatory here comes dangerously close to saying that what really does the causing is 'the having of a property at a time' (i.e., an event) rather than the agent (Clarke 2003: 202; discussed in Steward 2012: 220). But, as Clarke himself notes, there are plausible cases in which an object, rather than its property, enters into a relation, even if it does so in virtue of a particular property (Steward notes that Clarke does not fully appreciate how this point bears on the timing issue [Steward 2012: 222]). Clarke considers the 'bigger than' relation: we might say that one object is bigger than another, in virtue of the two objects' respective sizes, without thereby suggesting that it is the sizes rather than the objects that stand in the 'bigger than' relation to one another (for discussion, see Griffith, unpublished and Steward 2012: 222). If we take seriously the idea of a substance-causal relation, there is room to allow that it is in virtue of 'properties at a time' that a substance enters into the causal relation, just as it is in virtue of size, that two objects can enter into the 'bigger than' relation.

\section{Reasons}

As discussed earlier, the agent-causalist can choose whether to posit reasons as partial causes or whether to understand reasons as explanatory in some nonefficient-causal 
way. But both routes lead to potential difficulties. If reasons are partial causes, does the reason causally act on the agent? It might seem problematic to understand the agent (a substance) as an effect (Clarke 2003: 158; see also Pereboom 2014: 59 for discussion). Suppose, instead, that the reason acts as an additional cause of the action - that is, the agent and the reason jointly cause it (Clarke seems to have this picture in mind). But how does this work? How is it that the right kind of reasons just happen to causally link up with the actions that I supposedly cause in virtue of them? (Pereboom 2014: 59, 60). Clarke suggests lawful connections between reasons and actions, but can this be worked out in a plausible way that does not seem ad hoc?

What about the noncausal approach? How do reasons explain behavior without causing it? How can we make sense of those cases in which the agent has multiple reasons, but only acts for one of those reasons? If reasons are not causes, we cannot say that the reason for which the agent acted was the one that caused the behavior. (Ginet discusses this sort of case in 1990 where he defends a noncausal view. For a more recent discussion see Ginet 2008.)

But there seem to be avenues of response available to the agent-causalist. Given the way that causation always seems to involve the convergence of various elements and conditions (i.e., a particular effect is never 'just' the result of one particular event), it may not be such a stretch to envision laws which allow substances and reasons to provide causal influence towards the same ends. This could be so whether substances and reasons act together as efficient causes, as Clarke suggests, or whether reasons act as structuring, rather than triggering causes, along the lines suggested by O'Connor. Alternatively, there are some persuasive points in favor of the idea that reasons have more explanatory power when they are understood noncausally. Take Davidson's famous example of a deviant causal chain whereby a climber lets go of his rope, allowing his companion to fall. The climber has the following desire-belief pair: he wants to save his own life and he thinks that he can do so by letting go of his rope. But in the example, the causal chain is deviant because the climber does not intentionally let go. Instead, this desire-belief pair shakes him up so much that he accidentally lets go (Davidson 1980: 79, cited in Lowe 2008: 182). As Lowe points out, "it has proved notoriously difficult to say, quite generally, how beliefs and desires should be supposed to cause behaviour if the behaviour is to qualify as rational action performed in the light of those beliefs and desires" (2008: 182). Lowe claims instead that rational action must be freely chosen by the agent in light of these beliefs and desires (2008: 182). (For another discussion of causal deviance see Bishop 1989.)

\section{Implausibility and Impossibility}

The second set of objections centers on purported implausibility (either metaphysical or empirical) and impossibility. These objections tend to be more charitable toward the view's sufficiency and coherence. They question, instead, whether such a view is realized in our world, or even in any possible world.

\section{Exceptionality}

The first objection takes us back to the issue of exceptionality (discussed earlier). Is the agent-causal relation exceptional in the natural world? If so, is this not too incredible to be believed, that we, and only we, are able to do this thing called agent-causing, 
while the rest of the natural world operates according to event-causal processes? In terms of the metaphysics of causation, shouldn't causation be a uniform phenomenon? Shouldn't all causal relations have the same relations and work in the same way? (see Clarke 2003).

There are a number of ways an agent-causalist might respond to these worries about exceptionality. One straightforward response is to suggest that it is not implausible to think that exceptional causal abilities would arise from exceptional features. Although the cognitive capacities of animals seem to fit along a continuum, it is difficult to deny that human beings are able to do and choose in ways that other creatures are not.

Conversely, some might worry that our unique capacities, while helping to ground responsibility, are not sufficient to account for such a dramatic metaphysical difference as the one between event-causal and agent-causal paradigms. But here it is important to recall that not all agent-causalists posit exceptionality. For example, theorists who hold that all causation is substance causation may have complications to explain, but they will not have to explain how agents are able to engage in a special causal relation unlike any other. On this view, all substances have causal powers, but of varying sorts (typically based on their having varying properties). Human agents can thus retain a level of uniqueness so as to ground responsible behavior, but they can do this without having to cause in a completely different way.

Helen Steward's naturalistic view is also able to avoid the exceptionality worry, but not by positing universal substance causation. As mentioned earlier, she endorses a pluralistic theory of causation, but theorizes that human beings are not the only substance-causers.

\section{Coincidence}

A final objection I will consider is Derk Pereboom's objection concerning coincidences (see Pereboom 2014: 65-9; Pereboom, this volume, pages 128-9). According to agent causation, agents produce physical effects in the world, including things like brain alterations and bodily movements. In most versions of agent-causation, agents are undetermined in doing so. Agents are afforded freedom from being determined by laws. But physical events are law-governed, and agent-effects, like brain changes or bodily movements, are physical. If determinism is true, but agents' choices are not determined, then "it would seem that we would at this point encounter divergences from the deterministic laws" (2014: 66). Or do agents just coincidentally happen to cause physical effects that dovetail with these laws? Even supposing determinism is not true, we would still expect divergences from the laws in terms of the antecedent probabilities of physical events. Lack of divergence in terms of the probabilities would also be a wild coincidence (2014: 67).

Pereboom notes that some agent-causalists, such as Chisholm, claim that there are divergences, probably in the brain (Pereboom 2014: 69). But Pereboom worries that we have no positive evidence to believe that this is true (2014: 69). Thus, it seems that the agent-causalist must choose between wild coincidences or empirically unsupported divergences.

In response, the agent-causalist might push harder against the assumption at the heart of the argument: i.e., that it is possible to assign probabilities to certain physical occurrences apart from those occurrences being determined by the choices of agentcauses. If we suppose that there are agent-causes, then we might question whether my 
arm has the same probability of rising, regardless of whether I (agent-causally) choose to raise it. Given some of the newer agent-causal positions on offer, this assumption may not be warranted. For example, Steward argues in favor of top-down causation as the means by which agents do their causing. On her view, agents are undetermined 'settlers,' but this settling does not exist apart from natural law (Steward 2012). Let us suppose such an agent raises her arm. The physical events (that appear to give us the probabilities of the arm's rising) are part of the top-down process of the agent's choosing to raise it. Some philosophers claim that when emergent properties come into play in top-down causation, there must be divergences from what the ordinary laws predict (see Pereboom 2015, where he discusses O'Connor's view). If this claim is correct, then the top-down view fares no better than Chisholm's (Pereboom, personal correspondence). But Steward argues that the top-down theorist need not and should not grant that the laws of physics alone yield such predictions (even in terms of fixing the probabilities) (2012:230, 231). If she is right, her top-down approach avoids Pereboom's objection.

Or, if one defends an 'all causation is substance causation' view, then it seems beside the point to suppose that agents must fit into an otherwise event-causal schema and seek to exploit gaps in the causal order. If all causation is substance causation, statistical likelihoods given by physical laws are just the likelihoods of how various substances will behave in certain circumstances. Thus again, there will be no division between the likelihoods of the physical components of action versus what the agent chooses, because there will not be two paradigms (event-causal and substance-causal) that we are trying to reconcile.

One might be concerned that these latter responses undermine the original appeal of agent causation as a view that is uniquely situated to give power and control to agents. For example, in discussing O'Connor's discussion of these probabilities, Pereboom suggests that the problem of divergence arises as a result of positing two different sorts of causal power so as to respond to the "disappearing agent objection" and so as to secure a genuine agential role for humans $(2014: 61,69)$. Does the agent-causalist make strides toward plausibility (by eradicating the problem of divergence) only to lose ground in terms of sufficiency?

More work needs to be done on this score, but I do not think such a trade-off is inevitable. It may depend, of course, on exactly what we are worried about when it comes to responsible agency. But it is not clear that solving the disappearing agent problem, for example, really does require positing a distinction between agential and other causes, since the core of the problem concerns reduction and passivity. It does not seem to follow directly from such worries that there must be two distinct kinds of causal power, one that applies to agent-causing and one that applies to the physical components of action (that it seems to follow may be the result of already assuming that the natural world can only involve reductive, event-causal processes). So it is not clear that the agent-causalist needs to invite the problem of divergence.

\section{Acknowledgments}

Many thanks to Randolph Clarke, Christopher Franklin, Derk Pereboom, Helen Steward, and Kevin Timpe for very helpful comments on an earlier draft. Some ideas presented here developed from a project undertaken while a fellow at the National Humanities Center, with funding from the Jessie Ball duPont Fund. I want to thank the Center and the duPont Fund, as well as Davidson College for sabbatical support. 


\section{Bibliography}

Baker, L. (2000) Persons and Bodies: A Constitution View. Cambridge: Cambridge University Press.

Bishop, J. (1989) Natural Agency. Cambridge: Cambridge University Press.

Chisholm, R. (1976) "The Agent as Cause," in M. Brand and D. Walton (eds), Action Theory. Dordrecht: D. Reidel, pp. 199-211.

Chisholm, R. (1982) "Human Freedom and the Self," in G. Watson (ed.), Free Will. Oxford: Oxford University Press, pp. 24-35.

Clarke, R. (1993) "Toward a Credible Agent-Causal Account of Free Will,” Noûs 27: 191-203.

Clarke, R. (2003) Libertarian Accounts of Free Will. New York: Oxford University Press.

Clarke, R. (2005) "Agent Causation and the Problem of Luck," Pacific Philosophical Quarterly 86: 408-21.

Clarke, R. (2013). "Agent Causation," in T. O'Connor and C. Sandis (eds), A Companion to the Philosophy of Action. Malden: Blackwell, pp. 218-26.

Clarke, R. and Capes, J. (2015) "Incompatibilist (Nondeterministic) Theories of Free Will," in E. Zalta (ed.), The Stanford Encyclopedia of Philosophy (Fall 2015 Edition), available from: http://plato.stanford.edu/ archives/fall2015/entries/incompatibilism-theories/ (accessed 15 June 2016).

Davidson, D. (1963) "Actions, Reasons, and Causes," The Journal of Philosophy 60: 685-700.

Davidson, D. (1980) "Freedom to Act," in D. Davidson (ed.), Essays on Actions and Events. Oxford: Clarendon Press.

Dretske, F. (1988) Explaining Behavior: Reasons in a World of Causes. Cambridge: MIT Press.

Franklin, C. (2014) "Event-causal Libertarianism, Functional Reduction, and the Disappearing Agent Argument," Philosophical Studies 170: 413-32.

Franklin, C. (2015) "Self-Determination, Self-Transformation, and the Case of Jean Valjean: A Problem for Velleman," Philosophical Studies 172: 2591-8.

Franklin, C. (forthcoming) "If Anyone Should Be an Agent-Causalist, then Everyone Should Be an Agent-Causalist," Mind.

Ginet, C. (1990). On Action. New York: Cambridge University Press.

Ginet, C. (2008) "In Defense of a Non-Causal Account of Reasons Explanations," The Journal of Ethics 12: 229-37.

Griffith, M. (2010) "Why Agent-Caused Actions Are Not Lucky," American Philosophical Quarterly 47: 43-56.

Griffith, M. (2016) "Agent Causation and Theism," in K. Timpe and D. Speak (eds), Free Will and Theism: Connections, Contingencies, and Concerns. Oxford: Oxford University Press.

Griffith, M. (unpublished) Substantial Agency.

Haji, I. (2004) "Active Control, Agent-Causation, and Free Action," Philosophical Explorations, 7: 131-48.

Harré, R. (2001). "Active Powers and Powerful Actors," Royal Institute of Philosophy Supplement 48: 91-109.

Hornsby, J. (2004) "Agency and Actions," in J. Hyman and H. Steward (eds), Agency and Action. New York: Cambridge, pp. 1-23.

Levy, N. (2011) Hard Luck: How luck Undermines Free Will and Moral Responsibility. New York: Oxford University Press.

Lowe, E.J. (2006) "Agent Causation," in D. Borchert (ed.), Encyclopedia of Philosophy, Volume 1, 2nd edition. Detroit: Macmillan Reference USA, pp. 88-90.

Lowe, E.J. (2008) Personal Agency: The Metaphysics of Mind and Action. Oxford: Oxford University Press.

Markosian, N. (1999) "A Compatibilist Version of the Theory of Agent Causation," Pacific Philosophical Quarterly 80: 257-77.

Markosian, N. (2012) "Agent Causation as the Solution to All the Compatibilist's Problems," Philosophical Studies 157: 383-98.

Mele, A.R. (2006) Free Will and Luck. New York: Oxford University Press.

Nelkin, D. (2011) Making Sense of Freedom and Responsibility. New York: Oxford University Press.

O'Connor, T. (2000) Persons and Causes: The Metaphysics of Free Will. New York: Oxford University Press.

O'Connor, T. (2007) "Is it All Just a Matter of Luck?" Philosophical Explorations 10: 157-61.

O'Connor, T. (2009) "Agent-Causal Power," in T. Handfield (ed.), Dispositions and Causes. Oxford: Oxford University Press.

Pereboom, D. (2001) Living Without Free Will. Cambridge: Cambridge University Press.

Pereboom, D. (2014) Free Will, Agency, and Meaning in Life. New York: Oxford.

Pereboom, D. (2015) "The Phenomenology of Agency and Deterministic Agent Causation," in H. Pedersen and M. Altman (eds), Horizons of Authenticity in Phenomenology, Existentialism, and Moral Psychology. New York: Springer, pp. 277-94. 


\section{AGENT CAUSATION}

Reid, T. (1788/1998) "Efficient Cause and Active Power: an Excerpt from Essays on the Active Powers of the Human Mind," in P. van Inwagen and D. Zimmerman (eds), Metaphysics: The Big Questions. Malden: Blackwell, pp. 226-7.

Steward, H. (2012) A Metaphysics for Freedom. Oxford: Oxford University Press.

Taylor, R. (1966). Action and Purpose. Englewood Cliffs: Prentice Hall.

Timpe, K. and Jacobs, J. (2015) "Free Will and Naturalism: How to be a Libertarian and a Naturalist Too," in K.J. Clark (ed.), The Blackwell Companion to Naturalism. Oxford: Blackwell, pp. 319-35.

van Inwagen, P. (2000) "Free Will Remains a Mystery," In J.E. Tomberlin (ed.), Philosophical Perspectives, 14. Malden: Blackwell, pp. 1-19.

Velleman, J. David. (1992) "What Happens When Someone Acts," Mind 101: 461-81.

Watkins, E. (2013), "Kant," in T. O'Connor and C. Sandis (eds), A Companion to the Philosophy of Action. Malden: Blackwell, pp. 521-7.

\section{Further Reading}

Chisholm, R. (1982) "Human Freedom and the Self," in G. Watson (ed.), Free Will. Oxford: Oxford University Press, pp. 24-35. (In this classic paper, Chisholm lays out why he thinks an agent-causal view is needed for free will and he presents the distinction between what he calls "transeunt" (i.e., event) causation and "immanent" (agent) causation. Even in the twenty-first century, many philosophers have Chisholm in mind when they think of agent causation.)

O'Connor, T. (2000) Persons and Causes: The Metaphysics of Free Will. New York: Oxford University Press. (O'Connor's book offers an important and distinctive version of agent causation with an emphasis on emergence. O'Connor's book has helped to usher in a new era whereby the agent-causal position is taken seriously.)

Clarke, R. (2003) Libertarian Accounts of Free Will. New York: Oxford University Press. (Although Clarke argues against the possibility of agent causation in his book, he also develops and defends the coherence of an interesting and important "integrated" agent-causal view, distinct from O'Connor's in significant ways, such as in understanding reasons as joint causes of action. Clarke's work has also been influential in the revitalization of the theory.)

Lowe, E. J. (2008) Personal Agency: The Metaphysics of Mind and Action. Oxford: Oxford University Press. (In this book, although Lowe sometimes characterizes his view as less than purely agent-causal—because agents do not cause actions-nonetheless this book develops an important version of agent-causal theory according to which only substances operate as genuine causes.)

Pereboom, D. (2014) Free Will, Agency, and Meaning in Life. New York: Oxford. (In this book, Pereboom considers a number of potential objections against agent-causalism, defending the view along some dimensions, but ultimately dismissing it due to purported implausibility.)

Steward, H. (2012) A Metaphysics for Freedom, Oxford: Oxford University Press. (Steward here defends a unique naturalistic account of agent causation.)

\section{Related Topics}

Event-Causal Libertarianism

Non-Causal Libertarianism

Skeptical Views about Free Will

The Luck and Mind Arguments

Thomas Reid

Immanuel Kant 


\section{8 \\ NON-CAUSAL \\ LIBERTARIANISM \\ Hugh J. McCann}

\section{Introduction}

Libertarianism traditionally takes its start from the idea that if human decisions and actions were subject to natural causation - that is, if they were caused in the way that the movements of the balls on a billiard table are-then the agent who decides or acts would be unable to do otherwise than he does. And if he is unable to do otherwise, so the argument runs, then he cannot justly be held responsible for his acts. It must be, then, that a responsible agent's actions are not subject to natural causation. Before going further, we should observe that beginning with Frankfurt (1969) the second premise of this argument, that is, that alternative possibilities for decision and action are required for moral responsibility, has been subject to vigorous dispute. Here, the premise will be assumed to be correct; readers interested in the dispute are referred to Chapter 15 of this volume.

If we grant the disputed premise, then it seems plausible to conclude that an agent whose decisions and actions occur by way of natural causation cannot be responsible for them. Following Hume, however, opponents of libertarianism have consistently claimed that an uncaused decision or action would have no explanation for its occurrence. Accordingly, we would have to treat it as a random or accidental event-one that befalls the agent more or less as a matter of luck and for which, again, he cannot rightly be held responsible (Hume 1970 [1788]: II, III, II; Ayer 1954; Mele 2006). This, together with the argument of the previous paragraph, raises the possibility that we are not responsible for our deeds whether they are caused or not (cf. Strawson 1994; Pereboom 2001). Traditional libertarians are therefore faced with the task of answering the Humean challenge by showing that the agent of a decision or action that is not the product of natural causation may nevertheless be legitimately answerable for it. For this there are three main options. First, we may argue that despite what was traditionally supposed, not all causation is deterministic, so that the doings of an agent who enjoys libertarian freedom can be caused yet not determined. One possibility here is that although the decision or volition is itself deterministically caused, some event pertinent to responsibility that precedes it is not; or, it may be that the causation of the decision or volitional activity is itself not deterministic, but only statistical or probabilistic. The supposed advantage in both cases is that the agent will have had legitimate alternatives even though what he does may be causally explained, thus satisfying the demands of 
both sides of the dispute. The second option for dealing with the Humean challenge is to adopt a concept of agent causation, according to which it is the agent himself, not antecedent events and conditions, who causes his decisions and actions. This is held to refute the determinist's charge that a free decision or act must be random, while retaining the libertarian's requirement that the deed did not come about by way of the sort of causation that prevails on the billiard table. Finally, the libertarian may take the position that the intrinsic features of active willing are such that decisions and actions cannot be random in any sense damaging to responsibility, and he may add that although acts of will are caused neither by their agents nor by other events, they are still explainable teleologically in terms of the agent's reasons. This is the position that has come to be known as non-causal libertarianism.

\section{Why Libertarianism?}

Non-causal libertarianism is best understood as a thesis that pertains in the first instance to mental acts, in particular, acts of deciding or intention formation, and the act or activity of volition, which is held to be the fundamental activity by means of which all bodily movements, and therefore all overt actions, are performed (Ginet 1990; McCann 2012). It will be best to focus our discussion on deciding, since the issues are at their clearest there. Suppose, then, that I am intent on enjoying some pleasurable reading this evening. Perusing the books in my den, I find two options that seem attractive: I may read the latest novel by my favorite mystery writer, or I may read a book about the battle of Gettysburg. In deciding between the two, I consider the desirable aspects of each, of which we may imagine that there are several. Among other things, the mystery may be shorter, and it offers the enjoyment of trying to solve a nice mental puzzle; as for the war book, military history may be a fascination of mine, and I might be especially taken by the issues of strategy and sacrifice that characterized Gettysburg. There could be much else on both sides, but let us suppose I eventually decide to read the book on Gettysburg. Now both determinists and libertarians would treat my decision as grounded in my reason for reading the book on Gettysburg - that is, in my desire to know more about Gettysburg and my belief that reading this particular book will provide that knowledge. The difference is that the determinist understands the grounding here to be a causal matter: by his account my reason causes me to decide as I do. The traditional libertarian, by contrast, denies this.

To understand what prompts the libertarian's denial we need to consider some of the phenomenology of deciding. Deciding (and this is true of volitional willing also) has what Carl Ginet calls the "actish" phenomenal quality (1990:13). This may be understood to have two aspects (McCann 2012: 254). First, when we decide we feel that we are being spontaneous: that we are doing rather than being done to, acting rather than being acted upon. Second, deciding is an intrinsically intentional activity: when we decide we intend to decide, and to decide exactly as we do. It is important to realize that this second aspect is not a matter of a decision being related to some earlier intention. It is, rather, an essential feature of the very act of deciding. Perhaps in looking through my books I already intended to decide on some reading for tonight. If so, then my decision to read about Gettysburg may be regarded as ratifying my earlier intention. But that is an altogether secondary matter. My decision would have been every bit as intentional if it had been made entirely on the spur of the moment, with never a prior thought about how I would spend my time this evening. In short, decision carries intention with 
it as a matter of necessity. That is why we never hear of anyone deciding by accident or inadvertently to do something. It is why the employee who says to his employer, "I'm sorry I missed work yesterday Boss, I unintentionally decided not to come" is doomed.

The two features just described are characteristic of all active willing. Together, they are foundational to our sense of personal autonomy, to our belief that when we engage in active exercises of the will, of which deciding is one, we are in control of what we do, and responsible for it. By contrast, the balls on the billiard table are not in control of what they do; they are at the mercy of the billiard player, who controls their movements by means of physical causation. Thus, it is easy to understand the motivation of the libertarian: he objects to the idea that our decisions and actions come to pass by way of natural causation because he feels that if this were so, the phenomenology that consistently attaches to deciding and acting would be uniformly deceptive. Instead of charting our own course in the world, we would be at the mercy of prior events, bereft of our seeming autonomy and lacking any true responsibility for our deeds.

It is necessary to observe, however, that there are two ways to articulate the libertarian's concern. One is in terms of operations of force of the kind at work on the billiard table, and the passivity of things that are acted upon. We all know what it is like to be subjected to physical force: we get bumped into on train platforms, buffeted about by the wind, and carried along by waves at the seashore. Our experience in these cases is one not of control but of being controlled, an experience not of activity but of passivity. We move, but we do not decide to move or move intentionally, and we do not consider ourselves responsible for these motions unless we have somehow contrived to have them occur through some earlier action of ours. So if we think of natural causation as a matter of things being made to do what they do by the application of physical force-or perhaps, in the case of mental events, of something analogous to it - then it is easy to see why libertarians are bothered by the prospect of determinism.

But there is a second and somewhat different way to articulate the libertarian's concern. We understand the interactions of billiard balls to be describable by scientific laws-laws, in this case, that are general in that they apply to all games of billiards (and to much else as well), but most importantly in that they allow no leeway for billiard balls to wander off on pathways of their own origination. Billiard balls do not move without a force being applied, and once a determinate force is applied, a ball will move in a determinate way, every time and with no option for variation. Indeed, determinism takes its name from the idea that all that goes on in the world is describable by such laws. Now the second way to think of the libertarian's concern is to see it as a worry that human decisions and actions will turn out to be describable by such laws. It would be wrong however - at least if the libertarian is thinking clearly about the matter- to see this as a worry about the laws themselves. Scientific laws never do anything. Laws are merely propositions — or if you do not like propositions, then sentences-which as far as worldly change is concerned are utterly inert. Their role is to describe what goes on in the world, not to legislate or to make it happen. The proper concern of the libertarian is, rather, that deterministic laws can be true of human willing only if in our decision making and acting there is something going on that is like what goes on in billiardsthat is, some sort of mechanism that would render our doings as passive in their origination as those of billiard balls. The worry about laws reduces, then, to the one about the phenomenology of willing turning out to be deceptive. The spontaneity we thought we possessed would be lost, not because the laws say it is not there, but because the reality that makes the laws true is different from the way it seems to us to be. We might feel 
that we are autonomous in our deciding and willing, but in reality, we would be as passive in these doings as we are in the onset of a desire, or the nagging recurrence of an unpleasant memory.

\section{Event-Causal Libertarianism}

With this in mind, let us turn to the first strategy for addressing the Humean challenge. The essence of this approach is to get rid of determinism while leaving alone the idea that human decisions and actions result from natural causation. On this strategy, then, we should presume that my decision to read about the battle of Gettysburg this evening is caused in just the way it would be in a fully deterministic world—caused, most likely, by my reason for reading this book, that is, by my desire to find out more about the battle and my belief that reading this book would be a good way to do so. The trick is to allow ourselves to say that my decision is not determined. On the first version of the strategy, this will be because some pertinent event earlier in the sequence leading up to my decision is not caused, or at least not deterministically caused. We may imagine, for example, that my first thought of reading about Gettysburg, or perhaps the onset of my desire to read about it, occurred in a way that involved significant randomness, but that thereafter things proceeded in a deterministic way (cf. Dennett 1978). Or, it could be that my decision to read about Gettysburg was preceded by a judgment on my part that this was the better of the two alternatives I was considering, or by my acting to form a preference in favor of it. If so, perhaps my mental act of judging or of forming the preference was not itself determined, but then served as a deterministic cause of my decision (cf. Ekstrom 2000).

Upon consideration, however, it is hard to see why libertarians should be moved by scenarios like this. Properly understood, as we have seen, the libertarian's concern is not simply to get rid of determinism, but to do so in a way that will offer some guarantee that the spontaneity and intrinsic intentionality he understands to characterize decision and volition are not deceptive. This version of event-causal libertarianism does nothing of the kind. Just the opposite: it makes my operations of active willing the immediate causal outcome of just the sorts of events and circumstances that would be held to cause them in a fully deterministic world. This is perhaps most obvious on the first of the possibilities described above, where my first thought of reading the book on Gettysburg, or the onset of my desire to do so, is imagined to be infected with randomness. The first appearance of a thought before the mind, and the onset of desire as well, are paradigm cases of mental events in which we are passive rather than active. If we were to discover tomorrow that such events occur at random, we would no more consider ourselves to be in voluntary control of them than we do now. Why suppose, then, that randomness in events like these should allay the fears of libertarians about deterministic causation of decision and volition themselves, which it does nothing even to reduce, much less eliminate? If anything, one would think the fears of the libertarian would be exacerbated rather than diminished.

The business of judging one course of action superior to another, or of forming a preference for it, is somewhat more complicated, and too much to go into fully here. But two observations are in order. First, even if such occurrences attended every case of responsible deciding and acting-which is a highly dubious proposition-they are not the sort of thing we would wish to occur entirely at random. We want our judgments of truth and falsity to be based on evidence, which they are not likely to be if we can just 'up and conclude' that a particular course of action is better or best. Similarly, we would 
not wish for an act of preference formation to occur just out of the blue. If it is not grounded in the agent's motives it counts for nothing as far as responsible freedom is concerned. For event-causal libertarianism to succeed, then, it has to be presumed that acts of these sorts are not random in any damaging sense, but instead are grounded in the agent's reasons in such a way as to make them responsible. But if this holds for these judgments of preference, then why should it not also hold for acts of decision making and volitional willing? There seems to be no reason why it should not.

The second observation to be made here is that even if mental acts of preferential judgement are not deterministically caused, agents would have no reason to feel directly responsible for a deterministically caused decision or action that followed upon the judgment. Yet it is in deciding and volitional acting that our phenomenological sense that we are free and responsible beings is paradigmatically located. In the end, then, none of the scenarios thus far considered is able to assuage the traditional libertarian's fear that his autonomy in the very acts of deciding and willing would be undone if these specific activities were found to occur through deterministic causation.

The event-causal libertarian does however have another option. It is to hold that as in the scenarios considered above the operations of decision and volitional action are subject to event causation, but with the proviso that the causation is not fully deterministic, only statistical or probabilistic. This implies no change as to what causation itself consists in. As with the strategies already considered, neither the nature of the causes nor the way they operate in the particular case at hand need differ from what would occur on any other event-causal model of decision and action. So we can imagine that my decision to read the book about Gettysburg was caused by my reason — that is, by my motivating desire and belief - in the same way that these would be held to cause it in a fully deterministic world. The difference is just that on this account the same desire and belief would not always cause me to decide as I did, even if the desire were of exactly the same strength (assuming we could measure that) and all other circumstances were precisely the same as well. The relation is only probabilistic: on another occasion I might have been caused by my reason for reading the other book to decide to read it instead. And the same would apply to my volitional activity in both cases. So we are now in a position to claim that in my very deciding and acting I did have alternative possibilities: my deciding and willing were not determined, even though they were caused by my reason, and so could presumably be explained in terms of it.

All the same this approach faces serious problems. For one thing, it is not obvious just what an event causal explanation of my decision to read about Gettysburg comes to if in precisely the same set of circumstances I might have decided to read the mystery novel. But even if we ignore this problem, there is still the difficulty that this approach does nothing to alleviate the libertarian's worries about event causation and the threat it carries: namely that an agent's decisions and actions, although they seem to him to be spontaneous, are, in fact, events in which he is completely passive. Why, if the causal relation is the same, should I think my decision to read about Gettysburg was any more free? Why should it make a difference that on some other occasion another reason of mine might have issued in a different decision? That the laws describing what occurs in situations of a specific kind are statistical rather than universal is irrelevant as long as what occurs in the particular case at hand is exactly what would have occurred in a fully deterministic world. From a libertarian perspective, such laws may guarantee that there were alternative possibilities, but they do nothing to insure that those possibilities were mine, in the sense that I was truly able to bring them to pass. So while it may be said that event-causal 
libertarianism leaves strict determinism behind, it does not appear to do so in a way that should alleviate the fundamental worry libertarians have about determinism.

\section{Agent-Causal Libertarianism}

It is at this point that agent causation may seem to offer an attractive option, as it at least has the virtue of addressing the issue of causation directly. The major objection lodged by determinists against traditional libertarianism, remember, is that it makes our decisions and actions no more than random occurrences-events that simply befall the agent without explanation, so that he cannot be responsible for them. And the claim is that this problem can only be resolved by giving up libertarianism, and opting for the view that our decisions and actions are brought about entirely by natural causes. Agentcausal libertarians hold, however, that there is another way: the agent himself, rather than prior events and circumstances, may be held to cause his action. This kind of view may seem especially attractive if, as many philosophers seem to do, we think of all causation as a kind of existence conferral, wherein the cause produces or brings about the effect. Agent-causal libertarianism then becomes a view according to which it is the agent who confers existence on his decisions and volitional doings, rather than any mental event or state that precedes them. So when I decide to read the book on Gettysburg, it is I myself who cause or bring about my decision; and I do so for the sake of the goal encapsulated in my reason, that is, to learn more about the battle. My decision is thus explainable in terms of my reason, and since it is I who cause it, the decision is not a random event, not something that befalls me, but rather an active doing over which I can claim complete control (O'Connor 2000; Chisholm 1966).

The virtue of agent-causal libertarianism is that it focuses on what is central to the free will problem - namely, what actually goes on when we decide or act-rather than on principles or laws that are alleged to describe it. Alas, however, the account that it gives invokes an operation that we seem unable to detect or describe, and that even if it existed, appears incapable of resolving the problem of free will. Consider again my act of deciding to read the book on Gettysburg. What counts here as the causing? What exactly do I do that counts as my conferring existence on my act? Nothing definite comes to mind, nor has anyone ever offered a description of such a doing. Even if such an activity could be discovered and described, moreover, it would seem to face the very difficulties it is intended to resolve. Perhaps my agent-causing of my decision was a separate act from the decision itself. If so, then we need to account for this act's existence, lest the determinist claim that it in turn must be an accident. And then we seem headed for a vicious regress. Perhaps, on the other hand, my agent-causing of my decision was part of the decision itself. But then the act of causing could not do its work until my decision was on hand, whereas once my decision was on hand there was no work to be done. Even if the alleged operation of agent causation exists, then, there seems to be no satisfactory way to account for its existence. And as long as this is so, the determinist will simply redirect his criticism of uncaused decision and volition to the operation of agent causing, and append to it the further complaint that the supposed operation is undetectable.

\section{Non-Causal Libertarianism}

The difficulties troubling versions of libertarianism that deal in terms of natural and agent causation may encourage us to try another approach: namely, to see how well 
libertarianism fares at coping with the Humean challenge on its own, without attending to the question of causation. And the fact is that it does rather well. The claim that an uncaused decision or action must count as an 'accident' that befalls the agent can be viewed from two perspectives, one practical and the other theoretical (McCann 2012). The practical perspective is subjective: it is the viewpoint of the agent who decides and acts. The theoretical perspective is by contrast objective: it is the perspective of someone, perhaps an onlooker, who seeks to understand-and perhaps to bring under control-the decisions or actions of someone else. Of these two perspectives, it is the practical one that is foundational to libertarianism. And from this perspective there is no such thing as an accidental decision or volitional act — at least as long as the phenomenology of deciding and acting can be trusted. That is what is illustrated by the example of the worker who explains to his boss that he did not make it to work yesterday because he accidentally decided not to come. The worker's excuse is futile not just because it is false, but because it is self-contradictory. From the perspective of the agent deciding and willing cannot be accidental. Just the opposite: they are paradigmatically exercises of voluntary control, not because of their relation to anything else but by their very nature, by virtue of their spontaneity and intrinsic intentionality. And what dooms the worker is that this perspective has crept into our discourse: it underlies our notions of what counts as accidental and what does not, so that his excuse is hopeless. Thus, while the determinist may claim that my decision to read about Gettysburg befalls me, or that its occurrence is an accident, from my perspective as an agent, this not only is not but cannot be so. Ironically, in fact, from my perspective, it is only if my act were causally determined that it might occur by accident, for then it might come to pass by way of some wayward factor that I was unable to foresee, and therefore unable to control in any way, deterministic or not.

From an onlooker's perspective, however, things are different, although the way in which they are different can be badly misunderstood. Even from a theoretical perspective, it is not really correct to speak of a libertarian free decision or act as something that befalls the agent, for even as observers we do not speak of events as accidental unless they fail to go according to some plan or expectation. Beta decay is not a deterministic process; it is describable only by statistical laws. But a particular instance of beta decay counts in itself neither as an accident nor as a stroke of fortune, good or ill. It is simply a fact, one that the physicist familiar with such things is prepared for, and seeks to describe and explain as best he can. Exercises of libertarian freedom should be treated the same way. In themselves they are not accidents, and to say that they befall their agents is simply to beg the question - to assume either that there is no phenomenal experience of agency, or that if there is, it is to be dismissed out of hand.

Nor should it be supposed that exercises of free agency can have no explanation. On this score, the agent-causal theory is on the right track, for exercises of active willing do have teleological explanations. To return to our example, when I decide to read the book about Gettysburg, the intention intrinsic to my act of deciding is not just an intention to decide something or other. It is an intention to decide to read this book and thereby to find out more about Gettysburg. My very act of deciding, that is to say, is an act in which the goal that is represented in my reason is adopted by me, not only as the content of the intention I form by deciding - that is, the intention to read the book about Gettysburg - but also as the content of the intention I have in deciding. My act of deciding can therefore be explained teleologically, as directed toward the end of reading the book, and the same will apply to the volitional activity I engage in when 
I carry out my intention. This kind of explanation, furthermore, need not be a strictly piecemeal matter, even in a world where actions have no causes. An onlooker seeking to understand operations of the will is not compelled to treat each decision or action in isolation from all others. Decisions tend to stand as precedents: what an agent decides to do in one case, as long as the outcome was satisfactory, is likely to be repeated in similar situations. Add to this the fact that an orderly life requires us to adopt and adhere to long term goals, and the further fact that such goals tend for the most part not to differ radically from person to person, and it can be expected that a fair amount of human behavior will be describable in statistical terms, even if it is not caused.

Of course, it hardly follows that there is nothing to the Humean challenge. At the bottom of the challenge is an uncomfortable contrast, namely that events like those that occur on the billiard table are at home in the world in a way that exercises of libertarian free will are not. The former emerge from the past in a completely orderly way. If we understand the nature of those events - that is, if we understand the physical laws that describe them-we are able to predict with confidence what the result will be if a particular ball is struck at a particular angle and with a particular velocity. With free decisions and actions it is not so. Often we can be reasonably sure what they will be. I can be confident, for example, that nearly all of the students in my courses will show up for the final exam-confident, in fact, even if I challenge their innate spirit of skepticism and rebellion by telling them I know they will turn up. But no matter how fully we understand human nature, and no matter how familiar we are with any particular person's habits and motivations, we can never, if libertarian freedom obtains, be entirely certain. We have to be ready for the day when things will not go as we expect, simply because people with free will sometimes behave differently, even in circumstances that duplicate those of previous occasions of decision or action. In short, exercises of libertarian freedom, even when they are correctly predicted, represent a new ontological departure, one that at the agent's whim alone could have gone differently.

Even here, however, it is important not to misunderstand. Someone might argue that the difference between those events that have natural causes and those that lack them is that we can account for the existence of the former but not the latter. It is simple: the events that occur on the billiard table receive their existence from events that have gone before, and the same for all other naturally caused events. The operations of a libertarian free will, by contrast, come from nowhere. Cognitively speaking, their existence is a complete mystery - one that, from the perspective of the observer, can only be resolved by rejecting libertarianism and reintroducing event causation. Here however we reach a point where, ironically enough, Hume suddenly becomes the libertarian's best ally (Hume 1955 [1748]: VI). For the truth is that when it comes to sheer existence we are just as much in the dark about the operations of billiard balls as we are about those of rational agents. There is no nexus of event causation to be observed, nothing that counts as the impact of one ball necessitating or conferring existence on the motion of another. Indeed, were we to set out in search of such a thing we would not even know what to look for. No one has ever described what such an operation would consist in, or given the faintest hint as to what sort of observation or apparatus might serve to detect it. Furthermore, the laws governing the transactions of the billiard table are, at least in classical physics, not diachronic but synchronic. Newton's first law does not say that an object not acted upon by a net force at $t$ will be at rest or in uniform rectilinear motion a moment later, but that it is at rest or uniform rectilinear motion at $t$. This alone entails that the acceleration of the object ball must occur while the cue ball is striking it, not 
afterward, for only while the two are in contact can the one act upon the other. The same is implicit in the third law, which calls for action and reaction that are simultaneous, not sequential; and the force law has acceleration occurring during the interval in which force is applied, not subsequently. Classical physics has of course long been superseded-but not, to my knowledge, in a way that changes any of this. And if this is so we have no legitimate reason to treat event causation as existential bootstrapping - that is, as an occult operation by which the present is somehow able to propel itself into the future.

Yet the Humean challenge still has a point, for it remains true that the events of the billiard table are at home in the world in a way that operations of libertarians' willing are not. On what I think is our best understanding, causation on the billiard table is simply a transfer of conserved quantities (Fair 1979). When the cue-ball strikes the object ball, a transfer of kinetic energy occurs from the former to the latter, a transfer that we observe as the deceleration of the cue-ball and the acceleration of the object ball. Like all physical objects, it belongs to the nature of billiard balls that they always behave this way. Thus, if we understand the laws of physics, if we know the positions and momenta of the balls on the table, and if we are prepared to presume that the world will go on existing, we will be able to predict pretty well what is going to happen. With free decision and volition, predictability is greatly diminished, because with these, the future arises from the past only through the filter of the agent's cognation and selection, so that each decision and action, even if it follows a familiar pattern, represents a new ontological beginning. As long as that is so, the Humean challenge will have a point, because it drives home to us a topic beyond the bounds of this chapter, namely the mystery of where things come from. It makes us wonder why it is that we live in a world where I choose to read my book on Gettysburg rather than my mystery novel. If we think about it, however, we will realize that this is a question that could have been asked even if the world were an entirely deterministic one, so that all a different world would take would be that there have been different causes from the beginning-or if not that, then from eternity.

\section{References}

Ayer, A.J. (1954) "Freedom and Determinism," in A.J. Ayer, Philosophical Essays. London: Macmillan, pp. 271-84.

Chisholm, R.M. (1966) "Freedom and Action," in K. Lehrer (ed.), Freedom and Determinism. New York: Random House, pp. 11-44.

Dennett, D.C. (1978) "On Giving Libertarians What They Say They Want," in D.C. Dennett, Brainstorms. Cambridge: MIT Press, 286-99.

Ekstrom, L. W. (2000) Free Will: A Philosophical Study. Boulder: Westview.

Fair, D. (1979) "Causation and the Flow of Energy," Erkenntnis 14: 219-50.

Frankfurt, H.G. (1969) "Alternative Possibilities and Moral Responsibility," Journal of Philosophy 66: 829-39.

Ginet, C. (1990) On Action. New York: Cambridge University Press.

Hume, D. (1955 [1748]) An Inquiry Concerning Human Understanding, C.W. Hendel (ed.). New York: Liberal Arts Press.

Hume, D. (1970 [1788]) A Treatise of Human Nature, P.H. Nidditch (ed.). New York: Oxford University Press.

McCann, H.J. (2012) "Making Decisions," in E. Sosa, E. Villanueva and B. Brogaard (eds), Philosophical Perspectives 22, Action Theory. Boston: Wiley-Blackwell, pp. 248-63.

Mele, A. (2006) Free Will and Luck. New York: Oxford University Press.

O'Connor, T. (2000) Persons and Causes: The Metaphysics of Free Will. New York: Oxford University Press. Pereboom, D. (2001) Living Without Free Will. New York: Cambridge University Press.

Strawson, G. (1994) "The Impossibility of Moral Responsibility," Philosophical Studies 75: 5-24. 


\section{Further Reading}

R. Clarke (2003), Libertarian Accounts of Free Will (New York: Oxford University Press) offers a detailed and thoroughgoing treatment of all types and aspects of libertarianism. J. M. Fischer (1994), The Metaphysics of Free Will (Oxford: Blackwell) defends at length the view that moral responsibility is in fact consistent with determinism. R. Kane (1960), The Significance of Free Will (New York: Oxford University Press) provides a nice treatment of libertarianism, with a creative theory of the process of libertarian decision making. E. J. Lowe (2008), Personal Agency: The Metaphysics of Mind and Action (New York: Oxford University Press) gives a strong defense of an agent causal view in the context of a thorough treatment of action theory.

\section{Related Topics}

Event-Causal Libertarianism

Agent Causation

Skeptical Views about Free Will

The Luck and Mind Arguments

David Hume 


\section{9 \\ FREE WILL AND MORAL SENTIMENTS Strawsonian Theories \\ Paul Russell}

Over the past few centuries, the free will debate has largely turned on the question of whether or not the truth of the thesis of determinism is compatible with the relevant form of freedom that is required for moral responsibility. This way of approaching the free will problem was fundamentally challenged by P.F. Strawson in his hugely influential paper "Freedom and Resentment," which was published in 1962. In this paper, Strawson pursues a line of argument that can be found in the work of several major figures in the "moral sense school," such as David Hume and Adam Smith. The strategy Strawson employs is one that begins with a complex and subtle description of the attitudes and practices that are constitutive of moral responsibility as we observe it in human life. According to Strawson, both sides in this debate fail to identify the real foundations of moral responsibility, which rests with the fabric of our human emotional psychology. When we start from inside these natural, human commitments, Strawson maintains, we are better placed to generate a viable and pertinent theory of human freedom as it relates to the requirements of moral responsibility.

\section{I}

In order to provide a clear exegesis of Strawson's core strategy, a few preliminaries are required. Strawson's way of categorizing the main parties involved in this dispute is in important respects unorthodox and in some ways misleading. He labels the relevant parties in terms of their metaphysical attitudes in respect of the implications of the thesis of determinism. The classical compatibilists are described as "Optimists," since they reject the suggestion that the truth of determinism would systematically discredit and dislodge our commitment to the attitudes and practices associated with moral responsibility. Those incompatibilists who are libertarians, and hold that we are free and responsible but that this requires the falsity of determinism, are labelled "Pessimists" in Strawson's schema. Libertarians are "Pessimists" because they believe that the (skeptical) implications of determinism would be bleak and depressing for us all. Those incompatibilists who maintain that, whether determinism is true or not, we lack the relevant sort of freedom needed for moral responsibility are labelled "Moral Skeptics." 
Although Moral Skeptics are not identified in terms of their metaphysical attitudes, they generally fall into the Pessimist camp more broadly conceived (indeed, unlike libertarians, they maintain that there is no escape from skepticism and any pessimistic implications it may carry). In important respects, Strawson rejects all these positions. At the same time, he also aims to reconcile Optimists and Pessimists by finding some measure of truth in both their positions. It is, above all, Strawson's concern to discredit the claims of skepticism - a view, he argues, that is neither justified nor liveable.

In the context in which Strawson first presented his theory, there was an impasse between the views of classical compatibilism, which relies on a "one-eyed utilitarianism," and various forms of (neo-Kantian) libertarianism, which rests on the "panicky metaphysics" of "contra-causal freedom" (Strawson 1962: 81-3). Strawson has little sympathy with either of these views and suggests that we must start our investigations elsewhere if we want to secure some agreement on this subject. The right place to start, he suggests, is with

the very great importance that we attach to the attitudes and intentions towards us of other human beings, and the great extent to which our personal feelings and reactions depend upon, or involve, our beliefs about these attitudes and intentions.

(Strawson 1962: 66)

This observation brings us to the role of reactive attitudes, which serve as the foundation for Strawson's naturalistic account of moral responsibility. In the case of personal reactive attitudes, "we demand some degree of goodwill or regard on the part of those who stand in [various] relationships with us" (Strawson 1962: 67). For example, in situations where one person is offended or injured by another, it is natural or normal to feel resentment. A full understanding of how reactive attitudes operate, and how some considerations serve to "modify or mollify" them, can provide us with a more general understanding of how moral reactive attitudes, such as praise and blame, operate and what relevance, if any, the thesis of determinism has with respect to these matters.

It is at this juncture that Strawson turns to his theory of excuses and exemptions and applies it to the justification of reactive attitudes. There are, he suggests, two broad categories of considerations that alter or inhibit our reactive attitudes towards an agent who has done us some injury or harm. First, there are specific excusing considerations that indicate that the agent's will was not of a kind that displays malice or a lack of due care or concern either for ourselves or others. In cases such as ignorance, accidents, or physical force, and so on, we see that the injury caused does not reflect any malicious or uncaring intent on the agent's part. However unfortunate the injury may be, the agent's quality of will is unobjectionable (Strawson 1962: 68). Another category of consideration is that of exemptions. Exemptions turn on the claim that the agent in question is in some way an inappropriate target or object of reactive attitudes-not just in the specific case at hand but more generally. In cases of this kind, we view the agent as somehow "abnormal" or "immature" (deranged, neurotic, an infant, etc.). In these circumstances, we are required to drop the participant stance that would engage our reactive attitudes and must instead adopt an 'objective attitude.' When we adopt the objective attitude to another human being we see them as an object of social policy but not as someone to reason with (Strawson 1962: 69, 70). 
Once we have identified the role of reactive attitudes (e.g., praise and blame) as constitutive of responsibility, and explained how these responses are or are not altered and modified in light of excusing and exempting considerations, then we are better positioned to answer the vexed question concerning the implications of determinism for these attitudes and the practices associated with them (e.g., punishment). Would the truth of determinism, Strawson asks, "lead to the decay or the repudiation of all such attitudes" (Strawson 1962: 70, 71)? Strawson answers this question firmly in the negative. In relation to this issue Strawson argues for two related but distinct points:

1. The truth of determinism does not serve to systematically discredit our reactive attitudes.

2. Even if we reached such a radical conclusion on the basis of theoretical or philosophical reasoning of some kind, it would still be psychologically impossible for us to simply abandon or jettison our commitment to these reactive attitudes.

Let us consider each of these claims in turn. The first claim depends on Strawson's analysis of excuses and exemptions. Strawson considers what relevance accepting the truth of determinism would have for our participant attitudes (e.g., resentment). Nothing about the thesis of determinism implies that agents are always ignorant about what they are doing, nor that they never act intentionally or that everything that is done is an accident or inadvertent (Strawson 1962: 70, 71). Similarly, nothing about this thesis implies that every agent is in some relevant way "abnormal" or "immature" (Strawson 1962: 71). If this was the case, then we would have to adopt the objective attitude to everyone and drop all our reactive attitudes. However, so long as an agent is not incapacitated from ordinary personal relationships and is neither a child nor abnormal (e.g., mentally ill, etc.), then no such policy is required of us. The upshot of this is that, contrary to the Pessimist, the thesis of determinism has no radical skeptical implications for our commitment to the attitudes and practices involved in moral responsibility.

How convincing is this line of argument? Strawson's argument, as presented, seems seriously incomplete, if not fatally flawed. The key issue here rests with the account offered of exemptions. Strawson's remarks on this subject, although crucial to his argument, are very brief. More importantly, what he says tends to conflate issues of "abnormality" and "immaturity" with that of incapacity. In a key passage, Strawson dismisses any effort to generalize exemptions on the basis of worries about determinism and argues that "it cannot be a consequence of any thesis which is not itself self-contradictory that abnormality is the universal condition" (Strawson 1962: 71). Although Strawson acknowledges that this might come across as "too facile," his account of what the relevant moral capacities do involve is very thin - too thin to bear the weight of the ambitious anti-skeptical conclusion that it must support. He does indicate what the relevant moral capacities do not involve; namely any form of libertarian "contra-causal freedom"- a condition of responsibility that, he claims, "cannot be coherently described" (Strawson 1980: 265). Beyond this, however, his positive or constructive remarks are both brief and sketchy, providing just a few sprinkled remarks concerning the need for a sense of reality (Strawson 1962: 72); an ability to be reasoned with (Strawson 1962: 69, 70); moral sense or a susceptibility to reactive attitudes (Strawson 1962: 75-7); and an awareness of our conduct in terms of conscious purposes (Strawson 1962: 75, 76, 78). Some incompatibilists are skeptics but not libertarians (i.e., they are not Pessimists in the narrower sense) and they may well agree with Strawson that there is no available 
coherent concept of freedom that serves the needs and aspirations of libertarians-but this does not defeat their skepticism. On the contrary, they will agree with (libertarian) Pessimists that the sort of capacities that Strawson briefly alludes to also fail to suffice as an account of the sort of moral capacities required to justify our reactive attitudes or moral sentiments. If something can be said on behalf of compatibilism with regard to this important matter, Strawson's account fails to provide it. This leaves the door open to the skeptic, as well as those who believe they can provide a more robust form of agency on the basis of the metaphysics of indeterminism and contra-causal freedom. Given these difficulties, even those broadly sympathetic to Strawson's approach must conclude that his argument falls short at this crucial juncture.

Strawson assumes that the skeptical challenge based on generalized exempting conditions can be swiftly swept aside on the ground that universal "abnormality" is impossible. We have noted that this way of interpreting and refuting the skeptical challenge is confused. Strawson has, however, another argument to back up his case against skepticism. Whatever our "theoretical" or skeptical philosophical reflections may suggest, Strawson argues, it is "practically inconceivable" for any reasoning of this kind to systematically dislodge our commitment to the reactive attitudes (Strawson 1962: 71, 72, 77; see also Strawson 1985: 11, 13, 39, 41).

The human commitment to participation in ordinary inter-personal relationships is, I think, too thoroughgoing and deeply rooted for us to take seriously the thought that a general theoretical conviction might so change our world that, in it, there were no longer any things as inter-personal relationships as we normally understand them ... A sustained objectivity of interpersonal attitude, and the human isolation which that would entail, does not seem to be something of which human beings would be capable, even if some general truth were a theoretical ground for it.

(Strawson 1962: 71, 72; and also Strawson 1985: 39)

According to Strawson, then, our human nature inoculates us against all radical skeptical threats of the sort that animate and concern the Pessimist. Skepticism is taken to imply that we must entirely jettison all reactive attitudes, which would, he claims, result in us adopting the "objective attitude" at all times to all people. This is something, if put into practice, that would certainly reduce us to a bleak and dehumanizing condition (Strawson 1962: 71-3, 77, 79). In summary, skepticism and the objective attitude that it implies, is not only unliveable, it would be unbearable. If it were a matter of decision and choice — as it is not - we would have every reason of a practical kind to reject any proposed move to a universal objective standpoint, bereft of the web of personal and emotional responses that make us human.

Does this argument fare any better than Strawson's previous argument to defeat skepticism? The answer to this is again negative. There are several different lines of possible criticism but I will focus on a particular confusion that lies at the heart of Strawson's strong naturalist rejoinder to the Skeptic or Pessimist. With respect to the claim that we are in some sense naturally committed to reactive attitudes we need to distinguish two distinct claims. First, there is the claim that our human constitution naturally renders us liable or prone to various forms of emotion, including reactive emotions broadly conceived, and that this liability or dispositional capacity neither requires nor is capable of rational justification (Strawson 1962: 81). Although this claim is credible it does 
not serve to discredit skepticism in the way Strawson supposes. Strawson needs a stronger form of naturalism, one that claims that we will continue to entertain and experience particular or individual tokens of reactive attitudes irrespective of any skeptical arguments or general theoretical truths that may be advanced against them. We might distinguish this stronger claim as token-naturalism as opposed to type-naturalism of the weaker kind, as associated with our emotional propensities and dispositions. (It is, of course, the distinction rather than the labels that matter here.)

Clearly, skeptical arguments could systematically discredit and dislodge our commitment to all tokens of reactive attitudes, even if we retain the weaker, type-naturalist propensity to these emotions. Imagine, for example, that we discover that everyone is subject to social manipulation or concealed control and conditioning of some kind. In these circumstances, the objection runs, the fact that we may retain a liability to reactive attitudes does not show that any tokens of this kind would still be justified. We may well find circumstances of this kind incredible or unlikely but they are, nevertheless, entirely coherent and conceivable and this reflects a basic distinction between two distinct levels of concern arising from the skeptical challenge and the associated demand for justifications. Contrary to Strawson's presentation of his argument, the skeptical objection is best interpreted at the token level, where it is not our liability to reactive attitudes that is in question but whether any tokens of these reactive attitudes can ever be justified as they arise (i.e., systematically, on a case by case basis).

Strawson and his followers might try to tough-out this approach by insisting that we should accept both type and token naturalism but this view has little to be said for it. First, it is simply not credible that we are psychologically constrained to retain a commitment to reactive attitudes that we reflectively judge to be unjustified or inappropriate. Second, even if this were true, it would not serve to discredit or refute skepticism. If our human psychology commits us to entertaining and experiencing reactive attitudes in these circumstances this may well be disturbing but it does not show that the token reactive attitudes in question are appropriate or justified, which remains the relevant focus of concern for the skeptic.

It is Strawson's further contention that were the case for skepticism accepted and followed through in practice (i.e., we undertake, systematically, to stop entertaining reactive attitudes), then a bleak inhuman condition involving the universal adoption of the objective attitude must follow. This further line of argument has also been challenged. Several critics have argued that Strawson's taxonomy of the reactive attitudes and the way they are related to moral and personal emotions, more generally, overstates their scope and extent (See, e.g., Wallace 1994: esp. Chapter 2; Pereboom 2001: esp. 199-207; Sommers 2007). One of the features of Strawson's analysis that may be questioned here is his assumption that the reactive attitudes comprehend all the various emotions involved in personal relationships (e.g., love and friendship). If these are distinct and separate categories of emotion then the whole-scale jettisoning of reactive attitudes need not imply the cold, bleak universal stance of the objective attitude that Strawson foresees. Moreover, while personal relations may be humanly inescapable, it does not follow that reactive attitudes are similarly inescapable. There may, moreover, be some forms of reactive attitude that are not threatened by the skeptical challenge, just as there may be moral emotions and responses that should not be assimilated to (moral) reactive attitudes.

All these matters leave room for modifications and amendments to Strawson's analysis of the implications of the skeptical challenge. They also leave room for more 
detailed and elaborate replies on behalf of Strawson (see, e.g., Shabo 2012). Without attempting to settle the issue here, it is safe to say that both Strawson's critics and his followers would generally agree that his account of the relationship between skepticism, objectivity and pessimism calls for a more nuanced and fine-grained analysis of reactive attitudes and what would be involved in attempting to live a human life altogether without them.

\section{II}

We have noted that one of the most significant gaps in Strawson's approach to moral responsibility is his thin account of moral capacity - a gap that leaves his argument open to the Pessimist objection that we still require a more robust conception of moral freedom (i.e., some mode of contra-causal freedom). Although this gap is problematic, several more recent compatibilist contributions have suggested ways of closing it, consistent with the compatibilist requirements, in general, and the Strawsonian approach, in particular. The most influential of these has been rational self-control or reasonresponsive theories. A theory of this kind has been advanced by R. Jay Wallace, who weaves it into a broadly Strawsonian framework (Wallace 1994; see also Fischer and Ravizza 1998, who present a related account of reasons-responsiveness). More specifically, Wallace combines a Strawsonian account of holding responsible with a Kantian theory of moral agency. To understand the relevant conditions of moral responsibility, Wallace claims, we need to provide an account of when it is fair to adopt the stance of holding an agent responsible. His account of holding responsible has, in this sense, priority over his account of being responsible. (See the discussion further below.)

Wallace's Strawsonian account of holding responsible involves a 'narrower' and more restricted interpretation of moral reactive attitudes. To hold an agent morally responsible, on this view, is to hold the person to moral expectations one accepts (Wallace 1994: 51). Our moral expectations are themselves supported by moral reasons that serve to generate obligations (Wallace 1994: 63-4). To hold someone to expectations of this kind must itself be understood in terms of our susceptibility to (moral) reactive attitudes (Wallace 1994: 21). When an agent violates a moral obligation a reactive attitude (e.g., resentment, indignation, or guilt) is called for and appropriate. There is, therefore, a mutual dependence between moral expectations and moral reactive attitudes. Although this 'normative' theory provides a tidy account of the structure of the beliefs involved in holding an agent responsible it also considerably 'narrows' the scope of moral responsibility. That is to say, given that reactive attitudes are appropriately triggered only when a moral obligation has been voluntarily violated, it follows that reactive attitudes are always negative in nature (Wallace 1994: 63, 64, 71). If this is the case then, on this analysis, an asymmetry arises with respect to responsibility, since there is no room left for holding agents responsible in terms of 'positive' reactive attitudes (e.g., approval, praise, etc.). Any account of this kind, it may be argued, is not only one-sided, it presents a truncated and impoverished description of moral life as it relates to responsibility (Russell 2013).

A further difficulty of Wallace's narrow account of moral responsibility is the way in which it commits him to the general apparatus of what Bernard Williams has described as "the morality system" (Williams 1985: Chapter 10; and cp. Wallace 1994: 39, 40, 64-6). The morality system is understood as a particular form of ethical life, associated with our modern Western culture. The narrow view, therefore, is committed to an 
account of moral responsibility that has a 'local' bias toward our modern Western culture, as manifest in the morality system. This bias excludes other cultures, such as the ancient Greeks or shame cultures, as being, at best, 'analogous' to ours, since they involve different moral beliefs with distinct patterns of emotional response (Wallace 1994: 65, 66). Quite apart from anything else, this form of 'localism' or bias to the morality system, considered as serving as the relevant standard of true or real responsibility, removes all commitment not just to token-naturalism but also to type-naturalism. It discredits (Strawsonian) type-naturalism because it maintains that the framework of moral responsibility is erected around culturally local forms of moral emotion. If this is correct, then, contrary to Strawson, we still require an external rational justification for this entire framework and remain vulnerable to global skepticism at this level (Russell 2013).

Let me now turn to the other strand in Wallace's Strawsonian program, his Kantian theory of moral agency, understood as an effort to provide a theory of moral capacity that does not presuppose any "strong freedom of the will" and alternative possibilities (Wallace 1994: 86). Wallace's theory suggests, instead, a requirement of "normative competence." A theory of this kind, Wallace argues, should be understood in terms of (i) the power to grasp and apply moral reasons, and (ii) the power to control or regulate behavior in light of such reasons (Wallace 1994: 86, 157). Agents who have these powers are capable of "reflective self-control." Although determinism may deprive us of genuine alternatives, it does not in itself deprive us of the relevant paired powers of normative competence that Wallace has identified. In embracing this general picture of moral capacity and normative competence, Wallace joins the ranks of a number of contemporary compatibilists who have argued that our dispositional abilities of rational self-control serve as the relevant basis of freedom and moral responsibility (Dennett 1984; Scanlon 1998; Wolf 1990; and Fischer and Ravizza 1998). What is distinctive about Wallace's approach is the way he has fused this theory with a Strawsonian understanding of holding responsible (but see also McKenna 2012 and Shoemaker 2015).

Although Wallace's Kantian theory of agency fills a significant gap in Strawson's overall naturalistic argument, it encounters its own set of difficulties and objections. The most important of these is the question of whether his account of rational self-control suffices as the relevant base capacity for responsible agency. The obvious objection, from an incompatibilist perspective, is that the mere possession of such (dispositional) powers does not give the agent control over the way in which they are actually exercised. What the incompatibilist is looking for here, and will not find in Wallace's discussion, is a convincing account of how it can be fair to hold a person responsible for conduct that flows from powers that are exercised in ways over which the agent has no (ultimate or final) control. The deep worry here, about fairness, is itself rooted in concerns about history and luck.

A particularly influential discussion of this problematic dimension of the Strawsonian strategy is presented by Gary Watson (Watson 1987). One of Watson's central concerns is "the historical dimension" of the problem of responsibility, which he develops by describing in some detail an actual case of a vicious murderer (who was eventually executed). Watson describes two distinct perspectives from which we may consider this case (and other cases similar to it). The first aims to trigger our strong negative reactive attitudes by focusing on the brutal and cruel nature of the crime itself. With respect to this crime there were no evident excusing or exempting considerations other than the "extreme evil" of the act itself (Watson 1987; 94-7). From another perspective, however, we may focus our attention on the background formative conditions on the 
character and motivations of the criminal, which in this, as in many other cases, involves a brutal and harsh childhood and adolescence. A "history that involves unfortunate formative circumstances" (Strawson 1962: 70; Watson 1987: 90) does much to explain "the roots of evil" and why the criminal ended up doing what he did. Although reflections of this kind may not, necessarily, generate skepticism, they will (or should) generate some degree of "ambivalence" (Watson 1987: 101). We oscillate between viewing the criminal as a victimizer and a victim —an instability in our responses that generates deep emotional conflict.

What is operating and affecting our responses and reactions in cases of this kind is an awareness of moral luck. Watson put the problem this way:

If determinism is true, then evil is a joint product of nature and nurture. If so, the difference between any evil person and oneself would seem to be a matter of moral luck. For determinism seems to entail that if one had been subjected to the internal and external conditions of some evil person, then one would have been evil as well. If that is so, then the reflections about moral luck seem to entail that the acceptance of determinism should affect our reactive attitudes ... determinism seems to be relevant to reactive attitudes after all.

(Watson 1987: 103, 104)

The only way to avoid this is to employ the apparatus of libertarian metaphysics in an effort to show how we can be responsible for ourselves. According to Watson, this is an "unbearable burden" and a hopeless enterprise (Watson 1987: 106). The underlying intuition supporting these libertarian ambitions is that we must somehow have consented to evil and unless the consent was undetermined we would not truly be originators of our deeds—we would be mere products and not producers (Watson 1987: 107).

These reflections about "the historical dimension" of the concept of responsibility take us well down the path to skepticism. However, although Watson insists that the historical dimension is "a potential source of skepticism" in relation to our attitudes and practices of holding responsible, he resists skepticism. Instead, he considers the possibility that we might strip away "retributive sentiments" but still retain a commitment to holding responsible in the more limited sense of making an appeal or demand to others as moral agents, without simply collapsing into the objective attitude (Watson 1987: $110,111)$. A number of others, pursuing similar lines of thought, have argued that the implications of historical considerations take us well down the road to full-blown skepticism about moral responsibility (see, e.g., Strawson 1994; Pereboom 2001; Levy 2011).

\section{III}

Another line of criticism levelled against the Strawsonian strategy is that while accounts of moral capacity in terms of our powers of rational self-control are the right basis for responding to the skeptical challenge, a solution along these lines serves to show that the Strawsonian approach, with its focus on reactive attitudes and holding responsible, is the wrong foundation for a satisfactory theory of responsibility. The general problem here, as Angela Smith argues, is that the Strawsonian strategy turns on a confusion between conditions under which it is appropriate to judge someone to be responsible with conditions under which it is fair to blame them or hold them responsible (Smith 2007). Being responsible is a matter of the agent being 'culpable' or 'at fault'-as when 
an agent fails to act on available moral reasons. Blaming, however, involves something more than the mere judgment that the agent was at fault. Although it may not involve overt or expressed retributive activity, it must involve some relevant degree of feeling, whereby the agent is resented or the object of indignation or anger. Although blaming may presuppose fault or culpability, it does not follow from this that blame is always appropriate when an agent is judged culpable or at fault. Even if the agent is clearly responsible for wrongful conduct of some kind, various considerations, distinct from the considerations relating to the agent being responsible, may prohibit or discredit (active) blaming in these circumstances.

The criticisms offered above rely on the supposition that being responsible is both prior to and independent of holding responsible. The problem with the Strawsonian approach, critics argue, is that it gets this relationship backwards, since Strawson's analysis begins with an account of the reactive attitudes. There are, however, several features of this account that may be challenged. In order to understand the relationship between being and holding responsible, let us return to Wallace's split between Kantian agency and Strawsonian holding responsible. On Wallace's construal, it is entirely probable that an individual may have powers of rational self-control but lack any capacity for reactive attitudes. In these circumstances, an agent would be responsible but unable to understand (i.e., from the 'inside') what is involved in being held responsible or holding others responsible. One important objection to this is that, with regard to actual (real) human beings, there is an intimate relationship between the effective development and functioning of responsiveness to moral reasons and the possession of a moral sense, where the latter involves an ability to feel and understand moral sentiments and reactive attitudes. We generally find that agents who satisfy conditions of reasons-responsiveness also satisfy the condition of moral sense and this is not accidental. The two capacities are interdependent and interconnected. Responsible agents, therefore, must also be capable of holding themselves and others responsible-we cannot separate these issues in the way that some of Strawson's critics suppose (Russell 2004; McKenna 2012).

Michael McKenna has recently advanced a new theory of responsibility that is broadly Strawsonian in nature and that pays particular attention to the relationship between being and holding responsible (McKenna 2012). Although McKenna agrees with Strawson that we cannot understand responsibility without reference to holding responsible, and that holding responsible must be explained in terms of the operation of reactive attitudes, he argues that we need to find a more balanced account of the relationship between being and holding responsible-an account that rejects the suggestion that either one is in some way prior to the other (McKenna 2012:3, 4). The key to understanding this relationship, and the symmetry that it involves, McKenna suggests, is to consider it in terms of the analogy between responsibility and conversation. Clearly a competent speaker must not only be able to express herself but also be able to interpret and understand those who may reply to what she says. This is essential if the speaker is to be able to properly appreciate the significance of her own remarks and contribution to a conversation. In the same way, McKenna argues, a responsible agent must, like a competent speaker, be able to appreciate the significance of her act and the quality of her will with which she acts. This is possible only if she is able to interpret the way her acts are received and responded to by others. It follows that competence as a moral agent requires abilities on both sides of this divide and these skills cannot be prised apart (McKenna 2012: 86, 97, 99, 100, 196, 213). 
The conversational analogy suggests a "three-stage" structure for our understanding of responsibility. The first stage is "moral contribution," which occurs when an agent "opens up the possibility of a conversation about the moral value of her action" (McKenna 2012: 88, 89). The second stage is "moral address," when members of the moral community hold the agent morally responsible by directing their reactive attitudes at her (e.g., by blaming her). The third and final stage is "moral account," when the agent has the opportunity to justify, excuse or repudiate her conduct. As the analogy with conversation or "dialogue" suggests, no priority should be given to the stage of moral address (McKenna 2012: 212, 213). At the same time, as McKenna points out, it is also clear that no agent who is incapable of making sense of the reactive emotions of others in response to her conduct can be fully capable of appreciating the quality of will with which she acts or the significance of what she does.

McKenna employs the conversational model to elucidate our understanding of blame and desert. The basic point of blame is to communicate with the wrongdoer and, as such, blame is both public and directed at the wrongdoer. Given these conversational constraints, blame will generally involve some measure of harm to the agent (McKenna 2012: 135, 153). The value of blame, according to this account, rests with several non-instrumental goods that it secures. These include the good that is manifest in the blamer's commitment to morality and the generation of "dialogue aimed at resolution and reconciliation" (McKenna 2012: 167-9). What is crucial, however, as the conversational model suggests, is that blaming responses directed at the agent are fitting, where this is understood in terms of modes of expression that serve to "move the dialogue further along" (McKenna 2012: 142).

Another important contribution to Strawsonian theory that has appeared recently is David Shoemaker's "tripartite theory of responsibility" (Shoemaker 2015). In Responsibility from the Margins, Shoemaker aims to extend and improve upon Strawson's project to provide an account of moral responsibility based upon a description of the role of moral sentiments in this sphere. As with McKenna's study, Shoemaker also pays particular attention to the importance of the agent's quality of will and the way in which this relates to the full range of reactions that are elicited. According to Shoemaker, however, there is a significant failing in most quality of will theories-including Strawson's. These theories tend to be "monistic," by which Shoemaker means that they fail to adequately distinguish the various kinds of quality of will, along with the distinct forms of sentimental response that they occasion. As a result of this coarse-grained approach, Shoemaker argues, we have difficulty dealing with "marginal agents" (e.g., psychopaths, autistics, those who suffer from dementia, etc.) who do not fit neatly into the framework provided by monistic theories. Shoemaker maintains that his "tripartite theory" offers a more nuanced account of these matters, one that deals more adequately with the complexities that these marginal cases present to us.

There are, Shoemaker suggests, three distinct types of responsibility that correspond to three aspects of quality of will. The "three agential factors" that we care about are character, judgment and regard. Our responsibility sentiments, he argues, have "fulfillment conditions" that depend on what specific sort of quality is being targeted. For example, quality of regard is evaluated in terms of anger or gratitude, whereas quality of character is captured by emotional responses such as disdain and admiration. Each type of responsibility correlates with the relevant feature or dimension of quality of will and the distinct sort of responsibility sentiments that are suitable to them. Attributability responsibility is concerned with "volitional structures" and the way they reflect our deep 
selves. Answerability responsibility focuses on the judgments agents make about the worth and relative weight of reasons and distinct responses involved and, so considered, should be construed as demands for justifications. Finally, accountability responsibility involves the distinct responses of anger or gratitude in relation to the degree of regard and empathy that an agent may display. The particular value of displaying anger, Shoemaker maintains, is to be found in the role that it plays in preserving the moral community and generating empathetic concern.

Shoemaker employs the structure of his pluralist, tripartite theory to help us make better sense of the various "hard" cases we find on the margins of the moral community. With the tripartite apparatus in place we may find that there are agents who are responsible in all three aspects and others who are responsible in none. Just to take one important example, in the case of psychopaths their capacity for regard is damaged due to their incapacity for empathy, and so they are not accountability responsible. However, psychopaths may still manifest quality of will in respect of character and be capable of some form of rational judgment. To this extent, they may be considered responsible in the attributability and answerability senses but not the accountability sense. Shoemaker provides similar, nuanced analyses of other marginal cases and draws significant practical conclusions about how we should treat and approach these individuals.

Let us now return to a theme in Strawson's contribution that we considered earlierthe question concerning the relationship between skepticism and pessimism. As we noted, Strawson's remarks on this subject suggest that skepticism about moral responsibility implies a universal objective attitude and that we would find a life of this nature to be bleak and humanly impoverished (Strawson 1962: 71, 73, 79). This is a claim that both Strawson's followers and critics have challenged (e.g., Wallace 1994: 27, 28; Pereboom 2001: 90-8). The question arises, nevertheless, as to whether or not the defeat of skepticism, along the naturalist lines that Strawson advances, would serve to vindicate optimism? Strawson's own remarks certainly suggest the more optimistic view. However, against this suggestion, it may be argued that nothing that Strawson or his followers have argued or advanced serves to discredit the view that agents who satisfy the general conditions of freedom and responsibility, as described, may still be subject to various modes of fate and luck. Although the critical compatibilist may agree that this does not serve to support skeptical conclusions, the persistence of responsible agency in these circumstances can hardly be construed as comforting or without its own disconcerting and disturbing implications. If this is correct, then the success of the Strawsonian strategy, while it may serve to defeat skepticism, does not serve to vindicate any form of easy or complacent optimism (Russell, forthcoming).

\section{IV}

It is evident that Strawson's approach to the free will problem has generated an extensive and rich set of replies and responses over the past half-century. Moreover, as we have noted, Strawson's contribution has changed in fundamental terms much of the way in which this debate is conducted. The key features that are essential to this approach include the following. First, from a methodological point of view, the Strawsonian approach places emphasis on the relevance of descriptive moral psychology for our understanding of these matters. Second, and related to this, the Strawsonian approach identifies moral sentiments or reactive attitudes as the foundation of any 
adequate analysis of the conditions of responsibility and the forms of freedom that this is required for it. Third, the Strawsonian approach employs these broadly naturalistic components (i.e., the two items previously mentioned) to defeat the skeptical threat as associated with the free will problem. Finally, this approach may be presented as aiming to vindicate common sense against various forms of philosophical extravagance rooted in an excessive rationalism. The deep diagnosis provided is that the free will problem is generated by misplaced philosophical demands for modes of justification that have their roots in a failure to ground our investigations in an account of the operations of human nature as we observe them. Each one of these components faces objections and difficulties of their own. Nevertheless, taken as a whole, the theory provided is both ambitious and sophisticated and one that all parties to this debate must address and consider.

\section{Bibliography}

Dennett, D. (1984) Elbow Room: The Varieties of Free Will Worth Wanting. Oxford: Clarendon Press.

Fischer, J. and Ravizza, M. (1998) Responsibility and Control: A Theory of Moral Responsibility. Cambridge: Cambridge University Press.

Levy, N. (2011) Hard Luck. Oxford: Oxford University Press.

McKenna, M. (2012) Conversation and Responsibility. New York: Oxford University Press.

McKenna, M. and Russell, P. (eds) (2008). Free Will and Reactive Attitudes: Perspectives on P.F. Strawson's "Freedom and Resentment." London: Ashgate.

Pereboom, D. (2001) Living Without Free Will. Cambridge: Cambridge University Press.

Russell, P. (1992) "Strawson's Way of Naturalizing Responsibility," Ethics 102: 287-302.

Russell, P. (1995) Freedom and Moral Sentiment: Hume's Way of Naturalizing Responsibility. New York: Oxford University Press.

Russell, P. (2004) "Responsibility and the Condition of Moral Sense," Philosophical Topics 32: 287-305.

Russell, P. (2011) "Moral Sense and the Foundations of Responsibility," in R. Kane (ed.), The Oxford Handbook of Free Will, 2nd edn. New York: Oxford University Press, pp. 199-220.

Russell, P. (2013) "Responsibility, Naturalism and 'The Morality System,"” in D. Shoemaker (ed.), Oxford Studies in Agency and Responsibility, Vol. I. New York: Oxford University Press, pp. 184-204.

Russell, P. (forthcoming) "Free Will Pessimism," in D. Shoemaker (ed.), Under Consideration with Oxford Studies in Agency and Responsibility, Vol. III. New York: Oxford University Press.

Russell, P. and Deery, O. (eds) (2013) The Philosophy of Free Will: Essential Readings from the Contemporary Debates. New York: Oxford University Press.

Scanlon, T.M. (1998) What We Owe to Each Other. Cambridge: Harvard University Press.

Shabo, S. (2012) "Where Love and Resentment Meet: Strawson's Intrapersonal Defence of Compatibilism," The Philosophical Review 121: 95-124.

Shoemaker, D. (2015) Responsibility from the Margins. New York: Oxford University Press.

Smith, A. (2007) "On being responsible and holding responsible." Journal of Ethics 11: 465-84.

Sommers, T. (2007) "The Objective Attiude," The Philosophical Quarterly 57: 321-41

Strawson, G. (1994) "The Impossibility of Ultimate Moral Responsibility," Reprinted (with some modifications) in Russell, P. and Deery, O. (eds) (2013) The Philosophy of Free Will: Essential Readings from the Contemporary Debates. New York: Oxford University Press, pp. 363-78.

Strawson, P.F. (1962) "Freedom and Resentment," Reprinted in Russell, P. and Deery, O. (eds) (2013) The Philosophy of Free Will: Essential Readings from the Contemporary Debates. New York: Oxford University Press, pp. 63-83.

Strawson, P.F. (1980). "Replies," in Z. Van Straaten (ed.), Philosophical Subjects: Essays Presented to P.F. Strawson. Oxford: Clarendon Press, pp. 260-96.

Strawson, P.F. (1985) Skepticism and Naturalism: Some Varieties. London: Methuen.

Watson, G. (1987) "Responsibility and the Limits of Evil: Variations on a Strawsonian Theme," Reprinted in Russell, P. and Deery, O. (eds) (2013) The Philosophy of Free Will: Essential Readings from the Contemporary Debates. New York: Oxford University Press, pp. 84-113.

Wallace, R. Jay (1994) Responsibility and the Moral Sentiments. Cambridge: Harvard University Press.

Williams, B. (1985) Ethics and the Limits of Philosophy. Cambridge: Harvard University Press.

Wolf, S. (1990) Freedom within Reason. New York: Oxford University Press. 


\section{Further Reading}

McKenna, M. (2012) Conversation and Responsibility. New York: Oxford University Press. (An important effort to develop the Strawsonian theory by way of drawing on the analogy between being capable of participating in a conversation and being a member of the moral community and the modes of communication that this involves.)

McKenna, M. and Russell, P. (eds) (2008). Free Will and Reactive Attitudes: Perspectives on P.F. Strawson's "Freedom and Resentment." London: Ashgate. (A collection of some of the most important and influential discussions in response to P.F. Strawson's "Freedom and Resentment".)

Russell, P. (1992) "Strawson's Way of Naturalizing Responsibility," Ethics 102: 287-302. (An analysis and critique of the core arguments advanced in Strawson's "Freedom and Resentment" (reprinted in McKenna and Russell 2008).)

Shoemaker, D. (2015) Responsibility from the Margins. New York: Oxford University Press. (An ambitious and wide ranging application of Strawsonian themes arguing for the 'pluralist' thesis that there are three distinct modes of responsibility that need to be distinguished, which helps us make better sense of a number of difficult cases arising on the fringes of the moral community.)

Strawson, P.F. (1962) "Freedom and Resentment," Reprinted in Russell, P. and Deery, O. (eds) (2013) The Philosophy of Free Will: Essential Readings from the Contemporary Debates. New York: Oxford University Press, pp. 63-83. (The seminal statement of the Strawsonian approach, around which most of the subsequent philosophical literature has developed.)

Wallace, R. Jay (1994) Responsibility and the Moral Sentiments. Cambridge: Harvard University Press. (A highly influential effort to revise and reconstruct a broadly Strawsonian account of holding responsible with a Kantian theory of moral agency.)

Watson, G. (1987) "Responsibility and the Limits of Evil: Variations on a Strawsonian Theme," Reprinted in Russell, P. and Deery, O. (eds) (2013) The Philosophy of Free Will: Essential Readings from the Contemporary Debates. New York: Oxford University Press, pp. 84-113. (An illuminating and sympathetic examination of problematic aspects of Strawson's theory, addressing in particular issues of luck and history as they generate skeptical concerns.)

\section{Related Topics}

Reasons-Responsive Views

Classical Compatibilism

Skeptical Views about Free Will

Nonstandard Views

David Hume

Blame 


\section{0 \\ REVISIONISM \\ Kelly McCormick}

Revisionism is the view that we can and should distinguish between what we think about moral responsibility and what we ought to think about it, that the former is in some important sense implausible and conflicts with the latter, and so we should revise our concept accordingly. This explicit distinction between what we do think and what we ought to think represents a significant departure from traditional methodological approaches to theorizing about moral responsibility (and the kind of free will relevant to responsibility). Here I aim to provide a clear picture of the contours of revisionism. I will do so in part by identifying and assessing three unique challenges any successful revisionist account must meet. I argue that revisionists can meet these challenges, although doing so requires some refinement of previous attempts. I conclude with some remarks on the advantages of the overall revisionist program, and on why revisionism is ultimately worth pursuing.

\section{What is Revisionism?}

Any introduction to revisionism must first identify the variety of ways the view differs from more traditional approaches to theorizing about moral responsibility. And attempts to do so will of necessity draw heavily on the work of Manuel Vargas. While strands of revisionism can be found in precursors and contemporaries such as Smart (1961), Heller (1996), Hurley (2000), Walter (2004), Nichols (2007), Weigel (2013), and McGeer (2013), Vargas has primarily taken on the task of systematically developing and defending the view thus far (see Vargas 2005, 2009, 2011, 2013; Fischer et al. 2007).

There are a number of distinctions that play a role in demarcating revisionism from other views. Most central is the revisionist distinction between diagnostic and prescriptive accounts of moral responsibility. A diagnostic account of responsibility is one that most accurately reflects our widely shared commitments as they stand. In other words, diagnostic accounts aim to provide a descriptive picture of what we do think about moral responsibility, or of our folk concept. There is of course room for disagreement about how to delineate the bounds of our folk concept, and this issue will be discussed in greater detail below. As a first pass we might understand a diagnostic account as aiming to identify at least some widely shared conceptual or semantic features of our ordinary thinking about moral responsibility. Alternatively, one might provide a prescriptive account of moral responsibility. Here the goal is to provide an account of what 
we should, all things considered, take moral responsibility to be. A prescriptive account therefore is not wedded to our actual beliefs, intuitions, and theoretical commitments regarding responsibility, at least not to the same extent as a diagnostic account. While there may turn out to be little difference between our best diagnostic and prescriptive accounts, the distinction between prescription and diagnosis serves to disentangle the potentially distinct projects of determining what we do think and what we ought to think about moral responsibility.

With the diagnostic/prescriptive distinction in hand, a further distinction can be made between conventional and revisionist views. This distinction involves the extent to which the diagnostic and prescriptive accounts on offer are compatible. On a conventional view, our best prescriptive account of what we ought to take moral responsibility to be does not conflict with our best diagnostic account. Revisionist views, on the other hand, maintain that our best prescriptive account of responsibility is not only different from, but also directly conflicts with, our best diagnostic account. In particular, revisionists will identify some feature of our folk concept that is deeply problematic, and argue that we ought to abandon this feature and revise our concept accordingly. We ought to accept that responsibility is in some important sense different from what we currently take it to be.

With these distinctions in mind, there are three unique challenges for revisionism. First, revisionists must address the descriptive task of providing an account of our folk concept, and provide good reason to think that there is some important feature of this concept that is sufficiently problematic to recommend that we excise it from the concept altogether. Here, revisionists will likely appeal to arguments that the problematic feature in question makes the folk concept as it stands naturalistically implausible, normatively inadequate, or perhaps even both. I will hereafter refer to this as the diagnostic challenge for revisionism. Second, revisionists must motivate why, in light of this implausibility, our folk concept ought to be revised rather than eliminated entirely. Call this second task the motivational challenge. Finally, revisionists must meet the prescriptive challenge and provide an account of how, all things considered, we ought to revise our concept. I begin with a discussion of revisionist approaches to meeting this third challenge.

\section{Meeting the Prescriptive Challenge}

One initial worry for revisionist attempts to meet the prescriptive challenge is how they can ensure that the prescriptive account on offer is in fact an account of genuine moral responsibility, or at least something close enough to be appropriately referred to by the term. If it is not, then opponents will claim that revisionists have changed the subject and are not warranted in doing so (see McKenna 2009; Pereboom 2009). In order to avoid such charges, revisionists must therefore tie their prescriptive account closely to our responsibility-related practices, attitudes, judgments, and inferences. Vargas himself does this via a basic constraint on revisionist prescriptive theory construction: a successful prescriptive account must respect the work of the concept of moral responsibility, characterized as the following:

Regulating inferences about differential moral praiseworthiness and blameworthiness, marking those who are praiseworthy or blameworthy and those who are not.

(Vargas 2013: 100) 
This characterization makes revisionist prescriptive theory construction beholden to preserving whatever it is that makes moral praising and blaming appropriate. However, it also gives rise to one of the most prominent objections to revisionism, namely the charge that the prescriptive account on offer fails to deliver desert of moral praise and blame. For example, a particular prescriptive account might preserve the work of the concept as characterized above, but do so by appealing only to forward-looking, consequentialist considerations. On such an account - and there are a variety of ways the details might be spelled out-what regulates our inferences about differential moral praise and blame are things such as the beneficial moral or social consequences of judging and holding people responsible (see Schlick 1939 and Smart 1961 for instructive examples). But many have stipulated that the kind of moral responsibility at issue in the larger free will debate is whatever it is that makes agents deserving of moral praise and blame in the basic (non-consequentialist) sense (see Pereboom 2001, 2014). If we accept this stipulation, then a prescriptive account of moral responsibility that preserves the work of the concept must include some explicitly backward-looking considerations. It must deliver an account of responsibility on which our inferences about differential praise and blame are, at least in part, governed by considerations having to do with the agent herself (the quality of her will, her responsiveness to reasons, her access to alternatives, etc.), and not merely the forward-looking effects of holding her and others responsible. If basic desert matters, then a prescriptive account that explains what makes moral praising and blaming merely appropriate, but not deserved in the basic sense, is not an account of genuine moral responsibility.

Should we accept the stipulation that an account of genuine responsibility must deliver basic desert of moral praise and blame? Here matters are tricky. To my knowledge there are no explicit arguments for the claim that an account of genuine responsibility requires an account of when agents deserve moral praise and blame in the basic sense, and it is not at all clear how such arguments might proceed (perhaps, though, Galen Strawson [1993] might provide a starting point). And, this stipulation itself is by no means uncontroversial (for dissenting views about the centrality of basic desert see McKenna [2012] and Nahmias [2014]). Regardless, in light of concerns about the importance of basic desert revisionists have at least two options. First, they might accept Vargas' characterization of the work of the concept of moral responsibility above, and provide their own arguments for the claim that basicdesert-entailing-responsibility is not in fact what is at issue in the larger free will debate (or if it is, that it should not be). Regardless of whether or not basic-desert-entailingresponsibility is what we philosophers have thus far been interested in, we can actually get everything we care about regarding our responsibility-related judgments and practices without it. This appears to be the route Vargas himself takes (Vargas 2013: 249-66).

Alternatively, revisionists might grant the importance of basic desert and refine Vargas' characterization of the work of the concept to reflect this. As a first pass, such a departure might be characterized as follows:

The work of the concept of moral responsibility is to regulate inferences about differential moral praiseworthiness and blameworthiness, marking those who are deserving of moral praise and blame in the basic (non-consequentialist) sense and those who are not. 
It is beyond my current purposes to adjudicate the matter of which of these characterizations of the work of the concept revisionists ought to accept. Each appears to be a live option, although neither is entirely unproblematic. Vargas's characterization allows that our responsibility-related practices might be justified on consequentialist grounds, and perhaps even that moral praise and blame themselves should be understood in consequentialist terms. But this leaves his particular prescriptive account open to potential objections regarding shallowness and subject-changing. Conversely, the basic-desert characterization allows revisionists to meet opponents like Pereboom squarely on their own terms. But, thus far, no one has attempted to offer a systematized revisionist prescriptive account that preserves this characterization of the work of the concept. While Vargas' own account may, with some minor alteration, be able to preserve the basic-desert characterization, more work must be done in order to make this explicit.

Here I wish only to flag considerations of basic desert as something future attempts to defend revisionism must address. I now set this issue aside and proceed to a brief discussion of the methodology for revisionist prescriptive theory construction itself.

In addition to preserving the work of the concept there are three basic criteria that must be met in order for a revisionist prescriptive account of moral responsibility to be successful:

(C1) It must provide justification for the responsibility system.

(C2) It must be naturalistically plausible.

(C3) It must be normatively adequate.

(Fischer et al. 2007: 153-5; Vargas 2013: 99-132)

Meeting $(\mathrm{C} 1)$ is best understood as requiring affirmative answers to two questions:

The external question: is there anything that would, in general, justify our participation in the practice of moral praising and blaming?

The internal question: can we explain our patterns of responsibility assessment in ways that make it plausible that they are tracking normatively relevant features of agents in the world?

(Vargas 2013: 131)

Revisionists must provide (contra P.F. Strawson 1962) justification that is both internal and external to our responsibility-related practices. By itself, internal justification explains only what regulates our practices as they stand. But, in providing a prescriptive account revisionists are after what these responsibility-related practices should be like. Furthermore, in light of the problematic features of our folk concept identified by revisionists in meeting the diagnostic challenge, revisionists also owe us a story about how we can and should continue participating in these practices at all. And so we need an affirmative answer to the external question. But that answer must not depend on a notion of responsibility that fails to track whatever normatively relevant features of agents ground our interests in these practices in the first place, or worries about subject changing will again loom large. So, in order to meet $(\mathrm{C} 1)$ revisionists must provide affirmative answers to both the internal and external questions (see also Vargas 2013: 131, 132).

In regard to (C2), the standard of naturalistic plausibility requires that, all else being equal, there is something that speaks in favor of the prescriptive account on offer. 
This standard can be contrasted with a more minimal standard of naturalistic compatibility requiring only that an account of responsibility avoids contradicting our best scientific worldview (Vargas 2013: 58-60). (C2) might also be interpreted in either a threshold (we might stipulate a particular measure of plausibility a successful account must meet) or scalar (the account must fare better than our problematic folk concept on the spectrum of plausibility) way (see Vargas 2013: 58-60). Finally, in order to assess (C3) and determine the degree to which an account is normatively adequate, Vargas makes explicit a number of additional sub-requirements. Here it is beyond my current purposes to discuss them in detail, but taken together, they all concern the relationship between the prescriptive account of responsibility on offer, our wider normative notions, and morality more generally (see Vargas 2013: 102).

With these guidelines in mind, revisionists must first characterize the work of the concept, provisionally accept this characterization and the framework of our responsibilityrelated practices as we find them, and go on to construct a prescriptive account of moral responsibility capable of grounding and explaining them. And they do so by providing answers to the internal and external questions discussed above, answers that are naturalistically plausible and normatively adequate. I turn now to possible revisionist strategies for meeting the diagnostic and motivational challenges.

\section{Meeting the Diagnostic Challenge}

How might revisionists go about identifying some feature of our folk concept sufficiently problematic to recommend that it be jettisoned entirely? This is a difficult question, and one further complicated by ambiguity regarding what counts as a genuine feature of our folk concept. As a working understanding, we might take revisionists' attempts to meet the diagnostic challenge as attempts to identify some problematic feature of our widely shared conceptual commitments about moral responsibility. Whether or not this feature should be understood as constitutive of our folk concept - as opposed to merely representative of widely held beliefs about responsibility - will be discussed at length below, and so I bracket such concerns for now (for further argument that revisionists face no unique theoretical burdens in regard to concept individuation see McCormick 2013).

Vargas himself offers the following response to the diagnostic challenge: our folk concept of moral responsibility is significantly libertarian, and these libertarian features are sufficiently problematic to move us to either revision or elimination. The former claim, that our folk concept is significantly libertarian, is motivated by a family of considerations. These include recent empirical data indicating that abstract, general cases involving agents and their actions tend to elicit predominantly incompatibilist responses from ordinary subjects (Nahmias et al. 2007; Nichols and Knobe 2007), the naturalness and intuitiveness of various philosophical arguments in favor of libertarianism (especially van Inwagen's [1983] Consequence Argument and Pereboom's [2001] Four Case Manipulation Argument), and a variety of cultural and historical considerations (see Vargas in Fischer et al. 2007). Taken together, these considerations provide strong, although defeasible, evidence that our folk concept of moral responsibility is, to some extent, libertarian.

However, this is not to say that our folk concept is entirely libertarian. None of the above considerations show that significant strands of compatibilism do not also play a role in our folk thinking about moral responsibility. It may be the case that our folk concept is fragmented, or has contradictory compatibilist and incompatibilist elements 
(see Feltz and Cokely 2008, 2009). Or, it may be the case that our folk concept of moral responsibility is contextual and has different applications depending on particular situational differences (see Heller 1996; Woolfolk et al. 2006; Doris et al. 2007). Regardless, the family of considerations discussed above provides good prima facie reason for accepting the presence of significantly libertarian elements in our folk thinking about moral responsibility, while allowing that there may be (and likely are) other non-libertarian elements (for discussion of the extent to which recent empirical work suggests that our intuitions about free will and moral responsibility are inconsistent see Weigel [2013]).

In order to meet the diagnostic challenge fully though, revisionists must show that the libertarian features of our folk thinking are deeply problematic and should thus be jettisoned. Here again Vargas' work is instructive. He argues first that the libertarian elements of our folk concept are naturalistically implausible. While libertarianism may be consistent with a scientifically plausible worldview, there is no good positive evidence to support the claim that we have the kind of agency, psychology, or neurophysiology required by the varieties of libertarianism (Vargas 2013: 60-70; see also Pereboom 2014: 50-70).

Furthermore, this lack of evidence raises a serious normative worry regarding the fairness of our current responsibility-related practices. The practice of moral praising and blaming presupposes that the appropriate targets of praise and blame have a certain kind of agency, whatever it may be. If it is some kind of libertarian agency, and we have no good evidence for thinking that we actually have this kind of agency, then it seems that we are left merely hoping that the practice of moral praising and blaming is justified (Vargas 2009: 52). This leaves open the possibility that the practice results in radical and widespread unfairness. After all, blaming in particular often results in negative affective responses such as anger and resentment, punishment, and thus, varying degrees of harm. If the justification for blame depends on the fact that we have a certain kind of libertarian agency and we have no good reason to think that we have this kind of agency, we should either excise this feature of the practice (namely, give up our libertarian conceptual commitments) or eliminate the concept of moral responsibility entirely.

But what if the above diagnosis gets things wrong? At the very least, there has been a recent explosion of empirical data on the intuitions of ordinary language users, some of which casts doubt on the intuitiveness of incompatibilism (see Nahmias et al. 2006, 2007; Nahmias 2011). Vargas himself anticipates this worry. He argues that even if it turns out that our folk concept of moral responsibility is not at all libertarian, this poses a mere terminological objection to revisionism (Vargas 2011: 469). If, in this case, the correct diagnostic account no longer conflicts with the prescriptive account on offer, then the alleged revisionist view at issue would turn out to be conventional. And this need not undermine the plausibility of the relevant prescriptive account itself.

So why worry about meeting the diagnostic challenge in the first place? Even if a particular diagnosis of our folk concept is mistaken, treating this descriptive project as explicitly distinct from the prescriptive project still sets revisionism apart from its conventional counterparts. That revisionists who err in their diagnosis may ultimately end up in the same place as their conventional counterparts-with a prescriptive view that does not conflict with our folk concept - does not diminish the value of their distinct approach to getting there. Given the wealth of conflicting empirical data a healthy degree of suspicion about our folk concept is appropriate. Revisionism respects this 
suspicion. And if the problematic features revisionists identify turn out to fall short of being genuine features of our folk concept, then at the very least, they have identified potential conceptual commitments we should take great care to ensure do not end up creeping into our folk thinking.

Finally, it is important to note that the claim that our folk concept of moral responsibility is to some extent libertarian is relatively uncontroversial. Most incompatibilists will agree with this claim outright, and even those firm in their compatibilist convictions often attempt to explain why apparent libertarian intuitions are mistaken rather than deny that we ever think this way in the first place. So, while revisionists can make the terminological concession that the prescriptive account they offer does not in fact conflict with our best diagnostic account, the relatively uncontroversial nature of the diagnostic account laid out in this section makes need for such concession seem unlikely.

\section{Meeting the Motivational Challenge}

Upon meeting the diagnostic challenge, revisionists are faced squarely with the motivational challenge, and in meeting it, they must thread a kind of needle. They must show that there is something seriously wrong with our folk concept (in order to meet the diagnostic challenge) but also block the conclusion that the concept itself cannot be salvaged.

The first step in motivating revision over elimination is appeal to what Vargas refers to as a principle of philosophical conservatism: we should abandon our standing commitments only as a last resort and, when we do abandon them, there is pressure to limit the scope of revision as much as possible (Vargas 2013: 73-4). That is because widespread revision of our beliefs will likely have a large impact on the stability of our overall doxastic commitments. We greatly value the stability of these commitments, and so, in lieu of significant pressure to revise them, they have a kind of "doxastic inertia" (Vargas 2013: 74). But embracing eliminativism about moral responsibility is likely to do a great deal of violence to our overall web of doxastic commitments. For example, while Derk Pereboom $(2001,2009,2014)$ argues that a particular brand of eliminativism, hard incompatibilism, can preserve analogues of many of our responsibility-related commitments, even he grants that those commitments which presuppose basic desert of moral praise and blame must be abandoned. These include commitments involving retributive punishment, resentment, and moral anger, which indeed represent significant strands in the web of our overall doxastic commitments. So, if we accept a basic methodological principle of philosophical conservatism it seems elimination ought to be adopted over revision only as a last resort (Vargas 2013: 73).

However, in order to meet the motivational challenge fully, revisionists must also clarify precisely how revisionism differs from eliminativism. There are at least two ways revisionists can make this distinction. First, they might argue that the problematic features of our folk concept identified in meeting the diagnostic challenge are not constitutive features of our concept, and so we can successfully give them up and revise accordingly. Vargas refers to this brand of revision as connotational revision (Vargas 2013: 88). The second option is for revisionists to allow that the problematic libertarian features of our folk concept are in fact constitutive, but show that there is a nearby concept that, while distinct, preserves the work of the concept. Vargas refers to this brand of revisionism as denotational revision (Vargas 2013: 88). This distinction can also be put in terms of semantic content. While the connotational revisionist will argue that the libertarian 
features of our folk concept are not reference-fixing and thus can be abandoned without requiring changes to the way the term 'moral responsibility' refers, denotational revisionists will argue that these features do constitute reference-fixing semantic content but that we can successfully shift the reference of the term (see also Nichols [2013] and Nichols [2014] for an alternative characterization of this distinction in terms of causalhistorical and descriptivist views of reference).

Here a less theoretically loaded example may be instructive. Consider a toy concept, SHMALE. Assume that it is widely believed that shmales are very large fish that spend most of their time in the deepest parts of the ocean but are occasionally observed coming to the surface. Assume also that the reference of the term 'shmale' is fixed descriptively, and that the fact that shmales are large fish is a part of the relevant description. Now, imagine we come to discover that shmales are in fact mammals, not fish. Upon discovery of this fact, there are three possibilities for the concept SHMALE. One possibility is that, though it is widely believed that shmales are fish, being a fish is not a necessary or constitutive feature of the concept SHMALE. Furthermore, while being a fish is currently a part of the description that fixes the reference of the term 'shmale,' we can successfully refer to shmales without it. In this case, connotational revision is appropriate. We can carve out the feature of being a fish from the concept of SHMALE and from the description that fixes the reference of the term 'shmale,' all the while preserving the overall concept and continuing to refer successfully. On the other hand, perhaps it is not merely widely believed that shmales are fish. Rather, the fact that shmales are fish is a necessary, constitutive feature of the concept SHMALE and the term 'shmale' fails to refer if being a fish is dropped from the description that fixes its reference. In this case, either denotational revision or elimination is called for. If, for example, we can no longer make sense of the notion of a shmale without fish-hood, and the concept SHMALE can no longer play any of the useful theoretical roles we want it to without fish-hood (for example, distinguishing shmales from non-shmales), then elimination is appropriate. But, perhaps we can make sense of what shmales are without fish-hood, though we realize that they are drastically different from what we thought they were. In this case we might acknowledge that shmales, strictly speaking, do not exist. But that there is a nearby concept, SHMALE*, and a term 'shmale*' that can be used to refer to creatures that do exist. We had been mistakenly calling them shmales, but upon discovery that they are mammals we can still continue to refer to them with a distinct term. And we can continue to think about them with a distinct, but closely related and perhaps even more theoretically useful concept. In this case, denotational revision is appropriate.

Vargas himself avoids explicit commitment to either connotational or denotational revision, and instead endorses what he refers to as semantic agnosticism (Vargas 2013: 89). Unfortunately, this position gives rise to confusion about what revisionism really amounts to. First, connotational and denotational versions of revisionism are each saddled with distinct worries about how they should be classified. If the content the connotational revisionist argues we should jettison is not constitutive of our concept or reference-fixing, why think that there is really a substantive conflict between the diagnostic and prescriptive accounts on offer? And if the content the denotational revisionist argues we should jettison is constitutive or reference-fixing, why think that at the end of the revisionist project the concept has been revised rather than eliminated? In failing to commit to one or the other of these positions, semantic agnosticism leaves revisionism open to both worries. 
Furthermore, revisionists should not opt for connotational revision because this brand of revision is faced with a dilemma. Either the content connotational revisionists recommend jettisoning is so widespread that it is difficult to see why it should not be considered constitutive or essential (and thus connotational revision collapses into denotational revision), or it is not widespread enough to motivate the claim that there is a genuine conflict between the standing concept identified in meeting the diagnostic challenge and the prescriptive account on offer (and thus connotational revision collapses into conventional theorizing). If this is correct, then connotational revision is not in fact a viable option for revisionists. Rather than following Vargas and embracing semantic agnosticism, revisionists should instead go all in for denotational revisionism.

But what of the remaining worry that denotational revision collapses into eliminativism? In some ways denotational revisionism does collapse into eliminativism. Like eliminativists, denotational revisionists are committed to the view that our standing concept should be given up and that something has gone wrong with the reference of the term 'moral responsibility.' Precisely what depends on one's preferred diagnostic account. But this does not mean that denotational revisionism is not a unique position. Unlike eliminativism, denotational revisionism is a success theory. Here the difference can be stated most clearly in semantic terms. Eliminativists hold that there is no extension of 'moral responsibility', and thus, that we should stop using the term and overhaul or jettison those practices that depend on its successful reference. Denotational revisionists might agree that the term has no extension, or allow that it does but that there is something naturalistically implausible or normatively inadequate about whatever properties the term picks out. Regardless, denotational revisionists go one step further than eliminativists in arguing that we are warranted in shifting reference to some 'nearby' properties. As denotational revisionists, we might think of 'moral responsibility' as a theoretical term that initially missed the mark, but that we find we can eventually use to refer to something very close to what we were looking for at the outset, something that may even do a better job playing the relevant theoretical role.

It may be the case that calling this kind of view a brand of revisionism is somewhat misleading. Perhaps a more accurate characterization of denotational revisionism is to call the view replacementism (McCormick 2013). But this is again merely a terminological matter. The important conclusion to be drawn is that semantic agnosticism is not a tenable position for revisionists. Rather, revisionists ought to abandon it and embrace denotational revisionism (or replacementism). Doing so leaves revisionists in a far better position to diffuse worries that the view collapses into conventionalism or eliminativism.

\section{Why be a Revisionist?}

In light of the challenges outlined above, one might wonder why anyone would opt to defend revisionism in the first place. Here I conclude by identifying two unique features of revisionism that make the view appealing. While these are not the only considerations that recommend revisionism, I take them to be sufficient to motivate the idea that the view is ultimately worth pursuing.

First, revisionism has the potential to reframe some of the apparently intractable features of the larger free will debate, especially those sub-debates grounded in the trading of intuitions about further refined cases and counterexamples (see McCormick 
2015). The revisionist distinction between diagnostic and prescriptive accounts of moral responsibility casts at least a shadow of doubt on the reliability of our intuitions about moral responsibility. If our concept of moral responsibility is significantly flawed, then perhaps methodology traditionally used to map our concepts should be abandoned (or at least restricted) in this domain. Acknowledging that our best diagnostic and prescriptive accounts of moral responsibility not only come apart, but may in fact conflict, can therefore serve to shift our focus away from attempts at concept-mapping and towards more explicitly normative concerns. Revisionism therefore has the potential to put the moral back in our theorizing about moral responsibility.

For those in need of a further push towards revisionism, it might be found in the recent explosion of empirical data on the intuitions of ordinary language users about free will and moral responsibility. It is not at all clear what conventional theorists can and should do with this data. If they accept it, it provides a bulk of evidence that our ordinary judgments about moral responsibility are far more diverse, fragmented, and perhaps even contradictory than conventional theories often assume. Whatever one's preferred conventional theory of responsibility, there will be a great deal of explaining to do regarding this evidence about our ordinary judgments. For example, conventional compatibilists must explain why people consistently demonstrate incompatibilist commitments under certain conditions (see Nichols and Knobe 2007), and conventional incompatibilists must explain why people consistently demonstrate compatibilist commitments under others (see Nahmias et al. 2005, 2006, 2007; Nahmias 2006, 2011). This is no easy task for a theory that is intended to provide an analysis of our concept of moral responsibility, as conventional theories are. Revisionism, on the other hand, is uniquely equipped to accept this data as it comes (warts and all) and deem some ordinary judgments unworthy of our continued rational commitment without any widespread attributions of error to the folk (see McCormick 2014). For revisionists, it is not that these problematic beliefs and commitments get things wrong in some deep metaphysical sense, but rather that we ought not to, rationally speaking, go on maintaining them. Thus, if one takes seriously the idea that avoiding widespread attributions of error to the folk is a theoretical virtue, revisionism looks very appealing indeed.

In light of these considerations if, as I have attempted to show here, revisionists have tenable strategies for responding to the three challenges discussed above, it looks like they have earned a place in the landscape of the philosophical discussion of free will and moral responsibility.

\section{References}

Doris, J., Knobe, J., and Woolfolk, R. (2007) "Variantism about Responsibility," Philosophical Perspectives 21: $183-214$.

Feltz, A. and Cokely, E.T. (2008) "The Fragmented Folk: More Evidence of Stable Individual Differences in Moral Judgments and Folk Intuitions," in B.C. Love, K. McRae, and V.M. Sloutsky (eds), Proceedings of the 30th Annual Conference of the Cognitive Science Society. Austin: Cognitive Science Society, pp. 1771-6.

Feltz, A. and Cokely, E.T. (2009) "Do Judgments about Freedom and Responsibility Depend on Who You Are?" Consciousness and Cognition 18: 342-50.

Fischer, J.M., Kane, R., Pereboom, D., and Vargas, M. (2007) Four Views on Free Will. Malden: Blackwell.

Heller, M. (1996) "The Mad Scientist Meets the Robot Cats: Compatibilism, Kinds, and Counterexamples," Philosophy and Phenomenological Research 56: 333-7.

Hurley, S. (2000) “Is Responsibility Essentially Impossible?" Philosophical Studies 99: 229-68. 


\section{REVISIONISM}

McCormick, K. (2013) “Anchoring a Revisionist Account of Moral Responsibility,” The Journal of Ethics and Social Philosophy 7: 1-19.

McCormick, K. (2014) "Holding Responsibility Hostage: Moral Responsibility, Justification, and the Compatibility Question,” The Journal of Value Inquiry 48: 623-41.

McCormick, K. (2015) "Companions in Innocence: Defending a New Methodological Assumption for Theorizing About Moral Responsibility,” Philosophical Studies 172: 515-33.

McGeer, V. (2013) "Civilizing Blame," in D. J. Coates and N. Tognazzini (eds), Blame: Its Nature and Norms. Oxford: Oxford University Press, pp. 162-88.

McKenna, M. (2009) "Compatibilism and Desert: Critical Comments on Four Views on Free Will," Philosophical Studies 144: 3-13.

McKenna, M. (2012) Conversation and Responsibility. New York: Oxford University Press.

Nahmias, E. (2006) "Folk Fears about Freedom and Responsibility: Determinism vs. Reductionism," Journal of Cognition and Culture 6(1-2): 215-37.

Nahmias, E. (2011) “Intuitions about Free Will, Determinism, and Bypassing," in R. Kane (ed.), The Oxford Handbook of Free Will, 2nd edn. New York: Oxford University Press, pp. 554-77.

Nahmias, E. (2014) "Response to Misirlisoy and Haggard and to Björnsson and Pereboom," in W. SinnottArmstrong (ed.), Moral Psychology Volume 4: Free Will and Moral Responsibility. Cambridge: MIT Press, pp. 43-57.

Nahmias, E., Coates, D.J., and Kvaran, T. (2007) "Free Will, Moral Responsibility, and Mechanism: Experiments on Folk Intuitions," Midwest Studies in Philosophy 31: 214-42.

Nahmias, E., Morris, S., Nadelhoffer, T., and Turner, J. (2005) "Surveying Freedom: Folk Intuitions about Free Will and Moral Responsibility,” Philosophical Psychology 18: 561-84.

Nahmias, E., Morris, S., Nadelhoffer, T., and Turner, J. (2006) "Is Incompatibilism Intuitive?" Philosophy and Phenomenological Research 73: 28-53.

Nichols, S. (2007) “After Incompatiblism: A Naturalistic Defense of the Reactive Attitudes," Philosophical Perspectives 21: 405-28.

Nichols, S. (2013) "Free Will and Error," in G. Caruso (ed.), Exploring the Illusion of Free Will and Moral Responsibility. Lanham: Lexington Books, pp. 203-18.

Nichols, S. (2014) Bound. Oxford: Oxford University Press.

Nichols, S. and Knobe, J. (2007) "Moral Responsibility and Determinism: The Cognitive Science of Folk Intuitions," Noûs 41: 663-85.

Pereboom, D. (2001) Living Without Free Will. Cambridge: Cambridge University Press.

Pereboom, D. (2009) "Hard Incompatibilism and Its Rivals," Philosophical Studies 144: 21-33.

Pereboom, D. (2014) Free Will, Agency, and Meaning in Life. Oxford: Oxford University Press.

Schlick, M. (1939). The Problems of Ethics, trans. D. Rynin. New York: Prentice Hall.

Smart, J.J.C. (1961) "Free Will, Praise, and Blame,” Mind 70: 291-306.

Strawson, G. (1993) “The Impossibility of Moral Responsibility,” Philosophical Studies 75: 5-24.

Strawson, P.F. (1962) "Freedom and Resentment," Proceedings of the British Academy XLVIII: 1-25.

van Inwagen, P. (1983) An Essay on Free Will. Oxford: Clarendon.

Vargas, M. (2005) “The Revisionist's Guide to Responsibility,” Philosophical Studies 125: 399-429.

Vargas, M. (2009) "Revisionism About Free Will: A Statement and Defense,” Philosophical Studies 144: 45-62.

Vargas, M. (2011) "Revisionist Accounts of Free Will: Origins, Varieties, and Challenges," in R. Kane (ed.), The Oxford Handbook of Free Will, 2nd edn. Oxford: Oxford University Press, pp. 457-74.

Vargas, M. (2013) Building Better Beings: A Theory of Moral Responsibility. Oxford: University Press.

Walter, H. (2004) "Neurophilosophy of Moral Responsibility: the Case for Revisionist Compatibilism," Philosophical Topics 32: 477-532.

Weigel, C. (2013) "Experimental Evidence for Free Will Revisionism," Philosophical Explorations 16: $31-43$.

Woolfolk, R., Doris, J., and Darley, J. (2006) "Identification, Situational Constraint, and Social Cognition: Studies in the Attribution of Moral Responsibility," Cognition 100: 283-301.

\section{Further Reading}

For early strands of revisionism prior to Vargas see Smart, J.J.C. (1961) "Free Will, Praise, and Blame," Mind 70: 291-306; Heller, M. (1996) "The Mad Scientist Meets the Robot Cats: Compatibilism, Kinds, and Counterexamples," Philosophy and Phenomenological Research, 56: 333-7; and Hurley, S. (2000) "Is Responsibility Essentially Impossible?" Philosophical Studies 99: 229-68. And for Vargas' initial characterization and defense of revisionism see Vargas, M. (2005) “The Revisionist's Guide to Responsibility," Philosophical Studies 


\section{KELLY MCCORMICK}

125: 399-429; Vargas, M. (2009) "Revisionism About Free Will: A Statement and Defense," Philosophical Studies 144: 45-62; and Vargas, M. (2011) "Revisionist Accounts of Free Will: Origins, Varieties, and Challenges," in R. Kane (ed.), The Oxford Handbook of Free Will, 2nd edn. Oxford: Oxford University Press, pp. 457-74. Finally, for the most thoroughly developed defense of revisionism currently on offer see Vargas, M. (2013) Building Better Beings: A Theory of Moral Responsibility. Oxford: Oxford University Press.

\section{Related Topics}

Skeptical Views about Free Will

Folk Intuitions

Blame 


\title{
11 \\ SKEPTICAL VIEWS ABOUT FREE WILL
}

\author{
Derk Pereboom
}

\section{Introduction}

According to free will skepticism, we human beings lack the sort of free will that is at issue in the traditional debate. On one way to construe this claim, we lack the sort of free will required for moral responsibility in a desert-involving sense. Historically, the most prominent variety of free will skepticism is hard determinism, which claims that because causal determinism is true and compatibilism is implausible, we do not have free will of such a kind. This position is defended by Baruch Spinoza (1677/1985), Paul Holbach (1770), Joseph Priestley (1788/1965), B. F. Skinner (1971), Ted Honderich (1988), and Bruce Waller (1990). Over the past three decades, philosophers have set out varieties of free will skepticism that do not depend on the truth of causal determinism. Such views are defended by Galen Strawson $(1986,1994)$, Derk Pereboom (1995, 2001, 2014), Tamler Sommers (2007, 2012), Neil Levy (2011), Thomas Nadelhoffer (2011), Gregg Caruso (2012), and Benjamin Vilhauer (2015). A distinctive and currently prominent route to free will skepticism invokes neuroscientific evidence. According to Benjamin Libet and Daniel Wegner, we lack free will because there is no conscious state of willing that is causally efficacious in producing action (Libet 1985, 2004; Wegner 2002; cf. Harris 2012). In Libet's view, any state that is conscious comes too late in the causal sequence to be efficacious in producing action, and instead, unconscious neural states cause action.

What exactly is the free will skeptic claiming when she argues that we lack the sort of free will required for moral responsibility in the sense at issue in the traditional debate? Our practice of holding each other morally responsible is complex, and involves a number of aspects or senses of responsibility. Some of these senses, for instance those that aim specifically at behavioral reform, are uncontroversially compatible with causal determination, and hence can be accommodated by the free will skeptic. Yet there is one particular sense, and a correlated type of free will, that has been at issue in the debate, and it is not uncontroversially compatible with causal determination:

For an agent to be morally responsible for an action in the basic desert sense is for it to belong to her in such a way that she would deserve blame if she understood that it was morally wrong, and she would deserve credit or perhaps praise if she understood that it was morally exemplary. The desert invoked here is basic in 
the sense that the agent, to be morally responsible, would deserve the blame or credit just because she has performed the action, given sensitivity to its moral status, and not by virtue of consequentialist or contractualist considerations.

(Pereboom 2001, 2014; cf. Feinberg 1970)

Basic desert moral responsibility is often thought to be presupposed by our reactive attitudes, such as indignation and moral resentment (Strawson 1962). If so, the legitimacy of these attitudes is also called into question by the free will skeptic. But there are senses of moral responsibility that do not feature basic desert. For example, an agent might be held to be morally responsible when his dispositions to act badly might be modified or eliminated by blaming, and his dispositions to act well strengthened by praising (Schlick 1939; Smart 1961). Or an agent might be regarded as morally responsible when it is legitimate to expect her to respond reasonably to such questions as: "Why did you decide to do that? Do you think it was the right thing to do?" and that she evaluates critically what her actions indicate about her moral character (Bok 1998; Scanlon 1998; Smith 2008). Incompatibilists would not consider the control required for moral responsibility in these senses to be incompatible with determinism, and hence it is open to free will skeptics to affirm these senses. Not so for the basic desert sensethe sense at issue in the debate. Unless otherwise indicated in this entry I will use 'moral responsibility' to signify that sense.

\section{Two Hard Determinist Accounts}

Baruch Spinoza maintained that due to the truth of causal determinism, we lack absolute or free will, which for him is the sort of free will required for deserved praise and blame (Spinoza 1677/1985: 440-4, 483-4, 496, 497; cf. Della Rocca 1998):

In the Mind there is no absolute, or free, will, but the Mind is determined to will this or that by a cause which is also determined by another, and this again by another, and so to infinity.

(Ethics IIP48/129)

The driving element of the proof of this proposition is that "all things have been predetermined by God, not from freedom of the will or absolute good pleasure, but from God's absolute nature, or infinite power" (Ethics I Appendix, II/77). Spinoza also offers an explanation of why we nevertheless believe we are free: "experience itself, no less clearly than reason, teaches that people believe themselves to be free because they are conscious of their own actions and ignorant of the causes by which they are determined" (Ethics IIIP2s, II/143). For Spinoza, skepticism about free will is not harmful but rather advantageous, since the belief that everything that happens is necessitated by God issues in a kind of equanimity. The particular benefits include liberation from harmful emotions: "this doctrine contributes to communal life by teaching us to hate no one, to disesteem no one, to mock no one, to be angry at no one" (1677/1985: 490). Far from being harmful, in Spinoza's conception, the skeptical perspective is to be recommended for its moral and psychological benefits.

Ted Honderich (1988), like Spinoza, is a hard determinist, but sets out a different kind of argument for this position. Honderich first of all invokes a sophisticated version of non-cognitivism about moral judgments, in particular about judgments that attribute 
moral responsibility. Such judgments, he contends, essentially express attitudes, do not report moral facts, and lack truth value. Still, they involve propositional content in a distinctive way. For a case at issue, one might morally disapprove of a corrupt politician for some action, and this disapproval may include a retributive desire. If so, the attitude will take the action to be originated by the agent in such a way as not to be causally determined by factors beyond his control, and in this way, it features a commitment to indeterministic propositional content.

Having a retributive desire towards the politician while also believing he did not originate his action indeterministically need not involve having inconsistent beliefs. Still, Honderich maintains that given human nature, if someone targets the politician with a retributive desire, she will also believe that the politician originated the action, and the belief will serve as support for the attitude. Given human nature, "If I lose the belief, I cannot persist in the attitude or the behavior. Currently, at any rate, that is a psychological impossibility" (Honderich 1996). In addition, Honderich (1988) sets out a thorough empirical argument for the claim that determinism is in fact true. As a consequence, he counsels us to reconsider the responsibility-related attitudes we naturally hold. At the same time, he contends that much of what is important to human life that would appear to be threatened can be retained, with a focus on our aspirations for achievement and meaning in our lives.

\section{Free Will Skepticism and Neuroscience}

In recent decades, certain neuroscientific studies conducted by scientists such as Benjamin Libet and Daniel Wegner have been taken to demonstrate that we do not have free will (Libet 1985, Wegner 2002; cf. Harris 2012). In their accounts, we lack free will because there is no conscious state of willing that is causally efficacious in producing action. In Libet's view, any state that is conscious comes too late in the causal sequence to be efficacious in producing action. Rather, unconscious neural states cause action. Brian Leiter (2007) points out that this view has a progenitor in Friedrich Nietzsche, who contends that any state picked out by conscious phenomenology is not causally connected to the resulting action. Instead actions are physiologically caused.

In a number of Libet's studies $(1985,2004)$, subjects whose brains are monitored by EEG (electroencephalogram) are asked to flex their right wrists whenever they wish (the description of these studies is from Mele [2013]). When participants are regularly reminded not to plan their wrist flexes and when they do not afterward say that they did some planning, an average ramping up of EEG activity ( $550 \mathrm{~ms}$ before muscle motion begins) precedes the average reported time of the conscious experience ( $200 \mathrm{~ms}$ before muscle motion begins) by about a third of a second. Libet claims that decisions about when to flex were made at the earlier of these two times (1985: 536).

About such studies, Soon et al. write: "Because brain activity in the SMA consistently preceded the conscious decision, it has been argued that the brain had already unconsciously made a decision to move even before the subject became aware of it" (2008: 543). In pursuit of additional evidence, they designed an experiment in which subjects monitored by fMRI (functional magnetic resonance imaging) are instructed to do the following "when they felt the urge to do so": "decide between one of two buttons, operated by the left and right index fingers, and press it immediately" (2008: 543). They found, by using readings from the frontopolar cortex and the other in the parietal cortex, that they can predict with approximately 60 percent accuracy which button 
participants will press several seconds in advance of the actual button press (2008: 544; cf. Soon et al. 2008, supplementary figure 6; Haynes 2011: 93).

Here is Al Mele's (2013) formulation of the argument against free will suggested by these studies:

1. The overt actions studied in these experiments do not have corresponding consciously made decisions or conscious intentions among their causes (empirical premise).

2. So probably no overt actions have corresponding consciously made decisions or conscious intentions among their causes (inference from 1).

3. An overt action is a free action only if it has a corresponding consciously made decision or conscious intention among its causes (theoretical premise).

4. So probably no overt actions are free actions (conclusion).

An objection to premise 1, set out in detail by Mele (2009), is that there is no reliable way to tell which phenomena correspond to which neural events. In the Libet studies, it is a challenge to determine what the readiness potential corresponds to- - for example, whether it is in fact a decision or an intention formation, or instead just an urge. If the readiness potential corresponds to a mere urge, the experimental result will allow that the decision or intention formation is a conscious event after all.

A further objection is raised by Eddy Nahmias (2014). It is generally agreed that free actions, should they exist, would result from a chain of events that extends backward in time indefinitely. At some point in the past, the agent will not be conscious of events in this chain. Consequently, all free actions would be caused, at some point in their causal histories, by unconscious events. Now the concern for free will raised by Libet's studies is that the crucial factors in the history of an action are not conscious. But Nahmias objects that the no-free-will conclusion cannot be secured against the determinist compatibilist just by showing that there are unconscious events that causally determine action, for the reason that every case of free action would feature such events.

Nahmias (2014) also draws our attention to a peculiar feature of the Libet-style experimental situations. They all feature a general conscious intention to flex at some remote time in the future, and what is tested for is the implementation of this general decision at a later moment. Nahmias points out that when we drive cars or cook meals we often form a general conscious intention to act in some way at a later time, whereupon the particular implementation of the general conscious intentions is not preceded by an additional specific conscious intention, and this pattern does not call free will into question. For instance, an agent might form the general conscious intention to drive home from work, while the particular turns she makes on the way are not preceded by further conscious intentions - she might instead be on auto-pilot. Nevertheless, in such cases the initial general conscious intention has a key role in producing action, and freedom of action is not threatened. In Libet's studies, the unconscious specific implementations of initial general conscious intentions are mirrored in the driving example Nahmias adduces, and if the driving example poses no threat to free will, neither do the findings of the Libet studies.

\section{Galen Strawson's Basic Argument}

Since the development of quantum mechanics in the first half of the twentieth century, the possibility of fundamental indeterministic physical laws has been taken more 
seriously than it was previously. Partly because of this, contemporary free will skeptics are often agnostic about causal determinism, and instead argue that their position is reasonable on either deterministic or indeterministic presuppositions.

A number of free will skeptics contend that free will is in fact impossible independently of whether our actions are deterministically caused. Most prominently, Galen Strawson contends, by way of his Basic Argument, that the notion of moral responsibility at stake in the debate-ultimate responsibility — requires conditions on agency that are impossible for us to satisfy, and that this can be established independently of the causal determination of our actions (1986: 25-60, 1994). Strawson is thus a no-free-willeither-way theorist, that is, he maintains that for us moral responsibility is impossible whether or not our actions are causally determined.

The core idea of the Basic Argument can be expressed as follows. When an agent acts, she acts because of the way she is. To be ultimately responsible for acting, the agent must then be ultimately responsible for the way she is, at least in key mental respects. But if an agent is to be ultimately responsible for the way she is in those key mental respects, she must be ultimately responsible for the way she is that resulted in those mental respects. This reasoning generates a regress, which indicates that finite beings like us cannot satisfy the conditions on ultimate responsibility. The conclusion is that finite agents like us can never be ultimately responsible for our actions.

A variation on this argument invokes the premise that an action for which an agent is ultimately responsible must have a complete causal explanation in terms of her reasons alone. More precisely, such an action must be rational, and rational actions must have an explanation in terms of reasons the agent has that indicates all of what there was about the agent, mentally speaking, that causally brought it about that she performed the action she did (1986: 52-6). We can now ask: how do the reasons that the agent has themselves come to be? If they are generated by a non-rational process, then the action is "rationally speaking random." But if they are generated rationally, then this generation must be based on further reasons, and the same question can be asked about those further reasons. Thus because there can be no infinite regress of generation by reasons, actions must always be "rationally speaking random," and thus, not free in the sense required for ultimate responsibility.

Randolph Clarke (2005) contests Strawson's claim that moral responsibility requires that the agent be in rational control of all the mental factors that contribute to the action. Suppose we are created as agent-causal libertarian beings, pre-programmed with a set of strong self-interested motivations and set of roughly equally strong altruistic motivations, and motivations of no other kinds (e.g., to do evil for evil's sake). These fundamental motivations thus come to be non-rationally. Basic Argument-style reasoning might well show that we're not morally responsible for the fact that our actions are all either self-interested or altruistic. But when it is up to someone to make either a self-interested choice or an altruistic choice, and she makes the altruistic one, it seems that she can be morally responsible for making the altruistic one rather than the selfinterested one.

Clarke's criticism of Strawson's argument might be supported by the charge that the standard for rationality it assumes is too stringent (Pereboom 2001). Imagine that you are in a situation of conflict between self-interested and moral reasons; one possible decision is morally justified but is not on balance in your self-interest, the other is not morally justified but is in your self-interest. You have the capacity to make either choice, you make the moral one, and this decision is on balance justified by your reasons overall. 
Strawson would argue that the agent is unfree because the choice is not fully caused by your reasons, and thus rationally speaking random. Yet in this situation it is intuitive that the action might well be sufficiently connected to your reasons to count as rational. The rationality of action would then not require its complete determination by the agent's reasons, but rather only being justified by them (cf. Pereboom 2001).

Saul Smilansky (2000) concurs with Strawson's argument that the sort of free will required for moral responsibility is impossible for us, and thus, he too is a no-free-willeither-way theorist. Nevertheless, he believes that he can at the same time accept a view that combines aspects of both hard determinism and compatibilism, since what he calls the Assumption of Exhaustiveness - that one must either be a compatibilist and not an incompatibilist, or an incompatibilist and not a compatibilist-is false (Smilansky 2000). The most striking aspect of Smilansky's view is that we should maintain the illusion of free will, and that we should do so for practical reasons. For instance, he argues that a valuable type of self-respect would be undermined if determinism were true, and that illusion of free will is needed to maintain this self-respect. He also contends that the illusion of free will is required to sustain certain valuable aspects of criminal justice, for example, that only those who have committed crimes should be punished, and that we should punish criminals rather than provide luxurious accommodations for them (Smilansky 2000, 2011). But even if Smilansky is recommending that we retain the view we ordinarily hold, it is still clear that his philosophical position is skeptical, for he contends that the goods at issue require an illusion of free will, and not its reality.

\section{Neil Levy's Argument for Free Will Skepticism}

The case that Neil Levy makes for free will skepticism is also not dependent on truth of causal determinism. Free will, he contends, is ruled out on either determinism or indeterminism for reasons of luck. The notions of luck that Levy invokes involve lack of direct control, but other considerations as well. One of these notions is luck in the chancy sense:

An event or state of affairs occurring in the actual world is chancy lucky for an agent if (i) that event or state of affairs is significant for that agent; (ii) the agent lacks direct control over that event or state of affairs; and (iii) that event or state of affairs fails to occur in many nearby worlds; the proportion of nearby worlds that is large enough for the event to be chancy lucky is inverse to the significance of the event for the agent.

(Levy 2011: 36)

The contrasting notion of non-chancy luck is relevant to assessing the responsibilityyielding potential of psychological dispositions. Dispositions of this sort may be produced deterministically by stable factors such as genetics, yet at the same time be lucky due to variation in the disposition within the relevant reference group:

An event or state of affairs occurring in the actual world that affects an agent's psychological traits or dispositions is non-chancy lucky for an agent if (i) that event or state of affairs is significant for the agent; (ii) the agent lacks direct control over that event or state of affairs; (iii) events or states of affairs of that kind vary across the relevant reference group, and (iv) in a large enough proportion of cases that event or state of affairs fails to occur or be instantiated in 
the reference group in the way which it occurred or was instantiated in the actual case.

Levy argues that both the libertarian and compatibilist accounts of freely willed actions render them lucky in a sense that rules out moral responsibility. His key argument turns on the notion of a contrastive explanation for action. We might ask about Kane's (1996) example of the businesswoman on her way to work who sees an assault in an alley: why did Anne stop and help rather than continue on to work? Levy argues that libertarian accounts of free will cannot yield such contrastive explanations, and that this indicates that such actions are lucky in a sense that rules out moral responsibility. The agentcausal libertarian might reply by proposing that the ability to substance-cause a decision and in the same context to substance-cause a refraining from this decision instead is a fundamental causal power possessed by the agent-as-substance, and that this yields contrastive explanations. Why did Anne decide to stop and help rather than continuing on to work? She exercised her agent-causal power to stop and help for moral reasons rather than exercising it to continue on to work for prudential reasons. But Levy contends that such agent-caused decisions would also be chancy lucky (2011: 63-76).

Levy argues that compatibilist accounts allow for the relevant sorts of contrastive explanations, but that these explanations themselves indicate or invoke luck. When the agent's endowment settles the action, agency is infected with non-chancy constitutive luck. On other occasions the settling of the action will be chancy, and then chancy luck undermines responsibility. In response to the first possibility, compatibilists are apt to provide resistance to the worry of endowment settling an action. A further vehicle such as a manipulation argument (see below) might stand to have additional potential for engaging his compatibilist opposition.

\section{Derk Pereboom's Free Will Skepticism}

My own case for the skeptical view features distinct arguments that target three rival views, event-causal libertarianism, agent-causal libertarianism, and compatibilism, and then claims that the skeptical position is the only one that remains standing.

\section{Against Event-Causal Libertarianism}

According to event-causal libertarianism, actions are caused solely by way of events, standardly conceived as objects having properties at times, and some type of indeterminacy in the production of actions by appropriate events is held to be a decisive requirement for moral responsibility (Kane 1996; Ekstrom 2000; Balaguer 2010). According to agent-causal libertarianism, free will of the sort required for moral responsibility is accounted for by the existence of agents who possess a causal power to make choices without being causally determined to do so (Kant 1781/1787/1987; Reid 1788/1983; Chisholm 1964; Taylor 1974; O'Connor 2000; Clarke 2003; Griffith 2010). In this view, it is essential that the causation involved in an agent's making a free choice is not reducible to causation among events involving the agent, but is rather irreducibly an instance of the agent-as-substance causing a choice not by way of events. The agent, fundamentally as a substance, has the causal power to cause choices without being determined to do so. 
Critics of libertarianism have argued that if actions are undetermined, agents cannot be morally responsible for them. A classical presentation of this objection is found in Hume's Treatise of Human Nature (Hume 1739/1978: 411, 412; cf. Mele 2006). In Hume's version, the concern highlighted is that if an action is uncaused, it will not have sufficient connection with the agent for her to be morally responsible for it. This idea might profitably be explicated as follows. For an agent to be morally responsible for a decision, she must exercise a certain type and degree of control in making that decision. In an event-causal libertarian picture, the relevant causal conditions antecedent to a decision-agent-involving events-do not settle whether this decision will occur, and the agent has no further causal role in determining whether it does. With the causal role of these antecedent conditions already given, it remains open whether the decision occurs, and whether it does is not settled by anything about the agent. Thus, intuitively, the agent lacks the control required for being morally responsible for the decision. Since the agent 'disappears' at the crucial point in the production of the decision - when its occurrence is to be settled - I call this the disappearing agent argument (Pereboom 2004, 2014).

\section{Against Agent-Causal Libertarianism}

The agent-causal libertarian's solution to this problem is to specify a way in which the agent could have the power to settle which of the antecedently possible decisions actually occurs. The proposed solution is to reintroduce the agent as a cause, this time not merely as involved in events, but rather fundamentally as a substance. The agent-causal libertarian maintains that we possess a distinctive causal power-a power for an agent, fundamentally as a substance, to cause a decision without being causally determined to do so (Kant 1781/1787/1987; Chisholm 1964, 1976; O'Connor 2000; Clarke 2003; Griffith 2010).

Kant (1781/1787/1987) expresses an influential concern for the agent-causal libertarian view, that it might not be reconcilable with what we would expect given our best empirical theories. Kant himself believed that the physical world, as part of the world of appearance, is governed by deterministic laws, whereas the "transcendentally free" agent-cause would exist not as an appearance, but as a thing in itself. In this agentcausal picture, when an agent makes a free decision, she causes the decision without being causally determined to do so. On the route from this undetermined decision to its effects, changes in the physical world, for example, in her brain or some other part of her body, are produced. However, it would seem that we would at these points encounter divergences from the deterministic laws, for the changes in the physical world that result from the undetermined decision would themselves not be causally determined. One might respond that it is possible that the physical alterations that result from every free decision just happen to dovetail with what could in principle be predicted on the basis of the deterministic laws, so nothing actually occurs that diverges from them. But this proposal would appear to involve coincidences too wild to be credible. Consequently, agent-causal libertarianism appears not to be reconcilable with a deterministic law-governed physical world.

Some of those who have in recent times developed the libertarian agent-causal view, such as Randolph Clarke (1993, 2003) and Timothy O'Connor (2000, 2009), suggest that quantum mechanical indeterminacy can advance the reconciliation project. On one interpretation of quantum mechanics, the physical world is not governed by deterministic laws, but rather by laws that are fundamentally merely probabilistic or 
statistical. Suppose (and this is controversial) that quantum indeterminacy percolates up to the level of human action, so that alternative actions are significantly probable. Then it might seem that agent-causal libertarianism can be reconciled with the physical laws. But still, wild coincidences would also seem to arise on this suggestion (Pereboom 1995, 2001). Consider the class of possible actions each of which has a physical component whose antecedent probability of occurring is about 0.32 . It would not violate the statistical laws in the sense of being incompatible with them if, for a large number of instances, the physical components in this class were not actually realized close to 32 percent of the time. Instead, the import of the statistical law is that for a large number of instances, it is correct to expect physical components in this class to be realized nearly 32 percent of the time. Are free choices on the agent-causal libertarian model compatible with this expectation? If they were, then for a large number of instances, the possible actions in our class would almost certainly be freely chosen nearly 32 percent of the time. However, if the occurrence of these physical components were settled by the choices of libertarian free agent-causes, then their actually being chosen close to 32 percent of the time would again amount to a coincidence too wild to be credible. (For a discussion of objections to this argument, see O'Connor [2009] and Pereboom [2014: Chapter 3]).

If the libertarian agreed to these arguments, she might propose that there are indeed departures from the probabilities that we would expect given the physical laws. Roderick Chisholm (1964) proposes a solution of this sort. An objection to this proposal is that we would seem to lack any evidence that departures from the known physical laws occur in the brain when we make decisions. The libertarian might reply that neuroscience is still developing, and that the evidence in question might still be found.

\section{Against Compatibilism}

The remaining alternative to skepticism about free will is compatibilism. One way to argue against compatibilism begins with the intuition that if an agent is causally determined to act by, for example, scientists who manipulate her brain, then she is not morally responsible for that action, even if she satisfies the prominent compatibilist conditions on moral responsibility (Taylor 1974; van Inwagen 1983; Ginet 1990; Mele 1995, 2006; Pereboom 1995, 2001, 2014; Kane 1996). The key subsequent step is that there are no differences between such manipulated agents and their ordinary deterministic counterparts that can justify the claim that the manipulated agents are not morally responsible while the determined agents are.

My multiple-case version of such an argument first of all develops examples of an action that results from an appropriate sort of manipulation and in which the prominent compatibilist conditions on moral responsibility are satisfied (Pereboom 1995, 2001, 2014). In the setup, in each of the four cases the agent commits a crime, say homicide, for the sake of some personal advantage. The cases are designed so that the crime conforms to the prominent compatibilist conditions. This action meets the conditions set out by Hume: the action is not out of character because for the agent it is generally true that selfish reasons typically weigh heavily, and the desire that motivates him to act is not irresistible for him, and in this respect he is not compelled to act (Hume 1739/1978). The action satisfies the condition advocated by Harry Frankfurt (1971) - his effective desire (i.e., his will) to commit the crime conforms appropriately to his second-order desires for which effective desires he will have. That is, he wills to kill the victim, and 
he wants to will to do so, and he wills this act of murder because he wants to will to do so. The action also meets the reasons-responsiveness condition proposed by John Fischer and Mark Ravizza (1998): his desires can be modified by, and some of them arise from, his rational consideration of the reasons, and if he understood that the bad consequences for himself that would result from the crime would be more severe than they are actually likely to be, he would have refrained for that reason. This agent in addition satisfies the condition set out by Jay Wallace (1994): he has the general ability to grasp, apply, and regulate his actions by moral reasons. When the reasons of self-interest that count against acting morally are weak, he will tend to regulate his behavior by moral reasons instead (further advocates of compatibilist conditions that foreground rationality include Wolf [1990], Bok [1998], and Nelkin [2008, 2011]). This ability also allows him to develop his moral character over time, a condition Mele highlights $(1995,2006)$.

The individual manipulation cases featured in the argument, considered separately, indicate that it is possible for an agent not to be morally responsible in the basic desert sense even if these prominent compatibilist conditions are satisfied, and that these conditions are therefore insufficient. The argument has additional force by virtue of setting out three manipulation cases, each of which is progressively more like a fourth, in which the action is causally determined in a natural way. The first case involves manipulation that is immediately causally determining - the neuroscientists directly control the agent's reasoning from moment to moment. The second is just like the first, except that it restricts the manipulation to a time at the beginning of the agent's life. The third case is also similar, except that the manipulation results from the strict upbringing on the part of his community. The fourth is the natural or ordinary deterministic case. The aim is to formulate these cases so that it is impossible to point to a difference between any two adjacent cases that would explain in a principled way why the agent would not be morally responsible in the basic desert sense in one but would be in the other. The conclusion is that the agent is not morally responsible in this sense in all four cases, and the best explanation for this must be that he is causally determined by factors beyond his control in each of them, and this result conflicts with the compatibilist's central claim.

There are two prominent kinds of compatibilist responses to this argument (McKenna 2008). A soft-line reply claims that there is a principled line to be drawn between cases after all. For example, a number of critics have argument that in Case 1, with the agent being manipulated moment by moment, his agency is bypassed altogether, and he is not responsible for this reason (Fischer 2004: 156; Mele 2005; Baker 2006; Demetriou 2010). But his agency is intact in Case 2, and here, these critics contend, he is indeed plausibly morally responsible. A hard-line reply, by contrast, claims that there is no difference relevant to moral responsibility among the cases, and that the judgment that Plum is not responsible in Case 1 is subject to reasonable challenge (McKenna 2008; Haas 2012). In this way, the verdict that the agent is responsible in the ordinary deterministic case can be defended.

\section{Living Without Free Will}

If the one or more of the arguments made for free will skepticism is convincing, one can conclude that we lack the sort of free will required for moral responsibility in the basic desert sense. The concern for the skeptical position is not that there is considerable empirical evidence that it is false, or that there is a powerful argument that it is incoherent. The main question it raises is instead practical: can we live with the conviction 
that it is true? A number of free will skeptics, including Honderich (1988), Pereboom (1995, 2001, 2014), Levy (2011), and Caruso (2012) argue that we in fact can. Here I will restrict the discussion to two practical issues. The first concerns the extent to which the skeptical view can retain our conception of morality and responsibility, and the second to the degree to which it coheres with the emotions required for good personal relationships.

\section{Morality and Responsibility}

Accepting free will skepticism requires giving up our ordinary view of ourselves as blameworthy or praiseworthy for our actions in the basic desert sense. One might first contend that if we relinquished this belief, we could no longer legitimately judge any actions as morally bad or good. However, even if we came to believe that a serial killer was not blameworthy due to a degenerative brain disease, we could still agree that his actions are morally bad. But secondly, if determinism precluded basic desert blameworthiness, would it not also undercut judgments of moral obligation? If 'ought' implies 'can,' and if because determinism is true an agent could not have avoided acting badly, it would be false that she ought to have acted otherwise. Moreover, if an action is wrong for an agent just in case she is morally obligated not to perform it, determinism would also undercut judgments of moral wrongness (Haji 1998). In response, even if the skeptic were to accept all of this (and she might resist at various points; cf. Pereboom 2014: Chapter 6), axiological judgments of moral goodness and badness would not be affected (Haji 1998). So, in general, free will skepticism can accommodate judgments of moral goodness and badness, which are arguably sufficient for moral practice.

Third, the critic might object that if we ceased to consider agents as blameworthy in the basic desert sense, we would be left with inadequate resources for addressing immoral behavior (e.g., Nichols 2007). However, the skeptic might turn instead to other senses of moral responsibility that have not been a focus of the free will debate (Pereboom 2013, 2014: Chapter 6). When we encounter immoral action, we might ask the agent to consider what his actions indicate about his intentions and character, to demand apology, or to request reform. Engaging in such interactions is reasonable in view of the right of those wronged or threatened by wrongdoing to protect themselves from bad behavior and its consequences. We also have an interest in the wrongdoer's moral formation, and the address described natural functions as a stage in this process. Furthermore, we may also have a stake in reconciliation with the wrongdoer, and calling him to account plausibly serves as a step toward securing this aim. The main thread of the historical free will debate does not pose determinism as a challenge to moral responsibility conceived in this way, which the free will skeptic can therefore endorse.

\section{Personal Relationships and Emotion}

Is the assumption that we are morally responsible in the basic desert required for meaningful relationships? The considerations raised by P. F. Strawson in his essay "Freedom and Resentment" (1962) suggest a positive answer. In Strawson's conception, our justification for claims of blameworthiness and praiseworthiness is grounded in the system of human reactive attitudes, such as moral resentment, indignation, guilt, and gratitude. He argues that because the practice of holding morally responsible is grounded in this way, the truth or falsity of causal determinism is not relevant to whether we legitimately 
hold agents morally responsible. But if causal determinism were true and did threaten these attitudes, as the free will skeptic is apt to maintain, we would face instead the prospect of the cold and calculating objectivity of attitude, a stance that relinquishes the reactive attitudes, and in Strawson's view, rules out the possibility of meaningful personal relationships.

Strawson may be correct to maintain that objectivity of attitude would seriously hinder our personal relationships (for a contrary perspective, see Sommers [2007]). However, a case can be made that he is mistaken to claim that this stance would be appropriate if determinism did pose a genuine threat to the reactive attitudes (Pereboom 1995, 2001, 2014). While, for example, species of moral anger such as resentment and indignation might be undermined if free will skepticism is true, these attitudes may be suboptimal relative to alternative attitudes available to us, such as concern, disappointment, sorrow, and moral resolve. The general skeptical proposal is that the attitudes that we would want to retain either are not threatened by a skeptical conviction because they do not have presuppositions that conflict with this view, or else have alternatives that are in the clear. And what remains does not amount to Strawson's objectivity of attitude, and is sufficient to sustain meaningful personal relationships.

Guilt also appears threatened by free will skepticism, and one might argue that this consequence is more difficult to accommodate. The skeptic's position would undermine guilt because it would seem to involve a sense that one is blameworthy in the basic desert sense for an immoral action one has performed. There is much at stake here, the objector might contend, because without guilt, we would not be motivated to moral improvement after acting badly, and we would be kept from restoring relationships that have been impaired. In addition, the objector continues, because guilt is undermined by the skeptical view, repentance is also ruled out, since feeling guilty is a prerequisite for a repentant attitude. In response, suppose instead you acknowledge that you have acted immorally, and as Bruce Waller advocates, you feel deep sorrow for what you have done (Waller 1990, 165, 166; cf. Bok 1998), and as a result, you resolve to do what you can to eradicate your disposition to behave in this bad way. These responses can secure the good that guilt can also realize, and they are compatible with the free will skeptic's view.

Gratitude arguably presupposes that the agent to whom one is grateful is praiseworthy in the basic desert sense for a beneficial act (cf. Honderich 1988, 518, 519). Yet even if this is so, certain core aspects of gratitude would be in the clear, and these aspects arguably provide what is required for meaningful personal relationships. Gratitude involves being thankful toward the person who has acted beneficially. But one can be thankful to a young child for some kindness without believing that she is praiseworthy in the basic desert sense. Gratitude typically also involves joy as a response to what someone has done. But the skeptical view does not pose a threat to being joyful and expressing joy when others act beneficially.

Some of the recommended emotional transformations may not be possible for us. For instance, in certain situations refraining from moral anger may be beyond our power, and thus even the committed skeptic might not be able to make the change the skeptical view suggests. Here Shaun Nichols (2007) cites the distinction between narrow-profile emotional responses, which are local or immediate emotional reactions to situations, and wide-profile responses, which are not immediate and can involve rational reflection. We might expect to be unable to significantly reduce narrow-profile moral anger as, for example, an immediate reaction upon being deeply hurt in an intimate personal relationship. But in wide-profile cases, diminishing or even eliminating moral anger is open, 
or at least disavowing it in the sense of rejecting any force it might be thought to have in justifying harmful reactions to the wrong done. This modification of moral anger and its typical presuppositions is arguably advantageous for our relationships, and stands to help bring about the equanimity that Spinoza believed free will skepticism, more generally, can secure.

\section{Bibliography}

Baker, L. (2006) "Moral Responsibility Without Libertarianism,” Noûs 40: 307-30.

Balaguer, M. (2010) Free Will as an Open Scientific Problem. Cambridge: MIT Press.

Bok, H. (1998) Freedom and Responsibility. Princeton: Princeton University Press.

Caruso, G. (2012) Free will and Consciousness: A Determinist Account of the Illusion of Free Will. Lanham: Lexington Books.

Chisholm, R. (1964) "Human Freedom and the Self." The Lindley Lecture. Lawrence: University of Kansas. Reprinted in Watson, G. (ed.) (1980) Free Will. Oxford: Oxford University Press, pp. 24-35.

Chisholm, R. (1976) Person and Object. La Salle: Open Court.

Clarke, R. (1993) “Toward a Credible Agent-Causal Account of Free Will,” Noûs 27: pp. 191-203.

Clarke, R. (2003) Libertarian Theories of Free Will. New York: Oxford University Press.

Clarke, R. (2005) "On an Argument for the Impossibility of Moral Responsibility," Midwest Studies in Philosophy 29: 13-24.

Della Rocca, M. (1998) "Frankfurt, Fischer and Flickers," Noûs 32: 99-105.

Demetriou, K. (2010) "The Soft-Line Solution to Pereboom's Four-Case Argument," Australasian Journal of Philosophy 88: 595-617.

Ekstrom, L. (2000) Free Will: A Philosophical Study. Boulder: Westview.

Feinberg, J. (1970) "Justice and Personal Desert," in J. Feinberg, Doing and Deserving. Princeton: Princeton University Press, pp. 55-94.

Fischer, J. (2004) "Responsibility and Manipulation," Journal of Ethics 8: 145-77.

Fischer, J., and Ravizza, M. (1998) Responsibility and Control: A Theory of Moral Responsibility. New York: Cambridge University Press.

Frankfurt, H. (1971) "Freedom of the Will and the Concept of a Person," Journal of Philosophy 47: 43-56.

Ginet, C. (1990) On Action. Cambridge: Cambridge University Press.

Griffith, M. (2010) "Why Agent-Caused Actions are not Lucky," American Philosophical Quarterly 47: 43-56.

Haas, D. (2012) "In Defense of Hard-Line Replies to the Multiple-Case Manipulation Argument," Philosophical Studies 163: 797-811.

Haji, I. (1998) Moral Accountability. New York: Oxford University Press.

Harris, S. (2012) Free Will. New York: Free Press.

Haynes, J.D. (2011) "Beyond Libet: Long-term Prediction of Free Choices from Neuroimaging Signals," in W. Sinnott-Armstrong and L. Nadel (eds), Conscious Will and Responsibility. Oxford: Oxford University Press, pp. 85-96.

Hieronymi, P. (2001) "Articulating an Uncompromising Forgiveness," Philosophy and Phenomenological Research 62: 529-54.

Holbach, P.H.T. (Baron) (1770) Système de la Nature, ou Des Loix du Monde Physique et du Monde Moral. Amsterdam: Marc-Michel Rey.

Honderich, T. (1988) A Theory of Determinism. Oxford: Oxford University Press.

Honderich, T. (1996) "Compatibilism, Incompatibilism, and the Smart Aleck," Philosophy and Phenomenological Research 56: 855-62.

Hume, D. (1739/1978) A Treatise of Human Nature. Oxford: Oxford University Press.

Kane, R. (1996) The Significance of Free Will. New York: Oxford University Press.

Kant, I. (1781/1787/1987) Critique of Pure Reason, trans. P. Guyer and A. Wood. Cambridge: Cambridge University Press.

Leiter, B. (2007) 'Nietzsche's Theory of the Will," Philosophers' Imprint 7: 1-15.

Levy, N. (2011) Hard Luck: How Luck Undermines Free Will and Moral Responsibility. Oxford: Oxford University Press.

Libet, B. (1985) "Unconscious Cerebral Initiative and the Role of Conscious Will in Voluntary Action," Behavioral and Brain Sciences 8: 529-66.

Libet, B. (2004) Mind Time. Cambridge: Harvard University Press. 


\section{DERK PEREBOOM}

McKenna, M. (2008) “A Hard-Line Reply to Pereboom's Four-Case Argument,” Philosophy and Phenomenological Research 77: 142-59.

Mele, A. (1995) Autonomous Agents. New York: Oxford University Press.

Mele, A. (2005) "A Critique of Pereboom's 'Four-Case Argument' for Incompatibilism," Analysis 65: 75-80.

Mele, A. (2006) Free Will and Luck. New York: Oxford University Press.

Mele, A. (2009) Effective Intentions. New York: Oxford University Press.

Mele, A. (2013) "Free Will and Neuroscience," Philosophic Exchange, 43: 1-17.

Nadelhoffer, T. (2011) "The Threat of Shrinking Agency and Free Will Disillusionism," in L. Nadel and W. Sinnott-Armstrong (eds), Conscious Will and Responsibility. Oxford: Oxford University Press, pp. 173-88.

Nahmias, E. (2014) "Is Free Will an Illusion? Confronting Challenges from the Modern Mind Sciences," in W. Sinnott-Armstrong (ed.), Moral Psychology, Vol. 4. Cambridge: MIT Press, pp. 1-25.

Nelkin, D. (2008) "Responsibility and Rational Abilities: Defending an Asymmetrical View," Pacific Philosophical Quarterly 89: 497-515.

Nelkin, D. (2011) Making Sense of Freedom and Responsibility. Oxford: Oxford University Press.

Nichols, S. (2007) "After Compatibilism: A Naturalistic Defense of the Reactive Attitudes," Philosophical Perspectives 21: 405-28.

O'Connor, T. (2000) Persons and Causes. New York: Oxford University Press.

O'Connor, T. (2009) "Agent-Causal Power," in T. Handfield (ed.), Dispositions and Causes. Oxford: Clarendon Press, pp. 189-214.

Pereboom, D. (1995) "Determinism al dente," Noûs 29, 21-45.

Pereboom, D. (2001) Living Without Free Will, Cambridge: Cambridge University Press.

Pereboom, D. (2004) "Is Our Conception of Agent Causation Coherent?" Philosophical Topics 32: 275-86.

Pereboom, D. (2008) “A Hard-Line Reply to the Multiple-Case Manipulation Argument," Philosophy and Phenomenological Research 77: 160-70.

Pereboom, D. (2009) "Free Will, Love and Anger," Ideas y Valores 141: 5-25.

Pereboom, D. (2013) "Free Will Skepticism, Blame, and Obligation," in N. Tognazzini and D.J. Coates (eds), Blame: Its Nature and Norms. New York: Oxford University Press, pp. 189-206.

Pereboom, D. (2014) Free Will, Agency, and Meaning in Life. Oxford: Oxford University Press.

Priestley, J. (1788/1965) A Free Discussion of the Doctrines of Materialism and Philosophical Necessity, in a Correspondence Between Dr. Price and Dr. Priestley, 1788, Part III, pp. 147-52; reprinted in Passmore, J. (ed.). (1963) Priestley's Writings on Philosophy, Science, and Politics. New York: Collie.

Reid, T. (1788/1983) "Essays on the Active Powers of Man," in Sir W. Hamilton (ed.), The Works of Thomas Reid. Hildesheim: G. Olms Verslagsbuchhandlung.

Scanlon, T. M. (1998) What we Owe to Each Other. Cambridge: Harvard University Press.

Schlick, M. (1939) "When is a Man Responsible?" in Problems of Ethics. David Rynin, tr., New York: Prentice-Hall, pp. 143-56.

Skinner, B.F. (1971) Beyond Freedom and Dignity. New York: Alfred A. Knopf.

Smart, J. J. C. (1961) "Free Will, Praise, and Blame," Mind 70: 291-306.

Smilansky, S. (2000) Free Will and Illusion. Oxford: Oxford University Press.

Smilansky, S. (2011) "Hard Determinism and Punishment: A Practical Reductio," Law and Philosophy 30: 353-67.

Smith, A. (2008) "Control, Responsibility, and Moral Assessment," Philosophical Studies 138: 367-92.

Sommers, T. (2007) "The Objective Attitude," Philosophical Quarterly 57: 321-41.

Sommers, T. (2012) Relative Justice: Cultural Diversity, Free Will, and Moral Responsibility. Princeton: Princeton University Press.

Soon, C.S., Brass, M., Heinze, H.J., and Haynes, J.D. (2008) "Unconscious Determinants of Free Decisions in the Human Brain," Nature Neuroscience 11: 543-5.

Spinoza, B. (1677/1985) Ethics, in The Collected Works of Spinoza, Vol. 1. E. Curley (ed. and trans.). Princeton: Princeton University Press.

Strawson, G. (1986) Freedom and Belief. Oxford: Oxford University Press.

Strawson, G. (1994) "The Impossibility of Moral Responsibility," Philosophical Studies 75: 5-24.

Strawson, P. F. (1962) "Freedom and Resentment," Proceedings of the British Academy 48: 187-211.

Taylor, R. (1974) Metaphysics. Englewood Cliffs: Prentice Hall.

van Inwagen, P. (1983) An Essay on Free Will. Oxford: Oxford University Press.

Vilhauer, B. (2015) "Taking Free Will Skepticism Seriously," Philosophical Quarterly 62: 833-52.

Wallace, R.J. (1994) Responsibility and the Moral Sentiments. Cambridge: Harvard University Press.

Waller, B. (1990) Freedom Without Responsibility. Philadelphia: Temple University Press.

Wegner, D. (2002) The Illusion of Conscious Will. Cambridge: MIT Press.

Wolf, S. (1990) Freedom within Reason. Oxford: Oxford University Press. 


\section{Further Reading}

Here is a list of books of the last quarter century arguing for some type of skeptical view about free will from a philosophical perspective:

Caruso, G. (2012) Free Will and Consciousness: A Determinist Account of the Illusion of Free Will. Lanham: Lexington Books. (Caruso argues for a skeptical view based on both philosophical and empirical considerations and argues that the view is practically viable, in particular as it concerns criminology.)

Honderich, T. (1988) A Theory of Determinism. Oxford: Clarendon Press. (This book develops a detailed empirical argument for determinism and for a skeptical perspective on free will and moral responsibility.)

Levy, N. (2011) Hard Luck. Oxford: Oxford University Press. (Levy argues for free will skepticism by arguing that both deterministic and indeterministic views of agency are subject to responsibility-undermining forms of luck.)

Pereboom, D. (2001) Living without Free Will. Cambridge: Cambridge University Press.

Pereboom, D. (2014) Free Will, Agency, and Meaning in Life. Oxford: Oxford University Press. (Pereboom defends the skeptical view by developing arguments against competing positions and arguing that a skeptical perspective is practically viable.)

Smilansky, S. (2000) Free Will and Illusion. Oxford: Oxford University Press. (Smilansky accepts Strawson's basic argument, but argues that practical reasons count in favor of non-skeptical beliefs and practices.)

Sommers, T. (2012) Relative Justice: Cultural Diversity, Free Will, and Moral Responsibility. Princeton: Princeton University Press. (Sommers argues for a skeptical conclusion from the premise that human cultures feature rationally irresolvable disagreements about moral responsibility.)

Strawson, G. (1986) Freedom and Belief. Oxford: Oxford University Press. (This book sets out the basic argument against ultimate moral responsibility and develops a number of possible practices that take on a skeptical perspective.)

Bruce Waller is a skeptic about moral responsibility but not about free will. Here are three books in which he develops his view:

Waller, B. (1990) Freedom without Responsibility. Philadelphia: Temple University Press.

Waller, B. (2011) Against Moral Responsibility. Cambridge: MIT Press.

Waller, B. (2014) The Stubborn System of Moral Responsibility. Cambridge: MIT Press.

The following two books argue for skepticism about free will from a neuroscientific and psychological point of view:

Libet, B. (2004) Mind Time. Cambridge: Harvard University Press.

Wegner, D. (2002) The Illusion of Conscious Will. Cambridge: MIT Press.

Sam Harris's popular book argues for a skeptical position on free will and also discusses the neuroscientific arguments:

Harris, S. (2012) Free Will. New York: Free Press.

\section{Related Topics}

Event-Causal Libertarianism

Agent-Causal Libertarianism

Non-Causal Libertarianism

Free Will and Moral Sentiments: Strawsonian Views

Revisionism

Nonstandard Views

Manipulation Arguments

The Luck and Mind Arguments

The Stoics on Fate and Freedom

Free Will and Theological Determinism

Free Will and Providence

Deliberation

Blame

Mental Illness and Psychopathy

Determinism 


\section{2 \\ NONSTANDARD VIEWS Saul Smilansky}

As I have claimed in the past, we live in the heroic age of free will philosophy: more new good ideas and arguments have been presented, and more philosophical progress made in the last 60 years than since the problem was recognized, some 2,000 years ago. As we shall soon see, the free will problem is actually a conjunction of five questions or problems; the last three were hardly recognized before 1960. This truly outstanding progress can be divided into two types: the larger body of work consists of the greater understanding and sophistication of what can be described as the 'standard' views. A much smaller but still not insubstantial body of work has been developed in what can be described as 'nonstandard views.' In this chapter. I will review some of the fascinating developments in the nonstandard direction.

\section{The Distinction Between 'Standard' and 'Nonstandard' Views}

Philosophical views do not wear badges declaring that they are 'standard' or 'nonstandard.' So when undertaking the task of considering the nonstandard views, I had to determine how to decide which, among the very large variety of extant positions, should be put under this heading. One possible sense of 'nonstandard' refers to the oddness of the content. However, philosophical oddity or eccentricity is not a plausible criterion here: even if we could agree on this matter, many standard views are manifestly odd. In fact, I have argued that the free will problem is a distinct example of what I have termed "crazy ethics" (Smilansky 2013). Another possibility would be to compare contemporary discussions to those of previous periods, seeking to identify innovation. Yet here as well, many mainstream contemporary positions, which are surely 'standard' to the current debate, if anything is, would have been thought radically eccentric as late as the middle of the twentieth century. A notable example of these two features is John Martin Fischer's "semi-compatibilism" (Fischer and Ravizza 1998), which is based upon the (post Frankfurttype-examples-based) rejection of the ability to do otherwise, yet affirms free will, moral responsibility, desert, blame and praise. This is clearly both a radical philosophical move and a clear break with the past, yet Fischer is the contemporary compatibilist standard, the 'establishment'; it would make no sense to label his view as 'nonstandard.'

In the end, I have opted for the following demarcating line: 'standard' views are those that are (i) distinctly libertarian, compatibilist, or hard determinist (or otherwise free-will-denying) positions, (ii) more or less within the paradigmatic view that takes 
free will to be a condition for moral responsibility, which is, in turn, a condition for desert, blame, and praise and other related beliefs, attitudes, and practices. So any strictly libertarian, compatibilist or hard determinist position relating to this paradigm will be marked as 'standard' and thus not considered here. This already seems to exclude all libertarian views from our discussion. Of course there can be unusual or 'nonstandard' explications of either libertarianism, compatibilism, or hard determinism, within the traditional paradigm, but those views will not be considered here as nonstandard. We will hence exclude from the nonstandard family any view that shares (i) and (ii). 'Nonstandard' views are, then, whatever remains.

As we shall see, this includes various types of positions: in other words, in order to make the 'nonstandard' listing a position can diverge from the three 'classical' positions or abandon the paradigmatic view in various ways. Despite the fact that the nonstandard component of the free will debate is much smaller than the standard, the potentially relevant literature is still very large. My survey is hence necessarily selective, and cannot note all of the interesting work even within my sphere. I apologize to whoever has been left out, because of my need to select (or ignorance).

\section{The Free Will Problem: The Five Questions}

In order to better see the distinction between the standard and nonstandard views, and to begin to map the nonstandard varieties, it is important that we see the distinct questions that make up the free will problem. I believe that the best way to understand the free will problem is to see it as a combination of five questions; the first two are the more familiar ones (the 'standard' questions) but, as we shall see, the last three are also crucial. The questions are:

1. Is there libertarian free will? (Here would be included as sub-questions the issue of determinism, the question of the helpfulness of indeterminism, the question of whether libertarian free will is at all coherent, and so on.) Libertarians, of course, think that that there is libertarian free will; compatibilists (typically) and hard determinists (HD) disagree. (I will consider hard determinism to be a combination of incompatibilism and the rejection of libertarianism. On this view, HD need not strictly be deterministic, that is, if it accepts the possibility of quantum mechanics indeterminism, but holds that it cannot give us robust libertarian free will. This allows us to keep to the familiar three-part terminology.) The first question is metaphysical or ontological.

2. If libertarian free will does not exist, do we still have moral responsibility and the related notions such as desert? This is, of course, the familiar compatibility question: is moral responsibility compatible with determinism or, better, is it compatible with the absence of libertarian free will irrespective of determinism? Compatibilism and hard determinism are opponents on the compatibility question. This question, in my opinion, is mostly ethical.

3. If we have no moral responsibility in light of the absence of libertarian free will, or if moral responsibility is at least seriously weakened by the absence of libertarian free will, is this good or bad? In other words, are we better off without (or with much less) valid attribution of free will and moral responsibility, so that we ought to welcome the absence of libertarian free will, or are we worse off? This question is both ethical and psychological. 
4. Can common beliefs, attitudes and practices concerning free will, moral responsibility, desert and so on change and, if so, how radical can this change be; and what forms can it take? This question is mostly psychological, sociological, and historical.

5. What can and what should we do about the replies to questions one to four? (Here would be included as sub-questions descriptive questions that concern the nature of folk belief and the possibility of radical change, and normative questions such as whether the continuation of widespread false belief can be tolerated.)

\section{Mapping the Nonstandard Views}

With the help of these questions, we can begin to see the nonstandard views. As we shall see, the reason for this variety is that 'becoming nonstandard' can take a number of distinct forms:

(i) First, one can remain within the scope of the first, 'standard' two questions, but give a nonstandard reply. Since we are bracketing the first (libertarian/determinism) question, this means that one would give a nonstandard reply to the compatibility question, which breaks the monistic focus on either compatibilism or hard determinism; that is, a reply that is neither strictly compatibilist nor hard determinist.

(ii) Second, one's view can become nonstandard because one puts forth positions that respond to the nonstandard questions (\#3 to 5 according to my demarcation), which have been relatively neglected as compared to the first two, standard questions.

(iii) Third, a view can become nonstandard if it understands the free will problem in a way that bypasses the standard free will-moral responsibility-desert paradigm (e.g., utilitarianism on moral responsibility); or interprets it in ways that are radically novel in terms of the contemporary debate (e.g., contractualism).

These three forms of being 'a nonstandard view' diverge into many distinct views. I will divide them into seven broad families:

\section{Complex Positions on the Compatibility Question}

Throughout its history, the compatibility question on the free will problem has been conducted under the Assumption of Monism, whereby we can be either compatibilists or incompatibilists (and hence, given the absence of libertarian free will, either compatibilists or hard determinists). Yet this standard assumption is false (Smilansky 2000); we can combine some measure of both. This has reluctantly gained some recent support, yet nearly all the work on the compatibility question still seems to assume that matters are 'either-or.' The importance of this 'dualistic' or pluralistic possibility has not been sufficiently internalized in the debate. An early anticipation is Jonathan Glover's unduly neglected "Self-creation" (1983). Ted Honderich (1988) proposes an "emotive" account, which affirms compatibilist-like attitudes within a framework skeptical of traditional free will views. Martha Klein (1990) considers the limitations of compatibilism yet partly affirms it. Paul Russell (e.g., 2013) offers a "pessimistic" compatibilism that is aware of its inability to fulfill traditional optimistic compatibilist claims (cf. Cuypers 2013). 
Another way in which the standard Assumption of Monism has been rejected is that of contextualism (e.g., Hawthorne 2001; Feldman 2004). Contextualist views hold that one ought to be compatibilist or hard determinist in response to the context: in some contexts, the appropriate attitude toward the compatibility question is the former, and in other contexts, it is the latter.

The most extreme 'complex position' on the compatibility question has been proposed by Saul Smilansky (2000: Part I), who shares the contextualist thought that sometimes we ought to be compatibilists and sometimes hard determinists, but adds that to some extent we ought to be both at the same time, so that at least on some occasions a view trying to combine the insights of both contrasting positions together is the most convincing. Neither compatibilism or hard determinism is, according to this view, the whole truth, but both see part of the true, inherently complex, picture.

\section{Happy Hard Determinism}

Throughout the free will debate, almost everyone thought that free will and moral responsibility could be defended through libertarianism and, if not, then through compatibilism. The possibility that it could not be defended at all, that is, the position of hard determinism, while recognized, was shunned because it was thought that living without free will and moral responsibility (and the concomitant beliefs, reactions, and practices) would obviously be awful. This almost universal consensus has also been forcefully challenged in our generation (see, e.g., Waller 1990, 2011; Pereboom 2001, 2014, Chapter 11, this volume; Sommers 2007, 2012; Levy 2011).

It might be thought that if hard determinism as such has been left in the 'standard' camp, and if most philosophical hard determinists seem to belong in the 'happy' camp, then it makes little sense to place 'happy hard determinists' as putting forth nonstandard views. This is a matter of typological arrangement and reasonable people can of course disagree here. I think that it makes sense to incorporate 'happy' hard determinism into the nonstandard fold for two reasons: first, because the feature of 'happiness' in the hard determinist views is a response to the third, nonstandard question. Second, because the means involved in the defense of the 'happy' interpretation are, typically, clearly nonstandard (such as utilitarianism). Hence the defense of the 'happy' interpretation takes its proponents into nonstandard territory, in the free will debate. There is no difficulty in (i) seeing the defense of hard determinism versus compatibilism (i.e., the rejection of free will and moral responsibility due to determinism, or due to the absence of libertarian free will irrespective of determinism) as an engagement in the standard debate (the 'compatibility question'); while (ii) seeing arguments by hard determinists to the effect that living without belief in free will and moral responsibility would make us better off, as an engagement in a nonstandard debate. Hard determinism is responding here to different questions, one standard and another nonstandard. That seems to me the most accurate and fruitful way to cut the pie.

\section{Utilitarian Inclinations}

Utilitarianism is one of the classical, standard normative theories, together with deontology, contractualism, and virtue ethics. We risk conceptual confusion here if we use the broader term, 'consequentialism.' Some consequentialists have seen the maximization of, say, desert, as that which ought to be aimed for. But the view we are after sees 
maximization as an alternative to concern with (free will based) desert, rather than a way of having as much of it as possible. Hence it is preferable to use the term 'utilitarianism' here, without necessarily accepting all the philosophical commitments of historical utilitarianism.

Why, then, if utilitarianism is one of the standard positions on normative ethics, should it find itself relocated into the nonstandard camp, in the discussion of free will? I see two reasons as compelling here. First, utilitarianism has, in fact, been rather minor in the free will debate. This is perhaps largely due to a selection process: if one is inclined toward utilitarianism, one would typically find little interest in the free will debate, except on the level of error theory, or moral pragmatics. For if we hold people responsible, blame and praise them, and so on, only because and in accordance with what happens to be most utility maximizing, then there is no inherent interest in whether people are 'really' free, or responsible, or deserving. So philosophers who have been seriously concerned over the free will problem have, naturally, tended not to be utilitarians; indeed, they have tended to be deontologists, or at least normative pluralists with deep deontological commitments.

The second and more important reason why utilitarianism is nonstandard in the free will debate is that it replaces the concern with free will and the concomitant notions with an alternative story, which gives no moral weight to that problem itself. It might well be utility maximizing for the Folk to hold views that are related to free will (e.g., that we punish people because they deserve to be punished, since they chose out of free will to do wrong) but, again, the real justification for any practice (such as punishment) is, in the end, strictly utilitarian. A good example of the way in which utilitarianism views the free will problem is shown by J.J.C. Smart (1961). More recently, Neil Levy (2012), arguing in particular against Smilansky's pessimistic conservatism (Smilansky 2011), has argued that the balance of considerations should lead us toward giving up belief in free will and moral responsibility as fundamentally necessary for the justification of punishment. Traditional social beliefs prevent the radical reform of penal institutions, Levy argues; hence, rather than maintaining the free will paradigm, broadly utilitarian ideas should be our sole guide on these matters.

However, particularly in more recent years, some inclination toward utilitarianism can be discerned in people who clearly have been deeply concerned over free will. Such 'free will internalists' have tilted in the utilitarian direction because of the conclusions they have reached within the free will debate, rather than (as with Smart, for example), beginning with utilitarianism and thereby rejecting the inherent importance of the free will problem from the outset. Such developments can be found within both compatibilism and hard determinism. Perhaps the most striking example of the first is Manuel Vargas, who has offered a 'revisionist' position in defense of compatibilism (e.g., Vargas 2005,2013 ). Rather than defend compatibilism in the traditional ways (based upon the free will-moral responsibility-desert paradigm), Vargas sees our practices of holding people responsible and meting out to them the respective attitudes, rewards and punishments as basically forward-looking. This puts him broadly in the utilitarian camp.

Hard determinists struggling with the practical implications of the rejection of free will, moral responsibility and desert, have tilted in a similar direction. A notable example here is Derk Pereboom (e.g., 2001, 2014), who sees our practices as requiring defense in the light of their effects. Since backward-looking desert is ruled out by hard-determinism, we are left only with broadly forward-looking justification for practices and attitudes that will motivate people in a beneficial way. 
Curiously, we find compatibilists and hard determinists both taking the 'utilitarian turn,' and ending up with quite similar nonstandard forward-looking approaches.

\section{Contractualism}

The case for considering contractualism to be a 'nonstandard' view is in part similar to that made for utilitarianism, but while utilitarianism is manifestly nonstandard on free will, this is less clear with respect to contractualism. Contractualism will be considered here as the view according to which the central free will notions (moral responsibility, desert, and blame and praise, for example) are justified and defined by their being chosen (in fact or, more plausibly, hypothetically), by human agents establishing the moral order; by the moral contract. So while with utilitarianism we praise because, overall and in the long term, praising is likely to maximize well-being (or the like), with contractualism, we praise because doing so is something we agree upon, in some sense as, say, serving the interests of rational individuals agreeing upon a social contract for their mutual benefit. This allows for a notion of desert constructed by the contract (although not for a pre-institutional inherent notion of desert guiding the formation of any acceptable social contract, as in the traditional paradigmatic positions on free will and moral responsibility).

In terms of the contemporary free will debate, contractualism has played only a very limited part; again, in striking contrast to its role in normative ethics and areas influenced by it, such as distributive justice. Compatibilists have defended free will and moral responsibility, hard determinists have rejected them, contextualists, compatibilitydualists and others have offered mixed positions - all without much recourse to contractual thoughts. Again, the contemporary free will debate has been broadly deontological in character.

Within the free will debate, the major exception has been Thomas Scanlon. In Scanlon (1988) and consequent work, he has sought to incorporate notions such as blame into his form of contractualism. Scanlon himself has sent contrasting messages, for example, concerning the notion of desert (see Scanlon 1988 versus Scanlon 2008). I do not have the space for a detailed discussion here but clearly the place where contractualism has made some roadway into the contemporary free will debate has been through Scanlon's work. Another contribution has been James Lenman's defense of contractualism in the free will context. In Lenman (2006), he sets out to defend contractualism as the best explication of free will-related morality but without distinct Scanlonian commitments. These two authors see free will and moral responsibility as following from the actual and/or morally proper contractual construction.

The sphere where contractualist argumentation has engaged the free will issue in an influential way has been within the philosophy of law. An established tradition (e.g., Hart 1970; Honore 1999; Gardner 2007) has defended versions of contractualism as the best way to make sense of our attitudes concerning responsibility, blame, and punishment. It is perhaps understandable that a down-to-earth philosophy of law approach has resisted thoughts about a broad destructive skepticism based upon the free will problem, and looked favorably on the prospects for a 'positivistic' defense of compatibilism and the present social order, based upon social agreement. It is striking that up until this point these debates within legal philosophy have had very little effect and indeed have hardly been noticed in the contemporary philosophical (non-legal) free will debate as such. 
What are the prospects for contractualism to move into the mainstream of the free will debate? Such prospects seem to me to be clearly better than is the case with utilitarianism. The logic of utilitarianism leaves no room for concern over the free will issue, as such. Redefining 'blameworthy' as 'currently happens to be utility-maximizing to blame' is a rejection of the free will and desert-based standard notion of blameworthiness and praiseworthiness; utilitarianism replaces concern over free will rather than explicating it. With contractualism there is perhaps a possibility for separating the grounds for a system of desert (contractual agreement) from the forms (where desert will always be required, as it is in the traditional free will-moral responsibility-desert paradigm).

However, on a deeper level, I think that contractualism as well is too external to the free will problem in order to be adequate as an explication of this problem. While contractualism can allow inherent importance to desert (in a way that utilitarianism cannot), it does not recognize pre-institutional desert; and, arguably, that is the proper demarcation line. Agreement, however morally important in other contexts, does not seem, in the end, to be the proper locus of concern in the free will problem. People who believe that free will matters greatly, whether compatibilist or incompatibilist, and whether we have it or not, believe that agency is inherently morally salient, in a way that does not depend on whether taking agency seriously is utility-maximizing, or would be chosen within some actual or hypothetical contracting situation. We still care about whether someone deserves blame, regardless of whether blaming him or her maximizes utility, and regardless of whether or not a contract is involved.

The basic intuition can be discerned already in the emerging biblical aversion to the idea of the "Sins of the father visiting upon the heads of the children": since the sons have no control over the actions of their fathers, it would be unjust to punish them for those actions. Concern over the free will problem as a fundamental moral conundrum follows from such an underlying evaluation, and cannot be reduced to what is a very different sort of concern; that is, the contractual concern with the fairness of arrangements that follow from agreements conducted under certain conditions.

\section{Reactive-Naturalism}

The philosophical debate on free will has focused on the first two questions of my fivefold division, namely, the one about the existence of libertarian free will and the compatibility question. As a result, primarily of P.F. Strawson's classic paper, "Freedom and resentment" (Strawson 2003 [originally 1961]) and subsequent discussions and developments (see Strawson 1987; McKenna and Russell 2008), my fifth question, of how we ought to deal with whatever we may come to believe on the free will problem, as distinct from the question of what - as philosophers-we ought to believe, is seen in its full salience. Strawson indeed seems to think that what he takes to be the inevitable stability of our reactions, and the practices that follow them, in a sense replaces the issue of truth. Hence his reply to my fourth question (whether the pertinent beliefs, attitudes and practices can change) makes concern over the fifth unnecessary - since not much if anything can be done, given that our emotions-based lives are not really under threat, there is no need to concern ourselves with what we ought to do.

But we can consider a variety of positions as forms of 'Reactive-naturalism,' (RN) and Strawson's "no need to worry" attitude can be distinguished from the more basic RN stance (that he also shares), which puts at the center of the debate our emotional, reactive lives, rather than our beliefs. Honderich's emphasis on the "affirmation" of the 
free will truths (Honderich 1988) involves a similarly 'emotive' tilt, without Strawson's conservatism. Russell (1995) also emphasizes the emotive aspects of agency and responsibility-attitudes, in a broadly Humean direction.

\section{Illusionism}

Illusionism on free will is the position according to which certain beliefs (primarily in libertarian free will) are false, but overall useful, so that we can see them as 'positive illusions.' While there are occasional historical references to such ideas (e.g., those of Nietzsche), it has not found systematic philosophical defenders until quite recently, in the work of Saul Smilansky (e.g., 2000, 2001, 2012). The value of illusion is defended in two ways: first, as a practical way to mediate the complexity of the insights of both compatibilism and hard determinism. In particular, Smilansky argues that false libertarian beliefs are the best way of dependably defending the compatibilist "Community of Responsibility," and that compatibilist beliefs, even if partly justified, could not in fact do the job. People would be unlikely to take seriously matters such as the importance of the concern over moral innocence, or to appreciate and respect themselves and others as a result of their efforts and deeds, if they began to think that people could not have strictly done otherwise than they have done, and that in fact all that they do is merely an "unfolding of the given," ultimately beyond their control. This would have direct practical implications. Second, beyond defending the partly valid compatibilist insights from the inclination to go all the way towards hard determinism, utilitarianism, or nihilism. Illusionism is seen as a vital defensive way of avoiding the deep true implications of an internalization of the absence of libertarian free will, in terms of the meaning of life, respect for persons, and moral justification.

One way of understanding illusionism that might be helpful, is as a development of P.F. Strawson's reactive-naturalism. Illusionism is based upon an acceptance of the Strawsonian emphasis upon the centrality of free will and moral responsibility in our lives, coupled with a rejection of Strawson's "no need to worry" reply to the fourth ("possibility of change") question, as complacent. Thus Illusionism recommends the maintenance of illusion on the fifth ("what to do") question (see Smilansky 2001).

\section{Other Views}

Beyond these six families of nonstandard views, a few other views need to be noted. One that is clearly nonstandard, and in a way that defies characterization in terms of the other families of views, is Tamler Sommers's metanormative relativism (2012). According to Sommers, there is no objective moral standard that allows us to criticize certain cultures which practice (say) collective punishment; and he does not care about individual agency and responsibility for the sake of 'just' punishment. Earlier, Richard Double (1991) has argued for an "anything goes" relativism as between free will positions (such as the compatibilist versus hard determinist interpretations).

Ben Vilhauer (2009) has argued that we can think of desert even under hard determinist views, grounding the desert in personhood rather than agency. He is skeptical about free will-based desert but thinks that desert can be kept on the basis of universal personhood.

Susan Wolf (1990) and Dana Nelkin (2011) have offered different 'asymmetrical' accounts, whereby attitudes toward praise and toward blame in the free will context 
ought to be completely different. If applied such views are likely to lead into 'nonstandard' territory in terms of the criteria I presented at the beginning of this chapter (e.g., rejecting the paradigmatic connection between free will and blame), and yet Wolf and Nelkin present their views as explications of compatibilism, that is (in my terminology), as coming under a 'standard' heading.

\section{Conclusion}

The contemporary debate on the free will problem is a curious combination of conservatism and innovation. On the one hand, nearly all of the debate goes on as it has done, traditionally, in the explication of three distinct views (libertarianism, compatibilism, hard determinism) and two traditional questions (the libertarianism/determinism question and the compatibility question). The explication of each view, and argumentation on the two standard questions, are highly sophisticated and innovative. Yet, at the same time, the standard positions and the standard two questions remain dominant in the debate.

When writing this I am aware that this picture may well become dated in the coming decades; it is a synopsis of the current situation. In fact, I hope that my discussion will help us to become more aware of the nonstandard questions and views. For, as I have argued here, within the standard framework there is in fact a richness of both questions and answers that are waiting to burst out, and to some extent have begun to do so since the 1960s. Some positions have received much attention (e.g., P.F. Strawson's), others have been noted in the debate but are still quite marginal (e.g., 'illusionism'), while others remain surprisingly 'under the radar' of contemporary philosophical (non-legal) discussion (e.g., 'contractualism').

A similar picture emerges within the recent flowering of 'experimental philosophy,' the attempt to understand empirically prevailing attitudes on free will and moral responsibility. Most of this literature is concerned with the standard questions, such as whether people believe in libertarian free will, or whether they are compatibilists or incompatibilists on free will, moral responsibility or punishment (for an excellent survey article, see Nichols and Knobe 2007). However, some experimental-philosophy work has focused upon the nonstandard questions and nonstandard views, as I have described them (see, for example, Nadelhoffer and Feltz 2007; Vohs and Schooler 2008).

There is reason to expect that the nonstandard questions and nonstandard views will both receive more attention in the future. To what extent they will themselves become, in time, 'standard' is a complex topic. In terms of philosophical 'fit,' I have above cast doubt on this concerning a number of the positions (e.g., utilitarianism), arguing that some nonstandard views are better seen as replacing rather than as being internal to the free will issue. It is also likely that further nonstandard positions will emerge. The actual nature of the future debate on free will is not something that can be predicted. In any case, the nonstandard questions and the nonstandard views will continue to enrich philosophical thought on the free will problem.

\section{Acknowledgments}

I am grateful to the editors for the invitation to contribute to this volume, and very grateful to Meghan Griffith, Zohar Idelson, Iddo Landau, and Daniel Statman, for helpful comments on drafts of the chapter. 


\section{Bibliography}

Cuypers, S. (2013) "Moral Shallowness, Metaphysical Megalomania, and Compatibilist-Fatalism," Ethical Theory and Moral Practice 16: 173-88.

Double, R. (1991) The Non-reality of Free Will. New York: Oxford University Press.

Feldman, F. (2004) "Freedom and Contextualism," in J. Campbell, M. O'Rourke, and D. Shier (eds), Freedom and Determinism. Cambridge: MIT Press, pp. 255-76.

Fischer, J. and Ravizza, M. (1998) Responsibility and Control. Cambridge: Cambridge University Press.

Gardner, J. (2007) Offences and Defences. Oxford: Oxford University Press.

Glover, J. (1983) "Self-creation," Proceedings of the British Academy 69: 445-71.

Hart. H.L.A. (1970) Punishment and Responsibility. Oxford: Clarendon Press.

Hawthorne, J. (2001) "Freedom in context," Philosophical Studies 104: 63-79.

Honderich, T. (1988) A Theory of Determinism. Oxford: Clarendon Press.

Honore, T. (1999) Responsibility and Fault. Oxford: Hart Publishing.

Klein, M. (1990) Determinism, Blameworthiness and Deprivation. Oxford: Oxford University Press.

Lenman, J. (2006) "Compatibilism and Contractualism: The Possibility of Moral Responsibility," Ethics, 117: 7-31.

Levy, N. (2011) Hard Luck. Oxford: Oxford University Press.

Levy, N. (2012) "Skepticism and sanction," Law and Philosophy 31: 477-93.

McKenna, M. and Russell, P. (eds) (2008) Free Will and Reactive Attitudes: Perspectives on P.F. Strawson's "Freedom and Resentment." Farnham: Ashgate.

Nadelhoffer, T. and Feltz, A. (2007) "Folk Intuitions, Slippery Slopes, and Necessary Fictions: An Essay on Saul Smilansky's Free Will Illusionism," Midwest Studies in Philosophy, 31: 202-13.

Nelkin, D. (2011) Making Sense of Freedom and Responsibility. New York: Oxford University Press.

Nichols, S. and Knobe, J. (2007) "Moral Responsibility and Determinism: The Cognitive Science of Folk Intuitions," Noûs 41: 663-85.

Pereboom, D. (2001) Living Without Free Will. Cambridge: Cambridge University Press.

Pereboom, D. (2014) Free Will, Agency and Meaning in Life. New York: Oxford University Press.

Rawls, J. (1971) A Theory of Justice. Cambridge: Harvard University Press.

Russell, P. (1995) Freedom and Moral Sentiments. New York: Oxford University Press.

Russell, P. (2013) “Compatibilist-Fatalism: Finitude, Pessimism, and the Limits of Free Will," in P. Russell and O. Deery (eds), The Philosophy of Free Will. Oxford: Oxford University Press, pp. 450-72.

Scanlon, T.M. (1988) "The Significance of Choice," in S.M. McMurrin (ed.), The Tanner Lectures on Human Values. Salt Lake City: University of Utah Press, pp. 149-216.

Scanlon, T.M. (2008) Moral Dimensions: Permissibility, Meaning, Blame. Cambridge: Harvard University Press.

Smart, J.J.C. (1961) "Free Will, Praise and Blame," Mind 70: 291-306.

Smilansky, S. (2000) Free Will and Illusion. Oxford: Oxford University Press.

Smilansky, S. (2001) "Free Will: From Nature to Illusion," Proceedings of the Aristotelian Society 101: $71-95$.

Smilansky, S. (2011) "Hard Determinism and Punishment: A Practical Reductio," Law and Philosophy 30: 353-67.

Smilansky, S. (2012) "Free Will and Moral Responsibility: the Trap, the Appreciation of Agency, and the Bubble," Journal of Ethics 16: 211-39.

Smilansky, S. (2013) "Free Will as a Case of 'Crazy ethics," in G.D. Caruso (ed.), Exploring the Illusion of Free Will and Moral Responsibility. Lanham: Lexington Books, pp. 103-120.

Sommers, T. (2007) "The Objective Attitude," Philosophical Quarterly 57: 321-41.

Sommers, T. (2012) Relative Justice. Princeton: Princeton University Press.

Strawson, P.F. (1987) Skepticism and Naturalism. London: Methuen.

Strawson, P.F. (2003) "Freedom and Resentment," in G. Watson (ed.), Free Will. Oxford: Oxford University Press, pp. 72-93.

Vargas, M. (2005) "The Revisionist's Guide to Moral Responsibility," Philosophical Studies 125: 399-429.

Vargas, M. (2013) Building Better Beings. Oxford: Oxford University Press.

Vilhauer, B. (2009) "Free Will Skepticism and Personhood as a Desert Base," Canadian Journal of Philosophy 39: 489-511.

Vohs, K. and Schooler, J. (2008) "The Value of Believing in Free Will: Encouraging a Belief in Determinism Increases Cheating," Psychological Science 19: 49-54. 


\section{SAUL SMILANSKY}

Waller, B. (1990) Freedom Without Responsibility. Philadelphia: Temple University Press.

Waller, B. (2011) Against Moral Responsibility. Cambridge: MIT Press.

Wolf, S. (1990) Freedom Within Reason. New York: Oxford University Press.

\section{Further Reading}

Feldman, F. (2004) "Freedom and Contextualism," in J. Campbell, M. O'Rourke, and D. Shier (eds), Freedom and Determinism. Cambridge: MIT Press, pp. 255-76. (Contextualism in the free will context.)

McKenna, M. and Russell, P. (eds.) (2008). Free Will and Reactive Attitudes: Perspectives on P.F. Strawson's "Freedom and Resentment." Farnham: Ashgate. (A collection of key papers on P.F. Strawson's views and those influenced by him.)

Pereboom, D. (2014). Free Will, Agency and Meaning in Life. New York: Oxford University Press. (A defense of 'happy hard determinism'.)

Russell, P. (2013) "Compatibilist-Fatalism: Finitude, Pessimism, and the Limits of Free Will," in P. Russell and O. Deery (eds), The Philosophy of Free Will. Oxford: Oxford University Press, pp. 450-72. (A complex view, broadly compatibilist but sensitive to the limitations of compatibilism.)

Scanlon, T.M. (1988) "The Significance of Choice," in S.M. McMurrin (ed.), The Tanner Lectures on Human Values. Salt Lake City: University of Utah Press, pp. 149-216. (An attempt to understand the free will problem in a broadly contractual way.)

Smilansky, S. (2000). Free Will and Illusion. Oxford: Oxford University Press. (A defense of a 'compatibilitydualism,' which combines compatibilism together with hard determinism, and of Illusionism on free will and moral responsibility.)

Strawson, P.F. (2003) "Freedom and Resentment," in G. Watson (ed.), Free Will. Oxford: Oxford University Press, pp. 72-93. (The classic paper, a defense of the broadly Humean 'no need to worry' stance about the free will problem.)

Vargas, M. (2013). Building Better Beings. Oxford: Oxford University Press. (A revisionist defense of compatibilism.)

Vohs, K. and Schooler, J. (2008) "The Value of Believing in Free Will: Encouraging a Belief in Determinism Increases Cheating," Psychological Science, 19: 49-54. (A key early study on the prospects of living without belief in libertarian free will.)

Waller, B. (2011) Against Moral Responsibility. Cambridge: MIT Press. (A defense of 'happy hard determinism' concerning moral responsibility.)

\section{Related Topics}

Free Will and Moral Sentiments: Strawsonian Views

Revisionism

Skeptical Views about Free Will

Folk Intuitions 


\section{Section II}

\section{MAJOR ARGUMENTS}

In his masterwork, An Essay Concerning Human Understanding, John Locke gives the example of a man who is carried into a room while asleep and then locked inside. When the man wakes, he finds that there is another person in the room. The man really wishes to converse with this person, so he wants to remain in the room. What are we to make of such a case? Locke suggests that the man stays in the room voluntarily, in spite of the fact that he is unable to leave. The example pushes us to clarify our intuitions about certain features of choice and freedom and is part of a long tradition of using thought experiments in this context.

In the twentieth century, Harry Frankfurt famously developed a similar scenario in order to challenge a common assumption about the connection between moral responsibility and alternatives (Fischer notes the structural similarities of the Lockean and Frankfurt cases in Fischer [2010]). Frankfurt's challenge constitutes a form of 'major argument' in the free will and responsibility realm. The major arguments of the free will debate involve attempts to defend or deny important principles or positions, rather than focusing on the details of, for example, what a compatibilist or incompatibilist version of free will should look like. Some of the major arguments use thought experiments, while others argue more directly for their conclusions via purportedly intuitive premises.

As indicated earlier, Frankfurt utilizes a thought experiment. He asks us to consider a circumstance in which there is a 'counterfactual intervener.' A counterfactual intervener is someone who is standing at the ready in order to force an unwitting agent to perform a particular action if intervention seems to be required-that is, if the agent were not going to perform the action otherwise. In the examples, we are asked to suppose that the agent performs the action on his own, and thus no actual intervention is required. Frankfurt argues that such cases work as counterexamples against the Principle of Alternate (or Alternative) Possibilities (PAP). PAP says that one is morally responsible (or free) only if one could have done otherwise. Intuitively, we have an agent who is responsible even though the presence of the intervener removes alternatives. There has been an enormous explosion of literature on such cases and the debate continues as to whether these examples disprove PAP. Carolina Sartorio discusses the intricacies of these cases in her entry.

But what is at stake if the Frankfurt examples succeed in disproving PAP? A number of philosophers suggest that getting rid of PAP eliminates a powerful argument for incompatibilism, paving the way for more effective compatibilist accounts of free will 
and/or responsibility. Without PAP, there is no worry about determinism as an eliminator of alternatives. Determinism may very well eliminate them, but who cares, if they are not needed anyway? But as Kevin Timpe discusses in his entry, there is still controversy about whether free will ought to be understood according to a leeway conception (requiring alternatives) or a sourcehood conception (according to which the agent must be the source of her action in the appropriate way). And even if the verdict comes down on the side of sourcehood, there is the further question as to whether determinism rules it out.

So the compatibilism/incompatibilism debate is far from over in virtue of resolving issues about PAP and Frankfurt examples. For example, some philosophers claim that one of the most important arguments for incompatibilism, the Consequence Argument, relies on "a different concept than the ability to do otherwise" (see Campbell, this volume, page 151). This argument was first put forward by Peter van Inwagen. If determinism is true, the past and the laws of nature fix all future events, including all of our choices and actions. Our choices/actions are consequences of the past and laws. Van Inwagen argues that the past and laws are not up to us, so then neither are the consequences of the past and laws (namely, our actions). In his entry, Joe Campbell discusses different treatments of this argument, along with compatibilist responses.

But if considerations about PAP and consequences fail to resolve the stalemate between compatibilists and incompatibilists, there are yet more avenues to pursue. For example, manipulation arguments are sometimes used to defend the incompatibility of determinism and free will. These arguments function by comparing manipulated agents to determined agents. To put it roughly, if manipulated agents are not free and there is no freedom-relevant difference between manipulated agents and determined agents, then determined agents are not free either. But as Kristin Mickelson points out, on some interpretations of manipulation arguments, what such arguments actually show, if successful, is that free will is impossible irrespective of determinism. They do this by highlighting concerns about "constitutive luck."

Luck of various kinds enters the free will debate at different points. Whereas constitutive luck raises concerns about our inability to create ourselves, luck of another sort plays a prominent role in exposing worries about action that is not determined. If a choice or action is the result of some sort of indeterministic process or event, many have argued that it is therefore at least partly a matter of luck that I chose to, say, stay at home rather than going out. As Christopher Franklin notes, this luck argument cuts across the compatibilism/incompatibilism divide because it creates a potential problem for anyone who thinks that undetermined choices can be free (many compatibilists want to say we are free whether our actions are determined or not).

As one can tell from an overview of these arguments, whether the past and laws (or causes) determine the future figures heavily in the literature. But causal or nomological determinism may not be the only potential threat to free will. There are also arguments for Logical Fatalism. Could it be, for instance, that bivalence (that every proposition is either true or false) entails that we cannot be free in the leeway sense? To put it roughly, if it is already true today that I will go on a hike tomorrow, does this mean that I cannot do otherwise than to hike tomorrow? Alicia Finch spells out the contours of the debate in her entry.

As the chapters in this section illustrate, the major arguments at work in the free will debate are nuanced, complex, and far from being the end of the story. The arguments 
and responses show the ingenuity, creativity, and rigor philosophers employ in order to further our understanding of free will and responsibility.

M.G.

\section{Acknowledgment}

Thanks to Kristin Mickelson for helpful comments on an earlier draft of this introduction.

\section{Reference}

Fischer, J. (2010) "The Frankfurt Cases: The Moral of the Stories," The Philosophical Review 119: 315-36. 
$\because$ Taylor \& Francis Taylor \& Francis Group http://taylorandfrancis.com 


\section{3 \\ THE CONSEQUENCE ARGUMENT \\ Joe Campbell}

\section{Introduction}

The phrase 'consequence argument' was first used by Peter van Inwagen as the name for the following informal line of reasoning:

If determinism is true, then our acts are the consequences of the laws of nature and events in the remote past. But it is not up to us what went on before we were born, and neither is it up to us what the laws of nature are. Therefore, the consequences of these things (including our present acts) are not up to us.

(van Inwagen 1983: 16; see also Fischer and

Pendergraft [2013: 575])

The classical convention is that the consequence argument is an argument for classical incompatibilism: if determinism is true, then no one is or ever was able to do otherwise. The classical convention is controversial since van Inwagen's informal argument is about what is or is not up to us, which is perhaps a different concept than the ability to do otherwise (cf. Carroll and Markosian 2010: Ch. 3). Nonetheless, I adopt the classical convention in this chapter, for it simplifies an already complex discussion.

Given the classical convention, the consequence argument is distinguished from other important arguments, such as the direct argument (van Inwagen 1980,1983), the ultimacy argument (Strawson 2010: Ch. 2), the manipulation argument (Pereboom 2001; Mele 2006), the control argument (Carroll and Markosian 2010: 63-4), and the new argument against compatibilism (Mumford and Anjum 2014). These arguments offer conclusions that are broader, narrower, or otherwise different from classical incompatibilism and they are not discussed further in this chapter.

This chapter covers contemporary versions of the consequence argument. Important examples include: Carl Ginet (1966, 1980, 1983, 1990), David Wiggins (1973), van Inwagen (1975, 1983, 1989, 2000), James Lamb (1977), John Martin Fischer (1983, 1994), N. M. L. Nathan (1984), David Widerker (1987), Timothy O'Connor (1993, 2000), Alicia Finch and Ted Warfield (1998), Michael Huemer (2000), Warfield (2000), John Carroll and Ned Markosian (2010), Andrew Bailey (2012), Finch (2013), and Alexander Pruss (2013). There is not enough space to talk about all of the above. Instead, I divide versions of the consequence argument into two types: transfer versions 
and extension versions (cf. Widerker 2014). I discuss representative examples of each type, respectively, below.

Contemporary formulations of the consequence argument hit their stride with the publication of van Inwagen's An Essay on Free Will (1983: Ch. III), where he presents three formal versions of the argument. Two of van Inwagen's arguments- the first (or main) argument (1975, 1983: 68-78) and the third argument (1983: 93-104; 1989: 404, 405) — are transfer versions of the consequence argument and are discussed shortly. The second argument $(1974,1983: 78-93)$ and other extension versions are examined later. At the end of the chapter, we consider the relationship between the two versions and whether they "stand or fall together" (Fischer and Ravizza 1996: 216).

\section{Transfer Versions of the Consequence Argument}

\section{The First Argument}

Transfer versions of the consequence argument incorporate grounding propositions and modal transfer principles, specifically no-choice transfer rules, in order to prove incompatibilism (cf. Campbell 2008, 2010, 2011). Grounding propositions are propositions that are claimed to be fixed, or practically necessary. A proposition is practically necessary provided that no human being has or ever had a choice about whether it is true (van Inwagen 1983; Kapitan 2002). In the context of transfer versions of the consequence argument, such propositions serve to ground our lack of choice. The past and the laws are fixed in the sense that they are beyond our control, things about which we have no choice.

Transfer versions of the consequence argument attempt to transfer the practical necessity of propositions about the past and the laws onto other propositions through the use of no-choice transfer rules. Here is a particular instance of a no-choice transfer rule: if we have no choice about propositions about the past or the laws and they entail propositions about the future, then we have no choice about propositions about the future. In order to appreciate the intuitive plausibility of no-choice transfer rules consider the thesis of determinism: "given the past and the laws of nature there is only one possible future" (van Inwagen 1983: 65). Supposing determinism, there is a transfer of truth: the truth of propositions about the past transfers onto propositions about the future via the laws of nature. It is reasonable to think that the practical necessity of the past and the laws might similarly transfer.

Transfer versions of the consequence argument take the form of a conditional proof and they have distinguishable parts, for example:

- The assumption of determinism

- Grounding propositions about the fixity of the past and the laws

- A no-choice transfer rule

The assumption of determinism cannot be denied since it is not an explicit premise of the consequence argument but an assumption for purposes of conditional proof. Thus, there are four types of reply to transfer versions of the consequence argument.

- Deny the fixity of past

- Deny the fixity of the laws 
- Deny the validity of a no-choice transfer rule

- Deny the validity of the consequence argument

We begin with van Inwagen's first argument. Then we explore examples of each of these four responses to the argument.

The first argument requires a setup. Suppose there is a judge, J, who needs to raise his hand at some time, $\mathrm{T}$, to prevent an execution. Suppose also that J refrains from raising his hand at $\mathrm{T}$. You may add whatever additional factors you deem important to J's free will: J is not bounded, injured, or suffering from paralysis; he is calm and takes the time to make a rational, deliberative choice; he is not under the influence of hypnosis, drugs, etc. In all respects, J is normal and his decision is rational (van Inwagen 1975: 190, 191).

Let ' $\mathrm{J}$ ' denote the judge, ' $T$ ' denote the time that he should have raised his hand, ' $T$ ' ' denote an instant prior to J's birth, ' $P_{0}$ ' denote the proposition that expresses the state of the world at $T_{0}$, 'P' denote the proposition that expresses the state of the world at $\mathrm{T}$, and ' $\mathrm{L}$ ' denote the conjunction of the laws. Here is the first argument:

(1) If determinism is true, then the conjunction of $P_{0}$ and $L$ entails $P$.

(2) If $\mathrm{J}$ had raised his hand at $\mathrm{T}$, then $\mathrm{P}$ would be false.

(3) If (2), then if J could have raised his hand at T, J could have rendered P false.

(4) If J could have rendered $P$ false, and if the conjunction of $P_{0}$ and $L$ entails $P$, then J could have rendered the conjunction of $P_{0}$ and $\mathrm{L}$ false.

(5) If $\mathrm{J}$ could have rendered the conjunction of $P_{0}$ and $\mathrm{L}$ false, then $\mathrm{J}$ could have rendered $L$ false.

(6) J could not have rendered L false.

(7) If determinism is true, J could not have raised his hand at T (1975: 191).

That is the first argument. Since there is nothing particular about the Judge's action, the argument can be generalized and classical incompatibilism appears to follow.

Let us consider versions of the different responses noted above. First, if time travel is possible, we can question the fixity of the past. Consider James Cole (Bruce Willis) in the film Twelve Monkeys. James is sent back to collect information about a previous biological catastrophe. Once there, he wants to alter history. Despite his efforts nothing ever changes, and that is what makes his story so tragic. James' actions seem fated, beyond his control. Conversely, why think that James can't do otherwise just because we know he won't do otherwise? James, presumably, cannot lose those capacities salient to free will merely by traveling in time. He was able to do otherwise prior to time traveling. Ergo, why suppose he does not retain those abilities while time traveling? The possibility of time travel gives us a reason to reject premise (5) since that premise assumes that our inability to change the past rests on our ability to do otherwise.

One way to make this view more plausible is to claim that the truth-conditions for sentences with terms such as 'can' and 'able' are relative to context (Lewis 1976; Campbell 2005). At one point in the film, James is convinced that he is not a time traveler. It is plausible to suggest that, in this context, utterances of the phrase "James could have done A," where A is some particular action that James does not perform, are true since James has what it takes and is not restricted in any obvious way. On the other hand, if we look at the situation from a God's-eye perspective, knowing that James does not do 
A, we might be inclined to judge differently. In this way, contextualism helps to provide a classical compatibilist solution to the consequence argument, since it is possible that one is able to do otherwise even if determinism is true. The fact that in some contexts James cannot do otherwise does not diminish the fact that in other contexts-even deterministic contexts- - he can do otherwise.

A second approach comes from adopting Humeanism, aka a weak view of laws of nature (Beebee and Mele 2002; Perry 2004). Just as the proponent of time travel questions the fixity of the past, the Humean questions the fixity of the laws. According to Humeanism, laws are true because of the events that occur. If things had gone differently, then the laws would have been different. This is contrasted with a strong view of laws, where "the truth of laws [is] established by something else, so that events conform to them because they are laws" and not vice versa (Perry 2004: 237). Proponents of Humeanism reject premise (6) of the first argument. The laws are what they are in part because I do what I do. If I had done otherwise, then the laws would have been different (Westphal 2003). Hence, the laws cannot ground my inability to do otherwise. Adopting Humeanism or the possibility of time travel is often met with an incredulous stare. Let us explore other options.

According to van Inwagen, premise (4) is supported by a more general rule:

(S) If $S$ can render $R$ false, and if $Q$ entails $R$, then $S$ can render $Q$ false $(1975,192)$.

(S) is equivalent to the following no-choice transfer rule:

- If $\mathrm{S}$ cannot render $\mathrm{Q}$ false, and if $\mathrm{Q}$ entails $\mathrm{R}$, then $\mathrm{S}$ cannot render $\mathrm{R}$ false.

Consider a slightly amended version of Perry's $(2004,247)$ counterexample to the validity of these principles. Let $\mathrm{R}$ be the proposition that Joe raises his hand at $\mathrm{t}$, where $t$ is some future time. Let $\mathrm{Q}$ be a conjunction: that Joe raises his hand at $\mathrm{t}$ and that Joe's mother ate a cookie in 1950. Note that Q includes $\mathrm{R}$ as one of its conjuncts. Thus, Q entails R. Suppose also that Joe's mother did not eat a cookie in 1950. Presumably, Joe can render $\mathrm{R}$ false by not raising his hand at $t$. $Q$ entails $R$ but Joe cannot render $Q$ false since $Q$ was rendered false by his mother in 1950. Unfortunately, van Inwagen restricts (S) so that it only ranges over true propositions $(1983,68)$. Hence, Perry's example is not really a counterexample to $(\mathrm{S})$.

David Hume (Russell 2014) and David Lewis (1986: ix) are classical compatibilists and Humeanists about laws of nature, though both offer responses to the consequence argument that do not directly depend on Humeanism. According to Lewis, for instance, the expression 'render a proposition false' is ambiguous. Intuitively, I am able to raise my hand, thereby rendering it true that my hand is raised; or I can leave my hand by my side, thereby rendering it false that my hand is raised. Lewis holds that I was able to render a proposition false in the strong sense if I was able to do something such that the proposition would have been falsified by my action or a consequence of my action; whereas, I was able to render a proposition false in the weak sense if "I was able to do something such that, if I did it, the proposition would have been falsified (though not necessarily either by my act, or by any event caused by my act)" (1981: 120). Given the weak sense of 'render false,' which Lewis favors, one should deny premise (6) but given the strong sense of 'render false' one should deny premise (5) (1981: 120). This response need not assume Humeanism about laws. 
To drive that last point home, consider Keith Lehrer's comments on the consequence argument (Lehrer 1980; Suster 2012). Let $S$ be a person, A an action, and $t$ a time. Lehrer writes:

"If S had done $A$ at $t$, then, of course, either the laws of nature would have been different or the state of the universe would have been different. But that is not to say that the person could have brought about these conditions."

(1980: 199)

Lehrer's response is not committed to Humeanism since it is a response that applies as much to the past as it does to the laws. The Lehrer/Lewis view recognizes that, given determinism, my actions are the consequence of the past and the laws. Nonetheless, I can do otherwise and my ability to do otherwise does not require the ability to render propositions about the past or the laws false in the strong sense. The weak sense of rendering a proposition false is not a causal power, so it is not the power to change the past or the laws, which would be miraculous (Holliday 2012, 186). The Lehrer/Lewis view is no more committed to Humeanism than it is to time travel. Lewis denies the validity of the first argument because it commits the fallacy of ambiguity. Therefore, even if the consequence argument is formally valid, it is still possible for the argument to be invalid do to linguistic maladies such as ambiguity.

\section{The Third Argument}

In the third argument, van Inwagen employs an $\mathrm{N}$-operator, where ' $\mathrm{Np}$ ' stands for " $\mathrm{p}$ and no one has, or ever had, any choice about whether $p$ " (1989: 404). (If one likes, she may substitute 'no human being' for 'no one,' though I don't think that is necessary). Given the classical convention, 'no one has, or ever had, any choice about whether p' means 'no one is able to act so as to ensure that p' (van Inwagen 1983: 67-8, fn. 31, 233-4; Finch and Warfield 1998; Crisp and Warfield 2000: 174, 181, 182).

Van Inwagen claims that according to the logic of the $\mathrm{N}$-operator the following two inference rules are valid:

$$
\begin{aligned}
& (\alpha) \square p \vdash \mathrm{N} p ; \\
& (\beta) \mathrm{N} p, \mathrm{~N}(p \supset q) \vdash \mathrm{N} q,
\end{aligned}
$$

where ' $\vdash$ ' represents the entailment relation, ' $\square p$ ' stands for ' $p$ is logically necessary' and ' $\supset$ ' designates the material implication relation (1983: 94, 1989: 227). Roughly, a proposition is logically necessary if and only if it is true in all logically possible worlds. According to principle $(\alpha)$, if something is logically necessary it follows that it is true and no one has or ever had a choice about whether it is true (cf. Kearns 2011 for possible counterexamples). For instance, given that it is logically necessary that it is raining or not it follows that it is true and no one has or ever had a choice about whether it is raining or not.

Rule $(\beta)$ is a no-choice transfer rule, a kind of modal modus ponens. Rule $(\beta)$ transfers the inability to ensure that a proposition is false onto other true propositions. If you have no choice about whether a proposition is true and you have no choice whether the proposition is true only if some other proposition is true, then you have no choice about 
whether the other proposition is true. Suppose that under the right conditions the sun always shines on the roof of your house. You have no choice about whether the conditions are right, and you have no choice about the connection between the right conditions and where the sun shines, so you have no choice about whether the sun shines on the roof of your house. Rule $(\beta)$ has some intuitive pull.

Principles $(\alpha)$ and $(\beta)$, together with reasonable assumptions about the past and the laws, suggest that if determinism is true, no one is or ever was able to ensure that any true proposition is false. Let $P_{0}$ be any true proposition about the remote past, a time "before there were any human beings" (van Inwagen 1989: 224; see Finch and Warfield 1998). $L$ and $P$ are the same as in the first argument, and ' $\&$ ' stands for the conjunction relation. Here is the third argument (1983: 93-104, 1989: 404, 405).
(1) $\square\left(\left(P_{0} \& L\right) \supset P\right)$
(2) $\square\left(P_{0} \supset(L \supset P)\right)$
(3) $\mathrm{N}\left(P_{0} \supset(L \supset P)\right)$
(4) $\mathrm{NP} P_{0}$
(5) $\mathrm{N}(L \supset P)$
(6) $\mathrm{NL}$
(7) NP

assumption of determinism

(1) by exportation

(2) by $(\alpha)$

fixity of the past

(3), (4) by ( $\beta$ )

fixity of the laws

(5), (6) by ( $\beta$ )

One might wonder about principle $(\beta)$. In fact, decisive counterexamples to principle ( $\beta$ ) have been offered (Widerker 1987; McKay and Johnson 1996).

In reply, McKay and Johnson suggest replacing the $\mathrm{N}$-operator with a weaker operator (1996; cf. Huemer 2000; van Inwagen 2000). Another response is to replace rule ( $\beta$ ) with a stronger principle (Widerker 1987; Finch and Warfield 1998; Huemer 2000):

$\left(\beta^{*}\right) \mathrm{N} p, p$ entails $q \vdash \mathrm{N} q$.

According to principle $\left(\beta^{*}\right)$, the $\mathrm{N}$-operator is closed under entailment. Thus, if no one has a choice whether a proposition is true, and that proposition entails another proposition, then no one has a choice whether the other proposition is true. There are no known counterexamples to principle $\left(\beta^{*}\right)$. Perry's counterexample to rule $(S)$ will not work since it rests on a false proposition.

Given the responses in the previous section, one might question the fixity of past, premise (4) of the third argument. There are two arguments for premise (4) (Campbell 2007).

(a) $\mathrm{NP}_{0}$ because "no one can change the past" (van Inwagen 1983: 92);

(b) $N P_{0}^{0}$ because $P_{0}$ is a true proposition about the remote past, a time "before there were any human beings" (van Inwagen 1989: 224).

Argument (a) depends on the fixity of the past alone whereas argument (b) depends on the fixity of the remote past.

Most defenses of $\mathrm{NP}_{0}$ start with argument (a): no one can change the past, therefore $N P_{0}$. One might argue: $P_{0}$ is true and no one has a choice about whether $P_{0}$ because 
there is nothing anyone can do to make $P_{0}$ false (cf. Pruss 2013: 431). Yet if $P_{0}$ serves to ground our lack of freedom, this argument is problematic. Let $p$ be the proposition that Joe's mother did not eat a cookie in 1950. Joe's mother has no choice about whether $p$ since there is nothing that she can do about it now. Yet it does not follow that Joe's mother never had a choice about whether p. Given that she was alive in 1950, there is no reason to think that she was unable to eat a cookie in 1950 (cf. Pruss 2013: 430).

Alexander Pruss defends a stronger claim, equivalent to $N\left(P_{0} \& L\right)$ : "it is implausible that there is something we can do such that were we to do it, the conjunction of laws and pre-human past wouldn't hold" (2013: 433). Like the first and third arguments, Pruss' argument requires "a statement of the complete state of the world in the prehuman past" (2013: 430) not just a statement about the past. As Jiji Zhang puts it: "In general, the nomological necessitation of a state by another stands against one's freedom with respect to the former only if the latter is not under one's control" (2013: 349). Thus, the need for argument (b).

In argument (b), it is essential that $P_{0}$ describe the state of the world at a time prior to the existence of human beings. The central claim is that no one has, or ever had, any choice about whether $P_{0}$, that is, about whether some proposition about the remote past is true. This is not a claim about the past in general. No one was around at $T_{0}$ to have had a choice about whether $P_{0}$. In argument $(\mathrm{b})$, it is not the pastness of the past that gives it its necessity. Rather it is the remoteness of past events, the fact that the past continues back to a time prior to human existence. As Carolina Sartorio (2015) expresses it, the real threat to our free will is about "factors beyond our causal reach." Leigh Vicens writes, in a different context, that the consequence argument hinges on the claim that "an action ultimately determined by factors outside of the actor's control is not free" (2012: 145; see also Pereboom 2014: fn. 1).

Consider the example of Oscillating Adam, who lives in a deterministic world where time is circular. There is no beginning or end to Adam's existence. He is in the grips of an everlasting, eternal recurrence. Adam spends his time growing 'older' and getting 'younger.' He begins each cycle with powers comparable to the average 25-year-old and eventually develops powers comparable to the average 50-year-old. Then he slowly regresses back to the state at which he began, and the cycle starts all over again (Campbell 2010). There is little reason to think that Oscillating Adam is impossible but the third argument does not show that he is unable to do otherwise, given determinism, for Oscillating Adam has no remote past. This example equally questions the first argument.

There are other counterexamples of this kind, as well. Original Adam assumes that Adam is cotemporaneous with a physical world that was created ex nihilo (Campbell 2007; cf. Brueckner 2008; Loss 2009). Infinite Adam assumes that Adam is cotemporaneous with an eternal universe (Finch 2013). The point is similar in each case. Unless it can be shown that these Adams are impossible, transfer versions of the consequence argument are not arguments for classical incompatibilism. This is the no past objection (Bailey 2012; Zhang 2013; C. Franklin, manuscript, "In Defense of the Consequence Argument: Reply to Campbell").

Given the no past objection, the consequence argument does not establish classical incompatibilism. At most, it supports a weaker thesis: determinism together with a contingent proposition about the actual world (e.g., persons have a remote past) entail that no one has free will (Warfield 2000; Campbell 2007; Pereboom 2014; Sartorio 2015; C. Franklin, manuscript, "In Defense of the Consequence Argument: Reply to Campbell"). 
Call this view weak incompatibilism, or if you prefer strong enough incompatibilism (thanks to Dan Speak). Either way, it is not the thesis of classical incompatibilism.

Here is a synopsis of the main results so far. There are two types of principles used in transfer versions of the consequence argument: grounding propositions, claims about the practical necessity of the past and the laws, as well as no-choice transfer rules, which transfer that necessity onto all other true propositions. Forgetting time travel and Humeanism, it is easy to establish the needed grounding propositions, given a remote past. Yet having a remote past is not an essential feature of deterministic worlds. Nonetheless, we only need to tweak the definition of 'incompatibilism' in order to save the consequence argument. Fair enough, but other philosophers find this approach ad hoc.

\section{Extension Versions}

\section{The Second Argument}

Extension versions of the consequence argument do not explicitly endorse no-choice transfer rules, though they may make assumptions about the fixity of the past and the laws (Zhang 2013: 351). Extension versions get their name because they favor extension principles (Haji 2009: 53) over no-choice transfer rules when clarifying the consequence argument. Van Inwagen writes: "it seems that our freedom can only be the freedom to add to the actual past; it seems that our freedom can only be the freedom to act in accordance with the laws of nature" (2000: 167). If determinism is true, then there can only be one "extension of the actual past, holding the laws fixed" (Fischer 1994: 88). Thus, no one can ever do otherwise.

In van Inwagen's second argument, abilities to do otherwise are understood in terms of having 'access' to certain possible worlds (1983: 86). Thus, "an unexercised ability is treated as an ability to realize some unrealized possibility" (1983: 86; cf. Zhang 2013, 351). Van Inwagen continues:

To say that a person can bring about an event satisfying a certain description is to say that he has access to at least one possible world in which an event satisfying that description happens.

To convey this, van Inwagen introduces a "non-temporal relation between persons and possible worlds" (1983: 89). 'Hxy' stands for "x had, has, or will have access, at some point in his life, to y" (1983: 90). According to van Inwagen:

$s$ has access to the set of worlds $x=\mathrm{df}$. $(\exists y)(y$ is true in just exactly those worlds that belong to $x$ and $s$ can render the denial of $y$ false) (cf. 1983: 90),

where $x$ and $y$ are variables ranging over possible worlds and propositions, respectively. This leads to the minimal free will thesis (MFT):

$$
(\exists x)(\exists y)(\text { Hxy \& y } \neq \text { A) (91), }
$$

where A is the actual world. According to MFT, an agent is able to do otherwise if and only if there is a non-actual possible world to which she has access. 
There are two main assumptions of the second argument.

MAA: $(x)(y)(H x y \supset$ SyA).

MAB: $(x)(y)(H x y \supset N y A)(92)$.

Van Inwagen writes: "MAA asserts that every world to which any person has access must be indistinguishable from the actual world at some instant" and "may be regarded as a statement of the familiar principle that no one can change the past" (1983: 92). In addition:

MAB asserts that no person has access to any world in which the laws of nature are different from what they are in the actual world. This seems undeniable, for, as we have seen, no one can render a law of nature false. Moreover, it is clear that it is not up to anyone whether any given true proposition is a law of nature.

(van Inwagen 1983: 92)

According to van Inwagen, free will skepticism is "derivable from DA [determinism], MAA, and MAB" (1983: 93). The conclusion is: "if determinism is true, then no one has access to any non-actual world" (1983: 93), and classical incompatibilism follows.

Does the second argument, like transfer versions, depend on the contingent assumption of a remote past? That is a difficult question. On the one hand, van Inwagen claims that MAA "may be regarded as a statement of the familiar principle that no one can change the past" (1983: 92). On the other hand, the argument does not incorporate a proposition like $P_{0}$ grounding our lack of power or ability in some proposition about the remote past. The argument appears to show that any agent, maybe even Oscillating Adam, is unable to do otherwise, for ultimately only the actual world is accessible given determinism. Let us return to this issue later.

\section{The Basic Argument and Other Extension Principles}

The basic argument (Fischer 1994: Ch. 5) is another non-transfer version that incorporates an extension principle: "an agent can do $X$ only if his doing $X$ can be an extension of the actual past, holding the laws fixed" (Fischer 1994: 88; cf. Haji 2009: 53). Here is Ish Haji's version of the basic argument:

Assume that determinism is true. Suppose Finn tosses a ball at $\mathrm{t} 2$. The state of the world at an earlier time, t1, and the laws entail that Finn tosses the ball at t 2 (assuming determinism). Holding fixed the laws, if determinism is true, there is only one extension of the past into the future, an extension that includes Finn's tossing the ball at t2. The Extension Principle entails that an agent can do something only if his doing it could be an extension of the actual past (holding fixed the laws). Thus, holding the natural laws fixed (and assuming determinism), it is false that Finn's refraining from tossing the ball at $\mathrm{t} 2$ could be an extension of the actual past. It follows that Finn cannot refrain from tossing the ball at t2.

(Haji 2009: 54)

Like the second argument, the basic argument does not make an explicit claim about the remote past yet classical incompatibilism seems to follow. 
In Ginet's most recent version of the consequence argument, aka Ginet's argument, 'Oxy' means 'it is open to $\mathrm{x}$ to act in such a way that had $x$ so acted, $x$ would have made it the case that $y$;' $b_{t}$ is "a true proposition entirely about what happened before $t$ " (1990: $102) ; a_{t}$ is "a proposition (true or false) as to what happens at or after $t$ " (1990: 102); 'Lp' means " $p$ is entailed by the laws of nature" (1990: 105). There are two key assumptions.

- The Principle of the Fixity of the Given Past (PFGP): For all $S, t, b_{t}$, and $p_{t}: \mathrm{O}_{S t} p_{t} \rightarrow \mathrm{O}_{S t}$ $\left(b_{t} \& p_{t}\right)(1990: 103)$.

- The Principle of the Inescapability of the Laws (PIL): Lp only if for all $S$ and $t: \sim \mathrm{O}_{S t} \sim p$ (1990: 105).

Taken together, PFGP and PIL comprise Ginet's extension principle: "freedom is freedom to add to the given past" (1990: 102, 103), which includes both propositions about the past and the laws.

Similarly, Warfield offers an extension principle in his new version of the consequence argument:

$$
\forall x \forall s(F s x \supset \diamond(H \& x))
$$

where ' $\forall$ ' represents the universal quantifier, ' $F s x^{\prime}$ ' stands for 's is free to make it the case that $x$,' and ' $H$ ' represents a conjunction of the state of the world at some time in the remote past together with the laws. Intuitively, if someone is free to do something, then that something is an extension of the past and the laws. Recent arguments by Bailey (2012) and Finch (2013) have adopted similar extension principles.

\section{Reply to Extension Versions}

There are important differences between transfer and extension versions of the consequence argument, so how do criticisms of the former relate to the latter, supposing they do relate? One might say that all versions of the consequence argument use transfer principles but whether or not this is so is discussed in more detail below. In the meantime, we can note some provisional points.

Extension principles make claims about the fixity of the past and the laws; some are more explicit than others. For instance, responses from proponents of time travel and Humeanism work as well on extension versions as they do on transfer versions. Granted, extension versions make no appeal to a remote past. Still, they are not immune to the no-past objection. As Jiji Zhang (2013) notes, van Inwagen signals the need for the assumption of a remote past in his second argument:

Every world to which any person has access must be indistinguishable from the actual world at some instant. Or, alternatively, every world to which any person has access must share a slice with the actual world. For example, however many possible worlds I have access to, surely they must all be indistinguishable from the actual world at some time in the remote past - say, 10,000 BC, or indeed, any time before I was born.

(van Inwagen 1983: 92; Zhang 2013: 351)

Bailey's argument and others are subject to this same critique (2012: 350, 351). 


\section{Meta-issues}

What is the relationship between the transfer and extension versions of the consequence argument? Do all versions of the consequence argument "stand or fall together" (Fischer and Ravizza 1996: 216)?

One thing to keep in mind is that there are two transfer proposals. According to the strong transfer proposal, all versions of the consequence argument are transfer versions and assume some no-choice transfer rule. According to the weak transfer proposal, all versions of the consequence argument assume some transfer rule, though not necessarily a no-choice transfer rule. Widerker (2014), for instance, distinguishes between unavoidability transfer principles-which we have been calling 'no-choice transfer rules'-and avoidability transfer principles. He claims that extension principles are avoidability transfer principles. Widerker accepts the weak transfer proposal but not the strong proposal.

Van Inwagen goes further than Widerker: "all (logically adequate) arguments for incompatibilism must make some sort of implicit or hidden or covert appeal to Beta" (1994: 95; see also 96), a no-choice transfer rule. Van Inwagen continues "there will be some premise or premises in any technically satisfactory argument for incompatibilism that the incompatibilist would have no reason to accept if he did not accept the validity of Beta" (1994: 98). This is an endorsement of the strong transfer proposal. Elsewhere, he adds: "if there were some fundamental mistake common to all three arguments, it would be at least likely to reveal itself in one of them, however well hidden it was in the others" (1983: 57).

In reply, Fischer and Ravizza offer the conditional version of the consequence argument, which "does not explicitly or implicitly rely on principle Beta" (1996: 214). They write:

The Conditional Version of the argument for incompatibilism proceeds, very roughly, as follows. Suppose that causal determinism is true. It follows that a statement describing the universe in the past, together with the conjunction of the laws, entails that you behave as you are now. Now one of the following conditionals must be true. (1) If you were to do otherwise now, then the universe would have been different in the past than it actually was; (2) If you were to do otherwise now, then the natural laws would be different from what they actually are; or (3) If you were to do otherwise now, then either the universe would have been different in the past than it actually was or the natural laws would be different from what they actually are. But given the fixity of the past, it is plausible to say that (I) if (1) were true, then you cannot do otherwise now. And given the fixity of the natural laws, it is plausible to say that (II) if (2) were true, then you cannot do otherwise now. And given the above, it is plausible to say that (III) if (3) were true, then you cannot do otherwise now. So (IV) you cannot do otherwise now.

(Fischer and Ravizza 1996: 214, 215)

Does the conditional version of the consequence argument require a no-choice transfer principle? Does it require an extension principle? I leave to the reader the exercise of determining the answer to these questions as well as the task of deciding whether the consequence argument is sound. 


\section{Bibliography}

Bailey, A. (2012) "Incompatibilism and the Past," Philosophy and Phenomenological Research 85: 351-76.

Baker, L. (2008) "The Irrelevance of the Consequence Argument," Analysis 68: 13-22.

Balaguer, M. (2010) Free Will as an Open Scientific Problem. Cambridge: MIT Press.

Beebee, H. and Mele, A. (2002) "Humean Compatibilism," Mind 111: 201-423.

Blum, A. (2000) “'N," Analysis 60: 284-6.

Blum, A. (2003) "The Core of the Consequence Argument," Dialectica 57: 423-9.

Borland, T. (2010) "Omniscience and Divine Foreknowledge," in J. Fieser and B. Dowden (eds), The Internet

Encyclopedia of Philosophy, available from: http://www.iep.utm.edu/omnisci/ (accessed 22 June 2016).

Brueckner, A. (2008) "Retooling the Consequence Argument," Analysis 68: 10-13.

Brueckner, A. and Buford, C. (2011) "Bailey on Incompatibilism and the 'No Past Objection'," Logos and Epistem 2: 613-17.

Campbell, J. (2005) "Comptatibilist Alternatives," Canadian Journal of Philosophy 35: 387-406.

Campbell, J. (2006) "Farewell to Direct Source Incompatibilism," Acta Analytica 21: 36-49.

Campbell, J. (2007) "Free Will and the Necessity of the Past," Analysis 67: 105-11.

Campbell, J. (2008) "Reply to Brueckner," Analysis 68: 264-9.

Campbell, J. (2010) "Incompatibilism and Fatalism: Reply to Loss," Analysis 70: 71-6.

Campbell, J. (2011) Free Will. Cambridge: Polity Press.

Campbell, J., O'Rourke, M., and Shier, D. (eds) (2004) Freedom and Determinism. Cambridge: MIT Press.

Carlson, E. (2000) "Incompatibilism and the Transfer of Power Necessity," Noûs 34: 277-90.

Carlson, E. (2003) "On a New Argument for Incompatibilism," Philosophia 31: 159-64.

Carroll, J. and Markosian, N. (2010) "Freedom and Determinism," in J. Carroll and N. Markosian, An Introduction to Metaphysics. Cambridge: Cambridge University Press, pp. 45-78.

Carroll, John W. (2014) A Time Travel Dialogue. Cambridge: Open Book Publishers.

Crisp, T. and Warfield, T. (2000) "The Irrelevance of Indeterministic Counterexamples to Principle Beta," Philosophy and Phenomenological Research 61: 177-84.

Finch, A. (2013) "On Behalf of the Consequence Argument: Time, Modality, and the Nature of Free Action," Philosophical Studies 163: 151-70.

Finch, A., and Warfield, T. (1998) "The Mind Argument and Libertarianism," Mind 107: 515-28.

Fischer, J. (1983) "Incompatibilism," Philosophical Studies 43: 127-37.

Fischer, J. (ed.) (1986) Moral Responsibility. Ithaca: Cornell University Press.

Fischer, J. (1989) "Introduction: God and Freedom," in J. Fischer (ed.), God, Foreknowledge, and Freedom. Stanford: Stanford University Press, pp. 1-56.

Fischer, J. (1994) The Metaphysics of Free Will: An Essay on Control. Oxford: Blackwell Publishers.

Fischer, J. (2004) "The Transfer of Nonresponsibility," in J. Campbell, M. O'Rourke, and D. Shier (eds), Freedom and Determinism. Cambridge: MIT Press, pp. 189-209.

Fischer, J. and Pendergraft, G. (2013) "Does the Consequence Argument Beg the Question?" Philosophical Studies 166: 575-95.

Fischer, J. and Ravizza, M. (1996) "Free Will and the Modal Principle," Philosophical Studies 83: 213-30.

Fischer, J. and Ravizza, M. (1998) Responsibility and Control: A Theory of Moral Responsibility. Cambridge: Cambridge University Press.

Frankfurt, H. (1969) "Alternate Possibilities and Moral Responsibility," The Journal of Philosophy 66: 828-39. Reprinted in Fischer (1986) and Pereboom (2009).

Garson, J. (2014) "Modal Logic," in E. Zalta (ed.), The Stanford Encyclopedia of Philosophy, available from: http://plato.stanford.edu/archives/sum2014/entries/logic-modal/ (accessed 22 June 2016).

Ginet, C. (1966) "Might We Have No Choice?" in K. Lehrer (ed.), Freedom and Determinism. New York: Random House, pp. 87-104.

Ginet, C. (1980) "The Conditional Analysis of Freedom," in P. van Inwagen (ed.), Time and Cause: Essays Presented to Richard Taylor. Dordrecht: D. Reidel, pp. 171-86.

Ginet, C. (1983) "In Defense of Incompatibilism," Philosophical Studies 43: 391-400.

Ginet, C. (1990) On Action. Cambridge: Cambridge University Press.

Haji, I. (2009) Incompatibilism's Allure: Principle Arguments for Incompatibilism. Peterborough: Broadview Press.

Hetherington, S. (2006) "So-far Incompatibilism and the So-far Consequence Argument," Grazer Philosophische Studien 73: 163-78.

Hill, C. (1992) "Van Inwagen on the Consequence Argument," Analysis 52: 49-55. 
Hobart, R.E. (1934) “Free Will as Involving Determination and Inconceivable Without It,” Mind 43: 1-27.

Hoefer, C. (2010) "Causal Determinism," in E. Zalta (ed.), The Stanford Encyclopedia of Philosophy (Spring 2010 Edition), available from: http://plato.stanford.edu/archives/spr2010/entries/determinism-causal/ (accessed 22 June 2016).

Holliday, W. (2012) "Freedom and the Fixity of the Past," The Philosophical Review 121: 179-207.

Horgan, T. (1985) "Compatibilism and the Consequence Argument," Philosophical Studies 47: 339-56.

Huemer, M. (2000) "Van Inwagen's Consequence Argument," The Philosophical Review 109: 525-44.

Kane, R. (ed.) (2002) The Oxford Handbook of Free Will. Oxford: Oxford University Press.

Kane, R. (ed.) (2011) The Oxford Handbook of Free Will, 2nd edn. Oxford: Oxford University Press.

Kapitan, T. (2002) “A Master Argument for Incompatibilism?" in R. Kane (ed.), The Oxford Handbook of Free Will, 1st edn. New York: Oxford University Press, pp. 127-57.

Kearns, S. (2011) "Responsibility for Necessities," Philosophical Studies 155: 307-24.

Lamb, J. (1977) "On a Proof of Incompatibilism," The Philosophical Review 86: 20-35.

Lehrer, K. (1980) "Preferences, Conditionals and Freedom,” in P. van Inwagen (ed.), Time and Cause: Essays Presented to Richard Taylor. Dordrecht: D. Reidel, pp. 187-201.

Lewis, D. (1976) "The Paradoxes of Time Travel," American Philosophical Quarterly 13: 145-52.

Lewis, D. (1981) “Are We Free to Break the Laws?” Theoria 47: 113-21. Reprinted in Lewis (1986).

Lewis, D. (1986) Philosophical Papers, Vol. II. Oxford: Oxford University Press.

Loss, R. (2009) "Free Will and the Necessity of the Present," Analysis 69: 63-9.

Loss, R. (2010) "Fatalism and the Necessity of the Present: Reply to Campbell," Analysis 70: 76-8.

McKay, T. and Johnson, D. (1996) “A Reconsideration of an Argument Against Compatibilism," Philosophical Topics 24: 113-22.

McKenna, M. (2008) “A Hard-line Rely to Pereboom's Four-Case Manipulation Argument,” Philosophy and Phenomenological Research 77: 142-59.

McKenna, M. (2009) "Compatibilism," in E. Zalta (ed.), The Stanford Encyclopedia of Philosophy (Winter 2009 Edition), available from: http://plato.stanford.edu/archives/win2009/entries/compatibilism/ (accessed 22 June 2016).

Mele, A. (2006) Free Will and Luck. New York: Oxford University Press.

Mumford, S. and Anjum, R.L. (2014) “A New Argument Against Compatibilism,” Analysis 74: $20-5$.

Nathan, N.M.L. (1984) “A New Incompatibilism,” Mind 93: 39-55.

Nelkin, D. (2001) "The Consequence Argument and the Mind Argument," Analysis 61: 107-15.

Nelkin, D. (2011) Making Sense of Freedom and Responsibility. Oxford: Oxford University Press.

Nelkin, D. and Rickless, S. (2002) "Warfield's New Argument for Incompatibilism," Analysis 62: 104-7.

O'Connor, T. (1993) "On the Transfer of Necessity," Noûs 27: 204-18.

O'Connor, T. (ed.) (1995) Agents, Causes, and Events: Essays on Indeterminism and Free Will. Oxford: Oxford University Press.

O'Connor, T. (2000) Persons and Causes. Oxford: Oxford University Press.

Pereboom, D. (1994) "Determinism al Dente," Noûs 29: 21-45. Reprinted in Pereboom (2009).

Pereboom, D. (ed.) (1997) Free Will. Indianapolis: Hackett Publishing Company.

Pereboom, D. (2001) Living Without Free Will. Cambridge: Cambridge University Press.

Pereboom, D. (2008) "A Hard-Line Reply to the Multiple-Case Manipulation Argument," Philosophy and Phenomenological Research 77: 160-70.

Pereboom, D. (ed.) (2009) Free Will, 2nd edn. Indianapolis: Hackett Publishing Company.

Pereboom, D. (2014) Free Will, Agency, and Meaning in Life. Oxford: Oxford University Press.

Perry, J. (2004) "Compatibilist Options," in J. Campbell, M. O'Rourke, and D. Shier (eds), Freedom and Determinism. Cambridge: MIT Press, pp. 231-54.

Prior, A. (1967) Past, Present and Future. Oxford: Clarendon Press.

Pruss, A. (2013) "Incompatibilism Proved," Canadian Journal of Philosophy 43: 430-7.

Ravizza, M. (1994) "Semi-Compatibilism and the Transfer of Non-Responsibility," Philosophical Studies 75 : 61-93.

Russell, P. (2014) "Hume on Free Will," in E. Zalta (ed.), The Stanford Encyclopedia of Philosophy (Winter 2014 Edition), available from: http://plato.stanford.edu/archives/win2014/entries/hume-freewill/ (accessed 22 June 2016).

Sartorio, C. (2015) "The Problem of Determinism and Free Will is not the Problem of Determinism and Free Will,” in A. Mele (ed.), Surrounding Free Will. Oxford: Oxford University Press, pp. 255-73.

Sehon, S. (2011). "A Flawed Conception of Determinism in the Consequence Argument," Analysis 71: $30-8$. 


\section{JOE CAMPBELL}

Slote, M. (1982) "Selective Necessity and the Free-Will Problem," The Journal of Philosophy 79: 5-24.

Speak, D. (2011) "The Consequence Argument Revisited," in R. Kane (ed.), The Oxford Handbook of Free Will, 2nd edn. New York: Oxford University Press, pp. 115-30.

Strawson, G. (2010) Freedom and Belief, revised edition. Oxford: Oxford University Press.

Suster, D. (2012) "Lehrer and the Consequence Argument," Philosophical Studies 161: 77-86.

Taylor, C. and Dennett, D. (2002) "Who's Afraid of Determinism? Rethinking Causes and Possibilities," R. Kane (ed.), The Oxford Handbook of Free Will, 1st edn. New York: Oxford University Press, pp 257-77.

van Inwagen, P. (1974) "A Formal Approach to the Problem of Free Will and Determinism," Theoria: A Swedish Journal of Philosophy 40: 9-22.

van Inwagen, P. (1975) "The Incompatibility of Free Will and Determinism," Philosophical Studies 27: 185-99. Reprinted in Pereboom (2009).

van Inwagen, P. (1980) "The Incompatibility of Responsibility and Determinism," Bowling Green Studies in Applied Philosophy 2: 30-7. Reprinted in Fischer (1986).

van Inwagen, P. (1983) An Essay on Free Will. Oxford: Clarendon Press.

van Inwagen, P. (1989) "When is the Will Free?" Philosophical Perspectives 3: 399-422. Reprinted in O'Connor (1995: 219-38).

van Inwagen, P. (1994) "When the Will is Not Free," Philosophical Studies 75: 95-113.

van Inwagen, P. (2000) "Free Will Remains a Mystery," Philosophical Perspectives 14: 1-19. Reprinted in Kane (2002).

van Inwagen, P. (2013) “A Dialogue on Free Will,” Methode 2: 212-21.

Vicens, L. (2012) "Divine Determinism, Human Freedom, and the Consequence Argument," International Journal for the Philosophy of Religion 71: 145-55.

Vihvelin, K. (2011) “Arguments for Incompatibilism," in E. Zalta (ed.), The Stanford Encyclopedia of Philosophy (Spring 2011 Edition), available from: http://plato.stanford.edu/archives/spr2011/entries/incompatibilismarguments/ (accessed 22 June 2016).

Vihvelin, K. (2013) Causes, Laws, and Free Will. Oxford: Oxford University Press.

Warfield, T. (1996) "Determinism and Moral Responsibility are Incompatible," Philosophical Topics 24: 215-26.

Warfield, T. (2000) "Causal Determinism and Human Freedom are Incompatible: A New Argument for Incompatibilism," Philosophical Perspectives 14: 167-80.

Warfield, T. (2003) "Compatibilism and Incompatibilism: Some Arguments," in M.J. Loux and D.W. Zimmerman (eds), The Oxford Handbook of Metaphysics. Oxford: Oxford University Press, pp. 613-30.

Westphal, J. (2003) "A New Way with the Consequence Argument, and the Fixity of the Laws," Analysis 63: 208-12.

Westphal, J. (2012) “Is There a Modal Fallacy in van Inwagen's 'First Formal Argument'?" Analysis 72: 36-41.

Widerker, D. (1987) "On an Argument for Incompatibilism," Analysis 47: 37-41.

Widerker, D. (2002) "Farewell to the Direct Argument," The Journal of Philosophy 99: 316-24.

Widerker, D. (2014) "The Consequence Argument: Exciting News," Flickers of Freedom blog, available from: http://philosophycommons.typepad.com/flickers_of_freedom/2014/06/the-consequence-argument-excitingnews/comments/page/1/\#comments (accessed 22 June 2016).

Wiggins, D. (1973) "Towards a Reasonable Libertarianism," in T. Honderich (ed.), Essays on Freedom of Action. London: Routledge and Kegan Paul, pp. 31-62.

Zhang, J. (2013) "Can the Incompatibilist Get Past the No Past Objection?" dialectica 67: 345-52.

\section{Further Reading}

Fischer, J. (1994) The Metaphysics of Free Will: An Essay on Control. Oxford: Blackwell Publishers.

Haji, I. (2009) Incompatibilism's Allure: Principle Arguments for Incompatibilism. Peterborough: Broadview Press. (Fischer's basic argument is another influential version of the argument. It is discussed by Haji in detail together with related arguments.)

Pruss, A. (2013) "Incompatibilism Proved," Canadian Journal of Philosophy 43: 430-7. (This is the best and most recent formal version of the consequence argument.)

van Inwagen, P. (1983) An Essay on Free Will. Oxford: Clarendon Press. (The best place to start is with van Inwagen's seminal book, which inspired most subsequent versions of the consequence argument.) 
Zhang, J. (2013) "Can the Incompatibilist Get Past the No Past Objection?" dialectica 67: 345-52. (Zhang extends my criticism of the first and third versions of the consequence argument onto the second version and, thus, Fischer's basic argument.)

\title{
Related Topics
}

\author{
Semicompatibilism \\ Classical Compatibilism \\ Dispositional Compatibilism \\ Logical Fatalism \\ The Luck and Mind Arguments \\ Leeway vs. Sourcehood Conceptions of Free Will \\ Free Will and Theological Fatalism \\ Free Will and Theological Determinism \\ Determinism \\ Free Will and Time Travel
}




\section{4 \\ THE MANIPULATION ARGUMENT \\ Kristin Mickelson}

The Manipulation Argument has recently taken center stage in the free-will debate, yet little else can be said of this newcomer that is uncontroversial. At present, even the most fundamental elements of the Manipulation Argument-its structure, conclusion, and target audience-are a matter of dispute. As such, we cannot begin, as we ideally would, with a simple and relatively uncontroversial overview of the argument. Instead, clarifying the debate over the basic structure and general conclusion of the Manipulation Argument will be our goal.

In most discussions, the Manipulation Argument is understood as a formal template for an argument; each instance of the template is a distinct manipulation argument. The details of individual manipulation arguments greatly vary, but each proceeds something like this:

Imagine that mischievous neuroscientists have developed technology which allows them to covertly invoke any mental states they like in their chosen victim, 'Vic.' The neuroscientists have grown tired of Vic's wife, so they press a series of buttons which cause Vic to undergo a process of reasoning which ends with his decision to kill her. Since there is nothing standing in Vic's way, he carries out the plan. Now, a question: Is Vic free and morally responsible for killing his wife? It certainly seems not: although Vic's decision to kill his wife is the causal product of his own inner states, these states are ultimately under the causal control of the neuroscientists. As such, Vic seems no more free-and, so, no more morally responsible - than a marionette. But, assuming that the laws of nature are deterministic, it seems that we, too, are mere marionettes: each of us is bound by 'causal strings' to facts in the distant past over which we had no control. Being subject to deterministic causal laws, then, is no different than being subject to freedom-undermining manipulation.

Because manipulation arguments typically compare scenarios involving freedom-undermining manipulation to scenarios involving deterministic laws of nature (where a realist view of the laws is tacitly assumed), it seems that such arguments indicate that there is an antagonistic metaphysical relationship between free action and deterministic laws. As such, the Manipulation Argument was originally considered a new way-and perhaps the best way (Taylor 1963: 45; Pereboom 2001: 89; McKenna 2010: 440)—-to argue for the incompatibilist view that deterministic laws undermine free will. 
However, recent work suggests that classifying the Manipulation Argument as an argument about the incompatibility of free will and deterministic laws may obscure the logic and lessons of its best instances. While all manipulation arguments target the view that it is possible for a normal human to act freely in a deterministic universe, the question of whether a properly fleshed out manipulation argument tells us something morelike why it is impossible for a human to act freely in a deterministic universe-has given rise to substantive debates about how to best understand these arguments. For example, Kristin Mickelson (2015b) and Neil Levy (2011) deny that manipulation arguments teach us that deterministic natural laws pose a threat to free will; instead, they propose that manipulation arguments support the conclusion that free action is impossible tout court due to the insurmountable problem of constitutive luck (this position is described in 'The Explanation Step' below). On this 'constitutive luck' interpretation, manipulation arguments challenge every view that is committed to the metaphysical possibility of free action, including free-will libertarianism (discussed in Ekstrom [Chapter 6], Griffith [Chapter 7], McCann [Chapter 8], this volume). At the very least, then, the standard classification of the Manipulation Argument as an 'argument for incompatibilism' misleadingly implies that there is a consensus regarding the challenges that manipulation arguments pose and to whom.

The dispute over the proper conclusion of the Manipulation Argument stems largely from the disagreement over the answer to one key question: must a successful instance of the Manipulation Argument explain why no one can act freely in a deterministic universe-and, if so, what is this explanation? Competing answers to this question give rise to rival views about how best to summarize the Manipulation Argument as a formal template, how that template is best fleshed out, and what conclusion its best instance(s) support. This chapter provides an introduction to the Manipulation Argument through a discussion of the most fundamental disagreements about its formal structure.

\section{The Structure of Manipulation Arguments}

Contemporary interest in manipulation arguments is largely a response to Derk Pereboom's Four-case Argument $(1995,2001,2014)$, the revitalization of an earlier manipulation argument from Richard Taylor $(1963: 45,46)$. Each of these manipulation arguments has three discrete steps: (i) Counterexample; (ii) Generalization; and (iii) Explanation. Each step provides the foundation for the conclusions drawn in subsequent steps. Roughly, the initial Counterexample Step concludes that philosophers have not yet identified a set of necessary and jointly sufficient conditions for free action according to which it is possible for a normal human person to act freely in a deterministic universe; the Generalization Step concludes (minimally) that there is in principle no such set; and the Explanation Step provides a freedom-denying explanation for why this is so. Let us look at each step in turn, using Pereboom's Four-case Argument as our example.

\section{The Counterexample Step}

The Four-case Argument begins with a story of Professor Plum, hereafter 'Plum1,' who is manipulated by neuroscientists to kill Ms. White:

\section{Case 1}

Professor Plum was created by neuroscientists, who can manipulate him directly through the use of radio-like technology, but he is as much like an ordinary 
human being as is possible, given this history. Suppose these neuroscientists "locally" manipulate him to undertake the process of reasoning by which his desires are brought about and modified-directly producing his every state from moment to moment.

(Pereboom 2001: 113)

Pereboom expects the intuitive judgement of Case 1-at least among members of the dialectically appropriate target audience (Mele 2008; Pereboom 2008; McKenna 2014) — will be that Plum1 is not free or morally responsible for killing Ms. White. Let us call this a 'victim judgment.' Yet, claims Pereboom, Plum1 satisfies all freedom-neutral metaphysical conditions on basic agency as well as the epistemic conditions on moral responsibility (2001: 111). As such, if Plum1 lacks moral responsibility, it is presumably because he lacks free will (understood roughly as the set of metaphysical, as opposed to epistemic, control conditions on moral responsibility). For this reason, the Four-case Argument-and every manipulation argument-is generally considered an argument about free will, even though it trades in intuitions about moral responsibility.

Pereboom contends that Plum1 satisfies all of the necessary conditions for free action hitherto proposed by advocates of the view that it is metaphysically possible for a normal human living in a deterministic universe to perform a free action. In defense of this claim, Pereboom provides a review of the most prominent of these conditions and contends that Plum1 satisfies each: (i) constancy of character; (ii) lack of constraint by irresistible desire; (iii) proper conformity of first-order and second-order desires; (iv) the capacity to regulate one's behavior based upon a moderately reasonsresponsive deliberation process; and (v) the capacity to understand and regulate one's behavior based on moral reasons (Pereboom 2001: 100-110; 2014: 75). Assuming that Plum1 satisfies each of these conditions and yet Plum1 is not free or morally responsible for killing Ms. White, Case 1 reveals that these proposed necessary conditions are not jointly sufficient for free agency. Pereboom's Counterexample Step concludes that, even according to the intuitive judgments of the target audience, philosophers have yet to provide a set of necessary and jointly sufficient conditions for free action that can be satisfied by an ordinary human living in a universe with deterministic laws.

In order to properly understand the conclusion of the Counterexample Step and the remainder of the Four-case Argument, it is essential to recognize that Pereboom states his argument in terms of "human beings." While manipulation arguments can be understood as a strategy for teasing out which properties are relevant to our acting freely, Pereboom's argument seems to rest upon a substantive (and controversial) assumption about the nature of normal human beings. Prior to laying out the Four-case Argument in Living Without Free Will, Pereboom explicitly argues against the view that humans are agent causes, roughly the sort of agents who have a primitive "causal power to choose without being determined by events beyond the agent's control, and without the choice being a truly random or partially random event" (2001: 55). Pereboom argues that such agent causation is not "compatible with the physical world's being governed by exceptionless physical laws" (2001: 85), regardless of whether those laws are deterministic or indeterministic. Rather, Pereboom continues, it seems that agent causes would have to "override" such laws in order to act freely, but there is no evidence humans can do this (2001: 86; for alternative views on agent causation, see Griffith: Chapter 7, this volume). So, while Pereboom is sympathetic to the view that "overriding" agent causation is metaphysically possible and that such agents could perform a free action, he presents his 
Four-case Argument against the background assumption that humans are not such agent causes; we humans are subject to-unable to override, trump, break, change, or otherwise perform a miracle relative to- the laws of nature.

Abstracting from the details of the Four-case Argument, we may summarize the Counterexample Step in less anthropocentric terms. The Counterexample Step is designed to elicit the intuitive judgment-a victim judgment- that the victim in the manipulation story lacks freedom and moral responsibility. It is expected that this victim judgment will be sufficiently strong and clear that, in effect, those who have it must accept that it provides a data point which any viable theory of free will must accommodate. However, the victim purportedly satisfies all hitherto proposed analyses of free will according to which it is possible for someone (human or not) who is subject to the laws of nature to act freely in a universe with deterministic laws. Assuming that the victim in the story satisfies these purportedly necessary conditions for free action and yet the manipulation story elicits a victim judgment, it seems that the Counterexample Step challenges the adequacy of all hitherto proposed analyses of free will according to which it is possible for someone (human or not) who is subject to the laws of nature to act freely in a universe with deterministic laws.

Because much of the basic vocabulary of the free-will debate is ambiguous (Mickelson 2015a), let us introduce terminology that will allow us to achieve the level of precision required for our discussion. Say that compossibilism is the view that it is metaphysically possible for someone to perform a free action in a universe with deterministic laws, and incompossibilism is the negation of compossibilism (Mickelson 2015b). Then say compossibilism* is the narrower view that it is metaphysically possible for someone who is subject to deterministic laws to perform a free action, and its negation is incompossibilism*. Roughly, then, the Counterexample Step concludes that there is currently no adequate compossibilism*-friendly analysis of the concept free will.

A final point about the language of the Counterexample Step will illuminate the significance of drawing a distinction between compossibilism* and compossibilism. The Four-case Argument-like most manipulation arguments-is stated in terms of causal determination and deterministic physical laws rather than the thesis of determinism. This is significant. Determinism is, roughly, the thesis that due to the past and the laws of nature, there is exactly one physically possible future (cf. van Inwagen 1983: 65). Given this definition of 'determinism,' and a realist view of the laws (a standard assumption in this context), it follows from the assumption that determinism is true that nothingnot even God-can make the future diverge from the one that is fixed by the natural laws (cf. Sehon 2011). In other words, if determinism is true, then everything that exists is subject to the laws of nature. As such, it would be impossible for an overriding agent cause (of the sort that Pereboom describes) to act freely when determinism is true. However, it is an open question whether miracles relative to the laws of nature are metaphysically possible. Indeed, Pereboom accepts that it is possible for something to violate (override, trump, break) deterministic natural laws in his defense of overriding agent causation. Assuming that it is possible for an overriding agent cause to perform a free action in a universe with deterministic laws, compossibilism is true. That is, Pereboom is sympathetic to compossibilism, and he does not argue that Case 1 is a counterexample to this view. By describing Plum1 as roughly an "ordinary human being" against the background assumption that humans are subject to the laws of nature, Pereboom narrows the target of his Counterexample Step from all extant compossibilism-friendly analyses of free will to contemporary accounts of compossibilism*. 


\section{The Generalization Step}

In the Generalization Step of the Four-case Argument, Pereboom uses the victim judgment elicited in the Counterexample Step to motivate a generalization argument. This generalization argument is (following McKenna 2004) most commonly summarized as follows:

1. Victim Premise. Plum1 lacks freedom and moral responsibility for killing Ms. White.

2. No-difference Premise. There is no freedom-relevant or responsibility-relevant difference between Plum1's killing Ms. White and any action performed by a normal human living in a universe at which the laws of nature are deterministic (i.e., a deterministic universe).

3. Conclusion. So, no normal human living in a deterministic universe ever performs a free action.

The sole support for the Victim Premise is the victim judgment elicited in the Counterexample Step. So, assuming that the initial Counterexample Step is successful, the proponent of a manipulation argument need not offer any additional support for the Victim Premise.

The main support for the No-difference Premise comes in the form of a No-difference Defense. This No-difference Defense proceeds by transforming the initial covert manipulation case "in perfectly realistic ways, so as to coincide with actual and familiar cases" (Taylor 1963: 45, 46). This procedure results in a series of 'bridge' cases that span between a manipulation case on one end and a 'normal' case on the other. Each new bridge case is created by removing some apparently freedom-relevant feature $F$ that is present in previous cases of the series. The new case (without $F$ ) is then compared to early cases in the series, and it is argued that there is no freedom-relevant difference between the new case and the original manipulation case. The conclusion is then drawn that $F$ is not a freedom-relevant difference after all. The goal of this process is to eliminate all of the apparent freedom-relevant differences between the manipulation scenario and the normal scenario, thereby supporting the claim that the protagonist in each scenario of the series has the same status with respect to free agency.

Pereboom's No-difference Defense of Premise 2 begins with bridge cases Case 2 and Case 3. The actions of Plum in Case 2, hereafter 'Plum2,' are indirectly controlled by the neuroscientists through covert programing:

Plum is like an ordinary human being, except that he was created by neuroscientists who, although they cannot control him directly, have programmed him to weigh reasons for action so that he is often but not exclusively egoistic, with the result that in the circumstances in which he now finds himself, he is causally determined to undertake the [process of reasoning that results in his killing Ms. White].

(Pereboom 2001: 113, 114)

Pereboom expects that Case 2 will elicit the same intuitive reaction as Case 1 -namely, the victim judgment that Plum2 does not act freely or morally responsibly when he kills Ms. White. Indeed, Pereboom proposes that Case 2 could serve as the foundational counterexample story should Case 1 fail—say, for example, because Plum1 fails 
the necessary conditions of agency (Fischer and Ravizza 1998: 234, 235, n. 28; Mele 2005: 78; Baker 2006: 320; Demetriou 2010). According to Pereboom, Case 2 allows us to see that eliminating the moment-by-moment causal control exerted by the neuroscientists in Case 1 does not transform Plum into a free and responsible agent, so this feature of Case 1 is not freedom-undermining. Next, Pereboom describes Case 3, a near-normal situation in which overbearing parents impose rigorous training on young Plum. Finally, Pereboom argues there is no principled difference between the Plums in the first three cases and Case 4, a case in which Plum ('Plum4') is a perfectly normal human being who is born into a deterministic universe. As such, the No-difference Defense shows that anyone who denies that Plum1 is a free and responsible agent must, on the pain of inconsistency, make the same judgment of Plum4.

There is no magical number of bridge cases that a No-difference Defense must have, and new bridge cases may be added as needed to meet new objections. For instance, after laying out his initial four cases, Pereboom offers a few more-which favors the Four-case Argument's alternative name, the "Multiple-case Argument" (Pereboom 2008). Among others, Pereboom forwards a case in which Plum's states are spontaneously induced by a machine rather than by external agents. This bridge case is designed to forestall the specific proposal that having one's states induced by another agent or intelligent designer is a freedom-relevant feature difference between Case 1 and Case 4 (Pereboom 2001: 114-16). Additional cases and supplemental argument might be added to address any other proposed freedom-relevant difference between Plum1 and Plum4 (e.g., McKenna 2008: 152, 153). If Pereboom is right that there is no freedom- or responsibility-relevant difference between these Plums, then either all of the Plums are free and morally responsible for killing Ms. White or none of them is; the No-difference Premise is true.

The conclusion of Pereboom's generalization argument is restricted to humans who are living in a deterministic universe, where humans are assumed to be among the class of metaphysically possible beings who are subject to the causal laws. However, Pereboom's proposed generalization argument technically leaves open the question of whether being subject to deterministic laws and/or living in a deterministic universe are freedom-relevant features of the cases. In principle, Pereboom's No-difference Defense could be expanded to eliminate the qualifications that appear in his preferred statement of the No-difference Premise. This expanded argument would result in a stronger instance of the No-difference Premise and the resulting manipulation argument would reach a bolder conclusion. For example, working along such lines, Mele forwards Case 2a (as part of a critique of the Four-case Argument) in which Plum2's deterministic programming is replaced with an indeterministic version:

It [the program in Case 2a] works just like the program in case 2 except that there is a tiny chance every few seconds that the program will incapacitate Plum. As it happens, Plum is not incapacitated. If Plum is not morally responsible for the killing in case 2, he is not morally responsible for it in case 2a either. Surely, blending this possibility of incapacitation into case 2 does not transform it from a case of non-responsibility into one of responsibility. Here again that the causation in Pereboom's case is deterministic is not essential to Plum's lacking moral responsibility for the killing. 
Mele proposes that, intuitively, adding indeterministic causation into the scenario does not "transform" an unfree agent into a free one. Assuming that Mele is right-pace event-causal libertarians such as Robert Kane (1996) — that adding indeterministic causation does not help Plum to have free will, Case 2a casts doubt on Pereboom's proposal that deterministic causation in the original scenario positively hurts. The addition of Case 2a to Pereboom's original series of cases shows how one might develop a No-difference Defense that rules out the deterministic causation as a freedom-undermining feature in Pereboom's original four cases. If deterministic causation is not a freedom-relevant feature of the cases, then Pereboom's inclusion of this constraint arbitrarily limits the No-difference Premise's scope and, by extension, the ultimate conclusion of the Generalization Step. This means that the 'lives in a deterministic universe' constraint can, and perhaps should, be eliminated from both Pereboom's No-difference Premise and the conclusion of his generalization argument.

Assuming that deterministic laws (qua being deterministic) do not pose a threat to free will, perhaps the problem is being subject to causal laws (irrespective of whether those laws are deterministic or probabilistic). A manipulation argument could be developed to test this proposal. For example, one might offer a bridge case describing an actor-such as Pereboom's law-trumping agent cause-who is not subject to the laws of nature. Using this case, one could develop a No-difference Defense of the conclusion that (pace Pereboom) being subject to the causal laws is not a freedom-relevant property. Continuing along such lines, one might argue that there is no freedom-relevant difference between the manipulation victim and someone who satisfies the necessary and sufficient conditions of being an agent cause (King 2013: 72).

In principle, a No-difference Defense might be used to address every purportedly freedom-relevant feature of the original manipulation case, thereby eliminating all constraints from Pereboom's original No-difference Premise. The resulting No-difference Premise would state that there is no freedom-relevant difference between the manipulation victim and any metaphysically possible being (including God) in any metaphysically possible conditions (e.g., whether the laws are indeterministic or non-existent). By extension, the resulting generalization argument would be an argument for unqualified free-will impossibilism, the view that free action is metaphysically impossible. Such a manipulation argument would constitute a challenge to all compossibilist and libertarian views alike.

In summary, the conclusion of the Generalization Step may vary widely, depending on how the No-difference Defense is fleshed out. However, this flexibility in the structure and conclusion of manipulation arguments is not captured by the standard formal summary of the Pereboom's generalization argument. It seems, then, that Pereboom's proposed generalization argument is better understood as an instance of a more generic template that proceeds something like this:

\section{The Generalization Argument Template}

1. Victim Premise. The victim V (in the initial manipulation case) is not free or responsible for performing action $A$.

2. Generalization Premise. If (and only if) $V$ is not free or responsible for performing $A$, then no B-type being living in C-type conditions performs a free action for which he is also morally responsible.

3. Conclusion. No B-type being living in C-type conditions performs a free action for which he is also morally responsible. 
Notably, the Generalization Argument Template (hereafter, the 'Generalization Argument') does not have a 'No-difference' premise. This is because the biconditional Generalization Premise more explicitly captures the key inference of the Generalization Step. An instance of the Generalization Premise is, minimally, supported by a No-difference Defense and the assumption that like cases should be treated alike (McKenna 2012: 150). Since every instance of the Generalization Argument is valid, the only remaining question is whether, given the details of a specific manipulation story, any instance has true premises.

Given that the details of the foundational manipulation story are critical to the success of both the Counterexample and Generalization Steps, it is worth noting that some prominent manipulation cases have limited potential when understood as manipulation arguments. For instance, Mele's Ann/Beth cases (Mele 1995: 145, 146, 2006: 164-7) and McKenna's Suzie Instant/Suzie Normal cases (McKenna 2004: 180, 181, 2012:160-6) are primarily used to mediate an in-house debate among historical and ahistorical compossibilists*. The victims in these manipulation stories do not satisfy any history-sensitive conditions on free will, for example, Mele's "bypass" condition (Mele 1995). However, they do seem to satisfy all hitherto proposed ahistorical necessary conditions on free action, such as Harry Frankfurt's requirement of a proper alignment between one's first-order and second-order desires (Frankfurt 1971). As such, these manipulation cases may constitute counterexamples to extant ahistorical analyses of free will, but not to their history-sensitive rivals. So, while there is no in-principle reason that such cases cannot be used in a manipulation argument (McKenna 2012: 169), proponents of history-sensitive compossibilism* are well-positioned to reject any such manipulation argument both on the grounds that such stories do not constitute counterexamples to their preferred history-sensitive analyses of free will and that there is a freedom-relevant difference that blocks the generalization from the manipulation scenario to normal deterministic scenarios.

\section{The Explanation Step}

Most formal summaries of the Four-case Argument characterize it as a mere combination of the Counterexample and Generalization Steps, but these two steps do not fully capture Pereboom's original argument. Pereboom—like Taylor before him (1963: 46) — argues that the protagonist in each of his cases lacks freedom and responsibility because the decision to kill is an "alien-deterministic event," that is, a decision "produced by a deterministic process that traces back to causal factors beyond [the actor's] control" (Pereboom 2001: 126). As Pereboom develops his manipulation argument, then, it is an argument for incompatibilism, understood roughly as the thesis that necessarily, if someone is subject to deterministic causal laws then that person lacks free will (at least in part) because she is subject to deterministic laws (McKenna 2010: 432; Levy 2011; Mickelson 2015a). Indeed, Pereboom contends that the Four-case Argument concludes specifically to causal-history or source incompatibilism, an explanatory subtype of incompatibilism according to which causal determination is a threat to free will because it prevents one from being the freedom-relevant source of his own actions (Pereboom 1995; McKenna 2000; King 2013: 79). However, the logical form of the Generalization Argument guarantees that every instance has a negative non-explanatory conclusion, such as incompossibilism* or impossibilism; no instance concludes with the positive identification of a freedom-undermining feature that is present in both the manipulation case and the end case. Since the Counterexample and Generalization Steps alone 
cannot capture the conclusion of the Four-case Argument, Pereboom's argument is not adequately represented by these steps alone.

Pereboom upgrades his Four-case Argument from an argument for mere incompossibilism* to an argument for incompatibilism by adding a best-explanation argument. According to Pereboom the best explanation for Plum's lack of free agency in Case 1 through Case 4 is that the Plum in each case is subject to deterministic causation and this prevents him from being the freedom-relevant source of his actions laws (2001: 112-15). Pereboom sets the stage for this best-explanation argument in the Generalization Step, where he uses a No-difference Defense to rule out anticipated but (purportedly) unviable explanations for Plum1's lack of free agency. However, it is not until the Explanation Step of the Four-case Argument that Pereboom finally completes the positive task of identifying deterministic causation as the freedom-undermining feature that is present in both the initial manipulation case and the normal end case.

Although Pereboom develops the Four-case Argument as an argument for source incompatibilism and manipulation arguments are commonly thought to be homing in on sourcehood requirements for free action, there is growing disagreement about whether manipulation arguments favor a specifically incompatibilist notion of sourcehood. As noted above, it is in principle possible to develop an instance of the Generalization Argument that concludes to impossibilism. Assuming that the goal of the Explanation Step is to provide the best explanation for the impossibility of free will, one might argue-as some have (Levy 2011: 86-9; King 2013: 78; Mickelson $2015 \mathrm{~b}$ ) - that the lack of free action in the manipulation and normal scenarios is due to a pernicious sourcehood problem known as constitutive luck. Following Thomas Nagel (1979), Levy describes constitutive luck as "luck in the traits and dispositions that make one the kind of person one is" (Levy 2011: 29). With his "Basic Argument," Galen Strawson famously argues that constitutive luck poses an insurmountable threat to free will (cf. Strawson 1986: 28-9). According to Strawson, free action requires "a starting point in the series of acts of [intentionally] bringing it about that one has a certain nature-a starting point that constitutes an act of ultimate self-origination" (Strawson 2011). Only a causa sui (a being who self-creates ex nihilo) would satisfy Strawson's stringent starting-point condition; anyone who does not satisfy this starting-point condition suffers from freedom-undermining constitutive luck. However, assuming that such robust self-creation is metaphysically impossible, it follows that there is no possible agent who ever satisfies this starting-point condition. Whether the laws are deterministic or indeterministic is irrelevant to the fact that no actor is a causa sui at any given time at which that actor exists, so the constitutive-luck explanation seems to imply that the laws of nature are totally irrelevant to the fact that no one ever performs a free action. This demonstrates that proponents of the constitutive-luck explanation may agree with Pereboom that each of the Plums has a freedom-undermining sourcehood problem and yet deny that it is metaphysically possible for deterministic laws to play a role in undermining free will (even in the modest sense that such laws prevent people from overcoming constitutive luck). In other words, if the constitutive-luck diagnosis is correct, then impossibilism is true, but incompatibilism - in virtue of its mistaken explanatory thesis-is false.

Whatever specific freedom-undermining feature is ultimately identified in the Explanation Step, the proposed diagnosis seems to clarify and reaffirm the conclusions drawn in earlier steps of the manipulation argument in at least three ways. First, the diagnosis forwarded in the Explanation Step of a manipulation argument illuminates the scope of 
the conclusion of the Generalization Step. As discussed above, there is no in-principle reason that an instance of the Generalization Argument must conclude to a restricted thesis such as incompossibilism* rather than to incompossibilism or the completely unrestricted thesis of impossibilism. As such, any limitations on the scope of an instance of the Generalization Premise and, by extension, the conclusion of an instance of the Generalization Argument seem arbitrary in the absence of a diagnosis of the freedomundermining feature that is common to all cases. For example, only by proposing that deterministic laws undermine the free will of anyone who is subject to them does Pereboom illuminate why his generalization argument concludes to incompossibilism* rather than to some less restricted thesis. Second, a best-explanation argument adds positive support for a proposed instance of the Generalization Premise by identifying the freedom-undermining feature that is (purportedly) present in both the initial manipulation case and normal end case. Finally, it seems that the Explanation Step may bolster the Counterexample Step. The central purpose of the Explanation Step is to identify the specific freedom-undermining feature $F$ that is present in each of the cases, from the initial manipulation case to the normal end case. As such, the proposed explanation for the victims' lack of freedom and responsibility suggests a second best-explanation argument, this one aimed at explaining the intuitive judgement that the manipulation victim lacks free will: the best explanation for one's victim judgment is that it is a response to $F$. As such, the proposed explanation seems to sanction a key methodological background assumption of the Counterexample Step, namely that the victim judgment is a rational response to some freedom-undermining feature of the initial manipulation case —an assumption that has not been immune to criticism (e.g., McKenna 2008: 157; Spitzley 2015). Of course, it is ultimately an empirical question why a particular manipulation case elicits a particular intuition from a particular person, and it is far from obvious that every feature tracked by a victim judgment (even if that judgment is correct and its source can be identified) is metaphysically relevant to free will.

\section{Non-diagnostic Manipulation Arguments}

While the Explanation Step provides a diagnosis that both answers pressing philosophical questions and nicely rounds out the overall manipulation argument, not everyone agrees that manipulation arguments require an Explanation Step (Mele 2008: 278; Pereboom 2014: 79, 80, n. 3; Mickelson 2015b). Since the purpose of the Explanation Step is to give a positive diagnosis of someone's lack of freedom and moral responsibility, let us classify manipulation arguments that flesh out the Explanation Step as 'diagnostic' arguments and those that do not as 'non-diagnostic.' A closer look at Alfred Mele's Zygote Argument, the most prominent non-diagnostic manipulation argument in the current literature, will help us to decide whether the benefits of dropping the Explanation Step are outweighed by the costs.

Mele begins the Zygote Argument with a story that is, in its basic metaphysical details, similar to Pereboom's Case 2:

\section{The Zygote Case}

Diana creates a zygote $Z$ in Mary. She combines Z's atoms as she does because she wants a certain event $\mathrm{E}$ to occur 30 years later. From her knowledge of the state of the universe just prior to her creating $\mathrm{Z}$ and the laws of nature of her 
deterministic universe, she deduces that a zygote with precisely Z's constitution located in Mary will develop into an ideally self-controlled agent who, in 30 years, will judge, on the basis of rational deliberation, that it is best to $A$ and will $A$ on the basis of that judgment, thereby bringing about $\mathrm{E}$. If this agent, Ernie, has any unsheddable values at the time, they play no role in motivating his A-ing. Thirty years later, Ernie is a mentally healthy, ideally self-controlled person who regularly exercises his powers of self-control and has no relevant compelled or coercively produced attitudes. Furthermore, his beliefs are conducive to informed deliberation about all matters that concern him, and he is a reliable deliberator.

(Mele 2006: 188, 2013: 175, 176)

Mele proceeds under the assumption that the Zygote Story will elicit (in at least some members of its target audience) the intuition that Ernie lacks freedom and moral responsibility for A-ing. This intuition provides support for Premise 1 of the Zygote Argument, which proceeds as follows:

\section{ZAM}

1. Ernie is not a free agent and is not morally responsible for anything.

2. Concerning free action and moral responsibility of the beings into whom the zygotes develop, there is no significant difference between the way Ernie's zygote comes to exist and the way any normal human zygote comes to exist in a deterministic universe.

3. So in no possible deterministic world in which a human being develops from a normal human zygote is that human being morally responsible for anything he or she does.

(Mele 2013: 176, my emphasis)

With this generalization argument, Mele's version of the Zygote Argument comes to an end; there is no crowning Explanation Step.

Mele recognizes that the Zygote Argument and the Four-case Argument have a different formal structure. According to Mele, premise 2 of ZAM is a negative "no-difference" claim while the second premise of the Four-case Argument is a positive best-explanation claim (2008). However, Mele describes both of these manipulation arguments as ending with roughly the same conclusion. Overall, Mele's description gives the impression that each of these arguments is best understood as an instance of the Generalization Argument, where the main formal difference between the two is the way they support their respective generalization premises: the Four-case Argument includes positive support in the form of a best-explanation argument, but the Zygote Argument does not. So framed, the best-explanation argument in the Four-case Argument seems superfluous, for a No-difference Defense provides adequate support for the key generalization inference. This framing leads Mele to suggest that one "fallback" position open to proponents of the Four-case Argument is to drop its best-explanation argument (Mele 2008: 278). The main benefit of adopting this fallback position is that the resulting version of the Fourcase Argument would be immune to criticisms targeting its best-explanation argument (Mele 2008: 276-8). However, the proposed fallback position also comes at a cost: to drop the best-explanation argument is to forsake the Four-Case Argument's original, explanatory conclusion that deterministic causation poses a threat to free will. 
To make the cost of dropping the Explanation Step still clearer, consider the difference between the conclusion of ZAM and the conclusion of the Generalization Step of the Four-case Argument: the Four-case Argument concludes to the modest thesis of incompossibilism*, but ZAM's final conclusion is more modest still. ZAM's conclusion is restricted to the narrow subset of metaphysically possible beings that are human, developed from a normal human zygote, and who live in a universe with deterministic laws. But is the property of being human or having developed from a normal human zygote a freedomrelevant feature of a person? Or, more generally, is having a first moment of existence relevant to free action (Campbell 2007; Bailey 2012)? How about whether an agent is able to break or override causal laws? Do deterministic laws preclude freedom-relevant sourcehood-or is the only genuine threat to free action constitutive luck? A nondiagnostic manipulation argument such as ZAM, does not—and cannot-answer any of these historically popular and philosophically pressing questions.

\section{Conclusion}

Summing up, there is presently no uncontentious formal characterization of the Manipulation Argument. Minimally, it seems that the Manipulation Argument outlines a persuasive argument for a version of the non-explanatory thesis that necessarily, no one who is subject to the laws can act freely in a deterministic universe. However, it remains unsettled whether the Manipulation Argument is also essentially an argument for some positive, explanatory thesis-and, if so, whether this thesis is incompatibilism, as the first manipulation arguments suggest, or some other explanatory view, as the newer constitutive-luck variants suggest. Still, the Manipulation Argument has been instrumental in exposing the explanatory gap between views such as incompossibilism and incompatibilism, and it provides an excellent framework for future discussions on whether and how best to close it. Such contributions make the Manipulation Argument worthy of its pride of place in the contemporary free-will debate and indicate that the argument will continue to bear fruit for many years to come.

\section{Bibliography}

Bailey, A. (2012) "Incompatibilism and the Past," Philosophy and Phenomenological Research 85: 351-76.

Baker, L. (2006) "Moral Responsibility without Libertarianism," Nô̂s 40: 307-30.

Campbell, J. (2007) "Free Will and the Necessity of the Past," Analysis 67: 105-11.

Demetriou, K. (see also K. Mickelson) (2010) "The Soft-Line Solution to Pereboom's Four-case Argument," Australasian Journal of Philosophy 88: 595-617.

Fischer, J. and Ravizza, M. (1998) Responsibility and Control: A Theory of Moral Responsibility. Cambridge: Cambridge University Press.

Frankfurt, H. (1971) "Freedom of the Will and the Concept of a Person," Journal of Philosophy 68: 5-20.

Kane, R. (1996) The Significance of Free Will. Oxford: Oxford University Press.

King, M. (2013) "The Problem with Manipulation," Ethics 124: 65-83.

Levy, N. (2011) Hard Luck: How Luck Undermines Free Will and Moral Responsibility. New York: Oxford University Press.

McKenna, M. (2000) "Source Incompatibilism, Ultimacy, and the Transfer of Non-responsibility," American Philosophical Quarterly 38: 37-51.

McKenna, M. (2004) "Responsibility and Globally Manipulated Agents," Philosophical Topics 32: 169-92.

McKenna, M. (2008) "A Hard-Line Reply to Pereboom's Four-Case Argument," Philosophy and Phenomenological Research 77: 142-59.

McKenna, M. (2010) "Whose Argumentative Burden, Which Incompatibilist Arguments? - Getting the Dialectic Right," Australasian Journal of Philosophy 88: 429-43. 


\section{KRISTIN MICKELSON}

McKenna, M. (2012) "Moral Responsibility, Manipulation Arguments, and History: Assessing the Resilience of Nonhistorical Compatibilism," Journal of Ethics 16: 145-74.

McKenna, M. (2014) "Resisting the Manipulation Argument: A Hard-Liner Takes It on the Chin," Philosophy and Phenomenological Research 89: 467-84.

Mele, A. (1995) Autonomous Agents. New York: Oxford University Press.

Mele, A. (2005) “A Critique of Pereboom's 'Four-Case Argument' for Incompatibilism,” Analysis 65: 75-80.

Mele, A. (2006) Free Will and Luck. New York: Oxford University Press.

Mele, A. (2008) "Manipulation, and moral responsibility," Journal of Ethics 12: 263-86.

Mele, A. (2013) "Manipulation, Moral Responsibility, and Bullet Biting," Journal of Ethics 17: 167-84.

Mickelson, K. (2015a) “A critique of Vihvelin's Threefold Classification,” Canadian Journal of Philosophy, 45: 85-99.

Mickelson, K. (see also K. Demetriou) (2015b) "The Zygote Argument is Invalid-Now What?" Philosophical Studies 172: 2911-29.

Nagel, T. (1979) "Moral luck," in Mortal Questions, New York: Cambridge University Press, pp. $24-38$.

Pereboom, D. (1995) "Determinism al Dente," Nô̂s 29: 21-45.

Pereboom, D. (2001) Living Without Free Will. Cambridge: Cambridge University Press.

Pereboom, D. (2008) "A Hard-Line Reply to the Multiple-Case Manipulation Argument," Philosophy and Phenomenological Research 77: 160-70.

Pereboom, D. (2014) Free Will, Agency, and Meaning in Life. Oxford: Oxford University Press.

Sehon, S. (2011) "A Flawed Conception of Determinism in the Consequence Argument," Analysis 71: 30-8.

Spitzley, J. (2015) "The Importance of Correctly Explaining Intuitions: Why Pereboom's Four-Case Manipulation Argument is Manipulative," Journal of Cognition and Neuroethics 3(1): 363-82.

Sripada, C. (2012) "What Makes a Manipulated Agent Unfree?" Philosophy and Phenomenological Research 85: 563-93.

Strawson, G. (1986) Freedom and Belief. Oxford: Clarendon Press.

Strawson, G. (2011) "Free Will” in E. Craig (ed.), Routledge Encyclopedia of Philosophy, London: Routledge, available from: www.rep.routledge.com/articles/free-will/v-2/, DOI:10.4324/9780415249126-V014-2 (accessed 10 July 2016).

Taylor, R. (1963) Metaphysics. Engelwood Cliffs: Prentice-Hall, Inc.

van Inwagen, P. (1983) An Essay on Free Will. New York: Oxford University Press/Clarendon Press.

\section{Further Reading}

For an excellent overview of the literature, see D. Pereboom's "A Manipulation Argument against Compatibilism," in Free Will, Agency, and Meaning in Life (2014: Chapter 4). Replies to the Manipulation Argument are often classified based on the premises of the Generalization Argument: a 'hard-line' reply rejects the Victim Premise while a 'soft-line' reply rejects the Generalization Premise. For an introduction to such replies, see M. McKenna (2012, 2014); D. Pereboom (2008); Fischer, J.M. (2011) “The Zygote Argument remixed," Analysis 71: 267-72; K. Demetriou (2010); Haji, I. and Cuypers, S. (2006) "Hard- and Soft-Line Responses to Pereboom's Four-Case Manipulation Argument," Acta Analytica 21: 19-35. For replies targeting the Explanation Step, see Mickelson (2015b) and Mele (2005). For alternative response strategies, see Kearns, S. (2012) "Aborting the Zygote Argument," Philosophical Studies 160: 379-89; Todd, P. (2011) "A New Approach to Manipulation Arguments," Philosophical Studies 152: 127-33; King (2013); Tognazzini, N. (2014) "The Structure of a Manipulation Argument," Ethics 124: 358-69. For a synopsis of relevant experimental philosophy, see (esp. Section 9.4) of G. Björnsson and D. Pereboom's "Traditional and Experimental Approaches to Free Will and Moral Responsibility," in J. Sytsma and W. Buckwalter (eds), A Companion to Experimental Philosophy (2016).

\section{Related Topics}

Skeptical Views about Free Will

The Consequence Argument

Leeway vs. Sourcehood Conceptions of Free Will

Folk Intuitions

Free Will and Theological Fatalism

Free Will and Providence

Determinism 


\section{5 \\ FRANKFURT-STYLE EXAMPLES \\ Carolina Sartorio}

\section{Introduction}

We tend to think of ourselves as free and morally responsible agents. But what does acting freely (in the relevant sense) involve? According to the traditional view of freedom, it requires having the ability to select from a number of alternative possibilities that are open to us at different points in our lives. This idea is captured by the Principle of Alternative Possibilities:

PAP: An agent acts freely (in a way that is relevant to his moral responsibility) only if he could have done otherwise (or had the ability to do otherwise).

There was a time when almost everyone believed in this principle. Incompatibilists argued that, if determinism is true, we never have the ability to do otherwise, and so determinism is incompatible with freedom and responsibility; compatibilists argued that determinism is compatible with having the ability to do otherwise, in the relevant sense, and so it is compatible with freedom and responsibility.

Harry Frankfurt's paper "Alternate Possibilities and Moral Responsibility" (Frankfurt 1969) radically changed the shape of the debate between compatibilists and incompatibilists. It argued against PAP, and thus against the traditional view of freedom. (Frankfurt's main concern was moral responsibility, but his argument can easily be reformulated in terms of the type of freedom that is relevant to responsibility, so this is how I will understand it here). Frankfurt's argument appealed to some hypothetical scenarios that have since then been called Frankfurt-style examples. Frankfurt-style examples have been the focus of much lively discussion in recent years, and the debate continues, as lively as ever, to this date.

Here, I'll focus on different aspects of the debate over Frankfurt-style examples, with a particular emphasis on the most recent developments, as well as on some issues that are still quite underexplored in the literature and that are likely to receive more attention in future years.

\section{Frankfurt's Original Examples}

Frankfurt argued that, although PAP seems initially plausible, its plausibility is a mere illusion. This illusion, he argued, can be explained away once a conceptual distinction 
is made between two types of factors: (i) the factors that make an act by an agent inevitable, or that make it the case that the agent lacks the ability to do otherwise, and (ii) the factors that actually explain the agent's act. I'll refer to factors of the first kind as 'inevitability factors' and to factors of the second kind as 'explanatory factors.'

Frankfurt argued that the reason PAP has seemed initially plausible is that we naturally tend to conflate the two kinds of factors. When we think about scenarios where an agent lacks the ability to do otherwise, we naturally think of scenarios where the inevitability factors (those by virtue of which he cannot do otherwise on that occasion) are also the explanatory factors. For example, when an agent is coerced into doing something by an external threat, and thus doesn't act freely and is not responsible for what he does, the threat both makes his act unavoidable and explains his act. However, we can imagine scenarios where the inevitability factors aren't the explanatory factors. In some of those cases the agent seems to act freely and be responsible for his act, even though he lacks the ability to do otherwise.

Frankfurt illustrated this idea with examples. The most famous one involves a nefarious neuroscientist who plays the role of a counterfactual intervener. Here is a version of such a case:

BLACK AND JONES: A neuroscientist, Black, wants Jones to perform a certain action. Black is prepared to go to considerable lengths to get his way, but he prefers to avoid showing his hand unnecessarily. So he waits until Jones is about to make up his mind what to do, and he does nothing unless it is clear to him (Black is an excellent judge of such things) that Jones is going to decide to do something other than what he wants him to do. If it were to become clear that Jones is going to decide to do something else, Black would take effective steps to ensure that Jones decides to do what he wants him to do, by directly manipulating the relevant processes in Jones's brain. As it turns out, Black never has to show his hand because Jones, for reasons of his own, decides to perform the very action Black wants him to perform.

In this case, Jones seems responsible for his choice because he made it completely on his own; Black never intervened. But it seems that, given Black's presence, Jones couldn't have made a different choice (Black wouldn't have let him).

So BLACK AND JONES seems to be a counterexample to PAP: it seems to show that being responsible doesn't require the ability to do otherwise. This is what we see, Frankfurt argues, when the inevitability factors come apart from the explanatory factors. Here, the inevitability factors are the facts concerning Black, his existence and intentions. Given that Black never intervenes, the inevitability factors are not part of the actual explanation of Jones's action. But, intuitively, the only factors that can be relevant to Jones's responsibility for his act are the factors that actually explain why he acted (the explanatory factors). The explanatory factors in this case are Jones's own reasons and process of deliberation. This is why Jones seems to be responsible even though he couldn't have done otherwise.

Frankfurt's argument has convinced many people, including many compatibilists and incompatibilists. But PAP continues to have advocates, who have responded to Frankfurt's argument in a number of different ways. In the next section, I explain the main moves, and how the dialectic has unfolded from there. 


\section{The Main Replies and the New Examples}

A natural response on behalf of PAP is to say: in BLACK AND JONES, Jones isn't able to make a different choice, but he is able to at least try to make a different choice. Of course, had he tried, the neuroscientist wouldn't have let him make him a different choice, but it was open for him to at least try. So Jones still has alternatives, and those alternatives are enough to make him responsible for his choice. This style of reply is known as the 'flickers of freedom' reply (see van Inwagen 1983; Naylor 1984; McKenna 1997; Wyma 1997; Otsuka 1998; the label is from Fischer 1994: Chapter 7).

In turn, advocates of Frankfurt's argument counter-replied by offering Frankfurt-style scenarios where the alternatives that the agent has are not sufficiently 'robust' to ground his responsibility (see Fischer 1994, 1999; Pereboom 2001, 2014; McKenna 2003). Frankfurt himself imagined a scenario of this kind in a footnote to his original paper (Frankfurt 1969: footnote 3). He imagined that the basis for predicting what Jones was about to decide was an involuntary twitch of his face. Jones could have exhibited this sign or failed to exhibit it. But, obviously, Jones didn't have any control over this, since it's an involuntary movement of his face, so the fact that he has alternatives of this kind doesn't seem relevant to his responsibility. Frankfurt-style scenarios of this kind, where what would have triggered the neuroscientist's intervention is an early involuntary sign, are commonly known as 'prior-sign' examples.

The appeal to the concept of robust alternatives has played a key role in the literature on Frankfurt-style examples in recent years: much of the discussion has now shifted from the question whether it's possible to build Frankfurt-style examples without alternatives to whether it's possible to build Frankfurt-style examples without sufficiently robust alternatives. Why is this the right way to think about the debate over Frankfurt-style examples? Here is one way to see this. When we ask what our freedom consists in, we are not just interested in finding necessary and/or sufficient conditions for freedom; we are interested in finding conditions that can plausibly ground our freedom, in the sense that they are at least part of what makes us free, or of that by virtue of which we are free (the literature on the concept of grounding has itself grown a lot in recent years; for a recent overview, see Raven [2015]). Arguably, then, PAP should be interpreted as something like the view that freedom/responsibility are grounded in the availability of alternative possibilities (see Leon and Tognazzini 2010; Sartorio 2016). As a result, the relevant alternative possibilities are bound to be 'robust,' in the sense that they should be able to ground the agent's freedom. And the alternatives that the agent has in the prior-sign examples described above don't seem robust in this sense.

At this point, there is another natural reply on behalf of PAP, at least from the incompatibilist standpoint. It takes the form of a dilemma. Consider the relation between the involuntary sign and the agent's choice in prior-sign cases. There are two possibilities: either that relation is deterministic or it is indeterministic. So assume, first, that it's deterministic. Then the claim that Jones is responsible for his choice seems to beg the question against the incompatibilist, who believes that determinism is incompatible with responsibility. On the other hand, assume that the relation is indeterministic. Then there seems to be no reason to think that Jones's choice was unavoidable, for he could still have failed to make it, after having shown or not shown the relevant sign. Either way, there seems to be no counterexample to PAP (or, at least, to an incompatibilist version of it). This reply is commonly known as 'the dilemma defense' (see Widerker 1995; Ginet 1996; Kane 1996). 
Again, advocates of Frankfurt's argument counter-replied in different ways. Some attacked the deterministic horn; others the indeterministic horn. Fischer (2010) attacked the deterministic horn by arguing that for a Frankfurt-style example to work we don't need to assume that the agent is responsible; all we need to assume is that, if he is not responsible, it's not because he wasn't able to do otherwise. As a result, Fischer argued, the argument based on prior-sign examples does not beg the question against the incompatibilist. Haji and McKenna (2004) developed a similar strategy of argumentation by distinguishing different dialectical contexts in which the debate about Frankfurt-style examples can be framed. Others attacked the indeterministic horn by offering different Frankfurtstyle examples that are indeterministic in nature. The new examples are attempts to close off all (robust) alternatives without assuming determinism, while still preserving the intuition that the agent is responsible for what he does. Some of them involve other types of prior signs (Stump 1996, 2003; Haji 1998; Pereboom 2000, 2001, 2014; Hunt 2005); others don't involve any prior signs at all (Mele and Robb 1998, 2003; Hunt 2000; McKenna 2003). In Pereboom's case, for instance, the prior sign involves a condition that is necessary but not sufficient for the agent to make a different choice. The scientist knows the agent's psychological profile very well and he knows that, for the agent to choose otherwise, it is causally necessary that a certain moral reason occur to him with a certain force (perhaps as a result of his voluntary activity, of his forcing himself to consider that reason). But, if he were to make such a moral reason occur to him at any point, as far as the agent is aware he could still choose to ignore it. Unbeknownst to the agent, however, the scientist has implanted a device in the agent's brain to ensure that he makes a certain morally reproachable choice. The device would be triggered only if it sensed that the moral reason occurred to the agent with the specified force. As a matter of fact, however, that moral reason never occurs to the agent, so the scientist never intervenes. The agent appears to be responsible for his choice, but Pereboom argues that he lacks robust alternative possibilities. (Although he could have forced himself to consider the relevant moral reason, Pereboom argues that this isn't a robust enough alternative because, as far as he knows, he wouldn't have escaped responsibility for his choice simply by doing that, since he believed that he could have decided to ignore that moral reason).

The literature contains several other defenses of PAP from the threat of Frankfurt-style cases. The 'timing' defense urges us to pay close attention to time and argues that, although the agent in certain Frankfurt-style cases may be responsible for making the relevant choice right then (at the precise time at which he made it, which he could have avoided doing), he is not responsible for making the choice simpliciter, at some time or other (see Ginet 1996, 2002; Franklin 2011; Palmer 2011). The 'agent-causal' defense (Rowe 1991; O'Connor 2000) interprets PAP in terms of agent-causation instead of ordinary event-causation, that is, as the claim that responsibility for a choice that one agent-causes requires the power not to agent-cause it. Frankfurt-style cases are not counterexamples to this claim, for an agent in a Frankfurt-style scenario retains the power not to agent-cause his choice: if the neuroscientist had intervened, he would have failed to agent-cause his choice. (Sartorio [2012] discusses a similar reply for an event-causal version of PAP.) In turn, Alvarez (2009) and Steward $(2008,2009)$ have offered an 'action-theoretic' defense of PAP. Their defense is based on the claim that something is not a genuine action unless the agent could have refrained from performing it. If this claim is true, it follows that Frankfurt-style cases are not counterexamples to PAP (for, if it's really the case that the agent couldn't have refrained from performing it, then it's not a genuine action, and thus it falls outside of PAP's scope). There are also "dispositionalist" 
defenses of PAP, which consist in arguing that agents in Frankfurt-style cases have the ability to do otherwise because they have all the relevant dispositions (see Smith 2003; Vihvelin 2004, 2013; Fara 2008). By appeal to the recent literature on dispositions, these solutions claim that the reason it might have seemed that agents in Frankfurt-style cases don't have the ability to do otherwise is that the relevant dispositions are 'masked' or 'finked,' given the presence of the neuroscientist (for a discussion of these ideas, see Clarke [2009]). Nelkin (2011) develops a similar strategy in terms of certain interferencefree abilities that agents can retain even when placed in Frankfurt-style scenarios. Finally, there are some defenses of PAP that attempt to undermine the intuitions about Frankfurt-style cases by appeal to considerations about the nature of blameworthiness. Widerker's "W-defense" attacks the claim that an agent such as Jones is blameworthy by posing the question: "If he is blameworthy, then what should he have done instead?" (Widerker 2003). The fact that he couldn't have done anything different seems to suggest that he can't really be blameworthy. The debate over these issues tends to be intertwined with the debate over the plausibility of the ought-implies-can principle (the claim that a moral obligation to do something requires the ability to do that thing). For example, Fischer (2006) argues that the W-defense fails because Frankfurt-style cases also work as counterexamples to the ought-implies-can principle: Jones couldn't have done otherwise, but he still ought to have refrained from doing what he did. (For other views on this issue, see Copp 2003; McKenna 2008; Capes 2010; Moya 2011).

\section{The Retreat from the Counterexample Strategy}

As we have seen, Frankfurt's examples generated a lively debate that went far beyond Frankfurt's original argument. But, for the most part, the literature on Frankfurt-style scenarios has assumed that the examples are successful if and only if they constitute clear counterexamples to PAP. However, Frankfurt himself has recently challenged this assumption. He has argued that, even if the examples didn't succeed as direct counterexamples to PAP, they could still succeed in challenging the traditional view of freedom because they could help undermine PAP's intuitive appeal (Frankfurt 2003; see also Zagzebski 2000; McKenna 2008).

Recall the way in which Frankfurt originally introduced the examples. He did it by first drawing a distinction between two kinds of factors: inevitability factors and explanatory factors. He then explained how, although we tend to conflate them, the two types of factors can come apart, and he used Frankfurt-style examples to illustrate this. Once it becomes clear that inevitability factors and explanatory factors can come apart in this way, Frankfurt suggested, PAP loses much of its initial appeal. For then we can appreciate more clearly the fact that all that really matters to our freedom is the actual explanation of our behavior, and not whether we are able to do otherwise. As a result, even if it were not dialectically possible to offer any persuasive Frankfurt-style scenarios without (robust) alternatives, there would still be some reason for thinking that having alternatives is not relevant to acting freely and being responsible. So Frankfurt-style examples can play an important role in an argument against the traditional view of freedom without constituting direct counterexamples to PAP. This is a significantly different way of looking at the dialectic.

To illustrate this point further, consider the following analogy. Another important metaphysical concept that philosophers have struggled to give an account of is the concept of causation. Different accounts have been offered of that concept. A quite natural 
one appeals to the concept of lawful sufficiency (i.e., logical sufficiency, given the laws of nature), or, if the laws are indeterministic, the more inclusive concept of probabilityraising. A traditional 'regularity' view of causation is an account of that kind; roughly (assuming determinism) it says that something is a cause just in case it's a lawfully suffcient condition for the effect (or an indispensable part of some lawfully sufficient condition, as in Mackie [1965]). Preemption scenarios appear to be counterexamples to this idea. In a preemption scenario, there are two processes that are lawfully sufficient for an effect but only one of them (the preemptor) is actually efficacious; the other one (the preempted process) remains causally inert, as a mere backup. For example, if Suzy and Billy both throw rocks at a window and Suzy's rock gets there first, the process involving Suzy's rock preempts the process involving Billy's rock. Preemption scenarios are a problem for regularity views because the preempted process is lawfully sufficient for the effect without being a cause. So, in this case, preemption scenarios play the role that Frankfurt-style examples play in the debate over PAP. (They are also particularly apt in this context, for note that Frankfurt-style scenarios themselves are a type of preemption scenario, one where the causal result is a choice by an agent, the preempted process is the process involving the neuroscientist, and the preempting process is the agent's own deliberation).

Now, while these are not knockdown arguments against the regularity view of causation (advocates of the view, such as Mackie himself, claim that they can successfully deal with the problem), one could argue that preemption scenarios are still helpful in a deeper and more general kind of way. For they can open our eyes to the idea that lawful sufficiency (or probability-raising) is not what really matters to being a cause (at least as far as a productive notion of causation is concerned); what really matters is the existence of a physical connection, or of a continuous process, or of some other relation of a similar kind between cause and effect. One could argue, moreover, that the reason we couldn't see this clearly before is that, in ordinary cases, lawful sufficiency and this other relation tend to go hand in hand, whereas we can see this much more clearly in preemption cases, where the two come apart.

Similarly, then, perhaps Frankfurt-style cases can be helpful, partly thanks to their artificiality, because they can help us see more clearly a distinction that tends to be muddled in ordinary cases where agents are unable to do otherwise: the distinction between inevitability and explanatory factors. As a result, they can help us zero in on what really matters to freedom.

\section{The Motivation for an Alternative View of Freedom}

I have distinguished two different roles that Frankfurt-style examples can play: the role of acting as direct counterexamples to PAP, and the role of helping disarm PAP's initial plausibility. Both of these are negative roles, in that they are attempts to undermine a certain view of freedom. But there is also a positive role that Frankfurt-style examples can play, one that is related to the second negative role but also importantly different from it. This third role tends to be even more underemphasized than the second negative role, but it is also extremely important. It is the role of motivating a different view of freedom, one that is not at all based on the availability of alternative possibilities, but only on the relevant actual sequences or actual explanations of behavior.

Frankfurt's own view is that acting of one's own free will requires acting from a will that one wishes to have, that is, acting from first-order desires that suitably mesh with higher-order desires (see Frankfurt 1971; see also Watson [1975] for a development of a 
non-hierarchical mesh view of freedom). But in recent years, Frankfurt-style scenarios have inspired and motivated some views of freedom that emphasize other aspects of the actual explanation of behavior, in particular, the reasons-responsiveness of agents or of the relevant mechanisms, and that have come to be known as 'actual-sequence views.' (The first comprehensive development of such a view is Fischer and Ravizza [1998]; see also Fischer 2006, 2012; McKenna 2008, 2013; Sartorio 2011, 2016). Again, these are actual-sequence views partly because they do not take the freedom of an agent to depend on the existence of alternative possibilities accessible to the agent. But the issue of how it is that Frankfurt-style cases motivate the new views, or what kinds of principles about freedom they support, besides the mere rejection of the alternative- possibilities requirement-in other words, the positive insights about freedom motivated by the examples-has not yet received enough attention in the literature.

Although Frankfurt's main goal in his original paper was to argue against PAP, he also suggested that Frankfurt-style examples motivate a different view of freedom, one uncommitted to PAP. Frankfurt suggested that reflection on the examples motivates the following principle about what is relevant to responsibility:

RELEVANCE: The explanatory factors (those factors that actually explain the agent's behavior), and only those factors, are relevant to the agent's responsibility for his behavior.

(Frankfurt 1969)

Again, Frankfurt thought that Frankfurt-style examples can help us see how the inevitability factors and the explanatory factors can come apart, and thus they can help us see the irrelevance of the inevitability factors and the relevance of the explanatory factors. So, at the same time that they can be used to undermine PAP, they can be used to motivate a different view of freedom, one according to which acting freely is just a matter of having a certain kind of actual causal history or actual explanation.

Now, RELEVANCE has been forcefully contested. What's more, the main actualsequence views currently on offer don't seem to respect it. Here are a couple of apparent counterexamples to it:

SQUEAKY BUTTON: I love squeaky sounds. I know that pushing a certain button would result in a squeaky sound, so I push the button to hear the sound. I also know that pushing the squeaky button will result in a remote village being wiped out, but that's not what motivates me to push the button (I'm not that evil!).

(From Sartorio 2011, 2016. This style of objection was originally pressed by Widerker [2000, 2003], by appeal to similar examples. See also Palmer 2014.)

SHARKS: A child is drowning in a pond nearby. I think I could easily rescue him, but instead of trying to save him I keep walking along the shore, unmoved by the situation, and the child dies. Unbeknownst to me, there were hungry sharks in the water. Had I tried to save the child, they would have attacked me, and I wouldn't have been able to rescue him.

(From Fischer and Ravizza 1998. This style of objection was first pressed by van Inwagen [1983] and Ginet [1996], by appeal to similar examples.) 
In SQUEAKY BUTTON, I am clearly blameworthy for causing the village's destruction. My belief that the village would be wiped out as a result of my pressing the button is clearly relevant to my responsibility (since, had I not been aware of the consequences of pushing the button, I wouldn't have been responsible for causing the village's destruction). However, that belief is not part of the actual explanation of my behavior, for I didn't push the button motivated by that belief (I only pushed it because I wanted to hear the squeaky sound). Thus, a factor that doesn't help explain my behavior can still be relevant to my responsibility for that behavior; in other words, RELEVANCE seems false. In turn, in SHARKS, I am clearly not blameworthy for not saving the child (of course I could be blamed for not trying to save him, but it seems wrong to blame me from not saving him, given that I couldn't have saved him). And the sharks' presence is relevant to my lack of responsibility (for, if the sharks had not been present, then I would have been responsible for not saving the child). However, the sharks are not part of the actual explanation of my behavior (they were not the reason I didn't jump in; I wasn't even aware of their presence!). Thus here, too, a factor that doesn't help explain my behavior can be relevant to my responsibility for that behavior.

So these examples suggest that RELEVANCE is false. If Frankfurt-style examples support a new view of freedom that is based exclusively on actual sequences, it doesn't seem to be one that entails RELEVANCE. Frankfurt responds to some of these objections in Frankfurt (2003) (I discuss some of his replies below). More recently, and motivated by the threat posed by the counterexamples, Fischer has proposed a weaker formulation of the principle, one that is designed to avoid at least some of them:

RELEVANCE*: If a fact is irrelevant to the explanation of the person's action, then it is irrelevant to the issue of the person's "moral responsibility at all," i.e. to the issue of whether the agent is morally responsible to at least some degree for at least something.

(Fischer 2013)

Note that this principle clearly avoids the problem with SHARKS (although it is less clear that it helps with SQUEAKY BUTTON). For the presence of the sharks is irrelevant to the issue of the agent's responsibility "at all": even when the sharks are present, I am still responsible for something, such as for not trying to save the child.

On the downside, however, RELEVANCE* seems too weak as an attempt to capture the insight behind Frankfurt-style cases. For Frankfurt-style cases don't only seem to motivate the idea that our responsibility for something or other (our responsibility "at all," in Fischer's terminology) depends exclusively on factors that actually explain how we act; they also, more strongly, seem to motivate the idea that responsibility for something in particular depends exclusively on the actual explanation of that very thing. For example, my responsibility for an action or a choice depends exclusively on how I came to perform the action or make the choice. And, similarly, my responsibility for an outcome such as the child's death depends exclusively on the actual causal history of the death (in particular, on my involvement in it).

Another way of formulating the view inspired by Frankfurt-style cases that has been explored in the literature, and that is also suggested by some passages in Frankfurt's paper, takes the form of a supervenience principle. Here is a possible formulation of that principle:

SUPERVENIENCE: An agent's responsibility (freedom) with respect to X supervenes on the actual sequence issuing in $\mathrm{X}$. 
SUPERVENIENCE states that there cannot be a difference in responsibility (or freedom) without a difference in the actual sequence. In other words, whenever the actual sequence is the same, the agents are equally responsible (or free). Fischer once explicitly embraced SUPERVENIENCE, at least when X is an action by an agent (see Fischer 1987). (It is unclear what relationship Fischer would say exists between that principle and the principle discussed above, RELEVANCE*; unfortunately, Fischer doesn't discuss that connection explicitly). Sartorio $(2011,2016)$ embraces a generalized version of SUPERVENIENCE.

Like Fischer's principle RELEVANCE*, SUPERVENIENCE is weaker than RELEVANCE. For there could be 'extrinsic' factors (factors that are external to the actual sequence or causal history of an act) that still determine what the causal history is, or its actual composition, and thus, whether the act is free and whether the agent is responsible. In that case, SUPERVENIENCE could be true while RELEVANCE is false (extrinsic factors can be relevant to freedom even if freedom supervenes on actual sequences; see Sartorio 2011, 2016). Unlike Fischer's principle RELEVANCE*, however, SUPERVENIENCE doesn't seem too weak, or removed from the original insight offered by Frankfurt cases, for it still ties the agent's responsibility or freedom for something with the actual explanation of that same thing.

Do examples such as SQUEAKY BUTTON and SHARKS threaten SUPERVENIENCE in the same way they threaten RELEVANCE? Arguably, SHARKS is no longer a counterexample, for the causal history of the child's death is presumably different when the sharks are present and when they are not; in particular, when they are not present, my failure to jump in is a cause of the child's death, but not so when they are present. This fits well with the idea that I can only be responsible for the child's death, and thus for not saving the child, if I am causally connected to his death in the relevant way. A solution of this kind relies on a causal interpretation of actual sequences. Sartorio develops an actual-sequence view based on a causal interpretation of actual sequences, and argues that SUPERVENIENCE can accommodate examples like SHARKS in Sartorio (2016).

Conversely, SQUEAKY BUTTON seems to raise different types of issues from those raised by SHARKS. Compare the SQUEAKY BUTTON scenario with a similar scenario where I'm unaware of the destruction I'm causing by pushing the button. The causal history of my behavior and of the destruction seems to be the same in the two cases (in both cases I push the button because I want to hear the squeaky sound, and the village is destroyed as a result); however, there is a difference in my responsibility: I'm responsible for the destruction in one case but not in the other.

Now, here it might be important to bring to bear the distinction between freedom, or the freedom component of responsibility, and responsibility itself. When Frankfurt suggested the RELEVANCE principle, he seemed to have responsibility in mind, and many others who have followed his lead do too. But responsibility has an epistemic component too. Roughly, in order to be responsible one must be aware of the moral significance of what one is doing. And there is no obvious reason to think that what goes for the freedom component of responsibility should also go for the epistemic component. So a promising option (at least one that deserves further exploration) is to restrict SUPERVENIENCE or similar principles to the freedom component of responsibility, and to claim that freedom supervenes on actual sequences, although perhaps responsibility doesn't, due to its epistemic component (see Sartorio 2016). Otherwise put, responsibility only supervenes on actual sequences when the agent's epistemic state is 
held fixed. This avoids the problem with SQUEAKY BUTTON, for the responsible and non-responsible agents are not in the same epistemic state.

When Frankfurt replied to the objections to the RELEVANCE principle, he suggested other possible ways of addressing the problem (see Frankfurt 2003; see also McKenna 2008). He suggested that examples like SQUEAKY BUTTON are not counterexamples to RELEVANCE, when that principle is properly understood, because the full explanation of the agent's act in that case includes the sort of act that he thought he was performing. Thus, if I am aware of the fact that I am acting wrongly by pressing the button, then a full explanation of what I do will include my awareness of my wrongdoing, even if it is not a cause of my act. Perhaps Frankfurt would say something similar about how the examples bear on SUPERVENIENCE. Perhaps he'd say that SUPERVENIENCE should be understood as the claim that an agent's responsibility for an act supervenes on the 'full' explanation of the act, in this broader sense.

This brings me to one final central issue. When advocates of the actual-sequence view say that freedom is just a function of actual sequences or actual explanations, what exactly should we take actual sequences or actual explanations to be? Initially, at least, it seems that a very natural interpretation is to take actual sequences to be just actual causal histories (this idea is developed in Sartorio 2016). As we have seen, Frankfurt himself doesn't seem to understand actual sequences in this way, for he takes the actually explanatory factors to include factors that go beyond the causes of the action. Fischer and Ravizza, in turn, seems to interpret actual sequences as including some modal properties of sequences that are not actually explanatory or causally efficacious in themselves, such as the 'reasons-responsiveness' of sequences (see Fischer and Ravizza 1998; see also McKenna 2013). Again, how we interpret actual sequences is tied to the issue of what we take the real insight behind Frankfurt-style examples to be. This is an issue that is still quite underexplored in the literature, and that deserves more attention than it has so far received.

\section{Conclusions}

The literature on Frankfurt-style examples is now huge, and rightly so, but it is likely to keep growing in new directions. As we have seen, the examples can play a variety of related roles in the debate about the nature of freedom and responsibility. First, they can be regarded as direct counterexamples to PAP, the principle that crystallizes the traditional view of freedom. Most of the debate about Frankfurt-style cases has focused on this role. But there are two other main roles for Frankfurt-style cases to play, which seem at least as important, if not more important. A second negative role is the role of supporting the argument against the traditional view of freedom more indirectly, by helping to undermine its initial plausibility, instead of by providing a direct counterexample to it. And a third and positive role is the role of motivating a different view of freedom, one according to which freedom is only a matter of the actual sequence having certain features, or of our acts being caused in the right kind of way.

\section{Acknowledgments}

Thanks to Meghan Griffith, Michael McKenna, and Derk Pereboom for helpful comments. 


\section{Bibliography}

Alvarez, M. (2009) "Actions, Thought-Experiments and the 'Principle of Alternate Possibilities," Australasian Journal of Philosophy 87: 61-81.

Capes, J. (2010) "The W-Defense," Philosophical Studies 150: 61-77.

Clarke, R. (2009) "Dispositions, Abilities to Act, and Free Will: The New Dispositionalism," Mind 118: $323-51$.

Copp, D. (2003) “'Ought' Implies 'Can,' Blameworthiness, and the Principle of Alternate Possibilities,” in D. Widerker and M. McKenna (eds), Moral Responsibility and Alternative Possibilities. Aldershot: Ashgate, pp. $265-300$.

Fara, M. (2008) "Masked Abilities and Compatibilism," Mind 117: 843-65.

Fischer, J. (1987) "Responsiveness and Moral Responsibility," in F. Schoeman (ed.), Responsibility, Character, and the Emotions: New Essays in Moral Psychology. Cambridge: Cambridge University Press, pp. 81-106.

Fischer, J. (1994) The Metaphysics of Free Will. Oxford: Blackwell.

Fischer, J. (1999) "Recent Work on Moral Responsibility," Ethics 110: 93-139.

Fischer, J. (2003) "Responsibility and Alternative Possibilities," in D. Widerker and M. McKenna (eds), Moral Responsibility and Alternative Possibilities. Aldershot: Ashgate, pp. 27-52.

Fischer, J. (2006) My Way: Essays on Moral Responsibility. New York: Oxford University Press.

Fischer, J. (2010) "The Frankfurt Cases: The Moral of the Stories," The Philosophical Review 119: 315-36.

Fischer, J. (2012) Deep Control: Essays on Free Will and Value. New York: Oxford University Press.

Fischer, J. (2013) "The Path of Life," Presidential address, given to the American Philosophical Association (Pacific Division). Proceedings and Addresses of the American Philosophical Association 87: 60-77.

Fischer, J. and Ravizza, M. (1998) Responsibility and Control: An Essay on Moral Responsibility. Cambridge: Cambridge University Press.

Frankfurt, H. (1969) "Alternate Possibilities and Moral Responsibility," Journal of Philosophy 66: 829-39.

Frankfurt, H. (1971) "Freedom of the Will and the Concept of a Person," Journal of Philosophy 68: 5-20.

Frankfurt, H. (2003) "Some Thoughts Concerning PAP," in D. Widerker and M. McKenna (eds), Moral Responsibility and Alternative Possibilities. Aldershot: Ashgate, pp. 339-46.

Franklin, C. (2011) "Neo-Frankfurtians and Buffer Cases: The New Challenge to the Principle of Alternative Possibilities," Philosophical Studies 152: 189-207.

Ginet, C. (1996) "In Defense of the Principle of Alternative Possibilities: Why I Don't Find Frankfurt's Argument Convincing," Philosophical Perspectives 10: 403-17.

Ginet, C. (2002) "Review of Living Without Free Will," Journal of Ethics 6: 305-9.

Haji, I. (1998) Moral Appraisability. New York: Oxford University Press.

Haji, I. and McKenna, M. (2004) "Dialectical Delicacies in the Debate about Freedom and Alternative Possibilities," Journal of Philosophy 101: 299-314.

Hunt, D. (2000) "Moral Responsibility and Unavoidable Action," Philosophical Studies 97: 195-227.

Hunt, D. (2005) "Moral Responsibility and Buffered Alternatives," Midwest Studies in Philosophy 29: 126-45.

Kane, R. (1996) The Significance of Free Will. Oxford: Oxford University Press.

Leon, F. and Tognazzini, N. (2010) “Why Frankfurt-Examples Don't Need to Succeed to Succeed," Philosophy and Phenomenological Research 80: 551-65.

McKenna, M. (1997) "Alternative Possibilities and the Failure of the Counterexample Strategy," Journal of Social Philosophy 28: 71-85.

McKenna, M. (2003) "Robustness, Control, and the Demand for Morally Significant Alternatives," in D. Widerker and M. McKenna (eds), Moral Responsibility and Alternative Possibilities. Aldershot: Ashgate, pp. 201-18.

McKenna, M. (2008) "Frankfurt's Argument against Alternative Possibilities: Looking Beyond the Examples," Noûs 42: 770-93.

McKenna, M. (2013) "Reasons-Responsiveness, Agents and Mechanisms" in D. Shoemaker (ed.), Oxford Studies in Agency and Responsibility, Vol. 1. New York: Oxford University Press, pp. 151-83.

Mackie, J. (1965) "Causes and Conditions," American Philosophical Quarterly 2: 245-64.

Mele, A. and Robb, D. (1998) "Rescuing Frankfurt-Style Cases," The Philosophical Review 107: 97-112.

Mele, A. and Robb, D. (2003) "Bbs, Magnets and Seesaws: The Metaphysics of Frankfurt-style Cases" in D. Widerker and M. McKenna (eds), Moral Responsibility and Alternative Possibilities. Aldershot: Ashgate, pp. 127-38.

Moya, C. (2011) "On the Very Idea of a Robust Alternative," Crítica 43: 3-26.

Naylor, M. (1984) "Frankfurt on the Principle of Alternate Possibilities," Philosophical Studies 46: 249-58. 


\section{CAROLINA SARTORIO}

Nelkin, D. (2011) Making Sense of Freedom and Responsibility. New York: Oxford University Press.

O'Connor, T. (2000) Persons and Causes: The Metaphysics of Free Will. New York: Oxford University Press.

Otsuka, M. (1998) "Incompatibilism and the Avoidability of Blame," Ethics 108: 685-701.

Palmer, D. (2011) "Pereboom on the Frankfurt Cases," Philosophical Studies 153: 261-72.

Palmer, D. (2014) "Deterministic Frankfurt Cases," Synthese 191: 3847-64.

Pereboom, D. (2000) "Alternate Possibilities and Causal Histories," Philosophical Perspectives 14: 119-38.

Pereboom, D. (2001) Living Without Free Will. Cambridge: Cambridge University Press.

Pereboom, D. (2014) Free Will, Agency, and Meaning in Life. Oxford: Oxford University Press.

Raven, M. (2015) "Ground," Philosophy Compass 10: 322-33.

Rowe, W. (1991) Thomas Reid on Freedom and Morality. Ithaca: Cornell University Press.

Sartorio, C. (2011) "Actuality and Responsibility," Mind 120: 1071-97.

Sartorio, C. (2012) "Causation and Freedom," The Journal of Philosophy 109: 629-51.

Sartorio, C. (2016) Causation and Free Will. Oxford: Oxford University Press.

Smith, M. (2003) "Rational Capacities, or: How to Distinguish Recklessness, Weakness, and Compulsion," in S. Stroud and C. Tappolet (eds), Weakness of Will and Practical Irrationality. Oxford: Clarendon Press, pp. $17-38$.

Steward, H. (2008) "Moral Responsibility and the Irrelevance of Physics: Fischer's Semi-compatibilism vs. Anti-fundamentalism," Journal of Ethics 12: 129-45.

Steward, H. (2009) "Fairness, Agency and the Flicker of Freedom," Noûs 43: 64-93.

Stump, E. (1996) "Libertarian Freedom and the Principle of Alternative Possibilities," in D. Howard-Snyder and J. Jordan (eds), Faith, Freedom, and Rationality: Essays in the Philosophy of Religion. Lanham: Rowman and Littlefield, pp. 73-88.

Stump, E. (2003) "Moral Responsibility without Alternative Possibilities," in D. Widerker and M. McKenna (eds), Moral Responsibility and Alternative Possibilities. Aldershot: Ashgate, pp. 139-58.

van Inwagen, P. (1983) An Essay on Free Will. Oxford: Clarendon Press.

Vihvelin, K. (2004) "Free Will Demystified: A Dispositional Account," Philosophical Topics 32: 427-50.

Vihvelin, K. (2013) Causes, Laws, and Free Will. New York: Oxford University Press.

Watson, G. (1975) "Free Agency," Journal of Philosophy 72: 205-20.

Widerker, D. (1995) "Libertarianism and Frankfurt's Attack on the Principle of Alternative Possibilities," The Philosophical Review 104: 247-61.

Widerker, D. (2000) "Frankfurt's Attack on the Principle of Alternative Possibilities: A Further Look," Philosophical Perspectives 14: 181-201.

Widerker, D. (2003) "Blameworthiness, and Frankfurt's Argument Against the Principle of Alternative Possibilities," in D. Widerker and M. McKenna (eds), Moral Responsibility and Alternative Possibilities. Aldershot: Ashgate, pp. 53-74.

Wyma, K. (1997) "Moral Responsibility and Leeway for Action," American Philosophical Quarterly 34: 57-70.

Zagzebski, L. (2000) "Does Libertarian Freedom Require Alternate Possibilities?" Philosophical Perspectives 14: $231-48$.

\section{Further Reading}

Widerker, D. and McKenna, M. (2003) Moral Responsibility and Alternative Possibilities: Essays on the Importance of Alternative Possibilities: Aldershot: Ashgate. (The most comprehensive collection of papers to date on Frankfurt-style cases.)

\section{Related Topics}

Semicompatibilism

Leeway vs. Sourcehood Conceptions of Free Will 


\section{6 \\ LOGICAL FATALISM \\ Alicia Finch}

There are three components of logical fatalism (hereafter fatalism): (i) bivalence, the thesis that every proposition is either true or false (and no proposition is both true and false); (ii) the thesis that free action is impossible; and (iii) the thesis that bivalence entails that free action is impossible. The pith of the argument is this:

Assume that it is true that agent $S$ performs act $A$ at time $t$, where time $t$ is in the future. Since it is already true that $S$ will perform $A$ at $t, S$ cannot not perform $A$ at $t$. But if $S$ cannot not perform $A$ at $t, S$ will perform $A$ at $t$ non-freely. Given that $S, A$, and $t$ might be any agent, any act, and any future time, free action is impossible.

Because this argument depends on certain assumptions about the definition of free action, I will pause to say a few words about the debate over this definition. Participants in the debate fall into two camps. So-called leeway theorists contend that free action "requires alternative possibilities," so that an agent acts freely only if she is "able to do otherwise" than she actually does. Source theorists, by contrast, maintain that if an agent is the source of an action (in some relevant sense of 'source'), she acts freely even if she lacks alternative possibilities. The leeway-sourcehood debate is orthogonal to the fatalism debate. Indeed, the fatalism debate is for leeway theorists only. After all, unless free action "requires alternative possibilities," bivalence seems to pose no threat to free action.

In this chapter, I will offer a brief history of this debate, present what I take to be the strongest argument for fatalism, and consider the dialectical options available to its opponents. These options include: (i) denying that it is possible for propositions to be true at times; (ii) contending that propositions change truth values (which implies either the falsity of bivalence or the falsity of every proposition of the form $<S$ will freely perform act $A>$ ); (iii) contending that there are cases in which it is now up to an agent which states of affairs obtained in the past; and (iv) denying the validity of so-called 'Diodoran principles.' Along the way, I will indicate the structural similarity between the argument for fatalism, on the one hand, and the Consequence Argument for the incompatibility of free action and determinism, on the other.

\section{A Brief History of the Debate}

Within the western philosophical tradition, Aristotle's De Interpretatione (1963: Chapter 9) seems to be the origin of the argument for fatalism, although Aristotle himself was no 
fatalist. He presents the argument in the context of making a case against bivalence, reasoning that if bivalence were true, everything that happens would happen of necessity and, thus, "there would be no need to deliberate or take trouble." Implying that there is, in fact, a need to deliberate or take trouble, Aristotle concludes that bivalence is false: contingent propositions about the future are neither false nor true. The fatalist, obviously, sees modus ponens where Aristotle sees modus tollens.

One generation after Aristotle, members of the Dialectical School revisited this line of thought as they began building systems of modal logic. With Aristotle's argument against bivalence in mind, Diodorus offered the so-called "Master Argument" for the impossibility of contingently true propositions about the future. Unfortunately, so few of Diodorus's manuscripts survive that it is unclear exactly how he formulated the argument in question. We do know, however, that a key premise was the principle that "Nothing impossible follows from the possible." If ' $-\langle p$ ' designates 'it is not possible that $p$ ' and ' $\square(p \rightarrow q)$ ' designates that $p$ entails $q$, this principle may be formulated as: $\{-\checkmark q, \square(p \rightarrow q)\}$ $\vdash-\diamond p\}$. As Kapitan (2002) points out, many variations on this principle have been introduced into the debate over the Consequence Argument for the incompatibility of free action and determinism. While participants in that debate tend to speak of " $\beta$-like principles" (in reference to van Inwagen's 'Principle $\beta$,' which he introduced in his 1983 presentation of the Consequence Argument) or "transfer of necessity principles," I will use the term 'Diodoran Principles' to refer to all relevantly similar principles.

When Christianity came to dominate Western philosophy, interest in theological fatalism supplanted interest in logical fatalism. According to theological fatalism, since an omniscient God knows what agents will do before they do it, it is impossible for agents to act other than they do. Toward the end of the medieval era, William of Ockham offered an approach to the problem of theological fatalism according to which we now have a choice about what God has always believed. Among contemporary scholars, Ockhamism is a relatively popular response to theological fatalism; in what follows, I will discuss the Ockhamist response to logical fatalism.

A. N. Prior, spent the 1950 s and 1960 s grappling with the argument for logical fatalism, which "brought together three of [his] great interests: indeterminism, modal logic, and the logic of time" (Copeland 2008). Having studied Aristotle, Stoic logicians (including Diodorus), and medieval logicians (including Ockham), Prior developed a groundbreaking tense logic with which he reformulated Diodorus's Master Argument. Like Aristotle, he responded to the argument with the claim that propositions can change their truth values. Unlike Aristotle, he maintained a commitment to bivalence, suggesting instead that all contingent propositions about the future are false (unless entailed by contingent propositions about the past, contingent propositions about the present, and necessary propositions). I will discuss this position briefly in what follows, though it is beyond the scope of this chapter to do justice to Prior's work.

\section{The Argument}

I begin my presentation of the argument for fatalism with a necessary consequence of the (leeway theorist's) definition of free action:

(FA) Necessarily, $S$ freely performs $A$ at $t$ only if (i) $S$ performs $A$ at $t$ and (ii) for some time $t$ - such that $t$ - is earlier than $t$, it is up to $S$ at $t$ - whether $S$ performs $A$ at $t$; 
where:

(UP) It is up to $S$ at $t$ - whether $S$ performs $A$ at $t=\mathrm{df}$. (i) $t$ - is earlier than $t$ and

(ii) $S$ at $t$ - is both (a) able to perform $A$ at $t$ and (b) able to refrain from performing $A$ at $t$;

and:

'S' designates some arbitrary agent $S$,

'A' designates some arbitrary action A,

' $t$ ' designates some arbitrary time $t$,

and:

't-' designates some arbitrary time $t$ - such that $t$ - is earlier than $t$.

With this, the fatalist's concern may be stated rather simply: since there is no time at which it is not true that $S$ performs $A$ at $t$, there is no time at which it is up to $S$ whether $S$ performs $A$ at $t$.

In order to present the concern as a formal argument, I will follow Peter van Inwagen in employing the idiom of "being able to render a proposition false" (van Inwagen introduces this idiom in the context of his presentation of the Consequence Argument: 1983: 66-8). Although the locution is strange, the notion is relatively straightforward, provided that we make certain stipulations. First, let us stipulate that for any action A performed by any agent $S$ at any time $t$, there is a corresponding proposition $p_{\mathrm{A}}$ such that:

' $p_{\mathrm{A}}$ ' designates the proposition that $S$ performs $A$ at $t$.

Let us further stipulate not only that:

Necessarily, it is up to $S$ at time $t$ - whether $S$ performs $A$ at $t$ if and only if it is up to $S$ at $t$ - whether $p_{A}$,

but also that whatever it is for it to be up to $S$ at time $t$ - whether $S$ performs $A$ at $t$, this is what it is for it to be up to $S$ at $t$ - whether $p_{A}$. In other words, let us stipulate that the definition of "It is up to $S$ at $t$ - whether $S$ performs $A$ at $t$ " is the definition of "It is up to $S$ at $t$ - whether $p_{A} . "$

And now let us imagine a particular case. In particular, let us imagine that Mary freely marries Harry at noon on March 13, 3013, and that time $t_{-}{ }_{M}$ is the one and only time at which it is up to her whether she does so. Let us stipulate that:

' $t_{\mathrm{M}}$ ' designates noon on March 13, 3013;

and:

' $p_{\mathrm{M}}$ ' designates the proposition that Mary marries Harry at $t_{\mathrm{M}}$. 
And let us be clear: $p_{\mathrm{M}}$ is false if and only Mary does not marry Harry at $t_{\mathrm{M}}$, and Mary does not marry Harry at $t_{\mathrm{M}}$ if and only if Mary refrains from marrying him at $t_{\mathrm{M}}$. With this, it should be evident that each of these is equivalent to the other:

- Mary freely marries Harry at $t_{\mathrm{M}}$.

- Mary marries Harry at $t_{\mathrm{M}}$ and it is up to Mary at $t_{-}{ }_{\mathrm{M}}$ whether Mary marries Harry at $t_{\mathrm{M}}$.

- $p_{M}$ and it is up to Mary at $t_{-}$whether $p_{M}$.

- $p_{M}$ and Mary at $t_{-}$is able to refrain from marrying Harry at $t_{M}$.

- $\quad p_{M}$ and Mary at $t_{-}$is able to do something (i.e., refrain from marrying Harry, not marry Harry) such that, if Mary were to do it, $p_{M}$ would be false.

At this point, the basic notion of being able to render a proposition false should be clear enough:

(RPF) $S$ at $t$ - is able to render proposition $p$ false ${ }_{\text {df. }} S$ at $t$ - is able to do something such that, if she were to do it, $p$ would be false,

provided that "doing something" is construed broadly enough so that "not performing act A" or "refraining from performing A" counts as "doing something." In the case of Mary and Harry, Mary at $t_{-}{ }_{M}$ is able to do something that would render $p_{M}$ false if, for instance, Mary at at $t_{-}$is able to postpone the wedding, leave Harry at the altar, utter "I don't" when asked whether she does, or take so long to respond to the relevant query that Harry says, "Never mind!" and storms out. Provided that Mary freely marries Harry at $t_{\mathrm{M}}$ and $t_{-}{ }_{\mathrm{M}}$ is the one time at which it is up to Mary whether she does so, it follows that there is something Mary at $t_{-}$can do such that, if she were to do it, $p_{M}$ would be false; it follows, that is, that Mary at $t_{-}$is able to render $p_{M}$ false.

Of course, the fatalist's point is that no one ever acts freely; as such, let us consider the notion of not being able to render a proposition false. In his classic formulation of the Consequence Argument, van Inwagen made use of an $\mathrm{N}$-operator, where the sentence 'Np' was to be read as " $p$ and no one has, or ever had, any choice about whether p" (93), which is equivalent to " $p$ and no one is, or ever was, able to render $p$ false." Taking a cue from van Inwagen, I will use a similar N-operator, where:

' $N_{s, t} p$ ' designates: $p \&$ it is not up to $S$ at $t$ whether $p$.

I offer that $N_{s, t} p$ is equivalent to:

$\left(N_{s, t} t^{*}\right) p \& S$ at $t$ is unable to render $p$ false;

$\left(N_{s, t} p^{* *}\right) p \&$ it is not the case that there is something $S$ at $t$ can do such that, if $S$ were to do it, $p$ would be false;

and:

$\left(N_{s, t} p^{* * *}\right) p \&$ there is nothing $S$ at $t$ can do such that, if $S$ were to do it, $p$ would be false; 
Anyone familiar with McKay and Johnson (1996) might wonder whether it would be better to replace 'would' with 'might' in $\left(N_{s, t} p^{* *}\right)$ and $\left(N_{s, t} p^{* * *}\right)$. Fortunately, in the context at hand, nothing hinges on whether ' $N_{s, t} p$ ' is read in terms of 'would' or 'might,' so I will simply adopt the 'would' reading.

With the $\mathrm{N}$-operator in view, I introduce a Diodorian Principle. Though many are available, I will rely on this one in particular:

$$
\text { (DP) }\left\{\mathrm{N}_{s, t,} p, \square(p \rightarrow q)\right\} \vdash \mathrm{N}_{s, t} q
$$

Such principles are familiar to anyone familiar with the debate over the Consequence Argument. Indeed, unless there is a valid Diodoran Principle, the Consequence Argument is invalid.

Moreover, both the Consequence Argument and the argument for fatalism depend on some version or other of either the Principle of the Fixity of the Past or the Principle of the Fixity of the Present. The former is the principle that:

(FP): Necessarily, for any agent $S$, any proposition $p$, and any time $t$, if (i) $p$ describes a state of affairs that obtains prior to $t$, (ii) it is not up to $S$ at $t$ whether $p$;

while the latter is the principle that:

(FP*): Necessarily, for any agent $S$, any proposition $p$, and any time $t$, if (i) $p$ describes a state of affairs that obtains at $t$, (ii) it is not up to $S$ at $t$ whether $p$;

In what follows, I will narrow my focus to to the Fixity of the Past: I do so only for the sake of brevity; every claim that I will make about the Fixity of the Past could be made, mutatis mutandis, about the Fixity of the Present.

At this point, the argument for fatalism and the Consequence Argument diverge: the latter but not the former depends on the thesis that it not up to anyone what the laws of nature are; the former but not the latter depends on both of these principles:

(Truth-at-t): Necessarily, for any proposition $p$, if $p$ is true, there is some time $t$ such that $p$ is true at $t$.

(Immutability): Necessarily, for any proposition $p$, for any time $t$, and for any time $t^{*}, p$ is true at $t$ if and only if $p$ is true at $t^{*}$.

In what follows, I will consider objections to these principles, just as I will consider objections to the Diodoran principle and the Fixity of the Past. For now, I simply note that while it is possible to formulate the argument for fatalism without explicitly invoking them, these principles (or, at least, quite similar principles) seem essential to the argument. 
I have already said that the argument begins with the assumption of bivalence. Given bivalence, it follows that proposition $p_{A}$ has a truth value; let us assume that $p_{A}$ is, in fact, true. Stipulating that $t_{-1 B}$ is a time approximately one billion years before $t$-, the argument for fatalism can be formulated such that:
1. $p_{\mathrm{A}}$
2. $\square\left(p_{A} \leftrightarrow p_{A}\right.$ is true at $\left.t\right)$
Bivalence, Assumption
3. $\square\left(p_{A}\right.$ is true at $t \leftrightarrow p_{A}$ is true at $\left.t_{-1 B}\right)$
Truth-at-t
4. $\square\left(p_{A}\right.$ true at $\left.t_{-1 B} \leftrightarrow p_{A}\right)$
Immutability
5. $N_{s, t}\left(p_{A}\right.$ is true at $\left.t_{-1 B}\right)$
2, 3
6. $N_{s, t} p_{A}$
Fixity of the Past
$4,5, \mathrm{DP}$

Because any time earlier than $t$ may be substituted for $t_{-1 B}$, this argument purports to show that the proposition that $S$ performs $A$ at $t$ entails that it is never up to $S$ whether $S$ performs $A$ at $t$ : free action is impossible.

\section{Response 1: Rejecting Truth-at-t}

What does it mean to say that a proposition is true-at-a-time as opposed to true simpliciter? In An Essay on Free Will, Peter van Inwagen suggests that the expression is meaningless. More exactly, he points to similar expressions (e.g., 'true at some particular moment,' 'true at every moment,' 'became true,' 'remained true,' 'is unchangeably true,' and so on), and offers that he does not "see what these phrases mean if they are used as they are used in the above argument for fatalism" (1983: 35). He grants that if he were to say, "Municipal bonds are a good investment," and if someone were to respond with "That used to be true but it isn't true anymore," his respondent's words "would be a model of lucidity" (1983: 35). After all, his respondent's meaning could easily be captured with sentences that do not invoke the notion of true-attime-t, for example, "In 1945, municipal bonds were a good investment. In 2015, municipals bonds are not a good investment." But how could one capture the meaning of "It was true one billion years ago that Mary marries Harry in 3013" without using the notion of truth at a time? Van Inwagen conducts a survey of plausible candidate meanings and argues that each is unsatisfactory. He seems to suggest that it follows that these expressions are meaningless. Of course, if these expressions are meaningless, so is the premise that $\left\langle p_{A}\right.$ is true at $\left.t_{-1 B}\right\rangle$. In this case, the argument for fatalism is unsound.

Unfortunately, it is impossible to do justice to van Inwagen's position here, just as it is impossible to consider the various ways a fatalist might respond. I will simply gesture at two responses on behalf of the fatalist. First, one might baldly assert that ' $p$ is true at $t$ ' means whatever ' $p$ is true' means: to say that a proposition is true at a time is just to say that it is true simpliciter. If one supposes that nothing exists outside of time, one might be sympathetic toward this view. Second, one might offer a tu quoque response by arguing that: (i) for any true proposition, either it is true at a time or it is timelessly true, (ii) the notion of 'timeless truth' is meaningless, therefore, (iii) every true proposition is true at (at least) one time. 


\section{Response 2: Rejecting Immutability}

Opponents of fatalism who affirm the truth-at-t principle might consider rejecting Immutability and embracing the 'open future view,' which Patrick Todd (forthcoming) defines as "the view that there are some events (or states of affairs, or ... ) such that it is not true that they will occur and not true that they will not occur." Proponents of this view can acknowledge a distinction between (i) contingent propositions about the future that are entailed by contingent propositions about the past and present and necessarily true propositions and (ii) contingent propositions about the future that are not so entailed. The pith of the open future view is that there are propositions of the latter sort (hereafter 'un-entailed future contingents'), and that if an un-entailed future contingent says either that some event will occur or that some event will not occur, that proposition is not true: the future is 'open' insofar as it is not yet a 'fact' whether certain events will (or will not) occur. In response to the argument for fatalism, the open futurist contends that there are no true propositions of the form $<S$ will freely perform $A>$. In the case of Mary and Harry, for instance, it is not true that Mary marries Harry in March of 3013. Ex hypothesi, this proposition will become true because, ex hypothesi, the ceremony will take place. Until 3013, though, it is not the case that the proposition is true. As my brief discussion of the history of the debate suggested, anti-fatalists who deny Immutability may either (i) join Aristotle in rejecting bivalence or (ii) join Prior in asserting the falsity of all un-entailed future contingents. In a moment, I will discuss the latter option. First, I turn to bivalence denial.

Bivalence, again, is the thesis that every proposition has exactly one truth value and there are no truth values other than truth and falsity. Open futurists who reject bivalence insist that un-entailed future contingents are neither true nor false. They might contend that such propositions have a truth value other than truth or falsity, or that such propositions have no truth value at all. Such a response to fatalism is certainly straightforward. After all, if propositions about the future are neither true nor false, their truth values do not impinge upon agents' abilities to do other than they do. Moreover, this straightforward response has a ring of plausibility to it. One might well reason that until something happens, there is no fact about whether it happens, and if there is no fact about whether something happens, the proposition that it happens is neither true nor false. At first blush, this response might seem very plausible indeed.

This response might seem less plausible, though, when one considers that classical logic is bivalent. To deny bivalence is, thus, to commit to the thesis that "classical logic is wrong - that it provides an inadequate model of (genuine) logical truth and logical consequence" (Sider 2010: 72). Fortunately for the bivalence denier, various three-valued (trivalent) systems of logic are on offer (see, for instance, the systems developed by Jan Kukasiewicz and Stephen C. Kleene). In addition to truth and falsity,

"The third truth value is (in most cases, anyway) supposed to represent sentences that are neither true nor false, but rather have some other status. This other status could be taken in various ways, depending on the intended application, for example: 'meaningless,' 'undefined,' or 'indeterminate."' 
With respect to the intended application of the third truth value, I note that sentences expressing future contingent propositions are not the only plausible candidates. One might reasonably suppose that a sentence is neither true nor false if, for instance (i) it involves a vague term, (ii) it expresses a proposition that involves a false presupposition (perhaps that the present king of France is bald), or (iii) it includes a reference to a fictional entity. Given that trivalent logic systems already exist, and given that concerns about vagueness, false presuppositions, and fictional entities provide additional reasons for rejecting bivalence, perhaps the rejection of classical logic is not too high a price to pay for a response to the fatalist.

Not so, say Russellian open futurists (so named by Patrick Todd, forthcoming). As open futurists, they reject Immutability and contend that no future contingent propositions are true. However, they contend that with respect to the choice between (i) rejecting classical logic and (ii) holding that all un-entailed future contingents are false, the latter option is far more economical. At the heart of their view is the thesis that a proposition is true if and only if the corresponding state of affairs obtains. Since future contingent states of affairs (such as Mary's marrying Harry) do not (yet) obtain, the corresponding future contingent propositions are not (yet) true. Moreover, given bivalence, a proposition is not true if and only if it is false. Hence, future contingent propositions are false.

An obvious objection arises: if Russellian open futurism is true, it is false that Mary will marry Harry and it is false that Mary will not marry Harry. Given that this result seems inconsistent with the Law of Non-Contradiction (according to which it is necessarily the case that $-(p \&-p))$, one might be suspicious of the Russellian open futurists' claim that they are able to maintain a commitment to classical logic. Russellian open futurists will respond that $<$ Mary will not marry Harry $>$ is not the negation of $<$ Mary will marry Harry $>$. Indeed, according to their view, (i) for any proposition $p$, the negation of $p$ is equivalent to the proposition $<$ It is false that $p>$ and that (ii) $<$ It is false that Mary will marry Harry $>$ is not equivalent to $<$ Mary will not marry Harry $>$. Again, to say that it is false that Mary will marry Harry is to say that the state of affairs of Mary's marrying Harry does not obtain, which is not to say that this state of affairs will not obtain, ever. As such, they contend, there is no contradiction in claiming both that it is false that Mary will marry Harry and false that she will not marry him.

At this point, it should be clear that the difference between Russellian open futurism and open futurism with bivalence denial is subtle. While proponents of the former view contend that its consistency with classical logic gives it a dialectical advantage over the latter, the significance of that advantage is not obvious. In order to assess its significance, one would need to explore the philosophy of logic in more depth than the limitations of this chapter allow. I will thus set aside the open futurists' internecine dispute about bivalence and classical logic.

Instead, I will raise a more general question about open futurism. When I introduced the view, I conceded the plausibility of the thesis that there is not yet a 'fact' about whether Mary will marry Harry. I now point out that it also seems plausible that if (i) Mary does indeed marry Harry on March 13, 3013, and if (ii) I now assert that Mary will marry Harry on that day, then (iii) I am now asserting a true claim. According to open futurists, however, even if Mary and Harry go through with the ceremony, I nonetheless fail to speak truly when I assert that they will do so. Granted, this is hardly a decisive objection. Nonetheless, the open futurist ought to acknowledge that as we go about our ordinary lives, many of us assume that (i) some of our beliefs about 
what will happen are true and (ii) some statements about the future are true. It seems as if we regularly make predictions about what will happen, and then wait to see whether our predictions are correct. In so doing, we seem to assume that it is possible for a future contingent proposition to be true. If the open futurist's response to fatalism is correct, these widespread assumptions are problematic. This seems to be a strike against open futurism.

But, of course, every response to fatalism has at least one strike against it. On this note, I turn to Ockhamism.

\section{Response 3: Ockhamism}

As Ockhamism is usually presented, its central thesis is that there is a distinction between so-called hard facts and so-called soft facts. While providing a clear and precise characterization of this distinction is difficult, the general idea is that,

"a hard fact about the past is entirely about the past whereas a soft fact is not: a hard fact about, say, $t_{-1 B}$ is a fact whose obtaining is entirely independent of whatever might happen after $t_{-1 B}$, whereas a soft fact about $t_{-1 B}$ somehow depends on, or involves, or includes events that take place at later times."

(See Finch and Rea 2008)

I follow Finch and Rea in characterizing the distinction in terms of future-directedness, stipulating that a soft fact is a state of affairs that obtains and is future-directed, and a hard fact is a state of affairs that obtains and is not future-directed, where "a state of affairs $S$ is future-directed just in case either S's obtaining entails that some contingent thing will exist or S's obtaining entails that no contingent thing will exist." Of course, whether a fact is hard or soft is relative to a time.

Once they draw this distinction, Ockhamists may object that the fatalists' argument trades on ambiguity regarding the principle of the Fixity of the Past. After all, they will say, the Fixity of the Hard Past is obviously true:

(FHP) Necessarily, for any agent $S$, any proposition $p$, and any time $t$, (i) if $p$ describes a state of affairs $O$ that is a hard fact at $t$, (ii) it is not up to $S$ at or after $t$ whether $p$ (is true),

but the Fixity of the Soft Past is false:

(FSP) Necessarily, for any agent $S$, any proposition $p$, and any time $t$, (i) if $p$ describes a state of affairs $O$ that is a soft fact at $t$, (ii) it is not up to $S$ at or after $t$ whether $p$ (is true).

Given that the fatalists' argument is sound only if the latter principle is true, Ockhamists reject fatalism.

Fatalists obviously deny the relevance of this distinction. They contend that with respect to propositions about the past, it is in virtue of their being about the past, and not in virtue of their being about a particular kind of fact, that agents lack power over their truth values. Ockhamists may respond that this approach rests on a misunderstanding about what it is to be able to render a proposition false. 
In order to appreciate the Ockhamists' response, let us recall that the Principle of the Fixity of the Past must be read as including a counterfactual conditional: if $p$ describes a state of affairs that obtains prior to $t$, there is nothing that $S$ at or after $t$ can do such that, if $S$ were to do it, $p$ would be false. If we consider the hard fact that Ockham died in 1347, it follows from the Principle of the Fixity of the Hard Past that:

Ockham dies in 1347 and there is nothing anyone can now do such that, if she were to do it, it would be false that Ockham dies in 1347.

The Ockhamist and the fatalist agree that everyone lacks this power.

With respect to the soft facts relating to Mary's wedding, though, Ockhamists can deny that:

Mary marries Harry at noon on March 13, 3013, and there is no time at which anyone can do anything such that, if she were to do it, it would be false that Mary marries Harry at noon on March 13, 3013.

In the case of Mary and Harry, Ockhamists will say, Mary at $t_{-}{ }_{M}$ is able to do something such that, if she were to do it, it would be false that Mary marries Harry at noon on March 13, 3013. I have already suggested that $t_{-}$may be a time at which Mary is able to postpone the wedding, leave Harry at the altar, utter "I don't," or remain silent so long that Harry himself stops the ceremony. Ockhamists qua Ockhamists need not give a full account of the genesis of Mary's free action. Their contention is that since Mary freely marries Harry at $t_{M}$ and $t_{-}{ }_{M}$ is the one time at which it is up to Mary whether she does so, it follows that there is something she can do. On pain of begging the question, Ockhamists insist, fatalists cannot respond by simply denying that Mary has these abilities. Fatalists owe Ockhamists an argument.

Of course, fatalists will say that they have already given an argument: the burden is on the Ockhamist to explain how it is possible for someone to do something such that, if she were to do it, the past would be different than it is.

To be clear, Ockhamists do not claim that agents can change the past, which would be absurd. Rather, they contend that if, for instance, Mary were to refuse Harry, it never would have been true that Mary marries Harry at noon on March 13, 3013. Soft facts somehow depend on, or obtain in virtue of, or obtain because of states of affairs that obtain in the future. So, for instance, one billion years ago, it was a soft fact that Mary marries Harry in 3013. That this was then a fact depends on what happens in 3013. As an Ockhamist might say, "Mary does not marry Harry in 3013 because it was true one billion years ago that she will do so; rather, it was true one billion years ago that Mary marries Harry in 3013 because she will, in fact, marry Harry on that date."

Unfortunately for Ockhamists, it is not clear what notion of 'dependence' they have in mind. One might suppose that they are committed to some kind of backward causation and, as such, are susceptible to the many objections that have been raised against it. However, Ockhamists themselves typically deny that they have this commitment and it seems that there are other notions of dependence that seem to better capture what is at the heart of Ockhamism. For instance, one might follow Todd (2013) in saying that soft facts are grounded in or ontologically dependent on hard facts. As promising as that suggestion might be, though, unless Ockhamists can explain what it is for one fact to ground, or ontologically depend on, another, their response to fatalism is incomplete. 
And as even a quick survey of the literature on grounding and ontological dependence shows (see, e.g., Correia and Schneider 2012), providing such an explanation is no mean feat.

\section{Response 4: Rejecting Diodoran principles}

One response to fatalism remains: rejecting Diodoran principles. While I formulated the fatalist's argument by way of the principle that (i) if $p$ is true and it is not up to $S$ at $t$ whether $p$, and (ii) if $p$ entails $q$, (iii) then $q$ is true and it is not up to $S$ at $t$ whether $q$, there are, as I said, many principles that have the same form as Diodorus'. As anyone familiar with the literature about the Consequence Argument knows, one might reasonably object to one formulation of such a principle while affirming the validity of another. For instance, McKay and Johnson (1996) present a counterexample to $\beta$, the Diodoran principle van Inwagen offered in An Essay on Free Will, but endorse a $\beta$-like (Diodoran) principle that is not susceptible to the counterexample in question. The strategy I am considering in this section is the wholesale rejection of all Diodoran principles. For ease of exposition, though, I will speak as if there is only one and that it is to be formulated as I formulated it here.

Unfortunately, in the context of the fatalism debate, having a fruitful discussion about the truth of the Diodoran principle may be impossible. On the one hand, there seems to be nothing to say in its favor except that it seems obviously true. One could ask rhetorical questions or state the principle in various ways, but the pith of the case for the Diodoran principle is an imperative: "look at it!" (As it happens, this case is quite strong: look at it indeed!) On the other hand, it is not as if it would be useful in this context, to try to provide a counterexample to it. After all, in order to provide a counterexample, we would need to describe a scenario in which (i) $q$ and it was up to $S$ at $t$ whether $q$, (ii) $p$ entails $q$, and (iii) $p$ and it is not up to $S$ at $t$ whether $p$. But the fatalists' very point is that it is logically impossible that there is any scenario in which (i) $q$ and it is up to $S$ at $t$ whether $q$. Fatalists can concede that there are cases in which it appears that agents act freely: they offer their argument to show that appearances are misleading. However, fatalists qua fatalists will reject any proposed counterexample as illegitimate. Debate between a fatalist and someone who does not accept the validity of the Diodoran principle will quickly reach an impasse.

At the outset of this chapter, I said that as I presented the argument for fatalism, I would indicate the ways in which it is structurally similar to the Consequence Argument for the incompatibility of free action and determinism. I note here that this structural similarity is convenient for compatibilists who are already committed to the invalidity of the Consequence Argument: they should simply deny the validity of the fatalist's argument and move on. Libertarians (incompatibilists who reject fatalism), by contrast, are not in such an easy dialectical situation. While there are other arguments for incompatibilism, there is no denying that the Consequence Argument is widely considered one of the best.

\section{Conclusion}

The argument for logical fatalism begins with bivalence and the (leeway theorists') definition of free action. Armed with (i) Truth-at-t, (ii) Immutability, (iii) the Fixity of the Past, and (iv) a Diodoran Principle, fatalists derive the conclusion that free action 


\section{ALICIA FINCH}

is impossible. While various responses to the argument are available, none is without cost. The question (as always in philosophy) is which costs one is willing to pay.

\section{References}

Aristotle (1963) Categories and De Interpretatione, trans. J. Ackrill. Oxford: Clarendon Press.

Copeland, B. (2008) "Arthur Prior," in E. Zalta (ed.), The Stanford Encyclopedia of Philosophy, available from: http://plato.stanford.edu/archives/fall2008/entries/prior/ (accessed 15 June 2016).

Correia, F. and Schneider, B. (eds) (2012) Grounding and Explanation. Cambridge: Cambridge University Press.

Finch, A. and Rea, M. (2008) "Presentism and Ockham's Way Out," in J. Kvanvig (ed.), Oxford Studies in Philosophy of Religion, Vol. 1. New York: Oxford University Press, pp. 1-17.

Kapitan, T. (2002) "A Master Argument for Incompatibilism?" in R. Kane (ed.), The Oxford Handbook of Free Will, 1st edn. New York: Oxford University Press, pp. 127-57.

McKay, T. and Johnson, D. (1996) “A Reconsideration of an Argument against Compatibilism," Philosophical Topics 24: 113-22.

Sider, T. (2010) Logic for Philosophy. Oxford: Oxford University Press.

Todd, P. (2013) "Soft Facts and Ontological Dependence," Philosophical Studies 164: 829-44.

Todd, P. (forthcoming) "Future Contingents Are All False! On Behalf of a Russellian Open Future," Mind. van Inwagen, P. (1983) An Essay on Free Will. Oxford: Clarendon Press.

\section{Further Reading}

Ockham, W. (1969) Predestination, God's Foreknowledge and Future Contingents, trans. M. McCord Adams and N. Kretzmann. Indianapolis: Hackett. (This volume includes Ockham's Treatise on Predestination and God's Foreknowledge with Respect to Future Contingents, Ordinatio [Distinctions 38 and 39], Commentary on Aristotle's De Interpretatione, Chapter 9, and Summa logicae, Part III [3], Chapter 30. Adams and Kretzman provide a helpful introduction to Ockham's thinking on the topic.)

Prior, A.N. (1957) Time and Modality. Oxford: Oxford University Press. (This monograph, based on his 1956 John Locke lectures, introduced Prior's work on tense and modal logic to a broad philosophical audience.)

\section{Related Topics}

Classical Compatibilism

The Consequence Argument

Theological Fatalism 


\section{7 \\ THE LUCK AND MIND ARGUMENTS \\ Christopher Evan Franklin}

\section{Locating the Luck and Mind Arguments}

The Luck Argument begins with the intuitively compelling idea that there is an inverse relation between luck and control: the more an action is subject to luck, the less it is under our control, and the more an action is under our control, the less it is subject to luck. The luckier my putt is, the less impressive it is that I made it. And if my putt is wholly a matter of luck, then it seems that the putt was not something I did at all. Luck and control thus appear to exclude each other: an action cannot be both wholly a matter of luck and wholly under our control.

The Luck Argument then calls attention to the apparent connection between luck and indeterminism: if an event is undetermined, then nothing made it happen. And surely if nothing made the event happen, then the event's occurrence is a matter of luck. Undetermined events, thus, are lucky events.

From these observations, the Luck Argument draws the conclusion that free actions, which must be under an agent's control, cannot be undetermined events: it is impossible for the free exercise of the will to be undetermined. Admittedly such a conclusion is counterintuitive. When people consider the various threats to the existence of free will and moral responsibility, notions such as determinism, genetics, and social engineering will immediately spring to mind. In this context the Luck Argument can seem puzzling: isn't indeterminism a refuge for free will and moral responsibility? Doesn't indeterminism provide the needed independence from the past and environment, allowing the world to be a garden of forking pathways, and we the captains who select among its many diverging paths?

The Luck Argument (Hume 1739/1978; Hobart 1934; Nowell-Smith 1948; Ayer 1954; Smart 1961; Russell 1984; Strawson 1986; Waller 1988; Double 1991; Haji 1999, 2001, 2012, 2013; Mele 1999, 2006; van Inwagen 2000; Levy 2011; Schlosser 2014) defends a negative answer to these questions. According to proponents of the Luck Argument, indeterminism is actually incompatible with free will. To clarify, the worry is not that free will is incompatible with indeterminism strictly speaking. The truth of indeterminism merely requires that there be at least one event that might not have occurred, given the exact same past and laws of nature. It is hard to see how the mere truth of this thesis could threaten the existence of free will (after all, perhaps indeterminism is restricted to distant galaxies, having only the faintest of effects on us). Rather, 
philosophers have worried that events that are undetermined cannot be instances of exercises of free will - it is in this sense that philosophers have argued that free will is incompatible with indeterminism. All uses of 'incompatibilism about free will and indeterminism' should be interpreted in this latter, more restricted fashion.

Since control comes in degrees, it is hard to nail down the Luck Argument in full generality. One might, for example, maintain that indeterminism does not preclude the possibility of exercising any control over our actions, but instead diminishes our control so severely that we never freely perform any of these actions. Nonetheless, the core of this argument can be characterized by the following two claims:

(LA1) If an event is undetermined, then it is a matter of luck.

(LA2) If an event is a matter of luck, then it is not an exercise of free will.

(LA1) is silent about whether an undetermined event is wholly or partly a matter of luck, and (LA2) is silent about whether luck precludes the possibility of an agent exercising any control or merely the degree of control necessary for free will and moral responsibility (here I assume that free will consists in the kind of control necessary for moral responsibility). The Luck Argument is really a family of arguments. What unites them is that they employ (LA1) and (LA2) in order to show that indeterminism is incompatible with free will. What differentiates them is how they fill in and defend these two premises. For example, some define 'luck' as an absence of a certain kind of explanation, and then argue that undetermined events are a matter of luck because they lack the relevant kind of explanation. Others leave 'luck' undefined and argue that undetermined action is a matter of luck because we cannot ensure whether such actions occur.

The usual target of the Luck Argument is libertarianism, the view according to which we are free and morally responsible, and yet freedom and responsibility are incompatible with determinism. Since libertarianism entails that indeterminism obtains, and since libertarians think that free will and moral responsibility entail that some free actions are undetermined, libertarians are committed to showing that indeterminism is compatible with free will and moral responsibility. According to the Luck Argument, this is a commitment they cannot make good on. But the actual target of the Luck Argument is broader than libertarianism: it raises problems for any theories that imply that free will is compatible with indeterminism, whether these theories be compatibilist or libertarian. While some compatibilists have argued that free will is not merely compatible with but requires determinism (Hume 1739/1978), most contemporary compatibilists pride themselves on claiming that freedom and responsibility do not turn on whether the universe is deterministic or indeterministic (Fischer and Ravizza 1998; Watson 1999; Vargas 2013). Following Vargas (2013), we can refer to compatibilists who think that free will is compatible with both determinism and indeterminism as "supercompatibilists." Thus, libertarians and most compatibilists are committed to dismantling the Luck Argument.

But then who endorses this argument? There are two dialectical contexts in which the Luck Argument usually appears: debates about the possibility (or actuality) of free will and debates about how best to formulate libertarianism. Many free will nihilists (Strawson 1986; Double 1991; Levy 2011) endorse the Luck Argument and employ it as part of a comprehensive argument for the impossibility of free will and moral responsibility. 
Oversimplifying, the idea here is that free will is incompatible with both determinism and indeterminism, and hence impossible. With respect to formulating libertarianism, many agent-causal libertarians employ the Luck Argument for more limited purposes: namely to show that event-causal libertarianism is an untenable theory. According to event-causal libertarians (Kane 1996; Ekstrom 2000; Balaguer 2010; Franklin 2011b), the role of the agent in performing free actions is exhausted by the causal role of mental states and events (e.g., desires and beliefs) involving the agent. Agent-causal libertarians (Chisholm 1966; O'Connor 2000; Clarke 2003; Griffith 2010; Steward 2012) contend that while part of the role of the agent might consist in the causal role of states and events involving the agent, the agent plays a further causal role: namely the agent himself, conceived of as an enduring substance, must be causally involved. The dispute between agent-causal and event-causal libertarians is not about whether agents cause things, since both think they do. The dispute is about whether an agent's causing a free action is reducible to states and events involving the agent causing the action. Eventcausal libertarians insist that it is so reducible, while agent-causal libertarians demur. Agent-causal libertarians who endorse a limited role of the Luck Argument aim to show that events that are nondeterministically caused solely by other events are lucky and thus cannot be instances of free and morally responsible action (Chisholm 1966; Griffith 2010). That is, they aim to show that exercises of free will require the agent to be an irreducible cause of an undetermined event. Finally, we even find some philosophers employing the Luck Argument within the event-causal libertarian's camp to help settle where in the action-sequence indeterminism should be located. For example, some argue that we can only avoid the worries raised by the Luck Argument if we locate indeterminism not at the moment of choice, but during the earlier deliberative process (Dennett 1978; Fischer 1995; Mele 1999; Ekstrom 2000).

We must sharply distinguish the Luck Argument from the problem of enhanced control-the problem of explaining how indeterminism is relevant to enhancing control (Watson 1999; Clarke 2003; Franklin 2011b). This problem, unlike the Luck Argument, is a distinctively libertarian problem. Libertarians contend that free will and moral responsibility are incompatible with determinism because agents in deterministic worlds cannot have the requisite kind or degree of control. They are, therefore, committed to the possibility of agents in indeterministic worlds having more or an enhanced degree of control with respect to agents in deterministic worlds. The problem is to explain how indeterminism is relevant to enhancing control. The Luck Argument, on the other hand, is a problem for anyone who thinks freedom and responsibility are compatible with indeterminism. Of course these issues are connected: if the Luck Argument is sound, the problem of enhanced control is insolvable. Nonetheless, dismantling the Luck Argument is not sufficient for solving the problem of enhanced control: there is nothing inconsistent in thinking that while indeterminism is irrelevant to enhancing control, it does not diminish it. There is some tendency in the literature to confuse these two issues. For example, Derk Pereboom's (2001, 2014) influential disappearing agent objection is often thought of as a version of the Luck Argument. According to Pereboom, agents who merely satisfy event-causal libertarianism lack the power to settle which of two causally possible actions they perform. The idea is that while such agents have the power to $\phi$ and the power to $\psi$, they lack the power to settle whether they $\phi$ rather than $\psi$. Closer inspection, however, reveals that Pereboom's argument is not about the problem of luck but rather the problem of enhanced control. His contention is not that indeterminism precludes agents' possessing the power to settle, but that 
event-causal libertarians' appeal to indeterminism is insufficient to ground agents' possessing this power.

As the title of this entry suggests, the Luck Argument is not the only influential argument that aims to show that indeterminism is incompatible with free will. Under the heading of "the Mind Argument" (so-called because these arguments so often appeared in the philosophy journal Mind), Peter van Inwagen (1983: 126-50) discusses three arguments, all of which aim to show that indeterminism is incompatible with free will. The first argument is a version of the Luck Argument, as it seeks to connect indeterminism with luck or chance and luck or chance with the absence of control. The second argument seeks to show, through a sorites-type thought experiment, that putatively free undetermined actions are no different than mere happenings. The third argument, which has received widespread attention, employs a key ingredient from van Inwagen's influential Consequence Argument (namely Rule $\beta$ ), to show that no one can control the outcome of an indeterministic process.

We are faced with the question of how to conceive of the relationship between the Luck and Mind Arguments. Putting aside the second argument (though see Shabo [2011, 2013, 2014] for development of it), I propose that we treat 'the Mind Argument' as referring exclusively to the third argument van Inwagen discusses, and 'the Luck Argument' to the first. This maps on well to the literature, as most discussions of 'the Mind Argument' are restricted to the third version (Finch and Warfield 1998; Clarke 2003; Franklin 2011a; Shabo 2013).

In what follows, I first discuss three influential formulations of the Luck Argument and then turn to the Mind Argument, offering some brief worries about each argument.

\section{The Ensurance Formulation}

Recall that the varying formulations of the Luck Argument employ and/or defend (LA1) and (LA2). The Ensurance Formulation of the Luck Argument has been most clearly and forcefully defended by Ishtiyaque Haji (1999, 2001, 2012, 2013; cf. Schlosser 2014). The core idea beyond this formulation is that if an agent performs an undetermined action $\phi$ at $t$, then she could not have ensured or guaranteed that she $\phi$-ed rather than $\psi$-ed at $t$. If my decision to walk to work was undetermined, then there is nothing about me, not my motivational state, beliefs, character, ability, or skill that ensures that I make this decision rather than, say, the decision to drive. Indeed, if the decision is undetermined, then there is nothing about the past and laws of nature that ensure that I make this decision rather than not. Thus, if my actions are undetermined, I cannot ensure them. And that seems to make them lucky.

I believe that something like this thought is behind most philosophers' suspicion that indeterminism is inimical to control. According to this formulation of the Luck Argument, indeterminism prevents agents from having the power to guarantee a particular outcome: agents try their best, but they cannot ensure what they will do. From this lack of ensurance, it is inferred that the action in question is a matter of luck, and thus we have (LA1) from above; and it seems that if an action is a matter of luck, then the action is not free and thus we have (LA2).

Opponents of the Luck Argument will want to raise worries about the notion of ensurance at the heart of this formulation. It is true that if my decision to walk to work is undetermined, then there is nothing prior to my making this decision that guarantees that I will make it. But why is that problematic? Admittedly, if my deciding to walk left 
it open whether I would in fact walk to work, and this not because I might change my mind and decide to drive instead, but simply due to the presence of indeterminism, then one might worry that indeterminism robs me of an important kind of control: namely the control to make decisions that, in turn, ensure what later actions I perform. But Haji's argument is stronger than this. He is contending that even my decisions must be ensured if they are to be free. The question naturally arises: ensured by what? Presumably not earlier decisions, since that would simply launch an infinite regress of decisions. It seems plausible to think that exercising our agency must have a beginning, and thus to require that all free exercises of agency be ensured would require that our first free actions be ensured by features of the world over which we never had any control. But that seems like a rather odd requirement for free will: why should free will require that our actions be wholly determined by factors over which we never had any control? At this point the Ensurance Formulation may begin to appear unmotivated.

\section{The Rollback Formulation}

Van Inwagen's (2000) well-known rollback thought experiment was originally introduced to show not that free will is incompatible with indeterminism, but that the agentcausal theory is irrelevant to solving the problem of free will-to explaining how free will is compatible with indeterminism. However, the thought experiment has taken on a life of its own, and in the hands of many is now used to develop the Rollback Formulation of the Luck Argument (e.g., Shabo 2013). We are asked to imagine that Alice is deliberating about whether to choose to tell the truth or to lie, that she is motivated and has the ability to do both, that she freely decides to tell the truth, and that this decision was undetermined. Next we are asked to imagine that God has caused the world to 'rollback' to precisely the state of the universe at the moment before Alice chose to tell the truth, let the world evolve from that point, and that we are in a position to observe this replay. Since Alice's choice is undetermined, she might choose to lie or she might choose to tell the truth in the 'replay.' Suppose that God does this 1,000 times: 1,000 times he causes the world to rollback to precisely the moment before Alice made her choice and then allows things to proceed. Furthermore, imagine that, after watching 726 replays, in about half of the replays, Alice has chosen to tell the truth, and in the other half, she has chosen to lie. After watching each of these replays, van Inwagen contends:

We shall be faced with the inescapable impression that what happens in the seven-hundred-and-twenty-seventh replay will be due simply to chance... [W] hat other conclusion can we accept about the seven-hundred-and-twentyseventh replay (which is about to commence) than this: each of the two possible outcomes of this replay has an objective, 'ground-floor' probability of $0.5-$ and there's nothing more to be said? And this, surely, means that, in the strictest sense imaginable, the outcome of the replay will be a matter of chance.

(van Inwagen 2000: 15)

Van Inwagen goes on:

If [Alice] was faced with telling the truth and lying, and it was a mere matter of chance which of these things she did, how can we say that —and this is essential 


\section{CHRISTOPHER EVAN FRANKLIN}

to the act's being free-she was able to tell the truth and able to lie? How could anyone be able to determine the outcome of a process whose outcome is a matter of objective, ground-floor chance?

The rollback thought experiment is supposed to bring forcefully home to us the thought that undetermined actions are lucky and that no one is able intentionally to prevent or bring about a lucky event. But not all share the intuition that this thought experiment is supposed to elicit. To begin to see this, we might ask how we would react if God rolled back the universe 1,000 times and Alice made the same decision every single time. For many, this would suggest her decision is not free. After all, if Alice really is torn about what to do, then wouldn't we expect that, under the present conditions, it was possible for her to make either decision? And given that it was possible for her to decide otherwise, then wouldn't we expect the replays to vary from playback to playback? Perhaps the variability in the playbacks is not as problematic as van Inwagen suggests.

\section{Explanatory Formulation}

The Explanatory Formulation of the Luck Argument maintains that luck is introduced into the action-sequence due to the unavailability of a certain kind of explanation. It is because the feature(s) necessary for the availability of such an explanation is (are) missing that the agent is subject to luck, so we have (LA1) from above, and, of course, luck intuitively seems to entail that the action in question is not free, and so we also have (LA2).

At times it has been suggested that undetermined action is essentially irrational action, or, at the very least, cannot be given a rational explanation (Ayer 1954), but few today make that claim. Rather most proponents of the Explanatory Formulation contend that undetermined action cannot be contrastively explained (Russell 1984; Waller 1988; Mele 2006; Levy 2011; Schlosser 2014). A contrastive explanation is an explanation of why one thing rather than another occurred. In the case of Alice above, a contrastive explanation of her choice to tell the truth would seek to explain why she chose to do this rather than lie. Many have thought that contrastive explanations are simply unavailable for undetermined events. Neil Levy nicely states this worry:

Now what brings it about that she $\phi$ s rather than $\psi s$ ? Nothing about her, her reasons, desires, volitions, or tryings. She does not control which alternative she settles for. The indeterministic causal process settles that. Thus, she experiences a diminution of control.

There are two main lines of response to this formulation. The first concedes that undetermined actions cannot be contrastively explained but denies that this is relevant to the agent's control. Some argue that whether an explanation is available for some action depends on certain pragmatic and epistemic conditions, whereas control exclusively depends on ontological conditions. Thus, we have little reason to think the absence of explanation entails the absence of control (Clarke 2003: 32; cf. Sorabji 1980; O'Connor 2000, 2009). The second line of response contends that we can give contrastive explanations of undetermined actions (Clarke 2003: 42-5; Franklin 2015). For example, 
and to oversimplify, I have appealed to Hitchcock's (1999, 2013) influential work on explanation to argue that we can provide a contrastive explanation of Alice's choice simply by citing her motivations that raised the likelihood of her so deciding (Franklin 2015). Suppose again that Alice chose to tell the truth and suppose that her belief that lying is wrong raised the probability of her choosing to tell the truth more than it raised the probability of her choosing to lie. The supposition here is not that Alice's belief made the probability of her choosing to tell the truth all things considered more probable, but simply that the belief raised the probability of her choosing to tell the truth more than it raised the probability of her choosing to lie. In such a case, Hitchcock, with certain suitable qualifications, maintains that Alice's belief explains why she chose to tell the truth rather than lie, even if it was all things considered more likely that she was going to choose to lie. Admittedly, we cannot give a contrastive explanation of her decision such that the factors cited guarantee that she chose to tell the truth rather than lie. But, I submit, that is a virtue of the account, not a vice. The attraction of libertarianism is that it promises to accord us, free agents, a fundamental role in the production of free decisions and actions. If libertarianism is true, then our free choices are neither the inevitable consequence of the past and laws of nature nor a simple function of our current motivational economy. On libertarianism we are fundamental sources of reality. Part of our fundamentality as agents requires that our exercises of agency not be explicable in certain senses in terms of other features of reality. If our exercises of free agency were made inevitable by the past and laws of nature, if there were conditions prior to and independent of our choices that guarantee that we will make the choices we make, then we would not be fundamental sources of reality but merely derivative sources. The very absence of this kind of explanation, the very absence of prior motivations that guarantee that we make one decision rather than another, is a requirement for agential fundamentality.

\section{The Mind Argument}

The Mind Argument is a direct argument for the incompatibility of indeterminism with free will and moral responsibility. The Luck Argument uses a middleman to try to establish this conclusion. It first attempts to show that indeterminism entails the presence of luck and then that luck entails the absence of control. The Mind Argument drops the middleman and argues that free will and moral responsibility are directly incompatible: it claims that indeterminism per se, regardless of any putative connection to luck, entails the absence of the degree of control necessary for free will and moral responsibility.

There are two key assumptions in the Mind Argument. The first is that someone is free with respect to action $\phi$ only if he had a choice about $\phi$. The second is that the following inference Rule $\beta$ is valid:

$$
\begin{aligned}
& N p \\
& \frac{N(p \rightarrow q)}{N q}
\end{aligned}
$$

where ' $\mathrm{N} p$ ' is to be read ' $\mathrm{p}$ and no one has or ever had a choice about whether $p$.' With these assumptions in place, van Inwagen argues that "no one has any choice about that 
which is undetermined" (1983: 142). He defends this claim by asking us to imagine a device, the salient features of which are a red light, a green light, and a button. When one presses the button there is an objective probability of one that either the red light or green light will flash, but an objective probability of less than one that the red light will flash and an objective probability of less than one that the green light will flash. Van Inwagen writes, "now suppose that you must press the button on this mechanism. Have you any choice about which of the lights will flash? It seems obvious that you have no choice about this" (1983: 142). The conclusion van Inwagen draws from this example is that no one has any choice about which light will flash, given that the button is pressed. Suppose you press the button and the red light flashes. According to van Inwagen, it is clear, since the connection between the button and the particular light flashing is nondeterministic, that you had no choice about whether the red light flashed given that the button was pressed. With these pieces in place, van Inwagen has the ingredients for a powerful argument that indeterminism is incompatible with free will.

Return to the case of Alice who made the undetermined choice to tell the truth. Focusing our attention on event-causal libertarianism, let us assume that Alice's choice to tell the truth—call it $\phi$-was nondeterministically brought about by some mental state $D B$ that favored it (for example, the belief that it is right to tell the truth and the desire to do what is right). It follows from this assumption that it was possible, given the past and laws, that $D B$ not have caused $\phi$. Suppose that had DB not caused $\phi$, then Alice would have chosen to lie-call this $\psi$ - and, let us further assume, that this action would have been nondeterministically brought about by a different mental state DB* that favored $\psi$ (for example, the desire to hide some fact and the belief that it will remain hidden if she lies). Finally, assume that Alice had no choice about $D B$ and $D B^{*}$. From our reflections on the simple device above, it follows that no one, let alone Alice, had a choice about whether $\phi$ follows $D B$, since $\phi$ followed nondeterministically from $\mathrm{DB}$ and no one has a choice about that which is undetermined. But then according to van Inwagen's inference Rule $\beta$, it follows that Alice had no choice about $\phi$. If Alice had no choice about $D B$ and she had no choice about $\phi$ 's following $D B$, then, according to rule $\beta$, she had no choice about $\phi$ itself. It follows from our assumption about free action that Alice's choice was not free. All these remarks generalize to all agents and all undetermined actions. Therefore, it appears that undetermined action cannot be free action.

The most significant problem with this argument is that Rule $\beta$ is invalid, as McKay and Johnson (1996) have shown and van Inwagen (2000) has conceded. Whether or not the argument can be reformulated with a new inference rule remains an open question (cf. Finch and Warfield 1998; Nelkin 2001). However, even assuming Rule $\beta$ is valid, one might argue that van Inwagen's device example is importantly disanalogous to standard libertarian theories. Most libertarians contend that indeterminism is located at the moment of action: what is undetermined is what an agent does (or chooses to do). There is no further requirement that the connection between the agent's action and consequences of this action be nondeterministic. But in the device example above, what is undetermined is not the agent's action of pressing the button, but the result of the agent's action, namely which light flashes. Thus, one might argue that, at best, van Inwagen's argument shows that if indeterminism is located after the moment of action, then control is diminished. But this conclusion alone does nothing to show that indeterminism located at the moment of choice or action diminishes control. Thus, it might seem that van Inwagen's argument has, at best, limited purchase on libertarians. 


\section{Conclusion}

The Luck and Mind Arguments present an important challenge to anyone who thinks that free will and moral responsibility are compatible with indeterminism-that is, anyone who thinks that it is possible that an agent perform an undetermined action that is free and for which he is morally responsible. According to these arguments, undetermined action cannot be something over which agents exercise sufficient control either for the action to be free or the agent to be morally responsible for it. For free will nihilists, the Luck and Mind Arguments are a powerful plank in their overall case against the possibility of free will and moral responsibility. For libertarians, these arguments serve as a barometer against which they determine how best to formulate libertarianism so as to defang the Luck and Mind Arguments-for example, either just how the agent must be involved in bringing about his free actions (fundamentally or reducibly) or proposals about where indeterminism should be located in the genesis of agential activity (in deliberation or choice or action or consequences of action?).

\section{References}

Ayer, A.J. (1954) "Freedom and necessity," in Philosophical Essays. New York: St. Martin's Press, pp. 3-20.

Balaguer, M. (2010) Free Will as an Open Scientific Problem. Cambridge: MIT Press.

Chisholm, R. (1966) "Freedom and Action," in K. Lehrer (ed.), Freedom and Determinism. New York: Random House, pp. 11-44.

Clarke, R. (2003) Libertarian Accounts of Free Will. New York: Oxford University Press.

Dennett, D. (1978) "On Giving Libertarians What They Say They Want," in D. Dennett, Brain Storms: Philosophical Essays on Mind and Psychology. Montgomery: Bradford books, pp. 286-99.

Double, R. (1991) The Non-reality of Free Will. New York: Oxford University Press.

Ekstrom, L.W. (2000) Free Will: A philosophical Study. Boulder: Westview Press.

Finch, A. and Warfield, T. (1998) "The Mind Argument and Libertarianism," Mind 107: 515-28.

Fischer, J.M. (1995) "Libertarianism and Avoidability: A Reply to Widerker," Faith and Philosophy 12: $119-25$.

Fischer, J.M. and Ravizza, M. (1998) Responsibility and Control: A Theory of Moral Responsibility. New York: Cambridge University Press.

Franklin, C.E. (2011a) "Farewell to the Luck (and Mind) Argument," Philosophical Studies 156: 199-230.

Franklin, C.E. (2011b) "The Problem of Enhanced Control," Australasian Journal of Philosophy 89: 687-706.

Franklin, C.E. (2015) "Agent-Causation, Explanation, and Akrasia: A Reply to Levy's Hard Luck," Criminal Law and Philosophy 9: 753-70.

Griffith, M. (2010) "Why Agent-Caused Actions Are Not Lucky," American Philosophical Quarterly 47: 43-56.

Haji, I. (1999) "Indeterminism and Frankfurt-type Examples," Philosophical Explorations 1: 42-58.

Haji, I. (2001) "Control Conundrums: Modest Libertarianism, Responsibility, and Explanation," Pacific Philosophical Quarterly 82: 178-200.

Haji, I. (2012) "Reason, Responsibility, and Free Will: Reply to My Critics," Journal of Ethics 16: 175-209.

Haji, I. (2013) "Event-Causal Libertarianism's Control Conundrums," Grazer Philosophische Studien 88: $227-46$.

Hitchcock, C. (1999) "Contrastive Explanation and the Demon of Determinism," British Journal of the Philosophy of Science 50: 585-612.

Hitchcock, C. (2013) "Contrastive Explanations," in M. Blaauw (ed.), Contrastivism in Philosophy: New Perspectives. London: Routledge and Kegan Paul, pp. 11-34.

Hobart, R.E. (1934) "Free Will as Involving Determination and Inconceivable Without It," Mind 43: 1-27.

Hume, D. (1739/1978) A Treatise of Human Nature, L.A. Selby-Bigge and P.H. Nidditch (eds), Oxford: Oxford University Press.

Kane, R. (1996). The Significance of Free Will. New York: Oxford University Press.

Levy, N. (2011) Hard Luck: How Luck Undermines Free Will and Moral Responsibility. New York: Oxford University Press. 


\section{CHRISTOPHER EVAN FRANKLIN}

McKay, T. and Johnson, D. (1996) “A Reconsideration of an Argument Against Compatibilism," Philosophical Topics 24: 113-22.

Mele, A.R. (1999) "Ultimately Responsibility and Dumb Luck," Social Philosophy and Policy 16: 274-93.

Mele, A.R. (2006). Free Will and Luck. New York: Oxford University Press.

Nelkin, D. (2001) "The Consequence Argument and the Mind Argument," Analysis 61: 107-15.

Nowell-Smith, P. (1948) "Free Will and Moral Responsibility," Mind 57: 45-61.

O'Connor, T. (2000) Persons and Causes: The Metaphysics of Free Will. New York: Oxford University Press.

O'Connor, T. (2009) "Agent-Causal Power," in T. Handfield (ed.), Dispositions and Causes. New York: Oxford University Press, pp. 189-214.

Pereboom, D. (2001) Living without Free Will. New York: Cambridge University Press.

Pereboom, D. (2014) Free Will, Agency, and Meaning in Life. Oxford: Oxford University Press.

Russell, P. (1984), "Sorabji and the Dilemma of Determinism," Analysis 44: 166-72.

Schlosser, M. (2014) "The Luck Argument against Event-causal Libertarianism: It Is Here to Stay," Philosophical Studies 167: 375-85.

Shabo S. (2011) "Why Free Will Remains a Mystery," Pacific Philosophical Quarterly 92: 105-25.

Shabo S. (2013) "Free Will and Mystery: Looking Past the Mind Argument," Philosophical Studies 162: 291-307.

Shabo S. (2014) “Assimilations and Rollbacks: Two Arguments Against Libertarianism Defended," Philosophia 42: $151-72$.

Smart, J.C.C. (1961) "Free-will, Praise and Blame," Mind 70: 291-306.

Sorabji, R. (1980) Necessity, Cause, and Blame. London: Duckworth.

Steward, H. (2012) A Metaphysics for Freedom. Oxford: Oxford University Press.

Strawson, G. (1986) Freedom and Belief. Oxford: Oxford University Press.

van Inwagen, P. (1983) An Essay on Free Will. Oxford: Clarendon Press.

van Inwagen, P. (2000) "Free Will Remains a Mystery," Philosophical Perspectives 14: 1-19.

Vargas, M. (2013) Building Better Beings: A Theory of Moral Responsibility. New York: Oxford University Press.

Watson, G. (1999) "Soft Libertarianism and Hard Compatibilism," Journal of Ethics 3: 351-65.

Waller, B. (1988) "Free Will Gone Out of Control: A Review of R. Kane's Free Will and Values," Behaviorism 16: $149-57$.

\section{Further Reading}

Clarke, R. (2003) Libertarian Accounts of Free Will. New York: Oxford University Press. (Chapters 5 and 9 provide an invaluable discussion and assessment of the Luck Argument for event-causal and agent-causal libertarianism.)

Franklin, C.E. (2011) "Farewell to the Luck (and Mind) Argument," Philosophical Studies 156: 199-230. (Offers a taxonomy and criticism of the various formulations of the Luck and Mind Arguments.)

Mele, A.R. (1999) "Ultimately Responsibility and Dumb Luck," Social Philosophy and Policy 16: 274-93; and van Inwagen, P. (2000) "Free Will Remains a Mystery," Philosophical Perspectives 14: 1-19. (These contain two of the most influential formulations of the Luck Argument.)

\section{Related Topics}

Event-Causal Libertarianism

Agent Causation

Non-Causal Libertarianism

Skeptical Views about Free Will

The Consequence Argument 


\section{8 \\ LEEWAY VS. SOURCEHOOD CONCEPTIONS OF FREE WILL \\ Kevin Timpe}

\section{Introduction}

One reason that many of the philosophical debates about free will might seem intractable is that different participants in those debates use various terms in ways that not only don't line up, but might even contradict each other. For instance, it is widely accepted to understand libertarianism as "the conjunction of incompatibilism [the thesis that free will is incompatible with the truth of determinism] and the thesis that we have free will" (van Inwagen 1983: 13f; see also Kane 2001: 17; Pereboom 2006: xiv). (However, for van Inwagen's later reservations about the use of the term 'libertarianism,' see van Inwagen 2008: 331f). This makes perplexing a number of views that have the name 'libertarian compatibilism' (see Vihvelin 2000; Arvan 2013) as on the standard use of the terms involved, this name appears to involve a contradiction.

Even the meaning and usage of the term 'free will' is itself contested. Manuel Vargas writes that "'free will' is a term of both ordinary and technical discourse" (Vargas 2013: 325). However, it is not clear if the ordinary use of the term always tracks the technical use. In an influential paper on "How to Think About the Problem of Free Will," Peter van Inwagen claims that "the phrase 'free will' . . . hardly exists except as a philosophical term of art. Its non-philosophical uses are pretty much confined to the phrase 'of his/her own free will' which means 'uncoerced"' (van Inwagen 2008: 320, footnote 1). To many of us, a look at the philosophical literature of the past millennium suggest a use that need not be a technical notion, even if it is often used in a technical way.

No matter how this debate about the 'ordinary use' of the phrase turns out, recognizing that 'free will' gets used in different ways and being careful in such usage is important in order to avoid what Chalmers has called 'merely verbal disputes' (Chalmers 2011).

For this reason, I want to be very clear in understanding and defining free will. There seem to be at least two different fundamental notions of what free will is in the contemporary literature. The first of these, which seems to have garnered the most attention in the last century, works under the assumption that for a person to rightly be said to have free will, she must have the ability to do otherwise than what she does, in fact, do. Under this view, I could be said to have freely chosen to drive to work only if 
I also could have freely chosen, for example, to bike to work or to skip work altogether. This approach to free will is referred to as a 'leeway-based approach' (see Timpe 2012) or an 'alternative-possibilities approach' (see Sartorio 2016).

In contrast, a smaller percentage of the extant literature focuses primarily on the issues of 'source,' 'ultimacy,' and 'origination.' This second approach doesn't focus immediately on the presence or absence of alternative possibilities. On this approach, I freely choose to drive to work only if I am the source of my choice and there is nothing outside of me from which the choice is ultimately derived. In what follows, we refer to the first of these conceptions-the conception that free will is primarily a matter of having alternative possibilities—as the 'leeway-based' conception. Similarly, we will refer to the second of these conceptions - that free will is primarily a matter of our being the source of our choices in a particular way-as the 'sourcehood' conception. (John Fischer and Carolina Sartorio refer to sourcehood views as 'actual sequence' views; see Fischer 2006 and Sartorio 2016).

Both of these conceptions can be seen in the following passage taken from Robert Kane:

We believe we have free will when we view ourselves as agents capable of influencing the world in various ways. Open alternatives, or alternative possibilities, seem to lie before us. We reason and deliberate among them and choose. We feel (1) it is 'up to us' what we choose and how we act; and this means we could have chosen or acted otherwise. As Aristotle noted: when acting is 'up to us,' so is not acting. This 'up-to-us-ness' also suggests (2) the ultimate control of our actions lies in us and not outside us in factors beyond our control.

(Kane 2005: 6)

In the next two sections, I look in greater detail at each of these two approaches to the nature of free will, and how they each seek to understand what it means for an action to be 'up to us.' I also show how the differences between these two conceptions cut across the debate about what Kane refers to as the Compatibility Question: "Is free will compatible with determinism?" (Kane 1996: 13). Along the way, I also briefly point out a number of ways how which of these conceptions is at work shapes how one engages various arguments and other issues regarding free will that are treated in greater detail elsewhere in this volume.

\section{Leeway-Based Conceptions}

As mentioned above, the vast majority of the contemporary free will literature focuses on the first of these two conceptions. This conception is so prevalent that Joseph Campbell calls it "the classical view" (Campbell 2011:5) and John Martin Fischer refers to it as the traditional view: "Traditionally the most influential view about the sort of freedom necessary and sufficient for moral responsibility posits that this sort of freedom involves the availability of genuinely open alternative possibilities at certain key points in one's life" (Fischer 1999: 99). Much of the discussion of free will in the second half of the twentieth century clearly evidences a concern with leeway and the ability to do otherwise. Consider the following quotations:

When I am said to have done something of my own free will it is implied that I could have acted otherwise ... To say that I could have done otherwise is to 
say, first, that I should have acted otherwise if I had so chosen; secondly, that my action was voluntary in the sense in which the actions, say, of the kleptomaniac are not; and thirdly, that nobody compelled me to choose as I did: and these three conditions may very well be fulfilled. When they are fulfilled, I may be said to have acted freely ... It may be said of the agent that he would have acted otherwise if the causes of his action had been different.

(Ayer 1997: 100, 110, 117)

It seems to be generally agreed that the concept of free will should be understood in terms of the power or ability of agents to act otherwise than they in fact do.

(van Inwagen 1983: 162)

These examples could be multiplied quite easily. While many philosophers approach free will presupposing the leeway conception, some go so far as to define free will in terms of it. Peter van Inwagen, for instance, writes that "to be able to have acted otherwise is to have free will" (van Inwagen 1983: 162), thereby identifying free will with the having of alternative possibilities. Similarly, Randolph Clarke writes: "I shall say that when an agent acts freely (or with free will), she is able to do other than what she does" (Clarke 2003: 3). I think that the fact that there are two competing conceptions of free will gives us good reason to resist this practice. For, as will be discussed below, it is a contentious issue whether the satisfaction of the alternative-possibilities condition is required for moral responsibility. We could, of course, reserve the use of 'free will' to mean the alternative-possibilities condition, and use some other term or phrase to refer to the kind of control required for moral responsibility. Some in the literature already use the term 'the control condition' in just this way. But I find this way of speaking to be clumsy and awkward. Consider also John Fischer's "semi-compatibilist" position (more on this view below). On the semi-compatibilist's view, satisfaction of the alternative-possibilities condition-which he often refers to as "regulative control"-is not required for moral responsibility, but another kind of control—-guidance control"is required for moral responsibility. Fischer writes: "moral responsibility does not require the sort of control that involves genuine metaphysical access to alternative possibilities ('regulative control'). Rather, 'guidance control' is the freedom-relevant condition necessary and sufficient for moral responsibility" (Fischer 2005: 148). The substantial influence of Fischer's view on the contemporary free-will literature gives us another reason to resist equating free will with the alternative-possibilities condition at the very beginning.

As indicated above, I grant that this conception has been the dominant approach for much of the last century, even among compatibilists. In his contribution to this volume, Berofsky differentiates a number of subspecies of leeway compatibilism:

Leeway compatibilism is the weak view that freedom is constituted by the presence of these multiple opportunities for action and determinism would certainly seem to be compatible with freedom in this sense. But the more interesting position is the stronger claim that freedom is constituted by the power to take advantage of these opportunities ... Since, obviously, the agent has the power to act as he does, the crucial component of freedom is the power to act otherwise, so-called counterfactual power.

(Berofsky, this volume, 43) 
The exact role that alternative possibilities play on these sorts of compatibilist views will depend on the details of the view under consideration.

David Lewis' "Are We Free to Break the Laws" is an influential instance of leeway-based compatibilism. There Lewis is primarily concerned with what he calls 'soft determinism,' the view that 'sometimes one freely does what one is [causally] predetermined to do; and that in such a case one is able to act otherwise though past history and the laws of nature determine that one will not act otherwise" (Lewis 1981: 113). Though he himself thinks that causal determinism is false, Lewis thinks that soft determinism is possibly true. Insofar as he thinks that there is at least one possible world where determinism is true and agents in that world still have the ability to do otherwise, his view can be seen as a form of leeway compatibilism. Lewis holds that if a determined agent had done otherwise, a miracle would have been involved. (For this reason, his view is referred to as "local miracle compatibilism."). But he distinguishes two different ways this claim can be understood. The weaker of the two claims is that in virtue of being free an agent is able to do something such that, if she were to do it, a law of nature would be broken. The stronger claim, which Lewis rejects, is that the agent is able to break a law of nature.

The ability to do such that a miracle would have been performed is not the only, or even the leading, form of leeway compatibilism. Consider what Peter van Inwagen refers to as conditionalism (van Inwagen 1983: 114) and others refer to as the conditional analysis. According to conditionalism, the proposition 'an agent could have done other than $A$ ' is to be understood along the lines of 'the agent would have done other than $\mathrm{A}$ if some condition $\mathrm{C}$ had been fulfilled.' One way of specifying condition $\mathrm{C}$ is with 'had the agent willed or chosen to do so.' For example, G. E. Moore writes that

[t]here are certainly good reasons for thinking that we very often mean by 'could' merely 'would, if so and so had chosen'. And if so, then we have a sense of the word 'could' in which the fact that we often could have done what we did not do, is perfectly compatible with the principle that everything has a cause.

(Moore 1912: 131)

And Ayer's commitment to conditionalism can be seen in the quotation above in the previous section. If the ability to do otherwise is to be understood as Moore, Ayer, and other proponents of conditionalism understand it, then given that the conditional could be true even if the antecedent of that conditional were determined to be false, having the ability to do otherwise would still be compatible with the truth of causal determinism.

However, such subjunctive accounts of the ability to do otherwise are thought by many to be a weakness in this sort of compatibilist position. Though a compatibilist himself, Michael McKenna describes the situation as follows:

Compatibilists were shouldered with the burden of crafting fancy counterfactual theories of agential ability, many of which were regarded as no more than one click away from smoke and mirrors. (And short of alchemy, smoke and mirrors is about the best one can offer). 
Conditionalism's analysis of the ability to do otherwise will only succeed if the antecedent is fulfillable by the agent.

However, if determinism is true, then whatever is used to fill in the antecedent of the conditional will be false precisely because it is determined to be false:

I could not have decided, willed, chosen or desired otherwise than I in fact did .... We will then want to know whether the causes of those inner states were within my control; and so on, ad infinitum. We are, at each step, permitted to say 'could have been otherwise' only in a provisional sense ... but must retract it and replace it with 'could not have been otherwise' as soon as we discover, as we must at each step, that whatever would have to have been different could not have been different.

(Taylor 1963: 44)

It is for this sort of reason that numerous incompatibilists have argued that such accounts are 'absurd' and 'incoherent.' And though compatibilist themselves, the above considerations have led John Martin Fischer to write that conditionalism "has fatal problems" (Fischer 2007: 50) while Joseph Campbell says that it is "prone to clear and decisive counterexamples" (Campbell 2011: 88).

More recently, the leading leeway compatibilist views are dispositional in nature. At the heart of dispositional compatibilist views is the claim that free will is primarily a (or set of) dispositional causal power(s). Having the relevant dispositions is consistent with the truth of determinism since determinism doesn't rule out dispositional powers. (Even if determinism is true, the glass is still fragile if it is disposed to break when struck.) And these dispositional powers also get us the ability to do otherwise. As Kadri Vihvelin says in her contribution to this volume,

We have the free will we think we have, including the freedom of action we think we have, by having some bundle of abilities and being in the right kind of surroundings - the surroundings that are test cases for the relevant dispositions .... On my view, these commonsense beliefs are true in virtue of the facts about my abilities and my surroundings. I was free to decide otherwise because I had and exercised the ability to decide, on the basis of deliberation, whether to get the coffee or continue typing.

(Vihvelin, this volume, 58)

Further discussion of dispositional compatibilist views can be found there.

I will refer to those incompatibilists who endorse a leeway-based conception of free will as 'leeway incompatibilists.' Leeway incompatibilists are thus those incompatibilists who think that having alternative possibilities is at the heart of free will. Given that the incompatibilist thinks that free will requires there to be indeterminism in the world, it should not be surprising that many incompatibilists have focused on the ability to do otherwise. Van Inwagen's view, mentioned above, is probably the best-known leeway incompatibilist view.

This conception has been central to some of the most influential arguments for incompatibilism (e.g., I think a leeway conception is at the heart of the Consequence Argument), and a leeway-based understanding has been reinforced by the importance and influence of those arguments. Another important motivation for leeway-based 
approaches is the Kantian-inspired 'ought implies can' principle. For those who think of free will as necessary for moral responsibility, it might seem that an agent can only be obligated to perform a particular action if she can perform it. If an agent is blameworthy for doing something that she ought not to have done (or is blameworthy for not doing something that she ought to have done), then the 'ought implies can' principle requires that she could have refrained from doing it (or could have done what she refrained from doing). Davids Widerker and Copp each have arguments that the need for leeway follows from the 'ought implies can' principle (see their contributions to Widerker and McKenna 2003). Briefly considered, suppose that Emmaline does something blameworthy such that she ought to have refrained from doing it. According to the Kantian dictum, saying that she ought to have refrained entails that she could have refrained. But Emmaline could not have refrained, according to the incompatibilist, unless her refraining was consistent with the conjunction of the past and the laws of nature. But if she did a blameworthy action and, when she did so, it was consistent with the conjunction of the past and the laws of nature that she refrained from performing that very act, then Emmaline has alternative possibilities regarding the action in question. And the point about this action generalizes to all morally responsible actions.

Whereas 'ought implies can' might be seen as suggesting a leeway approach, it has also contributed to the prevalence of the Luck and Mind arguments against leeway-based libertarian views. The basic idea here is that if an event is undetermined, then nothing made it happen. And if nothing made an event happen, then the agent in question couldn't control that event: an action cannot be both a matter of luck and under the agent's control. Similarly, the Mind Argument argues directly from the leeway that indeterminism provides to the lack of free will. (For a further discussion of these arguments, see Franklin's chapter in this volume on 'the Luck and Mind Arguments'; as Franklin there notes, the Luck Argument isn't restricted to libertarian views).

The mere possibility of something else happening would seem to undermine rather than enhance control, and thus it's hard to see how alternative possibilities could be the heart of free will. As Fischer noted in an early paper on incompatibilist responses to Frankfurt-cases, "[f]or the agent to have control, in the relevant sense, there must be an alternate sequence in which the agent does otherwise as a result of an appropriate sort of chain of events" (Fischer 1982: 31; see also Timpe 2012: Chapter 10). Rather than merely having alternative possibilities, many think that in order to be relevant to the agent's free will the remaining alternative possibilities must be under the control of the agent in some appropriate way. Insofar as it is an incompatibilist theory, whatever it is about the agent in virtue of which she controls what alternative possibility becomes actual will have to be something that is not causally determined by anything outside of her. Most often, the language used at this point is that of the agent being the 'source' of the action, or the action 'originating' in the agent in some particular way, or the agent 'initiating' the choice, or the outcome 'ultimately' being up to the agent.

\section{Sourcehood Conceptions}

In part because of the kinds of considerations raised above regarding both leeway compatibilism and leeway incompatibilism, it is not clear that the having of alternative possibilities, as per leeway-based approaches, is central to the nature of free will. 
One reason is that it does not seem that the mere having of alternative possibilities will be sufficient for free will, since to say what 'could have happened instead' doesn't address why what happened did happen. A number of philosophers, incompatibilists and compatibilists alike, therefore reject leeway-based approaches and advocate instead for views according to which being the 'source' of the action in the relevant way is more fundamental. (I say 'more fundamental' because some source-based theorists think that satisfying the sourcehood condition on free will would entail also satisfying some alternative possibilities condition. See, for instance Timpe [2012: Chapter 9]. There also could be views according to which alternatives and sourcehood are equally fundamental. See Tognazzini [2011] for a relevant discussion, including five different formulations of the fundamental source incompatibilist thesis.) Of course, specifying what is required for 'being the source in the right way' is contested.

Derk Pereboom nicely captures why some incompatibilists endorse source-based views as follows:

I oppose a type of incompatibilism according to which the availability of alternative possibilities is the most important factor for explaining moral responsibility, and accept instead a variety that ascribes the most significant explanatory role to the way in which the agent actually produces the action. In metaphysical terms, the sort of free will required for moral responsibility does not consist most fundamentally in the availability of alternative possibilities, but rather in the agent's being the causal source of her action in a specific way.

(Pereboom 2013: 421)

Michael McKenna writes as follows:

Source incompatibilists hold that determinism does rule out free will. But it does so, not because it rules out alternative possibilities, but instead, because, if true, the sources of an agent's actions do not originate in the agent but are traceable to factors outside her.

(McKenna 2003: 201)

And McKenna has more recently written, "the core [source] incompatibilist thought is that an agent is the ultimate cause of his action only if he contributes some necessary ingredient to it that cannot be traced back to causally sufficient conditions obtaining independently of him." (McKenna 2010: 437. He, of course, doesn't endorse such a position.)

Robert Kane's view is the most worked out source incompatibilist view (see Kane 1996, 2005), and his view has shaped the views of many other source incompatibilists (see Goetz 2011 and Timpe 2012). It is plausible that the sourcehood condition is more important for free will than the mere having of alternatives for libertarianism, though I think the relationship between the sourcehood condition and the alternative-possibilities condition is complex. As I've argued elsewhere (Timpe 2012: Chapter 9), it may be that satisfying the sourcehood condition, on the assumption of incompatibilism, at any time will entail satisfying some alternative possibilities condition at that or an earlier time (for reasons related to tracing). For if, again on the assumption of incompatibilism, an agent is the source of her action, then it will be an action that is not causally determined. And if it's not causally determined, then there will be two or more alternative possibilities 
compatible with the state of the universe immediately prior to the agent's origination of her action. (See also Zagzebski 2000, 2014, for related arguments; for a slightly different take on what makes a view an actual-sequence view, see Sartorio 2016: Chapter 1). And proponents of agent-causation, most but not all of whom are incompatibilists, will "understand sourcehood in terms of an agent's literally being the uncaused cause of his or her actions" (Tognazzini 2011: 74).

Both of the leading contemporary compatibilist accounts of free will are best understood as source-based views. (These views are dealt with in more detail elsewhere in this volume. See the chapters by Fischer and Jaworska). Consider Harry Frankfurt's hierarchical compatibilism. In an early version of this view, a person has free will (or what Frankfurt calls "freedom of the will") if she has second-order volitions in the actual sequence-that is, if she has a desire that certain other of her desires actually move her to action-and if those second-order volitions mesh with her first-order desires. Just as freedom of action is being able to do what one wants to do, freedom of the will is being able to have the kind of will that one wants to have. It is for this reason that Frankfurt's account is often called a 'structural' or 'hierarchical' account, since he understands freedom of the will to be primarily a function of having a certain kind of structural or hierarchical mesh between one's first- and second-order desires and volitions.

A wants the desire to $\mathrm{X}$ to be the desire that moves him effectively to act. It is not merely that he wants the desire to $\mathrm{X}$ to be among his desires by which, to one degree or another, he is moved or inclined to act. He wants this desire to be effective- - that is, to provide the motive in what he actually does.

(Frankfurt 1988: 15)

On this view, having free will is primarily a function of having that choice's source be located in the agent in a particular way-namely if the first-order volition meshes with the agent's second-order desire for the first-order desire to become a volition. And since having the will one wants to have is independent of whether one could have had a different will, Frankfurt's account isn't based on an alternative-possibilities condition. A natural way of understanding Frankfurt's view at this point is as involving a certain kind of sourcehood condition, which might be put as follows:

A person wills freely only if he wills in a way that is consistent with a secondorder desire.

This early way of putting it was criticized by, among others, Gary Watson: "Since secondorder desires are themselves simply desires, to add them to the context of a conflict is just to increase the number of contenders; it is not to give a special place to any of those in contention" (Watson 1975: 218). In response to this kind of criticism, Frankfurt later came to add that wholehearted identification was also necessary. Wholehearted identification, for Frankfurt, does not require the complete absence of conflicts among an agent's desires. Rather, Frankfurt understands that an agent can be wholehearted even if his desires conflict so long as he decisively identifies with one of these desires and separates himself from the other. As Frankfurt puts it, "the conflict between the desires is in this way transformed into a conflict between one of them and the person who has 
identified himself with its rival" (Frankfurt 1988: 172). In earlier work, I described Frankfurt's view as follows:

According to Frankfurt, a person chooses freely only if he chooses in a way that is consistent with a second-order desire that he whole-heartedly identifies with-that is, if the source of that volition is a desire with which the agent unwaveringly aligns himself.

(Timpe 2012: 125)

Since Frankfurt grounds freedom of the will in the agent's choice originating in his volitional structure in a particular way, not only is free will internal to the agent's volitional structure but it more specifically involves the source of the agent's first-order volitions being located in those second-order desires with which she identifies.

Similarly, John Martin Fischer's view (developed originally with Mark Ravizza) is also best viewed as a form of source compatibilism. Fischer calls his view 'semi-compatibilism;' by this he means that the truth of causal determinism is compatible with moral responsibility even if causal determinism ends up being incompatible with a certain kind of freedom. Fischer differentiates between two kinds of control: guidance control and regulative control. Regulative control involves alternative possibilities. And while Fischer thinks that "it's natural to think that we need alternatives in order to be responsible" (Fischer 2000a: 326), for reasons that have to do with Frankfurt-style examples he does not think that this is the kind of freedom or control needed for moral responsibility. Instead, what is required here is guidance control, which is best understood as a form of sourcehood.

Fischer's discussion of guidance control is extensive, but we can focus here on the two central aspects that he thinks are needed for an agent to have guidance control. "Guidance control of one's behavior has two components: the behavior must issue from one's own mechanism, and this mechanism must be appropriately responsive to reasons" (Fischer 2002: 307). The responsiveness that Fischer and Ravizza take to be required here requires that the agent act on a mechanism that is moderately reasons responsive.

The second requirement for guidance control is that the agent takes responsibility for the reasons-responsive mechanism that results in his choices; that is, that the mechanism is his own or one for which he has taken responsibility. This feature of Fischer's view marks an important difference with Frankfurt. Recall that in Frankfurt's view, all that is needed is the right sort of hierarchical mesh among an agent's desires, including wholehearted identification. Numerous philosophers have objected to this feature of Frankfurt's account, since they think it leads to the conclusion that manipulation need not undermine control. Frankfurt himself admits that manipulated agents could still be free: a "manipulator may succeed, through his interventions, in providing a person not merely with particular feelings and thoughts but with a new character. That person is then morally responsible for the choices and the conduct to which this character leads" (Frankfurt 2002: 28). However, Fischer is sensitive to this worry:

I think that manipulation cases are a compatibilist's dirty little secret. Compatibilists don't like to admit that this is a problem ... [But] we compatibilists have to deal with this. In my view, honestly, Harry Frankfurt really has not addressed this problem. He has discussed it in different ways and in different places and it doesn't add up to much.

(Fischer 2000b: 390) 
One can think of Fischer's ownership requirement as an attempt to avoid the problems regarding manipulation besetting Frankfurt's account: "the mere existence of a mesh is not sufficient for [the kind of freedom required for] moral responsibility; the history behind the mesh is also relevant" (Fischer and Ravizza 1998: 196).

Rather than primarily focusing on the mesh within an agent's volitional structure, Fischer thinks responsibility must involve the agent's taking responsibility. This involves three related elements:

Taking responsibility involves three elements. First, the agent must see that his choices have certain effects in the world - that is, he must see himself as the source of consequences in the world (in certain circumstances). Second, the individual must see that he is a fair target for the reactive attitudes as a result of how he affects the world. Third, the views specified in the first two conditions- that the individual can affect the external world in certain characteristic ways through his choices, and that he can be fairly praised and/or blamed for so exercising his agency — must be based on his evidence in an appropriate way.

(Fischer 2006: 224)

Putting these various elements together, we can understand Fischer's view as follows: According to Fischer, a person chooses freely only if he chooses as he does

1. because of an appropriately reasons-responsive mechanism; and

2. he sees that mechanism as his own in an appropriate way.

We might think of these two aspects as respectively insisting on the agent having the right kind of reasons-responsiveness and the right history behind that reasons-responsiveness. Taken together, these two aspects clearly mark it as a sourcehood approach—or as Fischer often puts it, an 'actual-sequence' approach to free will and moral responsibility.

Here, the goal hasn't been to criticize either Frankfurt's or Fischer's view (though see Timpe 2012: Chapter 8). Rather, the aim was to show how both of these exceedingly influential contemporary compatibilist accounts are best seen as focusing on sourcehood rather than leeway.

\section{Conclusion}

In the previous sections, I've explored both leeway and sourcehood conceptions of free will, and how each aims to account for what it means for an action to be 'up to us.' I've also shown how this division is orthogonal to the Compatibility Question.

In closing, it should also be noted that which of these two fundamental conceptions of free will is assumed makes a difference to how one evaluates some of the most influential arguments regarding the relationship between free will and the truth of causal determinism. A number of these connections have already been made, such as the connection between leeway and the Luck and Mind arguments. And though I haven't here made the case, I think that a similar claim could be defended regarding the Consequence Argument (see the chapter in this volume by Campbell). Furthermore, the ability to do otherwise that is at the heart of leeway-based approaches has led to the enormous literature devoted to Frankfurt-style counterexamples to the Principle of Alternative Possibilities. See Carolina Sartorio's chapter in this volume for more on these examples and the role 
they play in adjudicating leeway versus sourcehood views. As she notes there, a key role that these kinds of cases involve is in terms of "motivating a different view of freedom, one that is not at all based on the availability of alternative possibilities, but only on the relevant actual sequences or actual explanations of behavior" (Sartorio, this volume, page 184). This alternative is, of course, sourcehood. For a treatment of the central role that causation plays in a source-based view, see Sartorio (2016).

So while I think that the Compatibility Question is an important question that will rightly continue to attract attention in the contemporary debates about the nature of free will, there are other issues that also deserve continued attention-including, I would say, whether free will is ultimately understood along the lines of leeway or sourcehood.

\section{Acknowledgments}

Thanks to Meghan Griffith, Neal Tognazzini, and Paul Franks for helpful comments on earlier drafts of this chapter.

\section{References}

Arvan, M. (2013) "A New Theory of Free Will," Philosophical Forum 44: 1-48.

Ayer, A.J. (1997) "Freedom and Necessity," in D. Pereboom (ed.), Free Will. Indianapolis: Hackett, pp. $110-18$.

Campbell, J.K. (2011) Free Will. New York: Polity.

Chalmers, D. (2011) "Verbal Disputes," The Philosophical Review 120: 515-66.

Clarke, R. (2003) Libertarian Accounts of Free Will. New York: Oxford University Press.

Fischer, J.M. (1982) "Responsibility and Control," The Journal of Philosophy 79: 24-40.

Fischer, J.M. (1999) "Recent Work on Moral Responsibility," Ethics 110: 93-139.

Fischer, J.M. (2000a) "Problems with Actual-Sequence Incompatibilism," Journal of Ethics 4: 323-8.

Fischer, J.M. (2000b) "Responsibility, History, and Manipulation," Journal of Ethics 4: 385-91.

Fischer, J.M. (2002) "Frankfurt-type Examples and Semi-compatibilism," in R. Kane (ed.), The Oxford Handbook of Free Will. New York: Oxford University Press, pp. 281-308.

Fischer, J.M. (2005) "Reply: The Free Will Revolution," Philosophical Explorations 8: 145-56.

Fischer, J.M. (2006) My Way: Essays on Moral Responsibility. Oxford: Oxford University Press.

Fischer, J.M. (2007) "Compatibilism," in D. Pereboom, J.M. Fischer, R. Kane, and M. Vargas (eds), Four Views on Free Will. Oxford: Blackwell, pp. 44-84.

Fischer, J. M. and Ravizza, M. (1998) Responsibility and Control. Cambridge: Cambridge University Press.

Frankfurt, H. (1988) The Importance of What We Care About. New York: Cambridge University Press.

Frankfurt, H. (2002) "Reply to John Martin Fischer," in S. Buss and L. Overton (eds), Contours of Agency: Essays on Themes from Harry Frankfurt. Cambridge: MIT Press, pp. 27-32.

Goetz, S. (2011) Freedom, Teleology, and Evil. London: Continuum.

Kane, R. (1996). The Significance of Free Will. New York: Oxford University Press.

Kane, R. (2001) "Introduction,” in R. Kane (ed.), Free Will. Malden: Blackwell, pp. 1-26.

Kane, R. (2005) A Contemporary Introduction to Free Will. Oxford: Oxford University Press.

Lewis, D. (1981) “Are We Free to Break the Laws?” Theoria 47: 113-21.

McKenna, M. (2003) "Robustness, Control, and the Demand for Morally Significant Alternatives: Frankfurt Examples with Oodles and Oodles of Alternatives," in D. Widerker and M. McKenna (eds), Moral Responsibility and Alternative Possibilities: Essays on the Importance of Alternative Possibilities. Burlington: Ashgate, pp. 201-17.

McKenna, M. (2005) "Where Frankfurt and Strawson Meet," Midwest Studies in Philosophy 29: 163-80.

McKenna, M. (2010) "Whose Argumentative Burden, Which Incompatibilist Arguments?-Getting the Dialectic Right," Australasian Journal of Philosophy 83: 429-33.

Moore, G. E. (1912). Ethics. London: Williams and Norgate.

Pereboom, D. (2006) Living Without Free Will. Cambridge: Cambridge University Press. 


\section{KEVIN TIMPE}

Pereboom, D. (2013) "The Philosophy of Free Will," in P. Russell and O. Deery (eds), The Philosophy of Free Will. Oxford: Oxford University Press, pp. 421-48.

Sartorio, C. (2016) Causation and Free Will. Oxford: Oxford University Press.

Taylor, R. (1963) Metaphysics. Englewood Cliffs: Prentice Hall.

Timpe, K. (2012) Free Will: Sourcehood and Its Alternatives, 2nd edn. London: Bloomsbury.

Tognazzini, N. (2011) "Understanding Source Incompatibilism," The Modern Schoolman 88: 73-88.

van Inwagen, P. (1983) An Essay on Free Will. Oxford: Clarendon Press.

van Inwagen, P. (2008) "How to Think about the Problem of Free Will," Journal of Ethics 12: 327-41.

Vargas, M. (2013) "Situationism and Moral Responsibility: Free Will in Fragments," in J. Kiverstein, A. Clark, and T. Vierkant (eds), Decomposing the Will. Oxford: Oxford University Press, pp. 325-50.

Vihvelin, K. (2000) "Libertarian Compatibilism," Philosophical Perspectives 14 (Action and Freedom): $139-66$.

Watson, G. (1975) "Free Agency," Journal of Philosophy 72: 205-20.

Widerker, D. and McKenna, M. (eds.) (2003) Moral Responsibility and Alternative Possibilities: Essays on the Importance of Alternative Possibilities. Burlington: Ashgate.

Zagzebski, L. (2000) "Does Libertarian Freedom Require Alternate Possibilities," Philosophical Perspectives $14: 231-48$.

Zagzebski, L. (2014) "Divine Foreknowledge and the Metaphysics of Time," in A. Ramelow (ed.), God: Reason and Reality. Munich: Philosophia Verlag, pp. 275-302.

\section{Further Reading}

Clarke, R. and Reed, T. (2015) "Free Will and Agential Powers," in D. Shoemaker (ed.), Oxford Studies in Agency and Responsibility, Vol. 3. Oxford: Oxford University Press, pp. 6-33. (Argues that having free will depends on having certain powers, with a focus on what it means for those powers to be 'up to oneself'.)

Sartorio, C. (2016) Causation and Free Will. Oxford: Oxford University Press. (An excellent extended discussion of the role that sourcehood and leeway play in free will from a compatibilist perspective.)

Timpe, K. (2012) Free Will: Sourcehood and Its Alternatives, 2nd edn. London: Bloomsbury. (Explores in greater length the relationship between the compatibility question and the contrast between leeway and sourcehood views.)

Timpe, K. and Jacobs, J. (2015). "Free Will and Naturalism: How to be a Libertarian and a Naturalism Too," in K.J. Clark (ed.), Blackwell Companion to Naturalism. Chichester: Wiley-Blackwell, pp. 319-55. (Gives an account of the agential powers that could ground sourcehood, while being neutral with respect to the compatibility question.)

Tognazzini, N. (2011) "Understanding Source Incompatibilism," The Modern Schoolman 88: 73-88. (Carefully delineates a number of different ways of describing source incompatibilism.)

\section{Related Topics}

Semicompatibilism

Classical Compatibilism

Event-Causal Libertarianism

Agent Causation

The Consequence Argument

The Manipulation Argument

Frankfurt-Style Examples 


\section{Section III}

\section{HISTORICAL FIGURES}

David Hume once wrote that the question of the nature of free will is "the most contentious question of metaphysics" (Hume 1975, 95). Whether or not this is true (how would one judge if free will is more contentious than the nature of causation or the existence of universals?), it is certainly the case that Western philosophy has a long and venerable tradition of reflecting on the nature of free will. Many of the philosophical giants of the medieval, modern, and contemporary periods have addressed free will as part of their philosophical systems.

The primary goal of this section is to collect in one place what many of the most important philosophers in history have had to say about free will. Even though this section of the volume has more entries than any of the other five sections and comprises over a quarter of the length of the entire volume, two related limitations must be explicitly stated. The first is that despite the length of this section, it unfortunately leaves out a number of important historical figures who have engaged the nature of free will. We have tried our best to include those figures who have been most influential in the history of philosophical reflection on free will, but we realize that some of our choices to include certain individuals and to exclude others will likely be contentious. This is a limitation that simply couldn't be avoided.

Second, as even a quick glance at the contents for this section will reveal, it has many of the same biases that philosophy in the English-speaking world does. It focuses almost exclusively on Western philosophy, for instance, rather than Eastern (or African, or ... ) philosophy. Relatedly, it is also dominated by male voices. While we think that this is an unfortunate aspect of the Western philosophical tradition, given that the goal of this section is, as stated above, to set out what many of the most important philosophers in that tradition have said about free will, the limitations of this section seem necessary.

The majority of the figures included here will come as no surprise. A selection that did not include Augustine or Hobbes or Hume or Reid would contain an obvious lacuna. But this section begins with what may seem an unusual choice-Aristotlesince a number of scholars have argued that Aristotle's corpus contains no conception of the will, and thus no free will can be found in his thought. However, Karen M. Nielsen argues that there is a conception of the will that can be found in Aristotle, though under a different description. She also shows how this conception is taken up by later Aristotelians, shaping how later influential figures would understand free will. In the next chapter, Tim O'Keefe argues that the Stoics were the first philosophers to directly 
address the compatibility of free will with determinism, but that this compatibility is rooted in their fatalistic approach — an approach that would largely be rejected by subsequent philosophers.

In canvassing those figures of the medieval and modern periods contained herein, the contributors not only try and present the relevant figures' views on their own terms and within the context of their larger thought, but they've also tried to note, even if just in passing, how those views relate to issues and arguments that play an important role in contemporary debates.

This section ends with an attempt to expand beyond Western philosophy by including chapters on Chinese and Indian philosophy. While Chinese philosophy did not directly address free will until nineteenth-century Western philosophical work, like that of Kant, was translated into Chinese, it did address a number of issues that are closely related to Western discussions of free will. Marchal and Wenzel lay out, in broad perspective, how various notions in pre-modern China resemble, and also differ from, Western conceptions of freedom and responsibility. And Arindim Chakrabarty canvases various schools of Indian philosophy, ranging from 1000 BCE through the twentieth century, to give a thorough and developmental overview of how a wide range of issues related to free will have been understood on the subcontinent. These two chapters hope to bring previously under-engaged resources into discussion with the West's discussion of free will.

K.T.

\section{Reference}

Hume, D. (1975) Enquiry Concerning Human Understanding. Oxford: Clarendon Press. 


\section{9 \\ ARISTOTLE \\ Karen Margrethe Nielsen}

In her recent paper "Free Will in Aristotle?" Dorothea Frede makes a claim that is emblematic of the attitude to the question in scholarship over the past century.

In principle one could make short shrift with the question of free will in Aristotle. Given that he has no concept of a will, there is a fortiori no concept of a free will. To explain the reason for this seeming gap in Aristotle's psychology takes somewhat longer.

(Frede 2015: 39)

The aim of this chapter is to challenge the premise of D. Frede's "bypass" argument, viz., the premise that Aristotle has no concept of a will. As early as 1923, W.D. Ross remarks that "it has often been complained that the psychology of Plato and Aristotle has no distinct conception of the will” (Ross 1923: 199). Ross maintains that Aristotle shares "the plain man's belief in free will" (sic), though he complains that Aristotle "did not examine the problem very thoroughly, and did not express himself with perfect consistency" (1923: 201). The French scholar René-Antoine Gauthier is more emphatic in his rejection of the idea: "in the psychology of Aristotle the will does not exist" (Gauthier and Jolif 1970: 218). In Three Rival Versions of Moral Enquiry, Alisdair MacIntyre equally dismisses the thought of a notion of will in Aristotle: "Aristotle, like every other pre-Christian author, had no concept of the will and there is no conceptual space in his scheme for such an alien notion in the explanation of defect and error" (MacIntyre 1990: 111). In his posthumously published Sather lectures, A Free Will - Origins of the Notion in Ancient Thought (2011), Michael Frede concurs with this judgment about Plato and Aristotle, but denies that the notion of will is due to Christian influence. Challenging Albrecht Dihle's claim in The Theory of Will in Classical Antiquity (1982) that Augustine discovered the will, he instead attributes the discovery to the Roman Stoic Epictetus (c. AD 55-135) and his account of rational assent (sunkatathesis). Although Aristotle, according to M. Frede, had a notion of willing (boulêsis), he lacks the specific notion of willing required for a concept of the will; namely the view that whenever we do something of our own accord, or voluntarily (hekôn), we do so through an act of will. It is only when we hold that all voluntary actions have volitions as their immediate cause, whether the act is motivated by rational or non-rational desire, that we have a notion of will. Augustine is heir to this Stoic notion rather than the discoverer of the will in his own right, says M. Frede.

By contrast with Epictetus, Aristotle holds that our voluntary actions are sometimes caused by non-rational desires without any direct involvement of reason. We crave 
sweets or sex or revenge, and pursue these aims, without ratification from a faculty of assent, or, as some later authors were to argue, from a faculty of will that is separate from reason.

These authors all converge on the same conclusion-that there is no notion of will in Aristotle. But they do so from very different vantage points, relying on different criteria of attribution. We may therefore wonder whether they agree in words rather than substance. If, by contrast, Aristotle has a notion of will, then the question of free will in Aristotle remains open. He may have a notion of will, but lack a notion of free will, or he may have neither, or both.

\section{Rival Conceptions of Will}

To consider these possibilities, we must distinguish between having 'the' concept of will and having a conception of will. A conception of the will is a specific account of what the will is. The concept of justice has many articulations, such as justice as fairness (Rawls), psychological harmony (Plato), or another's good (Thrasymachus). These conceptions all purport to explain the nature of justice, and as such, they are rival conceptions of one thing-justice. If we elide this distinction, we will deny that an author has a concept of will simply because he lacks our favored conception, an attitude that quickly shortcircuits the inquiry.

Recognizing the concept/conception distinction has been surprisingly hard for authors considering the genealogy of the will. Most scholars deny that there is such a thing as 'our' notion of the will, a notion that remains unchanged from its moment of conception to the present day. However, the same scholars often write as if there is such a thing as the concept of the will-a nuclear idea specified via a set of necessary and sufficient conditions - that came into existence at a particular point in the history of philosophy and was transformed by later thinkers. This helps explain why there is such a diversity of opinion about who discovered the will (the most eccentric perhaps being R.A. Gauthier's case for the seventh-century AD church father Maximus the Confessor [1954]). But as Charles Kahn observes, "the historical problem of the emergence of the will is not a single problem, but a labyrinth of problems where different threads lead in different directions" (Kahn 1985: 234). There is no single concept of 'the will' designated in modern usage, and so trying to trace this concept back to its source is futile.

Instead of thinking of the will as a 'unit idea' in Lovejoy's sense, we should treat it as a concept that can be fleshed out in many different ways. A concept of will should arguably be rooted in moral psychology and/or legal theory, and it should help handle a number of (historically evolving) questions, such as why we are responsible for some acts and not others, why some people are legally accountable and others are not; why one person is virtuous while another is vicious, and why one act is free while another is subject to constraints, and further why some acts are 'weak' or 'irrational,' while others reflect the agent's best judgment. The list is by no means exhaustive, nor does every notion of will address itself to every conceivable question one could reasonably ask. But this gives a sense of the types of roles the notion has been used to fill.

\section{The Case for Aristotle's Nescience}

Historically, the case for Aristotle's nescience has rested on two main criteria. The first is psychological. Like all Greek thinkers, Aristotle has no space for a separate faculty of 
will in his psychology—an independent 'part' of the soul over and above reason and appetite. Instead, he holds that some desires originate in practical reason itself, when it judges that an end is good (viz., wish [boulêsis]) and decides to pursue it after deliberating (viz., decision [prohairesis]) (Nicomachean Ethics [EN] III 3 1113a3-13). Thus, if Aristotle has a notion of will, it is intellectualist rather than voluntarist in nature. If we think voluntarism is a necessary feature of any concept of will, then no Greek thinker has a concept of will. The second criterion concerns the origin of voluntary action. Even if we allow that intellectualist notions of the will are possible, and that the will could be a function of reason, one might think that Aristotle lacks the right model of reason's role in voluntary action. Aristotle denies that all voluntary acts are caused by rational desires. Even acts caused by non-rational desires (viz., appetite [epithumia] and spirit [thumos]) are voluntary (EN III 1 1111a25-b3). In the case of mature human agents, although not young children and animals, such acts are no less subject to praise and blame than those we rationally endorse. The incontinent agent (akratês) is blameworthy when he acts contrary to his better judgment and prohairesis, since he had the ability to be governed by reason when he succumbed (EN VII 4 1148b5-6, 10 1152a7-25). The fact that reason never intervenes, means that the akratês did not act on his decision (prohairesis), although he did act willingly (hekôn) when he followed his appetite (epithumia) contrary to reason (EN VII 10 1152a16-17). Therefore, not every act we willingly do is done through an act of will (boulêsis, prohairesis). If, like later Stoic thinkers, Aristotle had held that reason always assents before we act (as opposed to merely acquiescing or standing by when appetite has its way), he could have had an intellectualist conception of the will. But, unlike the Stoics, he does not think reason is always responsible in this way, since some voluntary acts are caused directly by a non-rational part of the soul (the Stoics deny that the soul is divided into rational and non-rational parts). Nor does Aristotle hold that in cases of motivational conflict, reason appears in two guises, first as the source of rational desires urging us toward what we judge is good, and then as an umpire who adjudicates conflicts between rational and non-rational desires by weighing in on one side.

Are these reasonable criteria? The first criterion seems too restrictive, since it arbitrarily rules out intellectualist conceptions of will. The second criterion may seem less arbitrary, for it reflects the absence in Greek of a triad of terms with the shared derivation of the Latin verb velle (I want), the adjective voluntarium (voluntary) and the verbal noun voluntas (will or volition). The corresponding Greek terms-boulomai (I want), hekousion (voluntary) and boulêsis (wish or volition)—do not suggest a correspondence between the class of acts that we do on the basis of a wish or willing, and the class of voluntary acts. As a result, we may think that Greek thinkers were prevented by a quirk of Greek language from articulating the concept of a will.

However, the Latin notion of 'voluntas' has Greek origins. In the Tusculan Disputations 4.6.12, Cicero renders the technical Stoic notion of wish (boulêsis) with voluntas, thereby introducing the noun into the Latin philosophical lexicon. Cicero's is a reasonable translation, but not if we take it to entail that all and only voluntary acts are caused by a willing. For as Cicero well knows, the Stoics do not think that all voluntary acts are caused by willings or wishes. Only the wise man ('sage') is capable of forming a wish, since a wish is a fully rational impulse (eupatheia) that reflects the sage's knowledge of good and bad. Non-sages (which includes all of us) instead have emotions (pathê), which are based on opinion, and reflect our folly. Still, fools are no less responsible than sages, and our acts no less up to us than the perfectly virtuous acts of the sage are up to 
him. It would be a mistake to hold that Cicero inadvertently invented the concept of the will in his library in Tusculum in $45 \mathrm{BC}$, on the assumption that the connections suggested by the Latin conceptual triad is a necessary precondition for the existence of the concept of will.

Critics have been quick to note that if Aristotle lacks a concept of will, he also lacks the notion of weakness of will (another 'bypass' argument). Instead of translating 'akrasia' as 'weakness of will,' generations of scholars have been taught to prefer alternatives such as 'incontinence, 'lack of self-mastery,' and other terms that don't assume the will. Notice, however, that accepting the second criterion undermines the possibility of weakness of will in another way. If every voluntary act is caused by volition, volition lacks a special relation to what the agent rationally wants that makes weakness of will an appropriate label. For according to the second criterion, volition would be the cause of action whether we succumb or resist. On this line of thought, akrasia turns out to be a failure of our volitions to conform to rational judgments, or a vacillation of reason, rather than a failure of the will (prohairesis) to prevail. Surprisingly, the expression 'weakness of will' makes better sense on an Aristotelian model of the mind, where only rational desires reflect what we may call the agent's will-his prohairesis. This should make us weary of accepting the necessity or sufficiency of the second criterion without further scrutiny. It may turn out to articulate a particular conception of the will rather than a necessary constituent of the concept of will as such.

\section{Aristotle's Wish}

These worries won't impress us if we think that the notion of the will is a dead end in the history of philosophy — an aberration rather than an important discovery. In The Concept of Mind, Ryle scoffs that, like "phlogiston" and "animal spirits," "volition" is a technical term without a referent:

The fact that Plato and Aristotle never mentioned them in their frequent and elaborate discussions of the nature of the soul is due not to any perverse neglect by them of notorious ingredients of daily life, but to the historical circumstance that they were not acquainted with a special hypothesis the acceptance of which rests not on the discovery, but on the postulation, of these ghostly thrusts.

(Ryle 1949: 64, 65)

If we accept Ryle's diagnosis, it is perhaps unsurprising that scholars examining the history of the notion of will have tended to elide the concept/conception distinction. Qua technical term, the concept exists by stipulation, rather than through a refinement of a pre-philosophical use. There is no pre-theoretical use of the term 'phlogiston,' and so no pre-theoretical concept to quibble about; ditto for the concept of will.

In fact, Ryle is wrong to treat 'the will' (rather than specific definitions of it) as a technical term. For it isn't true that the notion of volition originates in philosophical treatises. In Homeric epic, "I will" (boulomai) is used by the Gods in place of "I intend" (ethelo), presumably because nothing could prevent them from effectuating their wishes. Characters in Greek drama and defendants in Greek courts of law likewise use volitional terminology to describe their wishes and intentions, and class their own acts as voluntary and involuntary. Aeschylus' Prometheus declares "hekôn, hêkon 
hemarton" - "willingly, willingly I erred" (266) several decades before Plato's Socrates said that this can't be so. Starting in the 350s BC, Attic orators such as Demosthenes and Aeschines describe the 'prohairesis,' or moral persona, of the defendant as a way to bolster or undermine their case. In fact, we find extensive use of the very terms that philosophers harness in literary sources. When Aristotle offers his analysis of voluntary action, wish and decision in Nicomachean Ethics III.1-5 as an "aid to lawgivers" (1109b34-5), he signals that he is intervening in an ongoing debate about the nature of responsibility and what is up to us (to eph'hêmin) in Athenian law. Aristotle holds that crimes of passion, which are caused by non-rational desires, are culpable, just like acts done from forethought (ek pronoias) and decision. He does not quite explain why, however, beyond stating that in such cases, "the principle (archê) of moving the limbs that are the instruments [of the action]" is "in us," whereas involuntary acts have an external principle. And when the principle is "in us," it is also "up to us to act or not to act" (EN III 1 1110a15-18). By Aristotle's own admission, even non-rational animals and young children are "principles of action," though they don't (yet) merit praise or blame. Aristotle must therefore hold that it being up to us to act or not act is a necessary, rather than sufficient, criterion for moral accountability (Irwin 1982). What distinguishes accountable and non-accountable agents is the presence in the former of a faculty of deliberation and decision. Mature human agents are responsible when they act on non-rational desires because they are 'kurioi' or 'in control of' their acts in a way that brutes and young children are not (EN III 1113b32, 1114a32; Metaphysics IX 5 1048a10). When we understand what it means to be master of one's acts, we will see that Aristotle ascribes a particular power to mature, rational animals that we may, without anachronism, call a power of 'the will.' It is the presence of this power, whether it is exercised or not, that explains why we can be held to account, even when we do not act on the basis of deliberation and decision.

Aristotle is right to hold that not all acts are caused by rational desires (boulêseis), to the extent that not all of them reflect our rational endorsement. The alternativepositing tacit acts of rational assent as the cause even in cases of mindless munching, acts of rage, and unthinking action—seems like a theoretical afterthought. However, since our desires are reasons-responsive (which is just another way of saying that their strength can be influenced by reason in its practical role), we are capable of self-mastery in a way that non-rational animals and young children are not. By reserving the notion of volition (boulêsis and prohairesis) to mature rational agents, Aristotle marks this difference between kinds of self-movers. Only the former can be mastered by reason, and therefore, only mature rational agents are capable of virtue and vice in the strict sense.

One might think that Aristotle's 'wish' is a poor candidate for volition, since we can entertain idle wishes or wish for the impossible. Aristotle distinguishes between mere wishes, which can be for possible as well as impossible states of affairs, and wishes that form the basis of what we may call intentions to act. These are wishes for ends that we 'lay down' and use as the starting point in deliberation-ends that we choose to pursue, and that are objects of a hairesis, or choice (EN III 3 1112b16) When we have found appropriate means to those ends, we make a decision (prohairesis), which the Eudemian Ethics (EE) explains as commitment to do "this for the sake of (pros) that" (EE II 11 1227b36-7). It is only when the motive power of a wish has been transformed into a decision, a specific kind of wish, that we will to act. Therefore, only wishes for ends that have been 'laid down' in deliberation result in volitions. Aristotle holds that the state of our prohairesis determines the nature of our characters, just as later authors hold that 
the quality of the agent's will determines his character (EN III 2 1111b6-7). Virtue is a hexis prohairetikê, a state concerned with decision (EN II 6 1107a1, EE II 10 1227b511). If, then, Aristotle has a notion of will, the faculty of will would belong to the part of the soul that makes decisions. This is the part that Aristotle in the Nicomachean Ethics calls "to hêgoumenon," or the commanding part (EN III 3 1113a7). The Magna Moralia (MM) names the deliberating and deciding part of the soul to prohairetikon (MM I 34 1196b28), while the Eudemian and Nicomachean Ethics prefer to call it to logistikon or to bouleutikon, the calculating or deliberating part. For Aristotle, then, the notion of prohairesis would be the closest we get to a concept of will- the part of the soul that is "to hêgoumenon" insofar as it is bouleutikon and prohairetikon is the faculty of will. The fact that this faculty belongs to reason makes Aristotle's theory of will intellectualist.

Virtue and vice in the strict sense (as opposed to mere emotional tendencies, which Aristotle calls "natural" virtue and "natural" vice) are states that we develop through habituation that involves our rational faculties. It is only when we decide on virtuous acts and decide on them for their own sakes (for the reasons because of which they are virtuous), knowing that they are such, that we can be said to act from virtue (EN II 4). Virtue is therefore a state that decides (a hexis prohairetikê) rather than a state that simply lies in the mean with respect to action and passion. An animal or a young child can be conditioned into temperate behavior, but they cannot be self-governed by reason or masters of their own acts because they are unable to decide on virtuous acts for the reason because of which they are virtuous. To be fully virtuous, we must consistently make the right decisions for the right reasons, and then act on these decisions. And this requires that we deliberate well and possess prudence (phronêsis) —an intellectual virtue-rather than merely a knack for hitting on the right thing to do. Aristotle can therefore view virtue and vice as states that reflect the quality of our will, prohairesis, while recognizing that not all acts for which we are morally accountable reflect our rational endorsement. It is the quality of the act, and the fact that the principle of movement was in an agent capable of being governed by reason that makes it blameworthy or praiseworthy. If we were simply passive bystanders to any conflict between reason and passion, rather than agents who can resolve conflicts and master our own desires by rational means, then we would not be proper subjects of praise or blame. This means that there is a difference between what we may call the 'merely' voluntary acts of mere self-movers, and the voluntary acts of agents capable of rational self-governance. The difference is not a difference in the causal ancestry of the act, but rather in the psychological context in which it occurs; for certain counterfactual propositions will be true of rational self-movers that aren't true of non-rational self-movers. And these counterfactual propositions are true in virtue of our ability to recognize and be motivated by right reason.

I have argued that if, instead of assuming that there is such a thing as the-one and only-concept of the will, we recognize that there could be many, then the question of will in Aristotle seems rather less straightforward, and we may find room for Aristotle's theory of prohairesis in the history of the notion of will.

Aquinas holds that Aristotle recognizes the existence of the will, and that his account of boulêsis in the Nicomachean Ethics attributes to practical reason a function which later authors, such as Augustine, attribute to the will (for a defense of Aquinas, see Irwin 1992). If, on the contrary, we maintain that Aquinas misreads Aristotle, and that the roots of Aquinas' own theory of the will must be sought elsewhere, or in 
a creative appropriation of Aristotle's philosophy of action, then we need to pinpoint exactly where Aquinas misunderstands Aristotle. René-Antoine Gauthier (1970) has proposed that appearances to the contrary, Aristotle never ascribes any desires to reason: all desires originate in the non-rational part of the soul. This means that there are no 'essentially' rational desires by Aristotle's lights. Whether Gauthier is right to defend this claim is a matter of textual interpretation. However, even if we agree with Gauthier's contentious interpretation, it is worth noting that his criterion for ascribing a theory of will to Aristotle is itself contentious. We can either argue that the will is a particular power of reason to cause desires, regardless of to which part of the soul these desires belong, or we may argue that Gauthier is right to hold that the existence of 'essentially' rational desires is the crucial matter, but maintain that Aristotle does hold that wish and decision are essentially, rather than derivatively, rational desires.

\section{Will, Causality, and Freedom}

The notion of will that emerges if we reject the criteria outlined above remains neutral on the question of freedom from causal determination. For Aristotle, to have a will would be to be able to be mastered by reason. Whether we can act or not act given the very same desires and the very same beliefs is a question orthogonal to Aristotle's concerns, presumably because the idea of universal efficient-causal determination does not interest him much-since it threatens to elide the very distinction between causes that Aristotle takes to be crucial for explanation in the scientific and practical realm. We may infer that Aristotle's account of the will, deliberation and decision is compatible with compatibilism. In particular, Aristotle's notion of what is "up to us" does not entail that he is a libertarian. It concerns our ability to be "principles of action," but all that means is that we can act on our own desires and beliefs/appearances, regardless of their origin. That is why non-human animals are principles of actions no less than human agents, and why their acts are up to them no less than ours. Even if Aristotle's notion of what is up to us had been indeterminist (which it isn't), it could in any case not ground his theory of responsibility. For Aristotle holds that the movements of babies and brutes are no less up to them than our actions, yet he nowhere indicates that they bear responsibility for their acts or omissions, like we do. Otherwise put: Aristotle could not invoke libertarian freedom to explain why we are responsible.

This concept of the will precludes a notion of a free will in the sense specified, for example, by Susanne Bobzien, namely as the possession of "a specific part or faculty of the soul" - a will — "by means of which I can decide between alternative courses of action independently of my desires and beliefs, in the sense that it is not fully causally determined in which way I decide" (Bobzien 1998: 133, 134). However, just as the voluntarist notion of will is not the only horse in town, this peculiar, if influential, conception of a free will is not the only notion of free will. Though Aristotle does not explicitly speak of a 'free will,' his notion of the will may be compatible with a notion of free will which is closely related to moral responsibility (though not, as we have seen, with this one, which is voluntarist). I have suggested that insofar as Aristotelian decision (prohairesis) can control our non-rational desires, and hence master the soul, it is reasonable to treat it as a will. To have a will is to be able to be governed by reason rather than by the strength of one's non-rational desires. If, by a 'free will,' we mean a state that decides based on the true conception of what ends are worth pursuing, and of 
the right means to these ends, then Aristotle might agree, although he does not explicitly say that human beings can aspire to having a free will. A free will on this conception is a rational will, rather than a will that is causally independent of our beliefs and desires. In Nicomachean Ethics VI 1 (and Eudemian Ethics V 1) Aristotle describes prudence as the state that makes us do the right thing for the right reason, and as such prudence is a "true state." It is the best state of the part of the soul concerned with deliberation and decision. We might argue, then, that Aristotle treats a prudent soul as free, in the sense that it is "kurios" or master of the whole soul in virtue of its knowledge, and not "dragged around" like a slave by non-rational desires. But this kind of freedom is compatible with causal determinism, and so if we are prepared to allow that Aristotle has a notion of a will, and perhaps even an implicit notion of a free will, it still remains to decide whether it is determinist, indeterminist or (what is more likely in my view), undecided on the matter.

Later Aristotelians, in particular the late second-century AD commentator Alexander of Aphrodisias, maintained that Aristotle's notion of what is up to us is radically indeterminist, in that it introduces a two-sided potentiality for acting and not acting all things being equal. In the very same circumstances, being the same agents, with the same beliefs and desires, we have the capacity to either do an act or do something else entirely, and that is why we, unlike children and non-rational animals, are morally responsible. To defend this claim, Alexander must argue in the teeth of textual evidence that Aristotle distinguishes between voluntary acts and acts that are up to us, such that acts are only "up to" creatures capable of rational assent. This is a misreading of Aristotle's theory, however, and in particular a misreading that is motivated by Alexander's polemical aim, for he seeks to harness Aristotle's theory in his fight against Stoic universal causal determinism and Chrysippus' compatibilist account of what is up to us. Aristotle is thereby transformed into a libertarian avant la lettre, at considerable cost to our understanding of his theory. When Aristotle argues that mature human agents are responsible for their acts even when they do not act on rational desires, he holds that they are the kinds of beings who can recognize right reasons for acting and be influenced by them, even if in their particular circumstances it is fully causally determined that they do not pause to deliberate. What distinguishes cases of psychological compulsion (Aristotle mentions trichomania and the brutish desire to roast one's enemies on a spit [EN VII 5 1148b29, b24]) from voluntary acts stemming from non-rational desires, is that these desires were amenable to reason both in general and at the time when we acted, even if this potential was never realized given the circumstances.

In summary, Aristotle holds that an act is voluntary if its principle (archê) is in the agent, and involuntary if it has an entirely external principle. This principle is the cause that explains the act, and it may be either a rational or a non-rational desire. Mature human agents are normally, though not always, capable of governing their own behavior through deliberation and decision, and this capacity means that we are responsible even when we fail to pause to think or when we let non-rational appetites lead us astray. It is because we can be governed by reason that we merit praise and blame, and that we can develop 'full' virtue and vice. We do not merit praise, as Alexander's libertarian reading would seem to suggest, because instead of doing a fine and praiseworthy act, we could have done a blameworthy and shameful act instead. In perfectly virtuous agents, the motivational preconditions for vicious acts are no longer present. 


\section{ARISTOTLE}

\section{Bibliography}

Bobzien, S. (1998) "The Inadvertent Conception and Late Birth of the Free Will Problem," Phronesis 43: $133-75$.

Dihle, A. (1982) The Theory of Will in Classical Antiquity. Berkeley: University of California Press.

Frede, D. (2015) "Free Will in Aristotle?" in P. Destreé, R. Salles and M. Zingano (eds), What is Up to Us. Sankt Augustin: Academia Verlag, pp. 39-58.

Frede, M. (2011) A Free Will - Origins of the Notion in Ancient Thought. Berkeley: University of California Press.

Gauthier, R.A. (1954) "Maxime le Confesseur et la psychology de l'acte humaine," Recherches de Théologie Ancienne et Medieval 21: 51-100.

Gauthier, R.A. and Jolif, J.Y. (1970) L'Éthique à Nicomaque, 2nd edn. Louvain: Publications Universitaires.

Irwin, T.H. (1982) "Reason and Responsibility in Aristotle," in A. Rorty (ed.), Essays on Aristotle's Ethics. Berkeley: University of California Press, pp. 117-56.

Irwin, T.H. (1992) "Who Discovered the Will?" Philosophical Perspectives 6: 453-73.

Irwin, T.H. (1999), Aristotle: Nicomachean Ethics, 2nd edn. Indianapolis: Hackett.

Kahn, C. (1985) "Discovering the Will from Aristotle to Augustine," in J.M. Dillon and A.A. Long (eds), The Question of Eclecticism. Berkeley: University of California Press, pp. 234-59.

MacIntyre, A. (1990) Three Rival Versions of Moral Enquiry. Notre Dame: Notre Dame University Press.

Ross, W. D. (1923) Aristotle. London: Methuen.

Ryle, G. (1949) The Concept of Mind. London: Hutchison.

\section{Further Reading}

Bobzien, S. (2013) "Found in Translation: Aristotle's Nicomachean Ethics 3. 5 1113b7-8 and its Reception," Oxford Studies in Ancient Philosophy 45: 103-48.

Kenny, A. (1979) Aristotle's Theory of the Will. London: Duckworth.

Nielsen, K.M. (2011) "Deliberation as Inquiry: Aristotle's Alternative to the Presumption of Open Alternatives," The Philosophical Review 120: 383-421.

Nielsen, K.M. (2012) "The Will - Origin of the Notion in Aristotle's Thought," Antiquorum Philosophia 6: 47-68.

Sauvé Meyer, S. (2011) Aristotle on Moral Responsibility. Character and Cause. Oxford: Oxford University Press.

Sauvé Meyer, S. (1998) "Moral Responsibility: Aristotle and After," in S. Everson (ed.), Companions to Ancient Thought, Volume 4: Ethics. Cambridge: Cambridge University Press, pp. 211-40.

Sharples, R.W. (2013) Alexander of Aphrodisias On Fate, 2nd edn. London: Bloomsbury.

Sorabji, R. (1983) Necessity, Cause and Blame: Perspectives on Aristotle's Theory. Ithaca: Cornell University Press.

\section{Related Topics}

Leeway vs. Sourcehood Conceptions of Free Will

The Stoics on Fate and Freedom

Augustine of Hippo

Thomas Aquinas

Self-Control and Akrasia

Deliberation 


\section{0 \\ THE STOICS ON FATE AND FREEDOM \\ Tim O'Keefe}

\section{Introduction and Overview}

Stoicism was one of the most influential philosophical schools of the Hellenistic era, the centuries following the death of Alexander the Great in 323 вCE (and of Aristotle in $322 \mathrm{BCE}$ ). The Stoics made pioneering contributions to logic, in their invention of propositional logic; to ethics, in their championing of virtue as the sole intrinsic good and vice as the sole intrinsic evil; and to many other fields. They are also responsible for devising a sophisticated compatibilist theory of free will, the first clearly compatibilist theory that we know of. Earlier philosophers such as Aristotle also had influential and thoughtful discussions of issues concerning moral responsibility and causal determinism. But even though Aristotle's theory of moral responsibility may be best understood as compatible with compatibilism about free will and determinism (see Meyer 2011 for an excellent interpretation of Aristotle along these lines), Aristotle does not squarely address the issue of whether free will and causal determinism are compatible. Some interpreters have thought that Aristotle's position entails incompatibilism, although he does not explicitly state that free will and determinism are incompatible.

A quick overview of what will follow: the Stoics are the first unambiguous compatibilists, in part because they are also one of the first unambiguous proponents of causal determinism, with everything that occurs having sufficient causal conditions for occurring exactly as it does and not otherwise. (The atomist Democritus is an earlier possible proponent of determinism but did not address what implications determinism might have on our freedom.) But the Stoics' causal determinism is in turn rooted in their pantheistic theology. God is the world, with his mind pervading the cosmos, and he orders the world in accordance with his providential plan. This providential plan is enacted through an everlasting series of causes that ensures that things occur as God wills them to. And so, the Stoics usually advance arguments to show that freedom and fate are compatible. One prominent objection to the Stoic notion of fate is the "lazy argument." If what is going to happen is already preordained, why should I now bother deliberating and acting to bring about one outcome rather than another? The Stoics reply that some events are "co-fated," with God fating both the future outcome and my causally effective action that will bring about that outcome, and that this suffices to show that action and deliberation are not futile. 
The Stoics' reply to the "lazy argument" depends only on showing that causally determined actions can still be causally effective, but their arguments for why fate is compatible with moral responsibility bring in their analysis of human action. According to the Stoics, because we possess reason, it is up to us whether to assent to impressions about how to act. So how we act depends on us, and this suffices for our actions to be "up to us" in a way that justifies praise, blame, reward, and punishment (that is, it is the kind of control needed for moral responsibility). They reject the notion that we must have an ability to choose among alternate actions in order for our actions to be "up to us," because such an ability would be incompatible with being virtuous and would introduce uncaused events. Despite their compatibilism, the Stoics reject negative reactive attitudes such as anger and retributive punishment on ethical grounds. And even though both virtuous and vicious people are equally responsible for what they do, in another sense, only the virtuous person is truly free, because he is free from destructive emotions and beliefs that would alienate him from himself. The virtuous person also willingly submits himself to God's will, and this submission helps bring him tranquility.

The Stoics are a large cast of people, stretching from the founder of the school, Zeno of Citium (334-262 BCE) to Roman Stoics such as Seneca (4 BCE-65 CE) and Epictetus (c. 55-135 CE). For the sake of this chapter, I will be presenting the Stoics as putting forward a unified position, especially as represented by Chrysippus (с. 280-206 вCE), who was the third head of the Stoa and is usually regarded as its greatest philosopher. But readers should be aware that this is not entirely accurate: some later Stoics explicitly dissent from Chrysippus, while others who mostly agree with him (such as Epictetus) may have subtle differences from him in their exact positions.

\section{God and Fate}

The Stoics believe that God is wise, good, perfectly happy, and creator of the world (Diogenes Laertius, Lives of the Philosophers 7.147, L\&S 54A). However, unlike in Judeo-Christian theology, God is not an immaterial entity separate from the world who created it ex nihilo. Instead, according to the Stoic Chrysippus, God is the world. His mind pervades and organizes all things (Cicero, On the Nature of the Gods 1.39, L\&S 54B; Alexander, On Mixture 225, 1-2, L\&S 54H). The Stoics believe that only bodies can act and be acted upon (Cicero, Academica 1.39, L\&S 45A), and God does act upon the world, so God is something bodily. In particular, he is "a designing fire which methodically proceeds towards creation of the world" and "a breath pervading the whole world" (Aetius, 1.7.33, L\&S 46A). This picture of the world as a blessed living being with its own mind is indebted to the creation myth in Plato's Timaeus, although the Stoics dispense with Plato's immaterial Craftsman who brings the world into existence using the Forms as his model.

Because God is good, he wishes to benefit everything (Clement, The teacher 1.8.63 $1-2, L \& S 60 I)$. So God's providential will is to make the world the best he can. God is extremely powerful but not omnipotent, as he is limited not only by what is metaphysically possible but also by what is physically possible. (For instance, God supposedly made human skulls as thin as they are, even though thicker skulls would have been better for the purpose of protecting our brains, as a byproduct of wanting to make us rationalanimals with thicker skulls would have been stupider [Gellius, 7.1.1-13, L\&S 54Q2].) 
Within these physical limits, the way God realizes his providential will is through setting up the causal order of the world to bring it about. Fate is an everlasting "ordering and sequence of causes," which brings about every single thing that has happened, is happening, and is going to happen. This is "not the 'fate' of superstition, but that of physics" (Cicero, On divination 1.125-6, L\&S 55L). So, for example, if God has it as part of his providential plan that I will recover from a deadly snakebite that I will suffer on 12:02 p.m. June 24,2025 , God will fate my recovery by building that future event into the overall organization of the cosmos from its foundation, so that the fated recovery will necessarily arise as the series of causes unspools itself over time.

\section{The Lazy Argument}

The "problem of free will and determinism," as it is usually discussed in the current philosophical literature, concerns whether causal determinism is compatible with the sort of freedom (or alternatively, with the sort of control over your actions) that is necessary for moral responsibility. But the Stoic notion of fate faced an even more serious charge: that it would render what will happen inevitable, thus making deliberation, and action more broadly, futile. The "lazy argument," which attempts to establish this conclusion, goes as follows (I have changed the example from the one Cicero uses. I also specify the argument in terms of fate operating via causal determinism, to fit the Stoic position, whereas the initial version of the argument Cicero considers is via the Principle of Bivalence, with statements about the future eternally having truth-values, although Cicero later recasts the argument in terms of causes):

Imagine that you've been bitten by a venomous snake, and you're trying to decide whether or not to rush to the hospital for anti-venom. However, if you accept that the outcome of the snakebite is fated, then either it's fated (and has always been fated) that you're going to recover from the snakebite, or it's fated (and has always been fated) that you won't recover and will die (Cicero, On Fate 29, L\&S 55S1). But if either of two alternatives has been fated from all eternity, that alternative is also necessary (Cicero, On Fate 21, L\&S 20E1), because the past is immutable. And because there is no point in deliberating about what is necessary, it's pointless for me to worry now about whether or not to go to the hospital, as if my present actions could change the outcome one way or the other (Cicero, De Fato 28-29, L\&S 55S1). A slightly different way of making the point: deliberating about what to do makes sense only if what will occur in the future is not already settled. But on the Stoic picture, the future is settled, via the causal sequences of fate that God built into the foundations of the world, so deliberating about whether or not to bring about $\mathrm{X}$ is pointless.

Chrysippus replies to the "lazy argument" as follows: just because it is fated that you will recover from the snakebite does not make your going to the hospital to get the antivenom pointless. Chrysippus says that certain events are "co-fated": for instance, it is fated (and causally determined) both that I will recover from the snakebite and that I will go to the hospital; it is through my fated action of going to the hospital that my fated recovery will occur. As long as my action of going to the hospital is causally efficacious in bringing about its purpose, it isn't pointless, and causally determined actions can be causally efficacious. Furthermore, even if it's causally determined that 
I will recover, counterfactuals such as "if I don't go to the hospital, I will die from the snakebite" can still be true (Cicero De Fato 30, L\&S 55S2-3).

Similar considerations establish the rationality of deliberation. Some might worry that deliberating about whether or not to perform some action is somehow a 'sham' or not genuine deliberation if what I am going to decide to do has already been predetermined. But going through the process of weighing the pros and cons of various courses of action to assess which one is best is itself an action that can be effective for coming to a more rational decision about what to do than I would come to if I didn't deliberate, even if the outcome of that deliberative process has itself been causally determined. (See also Coffman's chapter on deliberation.) For instance, if I am offered a job, it makes sense to think things through before making a decision rather than flipping a coin, even if God has made it part of his providential plan that I am going to accept the job. Just because it is fated that I will accept the job, it isn't fated that I will accept the job whether or not I think things through before making a decision, any more than it's fated I will recover from the snakebite whether or not I go to the hospital.

Some texts appear to undercut the story sketched above, where God brings about fated outcomes through the fated actions of humans. For instance, Zeno and Chrysippus give the following analogy to describe fate:

When a dog is tied to a cart, if it wants to follow it is pulled and follows, making its spontaneous act coincide with necessity, but if it does not want to follow it will be compelled in any case. So it is with men too: even if they do not want to, they will be compelled in any case to follow what is destined.

(Hippolytus, Refutation of all heresies 1.21, L\&S 62A)

This suggests that God has preordained certain outcomes that will happen no matter what decisions people make, with our decisions affecting only the manner in which this fated outcome occurs. God will bypass and override any efforts to defy him. (Perhaps if I irrationally decide not to go to the hospital after the snakebite, God implements a contingency plan he has ready to hand that ensures my recovery, albeit in a way that involves far more trouble and pain for me.)

This interpretation of the dog and cart metaphor should be resisted, as it is inconsistent with the overall Stoic picture, as least as put forward by Chrysippus. Instead, Chrysippus can be making the more general point that it is impossible to resist God's providential plan and the edicts of fate, because God's providential plan encompasses everything whatsoever that occurs in the cosmos, which would include even vicious actions (Plutarch, On Stoic Self-Contradiction, L\&S 54T). The Stoics also share the Greek ethical commonplace that vice is a kind of psychic disharmony and disorder that causes agitation and distress (Cicero, Tusculan disputations 4.29, 34-5, L\&S 61O). And so, vicious people who try to defy the will of God fail in their plan, as even their attempted defiance has been fated by God, but through their foolish actions they do 'succeed' in bringing about their own misery, just like the dog being dragged along the path.

\section{Action and What is $U p$ to Us}

While the Stoic response to the lazy argument might show why action and deliberation still make sense in a deterministic universe, they need to say more in order to counter the suspicion that human beings, in their theory, are merely passive puppets who 
cannot rightly be held accountable for what they do. They develop a theory of animal behavior generally and human action in particular that tries to counter this suspicion.

According to the Stoics, inanimate objects such as logs and stones are moved around from the outside. But organisms, which are animated by their psyches, have the cause of movement in themselves. (That organisms move themselves, of course, is compatible with the manner in which they move themselves being itself causally determined. And an organism's psyche, because it is causally effective and moves around the rest of the body, must itself be something bodily.) Animals move themselves when an impression occurs which arouses an impulse. For instance, a hungry dog may see a hunk of meat, and this arouses an impulse to run up to the meat and gobble it down. The impulse is triggered by the impression, but this is still a case of the dog moving itself toward the meat, not merely being passively pushed around by the impression.

In the case of rational animals, like humans, there is a crucial additional step. We have "reason, which passes judgment on impressions, rejecting some of these and accepting others, in order that the animal may be guided accordingly" (Origen, On principles 3.1.2-3, L\&S 53A). For instance, I may see a basket of chicken nuggets in front of me when I am hungry. But instead of saying, "mmmm, looks good," and straightaway gobbling them down, I think "eating meat produced by factory farms would be wrong" and refrain. On the other hand, Chrysippus believes that animals are made for the sake for human beings-for instance, that appetizing pigs have no purpose other than slaughter and that God created them as part of our cuisine (Porphyry, On Abstinence, 3.20.1, 3, L\&S 54P). And so, given his foolish and vicious views about the moral status of animals, Chrysippus gladly decides to chow down. (Impressions may include both non-normative and normative propositional content, for example, "there are some chicken nuggets in front of me" and "eating those chicken nuggets would be good for me.")

Any action proper will include this step of assent to an impression that leads to an impulse, and it is this additional step that distinguishes human action from mere animal behavior. The Stoic doctrine allows for there to be involuntary bodily reactions to stimuli, such as one's heart speeding up as a truck careens towards you. (See Seneca, On Anger 2.3.I-2.4, L\&S 65X.) And 'assent' need not be the result of a self-conscious, extended deliberative process. If you insult my hipster sideburns and I straightaway get angry and punch you in the face, I have assented to the impression that you have wronged me and it would be good to retaliate and cause you pain, even though I haven't thought it over carefully.

Chrysippus uses the analogy of a stone cylinder rolling down a slope to illustrate the Stoic doctrine. The cylinder's rolling down the slope may require an initial shove. But that initial shove only triggers the motion, and the primary cause of the motion is the cylinder's own shape and 'rollability.' Likewise, human action may require an initial impression as its trigger, but how a person acts depends on the person himself, on the sort of person he is and how he responds to his impressions (Cicero, On Fate 39-43, L\&S 62C).

\section{Determinism and Moral Responsibility}

The Stoic doctrine of assent is the linchpin of their defense of moral responsibility. Assent is up to us and under our control (even if also causally determined), and assents are the causes of our actions. And so, our actions are attributable to us, and we are rightly held responsible for them. In fact, says Epictetus, the one thing that God has 
placed under our control is the correct use of impressions (Epictetus, Discourses 1.1.7-12, L\&S 62K). I do not control whether I am healthy, although I can aim at maintaining my health, and I do not control whether other people hurl insults at me. But it is up to me whether I react angrily when I am insulted.

Chrysippus says that what we do is controlled by our will and intellect, and the misdeeds of bad people can rightly be attributed to their own vice. And because of this, he asserts,

the Pythagoreans are right to say 'You will learn that men have chosen their own troubles,' meaning that the harm that they suffer lies in each individual's own hands, and that it is in accordance with their impulse and their own mentality and character that they go wrong and are harmed.

(Gellius, 7.2-6-13, L\&S 62D)

Many people, however, may find this sense of assent being "up to us," namely that it causally depends on my present character, inadequate. Cicero expresses the reservation well. He approves of Chrysippus' distinction between a triggering cause and a primary cause of an action, saying that it is a promising route for keeping things up to us. But if it turns out that it's not in our power to make things turn out otherwise than they do turn out, then everything is still fated in a way that renders all of our actions involuntary, and hence not really up to us (Cicero, On Fate 45). That is, once an impression has occurred as a trigger to action, do I then have the ability to make results turn out otherwise, or not? Once the chicken-nuggets impression has struck me, do I have the ability either to eat the nuggets or not to do so? If I have this ability to do otherwise than I do, then my action is under my control. But if how I respond is "up to me" merely in the Chrysippean sense that it causally depends on my present character, which is itself "co-fated" and the way in which fate works God's will through the animal, then my action is both fated and not truly in my power, so that praise, blame, and punishment would not be justified.

In contemporary discussions of free will, this sort of condition on moral responsibility is called the Principle of Alternate Possibilities, or PAP. PAP states that a person is morally responsible for what they have done only if they could have done otherwise. Aristotle, for one, seems to endorse our possession of such an ability. He says that when acting is up to us, so is not acting, and if it's up to us to act nobly by performing some action, it's equally up to us to act shamefully by refraining from performing it (Nicomachean Ethics 3.5 1113b5-14). (It's a further question, of course, whether for Aristotle the possession of such an ability to do otherwise is compatible with causal determinism. See also the chapters by Sartorio and Timpe.)

Rather than trying to accommodate an ability to do otherwise within a deterministic world-view, the Stoics reject PAP. We don't have "the freedom to choose between opposite actions ... [instead], it is what comes about through us that is up to us" (Alexander On fate 181,13, L\&S 62G1). The Stoics give both ethical and metaphysical arguments against PAP.

I begin with the ethical. What is up to us? Let us presume that we are rightly praised or blamed, and rewarded or punished, only for things that are up to us. And if we accept PAP, then the actions of the virtuous person will be praiseworthy only if she is capable of acting in a way other than how she does act, and the virtuous person does act virtuously. But the truly virtuous person is incapable of acting viciously, of doing anything 
wrong. And so if we accept PAP, we would have to accept the absurd result that we should not praise virtuous people for acting virtuously. And so, we should reject PAP (Alexander, On fate 196,24-197,3, L\&S 61M). (The Stoics also likewise claim that vicious people are incapable of acting other than viciously, at least during the time when they are vicious, but are still rightly criticized for their vicious actions. However, I will concentrate on the case of virtue here.)

We may wish to reject instead the premise that a truly virtuous person is incapable of acting viciously. But the Stoics have good reasons for accepting that premise. Imagine that I am a virtuous person, and that I have promised my young daughter a piece of cake if she finishes her dinner. She finishes her dinner and asks for the cake. What will I do? Assuming that nothing odd has happened in the meantime-for instance, a fire has broken out and I have to leave the house with her-there is only one thing I will do in that particular situation: give her the cake as promised. Let us suppose that there were some small chance that I would not keep my promise-that I'd pretend to look for the cake and not find it, and lie to her about its being missing, so that I could have it for myself later. If I were capable of depriving my daughter of her promised cake so that I could chow down on it later, then I would not really be a virtuous person. There would have to be something wrong with me.

Someone may wish to assert that the virtuous person will not break his promise to his daughter, but that he is capable of doing so. The Stoics reject this response. Virtue is a reliable disposition to do what one should. I am not forced to get the cake for my daughter, but given the type of person I am, I am incapable of doing otherwise. As Seneca puts it,

the good man cannot not do what he does; for he would not be good unless he did it . . . there is a big difference between saying 'he cannot not do this' because he is forced and saying 'he cannot not want to.'

(Seneca On Benefits 6.21.2-3, quoted in Inwood 1985: 110)

The Stoics conceive of virtue as a kind of practical skill that allows a person to live well, and the wise person will consistently exercise this skill, so that everything he does he does well (Stobaeus 2.66,14-67,4, L\&S 61G). So an 'ability' to break my promise to my daughter is something I do not want to have, as it would be a defect, a form of folly, and a disability. And likewise with any other ability to act otherwise than I should.

The Stoics' second reason for denying that we have the power to choose between opposite actions is metaphysical rather than ethical. They assert that "if in identical circumstances someone will act differently on different occasions, an uncaused motion is introduced" (Alexander, On Fate 185,7-11, L\&S 62H). For example, imagine that on one occasion I refrain from eating the chicken nuggets in front of me. And on another occasion, with every single thing being exactly the same as far as my beliefs, desires, the precise content of the chicken nugget impression, etc., are concerned, I eat the nuggets. Then, say the Stoics, my actions would not have a cause.

This may appear too hasty. In his criticisms of Chrysippus, the academic skeptic Carneades denies the Stoic doctrine that human actions have past causes built into nature that inevitably bring them about (Cicero, On Fate 33, L\&S 70G11-15). It does not follow that they have no cause whatsoever. Instead, he proposes that there is a "voluntary motion of the mind" that has "as its own intrinsic nature that it should be in our power to obey us" (Cicero, On Fate 25, L\&S 20E7). If I decide to eat the nuggets, my 
action has a cause (me), and if I refrain, that also has a cause (me), but how I exercise this power, deciding whether to eat the nuggets or to refrain, is up to me. The Stoics, presumably, would find this inadequate. On Carneades' theory, my action may have a cause in some weak sense, but there would be no explanation at all for why I choose to refrain from eating the nuggets rather than eating them, so that much of human action would be fundamentally mysterious and inexplicable.

And so, the Stoics defend a picture of our actions being up to us that does not require any ability to do otherwise than one does. They believe that their doctrine of fate is compatible with all of our ordinary moral practices. Even if every action is fated, right reason still commands right actions and prohibits wrong ones. (That is, we can still give the reasons why breaking my promise to my daughter is irrational and wrong, and keeping my promise is rational and right. Fate does nothing to negate these reasons.) And if there are right and wrong actions, there are also virtue and vice, which are character traits that dispose us to act rightly and wrongly, respectively. But virtue is noble, and thus commendable, whereas vice is shameful, and thus reprehensible. And commendable things deserve honor, whereas reprehensible things deserve punishment (Alexander On Fate 207,5-21, L\&S 62J).

\section{Responsibility, Retribution, and the Reactive Attitudes}

In contemporary discussions of free will and moral responsibility, especially those inspired by Peter Strawson's "Freedom and Resentment," (1962) a common theme is that retribution and the negative reactive attitudes, such as resentment and indignation, are essential to genuinely holding others morally responsible for their misdeeds. If my dog urinates on my rug, I will be unhappy that he ruined the rug, and I may scold him and otherwise punish him with an eye to preventing him from doing it again. But this sort of 'blaming' and punishing of my dog for consequentialist reasons is not the same phenomenon as holding my dog morally responsible for what he does. On the other hand, if my friend were to get tipsy and urinate on my rug, I'd feel highly indignant toward him, and when I criticize him, it's because I feel that he hasn't shown me proper good will, with my criticism being an expression of my (backward-looking) indignation, not merely a (forward-looking) attempt to modify his behavior. And punishments, when they're a matter of holding the wrongdoer morally responsible for their misdeeds, likewise involve satisfying a desire for retribution, of giving somebody what they deserve.

Although it would be anachronistic to call him a Strawsonian, in the ancient world, Aristotle says some things that (broadly speaking) fall along these lines. Anger is a desire to return pain for pain (On the Soul 1.1, 403a25-403b3). In particular, it is a desire for revenge against somebody who you think has wronged you by treating you disrespectfully (Rhetoric 2.2, 1378a30-32). Sometimes, it is appropriate to feel anger and desire revenge, and hence there is a virtue of character (good temper) concerned with anger. The good-tempered person gets angry at the right things, at the right time, and to the right extent, and he is praiseworthy. Aristotle says that the person who is deficient with respect to anger, who does not get angry when shown disrespect, is unlikely to defend himself, and that putting up with insults to oneself and one's friends is slavish (Nicomachean Ethics 4.5, 1125b27-1126a8).

For Aristotle, retributive attitudes are not confined to wrongs against oneself. Righteous indignation is praiseworthy, and righteous indignation is (in part) a matter of feeling pleasure when people who deserve misfortune suffer misfortune (Eudemian Ethics 
$3.3,1233 \mathrm{~b} 23-27)$. Although righteous indignation is not itself a virtue of character (because it does not involve choice), it does tend toward the virtue of justice (Eudemian Ethics 3.3, 1234a24-33).

The Stoics sharply dissent from this picture- they think that even though wrongdoing merits censure and punishment, the wise person will never experience the negative reactive attitudes or engage in retribution. However, their grounds for rejecting the negative reactive attitudes and retribution differ from those typically given by contemporary skeptics about free will; that is, that determinism is incompatible with the sort of control over one's actions needed for genuine moral responsibility, and hence for justifiable resentment, indignation, and retribution. (Pereboom [2001] is an influential and representative example of such skepticism, and Pereboom [2014] an updated presentation of the position.)

Instead, the Stoics give moral arguments against such attitudes and actions. The Stoics think that virtue is both necessary and sufficient for happiness. The happy life will be utterly tranquil, and the wise person will suffer from no disturbing emotions (Seneca, Letters 92.3, L\&S 63F), which would include all negative reactive attitudes. Anger, for example, is a disturbing and irrational appetite to harm another person because you believe they have wronged you, based on the false judgment that harming them would be good (Andronicus, On passions I, L\&S 65B; Stobaeus 2.90,19, L\&S 65E1).

The virtuous person, by contrast, wishes to harm none but to benefit all. (In this respect, as in many others, the Stoics pick up elements of Socrates' ethics as presented in dialogues such as the Gorgias.) As noted above, God is good, and the nature of what is good is to benefit all unconditionally and harm none. We should seek to perfect ourselves and make ourselves like God—and the Stoics even say that the wise person is as virtuous as God (Plutarch, On Common Conceptions 1076A, L\&S 61J). We should regard ourselves as akin to all human beings, and we should seek to benefit as many people as we can (Cicero On Ends 3.62-8, L\&S 57F). Punishment is a fitting response to wrong doing, but right punishment is a correction of the person punished (Alexander, On fate 207,5-21, L\&S 62J).

It does not follow from this that my attitude towards my tipsy friend is no different than my attitude towards my inadequately trained dog. Because we have reason, we are capable of wrongdoing and vice, which are shameful and reprehensible, not merely unfortunate like my dog's accident. But our reason also gives us a capacity for right action and virtue, which are noble and praiseworthy. What is truly good exists only in what has reason, in humans and God, and not in plants and non-human animals (Seneca, Letters 124.13-14, L\&S 60H).

\section{The Freedom of the Wise Person and his Conformity to God's Will}

Both the wise person and the fool are responsible for their actions because the actions of each of them are equally a result of the agent's assent, and what we assent to is "up to us" and under our control. Nonetheless, in another sense, only the wise person is truly free. Epictetus often compares the foolish person to a slave, under the yoke of vicious and damaging desires (for instance, Handbook 14 and Discourses 2.2). Similarly, the Stoic emperor Marcus Aurelius (121-180 CE) likens the fool to a puppet who is jerked here and there by irrational impulses (for instance, Meditations 2.2, 6.16). We need to be careful in interpreting these metaphors: for Epictetus, the slavery of the fool is a willing slavery. And Marcus' puppet is not pulled about by a puppeteer against his will, 
but is more like a little windup toy, acting automatically and unthinkingly. (See Berryman [2010] for further discussion of the puppet metaphor.) The fool is dominated by desires and beliefs that are alien to his nature as a rational being, because right reason commands all virtuous actions and forbids all vicious actions. (This doctrine is echoed later by Thomas Aquinas, who says that the commands of the natural law are rooted in right reason and God's eternal law; see Summa Theologica I-II Q. 91 Art. 2, I-II Q. 94 Art. 3.) Only the wise person is free from these alienating and disturbing desires and beliefs; only the wise person has mastered himself and is in harmony with himself.

As explained above, that all events are fated is compatible with engaging in ordinary goal-directed action. Nonetheless, acknowledging fate is supposed to have an important practical impact on how the wise person seeks things. It's up to me to seek the antivenom, or to endeavor to get my daughter the promised slice of cake. But it's not entirely up to me whether my action achieves its aim. The hospital may not have anti-venom, or I might accidentally trip and fall on the way back to the table, ruining the last remaining slice of cake. In such cases, because all events are fated by God, it is God's will that my efforts fail. And because the wise person willingly conforms himself to the will of God, who is wise and orders all things for the best, he says to God without resentment, "your will be done."

This conformity to God's will means that even prospectively, the impulses toward action of wise people differ from those of the rest of us. The ordinary person, for example, simply seeks to be healthy when he is sick. But the wise person acts with 'reservation,' which involves adding the clause that he seeks to be healthy unless God wills otherwise. Seneca claims that acting with such reservation helps the wise person adapt to unforeseen events and ensures that nothing happens contrary to his expectations. (On Benefits 4.34.4, referred to in Inwood [1985: 120]. My discussion of reservation is indebted to his treatment of the topic on pp. 119-26.) As Epictetus advises, to do well in life, you shouldn't seek for things to happen as you wish them to; instead, you should wish for them to happen as they do happen (Handbook 8). Reservation allows the wise person to act on Epictetus' advice even in cases where what will happen is unclear. It is appropriate to seek to keep my promise to my daughter, and doing so is up to me. But if the world trips me up, I am not thwarted, and my tranquility is not disturbed.

\section{Acknowledgments}

I would like to thank Eddy Nahmias for his feedback regarding the contemporary literature on free will and determinism, and Jennifer Daigle, whose work on Aristotle on retributive attitudes has helped improve my understanding of the subject.

\section{Bibliography}

\footnotetext{
Most of the texts I refer to are collected in Long and Sedley (1987). In these cases, I provide the text number in their volume (and sometimes subsection numbers) as "L\&S < text number $>$." Unless otherwise noted, translations are from Long and Sedley, modified to meet United States conventions of spelling and punctuation, and paraphrases of ancient texts are based on their translations. I have made a few changes from Long and Sedley: I translate eph' hêmin with the more literal "up to us" rather than "in our power," and I translate to kalon and aischron using "the noble" and "the disgraceful" (or related terms) rather than "moral rectitude" and "turpitude."

Berryman, S. (2010) "The Puppet and the Sage: Images of the Self in Marcus Aurelius," Oxford Studies in Ancient Philosophy 38: 187-209.
} 


\section{TIM O'KEEFE}

Inwood, B. (1985) Ethics and Human Action in Early Stoicism. Oxford: Oxford University Press. Meyer, S. (2011) Aristotle on Moral Responsibility. Oxford: Oxford University Press.

Pereboom, D. (2001) Living Without Free Will. Cambridge: Cambridge University Press.

Pereboom, D. (2014) Free Will, Agency, and Meaning in Life. Oxford: Oxford University Press.

Strawson, P.F. (1962) "Freedom and resentment," Proceedings of the British Academy 48: 1-25.

\section{Further Reading}

Bobzien, S. (1998) Determinism and Freedom in Stoic Philosophy. Oxford: Oxford University Press. (This is the definitive work on its subject: rigorous, thorough, and groundbreaking.)

Brennan, T. (2005) The Stoic Life: Emotions, Duties, and Fate. Oxford: Oxford University Press. (This is an accessible survey of Stoics' views on action-theory, ethics, and fate, that usefully dissents from Bobzien and Inwood on certain points.)

Inwood, B. (1985) Ethics and Human Action in Early Stoicism. Oxford: Oxford University Press, 1985. (This is slightly broader in its focus and less technical than Bobzien. It contains excellent discussions of Stoic action-theory, how their action-theory shapes their ethics, "reservation," and the passions.)

Long, A. and Sedley, D. (1987) The Hellenistic Philosophers. Cambridge: Cambridge University Press. (Since we unfortunately possess no complete texts from the early Stoics and reports on their views are widely scattered among later authors, this is an essential compendium of ancient texts regarding the Stoics, as well as the Epicureans and Academic skeptics. Volume 1 contains translations of the texts, organized by subject, along with an excellent commentary, while volume 2 contains the Greek and Latin texts with notes.)

\section{Related Topics}

Free Will and Moral Sentiments: Strawsonian Views

Skeptical Views about Free Will

The Luck and Mind Arguments

Aristotle

Deliberation

Free Will and Theological Fatalism

Free Will and Theological Determinism

Free Will and Providence 


\section{1 \\ AUGUSTINE OF HIPPO \\ Jesse Couenhoven}

Given Augustine's immense standing as the greatest theological 'Doctor' recognized by both Catholics and Protestants, his legacy was bound to be contested. Even so, those who attempt to acquaint themselves with the enormous literature on Augustine's views about free will, sin, and grace might find themselves surprised by the diversity of interpretations on offer. As Eleonore Stump has written, "historians of philosophy read Augustine on free will so variously that it is sometimes difficult to believe they are reading the same texts" (Stump 2001: 124).

My suggestion in this chapter is that the best way through the fog of scholarship surrounding Augustine's views about freedom is to take a developmental and historical approach to the complexities of his many writings (cf. the 'genetic-historical' approach to Karl Barth in McCormack 1997). From that perspective, a fair amount of what has been said about Augustine is at least partially right. At the same time, those who have not taken the time to attend to the complexity of and developments in Augustine's views can hardly help but get important points wrong. Augustine revised his views about freedom in important ways, but his views also exhibited a fundamental continuity and consistency for much of his career. Augustine the recent convert may not have been quite sure of his views, but Augustine the bishop was one of the first theological compatibilists, who believed that responsibility is compatible with at least certain kinds of necessity and that human freedom requires determination by divine grace.

\section{Augustine on Free Will: A Brief Survey}

It may be helpful to begin with a brief survey of some influential accounts of Augustine's views. The later sections of this chapter will not focus on these accounts, but readers should not find it too hard to infer where I think they go right, and where they go wrong.

Perhaps surprisingly, although Augustine is widely known for his doctrines of original sin and predestination, he is also widely thought to have been among those who consider freedom incompatible with determination. Christopher Kirwan reads him as a confused libertarian: dismissing Augustine's "oft repeated idea" that the unregenerate are "free" only for sin as unappealing, he bases his claim that Augustine understands free will as a freedom of indifference mainly on his reading of Augustine's early On Free Choice (Kirwan 1989). (Babcock [1988] similarly concludes that Augustine does not offer a coherent account of moral agency.) When he considers whether Augustine's 
mature theology of grace coheres with this view, he cites Augustine's statement in the Retractions that "I tried hard to maintain the free decision of the human will, but the grace of God was victorious" (Augustine 1999e: 2.1) and concludes that Augustine was inconsistent.

Eleonore Stump reads Augustine as a "modified libertarian” (Stump 2001). Roughly, he held that free will and moral responsibility are incompatible with causal determinism, but not that the ability to do otherwise is necessary for free will or moral responsibility. (Fischer [1994] has called a similar view hyper-incompatibilism. Stump's account also anticipates claims now being made by source incompatibilists.) She takes Augustine at his word when he claimed that his early views, expressed in On Free Choice, were consistent with his later, anti-Pelagian views. Throughout his life, she argues, Augustine maintained both that humans are unable to effectively will the good without the aid of grace, and that because we are able to ask God for help in integrating our desires, our own intellects and wills are the ultimate source of our behavior. However, Stump puzzles over how to fit Augustine's late view of grace into this picture, and concludes that either Augustine set himself a problem he could not solve, or that he may have actually been some sort of compatibilist.

Other recent readers have suggested that Augustine developed a view kin to Susan Wolf's 'reason view.' James Wetzel has suggested that both Wolf and Augustine are "maximally intellectualist" in their understanding of freedom (Wetzel 1992, see also TeSelle 2002). That is, both believe our behavior is most our own when it is a product of our perception of the good, and that irrational behaviors are less than free. This seems to account for Augustine's sense that the heavenly saints are more free than earthly sinners. Yet it leaves open obvious questions about how Augustine considered it fair for God to blame unfree sinners who are trapped in ignorance and weakness.

John Rist seeks to make headway on this problem with the suggestion that Augustine believed in two freedoms, a higher teleological freedom associated with perfect rationality and goodness, and a lower freedom associated merely with responsibility. Rist reads Augustine as both a compatibilist and an incompatibilist about this lower freedom. Augustine was a libertarian about Adam and Eve's prelapsarian freedom, but Augustine's mature doctrine of grace made him a theological compatibilist about postlapsarian agency. Rist notes that Augustine's God shapes the human will in a way that leaves no room for human autonomy. Rist finds this combination of views both insightful and an unsatisfactory mess, and he worries that Augustine sometimes gave up too much of human agency in favor of saving divine omnipotence (Rist 1969: 440, 2014: Chapter 2).

Gerald Bonner has taken this latter concern further with the argument that Augustine's doctrines of original sin and predestination eventually led the late Augustine to give up on anything like what we mean by free will (Bonner 2007). Bonner seems to think of free will solely in libertarian terms, however. By contrast, two recent theological readings of Augustine have noted his late emphasis that human agency can be both determined (by original sin or by divine grace) and voluntary — which makes Augustine a compatibilist, though neither reading uses that philosophical terminology. Although Alistair McFadyen (2001: Chapter 8) and Ian McFarland (2010: Chapter 3) draw on Augustine's texts in quite different ways, both argue that Augustine's late view of sin has at its core the notion that sinful wills are not so much disempowered as "bent" in their loves. Sinners do what they want, though they lack control over what they find appealing. McFadyen leaves open the question of whether this theme allows Augustine to resolve the questions about freedom and responsibility raised by his theology. McFarland 
worries that Augustine sometimes also suggests that we can be blamed only for what we undeterminedly choose. Thus, from a different point of view, McFarland echoes Kirwan's worry that Augustine was inconsistent.

\section{On Reading Augustine on Free Will}

Why is Augustine read so diversely? The most obvious reason is that he can be difficult to comprehend. He rarely defined his terms. Augustine's views were not systematically expressed; to the contrary, they were often polemically expressed by a master of rhetoric whose aim was as much to impress or delight his audience as to clarify his position or advance a philosophical or theological discussion. For these reasons, among others, Augustine sometimes contradicted himself, or overstated his case, tried out ideas only to drop them, or simply failed to develop the implications of a view he advocated.

The challenges of reading Augustine could be better addressed, however, if Augustine's readers were more careful about being up to the task. One issue is that Augustine's expositors often lack the philosophical sophistication with ancient and modern discussions of freedom and responsibility needed to fully engage Augustine's views. Because Augustine is widely categorized as a theologian, it has taken his modern readers some time to see that he was a sophisticated heir of both Stoic and neo-Platonic action theory.

A second issue is highlighted by Isidore of Seville's famous comment that anyone who claims to have read all of Augustine's works is a liar. Isidore is typically taken to have meant that Augustine wrote too much for any one scholar to have read. Given his historical context, however, it is likely that Isidore was referring to the unavailability of many of Augustine's works during the early Middle Ages (as Kelly 1999: 131, argues). Both considerations apply to recent scholarship on Augustine. Until recently, the larger part of Augustine's works were not available in English, which influenced what the English speaking world read of Augustine. Moreover, daunted by the size and variety of Augustine's corpus, many scholars have sought to break Augustine's views into manageable pieces. Philosophers often separate Augustine's 'philosophical' early work on freedom from his later 'theological' discussions of sin and grace. For their part, theologians and historians who read Augustine have not always been philosophically astute enough to see what Augustine was up to. In various ways, therefore, accounts of Augustine on free will have tended to be selective readings.

\section{Augustinian Freedom: A Historical-Developmental Account}

A better integrated reading of Augustine begins with the recognition that Augustine's views developed in conversation with his own dynamic and complex intellectual context. It is a truism for some that Augustine was the first to articulate the idea of free will (see, for instance, Arendt 1978: 84ff). However, this claim is misleading in a number of respects. Because of his status, Augustine has often been wrongly credited with inventing ideas that he inherited and developed. The idea of a just war, which he learned from Cicero and Ambrose, is an example; his infamous doctrine of original sin, which he drew from Tertullian and other African speculation about baptism and inherited guilt, is another (see, respectively, Mattox 2006: Chapter 1; Couenhoven 2005). The first great theorist of anything like what we have in mind when we speak of free will may have been the first great Christian theologian, Origen, who was a kind of libertarian (see Frede 2011). Rather than the inventor of the idea of free will, therefore, Augustine 
is a reference point for it, the source of a conversation about free will we have inherited from him through centuries of further conversation partners.

A further complexity that must be kept in mind is how deceptive it can be to say that Augustine had a concept of free will as such. He wrote a great deal about the voluntas. Translating that term by 'will' can obscure the fact that Augustine did not have a faculty psychology, or an idea of the will as a singular locus of responsible activity. Nor did he distinguish volitional from intellective powers. Given our typical associations with the term, it can be quite misleading to read Augustine as a theorist of free will. It is more illuminating to simply read Augustine as having developed, over time, conceptions of freedom and responsible agency that sought to make philosophical and psychological sense of his theological convictions about original sin, infant baptism, divine foreknowledge and grace, predestination, and related topics. Part of the interest and difficulty of reading Augustine is the fact that he did so in dialogue with his Christian, Platonist, and Stoic forbearers, often both appropriating and dissenting from all of those parties.

Augustine's first major work on these topics, typically translated as "On Free Choice of the Will," concerned what he called the liberum arbitrium of the voluntas (for more on these terms, see Couenhoven 2013: Chapter 3). In many ways, this dialogical work was not the expression of a settled position but an experimental foray. Augustine brought the first two parts of the book to their climax with the claim that what we choose or consent to (liberum arbitrium) is within our power to control. The idea that we nondeterminedly choose in ways that allow our ultimate moral and spiritual identities to be up to us was, more or less, the Christian Platonist view Augustine had learned prior to his conversion. It appealed to him in part because it seemed to offer an appropriately non-Manichean solution to the problem of evil.

Notably, however, this book was left unfinished until, about six years later, in 395, Augustine returned to his dialogue, adding a third part. In this concluding discussion, Augustine raised questions about whether postlapsarian sinners, or saints saved by grace, really have the power for self-determination that his book had been celebrating. Our choices, he suggested, are motivated by the mind's desires (voluntas), which is too fundamental a part of who a person is to be changed from evil to good via the choices it itself motivates. Change is possible, but only with divine assistance.

Augustine did not, at this point, put this psychology to work in his understanding of prelapsarian humanity. Though he had begun to question whether sinners have a libertarian freedom to achieve virtue and vice, he continued to take for granted that Adam and Eve must have had such agency. He still considered a version of the 'free will defense' a crucial part of Christian thought (I argue that he later rejected free will theodicy in Couenhoven 2007). Accordingly, he defined sin as "the will to retain and follow after what justice forbids, and from which it is free to abstain" (Augustine 1890: 11.14; this definition was to cause Augustine much trouble in the Pelagian debates about original sin). Although Augustine now believed that sinners cannot make themselves good, he thought they could at least seek God's grace. Thus, the early Augustine modified his libertarian inheritance without entirely rejecting it. At the same time, by raising questions about the theological and psychological adequacy of the teaching about human agency he had inherited, Augustine had begun to move toward what would become his distinctive view.

A year later, in his "Replies to [the Manichean] Simplicianum," Augustine had settled on the position that he would develop for the rest of his career, most rigorously in his anti-Pelagian treatises. Augustine's career as a Christian intellectual is commonly broken 
into four stages: the neo-Platonic philosophical period right after his baptism, the anti-Manichean period, the anti-Donatist period, and finally, the anti-Pelagian period. While this approach captures something important about the changes in Augustine's major conversation partners and, at points, his writing style, it is important to note the equally significant consistency in the main themes Augustine pursued in his occasional writings throughout his career. Augustine's 'philosophical' period clearly overlapped with his writings against the Manichees; much of his early writing was an attempt to think through his transition away from Manicheanism. I have suggested, in addition, that Augustine's early writing was a time of questioning and exploration more than it was a time of defending settled views. Once Augustine's thinking about freedom and agency found its footing, he would make a variety of changes to his position, but only in attempts to develop the radical implications of his starting point (for detailed explorations of the shifts in Augustine's thought, see Burns 1980; Cary 2008).

Augustine's new starting point was influenced above all by Romans 9, where the Apostle Paul discusses God's power to save. In response to the Manichees, Augustine indicated that what he learned from Paul was that because God's election of his people is entirely gratuitous, it is not based on any human merit. This claim expressed Augustine's growing conviction that in spite of their differences the Roman philosophies and theologies influential in his context shared a conceptual mistake. They taught that a select few can work their way to a salvation that is achieved through self-purification. The means of that purification might differ in one way or another, and so too the nature of the good life that one sought. But what all fundamentally pagan views have in common is a theological error correlated with a psychological error. Because they did not recognize Christ as savior, the pagans were unable to recognize the necessity of being saved by divine help. We are made new in Christ, Augustine thought, because that is the only way for us to be saved at all. God's saving action thus teaches us who we are and what our situation is like. Those who believe that we can achieve virtue and salvation apart from Christ not only denigrate God's gracious work but misunderstand themselves. Theologically, therefore, Augustine's position was that Manicheanism is wrong because human beings do not do anything prior to receiving God's grace that makes them particularly deserving of it. The psychological corollary is that divine action has priority over human action because the former makes it possible for the latter to be transformed and to have the power to successfully seek the good. Without such grace humanity is trapped in a willing yet helpless bondage to evil.

This philosophical theology of human action differed in significant ways from the one to which Augustine was converted, and it took him another 20 years to think his position through. Along the way he changed his mind about a variety of the details of his position. But he would become more and more radically and consistently compatibilist as he argued against a series of opponents he viewed as propounding similar errors that put human moral accomplishments prior to divine grace. The Donatists were an African Catholic sect for whom the power of the sacraments depended on the purity of the priests who administer them. That sacramental theology seemed to Augustine to make the dual errors of trying to add to Christ's saving work and asking too much of human virtue. The Pelagians, though loosely affiliated and largely Italian, were like the Manichees and Donatists in being spiritual elitists for whom salvation depended on one's own moral achievements. For them, Christ was another sage, an example for the elite to follow. In City of God, Augustine also took aim at the Stoics, who celebrated their own heroic virtue in the belief that they could avoid the morally and spiritually 
tragic without God's help, via the power of their free decisions. Thus, whether Augustine was writing about evil, the sacraments, original sin, predestination, or the city built on love, his fundamental theme was the irreplaceable necessity of God's salvation in Christ, and the corresponding limitations of any purely human effort to achieve virtue.

\section{Augustine's Compatibilism: A Sketch}

In his late works, Augustine subscribed to compatibilist conceptions of freedom and human responsibility, goods he considered compatible with divine determinations such as predestination. He wrote, for instance, in City of God that " . . . if necessity is defined in the sense according to which we say that it is necessary for something to be as it is or to happen as it does, I see no reason to fear that it will eliminate our freedom ..." (Augustine 2012: V.10).

Readers who take Augustine to be a libertarian typically misread him because they pay too little attention to the late works in which he expressed his mature doctrines of original sin and predestination. However, another source of confusion lies in the form Augustine's compatibilism took. Compatibilists are widely expected to believe in determinism, so it can be surprising to discover that Augustine did not.

On Augustine's mature view, the grace God offers the predestined elect is necessarily accepted by those to whom it is given (Augustine 1999c: 8.13). Those who are not given such grace cannot avoid sin. Augustine's doctrine of original sin, which taught that all human beings procreated without special divine intervention are born with distorted loves (concupiscence), indicated that human beings are necessarily sinful. These views about sin and grace are sometimes thought to be deterministic, but Augustine was keen to argue otherwise (e.g., Augustine 1999c: 10.19; Augustine did not believe in causal determinism, or fatedness by heavenly bodies, and was probably an occasionalist; see Couenhoven 2013: 3.5).

It was essential, Augustine believed, to the definition of sin that God does not cause us to act sinfully, but only permits us to. For something to be sin-and thus evil, a privation of the good-it has to be against the divine will in a way that it could not be if God played a positive role in promoting it. It was also important to his theodicy for Augustine to argue that God does not direct every detail of creation's existence, and thus that there is no thoroughgoing divine determinism. It is true that God has oversight over all creation. Augustine argued at length in City of God that human kingdoms are established by divine providence. However, Augustine also maintained that "[God] is not the giver of all wills." (Augustine 2012: V.9.) There are many times when God simply allows us to do as we please. Adam and Eve's fall from innocent perfection into sin is the prime but not the sole example of such a situation, where God foreknew a thing that God did not cause (Augustine 1999c: 10.19).

Thus, Augustine's commitment to predestination did not imply a commitment to thoroughgoing divine determinism. Predestination creates only a positive kind of necessity, one that fulfills the ends for which God made us (Augustine subscribed to what we call single, not double, predestination). And although it is clear that the "blessed necessity" created by grace can limit and direct human choices, Augustine was eager to affirm that it does not remove the ability to act from one's voluntas, or to consent to the desires one might have.

In relation to his doctrine of sin, Augustine left open the possibility that humans might at times be undetermined in their imperfection. For instance, there may be times 
when one does not find anything attractive enough that it trumps one's other options. In such cases a person may choose quite randomly. However, Augustine was convinced that indeterminacy of this sort cannot save sinners, since they need a renewed way of being that forms good habits of action. That cannot happen by chance.

What made Augustine a compatibilist was not a belief in determinism-for various theological reasons Augustine rejected all the forms of determinism available to himbut his conviction that true freedom requires divine determination and that praise and blame are compatible with being determined by grace or by original sin. As he developed the logic of these claims, Augustine articulated a compatibilist picture of human agency.

\section{Augustine on Bondage to Sin and Freedom in Christ}

As a rhetorician, Augustine delighted in highlighting the paradoxical freedom of those who are slaves to Christ, and the bondage of those who are slaves to sin. Building on the moral psychology he had begun to develop in his early work on the liberum arbitrium of the voluntas, he argued that whenever we consent to a desire and choose to act we do so for reasons; we are motivated to do so by our beliefs and loves. Augustine liked to remind his readers that, as his teacher Ambrose had said, what comes into our thoughts and hearts is not in our power to control-not directly, at least. This means we have limited control over our character, which is composed of what we desire and think about. Since we have limited control over the virtues and vices that characterize us, we also have limited control over our choices or actions, which flow from our character. Augustine's sense that both the virtuous and the vicious lack control lay behind his willingness to speak of both saints and sinners as serving what they love.

Inspired by God's freedom for perfect relationships, Augustine considered the highest kind of freedom an inability to love wrongly that does not require having alternatives. This freedom, which only the just and good can have, he called libertas. Sinners can achieve libertas only in Christ, who heals their broken voluntas. God's operative grace, Augustine believed, is not agency-demeaning but agency-enhancing, if we understand the nature of our agency rightly. When grace reshapes human beliefs and desires-when it reshapes the voluntas - God may significantly restrict human choice. God does not, however, undermine but actually enhances voluntary agency. Augustine considered this a fine trade off. As he saw it, choice is only a minor good, an occasional means to an end rather than an end in itself. Choice cannot give us the power to define ourselves because the choices we make are sourced in our existing way of being in the world. By contrast, divine grace enriches human agency by empowering it for the good. Human beings can fully realize themselves only when they are able to wholeheartedly pursue the good, acting as they want and wanting thus for only the best reasons, without the internal division and hesitation that choice bespeaks.

From Augustine's point of view, the agential problem with sinners is not that they are determined - after all, the saints are also determined, by love. The sinners' problem is that they cannot get what they truly want. Fundamentally, he believed, human beings are dependent, spiritually hungry beings who (whether they know it or not) yearn for a relationship with God, and with the goods through which God displays glory. Hence the famous beginning to his Confessions: "you have made us for yourself, and our heart is restless until it rests in you" (Augustine 1960: 1.1). Sinful desires are self-defeating because they deny this reality, and ask God's good creation to be for them what it is not—an ultimate rather than a finite good. 
To be a sinner, Augustine believed, is to be at odds with oneself, trapped by a twisted second nature, original sin, that undermines the good for which human nature was created. He found the agency of sinners lacking in significant respects, and he displayed a good deal of compassion for sinners, among whom he located himself. He acknowledged that his own sin was often involuntary. Often he had thought he was making his life better when in fact he had been making chains for himself out of the things he loved. Augustine's problem, caused by the original sin inherited from his own origins, was both ignorance and weakness. He was unable to see the good clearly, and he was unable to care wholeheartedly about even the goods he did know. He was divided against himself. In the Confessions, Augustine spoke of himself as a person in fragments, not a person of a single will but of partial loves, fears, and wishes. This problem was compounded by the fact that he was unable to be honest with himself-he hid his lust for power (libido dominandi) and greed for love with philosophical and religious pieties. Such, Augustine concluded, is the life of a sinner. It is a life of such severely diminished agency that it is properly thought of as kin to being tied down.

\section{Augustine on Responsibility and Blame}

Augustine's suggestion that sinners are unfree raises a natural question: how is it fair to blame them? Being trapped by original sin seems a clear case of lacking agency, and thus, responsibility. Interestingly, this was a claim Augustine both endorsed and rejected. He endorsed this claim insofar as he recognized the enslavement of the voluntas as an involuntary state that sinners suffer. After Adam and Eve, sinners find evil within themselves before they have any chance to choose it.

At the same time, Augustine thought Scripture made it obvious that God blames sinners, and rebukes and even punishes them. He argued that doing so is not without propriety, because it may very well be the case that we, who care what others think about us, will be swayed by rebukes or empowered by admiration (Augustine 1999d: 3.5, 5.7-6.9). God often ordains our interactions with one another to be instruments by which we are offered teaching and correction.

Augustine built on this observation with the further argument that it is proper to offer rebukes or praise because sinners and saints are not simply passive before their vices and virtues. Augustine blamed those who did not believe in God because it was their own voluntas that disbelieved and did not love (on similar grounds, he also gave credit to those who did believe, even though believing was not up to them; Augustine 1999c: 6.11). He made it clear in his Confessions that in spite of his fractured being, it was nevertheless he who had willed career success, who had desired fame and enjoyed the admiration of his peers. He had been a fool, unwise and misguided. He could not say, therefore, that God or original sin had "made" him do these things. He had not been forced. He had loved and believed; it was his own mind that was in the right and wrong. In what might well have been a reference to his old self, Augustine noted that "when someone says, 'I cannot do what is commanded because I am conquered by my concupiscence,' he, of course ... recognizes his own evil in himself, and grieves" (Augustine 1999b: 3.5).

Significantly, the fact that Augustine accepted responsibility for his beliefs and desires did not mean that God did not share in that responsibility. After all, God was not only his conversation partner but the one who made Augustine's testimony possible in the first place. God had permitted him to fall into these paths, and had not stopped him. 
But Augustine believed that God had done so for the sake of greater goods that God was gradually revealing to him, and which Augustine could begin to see as he looked back over his life. So while God bore some responsibility for Augustine's wayward life, on the whole, Augustine sought to praise God for the turns his story had taken. He did not see that he was in a position to blame God. He did not fully understand God's ways, but that was precisely why Augustine thought it better to wait and see where things were going (Augustine 1999d: 8.17).

Parallel points apply to Augustine's views about the agency of sinners who have begun to be transformed by prevenient and then operative grace. When God decides to turn a heart toward true love, as Jesus had dramatically done in the case of St. Paul, the target of God's love cannot reject God's offer. Yet Augustine sought to avoid fatalism by insisting that the grace God offers to the elect "does not destroy the human will, but changes it from an evil will to a good will and, once it is good, helps it" (Augustine 1999b: 20.41). Only via our own voluntary agency are we able to be genuine partners of God, which means that God's agency must work through ours if it is to be we who are saved. God may clarify our vision so that we are able to see what is truly worthy of love, and how to love well, but we are the ones who love. Thus, although God often speaks through us, God does not speak for us. So, Augustine urged,

Let no one, then, accuse God in his heart, but let each person blame himself when he sins. And when he does something as God wants, let him not take this away from his own will. For, when he does it willingly, he should call it a good act, and he should hope for [a] reward.

(Augustine 1999b: 2.4)

We can summarize Augustine's claims by saying that though he did not think of sinners who sin involuntarily as significantly free, he did consider them responsible and accountable. Likewise, although he insisted that sinners saved by grace cannot claim credit for making themselves who they have become, he did hold them responsible for their renewed beliefs and desires, and the actions that flowed from them. As significant personal agents, whose beliefs and desires make a difference for better and worse, human beings deserve to be praised and blamed for who they are. The personal qualities shown in a person's attitudes and behavior matter; having the kind of voluntary agency a human being has, and the abilities to think, dream, wish, and so on that go along with it, means that they are responsible agents, accountable for who they are. Thus, Augustine wrote, our believing and willing "are due to [God] because he prepares the will, and both are due to us because they are not done unless we are willing" (Augustine 1999c: 3.7).

One image Augustine used to convey his compatibilism is that of prayer. As the activity proper to those who wait upon the Lord to renew their strength, prayer is a metaphor for the Christian life that sums up the dynamic Augustine had in mind when he asked, "What do you have that you have not received?" (Augustine 1999a: 2.3-7.15). The Confessions took the form of an extended prayer because in that text Augustine expressed his sense that whatever sense his life story made was owed to God's gracious planning. In his prayers he testified about his reliance on God while also displaying his own agency by speaking in his own voice. He was a dependent agent, but not in such a way that he was not also a responsible agent in his own right. He spoke for himself, expressing his own beliefs and desires in the manner appropriate to a genuine conversation partner with God, even if that voice was given to him by his maker. 


\section{Conclusion: Responsibility and Involuntary Sin}

Augustine's philosophical theology of human agency reached its most complex and consistent articulation in his "Unfinished Work" — dying while still writing it. There he emphasized that agency can be both voluntary and necessary. Talk of voluntary agency can seem opaque, but Augustine's suggestion that it is misleading to call sinners free, and his consistent use of metaphors like fall, stain, infection, and wound to describe the bondage of sin, suggest that he did not associate blameworthy agency with being in control, but rather with ownership of a particular sort. Associating sin with ignorance and weakness implied that we can be culpable for evils that are not simply up to us, or even entirely willing. Responsibility for it depends on the fact that sinners cannot disclaim ownership of the voluntas with which they find themselves, their own twisted beliefs and loves. One sign of this ownership is the fact that we naturally consent to acting out the beliefs and loves with which we find ourselves. Augustine did not, however, argue that responsibility depends on choice or consent (liberum arbitrium). More fundamentally, Augustine believed that evil beliefs and loves are blameworthy in themselves, even when they are not consented to:

It is not what I want to that I do. After all, what does the law say? You shall not lust. I too don't want to lust, and yet I do lust; although I don't yield consent to my lust, although I don't go after it. I stand up to it, you see, I turn my mind away from it, I refuse it any weapons, I restrain my members. And yet what I don't want occurs in me.

(Augustine 1992: 154.10)

The desire Augustine had in mind was not necessarily sexual; it could be a greed for possession or domination of some other sort. The law to which he referred was the tenth of the ten commandments, forbidding covetousness. His point was that even his unbidden thoughts and yearnings reflected on him in a deep way because he was active in them, and they expressed the person he was, whether he liked it or not (a recent philosophical view with some similarities is Smith 2005, 2008). He would not be liberated from such internal conflict until, by grace, that day when his mind would no longer be fractured and he would be able to wholeheartedly love the good for which he was made.

\section{References}

Arendt, H. (1978) The Life of the Mind, Volume Two: Willing. New York: Harcourt Brace Jovanovich.

Augustine, St. (1890) "On Two Souls," 392, 393, in P. Schaff (ed.), trans. Rev. R. Stothert and A.H. Newman, The Writings Against the Manicheans and Against the Donatists. Nicene and Post-Nicene Fathers of the Christian Church. Newman. Grand Rapids: William B. Eerdmans, pp. 158-88.

Augustine, St. (1960) Confessions, 398. Trans. J.K. Ryan. New York: Doubleday.

Augustine, St. (1992) "Sermons (148-183)," in J.E. Rotelle, O.S.A (ed.), trans. E. Hill. The Works of St. Augustine, III/5. Hyde Park: New City Press.

Augustine, St. (1999a) "The Gift of Perseverance, 427/8," in J.E. Rotelle, O.S.A (ed.), trans. R.J. Teske. The Works of Saint Augustine, Vol. I/26. Hyde Park: New City Press.

Augustine, St. (1999b) "Grace and Free Choice, 426," in J.E. Rotelle, O.S.A (ed.), trans. R.J. Teske. The Works of Saint Augustine, Vol. I/26. Hyde Park: New City Press.

Augustine, St. (1999c) "The Predestination of the Saints, 427/8," in J.E. Rotelle, O.S.A (ed.), trans. R.J. Teske. The Works of Saint Augustine, Vol. I/26. Hyde Park: New City Press.

Augustine, St. (1999d) "Rebuke and Grace, 426/7," in J.E. Rotelle, O.S.A (ed.), trans. R.J. Teske. The Works of Saint Augustine, Vol. I/26. Hyde Park: New City Press. 


\section{AUGUSTINE OF HIPPO}

Augustine, St. (1999e) Retractions, 426/7, trans. Sister M. Inez Bogan, R.S.M. Washington, DC: Catholic University of America Press.

Augustine, St. (2012) The City of God, 413, trans. W. Babcock. Hyde Park: New City Press.

Babcock, W.S. (1988) "Augustine on Sin and Moral Agency." Journal of Religious Ethics 16: 28-55.

Bonner, G. (2007) Freedom and Necessity: St. Augustine's Teaching on Divine Power and Human Freedom. Washington, DC: The Catholic University of America Press.

Burns, J. P. (1980) The Development of Augustine's Doctrine of Operative Grace. Paris: Etudes Augustiniennes. Cary, P. (2008) Inner Grace: Augustine in the Traditions of Plato and Paul. New York: Oxford University Press. Couenhoven, J. (2005) “Augustine's Doctrine of Original Sin,” Augustinian Studies 36: 359-96.

Couenhoven, J. (2007) "Augustine's Rejection of the Free Will Defence: An Overview of the late Augustine's Theodicy," Religious Studies 43: 279-98.

Couenhoven, J. (2013) Stricken by Sin, Cured by Christ: Agency, Necessity, and Culpability in Augustinian Theology. New York: Oxford Unversity Press.

Fischer, J. M. (1994) The Metaphysics of Free Will. Malden: Blackwell.

Frede, M. (2011) A Free Will: Origins of the Notion in Ancient Thought. Los Angeles, CA: University of California Press.

Kelly, J.F. (1999) "Carolingian Era, Late," in A.D. Fitzgerald (ed.), Augustine Through the Ages. Grand Rapids: William B. Eerdmans, pp. 129-32.

Kirwan, C. (1989) Augustine. London: Routledge.

McCormack, B. L. (1997) Karl Barth's Critically Realistic Dialectical Theology: Its Genesis and Development 1909-1936 (Clarendon Paperbacks). Oxford: Oxford University Press.

McFadyen, A.I. (2001) Bound to Sin: Abuse, Holocaust and the Christian Doctrine of Sin. New York: Cambridge University Press.

McFarland, I.A. (2010) In Adam's Fall: A Meditation on the Christian Doctrine of Original Sin. Malden: Wiley-Blackwell.

Mattox, J.M. (2006) St. Augustine and the Theory of Just War. London: Bloomsbury Academic.

Rist, J.M. (1969) "Augustine on Free Will and Predestination," Journal of Theological Studies 20: 420-47.

Rist, J.M. (2014) Augustine Deformed: Love, Sin and Freedom in the Western Moral Tradition. Cambridge: Cambridge University Press.

Smith, A. (2005) "Responsibility for Attitudes: Activity and Passivity in Mental Life," Ethics 115: 236-71.

Smith, A. (2008) "Control, Responsibility, and Moral Assessment," Philosophical Studies 138: 367-92.

Stump, E. (2001) "Augustine on Free Will," in E. Stump and N. Kretzman (eds), Cambridge Companion to Augustine. New York: Cambridge University Press, pp. 124-47.

TeSelle, E. (2002) "Exploring the Inner Conflict: Augustine's Sermons on Romans 7 and 8," in D. Patte and E. TeSelle (eds), Engaging Augustine on Romans. Harrisburg: Trinity Press International, pp. 111-46.

Wetzel, J. (1992) Augustine and the Limits of Virtue. New York: Cambridge University Press.

\section{Further Reading}

Brown, P. (2000) Augustine of Hippo: A Biography, a new edition. Berkeley: University of California. (Though now dated in some respects this remains the best overall biography of Augustine.)

Dodaro, R. (2004) Christ and the Just Society in the Thought of Augustine. New York: Cambridge University Press. (This book insightfully relates Augustine's politics in City of God to the ideas about human nature being explored in his ongoing debates with the Pelagians.)

Fitzgerald, A.D. (ed.) (1999) Augustine Through the Ages. Grand Rapids: William B. Eerdmans. (A massive encyclopedia filled with articles by top scholars, this is an excellent resource.)

Rist, J.M. (1994). Augustine: Ancient Thought Baptized. New York: Cambridge University Press. (Rist's effort to put Augustine's thought in its ancient context has been widely praised.)

Wetzel, J. (2010). Augustine: A Guide for the Perplexed. New York: Continuum. (An accessible recent meditation on central Augustinian themes written by a scholar with a reputation for fairmindedness and lyrical prose.)

\section{Related Topics}

Free Will and Theological Fatalism

Free Will and Grace

Free Will and Providence 


\section{2 \\ ANSELM OF CANTERBURY \\ Sandra Visser}

According to Anselm, what is free will?

Anselm tells us that freedom is the power to preserve justice, and that justice is rectitude of will preserved for its own sake. So, free will is the power to preserve rectitude of will for the sake of that rectitude itself (DLA 3; DC 1.6). But this isn't a terribly helpful definition. It doesn't even appear to be in the near neighborhood of what one might offer as a first stab at a definition of free will. Anselm, clearly an attentive and practiced teacher, knew this, however. In explaining free will, he begins where many Christians first thinking about free will would begin: is free will the power to sin or not to $\sin$ ? The answer to this question, stripped of its Christian overtones, would seem to entail that free will is the power to choose between alternatives. We'll return to this question. That the question about alternatives is also about sinning is an important one for understanding some underlying questions that Anselm believes a successful theory of free will should answer.

Anselm immediately rejects the possibility that free will should include, even conceptually, the power to sin for the simple reason that he believes that both God and the unfallen angels have free will and it is impossible that they sin. But this position appears to leave Anselm with another problem. How is it that humans freely sin if being able to sin isn't even conceptually a part of freedom? Anselm's reply, on a first read, is puzzling indeed: "It was through the power of sinning, and spontaneously, and through free choice, and not out of necessity that our nature, and that of the angels, first sinned" (DLA 2). Anselm knows that this answer is utterly confusing, since he has his interlocutor reply: "I need you to explain that, because it's obscure to me." Anselm's response does not, unfortunately, make his position entirely clear on its own. So, rather than follow Anselm's direct response at this point, I will instead turn to a different, but obviously related, place to start in answering the real starting point for Anselm's discussion of free will, namely, the problem of evil. Understanding Anselm's response to this problem when more explicitly addressed will provide the distinctions we need to understand Anselm's rather unhelpful response to the question of the relationship between sinning and freedom.

We can begin by considering why Anselm thinks we have free will. Anselm says that

I think it worth asking how such a will came to be present in human beings. But if we pay attention to the original creation of rational nature, we will easily detect the cause of such a will. God's aim was to make rational nature both just 
and happy for the purpose of enjoying God himself .... [R]ational nature could not be either just or happy without the will for justice and happiness.

So, in order for us to be either just or happy, we need a will, and with it the ability to act spontaneously. Without that, we would only have our natures, by which we operate necessarily.

What is clear from this discussion is that on this point Anselm would take issue with the trend in contemporary philosophy (Kane 2005, 2007) that wishes to maintain that actions that are the result of a consistent character trait are free. And this is the case even though Anselm rejects PAP as being necessary for the exercise of free will. The reason is that, while PAP is unnecessary, as one can preserve justice for its own sake in the absence of alternatives (see below), one's character (to the extent that it even makes sense to talk of character in Anselm) is either part of our nature, and so necessitated, or a result of our preserving rectitude. In the latter case, any action will only be consistent with our character, but not flow from it. If the motivation is something other than justice itself, it won't be free. See below for a discussion of character development in Anselm.

We can see that all things which have a nature operate necessarily by considering what Anselm says about God's creative activity. He says that (in the case of humans, though by extension all of creation) "God brings about everything that is done by either nature or will, since God creates nature and the instrument for willing together with its affections, without which that instrument brings about nothing" (DC 3.12). And we know that whatever God brings about comes about by necessity.

But neither can he (God) will for someone who has it to abandon it unwillingly, because of some necessity, for that would mean God was willing for someone not to will what God wills for him to will, which is impossible.

$(D C 1.6)$

Now the will as instrument moves all the other instruments that we employ spontaneously, both those that are in us (such as hands, the tongue, and sight) and those that are outside us (such as a pen and an ax), and it brings about all voluntary motions. In fact, it moves itself by means of its own affections. Hence, it can be described as an instrument that moves itself. I say that the will as instrument brings about all voluntary motions.

(DC 3.12)

So we see that according to Anselm the will, in contrast to other aspects of our nature, acts spontaneously, rather than out of necessity (you might say that it necessarily acts spontaneously). The whole point of God giving humans a will is so that they gain the ability for self-initiated action. Thus, Anselm's theory of free will is incompatibilist. In fact, it is properly classified as an agent-causal theory since Anselm indicates that the will moves itself and only rational agents have wills. It is clear to Anselm that we have a will, then. But Anselm also thinks it is obvious that our will isn't always free.

But since we do not have free choice in all matters, it is important to investigate the extent and the nature of that freedom of choice that we believe human 
beings always possess, and what choice itself is. For choice is not the same thing as the freedom by which choice is called free. We talk about freedom and choice in many contexts. For example, we say that someone has the freedom either to speak or to keep silent, and that it is up to his choice which of the two he wills. And we often speak in similar ways of freedom and choice that are not always present or are not necessary for the salvation of our souls. The only question at issue now, however, concerns that choice and that freedom without which human beings cannot be saved.

In his writings, Anselm is consistent in having free will as it relates to salvation as his target, since the only thing worth having freedom for, is for salvation. The garden variety choices that we think of as free are unimportant in comparison with salvation. There are things we can say about those choices as we understand Anselm's theory of free will as it relates to salvation. "It is important to keep in mind that, as I said above, this question concerns only the free choice without which no one merits salvation once he has attained the age of reason" (DC 3.2).

Several things are clear from this passage. First, Anselm thinks there are varieties of free will, primarily because we use the word in a variety of contexts which he leaves unspecified (DLA 3). As we can see, the common parlance isn't one he's particularly interested in. It's easy to see from his writing that in our common usage we are free to the extent that our actions aren't compelled. So, as long as we have at least two advantageous options, our will and the actions which result, can reasonably be considered free.

Second, Anselm more clearly here distinguishes between the will itself and actions that proceed from it. In fact, Anselm regularly attributes a wide variety of powers to the will. We see him doing this methodically in On Freedom 13, and we see the results throughout his work. An incomplete list of powers we find in Anselm includes: the power not be a slave (DLA 2), the power to see a mountain (DLA 3), a power of overcoming (DLA 5), a whole host of weird powers in DLA 13, the power to receive perseverance (DCD 3), the power to exceed (DCD 14), the power not to die (CDH 1.18), the power to discern good from bad (CDH 2.1), a bunch of weird powers ( $\mathrm{CDH} 2.16)$, the power to reproduce just children (DCD 26), and the power to use or not use clothing (DC 3.5).

We are now in a position to understand Anselm's rather confusing answer to the student that we left earlier. This helps us to begin to understand Anselm's answer to the question about how it is that we can have free will but that it is unconnected with being able to sin. Our sinning, insofar as it is a product of the will, and thus spontaneous, can be understood as free, but insofar as it is not directed at the proper end, it is not properly called or even connected with free will. But the third thing to notice about our passage above is that Anselm's interest in his writing is that freedom without which humans cannot be saved. To that type of freedom we now turn.

When is the will free? What we find out in On Freedom of Choice is that the context in which Anselm really cares about this question is the context in which our wills are free as opposed to in slavery to sin. So, again, when is the will free? The answer is obvious: the will is free when it is doing what God made it for. And we have seen above that God made wills so that humans could be in union with him. And humans only deserve to be in union with him if they are doing what is right - that is, what is 
just. So, when we use the power of the will in order to preserve justice, we are acting freely. And if we do that, we deserve to be happy. If we misuse our free will, that is, if we use our wills to sin by pursuing happiness over justice, or even by pursuing justice in order to be happy, we will have lost said justice and be slaves to our desire for happiness. It is for this reason that Anselm says that "natural freedom of choice is otiose without justice" (DC 3.13). It is also for this reason that Anselm is not really interested in those exercises of the will, which while they may be called free, are only the result of willing between two types of advantage. Finally, it makes a lot more sense of Anselm's definition of free will: freedom is the power to preserve justice for its own sake.

There is one residual question to answer. Why is it that Anselm says we must preserve justice rather than act out of justice or act for justice or something else? Why preserve? It is preserve because Anselm thinks that justice is given to a human and that happiness is earned and results in being given an appropriate number of advantages without disadvantages (DC 3.13; On Freedom throughout). If you do not have an upright will, you cannot generate one, so the most one could do is to preserve an upright will if it were given. Thus, preserve. It also makes sense of the theology that Anselm wishes to defend. Once one has lost one's uprightness of will through an unjust action, one cannot get it back of one's own accord. It must be given to the person by God. This is what grace is, according to Anselm: the giving of rectitude by God. "Once the will as instrument loses its instrument for willing justice (in other words, once it loses rectitude), there is no way it can will justice, unless its rectitude is restored through grace" (DC 3.13).

Anselm's view also gives him a theory with which he can satisfy those (probably his students) who chafe under the impression that since grace is gift, human freedom of choice is rendered inoperative with respect to salvation. As Anselm writes, "there is no doubt that whoever among them is saved is saved on account of justice" (DC 3.2). Although no one receives rectitude except by God's grace, humans preserve it through free will. So Anselm concludes that "no creature has this rectitude of will ... except through God's grace. We have, however, shown that this rectitude can be preserved through free choice ... Therefore ... we have found that his grace for saving human beings is compatible with free choice" (DC 3.3).

One interesting consequence of Anselm's view is that a human will regularly lose his salvation, which must be earned through preserving uprightness for the sake of that uprightness alone. It is pretty clear that humans regularly act unjustly. And so, according to Anselm, those people will also regularly lose their faith, for they fail to preserve righteousness for its own sake. Their only hope of salvation is again dependent on God's granting them uprightness of will. Even once one has lost salvation, one cannot ask for it except in an unrighteous, prudential way. One can no longer even desire uprightness of will for its own sake. Anselm's model is clearly the Benedictine notion of continuous conversion. His view helps make sense of some of his letters, such as one in which he congratulates his sister and brother-in-law on having lost all but one of their children in infancy.

If you are wise and give the matter your wise consideration, you will understand that God has done you a great mercy, because he took away from you an incitement to love this present age and to long for things that pass away, by taking from you your heirs in this life and making your children his own heirs, 
his own children, in eternal life. Now give thanks to God because you have been relieved of your burden and set free to hasten toward God with all your heart, all you effort, and all your strength; and be anxious for nothing but the salvation of your souls.

(Letter 211, see also Letter 258)

Salvation is a very tenuous thing on his view.

His view also has the result that there's not much hope in the way of character development for humans, either. This perhaps explains why Anselm writes almost nothing about ethics as it relates to our fellow human beings, limiting his discussions to our relationship to God alone. It's more a matter of trying to preserve justice for its own sake. But there is not really a way in which one can get better or experience growth in preserving justice. The best that Anselm can do is to suggest that we do this more firmly, but not that we might grow ever better. He writes:

Those who say, 'Turn us, O God,' have already turned to some extent, since they have an upright will when they will to be turned. They pray in virtue of what they have already received, in order that their turning might be increased, like those who were already believers and said, 'Increase our faith.' It is as if both were saying, 'Increase in us what you have already given us; bring to completion what you have already begun.'

$(D C 3.6)$

Thus, we can understand character growth in Anselm as being such that humans preserve justice in more and more areas. Although Anselm generally writes as if justice is an all or nothing deal—-that you're either just or you're not—-there is one passage in which he indicates otherwise. He writes:

I have said that every instance of justice is rectitude of will preserved for its own sake. From this it follows that everyone who has this rectitude has justice and is just (since everyone who has justice is just). But I do not hold that eternal life is promised to all the just; it is promised only to those who are just without any injustice. [ . . . ] Some people, after all, are just in one respect and unjust in another: for example, someone who is chaste but envious.

$(D C 3.4)$

If this is Anselm's considered position, then character growth could be understood as more firmly preserving justice in more and more areas, so that one would lose justice in fewer and fewer areas. One would still be in the position of relying on God to graciously restore rectitude in any area in which one lost it, but it would make at least a little, unsatisfactory, sense of character development. It certainly would not be a development born of habituation or repeated trials and failures.

\section{Acknowledgments}

I am grateful for the helpful and insightful comments of Thomas Williams and Kevin Timpe on earlier drafts of this chapter. 


\section{Bibliography}

References to Anselm are given as follows:

$$
\begin{aligned}
& D V=\text { De veritate } \\
& D L A=\text { De libertate arbitrii } \\
& D C D=\text { De casu diabolic } \\
& D C=\text { De Concordia } \\
& C D H=\text { Cur Deus Homo }
\end{aligned}
$$

English translations are from Williams, T. (ed. and trans). (2007) Anselm: Basic Writings. Indianapolis: Hackett.

Kane, R. (2005) A Contemporary Introduction to Free Will. New York: Oxford University Press.

Kane, R. (2007) "Libertarianism" in J. M. Fischer, R. Kane, D. Pereboom, and M. Vargas, Four Views on Free Will. Oxford: Blackwell, pp. 166-83.

\section{Further Reading}

Williams, T. (ed. and trans). (2007) Anselm: Basic Writings. Indianapolis: Hackett. (Anselm's texts on freedom.)

\section{Related Topics}

Event-Causal Libertarianism

Agent Causation

Augustine of Hippo

John Duns Scotus 


\section{3 \\ THOMAS AQUINAS \\ Harm Goris}

Thomas Aquinas (1224/5-1274) discusses human free will in many places in his writings, dealing with various aspects and contexts. I shall order the diverse and sometimes scattered passages under two main headings, dubbed 'theological' and 'anthropological,' and subdivide each again in two. The theological discussions about human free will center around two divine attributes: God's foreknowledge and God's causality. The former would imply that the whole future, including what we shall do, is now already determinate. And if God causes everything and his will cannot be thwarted, human actions would be necessary outcomes of God's acting. The two anthropological issues deal with the dominant role Aquinas attributes in his philosophical analysis to the human intellect in relation to the will, and with the Christian doctrine that humans are enslaved to sin. I shall first elaborate on the fourfold distinction itself and then discuss Aquinas' views on each of these four problems.

\section{Two Theological and Two Anthropological Problems}

Not all agree why and how the problems associated with divine foreknowledge and divine causality should be distinguished in Aquinas' thought. One of the most influential Thomist commentators, Domingo Bañez (1528-1604), claimed that the doctrine of God's will as First Cause suffices to account for the certainty of God's foreknowledge. By his will, God has decided from all eternity what He is going to make happen during the course of history and this also explains why God foreknows the future (Bañez 1934: 350-1). However, it sits ill with the fact that Aquinas always gives separate arguments for each of the two problems.

Aquinas is very sensitive to the possibilities and limitations of human language and understanding regarding the mystery of God. That is why he carefully analyses how people talk about God. He bases the distinction between the problem of divine foreknowledge and the problem of divine causality, on a specific distinction in the 'divine names,' that is, in the words we use in talking about God (cf. Summa Theologiae I q. 13 a. 7). Some properties and actions are said of God 'eternally' (ab aeterno), for example, that God is, lives, is wise, or knows, because God is, lives, is wise and knows immutably from all eternity. Other properties and actions are predicated of God 'temporally' (ex tempore), for example, that God creates, is the savior, liberates Israel from Egypt, or becomes human. These predicates signify the divine activity itself, but they also imply at the same time its external effects in created reality. That is why they apply to God in time and not immutably. After all, otherwise every creature would be eternally created, 
Israel would eternally be liberated from Egypt, etc. Nonetheless, the predicates ex tempore do not imply a real change on God's part, only a real change in time on the part of created reality, effected by God. As to God, the predicates signify a so-called 'Cambridge change'; as to created reality, they signify the real effects of God's activity in history. As a consequence, Aquinas would never speak about divine causation as timeless or eternal. However, Aquinas thinks that it is instantaneous: when God is said to cause something, the effect is said to occur at the very same time, without any temporal delay (Summa Theologiae I q. 46 a. 2 ad 1).

From these considerations, Aquinas elaborates the two theological problems. The first one I shall label 'temporal fatalism.' It concerns the diachronic relation between God's foreknowledge and the future events that are said to be known. Though for the eternal God nothing is future, we, being in time, must talk about his foreknowledge (Summa contra Gentiles I c. 67 rursus). The meaning of the verb 'to know', implies that what is known must be true and must be the case. This causes no problems when it is about the past or the present. But when the object known concerns a future contingency, that is a future event that is not causally determined by present natural tendencies, the consequence is that the future is not open, but is as closed, fixed, definite and determinate as the past and present are. It should be noted that this necessity of the future is not logical or causal or given with the natural laws of physics. It is another kind of necessity that has to with the nature of time. It goes against the common-sense idea that the future is open in contrast with the past and present (Summa Theologiae II-II q. 49 a. 6), which Aquinas thinks is a necessary condition for freely willed actions. One could label it 'temporal' or 'factual' necessity. Furthermore, it should be noted that the meaning of 'to know' does not by itself express on what ground God knows the future, for example, through observation or by knowing his own intention. Aquinas thinks that in reality, God's foreknowledge is practical, but points out that its causal character as such is not implied by the very term 'to know' (De Veritate q. 2 a. 14). The only question that matters in the context of divine foreknowledge is whether the future is open or closed. Hence my use of the expression 'temporal fatalism.'

The second theological problem is about the synchronic relation between God's causal activity, said to occur at a specific moment, and the effects produced simultaneously. Aquinas connects this with God's will, not taken in the sense of God's free, purely intentional activity within Himself, which is ab aeterno, but in the sense of God's external activity resulting in created effects ex tempore (De Veritate q. 23 a. 4 ad 15). Because everything is subject to God's causal activity and nothing can hinder its outcome, all of created reality, including the acts of human free will, seem to be causally necessitated.

The second main perspective from which Aquinas discusses human free will is anthropological. It looks at the human person himself, either from the perspective of his natural capacities or from the perspective of his concrete situation. The distinction between the two perspectives touches upon the much-debated issue among Thomists whether Aquinas considers human beings also in a neutral, purely natural state (natura pura) apart from their positive, graced or negative, sinful relation to God (Mulcahy 2011). In my reading of Aquinas, he does. But it concerns a metaphysical analysis of human nature in the abstract. It isolates conceptually what is essential to human nature as such, its powers and their activities and interactions, prescinding from the larger theological framework of salvation history, in which human beings actually exist. In this analysis, Aquinas offers an explanation of free will in terms of the natural 
faculties of intellectual reason and will, of the bodily emotions, and their interactions. The key problem here is Aquinas' putative intellectual determinism. Aquinas seems to suggest that because the human being is essentially a rational being, human will simply has to follow what the intellect judges to be good.

Next, Aquinas also considers human free will in its actual, concrete, historical situatedness, along the axes of sin and grace. It could be labeled Aquinas's 'soteriological' account of free will, in contrast with the former, 'metaphysical' analysis. The key question here is the one that Augustine and Pelagius and, later, Luther and Erasmus disputed: are we free with respect to God's offer of grace or is our will in fact completely subject to sin apart from God's gracious help.

\section{Foreknowledge and Temporal Fatalism}

Aquinas solves the problem of the apparent incompatibility of God's foreknowledge and human freedom by referring to God's eternity. He uses Boethius' picture of God overseeing the whole course of time like someone who observes from on high a procession that moves along on the plain below, and also the Neoplatonic metaphor of the center of a circle, to which the whole circumference is equally present (De Rationibus Fidei c. 10). God's eternity surrounds the whole of time (Summa Theologiae I q. 14 a. 13). Aquinas argues that, because all that occurs in time, including the future, is present to God, the future is determinate for him, and therefore, can be known by him. However, the picture is highly ambivalent for it seems to imply exactly what is problematic in temporal fatalism, viz., that there is no modal distinction between, on the one hand, past and present, and, on the other hand, the future (Lewis 1988). It suggests that in the end Aquinas adopts a specific metaphysical view on time, known as the 'tenseless,' 'static,' 'eternalist, 'block-universe,' or 'B-theory' of time, in which what is future to us now, is in itself as determinate as what is past or present to us. In this view, time is nothing but the fourth dimension, comparable to the three spatial dimensions, and all that is past, present or future relative to us, exists in itself in an atemporal matrix. It is contrasted with a 'tensed,' 'dynamic,' 'presentist,' or 'A-theory' of time according to which the ever moving 'now' has some kind of metaphysical priority. There are different versions of the tensed theory, but what matters is that the openness of the future as contrasted with the closedness of past and present, is only possible in a tensed view on time. The common reading of Aquinas's use of Boethius' picture implies that Aquinas is - unwittingly —inconsistent: he poses the problem of God's foreknowledge in terms of a tensed theory of time with an open future but solves it by a tenseless view on time (Zagzebski 1991: 46-56).

Though it is a bit speculative, I would like to offer an alternative interpretation. According to this reading, the presence of all past, present and future events in time to God, is not based on their tenseless existence in a block-universe, but on God's own and inexpressible mode of existence, viz., eternal existence. In Aquinas' theology, 'eternity' is not a positive attribute of God, but functions in the framework of negative theology. In the Summa Theologiae, Aquinas discusses eternity in the context of explaining "how God is not" (Summa Theologiae I q. 3, prooemium). Because of God's eternity, all of time is "quasi present" (Summa contra Gentiles III c. 66, rursum) to Him. While the future is open and indeterminate in itself, and hence unknowable in itself (cf. De Malo q. 16 a. 7), it is present-to-eternity and hence determinate and knowable to God. We cannot further comprehend this presence-to-eternity for that would imply knowing what eternity is 
and, hence, knowing what God's essence is. On this reading, Aquinas uses the Boethian picture only negatively, to point out that God is not in time, but not as a positive representation from some kind of super-divine standpoint that encompasses God's eternity and its relation to an allegedly tenseless time.

This reading also fits with Aquinas' view on propositions about future contingents. Such propositions, he thinks, lack a truth value: they are neither true, nor false, but are indeterminate. In the background is Aristotle's view that the truth value of a proposition can change. For example, 'Harm Goris is typing now' is true as long as I am typing but the very same sentence becomes false when I start drinking my coffee. Modern logicians will point out that the change of truth value is only due to the fact that the sentence is somehow incomplete: the change depends on the ambiguity of the term 'now,' which refers to different moments of time depending on the moment the sentence is uttered, so that the same type of sentence expresses in fact different propositions. They will argue that if the term 'now' is replaced by a definite date and time indication, for example, $9.00 \mathrm{a} . \mathrm{m}$. CET on December 1, 2014, the sentence no longer changes its truth value and expresses one proposition. Maybe Aristotle himself did not consider this argument explicitly. However, in the famous discussion in Perihermeneias 9, Aristotle discusses a contradictory pair: "there will be a sea battle tomorrow" and "there will not be a sea battle tomorrow." A consequence of considering two contradictory sentences is that the temporally indefinite index 'tomorrow' in each of the single sentences becomes (relatively) temporally definite when the sentences are combined in forming a contradiction. For there is only a contradiction if the term 'tomorrow' refers to one and the same date. Hence, the change of truth value of a sentence because of its temporal indefiniteness, does not play a role in this context. It is not obvious that Aristotle was fully aware of this logical consequence, but later commentators such as Ammonius and Boethius apparently were. They introduced the qualification 'determinately' (determinate or definite) and claimed that sentences about future contingents were not "determinately true or false." It was adopted by medieval commentators, including Aquinas. Often, the 'determinately' is interpreted as a modal qualification, meaning that a sentence about a future proposition is not necessarily true or false but only contingently. But in my view, this is not what Boethius and the medievals meant. 'Determinately' means that in the case of two contradictory sentences (which have to be temporally definite in relation to one another), the truth values 'true' and 'false' are distributed over the two sentences. Take, for example, a contradictory pair of past contingents, 'there was a sea battle yesterday' and 'there was not a sea battle yesterday:' one of the sentences is true and the other one false, and it is determinate which one is true and which one is false. However, this is denied in the case of future contingents. 'There will be sea battle tomorrow' may be said to be either-true-or-false, but it is not determinate which truth value the sentence has. In short, it lacks a truth value or it can be said to have a neutral truth value.

Besides the question about the temporal definiteness of sentences, there is a second problem, which has to do with tenses. Unlike many modern logicians, Aquinas thinks that propositions are always tensed. Take for example the temporally definite but tensed sentence 'there will be a sea battle on December 1, 2014,' uttered on November 30, 2014. And the sentence 'there was a sea battle on December 1, 2014,' uttered on December 2, 2014. Most modern textbooks in logic will say that the two differently tensed sentences express on one hand the same proposition and for logical clarity each should be rephrased as 'There is a sea battle on December 1, 2014,' where 'is' is 
understood logically as a tenseless verb, though it is grammatically a present tense. Aquinas denies this move. The two sentences express two different propositions even if they seem to refer to the same event. This is because, for Aquinas, a proposition reflects the human mode of knowing. We need not go into all the details about Aquinas' theory of knowledge, but the fact that humans derive their (intellectual) knowledge from the senses is the reason why we always include tenses when forming a proposition (Summa contra Gentiles II, c. 96, palam). An important axiom in Aquinas' epistemology is that knowledge does not only depend on extramental reality, but is also always determined by 'how it is known,' that is, by 'the mode of the knower.' The mode of being of the extramental object need not coincide with the mode of the knower. Human beings can know particulars (e.g., Peter and Mary) as universals (e.g., 'human being'). But the two can also correspond: human beings know events in time in a temporal way, viz., through tensed propositions. However, God — and also angels—knows events in time in a non-temporal way. God knows all that happens throughout history, including the future, in an eternal way: 'He knows temporal events in an atemporal way' (In I Sent. d. 38 q. 1 a. 3 ad 3). As humans, we cannot express the divine mode of knowing and can only say that it is not by means of (tensed) propositions. Therefore, Aquinas can maintain that propositions about future contingents lack a truth value-for future contingents cannot be known in a temporal way-and, at the same time, that God foreknows the future.

\section{Divine Causality and Causal Determinism}

Aquinas solves the problem of the apparent incompatibility between God's irresistible causality and human freedom by referring to the transcendence of divine causality. We find this solution only in his later works. Earlier in his career, Aquinas still remains within an Aristotelian conceptual framework of causation. He argues that in an ordered series of causes, the first or remote cause can be necessary, but when the secondary, proximate cause works contingently, the ultimate effect is also contingent. For example, the sun, which is a necessary cause and cannot not shine, causes a tree to bloom, but only through the mediation of the vegetative force of the tree, which is a contingent cause. The ultimate effect, the bloom, has the modal character of its proximate cause, the vegetative force, and is therefore contingent. Aquinas realizes that this argument is insufficient in the case of divine causation because the final effect cannot evade God's providence. However, he does not yet know how to save the absolute efficacy of God's causal activity. He either circumvents the issue by relegating it to the certainty of God's knowledge (In I Sent. d. 38 q. 1 a. 5) or comes up with a kind of statistical solution: what God ordains may fail in a particular instance, but God will provide so many occasions that in the end the proximate, contingent cause, in particular human free will, will perform the outcome that God wills (De Veritate q. 6 a. 3).

In his mature view, Aquinas abandons the idea that the divine cause is merely the first one in a descending series of causes. He recognizes that this idea implies a kind of Neoplatonic emanation scheme in which the first cause works by natural necessity and not intentionally, and in which the first cause also has no direct bearing on the final effect but is remote from it through a series of intermediate causes. Both elements, viz., natural necessity of the first cause and distance to the final, particular effects, are contrary to what the Christian faith teaches about God's causality. Aquinas still thinks that within the order of created reality, a created first necessary and remote cause, for 
example, the sun, may have a contingent effect when its causal influence is mediated by a secondary contingent created cause. But God's will as cause is outside of and transcends the whole order of created reality and its causal chains. Divine causality is directly involved in every stage of causal processes in created reality. The contingency of an effect still depends on the contingency of its proximate created cause but, Aquinas adds, it depends even more on God's will which causes it to be (De Veritate q. 23 a. 5). In his commentary on the Perihermeneias, Aquinas writes:

The divine will must be understood as existing outside of the order of beings, or as a cause that pours out the whole being (totum ens) and its differences; possible and necessary are differences of being. And therefore necessity and contingency in things originate from the divine will itself, as does the distinction between the two according to the nature of the proximate causes... And according to the condition of these causes, the effects are said to be necessary or contingent, although all depend on the divine will as on a first cause that transcends the order of necessity and contingency. But this cannot be said of the human will, or of any other cause, because every other cause already falls under the order of necessity or contingency.

(In I Periherm. 1.14 nr. 22; cf. also In VI Metaph. 1.3 nr. 1222)

The young Aquinas had been committed to an Avicennian essentialist metaphysics, in which the distinction between God and created reality is conceived in terms of logic based modalities: God is by definition necessary and creatures are by definition contingent beings. Aquinas gradually moved away from this position and developed a metaphysics of being (esse), in which the distinction between the Creator and creation is expressed more radically, viz. in terms of being versus nothing. Apart from God, apart from the causal dependency on the Creator, the creature is not just a contingent or possible being, it is utterly nothing: "a creature has being only from something else, left to itself and considered in itself it is nothing" (De Aeternitate Mundi). While the distinction between 'necessary being' and 'contingent being' is still a difference within being, the contrast between 'being' and 'nothing' is more fundamental. This involves also a different concept of modality: necessity and contingency are no longer based on logical definitions but on metaphysical, natural principles. Hence, certain created beings such as angels, which are purely immaterial, and celestial bodies, which according to Aristotle are incorruptible because they are not composed of dissolvable material elements, are absolutely necessary beings although they depend on God's free will (Summa contra Gentiles II, c. 30 , licet).

In the same way as God causes the being of necessary and contingent creatures, $\mathrm{He}$ also causes their causal activity and efficacy. Aquinas is not an occasionalist who denies all creaturely causation and attributes all that happens exclusively to God. God communicates not only being to creatures, but also their proper activity and causation (Summa contra Gentiles III c. 69, adhuc; De Potentia q. 3 a. 7). According to Aquinas, the common effect of each cause, also of each created cause, is "to be" (esse): each cause gives being, makes that something actually is (Summa contra Gentiles III c. 66). But like their essence, also the causal powers of creatures are limited. They cannot cause being as such out of nothing, but can only work on something preexistent and change that either accidentally (e.g., changing the color of an object) or substantially (e.g., changing wood into a house) (Summa contra Gentiles II c. 21, adhuc). Their causal efficacy is 
limited to the categorical determinations of being. While creatures cause something to be such (accident change) or to be this (substantial change), they cannot cause something to be this or to be such. This is what Aquinas means when he says that every created agent causes or gives being, not by their own power, but 'in virtue of the divine power' (Summa contra Gentiles III c. 66). Just to avoid misunderstanding: Aquinas does not want to suggest as if God gives a kind of generic being, which subsequently is determined and particularized by created agents. "To be" (esse) is not a univocal, generic category in Aquinas' metaphysics, but "the actuality of each thing" (Summa Theologiae I q. 4 a. $1 \mathrm{ad}$ 3) and "more intimate and deeper than anything else" (Summa Theologiae I q. 8 a. 1). The divine cause and created agents are not in competition. Rather, at a transcendental level the divine agent causes that created agents have their own causal activity and produce necessary or contingent effects, dependent on the nature of these created causes, at the categorical level. If God's causal influence stopped, all [created] operations would stop (Summa contra Gentiles III c. 67, amplius). In this way Aquinas can conclude that "God immediately works in every [created] agent, without excluding the agency of the [created] will and nature" (De Potentia q. 3 a. 7). Aquinas maintains that God's causation is necessary in the sense that "it is necessary that the effect happens contingently or by necessity" (In VI Metaph. $1.3 \mathrm{nr}$. 1222), but it seems that this involves only the temporal necessity of the actual present. Remember that in Aquinas' view God's causal efficacy does not require a lapse of time but is instantaneous. At the very moment God causes a concrete, particular effect of a created cause, the effect is actual. As soon as it exists, the effect is necessary even if it proceeds from a contingent or free created cause, in the sense that it can no longer not be. The present as such is determinate and necessary, as is the past (Summa Theologiae II-II q. 49 a. 6). That Socrates sits is by itself contingent, but when he sits it is necessary that he sits (Summa Theologiae I-II q. 14 a. 6 ad 3). For Aquinas this is an innocuous kind of necessity.

\section{Voluntarism and Intellectualism}

In Aquinas' view, the human will is by its very nature a rational appetite. It must have reasons to will something, otherwise its act would be blind, arbitrary, capricious, or accidental. That is why Aquinas, in line with almost all his predecessors, prefers to speak of "free decision" or "free choice" (liberum arbitrium), which by definition presupposes rational cognition, than merely of "free will" (libera voluntas). Aquinas thinks that the will can only will something when it has been understood and proposed by the intellect as something good and attractive (correctly or not, that is irrelevant), and he writes: "the whole concept of freedom depends on the mode of knowledge. For appetite follows knowledge because appetite is only for what is good as it is proposed to it by the cognitive power" (De Veritate q. 24 a. 2). It seems then that for Aquinas the will is a passive faculty and cannot but follow what has been determined by the intellect as good (Summa Theologiae I q. 80 a. 2). This position is known as 'intellectualism' and it is contrasted with 'voluntarism,' which attributes more autonomy and independence to the will as a free agent. In the late 1260s, a heated debate arose and extreme forms of intellectualism were censored by ecclesiastical authorities in 1270 and 1277, and some were of the opinion that the condemnation also regarded Aquinas. In contrast, Franciscan theologians, like Duns Scotus, developed strong voluntarist theories (Hoffmann 2010). Also today, some think that Aquinas' view represents a strong determinist form of intellectualism (for an overview, cf. Wang 2009: 226-33). 
However, I shall argue that a reading of Aquinas that allows for a genuine activity of the will is more plausible.

According to Aquinas, the human intellect can present only two objects to which our will adheres by necessity: beatitude and the divine essence. But the significance of each for human freedom in this life is limited. Aquinas takes beatitude, for which he also uses the terms "final end" or "the good in general" or "the perfect good," in a purely formal sense as that which satisfies our will completely. But it is not decided what people think makes up the actual content of beatitude. Some value riches, others pleasure, or fame, or power (Summa Theologiae I-II q. 1 a. 7, q.2, q. 5 a. 8). The other necessary willed object, the divine essence, which is truly the highest goodness, cannot be seen by the human intellect in this life, but only in the afterlife.

This means that all the concrete, particular goods that the human intellect can understand in this life, are not completely and absolutely good and, therefore, they can also be understood insofar as they lack goodness. As a consequence, in principle the will can either set them aside or approve them (Summa Theologiae I-II q. 10 a. 2). Taking a bitter medicine can be judged by reason as good for health and also bad for taste. It is up to the will to choose the good of health or the good of sensual pleasure. The will can only choose what the intellect has understood to be a good, but because the intellect proposes alternative particular goods, "the will does not by necessity follow reason" (De Veritate q. 22 a. 15), that is, it need not choose what has been judged rationally the best option, it does not have to make the right choice.

Moreover, the will is not only free as to what it chooses from the alternative goods that reason proposes (freedom with regard to the 'specification of the act'), it is also free in moving the intellect to act and to consider ends and deliberate about means or in stopping the intellect's activity (freedom with regard to the 'exercise of the act'). Even whether to actually think of the final end, that is, of beatitude, or not, is up to the will as an agent cause (De Malo 6). However, this decision is again based on a previous deliberation and choice. Aquinas avoids an infinite regress by founding the freedom of the will with regard to the exercise of the act ultimately in an external, transcendental source, viz., God, who as the First Mover moves the human will according to the latter's own, viz., free nature (De Malo 6, Summa Theologiae I q. 82 a. 4 ad 3, I-II q. 9 a. 4). As we saw in previous the section, Aquinas argues that this divine causality does not impose necessity.

In principle then, considered in the abstract, human will is free both on the level of the specification and of the exercise of the act. However, when it comes to the will of a particular person in a concrete situation there are certain factors that incline her to a specific choice. In De Malo 6, Aquinas lists three categories. First, reason can judge that one good outweighs the alternative good, as in the example of the bitter pill. Right reason inclines the will to choose what is reasonably better. But inclination is not necessitation and the will remains free to choose the other good. Second, reason may focus on one specific circumstance and neglect others. This is because often an external or internal event happens to come up that calls for the attention of the intellect. A sudden feeling of pain or accidentally seeing an advertisement about health hazards can focus the attention of the intellect on worries about one's physical well-being to the exclusion of deliberations about the price, taste, or effectiveness of drugs. Nevertheless, the will remains free to ignore such pressing coincidences or prompt the intellect also to consider other circumstances. The third category is the most interesting one. It regards the natural constitution and the character of the person. Aquinas often cites 
Aristotle's saying from Ethics 3.5 (1114a32-b1): "as each one is, so the end appears to him." By nature, human beings are disposed to will to live (and to avoid physical pain, etc)., but again these natural inclinations are not absolute as the example of the selfsacrifice of martyrs shows. More relevant to freedom are those personal dispositions that are under the control of the will itself, in particular the virtues and vices a person can acquire, and the passions, which a person can rule through his intellect and the will. For Aquinas, the good is not some purely objective, disinterested thing, but is always related to the person who wills the good and who is motivated by it. It is not merely understood as good in itself, but also as 'fitting' (conveniens) to the person:

That which has been understood as something good and fitting, moves the will by way of an object. However, that an object appears as good and fitting, is because of two things, viz., the condition of the object proposed and the condition of the one to whom it is proposed. For 'fitting' is a relative notion and, therefore, depends on both relata. That is why a taste which is differently disposed, will not accept in the same way something as fitting and as not fitting. As the Philosopher says in book three of the Ethics: "as each one is, so the end appears to him."

(Summa Theologiae I-II q. 9 a. 2)

A good, virtuous person will perceive other goods as fitting to her than a vicious person. We also have to keep in mind that for Aquinas, it is the whole person who wills and who understands, not the will or the intellect as such, despite common usage (Summa Theologiae II-II q. 58 a. 2). Will and intellect are the powers the person uses in order to understand and to will: "I understand because I want to; and likewise I use all the powers and dispositions because I want to" (De Malo 6). The phrase "because I want to" also illustrates that according to Aquinas the character of a person deeply influences her moral evaluations and choices, but like the other categories of inclinations, it does not necessitate them. Virtues incline to act "promptly, without hesitation and pleasurably, without effort" (De Virtutibus in communi a. 9 ad 13), but ultimately, the will remains free. However difficult, a person can act out of character or can over time further develop his character. In a genuine sense, it is up to us what kind of person we want to become and to develop a taste for what is truly good. This brings us to the fourth problem about free will in Aquinas: how far does the freedom of human persons actually reach within the concrete historical context of our lives, marked by original sin and histories of personal failures.

\section{Sin and the Necessity of Grace}

Human nature and its powers, such as the will, do not exist in the abstract, and hence, are not agents. First, as mentioned above, it is the one, whole human person who acts. Being an embodied soul (or ensouled body) and a rational animal (animal rationale) by nature, the human person integrates in his voluntary acts also the activity of bodily powers and of powers he shares with other animals, in particular the sensory passions (roughly equivalent to what we call 'emotions'). Second, as a historical being and a political and social animal (animal politicum et sociale: Summa Theologiae I-II, q. 72 a. 4) by nature, the human person is not an isolated individual but member of the whole of humankind over time. As a Christian theologian, Aquinas interprets the whole of 
human history from the perspective of the redemption by Christ. The redemption by Christ is both universal and radical, which implies that all human beings must be in need of liberation from some kind of fundamental shortcoming, further specified since Augustine as 'original sin.' This shortcoming does not belong to human nature as such, which has been created good by the good Creator. But it belongs to the actual state of human nature in concrete persons. After the Fall, human nature exists only as deeply wounded or corrupted.

The human being was originally created by God not in the state of pure nature, but in a special state of grace, called 'original justice.' With sanctifying, supernatural grace, Adam and Eve also received some extra gifts, in particular a perfect harmony within the human person: the body was fully ruled by the soul, the sensory powers functioned perfectly because they were totally under the guidance of the rational powers of the soul, and the human will was completely attuned to God as its final end (Compendium Theologiae I c. 186). When by the Fall, the human will turned away from God, the human being lost original justice: both sanctifying grace and the extra gifts. This did not mean that human nature was left in a state of integrity (status naturae integrae) in which the human being could will and establish her own, natural human good through her own natural powers (Summa Theologiae I-II q. 109 a. 2-4). The natural powers remained intact, otherwise the sinner would no longer be human, but their functioning was severely impaired (Summa Theologiae I-II q. 85 a. 1).

As regards the will, its freedom in desiring and choosing the truly good is deeply hampered after the Fall in four ways (Summa Theologiae I-II q. 85 a. 3). First, from the side of the intellect. In the absence of the virtue of prudence, the intellect misjudges the situation and lacks relevant knowledge. As a consequence, one sins out of ignorance (Summa Theologiae I-II q. 76). Next, the will is hindered by the sensory appetite and its passions. Aquinas divides the sensory appetite in two: the concupiscibile pursues the sensible good as such, while the irascibile is concerned with overcoming obstacles in that pursuit. When it lacks the virtue of temperance, the concupiscibile inclines the will to choosing what is pleasurable to the senses instead of what is rationally good. Then one sins out of concupiscence. Likewise, when the irascibile is not formed by the virtue of fortitude, the will gives in too easily when hard choices should be made, and the person sins out of weakness (Summa Theologiae I-II q. 77). Finally, the will itself is affected. Without the virtue of justice, the will excessively desires and loves created, temporal goods, for example, riches, pleasure, or fame. It deliberately wants these more than reason, and also divine law and the love of God, propose. The will is prepared to suffer the loss of higher, spiritual goods in order to acquire a temporal good. You know that the loss is evil and you would prefer to have the temporal good together with the spiritual goods. But knowing that you cannot have your cake and eat it, you willingly choose the temporal good and accept losing spiritual goods. In this case, one sins out of malice (Summa Theologiae I-II q. 78 a. 1). While the first three inclinations as such lessen one's moral liability, the latter aggravates the sin (Summa Theologiae I-II q. 76 a. 4, 77 a. 8).

All these negative inclinations do not necessitate the will to make only bad choices. Occasionally, one might act out of character, but not for long. Inevitably, wounded nature will lead to mortal sin and aversion from God (Summa Theologiae I-II q. 109 a. 8). Then one depends on God's grace not only for elevating human nature itself and ordering the will to the supernatural good of the beatific vision, but also for healing the wounds of human nature and ordering the will to the connatural good (Summa Theologiae I-II q. 109 a. 2). In this way, Aquinas may not be as dramatically negative about the human 
will after the Fall as Augustine or Luther, but he certainly acknowledges the necessity of grace in liberating the will from evil.

\section{References}

Latin texts of Aquinas are available from: www.corpusthomisticum.org. A list of English translations by Thérèse Bonin is available from: www.home.duq.edu/ bonin/thomasbibliography.html.

Bañez, D. (1934) Scholastica Commentaria in Primam Partem Summae Theologiae S. Thomae Aquinatis. Madrid: F.E.D.A.

Hoffmann, T. (2010) "Intellectualism and Voluntarism," in R. Pasnau (ed.), The Cambridge History of Medieval Philosophy, Vol. 1. Cambridge: Cambridge University Press, pp. 414-27.

Lewis, D. (1988) "Eternity, Time and Tenselessness," Faith and Philosophy 5: 72-86.

Mulcahy, B. (2011) Aquinas's Notion of Pure Nature and the Christian Integralism of Henri de Lubac: Not Everything is Grace. New York: Peter Lang.

Wang, S. (2009) Aquinas and Sartre. On Freedom, Personal Identity, and the Possibility of Happiness. Washington, DC: The Catholic University of America Press.

Zagzebski, L. (1991) The Dilemma of Freedom and Foreknowledge. Oxford: Oxford University Press.

\section{Further Reading}

Goris, H. (2005) "Divine Foreknowledge, Providence, Predestination, and Human Freedom," in R. Van Nieuwenhoven and J. Wawrykow (eds), The Theology of Thomas Aquinas. Notre Dame: University of Notre Dame Press, pp. 99-122. (Elaboration of Aquinas' view on the compatibility of God's foreknowledge and causality with human free will.)

Irwin, T. (2007) 'Aquinas,' in T. Irwin, The Development of Ethics. A Historical and Critical Study, Vol. 1. Oxford: Oxford University Press. (Extensive survey of Aquinas' moral philosophy and moral theology.)

Pope, S. (2002) The Ethics of Aquinas. Washington, DC: Georgetown University Press. (Detailed interpretation of Aquinas' analysis of the human will and its acts.)

Stump, E. (2003) Aquinas. Routledge: London. (Especially Chapter 9. Easily accessible introduction to Aquinas' view on human free will; argues for a libertarian instead of a compatibilist reading of Aquinas.)

Torrell, J. P. (2001) "Nature et Grâce chez Thomas d'Aquin," Revue Thomiste 101: 167-202. (Introduction to the theological question of the relations between nature, sin, and grace in Aquinas.)

\section{Related Topics}

Agent Causation

Logical Fatalism

Aristotle

Augustine of Hippo

Free Will and Theological Fatalism

Free Will and Theological Determinism

Free Will and Grace

Free Will and Providence 


\section{4 \\ JOHN DUNS SCOTUS \\ Thomas Williams}

\section{The Historical and Conceptual Background}

In 1277, the Bishop of Paris, Stephen Tempier, prohibited the teaching of 219 theological and philosophical theses that had been maintained by unnamed members of the Faculty of Arts at the University of Paris. The prohibition, which has come to be known as the Condemnation of 1277 , is often treated as a significant turning point in medieval philosophy and theology. Among the prohibited theses were 16 propositions about the will and its freedom. The condemned propositions are a somewhat disparate group, but many of them concern the dependence of the will on the intellect. For example, teachers in the arts faculty were forbidden to teach that the rational soul is "in potency to opposites"-roughly what we would express nowadays by saying that it has the power to do otherwise-only because reason can know opposites; they were forbidden to maintain "that the will necessarily pursues what is firmly held by reason, and that it cannot abstain from that which reason dictates." Both of those theses had arguably been taught by Thomas Aquinas, who had died three years before- though he had been in the Faculty of Theology, not Arts, and scholars disagree about whether Aquinas was a target of the Condemnation (for a convincing case that he was, see Wippel 1995). The Condemnation encourages a picture of freedom in which the will is free in its own right, and not merely because of its association with reason, and indeed, is free to act contrary to reason, rather than being in some sense necessitated by what reason holds.

Contrary to what one might expect, medieval academics were no more likely than today's academics would be to acquiesce in anyone's demands that they change their research and teaching to conform to some administrator's preferences. For all that the Condemnation of 1277 has been treated as a pivotal moment in the history of medieval philosophy and theology, the condemned theses did not disappear; scholars continued to defend views such as Aquinas's concerning the nature of freedom and the relationship between intellect and will. Yet the Condemnation certainly gave impetus to further critiques of such views, and it encouraged the development of accounts of freedom as rooted in a self-determining will.

Writing roughly 20 to 30 years after the Condemnation, John Duns Scotus (1265/661308) offered an account of freedom that was very much in the spirit of the Condemnation. For him, freedom depends on the will, which can act contrary to the judgment of reason. Freedom must be rooted in the will rather than the intellect, he thinks, because only the will acts contingently in a robust sense of that word, a sense that Scotus himself would do a great deal to clarify. In one sense, however, Scotus defies the spirit of the 
Condemnation. Tempier blamed the "obvious and loathsome errors" of the arts faculty on their overreliance on "pagan writings," but Scotus is quite happy to cite Aristotle in support of his understanding of freedom. I begin my discussion of Scotus's account of freedom by examining how Scotus uses Aristotle to develop his notion of a "rational power," one that acts contingently, and I explore Scotus's understanding of contingency, showing how it is a response to views like Aquinas's that root freedom in the intellect rather than in the will. I then note an apparent tension in Scotus's thought: his account of the will as a rational power involves the claim that freedom is a brute fact, something that admits of no further explanation; and yet he appears to offer an explanation for the will's freedom by appealing to the two dispositions or "affections" that Anselm had identified in On the Fall of the Devil. After examining the development of Scotus's use of Anselm over his brief career, as well as the main competing interpretations of the two affections in Scotus, I offer a new account that reconciles the Aristotelian and Anselmian strands in Scotus's thought and explains both the scope and the limitations of freedom as Scotus understood it.

\section{Freedom as a Brute Fact: Will as Rational Power}

In his Questions on the Metaphysics, Book IX, q. 15, Scotus asks whether Aristotle's distinction between rational powers, which are powers for opposites, and irrational powers, which are for only one of a pair of opposites, was drawn correctly. He answers that it was and goes on to explain, first, how it ought to be understood and, second, what its cause is.

By a "power for opposites," Scotus clarifies, we mean a power for opposite actions, not merely for opposite effects or products. The sun can soften wax and harden mud, but that is not the kind of "opposite" Scotus has in mind. At issue is a power that is sufficient for eliciting both an act and its negation (as would be the case if the sun had the power either to soften wax or not soften it) or for eliciting opposite acts (as would be the case if the sun had the power either to soften wax or to harden it). Aristotle, according to Scotus, had explained this difference by appealing to the difference between a natural form and an understood form. A natural form can act in only one determinate way: the form of fire heats and can only heat. But on the basis of an understood form, one can act in opposite ways: by having the form of fire in my understanding, I can know both fire and non-fire. Scotus argues, on several grounds, that this difference is an inadequate basis for the distinction between rational and irrational powers. Instead, the fundamental distinction in the domain of active powers has to do with the differing ways in which these powers elicit their acts. There are only two possible ways of eliciting acts:

Either a power is by its very nature (ex se) determined to acting in such a way that, as far as it is up to that power, it cannot not act when it is not impeded by something extrinsic to it; or else it is not by its very nature determined, but can do this act or the opposite act and can also act or not act. The first power is commonly called 'nature' and the second is called 'will.'

(In Metaph. IX, q. 15, n. 22)

The division into nature and will is the most basic division of active powers. And what is the cause of this division? Scotus says that there is no cause: it is a brute fact 
that will is a power for opposites and nature is not. Just as that which is hot heats, and there is no further explanation for why it heats, so too there is no further explanation for why it heats determinately; nor is there any further explanation for the fact that a will does not will determinately. Moreover, the will's mode of acting is so distinct from the mode of acting proper to every other active power that "it appears altogether ridiculous to apply universal propositions concerning active principles to the will, simply because they have no exception in any active principle other than will" (In Metaph. IX, q. 15, n. 44).

One would expect, given general Aristotelian metaphysical principles, that what is in itself indeterminate would require some extrinsic cause to determine it. Scotus argues, however, that this is not so. There are two kinds of indeterminacy:

There is a certain indeterminacy of insufficiency, in other words, an indeterminacy of potentiality and deficient actuality, as matter that does not have a form is indeterminate with respect to doing the action of that form; and there is another indeterminacy of superabundant sufficiency, which derives from an unlimitedness of actuality, whether altogether or in some particular respect.

$$
\text { (In Metaph. IX, q. 15, n. 31) }
$$

Something that is indeterminate in the first way does not act unless it is determined to some form by something else, but something that is indeterminate in the second way can determine itself. If there were no such thing as the indeterminacy of superabundant sufficiency, Scotus argues, it would be impossible for God to act, since God is "supremely undetermined to any action whatsoever" (In Metaph. IX, q. 15, n. 32).

Scotus's distinction between rational and irrational powers depends on his notion of synchronic contingency: a rational power has, and an irrational power lacks, the ability to act otherwise at the very moment of acting. Scotus describes the contingency of the will's acts in this way:

This logical possibility [of willing different objects] does not exist according as the will has acts successively, but in the same instant. For in the same instant in which the will has one act of willing, it can have an opposite act of willing in and for that very same instant ... Corresponding to this logical potency is a real potency, for every cause is prior in understanding with respect to its effect. Thus, the will, in the instant in which it elicits an act of willing, is prior in nature to its volition and is related contingently to it. Hence, in that instant in which it elicits a volition, it is contingently related to willing and has a contingent relation to willing-against - not because at some earlier time it had a contingent relation to willing, for at that time it was not a cause; but now, when it is a cause eliciting an act of willing, it has a contingent relation to the act, so that what is willing $a$ can will-against $a$.

$$
\text { (Lect. 1, d. 39, q. 1-5, nn. 50, 51) }
$$

Aristotle had said that "whatever is, when it is, necessarily is" (De interpretatione I.9, 19a23-4). Whatever exactly this is supposed to mean, Scotus says, it would be absurd to say (as some do) that nothing that exists now is contingent now, but rather it was contingent only at some earlier time at which it was still possible for it not to come about. He ridicules "the absurdity of this position, that necessity and contingency are not 
genuine features of beings when they exist, but only necessity, and never contingency" (In Metaph. IX, q. 15, n. 64). Moreover,

when the will is engaging in a given volition, it is engaging in it contingently at that time, and that volition is from the will contingently at that time; for if it is not contingent at that time, it is never contingent, since it is not from the will at any other time.

(In Metaph. IX, q. 15, n. 65)

Scotus argues that any view that roots freedom in the intellect rather than in the will commits precisely this absurdity (see Williams 1998). For at the very moment when the intellect judges that one should do $x$ rather than $y$ or choose $A$ for the sake of its good-making features $F$ and $G$ (rather than reject it because of its deficiencies $H$ and $I$ ), it cannot judge otherwise than it in fact does. It is not enough to say that the intellect's capacity for abstract thought means that in principle it could judge otherwise; it is not even enough to say that at some time in the past it was possible for things to turn out in such a way that the intellect would not now be making the judgment it is in fact making. The question is whether its judgment is contingent at the very moment when it judges, and Scotus sees no way to affirm that kind of genuine contingency-synchronic contingency - in the intellect. So if the will always wills in accordance with the intellect's judgment, there will be no genuine contingency in the will either, and consequently, no freedom.

\section{Freedom as Requiring Explanation? The Two Affections of the Will}

But why, if the will's mode of acting admits of no more basic explanation, does Scotus appear to offer an explanation for it in terms of the two "affections" of the will? Scotus gets the idea of two affections or fundamental inclinations in the will from Anselm, who had identified an affection for the advantageous (affectio commodi) and an affection for justice (affectio iustitiae) in the course of explaining the primal sin of the angels in On the Fall of the Devil. It is clear that Anselm intends the two affections as an explanation of the will's freedom, and readers of Scotus have assumed that he too means to explain the will's freedom by appeal to the two affections. Interpretations have differed, however, about how that explanation is supposed to work. According to the most common interpretation (e.g., Boler 1993; Wolter 1997: 13; Osborne 2014: 24) the affection for the advantageous is an inclination to pursue what is beneficial for oneself and the affection for justice is an inclination to love things (including other people) in accordance with their intrinsic worth. Now Scotus is quite emphatic that the will cannot have (or be) only an affection for the advantageous, because if it were, it would operate deterministically and would therefore be a natural, not a rational power. But the standard interpretation leaves it wholly mysterious how the affection for justice helps matters, because it is not at all clear why a disposition to love things in accordance with their intrinsic worth would operate any less deterministically than the affection for the advantageous; and a will with two deterministic inclinations is no freer than a will with only one.

An alternative interpretation (Williams 2002, 348-9) emphasizes that Scotus identifies the affection for the advantageous with intellectual appetite: the will's disposition to choose what the intellect presents to it as perfective. On this interpretation, Scotus thinks of the affection for the advantageous as being exactly what Thomas Aquinas had 
claimed the will is, and he rejects Aquinas's account of the will because it does not provide for genuine freedom in the will. The affection for justice, then, is the will's capacity to choose in accordance with what is morally right. Such choices must be free if they are to be genuinely morally praiseworthy, and the affection for justice is what provides such freedom. But as the proponent of this interpretation has acknowledged, this account of the affection for justice would seem to provide for freedom only on those occasions on which the will is faced with a choice between happiness and morality, whereas Scotus (as we shall soon see in more detail) does not limit the will's freedom to instances of conflict between happiness and morality. He ascribed to the will a much more wide-ranging, a much more ubiquitous, sort of freedom, which this understanding of the two affections does nothing to explain.

To get clear on how, or whether, the two affections are intended as an explanation of the will's freedom, it is helpful to attend to the context in which Scotus discusses them and to the history of his career. Scotus discusses the two affections in his discussion of the fall of the devil, which occurs in his commentary on Book II, distinction 6, of the Sentences of Peter Lombard. For the medieval theologian-in-training, commenting on the Sentences was roughly equivalent to today's dissertation: a crucial, culminating step in the completion of one's degree. We have three versions of his lectures on Book II. The first, called the Lectura, dates from 1298 to 1299, when Scotus lectured on the Sentences as a student at Oxford. Soon afterward, Scotus began to prepare his lectures for publication; the result, left incomplete at his death, is called the Ordinatio (from the Latin word ordinare, "to set in order," here meaning "revise for publication"). The revision of Book II probably dates to 1301. He lectured again on the Sentences in Paris, probably in 1302 to 1303, and we have student notes of these lectures, called the Reportatio.

As Peter King (2010) has shown, Scotus's use of Anselm's two-wills theory undergoes dramatic development over the roughly five years between the Lectura and the Reportatio. The discussion in the Lectura is, as King puts it, "at best perfunctory, at worst confused" (2010: 368). By the time of the Ordinatio, however, Scotus has developed his account of the two affections in ways that make it look fairly un-Anselmian. No longer are the two affections two distinct and (in principle) separable dispositions that belong to the will, as they had been for Anselm; the two affections are not really distinct from each other or from the will itself. The affection for the advantageous is not a part of the will; it is the will qua intellectual appetite. And the affection for justice is not a part of the will; it is the will qua free rational power (Ord. II, d. 6, q. 2, n. 50). Still, the relationship between the will-as-appetite and the will-as-free remains somewhat unclear in the Ordinatio. They are not two parts of the will, but they do seem still to be two aspects of the will; the affection for justice has the task of moderating or regulating the affection for the advantageous in conformity with a higher will, which is God's will.

By the time of the Reportatio discussion, the terminology from Anselm remains, but none of Anselm's doctrine is left. The affection for justice, Scotus says, is "the ultimate specific difference of free appetite" (Rep. II, d. 6, q. 2, n. 9): in other words, the affection for justice is what sets free appetites apart from unfree appetites. They are related in the way that genus and species are related: rationality is what sets human beings apart from other animals, but in a human being rationality and animality are not really separable from each other or from the human being. Thus, the two affections are not two distinct kinds of motivation, as they were for Anselm, or even two aspects of the will, as they were in Scotus's Ordinatio. The two together constitute a free will: but in that free will they are separable neither from each other nor from the will itself. 
So, contrary to appearances, the two affections - at least by the time of the Reportatio, and arguably by the time of the Ordinatio-do not explain the freedom of the will. Thus, there is no contradiction between the view Scotus expresses in Questions on the Metaphysics IX, q. 15, and his later account of the two affections. The will's mode of actingbeing a will as opposed to a nature, a rational power as opposed to an irrational power-remains unexplained. And this is as we should expect, given the chronology of Scotus's writings. For although the Questions on the Metaphysics may well have been begun early in his career, Book IX appears to have been revised after 1300_right around the time he was revising Book II of the Ordinatio, or even as late as his lectures in Paris in 1302 to 1303 , which are recorded in the Reportatio. So it seems reasonable that the revised versions of the lectures on the Sentences and the contemporaneous account in the Questions on the Metaphysics all put forward at least roughly the same view of the will's freedom as an irreducible fact not susceptible of further explanation.

\section{The Scope of the Will's Freedom}

In Reportatio IV, d. 49, qq. 8-9 Scotus asks two questions: "Do all human beings will happiness supremely and necessarily?" and "Is everything that is desired, desired on account of happiness?" The crucial distinction, he says, is between the will's natural appetite and its free appetite (Rep. IV A, d. 49, qq. 8-9, n. 15). The will's natural appetite, like any other natural appetite, is an inclination or directedness to its proper perfection. The proper perfection of the will is happiness, and so the natural appetite is bound necessarily to will happiness. But the natural appetite is not an act of the will. When the will acts, it acts freely. Granted, the natural appetite is so fundamental to the will that the will does in fact generally will happiness. Even the damned, human beings and angels alike, will their own happiness. In fact, Scotus says, they very likely will it even more intensely than we do in this present life. The problem is that they do not moderate their desire for happiness so as to accord with the divine will (Rep. IV A, d. 49, qq. 8-9, nn. 42-6).

Thomas Aquinas had argued that the will necessarily wills happiness as understood universally but not as understood in particular: roughly, we have to will a fulfilling and flourishing life, and everyone does so; but not everyone wills the life that in fact meets that description-the vision of God-so obviously the will does not necessarily will happiness as understood in particular. Scotus, however, will have nothing to do with this distinction (Rep. IV A, d. 49, qq. 8-9, nn. 24-8). All one has to do to see what is wrong with the distinction, he believes, is to look at the arguments that supposedly show why the will necessarily wills happiness. According to the standard psychology, the will can refuse to will something only if it has some admixture of evil or at least deficiency of goodness. So if happiness is presented to the will by the intellect, the will has no choice but to will it, because happiness has no evil and is complete in goodness. If this argument works, Scotus says, it should apply even more decisively to happiness in particular than universally. For the goodness of the particular object in which happiness is found is more complete, and its freedom from any taint of evil is more obvious, than the goodness of happiness conceived of merely abstractly.

So in fact, confronted with happiness either universally or in particular, the will can either will it (velle) or fail to will it (non velle). What the will cannot do is to will-against it (nolle). Willing-against, like willing, is a positive act elicited by the will; it is therefore not to be identified with merely not-willing, or failing to will, which implies that no act is elicited by the will. In a similar way, when confronted with unhappiness, the will can 
either will-against it or fail to will it. What the will cannot do is positively to will unhappiness. Confronted with any object other than happiness or unhappiness, the will is free to elicit either an act of willing or an act of willing-against; it is also free to elicit no act at all with respect to that object.

If the will is not bound to will happiness, it clearly seems to follow that it is not bound to will everything else for the sake of happiness. There are two ways in which the will can will something without willing it for the sake of happiness. One way is 'negatively,' when one simply omits to consider the relation of the willed object to happiness. The other way is 'contrarily,' when one wills something knowing full well that it cannot be ordered to happiness. For example,

a believer can conceive of happiness in particular, as the enjoyment of the one divine essence in the Three Persons, and can conceive of something that is in no way directed toward that happiness - say, fornication. So, with that apprehension of fornication, which can in no way be directed toward happiness, remaining present, he can desire fornication. But in thus desiring fornication, he is not desiring it as directed toward happiness.

(Rep. IV A, d. 49, qq. 8-9, n. 57)

\section{What Rationality Does and Does Not Mean for Scotus}

Thus the scope of the will's freedom is very great. Every elicited act of the will is free, Scotus says; and it seems that the only limitations on the will's acts are that it cannot will-against happiness and it cannot will in favor of unhappiness. It appears, then, that the will is free to act irrationally: to choose lesser goods over greater, to spurn happiness itself, even perhaps to choose something for no reason at all. Some commentators favorable to Scotus have found this an unattractive picture of the will's freedom and have sought to use Scotus's description of the will as a rational power to argue that the will's action is not irrational in the sense of being arbitrary, capricious, whimsical, or unmotivated. In this vein Mary Beth Ingham writes:

For Scotus ... freedom is related to rationality because the will is the rational potency. Indeed, it is the will's rationality that grounds its freedom. Therefore, when Scotus states that the will is free to act counter to what the intellect decides, he is not affirming that the will's freedom lies in its independence from rationality. Scotus's particular version of voluntarism is not, then, libertarian in the sense that freedom is opposed to reason or to questions of rationality.

(Ingham 2001: 181, 182)

But contrary to what Ingham says here, it must be borne in mind that to call the will 'rational' for Scotus is nothing more or less than saying it is a power for opposites. Given what 'rational' means in the expression 'rational power,' there is no entailment whatever from the claim that the will is a rational power to any claim about the mysteriousness or non-mysteriousness of the will's eliciting of its own acts. Scotus in fact argues at length that the will's freedom allows us to act against our own interests (Ord. I, d. 1, p. 1, qq. 1-2).

Even more strikingly, he in effect argues that the will has the power to determine what will count as reasons for it. In Ord. I, d. 1, p. 2, q. 2, he asks whether the will 
necessarily enjoys (frui) the end when that end is apprehended by the intellect. He considers an argument for the affirmative:

'Delight is the conjunction of something suitable with that for which it is suited' (Avicenna, Metaphysics VIII). The end is necessarily suitable to the will. Therefore, when it is conjoined with the will there is delight, and therefore enjoyment (fruitio).

Against this, Scotus argues as follows:

I say that a given thing is either aptitudinally suitable or actually suitable. What is aptitudinally suitable is what is suitable in and of itself and in virtue of the nature of the thing [to which it is suited]. Such a thing is actually suitable to everything that has no power over whether something is suitable or unsuitable to it ... But it is in the will's power whether something is actually suitable to it or not. For no thing is actually suitable to the will unless that thing actually pleases the will. Consequently, I deny the minor premise, where it is said that "the end is necessarily suitable to the will." For that is true only of aptitudinal suitability, not of actual suitability.

Not just anything is a possible reason for us to act: some objects are 'aptitudinally suitable,' and others are not, because of the kinds of creatures we are. (Something's being an apple can be a possible reason for me to will to eat it; something's being a pile of shards of glass cannot). But whether any possible reason will be an actual reasonwhether what is aptitudinally suitable will also be actually suitable-is up to the will.

Nonetheless, human choices are generally responsive in some intelligible way to what reason presents to us as good and worthy of choice. It is not, however, because the will is rational, but rather because it is an appetite, that human choices are rooted in human nature. As an appetite, the will is aimed at what is good and perfective; as an intellectual appetite, more precisely, it is aimed at what the intellect reveals to be good and perfective. Because this intellectual appetite is free-self-regulating and indeterministic - it is not on auto-pilot; it does not simply will whatever intellect presents as best. But it does remain rooted in nature. Only certain kinds of things, those that are 'aptitudinally suitable,' are even possible objects of choice for the will. Yet because following the moral law is fundamentally not a matter of seeking what is good according to nature, but rather of subjecting ourselves to a higher will (Boler 1993; Williams 1995, 1998; King 2010), the human will must have a capacity for self-regulation that to some extent transcends nature. According to Scotus, at least from about 1300 on, that capacity for self-regulation is not an additional motivation over and above the will's natural appetite for happiness; it is, rather, the will's capacity to determine which reasons it will act on, whether it has any motivation to act on those reasons or not.

\section{Bibliography}

Citations to the works of Scotus are given using standard internal divisions as follows:

In Metaph. = Questions on the Metaphysics. Books VI-IX (1997) G. Etzkorn, R. Andrews, G. Gál, R. Green, F. Kelly, G. Marcil, T. Noone, and R. Wood (eds) (St Bonaventure edition, vol. IV). St Bonaventure: Franciscan Institute Publications. 


\title{
JOHN DUNS SCOTUS
}

Lect. = Lectura. Book I, d. 8-45 (1966) C. Balić, M. Bodewig, S. Bušelić, P. Čapkun-Delić, I. Jurić, I. Montalverne, S. Nanni, B. Pergamo, F. Prezioso, I. Reinhold, and O. Schäfer (eds) (Vatican edition, vol. XVII) Vatican City: Typis Polyglottis Vaticanis. Book II, d. 1-6 (1982) L. Modrić, S. Bušelić, B. Hechich, I. Jurić, I. Percan, R. Rosini, S. Ruiz de Loizaga, and C. Saco Alarcón (eds) (Vatican edition, vol. XVIII) Vatican City: Typis Polyglottis Vaticanis.

Ord. = Ordinatio. Book I, d. 1-2 (1950) C. Balić, M. Bodewig, S. Bušelić, P. Čapkun-Delić, I. Jurić, I. Montalverne, S. Nanni, B. Pergamo, F. Prezioso, I. Reinhold, and O. Schäfer (eds) (Vatican edition, vol. II) Vatican City: Typis Polyglottis Vaticanis. Book II, d. 4-44 (2001) B. Hechich, B. Huculak, I. Percan, and S. Ruiz de Loizaga (eds) (Vatican edition, vol. VIII) Vatican City: Typis Polyglottis Vaticanis.

Rep. $=$ Reportatio. $\mathrm{T}$. Williams (ed.), available from: ethicascoti.com/additionaltranslations.html (accessed 22 June 2016).

All translations are my own.

Aristotle (1963) Categories and De Interpretatione, trans. J. Ackrill. Oxford: Clarendon Press.

Boler, J. (1993) "Transcending the Natural: Duns Scotus on the Two Affections of the Will," American Catholic Philosophical Quarterly 67: 109-26.

Ingham, M. (2001) "Letting Scotus Speak for Himself," Medieval Philosophy and Theology 10: 173-216.

King, P. (2010) "Scotus's Rejection of Anselm," Archa Verbi: Subsidia 5: 359-78.

MacDonald, S. (1995) "Synchronic Contingency, Instants of Nature, and Libertarian Freedom: Comments on 'The Background to Scotus's Theory of Will,"' Modern Schoolman 72: 169-74.

Osborne, T. (2014) Human Action in Thomas Aquinas, John Duns Scotus, and William of Ockham. Washington, DC: The Catholic University of America Press.

Williams, T. (1995) "How Scotus Separates Morality from Happiness," American Catholic Philosophical Quarterly 69: 425-45.

Williams, T. (1998) "The Libertarian Foundations of Scotus's Moral Philosophy," The Thomist 62: 193-215.

Williams, T. (2002) "From Metaethics to Action Theory," in T. Williams (ed.), The Cambridge Companion to Duns Scotus. Cambridge: Cambridge University Press, pp. 332-51.

Wippel, J. (1995) "Thomas Aquinas and the Condemnation of 1277," The Modern Schoolman 72: 233-72.

Wolter, A., Frank, D. (ed.) (1997) Duns Scotus on the Will and Morality, 2nd edn. Washington, DC: The Catholic University of America Press.

\section{Further Reading}

Dumont, S. (1995) "The Origin of Scotus's Theory of Synchronic Contingency," The Modern Schoolman 72: 149-67. (Explains what is new and distinctive in Scotus's theory of will as a simultaneous power for opposites.)

Hoffmann, T. (2013) "Freedom Beyond Practical Reason: Duns Scotus on Will-Dependent Relations," British Journal for the History of Philosophy 21: 1071-90. (Argues for the importance of Scotus's idea that the will is a power capable of relating one thing to another.)

Kent, B. (1995) Virtues of the Will: The Transformation of Ethics in the Late Thirteenth Century. Washington, DC: The Catholic University of America Press. (Extensive treatment of the development of accounts of freedom and virtue after Aquinas.)

Pini, G. (2013) "What Lucifer Wanted: Anselm, Aquinas, and Scotus on the Object of the First Evil Choice," Oxford Studies in Medieval Philosophy 1: 61-82. (Comparative historical and philosophical study of moral psychology through accounts of the fall of the angels.)

\section{Related Topics}

\author{
Agent Causation \\ Aristotle \\ Anselm of Canterbury \\ Thomas Aquinas \\ The Relationship between Moral Responsibility and Freedom \\ Mental Causation
}




\section{5 \\ RENÉ DESCARTES \\ C. P. Ragland}

René Descartes firmly believed in the reality and importance of human free will, but his remarks about it were not systematic. Consequently, it can be difficult to understand what exactly he thinks freedom is. This chapter will attempt to make some headway on that question, explaining first why freedom matters for Descartes, then how he understands its nature, and finally, what this view implies for his physics and theology.

\section{Why Freedom Matters to Descartes' Project}

In his six Meditations on First Philosophy, Descartes aims to establish something "firm and lasting" in the sciences. Freedom plays a crucial role in this project, taking center stage in the Fourth Meditation, where it solves an important problem arising from his earlier arguments.

In the Third Meditation, Descartes notes that to achieve his goals for the sciences, he must become sure of the "truth rule" (AT 7:70/CSM 2:49), which says: "Whatever I perceive very clearly and distinctly is true" (AT 7:35/CSM 2:24). He initially doubts the truth rule because he worries that his faculties of perception (sensation and reason) may not really aim at truth. This would be the case, for example, if his creator were a deceiver (AT 7:36/CSM 2:25). However, as the Third Meditation unfolds, Descartes proves that he has been created by an all-powerful and benevolent God. Because God wants us to know the truth, we can trust our faculties. Knowledge of God, it seems, secures knowledge of the truth rule (AT 7:53-4/CSM 2:37-8).

But as the Fourth Meditation opens, Descartes finds a fly in the ointment. He thinks of an argument against God that seems just as strong as his Third Meditation argument for God: if we were made by an omnipotent God, and God does not want us to make mistakes, then error should be impossible. But we form false beliefs all the time. Therefore, it seems, our creator must lack either omnipotence or perfect goodness (AT 7:54/CSM 2:38).

This argument throws the truth rule back into doubt by calling into question the consistency and reliability of our faculty of reason. In the Third Meditation, reason seemed to demonstrate that our maker is an omniperfect God. But now it also seems to demonstrate that our maker cannot be such a God. If both demonstrations are truly products of reason, then reason is self-contradictory and cannot provide a trustworthy backing for the truth rule.

This, the central problem of the Fourth Meditation, is an epistemological version of the 'logical problem of evil' for theism. To solve it, Descartes needs to show that the 


\section{RENÉ DESCARTES}

argument against God does not really work. Specifically, he needs to show that our creation by an omnipotent, veracious God does not necessarily entail our infallibility. To do this, he employs a version of the 'free will defense' (see Plantinga 1990).

Descartes begins his defense by noting that when we form beliefs, we employ two distinct faculties: the intellect and the will. The intellect allows us to 'see' propositions, that is, grasp their meaning. With the will, we actively affirm, deny, or suspend judgment concerning propositions displayed in the intellect. The intellect grasps propositions either clearly and distinctly or with some degree of obscurity or confusion, and the will responds differently in each case (AT 7:56-9/CSM 2:39-41).

When we see a proposition clearly and distinctly, we cannot help believing it. For example, when Descartes considers " $2+2=4$ " or "I exist (since I am thinking)," he says: "I could not but judge something which I understood so clearly to be true" (AT 7:58/ CSM 2:41). However, it is relatively rare for us to grasp things clearly and distinctly. Most of the time, when our intellect's grip on a proposition is even slightly obscure or confused, the will can go ahead and affirm the proposition, but can also deny it or suspend judgment (AT 7:59/CSM 2:41).

We can do any of these things, but what should we do? Descartes answers:

If . . . I simply refrain from making a judgment in cases where I do not perceive the truth with sufficient clarity and distinctness, then it is clear that I am behaving correctly ... But if in such cases I either affirm or deny, then I am not using my free will correctly.

(AT 7:59/CSM 2:41)

With this rule in place, Descartes can finish his free will defense.

God's goodness and omnipotence entail that we cannot err when we use our cognitive faculties correctly. Our cognitive equipment is guaranteed to function perfectly when used according to manufacturer instructions. And the instructions are clear: we should assent only to what we clearly and distinctly $(C \& D)$ perceive. But we are still free to flout the rule. We can-and often do-misuse our wills by assenting (or dissenting) when we really should suspend judgment. As Descartes puts it:

It is surely no imperfection in God that he has given to me freedom to assent or not to assent to things about which he has not placed a clear and distinct perception in my intellect. But it is undoubtedly an imperfection in me that I do not use that freedom well and make judgments about things that I do not rightly understand.

(AT 7:60-1/CSM 2:42; my translation)

God and error can coexist because God is not responsible for error-we are. Because misuse of the will is possible, error is possible even on the assumption that God is no deceiver. Therefore, the existence of error gives us no reason to doubt God's goodness or power. The argument against God turns out to be specious, and the threat to reason's consistency merely apparent. Since God's goodness and power entail the truth rule, that principle is now fully vindicated. As Descartes writes: "I shall unquestionably reach the truth, if only I give sufficient attention to all the things which I perfectly understand, and separate these from all the other cases where my apprehension is more confused and obscure" (AT 7:62/CSM 2:43; see also AT 7:15/CSM 2:11). 
Descartes' free will defense faces some serious objections. First, we might wonder whether God could have made us such that we would always freely suspend judgment when we should. Descartes responds that God indeed could have done this, but had a good reason (perhaps involving the overall perfection of the universe) to make us vulnerable to error (AT 7:61/CSM 2:42-3). Next, we might object to Descartes' claim that we form beliefs at will: is it really plausible that we can suspend judgment about things that seem overwhelmingly probable? (Newman [2015] offers a way to help Descartes meet this objection). Finally, as Della Rocca (2006) suggests, Descartes' procedure may be viciously circular: Descartes' reason for thinking that we should assent only to $C \& D$ perceptions seems to be that only such perceptions are guaranteed to be true-but the truth of C\&D perceptions is the very point at issue!

These problems are perhaps mitigated somewhat by the fact that Descartes does not need his free will defense to be true or plausible. Its logical coherence is enough to solve his problem (though he does, in the end, believe we really are free, since we C\&D perceive this (AT 8A:19/CSM 1:205-6; see also AT 5:159/CSMK 342). But Descartes is not out of the woods yet, for his notion of freedom itself seems incoherent at first glance.

Descartes appears to maintain that freedom both does and does not require 'two-way' power, or the ability to do otherwise than we actually do. He says that we freely believe $C \& D$ perceptions despite being unable to do otherwise, and that we believe unclear perceptions freely because we are able to do otherwise. To see just how serious this problem is for Descartes, let us scrutinize his view of freedom.

\section{What Freedom Is}

A quick look at the relevant texts only seems to heighten the problem. Descartes defines freedom as follows:

The will, or freedom of choice ... [A] simply consists in this: that we are able to do or not do (that is, to affirm or deny, to pursue or avoid); or better, [B] simply in this: that we are carried toward what the intellect proposes for affirmation or denial or for pursuit or avoidance in such a way that we do not feel ourselves determined to it by any external force.

(AT 7:57/CSM 2:40; my translation)

Section (A) defines freedom as two-way power, and section (B) seems to reinforce this idea by associating freedom with the absence of external determination. For it has often been thought that determinism by external forces threatens freedom precisely because it takes away our ability to do otherwise than we do.

However, when Descartes discusses the effect of clear and distinct perceptions on the will, he says:

I could not but judge something which I understood so clearly to be true; not because I was compelled so to judge by any external force, but because a great light in the intellect was followed by a great inclination in the will, and thus I have believed this more spontaneously and freely as I have been less indifferent to it.

(AT 7:58-9/CSM 2:41; my translation and italics) 


\section{RENÉ DESCARTES}

In a rigid translation of the original Latin, Descartes here says that he "was not able not to judge true" what he C\&D perceived. And yet, he assented to it freely. This clearly implies that we can be free without being able to do otherwise (for similar passages, see AT 7:69/CSM 2:48; AT 7:145/CSM 2:104; AT 7:166/CSM 2:117; AT 8a:21/CSM 1:207; AT 3:64/CSMK 147; AT 4:115-16/CSMK 233-4).

In the light of this text, it is natural to wonder whether Descartes ever really meant to define freedom as two-way power (Kenny 1972 and Beyssade 1994 suggest this). Perhaps he intended part (B) — which defines freedom as the absence of external determination - to retract and replace part (A)'s identification of freedom with two-way power. After all, some philosophers (so-called 'source incompatibilists') think that external determination threatens freedom even if it does not require two-way power. For example, Spinoza thought that God can only act in one way, but is nevertheless free because completely self-determined (from within, not by anything outside) (Ethics Part I, Propositions 33 and 17; see Spinoza 1985). Therefore, Descartes' mention of freedom from determinism need not imply his commitment to two-way power.

However, Descartes elsewhere makes clear that he does require two-way power for freedom. For example, in the Principles of Philosophy he says:

It is a supreme perfection in man that he acts voluntarily, that is, freely; this makes him in a special way the author of his actions and deserving of praise for what he does. We do not praise automatons for accurately producing all the movements they were designed to perform, because the production of these movements occurs necessarily. It is the designer who is praised ... for in constructing [automatons] he acted not out of necessity but freely. By the same principle, when we embrace the truth, our doing so voluntarily is much more to our credit than would be the case if we could not do otherwise.

(AT 8A:19/CSM 1:205)

Similarly, in a letter he says that we have "a positive faculty of determining oneself to one or other of two contraries, that is to say, to pursue or avoid, to affirm or deny," and that the will "has this faculty not only with respect to those actions to which it is not pushed by any evident reasons on one side rather than on the other, but also with respect to all other actions" (AT 4:173/CSMK 245). The will is always able to do otherwise, even when "a great light in the intellect" is "followed by a great inclination in the will" (AT 7:58-9/CSM 2:41). This letter says, in other words, that we can keep ourselves from assenting to what we $C \& D$ perceive! So it seems we cannot avoid incoherence in Descartes' view of freedom by denying that he identifies freedom with two-way power.

However, as this letter continues, Descartes himself suggests a different resolution to the problem. He distinguishes two different senses of ability or power.

When a very evident reason moves us in one direction, although morally speaking we can hardly move in the contrary direction, absolutely speaking we can. For it is always open to us to hold back from pursuing a clearly known good, or from admitting a clearly perceived truth, provided we consider it a good thing to demonstrate the freedom of our will by so doing.

(AT 4:173/CSMK 245; my italics) 
Whenever Descartes says that C\&D perceptions determine the will, he is speaking morally; when he says that the will always has two-way power, he is speaking absolutely. When we C\&D perceive something, we are 'morally speaking' unable to withhold assent from it, but nevertheless retain the ability to do otherwise 'absolutely speaking.' When we perceive something obscurely, we have both a moral and an absolute ability to withhold assent.

This moral/absolute distinction saves Descartes from formal contradiction, but raises two further questions: (1) What exactly is the difference between 'moral' and 'absolute' power? (2) Why is 'moral' two-way power required in cases of obscure perception, but not in cases of $C \& D$ perception? In response to the first question, two possible answers are worth considering here.

First, as Alanen (2002) and Moyal (1996) suggest, being 'morally unable' to withhold our assent from C\&D ideas may simply mean being morally required to assent to them. It does not mean that we are psychologically compelled to assent. We could hold back, but then we would be doing something wrong. If this suggestion is right, then for Descartes the will's activity can never truly be determined by the intellect.

This interpretation, however, clashes with Descartes' theory of motivation (AT 7:431-3/CSM 2:291-2). He holds that we are inclined towards a course of actionincluding the action of assenting-only if it appears somehow good (AT 11:464/CSM 1:392; AT 1:366; CSMK 56), and that we are psychologically capable of doing something only if we are somehow inclined toward it - that is, if we want to do it for some reason (AT 1:366; CSMK 56). When we perceive some proposition P obscurely, we will be inclined to assent to it (for the reasons suggesting its truth), but at same time also inclined to withhold our assent (if only because the reasons in support of $P$ are inconclusive) (AT 7:59/CSM 2:41). But if we C\&D perceive $P$ (and are not thinking of anything else) then we will see assenting to $P$ as good, and will have no reason to withhold assent. Desiring only to assent, we will be psychologically unable to do anything else.

So it seems that for Descartes, the intellect does sometimes determine the will. Indeed, Descartes seems to have this motivational point in mind when he asserts the will's "absolute" ability to withhold assent. He says: "it is always open to us to hold back ... provided we consider it a good thing to demonstrate the freedom of our will" (AT 4:173/CSMK 245; my italics). If we could hold back even when we are inclined only in one direction, then there would be no need for Descartes to add the proviso requiring a contrary inclination.

In light of this proviso, the following seems a better way to understand the moral/ absolute distinction. Our 'moral' abilities are categorical powers: things we can do given our actual circumstances. Our 'absolute' abilities are hypothetical powers: things we could do if we were in relevantly similar-but nevertheless different-circumstances. When we $C \& D$ perceive $P$, we are categorically unable to hold back our assent. But we still have the hypothetical ability to withhold assent from $P$, since we could suspend judgment about $P$ if we perceived it with any degree of obscurity or confusion (as would likely occur if we were distracted by the thought of proving our freedom). We are 'absolutely speaking' able to withhold assent because we could do so in an 'alternative scenario.'

Clearly, this alternative scenario needs to be possible, but in what sense? Is it enough for it to be logically possible (non-contradictory in itself), or does it also need to be a scenario that was, at some point in the past, possible for us to bring about? If the former, 


\section{RENÉ DESCARTES}

then Descartes thinks we could be free even if the intellect always determined the will; he thinks that freedom is in principle compatible with intellectual determinism. If the latter, then he is at bottom a kind of libertarian, who thinks that our actions can be both free and determined only if the determining factors are themselves somehow under our control.

Descartes' views about voluntary direction of attention suggest that in fact, actual humans always enjoy the kind of control required by libertarians. For Descartes, we $C \& D$ perceive things only if we first concentrate on them, focusing our attention in the right way. In the Principles of Philosophy, he says: 'I call a perception 'clear' when it is present and accessible to the attentive mind" (AT 8A:22/CSM 1:207; see also AT 10:368/CSM 1:14), and in his Conversation with Burman, he says the following about ideas that can be $C \& D$ perceived:

Men who are creatures of the senses, as we all are at a pre-philosophical level, do not think about these or pay attention to them. On the contrary ... we neglect them and think about them only in a confused manner ... Indeed if people were to think about these principles in the abstract ... no one would ever have been a sceptic; for they cannot be denied by anyone who carefully focuses his attention on them.

(AT 5:146/CSMK 332-3; my emphasis)

When we don't pay sufficient attention, we can be sceptics, withholding assent even from self-evident truths. Our assent is compelled only when we focus enough to perceive clearly and distinctly. Therefore "it is not enough to have a good mind; the main thing is to apply it well" (AT 6:2/CSM 1:111; my emphasis). Furthermore, we freely decide how to focus our attention. In Passions of the Soul, Descartes speaks of the "volition" or decision "to fix our attention for some time on some particular object" (AT 11:361/CSM $1: 344$ ) or "to apply our mind to some object which is not material" (AT 11:343/CSM $1: 335)$. So when our will is compelled by $C \& D$ perceptions, it is only because we have already freely decided to concentrate hard enough perceive things clearly. The will remains self-determining in a fairly robust libertarian sense.

However, Descartes does not seem to think that this kind of self-determination is essential to the will's freedom. In the Fourth Meditation, he says:

God could easily have brought it about that without losing my freedom, and despite the limitations in my knowledge, I should nonetheless never make a mistake. He could, for example ... have impressed it unforgettably on my memory that I should never make a judgment about anything which I did not clearly and distinctly understand.

\section{(AT 7:61/CSM 2:42; my emphasis)}

Instead of us, God could have made people who are always aware of the rule that governs assent. Descartes says that this rule is "clear by the natural light," which means that one cannot think of it without clearly perceiving — and hence believing - it (AT 7:145/CSM 2:104; AT 8A:16/CSM 1:203). So these people not only would continually think of the rule, but also would continually assent to its truth. And this assent would not depend on any of their prior decisions about how to direct their attention (for in this one respect, their attention would be fixed). Nevertheless, these people would not 
have lost their freedom. They are still 'absolutely speaking' able to withhold assent from the rule, because they would be able to do so if they perceived it unclearly. So in principle, freedom requires only a purely hypothetical two-way power (i.e., it requires that we be able to do otherwise in an alternative scenario that is merely logically possible). Therefore, the concept of freedom in itself does not require the absence of determinism.

Now that the nature of 'absolute' two-way power is clear, we must consider a puzzle about 'moral' or categorical two-way power: why does Descartes take freedom to require that we be categorically able to withhold assent from unclear perceptions, but not from clear ones? Why is freedom with respect to obscure perceptions different from our freedom with respect to C\&D perceptions? If he cannot answer this question, Descartes' view will appear ad hoc (see Rosenthal 1986).

Fortunately, an answer is not far to seek. Near the end of the Fourth Meditation, Descartes speaks repeatedly of the "power to avoid error" (AT 7:61/CSM 2:43). Such power seems to be the essence of freedom for Descartes. In other words, freedom is the categorical ability to get things right. This ability implies two-way power in some circumstances, but not in others. If we are able to err or go wrong, then we will count as free only if we also can do otherwise (i.e., only if we can do what is right). But when we necessarily get things right — such as during C\&D perception-we are clearly able to get things right. We have the power that makes us free, and being able to do otherwise would contribute nothing more to our freedom.

Cartesian freedom is thus 'asymmetrical' in its relation to determinism (Wolf 1980): it is compatible with being determined to do good (or to assent to truth), but not with being determined to do evil (or to assent to falsehoods). Prior to Descartes, the medieval philosopher Anselm of Canterbury advocated a similar view of freedom (see De Libertate Arbitrii, chs. 1 and 2, in Anselm 2000).

\section{Freedom, Laws of Nature, and Providence}

Descartes thinks that in fact we often freely make mistakes (in the moral realm, we sin; in the epistemic realm, we judge too quickly). Given his view of freedom, these mistakes cannot be inevitable for us. Neither the laws of nature nor God could predetermine us to commit them. Therefore, we would expect Descartes to deny physical or theological determinism, and that is what he does.

For Descartes, laws of nature (stemming from God's immutability) govern the motions of bodies (AT 8a:61-6/CSM 1:240-3). Many events in the human body fall under these laws (AT 11:341-2/CSM 1:335), but not the ones caused directly by the mind. For example, when we freely decide to walk, this mental event causes our legs to start moving (AT 11:343/CSM 1:35). Unlike most physical events, this motion in our legs cannot be explained by previous physical events together with the laws of nature (AT 8a:315/CSM 1:279). It is not subject to physical determinism, for the simple reason that it is directly caused by the mind.

Descartes views the mind as essentially free, so for him all of our voluntary bodily actions create breaks in the series of physical causes. So it may seem that for Descartes, all of our free actions are miracles (violations of nature's laws). This is especially worrisome for him because free actions seem to add new motion to the world (the legs, previously at rest, are set in motion by the mind, not by other bodies), but Descartes holds 


\section{RENÉ DESCARTES}

that the world contains the same quantity of motion at all times (AT 8A:61/CSM $1: 240)$. However, Descartes did not seem to be particularly concerned about this problem, and it is not clear whether, or how, he tried to resolve it (for an influential discussion of this problem, see Garber 2001).

Descartes seems more concerned about how to relate our misuses of freedom to divine providence. The traditional doctrine of providence teaches that before creating the world God already has a plan for history - a plan that, in Descartes' words, "extends to all the most particular actions of men" (AT 4:315/CSMK 273) so that "the least thought cannot enter the mind of man if God has not wished and willed from all eternity that it enter therein" (AT 4:313-4/CSMK 272).

Furthermore, "nothing can possibly happen other than as it has been determined from all eternity by this Providence" (AT 11:438/CSM 1:380). But if God planned for us to make mistakes from all eternity, and God's plan cannot be frustrated, then doesn't God determine us to go wrong? How, then, are we free? How do we still have the (categorical) ability to get things right?

In some of his letters, Descartes suggests an answer to these questions. Before creating, God knows what any possible creature would freely choose to do any possible situation she might face. To ensure that the providential plan is fulfilled, God simply needs to create those creatures who will freely fulfill it of their own accord (AT 4:353/CSMK 282). However, it is not clear how this "middle knowledge" solution to the problem of freedom and providence can work for Descartes. For he insists that God freely created the "eternal truths" (AT 1:145/CSMK 22-3; AT 4:118-19/CSMK 235; AT 7:431-3/ CSM 2:291-2), which would include truths about what possible creatures would freely choose (Ragland 2005). This would seem to make God ultimately responsible for our errors, even if God does not directly cause them.

It is not surprising, then, that in his official published position on this problem (in Principles of Philosophy), Descartes appealed to mystery:

We can easily get ourselves into great difficulties if we attempt to reconcile... divine preordination with the freedom of our will, or attempt to grasp both these things at once... But we shall get out of these difficulties if we remember that our mind is finite, while the power of God is infinite ... We may attain sufficient knowledge of this power to perceive clearly and distinctly that God possesses it; but we cannot get a sufficient grasp of it to see how it leaves the free actions of men undetermined.

(AT 8:20/CSM 1:206)

Though we cannot understand how, God mysteriously leaves our free actions undetermined while still maintaining providential control.

Like the original problem of the Fourth Meditation, the problem of providence and freedom seems to throw our faculty of reason into conflict with itself. When we think of God, we must conclude that providence determines our actions, but when we think of ourselves, we cannot help but believe that we act independently (AT 4:332-3/CSMK 277). In light of this apparent inconsistency in the deliverances of reason, Descartes' appeal to mystery is unsatisfying. If we cannot clearly explain why this conflict of perspectives is merely apparent, it seems that (from Descartes' point of view) our confidence in reason should be shaken, and everything plunged into doubt. 


\section{References}

In-text references to Descartes use the following abbreviations:

AT Adam, C. and Tannery, P. (eds) (1974-86) Oeuvres de Descartes, 2nd ed., 11 vols. Paris: Vrin/C.N.R.S.

CSM Cottingham, J., Stoothoff, R., and Murdoch, D., trans. (1984/1985) The Philosophical Writings of Descartes, Vol. 1 and 2. Cambridge: Cambridge University Press.

CSMK Cottingham, J., Stoothoff, R., Murdoch, D., and Kenny, A., trans. (1991) The Philosophical Writings of Descartes, Vol. 3. Cambridge: Cambridge University Press.

References to CSM and AT cite the volume first, followed by a colon and the page number. Translations are from CSM or CSMK unless otherwise noted.

Alanen, L.K. (2002) "Descartes on the Will and the Power to do Otherwise," in H. Lagerlund and M. Yrjönsuuri (eds), Emotions and Choice from Boethius to Descartes. Dordrecht: Boston: Kluwer Academic Publishers, pp. 279-98.

Anselm (2000) Complete Philosophical and Theological treatises of Anselm of Canterbury, trans. J. Hopkins and H. Richardson. Minneapolis: A.J. Banning Press.

Beyssade, M. (1994) "Descartes's Doctrine of Freedom: Differences between the French and Latin Texts of the Fourth Meditation," in J. Cottingham (ed.), Reason, Will, and Sensation: Studies in Descartes's Metaphysics. Oxford: Clarendon Press, pp. 191-206.

Della Rocca, M. (2006) "Judgment and Will," in S. Gaukroger (ed.), The Blackwell Guide to Descartes' Meditations. Malden: Blackwell, pp. 142-59.

Garber, D. (2001) Descartes Embodied: Reading Cartesian Philosophy Through Cartesian Science. Cambridge: Cambridge University Press.

Kenny, A. (1972) “Descartes on the Will," in R.J. Butler (ed.), Cartesian Studies. Oxford: Blackwell, pp. 1-31.

Moyal, G.J.D. (1996) "Magicians, Doubters and Perverts," Revue Internationale de Philosophie 50: 73-107.

Newman, L. (2015) "Attention, Voluntarism, and Liberty in Descartes' Account of Judgment," Res Philosophica 92: 61-91.

Plantinga, A. (1990) "God, Evil, and the Metaphysics of Freedom," in M.M. Adams and R.M. Adams (eds), The Problem of Evil. Oxford: Oxford University Press, pp. 83-109.

Ragland, C.P. (2005) "Descartes on Divine Providence and Human Freedom," Archiv für Geschichte der Philosophie 87: 159-88.

Rosenthal, D.M. (1986) "Will and the Theory of Judgment," in A.O. Rorty (ed.), Essays on Descartes' Meditations. Berkeley and Los Angeles: University of California Press, pp. 405-34.

Spinoza, B. (1985) The Collected Works of Spinoza, Vol. I. Princeton: Princeton University Press.

Wolf, S. (1980) “Asymmetrical Freedom,” Journal of Philosophy 77: 151-66.

\section{Further Reading}

Naaman-Zauderer, N. (2010) Descartes' Deontological Turn: Reason, Will, and Virtue in the Later Writings. Cambridge: Cambridge University Press. (This book explores connections between Descartes' "ethics of belief" and his more general ethical writings.)

Newman, L. (1999) "The Fourth Meditation," Philosophy and Phenomenological Research 59: 559-91. (This is a ground-breaking overview of the importance of the Fourth Meditation and the nature of Descartes' free will defense.)

Ragland, C.P. (2016) The Will to Reason: Theodicy and Freedom in Descartes. New York: Oxford Univerity Press. (This volume covers many of the issues discussed here, as well as other related issues, in much greater depth.)

\section{Related Topics}

Reasons-Responsive Views

Leeway vs. Sourcehood Conceptions of Free Will

Augustine of Hippo

Anselm on Canterbury

Thomas Aquinas

Thomas Hobbes and John Bramhall

John Locke 


\section{6 \\ GOTTFRIED LEIBNIZ \\ Julia Joráti}

Leibniz was obsessed with freedom. He turns to this topic again and again throughout his long career. And what he has to say about freedom is much more resourceful and inventive than typically acknowledged. While building on medieval theories-for instance by describing freedom in terms of the relation between the agent's will and intellect-he also adds radically new elements and even anticipates some views that are popular today.

The combination of theses about free will that Leibniz endorses in his mature writings is unusual and may at first appear inconsistent: (i) he claims that some of our actions are free; (ii) he links free agency closely to agent causation and in fact appears to deny that there is event causation; and (iii) he accepts a form of determinism. In other words, Leibniz endorses what we can describe as an agent-causal compatibilist theory of freedom. The three theses may seem to be in tension not only because proponents of agent causation views are typically incompatibilists, but also because determinism is often defined in a way that presupposes event causation. As we will see soon, however, the tension is merely apparent. Leibniz's version of agent-causal compatibilism is perfectly coherent and has some unique advantages over rival accounts.

\section{Three Conditions for Freedom}

In order to be free, Leibniz sometimes tells us, an agent must meet three necessary and jointly sufficient conditions:

Freedom ... consists in intelligence, which includes a distinct knowledge of the object of deliberation, in spontaneity, by which we determine ourselves, and in contingency, that is, in the exclusion of logical or metaphysical necessity. ... The free substance determines itself by itself, following the motive of the good recognized by the understanding, which inclines it without necessitating it; and all the conditions of freedom are contained in these few words.

( $T$ §288; cf. CD §20; SLT 94)

Intelligence, spontaneity, and contingency, according to this passage, are the three components of Leibniz's account of freedom. The passage even explains what, roughly, these three terms are supposed to mean: in order to act freely, an agent must deliberate and know the object of this deliberation - which, apparently, must have something to do with goodness. Further, she must determine herself by herself, and she must not be 
necessitated logically or metaphysically. From this short passage, in fact, we learn quite a lot about Leibniz's views on freedom. We learn that only deliberate-in the sense of deliberation-based - actions are free, that freedom requires some kind of self-determination, that free actions aim at something that the agent takes to be good, and that freedom is compatible with inclination but not with logical or metaphysical necessitation. The passage also raises a number of questions, though. What, for instance, is the difference between inclining and necessitating? And what kind of self-determination does Leibniz have in mind?

\section{Spontaneity and Agent Causation}

Let us first take a closer look at Leibniz's account of spontaneity or self-determination. What does it mean for an action to be spontaneous, or for an agent to determine herself by herself? It does not mean - even though the term may suggest it - that the action is capricious, uncaused, or undetermined. Leibniz reminds us repeatedly that he views the inner workings of minds as perfectly deterministic. A sufficiently intelligent being who knows everything about your mind's current states can deduce all of its future states, including the free ones (see WF 25; AG 211). That is because for Leibniz, each mind has a nature that prescribes all of its states, or, as Leibniz sometimes puts it, each mind is governed by a deterministic law that dictates all of the states it will ever have (WF 49; WF 206). This is, in fact, connected to Leibniz's acceptance of the principle of sufficient reason: for anything that happens, there must be a reason explaining why it, rather than anything else, happens. I will return to Leibniz's determinism below when I discuss the contingency condition.

What it means to say that an action is spontaneous or that an agent determines herself by herself, Leibniz sometimes tells us, is that the action is not caused by anything or anybody external to the agent, or conversely, that the principle of action is internal to the agent. (I am bracketing divine concurrence here; for a detailed discussion, see von Bodelschwingh 2011). In the Theodicy, for instance, Leibniz explains that spontaneity "belongs to us in so far as we have the source of our actions within us" (T §290; cf. SLT 97). This does not mean, however, that we cannot be influenced by our perceptions of external things, as Leibniz sometimes stresses: "when we speak of ... spontaneity, of the inward principle of our actions, we do not exclude the representation of external things; for these representations are in our souls" (H 421). Leibniz seems to be saying that when you decide to take a sip of the coffee in front of you, for instance, your perception of the coffee plays a role in your choice without undermining your spontaneity.

Why does that type of influence not take away our spontaneity? You might suspect that it is because this influence goes 'through us' in the right way. The coffee, one might be tempted to think, does not directly cause your action, but merely causes a mental state in you, which, in turn, causes your action. Yet, this proposal is mistaken in two ways. First, I do not think that mental states can efficiently cause anything for Leibniz; only agents or substances can be efficient causes. I return to this below. Second, Leibniz holds-strangely enough - that strictly speaking no mental state or perception is caused by external things such as mugs of coffee. Indeed, he denies that created things interact causally. Your perceptions of the coffee, then, are not caused by the coffee. Rather, you perceive the coffee solely because of your nature and your prior states. Even if your soul were the only substance that God created, you would have a coffee perception. 
The same applies if you subsequently burn your tongue when drinking the coffee: your pain is not caused by the coffee, but by you. In fact, this is true for any changes in your mental states.

Luckily, God has arranged things in such a way in the actual world that there is a perfect correspondence between your perceptions and external things. This correspondence, however, is pre-established by God; your perceptions correspond to external things without being caused by them (see L 593). That means that human minds are spontaneous in a very strong sense for Leibniz: external things are not even partial or indirect causes of any of our mental states. The principles of our actions are entirely within us. This in fact is one major advantage of Leibniz's version of compatibilism. While almost all other versions are committed to saying that free actions are ultimately determined by external things, or by events that occurred before the agent was born, Leibniz can deny this. Your actions are determined only by you (at least if we bracket God's role; more on this below).

As if denying the interaction between our minds and external objects was not already radical enough, Leibniz applies the same reasoning to the relation between our minds and our bodies. Your hand's motion toward the coffee mug is not caused by your decision or by your mind, strictly speaking. Your mind is unable to interact causally with your hand, and the correspondence between what you decide to do and what your body does is again merely due to divine pre-established harmony (see AG 319; L 587; WF 199). Consequently, the only things that we can cause, or the only actions we can perform, are our own mental states. The result of your decision to reach for the coffee is, in a way, merely your perception of your hand's movement toward the mug. This change in your perceptions is what your action consists in. (If this strikes you as ridiculous, you're not alone. But bear with Leibniz a bit longer: the theory of freedom he builds from these elements really is quite ingenious).

Leibniz claims that he can preserve the traditional way of talking about things interacting with each other, which somewhat cushions the punch of his metaphysics. Here's how: he introduces a less strict and, as he sometimes puts it, "ideal" sense in which what happens in one creature can explain what happens in another. Imagine you sustain a nasty mosquito bite. Leibniz would say that the pesky insect explains your discomfort in the following sense: God created your soul — a substance that as he foresaw would at a particular time perceive pain - in part because he wanted to create the mosquito (see AG 279). After all, God does not desire imperfections or evils such as your pain for their own sake, but permits them only insofar as they are required for the overall perfection or harmony of the world. Imperfections, in this sense, are in need of a special explanation. For this reason, Leibniz sometimes says that an imperfection in one substance is explained by a corresponding perfection in another substance, and that the latter substance ideally influences the former in this respect $(M \S 51 ; T \S 66)$. Since a perfection in the mosquito corresponds to the imperfection in you, we can say that this annoying insect is influencing you ideally, even though it is not causing your pain strictly speaking. This Leibnizian move allows us to view ourselves, in accordance with common sense, as sometimes acting on other things and sometimes being acted upon: the mosquito acts on you when it bites you, and you act on it when you subsequently kill it.

Because Leibniz denies that created substances interact causally, he takes there to be spontaneity all over the place: the pain you feel when sipping the piping hot coffee is as spontaneous as your deliberate act of picking up the mug. None of your mental states 


\section{JULIA JORÁTI}

are caused by anything external to you; the principles of all of these states are within you. How exactly does that work? On my view, the best way of understanding this ubiquitous spontaneity is as ubiquitous agent causation. This means that all genuine efficient causes, for Leibniz, are agents or substances; events, facts, or states of substances cannot cause anything. Even though some interpreters disagree with me here, Leibniz says so explicitly in a few texts, most clearly perhaps in "On Nature Itself": "everything that acts is an individual substance" ( $\$ 9$, AG 160; cf. Bobro and Clatterbaugh 1996). Strictly speaking, then, your perceptions or inclinations do not efficiently cause your actions; rather, you agent-cause these actions because you are inclined or motivated in a certain way. This motivating or inclining, in turn, is not an instance of efficient causation (see LC5 $\$ 15$ and $H 428$ ); the influence of reasons and motivations is probably best understood in terms of final causation (we need not worry about the details of that here). All efficient causation, in this picture, is therefore agent or substance causation. This means that the causal chains that an agent originates are not really chains at allthey consist of only one link, since the states that a substance causes do not in turn cause anything else.

The fact that spontaneity and agent causation are ubiquitous may suggest that these two notions cannot help us understand what makes free agency special. Yet, that would be too rash. As already seen, Leibniz is happy to say that in some sense, external things can influence us, even though strictly speaking, they never act on us. This talk of ideal influence captures something real and significant, namely the correspondence between perfections and imperfections. To the extent that external things ideally influence you, you are imperfect, and to the extent that you ideally influence them, you are perfect. If we take this kind of influence seriously, we can distinguish different degrees of spontaneity: the less you are ideally influenced by external things, the more spontaneous you are. Hence, in addition to the ubiquitous type of spontaneity that is present in all actions to the same extent, Leibniz can acknowledge another type that comes in degrees. These degrees correspond to the degree to which we are free from ideal external influence. Let us call the latter type 'agent spontaneity' (see Rutherford 2005; Jorati 2015).

Plausibly, agent spontaneity is more relevant to freedom than the ubiquitous kind of spontaneity. After all, unless Leibniz wants to change the notion of freedom very radically, cases like the burning sensation on your tongue are not at all promising candidates for free actions because they are not things that you do, in any relevant sense. At a minimum, it seems, free actions must be cases in which we can describe the agent as acting, rather than as being acted upon. Leibniz's claim that free actions must be spontaneous can therefore be informative after all, if we understand him as referring to agent spontaneity.

We can get even more specific about the spontaneity of free actions. Suppose you attend a lecture and the speaker says something that you know to be false. You deliberate about what you should do, conclude that it's best to point out the mistake, and immediately do so. This, according to Leibniz's definition, is a clear example of a free action. In what way is this action spontaneous? Well, like all actions, it is of course spontaneous in the sense that strictly speaking, nothing outside of you causes it. Moreover, it is agent-spontaneous to a very high degree: you are not ideally influenced by external things (except in negligible ways, perhaps).

There is, however, yet another way to think about the degree of spontaneity that your action possesses. As mentioned, all of an agent's states are dictated by her nature. 
What is important for free actions, according to Leibniz, is that they are dictated by the rational part of the agent's nature, that is, that the agent's rational faculties-will and intellect-play a central role. If an action is exclusively the outcome of non-rational inclinations, such as passions and instincts, it is not free. Likewise, to the extent that such non-rational factors play a role in free actions, the action is less free. Interestingly, Leibniz treats non-rational inclinations as external to the free agent in important ways: some represent the ideal influence of the agent's body and are thus external to her soul, and others he describes as external to the rational faculties of the agent, and hence as external to the rational self (SLT 94 and 98; T §228). Suppose, for instance, that in our example, part of your motivation for pointing out the speaker's mistake is that you subconsciously desire to get back at her for being rude to you earlier. Since you are unaware of this desire, and since it was not something you consciously considered during your deliberation, Leibniz would view it as a non-rational inclination and as external in the above sense. To the extent that this desire motivates you to criticize the speaker, then, your action is less free.

I find it helpful to describe this as a third and even more demanding type of spontaneity that I call 'rational spontaneity': the most spontaneous actions in this sense are the actions that are coming entirely from the rational faculties of the agent; non-rational factors are not playing any role whatsoever. For Leibniz, only God's actions are perfectly spontaneous in this sense because creatures are always influenced by non-rational factors (see $T$ §288). Created agents can only possess rational spontaneity to lower degrees, and the more rationally spontaneous their actions are, the freer they are.

Based on the distinction between rational actions and actions that are dictated by non-rational factors such as passions, Leibniz even provides a compatibilist account of what it means to have control over one's actions. This account in some ways anticipates Fischer and Ravizza's (1998). To the extent that we determine our actions based on a conscious weighing of reasons, Leibniz proposes, we are in control. To the extent that passions dictate our actions, on the other hand, we are at the mercy of quasi-external forces of which we are not fully aware and whose influence we do not consciously endorse. Leibniz sometimes calls the latter "bondage" and the former the "mastery" or “dominion” of reason ( $T \S \S 64,228$, and 326; NE 196).

\section{Intelligence}

To the extent that an action is free, then, it exhibits rational spontaneity. This is closely connected to one of the other two necessary conditions for freedom that Leibniz mentions: intelligence. In order to act freely, an agent must deliberate, distinctly perceive the object of her deliberation, and recognize "the motive of the good," as Leibniz says in the passage with which I started (i.e., T §288). The relevant kind of deliberation, this passage suggests, is deliberation about what is best to do. Before acting freely, the agent needs to consider at least two options and compare them, trying to figure out which one is best. If the agent has only one option, Leibniz claims, she is not free (see A 1.17.611). A free action, then, is an action that an agent performs because she has judged it, after comparing it to at least one other option, to be best.

One thing that is important to note about this understanding of freedom is that it is a clear departure from certain medieval views on the relationship between intellect and will, such as Molinist ones. For Molinists, free agents do not always choose the option 
that their intellects judge to be best. As long as an option is viewed as good in some respect, for such views, the agent can choose it freely. For instance, you can freely choose to buy a certain type of coffee without judging it to be better than the other options you considered; in fact, you can choose it freely even though you judge a different type to be better overall. Leibniz, on the other hand, thinks that the only way for us to perform an action that we do not judge to be best is unfreely, for instance when a strong contrary passion overbalances our rational desires. And if you can't decide which option is best, you cannot freely choose any of them. Accordingly, the will, for Leibniz, is merely the inclination to act in accordance with the intellect's judgments; it is not a radically independent faculty (see Greenberg 2005).

\section{Contingency and Determinism}

Having examined Leibniz's views on spontaneity and intelligence, let us turn to the third necessary condition for freedom that Leibniz lists in Theodicy \$288: contingency. In what sense are free actions contingent, for Leibniz? In the continuation of the passage from Theodicy $\$ 288$, Leibniz says, "infallible determination . . . destroys neither freedom nor contingency." Whatever it means to say that free actions are contingent, then, it is clear that freedom and the relevant kind of contingency are compatible with infallible determination. There are many other passages in Leibniz's writings that show that he takes determinism to be compatible with freedom. For instance, he says, "Predetermination or the predisposition by causes ... is very far from introducing the kind of necessity which, as we have said, is contrary to contingency, freedom, or morality" (CD §106). Being predetermined to perform a certain action, accordingly, is compatible with performing this action freely and contingently, and it is compatible with being morally responsible for the action (cf. H 420).

An infallibly determined action, then, can be free and contingent. We have already seen, however, that freedom is incompatible with logical or metaphysical necessitation. What is the difference between infallible determination and these freedom-undermining kinds of necessitation? Without going into the gritty details, I think it is the same difference as the one between inclining and necessitating that Leibniz mentions earlier in Theodicy \$288. That becomes particularly clear in a different text, in which Leibniz tells us more about the ways in which our free actions are predetermined:

Every cause in the world has been determined to produce such-and-such an effect under such-and-such circumstances, and even we are determined to take the side toward which the balance of the deliberation in which enter true or false reasons, as well as the passions, makes us lean the most ... Thus although these determinations do not strictly speaking necessitate, they do not fail to incline, and we always follow the side where there is the greatest inclination or disposition.

(SLT 96, translation altered)

This passage states not only that all causation in the world is deterministic, but also that our minds are determined by inclinations, analogously to the way in which a balance is determined by weights. When we are thinking about what to do, our passions and the reasons we consider are our inclinations to perform one of the available courses of action. What we end up doing, according to this passage, is determined by the 'weight' 
of these inclinations: we always do what, given all the passions and reasons, we are most inclined to do. Saying that we are only inclined but not necessitated to act in certain ways, then, most plausibly means that we are determined by reasons and passions, rather than in some other way (cf. WF 180f; NE 178, 182, and 196; H 406f). Note a crucial disanalogy between weights in a balance and inclinations in a mind, however: weights are efficient causes while inclinations or reasons most plausibly are not. Leibniz views reasons and inclinations, I think, simply as the agent's tendencies to act in certain ways; they are not entities that act on the agent or efficiently cause an action.

But, you may ask, how can Leibniz possibly be a determinist and a compatibilist, given his commitment to agent causation? Agent-causal theories of freedom, after all, are typically incompatibilist, that is, they are usually theories according to which freedom requires indeterminism. It is easy to see why: if some actions are agent-caused and do not have event causes, determinism as it is often understood must be false. After all, a common way to define determinism is in terms of event causation: every event is caused and physically necessitated by prior events (e.g., Markosian 1999: 258, 262). According to this kind of definition, determinism is not compatible with the view that some actions have only agent causes. It is for this very reason, it seems, that some scholars argue that Thomas Aquinas could not have been a compatibilist (e.g., Stump 2003: 286, 304f.). Agent-caused actions are not parts of deterministic causal chains that start outside the agent or in the distant past, and determinism is often understood in terms of such causal chains. In fact, those who find agent-causal theories of freedom attractive usually do so precisely because these theories allow us to break free from the chains of causal determinism. Ned Markosian, one of the very few contemporary proponents of agent-causal compatibilism, reconciles compatibilism with agent causation only by arguing that free actions have both agent causes and event causes (Markosian 1999: 269f.). How, then, can it be true that Leibniz is a determinist but denies that there is any event causation?

The answer, I think, is that characterizations of determinism in terms of event causation or causal chains are overly narrow. Definitions of determinism should be neutral with respect to kinds of causation because agent-causal theories can be just as deterministic as event-causal theories. Leibniz's views are a case in point: God, according to Leibniz, created substances that will infallibly, in accordance with their natures, produce a particular series of states, and these states are all that ever happens naturally. The way God set up the world in the beginning, then, fixes everything natural that is going to happen in the world thereafter. It takes a miracle-literally! - to prevent any of these events from occurring. If that is not determinism, I don't know what is. Definitions of determinism, then, should not settle the question whether there is event causation. And some characterizations, in fact, are neutral in precisely this way. Carl Hoefer, for instance, suggests the following definition: "The world is governed by ... determinism if and only if, given a specified way things are at a time $t$, the way things go thereafter is fixed as a matter of natural law" (2010, italics omitted. See also van Inwagen 2008: 330). Even Markosian, after considering several event-causal characterizations, formulates what he calls "the strongest definition of Determinism" as follows: "There is at any instant just one physically possible future" (1999: 264). On such definitions, Leibniz is a determinist about the natural world and, since he thinks that some actions are free, a compatibilist.

Accepting determinism, then, does not commit us to accepting event-causal determinism. Nor, in fact, does it commit us to accepting what one might call external determinism. 
As seen, Leibniz holds that our actions are determined only by us, that is, by our natural tendencies. Nothing outside of us ever determines our actions, not even indirectly. My actions are not parts of causal chains going back in time to the beginning of the world, nor do my actions have any external agent causes (again, bracketing God's concurrence). Likewise, my natural inclinations, which determine my actions, are not in turn determined or caused by any outside thing or person.

Saying that the natures or natural inclinations of created substances are not caused by anything external may sound preposterous. If the way God set things up when he created the world determines everything that is going to happen in the natural course of events, but you weren't around at the beginning of the world, wouldn't your nature have to be the product of some other substances that existed before you? Perhaps your parents? And if that is the case, are your actions not indirectly determined by something external to you after all? The way Leibniz gets around this problem again involves a radical move: he insists that in a way, you were around at the very beginning of the world, and so was every other substance that ever existed or will ever exist. God produced all of his creatures simultaneously, in the very beginning. (God could of course add new substances to the world whenever he pleases, but Leibniz thinks that would be too much direct divine intervention). God initially created you, however, not as a rational mind with a human body, but rather as a very imperfect substance without consciousness or memory and with a microscopically small body. It is only when your parents conceived you that you started developing into a full human being. This is, in fact, connected to Leibniz's denial of causal interaction: your parents couldn't have literally produced you because created substances cannot interact. God is the only agent capable of causing changes in other things, and of creating new substances. Your parents, then, did not produce you, strictly speaking; God did. Your parents in fact had no genuine influence on you at all!

As a result, no other creature determines or influences your actions, not even indirectly. Nor do you owe your existence and your nature to any other created substances. This leads naturally to another question, though: don't you owe your existence and nature to God, according to Leibniz? And doesn't this entail that God determines your actions, similarly to the way in which an engineer determines the movements of a machine she invents? Here again, Leibniz has an answer: God didn't really invent you. He merely discovered your essence in his intellect, and he chose to actualize you because you are a member of the best of all possible worlds (see LC5 \$6). The situation is therefore not analogous to an engineer who designs and then constructs a certain machine, but rather to an engineer who finds a blueprint and builds the machine that the blueprint describes. Like this second engineer, God didn't strictly speaking give you any characteristics. Instead, all of the characteristics that you have were already included in the essence that God discovered in his intellect. Could God have created a person similar to you who never burns her tongue? Maybe, but according to Leibniz, this person would not be you. This allows him to deny that God in some sense made you burn your tongue, or that he manipulated you into acting in the way that you acted (see WF 188). You can't reasonably complain that God made you drink scalding hot coffee, Leibniz would say; that's all on you. At most, you could complain about God's creating you at all-a person who, as God fully well knew, would inevitably drink hot coffee and burn her tongue (see AG 61). The engineer who merely finds the blueprint, after all, can't be held responsible for particular features of the design; she can merely be held responsible for her decision to build that machine. 


\section{GOTTFRIED LEIBNIZ}

\section{Conclusion}

Leibniz, like many other philosophers, takes free will to be compatible with determinism, but his version of compatibilism is unique and intriguing. To be free, Leibniz claims, an action must first of all be spontaneous, that is, the principle of the action must be in the agent. This spontaneity, I have argued, is a deterministic form of agent causation: actions are caused by agents, rather than by events internal or external to the agent, and they are agent-caused in a way that is dictated by the agent's nature. While all actions are agent-caused and immune from external influence, free actions are special in that they result from the agent's rational assessment of the merits of at least two available courses of action. Freedom, then, requires both spontaneity and intelligence. It also requires contingency, which, for Leibniz, appears to mean that free actions are determined only by the agent's inclinations or motives. The payoffs of Leibniz's idiosyncratic metaphysics are immense: he can maintain, without introducing indeterminacy into his system, that nothing outside of the agent determines her free actions.

\section{Acknowledgments}

I thank Derk Pereboom, Kevin Timpe, Stephen Puryear, Qu Hsueh Ming, Joseph Anderson, Juan Garcia, and Issei Takehara for comments on earlier drafts.

\section{References}

I am using the following abbreviations to refer to Leibniz's works. All translations are mine unless an English edition is cited.

A = Sämtliche Schriften und Briefe (1923-) Deutsche Akademie der Wissenschaften (ed.). Berlin: Akademie Verlag, cited by series, volume, page.

$A G=$ Philosophical Essays (1989) trans. R. Ariew and D. Garber. Indianapolis: Hackett.

$C D=$ Causa Dei, cited by section number as in G 6:439-462.

$\mathrm{G}=$ Die philosophischen Schriften von Gottfried Wilhelm Leibniz (1875-90) C.I. Gerhardt (ed.). Berlin: Weidmann, cited by volume and page.

$H=$ Theodicy (1985) trans. E.M. Huggard. La Salle: Open Court.

$L=$ Philosophical Papers and Letters (1969) trans. L. Loemker. Dordrecht: Reidel.

LC5 = "Fifth Letter to Clarke," in Correspondence [between Leibniz and Clarke] (2000) trans. R. Ariew. Indianapolis: Hackett, original text in G 7:352-440.

$\mathrm{M}=$ Monadology, cited by section as in G 6:607-623.

$N E=$ New Essays on Human Understanding (1996) trans. P. Remnant and J. Bennett. New York: Cambridge University Press, original text in A.6.6.

SLT $=$ The Shorter Leibniz Texts (2006) trans. L. Strickland. New York: Continuum.

$T=$ Theodicy, cited by section number as in G 6:102-365.

WF = Leibniz's 'New System' and Associated Texts (1997) trans. R.S. Woolhouse and R. Francks. New York: Oxford University Press.

Bobro, M.E. and Clatterbaugh, K. (1996) “Unpacking the Monad: Leibniz's Theory of Causality,” Monist 79: $408-25$.

Fischer, J.M. and Ravizza, M. (1998) Responsibility and Control: A Theory of Moral Responsibility. Cambridge: Cambridge University Press.

Greenberg, S. (2005) "Leibniz Against Molinism: Freedom, Indifference, and the Nature of the Will," in D. Rutherford and J.A. Cover (eds), Leibniz: Nature and Freedom. Oxford: Oxford University Press, pp. 217-33.

Hoefer, C. (2010) "Causal Determinism," in E. Zalta (ed.), The Stanford Encyclopedia of Philosophy (Spring 2010 Edition), available from: http://plato.stanford.edu/archives/spr2010/entries/determinism-causal/ (accessed 22 June 2016). 


\section{JULIA JORÁTI}

Jorati, J. (2015) "Three Types of Spontaneity and Teleology in Leibniz," Journal of the History of Philosophy 53: 669-98.

Markosian, N. (1999) "A Compatibilist Version of the Theory of Agent Causation," Pacific Philosophical Quarterly 80: 257-77.

Rutherford, D. (2005) "Leibniz on Spontaneity," in D. Rutherford and J.A. Cover (eds), Leibniz: Nature and Freedom. Oxford: Oxford University Press, pp. 156-80.

Stump, E. (2003) Aquinas. London: Routledge.

van Inwagen, P. (2008) "How to Think about the Problem of Free Will," The Journal of Ethics 12: 327-41.

von Bodelschwingh (Jorati), J. (2011) "Leibniz on Concurrence, Spontaneity, and Authorship," The Modern Schoolman 88: 267-97.

\section{Further Reading}

Davidson, J. (2011) “Leibniz on Free Will," in B. Look (ed.), The Continuum Companion to Leibniz, London: Continuum, pp. 208-22. (This article provides an accessible overview of Leibniz's views on freedom and their relation to his contemporaries and predecessors.)

Jolley, N. (2005) Leibniz. New York: Routledge. (This is a general introduction to Leibniz's system with a helpful chapter on free will.)

Murray, M.J. (2005) "Spontaneity and Freedom in Leibniz," in D. Rutherford and J. Cover (eds), Leibniz: Nature and Freedom. Oxford: Oxford University Press, pp. 194-216. (This chapter contextualizes Leibniz's references to spontaneity as well as Leibniz's theory of free will more generally.)

\section{Related Topics}

Classical Compatibilism

Agent Causation

Thomas Aquinas

Thomas Reid

Free Will and Theological Determinism

Determinism 


\section{7 \\ THOMAS HOBBES AND
JOHN BRAMHALL}

A. P. Martinich

\section{The Basic Positions of Hobbes and Bramhall}

Hobbes is a classic determinist and mechanist. He believed that every event has a cause; furthermore, all causation occurs through the contact of one moving body with another body. Since actions are events, they are caused by one moving body making contact with another body. So all actions are caused by some earlier cause. More specifically, the immediate cause of an action, whether that of a human being or a beast, is a desire. This desire, because it is the one that causes an action, is called 'willing' or 'a will' (EW 4: 239-40, 5: 33-5, 38-9); see the Bibliography for abbreviations). It is preceded by some event, probably an event of reasoning that causes the willing. Hobbes calls a chain of alternating desires "deliberation" (EW 4: 272-3). Hobbes denies that "the will ${ }_{1}$ wills" because if it did, then there could be a will 2 that wills the will, ad infinitum and ad absurdum (EW 5: "To the Reader"). For Hobbes, it is the beast or human being that acts. Being ultimately the effect of an external cause does not mean that the agent did not have liberty to act or did not act freely: "Liberty is the absence of all impediments to action that are not contained in the nature and instrinsical quality of the agent" (EW: 4: 273; see also Leviathan, chapter 14.2). Since only bodies act, liberty applies to them; so it is incoherent to say that a will is free. And it applies as much to inanimate objects as animate ones. Water that runs downhill has as much liberty as a person who walks down a street. Also, being ultimately the effect of an external cause does not mean that either the will or the human being is compelled to act by the cause (EW 4: 261).

Hobbes's theory was challenged in a face to face debate between him and Bishop John Bramhall in 1645, during their exile in France during the English Civil War. Each wrote up their positions and they were later published as were extensive replies to each other (Martinich 1999: 266-71). The debate is a classic confrontation between an early modern determinist and a libertarian. Hobbes' view, which has historically been more influential than Bramhall's, can best be understood in the context of this debate.

Bramhall initially explains his position negatively: human actions are not necessitated (EW 5: 95; see also EW 5: 56; cf. EW 4: 240-1). He commits himself to two scholastic concepts of liberty: "a liberty to do this or that good," and "a liberty to do and not do good and evil" (EW 5: 56). Also scholastic is his commitment to "liberty 
of election," where election is "an act of judgment and understanding" (EW 5: 56; cf. EW 4: 242, 264-5). What is essential to this view is the possibility that the agent could have done otherwise than she did; that is, that whenever an agent is free she had an option not to do what she in fact did. So if an apple is on a table in front of a person, she can either eat the apple or not, and whichever action she chooses she could have chosen otherwise. What she chose was not determined until she did choose: "they who might have done, and may do, many things which they leave undone; and they who leave undone many things which they might do, are neither compelled nor necessitated to do what they do" (EW 5: 95). In contrast, Hobbes thinks that what was not done was not able to be done because the desire necessary to do it was excluded by the prior history of the world of bodies in motion. He thinks that Bramhall confuses the liberty that people have when there is no external impediment to doing it with the ability to do otherwise (EW 5: 405). For Bramhall, liberty is in an agent. For Hobbes, liberty is determined by what is external to the agent (Hobbes 1651: 64, 107, 108).

Bramhall has the first-person experience of human beings on his side. People feel that they are free to choose between two actions; and that whatever they in fact choose to do, they could have done something else. Hobbes counters this intuition with an analogy that undercuts the reliability of what people think they experience:

A wooden top that is lashed by the boys, and runs about sometimes to one wall, sometimes to another, sometimes spinning, sometimes hitting men on the shins, if it were sensible of its own motion, would think it proceeded from its own will, unless it felt what lashed it. And is any man wiser, when he runs from one place to another for a bargain, and troubles the world with writing errors and requiring answers, because he thinks he doth it without other cause than his own will, and seeth not what are the lashings that cause his will?

(EW 5: 55)

\section{Some Specific Issues in the Debate}

Bramhall thought that he could win the debate with Hobbes with a straightforward constructive dilemma:

Either I am free to write this discourse for liberty against necessity, or I am not free. If I be free, I have obtained the cause, and ought not to suffer for the truth. If I be not free, yet I ought not to be blamed, since I do it not out of any voluntary election, but out of an inevitable necessity.

(EW 5: 29; cf. EW 5: 55)

Hobbes accepted the first disjunct that Bramhall is free to write the discourse. But Hobbes did not concede that Bramhall thereby won, for Hobbes holds that people are free or not depending upon external conditions. What is not free is the will.

When scholastic logicians considered necessity with respect to conditional sentences, they distinguished between those in which necessity attach to the 'then-' clause, and those in which necessity attached to the entire sentence. Hobbes rejected the distinction (EW 5:145) and thought the following was a valid argument: if a preceding event E1 causes an event E2, then E2 has to occur; and if E2 has to occur, then 
E2 is necessary. Bramhall would have insisted that Hobbes's argument is ambiguous between $\mathrm{A} 1$ and $\mathrm{A} 2$ :

A1. Argument concerning the necessity of the consequence.

1. Necessarily if a preceding event E1 causes an event E2, then E2 occurs.

2. A preceding event E1 causes E2.

Therefore,

3. Necessarily E2 occurs.

A2. Argument concerning the necessity of the consequent.

1. If a preceding event E1 causes an event E2, then E2 necessarily occurs.

2. A preceding event E1 causes E2.

Therefore,

3. Necessarily, E2 occurs.

And Bramhall would have held that the conclusions of instantiations of A1 do not follow because premise 2 is not necessary; and he would have held that the first premise of instantiations of A2 would be false because necessity does not attach to individual events. Neither Bramhall nor Hobbes proved that the other was wrong.

Another reason that Hobbes maintained his position was his odd view about the origin of certain tautologies about the future. About the proposition,

(R) It is necessary that to-morrow it shall rain or not rain.

he says, "If therefore it be not necessary it shall rain, it is necessary it shall not rain, otherwise there is no necessity that the proposition, it shall rain or not rain, should be true" (EW 4: 276). He asks in effect, "Where does the necessity of the rain or the absence of rain in R come from if not from the disjunct that is in fact true?" In other words, he thinks $(R)$ is equivalent to

(R') Either it is necessary that tomorrow it shall rain or it is necessary that it shall not rain.

Hobbes probably chose future tensed statements for $\mathrm{R}$ with a rhetorical purpose in mind. If he could have shown that a future tensed proposition was necessarily true, then it would follow that past tensed and present tensed statements about events are also necessarily true because they can or could have been expressed at an earlier time by future tensed statements like R (cf. EW 5: 35).

Hobbes's mistake is to think that the necessity in R comes from one of the disjuncts rather than from the combination of both disjuncts (cf. EW 5: 413-15 and 422-3). It is easy for contemporary readers to see that the disjunction is true because a truth-table shows that every assignment of truth values to the disjuncts makes the entire disjunction true. But Hobbes appeared not to see this.

Hobbes also has an odd view about the relation between necessity and contingency. For Hobbes, a person calls something 'contingent' when the person either does not 
know what caused it to be true or does not know whether it is true or false (EW 5: 49-50). That is, 'contingent' is an epistemic word. In contrast, Bramhall holds that both necessity and contingency belong to logic or metaphysics. Necessary truths must be true while contingent truths happen to be true because of empirical circumstances. In another possible world, those contingent propositions would have been false. Partly because of his nonstandard understanding of contingent propositions, Hobbes misunderstands Bramhall's claim that a sailor on a ship in a storm who chooses to throw his goods overboard might have chosen not to throw his goods overboard (EW 5: 251). Hobbes takes this to mean 'Possibly (the sailor chooses to throw his goods overboard and the sailor chooses not to throw his goods overboard).' Bramhall certainly meant something different, namely 'Possibly, the sailor chooses to throw his goods overboard and possibly, the sailor chooses not to throw his goods overboard.'

Behind the caviling about what choice or choices a sailor may have is the issue of culpability for bad actions. Bramhall was worried that if determinism were true, then people do not genuinely have choices to make; and so those sent to hell for bad actions are treated unjustly (EW 5:150). Hobbes responded to this worry by making the logical point that people are justly punished because their actions were "noxious;" it is irrelevant that they were necessitated or even "elected" (EW 4: 253-4; EW 5: 151-2). If Hobbes's view seems wrong it may be because a certain kind of necessitation sometimes completely excuses an action that does not conform to a law, such as a law against killing. Hobbes tried to relieve the appearance that he was mistaken by distinguishing between two ways in which an action may be necessitated (EW 5: 48-9; cf. EW 4: 261). One way occurs when an action from the outside does not cause the person to will the action. So if a tornado picks up one person and dashes him against another, thereby killing the other, the airborne person is not to be punished. The other way occurs when an external event causes a will that causes the action. Bramhall thinks that human action is not always ultimately caused by some external event. Suppose that some horrible story causes everyone to weep except one person, say, Ulysses. According to Bramhall, because the story does not cause Ulysses to weep, Ulysses must have a free will that resisted the cause. Hobbes's response in effect is that the story shows only that it is not necessary for Ulysses to weep. The fact that the story does not cause Ulysses to weep means that other motions in him prevented it (EW 4: 267-8; cf. EW 5: 306).

Praise gets treated in a parallel way to punishment. People praise others when those others do what is good, that is, do "as I would wish" or "according to the will of the state" (EW 4: 255; see also EW 5: 154). Hobbes's views have the consequence that he does not have the problem of explaining how all of God's actions can be good and also necessary, as competing views do (EW 4: 256-7, 262-3).

Although Hobbes was a determinist, he was not a fatalist, a person who believes that certain actions will occur no matter what they do. (See also the chapter on logical fatalism). In particular, if a person is fated to be alive on January 1, 2020, then it does not matter what he does; he will be alive on January 1, 2020. Hobbes said in effect that this view is as sensible as the view that "if I shall live till to-morrow, I shall live till to-morrow, though I run myself through with a sword to-day" (EW 4: 254; see also EW 5: 435). When it is necessary that something $E$ will happen, it is because it is necessary that certain other things, the causes of $E$, have happened or will happen. The story of the appointment in Samarra, which is supposed to illustrate fatalism, actually illustrates determinism. A person who flees to Samarra in order to escape Death whom he sees in 
the marketplace in Baghdad is in the chain of causes that result in his Death. If he had not fled to Samarra, he would not have died there. Consultations, admonitions, and other things can be causes in the necessitating chain of events.

Hobbes believes that God's foreknowledge proves that all events are necessary: "For whatsoever God foreknoweth shall come to pass, that is, it is impossible it should not come to pass, or otherwise come to pass than it was foreknown. But whatever was impossible should be otherwise, was necessary" (EW 5: 19; see also EW 5: 222; Hobbes 1651: 191). So in line with his understanding of sentences that include necessity and a conditional sentence, he would explain statements of foreknowledge as having the form, "If God knows that p, then necessarily p." One might object that God's foreknowledge does not settle the issue because God is not essential to the propositional form just set out. This form is equally true, "If Bachman knows that p, then p." Hobbes would retort that the difference between God's knowledge and Bachman's, other than the extent, is that "God makes the necessity of all things" and "the foreknowledge of God causeth nothing, though the will do" (EW 5: "To the Reader;" see also EW 5: 112, 175).

\section{Motivations for the Positions of Hobbes and Bramhall}

Bramhall was motivated by what he considered the abhorrent social and political consequences of determinism. Without free will, "all societies and commonwealths in the world" are overthrown: "the Laws are unjust which prohibit that which a man cannot possibly shun. All consultations are vain if everything be either necessary or impossible" (EW 4:15). He was also concerned to block unacceptable religious consequences. If sinners could not have done otherwise than they did, God would be unjust in punishing them. God himself would be culpable for those sinful actions because he would have been the cause of them.

The motivations for Hobbes's determinism may be primarily scientific. When he began to develop his physics, he was struck by the apparent fact that every change is part of a chain of bodies moving other bodies by contact. Because the chain of causes cannot go back infinitely-Hobbes was skeptical of any positive idea of infinity and any use of it to explain anything - there has to be a first moving cause, God (Hobbes 1651: 53). Also because there is one beginning of motion and causes form chains, causation is transitive, irreflexive, and asymmetric. While Bramhall and other scholastic philosophers could accept this, they could not accept Hobbes's additional claim that if $\mathrm{x}$ causes $\mathrm{y}$, then $\mathrm{x}$ temporally precedes $\mathrm{y}$. Hobbes's argument, simplified, is a dilemma. On the one hand, if a cause has to be simultaneous with the effect and if there is a time when the cause is not causing the effect, then the cause exists without the effect (Hobbes 1976: 316). But that is self-contradictory. On the other hand, if a cause has to be simultaneous with an effect and if the cause is causing the effect, then the cause exists as long as the effect exists. And that is obviously false since a parent may cause a child to exist, but the child can outlive the parent. So causes cannot be simultaneous with their effects. Causes cannot temporally follow effects because if an effect already exists, it does not need a cause. Therefore, causes must temporally precede their effects.

While I think that Hobbes's motivations are primarily scientific, this motive is consistent with a belief that the ultimate foundation of his determinism is connected with God's causal activity (EW 5: "To the Reader"). 


\section{A. P. MARTINICH}

\section{The Theological Background}

It may be surprising to find out that while both Bramhall and Hobbes were royalists, they became bitter enemies. Among the complex reasons for the animus, the theological reason was that Hobbes was (or represented himself as being) an English Calvinist while Bramhall, as a libertarian, was, to use the word then applied, an 'Arminian.' Although proponents of the two views asserted many of the same propositions-both views are Christian — such as that God is incomprehensible (EW 4:313), omniscient, omnipotent and omnibenevolent, each privileged different attributes when they discussed certain topics. Relevant to determinism, English Calvinists emphasized these:

English Calvinist Propositions: ('C' in the numbering indicates Calvinist)

C1. God is omnipotent.

C2. God is the cause of all things. ('Things' is used broadly to include events).

C3. God is the cause of all sins. (From C2)

C4. God is the cause of Adam's sin.

C5. If God is the cause of Adam's sin, then it was not possible for Adam not to sin.

C6. It was not possible for Adam not to sin. (From C4 and C5)

C7. It was necessary for Adam to sin. (From C6)

C1 was taken to be justified by Genesis 1, in which God creates or makes the world. There are several philosophical justifications. One is that since God is a perfect being or the greatest conceivable being, he must be omnipotent. Another is that to create something is to make something traverse an infinite distance, from nonbeing to being, and this can be done only by an omnipotent being. C2 was taken to be justified because Christians believe that there is one ultimate principle of reality: "In the beginning, God ..." If there were two ultimate principles, such as good and evil, then God would not be the ground of all reality; but he is. That is why God is everywhere (e.g., Aquinas, Summa theologiae, I, Q. 8. Art. 2-3). C3 and C4 follow from C2. About C3, Hobbes holds: "to cause sin is not always to sin" (EW 5: 297). But he refuses to assert C3 because that proposition is too easily misconstrued:

he [Bramhall] thinks he shall force me to say that God is the cause of $\sin$... to say that God is the cause of sin, because it sounds so like to saying that God sins, I can never be forced [to do] by so weak an argument as this of his.

(EW 5: 297)

Concerning C5, whatever God causes must exist. For Hobbes, no cause can fail to be effectual. To say that a cause did not produce its effect is to say something contradictory. C6 and C7 follow straightforwardly from C4 and C5.

In order to refute the Calvinists, Arminians claim that $\mathrm{C} 7$, combined with the moral principle,

8. If it is necessary for a person to do something, that person cannot rightly be punished for it. ('Ought' implies 'can.') 
entails

9. Adam cannot rightly be punished for sinning.

But 9 conflicts with 10 and 11:

10. God punished Adam for Adam's sin (cf. Genesis 3).

11. God is omnibenevolent.

9 and 10 seem to entail that God did something morally wrong and hence that:

12. God is not omnibenevolent.

But 12 is either blasphemous or heretical. Thus, Arminians thought they had refuted the Calvinist position.

But the Calvinists seemed to have the Bible on their side. For example, the Authorized Version of the Bible does not contain the term 'free will' at all. Moreover, St. Paul, in his "Epistle to the Romans" (9:21) says,

What then should we say? Is there injustice with God? God forbid. It is not therefore in him that willeth, nor in him that runneth, but in God that showeth mercy. . . . Therefore whom God willeth, he hath mercy on, and whom he willeth he hardeneth.

(EW 4: 248; see also EW 4: 241-51 and EW 5: 6-15)

Concerning the question of how God's actions can be just, Hobbes again answers by quoting St. Paul:

Who art thou, O man, that interrogatest God? Shall the work say to the workman, why has thou made me thus? Hath not the potter power over the clay, of the same stuff to make one vessel to honour, another to dishonour?

(EW 4: 248, and EW 5: 114)

For Hobbes "the power of God alone without other helps is sufficient justification of any action he doth." Hobbes says, "Power irresistible justifies all actions, really and properly. In whomsoever it is found; less power does not, and because such power is in God only, he must needs be just in all actions" (EW 4: 250 and EW 5: 104,143-4, 146). What makes an action of God's just is "his doing it" (EW 4: 249). Some Calvinists denied 11, as Hobbes did; other Calvinists did not (EW 5: 6 and Hobbes 1651: 190-1). But its proper understanding had to be made consistent with $(\mathrm{C} 1)$, rather than vice versa.

Hobbes's resolution of the problem being considered is to deny 8. As already explained, he held that there are two kinds of necessity, the kind that causes the motion of a body without causing the body to will the motion and the kind that causes the motion of a body by causing the body to will it. According to him, to sin is to have a will that causes a motion that violates a command of God. Adam broke God's command not to eat the fruit from the tree of the knowledge of good and evil. God did not sin because he is not subject to any command (EW 5: 295). Further, to cause someone to $\sin$ is not thereby to commit a sin. Suppose we know that the Son of God was the cause of Satan's sin, for example, in John Milton's Paradise Lost, Book V. The Son of God was the cause of Satan's sin but did nothing wrong. 
A standard Calvinist retort to the accusation implicit in C3 that God is the cause of all sins was that God is the cause of all actions, and some actions are sinful; but God is not the cause of the sinfulness because 'sinful' does not express a real property of things, but simply indicates that the action broke a law. Hobbes seems to have a sophisticated version of this. To sin is to break a law or command of God. God is the cause of sin, but it is the human being that wills the action that breaks the law. One might think that he should have embraced the following position: Distinguish "the action from the sin of the action, saying, God Almighty doth indeed cause the action, whatsoever action it be, but not the sinfulness or irregularity of it, that is, the discordance between the action and the law" (EW 4: 250 and EW 5: 116, 146-7). But he does not. Rather he simply asserts: "This I know; God cannot sin, because his doing a thing makes it just, and consequently, no sin" (EW 4: 250 and EW 5: 117; cf. EW 5: 138).

Just as Calvinists had problems with their view, Arminians such as Bramhall had problems too. Let us begin with the propositions that the latter privileged:

English Arminian Propositions: ('A' in the numbering indicates Arminian)

A13. God is omnibenevolent.

A14. God is the cause of all good things. (Genesis 1; and cf. C2)

A15. Human beings are the cause of all (human) sins. (Genesis 3 and Romans $5: 12$ )

A16. Human beings sin when they break God's laws through their free will.

A17. It was possible for Adam not to sin. (cf. C6)

A18. It was not necessary for Adam to sin. (cf. C7)

Where Calvinists emphasized God's omnipotence, Arminians tended to emphasize God's goodness (cf. C1 and A13). Their source for this is twofold. One is the refrain in Genesis 1 that occurs after five of the six days of creation, "And God saw that it was good" (EW 5: 192). The account says nothing about God ever creating anything evil. The second source is pagan Greek philosophy. Plato and neo-Platonic philosophers argued that the highest being is goodness itself or all-good; and Christian philosophers at least from the third century imported this idea into Christianity. Arminian scholastic philosophers continued this tradition.

A further element of the Arminian view is that goodness and being are "convertible" in the sense that to the extent that something is good it exists, and to the extent that something exists it is good ( $E W$ 5: 192). God is the greatest being because he is the greatest good, and vice versa. These well-intentioned ideas have the unfortunate consequence that God is not the sole ultimate principle or source of all reality (cf. EW 5: 142). Something, it seems, has to account for evil. Scholastic philosophers tended to say that the cause of sin was a privation of good, an absence of a due good; that is, a kind of nonbeing. The problem with this account is that it seems to have the consequence that if human beings are punished for sinful acts, they are being punished "for nothing." But nonbeing cannot cause anything. An alternative explanation is that the cause of sin is free will. But if evil is caused only through the free will of human beings, not to mention angels, then they also are ultimate principles because their causality and not God's explains evil. Free will, as Bramhall and other Arminians understand it, is an 
uncaused cause of action, just as God is an uncaused cause. Because human beings are not determined to one course of action, their actions stem from themselves, but this just embraces the problem that introduced this discussion. God has to play some role in the causation of the sinful action. A standard explanation of this role was to distinguish between God's will and God's permission. So God can cause a good action by simply willing it; but for evil actions, God's causal contribution is merely the permission that it be done, not a desire, to speak loosely, for it to be done. Hobbes will have none of this wordplay.

Such distinctions as these dazzle my understanding; I find no difference between the will to have a thing done, and the permission to do it, when he that permitteth can hinder it, and knows that it will be done unless he hinder it. Nor find I any difference between an action and the sin of that action; ... nor when one is cause both of the action and of the law.

$(E W 4: 250)$

One of Hobbes's complaints against scholastic philosophers is that they have been corrupted by pagan philosophy (Leviathan). Free will is a case in point. In addition to the fact mentioned earlier that the Bible does not use the term 'free will,' the term is self-contradictory (EW 5: "To the Reader"). Only bodies are free or unfree; and wills are desires, not bodies. Bramhall tried to interpret any language about intentional behavior as endorsing free will; but Hobbes interpreted intentional behavior in a way that did not employ free will. Another of Hobbes's complaints is that some of their claims are unintelligible, such as "the will willeth" and "the understanding understandeth" (EW 5: 4; cf. EW 5: 63-5). Since we have already considered Hobbes's opposition to (A16) and (A18), we do not need to comment on them further.

A final comment on the Calvinist/Arminian conflict is appropriate. The debate between Hobbes and Bramhall was in fact a replay of at least two other notable debates between Calvinists and Arminians in seventeenth-century English intellectuals, one between William Twisse and Thomas Jackson, and another between William Barlee and Thomas Pierce. The arguments and the objections on each side are similar to those used by Hobbes and Bramhall (Martinich 2012a, 2012b).

The acrid Bramhall/Hobbes debate had more than its share of fallacious reasoning. Did either convince the other of anything? Hobbes wrote, "Postscript. Arguments seldom work on men of wit and learning, when they have once engaged themselves in a contrary opinion" (EW 5: 435). Bramhall replied,

Though sophistical captions do seldom work on men of wit and learning, ... solid and substantial reasons work sooner upon them than upon weaker judgments ... Let sophisters and seditious orators apply themselves to the many-headed multitude, because they despair of success with men of wit and learning ... Since the former way hath not succeeded, T. H. hath another to shew as the causes of our errors.

(EW 5: 436)

\section{Acknowledgments}

I want to thank Jo Ann Carson and Leslie Martinich for commenting on this chapter. 


\section{A. P. MARTINICH}

\section{Bibliography}

Aquinas, T. Summa Theologiae. Prima pars.

Hobbes, T. (1651/2011) Leviathan, 2nd edn, A.P. Martinich and B. Battiste (eds). Peterborough: Broadview Press.

Hobbes, T. (1839-45a) "Of Liberty and Necessity," in English Works, Vol. 4, W. Molesworth (ed.). London: J. Bohm. Cited as EW 4.

Hobbes, T. (1839-45b) "Questions Concerning Liberty, Necessity, and Chance," in English Works, Vol. 5, W. Molesworth (ed.). London: J. Bohm. Cited as EW 5.

Hobbes, T. (1976) Thomas Hobbes's De Mundo Examined, trans. H.W. Jones. London: Bradford University Press.

Jackson, N. (2007) Hobbes, Bramhall, and the Politics of Necessity. Cambridge: Cambridge University Press.

Jesseph, D. (1999) Squaring the Circle: The War between Hobbes and Wallis. Chicago: University of Chicago Press.

Martinich, A.P. (1992) The Two Gods of Leviathan. Cambridge: Cambridge University Press.

Martinich, A.P. (1999) Hobbes: A Biography. Cambridge: Cambridge University Press.

Martinich, A.P. (2012a) "On Thomas Hobbes's English Calvinism: Necessity, Omnipotence, and Goodness," Philosophical Reasons 4/1: 18-30.

Martinich, A.P. (2012b) "Epicureanism and Calvinism in Hobbes's Philosophy: Consequences of Interpretation," Philosophical Reasons 4/3: 3-15.

Tyacke, N. (1978) Anti-Calvinists. The Rise of English Arminianism, 1590-1630. Oxford: Oxford University Press.

\section{Further Reading}

Jackson, N. (2007) Hobbes, Bramhall and the Politics of Liberty and Necessity. Cambridge: Cambridge University Press. (A full discussion of the debate about free will, with attention to the political and religious implications of the matter.)

Leibniz, G.F.W. (1985) Theodicy, trans. E.M. Huggard. La Salle: Open Court. (A commentary on the Hobbes-Bramhall debate by the great German philosopher.)

Mintz, S.I. (1962) The Hunting of Leviathan. Cambridge: Cambridge University Press. (In addition to the debate with Bramhall, criticisms of Hobbes's philosophy on the related issues of his materialism and mechanism are discussed.)

Overhoff, J. (2000) Hobbes's Theory of the Will. Lanham: Rowman \& Littlefield. (A discussion of Hobbes's theory of the will plus its relationship with the views of Martin Luther, John Calvin, Marin Mersenne, and others.)

\section{Related Topics}

Classical Compatibilism

Gottfried Leibniz

Free Will and the Problem of Evil

Free Will and Theological Determinism

Free Will and Providence

Determinism 


\section{8 \\ JOHN LOCKE \\ Antonia LoLordo}

Locke's discussion of freedom began as a digression. His Essay Concerning Human Understanding (hereafter ECHU) is an attempt to determine the scope and limits of the human cognitive faculties. Providing a general theory of how we acquire our ideas is one important part of this. Another important part is Locke's attempt to explain how we acquire some particularly complicated —and philosophically interesting-ideas such as the ideas of persons, identity, and freedom. As he attempted to do this, Locke somehow found himself also trying to explain what identity, persons, and freedom are. Many of Locke's readers over the years have found these metaphysical digressions more memorable than the theory of cognition which is his official subject.

However, Locke's discussion of freedom is not a mere digression. The notion of freedom plays a very important role in his system: it is relevant not just to metaphysics and the theory of the cognitive faculties, but also to educational theory, ethics, and political theory. Locke's influential (or, for his contemporaries, notorious) predecessor, Thomas Hobbes, argued for a metaphysical view of freedom that helped to guarantee that we can be free even in the most politically oppressive state. Locke's views on the metaphysics of freedom also have important connections with the practical. For Locke, to be a free agent is ultimately to be in control of one's own actions, volitions, and desires. This conception of free agency fits in well with the liberal political theory articulated in Two Treatises of Government. And in works such as Some Thoughts Concerning Education and Of the Conduct of the Understanding, Locke explains how we should educate our children-and ourselves-to achieve rational self-control and the proper use of our free agency.

\section{What Freedom Is}

The method Locke uses to develop his account of freedom will seem familiar if you've read many twentieth- and twenty-first-century discussions of free will: he provides a series of examples that are designed to elicit our intuitions, and then develops a general account that is grounded in them. Locke's examples are couched in terms of the will and the associated notions of volition and voluntary action, so it is important to first see how he understands the will.

Will, for Locke, is a power, one that can be used in various ways:

[The] Power which the mind has ... to order the consideration of any Idea, or the forbearing to consider it; or to prefer the motion of any part of the body to 
its rest, and vice versa in any particular instance, is that which we call the Will. The actual exercise of that power, by directing any particular action, or its forbearance is that which we call Volition or Willing. The forbearance or performance of that action, consequent to such order or command of the mind is called Voluntary.

(ECHU 2.21.5)

A volition is an exercise of will —an order to move your arm or think about an elephant. Actions that result from volitions are voluntary; actions that don't, aren't.

Locke's first example, the tennis ball, is designed to show that only beings with will can be free:

A Tennis-ball, whether in motion by the stroke of a Racket, or lying still at rest, is not by any one taken to be a free Agent. If we enquire into the Reason, we shall find it is, because we conceive not a Tennis-ball to think, and consequently not to have any Volition, or preference of Motion to rest, or vice versa; and therefore has not Liberty, is not a free Agent.

(ECHU 2.21.9)

This example may strike you as bizarre. Why would Locke even bother trying to convince his readers that tennis balls aren't free? Doesn't this go without saying?

One explanation is that Locke has in mind Hobbes' view that "freedom, signifieth properly the absence of ... external impediments of motion" (Hobbes, Leviathan 21). Thus for Hobbes, tennis balls can fly over nets freely, rivers can flow downstream freely-and human beings can act freely even in an authoritarian state.

A second example, the falling man, is closely related:

[A] Man falling into the Water, (a Bridge breaking under him,) has not herein liberty, is not a free Agent. For though he has Volition, though he prefers his not falling to falling; yet the forbearance of that Motion not being in his Power, the Stop or Cessation of that Motion follows not upon his Volition; and therefore therein he is not free.

(ECHU 2.21.9)

This is different from the tennis ball case because the falling man does have a will. However, his action is not the result of his will: he's not falling voluntarily. So only beings with a will can act freely, and they can only do so when they are acting voluntarily.

A third example, the man in the locked room, is designed to show that not all voluntary actions are free, and to help us figure out what else is needed:

[S]uppose a Man be carried, whilst fast asleep, into a Room, where is a Person he longs to see and speak with; and be there locked fast in, beyond his Power to get out: he awakes, and is glad to find himself in so desirable Company, which he stays willingly in, i.e. prefers his stay to going away. I ask, Is not this stay voluntary? I think, no Body will doubt it: and yet being locked fast in, 'tis evident he is not at liberty not to stay, he has not freedom to be gone. So that Liberty is not an Idea belonging to Volition ... but to the 
Person having the Power of doing, or forbearing to do, according as the Mind shall chuse or direct.

(ECHU 2.21.10)

The man in the locked room has the power to stay in the room if he wills to stay. But he lacks the power to leave if he wills to leave. This, Locke concludes, is why he does not stay in the room freely, even though he stays there voluntarily.

Locke thus defines liberty as "a power to begin or forbear, continue or put an end to several actions" (ECHU 2.21.7) and gives the following necessary and sufficient conditions for freedom in respect to a particular action:

So far as a man has a power to think, or not to think; to move, or not to move, according to the preference or direction of his own mind, so far is a man free. Wherever any performance or forbearance are not equally in a man's power... there he is not free, though perhaps the action may be voluntary.

(ECHU 2.21.8)

The term "preference" here needs clarification. I can prefer coffee to tea without directing myself to drink coffee, so Locke's reference to "the preference or direction of [the] mind" seems odd. However, Locke himself admits that the term is misleading - "though a Man would prefer flying to walking, yet who can say he ever wills it?" (ECHU 2.21.15). Thus, he warns the reader:

Ordering, Directing, Chusing, Preferring, etc. which I have made use of, will not distinctly enough express Volition, unless he will reflect on what he himself does, when he wills.

(ECHU 2.21.15)

The choice of terminology, then, is ultimately unimportant. We each experience our own will and its exercise. It is this experience, not the details of Locke's definition, which is supposed to make us understand what will and volition are.

\section{Freedom and Determinism}

Philosophers in the twentieth and twenty-first centuries talk about the problem of free will; philosophers in the seventeenth and eighteenth centuries talked about the problem of liberty and necessity. The term 'necessity' has many different uses, but in this context, to say that an action is necessary is to say that it is necessitated by the state of the world up until the moment the action occurs. In other words, in this context, to say that an action is necessary is to say that it is causally determined. Thus, the problem of liberty and necessity is the problem of whether freedom and determinism are compatible.

Almost all early modern philosophers agreed that we are free. They almost always thought, like Locke, that moral responsibility requires freedom. And almost all early modern philosophers also sympathized with Locke's claim that we "cannot have a clearer perception of any thing than that [we are] free" (Correspondence 4: \#1592). Just as we all know by experience that we will, we all know by experience that we are free. 
Hobbes and, later, David Hume, argued that freedom is compatible with complete causal determinism: we are free, even though everything we do-and everything we will-is determined. Many other philosophers disagreed, and saw in the determinism of Hobbes and Hume a threat to morality, religion, and even the stability of the state. They argued instead that human actions can be free only if they are not causally determined.

In this respect, Locke understands things differently from his contemporaries. He agrees that liberty and necessity are incompatible, but for him, this is not a substantive philosophical position. Rather, for Locke it is trivial that liberty and necessity are incompatible, because the idea of necessity just is the idea of the absence of liberty:

Whence the ideas of liberty and necessity. Every one, I think, finds in himself a power to begin or forbear, continue or put an end to several actions in himself. From the consideration of the extent of this power of the mind over the actions of the man, which everyone finds in himself, arise the ideas of liberty and necessity ... the Idea of Liberty, is the Idea of a Power in any Agent to do or forbear any particular Action, according to the determination of the mind ... where either of them is not in the Power of the Agent to be produced ... there he is not at Liberty, that Agent is under Necessity.

(ECHU 2.21.7-8)

And in the section entitled "Necessity, what," Locke says that "wherever thought is wholly wanting, or the power to act or forbear according to the direction of thought, there necessity takes place" (ECHU 2.21.13). So for Locke, the incompatibility of freedom and necessity is not the incompatibility of freedom and causal determinism.

In fact, Locke is often - perhaps almost always-thought of as a compatibilist about freedom and causal determinism. This is reasonable. The conditions on freedom of action we've just looked at make no reference to any element of indeterminism. All they require, for an agent to count as free with respect to a certain action, is that she can perform that action if she wills to perform it, and forbear performing that action if she wills to forbear performing it. There's no need to actually be able to will otherwise.

But unlike most early modern compatibilists, Locke does not argue that our actions are fully determined by antecedent causes. In fact, so far as I know he does not address the issue of universal determinism anywhere in his works. (He uses the term 'determine' frequently_ as when he remarks that a choice may "be determined . . by the darkness of the Night, or the illness of the Weather" (ECHU 2.21.33)—but what determines something in this sense is not what causes it). Locke's eighteenth-century readers thought that he remained completely silent on the issue of determinism, and they found this silence strange and frustrating (Harris 2005: 20-1). I have argued elsewhere that Locke's neutrality is deliberate. The account of freedom he puts forward is designed to work whether or not our actions are causally determined-just as Locke's account of personal identity is designed to work whether or not thought requires an immaterial substance in addition to the body (LoLordo 2012: 34-5).

\section{Freedom of Action vs. Freedom of Will}

This book is the Routledge Companion to Free Will, and this chapter is about Locke, but it's not about Locke on free will. For Locke thinks there is no such thing as free will. 
Indeed, he thinks that talk of free will is simply unintelligible. Will is the power to direct yourself towards some particular action. Liberty is the power to do (or not do) what you will to do (or will to not do). Will and liberty, in other words, are powers. And to say that one power has another power is to make a basic category mistake:

I leave it to be considered, whether [my definitions of will and liberty] may not help to put an end to that long agitated, and, I think, unreasonable, because unintelligible, question, viz. whether man's will be free, or no. For if I mistake not, it follows, from what I have said, that the question itself is altogether improper; and it is as insignificant to ask, whether man's will be free, as to ask, whether his sleep be swift, or his virtue square: liberty being as little applicable to the will, as swiftness of motion is to sleep, or squareness to virtue ... Liberty, which is but a power, belongs only to agents, and cannot be an attribute or modification of the will, which is also but a power.

(ECHU 2.21.14)

By the time Locke wrote this, philosophers had been debating the nature of free will for centuries. How does he think they could have missed the relatively obvious point that the will is not even the right sort of thing to be free?

Ultimately, Locke answers that debates about free will do touch on a genuine philosophical issue-but they are confused about what that issue is. We'll look at what Locke identifies as the real issue underlying confused debates about free will in a moment. But first, a short detour.

\section{Weakness of Will and Locke's Revisions}

The account of freedom we've been discussing so far is articulated in the first few sections of Locke's very long chapter on freedom. But after this, he goes on for many more pages about human psychology and motivation, before returning to the issue of freedom and bringing the chapter to a close. This fact requires some explanation.

One explanation is that this is just how Locke writes. The Essay as a whole is long$700+$ pages in the standard edition — and meandering. Locke says in the prefatory Epistle to the Reader that he was "too lazy, or too busy, to make it shorter." Both this self-effacing remark and the tentative, digressive nature of the book are typical features of the eighteenth-century genre called the essay.

But there's another, more interesting explanation as well. Locke's account of freedom is long and meandering because he made drastic revisions after the first publication of the Essay, and when he added new material, he did not always take the old material out.

When Locke was preparing the second edition of the Essay for the press, he wrote to his friend William Molyneux, asking for suggestions. Molyneux replied that he had some concerns about Locke's discussion of freedom:

This Thread seems so wonderfully fine spun ... that at last the Great Question of Liberty and Necessity seems to Vanish, and herein you seem to make all Sins proceed from our Understandings, or to be against Conscience; and not at all from the Depravity of our Wills. Now it seems harsh to say, that a Man shall be Damn'd, because he understands no better than he does.

(Correspondence 4: \#1579) 
In the first edition of the Essay, Locke says that we always will what appears best. He means that we always will to perform the action which we believe will have the best long-term consequences for us. But this doesn't mean that Locke thinks moral considerations can never motivate us. He holds that God will reward virtue and punish vice in the afterlife, thereby ensuring that we always have a compelling reason to do what morality demands. He also holds that God's plans for us are easily knowable and widely known. Thus, for most people, most of the time, doing what you believe is right is doing what you believe will have the best long-term consequences for you.

Molyneux objects that Locke's first edition view is incompatible with moral responsibility. It implies that whenever we fail to do the right thing, it is only because we were mistaken about what the right thing to do was. But, Molyneux objects, we don't normally think that people should be punished for having false beliefs. For one thing, our beliefs are not under our direct control in the way our actions are. We cannot simply will to have true beliefs about what morality demands.

Molyneux might also have objected that the view Locke articulates in the first edition of the Essay is empirically inadequate. Even in cases where the actions under consideration are morally indifferent, we do not always do what we believe to be best. We've all hit the snooze bar when we knew it was in our long-term interests to get up, or had another brownie or another glass of wine when we knew we'd regret it in the morning. This is the phenomenon called weakness of will.

Locke apparently found Molyneux's objection convincing. At any rate, soon after receiving the letter, Locke started revising his account of liberty, and in the second edition, he gave an entirely different explanation of why we will as we do.

An easy way to see how this explanation works is through the example of the habitual drunk:

[L]et a Drunkard see, that his Health decays, his Estate wastes; discredit and diseases, and the want of all things, even of his beloved drink, attends him in the course he follows: yet the returns of uneasiness to miss his companions; the habitual thirst after his Cups, at the usual time, drives him to the Tavern, though he has in his view the loss of health and plenty, and perhaps of the joys of another life: the least of which is no inconsiderable good, but such as he confesses, is far greater, than the tickling of his palate with a glass of Wine, or the idle chat of a soaking club.

(ECHU 2.21.35)

Locke's drunkard knows that he will ultimately regret his debauchery: the pleasure of an evening at the pub is far outweighed by the pain of ill health, poverty, and punishment in the afterlife. But he still has the desire — what Locke calls the "uneasiness"- to drink. The fact that the drunkard believes the best course of action is to stop drinking, and nevertheless continues to drink, shows that we do not always will what appears best.

Thus, from the second edition on, Locke argues that we will in accordance with our desires rather than the greatest apparent good. This amended view does a much better job of explaining weakness of will than the previous one. For it gives Locke a simple explanation of weakness of will: it occurs because sometimes our desires fail to match up with our beliefs about what's in our long-term best interest.

Molyneux worried that if our volitions follow our beliefs, then we are liable to punishment for something that is not under our control, or at least not under our 
direct control. We are mere pawns of our beliefs. In reply, Locke made our volitions flow from our desires instead of our beliefs. Now, Locke grants that our desires are not under our direct control. But he does not think we are mere pawns of our desires. Rather, he holds that we can gain indirect control over our desires if we use our God-given faculties correctly.

\section{Suspension}

I said earlier that although Locke thinks talk of free will is confused, he also thinks there's some genuine philosophical issue lurking in the neighborhood. We can now see what that issue is. For us to be genuine free agents, our actions—and hence our volitions and the desires they flow from-must be under rational control.

To guarantee that we have such control over our desires, Locke introduced another new element in the second edition: the power to suspend the prosecution of an immediately pressing desire while you deliberate about the best course of action. He holds that this power is crucially important. He says that it is "the hinge on which turns the liberty of intellectual beings" (ECHU 2.21.52). And he says that it:

[M]ay be well consider'd, whether the great inlet and exercise of all the liberty Men have, are capable of, or that can be useful to them, and that whereupon depends the turn of their actions, does not lie in this, that they can suspend their desires, and stop them from determining their wills to any action, till they have duly and fairly examin'd the good and evil of it, as far forth as the weight of the thing requires.

(ECHU 2.21.52)

And he says that:

[T] he mind having in most cases, as is evident in Experience, a power to suspend the execution and satisfaction of any of its desires; and so all, one after another, is at liberty to consider the objects of them; examine them on all sides, and weigh them with others. In this lies the liberty Man has; and from the not using of it right comes all that variety of mistakes, errors, and faults which we run into in the conduct of our lives, and our endeavours after happiness; whilst we precipitate the determination of our wills, and engage too soon, before due Examination. To prevent this, we have a power to suspend the prosecution of this or that desire; as every one daily may Experiment in himself. This seems to me the source of all liberty; in this seems to consist that which is (as I think improperly) call'd Free-Will.

(ECHU 2.21.47)

Notice that just as Locke claimed we all know by experience that we have the powers of will and liberty, he also claims that we all know by experience that we have the power to suspend and deliberate.

This power is important because it allows us to avoid being mere hostages of our desires, and instead to gain rational control of ourselves and our actions. Deliberation is the exercise of the human capacity to reason, and one of the central themes of the Essay is that although "the Comprehension of our Understandings, comes exceeding short of 
the vast Extent of Things" (ECHU 1.1.5), it is nevertheless sufficient to allow us to figure out how to act:

If we can find out those Measures, whereby a rational Creature put in that State, which Man is in, in this World, may, and ought to govern his Opinions, and Actions depending thereupon, we need not be troubled, that some other things escape our Knowledge.

(ECHU 1.1.6)

Deliberation helps us make our beliefs about what's best, more accurate. If I suspend the prosecution of my desire to hit the snooze bar and go back to sleep, I will be able to see that the short-term pleasure of sleeping in is outweighed by the longer-term pain of sleeping through an important meeting.

But deliberation also plays another role- one which is at least as important as the first, but much easier to miss. When we deliberate, we not only gain more accurate beliefs about what's best, we also improve the fit between our beliefs and desires. Locke makes this clear when he describes the result of "due consideration" of an absent good (ECHU 2.21.53):

[A]bsent good, though thought on, confessed, and appearing to be good, not making any part of this unhappiness in its absence, is justled out, to make way for the removal of those uneasinesses we feel; till due and repeated contemplation has brought it nearer to our mind, given some relish of it, and raised in us some desire: which then beginning to make a part of our present uneasiness, stands upon fair terms with the rest to be satisfied.

(ECHU 2.21.46)

Locke explained that there are two different mechanisms by which suspending and deliberating can bring about a change in our desires. One is that just paying attention to an absent good and trying to imagine it as vividly as possible can make us desire it. The second is that a process of habituation can bring us to desire something we previously believed to be good but felt no desire for:

Men may and should correct their palates, and give relish to what either has, or they suppose has none. The relish of the mind is as various as that of the body, and like that too may be altered ... A due consideration will do it in some cases; and practice, application, and custom in most. Bread or tobacco may be neglected where they are shown to be useful to health, because of an indifferency or disrelish to them; reason and consideration at first recommends, and begins their trial, and use finds, or custom makes them pleasant.

(ECHU 2.21.71)

The form of control over our desires which these mechanisms provide is not immediate. Nevertheless, it is a genuine form of control. And Locke insists that we should exercise this form of control over our desires:

[T]he just values of things are misplaced, and the palates of Men corrupted. Pains should be taken to rectify these; and contrary habits change our 
pleasures, and give a relish to that which is necessary or conducive to our Happiness.

(ECHU 2.21.69)

We should exercise control over our desires because we should do what is in our longterm best interest, and it is only by controlling our natural desires that we can be motivated to do so.

\section{Conclusion}

A number of Locke's predecessors held that the will must be able to act as an uncaused cause in order for human actions to be truly free, and truly their own. Locke, as we've seen, thinks the very notion of freedom of the will is unintelligible. But he sympathizes with his predecessors' hope that we can gain control over our desires. And he provides a way of gaining such control-by exercising the power to suspend the prosecution of our most pressing desires while we deliberate about what's best. When we exercise this power, our actions are not simply the products of whatever desire happens to be most pressing at the moment. Rather, they are the products of reason. And reason is at the core of the self, on Locke's view. After all, he defines a person as "a thinking intelligent being, that has reason and reflection, and can consider itself as itself, the same thinking thing, in different times and places" (ECHU 2.27.9).

We've seen that there are important changes between the first and second editions of the Essay. But in both editions, Locke offers the same definition of liberty: it is the power to act (or forbear acting) if you will to act (or will to forbear).

This definition doesn't explicitly invoke the power to suspend. However, Locke has been read as saying that we only act freely when our volitions follow a process of suspension and deliberation (Stuart 2013: 476). (Stuart rightly points out that suspending and deliberating is something that can occur extremely quickly; one needn't sit down and make a list of pros and cons to count as deliberating about what to do). This seems to imply that we are not morally responsible for actions done in haste or as the result of strong emotion - an implication that I think would be unacceptable to Locke.

What then is the relationship between liberty and the power to suspend and deliberate? The answer I favor is that possessing the power to suspend and deliberate is a global condition on free agency (cf. Yaffe 2000: 4, 5). For Locke, freedom-like personhoodis "a forensic term" (ECHU 2.27.26). And only beings who can suspend the prosecution of their desires and deliberate about what's best can be held morally responsible for their actions. Thus, only beings with the power to suspend and deliberate are free agents.

Locke says nothing about what brings about suspension. And it's not clear what he should, or could, say about this. If suspending and deliberating is an action (or forbearance) like any other, then, it seems, Locke must say that we suspend and deliberate just in case our strongest desire is to suspend and deliberate. But this doesn't fit everyday experience very well. When I stop to think before pouring myself another glass of wine, it's not because my desire to deliberate outweighs my greed. Moreover, if we can only suspend and deliberate in cases where our strongest desire is to suspend and deliberate, then it's unclear why the power to suspend is as important as Locke thinks it is. It's precisely when an irrational desire threatens to overwhelm everything else that we most need to exercise our power to suspend and deliberate. 
It's been suggested that the power to suspend and deliberate introduces an agent causal element into Locke's account of freedom (Lowe 2004; Schouls 1992; Bolton 2008). But although this suggestion may be appealing, there is not a great deal of textual evidence for it. Thus, we might be better off simply admitting that Locke never explains what brings about suspension. For when Locke talks about suspension, he is not giving a theory (Stuart 2013: 460): he is just pointing out something "evident in Experience" (ECHU 2.21.47). This might not satisfy all Locke's readers. But it is entirely in keeping with the Essay's overarching goal of showing that our understanding is far better suited to practical considerations than to metaphysics.

\section{References}

Bolton, M. (2008) "Locke and Leibniz on the Structure of Substances and Powers," in S. Hutton and P. Schuurman (eds), Studies on Locke. Dordrecht: Springer, pp. 107-26.

Harris, J. (2005) Of Liberty and Necessity. Oxford: Oxford University Press.

Hobbes, T. (1996) Leviathan, R. Tuck (ed.). Cambridge: Cambridge University Press.

Locke, J. (1976/1989) Correspondence, 8 volumes, E.S. de Beer (ed.). Oxford: Clarendon Press.

Locke, J. (1979) Essay Concerning Human Understanding, P.H. Nidditch (ed.). Oxford: Clarendon Press.

LoLordo, A. (2012) Locke's Moral Man. Oxford: Oxford University Press.

Lowe, E.J. (2004) "Locke: Compatibilist Event-Causalist or Libertarian Substance-Causalist?" Philosophy and Phenomenological Research 48: 688-701.

Schouls, P. (1992) Reasoned Freedom. Ithaca: Cornell University Press.

Stuart, M. (2013) Locke's Metaphysics. Oxford: Oxford University Press.

Yaffe, G. (2000) Liberty Worth the Name: Locke on Free Agency. Princeton: Princeton University Press.

\section{Further Reading}

Harris, J. (2005) Of Liberty and Necessity. Oxford: Oxford University Press. (An excellent overview of the early modern debate and its differences from twenty-first-century debates.)

LoLordo, A. (2012) Locke's Moral Man. Oxford: Oxford University Press. (An account of Locke's views on freedom that shows they are part of a comprehensive picture of moral agency.)

Lowe, E.J. (2004) "Locke: Compatibilist Event-Causalist or Libertarian Substance-Causalist?" Philosophy and Phenomenological Research 48: 688-701. (A short argument in favor of reading Locke as a libertarian.)

Stuart, M. (2013) Locke's Metaphysics. Oxford: Oxford University Press. (An excellent overview of Locke's metaphysics, with two long chapters on liberty.)

Yaffe, G. (2000) Liberty Worth the Name: Locke on Free Agency. Princeton: Princeton University Press. (A short and engaging account of why Lockean liberty matters.)

\section{Related Topics}

Classical Compatibilism

René Descartes

Gottfried Leibniz

Thomas Hobbes and John Bramhall

David Hume 


\section{9 \\ DAVID HUME \\ John Bricke}

The Scottish philosopher, David Hume (1711-1776), is, along with John Locke and George Berkeley, one of the classic British empiricists. He is committed to a fundamental distinction between what he terms relations of ideas and matters of fact, and, in particular, to a fundamental distinction between mathematics and the empirical sciences. As an empiricist, he is also committed to an experiential basis both for all empirical concepts, including all mental ones, and for the truth or falsity of any given empirical, including any given psychological, claim. Accordingly, he takes the concepts involved in the explanation of human actions - the concepts of belief, desire, emotion, volition, and will — to be empirical ones.

To be sure, Hume is a skeptic. But he is also, and crucially, a naturalist in his approach to human nature and the human mind. That is to say, he is concerned to understand human agents in causal terms, to provide causal characterizations of human cognitive, affective, and conative activities and responses. The three books of his A Treatise of Human Nature are devoted, respectively, to what he terms the understanding, the passions (including the will), and morals. Later works in the same naturalistic vein include An Essay Concerning Human Understanding, A Dissertation on the Passions, and An Enquiry Concerning the Principles of Morals. Of course, Hume is perhaps most widely known for his so-called regularity theory of causation, the theory that causality is a matter of constant conjunctions of states or events. For Hume, causes are sufficient conditions for their effects, conditions the presence of which necessitate the occurrence or obtaining of their effects. To be more precise, Hume distinguishes two dimensions, as we might say, of causation: the regular temporally ordered co-occurrence of causes and their effects; and the inferences human observers make from the presence of events of a given type (the causal events) to the expectation of events of the other type (the cause's effects). It is the latter that, in Hume's view, finds expression as the necessitation of its effects by a cause: "the necessity or power, which unites causes and effects, lies in the determination of the mind to pass from the one to the other" (Treatise 1.3.14).

How does Hume construe persons, that is, human beings, and how, in particular, does he construe human agents? Of course, persons or human beings are bodily organisms with minds. For Hume, more precisely, they are embodied bundles of perceptions. As bodily organisms they have brains, limbs, and a variety of sensory capacities. As minds, they are, reductively, bundles of perceptions, which is to say temporally extended collections of sensory experiences (visual, olfactory, and the like), thoughts (including beliefs), emotions, desires, and so-called volitions or acts of the will. In Hume's own 
words in the Treatise: a self or mind is "nothing but a bundle or collection of different perceptions, which succeed each other with an inconceivable rapidity, and are in a perpetual flux and motion" (Treatise 1.4.6). For Hume, there is no self or subject-no mind-behind or supporting the bundle of perceptions: there are no believers or agents behind - which is to say, not reducible to- the bundles of perceptions, bundles comprising the thoughts, passions, desires, and volitions that individual human beings have. In particular, there is no will, no non-reducible willing agent, behind the volitions, and thus, the intentional actions that human agents perform. Humean agents are, notwithstanding Hume's remarkable skeptical ruminations about our knowledge of the physical world, embodied bundles of perceptions. If Hume is right, we are such agents.

What makes Humean agents agents? Are Humean agents free agents? Hume's most extensive consideration of this question comprises two sections of the Treatise on the topic "Of liberty and necessity." He returns to the topic in Section 8 of his later Enquiry Concerning Human Understanding, in a section also entitled "Of liberty and necessity." In each case he undertakes to subvert a purported "liberty of indifference ... which means a negation of necessity and causes." We may focus narrowly on the question of the intentional actions that a human agent performs, bodily actions such as raising one's hand in order to cast a vote, and mental actions such as deliberating about the merits of the several candidates. Hume characterizes intentional actions in terms of the causal intersection of cognitive and conative states (beliefs and desires) with what he terms volitions or acts of the will. For Hume, an agent's actions are the causal products of his motives-his conative states or desires and his relevant beliefs. An agent wants to attract her friend's attention and believes that she can do so by waving her hand. She is thereby caused to form a volition to wave her hand, and thus to wave her hand.

That is a bare bones sketch of Hume's causal theory of intentional action. Intentional actions, whether bodily or merely mental, implicate the agent's desires, beliefs, and volitions (or acts of will). And specific such mental states and events, at a given time, constitute the causal conditions that give rise to the agent's action. Suppose that an agent raises her hand to vote or that, in her head, she makes plans for a picnic. In the envisaged circumstances, the agent's linked desires and beliefs are causally sufficient conditions for the agent's forming a volition to raise her hand (or to plan a picnic), and so necessitate her raising her hand (or planning a picnic). Such actions, whether bodily or 'merely mental' are, for Hume, voluntary actions.

Of course, some of an agent's actions are characteristic of the agent and may be said to derive from (or to causally implicate) the agent's character. For Hume, talk of an agent's character is talk of the agent's dispositions to act in certain ways in certain circumstances. Tom is a timorous person. He is disposed to act very cautiously in even the least threatening situations. Mary is a braggart. She is likely to toot her own horn when opportunity provides. Such characteristics of individuals are (though the term is not Hume's) dispositional properties of the individuals in question: they are disposed to act or respond in certain ways in certain sorts of perceived or envisaged situations. Their characteristics are causal characteristics of the individuals who have them.

The central present question concerns Hume's views (and his reasons for those views) on causation and human actions, whether bodily or merely mental. Is an agent's will free in at least some instances of the things the agent does? Do human agents have what may be called free will? Hume introduces two distinct conceptions of free will. On the first conception, a condition on an agent's will being free is that (some at least) of an agent's voluntary actions are not causally necessitated by the 
agent's character and circumstances. In particular, those voluntary actions are not necessitated by the agent's beliefs, desires, and other relevant psychological states. We may call this causal indifferentism. On the other conception, an agent is free to act in a certain way, or is free in acting in that way, provided the agent is not coerced to act in that way. Clarity about Hume's views on free will turns essentially on consideration of both lines of thought.

Before addressing the question of Hume's account of human action, however, it will be helpful to consider, briefly, his views about human cognitive activities (involving perception, thought, belief, and inference) and about human affective states or emotions. Hume's account is a naturalistic, causal account in both cases. He takes human perceptual experiences to be effects of interactions between an individual and his or her physical environment. Not concerned with the characterization of those interactions, however, he makes do with passing reference to the senses and to consequent activities of the "animal spirits" in the brain. He devotes Book I of the Treatise, "Of the Understanding," to explaining an agent's acquisition of concepts from perceptual and other such experience and the agent's subsequent deployment of such concepts in the agent's thoughts and beliefs about the way things are, in particular the agent's causal thoughts and causal inferences. Remarkably, he provides a causal account-specifically, a so-called associationist explanation-of causal inference.

Hume devotes the first two parts of Book II of the Treatise to a causal accountagain, an associationist account - of the person-directed passions of pride and humility (shame), love, and hatred. A person's being proud of herself because of some action she has done is to be understood in causal, specifically associationist, terms along the following lines. The person believes, say, that she has acted in a certain way in a difficult situation and she has a positive evaluative attitude towards her having acted in that way. She has, that is to say, a certain belief as well as a certain evaluative, specifically affective, attitude towards having acted in that way. That said, she has a consequent positive evaluative attitude, specifically an affective one, towards herself as the author of that action. She is, that is to say, proud of herself for having acted in that way. Had she a negative evaluative attitude towards having acted in a certain way, she would feel disappointed in herself-perhaps ashamed of herself-for having acted in that way.

According to Hume, the structural characteristics of evaluative attitudes towards others in light of their actions or other characteristics parallel those for pride and humility (which is to say, shame). Hume's generic terms for the relevant attitudes towards others are "love" and "hatred." Thinking of these as generic terms, we may construe instances of love, and by contrast hatred, to include liking or disliking others, approving or disapproving of them and their conduct, finding them commendable or finding them objectionable. Páll S. Árdal's book Passion and Value in Hume's Treatise is a full-dress interpretive and critical study of Hume's thinking on the self-directed and otherdirected passions prompted by the characteristics and actions of other persons and of one's self (Árdal 1966).

It is in the third part of Book Two of his Treatise ("Of the will and direct passions") that Hume provides a causal account of passions other than the above person-directed, affective ones. These are conative rather than affective passions. They are desires or aversions rather than affective responses to oneself or others. They are passions that lead, via volitions or acts of will (or intendings), to actions. In short, they are desires or aversions, if at times including person-directed ones. 
The other-directed passion of hatred prompts actions designed to injure the person hated. That of love prompts actions designed to assist, to please, to encourage another person. Such person-directed affective passions to the side, an agent's conative passions (desire and aversion) are directed towards the performance, via acts of the will or volitions, of actions designed to secure an agent's objectives or concerns and perhaps to forward (or impede) those of others. Wanting to enter his house, an agent withdraws the keys from his pocket and unlocks the door. Wanting to bake a pie, he assembles the makings of the pie, turns on the oven, and inserts what he has assembled in the pie pan. Wanting to please the person he loves, he tidies the house. Wanting to injure the person he hates, he maligns him to others over lunch.

Cognitive, conative, and affective events and states are essential elements in the mental lives of those bundles of perceptions that constitute the minds of embodied persons. Understanding and explaining an agent's activities, including her actions, is a matter of interpretation of her cognitive, conative, and affective states and events, in crucial part by the identification of their causes. Hume's is a thoroughly causal-in effect, a deterministic - account of all things human, including all human practices, and all human actions.

Hume's account of human action is an explicitly causal one. Human actions, in the standard case, are the causal product of an agent's desires, beliefs, and volitions. There are, in Hume's world, no uncaused instances of mental states, no intentional actions that are not the causal products of the beliefs and desires that cause them. Hume's is a strictly deterministic picture of human actions. If 'freedom' or 'liberty' entails the absence of causation, Hume's human agents have neither freedom nor liberty.

There is, however, another sense of the terms 'freedom' or 'liberty' (terms which Hume uses more or less interchangeably). Hume's explicit expression for this is "liberty of spontaneity." Taken generally, liberty of spontaneity is simply the ability to implement one's intentions or volitions, the possibility of one's volitions being causally effective. Such liberty is negated by what Hume terms "coercion;" at least that is the sort of limitation on liberty of spontaneity that he focuses on. But he surely would, even if he does not explicitly, endorse limitations that an agent's physical environment imposes. An easy example is Hume's often mentioned case of the prisoner, his jail, and his jailor. The prisoner, assumed to have neither influence nor money, can do no better than attempt to dig his way out. The convicted murderer is as certain that he will soon die because of the actions of his guards as because of the working of the gallows.

To be sure, Hume is committed to a vast variety of springs and principles that bear on the occurrence of human actions. He explicitly cites differences in the ages of agents, their sex, their childhood training, their intellectual abilities, their education, their social and political setting, their historical situation, and so on. The full set of conditions that bear on a given human agent's actions at a given time and place are presumably unspecifiable. Hume, the historian and would-be social and psychological scientist, has no illusions about that. But he does insist we know a good deal about the origins of human actions, including the origins of human beliefs and desires. And we know a good deal both about our own actions and about those of some others, and thus see them as, in brief, the causal products of the motives— the beliefs and desires— that a given agent has at a given time and in given circumstances. A product, if an unusual one, of his own time and place, Hume thinks of human beings-albeit bundles of 
perceptions on the mental side_-as causally embedded in their physical, political, and historical environments.

It is time to look more closely at some specific arguments Hume advances with respect to some of the issues adumbrated above. Let us look first at sections 2.3.1-2 of the Treatise ("Of liberty and necessity"). What does Hume actually say on the central issues addressed above? He purports to prove that "our actions have a constant union with our motives, tempers, and circumstances" (Treatise 2.3.1.4). Writing of "the common course of human affairs," he says that there is "no light in which we can take them"- whether in terms of sex, age, governments, social conditions, or methods of education - in which we do not find a "uniformity and regular operation of natural principle" (Treatise 2.3.1.5). "Are the changes of our body from infancy to old age more regular than those of our mind and conduct?" (Treatise 2.3.1.7). Treatise 2.3 ("Of the will and direct passions"), Sections 1 and 2 ("Of liberty and necessity"), make plain Hume's commitment to the causal necessitation of human actions in terms of the desires, beliefs, and circumstances (both social and physical) in which human agents form their volitions to act.

For Hume, the concept of causation is a concept of causal necessitation. That concept is the product of two linked things, "constant union and the inference of the mind" (Treatise 2.3.1.4). According to this conception, events or states of one type, type A, are regularly followed by events or states of another type, type B. Understood in terms of an inference of the mind, an event of the first type A is cause of an event of type B if and only if an impression of an event of the first type would determine someone, suitably conditioned, to form an expectation of an event of the second type. Causes are sufficient conditions for their effects, and awareness of a cause is sufficient, given appropriate experience or conditioning, for forming an expectation of its effect. Thus construed, causes necessitate their effects. Given suitable restrictions and caveats, Hume would take an event's cause to have been a necessary as well as a sufficient condition for that event's occurrence.

Hume is a causal determinist. Every state or event has another state or event as its cause: the occurrence of any event is governed by (strict) causal law. (This is not to say that the envisaged causal laws need be currently available.) This is a principle to which Hume found natural scientists of his period committed so far as the physical world, at least, was concerned. Hume's striking move is to suggest that a like principle applies in the case of human motivation, belief, and action. The "operations of external bodies are necessary [=necessitated], and . . . in the communication of their motion, in their attraction, and mutual cohesion, there are not the least traces of indifference or liberty" (Treatise 2.3.1.3). Hume offers the collision of billiard balls in illustration, and alludes to other illustrations to be found in botany, chemistry, biology, and meteorology. And he contends that the situation is essentially the same when one turns from the "actions of matter" to "actions of the mind." He commits himself to the project of a "science of man" (roughly, psychology, including social psychology), and so to the discovery of laws governing mental operations generally, and mental and bodily actions in particular. His associationist laws governing ideas, in Book 1 of the Treatise, and the so-called indirect passions (pride and humility [i.e., shame], love and hatred) in Book 2, are offered as contributions to that project. So, too, are the accounts of the moral sentiments, of the origin and exercise of the virtues and vices, and of the origin and exercise of complex social and political practices and arrangements that he provides in Book 3. In the sections of both the Treatise and the first Enquiry explicitly 
devoted to the question of liberty and necessity, however, he focuses particularly on the causation of "volitions" or "acts of the will." In drawing attention to regularities in human behavior, he, in effect, intimates candidate laws governing the occurrence of volitions, or, more broadly, of voluntary actions. In thus displaying parallels between the explanatory and evidentiary situations of the physical and the (nascent) behavioral ones, he calls into question the commonly made assumption of indeterminismthat of the absence of causal necessitation in the case of human action. He advances "the doctrine of necessity" - the principle of causal determinism-for "actions of the mind." Book I of the Treatise offered such laws governing human cognitive activity. Book II offers laws governing human emotions, volitions, and actions. Book III provides a naturalistic causal account of the moral sentiments. In the presently central case of "volitions and actions," Hume argues, just as in the central physical case of "figure and motion," one discovers the union and inference that, for Hume, constitute causal necessitation.

According to Hume, "[h]uman nature ... is composed of two principal parts, which are requisite in all its actions, the affections [here, desires and aversions] and understanding" (Treatise 3.2.2.14). Having a desire, an agent is in a goal-setting or practical state: in having a desire, he has a "designed end or purpose," is not "indifferent" to some or other actual or possible aspect of his situation, has a "propensity towards" or an "aversion" against some or other ways of behaving. In having a belief, an agent is in a purportedly informational state: she represents, or purports to represent, the way things are (including the ways that bear on her actions). The belief and desire that jointly constitute a reason for action must, of course, be suitably related: the belief must present information pertinent to the goal set by desire. Specifically, the belief must represent the bearing of possible actions, or the action to be explained, on the securing of what the agent desires. In Hume's example, the agent desires to keep his health and believes that exercising will contribute to his doing so: he has, then, a reason for exercising. (He may, of course, have countervailing reasons for not doing so). If the reason thus constituted by his desire and belief causes the agent to exercise, it is the reason from which he acts and may be invoked to explain his doing so. The desire constitutes, we may say, the motivational element in the reason for action-in short, the motive.

Hume typically renders desires as phenomenologically distinctive items in consciousness, as passions or so-called "impressions of reflection" that provide the sort of impetus to action indicated above. At times, and more plausibly, he represents them as enduring states of agents, perhaps as dispositions to have impressions of reflection of the kind just described.

According to Hume's determinism—specifically his "doctrine of necessity"-in every instance there are causally sufficient conditions, amongst the antecedents of an agent's having a given reason for action, for the agent's having that reason for action. Similarly, there are sufficient conditions for the agent's having the desires that are an ingredient in such reasons for action. There are, that is to say, causally sufficient conditions for the agent's having whatever motives for action that agent has.

On Hume's rendering, motives give rise to actions, whether mental or bodily, by giving rise to acts of will or volitions. "[B]y the will," he writes, "I mean nothing but the internal impression we feel and are conscious of, when we knowingly give rise to any new motion of our body, or new perception of our mind." (It would be well to substitute 'volition' 
for 'will' here. It is volitions, or willings, or acts of will that, in Hume's view, constitute the "internal impressions" here described). Wittgenstein famously posed the question "What is left over if I subtract the fact that my arm goes up from the fact that I raise my arm?" In answer, Hume would invoke an arm-raising volition.

Suppose that an agent raises his arm. Within the framework of Hume's determinism, the reason from which the agent acts is causally sufficient, in the circumstances, for the volition the agent forms. There are causally sufficient conditions for the agent's having that reason and for the reason's having the efficacy it then has. The volition is (in the circumstances) causally sufficient for the rehearsing of the proof, for the raising of the arm. And (in principle) all this is governed by some strict law or laws.

Serious questions can be raised about every element in Hume's representation of "the doctrine of necessity" and about the argumentation he provides in support of that doctrine. Does the history of the natural sciences in fact support the assumption of causal determinism? Must probabilistic laws give way, at least in principle, to strict ones? (Think of quantum indeterminacies in quantum physics). Is there any reason to think that psychological or psychophysical regularities, assuming there to be such, might or must give way to strict laws? How, in any case, is one to think of the intersection of physical and psychological considerations-an intersection Hume largely neglects while setting out his case for "the doctrine of necessity?" What, in particular, of the threat of overdetermination when one attempts to envisage that intersection in the explanation, via laws, of psychological events? And, in any event, are explanations of actions that cite an agent's reasons for performing those actions, even granting such explanations are causal explanations, explanations that work by registering regularities? (Think of Hume's example of exercising for one's health).

Having raised these questions about Hume's "doctrine of necessity," let us turn to the question of liberty. There is, in Hume's view, a clear sense in which one may speak of an agent's freedom to act. No agent has, if Hume's foregoing arguments are sound, a "liberty of indifference," where that is an alleged "negation of necessity and causes." But agents typically have a "liberty of spontaneity," a liberty "which is oppos'd to violence." Hume does not elaborate on his conception of liberty of spontaneity. He briefly notes the constraints that limit the actions of a "prisoner in chains." Surely he would hold that one hasn't liberty of spontaneity with respect to raising one's arm if someone stronger than oneself is holding it down. But he does not explicitly discuss such constraints on spontaneity as psychological compulsions, or threats of various kinds, or the many varieties of social and other such constraints.

"[T]he doctrine of liberty" - the libertarian's doctrine—is, Hume claims, "absurd ... in one sense, and unintelligible in any other" (Treatise 2.3.2.1). It is absurd if taken as a denial, for the case of human action, of the union and inference constitutive of causation. It is unintelligible if taken to rest on the unintelligible assumption of objective necessitation. But there is, he holds, an intelligible conception of liberty, and one that, compatible with causal determinism, marks a significant contrast amongst the things that human agents do.

There is, he claims in the Treatise, such a thing as "liberty of spontaneity" (Treatise, 2.3.2.1). An agent possesses such liberty provided that, or insofar as, he is not, in acting as he does, subject to "force, violence, and constraint." Hume expands on this notion of liberty in Section 8 of his Enquiry Concerning Human Understanding: "By liberty ... we can only mean a power of acting or not acting, according to the 
determinations of the will; that is, if we choose to remain at rest, we may; if we choose to move, we also may." This "hypothetical liberty" is, Hume continues, "that only species of liberty, which it concerns us to preserve." Rejecting the libertarian's "doctrine of liberty," he writes: "By liberty, then, we can only mean a power of acting or not acting, according to the determinations of the will; that is, if we choose to remain at rest, we may; if we choose to move, we also may." This "hypothetical [which is not to say questionable or unintelligible] liberty is universally" —and, Hume claims, correctly_-allowed to belong to everyone, who is not a prisoner and in chains." Over the next few pages it is said to be "opposed . . . to constraint and to external violence" and to be compromised by "ignorance and impotence." Hume does not give this species of liberty a name in the first Enquiry. Not to beg one of the interpretative questions, we may call it "liberty of implementability." It is a matter of the implementability of an agent's volitions. It has to do not with the causation of those volitions but with their efficacy in effecting what the agent wills to do. Clearly the liberty of implementability is compatible with Hume's determinism. (Read in this austere way, Hume's "liberty of implementability" contrasts with Locke's claim that "Liberty . . . consists in a Power to do, or not to do, to do, or forbear doing as we will.")

Hume, the compatibilist, does not advert to such constraints on an agent's freedom to act as threats, or coercion, or psychological compulsion. Despite such lacunae, however, the late Donald Davidson, himself a central contributor to philosophical theorizing about human action, includes Hume in a brief list of philosophers, historical and more contemporary, who "have done what can be done, or ought ever to have been needed, to remove the confusions that can make determinism seem to frustrate freedom" (Davidson 1973: 63).

\section{References}

References to Hume (2000) A Treatise of Human Nature, D. F. Norton and M. J. Norton (eds), Oxford: Oxford University Press, have the form T1.1.1 (and so Book 1, Part 1, Paragraph 1).

References to Hume (1999) An Enquiry Concerning Human Understanding, T.L. Beauchamp (ed.), Oxford: Oxford University Press, cite the relevant page number.

Árdal, P.S. (1966) Passion and Value in Hume's Treatise. Edinburgh: Edinburgh University Press.

Davidson, D. (1973) "Freedom to Act," in D. Davidson, Essays on Actions and Events. New York: Clarendon Press, pp. 63-82.

\section{Further Reading}

Bricke, J. (1996) Mind and Morality: An Examination of Hume's Moral Psychology. Oxford: Oxford University Press. (Contains a relevant chapter on moral agents.)

Flew, A. (1986) David Hume: Philosopher of Moral Science. Oxford: Basil Blackwell. (Includes a chapter "Necessity, Liberty and the Possibility of Moral Science".)

Garrett, D. (1997) Cognition and Commitment in Hume's Philosophy. New York: Oxford University Press. (Has a chapter "Liberty and Necessity".)

Jenkins, J. (1992) Understanding Hume. Edinburgh: Edinburgh University Press. (Contains a chapter "Are Our Choices Free?")

Penelhum, T. (1975) Hume. London: The Macmillan Press; Penelhum, T. (2000) Themes in Hume: The Self, The Will, and Religion. Oxford: Clarendon Press. (These books provide close readings of Hume on the question of free will.)

Stroud, B. (1977) Hume. London: Routledge and Kegan Paul. (Chapter 7 provides acute critical discussion of Hume on free will.) 
DAVID HUME

\section{Related Topics}

Classical Compatibilism

John Locke

Immanuel Kant

Thomas Reid

Deliberation

Blame

Mental Causation 


\section{0 \\ THOMAS REID \\ Terence Cuneo and Randall Harp}

There is a standard understanding of Thomas Reid's views regarding the will and action according to which Reid defends both a libertarian account of free will and an agent causal theory of action. While the standard understanding of Reid's views is probably correct, puzzles emerge when one digs deeper into what Reid says when he develops these views. In this chapter, we address three interpretive challenges that face those who wish to understand what Reid says about will and action, namely:

The Action Challenge: Reid claims that some of our actions are free. But what behaviors belong to the category action? Reid seems to say different things on this issue. In some places, he endorses a broad view according to which events, such as throwing baseballs, count as actions. In other places, he embraces a narrow view according to which only certain kinds of mental events count as actions. The issue presents a challenge to Reid's interpreters because how one answers it determines whether Reid's position is subject to familiar Frankfurt-style counterexamples. (See Frankfurt [1969] and Sartorio in the present volume [Chapter 15] for a discussion of these examples.)

The Motive Challenge: Reid claims that actions are ordinarily taken on the basis of motives. But Reid also endorses two accounts of motives that appear incompatible - one of which seems to fit better with his account of free action, the other of which seems to mesh better with broadly common sense views about the motivational roles of mental states such as desires. The fact that Reid works with two different accounts of motives presents a challenge to Reid's interpreters because neither account of motives seems to fit well with Reid's commitments.

The Volition Challenge: Reid claims that the agent is an efficient cause (that is, agent cause) of her actions and that actions consist in the exertion of active power. But what is the relation between being an efficient cause (i.e., a substance) and the exertion of active power? Reid never addresses this question, but it presents a challenge to Reid's interpreters, for without an account of this relation, Reid's agent causal view is at best obscure and at worst, incoherent (if, for example, every exertion of active power requires a further exertion of active power).

We won't attempt to resolve these interpretive issues in what follows. Instead, our aims are to make these interpretive issues explicit, explain why Reid's commitments generate them, and introduce the reader to the available options for resolving them. 


\section{The Action Challenge}

Let us say that every mental or bodily change in the world produced by an agent (or some part of an agent) is the actualization of a behavior-state. While the actualization of a behaviorstate is an event, it needn't be an action. Your digesting this morning's breakfast, for example, is the actualization of a behavior-state. In some sense, it is due to you (or some part of you), but it is not an action that you perform. In contrast, your deliberating about whether to visit the Taj Mahal is both the actualization of a behavior-state and an action that you perform, as the deliberation is due to you in a way that the digestion of your breakfast is not. But what explains the difference between these two cases? Why does the actualization of a behavior-state count as an agent's action in some cases but not in others? Reid has a very simple answer to these questions: the actualization of a behavior-state counts as your action, says Reid, just in case you are its efficient cause (EAP I.i: 13).

Reid's answer to what we might call the action problem presupposes a distinction between 'efficient' and 'physical' causality (see EAP I.vii: 41; COR: 178, for this terminology). Reid adopts the notion of an efficient cause from thinkers such as Samuel Clarke (1998/1705). An efficient cause is what we today would call an agent cause, and an agent cause is something endowed with what Reid calls active power. Since you are an agent, Reid holds that you are an agent cause and, hence, endowed with active power. It is important to emphasize that, while Reid holds that everything with active power must have a will, he distinguishes active power from will, writing that the "effect produced, and the will to produce it, are things different from active power, but we can have no conception of it [i.e., active power], but by its relation to them" (EAP I.v: 32). So, in Reid's view, active power is more fundamental than will, and is necessarily exerted when we will. "By the liberty of a moral agent, I understand, a power over the determination of his own will" (EAP IV.i: 267).

Reid adopts the notion of a physical cause from Hume (see Hume 1999/1748: sect. 7). Roughly, a physical cause is an event of some type that is connected by a law of nature to an event of some other type. When you throw a baseball at a window, for example, your throwing the baseball is a physical cause of the window's shattering, since events of the first type (i.e., throwing a baseball at a window) are connected by a law of nature to events of another type (i.e., a targeted window's shattering upon impact).

Efficient causality and physical causality appear to be very different. Agent causes are not, after all, events related to other events by natural laws; they are substances. And physical causes are not agents; they are events. Surprisingly, though, Reid maintains that they are very closely linked, holding that the only genuine causality in the world consists in the exercise of agent causality. If Reid is right, your deciding to throw a baseball at a window comes about through an exertion of your active power. You are this event's agent cause. But that the ball flies through the air and shatters the window upon impact is, Reid says, due to the exertion of God's active power, for the

physical laws of nature are the rules according to which the Deity commonly acts in his natural government of the world; and, whatever is done according to them, is not done by man, but by God, either immediately, or by instruments under his direction.

(EAP IV.xi: 251)

Reid, then, endorses a version of quasi-occasionalism-'quasi' because Reid allows that both human beings and God (and possibly other beings) are agent causes. Although 
Reid makes no effort to define the notion of an agent cause, he does specify an array of conditions that something must satisfy to be an agent cause. Among these is that an agent cause has active power, and that active power must come with options: "Power to produce an effect," Reid says, "implies power not to produce it" (EAP I.v: 29). Let us (following Yaffe 2004: Chapter 2) call this condition:

Power to do Otherwise: If an agent has the power to act in a certain way, then he also has the power not to act in that way.

Power to do Otherwise affords an even clearer understanding of Reid's answer to the action problem: it tells us that the actualization of any behavior-state of which someone is an agent cause must be such that that person had the power to not actualize that behavior-state when he did. Although this is helpful, we still don't know exactly what sorts of behavior-states, according to Reid, satisfy this condition. Do mental events such as imagining the Taj Mahal as well as bodily movements such as throwing baseballs satisfy Power to do Otherwise and, hence, count as actions?

Reid says different things on this matter. In some places, he acknowledges that there is an ordinary understanding of action that is broad according to which the actualization of a wide array of behavior-states such as throwing baseballs, flagging down cabs, and scratching one's ear count as actions (see EAP III.i.i: 97, IV.i: 198). Call this the wide understanding of action. In other places, Reid acknowledges that there is a 'philosophical' understanding of action according to which only the actualization of those behaviorstates that are the direct consequence of an exertion of active power-that is, only those behavior-states that are volitions-are actions (see EAP I.i: 13, IV.ii: 203). Call this the narrow understanding of action. Sometimes Reid seems to work with the wide (or 'broad') understanding; other times he appears to work with the narrow understanding. Each understanding has its pros and cons.

The virtue of the wide understanding is that it approximates our ordinary understanding of action according to which the actualization of behavior-states such as throwing baseballs and flagging down cabs are actions and, hence, behavior-states for which we can be held accountable. The wide interpretation, however, also has a downside, which is that it exposes Reid's view to counterexamples that are potentially quite damaging.

Reid would have been familiar with some of these counterexamples. Consider, for example, Locke's man-in-a-locked-room scenario, which is a precursor to so-called Frankfurt-style counterexamples. In Locke's presentation of the scenario, a man is locked in a room. Although the man decides to stay in the room, he lacks the power to leave because, unbeknownst to him, the door is locked. This case provides the materials for the following objection to Reid's view:

1. The actualization of a behavior-state $B$ counts as an agent's action at $t$ only if $B$ satisfies Power to do Otherwise at t. (from Reid's answer to the action problem and Power to do Otherwise)

2. The man in the locked room's behavior of staying in the locked room doesn't satisfy Power to do Otherwise: he has the power to stay in the room but lacks the power to refrain from staying in the room. (assumption)

3. So, when the man in the locked room decides to stay in the room, his behavior of staying in the room does not count as his action. (from 1,2) 
4. But his behavior of staying in the room does count as his action. (assumption)

5. So, (1) is false: it's not the case that the actualization of a behavior-state B counts as an agent's action at $t$ only if B satisfies Power to do Otherwise at $t$. (from 1-4)

Let's now add that, in Reid's view, the actualization of a behavior-state counts as an action if and only if it is a free action (EAP IV.i: 267, IV.iii: 212). Given this assumption, the argument just stated also implies:

6. The man in the locked room's behavior of staying in the locked room is not a free action.

This appears to be a problem for the wide understanding of action.

What we earlier referred to as the narrow understanding of action side-steps this objection completely, as it holds that the formation of volitions is the only type of action that the agent performs. If this is right, the correct way to describe the manin-a-locked-room scenario is to focus on the man's formation of volitions through the exertion of his active power. When the man decides to stay, his decision results from the exertion of his active power. But when he decides this, he could decide otherwise; he could decide not to stay. Of course he would be unable to execute his decision and leave because he would discover that the door to the room in which he's staying is locked. Still, his volition to stay satisfies Power to do Otherwise. Given Reid's further claim that the only types of actions are free actions, his decision to stay is a free action.

But there is a price for accepting the narrow view of action. This account not only radically constricts the range of behavior-states that can count as actions, but also 'internalizes' action, implying that none of the behaviors that we commonly call actions, such as throwing baseballs, could be actions (compare, for example, EAP I.i and I.vii: 36 with IV.i). For a philosopher who prided himself in defending common sense, this would not be a welcome result.

Reid himself never faces the Action Challenge head-on. But he does say some things that suggest a way of blunting its force. When Reid presents the narrow understanding of action, he acknowledges that the actualization of many behavior-states would not count as actions; only the formation of a volition through the exertion of active power would count as an action. Nonetheless, Reid continues, agents can be held morally responsible for the actualization of behavior-states that are not actions in the narrow sense, such as throwing baseballs at windows. Here is what Reid says:

That there is an established harmony between our willing certain motions of our bodies, and the operation of the nerves and muscles which produces those motions, is a fact known by experience. This volition is an act of the mind. But whether this act of the mind have any physical effect upon the nerves and muscles, or whether it be only an occasion of their being acted upon by some other efficient [cause], according to the established laws of nature, is hid from us.

Still,

the man who knows that such an event depends upon his will, and who deliberately wills to produce it is, in the strictest moral sense, the cause of the event; 
and it is justly imputed to him, whatever physical causes may have concurred in its production.

If Reid is right about this, we should distinguish an agent's being the cause of the actualization of a behavior-state from an agent's being the moral cause of an actualization of a behavior-state. An agent is the cause of the actualization of a behavior-state B when and only when she is the sole agent cause of the actualization of B (and all events that might be necessary for actualization of $B$, such as the operations of nerves and muscles that are necessary for the movement of the arm). When an agent is the cause of the actualization of a behavior state, then the actualization of that behavior-state is an action in the narrow sense. In contrast, an agent is a moral cause of the actualization of $\mathrm{B}$ when and only when she is an agent cause (though not necessarily the only agent cause) of B and can rightly be held accountable for the actualization of B. When an agent is a moral cause of the actualization of a behavior-state, then the actualization of that behavior-state is an action in the wide sense.

While distinguishing different types of action has the disadvantage of multiplying senses of 'action,' the disadvantage is probably only apparent; Reid is happy to allow that one and the same term expresses a multiplicity of meanings provided that such an allowance is justified. And, in this case, it looks as if it is. Given certain theoretical purposes in which we are attempting to identify, in a philosophical precise way, what counts as an action (and, hence, a free action), we need to operate with the narrow understanding of action. But, given certain practical purposes in which we engage in practices of holding each other accountable for what we do, we need to employ the wide understanding of action. If Reid is right, we need to employ multiple action concepts in order to serve this range of purposes.

\section{The Motive Challenge}

In his chapter "Observations Concerning the Will," Reid writes that "in all determinations of the mind that are of any importance, there must be something in the preceding state of the mind that disposes or inclines us to that determination." The reason is that if

the mind were always in a state of perfect indifference, without any incitement, motive, or reason, to act, or not to act, to act one way rather than another, our active power, having no end to pursue, no rule to direct its exertions, would be given in vain.

(EAP II.i: 51)

A close reading of the Active Powers reveals, however, that just as Reid operates with two different understandings of action, he also embraces two different accounts of motives that appear incompatible. The position Reid presents in the early chapter "On the Influence of Incitements and Motives on the Will" — what we'll call the wide account of motives - says that motives come in two sorts: some are mental states, while others are ends in the sense of being that for the sake of which an agent acts (EAP II.ii). The view of motives presented in the later chapter "Of the Influence of Motives" - what we'll call the narrow account of motives - says that motives come in only one sort: those ends for the sake of which an agent acts. 
Let us begin with the wide account of motives. Following Reid's terminology, call those motives that are mental states "incitements" and those that are not "ends." Reid says incitements come in two types. There are, in the first place, what Reid calls the "mechanical" principles of action. The mechanical principles of action include instincts for self-preservation, food, procreation, and the propensity to imitate (cf. EAP III.ii-iii). In addition, there are those incitements which Reid labels the 'animal' principles of action. The animal principles of action include what Reid calls the benevolent affections, such as gratitude and esteem; the malevolent affections, such as resentment and the desire to better someone else in some matter, as well as a multitude of other incitements, such as the desires for power and knowledge.

As for ends, these come in two different kinds. Call ends of the first sort agent-reasons. To acquaint yourself with this concept, think of some case in which you perform some action and the consideration in light of which you performed that action - that feature of your situation that, in your estimation, made the action worth performing or recommended its performance. This feature is an agent-reason. Reid says agent-reasons are the "rational principles" of action, of which there are two: first, one's "good on the whole" and, second, one's "duty" (EAP III.i). Reid calls these the rational principles of action because they "have no existence in beings not endowed with reason, and, in all their exertions, require, not only intention and will, but judgment or reason" (EAP III. iii.i: 152). Call ends of the second sort end-states. These are those states that an agent endeavors to actualize through the exertion of his active power. (One can think of end-states as a subset of behavior states: they are behavior-states that an agent can aim to actualize directly through the exertion of her active power). Examples of end-states would be your kicking a ball into the left-hand corner of the goal or pruning an apple tree.

Ends of both sorts play a role in action. Agents act to bring about end-states in light of agent-reasons. Somewhat more exactly, Reid's view is that, cases of indifferent action aside, an agent $S$ acts for the sake of an end if and only if there is some end-state $E$ such that $S$ actualizes $E$ through the exertion of his active power in light of some agent-reason $\mathrm{R}$.

What we are calling the narrow account of motives is less capacious than the wide account. For, according to the narrow account, motives are necessarily ends. Whatever role incitements play in action, according to this view, it is not that of being a motive.

Why would Reid have offered these conflicting accounts of motives, ultimately pairing the narrow account of motives with the narrow understanding of action? Here is a hypothesis: if the wide account of motives were correct, incitements would be physical causes of why we act. Remember, though, that Reid commits himself to the claim that all causality is agent causality. It follows that were a desire a physical cause of why you act, this physical cause would be the effect of the exertion of someone else's active power-presumably, God's—on you. This poses a threat to Reid's account of action according to which when you act-and, hence, act freely-that action consists not in the exertion of some other agent's active power but in your active power. This last claim is captured in the thesis that (following Yaffe 2004) we'll call:

Efficient-Causal Exclusivity: Every event that has an agent cause has one, and only one, agent cause. 
Given Efficient-Causal Exclusivity, we can state the Motive Challenge as follows:

$\left(1^{*}\right)$ If the narrow account of motives is true, then incitements have no motivational role to play in the production of action. For, if they did, actions would have too many causes.

$(2 *)$ If the wide account of motives is true, then the actualizations of behaviorstates that Reid maintains are paradigmatic actions are not actions at all, as they would have too many causes.

$\left(3^{*}\right)$ So, if either the narrow or the wide account of motives is true, then either incitements have no motivational role to play in the production of action, or the actualizations of behavior-states that Reid maintains are paradigmatic actions are not actions at all.

Like the Action Challenge, Reid never explicitly addresses the Motive Challenge. Nonetheless, Reid might have resources within his thought that allow him to address it. In Reid's view, an agent can be more or less responsible for an action, depending to what degree that action is the product of passion (EAP I.vii: 40). Although Reid does not develop this thought, it suggests that Reid was (at times) comfortable with the idea that actions can have multiple causes. And if actions can have multiple causes, then it would be possible for the actualization of a behavior-state to count as an agent's action even though it had multiple causes. Presumably, the test for whether the actualization of a behavior-state counts as an agent's action would be whether the agent could still rightly be held accountable (to some degree) for the action. Or to state the same point using the terminology introduced in the last section: the test for whether the actualization of a behavior-state counts as an agent's action is whether the agent is a moral cause of the actualization of that behavior-state. Of course, this maneuver would require Reid to reject Efficient-Causal Exclusivity. But, if he did, Reid could endorse the wide view of motives, provided that an agent is at least a partial cause of the actions he performs.

There is a way to develop this point. Drawing from Reid's own remarks, let us distinguish two types of agency, which we can call 'moral agency' and 'non-moral agency.' Now take some creature that actualizes some behavior-state B. If that agent's actualization of $\mathrm{B}$ is wholly determined by incitements that are operative within that creature, then it is a non-moral agent with respect to the actualization of $\mathrm{B}$. If that creature's actualization of $B$ is not wholly determined by incitements that are operative within it, then it is a moral agent with respect to the actualization of B. According to Reid, creatures such as dogs are probably non-moral agents, since (in all likelihood) their behavior is wholly determined by their strongest incitements (EAP II.ii: 53). Non-moral agents are not moral causes of their behavior, however, and so they do not perform actions in either the narrow or the wide sense (although Reid is happy to allow that we use the term 'action' to describe the behavior of non-moral agents; see EAP III.1.1).

Persons are more complex. In some cases, people actualize behavior-states strictly from desire or instinct. When they do, their agency is comparable to that of a dog; they are non-moral agents. In other cases, however, people can actualize behavior states through the exertion of active power. When they do, they are moral agents and can perform actions in both the narrow and the wide senses. 


\section{The Volition Challenge}

To this point, we've canvassed two interpretive challenges to Reid's views on will and action-what we've called the Action Challenge and the Motive Challenge. Both challenges exhibit a similar structure: they charge that Reid must surrender either some element of our broadly common sense understanding of agency or some element of his account of action. Since Reid holds that all (moral) actions are free actions, these challenges are ones that Reid must address if he is to vindicate his account of free action.

In this last section, we address a challenge that exhibits a different structure. This challenge begins with the observation that Reid's account of (moral) action-and, hence, free action-has a quadripartite structure. Any instance of free action includes (1) an agent; (2) the exertion of that agent's active power; (3) the formation of a volition; and (4) the effects of the operation of the volition. Reid's interpreters have puzzled over the relations that these four elements of free action bear to one another. The puzzle does not concern the relation between (3) and (4); the operation of one's volition is bound to its effects by natural laws. If you will yourself to throw a baseball, for example, that willing is bound together with the ball's flying through the air by natural laws of various sorts. Rather, the puzzle concerns the relations of (1), (2), and (3). In fact, some have worried that any plausible attempt to spell out the relations of these three elements involves Reid's position in a vicious infinite regress.

To appreciate why, first consider the relation between (1) and (3). Reid claims that agents are the cause of the determination of their wills (EAP I.v). But agents determine their wills through the exertion of their active power; it is (2) that connects (1) with (3). But now we face a puzzle about (2). Suppose (2) - the exertion of active power-is an event. Suppose, also, that every event must have a cause, as Reid claims (EAP IV.ii: 202, 203). In Reid's view, the cause of an event must be an efficient cause. And to be an efficient cause of some event, something must exert its active power to bring about that event. But if so, an agent cannot be the efficient cause of the exertion of her active power, for that would require there to be a volition $\mathrm{V}$ that brings about that exertion of her active power. But $\mathrm{V}$ is an event. So, $\mathrm{V}$ could bring about that exertion of her agent power only if there is some further volition $V^{\prime}$ that brings about $\mathrm{V}$. And so on, ad infinitum.

Reid's interpreters have suggested different solutions to this concern, which we call the Volition Challenge. In Thomas Reid on Freedom and Morality, William Rowe proposes an answer that he presents not as Reid's own but on Reid's behalf. The answer consists in denying that the exertion of active power is an event and, so, does not require a cause. Rowe's thought is that, under a charitable interpretation, Reid works with a narrow understanding of events according to which events are changes that things undergo. Since the exertion of active power is not a change that a thing undergoes, it is not something that requires a cause (see Rowe 1991: 146-61).

In Manifest Activity, Gideon Yaffe takes a different approach. Yaffe writes:

If exertion is understood as no different from effort, or trying, then there is no regress, and the relation between the agent and his exertion of power-in the only case, namely, that of failure, in which the exertion is anything at all-is the relation of efficient causation. If an agent succeeds in acting, then his exertion is no action; it is not something he did or, what's the same, something 
he efficiently caused. However, if he fails, then his exertion is his act; he is the efficient cause of it. Since, when he fails, he successfully exerted himself, his exertion to exert, in this case, is not some further action of which he is the cause. Exertion, in the case of success, is not action, and so is not something for which an efficient cause must be identified.

(Yaffe 2004: 155-6)

Yaffe claims that in cases of unsuccessful action, as when an agent tries to throw a baseball but fails (perhaps because of the sudden onset of paralysis) there is nonetheless a successful action performed, namely, the exertion. But when there is a successful action, the exertion to perform that action is 'absorbed' into the action. Since the successful action in this case is an exertion, there is no need to appeal to some further exertion that explains the exertion.

Each suggestion is intriguing but not entirely satisfactory. (It may be that no response to the Volition Challenge is). Rowe's suggestion restricts the meaning of the word 'event' in a way that has little intuitive or textual support. (Rowe readily admits the latter is true). And Yaffe's proposal that exertions or tryings disappear or are absorbed into actions also receives little textual support. Moreover, the proposal is puzzling. Why would tryings disappear or be absorbed into actions when we act? (Generally speaking, when some thing meets some success condition — such as a proposition's meeting the condition true - that thing does not disappear). It makes sense, then, to continue to look for other ways of addressing the Volitional Challenge.

One promising alternative, which meshes with Reid's texts, is to distinguish the efficient causal relation from being an efficient cause. As its name indicates, the efficient causal relation is a relation that an agent bears to an exercise of will or the effect of the exercise of will. For this relation to hold, it must be that (1) there is an agent endowed with active power; (2) that power is exerted; and (3) the exertion satisfies Power to do Otherwise. In contrast, an efficient cause is a person or agent. Reid repeatedly makes this point, stating: "That which produces a change by the exertion of its power, we call the cause" (EAP I.i: 13). And: "I consider the determination of the will as an effect. This effect must have a cause which had power to produce it; and the cause must be either the person himself, whose will it is, or some other being" (EAP IV.i: 201).

Now consider Reid's claim that every event or change has an efficient cause. This can be understood as stating either:

(a) Necessarily, every event $\mathrm{E}$ is such that there is an efficient cause to which $\mathrm{E}$ bears the efficient causal relation.

or:

(b) Necessarily, every event $\mathrm{E}$ has an efficient cause; there is some agent that brings about $\mathrm{E}$.

If Reid's claim that every event has a cause states (a), then the Volition Challenge looms. But if it states (b), then there is no such challenge, for (b) does not imply (a). Tellingly, Reid nowhere states that his claim ought to be read as (a), although his interpreters often read him as being committed to it (see, for example, Rowe 1991: 147; Yaffe 2004: 154). 
Now consider the exertion of active power, which we can assume is an event or change. Reid's view tells us that this event or change must have an efficient cause. If we understand Reid simply to commit himself to (b), then what he says is compatible with there being nothing that bears the agent causal relation to that event. And if that is so, no regress need get started. All that needs to be the case is for there to be an efficient cause in whom that exertion is related in the right way; the exertion must belong to or be grounded in the agent. So, our suggestion is that when Reid says that every event or change has an efficient cause, he commits himself only to the claim that that event or change must belong to or be grounded in some agent. For this to be true, there need be nothing that an agent 'does' to be the efficient cause of some exertion of active power. Rather, to say it again, it must simply be the case that that exertion belongs to or is grounded in that agent. To state the view we are attributing to Reid paradoxically, exertions of active power are uncaused (they do not bear the efficient causal relation to some agent) but have causes (they are grounded in some agent). Or to put the point less paradoxically, exertions of active power do not have causes but nonetheless are 'grounded exertions.'

What relation must an agent bear to exertions of her active power for her to be their cause? We've suggested that these exertions must belong to or be grounded in her person. Under this interpretation of Reid's view, the following claims are true: agents possess active power. When agents act, they do so through the exertion of active power; the exertion belongs to or is grounded in the agent. But agents do not exert active power in order to act; the exertion of active power is not a thing that agents (strictly speaking) do. One might be tempted to ask: But how does an agent act through the exertion of active power? Under the interpretation we're exploring, Reid's view must be that, although the question might seem intelligible, it is not.

\section{Acknowledgments}

Thanks to Kevin Timpe for his comments on a draft of this chapter.

\section{Bibliography}

Clarke, S. (1998/1705) A Demonstration of the Being and Attributes of God and Other Writings, E. Vailati (ed.). Cambridge: Cambridge University Press.

Frankfurt, H. (1969) “Alternate Possibilities and Moral Responsibility,” Journal of Philosophy 66: 829-39.

Harris, J. (2007) Of Liberty and Necessity. Oxford: Oxford University Press.

Hoffman, P. (2006) "Thomas Reid's Notion of Exertion," Journal of the History of Philosophy 44: 431-47.

Hume, D. (1999/1748) An Enquiry Concerning Human Understanding, T.L. Beauchamp (ed.). Oxford: Oxford University Press.

Reid, T. (2002) The Correspondence of Thomas Reid, P. Wood (ed.). Edinburgh: Edinburgh University Press (abbreviated as COR).

Reid, T. (2010/1788) Essays on the Active Powers of Man, K. Haakonseen and J. Harris (eds). Edinburgh: Edinburgh University Press (abbreviated as EAP).

Rowe, W. (1991) Thomas Reid on Freedom and Morality. Ithaca: Cornell University Press.

Rowe, W. (2004) "Thomas Reid's Theory of Freedom and Responsibility," in T. Cuneo and R. van Woudenberg (eds), The Cambridge Companion to Thomas Reid. Cambridge: Cambridge University Press, pp. 222-42.

Yaffe, G. (2004) Manifest Activity. Oxford: Oxford University Press.

\section{Further Reading}

Cuneo, T. (2011) “A Puzzle Regarding Reid's Theory of Motives," British Journal for the History of Philosophy 19: 963-82. (This paper explores Reid's answer to what we refer to as the Motive Challenge.) 


\section{TERENCE CUNEO AND RANDALL HARP}

Harris, J. (2007) Of Liberty and Necessity. Oxford: Oxford University Press. (This book is an instructive historical survey of how early moderns thought of the freedom of the will, which presents a variant of what we call above the 'standard interpretation'.)

Rowe, W. (1991) Thomas Reid on Freedom and Morality. Ithaca: Cornell University Press. (This is the first book-length discussion and defense of Reid's position, which also defends a variant of the standard interpretation.)

Van Cleve, J. (2015) Problems from Reid. Oxford: Oxford University Press. (Chapters 14 and 15 are a highly instructive discussion of Reid's views regarding will and action.)

Yaffe, G. (2004) Manifest Activity. Oxford: Oxford University Press. (This book provides a historically sensitive and sophisticated discussion of Reid's views regarding the will and action, also defending the standard interpretation.)

\section{Related Topics}

Agent Causation

Non-Causal Libertarianism

Frankfurt-Style Examples

Gottfried Leibniz

David Hume 


\title{
31 \\ IMMANUEL KANT \\ Benjamin Vilhauer
}

\begin{abstract}
Introduction
Kant's most distinctive ideas about free will are the ones he develops with his "critical turn" towards the doctrine he calls "transcendental idealism," which begins with his Critique of Pure Reason in 1781. Kant's most striking claim is that it is possible for human beings to have an incompatibilistic sort of free will even if determinism is true. Scholars have been intrigued and confounded by this claim ever since, and there is still little consensus on how it should be understood. Isn't this claim a straightforward contradiction? Was Kant really offering a compatibilist view in a confused way? The controversy is in part due to the fact that his views on free will are tied in tightly with the theory of transcendental idealism and its distinction between phenomena (things as they appear) and noumena (things as they are in themselves), which has divided scholars from the moment Kant first advanced it. I will begin with a brief explanation of transcendental idealism and its connection to free will, and go on to provide a brief overview of three important interpretations of Kant's free will theory, which I will call compatibilism, deflationism, and libertarianism. I will go on to discuss libertarianism in more detail, because it is the most textually accurate interpretation.
\end{abstract}

\section{Transcendental Idealism}

The core ideas in Kant's doctrine of transcendental idealism include (i) the "transcendental distinction" between noumena, or things as they are in themselves, and phenomena, or appearances, that is, things as they appear; (ii) the claim that phenomena are as they are not just because of the way noumena are, but because our own mental activity is involved in making them as they are; (iii) the claim that the mental activity involved in making phenomena as they are is necessary for us to have any experience of objects at all, and that we therefore cannot have experience of noumena; and (iv) the conclusion that since we cannot have experience of noumena, there are limits on what we can know about noumena. On this abstract characterization, transcendental idealism can sound anodyne, in the sense that most philosophers would probably acknowledge that we cannot stand apart from whatever mental activity is necessary for the world to appear to us, in order to know it independently of this activity. But Kant holds that the mental activity involved in making phenomena the way they are is quite radical. Kant argues that we have synthetic a priori knowledge about phenomena which is only possible if our minds contribute space and time to reality - that is, if the very fact of the spatial and temporal extension of phenomena is due to our own mental activity. 
For knowledge to be analytic, as Kant defines it, is for it to be a 'judgment' whose predicate is logically 'contained' in the subject. Kant gives the example of "All bodies are extended" (A7/B11). Synthetic knowledge involves judgments whose predicates are not contained in the subject: "in synthetic judgments I must have in addition to the concept of the subject something else $(X)$ on which the understanding depends in cognizing a predicate that does not lie in that concept as nevertheless belonging to it" (A8/B11). An example of synthetic a posteriori knowledge is 'some apples are red.' The predicate red is not contained in the subject apple, but my experience of a red apple provides the 'something else (X)' necessary to synthesize red and apple in the judgment. Synthetic a priori knowledge is a philosophical puzzle, because we cannot derive the needed X from experience. Kant thinks that we need to appeal to the idea that the mind idealistically contributes or 'constructs' the spatiotemporal form of the world to identify the $\mathrm{X}$ for synthetic a priori knowledge. His most accessible example involves arithmetic:

One might initially think that the proposition " $7+5=12$ " is a merely analytic proposition that follows from the concept of a sum of seven and five in accordance with the principle of contradiction. Yet if one considers it more closely, one finds that the concept of the sum of 7 and 5 contains nothing more than the unification of both numbers in a single one, through which it is not at all thought what this single number is which comprehends the two of them ... One must go beyond these concepts, seeking assistance in the intuition that corresponds to one of the two, one's five fingers, say, or (as in Stegner's arithmetic) five points, and one after another add the units of the five given in the intuition to the concept of seven.

Kant thinks that although we can know that $5+7$ equals 12 with the sort of necessity that marks it out as a priori rather than a posteriori knowledge, this knowledge nonetheless requires us to perform a synthesis of what he calls "intuitions" in space. Kant's view is that without space in which to count a set of 5 things together with a set of 7 things we cannot know that they make 12 . This synthesis is similar to the a posteriori synthesis in which my experience of the red apple synthesizes red and apple in the way needed to know that some apples are red. That is, my experience of the apple spatially presents an instance of apple that is coextensive with a red patch in the right way for me to judge that some apples are red. Kant explains the difference between the $a$ priori status of the mathematical knowledge and the a posteriori status of the apple-knowledge by holding that the $\mathrm{X}$ needed to synthesize mathematical knowledge is what he calls the pure form of space, which can only be available for the a priori synthesis of arithmetic if our minds idealistically contribute it to phenomenal reality, in contrast to the apple, which appears as it does not just because our minds impose the form of spatiality on it, but also because mind-independent noumena are as they are. That is, we can use empirical intuitions to add $5+7$, for example, our 'fingers' (and perhaps a couple of toes?), but also by counting pure intuitions, such as 'points,' which we can spatially locate in our minds' eyes, as it were, but are of course extensionless, and thus not experienceable objects. Even when we use our fingers, they must serve as proxies for pure intuitions - otherwise, Kant argues, we could not know that $5+7=12$ with the necessity proper to a priori knowledge. 
An equally important, but more complicated, example of synthetic a priori knowledge is our knowledge that determinism is true for the world of phenomena. I cannot attempt to do justice to the entirety of Kant's argument here, since it winds through the several of the most debated sections of the Critique of Pure Reason. (See Vilhauer (2010) for my view in more detail. Allison (2004) and Guyer (1987) are also useful references.) But the main ideas are as follows. Kant argues that we experience an objective order of events in time, but the concepts of those events do not on their own entail the order in which they occur, and since time itself is a form of intuition just like space, which we impose upon the mind-independent features of reality, we cannot take the order of events in time as something empirically given. Instead, our experience of an objective order of events in time is a cognitive achievement which depends upon an a priori synthesis of time in which the concept of deterministic causal law functions as an ordering principle that determines which events follow which other events. Said differently, Kant argues that it is only possible for us to experience an objective order of events insofar as we have synthetic a priori knowledge that deterministic causal laws govern all events and thereby establish an objective order, and he interprets this synthetic knowledge as implying that our minds idealistically contribute a scaffolding of deterministic causation to the world of phenomena along with the form of time, which governs not just the phenomena of the objects that appear to us in space like apples, but also our own actions:

All the actions of the human being in appearance are determined in accord with the order of nature by his empirical character and the other cooperating causes; and if we could investigate all the appearances of his power of choice down to their basis, then there would be no human action that we could not predict with certainty, and recognize as necessary given its preceding conditions.

(A549-50/B577-8)

It is important to note that Kant is not claiming that our ability to know the truth of determinism implies any actual capacity to predict human action. Kant's view is not that we can only experience objective successions of events if we know what the particular causal laws are which govern this succession. If that were his view, absurdity would threaten, since we could not experience objective succession until we had a complete natural science.

Kant accepts some empiricist ideas, and thus holds that we can only properly speaking have theoretical knowledge of objects that we experience in space and/or time. But this is often taken to imply a more complete exclusion of knowledge about noumena than his texts warrant. Theoretical knowledge, for Kant, is synthetic knowledge that particular predicates apply to things, and this is only possible with respect to spatial and/ or temporal appearances. However, it is possible to know that noumena exist without synthetically knowing that any particular predicates apply to them if the existence of noumena is implied by basic features of transcendental idealism which we know a priori. The idealistic contributions of space and the deterministic scaffolding of time only produces a formal outline of the phenomenal world, an empty manifold of blank deterministic spatiotemporal extension. The details of empirical reality must be 'filled in' by something mind-independent. Noumena are the ontological grounds of the particular features of empirical objects that cannot be derived from the formal outline our minds idealistically contribute. Our minds' contribution entails that the apple has spatial form 
and arises deterministically, but the particular spatial form it has, and the particular laws in accordance with which the apple tree grows and bears it, are as they are because of the phenomenal world's noumenal underpinnings. (In what follows I draw on earlier publications: Vilhauer 2004, 2008, 2010, 2014).

\section{Transcendental Freedom}

As I mentioned at the outset, Kant's view seems to be that despite the truth of determinism, it is still possible that we have an incompatibilist sort of free will. As the sketch of transcendental idealism presented above demonstrates, the determinism Kant endorses is ontologically circumscribed: determinism is a fact about the way we must order the appearances of reality we construct with the mind-imposed forms of space and time, rather than a fact about noumena, which are the ontological underpinnings of the appearances we construct. The solution to the free will problem Kant presents involves what he calls "transcendental freedom," which applies the transcendental distinction to agents, by distinguishing between what he calls agents' "empirical" (phenomenal) and "intelligible" (noumenal) characters: he holds that while we can know agents to be deterministic as they appear, it is nonetheless possible for them to be exempt from determinism as they are in themselves. On this theory, a subject would have

An empirical character, through which its actions, as appearances, would stand through and through in connection with other appearances in accordance with constant natural laws, from which ... they could be derived; and thus, in combination with these other appearances, they would constitute members of a single series of the natural order. Yet second, one would also have to allow this subject an intelligible character, through which it is indeed the cause of those actions as appearances, but which ... is not itself appearance. The first one could call the character of such a thing in appearance, the second its character as thing in itself.

(A539/B567)

Kant goes on to explain that:

In its intelligible character ... this subject would nevertheless have to be declared free of all ... determination by appearances ... and free of ... natural necessity ... Thus freedom and nature, each in its full significance, would both be found in the same actions, simultaneously and without any contradiction.

(A541/B569)

It must be emphasized that in the Critique of Pure Reason, Kant only claims that such transcendental freedom is theoretically possible, not that we can know we have it. The limitations on our knowledge of noumena imply that it is impossible for us to know that we have, or lack, transcendental freedom.

But what does Kant mean in saying that, in our intelligible character, we would be independent of natural necessity? The details of Kant's account will determine whether we should read Kant as, at heart, a compatibilist or incompatibilist in his ambitions. 
Kant explains that transcendental freedom:

(A) is required for holding people morally responsible, or "imputation": without transcendental freedom "no moral law is possible and no imputation in accordance with it" (CPrR 5:96);

(B) underwrites alternative possibilities: when an agent acts immorally, transcendental freedom allows us to explain how the agent's will, "regardless of all the empirical conditions ... could have and ought to have determined the conduct of the person to be other than it is" (A555/B583);

(C) is a kind of causality "through which something happens without its cause being further determined by another previous cause, i.e., an absolute causal spontaneity beginning from itself" (A446/B474);

(D) allows us to understand noumenal causation as grounding or causing phenomenal causation:

if the effects are appearances, is it also necessary that the causality of their cause ... must be solely empirical? Is it not rather possible that ... this empirical causality itself ... could nevertheless be an effect of a causality that is not empirical, but rather intelligible...?

(A544/B572);

(E) involves controlling not just our own actions, but (at least some part of) the deterministic empirical causal conditions of our phenomenal actions:

a rational being can now rightly say of every unlawful action he performed that he could have omitted it even though as appearance it is sufficiently determined in the past and, so far, is inevitably necessary; for this action, with all the past which determines it, belongs to a single phenomenon of his character, which he gives to himself ... as a cause.

(2C5:98, boldface added)

Elsewhere, Kant speaks of how reason creates an "order of its own, according to ideas, to which it adapts the empirical conditions" (A548/B576).

Point $\mathrm{E}$ is probably best understood as an elaboration of point $\mathrm{D}$; that is, as an explanation of what it means for empirical causality to be an effect of intelligible causation. E can sound bizarre. Is Kant saying that we can only have transcendental freedom if we create the entire history of the world? What he actually says is that we cause "all the past that determines" the phenomenal character, and does not further analyze what part of the phenomenal character's past determination we need to attribute to "ourselves as a cause" to sufficiently "adapt the empirical conditions" to accommodate alternative possibilities. An interpretation of this point must accommodate alternative possibilities without unduly distorting our pretheoretical conception of the scope of our causal responsibility if it is to avoid a reductio ad absurdum.

Points similar to A and B can be found in compatibilist as well as libertarian accounts of free will, even if they are not true of all compatibilist account; as a result, they do not help us determine whether Kant is a compatibilist or libertarian. Compatibilist accounts that seek to accommodate $\mathrm{C}$ are rare, but I will shortly discuss a compatibilist interpretation that may do so, although it fails to accommodate D. I will then look at a school 
of interpretation that I will refer to as 'deflationism,' which attempts to embody the virtues of both compatibilism and incompatibilism by means of a sort of dualism of conceptual schemes. It too may accommodate C, but not D. D on its own may be equivocal between compatibilist and incompatibilist interpretations, since the idea of noumenal causation grounding phenomenal causation on its own does not imply that such grounding works to undermine the significance of phenomenal determinism for free will. But D as understood in light of $\mathrm{E}$ makes this clear, and in my view only libertarian interpretations can accommodate $\mathrm{D}$ and $\mathrm{E}$ together.

\section{Compatibilism}

Kant clearly worries over the incompatibilist concern that there is a conflict between free will and determinism, and sounds very much like he rejects compatibilism altogether:

If I say of a human being who commits a theft that this deed is, in accordance with the natural law of causality, a necessary result of determining grounds in preceding time, then it was impossible that it could have been left undone; how then, can appraisal in accordance with the moral law ... suppose that it could have been omitted because the law says that it ought to have been omitted?

(CPrR 5:95)

There is, however, debate about whether what Kant rejects here is compatibilism in general, or just some kinds of compatibilism. Ralf Meerbote and Hud Hudson argue that transcendental freedom can be interpreted as a proto-version of Davidson's compatibilistic 'anomalous monism' (Meerbote 1984; Hudson 1994). Like Kant, Davidson analyzes agents in terms of two 'aspects' or 'levels,' which are distinct in one sense, but unified in another (Davidson 2001). Davidson's two aspects are physical and mental events, which are, on his view, token-identical but type-distinct: every mental event is also a physical event, but explanations of mental events do not include references to physical types, and explanations of physical events do not include references to mental types. Davidson holds that physical events are covered by deterministic laws, so mental events must be too, by way of their token-identity with physical events. But deterministic laws only reference physical types, so insofar as an event is individuated as a mental event, it is nominally independent of determinism. Since Davidson thinks that events can be causes only if they are covered by deterministic laws, he holds that mental events are causes only because of their identity with physical events. He thinks this allows us to make ordinary claims about mental causation, such as "my desire to wear a cowboy hat caused me to put on a cowboy hat." But he holds that this claim can only be true if there is a deterministic law linking the intentionality-laden events of desiring to wear a cowboy hat and putting on a cowboy hat which references the physical types included in their physical descriptions.

Meerbote and Hudson argue that Davidson's sort of mental event non-determinism is a helpful model for understanding the intelligible character's non-determinism. Since descriptions of mental events do not reference physical types and therefore have no connection in terms of their content with deterministic laws, we need not represent mental events as "further determined by another previous cause," arguably accommodating the above-described point $\mathrm{C}$ in Kant's theory. They draw on Davidson's view that we can make everyday causal claims about mental events, due to their token-identity 
with physical events. In this way, Davidson's mental causation becomes Kant's causality of the intelligible character.

An important objection to their interpretation is that it cannot accommodate point D in Kant's theory as described above, because they make the grounding relation run in the wrong direction. That is, according to anomalous monism, mental events are only causes at all by virtue of their identity with physical events, but Kant's own account turns on the idea that "empirical causality . . . could nevertheless be an effect of a causality that is not empirical, but rather intelligible" (A544/B572).

\section{Deflationism}

Another influential interpretation of Kant's theory of free will, which I'll call 'deflationism,' seeks to reject conventional approaches to the metaphysics of free will altogether. Deflationist interpreters of Kant include Henry Allison, Graham Bird, and Andrews Reath (Allison 1996; Bird 2006; Reath 2006). (They do not call themselves 'deflationists,' but I think the term usefully characterizes a strategy they share). They think Kant's idealist attack on metaphysical realism includes the idea that libertarian-style free will and the deterministic causation proper to theoretical reasoning only appear to clash when, under the illusion that reason can reveal things in themselves, we try to unify them in a comprehensive system of causal relations.

Like Meerbote and Hudson, deflationists reject the idea that noumena play the role of grounding phenomenal causation. Deflationists hold that the only things in Kant's ontology are deterministic phenomena, and that ideas about noumena are, as it were, inevitable optical illusions caused by ontological reasoning. According to Bird, "The realm of noumena is a necessary, unavoidable, conceptual shadow of our immanent experience" (Bird 2006: 706). Allison argues that "Kant's transcendental distinction is primarily between two ways in which things (empirical objects) can be 'considered' at the metalevel of philosophical reflection" (Allison 1996: 3).

Deflationists read Kant as an incompatibilist, however. They hold that the standpoint of practical (rather than theoretical) reasoning requires us to regard human beings as nondeterministic first causes of actions. According to Allison, "transcendental freedom .... is an explicitly ... incompatibilist conception (requiring an independence of determination by all antecedent causes in the phenomenal world) (Allison 1996: 1).

Deflationists think they can avoid the clash between deterministic and nondeterministic perspectives on agents by distinguishing between theoretical and practical rationality and assigning them to different spaces of reason, as it were-distinct spheres of rational activity which do not come into conflict even though they sit side by side in everyday reasoning. We simply use a different causal framework to think about human beings as agents than we use to think about them as deterministic objects. From a traditional metaphysical perspective, this approach seems incoherent. How can we simply regard deterministic agents as nondeterministic without contradicting ourselves? Deflationists think that the key can be found in Kant's idealism. As explained earlier, Kant's view is that the deterministic order of the phenomenal world is the result of the human mind's idealistic construction of the phenomenal world through its contribution of the forms of space and time. If the deterministic order is merely a consequence of our own rational activity, instead of a 
mind-independent aspect of reality, then it may not seem strange to suppose that reason could require the construction of an alternative non-deterministic causal framework alongside the deterministic one, to accommodate the standpoint of practical rationality.

This idea bears a family resemblance to the Wittgensteinian theme that seems to be in the background of P.F. Strawson's "Freedom and Resentment" (Strawson 1997): that is, the notion that the concepts of free will and determinism find their proper places in different conceptual schemes or language games. To doubt the existence of free will because of concerns about determinism is to raise an external question, that is, a question external to the language game in which free will plays its proper role.

However, the deflationary interpretation cannot accommodate point $\mathrm{D}$ above any better than the Hudson/Meerbote interpretation can-it solves the free will problem by keeping the deterministic causation and free will in separate spaces of reason, while Kant links them by grounding the former in the latter.

\section{Libertarianism}

The challenge for libertarian interpreters is to explain how transcendental freedom can play a role in shaping the deterministic causal series, so that an agent in her intelligible character creates alternative possibilities for her deterministic phenomenal character. Perhaps the most elegant response is the Molinist approach proposed by Derk Pereboom (Pereboom 2006), who posits a sort of noumenal coordinator role for God in aligning intelligible characters so that all our free choices conform to the same deterministic laws. That is, since God would know what every agent would freely choose in all possible situations, God is able to create precisely those agents whose free choices conform to the deterministic laws which God selects for the phenomenal world (Pereboom 2006: 557). But Pereboom's view faces the textual challenge that while Kant remarks frequently about God and the will (he holds, for example, that belief in God helps support our motivation to act morally) he does not remark on such a coordinating role for God in his metaphysics of free will. Further, Kant's discussions of point $\mathrm{E}$ above seem to make it clear that it is our noumenal wills which ground the phenomenal causation of our actions, not God's.

Libertarian interpreters who do not appeal to divine coordination must explain how there can be room in the deterministic causal order for each agent to play a role in structuring it. As we saw above in point E, Kant claims that transcendental idealism makes it possible to suppose that one's intelligible character causes not just one's phenomenal character, but "all the past which determines it" (CPrR 5:98). But what is the "past which determines it?" Does that mean we have to be responsible for all of history, as if we were each the God of our own universe? Some interpreters have thought so (Walker 1978: 148, 149). But there is an alternative. Determinism is the view that given the facts about the world at any one time and the causal laws, the facts about the world at all points in time are determined. We need not cause events prior to our phenomenal births to cause our phenomenal characters if we can cause the causal laws that determine our phenomenal characters. Some interpreters in the recent literature who offer accounts of this form include Eric Watkins, Robert Hanna, and myself (Vilhauer 2004, 2008, 2010, 2014; Watkins 2005; Hanna and Moore 2007). The idea is that each noumenal agent controls the laws of nature that govern that same agent as phenomenon. As Eric Watkins points out (Watkins 2005: 336), 
this can be framed as a response to Peter van Inwagen's Consequence Argument against compatibilism:

If determinism is true, then our acts are the consequences of the laws of nature and events in the remote past. But it is not up to us what went on before we were born, and neither is it up to us what the laws of nature are. Therefore, the consequences of those things (including our present acts) are not up to us.

(van Inwagen 1983: 56)

According to this libertarian line of interpretation, Kant counters by denying the claim that it is not up to us what the laws are. Kant does not deny it in the compatibilist style in which David Lewis denies it (Lewis 1981, also discussed in Hudson 1994 and Vilhauer 2004). Lewis denies the claim that it is not up to us what the laws are, not by arguing that we cause any of the laws to be as they are, but rather by arguing that it is sufficient to deny this claim to argue that we have abilities to act in ways which are such that, if we had acted in those ways, some laws of nature would have been different than they actually are. He thinks this sort of ability should be unobjectionable to compatibilists. Unsurprisingly, Lewis sees the idea of causal power over the laws as absurdly magical. Libertarian interpreters hold that Kant responds not in this compatibilist spirit but in a libertarian spirit, and embraces the idea that we have causal power over the laws. Can he do so without presenting an absurdly magical view of our abilities? I think he can, because such control follows from the transcendental distinction.

As explained earlier, in Kant's view, noumena explain the particular, contingent properties instantiated by empirical objects which cannot be derived from the formal constructive activity of the human mind, including the facts about the particular causal laws which govern them (Vilhauer 2004, 2008, 2010; Watkins 2005). This helps make sense of the idea that agents in their intelligible character are responsible for causal laws. However, if the laws of nature are structured in such a way that the laws governing my phenomenal actions also govern indefinitely many other events that are not my phenomenal actions, then this interpretation would still place human agents in an unacceptably magical or godlike position. This would be the case if laws of nature were necessarily repeatedly instantiated and thus governed indefinitely many events, or unified in such a way that all particular natural laws were implied by one completely general law (such as a law of physics). However, Kant's account of causation does not imply that the laws of nature have either of these features. If Kant accepted Humean inductivism, he would be forced to accept repeated instantiation, since in Hume's view, the very concept of causal law is abstracted from observing repeated successions of event-types. But as discussed above, Kant rejects this view. He thinks that our knowledge that all events are governed by deterministic laws is a condition for the possibility of the experience of objective succession, and this means that if we had to derive the concept of causal law from observations of objectively successive events, we could never arrive at the concept of causal law (Vilhauer 2010). This means Kant can allow for laws that are instantiated only once.

In fact, Kant not only holds that we can know there are laws without knowing that they are repeatedly instantiated, Kant also holds that we can know there are laws even in cases where it is impossible to know that there are repeatedly instantiated laws. This is demonstrated in Kant's theory of empirical psychology in his book Metaphysical 
Foundations of Natural Science. Kant is a dualist about mind and body, at least at the phenomenal level. He holds that there are laws of empirical psychology, but he also holds that there are limitations on our capacity to observe events in what he calls the "phenomenal soul" (roughly equivalent to what later philosophical psychologists called the "stream of consciousness"), which imply that we cannot repeat experiments in psychology (MNS 471), and if we cannot repeat experiments, we cannot know whether psychological laws are repeatedly instantianted. This feature of Kant's philosophy of science makes it natural to posit that the particular laws we determine as noumena are laws of empirical psychology (Vilhauer 2010).

Hanna and I both point out passages in Kant's Critique of Judgment that show that Kant rejects the view that laws are necessarily unified (e.g. CJ 20:208-11). The progress of natural science requires us to assume that there is a significant amount of unification among the laws of nature, but we cannot assume perfect unity. Hanna argues that Kant's account of the organic unity of living things suggests that single-instance natural laws are emergent features of the organisms that embody human beings (Hanna and Moore: 2007: 120-2). As I see it, this would lead to problematic complexity in the laws of matter, requiring indefinite increase in the fundamental forces of matter that Kant would oppose (MNS 523-35). I argue that single-instance laws are best understood as laws of empirical psychology, that is, they are instantiated in the phenomenal soul (Vilhauer 2010). Kant's phenomenal dualism about mind and body (e.g., A379) implies that laws governing the phenomenal soul and its interactions cannot be understood as laws of matter. So this interpretation avoids the problem of excessive complexity in the laws of matter. We must still posit forces to explain such interactions, but we can suppose that they are not forces of matter. This is just what Kant appears to do. He says we

attribute to the soul a vim locomotivam, because real movements of the body arise whose causes lie in the soul's representations, without thereby meaning to ascribe to the soul the only ways in which we are acquainted with moving forces (namely, through attraction, impact, repulsion, hence movement that always presupposes an extended being).

It must be emphasized that the guiding idea of the libertarian interpretation is not that we are involved in unknowable noumenal deliberations whose contents include propositions about causal laws. In this interpretation, the contents of our noumenal deliberations are just the propositions about actions, principles, ends, and means that we customarily regard as the contents of our deliberations. Kant draws a distinction between our thoughts and deliberations as we think them, and as they appear to us. We think our thoughts and deliberations in our intelligible character-we think them as they are in themselves (G 4:451-63). However, we can also regard our thoughts and deliberations as they appear to us in 'inner sense' as phenomena of empirical psychology that we can know to be necessitated by laws of empirical psychology, even though we do not know what these laws are. The practical-rationality principles which structure our deliberations and the theoretical-rationality causal laws we posit to explain the objective succession of their appearances are different in kind, and as a consequence of our theoretical ignorance of noumena, we cannot hope for a detailed explanation of why they correlate as they do-we can only posit that it is because their phenomenal causation is grounded in our noumenal will. The goal of Kant's theory, on this 
interpretation, is merely to argue that this sort of correlation is possible, and to use this idea to explain the possibility of alternative possibilities of action: our phenomenal actions would have been determined by different causal laws if we had chosen differently. As Kant puts it, "another intelligible character would have given another empirical one" (A556/B584).

\section{Objections to Libertarianism and Brief Replies}

Some may object that any conception of determinism that allows for the possibility of laws that are instantiated just once is a very weak conception of determinism. Libertarian interpreters need not deny this, but they should emphasize that the starting point for understanding Kant's determinism is that it is formal determinism, which entails that all events are covered by deterministic laws but entails nothing about repeated instantiation or unity of laws, and it is this formal status of Kantian determinism that entails its weakness. Further, libertarians need not deny that causal laws are universal in form, such that all events of type A cause events of type B. This sort of universality is compatible with once-instantiated laws as long as there are rare enough events to instantiate these events- that is, events that occur only once. It is highly plausible that events within our streams of consciousness are sufficiently complex and varied that they occur only once. The same claim could be made about brain events if individuated with significant spatial extension, and this point may be useful in developing a phenomenal physicalist version of Kantian libertarianism.

Others may object that the libertarian interpretation is exposed to an especially sharp version of Broad's "timing objection" against agent-causation theories. Broad objects that in eschewing event-causal explanations of actions, agent-causationists confront a problem about explaining why we act (or will) when we do. The libertarian interpretation appeals to both an idealism on which causal laws establish the order of time, and also an account of libertarian control exercised via the causing of causal laws. This may make a response to the timing objection especially difficult. But this might conceivably be turned to advantage, by showing why it may be a mistake to ask for a response to the timing objection. But this is a speculative proposal which I cannot investigate further here.

Finally, some may doubt that it is worth all this metaphysical effort to build a theory that claims that free will is a mere possibility that we can never know to obtain. My view is that the possibility of free will is the most that anyone can hope to demonstrate, and that a metaphysics similar to Kant's is necessary because Kant is right to think that there is no place for free will in the network of event-causation which constitutes the world we experience. (I think this holds even if the empirical world is indeterministic, since indeterminism would inject mere chance into our wills in a way that is just as inimical to free will as determinism is. See the chapter on the Mind and Luck Arguments). But what use is the mere possibility of free will when doing ethics? In his early critical ethics, Kant holds that this mere possibility is all the epistemic warrant we require to be justified in acting "under the idea of freedom," that is, in regarding and treating ourselves and each other as transcendentally free in our practices: he holds that we need no metaphysical backing to our practices beyond this mere possibility, given what he sees as the practical necessity of regarding ourselves as free (G 4:448). In his later critical ethics, apparently dissatisfied with his earlier skepticism, Kant holds that we must know we are actually transcendentally free to have any moral reasons at all. 
(He claims to discover a path to this knowledge through practical reasoning-we know we ought to act in certain ways, and 'ought' implies 'can,' therefore we can act in those ways-but scholars have doubted the force of this argument in a philosophical system built around limitations on knowledge of noumena). I think that the truth is somewhere in between. The mere possibility of transcendental freedom is enough to support the 'can' in the 'ought implies can' principle, and some kinds of praise. But it is not enough to support instances of holding morally responsible which involve serious retributive harm such as capital punishment, and Kant is an ardent supporter of capital punishment (Pereboom 2006; Vilhauer 2014, forthcoming). If the most we can know is that free will is possible, then we must give up Kant's retributivism. For this reason, I advocate a 'justificatory asymmetry' reconstruction of Kant's theory of freedom (Vilhauer 2015, forthcoming). In my view, Kantians should find this revisionism to be no great loss, since a reconstructed, non-retributive Kantian ethics may be more desirable on normative as well as metaphysical grounds.

\section{References}

Kant's texts will be cited by Akademie pagination (i.e., as paginated in Kants gesammelte Schriften (1902-), hrsg. von der Deutschen Akademie der Wissenschaften, 29 vols. Berlin: Walter de Gruyter). The translations used here are as follows, preceded by the abbreviation used here in citations:

A/B: Critique of Pure Reason (1998), in P. Guyer and A. Wood (trans. and eds). Cambridge: Cambridge University Press.

CJ: Critique of the Power of Judgment (2000), in P. Guyer and E. Matthews. (trans. and ed.). Cambridge: Cambridge University Press.

CPrR: Critique of Practical Reason (1996), in M. Gregor (trans. and ed.), Practical Philosophy. Cambridge: Cambridge University Press.

G: Groundwork of the Metaphysics of Morals (1996), in M. Gregor (trans. and ed.), Practical Philosophy. Cambridge: Cambridge University Press.

MNS: Metaphysical Foundations of Natural Science (2004), M. Friedman (trans. and ed.). Cambridge: Cambridge University Press.

Allison, H. (1996) Idealism and Freedom. New York: Cambridge University Press.

Allison, H. (2004) Kant's Transcendental Idealism, 2nd edn. New Haven: Yale University Press.

Bird, G. (2006) The Revolutionary Kant. Chicago: Open Court.

Davidson, D. (2001) "Mental Events," in Essays on Actions and Events. New York: Oxford University Press, pp. 207-24.

Guyer, P. (1987) Kant and the Claims of Knowledge. Cambridge: Cambridge University Press.

Hanna, R. and Moore, A. (2007) "Reason, Freedom and Kant: An Exchange," Kantian Review 12: 113-33.

Hudson, H. (1994) Kant's Compatibilism. Ithaca: Cornell University Press.

Lewis, D. (1981) "Are We Free to Break the Laws?" Theoria 47: 113-21.

Meerbote, R. (1984) "Kant on the Nondeterminate Character of Human Actions," in W. Harper and R. Meerbote (eds), Kant on Causality, Freedom, and Objectivity. Minneapolis: University of Minnesota Press, pp. 138-63.

Pereboom, D. (2006) "Kant on Transcendental Freedom," Philosophy and Phenomenological Research 73: 537-67.

Reath, A. (2006) "Kant's Critical Account of Freedom," in G. Bird (ed.), A Companion to Kant. Oxford: Blackwell, pp. 275-90.

Strawson, P.F. (1997), "Freedom and Resentment," in D. Pereboom (ed.), Free Will. Indianapolis: Hackett, pp. 119-42.

van Inwagen, P. (1983) An Essay on Free Will. New York: Oxford University Press.

Vilhauer, B. (2004) "Can We Interpret Kant as a Compatibilist about Determinism and Moral Responsibility?" British Journal for the History of Philosophy 12: 719-30.

Vilhauer, B. (2008) "Incompatibilism and Ontological Priority in Kant's Theory of Free Will," in P. Muchnik (ed.), Rethinking Kant: Current Trends in North American Kantian Scholarship. Newcastle upon Tyne: Cambridge Scholars Publishing, pp. 28-47. 


\section{IMMANUEL KANT}

Vilhauer, B. (2010) "The Scope of Responsibility in Kant's Theory of Free Will," British Journal for the History of Philosophy 18: 45-71.

Vilhauer, B. (2014) "Kant and the Possibility of Transcendental Freedom," in M. Altman (ed.), Palgrave Handbook of German Idealism. New York: Palgrave Macmillan, pp. 105-25.

Vilhauer, B. (2015) "Free will and the asymmetrical justifiability of holding morally responsible," Philosophical Quarterly 65: 772-89.

Vilhauer, B. (forthcoming) "An Asymmetrical Approach to Kant's Theory of Freedom," in D. Heide and E. Tiffany (eds), Kantian Freedom. New York: Oxford University Press.

Walker, R. (1978) Kant. Boston: Routledge and Kegan Paul.

Watkins, E. (2005) Kant and the Metaphysics of Causality. New York: Cambridge University Press.

\section{Further Reading}

Allison, H.E. (1990) Kant's Theory of Freedom. New York: Cambridge University Press. (In this book, along with the others cited above, Allison sets out what is perhaps the most influential deflationist account.)

Beck, L.W. (1987) "Five Concepts of Freedom in Kant," in J.T.J. Srzednick (ed.), Philosophical Analysis and Reconstruction. Dordrecht: Martinus Nijhoff, pp. 35-51. (This paper catalogues the various ways in which Kant employs the concept of freedom.)

Bok, H. (1998) Freedom and Responsibility. Princeton: Princeton University Press. (Bok presents a broadly Kantian defense of the compatibility of mechanism and free will which has deflationist elements but is aimed at contemporary discussions of free will and moral responsibility.)

Hogan, D. (2009) "Noumenal Affection," The Philosophical Review 118: 501-32. (Hogan argues that Kant accepted the idea that our minds are affected by unknowable things-in-themselves partly in order to accommodate libertarian free will.)

Strawson, G. (1986) Freedom and Belief. New York: Oxford University Press. (In many places this book explores the Kantian idea about whether it may be practically necessary to regard ourselves as having free will.)

Wood, A.W. (1984) "Kant's Compatibilism," in A.W. Wood (ed.), Self and Nature in Kant's Philosophy. Ithaca: Cornell University Press, pp. 73-101. (Wood argues that our intelligible characters structure our actions by selecting a subset of possible worlds from which the actual phenomenal world must be drawn.)

\section{Related Topics}

Agent Causation

Free Will and Moral Sentiments: Strawsonian Views

Skeptical Views about Free Will

The Consequence Argument

David Hume

Blame 


\section{2 \\ GEORG WILHELM \\ FRIEDRICH HEGEL \\ Christopher Yeomans}

\section{Introduction}

As one would expect for a figure whose primary period of philosophical activity was the first third of the nineteenth century, Hegel's views cannot be immediately identified with positions in our own contemporary debate on free will without substantial risk of anachronism. In fact, one way of beginning to come to terms with Hegel's views on free will is to see him as offering a neglected alternative to the array of positions in the field that has developed in Anglophone philosophy since the mid-twentieth century.

To oversimplify a bit, we can think of that field as being defined by the question of whether free will and determinism (or some version of necessity) are compatible with each other. This then combines with views about the truth or falsity of determinism to generate three standard positions. Hard determinists or skeptics about free will accept that our actions are necessary (i.e., determined), that such necessity is incompatible with their being free, and thus argue that our will is not free. Libertarians also hold that free will is incompatible with determinism, but assert that determinism is false and we do have free will. Compatibilists, however, tell us that the purported incompatibility between our actions being free and their being necessary is more apparent than real, and that if we just think more carefully about free will we can see that there is nothing in the core of the notion that is inconsistent with the necessity of action in a deterministic world. Hegel represents a neglected alternative that is akin to contemporary compatibilism in the following sense: he also wants to convince us that the purported incompatibility between free will and necessity is more apparent than real, but to do so by thinking more carefully about the notions of determination and necessity rather than about the notion of freedom. So it will turn out that we can perfectly well say of an action both that it was free and that it was necessary or determined.

But, in fact, Hegel thinks that to accomplish this deeper thinking about determination and necessity we must trace them to their mutual source in the notion of explanation. The kind of determination that is relevant for the question of free will is essentially explanatory determination, and necessity is one specific form of such an explanatory determination. On this view, the deeper way of framing the problem of free will is to see it as an apparent conflict between our (theoretical) commitments to the thoroughgoing explicability of the world and our (practical) commitments to our self-conception as free sources of our own actions. The key to solving the problem of free will is then to 
investigate the notion of explanation and its specific forms. The heart of this investigation is to be found in Hegel's metaphysics, and proceeds in three parts: first, a theorization of the explanatory relation as such; second, a conceptualization of the modalities (actuality, possibility, and necessity) as forms of explanatory relations; and third, a reconstruction and prioritization of teleological over causal/mechanical forms of explanatory relations.

\section{Three Challenges to the Possibility of Free Will}

In this section, we will tackle each of these three investigations in turn. For each, we will first set out some reasons for thinking that the concepts at issue are at least prima facie incompatible with free will. Then we will briefly consider Hegel's conceptualizations of those concepts, and finally, we will suggest how the conceptualizations he endorses show that the incompatibility is merely apparent and not real.

With respect to the contemporary Anglophone debate, one of the virtues of Hegel's way of framing the problem of free will as the contrast between explicability and free will rather than determinism and free will is the way that it draws into the core of the debate an argument from Galen Strawson that has been very influential and widely anthologized. This is an argument that purports to show that the constraint that free action be rational, and thus, explicable, is sufficient to rule out the possibility of free will, independent of the truth and falsity of determinism.

There is neither need nor room to reconstruct Strawson's argument in any detail here. Obviously, Hegel did not have access to Strawson's argument, and Strawson himself thinks that the argument's force is largely independent of its specific form. Simply put,

(1) You do what you do because of the way you are. So (2) To be truly morally responsible for what you do [i.e., to have a truly free will] you must be truly responsible for the way you are-at least in certain crucial mental respects. But (3) You cannot be truly responsible for the way you are, so you cannot be truly responsible for what you do on pain of an infinite regress.

(Strawson 2003: 219)

The "because of" in (1) gets its force and structure from representing the constraints of true or full explanation.

This is not a new argument; some version of it goes back at least to Hobbes, who claimed that "The will is not voluntary. For a man can no more say that he will will, than he will will will, and so make an infinite repetition of the word will, which is absurd, and insignificant" (Hobbes 2008: Chapter 12, paragraph 5). But the real question is, what is it about the nature of explanation that generates this conflict with free will by way of an infinite regress? It is our expectation of the externality of the explanation, that is, our need to have something other than or outside of the original phenomenon do the explaining. In the case of free will, it seems natural to think of this somethingthe explanans, to use a technical term-as a choice or decision that is external and perhaps prior to the action it explains (the explanandum). That prior choice then becomes an explanandum that requires its own explanans, and we are off on an infinite regress.

Hegel, however, thinks that this expectation has to be balanced by a corresponding internality of the explanation, and in two related senses. First, the explanans has to be 
internal to the explanandum in at least some respect, otherwise it is difficult to see how an explanation is supposed to improve our understanding of the original phenomenon. When we explain things, we don't just add another fact to the neighborhood of the original phenomenon; rather we learn more about it. Second, the explanans has to be internal to itself in the sense that it cannot automatically require a further explanation-if this were the case then we would never have any true or full explanations of any kind of phenomenon whatsoever. This point about internality has been recognized by a wide variety of contemporary Anglophone thinkers on explanation, and is at the heart of ordinary physical explanation (e.g., of the behavior of water by appeal to the fact that it is $\mathrm{H}_{2} \mathrm{O}$, or the explanation of the movement of a billiard ball by appeal to conservation of force).

Traditional accounts of free will essentially involve the internality at issue here. To cite only two examples important for Hegel, J.G. Fichte claimed that what we want out of a conception of free will is a kind of internal power whose exercises would be selfexplanatory $(1987: 20,21)$, and for Aristotle the heart of voluntary action is the notion of an internal moving principle (1999: III.i). Nonetheless, it is important that Hegel's view is not primarily oriented by the attempt to save free will-it is just an attempt to save explanation as such. And that attempt leads to the result that all explanations have to be at least partially self-explanatory or, to use a term from Robert Nozick, selfsubsuming (1983: 120).

There is no room to delve into the substantial complexity of Hegel's attempts to generate a structure that will balance both the internality and externality of explanation, but we have enough already to see how Hegel's conception of explanation demonstrates that the conflict between our commitments to the explicability of the world and to free will is more apparent than real. Strawson and Hobbes conceive of free rational action as being a function of principles (or mental states) that are independent of that action, and then demand that the action that follows from those principles can only be free if they are themselves chosen, that is, a function of a further set of principles (or mental states), and so on ad infinitum. But on the self-subsuming model of explanation suggested by Hegel, the principles of which the action is a function can be thought as features of the action itself (e.g., its consistency with the moral law, or its serving as a means for a good end). Conversely, we can think of the action itself as weighting the reasons and thereby making them a good explanation for the action. If this is the case, then there need be no infinite regress of choices.

It is easier to see the apparent conflict between free will and necessity and we can use the current locution 'alternate possibilities' to describe the feature of free will that appears to contrast with the necessity of action. On a rather natural construal of the modalities (i.e., of actuality, possibility, and necessity), if what we do is one from among a number of alternate possibilities, then what we actually do is merely possible and not necessary. If it is necessary, in contrast, then we couldn't have done otherwise. Thus, it looks as if we have to give up either our commitment to explaining events in the world in terms of necessitating conditions and/or natural laws, or our commitment to seeing ourselves as freely initiating courses of action. Hegel, however, thinks that a free action could be both merely possible in the relevant sense and necessary. And as with his thoughts on explanation, his claims about the modalities are motivated by general metaphysical reasons rather than specific intuitions about agency.

In fact, Hegel develops two different models of the relation between alternate possibilities and necessity, which go under the names 'real' and 'absolute' necessity. Both 
models are common, both have their value in our everyday and scientific understandings of the world, and on neither model are alternate possibilities and necessity incompatible with each other. To put it another way, there is a kind of indeterminism even within the necessity of an event, and the two models provide different interpretations of that indeterminism. In real modality, indeterminism is a kind of looseness of fit between the conditions and the event that leaves the latter undecided; in absolute modality, it is precisely the tightness of fit between the two that points to the fact that other tight fits are possible. We can briefly illustrate the difference here using an example (see Yeomans 2011: Chapter 7). One might think that it was necessary that person with a quick temper would become angry in response to an insult. In Hegel's view, that necessity is an explanatory relation between a possibility (the insult and the temper as conditions) and an actuality (being angry in some particular way). But this necessity, which would be a reliable piece of information in a workplace situation or in a detective novel, is compatible with a number of different responses. For example, the person insulted might hit the insulter, or might respond verbally by returning the insult. In such a situation, we might say that it was necessary that the person with the temper respond in some way, even though there might be a range of responses that would be compatible with that necessity. This way of thinking about the example uses the model of real modality, in which necessity is compatible with a looseness of fit between general conditions (the insult and the temper) and specific actualities that follow from it (hitting or responding verbally).

To use the model of absolute modality to analyze the example we come back to the point about internality discussed in the previous section on explanation. In this model, the temper (i.e., the agent's character) is itself the necessitating, explanatory connection between the condition of possibility (the insult) and the actuality (the response). But here, this necessary relation will not just mediate externally between the insult and the response; instead, it will make them what they are. Take the condition: for some statement to be an insult it must be taken as an insult by some hearer (either the target or bystanders, but here we focus on the former). As a character trait, a quick temper is in part defined by the readiness to take many statements to be insults. Modally speaking, Hegel thinks that there is something even deeper going on in cases like this. In shaping the conditions, the relation of necessity constructs a continuum of alternate possibilities in terms of which the actual response is to be interpreted. Both the condition and the actual action could have been formed differently by the agent's character: the insult could have been perceived to be more or less severe, and the resulting action could have been more or less far along a continuum running from minor annoyance to physical aggression. This means that the agent's character could have manifested itself anywhere along this continuum, from inappropriately self-deprecating to having a chip on her shoulder. Anywhere along that continuum we would find an intelligible, necessary relation between the condition (the insult) and the actuality (the response), and this intelligibility is inherently connected with recognition of the other possibilities along that continuum. So here, understanding the example under the model of absolute modality, we have a deeper necessity but also a deeper sense of alternate possibilitieshere one defined by the tight fit character makes between conditions and responses.

In fact, Hegel thinks that we do frequently look at the will in these two ways, and he connects the modal distinction to a distinction in models of the will indicated by two German terms, Willkür (freedom of choice) and Wille (free will). We use the model of freedom of choice when we consider the conditions of an action as independent 
antecedent events and ask what is necessary on their basis. Since Hegel thinks that our motivations are generally underdetermined in a variety of ways, even if we had very strict relations of necessity to attach to them, the outcomes would remain underdeterminedthis is looseness of fit again. From this point of view, the agent has precisely the alternate possibilities posited by libertarian theories. We use the model of free will when we take motivations to be specified and determined by the action itself, and thus, to have the tighter fit between conditions and responses characterized by absolute modality. But because that tight fit is generated by the process of action along a continuum of other possible tight fits, there remain alternate possibilities in the more compatibilist sense of different possible characters.

There is thus a sense in which Hegel's view too is a "compatibilism of incompatibilism and compatibilism," as Allen Wood has characterized Kant's view (1998). But the contrast is no longer between our commitments to the explicability of the world and our self-conception as free agents; rather, each modal model is available within the operation of each commitment, and there is no conflict within each model. The purported conflict results from a syncretism that takes the determinacy of motives from the free will model (without acknowledging the dependency of that determinacy on the agent's activity), and combines it with the independent, antecedent status of motives from the model of freedom of choice (without acknowledging the indeterminacy of motives which comes with such independence).

The basic problem of causal or mechanical explanations is one of passivity. If the world is exhaustively constituted as a causal web or chain, each link of which is an effect, it can come to look as if each link simply receives and passes on an impetus that comes to it from the prior link of the chain. But agency seems like an active phenomenon, an origination of some sort rather than a receptive continuation of some prior course of events. Furthermore, in the exhaustively causal picture whatever distinctive contribution each link makes would appear to be a matter of a fixed dispositional response to that impetus, which doesn't look like what we usually take to be agency either. The paradigmatic instances of agency seem instead seem to take initiative, to use resources given by the world in pursuit of the agent's goals. In Hegel's terms, there is an elasticity to goaldirected agency as opposed to the fixed passivity of causal relations. Thus there is an apparent conflict between our teleological self-conception and the explanatory commitments to an exhaustively causal world that at least eighteenth-century science seemed to demand.

Here we must be even briefer about the metaphysics. Suffice it to say that Hegel takes teleological explanations to be more fundamental than causal explanations because the identity conditions for the objects or events that are then causally related must be specified teleologically. That is, if objects and events did not have a teleological form that individuated them, there would be no stable relata for causation to relate, so teleological relations or processes are conditions for the possibility of causal relations. This argument does not deny that (efficient) causation takes place in the mental and natural world; it merely denies that only such causation takes place, or that all teleological processes can be reduced to efficient causal processes. The teleological processes in the world are ways of deploying causal processes in plastic and persistent attempts to achieve goals in given circumstances.

To turn to free will, the central difficulty for causal accounts of action is determining what particular kinds or forms of causal relations between motivations and outcomes make for action, out of all of the innumerable causal relations that are possible. Here is 
an example to motivate the difficulty: a waiter who desires to startle his employer by knocking over a stack of glasses is so unnerved by that desire that he involuntarily steps into the glasses, knocking them over and startling his employer. It seems that there is a causal relation between the desire to startle and the employer being startled, but it doesn't seem to be of the right kind. We are inclined to say that the waiter nonetheless inadvertently startled his employer (Wilson 1989). But it is difficult to see what general form proper, intentional causal chains have that distinguishes them from wayward, or deviant causal chains that make for unintentional actions.

The teleological account Hegel offers provides some resources to solve this problem. In this account, the end or goal represents the constancy of systematic orientation that is maintained behind but also through the manifold and changing causal processes that make up goal-directed behavior. Consider another version of the waiter example, in which the waiter feels his nervousness coming on and recognizes it as a resource that might be used to do what he might otherwise not have the nerve to do. He refrains from controlling his nervousness and instead lets it play out next to the stack of glasses. The glasses are spilled and the employer is startled. In that case, we should say that the waiter intentionally startled his employer.

What accounts for the difference between the cases? We might be tempted to locate the difference in an additional causal chain, for example, control by the higher order mental state. In this way of seeing things, the intention would cause the recognition of the nervousness as a resource and then its utilization. But it is not clear how this differs from the first case, in which the intention caused the nervousness which then caused the glasses to be spilled and the employer to be startled. Rather, we ought to say that the waiter in the second example acts intentionally because the control of the intention is represented by the plasticity with which the realization of that intention is pursued, and the way in which new means are recognized when they present themselves. That is, the plasticity or elasticity shows the way in which the goal illuminates context so as to reveal conditions as means, and this is an aspect of agency that cannot easily be captured on the model of a causal process or power.

Goal directedness gives us the orientation towards and in the world that is necessary for our self-understanding as originators of courses of action. If Hegel is right that such goal-directedness is both more fundamental than strictly causal connection, and is a metaphysical feature of both the natural and mental worlds, then again he has shown that the conflict between our commitment to explaining the world and our commitment to free will is more apparent than real.

\section{Hegel as Source Incompatibilist}

In the introduction to this chapter, I characterized Hegel as a neglected kind of compatibilist, because he held that our actions could be both necessary and free, so long as one understood necessity in the right kind of way. But here there is always possible a similar kind of response to the one that incompatibilists have to compatibilist understandings of free will. Just as incompatibilists complain that the compatibilist analysis of free will isn't really what we mean by that term, it is natural for both incompatibilists and more usual compatibilists to complain that Hegel's view isn't really what we mean by 'determinism' and 'necessity.' Those terms, so the objection goes, mean something more ordinary, something like efficient causation governed by natural laws. (Assuming, of course, that the natural laws at issue required particular outcomes rather than a 
probabilistic distribution of outcomes). On this construal, Hegel just holds that determinism is false, and must be so for us to have free will. Furthermore, one of the frequent motivations for compatibilism is its relative metaphysical modesty: it purports to present a view of free will that is consistent with a wide variety of metaphysical descriptions of the causal structure of the world (even, perhaps, indeterministic descriptions). As a result, most compatibilists have had relatively little interest in working on the other side of the equation, that is, developing a concrete account of the causality of the world and our actions within it. In the division of labor of this conversation, that task has been left to the libertarians. Hegel, in contrast, is very far from modest in the scope of his metaphysical claims and in their integration with his conception of the free will.

For both these reasons, Hegel might equally be characterized as an incompatibilist. And, in fact, I want to close this chapter by suggesting that the figure in the contemporary debate to whom Hegel is closest is actually a libertarian, Robert Kane. Kane is sometimes labeled a source incompatibilist, which simply means that on his view alternate possibilities matter to free will not in themselves, but because they are necessary if we are to be the ultimate sources of our own actions. For both Kane and Hegel, the need for this kind of singular significance- - to be someone who matters in the world in virtue of being the author and sustainer of one's own course of life—-generates a remarkable series of pluralities. That is, the number and kind of alternate possibilities are multiplied, even to the extent of partially undermining the agent's control in precisely the way that compatibilists and skeptics suspect. For Kane, truly free actions (what Kane calls "Self-Forming Willings") are cases in which we struggle to set the end that we want to set, and specifically because we also want to set some competing end, we could also set that competing end, and we have good reasons to do so. So as Kane sees it, these Self-Forming Willings are plural in three senses: they are plural voluntary, plural controlled, and plural rational. These track the three sense of willing itself, that is, that the will is desiderative, striving, and rational. (Strictly speaking this isn't quite right, since [a] voluntariness involves not merely desiring but desiring more than any other alternatives [and thus the plurality of voluntariness involves not merely desiring different things but the possibility that different things could be most desired]; and [b] voluntariness also requires lack of coercion. See Kane 1998: 30).

The indeterminism that makes Kane's view incompatibilist is most directly tied to plural control. Kane holds that this plurality has a consequence that compatibilists and hard determinists have often raised as an objection to libertarianism, namely that it actually undermines the agent's control. As Kane puts it,

Paradoxical as it may seem, in order to have ultimate control over their destinies, possessors of free will must relinquish another kind of control at pivotal points in their life histories, namely, an antecedent determining control that would guarantee how things will turn out in advance.

(Kane 1998: 144)

That is, in order to originate our actions, it has to be the case that even our own actions, resolutions and decisions do not completely eliminate alternate possibilities for future action. The objection is not wrong, but it does not have the force that the objector thinks it does. It simply shows that we are incomplete or imperfect originators of our actions, which is about as much as we ought to have expected to start out with. 
Hegel deeply accepts this paradox in his analysis of human free will. On the one hand, our rational will makes possible an active mental life that is of infinite value and is worthy of fundamental respect. On the other hand, the deep necessities of character that manifest themselves in that life are always also contingent and capable of radically altered manifestation in the practical circumstances of action over which the agent often has somewhat limited control. As does Kane, Hegel sees within each agent an internal plurality of goals that coexist in constant and sometimes uneasy tension with each other. The executive function of the will involves managing that tension, but it can only do so by identifying with particular goals, and so agents are constantly and necessarily imperfectly attempting to express the whole of their character through identification with one of its parts. This is a tough and interminable task, and so free will cannot be located in any simple causal or structural relation between an agent-or her intention - and an action. But we do sometimes succeed, and such success is a real achievement. Free will would not be worthy of such respect if it were not so difficult.

\section{References}

Aristotle (1999) Nicomachean Ethics, 2nd edn, trans. T. Irwin. Indianapolis: Hackett Publishing Company, Inc.

Fichte, J.G. (1987) The Vocation of Man, New Ed Edition, trans. P. Preuss. Indianapolis: Hackett Publishing Company, Inc.

Hobbes, T. (2008) Human Nature and De Corpore Politico, Reissue Edition, J.C.A. Gaskin (ed.). Oxford and New York: Oxford University Press.

Kane, R. (1998) The Significance of Free Will. New York: Oxford University Press.

Nozick, R. (1983) Philosophical Explanations, Reprint edition. Cambridge: Belknap Press.

Strawson, G. (2003) "The Impossibility of Moral Responsibility," in G. Watson (ed.), Free Will, 2nd edn. Oxford: Oxford University Press, pp. 212-28.

Wilson, G. (1989) The Intentionality of Human Action: (Stanford Series in Philosophy), Revised and Enlarged Edition. Stanford: Stanford University Press.

Wood, A.W. (1998) "Kant's Compatibilism," in P. Kitcher (ed.), Kant's Critique of Pure Reason: Critical Essays. New York: Rowman \& Littlefield, pp. 239-63.

Yeomans, C. (2011) Freedom and Reflection: Hegel and the Logic of Agency. New York: Oxford University Press.

\section{Further Reading}

Laitinen, A. and Sandis, C. (eds) (2010) Hegel on Action. London: Palgrave MacMillan. (A newer anthology representing the latest research.)

Pippin, R. (2008) Hegel's Practical Philosophy: Rational Agency as Ethical Life. Cambridge: Cambridge University Press.

Stepelevich, L. and Lamb, D. (eds) (1983) Hegel's Philosophy of Action. Atlantic Highlands: Humanities Press. (A classic anthology of papers on Hegel's philosophy of action.)

Yeomans, C. (2015) The Expansion of Autonomy: Hegel's Pluralistic Philosophy of Action. New York: Oxford University Press.

\section{Related Topics}

Free Will and Moral Sentiments: Strawsonian Views

Leeway vs. Sourcehood Conceptions of Free Will

Immanuel Kant

The Relation between Moral Responsibility and Freedom 


\section{3 \\ FRIEDRICH NIETZSCHE \\ Mattia Riccardi}

\section{The Puzzle}

Nietzsche's works confront the reader interested in the issue of free will, or, more generally, of freedom, with an interpretive puzzle. On the one hand, in both his published work and unpublished notes, passages abound where he seems to explicitly deny that we have anything like free will. On the other hand, Nietzsche often appeals to the notion of freedom and its cognates, in particular when he is in the business of sketching his own ideal of humankind. I shall offer a brief but illustrative sample of both cases.

In Human, All Too Human, the "total unfreedom of the human will" is said to be our "strongest knowledge" (HUH II, "Assorted Opinions and Maxims" 50). In Daybreak we read:

We laugh at him who steps out of his room at the moment when the sun steps out of its room, and then says: "I will that the sun shall rise;" and at him who cannot stop a wheel, and says: "I will that it shall roll;" and at him who is thrown down in wrestling, and says: "here I lie, but I will lie here!" But, all laughter aside, are we ourselves ever acting any differently whenever we employ the expression: "I will"?

In Twilight of the Idols, Nietzsche claims that the notion of "will" is but one of the "illusions and phantasms" of the "inner world" (TI, "The Four Great Errors" 3). The same diagnosis applies to the idea of the "will as causal agent," of "consciousness ('mind') as cause" and of "the I ('subject') as cause" (TI, "The Four Great Errors" 3). Thus, the very idea of mental causation substantiating the conception we have of ourselves as free agents is rejected in all its usual variants. Moreover, Nietzsche's rejection of free will seems to go hand in hand with his acceptance of determinism, as suggested, for instance, by the aphorism from Daybreak just quoted. In an unpublished note from 1887, we read that "to occur and to occur necessarily is a tautology" (KSA 12, 1887: 10[138]). Finally, (some version of) determinism seems presupposed by some of the ideas Nietzsche most wholeheartedly advertises, such as eternal recurrence and "amor fati."

I now turn to the second set of passages - those appealing to freedom and its cognates. In Twilight of the Idols, Nietzsche devotes an aphorism to his own "idea of freedom," its first characterization of it being "the will to be responsible for yourself" (TI, "Skirmishes of an Untimely Man" 38). Elsewhere, he envisages an ideal "free spirit" characterized by 
a "self-determination, a freedom of the will, in which the spirit takes leave of all faith and every wish for certainty, practiced as it is in maintaining itself on light ropes and possibilities and dancing even besides abysses" (GS 347). At least at face value, such passages seem to put forward a positive notion of freedom.

(In the Genealogy of Morality, Nietzsche introduces the character of a "sovereign individual" whom he describes, inter alia, as a "master of a free will" [GM II 2]. Interpreters claiming that Nietzsche proposes a positive ideal of freedom usually take the "sovereign individual" to embody it. What role this figure plays in the Genealogy remains highly controversial and has become the topic of an entire sub-literature. As it is impossible here to go into the details of such an intricate debate, I shall simply sidestep it).

\section{What's Beyond Dispute}

A first step toward a resolution of the interpretive puzzle consists in determining the specific notion of free will usually targeted in Nietzsche's writings. The claim I would like to defend is that the relevant notion amounts, roughly, to the capacity to ultimately originate the course of one's action. But what does this mean precisely? An action is ultimately originated if by backtracking the causal chain that leads to it we find that the last ring is the agent. Moreover, the agent's contribution cannot itself be the result of another causal chain starting outside of her. To have a handy label, I shall refer to this notion by the label ultimate free will. Roughly, it corresponds to the notion of free will that incompatibilists—-both hard incompatibilists and libertarians-agree in seeing as grounding ascriptions of moral responsibility. Nietzsche typically pursues two different lines of criticism against it. On the one hand, he questions its theoretical cogency as such. On the other hand, he tries to undermine its validity by arguing that it depends on a set of dubious evaluative commitments.

Aphorism 21 from Beyond Good and Evil nicely illustrates the first strategy:

The causa sui is the best self-contradiction that has ever been conceived, a type of logical rape and abomination. But humanity's excessive pride has got itself profoundly and horribly entangled with precisely this piece of nonsense. The longing for "freedom of the will" in the superlative metaphysical sense ... the longing to bear the entire and ultimate responsibility for your actions yourself and to relieve God, world, ancestors, chance, and society of the burden-all this means nothing less than being that very causa sui and, with a courage greater than Münchhausen's, pulling yourself by the hair from the swamp of nothingness up into existence.

(BGE 21)

It seems clear that Nietzsche's target is here ultimate free will as characterized above. To think of oneself as free in such a "superlative metaphysical sense," he tells us, amounts to think of oneself as a causa sui, i.e. as the genuine originator of oneself. This conception, however, is incoherent. But why is it so?

Advocates of ultimate free will usually acknowledge that many of our actions depend on our character or on previously acquired habits. Nonetheless, they argue, such actions can be said to be free in the relevant sense-for instance, as accountable in terms of merit-as long as we can say of the agent that "he was responsible for being the sort of 
person he had become at that time" (Kane 1996: 39). In other words, ultimate responsibility is transmissible from past free actions to current necessary actions, provided that the latter derives from traits, habits, etc., which have been brought about by the former. According to Nietzsche, however, this condition cannot be met, as no one is ever responsible - in the ultimate sense-for what one is at a certain time, for this is always part of some causal chain starting outside of one (on this point see Fischer [2007: 66-70], who also refers to Nietzsche's argument [2007: 70]; for a full endorsement of Nietzsche's causa sui argument, see Strawson 1994):

What is the only teaching we can have?-That no one gives people their qualities, not God or society, parents or ancestors, not even people themselves (-this final bit of nonsense was circulated by Kant-and maybe even by Platounder the rubric of "intelligible freedom"). Nobody is responsible for people existing in the first place, or for the state or circumstances or environment they are in. The fatality of human existence cannot be extricated from the fatality of everything that was and will be.

\section{(TI, "The Four Great Errors" 8)}

However, if what we consist in is just a "piece of fate," we must conclude "that nobody is held responsible any more, that being is not the sort of thing that can be traced back to a causa prima" (TI, "The Four Great Errors" 8).

The second strategy pursued by Nietzsche aims at showing that the conception of ultimate free will embodies a specific, and to his eyes highly questionable, evaluative stance. It is, namely, a certain "type of man"- the "majority of the dying, the weak and the oppressed of every kind"-who "needs to believe in an unbiased 'subject' with freedom of choice" (GM I 13). More specifically, Nietzsche argues that the extraordinary success of the psychological framework based on the conception of ultimate free will is due primarily to the justification it provides to our current practices of punishment:

Whenever a particular state of affairs is traced back to a will, an intention, or a responsible action, becoming is stripped of its innocence. The notion of will was essentially designed with punishment in mind, which is to say the desire to assign guilt.

(TI, "The Four Great Errors" 7)

To summarize, Nietzsche offers two reasons to reject ultimate free will. First, it amounts to an incoherent conception. Second, it expresses a contemptible, resentment-driven evaluative stance: no freedom worth wanting would look like that.

\section{The Real Issue}

In the previous section, I argued that Nietzsche rejects ultimate free will. This can be taken to mean that he rejects any notion of freedom whatsoever. A reading along these lines would therefore construe Nietzsche as a hard incompatibilist (see Leiter 2015). On an alternative reading, Nietzsche's dismissal of ultimate free will is still consistent with less "superlative" conceptions of freedom. According to this second strategy, he would therefore turn out to defend a version of compatibilism to the effect that, though determined, we still may be, in some sense, free (see, for instance, the recent pieces by Guay 
2002; Gemes 2009; Richardson 2009; Rutherford 2011; Constâncio 2012). The real controversy among Nietzsche interpreters concerns this point.

To start addressing this crucial issue, it is helpful to briefly consider Nietzsche's take on determinism. After having exposed the inconsistency of ultimate free will, aphorism 21 from Beyond Good and Evil invites the reader to "carry his 'enlightenment' a step further and to rid his mind of the reversal of this misconceived concept of 'free will:' I mean the 'un-free will,' which is basically an abuse of cause and effect" (BGE 21). In a similar vein, both "free will" and "unfree will" are counted in the Anti-christ among the "imaginary causes" postulated by Christianity (A 15). Should we then read the claim that the notion of unfree will is as ill-thought as that of free will as indicating that Nietzsche does not hold determinism to be true after all? This would be an overhasty conclusion, for his point in BGE 21 is merely that the conception of the will as "unfree" derives from a misapplication, or misunderstanding, of the concepts of cause and effect. Nietzsche often expresses skepticism about thinking of events as instances of universal causal laws. Relevantly, as it is surely no coincidence, aphorism 22 from Beyond Good and Evil is among the passages where he puts forward precisely this kind of criticism. It seems thus natural to read BGE 22 as explicating the way in which the notions of cause and effect are usually misunderstood such as to lead, inter alia, to the fallacious picture of an unfree will targeted in BGE 21. Most important for our issue, however, is that the positive view Nietzsche puts forward in BGE 22 ends up claiming "the same thing about this world," namely "that it follows a 'necessary' and 'calculable' course, although not because laws are dominant in it, but rather because laws are totally absent" (BGE 22). In a similar vein, we read in Gay Science: "Let us be aware of saying that there are laws in nature. There are only necessities" (GS 109). From this, there are two conclusions we can draw. First, Nietzsche does not question determinism as such, but only a nomological construal of it appealing to universal causal laws. Second - and for our issue more importantly-he thinks that by dropping the nomological construal we (can) obtain a version of determinism that no longer entails that the will is unfree.

Elsewhere Nietzsche addresses another misconception of determinism's consequences he labels "Mohammedan fatalism," that is, the view that each of us, however hard one tries to elude one's own fate, is doomed to succumb to it. This view, Nietzsche argues, motivates our natural discontent in response to determinism:

The fear most people feel in face of the theory of the unfreedom of the will is fear in face of Mohammedan fatalism: they think that man will stand before the future feeble, resigned and with hands clasped because he is incapable of effecting any change in it: or that he will give free rein to all his impulses and caprices because these too cannot make any worse what has already been determined.

\section{(HUH II, "The Wanderer and His Shadow" 61)}

Nietzsche makes here two points. First, Mohammedan fatalism is incoherent, since once determinism has been accepted the very idea of someone trying to resist one's destiny simply ceases to make any sense at all, for every effort we might possibly seem to make in order to avoid our fate would just be part of it. Second, this means that not only "the struggle is imaginary, but so is the proposed resignation to fate" (HUH II, "The Wanderer and His Shadow" 61). This last point is particularly relevant, as it highlights 
that for Nietzsche our lacking (ultimate) free will does not mean we have no choice but to surrender to alien forces just because "there's nothing we can do."

This cursory survey shows that Nietzsche takes determinism to entail neither that we lack any kind of freedom whatsoever, nor that we are completely at the mercy of extrinsic factors. Although this leaves room for compatibilism, it hardly suffices to conclude that that is the position he endorses. So it looks as if we have made no real progress concerning the main issue of disagreement. Fortunately, BGE 21 offers again a precious clue as to how to move forward. There, Nietzsche writes that "in the real life it is only a matter of strong and weak wills" (BGE 21). This seems to suggest two things. First, the kind of freedom that can be said, if at all, to obtain in our world is a matter of degree. Second, what determines its reach - the degree of freedom each of us enjoys-is the particular constitution of one's will. To spell out these points, we first need to know more about Nietzsche's view of the will.

\section{Nietzschean Will}

Remarkably, Nietzsche's own picture of how the will works is to be found in aphorism 19 from Beyond Good and Evil, that is, at a textual location very close to where he rejects the complementary notions of "free will" and "unfree will" as traditionally thought of. Again, this seems to suggest that the notions of "strong will" and "weak will" alluded to in BGE 21 are to be understood in light of the general model of the will sketched in BGE 19 (on this aphorism see Leiter 2007; Clark and Dudrick 2009). Nietzsche starts by pointing out that an instance of willing is a complicated psychological phenomenon, involving a range of different mental ingredients. First, and less important for his account, there is a "plurality of feelings" (BGE 19), both bodily and not, which contributes to its overall phenomenology. Second, willing involves what Nietzsche calls a "commandeering thought." Third, its most distinctive feature consists in its being a specific kind of "affect," namely, "the affect of the command" or, in another formulation, "the affect of superiority with respect to something that must obey" (BGE 19).

A straightforward relation seems to obtain between these last two and more central elements: willing is essentially the "affect of the command" because a "commandeering thought" is its basic ingredient (BGE 19). What looks quite puzzling is, rather, Nietzsche's overall talk of commanding and obeying. Only by taking a brief look at his philosophical psychology will we be in a position to make sense of it.

The basic notion of Nietzsche's philosophical psychology is that of drive (Richardson 2004; Katsafanas 2013). Roughly, a drive is a disposition to behave in certain ways. For instance, the sexual drive is a disposition to engage in a typical range of mating behaviors. Each of us, Nietzsche claims, is constituted by a number of such drives. As the many drives we harbor typically make for different, often blatantly opposite inclinations, an open contrast—or at least a constant tension—ensues between them. How are such conflicts resolved? An option here would be to think that some higher-order power, as the self's rational capacities, intervenes and settles the contrast by mediating between the drives. Nietzsche, however, rejects this solution: while "'we' believe we are complaining about the vehemence of a drive, at bottom it is one drive which is complaining about the other" (D 109; see also BGE 117). Whatever "procedure [of] our intellect" participates in the conflict's resolution, it acts only as "the blind instrument of another drive" (D 109). Thus, rather than seeing the transactions between the drives as negotiated by some external power, Nietzsche holds that their mutual arrangement 
results directly from the power relations obtaining between them. If such power relations prove somewhat stable, the drives end up building a hierarchical structure in which some drives dominate the others.

This framework illuminates Nietzsche's talk of command and obedience in BGE 19. The "commandeering thought" at the heart of any willing is issued by the dominant drive to the subordinated drives that are supposed to execute it. Nietzsche also appeals to this model in order to explain the peculiar phenomenology of agency. Accordingly, one typically "identifies himself with the accomplished act of willing" (BGE 19), that is, in a case of success, one assumes-at the personal level-the perspective of the dominating drive which — at the subpersonal level—managed to have the subordinated drives help execute its own command. Put differently, "the one who wills takes his feeling of pleasure as the commander" (BGE 19).

\section{Strong and Weak Wills}

According to Nietzsche, episodes of willing result from the specific arrangement of one's drives. With this conception in place, we are finally in a position to examine in which sense such episodes may be taken to express a will that is either "strong" or "weak." I shall start by investigating the latter case.

That a given episode of willing fails to be realized does not suffice to render one's will, on that occasion, weak. If I want to take a ride with my bicycle and find that it has been stolen, my desire will of course remain unsatisfied. Nonetheless, it would make no sense to characterize my situation as a case of weakness of the will. For the will to prove weak, the agential failure must depend on the subject herself, and not just on some external factor - as if I were to renounce the ride for not being able to overcome my usual laziness. In short, weakness of the will presupposes that something goes wrong within the agent.

What goes wrong in the akratic case is usually taken to be one's incapacity to act according to one's best judgment. Nietzsche's story, however, is a different one. As his model has it, successful agency occurs when the command issued by the dominant drive is executed by the subordinated drives. If this does not happen, no action follows to one's willing. As my want remains unsatisfied in virtue of something that goes wrong within myself, a case of this kind suitably qualifies as one of weakness of the will.

The key question, here, is about what precisely goes wrong. Under which conditions does the "commandeering thought" end lacking the solicited enforcement? Many of the things we do-in particular, many of those we most care about, such as taking a degree, climbing a mountain, or getting married—can be seen as the realization of corresponding wants. Such situations, however, require that we keep on wanting the relevant thing. Concluding a degree takes a couple of years. To climb a mountain, I have to persist and go on until I have reached its peak. As the necessary motivation and strength are often hard to preserve, such are the cases in which our will is most likely to fail. According to Nietzsche's picture, this happens when the hierarchy holding between one's drives turns out to be too unstable to guarantee the achievement of such goals.

The most blatant cases of failure are those where "anarchy threatens inside the instincts and ... the basic structure (Grundbau) of the affects, which we call 'life,' has been shaken" (BGE 258; translation changed). In such a condition, the agent's drives simply cease to stay in any clear arrangement whatsoever. For Nietzsche, this kind of "corruption" is typical of historical periods characterized by profound cultural change, 
like pre-revolutionary France or Greece during the twilight of the tragic age. Europe in the late nineteenth century is another such case: "In times like these, giving in to your instincts is just one more disaster. The instincts contradict, disturb, destroy each other; I even define modernity as physiological self-contradiction" (TI, "Skirmishes of an Untimely Man" 41; see also BGE 200, 208).

The way in which the will fails out of weakness lets us clearly appreciate what it means for it to be strong: to possess a stable hierarchy among one's drives. What this condition is supposed to enable is a certain kind of independence. To appreciate this point, consider again the case of anarchic will. For Nietzsche, weakness is due to the fact that - absent a dominant drive - any impulse coming from the outside is able to trigger one of our drives. Instead of acting, one merely reacts to external stimuli. Genuine action requires on the contrary that we not succumb to the urges of the many diverging drives: "the first preliminary schooling for spirituality" consists in "not to react immediately to a stimulus, but instead to take control of the inhibiting, shutting (abschliessenden) instincts" (TI, "What the Germans Lack" 6; translation changed). As this capacity to master the diverging inclinations constituted by our drives puts one in a position to pursue and realize one's goals, we can call it enkratic independence.

\section{Is a Strong Will a Free Will?}

Nietzsche rejects the traditional conception of free will according to which we have the capacity to ultimately originate our actions. He rather suggests to distinguish between strong and weak will. What makes one's will strong or weak is its particular constitution. A will resulting from a stable order between one's drives counts as strong, as it enables one to perform demanding actions such as climbing a mountain or taking a degree. Weakness of the will depends, on the contrary, on a chaotic arrangement between one's drives. In such a condition, we are simply hostage to arbitrary inclinations.

In Twilight of the Idols, Nietzsche claims that "[f]reedom means that the manly instincts which take pleasure in war and victory have gained control over the other instincts, over the instinct for 'happiness, for instance" (TI, "Skirmishes of an Untimely Man" 38). Conversely, he presents the kind of weakness embodied by an anarchic will as an illustration of "[w] hat I do not mean by freedom"” (41). This straightforward mapping of strength and weakness of will onto, respectively, freedom and lack thereof may lead one to think that Nietzsche simply identifies the latter notions with the former ones. This, however, would be a mistake.

Nietzsche's appeals to freedom and its cognates usually involve a feature that cannot be captured just in terms of strength of will. The clearest statement of this feature appears in one of his unpublished notes: "That you command to yourself, that means 'freedom of the will"' (KSA 12, 1886: 1[44]; see also GS 347, quoted in Section 1). This is a recurrent theme in his published works too. Individuality and "[f]reedom of thought" require that one "estimate oneself according to one's own measure and weight" (GS 117). A "well-turned-out person" stands out for his having only "a taste for what agrees with him" (EH, "Why I Am So Wise" 2). In Beyond Good and Evil, we read that a "faith that establishes rank order" is a prerequisite of "nobility" (BGE 287) as well as that the "noble type of person feels that he determines value" and is thus one who "creates values" (BGE 260). This is the reason why Nietzsche holds that "true philosophers are commanders and legislators," those "who first determine the 'where to?" and 'what for?' of people" (BGE 211). 
These passages bring out a second notion of independence that seems crucial to the ideal Nietzsche tries to convey by resorting to freedom talk. Roughly, the picture emerging is that of an agent who pursues goals she has herself established. However, as something appears to be a goal worth pursuing only from a certain evaluative viewpoint, the decisive feature is that one be able to set the values by which one guides one's lifethat one be, as Nietzsche puts it, a self-legislator. Let us call this capacity evaluative independence. How is it to be achieved?

Nietzsche holds that a "person's valuations reveal something about the structure of his soul and what the soul sees as its conditions of life, its genuine needs" (BGE 268). As the structure of one's soul consists in the arrangement between one's drives, one's evaluative viewpoint results from that very arrangement. Thus, evaluative independence also depends, at least in part, on a specific makeup of the soul. Nietzsche believes that socialization makes us internalize values by which we then guide our life. As an outcome, the members of a given community just end up conforming to the same set of imperatives coming from the outside - an "all-too-natural progressus in simile" (BGE 268). Note that nothing prevents this process of internalization to result, by certain individuals, in the obtaining of a stable order in one's soul. Put differently, and as testified by many cases of ascetic conduct or fanaticism, that one's valuations are firmly grounded in one's soul is fully compatible with those valuations expressing imperatives to which one simply defers. This means that to merely possess a strong will does not suffice to make one a self-legislator in Nietzsche's sense.

How then can one be able to create one's own values? A certain value can be said to be mine only if it reflects my nature. Thus, to be in a position to create values expressive of what I call my genuine self, I need to discover what "piece of fate" I happen to be. Though this clearly amounts to an exercise of self-knowledge, it is hard to figure out how Nietzsche conceives of it. Some interpreters (Guay 2002; Katsafanas 2011) argue that conscious self-reflection plays a decisive role in this process. This suggestion, however, does not seem to fit well with Nietzsche's profound skepticism about, if not straightforward denial of, consciousness' efficacy. Others (Richardson 2009; Rutherford 2011) argue that this kind of self-knowledge is made possible by genealogical inquiry, which, by uncovering the values embedded in our moral and, more generally, cultural practices, enables us to loosen the grip they have on us. This second strategy seems more in tune with Nietzsche's own recommendation that, in order to become "human beings who ... give themselves laws, who create themselves," we must first "become physicists" (GS 335), that is, learn more about our mundane nature of beings embedded in a physical and historical environment.

Let us take stock. According to Nietzsche strength of will makes for enkratic independence and therefore constitutes a necessary condition for the pursuit andlacking insuperable external impediments such as my bicycle's having been stolen-the realization of one's goals. However, it does not suffice for the kind of evaluative independence consisting in the capacity to create one's own values. This, however, is what Nietzsche praises as the rarest and highest accomplishment a human being can possibly attain.

\section{Freedom or Not?}

Our initial puzzle is still unresolved. In Nietzsche's middle-to-late works, the recurring appeal to "freedom" and its cognates is designed to convey his ideal of the highest 
human type: the creator of new values. But are we to take such a freedom talk at face value? Is Nietzsche really talking about (some kind of) freedom?

Leiter (2015) firmly rejects this conclusion by defending a hard incompatibilist reading. He recognizes that Nietzsche presents a strong-willed human being capable of self-control as his own ideal of humankind. However, Leiter argues that it involves no genuine notion of autonomy and, therefore, freedom. Other scholars favor compatibilist accounts (see the references provided). From a compatibilist view, all that is needed for one to be free is that one determines "from within" one's actions. Accordingly, these interpreters suggest that Nietzsche's account of (what I have here called) enkratic and evaluative independence articulates precisely such a picture of freedom.

In my view, it is very hard to adjudicate this debate. It is not only that each account has to deal with apparently recalcitrant passages-after all, this is a quite common trouble, and not only for Nietzsche's scholars. The conceptual side of the issue also seems intractable. On the one hand, compatibilists could point out that Leiter ties autonomy too tightly to responsibility: as Nietzsche rejects the notion of ultimate free will precisely because it substantiates ascriptions of moral responsibility, we should expect him to endorse a thinner notion of autonomy. On the other hand, Leiter could retort that compatibilist construals of freedom typically aim at preserving the intuitive appropriateness of such ascriptions: someone who is held free in the compatibilist sense still counts as morally accountable for what she does. This, however, cannot work in Nietzsche's case. Moreover, what can Nietzsche possibly mean with "responsibility" given that he rejects any morally relevant construal of the notion?

This tension seems to point to a deeper problem: the fundamental, probably unresolvable ambiguity or, if you prefer, context-sensitivity characterizing Nietzsche's usage of the word "freedom" and its cognates. More precisely, it seems that the way in which he employs freedom talk depends on the particular target Nietzsche has on a certain occasion. For instance, when he is attacking Christianity, he targets the freedom talk based on the notion of ultimate free will that he thinks underlies its practices. When he develops his critique of modernity, on the contrary, he resorts to freedom talk in order to convey his own counter-ideal. Thus, it is the specific purpose a certain work or even passage has that confers to it its characteristic compatibilist or incompatibilist flavor.

\section{Acknowledgments}

For comments on an earlier draft I thank Ken Gemes, Paolo Stellino, and Kevin Timpe.

\section{References}

Nietzsche's works are abbreviated as follows: A, Anti-christ; BGE, Beyond Good and Evil; D, Daybreak; EH, Ecce Homo; GM, Genealogy of Morality; GS, The Gay Science; HUH, Human, All Too Human; TI, Twilight of the Idols. References to these works are followed by book or essay number (Roman) and/or title (if needed) and section or aphorism number (Arabic).

References to Nietzsche's unpublished notes are to the Kritische Studienausgabe (KSA) followed by volume number (Arabic), year, and note number. Translations from KSA are mine.

Clark M. and Dudrick D. (2009) "Nietzsche on the Will: An Analysis of BGE 19," in K. Gemes and S. May (eds), Nietzsche on Freedom and Autonomy. Oxford: Oxford University Press, pp. 247-68.

Constâncio, J. (2012) “'A Sort of Schema of Ourselves:' On Nietzsche's 'Ideal' and 'Concept' of Freedom,” Nietzsche-Studien 41: 127-62. 


\section{FRIEDRICH NIETZSCHE}

Fischer, J.M. (2007) "Compatibilism," in J.M. Fischer, R. Kane, D. Pereboom, and M. Vargas (eds), Four Views on Free Will. Malden: Blackwell, pp. 44-84.

Gemes, K. (2009) "Nietzsche on Free Will, Autonomy and the Sovereign Individual," in K. Gemes and S. May (eds.) Nietzsche on Freedom and Autonomy. Oxford: Oxford University Press, pp. 33-50.

Guay, R. (2002) "Nietzsche on Freedom," European Journal of Philosophy 10: 302-27.

Kane, R. H. (1996) The Significance of Free Will. Oxford: Oxford University Press.

Katsafanas, P. (2011) "The Concept of Unified Agency in Nietzsche, Plato, and Schiller," Journal of the History of Philosophy 49: 87-113.

Katsafanas, P. (2013) "Nietzsche's Philosophical Psychology," in J. Richardson and K. Gemes (eds), Oxford Handbook of Nietzsche. Oxford: Oxford University Press, pp. 726-55.

Leiter, B. (2007) "Nietzsche's Theory of the Will," Philosophers' Imprint 7: 1-15.

Leiter, B. (2015) Nietzsche on Morality, 2nd edn. London: Routledge.

Nietzsche, F. (1878-1880/1996) Human, All Too Human. A Book for Free Spirits, trans. R.J. Hollingdale. Cambridge: Cambridge University Press.

Nietzsche, F. (1881/1997) Daybreak. Thoughts on the Prejudices of Morality, trans. R.J. Hollingdale. Cambridge: Cambridge University Press.

Nietzsche, F. (1882-7/2001) The Gay Science, trans. J. Nauckhoff and A. Del Caro. Cambridge: Cambridge University Press.

Nietzsche, F. (1886/2002) Beyond Good and Evil. Prelude to a Philosophy of the Future, trans. J. Norman. Cambridge: Cambridge University Press.

Nietzsche, F. (1887/1998) On the Genealogy of Morality. A Polemic, trans. M. Clark and A.J. Swensen. Indianapolis: Hackett.

Nietzsche, F. (1888a/2005) "The Anti-Christ," in F. Nietzsche, The Anti-Christ, Ecce Homo, Twilight of the Idols and Other Writings, trans. J. Norman. Cambridge: Cambridge University Press, pp. 1-68.

Nietzsche, F. (1888b/2005) "Ecce Homo," in F. Nietzsche, The Anti-Christ, Ecce Homo, Twilight of the Idols and Other Writings, trans. J. Norman. Cambridge: Cambridge University Press, pp. 69-152.

Nietzsche, F. (1888c/2005) "Twilight of the Idols," in F. Nietzsche, The Anti-Christ, Ecce Homo, Twilight of the Idols and Other Writings, trans. J. Norman. Cambridge: Cambridge University Press, pp. 153-230.

Nietzsche, F. (1980) Sämtliche Werke. Kritische Studienausgabe in 15 Bänden, G. Colli and M. Montinari (eds). Berlin and New York: De Gruyter.

Richardson, J. (2004) Nietzsche's New Darwinism. Oxford and New York: Oxford University Press.

Richardson, J. (2009) "Nietzsche's Freedoms," in K. Gemes and S. May (eds), Nietzsche on Freedom and Autonomy. Oxford: Oxford University Press, pp. 127-49.

Rutherford, D. (2011) "Freedom as a Philosophical Ideal: Nietzsche and his Antecedents," Inquiry 54: $512-40$.

Strawson, G. (1994) “The Impossibility of Moral Responsibility,” Philosophical Studies 75: 5-24.

\section{Further Reading}

Gemes, K. and May S. (eds.) (2009) Nietzsche on Freedom and Autonomy. Oxford: Oxford University Press. (A seminal collection of recent papers on Nietzsche's view of freedom, including some of the references provided above.)

Müller-Lauter W. (1999) Über Wahrheit und Chaos. Nietzsche-Interpretationen II. Berlin and New York: De Gruyter. (The classic contribution on the topic by one of the most influential German Nietzsche scholars.)

\section{Related Topics}

Classical Compatibilism

Agent Causation

Skeptical Views about Free Will

Self-Control and Akrasia

The Relationship between Moral Responsibility and Freedom

Determinism 


\section{4 \\ CHINESE PERSPECTIVES ON FREE WILL}

\section{Kai Marchal and Christian Helmut Wenzel}

\section{Introduction}

The problem of free will has many faces. When we have to make a decision, we usually think that in the end the decision is 'up to us.' We think we are basically free to choose and that we have 'free will.' We usually don't think our choice is predetermined by the past. But the classical natural sciences (roughly until the end of the nineteenth century) usually assume that everything that happens is determined by the past. They say that if we knew the physical states now, together with the laws of nature, and if we had enough computing power, we could do some calculation and in principle predict what will happen tomorrow. We could predict the movement of the stars, the weather, and anyone's choice. This idea is called Laplacian determinism. Thus, there is a tension between our idea of freedom and this kind of determinism. Furthermore, even if determinism is not true, it is difficult to give an account of how free will works, because it is difficult, or even impossible, to establish a middle position between chance and determinism. This also applies to our present time, in which classical physics has been superseded by quantum physics and certain indeterminacies have entered the game. Investigating these problems leads to issues about agency, responsibility, personal identity, causality, time, and many other topics. Such topics were first investigated by the Ancient Greeks and the Stoics and further developed under the influence of Christianity (the idea of God who gave us free will, including the ability to do evil) and the modern sciences.

Surprisingly, the problem seems to be absent in Chinese thought. Did the Chinese miss something or has the West been chasing an illusion? Only after Chinese scholars in the late nineteenth century began translating modern Western philosophers (especially Immanuel Kant) did free will emerge as an explicitly discussed philosophical problem. Even today, there are few books on free will in Chinese, and not many philosophers in the Chinese-speaking world seem to be troubled by the thought that human freedom could reveal itself to be completely illusory (for an exception see Xu 2008). Not surprisingly, a number of scholars have argued that pre-modern Chinese thought, or Chinese civilization in general, has not been aware of the problems of human freedom and free will at all (Jullien 2004; cf. also Hansen 1972). Yet this lack of awareness might not necessarily be seen as a disadvantage: one of the most famous Chinese philosophers of the twentieth century once reproached Kant for thinking about free will "in such a 
twisted and complicated way," thereby obviously implying that all would have been much easier if the Prussian thinker had been a Confucian (see Mou 2006: 115)!

This said, we do think that many pre-twentieth-century thinkers in China were concerned with issues that can be related to Western discussions about free will. Among these issues are the problems of fate, predetermination, agency, moral responsibility, choice, and chance. In other words, if we are willing to extend the historical and conceptual frame of our inquiry, Confucian, Daoist, and Buddhist perspectives may provide us with alternative standpoints from which we can ponder the question of whether rational agents possess a capacity to choose among alternatives and can be held responsible for their choices. In the following, we will introduce-albeit in very selective and simplified ways - certain perspectives that can be found in ancient China. We are aware that research on this topic is rare and that there is much more to be said. In summary, the present chapter is exploratory at most.

A few remarks on methodology are necessary. We should not assume that the world views underlying ancient Chinese reflections are easily intelligible to us. Ancient Chinese thinkers tried to answer questions that are very different from what professionally trained philosophers contend with today. They articulated their arguments in one of the tersest written languages ever invented by the human mind: Classical Chinese. In many passages, their arguments must be taken rhetorically and contextually; they often are veiled in metaphorical language or references to canonical passages that even readers at their time must have found difficult to understand. It is thus not surprising that many of these texts are objects of sinological controversy. When reading ancient Chinese philosophers today, one should resist the temptation to think that their arguments can easily be assimilated into current Western theories or frameworks. The very idea that we can pin down an exact equivalent to the term 'free will' in a text or passage from the Han (206 BC-220 AD) or Song (960-1279 AD) dynasties can be misleading. Yet similar hermeneutical difficulties arise when we seek to determine whether Aristotle's notion of prohairesis corresponds to free will. We should open ourselves to the idea that, in a global world, there are very different styles of reasoning, and human freedom is certainly among the problems which should not be discussed in terms of Western traditions alone (compare King 2011; and Denecke 2010: 326-46).

In this chapter, we will mainly quote from texts that are more than 2,000 years old. Are they still that relevant today? Yes, they are. In China's education system it has been standard practice, and still is so today, to memorize Classical texts from early childhood on. Hence the ideas expressed in these texts continue to shape Chinese culture and identity in ways that are different from what has been going on in the West. Confucius and other Classical thinkers have been shaping contemporary culture in Chinese-speaking societies more than Aristotle and Plato did in the West, where the world-view of the Enlightenment has in many ways superseded Roman and Ancient Greek cultures. With China reemerging as a global power and trying to redefine itself, the continuing influence of its classical heritage should not be underestimated. Intuitions about human freedom in contemporary East Asia are often still shaped by forms of reasoning first articulated by Classical Chinese thinkers. If we believe that philosophical theories about free will and moral responsibility at least partly rely on appeals to intuition (for example, Sommers 2012), we might want to explore these alternative intuitions. Seen in such a perspective, Chinese texts might well enrich ongoing debates about the free-will problem. 


\section{Four Corresponding Notions to Free Will in Pre-Modern China}

Searching for Chinese perspectives on free will, the first thing one might wish to do is clarify the relevant terminology. One can indeed single out a number of terms by which pre-modern Chinese thinkers refer to something like a faculty to make choices, or ways of making choices, and factors that influence or even control one's life, namely:

(1) $x \bar{\imath} n$ 心 (heart, heart-mind)

(2) xing 性 (human nature, characteristic tendencies, inborn capacity)

(3) ming 命 (lifespan, fate, command, allotment, endowment)

(4) zìrán 自然 (self-so, so of itself, nature, spontaneity)

There is another term in Classical Chinese, zhi 志, that has often been translated as 'will.' But a more precise translation is 'direction [of the heart-mind],' which will be discussed under (1). The above four terms are relatively open concepts that do not preclude the possibility of diverse interpretations and adaptations. Throughout the history of Chinese philosophy, there have been numerous debates among philosophical and religious schools about their precise meanings. It is thus unsurprising that modern philosophers in the Chinese-speaking world who employ such terms to translate free will and related concepts into Chinese have created a sort of hybrid discourse that is often rather confusing (compare Makeham 2012). Due to limited space, such modern discussions are omitted from this chapter.

\section{'Heart-Mind' (xin) and Moral Responsibility}

Debates on the nature of the 'heart-mind' (xin) are central to Chinese philosophical traditions. Already in literary and historical writings from the Zhou dynasty (c. 1046-256 $\mathrm{BC})$, the 'heart' (xin) is described as both a physical organ and as the center of human agency, possessing the faculties of both thought and emotion. Since these dimensions are never strictly separated, many translators render it as 'heart-mind.' For Confucius ( sixth to fifth century $\mathrm{BC}$ ), the 'heart-mind' is the locus of the self and is capable of choice. In one famous passage in the Analects, he describes how his life followed a consciously chosen life-plan. "At seventy," he finally declares, "I could follow my heart's [heart-mind's] desires without overstepping the bounds of propriety" (Lunyu 2.4; Confucius 2003: 9). In the writings of Mencius (fourth century BC), often referred to as the second most important thinker in the Confucian tradition, the 'heart-mind' takes center stage: Mencius regards it as the locus of personal self-determination (maybe even autonomy) and believes that authentic moral agency can only be achieved through a process of self-cultivation guided by one's 'heart-mind;' to achieve this goal one needs to engage in special techniques of nourishing the body, controlling the flow of one's Qi (conventionally glossed as breath, energy, material force), and causing one's inner virtues to be manifest in one's outer appearance. Mencius also calls this goal the state of an "unmoved heart-mind" (bu dong xin). In an oft-quoted passage (Mencius 2A/2), Mencius points out that the person with an "unmoved heart-mind" will not be fearful or affected by external factors; instead, he will be independent, capable of establishing the correct "direction" (zhi) in his life, and able to act in accordance with the virtues of "wisdom" (zhi) and "righteousness" (yi) (see Shun 1997: 72-6; Perkins 2014: 146, 147). Here we encounter moments of independence and control that are comparable to 
concerns in current (Western) discussions of free will. The idea of an 'unmoved heartmind' reminds us of the Stoic ideal of ataraxia (tranquility of the mind, absence of distress, worry, and passion), and the advice to act with 'wisdom' and 'righteousness' also seems close to Stoic ideas. But whether this advice by Mencius is supposed to lead to freedom through insight into the divine order of things or even to freedom as autonomy is a further question.

Mencius thinks that our 'heart-mind' has an innate tendency towards virtue (Mencius 2A/6). Through cultivation of one's 'heart-mind,' one can establish one's character and be in control over one's life. Mencius does not strictly distinguish between reason and emotion: Control encompasses both. At the same time, Mencius is well aware that many external factors are beyond the individual's control. He states,

Everything is fate. But one only accepts one's proper fate. For this reason, someone who understands fate does not stand beneath a crumbling wall. To die through fathoming the Way is one's proper fate. To die as a criminal is not one's proper fate.

(Mencius 7A/2; van Norden 2008: 171)

In other words, we should understand what is right (one's proper fate) and act on this insight, even if we have to die for it. Only in this way does one grasp one's 'proper fate' (see Perkins 2014: 137-9). Confucians have sometimes been accused of fatalism, as, for example, in the "Fei ming" (Against Fate) chapter of the Mozi (compare Mozi 2010: 318-49), but there is nothing fatalistic about Mencius' position: the goal of self-cultivation is to make oneself invulnerable to external forces and to be in control of one's inner world (and one's fate in that sense). Nevertheless, this position also implies that, under certain conditions, one must be resigned to whatever life one happens to lead and what these conditions are depends on the situation. In general, we may say that Confucians believe that self-cultivation leads to freedom.

In later centuries, Confucian scholars have developed further accounts of 'heartmind.' For example, Xunzi (са. 312-230 вс), one of the most systematic thinkers in ancient China, speaks of 'heart-mind' in terms of an almost omnipotent faculty:

The heart is the lord of the body and the master of one's spirit and intelligence. It issues orders, but it takes orders from nothing: it restrains itself, it employs itself; it lets itself go, it takes itself in hand; it makes itself proceed, it makes itself stop. Thus, the mouth can be compelled either to be silent or to speak, and the body can be compelled either to contract or to extend itself, but the heart cannot be compelled to change its thoughts.

(Xunzi 2014: 229)

This passage might remind us of Hobbes' definition of negative liberty (freedom as absence of external restraint). Yet Xunzi seems to hint at more than negative liberty, since the 'heart' does not just happen not to be constrained, but it cannot be constrained. Xunzi often sounds like a thinker who is concerned with human development, and he pays closer attention than Mencius to the process of deliberation and the moment of choice. He does not try to give a detailed account of the conditions of free agency, rather his ultimate aim is to achieve social and political order. Zhu Xi (1130-1200), an important Neo-Confucian thinker whose understanding of 'heart-mind' in many ways 
resembles Xunzi's, comes even closer to describing how agents, through reflective verification of ideas and beliefs achieve something like free, unconditioned agency. If a particular action flows naturally from the agent, it is directly motivated by the agent's virtue of 'wisdom' (zhi) (Wu 2008: 354). Nevertheless, even Zhu Xi did not entirely reject the idea that future events are often determined by fate and sometimes can be known only by means of divination. Thus, late in his life he once consulted the oracle (the Book of Changes) to make an important decision about his political career.

Such ideas of moral agency were also the basis for moral discourses of blame, which is characteristic of Confucian scholars of all sorts. Confucius criticized his disciple Zai Wo for his laziness (Lunyu 5.10). Zhu Xi, with reference to the Confucian canon, blamed various emperors for their moral flaws. Recently it has been argued that the Confucian understanding of moral responsibility is not rule-, but character-based. The agent can be held responsible for the failure to form a virtuous character, unless such failure is due to external factors such as milieu or environment (Jiang 2002). Indeed, many Confucians place an enormous responsibility on the individual. Since thinkers such as Mencius and Zhu Xi never established a definite border line between what is and what is not within one's control, but rather assume that such a line needs to be drawn anew in each particular situation, the individual agent can all too easily be blamed for not having made enough effort.

The Confucian scholars in Imperial China who acted as judges in trials found their answers to questions of choice and responsibility in legal handbooks, often taking into account existing hierarchies and patrilineal obligations (Epstein 2009). Unlike Aristotle or later European philosophers, Confucians never felt obliged to develop a more analytical, abstract account of individual responsibility. Moral agency was understood to be imbedded in a larger network of moral, ritual, cultural, and even economic factors. Although reflection about past behavior is important and one should reflect about one's own deeds constantly (see Lunyu 1.4), there is no indication that Confucians ever thought about the deeper (metaphysical) problem of alternative possibilities in the past and that one "could have done otherwise." What counts most was, and often still is, how to motivate the 'heart-mind' to achieve the final goal of moral self-transformation.

\section{'Human Nature' (xing)}

In many respects, 'xing' is a puzzling term, which has been at the center of numerous difficult discussions in the history of Chinese philosophy. It has been variously translated as "human nature," "characteristic tendencies," "inborn capacity," or even "interiority." While the Analects (Lunyu) do not record Confucius paying much attention to the term, Mencius used it to explain human agency as a capacity for spontaneous, prereflective action that is shared by all human beings. Ethical action is said to flow directly from human nature. Therefore, it is crucial that agents focus on their ethical predispositions which, though not acquired through learning, still need to be nurtured and refined (Shun 1997: 187-92; compare Perkins 2014: 140-50). The goal of self-cultivation is thus to bring out what is already there in the depths of human selfhood.

To what extent this deeper self needs to be discovered or just cultivated has been debated among Confucians. In one passage (7B/24), Mencius emphasizes that our ethical predispositions (being part of our human nature) are fully within our control, while many external circumstances are subject to fate ( $\mathrm{ming}$ ). Instead of ascribing the failure of one's ethical pursuits to external circumstances and fate, the 'gentleman' or 'superior 
person' (junzi) is supposed to strive even harder and focus on what is under his or her control-even in those situations in which all seems to depend on external and non-ethical factors. Mencius wants us to understand that there is no way of distinguishing in advance between normative constraints (what one should or should not do) and descriptive constraints (what one can or cannot do), since all depends on the particular situation and one's own efforts. Such a distinction can only be made locally (Shun 1997: 203-7). The best method for the superior person is to anchor ethical commitment in the latency of one's potential, thereby also expanding the space of moral obligation (Denecke 2010: Chapter four).

Mencius' conviction that all human beings share the very same nature has not been accepted by all Confucian thinkers. Quite a few of them (most importantly Dong Zhongshu, 179-104 BC) distinguish between different allotments that also reflect different social positions. Daoist thinkers have often tried to overcome the idea that human agency depends on some fundamental, fixed ground. Instead, they stress the importance of the natural flow of things, chance, and contingency. Zhuangzi (late fourth century $\mathrm{BC}$ ) takes human nature to be malleable: in the transformation of all things, the only paradigm of authentic action is spontaneous, non-intentional, non-deliberate action, sometimes even what is called 'non-action' (wuwei), such as when riding a bicycle without thinking about it (compare Slingerland 2003). According to the so-called Primitivist chapters of the Zhuangzi, each being has its own "nature;" only what accords with its "nature" is right for the particular being (Perkins 2014: 164-5). The influential commentator Guo Xiang (who died in $312 \mathrm{AD}$ ) understands Zhuangzi's nature as the "momentary determinacy" possessed by each individual thing (Ziporyn 2003: 143). Such determinacy is never definite and can undergo new transformations at any moment. Guo Xiang goes as far as claiming that freedom and necessity are two sides of the same coin: All changes, Guo claims in Brook Ziporyn's reading, "even when apparently coming from outside (i.e., what is 'encountered,' what one vanishes into), are to be considered the intrinsic and spontaneous transformations of their allotted determinacy" (Ziporyn 2003: 144). In this sense, human nature is identified with the idea of 'self-so' or 'so of itself:' nothing is grounded in anything else, everything is just the result of itself.

Chinese Buddhist thinkers have been influenced by Daoist visions. The term xing is used to translate the idea of Buddhahood or Buddha-nature (tathāgatagarbha, Buddhadhātu). According to the teachings of Chan and Huayan Buddhism, it is crucial to 'see nature' (jian xing) and thereby to realize Buddhahood (Gregory 1991). Since one of the most fundamental Buddhist assumptions is that both self and world are illusionary, it is not easy to see how the free-will problem can even become visible to Buddhist thinkers. By contrast, Neo-Confucians, such as Zhu Xi, accused Buddhists of ignoring the moral dimension of human nature (Gregory 1991: 297-304). For them, human nature is identified with the agent's true or deeper self, which should govern his inclinations and desires and thereby enable him to take full responsibility for his actions. At least in Zhu Xi's case, the attempt was made to connect such free agency with an understanding of the outside world through notions like Yin and Yang and the network of Qi-based forces (compare Kim 2000). Nevertheless, Neo-Confucians too had a tendency to retreat into the inner world and the narrative structure of certain canonical texts. As a result, the conditions of human agency are often developed only within an idealized account of Confucian civilization, and not on the level of external, empirically observable facts. 


\section{'Fate' (ming)}

Chinese ming is comparable to Greek moira. Both expressions originally referred to a goddess and also to one's share, allotment, endowment, destiny, lifespan, and fate. But there are differences. In Classical Chinese, ming stands for a command, especially from Heaven (tian), and also for one's predestined life span, future wealth, and position in life (i.e., the content of one's particular command or 'endowment'). However, ming's meaning is not that fixed. It is negotiable, open to interpretation and appeal, and not deterministic (see Raphals 2005: 76-88, 102; 2013: 13; and Campany 2005: 129-50). One can influence ming through ceremonies, gifts, repentance, pleas, and moral behavior (Schaberg 2005: 26-30,36), but to do so of course requires that one understands ming. Both the Greeks and the Chinese practiced ritualistic divination and interpreted signs, omens, and dreams, but for the Greeks fate was not negotiable. Humans were powerless regarding the spinning and binding of moira, and even the gods were sometimes subject to it. Latin fatum is usually also more irrevocable and fixed than is ming.

There are ambivalences in regard to Chinese fate (ming). Man is not always in harmony with Heaven (Puett 2005: 50-61) and the good person does not necessarily have a good fate. He might for instance die young. Thus Confucius lamented the early death of his best pupil with the words "Oh! Heaven has bereft me! Heaven has bereft me!" (Lunyu 11.9, Confucius 2003: 114). Fate often appeared to be random, amoral, and blind, and this applies not only to individuals but also to whole families and cultures. Kings and sages tried to mediate between Heaven and man, but tensions always remained. Interestingly, however, early Chinese thought did not have an idea of radical evil (Perkins 2014: 39). Confucius once said that it took him until the age of 50 to understand "Heaven's Mandate [ming]" (Lunyu 2.4, Confucius 2003: 9; Watson translates "the will of Heaven," see Confucius, trans. 2007: 20, our italics). There was often anxiety and uncertainty about divinations and fate, and historical documents such as the Shujing express that "Heaven's command is not easy" and "Heaven cannot be relied upon" (Schaberg 2005: 41).

References to fate can express a feeling of helplessness or lack of control. But sometimes there is also confidence, for instance when Confucius was asked whether Minister Gongbo Liao, who had attacked one of his disciples, should be executed. In his answer, he said "If the Way is destined to proceed, that is a matter of fate [ming]. And if the Way is destined to fail, that too is fate. How can Gongbo Liao change what is fated?" (The Analects 14.36, Confucius 2003: 168). In this statement, Confucius expresses his confidence that Heaven will protect his school. This is a political move, but it also has a ring of determinism and fatalism. Quite paradoxically, ming also has the rather opposite meaning of 'command' (thought to be issued by 'Heaven'); as such it has been described by various twentieth-century readers as a sort of moral imperative with binding force on all human beings. Thus, we are confronted with a deep semantic ambiguity: what determines one's life-options and restricts one's free choice can sometimes also be understood as a normative constraint. One seems to have a choice: "He who accords with Heaven is preserved; he who opposes Heaven is destroyed" (Mengzi 4A.7, Puett 2005: 56, 57). But to choose knowingly one has to know the will of Heaven, and whether one's choice is free, will still be a further question Mencius seems not to be aware of. If one thinks that Heaven is behind things and that Heaven is some kind of person or something one can please and correspond with, then it makes sense to negotiate with it or to delude it, but one cannot do this when dealing with laws of nature that are understood in a 


\section{CHINESE PERSPECTIVES ON FREE WILL}

mathematical or deterministic fashion. More generally, most later Confucians did not think of human actions as self-sufficient or self-contained, but rather as integrated into a holistic order associated with 'Heaven' or 'Heaven's Mandate' (tianming); thus, under certain circumstances it might be better to pray to spirits and other supernatural forces than to rely on human power alone (see Tillman 2004). Moreover, after the fourth century, popular understandings of fate were increasingly influenced by Buddhist speculations about karmic retribution, an extremely complex issue that we cannot address in the present chapter.

Faced with the problem of fate and allotment, many thinkers tried to withdraw from those things that seemed outside their control and to concentrate instead on selfcultivation and what can be controlled. In his poems, the third-century poet Tao Qian reflects on Confucian and Daoist ideals in order to discuss ways of coping with destiny (see Cai 2005: 169-202). A good example of concentrating on what can be controlled can be found in the ways 'day books' (rishu) were used (see Poo 2005: 107-25). These manuals were used at least since the third century $\mathrm{BC}$ and list the days of the year together with their implications regarding fate. They were used frequently not only by kings and the elite but also by the common people, and they are still used today. These books describe certain days as fortunate and others as unfortunate in regard to such things as birth or marriage. As one can freely choose the date of one's marriage, one can in certain respects control one's fate. One can choose an auspicious day, and people still do so today. Even regarding childbirth one can try to manipulate allotment and fate through the performance of rituals or deception (for instance, by making everybody believe that the child was born one day later).

'Day books' are in some sense lists of if-then statements, and today we might think of them as laws of physics. If you marry on such and such a day, then you will have many children (day book). If you drop a stone from such a height, then it will reach the ground in a certain amount of time (physics). Both kinds of if-then statements can be used to one's advantage, but in China there was no fear that such lists could control all of our actions. There are at least two reasons for this. First, 'day books' specify tendencies and not strict determinations; and second, they do not cover everything that happens. Hence no threat of any kind of all-encompassing (physical) determinism arose. Through resilience, awareness of timeliness, and knowledge in general, there was always room for maneuvering and strategy. In many Western societies, horoscopes are still used today, but not manuals for when to marry or when to start a company.

\section{'Self-so' (ziran)}

The notion of ziran (self-so, so of itself, nature, spontaneity) is central in Daoist texts such as the Laozi and Zhuangzi, named after their assumed authors (Zhuangzi lived in the late fourth century BC; Laozi might not have existed at all). Ziran is often translated as "so of itself," "naturally," "free," or "spontaneous." If one does something in a ziran way, one does it without effort and successfully. Things happen as if by themselves, spontaneously, freely, and without much thought. This notion is connected with wuwei, doing something without intention but successfully: things get done effortlessly even without one apparently doing anything.

These Daoist texts have been read throughout the centuries and are still widely read today. Laozi tends to be more political and cosmological, while Zhuangzi is more psychological and concerned with individual human affairs. The texts offer advice, an ideal of 
liberation, and explanations in connection with Dao (path, origin, principle, the Way), tian (Heaven), and Qi (Energy). Whether such explanations should be considered 'metaphysical' is disputed among Western sinologists and philosophers.

One can speak of 'freedom' in Zhuangzi by pointing out the aspects of liberation and self-realization that the text promises and readers usually find in it. Thus, Burton Watson says in the introduction to his translation that "the central theme of Chuang Tzu [Zhuangzi] may be summed up in a single world: freedom" (Chuang Tzu, trans. Watson 1964: 3). The freedom meant here is freedom from self-made worries, fear (especially fear of death), suffering, greed, vanity, and a general narrow-mindedness. This is some kind of negative freedom (freedom from certain things) and can be achieved by seeing the one-sidedness or even meaninglessness of conventional values and labels, and by opening up new horizons allowing us to see the multitudes of possibilities that lie before us but that we usually overlook (which would be a positive aspect of freedom). Zhuangzi often conveys this insight with humor. In Chapter 1, entitled "Free and Easy Wandering," Zhuangzi's interlocutor, the logician Hui Shi, tells of how he had a gourd so big he could find no use for it and therefore smashed it, whereupon Zhuangzi says:

Why didn't you think of making it into a great tub so you could go floating around the rivers and lakes, instead of worrying because it was too big and unwieldy to dip into things! Obviously you still have a lot of underbrush in your head!

(Chuang Tzu, trans. Watson 1964: 29)

That man also had a tree "too gnarled and bumpy to apply a measuring line to, its branches too bent and twisty to match up to a compass or square," upon which Zhuangzi replies:

Why don't you plant it in Not-Even-Anything Village, or the field of Broadand-Boundless, relax and do nothing by its side, or lie down for a free and easy sleep under it? Axes will never shorten its life, nothing can ever harm it. If there's no use for it, how can it come to grief or pain?

$(1964: 29,30)$

We should take things naturally, as they are, and not get entangled in endless comparisons based on overly fixed conceptions and rigid frames of mind (symbolized here by measuring line, compass, and square). Hence, freedom lies in liberation and self-realization.

Many translators, for instance A. C. Graham, speak of ziran as "spontaneity." For the followers of Laozi and Zhuangzi (who we today often call 'Daoists'), the goal is to respond spontaneously: naturally, immediately, without too much reflection, and without adding anything. Nature works this way, and we should follow its course. Thus in Chapter 5, "The Signs of Fullness of Power," Zhuangzi recommends that one "constantly goes by the spontaneous and does not add anything to the process of life" (Chuang Tzu, trans. Graham 2001: 82). This idea is illustrated by the famous story of cook (and butcher) Ding in chapter 3, entitled "What Matters in the Nurture of Life." Ding has butchered many oxen, but because he knows how to cut between the bones, in 19 years he never had to sharpen his knife. His skill is so great that he usually does not have to think at all while doing his work. He says: "I rely on Heaven's structuring, cleave along 
the main seams, let myself be guided by the main cavities, go by what is inherently so" (Chuang Tzu, trans. Graham 2001: 64).

This vision of freedom is 'negative' insofar as is it is freedom from certain constraints, but these are not just outer constraints. Freedom here is not simply being (outwardly) free (i.e., not hindered) and doing what one (inwardly) wants to do. Zhuangzi cuts deeper, namely into our wishes and desires. From the point of view of current Western debates on free will, one might be tempted to make comparisons with Harry Frankfurt and John Martin Fischer. Frankfurt distinguishes levels of beliefs and volition and suggests an inner harmony as the most meaningful concept of free will. Fischer focuses on what he calls "guidance control" (Fischer 1994: 132), which is comparable to Zhuangzi's skill stories such as the story of cook Ding. Guiding a car (Fischer's example) is like guiding a knife, both can be done "freely." But Zhuangzi is more radical. He does not even want us to distinguish between what we like and what we do not like. He wants us to follow nature as it is, "what is inherently so," "Heaven," and "the Way." This, however, becomes problematic when asking why one should not be equally a 'good killer' as one can be a 'good cook' such as Ding (see Wenzel 2003), or why one should not be allowed to simply say "Hitler happened" (Hansen 1992: 290). To avoid such conclusions, one has to broaden one's horizons beyond the here and now. The followers of Laozi and Zhuangzi were opposed to the Confucians, who set up moral standards and rules. But it is not clear what they offer in its place. Merely pointing to "Nature," "Heaven," and "the Way" as last grounds of justification will not do. (Neither does simply pointing to 'Geist,' 'substance,' or 'logic.')

The translation of ziran as "spontaneous" reflects a similar problem. Can action be completely 'immediate?' Would that not be some kind of causa sui or mere chance? If we cannot do anything 'immediately,' what should it be mediated by? Thus, in the current Western discussions on free will one worries that maybe in the end we are just the subjects and victims of determinations unknown to us. A positive account is offered in these discussions under the title of 'agent causation,' and modern Daoists who are theoretically inclined might want to look into such contributions.

The Daoists and their ideas of 'freely' following things as they naturally are, were not without their critics. Xunzi for instance (third century BC) argued that humans are not naturally good but need to make deliberate efforts to become good. Humans are like wood that needs to be bent and straightened. We have the ability to learn. We can transform and develop, and we should do so. As Mencius had already done, Xunzi makes some steps towards a theory of abilities and understanding. There are things that are possible for man to do, but that he does not necessarily do. "Thus, the petty man can [ke yi 可以] become a gentleman, but is not willing [bu ken 不肯] to become a gentleman" (Xunzi 2014: 255). He observes that it goes the other way as well (though probably for different reasons): "The gentleman can [ke yi] become a petty man, but is not willing [bu ken] to become a petty man." Both, the gentleman and the petty man, cannot be "made to," or "induced" [shi 使] to make the change (2014: 255). This might remind the modern reader of the problem in free-will discussions that "you could have done otherwise' and that 'I can now do this or that and the choice seems to be completely up to me.' But Xunzi does not develop a theory of free will. He merely observes the difference between ability and possibility, on the one hand, and actuality and lack of necessity on the other. Nevertheless, this is getting very close to the problem of agency and free will. (See also his discussion of 'heart-mind' above). 
The Han dynasty thinker Wang Chong (27-97) wrote extensively on the subject of ming, and the first chapters of his book Balanced Discourses (Lunheng) are devoted to an explanation of it. According to Wang, "Heaven" (tian) invests human beings with their "vital destiny" (ming), which is the result of natural processes and cannot be altered. These processes are without purpose. Wang was opposed to the common belief-articulated most prominently by Dong Zhongshu (about 179-104 BC) — that one's destiny is allotted by a conscious, moral power, "Heaven," which gives commands (see Cai 2005: 179-82). Wang argued for a "social destiny" that is influenced by stars and supernatural forces but can also be influenced by human efforts. However, since ming is unequally distributed among individuals, there are limits to such efforts. Ultimately, Wang Chong, like many other ancient Chinese thinkers, combined the view that one should accept one's fate with a "strong anti-fatalism and well-developed notions of strategy or maneuvering room within its decrees" (Raphals 2005: 102). He sometimes even comes close to accepting the 'lazy argument' (argos logos), saying that there is no need to strive, since whether or not one will have a long life and become wealthy and powerful has already been determined in the past. However, at least in the realm of morality, Wang never doubted the possibility of, and the need for, effort and self-cultivation (Wang 2011: 86; compare also Mencius 7A/3).

Ideas of physical atomism and all-pervading deterministic laws of nature did not emerge in Ancient China. Neither was there the Christian idea of an omniscient, omnipotent, and benevolent creator god. Thus, without the threat posed by physical determinism or divine foreknowledge, no worries about free will arose. In other words, Wang Chong was never confronted with a choice between hard determinism and the belief that agents have free will. As ancient Chinese culture lacked the (theological/ scientific) idea that foreknowledge of a human act makes that act necessary and therefore un-free (even if knowledge is not a cause), the kind of mixed position we see in Wang and so many others was commonly considered meaningful and convincing.

\section{A Few Remarks on Causality}

The general tendency in China has been to think of things as being connected not in linear chains of cause and effect, but in networks of mutual dependencies and reciprocal interrelatedness, as we have already expressed above. The polar oppositions of Yin and Yang and the more fluid interactions of the 'five phases' (water, wood, fire, metal, and earth) are the basic causes and principles of what happens. Heaven and earth have Yin and Yang, and so does man. Heaven, earth, and man follow and respond to each other. Nature is usually not conceptualized as neutral and amoral. Since the eleventh century, Neo-Confucian scholars have developed world-views that integrate such speculations with naturalistic understandings of 'principles' (li) existing directly in things, yet investigation of natural phenomena still required self-cultivation and moral perfection. It has often been argued that all this is very different from (Western) mechanistic understandings of nature in terms of atomism and billiard ball causation (see, for example, Defoort 1997).

The Chinese terms, shi 使 and gu 故, are often translated as "to cause." The term shi originally meant 'to send,' 'commission,' and 'tell' and has political and hierarchical undertones. (One is tempted to think of the saying 'saying so makes it so.') Also Greek aitia and Latin causa have their origin in social settings, but in the sense of legal justifications and explanations and not in the sense of commands. 
An exception to this general tendency to retain political undertones in discussions of causes were the Mohists, who are said to have belonged to the lower class of craftsmen and engineers during the fourth century BC and who were followers of Mozi (fifth century $\mathrm{BC}$ ). They pointed out the difference between shi as meaning "to tell" and shi as meaning "to cause" (compare Mozi 2010). The former does not necessarily lead to the expected result, but the latter does. They also discussed the difference between necessary and sufficient conditions and challenged the Confucian tradition by asking the Confucians to provide reasons $(g u)$ for their values and recommendations. $\mathrm{G} u$ meant not only "reason," but also "cause" and "purpose" (Lloyd 2007: 124-7). The Mohists emphasized that things might have more than one cause. They were aware of the uncertainty resulting from the attempt to determine the real causes of something. They were also opposed to Yin-Yang and 'five-phase' explanations. Unfortunately, they did not get much hearing. Zhu Xi, mentioned above, sometimes used the term gu, but he never thought about the cause-effect relationship more rigorously (Kim 2000: 305). In general, reason and cause were not carefully distinguished.

\section{Conclusion}

It is difficult to say something in general, or even universal, about 'free will,' because there has been such a long history of practices and debates and because there is so much cultural variation. Even current discussions in analytic philosophy are in a sense already part of history. Practices of what we now call, or would call, 'blame' and 'praise' vary widely. The same can be said about 'guilt' and 'shame,' 'freedom,' and 'will.' When moving into cultures that have very different roots from what we find in the West, such variation becomes particularly strong. One might even wonder whether it is possible at all to defend universal judgments about the conditions of free agency (see, for instance, Sommers 2012; Lotter 2012; compare also Wong 2006). This chapter is an attempt to introduce such a culture and to allow for such a move. We have focused on certain key terms such as xin, xing, ming, and ziran, because there have been discussions among Chinese scholars about these terms and the ideas they try to convey, and because we think these discussions are in certain respects comparable to discussions about free will in the West. We have tried to bring out such comparisons. Xin ('heart' or 'heart-mind') stands for the locus of the self and implies a capacity for choice, though not always involving reflective awareness. Xing ('nature,' 'human nature') refers to a capacity for spontaneous action that needs to be discovered or cultivated. Ming has often been translated as 'fate,' but it also means 'command,' and we do not always follow commands. Ziran ('so of itself') means 'spontaneous' less in the sense of some kind of causa sui, but more in the sense of an immediate, effortless, and successful action. One major difference we see consists in the presence of Christianity and the abstract, mathematical natural sciences in the West and their relative absence in China. Conversely, there have been notions such as dao in China that we do not find in the West. Such notions and ideas created backgrounds and frameworks within which philosophical discussions evolved.

The primary goal of these discussions in China was not to develop a universalist theory of free will, but rather the transformation of existing practices and self-identities in communities. Nevertheless, those thinkers' interests in the issue of human agency were not driven by practical or political issues alone, but also by deeper spiritual and even philosophical concerns. Now it is possible to conclude from all this that there is not much to be gained from China for contemporary discussions about free will. 
However, we cannot exclude the possibility that free will might not be a real problem at all. Then the Daoist or Confucian account might be more appealing. We should also notice that some of the questions debated by Western philosophers do not appear to be very meaningful to philosophers in East Asia. Broadly speaking, many Chinese and other East Asians do not share the Western belief in free will. But they often still explain, through the language of xin, xing, and ming, and other terms and ideas, why they feel responsible and ascribe responsibility to others (Ni 2002; compare Holenstein 2015). But what does this mean? We do not claim to have a solution to this puzzle.

\section{Acknowledgments}

For helpful suggestions and comments, we wish to thank Benjamin Gallant, Carine Defoort, Chan Kang, Edward Kanterian, Elmar Holenstein, Heiner Roetz, Herbert Hanreich, and Lee Ming-huei.

\section{Bibliography}

Cai, Z. (2005) "Multiple Vistas of Ming and Changing Visions of Life in the Works of Tao Qian," in C. Lupke (ed.), The Magnitude of Ming: Command, Allotment, and Fate in Chinese Culture. Honolulu: University of Hawaii Press, pp. 169-202.

Campany, R.F. (2005) “Living off the Books: Fifty Ways to Dodge Ming in Early Medieval China," in C. Lupke (ed.), The Magnitude of Ming: Command, Allotment, and Fate in Chinese Culture. Honolulu: University of Hawaii Press, pp. 129-50.

Chuang Tzu (1964) Chuang Tzu: Basic Writings, trans. B. Watson. New York: Columbia University Press. Chuang Tzu (2001) Chuang-Tzu: The Inner Chapters, trans. A.C. Graham. Indianapolis: Hackett Publishing. Confucius (2007) The Analects of Confucius, trans. B. Watson. New York: Columbia University Press.

Confucius (2003), Confucius, Analects. With Selections from Traditional Commentaries, trans. E. Slingerland. Indianapolis: Hackett Publishing.

Defoort, C. (1997) "Causation in Chinese Philosophy," in E. Deutsch and R. Bontekoe (eds), A Companion to World Philosophies. Malden/Oxford: Blackwell, pp. 165-73.

Denecke, W. (2010) The Dynamics of Masters Literature. Early Chinese Thought from Confucius to Han Feizi. Cambridge and London: Harvard University Press (Harvard University Asia Center).

Epstein, M. (2009) "Making a Case. Characterizing the Filial Son," in R.E. Hegel and K. Carlitz (eds), Writing and Law in Late Imperial China. Crime, Conflict, and Judgment. Seattle: University of Washington Press, pp. $27-43$.

Fischer, J.M. (1994) The Metaphysics of Free Will. Oxford: Blackwell.

Frankfurt, H. (1971) "Freedom of the Will and The Concept of a Person," Journal of Philosophy 68/1: 5-20.

Graham, A.C. (1985) Reason and Spontaneity. London: Curzon Press.

Graham, A.C. (1989) Disputers of the Tao. Philosophical Arguments in Ancient China. La Salle: Open Court.

Gregory, P.N. (1991) Tsung Mi and the Sinification of Buddhism. Princeton: Princeton University Press.

Hansen, C. (1972) "Freedom and Moral Responsibility in Confucian Ethics," Philosophy East and West 2: 169-86.

Hansen, C. (1992) A Daoist Theory of Chinese Thought. A Philosophical Interpretation. Oxford: Oxford University Press.

Holenstein, E. (2015) "Moral ohne Willensfreiheit. Verantwortung, Schuldbewusstsein und Nachsicht von Ostasien aus betrachtet,” in W. Behr, L. Di Giacinto, O. Döring, and C. Moll-Murata (eds), Auf Augenhöhe. Festschrift zum 65. Geburtstag von Heiner Roetz. Munich: Iudicium, pp. 357-70.

Ivanhoe, J.P. and van Norden, B.W. (2001) Readings in Classical Chinese Philosophy. New York: Seven Bridges Press.

Jiang, Xinyan (2002) "Mencius on Moral Responsibility," in X. Jiang (ed.), The Examined Life. Chinese Perspectives. Albany: State University of New York Press, pp. 141-60.

Jullien, François (2004) Detour and Access. Strategies of Meaning in China and Greece. trans. S. Hawkes. Cambridge: MIT Press.

Kim, Yung Sik (2000) The Natural Philosophy of Chu Hsi (1130-1200). Philadelphia: American Philosophical Society.

King, R.A.H. (2011) "Rudimentary Remarks on comparing ancient Chinese and Greco-Roman ethics," in R.A.H. King and D. Schilling (eds), How Should One Live? Comparing Ethics in Ancient China and Greco-Roman Antiquity. Berlin and Boston: De Gruyter, pp. 3-17. 


\section{CHINESE PERSPECTIVES ON FREE WILL}

Li, C. (2014) "Confucian Conception of Freedom," Philosophy East and West 64: 902-19.

Lloyd, G. (2007) Cognitive Variations: Reflections on the Unity and Diversity of the Human Mind. Oxford: Clarendon Press.

Lloyd, G.E.R. (1996) Adversaries and Authorities: Investigations into ancient Greek and Chinese Science. Cambridge: Cambridge University Press.

Lotter, Maria-Sibylle (2012) Scham, Schuld, Verantwortung. Über die kulturellen Grundlagen der Moral. Berlin: Suhrkamp.

Lupke, C. (ed.) (2005) Magnitude of Ming: Command, Allotment, and Fate in Chinese Culture. Honolulu: University of Hawaii Press.

Makeham, J. (ed.) (2012) Learning to Emulate the Wise: The Genesis of Chinese Philosophy as an Academic Discipline in Twentieth-Century China. Hong Kong: Chinese University Press.

Mou, Z. (2006) Xinti yu xingti (Two Forms of Moral Consciousness). Taipei: Zhengzhong shuju.

Mozi (2010) The "Mozi:" A Complete Translation, trans. I. Johnston. Hong Kong: Chinese University Press.

Ni, P. (2002) "The Confucian Account of Freedom," in X. Jiang (ed.), The Examined Life - Chinese Perspectives. Albany: State University of New York Press, pp. 119-39.

Perkins, F. (2014) Heaven and Earth are not Humane. The Problem of Evil in Classical Chinese Philosophy. Bloomington: Indiana University Press.

Poo, M. (2005) "How to Steer through Life: Negotiating Fate in the Daybook," in C. Lupke (ed.), The Magnitude of Ming: Command, Allotment, and Fate in Chinese Culture. Honolulu: University of Hawaii Press, pp. 107-28.

Puett, M. (2005) "Following the Commands of Heaven: The Notion of Ming in Early China," in C. Lupke (ed.), The Magnitude of Ming: Command, Allotment, and Fate in Chinese Culture. Honolulu: University of Hawaii Press, pp. 49-69.

Raphals, L. (2005) "Languages of Fate: Semantic Fields in Chinese and Greek," in C. Lupke (ed.), The Magnitude of Ming: Command, Allotment, and Fate in Chinese Culture. Honolulu: University of Hawaii Press, pp. 70-106.

Raphals, L. (2013) Divination and Prediction in Early China and Ancient Greece. Cambridge: Cambridge University Press.

Schaberg, D. (2005) "Command and the Content of Tradition," in C. Lupke (ed.), The Magnitude of Ming: Command, Allotment, and Fate in Chinese Culture. Honolulu: University of Hawaii Press, pp. 23-48.

Shun, K. (1997) Mencius and Early Chinese Thought. Stanford: Stanford University Press.

Slingerland, E. (2003) Effortless Action: Wu-Wei as Conceptual Metaphor and Spiritual Ideal in Early China. Oxford: Oxford University Press.

Sommers, Tamler (2012) Relative Justice. Cultural Diversity, Free Will, and Moral Responsibility. Princeton and Oxford: Princeton University Press.

Tillman, H. (2004) "Zhu Xi's Prayers to the Spirit of Confucius and Claim to the Transmission of the Way," Philosophy East and West 54: 489-513.

van Norden, B.W. (2008) Mengzi. With Selections from Traditional Commentaries. Indianapolis: Hackett Publishing.

Wang, C. (2011) Balance des Discours. Destin, Providence et Divination, trans. M. Kalinowski. Paris: Les Belles Lettres.

Wenzel, C. (2003) "Ethics and Zhuangzi: Awareness, Freedom, and Autonomy," Journal of Chinese Philosophy 30: $115-26$.

Wong, D.B. (2006) Natural Moralities: A Defense of Pluralistic Relativism. Oxford: Oxford University Press.

Wu, Q. (2008) "Zhuzi dui Zhiyan yangqi de quanshi: Fangfa yu ruijian" (Zhu Xi's Interpretation of Mencius 2A/2: Method and Insight), Zhongguo Zhexue yu Wenhua 3: 341-58.

Xu, X. (2008) Lijie ziyou yizhi (Understanding Free Will). Beijing: Beijing Daxue Chubanshe.

Xunzi (2014) Xunzi. The Complete Text, trans. E.L. Hutton. Princeton and Oxford: Princeton University Press.

Ziporyn, B. (2003) The Penumbra Unbound: The Neo-Taoist Philosophy of Guo Xiang. Albany: State University of New York Press.

\section{Further Reading}

We are not aware of any good books or articles on the issue of free will in China. It is still too novel. But here are some introductory readings on Chinese philosophy for the uninitiated Western mind, or readings on related issues:

Perkins, F. (2014) Heaven and Earth are not Humane. The Problem of Evil in Classical Chinese Philosophy. Bloomington: Indiana University Press. (This is about fate, human agency, and the observation that bad 


\section{KAI MARCHAL AND CHRISTIAN HELMUT WENZEL}

things happen to good people [the problem of evil]. Heaven and earth have parted ways, and the Chinese saw this as a problem.)

Ivanhoe, J.P. and van Norden, B.W. (eds) (2001) Readings in Classical Chinese Philosophy. New York: Seven Bridges Press.

Tiwald, J. and van Norden, B.W. (eds) (2014) Readings in Later Chinese Philosophy Han Dynasty to the 20th Century. Indianapolis: Hackett Publishing.

\section{Related Topics}

The Stoics on Fate and Freedom

Aristotle

Gottfried Leibniz

Indian Perspectives on Free Will

Situationism, Social Psychology, and Free Will

Free Will and Theological Fatalism 


\section{5 \\ FREE WILL AND FREEDOM IN INDIAN PHILOSOPHIES}

\section{Arindam Chakrabarti}

\section{Introduction}

No stereotype or synopsis can capture all the disputing treatments of the concepts of freedom, will, action, and agency in the widely divergent Indian philosophical traditions over three millennia. Nevertheless, one can ask if classical or modern Indian thinkers did at all have a clear concept of free will as the drive to act responsibly independently of external coercion. To use the meta-philosophical framework of ancient Jaina logic: in a way, they did; in a way, they did not need to; in a way, they did and they did not; and the question does not arise in quite the same way as in Western philosophies. In this overview, I first consider the pre-systematic views recorded in the early Upanishads and the Mahābhārata (which includes the Bhagavadgītā). Then, starting with early Philosophy of Grammar, Sāmkhya-Yoga, Jainism, and Buddhism, I rehearse, albeit not in a strictly chronological order, what a number of different schools of Indian philosophical thought, often in opposition to one another, have to say about human agency to actions, free will and about 'freedom to' and 'freedom from.'

\section{Is Free Will Unheard-of in the Vedas? The Will and its Doings in the $\bar{I} s \bar{a}$ Upanișad}

Let us start with early Vedic thought. İsá Upanișad, the last section of the most ancient part of the Yajur Veda (1000 BCE) begins with an ethical prescription to enjoy a full life of actions through giving up greedy attachment to the fruits of our actions. This terse but profound text ends with a prescribed prayer to sacrificial fire at the moment of death. The dying man should address Fire-a symbol of the power of volition and knowledge within each of us—and pray: "O Active Will! Remember what you did and what you will do, remember what you did and what you will do" (IU 17). Elsewhere, Fire-deified-is described as "the seer of the consequence of actions, the will within" (kavi-kratu). Here, the word used for active will is kratu, which can mean deliberation, desire to act, power of practical judgment, or volition. It is connected to the Greek kratos, which also means power and will. This prayer obliquely invokes the free active will of the dying person at three levels. First, as an injunction to remember one's deeds, it invokes freedom in so far as the addressee has the option of not obeying ityou may forget especially your own misdeeds at the very last moment of life, hence the 
admonition to try to recollect. Second, it speaks of responsibility for past deeds (krtam) - there is no doing without a doer who might not have done. Finally, it speaks of future projects and next life: what kind of actions will you choose to perform in the next life after death?

The concept of a human will that knows what it wants to do and has the ability to do seems as ancient as the early Upanishads. Yet, there has been an error perpetuated for more than a century by Western Sanskritist-historians of Indian philosophies, namely that the concept of free will is outside the ambit of all classical Indian thought because there is no entrenched philosophical synonym for 'free will' in Sanskrit, Pali, or Prakrit. This misconception is even more implausible than the outrageous early European orientalist verdict that the virtue of gratitude was unknown to Indians because there was no ancient Sanskrit equivalent of 'thank you' (Ward 1818: 210). As a matter of fact, there are many Sankrit equivalents for 'free:' svatantra, svarāt (self-sovereign), svairin (self-propelled), svacchanda (self-wished). There is also a clearly defined word for will or volition- $k r t i$ or prayatna - which is distinguished from both mental wish and bodily effort. There is the philosophically charged word for an independent doer primarily responsible for an action — kartā — which may simply mean maker or designer. The weaver is the relatively free maker of a piece of fabric, the potter of the clay pots. For a few-by no means all-Indian philosophers, God is inferred as the designer or maker of the fabric of this world.

But was free will or voluntary agency to actions seen to be a philosophical problem? Surely, the incompatibility between God's omniscience and human freedom to do or not do in the future, or free will as the source of human error and moral evil, were not as hot topics within Indian argumentative philosophical traditions as they were in their Judeo-Christian counterparts. Since the doctrine of original sin and its connection with the human privilege of freedom were never part of even the few theistic streams of Indian metaphysics, the theological versions of the problem did not loom as large as they did in the Judeo-Christian world.

But the status of free will or human striving (purușakāra) caught between the natural and moral orders appeared problematic for an entirely different reason. Rooted in the fundamental Vedic concept of cosmic moral order ( $r t a)$, according to which there is no undeserved suffering and no unmerited enjoyment in the world, the doctrine of karma and rebirth had spread all over India by at least as early as the time of the Buddha (see Doniger 1980; Phillips 2009; Burley 2016). This doctrine was interpreted in a fatalistic way by some pre-Buddha free thinkers who preached the futility of all human endeavor in the face of destiny. The Buddha rejected such fatalistic interpretation of karma, as he rejected the concept of any omnipotent God presiding over the law of karma. Interestingly, while the Nyāya Sūtra, the root text of the theistic Hindu philosophical school of Nyāya, suggests that God oversees the process of bringing to fruition the karmic results of human actions (NS 4.1.19), the text also goes on to deny that God has the power to arbitrarily prevent or promote the consequences of human action, since even God has to depend upon human initiative and effort (purusakāra) in presiding over cosmic retributive justice. Divine dispensation and destiny defer to the primary factor of what the person intentionally wills to do. So, can we change the course of our future lives? Can we reduce the pain of embodied existence by removing our current ignorance and by trying to do good from now on, given that our bodies and mental tendencies are determined by our own actions in past lives? A few Âjivika 
fatalists (senior contemporaries of the Buddha) said "no, we can't;" but most Indian philosophers said "yes, we can." (Indeed, ancient Indian medical texts argue that unless well-chosen therapy and medicine can prevent some deaths and positively affect the future health of sick people, the whole medical science would be pointless). Both the Buddha and the founder of Jaininsm, Mahāvīra, strongly rejected Ājīvika fatalistic amoralism.

Wherever we get records of two or more debating sides to a philosophical issue, we can-with no over-interpretation or stretching-assume that the issue was a felt and theorized philosophical problem. Raising the question "By what do we live?" in its first verse, the śvetâśvatara Upanișad goes on in its second verse to propose alternative answers:

Should time, or nature, or necessity, or chance, or the material elements be regarded as the cause? Or is life up to the living self who is called purusha?

(Nikhilananda 2003: 126)

Even early Sanskrit popular moral parables such as the Hitopadeśa ("Beneficial Teachings") lampoon the hard determinist as a lazy philosopher, one who would apply the law of bivalence to future tense sentences and claim, "Whatever will not happen will not happen, whatever will happen cannot be changed and made otherwise, why don't you drink this potion which kills the poison of worry" (H 1.29). So, even though they may not be as prominent as in the Christian West, many of the same philosophical issues regarding free will arise in early Indian thinking.

\section{Responsibility, Action, and Inaction in the Mahäbhārata and Bhagavad Gītā}

The dreary days following the great Mahābhārata war (controversially dated between 2500 to $1500 \mathrm{BCE}$ ), described in the epic bearing that name, must have been a time of civilizational soul-searching. The question "Who or what is responsible for this genocide?" is raised repeatedly, and fingers are pointed to the warrior-princes' lust for power, land, or a beautiful woman, to the virtuous hero Yudhisțhira's weakness for gambling, and above all to the conniving agency of Krishna, the 'devious' divinity who could prevent the carnage but did not. To promote the virtue of forgiveness, the following parable is told at the start of the thirteenth book, the Book of Teachings. A poisonous snake bites and kills the only son of the pious woman, Gautamī. A hunter hungry for retribution locates, catches, and ties up the snake and brings it to Gautamī for permission to kill it. Gautamī points out that such retribution is pointless because it will not bring her dead son back. The hunter keeps insisting that she must see her son's killer killed. At this point, the snake manages to stick its head out and argue that the death of the son must have been pre-destined by Destiny (or Time, $k \bar{a} l a$ ), and that because he did not kill anyone willfully or knowingly, he could not be "blamed" or "punished." In his defense of fatalism, the snake says:

You foolish fowler! How is it my fault? I have no will of my own, and am not independent. Not out of any spite against the child, but being propelled by Death I've bitten this child. Therefore, the sin, if any, should belong to Death.

(MBh XIII.1.29) 
When the fowler responds that the snake deserves to be killed even if it has been employed by someone else as an instrumental cause of the child's death, the argumentative snake enters into a deeper discourse on the metaphysics of causation, and claims that as an instrument akin to a potter's wheel and its pivotal rod, it is not independent, and thus, cannot be an agent. Finally, Death itself appears on the scene and joins the snake in blaming Destiny, with a complex debate between freedom and determinism ensuing while the bereaved mother, Gautamī, remains unshaken in her decision to forgive the snake. It is noteworthy that God does not make any appearance in this story, either as a killer or as a redeemer. In an earlier chapter, a wise bird tells a human king, "Destiny (daiva) and human agency work in reciprocal dependence. The noble ones take good initiatives, while eunuchs worship destiny" (MBh XII.139.78).

The moral dilemmas explored in the Mahäbhārata come to their sharpest focus with the 700 verses at the heart of this epic which are known as the "Bhagavad Gìtä"the Song of God. War-like, both by temperament and by caste-criterion, prince Arjuna suddenly has a change of heart on the eve of the war. He wants to drop out of the ensuing bloody battle for he does not want to kill his kinsfolk and respected elders on the other side. He seeks to renounce this gruesome military life, even if he has to beg for a living. But, Arjuna's charioteer-mentor Krishna convinces him that wisdom and emancipation consist not in ascetic inactivity but in the midst of vita activa-a life of engaged but unattached, zealous but non-egoistic, ethical work. Freedom lies in renouncing the fruits of action, not in renouncing actions. Though, Krishna also warns in this connection: "Even wise men are confounded about what is action versus what is mere omission or inaction" (BG 4. 16). In the eighteenth and final chapter, five causal conditions of any action are set out: (i) the body (locus); (ii) the conscious knower-agent; (iii) different sorts of instruments; (iv) exertion and efforts of many kinds; and finally (v) a divine factor (BG 18.14). However, we are told paradoxically at the end: "God dwells in the heart of all living beings, making them move around with his magical power as if on a motor-driven machine" (BG 18.61). Thus, the Bhagavad Gìtā's final stance on free will remains elusive. Krishna's final exhortation seems to juxtapose a metaphysic of divine predetermination with a libertarian appeal to free will, with no attempt at reconciliation: "Therefore get up, earn fame, defeat your enemies and enjoy the entire kingdom; I have already killed off those enemies in the future, just be an occasioning agent of victory" (BG 11.33).

\section{Pāninini and Bhartṛhari: The Grammar of Free Doership}

In the context of defining the six action-enabling conditions (kāraka-s) under which a noun stands in relation to a verb in a sentence, the great grammarian Pānini (third century $\mathrm{BCE}$ ) characterizes an agent as: "That direct participant in the accomplishment of an action which is free/independent" (svatantrah) (AA 1.4.54; see Cardona 2014). In explaining this idea of independence, Bhartrhhari, the fifth-century philosopher of language, lays down six criteria of free agency- $\mathrm{X}$ is an independent agent if:

(a) X started acting before drawing his power from other aiding factors, such as the instruments;

(b) X retains his preeminence by subjugating all other contributors to the action;

(c) the operations of all other causal factors are subject to the functioning of $\mathrm{X}$;

(d) if X stops functioning, all the other conditions stop producing effects; 
(e) $\mathrm{X}$ is non-substitutable with any surrogate, such that even if any other particular action-condition (e.g., the locus, instrument, the accusative) is missing or replaced, $\mathrm{X}$ has to be there for this action to be possible; and

(f) X can get the action done, even if indirectly from a distance, through its influence over other more directly involved employed agents.

\section{Yogavāsișțha's Promotion of Human Initiative and Free Will against Karma-Determinsm}

One of the strongest philosophical voices in support of libertarianism is that of the vast eighth-century text called Mokșopayya (the Means of Liberation, popularly known as Yogavāsisth ha). Its arguments in defense of human initiative and the power of creative will occur in the second chapter titled, "The Conduct of One Who Wishes to be Free":

The fruit of my endeavors will be commensurate with the intensity of my self-effort, and neither fate nor any God can ordain it otherwise ... In this world, everything except a corpse is active and such activity yields appropriate results.

(Venkatesananda 1993: 27 [translation altered])

This basic message is based on three sophisticated insights. First, it is acknowledged that any rationally reflective person should feel the tussle between destiny and free will, two forces locking horns within the human person like two embattled mountain-goats. But what is ordinarily taken to be destiny is just another name for one's own past actions, while free will is effective in one's own present and future actions. The good news is that the present can be more powerful than the past. Only fools rely exclusively on past merit and divine grace instead of rising up manfully, gnashing their teeth and grabbing their upper arms, firm in resolve to exercise self-effort now. Second, the way to intervene and give one's current decisions the upper hand in this tussle is through reasoning guided by scripture (śastra), because disciplined reasoning can correct our confused thinking and give us better control over our own passions and desires, without ascetic renunciation, for the sake of a more empowered engagement with an enjoyable world. Finally, the reason why we can each become our own world-maker is that the so-called objective world is after all an illusion, a fictional story we have repeatedly told ourselves. There is no external world constraining us from outside. It is all a projection of our own mind, on which our well-trained bias-free clear intelligence can have full control. We can create whichever world we wish to. In the Yogavasișțha, libertarianism comes at the expense of an extreme anti-realism about the external world.

\section{The Place of Will to Clean up the Blemishes of the Soul in Jainism and Gandhi's Activism of Non-Violence}

Diametrically opposed to this idealistic promotion of free will (in an illusory world) is the Jaina realist attitude towards the defiling veil of karma, especially violent karma. Karma in Jainism is almost physically conceived as dirt accumulating on the soul. But every soul has the freedom to start cleansing itself of it by austerities and practice of self-control and non-violence. Rigorous practice of non-injury (ahimssa) towards all living beings is the centerpiece of Jaina ethics. Non-violence is not passivity; it requires 
immense self-exertion. Every soul is intrinsically and potentially omniscient, infinitely blissful, and free from all blemishes or fetters. But the soul's embodiment is very real, and it inevitably brings entanglement in violent actions that result in thicker and thicker veils of ignorance and error upon the original transparency of the souls. Only the penance of voluntary suffering, practice of non-violence, and gaining control over one's cravings for psychophysical pleasures can radically transform a human being, step by step, into a liberated omniscient person. Epistemological non-violence lies in accepting all-even mutually contradictory non-Jaina world-views-as true of a many-faced reality, from their own perspectives.

Non-violence was just as important, in the early twentieth century, to M. K. Gandhi as it has been to two millennia of theory and practice of Jainism. Notorious for his experiments in ruling over one's own body and passions, Gandhi was deeply influenced by the high moralism of Jaina ethics, but with three major differences. While both Gandhian and the Jaina insistences on exercise of human free will are equally spiritual and individualistic, Gandhi appeals to grace of God and prayer like a devotional Hindu, unlike a Jaina self-helper, whose struggle against the defilements of carnal pleasures never seeks assistance of any Deity. Gandhi also applied the ethics of non-injury to the active politics of decolonization in ways undreamt of by Jainism. Finally, because of deference to Truth which he worshipped as God, Gandhi would also reject the possibility of any human ever being omniscient, a possibility which is presupposed by Jaina epistemology. We must remember that Gandhi had to believe in human free will because he was deeply influenced by Ralph Waldo Emerson, who explicitly appealed to human freedom to change from aggressive to non-aggressive ways of living in society and nature. Because of his insistence that virtues, such as the non-acquisition of wealth and property, are necessary for inner self-rule and true soul-power, Gandhi's concept of freedom may sound negative. But actually it is meant to be a deeply positive freedom to face the Truth, which requires freedom from aggressive avarice and attachment to private property.

\section{Is Cetanā free will? Early Buddhists on Karma, Causality, and Freedom without a Self}

Two cornerstones of early Buddhist philosophy were the theories of dependent origination and no-self. Dependent origination entails that everything is impermanent, that nothing arises without a causal condition, and that when a causal condition is in place, its result inexorably follows. This unfailing causal dependence applies equally to the material and the mental world. Behind mental events, there is no substantial ego or self which persists through the causal sequence of willing and executing an action. With these pivots in place, the idea of free will or an agent self should simply be out of the question. Yet, in an otherwise mechanistic early Buddhist moral psychology, a crucial role is assigned to cetanā, standardly translated as "volition." In his Ațthasālinī, Buddhaghosa (fifth century) characterizes cetan $\bar{a}$ as follows:

Cetanā motivates .... Its function of arranging and effecting comes to pass in healthy or unhealthy effects [i.e., good and bad karma] . . The cetana alone is exceedingly full of effort, exceedingly full of vigor, that is, it makes a double effort, a double exertion. 
The propulsion of cetana $\bar{a}$, which is compared in the early Buddhist Pali commentaries with a bird's first flapping of wings to ascend before calmly gliding in the sky, is connected with deliberative functions such as vitakka and vicāra (gathering information and considering pros and cons) that take place within any living human's psychophysical person-stream. The moral psychology of Buddhaghosa's Visuddhimagga ("The Path of Purification") includes a list of 36 profitable consciousness-factors such as "zeal, resolution, attention, and a cultivated voluntary state of neutrality" (1976: 470). So, even the Buddhists' goal of world-renouncing dispassion is to be attained by free will. The early Buddhist meditators are active suffering-eliminators zealously intervening in the causal chain of their psychological lives by adhering to the ethics of correct resolve (sammā sankappa). In the Emptiness (Mādhyamaka) school of Mahāyāna Buddhism, however, the distinction between conventional truth and ultimate truth would demote all moral responsibility, agency and capacity to change the course of one's mental flow into merely conventional truth. From the no-perspective perspective of ultimate truth, freedom, if any, would only amount to "having nothing left to lose" (see Garfield 2014; Meyers 2014).

\section{Sāmphyya Dualism of Inactive Free Consciousness and Active Deterministic Nature}

At first sight, Sāmphya metaphysics looks so radically fractured between the natural realm of causation and action and the subjective realm of consciousness where no change or causation takes place, that the question of free will cannot even be raised within it. The only type of real entity which is free from natural causal laws, eternally separate from the body, is consciousness. On this account, consciousness is not non-dual or universal (as in Advaita Vedānta; see "No Will, Free Will, or Unfree Will in Pantheistic and Theistic Vedānta"); instead, there are innumerable distinct subjects or centers of consciousness, Sāṃkhya being more Leibnizian than Spinozaistic in this respect. But these subjective consciousnesses have nothing to do with any mental or bodily movement or action, because all psychological states and physical events happen in a dynamic and unconscious material nature which is never 'free.' So what is free does not will, and what wills is not even conscious, let alone capable of free choice. To be free in the Sāmkhya sense is to be unchanging and hence inactive.

Perhaps this means that the problem of free will is not solved but dissolved or shown to be a pseudo-problem in Sāmkhya. What exactly, the classical Samkhyan will ask, is asserted when the will is claimed to be free? What would be the scenario of the will not being free? Suppose we say that if the future is fixed then the will is not free to change it. If the future is fixed because every particular event will inexorably cause another particular event to happen, then in the natural realm (prakrti) where causal laws always operate, the future is just as fixed as the past, and nature is blindly deterministic. On the other hand, if an unfixed future meant the absence of any causal law, then no agent can be in control of her own body or her actions. If the fixedness of the future means that some transcendent or external power has fixed the future at the very beginning of creation, then Sāmkhya philosophy would vigorously deny such pre-determination, at two deep levels. There is no such beginning of creation whence onwards all futures are pre-fixed, and there is no transcendent creator or power who could fix anything. So, the future is not fixed in this latter sense. Therefore, our wills could be free to cause our actions. 
Second, one draws the conclusion from the predictability of the future that we are not free to change anything; that is, the will is not free because the future is foreseeable (at least in principle by an omniscient being). Here also there is confusion between the epistemological and metaphysical questions. Can we know the general trends or even the particular events in the future? This is not to be confused with the question: Will what I shall do happen because I willed it or because of factors entirely out of my control? If we allow a conflation of the two questions then we are basically reducing the 'or' of active choice in 'I can either do it or not do it, or can do it in a different way,' to the 'or' of doubt, ignorance and indecision: 'either I shall do this or I shall do that, I do not know what exactly I shall end up doing.' In that case, we are free only as long as we are ignorant, indecisive, and non-omniscient. Omniscience, which was supposed to be the most liberating empowering state of knowledge, would then engender a feeling of unfreedom and constraint. That by itself should be a reductio ad absurdum of the reading of free will as entailing the unforseeability of the future (Hariharananda 1931).

When our conscious will causes an action, Sāmkhya insists, there are other causal conditions, such as our unconscious will, the influence of our accumulated samskārās (proclivities impressed upon our mind by past repetition), the material environment, and the condition of our bodies and their genetic constitution, etc., that are operative. The will can be said to be free even if it acts in unison and tension with these other factors, just as a king acts independently even when he is assisted by ministers. The question of a self which autonomously causes the will to act with or without any other auxiliary causal factors simply does not arise because the disembodied self in Sāmphya is changeless and inactive.

\section{“I Have Duties to Perform:” Mīmām̧sā Theory of the Free Agent as a Conscious Addressee of Imperatives}

For the Indian philosophical tradition of Vedic interpretation known as Mīmāmsāa, an agent is someone who is capable of performing what is enjoined by a moral or ritual injunction such as "Thou shalt speak the truth," or "Desirous of happiness, you must perform the fire-ritual daily." The exhortation goads the appropriate addressee, one who desires happiness and has other relevant qualifications, not by coercing him to act according to it, but by bringing about his understanding of the prescriptive sentence as the only means of knowing his duty. The Bhātța Mīmāmsā view is that the meaning of an injunction is the propulsion which makes it happen (bhaveana $)$, connoted directly in Sanskrit by an imperative verb-ending (see Ollett 2013). This urging propulsion again comes in two varieties. At the level of the sentence itself, it is the motivating push of the words (the optative verb-ending connoting 'should'), and at the level of the person who is enjoined to carry out the command, it is the push by the intended competent auditor-agent. The imperative means the ought-to-be-doneness of the action, which takes effect through the two urges mentioned above, and makes the entitled agent perform some dharma (duty). In this sense, dharma is outside the realm of facts, something not-already-accomplished (apūrva). Prābhākara Mīmāṃsā moral psychology explains this "urge" of bhävanā as a "cessation of indifference." Until one feels the flutter of this propelling force, one stays indifferent, volitionally unmoved. To initiate or goad (which does not mean to coerce by threats or abet with rewards) is to bring something about, namely karmic results, which were never there before (apürva). That first flutter of agency is the "enjoining force" (niyoga) that harnesses our will to the act. 


\section{Nyāya Theory of Action and its Conditions: From Cognition to Desire to Will to Action}

The Nyāya school of Indian thought, though primarily concerned with logic and epistemology, developed a complex theory of action in which will (krti) — a quality or attribute of the self-played an important role. The theory, in a nutshell, is this: Buddhist reductionists are mistaken in denying the existence of a diachronically identical substantial self over and above the stream of passing perceptions, thoughts and feelings. There does exist a self who, when embodied, enjoys pleasure and suffers pain, knows, remembers, desires and hates, and wills actions even if it is the body which moves the muscles and finishes the job. About a contemplated future action (that the body could perform), three pieces of knowledge may arise in the self: (i) knowledge that the action would be conducive to attainment of a result which is desired; (ii) knowledge that action would not spawn a consequence that would be counterbalancingly undesirable; and (iii) knowledge that the action is doable, within one's capacity. The presence of all three pieces of knowledge is sufficient for the mental causation of a desire to undertake that action. From that desire would arise a volition in the self, which (skidding over the interaction-issues of any self-body dualism) would result in bodily exertion and, barring other obstacles, the action being done. But, if there is a strict causal chain in which willing occurs in between mental knowing and desiring on the one hand and bodily trying and doing on the other, how could willing be open to doing something or not doing it?

Here, from within an alive Nyāya analytic tradition, I would like to append my own phenomenological semantics of 'or' to the above account of mental causation of will. If God's or anyone's foreknowledge of the future is taken to be a denial of free will, then by modus tollens, to the extent that Nyāya leaves room for free will, those human individuals who feel this freedom must suffer from doubt and indecision about the future. When we scratch the surface of the 'or' of deontic choice, the 'or' of doubt or epistemic indecision comes out.

Between the thirteenth and seventeenth centuries, New Nyāya developed a sophisticated logical interpretation of 'or' in the context of their analysis of the cognitive content of doubt, which I think can be used very fruitfully to reveal the deep structures of our feeling of freedom of choice. In daily life we seem to have two distinct experiences of alternatives, one in the empowering feeling of choice, and the other in the debilitating feeling of doubt or cognitive vacillation. The vacillating, doubting mind uses 'or' when it says, "Is that a man or a tree-trunk in front of me out there?" and "Is the cat in Schrödinger's box dead or alive when no one has as yet looked?" Now, imagine someone ordering food from a restaurant menu that offers a wide range of choices. The fact that the menu is not fixed and you can choose what you eat makes you feel empowered and happy. But after a while, when, like Buridan's ass, you feel tormented and torn between equally attractive but uncombinable alternatives, the process of choosing turns into the feeling of painful indecision. If a prescient being now tells you, "Here is what you are going to eat; I have already decided that," you will feel relieved and bullied at the same time-relieved of your painful doubt about the future and the ideal food, but bullied because the gastronomic dictator has stripped you of your right to choose. Why can't we combine both options?

In New Nyāya, however, it is a constraint on any correct account of the 'or' of doubt that an alternation should never be reducible to a conjunction. 'Either O/or Not-O' can never mean 'both.' In analyzing the content of paradigm examples of doubt like the 
perceptual vacillation "Is that a tree-stump or a man?" asked about a vaguely seen object at a distance in darkness, the Nyāyalī lāvatī (thirteenth century) suggests:

In doubting disjunction, there is only a single contentness resident in the single qualificand, which is simultaneously, not conjunctively but vacillatingly, qualified by two mutually opposed, predicated optionhoods. Here we need to introduce a different sui generis kind of cognitive content-a non-assertoric sub-variety of predicatehood. It is called: kotita or optionhood. The yonder object in darkness, if it is a tree-stump could not be a man, and if it is a man could not be a tree-stump, which one is it?

(see NL 408-16)

One reason why Nyāya did not employ the strategy of introducing possibility into the interpretation of disjunction is that the fundamental distinction between 'and' and 'or,' disjunction and conjunction, is lost once a disjunction is reduced to a conjunctive list of epistemic possibilities (for discussion of this strategy, see Zimmermann 2000). "The patient either has cancer or diabetes" becomes equivalent to "It is possible that the patient has cancer and it is possible that the patient does not have cancer, but may have diabetes." To analyze disjunction as a conjunction of modalized disjuncts (whether the possibilities are epistemic or deontic, i.e., "It is permissible that") is ultimately to smudge the sharp distinction between disjunction and conjunction. The Nyāya account of disjunctive doubt keeps the distinction clear by holding that the disjuncts of a doubting cognition are exclusive; the inclusive 'or' does not capture the content of a doubt. That is because one's uncertainty about whether some perceived object is a person or a tree-stump is actually structured as: "Is this a tree-stump or not? Is this a person or not?" Here, the mutual exclusivity of disjunction is laid bare. For Nyāya, every 'or' can be analyzed as a disjunction between each option (koți) and its negation. Similarly, the disjunction facing us in cases of free choice is also exclusive; when faced with the choice, "Should I do $x$ or not," the commission and omission of the act cannot be combined.

The swing-force of cognitive disjunction or uncertainty, I submit, lies at the heart of the so-called power of free choice. If free choice makes us fallible but more powerful than externally controlled infallible robots, then uncertainty must be empowering. Epistemic hesitancy may be the source of freedom and hence a strength rather than weakness. As long as a sophisticated analysis of the epistemic content of doubt is available, there is no reason for Indian logicians to feel defensive or apologetic about not having worked out a metaphysics of possible worlds in the vein of David Lewis.

A fascinating lexical fact that seems to support my hunch that the 'or' of doubt grounds the "or' of freedom is that the same Sanskrit word "vimarsa" that is used in Nyāya to mean doubt, is used in Kashmir Shaivism to mean that self-conscious, selfarticulating aspect of consciousness which makes it free. It is to this Kashmir Shaiva metaphysics of dynamic consciousness that we now turn.

\section{Portrait of the Knower-Doer as a Creative Artist Unbound in Kashmir Shaivism}

Building on the ancient grammarians' semantics of the autonomous agent (see "Pānini and Bharțhari: The Grammar of Free Doership" above), the Shaiva nondualists 
of Kashmir-primarily, Utpaladeva and his encyclopedic, versatile commentator Abhinavagupta (tenth/eleventh century $\mathrm{CE}$ ) - ascribe three powers to the conscious self: the power of knowledge, the power of desire, and the power of action. Each self, currently tainted by past karma which binds him, is capable of liberation by re-discovering its identity with God (Shiva). At a deeper level of analysis, the power of knowledge is shown to consist in three further powers of illumination (i.e., awareness), remembering and distinguishing. It is the exercise of these powers that makes consciousness reflexively self-aware, dynamic and playfully imaginative. Freedom is the very essence of consciousness which can be aware of anything it chooses (ruci). Engaging in, as it were, a cosmic sport, consciousness first contracts itself into limited knowledge, individuated embodiment, temporal sequence, and law-like causal regularity. But it is part of that sport to expand spontaneously after this contraction, recognizing its true identity with the absolute non-dual divine consciousness. In one place (IPVV II, p. 4), Abhinavagupta remarks that "the power of remembering is the ultimate freedom" of the self, because to remember is to feel free to connect back with the synthetic unity of universal consciousness. Not only do I relish my own freedom in the self-conscious movements of memory and imagination, but in communicative practice I also rely on your freedom-you being my own other-ed consciousness. The basic freedom of a vibrant, dynamic, agentive I-consciousness is the freedom to add to or subtract from an earlier experience at the time of recollection. It is a thorough idealist monism where each knower is a creative artist. There is no thinking without doing and playing. All addressing of others turns out to be self-addressing by a playfully self-othering consciousness. Abhinavagupta's analysis of freedom was used in all subsequent Sanskrit poetics to portray aesthetic imagination as free from the constraint of natural causal laws (niyati-kṛta-niyama-rahitā).

\section{No Will, Free Will, or Unfree Will in Pantheistic and Theistic Vedānta}

In the Pantheistic Advaita Vedānta of sankara, there are two levels of reality, the ultimately ontically real and the empirically transactionally practical. At the former level, all changes, distinctions and dualities are illusory, hence any question of action, free or unfree, simply does not arise, because the only reality-pure, formless, attributeless consciousness-does not act. It just self-luminously exists, infinitely and timelessly. At the latter pragmatic level, actions, error and knowledge are distinguished, and one person is distinguished from another. In this realm, there is some freedom, especially in the act of imagination that is said to be "up to the person" (purusa-tantra), unlike the act of knowledge which is "up to the external object" (vastu-tantra); a meditator is said to be free to will whatever contemplative state he wants to be in. This freedom to use imagination $(k a l p a n \bar{a})$ which gets thickened into contemplative concentration (see VPS, 253), is crucial to the attainment of an altered state of mystical experience in which the ultimate identity between the individual and universal consciousness (brahman) can be "realized," and the scales of illusory distinctions between subject and object can fall away from one's eyes.

In the two other theistic systems of Vedānta, namely Rāmānuja's Qualified NonDualism (Viśiștādvaita) and Madhva's Dualism (Dvaita), the question of free will is considered very differently and seriously. Because actions and their deserved fruits, distinctions between good souls and bad souls, and a God to whom we surrender in worship are all taken to be as objectively real as (religious) common sense takes them 
to be, the human agent has to negotiate the space between his own will and God's will. On Rāmānuja's account, God is the real controller, master and substance of the world including individual human souls, but he 'permits' or consents to the limited freedom with which individuals like us decide to take actions. As a result, the fruits of the action are enjoyed and suffered by us, thanks to the over-seeing permissive sovereignty of the Supreme Agent, who takes no responsibility for the good or bad we do. God is exonerated from the charge of partiality, inequity or cruelty in spite of the unfair distribution of moral and hedonic goods in the world, which keep some evil-doers suffering and some other good-doers in his grace, because there is no 'first act' of a finite individual that God made them do arbitrarily. The chain of prior karma goes back infinitely without a beginning. Under the omniscient oversight and graceful permission of God, human souls enjoy a limited measure of liberty to act rightly or wrongly (see Freschi 2015).

Even this limited freedom is denied by the radical Dualist Madhva. According to him, the only free agent is God and every other conscious self is entirely determined by God's will and the force of their past karma, so much so that some unfortunate souls are destined to eternal hell while others have the prospect of rising higher and higher as long as they, pre-ordained by God, come to acknowledge their own servitude to God and surrender to him. This is the only school of Vedānta that believes that some souls are doomed to eternal ignorance and suffering. Both of these religious doctrines are influential in large sections of South Indian Hindus. But it is the Non-Dualism (Advaita) of sankara that Swami Vivekananda tried to adapt to a practical spirituality acceptable to the West and Westernized Indians.

\section{Freedom and Determinism in the philosophy of Swami Vivekananda}

In one of his historic 1896 lectures delivered in New York, Swami Vivekananda asserts with characteristic boldness and directness that "free will is a misnomer. It means nothing—sheer nonsense" (1964: 14). A quick argument follows: all willing happens within the causal nexus of a cosmic illusion, or māy $\bar{a}$. Nothing within the realm of māya is really free. Hence no willing can be free. Even our false feeling that we are free to choose is itself unchosen. It is part of the illusion-generating power of māya that we are bound to feel as if we are the real doers when we are not.

Elsewhere, Vivekananda gives a Kantian kind of argument for empirical determinism. As an effect of belief and desire, and a cause of action, willing takes place within the phenomenal world which is conditioned by the laws of space-time and causation. Whatever is brought under the laws of cause and effect is deterministic and hence unfree. Willing is causal; thus it is unfree. With this collapsing of karma with lawgoverned causation, he then somewhat strangely resorts to Hume's views about the association of ideas, ending up with the view that laws, after all, are mind-made. We impute necessity where we perceive regularity. It is our empirically conditioned expectation of regular succession of similar events that projects causal laws on nature. We have at least two highly contentious claims juxtaposed here: First, that the moral retributive law of karma is but a version of natural causation. Second, that this causal law is superimposed on reality by the human mind due to its habit of expecting regular patterns of succession on the basis of past experience. Such a subjective view of causal necessity seems to clash with his other tenet that the will's freedom itself is a subjective illusion. In the final analysis, it seems that according to Vivekananda, the human mind 
is at the same time responsible for superimposing law-governedness on every event, including one's own mental acts of will, as well as creating the illusion of liberty. But how can liberty and necessity both be illusory? The free cosmic self is never engaged in action-it is a mere witness. In its self-forgetful sleep it dreams up a causally law-bound universe. Within this dreamland every event must have a cause. But here again, the individual self is having yet another dream or illusion and thinks that, unlike other natural objects, its own ego can do or not do something in different ways. Our agentive freedom is a dream within a dreamt determinism of nature.

In spiritual life, this freedom is best realized through a total surrender to God's will. If Thou and I are the same, "Thy will be done" does not amount to slavery because the addressee and the supplicating devotee are at bottom identical. Such surrender is no subjection of one's freedom; it is reclaiming one's freedom as a subject. A much more complex version of this position was later developed by Sri Aurobindo, who makes a distinction between "All-will" and individual free-will, aphoristically remarking, "My will is the first instrument of my Fate, Fate a Will that manifests itself in the irresistible subconscious intention of the world" (1998: 158).

\section{K.C. Bhattacharya on Subject as Freedom (not of the Will)}

Written in his unique analytic yet phenomenologically contemplative style, without any reference to any previous Indian or Western philosopher, K.C. Bhattacharya's original work, The Subject as Freedom, takes the subject to be an Unmeant Meaner, that is, the original source of intentionality. His philosophical reflections on "what intends by the word I . . . without being referred to by it" (1930: 193) passes through successive inward stages: bodily subjectivity, psychological subjectivity, and spiritual subjectivity. In each subsequent rung, freedom lies in the feeling that I can exist as other than the previous rung of subjectivity. Even though my body as perceived from outside is uniquely unlike other perceived objects, in bodily subjectivity, I identify with my active inner felt body through my freedom from all perceived objects (including my externally perceived body). In psychological subjectivity, as the introspected flow of ideas and feelings, the self is isolable from even this felt body. Going beyond introspection, at the highest level of spiritual subjectivity, the subject finds freedom even from this felt need to distinguish itself.

In other contexts, for example in his profoundly original paper "Reality of the Future" (1956) and in his commentaries on classical Sāmkhya and Yoga philosophies, K.C. Bhattacharya has discussed the nature of positive freedom to enact something in the future, and negative freedom in the sense of mukti (liberation). But the above densely argued concept of the subject, not merely as free but as freedom per se, is still waiting to be critically analyzed as a third dimension of freedom. Instead of the feeling "I could have done otherwise," this third sense of freedom consists in the feeling "I might not have been $x$," and ultimately in freedom even from that feeling.

\section{Karl Potter's New Interpretation of Karma, Pre-Existence and Compatibilism: The Determinist's Fallacy of Misplaced Determinateness}

In the late twentieth century, Karl Potter, an analytic philosopher very much in the New Nyāya tradition, defended and interpreted the karma doctrine as a response to the problem of freedom versus determinism (1967). He has even called the karma theory an 
a priori presupposition of all Indian metaphysics of morals, and yet he does not think that the individual's actions are externally determined if they are largely determined by pre-initiated (prārabdha) karma. Potter deepens the Nyāya notion of 'volition' in terms of trying to do something. Suppose I try to do some action A, for example, draw a human figure. If I succeed, I end up drawing either a male figure, or a female figure, or a tall lean male figure, etc. My goal of drawing a human figure leaves room for these distinct alternatives, each of which would count as succeeding to draw a human figure, not because of any slack in the causal connection between my trying to draw and the actual drawing that I accomplish. In comparison to every intended action that is a determinable, the actually accomplished act is a determinate. From the fact that John wanted to do a specific action, to infer that there exists one and only one particular action that John wanted to do is to commit what Potter calls the fallacy of misplaced determinateness. Since the object of my trying is an imagined act, and such an act-however narrowly specified by the intender-is not causally or logically constrained to be determinately one of its many alternative actualizations, our willed actions remain free.

\section{Conclusion}

From very early moral, ritual, and spiritual prescriptions all the way through nineteenthand twentieth-century moral, political, and metaphysical musings on freedom, a vast range of concepts of free will has been critically analyzed and debated in Indian philosophies of language, mind, and action. Neither Buddhist ego-erasing metaphysics nor Advaita (non-dualist) Vedantic mystical illusionism about the world has ever entailed a general jettisoning of the normative reactive stance towards human actions. Widespread belief in the law of karma existed and still exists side by side with skeptical or analytical questioning of the very reality of human bondage, and moral optimism about the attainability of freedom from ignorance and suffering. Nineteenth- and twentieth-century Indian neo-Vedantists, neo-Buddhists, Jain-influenced pacifists, and eclectic artists and thinkers have experimented with various concepts of freedom, within or against karma determinism. Currently, with the global growth of violence and economic inequality, "argumentative Indians" (Sen 2006) can still learn a lot from the Issā Upanișad prayer of the dying: "O Will, remember what you did, think of what you will do." Relentlessly disputatious South Asian philosophers have always claimed the freedom to disagree with the very tradition that they belong to. They should remember to think freely and keep up the will to tolerate everything except dissent-gagging intolerance.

\section{References}

AA Aștāadhyāȳ̄, in Sharma, R. (trans.) (ed.) (1992) The Aștāadhyāȳ of Pānini. English Translation of Adhyāya One with Sanskrit Text, Transliteration, Word-Boundary, Anuvrtti, Vṛtti, Explanatory Notes, Derivational History of Examples, and Indices. New Delhi: Munshiram Manoharlal, p. 268.

BG Bhagavad Gītāi in Mahābhārata (1933-1966), in V. Sukthankar, S.K. Belvalkar, and P. L. Vaidya (eds), Mahābhārata: Text as Constituted in its Critical Edition, Vol. 2. Poona: Bhandarkar Oriental Research Institute.

IPVV İśvarapratyabhijnāviurtivimarśin̄ (1942), in M.K.S. Sastri (ed.), Íśvarapratyabhijnāvivụtivimarśin̄̄ vol. 2. Bombay: Nirnaya Sagar Press, p. 4.

IU İśa Upanișad, in Olivelle, P. (1998). The Early Upanisads Annotated Text and Translation. New York, Oxford University Press, pp. 405-11. 


\section{FREE WILL IN INDIAN PHILOSOPHIES}

H Hitopadeśa (1896) in M.R. Kale, The Hitopadeșa of Narayana. Bombay, Sharada-Kridan Press, p. 5.

MBh Mahābhārata (1933-1966), in V. Sukthankar, S.K. Belvalkar, and P. L. Vaidya (eds), Mahābhārata:

Text as Constituted in its Critical Edition, Vols 3 and 4. Poona: Bhandarkar Oriental Research Institute.

NS Nyāya Sūtra (2003), in T. Nyaya-Tarkatirtha and A. Tarkatirtha, Nyāyadarșanam: with Vātsyāyana's Bhāsyya, Uddyotakara's Vārttika, Vācaspati Mișra's Tātparyațīkā and Viśvanātha's Vṛtti. Calcutta: Munshiram Manoharlal, p. 940.

VPS Vivaraṇaprameyasangraha (1990), in R.S. Tailanga, Vivaranaprameyasangrahah. Bhadain̄̄, Vārāṇasī: Kiṣ ora Vidyā Niketana.

Aurobindo (1998) The Complete Works of Sri Aurobindo: Essays in Philosophy and Yoga: Shorter Works; 1910-1950, vol. 13. Pondicherry: Sri Aurobindo Ashram Publ. Dept.

Bhattacharyya, K.C. (1930) The Subject as Freedom. Amalner: Indian Institute of Philosophy.

Bhattacharyya, K.C. (1956). "Reality of the Future," in K.C. Bhattacharyya and G. Bhattacharyya (eds), Studies in Philosophy. Calcutta: Progressive Publishers, pp. 271-80.

Buddhaghosa (1976) The Path of Purification (Visuddhimagga), trans. B. Nanamoli. Berkeley: Shambhala.

Burley, M. (2016) Rebirth and the Stream of Life: A Philosophical Study of Reincarnation, Karma and Ethics. London: Bloomsbury.

Cardona, G. (2014) "Paninian Grammarians on Agency and Independence," in M. Dasti and E. Bryant (eds), Free Will, Agency, and Selfhood in Indian Philosophy. New York: Oxford University Press, pp. 85-111.

Doniger, W. (ed.) (1980). Karma and Rebirth in Classical Indian Traditions. Berkeley: University of California Press.

Freschi, E. (2015). "Free Will in Viśiștādvaita Vedānta: Rāmānuja, Sudarśana Sūri and Veṅkațanātha," Religion Compass 9: 287-96.

Garfield, J.L. (2014). "Just Another Word for Nothing Left to Lose: Freedom, Agency and Ethics for Mādhyamikas," in M. Dasti and E. Bryant (eds), Free Will, Agency, and Selfhood in Indian Philosophy. New York: Oxford University Press, pp. 164-85.

Guenther, H.V. (1976) Philosophy and Psychology in the Abhidharma. Berkeley: Shambhala.

Hariharananda (1931) Karma-tattva: A Scientific Philosophical Exposition (in Bengali). Madhupur: Kapil Math, pp. 216-7.

Meyers, K. (2014) "Free Persons, Empty Selves: Freedom and Agency in Light of the Two Truths" in M. Dasti and E. Bryant (eds), Free Will, Agency, and Selfhood in Indian Philosophy. New York: Oxford University Press, pp. 41-67.

Nikhilananda (trans.) (2003) The Principal Upanishads. Mineola: Dover Publications.

Ollett, A. (2013) "What is Bhavana?" Journal of Indian Philosophy 41: 221-62.

Phillips, S.H. (2009) Yoga, Karma, and Rebirth: A Brief History and Philosophy. New York: Columbia University Press.

Potter, K. (1967) "Freedom and Determinism from an Indian Perspective," Philosophy East and West 17: $113-24$.

Sen, A. (2006) The Argumentative Indian. Picador: New York.

Venkatesananda (trans.) (1993) Vasistha's Yoga. Albany: State University of New York Press.

Vivekananda (1964) "The Free Soul," in The Complete Works of Swami Vivekananda, vol. 3, 9th ed. Calcutta: Advaita Ashrama.

Ward, W. (1818) A View of the History, Literature, and Mythology of the Hindoos: Including a Minute Description of their Manners and Customs, and Translations from their Principal Works. Serampore: Mission Press.

Zimmermann, T.E. (2000) "Free Choice Disjunction and Epistemic Possibility," Natural Language Semantics 8: 255-90.

\section{Further Reading}

Dasti, M.R. and Bryant, E.F. (eds) (2013) Free Will, Agency, and Selfhood in Indian Philosophy. Oxford: Oxford University Press. (Remains the best and recent-most collection of papers with detailed accounts of the treatment of the free will questions in Sāmkhya, in Bhartrhari's Philosophy of Grammar, in Advaita Vedānta, in Theravadin (realist) as well as Mādhyamika [anti-realist] Buddhism, in Jainism, Mīmāmsā, and in the devotional theistic school of Madhva Vedānta.)

Shaw. J.L. (2011) "Freedom: East and West," Sophia 50: 481-97. (Compares the standard Western arguments for compatibilism with the major Indian [Nyaya] views on belief, desire causing will and will causing 
actions and ends with a good summary of K.C. Bhattacharya's Advaita Vedānta influenced views of the subject as freedom.)

Freschi, E. (2015). "Free Will in Viśisțādvaita Vedānta: Rāmānuja, Sudarśana Sūri and Venkkațanātha," Religion Compass 9: 287-96 (As well as her papers on Mīmāmssā theory of action provide clear and nuanced interpretations of Indian analytic views about freedom of the will, agent-causation, and of libertarian arguments from ethical obligations.)

Potter, K. (1967) "Freedom and Determinism from an Indian Perspective," Philosophy East and West 17: 113-24; Potter, K. (1980) "The Karma Theory and Its Interpretation in Some Indian Philosophical Systems," in W. Doniger (ed.), Karma and Rebirth in Classical Indian Traditions. Berkeley: University of California Press, pp. 241-67. (These are both classics in the field.)

\section{Related Topics}

Leeway vs. Sourcehood Conceptions of Free Will

Gottfried Leibniz

Immanuel Kant

Chinese Perspectives on Free Will

Willpower, Freedom, and Responsibility

Free Will and the Problem of Evil

Mental Causation 


\section{Section IV}

\section{EMPIRICAL AND SCIENTIFIC WORK}

Vindicating free will requires more than constructing satisfactory responses to the traditional threats to it (divine foreknowledge and causal determinism, most centrally). Showing that free will is compatible with these conditions, or that they fail to hold, shows only that free will is metaphysically possible. Free will might be possible, but not possible for beings like us, due to our cognitive limitations, or to the vagaries of minds. The chapters in this section examine some of the possible threats to, or limitations of, human freedom, by way of an examination of how we are actually constituted and the kinds of pathologies to which we are subject.

Most of the chapters concentrate on threats to human freedom that arise out of recent work in scientific psychology. Some famous experiments in psychology seem to show that we are highly sensitive, in ways of which we are not aware and may not be able to control, to apparently innocuous facts about the circumstances in which we act. According to some psychologists, and some philosophers inspired by them too, we are creatures of our environment, pushed and pulled by the facts in ways we do not control. If this view is correct, then we would seem to lack autonomy, or reasons responsiveness, or the capacity to express our real selves in our actions. It would seem to follow that we lack free will, or at any rate that we have a vastly reduced capacity for freedom.

While the psychologists have produced evidence that seems to support this claim, neuroscientists have mounted an attack on another front. They have produced data that seems to show that we begin to act before we are conscious of deciding to act. That raises the possibility that our decisions are what psychologists call confabulations: epiphenomenal stories we construct to rationalize our actions. While the complaint that "my brain did it, not me" makes little sense (how can I be independent from my brain in the kind of way required to make the complaint meaningful?), if our decisions are not the causes of our actions, free will seems threatened.

The threats from psychology and neuroscience just outlined are problems for all of us. They confront us in virtue of the kind of beings we are. Other threats arise only for some of us. Philosophers have long tested theories of free will against the yardstick of addiction, but only recently have they come to enquire into the nature of addiction and just how, if at all, it threatens free will. Attention to the evidence, drawn from clinical experience, epidemiology and controlled experiments, reveals that many of the claims traditionally made about addiction by philosophers are nothing more than myths. 
Addictive desires are not literally irresistible, for example. They may not even be especially hard to resist, one by one at least. Nor are the cravings produced especially aversive. Yet addiction does seem to significantly reduce the freedom of sufferers. Given the failure of the most popular explanations for how it reduces freedom, we need to rethink addiction: either it does not threaten free will, or it does so in a different way altogether. Getting addiction right is important not only because it allows us to better understand a large class of agents, and better allocate responsibility for the actions they perform, but because understanding how it affects their freedom promises to illuminate everyone's agency.

Understanding, assessing and responding to the full range of threats to free will therefore requires grappling with the best science. But science offers us more than threats, and possible responses to them. It also helps us to understand how we come to be agents, to be able to grasp reasons and to guide our behavior in their light, and perhaps to illuminate the limits of these capacities. It also helps us to understand our capacity for self-control: to resist temptation and structure our lives in order to pursue the ends we value. Chapters in this section aim to lay bare how we come to be moral agents through the normal process of development and how we exercise self-control, as well as how self-control breaks down.

In recent years, philosophers have not only come to recognize the great value of the scientific perspective on human agency, some have come to believe that it is too important to the philosophical enterprise to be left to the scientists alone. The questions that scientists ask are not always the questions that are most pressing from a philosophical point of view. This insight has given rise to the so-called experimental philosophy movement, whereby philosophers turn scientists and test hypotheses in controlled experiments. The main focus of these experiments has been the intuitions-roughly, the gut feelings - of ordinary people, and the free will debate has been a rich source of material for experimental philosophy. Are ordinary people compatibilists? If they are, what difference does that make to the debate over the truth of the view? What features of thought experiments trigger our responses to them? And so on. One chapter in this section engages with these issues.

What emerges from these chapters is the building blocks for a more realistic view of human agency, one properly informed by the full range of sciences that are concerned with the kind of animal we are. The papers here are, in one way, more provisional than those in other sections, since they are reliant on the sciences and the sciences are constantly in a state of flux. But they remain a central, perhaps the most important, method we have for shining a light on ourselves. If we are to understand our own agency, we cannot neglect the contribution the sciences make to laying bare our cognitive capacities and the way in which these capacities cause behavior.

N.L. 


\section{6 \\ SITUATIONISM, SOCIAL PSYCHOLOGY, AND FREE WILL \\ Christian B. Miller}

While it was before my time, according to various accounts the situationist movement in psychology caused quite a stir in the late 1960s and 1970s, launching the longstanding 'person-situation debate' and calling into question widely held assumptions about personality, and indeed, about the viability of the entire discipline of personality psychology as a whole. More recently in philosophy, there has been a very active discussion over the past 15 years of similar situationist themes, led in particular by the work of Gilbert Harman and John Doris.

In both fields, much of the focus has been on the extent to which people possess certain traits. Less of a focus, but still of significant importance, is whether work in this area bears on issues of free will and moral responsibility. A small but growing literature in philosophy has carefully examined this question (Doris 2002, 2009; Nelkin 2005; Doris and Murphy 2007; Nahmias 2007; Talbert 2009; Mele and Shepherd 2013; Brink 2013; Vargas 2013). In this chapter, I briefly review the situationist movement in both psychology and philosophy before turning to some of the main connections that have been drawn to the topic of this companion.

The first two sections focus on situationism in psychology and philosophy respectively. Section three then quickly mentions two possible connections to free will and moral responsibility that do not seem promising, before sections four and five examine in more detail connections to reasons-responsiveness and unconscious processing respectively. Finally, section six ends with a practical application of becoming acquainted with the situationist literature.

\section{Situationism in Psychology ${ }^{1}$}

In psychology, there is no one position or set of clearly articulated claims which goes by the name of 'situationism.' Here I highlight three central ideas.

The view that is perhaps most famously associated with situationism can be stated as follows:

\section{Trait Rarity}

There is a large body of experimental evidence that is incompatible with the widespread possession of certain traits (Mischel 1968; Ross and Nisbett 1991; see Miller 2014: Chapter 4 for a review). 
The conception of traits which is being called into question involves broad or global traits that are cross-situationally consistent and situation or context free (see Miller 2014: Chapter 4 for discussion of these labels). These should sound like fairly traditional features of traits, and examples would include honesty and compassion as ordinarily understood.

Trait Rarity is an important claim in other contexts, but thus far it has not played a central role in discussions of responsibility. So let me turn to another common situationist claim, this time about the allegedly powerful role of situations in explaining much of our behavior. The idea gets expressed in stronger and weaker forms by situationists. An extreme version is:

\section{Extreme Forces}

Behavior is entirely a product of situational forces. Personality does not make any causal contribution. $^{2}$

More restrained than this claim is:

\section{Strong Forces}

Behavior is primarily a product of situational forces. Personality only has a modest causal contribution to make (Bowers 1973: 307-11, 315, 316, 319, 326, 328; Funder and Ozer 1983; Ross and Nisbett 1991: xiv; Funder 2007: 101, 112, 117).

Here it is easier to see how these claims might have some bearing on the topic of moral responsibility. But there has also been a consensus in psychology for a while now that the claims are false.

One reason why they are false is that the situations which we encounter do not directly produce intentional actions on our part. Rather, their influence is shaped by the mental states that make up our personalities, that is, our beliefs and desires and the interpretations which we give to situations. The causal relationship often goes in the other direction as well; our mental states have a significant impact on creating, selecting, and shaping the situations in which we find ourselves. So my behavior is directly the product of the mental forces in my psychology and only indirectly the product of situational ones (as they impact my mind), with both forces working together in an interactive relationship to produce this output (for much more, see Mischel 1968: 298, 299; Bowers 1973: 329; Wachtel 1973: 330; Ross and Nisbett 1991: 19, 154-6).

Despite this and other concerns, ${ }^{3}$ a more charitable interpretation of the basic situationist idea here can be formulated as follows:

\section{Surprising Dispositions}

The behavior of most individuals tends to be influenced by various situational forces which activate certain of our mental dispositions-certain beliefs, desires, emotions, and the like. Furthermore, the functioning of these dispositions in our minds and especially their degree of impact on behavior are often underappreciated by both ordinary people and even trained philosophers and psychologists. We can call them 'Surprising Dispositions' (Ross and Nisbett 1991: 46; Flanagan 1991: 292; Doris 2002: 63 fn. 5; Vranas 2005: 3; Nahmias 2007: 4; Russell 2009: 253, 277). 
Here are some examples of these dispositions:

- Dispositions to have certain beliefs and desires activated which are concerned with harming others in order to maintain a positive opinion of myself (Baumeister et al. 1996).

- Dispositions to have certain beliefs and desires activated which are concerned with harming others in order to obey instructions from a legitimate authority (Milgram 1974).

- Dispositions to have certain desires activated which are concerned with helping when doing so will contribute towards extending my good mood, and more so than any alternative reasonable means of doing so which is thought to be available (Carlson et al. 1988).

- Dispositions to have certain desires activated which are concerned with not helping when helping is thought to potentially earn the disapproval of those observing me (Latané and Darley 1970).

- Dispositions to have certain desires activated which are concerned with cheating when the benefits of cheating (significantly) outweigh the costs, while also desiring as much as possible to still be thought of as an honest person by oneself and others (Mazar et al. 2008).

Many other examples could also be given. What is going to be true of all these beliefs and desires is that they often operate unconsciously in most people, or at least the extent to which they are operative is often not consciously represented. For instance, it is well known that ordinary estimates of people's willingness to obey authority figures in doing horrendous actions are much lower than is reflected in actual behavior (Milgram 1974; for additional situations where participants' predictions of their moral behavior were significantly out of line with actual behavior, see Balcetis and Dunning 2013). Similarly, it is widely accepted by psychologists that fear of earning the disapproval of observers plays a significant role in studies of group helping, and yet notoriously, participants in those studies do not cite the role of unresponsive group members in explaining their failures to help (Latané and Darley 1970: 124).

To clarify the thesis above a bit more in light of these examples, it is important to stress that the 'surprising' part has more to do with the impact of these dispositions on our behavior, rather than with their mere existence in the first place. Most of us are likely aware that sometimes we do not want to do things that could merit the disapproval of others, for instance. But what is surprising to learn is that our helping avoidance desires can have such a significant impact on our behavior, and often when we do not even realize that they are functioning in the first place. Hence, I noted that it is especially their degree of impact on behavior that is often underappreciated by both ordinary people and even trained philosophers and psychologists.

But why should we believe that these Surprising Dispositions are even present in the first place in most people? Here, situationists in psychology point to a number of relevant studies, and given limitations of space I only mention a few of them here:

- Dime in the Phone Booth. Finding a dime or not in the coin return slot of a phone booth seemed to make a significant difference ( 88 percent versus 4 percent) to whether a participant would subsequently help pick up dropped papers (Isen and 
Levin 1972). There were replication problems with this study, but other studies on mood effects found a similar pattern (see Miller 2013a: Chapter 3).

- Lady in Distress. In Latané and Rodin's classic 1969 "Lady in Distress" experiment, the main dependent variable was whether participants exhibited any helping behavior after hearing a loud crash in the next room and a woman's scream, followed by cries of pain from a bookshelf apparently having fallen on top of her. Participants alone in the next room helped 70 percent of the time, while a participant in the same room with an unresponsive confederate helped only 7 percent of the time (Latané and Rodin 1969: 193-5; Latané and Darley 1970: 60-3).

- Obedience to Authority. In experiment 5, the most famous version of Stanley Milgram's shock experiments, 65 percent of participants inflicted apparently lethal 450-volt XXX shocks, and 80 percent gave shocks that were at least at the 270-volt level, to an innocent test taker in another room, under pressure from an experimenter. This despite the fact that at 270 volts the test taker was heard making agonizing screams and demanding to be let out, with the pleas getting desperate and hysterical at higher levels (Milgram 1974: 60).

- Bathroom. Forty-five percent of participants agreed to deliver some documents 40 meters away in the control condition of a study by Cann and Blackwelder, but 80 percent of people did so in the experimental condition. The only difference was that these participants had just exited a public bathroom (Cann and Blackwelder 1984: 224).

We can see how someone might connect these particular studies to the existence and influence of various Surprising Dispositions-studies such as these may reveal the existence and causally significant influence of dispositions to, for instance, obey authority figures (Obedience to Authority), relieve feelings of embarrassment (Bathroom), or maintain a good mood (Dime in the Phone Booth). ${ }^{4}$

My view is that psychologists have indeed provided us with ample empirical evidence to support the claim that there are many Surprising Dispositions which are widely held and which, when activated or triggered, can have a significant impact on our thoughts, motivation, and behavior (see Miller 2013a: Chapters 2-6, 9, 10; Miller 2014: Chapter 3). These dispositions will occupy a central role in the sections to come on moral responsibility.

\section{Situationism in Philosophy ${ }^{5}$}

While there were a few early discussions in philosophy of the situationist literature, Gilbert Harman and John Doris were primarily responsible for elevating its prominence at the turn of the century (Harman 1999, 2000, 2001, 2003, 2009; Doris 1998, 2002, 2010; Merritt et al. 2010). Their main focus, however, was much narrower than that of psychologists working in the 1960s and 1970s.

First, Harman and Doris were mostly concerned with specifically moral character traits, rather than traits in general. These character traits were, in turn, to be understood as the traditional Aristotelian moral virtues and vices, or causal dispositions that tend to give rise to patterns of appropriate thoughts and behavior which are both stable over time and consistent across situations. Second, unlike situationist psychologists, Harman and Doris had as their ultimate goal to advance a debate in normative ethical theory about the plausibility of Aristotelian virtue ethics. 
Their arguments tended to proceed in two broad stages. First, they argued for an empirical conclusion, roughly as follows:

(1) If there is widespread possession of the traditional virtues and vices understood, at least in part, as cross-situationally consistent 'global' character traits, then systematic empirical observation using appropriate psychology experiments will reveal most people acting virtuously in a wide variety of situations relevant to the particular virtue in question (Doris 1998: $523 \mathrm{fn} .23$ ).

(2) However, systematic empirical observation using appropriate psychology experiments fails to reveal that most people act in this kind of way.

(3) Therefore, given the psychological evidence, we are justified in believing on the basis of that evidence that most people do not possess the traditional virtues or vices. ${ }^{6}$

Thus, the main focus of their argument is the cross-situational consistency of traditional virtues and vices, and they claim that there is sufficient empirical evidence to conclude that most people are not consistently virtuous (or vicious) from one relevant situation to the next.

In the second stage of their argument, Harman and Doris use the conclusion in (3) to assess the plausibility of Aristotelian virtue ethical accounts, along with any other theories in ethics which rely on such traditional virtues and vices. Here it is much less clear how their argument is meant to go, but fortunately we can leave that discussion to one side since it does directly bear on the issues about freedom and responsibility to be considered below (for extensive discussion, see Miller 2014: Chapter 8).

\section{Two Initial Attempts to Connect Situationism to Free Will and Moral Responsibility}

I have spent a fair amount of time on some of the relevant background about situationism so as to illustrate a few of the complexities that can arise when trying to draw conclusions about freedom and responsibility from what 'situationists' hold. In this section, I now turn to the main focus of this companion, and begin by highlighting two areas where potential connections do not seem very promising. ${ }^{7}$ In doing so, I will tend to talk about freedom and moral responsibility together, and remain neutral on whether the former is a necessary condition on the latter (here I follow Nelkin 2005: 183 fn. 6. For some of the relevant debate about the relationship between freedom and responsibility, see Fischer and Ravizza 1998 and Chapter 53 of this volume).

Forging the Connection via Character. If it could be shown that free actions are only those actions that issue from character traits (more specifically, the traditional virtues or vices), then situationism in psychology might be taken to threaten the extent to which we act freely (Nahmias 2007: 7). As we saw, situationists in psychology tend to advance a Trait Rarity thesis.

But hardly anyone holds such a claim about free actions. And this is for good reason, as we normally consider plenty of cases of acting 'out of character' to be free and responsible (Nelkin 2005: 189-92; Brink 2013: 138). Furthermore, situationists in both fields typically are not rejecting the widespread possession of character traits in general, but only certain cross-situationally consistent ones. ${ }^{8}$ Doris, for instance, has long accepted 'local' character traits that are stable in narrowly defined situations (Doris 1998: 507-8, 
2002: $23,25,64)$. So even if it were to turn out that character traits and free actions are somehow linked, situationism need not lead to a general skepticism about people's characters.

Forging the Connection via Determinism. If psychological determinism is incompatible with freedom and/or responsibility, then perhaps situationist claims can support such determinism and thereby forge a connection this way.

But first there is the obvious point that each of the relevant studies showed individual differences in the behavior of the participants -45 percent and 80 percent helped in the two conditions of the Bathroom study, for instance. More importantly, issues about determinism do not seem to be at the heart of why some take situationism to be a threat to freedom. To see this, suppose that in Obedience to Authority, every single participant inflicted XXX level shocks. Or suppose that in the Dime in the Phone Booth study, every participant in both conditions had in fact helped pick up the dropped papers. Then would those results be seen as threatening to freedom/responsibility? From what philosophers writing on this topic have said, the answer is no. There seems to be something potentially disturbing about the particular pattern of results which was found in these studies, independent of what they might or might not show about determinism (Nelkin 2005: 193-4).

\section{One Prominent Connection: Reasons-Responsiveness}

Having put these initial attempts at forging a connection between situationism and freedom/responsibility to one side, the next two sections consider the leading attempts in the literature. The first and most widely discussed attempt is via reasons-responsiveness (see Chapter 3, this volume).

On John Fischer and Mark Ravizza's widely discussed approach to moral responsibility, an agent exhibits the kind of control needed for moral responsibility "insofar as the mechanism that actually issues in the action is his own, reasons-responsive mechanism" (1998: 39). Now it might not be immediately clear how this connects to the situationist experiments. After all, we already said that situational forces do not lead to intentional actions apart from the agent's psychological processing, and it is plausible to hold that participants in these studies were clearly acting from motivating reasons of various sorts, including reasons of obedience, embarrassment relief, and fear of embarrassment.

But what is equally clear is that they were not being influenced at all, or at least influenced nearly enough, by the morally right reasons. The suffering of the test taker or the woman pinned under the bookshelf is clearly far weightier from the moral point of view than are the considerations that seemed to predominately influence most of the participants. And it is responsiveness to right reasons that is a necessary condition on moral responsibility, at least according to some participants in the literature on situationism and responsibility (see Nelkin 2005: 199-200; Brink 2013: 131). Hence, the situationist experiments can be connected to the denial of moral responsibility via the reasons-responsiveness requirement.

A more developed version of this argument might draw on one of the central claims of situationism in psychology as follows:

(1) The behavior of most individuals tends to be influenced by various situational forces which activate certain Surprising Dispositions that are typically not sensitive 
to morally right reasons, but rather to morally neutral or morally problematic reasons. ${ }^{9}$

(2) Morally responsible behavior requires sensitivity to morally right reasons.

(3) Therefore, behavior which is significantly influenced by Surprising Dispositions, is not to that extent morally responsible behavior on the part of the agent in question.

Consider, for instance, the Bathroom study. A detailed look at the psychological literature on embarrassment and helping suggests that one of the leading models of the relationship between the two is that embarrassment often gives rise to a desire to relieve the embarrassment, and in appropriate circumstances helping another person can be seen as a means of doing so. Hence, there will be increased motivation to help, other things being equal (for relevant discussion, see Miller 2013a: Chapter 3). But clearly helping, to the extent that it is caused by a desire to eliminate feelings of embarrassment, is not helping done for morally right reasons.

So a case can indeed be made that situationism appears to threaten moral responsibility because it appears to threaten reasons-responsiveness, and reasons-responsiveness is required for moral responsibility. ${ }^{10}$ But does situationism really pose such a threat? Let me review several strategies for saying no.

First Strategy: Concession. One approach would be to concede that, with respect to the behaviors in studies such as Bathroom, the participants have either diminished or a complete lack of moral responsibility. At the same time, it could be pointed out that there are plenty of other morally relevant behaviors which do seem to be done for morally right reasons, and so moral responsibility remains widespread.

I see two costs with this strategy. First, giving up on moral responsibility in the cases in question would require a significant revision to our ordinary practices. Surely we are initially strongly inclined towards thinking that the participant in Lady in Distress is blameworthy for not doing anything, regardless of the confederate's inactivity. Second and more importantly, the Surprising Dispositions that have emerged in the situationist literature are both numerous and pervasive. In my own work, I have gone to some length to review the psychology literature in order to document the effects of dispositions associated with guilt relief, anticipated guilt avoidance, embarrassment relief, anticipated embarrassment avoidance, positive mood maintenance, negative mood relief, anticipated empathy avoidance, anticipated blame avoidance, and many others. The worry is that far from being rare, such dispositions to act for reasons that are often not morally right, are in fact pervasive and powerful.

Second Strategy: Modal. A better strategy is to note that reasons-responsiveness is not threatened just because someone actually acts for bad reasons. That would be an implausible sufficient condition to say the least. Rather, the key question is whether someone can act for good reasons, and much attention is paid to fleshing out this modal notion.

More precisely, the line of reasoning in (1) through (3) above seems to be assuming what Fischer and Ravizza call strong reasons-responsiveness, whereby if a mechanism "were to operate and there were sufficient reason to do otherwise, the agent would recognize the sufficient reason to do otherwise and thus choose to do otherwise and do otherwise" (1998: 63, emphasis theirs). But this requirement is too strong for moral responsibility (1998: 42, 43). Instead, it might be replaced with so-called weak reasonsresponsiveness, where the operation of the actual kind of mechanism is held fixed, 
and there only has to be some possible world where this reason is recognized and acted upon (1998: 64). Yet according to Fischer and Ravizza this requirement is too weak (1998: 65, 66).

What about Fischer and Ravizza's own 'moderate' proposal? Briefly, the agent's reactivity to reasons (in the form of choice and action) must only be as the weak proposal specified. But the agent's receptivity to reasons needs to be stronger, involving a certain regularity, that is, an understandable pattern of actual and hypothetical reasons-recognition (1998: 74).

Much needs to be said in fleshing out this proposal and then seeing how it would apply to the situationist literature. For instance, when it comes to dispositions involved in positive mood maintenance, they would likely facilitate an understandable pattern of reasons-recognition, but unfortunately, a pattern that is typically not going to involve good moral reasons. Rather they will be self-interested ones. Furthermore, it will not even be a pattern that is considered to be in line with the agent's own conscious values and principles, at least if the agent is a decently moral individual. Yet it would not immediately follow on Fischer and Ravizza's approach that actions produced by such dispositions would be free from moral praise and blame, since the dispositions only count as a sub-component of the larger mechanism involved in practical reasoning. Clearly a much longer treatment of these issues is needed (see Nelkin 2005: 199-204; Talbert 2009: 422, for further discussion, as well as the next section for additional suggestions).

Third Strategy: Revision. Perhaps we should hold on to the notion of reasons-responsiveness in general as central to moral responsibility, but alter the requirements on being so responsive in light of the situationist literature. These altered requirements, the thought is, might still hold even in the cases of moral behavior that have traditionally interested situationists (see Talbert 2009 and Vargas 2013. In Talbert's case, it is not clear if he would consider his proposal a weakening of a reasons-responsiveness approach or a replacement for it).

For instance, in response to the situationist literature, Manuel Vargas has advanced a version of Fischer and Ravizza's proposal according to which an agent is responsible with respect to some moral considerations if she, "possesses a suite of basic agential capacities implicated in effective self-directed agency ... and is also possessed of the relevant capacity for (A) detection of suitable moral considerations [in the circumstances] and (B) self-governance with respect to [those considerations]" (Vargas 2013: 335; see also Brink 2013: 131, 132). The key move is that self-governance in turn requires either actually being motivated by the right moral considerations, or counterfactually being so motivated in a suitable proportion of relevantly similar possible worlds where the person does detect them (Vargas 2013: 336).

To spell this out more concretely, take Lady in Distress again when a confederate is present. It is widely accepted that one of the central dispositions at work here is fear of embarrassment on the part of the participant if it were to turn out that there really is no emergency in the other room (Latané and Darley 1970: 38-40; Miller 2013a: Chapter 6). Oftentimes, including in this particular experimental context, such a disposition does not seem to be playing a role in detecting the right kinds of moral considerations or in motivating helping behavior when the person has already detected those considerations. But in Vargas's proposal, if the participant also has robust empathetic dispositions, then even if they were not active in the actual world, so long as they detect and motivate helping in a suitable number of relevantly similar possible worlds, then that is 
enough for the behavior in the actual world to still count as blameworthy. The presence and potential to function in relevant ways of the person's reasons-responsive capacities is sufficient, then, to secure moral responsibility, even if those capacities do not actually turn out to function in the moment. This strikes me as a promising route to take, but much more needs to be said (for related discussion, see Brink 2013: 140-2. Brink articulates a reasons-responsive approach to moral responsibility and argues that situationist studies are compatible with "most people [having] the capacity for recognizing and responding to reasons for compassionate behavior, even when they do not exercise these capacities" (2013: 142)).

\section{Another Prominent Connection: Unconscious Processing}

Another leading way to try to connect situationism and freedom/responsibility is via unconscious processing. Here is one attempt to spell out the connection:

(1) Free and/or morally responsible actions require expressions of agency.

(2) Agential behavior is caused by thoughts which, minimally, are conscious and informed. ${ }^{11}$

(3) Situationism supports the claim that much of our morally relevant behavior is caused by (or at least significantly causally influenced by) thoughts that are unconscious. ${ }^{12}$

(4) Therefore, we are justified in believing that much of our morally relevant behavior is not free and/or morally responsible. Or at least we are not justified in believing that it is.

This is meant to be a general reconstruction of how a certain line of reasoning often goes, while acknowledging that there are differences in the details. Sometimes the argument is put in terms of 'agency,' as above, and sometimes it is put in terms of 'personhood' or 'autonomy' (for agency, see Doris 2009; Vargas 2013: 330, and especially Mele and Shepherd 2013. For personhood, see Doris 2009. For autonomy, see Nahmias 2007). The standards in question for agential behavior vary somewhat in this literature on situationism and freedom too-consciousness of the thoughts giving rise to the behavior is one proposed requirement, and others mentioned in this context include self-conscious reflection, accurate self-reflection, reflective selfdirection, reflectively chosen principles, or knowledge of reasons (Nahmias 2007: 2-4; Doris 2009: 59, 60; Mele and Shepherd 2013: 62). Regardless of these differences, if it were to turn out that our behavior is primarily caused by unconscious psychological states, then in all these proposals, we would not be free and responsible in those particular instances (Nahmias 2007; Doris 2009; Baumeister et al. 2011: 333; although see Nelkin 2005: 202-4, who argues that reasons-responsiveness is really the heart of the worries about situationism and freedom, and not issues about unconscious processing).

Some of the experiments linked to situationism certainly lend support to the role of unconscious processing. As already noted, participants in group effect studies such as Lady in Distress typically deny that the presence of the confederate had any role to play in their not helping (Latané and Darley 1970: 124). Participants emerging from the bathroom presumably were unaware of the influence of embarrassment relief, as were participants similarly unaware of the role of positive mood maintenance in Dime in the Phone Booth. The situationist claim in Surprising Dispositions is a reflection of these particular studies, but also of hundreds of others that call attention to psychological 
dispositions that are not well appreciated but which can and often do work at the unconscious level.

Such results link up with a larger literature in social psychology on unconscious automaticity (see Chapter 38, this volume). John Bargh has helpfully identified the following features of processing that are typically related to automaticity-such processing is said to be unaware, relatively effortless, unintentional, autonomous, and involuntary (Bargh 1989: 3-5; see also the helpful taxonomy of deliberative agency, conscious agency, automatic agency, and automatistic agency in Levy and Bayne 2004). Bargh argues that these features are not all necessary for a process to be automatic, and often do not all jointly occur together. Rather they together serve to represent an extreme form of automaticity on one end of a broad continuum, with highly controlled processing on the opposite end of the spectrum.

Several psychologists have made bold statements about the extent to which unconscious thoughts causally give rise to behavior. Bargh himself claims that "there ultimately is no future for conscious processing in accounts of the mind, in the sense of free will and choice," and again that "Our psychological reactions from moment to moment . . are 99.44\% automatic" (quoted in Baumeister et al. 2011: 332). Similarly, Ap Dijksterhuis and his colleagues hold that, "Behavior does not originate with a conscious decision" (Dijksterhuis et al. 2007: 52). And now it looks as if the research that emerged from the situationist tradition in psychology could offer additional empirical support to the claim that unconscious automaticity is widespread.

This brief chapter is not the place to attempt a proper discussion of work on automaticity. Instead let me briefly highlight several strategies for resisting the more specific conclusion (4) of the argument above.

First Strategy: Concession. As with the topic of reasons-responsiveness, the simplest response is just to concede that, in cases such as Lady in Distress, the participant's failure to help was caused by unconscious processes which thereby undermined his agency in this instance, and so absolved him of freedom and/or responsibility. At the same time, careful experiments have yet to be done on a host of other, more ordinary moral situations in our day-to-day lives, and so it remains to be seen whether the results will generalize or not (for a version of this response, see Nahmias 2007: 11; Vargas 2013: 330).

But the costs with this response are familiar (and high, in my view). First, this just seems like the wrong thing to say in resisting the argument above-absent some general arguments about why there is no moral responsibility at all, surely in this case the participant is blameworthy at least to some degree for not helping. And second, not only are the relevant situationist experiments extensive in number, but when combined with the literature on unconscious automaticity, there would then seem to be little scope remaining for actions which are genuinely free and/or responsible (Doris 2009: 69, 70).

Second Strategy: Criticism and Counterevidence. A more aggressive response is to look closely at the studies which have been done in this area of psychology, and raise worries about their design and implications, as well as try to replicate some of the leading studies that have been much criticized in recent years. Such a strategy could naturally be combined with a search for more carefully done causal studies involving random assignments of participants which did find evidence that conscious thoughts causally influence behavior (see Nahmias 2007: 11, 12; Mele and Shepherd 2013: 76-80; Vargas 2013: 331, 332; and 
especially Baumeister et al. 2011; Newell and Shanks 2014). For instance, in a recent review article Roy Baumeister, E. J. Masicampo, and Kathleen Vohs (2011) found such evidence in a number of different research areas: mental simulation, implementation intentions, anticipated emotions, thoughts about past events, logical reasoning, detrimental thinking, simulations of other's thoughts, self-concepts, mental framing, communication, and overridden automatic impulses. As they conclude, "The evidence for conscious causation of behavior is profound, extensive, adaptive, multifaceted, and empirically strong" (Baumeister et al. 2011: 351).

Reviews such as Baumeister's serve as a helpful corrective for some of the badly overreaching claims made on behalf of unconscious automaticity. But even if conscious reasoning does play a significant causal role in many of these areas, it is not clear how much this would help with regard to the concerns of this chapter. More precisely, it is not clear how much it would help to secure freedom and/or responsibility with respect to those moral behaviors influenced by the Surprising Dispositions that have emerged in the situationist literature, such as embarrassment relief or guilt avoidance or positive mood maintenance. Once again that literature might have serious revisionary consequences.

Third Strategy: Broadening. The final strategy to be mentioned here is the one which, in my view, holds the most promise. It involves broadening the standards required for agential behavior so that unconscious mental states can still give rise to genuine actions, at least provided certain conditions are also satisfied. What would not be necessary (although it may still be sufficient) would be the satisfaction of more sophisticated requirements that would not be met in the cases that are of interest here, such as acts of reflection, having conscious awareness of reasons, performing second-order conscious assessments of desires, forming higher-order volitions, engaging in self-conscious deliberation, or the like.

There are a number of ways to develop this strategy, and unfortunately they cannot be reviewed here. To take one example, a straightforward proposal would be to require only counterfactual endorsement, or roughly the idea that if the agent in question were to be made aware of the mental states which had unconsciously given rise to her action, then for her action to be an expression of her agency, she would reflectively endorse those states (or do whatever else the correct standard is supposed to be on proposals that require conscious access to the processing that goes into behavior) (for a similar approach, see Bratman 1996: 204). Another proposal, which I myself have developed in some detail (Miller 2013b), is to require that there be a subconscious cognitive process that pairs the causally relevant unconscious mental states with the agent's most important relevant norms, and when doing so, does not return the output that there is an inconsistency between the two. In other words, there is psychological harmony between the agent's values and the particular desires, intentions, and so forth, even if she is not consciously aware of their presence in the moment (for a third approach, see Wigley (2007) who argues that "we do have rational control over our automatic behavior insofar as we can preset or revise the way it will function" (2007: 218). For yet another approach, see Doris (2002: 140-2) and his critical discussion of reflective approaches to agency in Doris 2009).

Regardless of the prospects for these particular proposals, developing a strategy in this ballpark strikes me as one of the most worthwhile research areas in the philosophy of action. 


\section{A Practical Application}

Much of this chapter has considered ways in which what I have called our Surprising Dispositions might threaten our freedom and/or moral responsibility. But let me end on a more positive note. For once research about these dispositions, such as obedience to authority or embarrassment avoidance, becomes more widely appreciated, that information may be able to play a valuable role in gradually weakening their strength. In future situations where they might be relevant, the hope is that their influence would not be felt as frequently, or at least that their influence would be outweighed by competing reasonsresponsive mechanisms. If so, then the scope of our agency, freedom, and moral responsibility can be enhanced (for related claims see Nahmias 2007: $12 \mathrm{fn}$. 50; Wigley 2007: 218; Brink 2013: 130; Vargas 2013: 341-43; and especially Mele and Shepherd 2013).

This is an empirical hypothesis, though, and unfortunately there are scarcely any published studies in psychology to use in assessing it. Let me mention two exceptions. Arthur Beaman and his colleagues (1978) had college students hear a social psychology lecture explaining the Latané and Darley (1970) model of group effects. They were subsequently presented with a staged emergency - a victim of a bicycle accident in one case, and a man sprawled against a wall in another. Helping in the presence of a nonresponsive confederate was 67 percent versus 27 percent for controls in the first study, and 42.5 percent versus 25 percent in the second (even though in this study the helping opportunity was two weeks later than the lecture) (Beaman et al. 1978: 407-8, 410). In a less rigorous study, Steven Samuels and William Casebeer contacted students from a social psychology class up to two years later, and for the question, "Did learning about helping behaviour lead you to help in any situation in which you believe you would not have otherwise helped?"-72 percent answered positively (Samuels and Casebeer 2005: 80).

But these studies are hardly enough, and clearly much more work needs to be done here to see if familiarity with situationism might actually be used to our moral benefit in the long run and enhance our capacities for free and responsible agency.

\section{Acknowledgements}

I am very grateful to the editors of this volume for inviting me to contribute, and to Neil Levy, Erik Helzer, Heidi Giannini, R. Michael Furr, and William Fleeson for helpful comments. The material in this chapter draws on a few paragraphs from Miller (2014): Chapter 4, one paragraph from Chapter 8 and Chapter 9, and a few paragraphs from Miller (2016). Reprinted with permission from Oxford University Press and Taylor and Francis. Support for this work was funded in part by a grant from the Templeton World Charity Foundation. The opinions expressed in this chapter are my own and do not necessarily reflect the views of the foundation.

\section{Notes}

1 Material in this section draws from Miller 2014 and Miller 2016.

2 Hence Skinner:

Every discovery of an event which has a part in shaping a man's behavior seems to leave so much the less to be credited to the man himself; and as such explanations become more and more 


\section{SITUATIONISM AND SOCIAL PSYCHOLOGY}

comprehensive, the contribution which may be claimed by the individual himself appears to approach zero.

(1955/1956: 52)

See also the relevant discussion in Flanagan (1991: 264) and Funder (2007: 107).

3 Another reason for suspicion is that personality and situations need not be thought of in 'zero-sum' terms, where the leftover variance not accounted for by a personality variable must thereby be accounted for by a situation variable. It could at least partially be accounted for in terms of person $\mathrm{x}$ situation interactions and other personality variables, that is, other traits or more specific mental states. This is a familiar point from the psychology literature, but is rarely made in the philosophy one. See, among many others, Bowers (1973: 319-33), Mischel and Shoda (1995: 257, 260), Nelkin (2005: 182 fn. 5), and Flanagan (2009: 64). For a thorough and technical critique, see Shoda (1999).

This point has been explored more rigorously in a well-known paper by David Funder and Daniel Ozer (1983). They took several classic experiments in the situationist tradition and calculated correlations between behaviors and situational variables. Here were the results (1983: 110):

$\begin{array}{llll}\text { Behavior } & \text { Situational Variable } & \text { Correlation } & \text { Study } \\ \text { Attribute Report } & \text { Incentive for Advocacy } & -0.36 & \text { Festinger and Carlsmith (1959) } \\ \text { Bystander Intervention } & \text { Hurry } & -0.39 & \text { Darley and Batson (1973) } \\ \text { Bystander Intervention } & \text { Number of Onlookers } & -0.38 & \text { Darley and Latané (1968) } \\ \text { Obedience } & \text { Victim's Isolation } & 0.42 & \text { Milgram (1974) } \\ \text { Obedience } & \text { Proximity of Authority } & 0.36 & \text { Milgram (1974) }\end{array}$

The upshot is that these correlations with respect to situational variables were not much greater than personality correlations reported by situationists, and yet the situational variables were clearly highly important in these studies. As Funder and Ozer note, "situational effects need not explain large percentages of the behavioral variance in order to be important; we suggest this might also be true of person effects" (1983: 111). For further discussion of these and others concerns, see Miller (2014: Chapter 4).

4 It is important to keep the studies themselves separate from the claims made by situationists in both psychology and philosophy. For instance, some critics have questioned the methodologies used in particular studies, and there have been some replication worries as well. Furthermore, even trusting the studies themselves, various attempts have been made to show how, for instance, they might still be compatible with the widespread possession of the broad traits that situationists in psychology reject. Fortunately, we do not need to consider these issues here. For a discussion of the various responses made to situationists in psychology and philosophy, see Miller (2014: Chapters 4 and 8).

5 Material in this section draws on Miller 2014.

6 While he does not formulate the argument this explicitly in either 1998 or 2002, something like the above reconstruction seems to be what Doris has in mind. See in particular his 1998: 505-7 and his recent co-authored paper Merritt et al. 2010: 357-8.

Note that the conclusion here is stated in terms of lacking the traditional virtues and vices. But at times Harman and Doris state their conclusion in terms of the absence of cross-situationally consistent traits of any kind. This, though, would be overreaching. For one thing, the Surprising Dispositions themselves are cross-situationally consistent traits (consider the variety of situations in which disapproval avoidance could manifest itself), and yet are widely accepted in the psychology literature. For more on these issues, see in particular Miller 2014: Chapter 8.

7 In this section I have been helped by Nelkin 2005. In addition to the two areas below, she also discusses three other potential connections which do not seem promising (the fundamental attribution error, weakness of will, and real-self views). For additional potential connections, see Vargas 2013: 328-30.

8 The 'certain' is important here-these are familiar character traits such as honesty and compassion. Indeed, the Surprising Dispositions themselves are constituent elements of cross-situationally consistent character traits, as a disposition such as fear of embarrassment can be activated in a wide variety of different situations. Yet as we have seen, situationists tend to be comfortable positing such dispositions. For more on this issue, see Miller (2013a: Chapter 7, 2014: Chapter 5).

9 As Neil Levy rightly noted in comments, the mechanism on which agents act is not constituted by a single disposition, and hence, so long as other dispositions are present in the agent and appropriately sensitive to right reasons, moral responsibility can still be preserved. This is the heart of the third response. 
10 As Nelkin formulates the connection,

the subjects seem to be acting for bad reasons, or at least not acting for good reasons, and they seem stuck doing so. At the same time, having the ability to act for good reasons is essential freedom and/or responsibility.

(2005: 199)

See also Doris and Murphy 2007: 26, 30 and Talbert 2009: 418-19, 422.

11 A commitment to something like this premise can be found in the work of Harry Frankfurt, Michael Bratman, Eleonore Stump, David Velleman, and Laura Ekstrom. For an extensive list of references, see Miller (2013b). Admittedly, in recent years support for this premise has waned, no doubt in part because of increased familiarity with research in psychology.

12 Some formulations of this premise would add that not only are the thoughts unconscious, but if the agent were to be aware of them, then she would reject them in light of her conscious principles and values. See, e.g., Nahmias 2007: 2.

\section{References}

Balcetis, E. and Dunning, D. (2013) "Considering the Situation: Why People are Better Social Psychologists than Self-psychologists," Self and Identity 12: 1-15.

Bargh, J. (1989) "Conditional Automaticity: Varieties of Automatic Influence in Social Perception and Cognition," in J. Uleman and J. Bargh (eds), Unintended Thought. New York: The Guilford Press, pp. 3-51.

Baumeister, R., Masicampo, E.J. and Vohs, K. (2011) "Do Conscious Thoughts Cause Behavior?" Annual Review of Psychology 62: 331-61.

Baumeister, R., Smart, L. and Boden, J. (1996) "Relation of Threatened Egoism to Violence and Aggression: The Dark Side of High Self-Esteem," Psychological Review 103: 5-33.

Beaman, A., Barnes, P., Klentz, B. and McQuirk, B. (1978) "Increasing Helping Rates through Information Dissemination: Teaching Pays," Personality and Social Psychology Bulletin 4: 406-11.

Bowers, K. (1973) "Situationism in Psychology: An Analysis and a Critique," Psychological Review 80: $307-36$.

Bratman, M. (1996) "Identification, Decision, and Treating as a Reason," Philosophical Topics 24: 1-18.

Brink, D. (2013) "Situationism, Responsibility, and Fair Opportunity," Social Philosophy and Policy 30: 121-49.

Cann, A. and Blackwelder, J. (1984) "Compliance and Mood: A Field Investigation of the Impact of Embarrassment," The Journal of Psychology 117: 221-6.

Carlson, M., Charlin, V. and Miller, N. (1988) "Positive Mood and Helping Behavior: A Test of Six Hypotheses," Journal of Personality and Social Psychology 55: 211-29.

Darley, J. and Batson, C. (1973) '“From Jerusalem to Jericho:' A Study of Situational and Dispositional Variables in Helping Behavior," Journal of Personality and Social Psychology 27: 100-8.

Darley, J.M. and Latané, B. (1968) "Bystander Intervention in Emergencies: Diffusion of Responsibility," Journal of Personality and Social Psychology 8: 377-83.

Dijksterhuis, A., Chartrand, T. and Henk, H. (2007) "Effects of Priming and Perception on Social Behavior and Goal Pursuit," in John Bargh (ed.), Social Psychology and the Unconscious: The Automaticity of Higher Mental Processes. Frontiers of Social Psychology. New York City: Psychology Press, pp. 51-131.

Doris, J. (1998) "Persons, Situations, and Virtue Ethics," Noûs 32: 504-30.

Doris, J. (2002) Lack of Character: Personality and Moral Behavior. Cambridge: Cambridge University Press.

Doris, J. (2009) "Skepticism About Persons," Philosophical Issues 19: 57-91.

Doris, J. (2010) "Heated Agreement: Lack of Character as Being for the Good," Philosophical Studies 148: $135-46$.

Doris, J. and Murphy, D. (2007) "From My Lai to Abu Ghraib: The Moral Psychology of Atrocity," Midwest Studies in Philosophy 31: 25-55.

Festinger, L. and Carlsmith, J. (1959) "Cognitive Consequences of Forced Compliance," Journal of Abnormal and Social Psychology 58: 203-10.

Fischer, J.M. and Ravizza, M. (1998) Responsibility and Control: A Theory of Moral Responsibility. Cambridge: Cambridge University Press.

Flanagan, O. (1991) Varieties of Moral Personality. Cambridge: Harvard University Press. 


\section{SITUATIONISM AND SOCIAL PSYCHOLOGY}

Flanagan, O. (2009) "Moral Science? Still Metaphysical after all these Years," in D. Narvaez and D. Lapsley (eds), Personality, Identity, and Character: Explorations in Moral Psychology. Cambridge: Cambridge University Press, pp. 52-78.

Funder, D. (2007) The Personality Puzzle, 4th edn. New York: W.W. Norton \& Company.

Funder, D. and Ozer, D. (1983) "Behavior as a Function of the Situation," Journal of Personality and Social Psychology 44: 107-12.

Harman, G. (1999) "Moral Philosophy meets Social Psychology: Virtue Ethics and the Fundamental Attribution Error," Proceedings of the Aristotelian Society 99: 315-31.

Harman, G. (2000) "The Nonexistence of Character Traits," Proceedings of the Aristotelian Society 100: 223-6.

Harman, G. (2001) "Virtue Ethics without Character Traits," in A. Byrne, R. Stalnaker, and R. Wedgewood (eds), Fact and Value. Cambridge: MIT Press, pp. 117-27.

Harman, G. (2003) "No Character or Personality," Business Ethics Quarterly 13: 87-94.

Harman, G. (2009) "Skepticism about Character Traits," The Journal of Ethics 13: 235-42.

Isen, A. and Levin, P. (1972) "Effect of Feeling Good on Helping: Cookies and Kindness," Journal of Personality and Social Psychology 21: 384-8.

Latané, B. and Darley, J. (1970) The Unresponsive Bystander: Why Doesn't He Help? New York: AppletonCentury-Crofts.

Latané, B. and Rodin, J. (1969) "A Lady in Distress: Inhibiting Effects of Friends and Strangers on Bystander Intervention," Journal of Experimental Social Psychology 5: 189-202.

Levy, N. and Bayne, T. (2004) "Doing without Deliberation: Automatism, Automaticity, and Moral Accountability," International Review of Psychiatry 16: 209-15.

Mazar, N., Amir, O. and Ariely, D. (2008) "The Dishonesty of Honest People: A Theory of Self-Concept Maintenance," Journal of Marketing Research 45: 633-44.

Mele, A. and Shepherd, J. (2013) "Situationism and Agency," Journal of Practical Ethics 1: 62-83.

Merritt, M., Doris, J., and Harman, G. (2010) "Character," in J. Doris and the Moral Psychology Research Group (eds), The Moral Psychology Handbook. Oxford: Oxford University Press, pp. 355-401.

Milgram, S. (1974) Obedience to Authority. New York: Harper \& Row.

Miller, C. (2013a) Moral Character: An Empirical Theory. Oxford: Oxford University Press.

Miller, C. (2013b) "Identifying with our Desires," Theoria 79: 127-54.

Miller, C. (2014) Character and Moral Psychology. Oxford: Oxford University Press.

Miller, C. (2016) "Assessing Two Competing Approaches to the Psychology of Moral Judgments," Philosophical Explorations 19: 28-47.

Mischel, W. (1968) Personality and Assessment. New York: John Wiley \& Sons.

Mischel, W. and Shoda, Y. (1995) "A Cognitive-Affective System Theory of Personality: Reconceptualizing Situations, Dispositions, Dynamics, and Invariance in Personality Structure," Psychological Review 102: 246-68.

Nahmias, E. (2007) "Autonomous Agency and Social Psychology," in M. Marraffa, M. De Caro, and F. Ferretti (eds), Cartographies of the Mind, Vol. 4. Dordrecht: Springer, pp. 169-85.

Nelkin, D. (2005) "Freedom, Responsibility and the Challenge of Situationism," Midwest Studies in Philosophy 29: 181-206.

Newell, B. and Shanks, D. (2014) "Unconscious Influences on Decision Making: A Critical Review," Behavioral and Brain Sciences 37: 1-19.

Ross, L. and Nisbett, R. (1991) The Person and the Situation: Perspectives of Social Psychology. New York: McGraw-Hill.

Russell, D. (2009) Practical Intelligence and the Virtues. Oxford: Clarendon Press.

Samuels, S. and Casebeer, W. (2005) "A Social Psychological View of Morality: Why Knowledge of Situational Influences on Behaviour Can Improve Character Development Practices," Journal of Moral Education 34: 73-87.

Shoda, Y. (1999) "A Unified Framework for the Study of Behavioral Consistency: Bridging Person X Situation Interaction and the Consistency Paradox," European Journal of Personality 13: 361-87.

Skinner, B. (1955/1956) "Freedom and the Control of Man," American Scholar 25: 47-65.

Talbert, M. (2009) "Situationism, Normative Competence, and Responsibility for Wartime Behavior," Journal of Value Inquiry 43: 415-32.

Vargas, M. (2013) "Situationism and Moral Responsibility: Free Will in Fragments," in A. Clark, J. Kiverstein, and T. Vierkant (eds), Decomposing the Will. Oxford: Oxford University Press, pp. 325-49. 
Vranas, P. (2005) "The Indeterminacy Paradox: Character Evaluations and Human Psychology," Nô̂s 39: $1-42$.

Wachtel, P. (1973) "Psychodynamics, Behavior Therapy, and the Implacable Experimenter: An Inquiry into the Consistency of Personality," Journal of Abnormal Psychology 82: 324-34.

Wigley, S. (2007) "Automaticity, Consciousness and Moral Responsibility," Philosophical Psychology 20: $209-25$.

\section{Further Reading}

Mischel, W. (1968) Personality and Assessment. New York: John Wiley \& Sons. (The classic statement of situationism in psychology.)

Ross, L. and Nisbett, R. (1991) The Person and the Situation: Perspectives of Social Psychology. New York: McGraw-Hill. (A more contemporary treatment of situationism in psychology.)

Doris, J. (2002) Lack of Character: Personality and Moral Behavior. Cambridge: Cambridge University Press. (The leading statement of situationism in philosophy.)

Miller, C. (2014) Character and Moral Psychology. Oxford: Oxford University Press. (A recent and thorough discussion of situationism in both philosophy and psychology.)

Nelkin, D. (2005) "Freedom, Responsibility and the Challenge of Situationism," Midwest Studies in Philosophy 29: 181-206. (An excellent resource to consult next for further discussion of situationism and free will.)

\section{Related Topics}

Neuroscientific Threats to Free Will

Empirical Perspectives on Consciousness and its Relationship to Free Will and Moral Responsibility Willpower, Freedom, and Responsibility

Deliberation

The Relationship between Moral Responsibility and Freedom

Free Will and the Phenomenology of Agency 


\section{THE ROUTLEDGE COMPANION TO FREE WILL}

Edited by Kevin Timpe, Meghan Griffith, and Neil Levy

First published 2017

ISBN: 978-1-138-79581-5 (hbk)

ISBN: 978-1-315-75820-6 (ebk)

\section{7 NEUROSCIENTIFIC THREATS TO FREE WILL \\ Joshua Shepherd}

(CC BY-NC-ND 4.0)

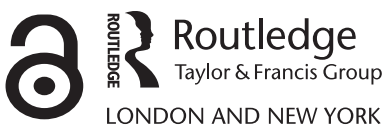


In this chapter, I review recent work on neuroscientific threats to free will. What is it for something to threaten free will? Consider, first, an apparent threat. You are walking in the dark, and a shadow looms in the distance. It certainly appears threatening, but you are not sure. What do you do? You consider the source of the threat (the thing casting the shadow, and you attempt to discover whether the threat is actual (an attacker) or merely apparent (a tree). And if the threat is actual, you attempt to discern what epistemic and behavioral changes are required of you.

It is clear that recent work in neuroscience-along with recent work in psychology (for which see Miller: Chapter 36, this volume)—represents at least an apparent threat. This is why the issue has received so much attention in the popular press, and in the scientific and philosophical literatures. What we are now trying to do is discern whether the threat is actual or merely apparent. If it is actual, then we will have to consider what epistemic and behavioral changes are required of us. If it is merely apparent, then we can go on our way.

Two questions will guide my discussion below. First, does current neuroscience present an actual threat? This involves consideration of the main neuroscientific results taken to threaten free will. I do this in the next two sections, "Seemingly Threatening Results," and "Do These Studies Actually Threaten Free Will?" Second, how does (or might) neuroscience threaten free will? This involves consideration of the source and nature of the apparent threat. Importantly, even if current neuroscience presents no threat, future neuroscience might. Understanding the nature of the apparent threat ought to help us as we look for emerging threats in the near future. In "How Might Neuroscience Threaten Free Will?" I consider recent work that is relevant to this question.

\section{Seemingly Threatening Results}

Amongst the seemingly threatening results, the most widely publicized stem from the work of Benjamin Libet and colleagues (see Libet et al. 1983). Libet had participants decide to flex a wrist while watching a clock and paying attention to the moment they felt an urge to flex. At the same time, Libet monitored electrical activity in the brains of participants. On average, participants reported feeling the urge to flex about 200 milliseconds before they began flexing. This is not that interesting. What was interesting was something happening in participants' brains before they felt the urge. At about 550 milliseconds before participants began flexing, electrical activity associated with voluntary action preparation began to emerge (more specifically, this is a negative shift in the so-called readiness potential, or RP). According to Libet and other interpreters of this experiment, it looked like this: there was a space of roughly 350 milliseconds during which participants sat watching a clock, while (unbeknownst to them) the brain had either already decided what to do, or was preparing the decision about what to do. Here is how Libet et al. (1983) put it in their seminal paper:

Since onset of RP regularly begins at least several hundreds of milliseconds before the appearance of a reportable time for awareness of any subjective intention or wish to act, it would appear that some neuronal activity associated with the eventual performance of the act has started well before any (recallable) conscious initiation or intervention could be possible. Put another way, the brain evidently 'decides' to initiate or, at the least, prepare to initiate the 
act at a time before there is any reportable subjective awareness that such a decision has taken place.

Recent work in the Libet tradition has further pressed this line of reasoning by uncovering evidence that in certain experimental conditions, a participant's decision can be predicted - to a level above chance — several seconds before the decision is made. Consider, for example, a recent study by Chun Siong Soon and colleagues (Soon et al. 2013). In this study, participants sat watching a computer screen that displayed changing letters and numbers. Participants were instructed to spontaneously decide whether to add or subtract the passing numbers, and to memorize the letter present when they made this decision. This allowed the experimenters to locate the time of the decision.

Using sophisticated statistical techniques, Soon et al. (2013) were able to decode signals in various regions of the brain that contained predictive information about the upcoming choice. More specifically, up to four seconds before the decision, signals in the medial frontopolar region of the brain predicted the upcoming decision with 59.5 percent accuracy, and signals in the precuneus and posterior cingulate predicted the upcoming decision with 59 percent accuracy.

I turn now to a different line of evidence. It is often taken to bolster the Libet-type results, and to pose a further threat to free will. Since the line of evidence actually encompasses work in both neuroscience and psychology, I will review one study from psychology, before returning to neuroscience. In this study, Daniel Wegner and Thalia Wheatley (1999) had participants sit opposite another person at a table, facing a wooden square which sat on top of a computer mouse. The other person was in fact in collaboration with Wegner and Wheatley. In the study, both people attempted to jointly move the wooden square. As they did so, they watched a cursor on a screen that contained many different objects. Participants were instructed to stop the cursor periodically. Now for a complication: participants wore headphones which played music and words. Participants were told that the words were random distracters, and that the music indicated when they were to stop the cursor. In reality, however, the words would prime the participants by naming objects on the screen.

The movements made by both the participants and the other person (the Wegner and Wheatley collaborator) occurred in two conditions. In one condition, the collaborator would surreptitiously bring the cursor to a stop at a certain object on the screen. In a second condition, the collaborator would not do this, thus allowing the participant to bring the cursor to a stop at a certain object on the screen. After this, participants offered a rating concerning what had just happened. The rating was on a 0 to 100 scale, with 0 indicating 'I allowed the stop to happen' and 100 indicating 'I intended to make the stop.' When the collaborator did nothing, the average participant rating was 56. When the collaborator surreptitiously brought the cursor to a stop, the average rating depended significantly on the words they were hearing through the headphones. If, 30 seconds before the stop, participants heard a word that matched where the cursor came to a stop, their average rating was 44 . But if 5 seconds before the stop, participants heard a word that matched where the cursor came to a stop, their average rating was 60 . This difference of 16 points on the scale is statistically significant. Wegner and Wheatley concluded that "the experience of will can be created by manipulation of thought and action ... and this experience can occur even when the person's thought cannot have created the action" (1999: 489). 
A very different study - this one from neuroscience-might seem to have the same moral. In this study, Joaquim Brasil-Neto and colleagues (1992) told participants to decide whether to move their right or left index finger after hearing a click. The machine responsible for the click either did or did not direct transcranial magnetic stimulation (TMS) to prefrontal or motor cortex. Interestingly, when TMS was applied to motor cortex, a certain portion of participants ( 80 percent of those who moved within $200 \mathrm{~ms}$ of the click) decided to move the finger corresponding to the place in motor cortex that received TMS. However, according to Brasil-Neto et al., participants reported no awareness of the effect of the TMS. However, those who moved more than $200 \mathrm{~ms}$ after the click showed no bias for that finger. Interpreting this result, Brasil-Neto et al. write "it is possible to influence movement preparation processes externally without disrupting the conscious perception of volition ... [our results] suggest that conscious perception of willing a particular action is preceded, and possibly generated, by cerebral processes that can be influenced by magnetic stimulation" (1992: 966).

These studies are central examples of the body of evidence often taken to threaten free will. Regarding this threat, at least two things deserve attention. First, although there are important differences between these studies, with respect to the purported threat to free will—and seen from a certain height—-these studies all tell a similar story. The story is this: with respect to intentional action, and decision-making, how things seem is not how things are. While it seems to most of us as though the conscious mind is in control of deliberation and decision, these studies suggest that this is incorrect. The studies in the Libet tradition suggest that the brain, rather than the conscious mind, takes care of all the significant work in decision-making. The conscious mind, so goes the suggestion, is passive and inefficacious, awaiting the result of the brain's work. This suggestion receives support from work in the Wegner tradition — work that suggests that the conscious experience of intentional action is in some sense misleading. In "Do These Studies Actually Threaten Free Will?" I review criticisms of these studies.

Second, these studies are not directly about free will. They are about the mechanisms that undergird decision-making, intentional action, and the conscious experience of decision-making and intentional action. So to understand the nature of the threat to free will these studies represent, we need to understand how decision-making, intentional action, and the conscious experience of decision-making and intentional action relate to free will. In other words, philosophical work is required in order to determine whether the threat is actual or merely apparent. In "How Might Neuroscience Threaten Free Will?" I review recent work in this connection.

\section{Do These Studies Actually Threaten Free Will?}

Philosophers—and increasingly, scientists—-have criticized the threatening studies in a number of ways (for a recent exception, see Caruso 2012). The literature is too big to review in detail: here I restrict attention to the studies reviewed above. Let us begin by considering studies in the Wegner tradition. These are studies that suggest that the conscious experience of intentional action is in some sense misleading. As Wegner has famously argued, "unconscious and inscrutable mechanisms create both conscious thought about action and the action, and also produce the sense of will we experience by perceiving the thought as cause of the action" (2002: 98).

But do the studies reviewed above offer support to this claim? A number of philosophers (e.g., Nahmias 2002; Bayne 2006) have noted that Wegner's claim seems to depend on 
a kind of inductive generalization: a move from the discovery that some conscious experiences of action are misleading to the claim that all (or most) conscious experiences of action are misleading. But this is problematic: that some experiences are misleading does not license the claim that the mechanisms responsible for these experiences are systematically misleading: much more evidence is needed to establish a claim like that (see Bayne 2006: 179, 180). Indeed, much subsequent work into the mechanisms responsible for generating (or the mechanisms that simply subserve) experiences of action indicates that they are quite reliable. The mechanisms responsible for our experiences of agency, while imperfect indicators of agency, appear to be closely related to the mechanisms responsible for initiating and controlling action (see Pacherie 2008, Synofzik et al. 2008). This at least suggests-without proving, of course- that our experiences of acting, deciding, and the like, are not systematically misleading (for more discussion of this point, see "Free Will and the Phenomenology of Agency," Chapter 56, this volume; Shepherd 2016).

Further, many have raised more specific problems with the central studies. I will focus on the Wegner and Wheatley study reviewed above (for discussion of the Brasil-Neto et al. (1992) study, see Shepherd 2013). Recall Wegner and Wheatley's interpretation of that study: "the experience of will can be created by manipulation of thought and action ... and this experience can occur even when the person's thought cannot have created the action" (1999: 489). Recall that on a 0 to 100 scale, participants offered ratings in the mid-50s where 100 represented 'I intended to make the stop.' Notice that this statement says nothing about the experience of will: it is about the existence of an intention. But even putting that complication aside, Joshua Shepherd (2013) has noted that "the rating of $56 \%$ indicates a degree of confusion about what, if anything, was decided," and further, that we do not know how participants interpreted the scale. Given this, it is plausible that participants "simply felt that the action occurred thanks in part to their participation," (Shepherd 2013:24) rather than that the action occurred because of some experience of will on their part. Given their actual data, Wegner and Wheatley's claim appears far too strong. (The same criticism applies to interpretations of a similar experiment given in Wegner et al. [2004].)

I turn to studies in the Libet tradition. The literature discussing these studies is large. But most agree that the most sophisticated treatment of these studies and their relevance for free will is Alfred Mele's (2009) book Effective Intentions (see also Bayne 2011 for an excellent discussion). In meticulous detail, Mele argues for the following claims (among others). First, it is doubtful that Libet-style studies show that the brain decides before the conscious mind is aware of the decision. Instead, these studies at best offer evidence of early nonconscious preparation for decision, which is compatible with the decision being made consciously. Second, Libet-style studies do not rule out the possibility that conscious intentions cause the relevant behavior-the wrist-flexing. Although it is sometimes asserted that Libet-style studies show intentions emerge 'too late' to do any causal work, Mele reviews work on reaction times that indicates Libet's data in fact leave enough time for participants in these studies to acquire intentions to flex and for these intentions to initiate the flexing. Third, since Libet-style studies involve simple actions such as the flexing of a wrist, it is unclear whether the data they generate speak to the kinds of decisions that matter- decisions that involve the weighing of reasons for and against action (for more on this point, see Roskies 2010). Indeed, Mele notes it is relatively unsurprising that we are not aware of what produces simple movements such as wrist-flexings. What would be surprising is a lack of awareness 
regarding our reasons for action in decisions that matter (for discussion of some relevant data on this point, see Miller: Chapter 36, this volume). Mele writes, "If we never had any more insight into why we decided as we did than [do participants in Libet-style experiments] ... we would be much more mysterious to ourselves than we actually are" (2009: 87).

Since the publication of Mele's book, emerging neuroscience has, if anything, trended in a free will-friendly direction. It looks, for example, like the Libet-style results do not generalize to decisions that matter. Susan Pockett and Suzanne C. Purdy review evidence that "RPs often do not occur at all before movements initiated as a result of decisions, as opposed to spontaneous urges" (2010: 34). And without any relevant RP pattern, there is little reason to think that the processes responsible for felt urges and wrist-flexes in Libet-style studies are also responsible for decisions and the experience of decision-making in other contexts.

Further, neuroscientists Aaron Schurger, Jacobo D. Sitt, and Stanislas Dehaene (2012) offer data supporting the view that the Readiness Potential — the signal often interpreted as the brain deciding or preparing to decide what to do-does not reflect anything like a decision. Instead, the Readiness Potential might reflect little more than neural noise- the kind of gradual increase in neural activity that precedes many spontaneous movements, but is not present in all cases of intentional movements. Schurger et al. (2012) summarize as follows:

We suggest reserving the term 'decision' to the commitment to move achieved once neural activity (spontaneous or goal directed) crosses a specific threshold ... The reason we do not experience the urge to move as having happened earlier than about $200 \mathrm{~ms}$ before movement onset is simply because, at that time, the neural decision to move (crossing the decision threshold) had not yet been made. A very similar fluctuation in neuronal firing could equally well, at some other time, have not preceded the movement ... We propose that the neural decision to move coincides in time with average subjective estimates of the time of awareness of intention to move and that the brain produces a reasonably accurate estimate of the time of its movement-causing decision events.

(Schurger et al. 2012: E2910)

This looks pretty devastating to anti-free will interpretations of the Libet data. Notice, though, that Schurger et al. (2012) continue to speak of what happens at $200 \mathrm{~ms}$ before a wrist flex as a "neural decision." But recent work indicates it is not even that. Han-Gue Jo and colleagues (Jo et al. 2013) had an expert meditator go through a Libet-style experiment. In one condition they asked the participant to notice when an urge to flex appeared in consciousness, and then to wait for as long as possible before flexing. When this was done, the RP showed a similar pattern before the urge appeared, but crucially, the RP did not immediately cause the wrist flexing. Instead, the participant waited for up to 3 seconds before flexing. It is plausible, then, that the RP reflects neural preparation not for a decision, but for the appearance of an urge to move in consciousness-an urge that at least some participants are free to follow or reject.

The proper conclusion, then, is that current neuroscience does not present an actual threat to free will. Even so, everyone should acknowledge that the science of agency is far from complete. It remains possible that future neuroscience will offer an actual 
threat to free will. As such, it is important to reflect on why current neuroscience is often taken to offer such a threat. This kind of reflection might help us see the kinds of results that may, in the future, actually threaten free will.

\section{How Might Neuroscience Threaten Free Will?}

Surveying recent work related to this question, at least four answers emerge. I will take them one at a time.

First, neuroscience might threaten free will if work in neuroscience is able to show that the brain is deterministic. Now, whether determinism is a threat depends on what conditions turn out to be required for the possession of free will. Compatibilists maintain that free will is compatible with the truth of determinism. So if neuroscientists were to show that the brain-and especially the processes responsible for deliberation and decision-making - operated according to deterministic causal laws, only libertarians about free will would find this threatening.

However, neuroscience is unlikely to show any such thing. Adina Roskies observes that since "we have no objective access to either determinism or indeterminism" the best we can do is to operationalize determinism as predictability (Roskies 2014: 105). Given this limitation, we are unlikely to discover compelling evidence for indeterminism deterministic systems can display stochastic, and thus seemingly indeterministic, behavior (although see Tse [2013] for an argument that the brain is an indeterministic system, and that this is crucial for our free will). But does this preclude us finding compelling evidence for determinism? Roskies asks us to imagine that we acquire full information about some area in the brain that subserves decision-making, such that "we could with perfect accuracy predict the subsequent behavior of the agent" (2014: 116). This might offer some inductive evidence in favor of determinism. But since any given brain area-and indeed, the brain itself - is an open causal system, it is always possible that an event somewhere else influences the operation of the system in question, rendering the process indeterministic. We might someday revise current physical theory in favor of determinism-but that will result from advances in theoretical physics, not advances in neuroscience.

Second, neuroscience might threaten free will if work in neuroscience is able to show that naturalism about the mental - the claim that minds operate entirely according to natural laws, and thus that there is no place for souls or otherwise non-natural substances in our understanding of agency-is true. As with determinism, whether naturalism about the mental threatens free will depends on what conditions turn out to be required for the possession of free will. Naturalism is threatening only if free will requires the operation of souls or otherwise non-natural substances.

There is evidence that some people understand free will in this way (Nadelhoffer et al. 2014). But there is evidence that some people do not understand free will in this way as well (Mele 2014). For all we currently know, evidence in favor of naturalism about the mental would threaten some people's understanding of free will. At this point one is tempted to ask: what about free will itself? Does free will really require non-naturalism about the mental? One's answer to this question will depend on one's view about a range of controversial views in metaphysics, the philosophy of mind, and the philosophy of action. Although most living philosophers - this one included — are naturalists about the mental, there remain many who disagree. This is not the place to settle disputes on this issue. But it is worth noting that even if neuroscience could demonstrate 
the truth of naturalism about the mental, serious philosophical work would be required to determine whether this presented an actual as opposed to a merely apparent threat to free will.

It is, of course, dubious that neuroscience could prove the truth of a metaphysical thesis like naturalism. But neuroscience might, as Eddy Nahmias argues, render naturalism more plausible "by providing increasingly complete explanations for observable events in the universe, including human behavior, in terms of natural processes and laws" $(2014: 8,9)$. It is thus plausible, then, that if free will requires non-naturalism about the mental, then neuroscience (with science generally) represents a threat to free will, one that non-naturalists about free will should be motivated to confront.

Third, neuroscience might threaten free will if work in neuroscience is able to show that talk of mental states and mental causes of action is eliminable-if the best explanation of human agency need refer only to causal processes at the neurobiological level. According to this possibility, neuroscience is showing (or will one-day show) that the best explanation of human agency need make no reference to intentions, decisions, and the like. Here is how the neuroscientist William T. Newsome articulates this possibility.

The critical question is whether our beliefs, values, and aspirations ... are real entities with real causal efficacy in the world or whether they are illusory constructs that we make up to describe our experience of a world whose causal determinants lie at a much more fundamental level. Many neuroscientists appear to subscribe to the latter point of view, leading to skepticism about our own ability to control our actions and effect change in the world. This conviction seems to be driven by a reductionist methodology (and ideology!) that is eliminative in the sense that it seeks to replace high-level constructs and processes with lower level explanations where fundamental truth is thought to lie.

(Newsome 2014: 93)

And here is Francis Crick endorsing the possibility as fact: "your memories and your ambitions, your sense of personal identity and free will are in fact no more than the behavior of a vast assembly of nerve cells and their associated molecules" (1994:3).

Now, most philosophers agree that if this kind of ruthlessly reductionist eliminativism were correct, free will would be under dire threat. But it is important to note that many philosophers, as well as many scientists, find nothing in current neuroscience that warrants this kind of eliminativism.

Newsome does a nice job of summarizing the reasons why. First, positing mental states such as beliefs, desires and intentions continues to give us extraordinary predictive power regarding human behavior - a predictive power neuroscience cannot, at present, match. Second, treating human agents as systems driven by mental states continues to give us extraordinary manipulative power regarding human behavior-a manipulative power neuroscience cannot, at present, match. Third, a theory that posits behaviorally relevant mental states such as beliefs, desires, and intentions is much more parsimonious than a theory that attempts to explain all behavior by reference to the interactions between the environment and the nervous system.

Although it might turn out to be true that the best explanation of human agency is eliminativist, at present, we have little reason to think this is so. However, neuroscience 


\section{NEUROSCIENTIFIC THREATS TO FREE WILL}

is young. It is possible that as knowledge about the brain increases, our folk psychological categories will come to seem less and less useful as explanatory constructs. If so, we will have to refine or eliminate these categories. But it is difficult to predict whether the growth of knowledge will constitute a threat to free will, or whether this growth will simply refine our understanding of how free will works. Even so, for those on the lookout for threats to free will, the eliminativist threat is something to keep in mind as neuroscience progresses.

Fourth, neuroscience might threaten free will if work in neuroscience is able to show that modular epiphenomenalism is true. Modular epiphenomenalism is, according to Eddy Nahmias, the view that "those modules involved in conscious decisions or intention formation do not produce our behavior; rather other modules or processes that involve no conscious states produce our behavior" (2014: 12). This looks like something that neuroscience might be able to confirm or disconfirm. Indeed, early indications such as those reviewed in the last section are that modular epiphenomenalism is false. But suppose we were to discover that it is true (at least sometimes). Would we thereby have discovered an actual threat to free will?

I can see at least two reasons to think that the answer is yes. The first stems from epistemic considerations. If modular epiphenomenalism is true, then the way things seem to us regarding decision-making is not the way that things are. While it seems like our deliberation is effective, and while it seems like we often consciously decide for reasons, in fact, the processes that produce our decisions and actions are opaque to us. This raises a problem about how well we understand what we are doing when we are acting. Perhaps we are often wrong about the considerations driving our intention acquisition and our subsequent action. If so, we might have reason to worry about whether such systematic illusion about the sources of our action is consistent with our actions being free. David Rosenthal suggests something like this thought in the following passage: "Acting freely consists not in our volitions being uncaused, but in those volitions fitting comfortably within a conscious picture we have of ourselves and of the kinds of things we characteristically want and do" (2002: 219). Plausibly, free willespecially the kind of free will required for attributions of moral responsibility-requires a lack of ignorance about what one is doing (Zimmerman 1997). Insofar as modular epiphenomenalism suggests that agents are often ignorant of why they decide as they do, modular epiphenomenalism will threaten free will.

A second reason modular epiphenomenalism might constitute an actual threat to free will has to do with consciousness. It is a widely held intuition that consciousness is somehow very important for free will (see, e.g., Shepherd 2012). Some philosophers appear to think consciousness is necessary (in some way) for free will. So, for example, Robert Kane has recently claimed that

if conscious will were an illusion or epiphenomenalism or eliminative reductionism were true, all theories of freedom and responsibility would be threatened, compatibilist and libertarian alike, since they all require, to some degree at least, causally efficacious conscious mental processes.

Gregg Caruso agrees, asserting that "Our folk psychological theory [of free will] requires not only mental causation but conscious will! (2012: 212). And Ted Honderich has recently claimed that "The subject of freedom and responsibility has never been 
separable from the subject of consciousness ... there is no question at all of freedom and responsibility with respect to what is unconscious" (2013:60).

Interestingly, however, not everyone shares this intuition. The neurologist Mark Hallett, for example, asks whether the purported inefficacy of conscious will actually threatens free will, and answers as follows. "Since 'I' am my brain, it is not necessary to ask this question only in relation to what is conscious. It is possible to say that a brain is free if the brain can function without external constraint" (Hallett 2013: 262). The philosopher Sven Walter rejects the importance of consciousness: "why should anyone accept that decisions and actions can be free only if they have been caused by the feeling of having consciously willed them? ... There are neither theoretical reasons for such a conception of free will, nor do there seem to be any pre-theoretic intuitions that mandate it" (Walter 2014: 18). And David Rosenthal downplays the difference between conscious and nonconscious mental states:

it is plain that there is no difference in respect of freedom between conscious and nonconscious volitions. In both cases volitions result from various antecedent mental occurrences of which we are largely unaware. Conscious volitions differ from those which are not conscious only in that we are conscious of them.

(2002: 219)

Which side is right? Answering this question will require an increase in attention to the relationships between consciousness, decision-making and intentional action (see "Free Will and the Phenomenology of Agency," Chapter 56, this volume; Levy: Chapter 38, this volume), as well as an increase in attention to the relationships between consciousness and free will. What about consciousness makes it important for free will, if it is? Recent work in the philosophy of action has begun to examine this question (see, e.g., Hodgson 2012; Tse 2013; Levy 2014). We might hope that progress in this area will substantially clarify the nature of the threat to free will presented by modular epiphenomenalism.

\section{Conclusion}

As we have seen, a range of results in neuroscience present an apparent threat to free will. These are results that suggest that with respect to decision-making and intentional action, how things seem is not how they are. I have reviewed a number of criticisms of the relevant neuroscience, however, and have suggested that the threat presented by current neuroscience is not actual, but merely apparent. Even so, given the relative youth of neuroscience, we can expect that advances in our knowledge of the brain will continue to present apparent threats to free will. Determining whether these apparent threats are actual threats—and if so, determining the epistemic and behavioral changes they require-will require continued attention to the neuroscientific details as well as to the philosophical issues raised by the details.

\section{Acknowledgments}

This work is supported by Wellcome Trust Investigator Award 104347. 


\section{References}

Bayne, T. (2006) "Phenomenology and the Feeling of Doing: Wegner on the Conscious Will," in S. Pockett, W.P. Banks, and S. Gallagher (eds), Does Consciousness Cause Behavior? Cambridge: MIT Press, pp. 169-86.

Bayne, T. (2011) "Libet and the Case for Free Will Scepticism," in R. Swinburne (ed.), Free Will and Modern Science. Oxford: Oxford University Press, pp. 25-46.

Brasil-Neto, J., Pascual-Leone, A., Valls-Solé, J., Cohen, L., and Hallett, M. (1992) "Focal Transcranial Magnetic Stimulation and Response Bias in a Forced Choice Task," Journal of Neurology, Neurosurgery, and Psychiatry 55: 964-6.

Caruso, G.D. (2012) Free Will and Consciousness: A Determinist Account of the Illusion of Free Will. Lanham: Lexington Books.

Crick, F. (1994) The Astonishing Hypothesis. New York: Scribner.

Hallett, M. (2013) "What Does the Brain Know and When Does It Know It?" in G.D. Caruso (eds), Exploring the Illusion of Free Will and Moral Responsibility. Lanham: Lexington Books, pp. 255-64.

Hodgson, D. (2012) Rationality + Consciousness = Free Will. Oxford: Oxford University Press.

Honderich, T. (2013) "Determinism, Incompatibilism and Compatibilism, Actual Consciousness and Subjective Physical Worlds, Humanity," in G.D. Caruso (ed.), Exploring the Illusion of Free Will and Moral Responsibility. Lanham: Lexington Books, pp. 53-64.

Jo, H.G., Hinterberger, T., Wittmann, M., Borghardt, T.L., and Schmidt, S. (2013) "Spontaneous EEG Fluctuations Determine the Readiness Potential: Is Preconscious Brain Activation a Preparation Process to Move?" Experimental Brain Research 231: 495-500.

Kane, R. (2014) "Free Will, Mechanism, and Determinism: Comments on Roskies, 'Can neuroscience resolve issues about free will?"' in W. Sinnott-Armstrong (ed.), Moral Psychology: Free Will and Moral Responsibility, Vol. 4. Cambridge: MIT Press, pp. 127-38.

Levy, N. (2014) Consciousness and Moral Responsibility. Oxford: Oxford University Press.

Libet, B., Gleason, C.A., Wright, E.W., and Pearl, D.K. (1983) "Time of Conscious Intention to Act in Relation to Onset of Cerebral Activity (Readiness-Potential): The Unconscious Initiation of a Freely Voluntary Act," Brain 106: 623-42.

Mele, A.R. (2009) Effective Intentions: The Power of Conscious Will. Oxford: Oxford University Press.

Mele, A.R. (2014) "Free Will and Substance Dualism: The Real Threat to Free Will?" in W. SinnottArmstrong (ed.), Moral Psychology: Free Will and Moral Responsibility, Vol. 4. Cambridge: MIT Press, pp. 227-34.

Nadelhoffer, T., Shepard, J., Nahmias, E., Sripada, C., and Ross, L.T. (2014) "The Free Will Inventory: Measuring Beliefs about Agency and Responsibility," Consciousness and Cognition 25: $27-41$.

Nahmias, E. (2002) "When Consciousness Matters: A Critical Review of Daniel Wegner's The Illusion of Conscious Will," Philosophical Psychology 15: 527-41.

Nahmias, E. (2014) "Is Free Will an Illusion? Confronting Challenges from the Modern Mind Sciences," in W. Sinnott-Armstrong (ed.), Moral Psychology: Free Will and Moral Responsibility, Vol. 4. Cambridge: MIT Press, pp. 1-26.

Newsome, W. T. (2014) "Neuroscience, Explanation, and the Problem of Free Will," in W. SinnottArmstrong (ed.), Moral Psychology: Free Will and Moral Responsibility, Vol. 4. Cambridge: MIT Press, pp. 81-96.

Pacherie, E. (2008) “The Phenomenology of Action: A Conceptual Framework," Cognition 107: 179-217.

Pockett, S. and Purdy, S. (2010) "Are Voluntary Movements Initiated Preconsciously? The Relationships between Readiness Potentials, Urges and Decisions," in W. Sinnott-Armstrong and L. Nadel (eds), Conscious Will and Responsibility: A Tribute to Benjamin Libet. Oxford: Oxford University Press, pp. 34-46.

Rosenthal, D.M. (2002) "The Timing of Conscious States," Consciousness and Cognition 1: 215-20.

Roskies, A. (2010) "Why Libet's Studies Don't Pose a Threat to Free Will," in W. Sinnott-Armstrong and L. Nadel (eds.), Conscious Will and Responsibility: A Tribute to Benjamin Libet. Oxford: Oxford University Press.

Roskies, A. (2014) “Can Neuroscience Resolve Issues about Free Will?" in W. Sinnott-Armstrong (ed.), Moral Psychology: Free Will and Moral Responsibility, Vol. 4. Cambridge: MIT Press, pp. 103-26.

Schurger, A., Sitt, J.D., and Dehaene, S. (2012) "An Accumulator Model for Spontaneous Neural Activity Prior to Self-Initiated Movement," Proceedings of the National Academy of Sciences 109: E2904-13.

Shepherd, J. (2012) "Free Will and Consciousness: Experimental Studies," Consciousness and Cognition 21: $915-27$. 
Shepherd, J. (2013) "The Apparent Illusion of Conscious Deciding," Philosophical Explorations 16: 18-30.

Shepherd, J. (2016) "Conscious Action/Zombie Action," Nô̂s 50(2): 419-44.

Soon, C.S., He, A.H., Bode, S., and Haynes, J.D. (2013) "Predicting Free Choices for Abstract Intentions," Proceedings of the National Academy of Sciences 110: 6217-22.

Synofzik, M., Vosgerau, G., and Newen, A. (2008) "Beyond the Comparator Model: A Multifactorial TwoStep Account of Agency," Consciousness and Cognition 17: 219-39.

Tse, P. (2013) The Neural Basis of Free Will: Criterial Causation. Cambridge: MIT Press.

Walter, S. (2014) "Willusionism, Epiphenomenalism, and the Feeling of Conscious Will," Synthese 191: 2215-38.

Wegner, D.M. (2002) The Illusion of Conscious Will. Cambridge: MIT Press.

Wegner, D.M., Sparrow, B., and Winerman, L. (2004) "Vicarious Agency: Experiencing Control Over the Movements of Others," Journal of Personality and Social Psychology 86: 838-48.

Wegner, D.M. and Wheatley, T. (1999) "Apparent Mental Causation: Sources of the Experience of Will," American Psychologist 54: 480-92.

Zimmerman, M.J. (1997) “Moral Responsibility and Ignorance," Ethics 107: 410-26.

\section{Further Reading}

Caruso, G.D. (2012) Free Will and Consciousness: A Determinist Account of the Illusion of Free Will. Lanham: Lexington Books. (A free will skeptic's interpretation of recent work in cognitive science.)

Levy, N. (2014) Consciousness and Moral Responsibility. Oxford: Oxford University Press. (The most thorough exploration to date of the role of consciousness in morally responsible action.)

Mele, A.R. (2009) Effective Intentions: The Power of Conscious Will. Oxford: Oxford University Press. (A systematic and illuminating discussion of Libet-style studies and their relevance to free will.)

Tse, P. (2013) The Neural Basis of Free Will: Criterial Causation. Cambridge: MIT Press. (A neuroscientist argues that recent work in neuroscience actually explains, rather than threatens, free will.)

\section{Related Topics}

Situationism, Social Psychology, and Free Will

Empirical Perspectives on Consciousness and its Relationship to Free Will and Moral Responsibility

Willpower, Freedom, and Responsibility

Addiction

Free Will and the Phenomenology of Agency 


\section{8 \\ EMPIRICAL PERSPECTIVES ON CONSCIOUSNESS AND ITS RELATIONSHIP TO FREE WILL AND MORAL RESPONSIBILITY Neil Levy}

It is traditional to distinguish two kinds of conditions that an agent must satisfy in order to qualify as acting with free will: a control condition and an epistemic condition. The control condition has attracted the bulk of philosophers' attention, largely because the debate has centered around the question whether free will is compatible with causal determinism (or, in a version now less central, with God's foreknowledge). Causal determinism (and foreknowledge) seem much more plausibly a threat to control than to the epistemic dimensions of freedom; while it might be plausible to think that I lack some kind of control over my behavior if how I will act is in some sense already settled prior to my making up my mind, it is much less plausible to think that my beliefs concerning the circumstances in which I act are undermined or altered by determinism or foreknowledge.

Latterly, however, the epistemic condition has been attracting more attention. A central reason for this shift has come from work in cognitive science. Research in psychology and in cognitive neuroscience have provided a wide range of evidence that agents lack awareness of important facts that nevertheless play a significant role in shaping their action. Cognitive neuroscientists have also produced evidence that we lack awareness of our intentions to act; this fact, they argue, shows that we lack free will or are not morally responsible for our actions. (In this chapter, I will not discuss these experiments, since they are well covered elsewhere in this volume). These experiments have made attention to the epistemic condition - to what agents need to be aware of in order to possess free will and/or to be morally responsible for their actions — an urgent concern.

In this chapter, I will outline the current debate over the extent to which agents need to be conscious of the facts to which they respond, as that debate has evolved in response to the findings of cognitive science. My aim is to assess the extent to which the 
empirical findings represent a serious threat to our capacity to act freely. In what follows, I understand 'free will' as a power of agents such that, by exercising that power in the appropriate circumstances, they are morally responsible for their actions. Moral responsibility, in turn, I understand as closely tied to desert of sanction or reward; to say that an agent is morally responsible for an action is to say that in virtue of having performing it she might justifiably be treated somewhat better or worse than otherwise (this is of course defeasible and frequently defeated). I do not claim that this is the only defensible understanding of either free will or of moral responsibility. Nevertheless, they are understandings that, as a matter of fact, are central to most debates about free will and moral responsibility — as this volume illustrates — and which have clear and direct links to important practical questions such as the justification of the criminal justice system.

Before turning to the experimental data and interpretation, one other preliminary remark. When philosophers talk about 'consciousness,' it is usually phenomenal consciousness they have in mind. Phenomenal consciousness is the kind of consciousness that has a certain 'feel' to it: it is the kind of consciousness at issue when we think about the ineffable quality of the taste of wine or the feel of the sun on your face. It is this kind of consciousness that gives rise to the so-called 'hard problem' of consciousness: how can mere matter give rise to properties that (according to some) are incommensurate with anything physical (Chalmers 1996)? Fortunately, we are not concerned with the hard problem here, because we are not concerned with phenomenal consciousness at all. Rather, we are concerned with agents' access (or lack of access) to representational contents. This notion of consciousness is akin to what Block (1995) calls access consciousness. Some philosophers object that this is not a notion of consciousness at all (Searle 1992; Burge 1997). I think, on the contrary, that prior to the 1990s, this notion was the central notion of consciousness; the only notion that Freud (for instance) utilized (as Block himself seems to recognize). In any case, it is the sense of consciousness at issue here.

\section{The Nature of the Threat to Free Will}

Intuitively, moral responsibility requires that agents be aware of central facts concerning their own actions (or be culpable for their lack of awareness). For instance, an agent who $\Phi$ s, believing that he is rendering aid to someone in need but who actually performs an action that is harmful — say giving a person who is dehydrated a drink to which he turns out to be allergic - seems to be excused blame in virtue of his ignorance of the fact that the action is harmful (unless there are grounds for holding him responsible for that ignorance). Some experiments suggest that agents may often perform morally significant actions while unaware of facts about those actions in a way that seems analogous to the ignorance of the agent above, but (unlike the agents in the vignette), responding to the facts of which they are unaware. These experiments raise in a stark manner the question whether it is conscious response to facts that matters, or whether nonconscious response might ground moral responsibility.

Consider the many experiments that demonstrate confabulation of criteria for choice (Dovidio and Gaertner 2000; Uhlmann and Cohen 2005; Son Hing et al. 2008). In typical experiments along these lines, subjects are asked to choose which of two candidates is better qualified for a job. One candidate belongs to a minority or is female; the other is white and/or male. The candidates also differ in their skills and experience, but 
in ways that leave both apparently well-qualified for the job (one might have more experience while the other might have better paper qualifications for instance). These experiments have two conditions: in one condition, the subjects get the resumes of the candidates with the white/male candidate possessing one set of qualifications and the female/minority candidate the other. In the other condition, the qualifications possessed by each are reversed (this may be done by simply changing the names on the resumes, using stereotypically black and white, or male and female, names).

In these experiments, a majority of applicants choose the male/white candidate in both conditions. Interestingly, however, their choice seems to be (often) driven not by overt sexism or racism, but by confabulation of merit. Subjects report that the qualifications possessed by the preferred applicant are clearly those that are most relevant for the job.

Note that the experiment was designed so that the confabulation was plausible: no matter how much each subject introspected, and no matter how committed any of them may have been to affirmative action, it is quite possible that they judged that so superior was the male/white candidate that they had no choice but to prefer him or her. It is only by virtue of looking at the responses across the groups that we can detect the fact that the choice was driven, more distally, by implicit biases. The fact was invisible to the subjects themselves. What they were conscious of was a confabulated criterion, whereas the processes that caused the confabulation worked unconsciously. So the decision had a moral character - that it was sexist or racist (for example) — that was due to subjects' unconscious biases.

The implicit bias literature is a rich source of other evidence that unconscious biases may lead people to behave in ways that are (variously) sexist, racist, homophobic, and so on, without their realizing and in some cases despite their sincere efforts to treat people fairly. Implicit biases predict a variety of relatively trivial actions that are nevertheless prejudicial-making less eye contact with black confederates, for instance (McConnell and Leibold 2001). More seriously, they predict a higher probability of judging that an ambiguous object in the hands of black person is a gun, compared to the same object in the hands of a white person (Payne 2006). It is plausible that this fact plays a role in explaining the higher risk of being shot by police that black people run in the United States.

In addition to morally significant actions caused by implicit biases, such actions may be caused by environmental primes. Whereas in the implicit bias cases actions have a moral character due to agents' implicit biases (because the following counterfactual is true: were the action controlled by agents' explicit attitudes alone, the action would lack that moral character), in priming cases, the moral character is due either to a prime of which the agent is unconscious, or to processes of which the agent is not conscious and which were triggered by the prime. Agents process primes for semantic contents, even when they are not conscious of the primes: for instance, in masked priming experiments (in which a word or image may be shown very briefly and then immediately masked to prevent retinal persistence) agents report seeing nothing, but their behavior may be influenced by the prime. In laboratory experiments that model real-life situations, primes are usually presented in full view of the subjects and the priming effect is said to occur when their behavior is modified without their noticing that the stimulus has had this effect.

For instance, a subtle cue can induce better behavior in people. Bateson et al. (2006) used a gloriously simple manipulation to induce more honesty in people. Placing a 
stylized picture of a pair of eyes over an 'honesty box' in which university staff were supposed to deposit money to pay for their coffees and teas induced a nearly threefold increase in the amount paid, compared to a control condition. Here the subjects were conscious of the image- though presumably they rarely attended to it-but not conscious of how it caused them to change their behavior.

All the cases outlined above involve agents engaging in morally significant actions that are responsive to information of which the agent is not conscious. Call the kind of consciousness lacking here state consciousness-lack of consciousness of a particular mental state. Agents may also perform morally significant actions in the absence of creature consciousness. Whereas a lack of state consciousness is a lack of access to the content of some state, the agent who lacks creature consciousness lacks access to the contents of any state. Absence of creature consciousness combined with apparently intentional action may be seen in absence seizures, complex partial seizures, fugue states, and somnambulism. Agents in such states may engage in sex, drive cars, and even assault other agents.

Should we hold agents morally responsible for these behaviors? More precisely, should we hold them responsible for the moral characters of these behaviors, moral characters due to facts (concerning themselves or concerning the external environment) of which they failed to be conscious? The subjects in the experiments mentioned might choose a man over a woman and do so because the preferred candidate is male; they thereby perform an action that might be said to be sexist. However, they are not conscious of the role that sex played in the choice: are they nevertheless blameworthy? The subject who paid for her coffee, yet might not have done so were it not for the influence of a cue whose influence she failed to detect performs an action that is honest. Is she praiseworthy for her honesty? There are a variety of answers to these questions in the literature.

\section{Responding to the Threat}

Some philosophers suggest that consciousness of the facts to which we respond is not especially significant for freedom or moral responsibility. Call these philosophers opponents of the consciousness thesis: the thesis that consciousness (of some kind) is a necessary condition of free will. In effect, these philosophers seem committed to saying that we may satisfy the epistemic condition on free will and/or moral responsibility even if we are not conscious of the facts in question. They point to how sophisticated nonconscious processes may be. Above, I remarked that absence of consciousness of a fact seems to threaten agents' control over their behavior. But nonconscious processes may realize exquisite control. Consider the behavior of agents who experience absence seizures, which are believed to produce a state of absent or greatly reduced consciousness in their sufferers. If they are already engaged in a complex action prior to the onset of the seizure, they will typically continue to perform the action, more or less successfully. They may, for instance, continue to drive a car: without hitting obstacles or pedestrians, they remain capable of navigating a series of lights and turns. Or they may continue to play a musical piece they had already begun (Penfield 1975).

Even more impressive, perhaps, is the complex behavior exhibited by conscious agents who nevertheless report that they are not conscious of the facts to which they respond. Elite athletes and expert musicians sometimes report that their best performances occur in a state in which they are not consciously guiding their actions (these 
states may correspond to the 'flow' state-a state of effortless engagement-made famous by Csikszentmihalyi [1990]). These performances seem to be paradigms of control, indicating that controlled processes need not be conscious processes. Some thinkers have concluded, accordingly, that nonconscious sensitivity to reasons is suffcient for responsibility-level control, at least in normal situations and for the normal brain (Suhler and Churchland 2009). (Suhler and Churchland [2014] is an important development and modification of the view.)

On the basis of the fact that agents may respond flexibly to (genuine) reasons in the absence of consciousness of these reasons (or of the reasons qua reasons), most philosophers seem to have concluded that lack of consciousness is not an excuse, though it may be (somewhat) mitigating. Many of these philosophers are motivated more by thought experiments and literary examples than by cognitive science. Several philosophers have cited the case of Huckleberry Finn, for instance, in arguing for the claim that consciousness is not directly relevant to agents' moral responsibility. Huck fails to turn the escaped slave Jim over to people who would return him to his 'owners,' despite his conscious judgment that helping Jim to escape is abetting theft. But Huck acts as he does in response to Jim's humanity. His responsiveness to genuine moral considerations reveals his quality of will, and renders him praiseworthy; it is revelatory of deep facts about Huck, whereas his conscious judgment is caused by relatively shallow facts about him (Arpaly 2002). Arpaly is explicit that this framework can fruitfully be applied to cases stemming from the experimental literature, although she does not treat such cases in any detail. Angela Smith, whose views also owe their development more to traditional philosophical methods than to cognitive science, has recently argued that her somewhat related view entails responsibility for actions stemming from implicit bias (A. Smith, unpublished: "Implicit Biases, Moral Agency, and Moral Responsibility"). On her view, which develops a framework she has defended over several important publications (Smith 2005, 2008), agents are responsible for attitudes that are properly attributable to them, and for the actions caused by such attitudes; attitudes are properly attributable to them when they reflect their judgments, conscious or unconscious. Implicit biases, Smith argues, are states with representational contents and this entails judgment-dependence of a kind sufficient to underwrite attributability.

Philosophers whose views are more directly driven by engagement with cognitive science have often reached the same conclusion via a different route. Building on Peter Carruthers' important work on the cognitive science of self-knowledge (Carruthers 2011), Matt King and Carruthers (2012) argue that consciousness or its lack can make no difference to moral responsibility because agents are never conscious of their attitudes in the right kind of way to underwrite moral responsibility. Rather, agents selfattribute attitudes on the basis of the same kinds of evidence they use to attribute attitudes to others: by some kind of interpretative process. King and Carruthers conclude that agents are morally responsible for all the behaviors driven by content-bearing states, no matter their source, rather than those driven by conscious ones alone. More generally, a number of philosophers have pointed to the fact that nonconscious processes are pervasively involved in all behavior, even the most deliberative and reflective: conscious control depends on nonconscious control. On this basis, they have pointed out that if consciousness is required for moral responsibility, it would seem that we are never morally responsible; this fact gives us a strong reason to reject the consciousness thesis (Suhler and Churchland 2009). 
A small number of philosophers, and a greater number of psychologists, have reached the opposite conclusion: that lack of consciousness excuses. These thinkers accept the evidence that nonconscious processes are pervasive, and that conscious control depends on nonconscious control, but they bite the bullet on the claim that if consciousness is a necessary condition of moral responsibility, we are never morally responsible. The most forceful advocate of this line among philosophers is Gregg Caruso (2012). For Caruso, so much happens outside our conscious awareness that we cannot possess the kind of control required for moral responsibility. Caruso cites a great deal of evidence (of the kind already outlined above) that factors of which we are not conscious may influence not merely how we act, but the moral character of our actions, in such a manner that we perform actions that have a moral significance of which we might be blissfully unaware. There is, as he says, a powerful pull toward excusing agents of moral responsibility in these kinds of cases; induction generalizes the intuition.

The dispute between those who hold and those who deny that consciousness is required for moral responsibility turns on a number of points. In keeping with the central focus of the free will debate, competing claims about control are central to the dispute. Reflecting recent developments in the literature however, some philosophers have emphasized attributability or the quality of agents' will in urging that consciousness is not required for moral responsibility. Properly assessing these claims requires the development of a satisfactory account of control, attributability, and other concepts central to the free will and moral responsibility literature. It also requires detailed attention to the empirical literature, in order to assess the degree to which nonconscious processes may realize responsibility-level control or be properly attributable to agents. For reasons of space, in this chapter I will set aside the topic of attributability and focus on questions of control.

Before we begin to explore these philosophical concepts and their (neuro)psychological underpinnings, it is worth pointing to what should be common ground between the various contending positions. No one maintains (nor should maintain) that consciousness of the central facts concerning a token action is required for the agent to be morally responsible for it. At most, defenders of the consciousness thesis should maintain that consciousness (of the right sort of facts) must feature appropriately in the history of the action in order for the agent to be responsible for it. Consider what psychologists call 'overlearned' actions. These actions may be carried out automatically, in response to triggering cues, and may proceed ballistically until completion of the action sequence. Such an action might be triggered in the absence of consciousness, and yet the agent might be morally responsible for it, on the grounds that she consciously inculcated such an action sequence in herself. For similar reasons, the appeal by opponents of the consciousness thesis to the fact that nonconscious processes may exhibit exquisite control may be undercut by the fact-if it is a fact-that agents have deliberately inculcated such responses in themselves. The control of the athlete or the musician may, for instance, be the product of hundreds of hours of training, in which she consciously sought to bring herself to respond appropriately without thinking.

Let us turn, now, to control, which is surely the most widely accepted necessary condition for moral responsibility. Prima facie, control has epistemic dimensions, such that the epistemic and control conditions are not as easily separated as many have thought (and as my introduction might have suggested) (Mele 2010; Levy 2011). But opponents of the consciousness thesis are right to point out that agents exercise control in ways that are responsive to facts regarding which they are unconscious (think, again, of the 
person who experiences an absence seizure while driving a car). Is this control sufficient to underwrite moral responsibility? The answer may depend on what we are holding the agent responsible for.

Consider the most dramatic cases in which the consciousness thesis is at issue: cases featuring assaults (even killings) by agents lacking creature consciousness. While the agents in these cases undoubtedly exercise control, they may not exercise control over the assault itself. Their control may extend only to the range of overlearned actions they perform: driving a car, opening a door, and so on. The assault itself may not be exercise of control, at least for an agent who lacks a history of violence (Levy 2014).

What makes the performance of overlearned actions an exercise of control but not the assault? Following the lead of Fischer and Ravizza (1998), we might understand control as consisting in a kind of sensitivity to reasons: an agent exercises control over a behavior when she would recognize and respond to a sufficient number and variety of reasons to act in a way that differs from the way she actually acts. Control comes in degrees: the broader the range of reasons she would respond to, the more control she has. Acquiring expertise in an activity is often a question of acquiring greater sensitivity to considerations as reasons to act otherwise, and acquiring the capacity to act appropriately. The driving behavior mentioned above is controlled because it remains sensitive to a range of environmental conditions, despite the absence of consciousness (it seems that sensitivity to reasons, of a particular kind, can itself be overlearned and thereby automated). However, if one or other of the views of consciousness that belong to what Tononi (2004) calls "the integration consensus" is correct, the agent may lack much control over the assault. In views that belong to the integration consensus, consciousness is required for actions to be driven by systems that are broadly sensitive to reasons; without it, actions are driven by systems that can process only a narrow range of reasons. If that is right, the assault may occur because of a lack of sensitivity to reasons: the agent fails to recognize a range of reasons that she herself would, were she conscious, take as reasons to act otherwise.

Whereas the actions of agents who lack creature consciousness are sensitive to only a narrow range of reasons (given the truth of the appropriate account of consciousness), in cases of absence of state consciousness the agent remains sensitive to a very broad range of reasons. Her control is therefore much greater than the control exhibited by the former kind of agent. There may be grounds, though, for denying that she has sufficient control over the moral character of the action, responsibility for which is in question. Just as the extent to which absence of creature consciousness excuses depends on empirical claims about what consciousness does, so the availability of mitigation or excuse depends on empirical claims about the kinds of processes that underwrite responsiveness to unconscious information.

There is a lively debate about the nature of the attitudes involved in unconscious bias. On some views, these attitudes are beliefs (Mandelbaum 2013, 2015; De Houwer 2014). If these implicit attitudes are beliefs, then there is no reason to expect that insofar as behavior is driven by these attitudes it will be any less reasons-responsive than behavior driven by conscious attitudes. Beliefs are, as Stich (1978) puts it, inferentially promiscuous, which is to say, roughly, that they are capable of interacting appropriately with any other representation, and that seems to entail broad and deep reasons-responsiveness.

The standard view among psychologists has hitherto been that implicit attitudes are associations, not beliefs. If implicit attitudes are associations, then behavior driven by them can be expected to be very much less sensitive to reasons than behavior driven by 
beliefs. Associations do not interact with other representations in ways that are sensitive to their semantic contents, and cannot serve as premises in reasoning: these facts entail that they exhibit little reasons sensitivity. The evidence amassed by Mandelbaum seems to show quite conclusively, however, that implicit attitudes are not just associations. Rather, they have some kind of propositional structure, in virtue of which they do interact with reasons appropriately. Nevertheless, it may be that Mandelbaum is too hasty in inferring from the fact that implicit attitudes have propositional structure to the conclusion that they are beliefs.

Elsewhere, I have argued that implicit attitudes are patchy endorsements (Levy 2015). Like beliefs, they have propositional structure, but this structure is patchy, such that they can interact appropriately only with some representations under some conditions. If implicit attitudes are patchy endorsements, then it is an empirical question, differing from case to case, whether they are able to interact appropriately with the semantic content of a particular reason.

That might seem to entail that the answer whether agents who lack state consciousness nevertheless exercise control over their behavior itself varies from case to case, and that therefore they are morally responsible for some actions caused by implicit biases and not others. I suggest that the class of cases is in which there is at least a prima facie case for excuse is broader than that. Though it is true that the extent to which the relevant mechanisms are capable of recognizing a particular reason varies from case to case, when an action has a moral character due to implicit bias, that moral character is evidence that the mechanism was not responsive to the right reasons. In such cases, the following counterfactual is often (and perhaps always) true: were the agent, or the relevant mechanism, capable of recognizing the right reasons, the action would not have had the character it had. Consider the experiments demonstrating confabulation of merit, for instance. In these experiments, participants ignored reasons they were perfectly capable of recognizing (that the minority or female candidate was at least equally well-qualified for the job). It is insensitivity to these reasons that explains the moral character of the actions. Had the relevant mechanism been capable of responding appropriately - and nothing in the patchy endorsements account entails that it could not, in principle, have been so capable - the action would not have that character.

There are possible cases in which an action has a moral character due to an implicit bias, yet the bias-constituting mechanism is capable of responding to relevant reasons. Cases like this will involve implicit mechanisms that recognize but devalue the reason, just as someone with a racist belief might recognize a black candidate's qualifications as a reason to hire her, but devalue this reason. Were implicit attitudes unconscious beliefs, it would be comparatively easy to see how they might cause actions which have a moral character due to their influence and in which the implicit attitude was appropriately sensitive-responsive and reactive (Fischer and Ravizza 1998) - to the relevant reasons. It is harder to see how patchy endorsements might cause actions that satisfy this kind of description. Sensitivity to the reason must be coupled with a great deal of other, belief-like, processing.

This brief survey of the empirically driven or sensitive philosophical literature on the extent to which consciousness of the reasons to which we respond is a necessary condition of moral responsibility for our actions is not exhaustive. It does, however, indicate the kinds of considerations that are relevant to the debate (as well as picking out the major landmarks in the landscape). Progress on these issues requires expertise in several different areas of philosophy: not just philosophy of action and of moral responsibility, 
but also philosophy of mind and of course detailed knowledge of the relevant cognitive science. Because the kind of expertise required remains relatively rare, and because the questions addressed are relatively novel, a wide variety of different questions remain to be explored in sufficient depth (concerning the nature of control and the extent to which it might be exercised by non-conscious processes; on the nature of attributability and whether - and when-non-conscious states are appropriately attributed to agents; on the nature of implicit attitudes, and so on). Given the rapid developments in this area, and the range of topics upon which it touches, it is emerging as one of the exciting debates in the philosophy of free will and moral responsibility.

\section{References}

Arpaly, N. (2002) Unprincipled Virtue: An Inquiry into Moral Agency. Oxford: Oxford University Press.

Bateson, M., Nettle, D., and Roberts, G. (2006) "Cues of Being Watched Enhance Cooperation in a RealWorld Setting," Biology Letters 2: 412-14.

Block, N. (1995) "On a Confusion About a Function of Consciousness," Behavioral and Brain Sciences 18: 227-87.

Burge, T. (1997) "Two Kinds of Consciousness," in N. Block, O. Flanagan, and G. Guzeldere (eds). The Nature of Consciousness: Philosophical Debates. Cambridge: MIT Press.

Carruthers, P. (2011) The Opacity of Mind. Oxford: Oxford University Press.

Caruso, G. (2012) Free Will and Consciousness: A Determinist Account of the Illusion of Free Will. Lanham: Lexington Books.

Chalmers, D. (1996) The Conscious Mind. Oxford: Oxford University Press.

Csikszentmihalyi, M. (1990) Flow: The Psychology of Optimal Experience. New York: Harper \& Row.

De Houwer, J. (2014) "A Propositional Model of Implicit Evaluation," Social and Personality Psychology Compass 8: 342-53.

Dovidio, J.F. and Gaertner, S.L. (2000) “Aversive Racism and Selection Decisions: 1989 and 1999," Psychological Science 11: 319-23.

Fischer, J.M. and Ravizza, M. (1998) Responsibility and Control: An Essay on Moral Responsibility. Cambridge: Cambridge University Press.

King, M. and Carruthers, P. (2012) "Moral Responsibility and Consciousness," Journal of Moral Philosophy 9: 200-28.

Levy, N. (2011) Hard Luck. Oxford: Oxford University Press.

Levy, N. (2014) Consciousness and Moral Responsibility. Oxford: Oxford University Press.

Levy, N. (2015) "Neither Fish nor Fowl: Implicit Attitudes as Patchy Endorsements," Noûs 49: 800-23.

McConnell, A.R. and Leibold, J.M. (2001) "Relations among the Implicit Association Test, Discriminatory Behavior, and Explicit Measures of Racial Attitudes," Journal of Experimental Social Psychology 37: 435-42.

Mandelbaum, E. (2013) "Against Alief," Philosophical Studies 165: 197-211.

Mandelbaum, E. (2015) “Attitude, Inference, Association: On the Propositional Structure of Implicit Bias," Noûs 50: 629-58.

Mele, A. (2010) "Moral Responsibility for Actions: Epistemic and Freedom Conditions," Philosophical Explorations 13: 101-11.

Payne, B. K. (2006) "Weapon Bias: Split Second Decisions and Unintended Stereotyping," Current Directions in Psychological Science 15: 287-91.

Penfield, W. (1975) The Mystery of the Mind: A Critical Study of Consciousness and the Human Brain. Princeton: Princeton University Press.

Searle, J. (1992) The Rediscovery of the Mind. Cambridge: MIT Press.

Smith, A. (2005) "Responsibility for Attitudes: Activity and Passivity in Mental Life," Ethics 115: 236-71.

Smith, A. (2008) "Control, Responsibility, and Moral Assessment," Philosophical Studies 138: 367-92.

Son Hing, L.S., Chung-Yan, G.A., Hamilton, L.K., and Zanna, M.P. (2008) "A Two-Dimensional Model That Employs Explicit and Implicit Attitudes to Characterize Prejudice," Journal of Personality and Social Psychology 94: 971-87.

Stich, S. (1978) "Beliefs and Subdoxastic States," Philosophy of Science 45: 499-518.

Suhler, C.L. and Churchland, P. (2009) "Control: Conscious and Otherwise," Trends in Cognitive Science 13: 341-7. 


\section{CONSCIOUSNESS AND FREE WILL}

Suhler, C.L. and Churchland, P. (2014) “Agency and Control," in W. Sinnott-Armstrong (ed.), Moral Psychology: Free Will and Moral Responsibility, Vol. 4. Cambridge: MIT Press, pp. 309-26.

Tononi, G. (2004) "An Information Integration Theory of Consciousness," BMC Neuroscience 5: 42.

Uhlmann, E.L. and Cohen, G.L. (2005) "Constructed Criteria: Redefining Merit to Justify Discrimination," Psychological Science 16: 474-80.

\section{Further Reading}

Brownstein, M. and Saul, J. (eds) (2016) Implicit Bias and Philosophy: Moral Responsibility, Structural Injustice, and Ethics, Vol. 2. Oxford: Oxford University Press. (This volume contains a number of high quality original essays on direct and indirect moral responsibility for the possession of implicit attitudes and for actions that they influence.)

Caruso, G. (2012) Free Will and Consciousness: A Determinist Account of the Illusion of Free Will. Lanham: Lexington Books. (The first book length defense of the claim that moral responsibility requires consciousness. Caruso argues that evidence from psychology indicates that this necessary condition is never satisfied.)

Levy, N. (2014) Consciousness and Moral Responsibility. Oxford: Oxford University Press. (My own book contrasts interestingly with Sher and Caruso. I argue, against Sher and others, that consciousness is a necessary condition of moral responsibility, and against Caruso that this is a condition that can be satisfied.)

Sher, G. (2009) Who Knew? Responsibility Without Awareness. New York: Oxford University Press. (As Sher shows, most philosophers seem to assume that consciousness is necessary for moral responsibility. In the first book length examination of the topic, Sher argues that this is a mistake.)

\section{Related Topics}

Neuroscientific Threats to Free Will

Determinism 
39

\title{
WILLPOWER, FREEDOM, AND RESPONSIBILITY
}

Chandra Sripada

\begin{abstract}
"The only way to get rid of temptation is to yield to it." Fortunately, Oscar Wilde's quip is not totally accurate. When temptation strikes, we can exercise willpower to defeat wayward motives. On Tuesday, I resolve that I will grade the stack of papers on my desk by the end of the week. On Sunday, the stack is still sitting there untouched and staring at me ominously. Right outside the window, my hammock is inviting me over for a nap. I needn't simply do what I most desire at the moment. Because I have the ability to exercise willpower, I can do what I had resolved to do and grade the papers.

Willpower has a number of important connections with free will and moral responsibility and in this chapter, I will survey some of them. I start with the question of what is willpower. Then I turn to the ways that successes and failures of willpower, respectively, relate to freedom and responsibility.
\end{abstract}

\section{What is Willpower?}

It is common to distinguish synchronic and diachronic forms of self-control, even if the boundary between the two is not always easy to draw. If I know the sight of the hammock will surely lure me in, then I might take the stack of papers to the library. There I won't see the hammock-or television or mountain bike or iPad-and hence won't get a chance to be tempted. Here, I exercise diachronic self-control; I strategically prevent a non-occurrent desire from becoming activated. Synchronic self-control involves attenuating or blocking a desire that is active (and indeed might be one's strongest) at the very time self-control is deployed.

Some forms of synchronic self-control are non-actional. If I have a weakness for cookies, I might cultivate a mental habit of reframing how I conceive of them. Whenever my mind turns to thoughts of eating cookies, I immediately tend to 'see' them as sickly lumps of fat and this blunts the desire to eat them (This example is from Kennett and Smith [1996]). It would be odd to say that habitual reframing of this sort constitutes an exercise of willpower.

Rather, willpower appears to consist in those forms of synchronic self-control that are actional. Right now, what I most want to do is eat the cookies that are sitting right there before me. However, I intentionally block my urge to reach for them, and, with considerable effort, shift my attention to other things. 
One might wonder if actional synchronic self-control is even possible. There is a postulate of philosophical psychology, one that some even take to be truistic, that if a person does anything at all intentionally, it will be in the service of her strongest desire. ${ }^{1}$ If my strongest desire is to eat the cookies, how then can I intentionally act to suppress my desire to eat the cookies?

At least three solutions to this puzzle of synchronic self-control have been offered. One approach says actional forms of synchronic self-control don't exist; non-actional forms, such as the habitual reframing strategy discussed earlier, are all there is (see Kennett and Smith 1996). Another solution focuses on the possibility of doing more than one thing at once. In one version of this approach, a person undertakes actional synchronic selfcontrol while concurrently acting on behalf of her (strongest) temptation-directed desire. If things go right, she can rebalance the relative strengths of her motives before she actually 'consummates' the forbidden act (see Mele 1987, 2003, for examples along these lines).

A third strategy says that actional synchronic self-control should be understood in terms of a divided mind. ${ }^{2}$ Consider a standard division of the mind into a reflective 'deliberative compartment' and a spontaneous 'emotional compartment.' Suppose one's strongest overall desire is an emotional compartment desire to eat the cookies. The divided mind view says that exercises of synchronic self-control can still be performed because they are proprietary actions - they are initiated and sustained by the deliberative compartment alone. As long as this compartment favors the exercise of synchronic self-control against an emotional compartment desire, then self-control will be exercised. There is an interesting ongoing debate about which of the preceding three accounts of synchronic self-control is correct. ${ }^{3}$

\section{How Successful Willpower Contributes to Freedom and Responsibility}

We desire various things: food, sex, relaxation, tranquility. A number of philosophers have thought that to be a free and morally responsible agent, it is not enough to merely have the capacity to desire. A person must also have capacities to reflect on and regulate her desires, to bring desire under the guidance of reason.

Harry Frankfurt (1971) noted that both humans and other animals have first-order desires, desires to do various things. But only humans have the capacity to step back from their motives and reflectively criticize them. On this basis, they form higher-order desires regarding which of their other desires should or should not be effective in action. For Frankfurt, free and morally responsible agency requires the appropriate mesh between first-order desires and desires of higher order.

One possibility is that higher-order desires are essentially inert; they serve to endorse or oppose other desires but otherwise don't motivate actions. Alternatively, one might suppose that higher-order desires are like any other desires in motivating actions that bring about the states of affairs at which the desires are directed. In the formation of this mesh, these higher-order desires presumably aren't inert, like an audience cheering for or against other desires but never influencing them. They are desires after all and must have some connection to action.

Frankfurt doesn't explicitly discuss how higher-order desires manage to bring about the states of affairs that they are directed at, but some of his writings are nonetheless suggestive that he thinks that these desires motivate exercises of willpower. For example, he discusses the case of an unwilling addict who has a first-order desire to use narcotics 
that is opposed by higher-order desires which strongly reject using the drug. Frankfurt says this addict "struggles desperately" against the desires to use narcotics. "He tries everything he thinks might enable him to overcome his desires for the drug" (Frankfurt 1971: 12). A natural way to make sense of these descriptions is that when a person's strongest first-order desire is opposed by desires of higher order, these higher-order desires can motivate intentional actions that block or attenuate the first-order desire, that is, they can motivate exercises of willpower.

Gary Watson (1975) proposes a bifurcated, rather than hierarchical, picture of the architecture of agency. But he shares with Frankfurt the idea that reflective control over one's desires is a critical feature of agency that is genuinely free. He proposes a division of the psyche between a motivational system, which contains desires and other appetitive states that move the person to action, and a valuational system, which generates judgments about what, all things considered, is the thing to do. Somewhat akin to Frankfurt, Watson proposes that freedom consists in the appropriate mesh between the verdicts of the systems.

Watson is clear, however, that the valuational system is not inert in achieving this alignment of verdicts.

[O]ne's valuational system must have some (considerable) grip on one's motivational system. The problem is that there are other motivational factors other than valuational ones. The free agent has the capacity to translate his values into action; his actions flow from his evaluational system.

(Watson 1975: 215-16)

An important component of the 'grip' that the valuational system has over the motivational system consists in the exercise of willpower. Without this critical regulative capacity, a person couldn't, at the time of action, intentionally defeat a contrary desire arising from the motivational system, and in doing so, act on what she judges all things considered best.

There is a distinction implicit in Frankfurt and Watson between two kinds of capacities at work in free and morally responsible agency, a distinction that John Martin Fischer and Mark Ravizza are particularly clear about. They distinguish reasons-receptivity, which involves recognition of reasons to act in certain ways across various counterfactual scenarios, from reasons-reactivity, which involves translating the reasons so recognized into action (Fischer and Ravizza 1998: Chapter 3). It seems plausible that both are critical for freedom and moral responsibility, although perhaps in different degrees. Willpower is a notable member of the latter set of capacities because when trying to translate one's recognitions of reasons into actions in their service, contrary motives are often encountered and regulative capacities are needed to surmount them.

\section{How Failures of Willpower Impair Freedom and Responsibility}

Can exercises of willpower overcome any desire, assuming the person is sincerely motivated to resist and tries to resist as hard as she can? Many think the answer is no, there are at least some desires that are irresistible. Irresistible desires show up routinely in the literature on freedom and moral responsibility in cases involving addicts, kleptomaniacs, phobics, and compulsives of various sorts (see Pickard [2015] for numerous examples from specific works). Moreover, that irresistible desires excuse a person from moral 
responsibility is a point of consensus, agreed upon by theorists as otherwise divergent in their views as Frankfurt (1971), Watson (1975), Susan Wolf (1993), T. M. Scanlon (1998), R. J. Wallace (1998), and Fischer (2012; Fischer and Ravizza 1998).

Despite the ubiquity of irresistible desires in the literature on freedom and moral responsibility, there is much work to do to better understand what they are and how they work. I now take up a number of key questions.

\section{Limitations on Willpower}

There is no doubt that motivation plays a role in strength of willpower. If I am highly motivated to stay on my diet, I will tend to resist my cravings for cookies more than were my motivation weaker. Another factor that influences the strength of willpower is skill. The kinds of things one does when exercising willpower-redirecting attention, reframing the meaning of situations, and vividly imagining future negative consequencestake considerable mental skill, at least to do well. An important further question, much discussed in the recent psychological literature, is whether there are any additional factors that set sharp constraints or limits on the efficacy of willpower. An extensive program of research conducted by Roy Baumeister and his colleagues provides an interesting perspective on this question.

Baumeister and colleagues propose a "muscle model" of willpower (Baumeister et al. 1998; Muraven and Baumeister 2000). Their body of research and findings in support of the model frequently employs the 'dual-task' paradigm, and it will be useful to briefly describe it. There are two groups, and both go through two phases. In phase 1, the 'depletion' group gets a hard self-control task while the control group gets an easy, but otherwise matched, version of this task. In phase 2, both groups get the same hard self-control task that differs from the phase 1 task. A commonly reported finding is that participants in the depletion group exhibit significantly worse self-control performance in the phase 2 task compared to the control group (but see Hagger and Chatzisarantis 2016 for an important pre-registered multi-site study that failed to replicate this effect).

Baumeister and colleagues' explanation of this finding is that like a muscle, selfcontrol becomes fatigued after prolonged use. They go further, however. It is still unclear why muscles fatigue, but a common hypothesis is some kind of energetic fuel is used up. Baumeister and colleagues propose that the depletion of self-control is to be similarly explained. Early on, it was proposed that the relevant energetic fuel for self-control is blood glucose (Gailliot and Baumeister 2007; Gailliot et al. 2007), but subsequent work has suggested alternative interpretations (Kurzban 2010; Beedie and Lane 2012).

Other theorists grant the observation that extended use of self-control (often) produces a sensation of mental fatigue. They disagree with Baumeister and colleagues principally on the mechanisms that produce this sensation. One recent influential model says that mental fatigue does not reflect the depletion of an energetic fuel, but rather plays a 'signaling' role about the availability of alternative ways to spend one's cognitive resources. According to this 'opportunity cost' model (Kurzban et al. 2013), one's cognitive resources are flexible and can be used for many different purposes. To help optimally allocate the use of these resources, the mind is equipped with computational modules that keep track of the gain available from persisting in a task versus the gains that would be available by allocating one's cognitive resources elsewhere. The sensation of mental fatigue is the means by which these computational modules bias motivation in favor of disengagement from the current task, thus freeing up resources to pursue alternatives. 
Importantly, the opportunity cost model doesn't see self-control as somehow inherently constrained, for example by limits on the availability of energetic fuels. The model treats self-control as essentially unlimited so long as the person remains most motivated to continue the current activity rather than use her cognitive resources for alternative purposes.

\section{Judgment Shift}

Suppose I judge I should stay on my diet but later give in and eat the cake. What happens to my earlier judgment that I should stay on my diet? One possibility is that this judgment changes at the time of giving in. Support for this "judgment shift" (Holton 2004) view comes from close observation of the phenomenology of giving in to temptation. Here is Gary Watson:

The mass of the boulder can overpower by bypassing my will, whereas desire cannot. Being overpowered by a hunk of stone means the full, unconflicted use of one's powers are insufficient to resist its force. Being defeated by a desire means one's capacities to resist are not unconflictedly employed. Hence one who is defeated by appetite is more like a collaborationist than an unsuccessful freedom fighter.

(Watson 1975: 6, 7)

Watson's model of giving in to temptation might be seen to threaten the idea that there are desires that are genuinely irresistible. His model proposes that reflective judgment cannot ever be surmounted by an opposed desire. Rather, it must always be co-opted into collaboration; only then can the wayward desire (now no longer wayward, of course) become effective in action. So on a first-pass reading, the model seems to imply we shouldn't allow claims of irresistibility to excuse a person's conduct. If someone says her reflective judgment was literally conquered by an opposing desire, we should respond that what she describes is impossible and she should simply have been more steadfast in holding on to her original judgment.

The first-pass reading appears, however, to not be what Watson has in mind. Watson is sensitive to the fact that it might not be possible to hold on to one's original judgment in the face of persistent, powerful opposed desires. Appetitive desire, Watson notes, produces an onslaught of mental "noise" and "clamor" and other distracting influences, making it hard to reason effectively. The legal theorist Stephen Morse expands on this idea:

[T]he addict, metaphorically, and in some cases perhaps literally, can think of nothing else but the desire to use the substance. One informant described the desire like "a buzzing in my ears that prevents me from focusing." ... There is only one tune or story in the addict's head and nothing can drive it out ... Fundamental components of rationality - the capacities to think clearly and self-consciously to evaluate one's conduct-are compromised.

(Morse 2000: 39)

In the model that emerges from the works of Watson and Morse, powerful opposed desires don't ever run roughshod over one's reflective judgments. Rather, they operate 
more insidiously by undermining reflective thought and reasoning. This produces a shift in judgment, allowing the temptation-directed desire to win out in the end.

Morse is clear that he rejects the notion of irresistible desires, since one's reflective judgments always shift rather than ever being overpowered. One might argue, however, that his nuanced and sophisticated model in fact vindicates the notion of irresistible desires and elucidates precisely how they work. If certain powerful appetitive desires produce defects in rationality that inexorably cause the person to shift judgment and cancel all resistance, shouldn't we call these desires irresistible?

\section{Counterfactual Tests for Irresistibility}

It is standard to try to ascertain whether a given desire is irresistible by means of a counterfactual test. Earlier, I proposed one version of a test:

(1) A desire is irresistible if, were the person sincerely motivated to resist and were she to try to resist as hard as she can, she would still fail.

One might wonder whether this test offers much illumination because it is unclear what it means to try to resist as hard as one can. Indeed, 'can' is itself a notion that is usually explicated in terms of counterfactuals, so (1), somewhat frustratingly, appeals to further counterfactuals that are just as obscure.

One way to retain the spirit of (1) but avoid appeals to further counterfactuals is to find some situation where a person's motivation to resist would surely be sincere and she would surely try as hard as she can to resist. This idea is embodied in the famous 'policeman at the elbow' test widely discussed among legal theorists.

(2) A desire is irresistible if, were a policeman standing right next to you, ready to arrest you for giving in to the desire, you would still fail at resisting.

This proposal might be seen to be needlessly specific. There are a large number of situations involving powerful incentives or reasons to reign in a wayward desire, and a policeman being at your elbow is just one of these. Thus one might propose a more general account.

(3) A desire is irresistible if in all situations where there is sufficient reason to do otherwise, you would still fail to do so.

This proposal says irresistibility requires no susceptibility to counterincentives (or to countervailing reasons) whatsoever. So long as there is a single counterfactual situation in which you would have successfully resisted a certain desire, then the desire is resistible.

Alfred Mele argues that proposals along the lines of (3) set the bar too high for irresistibility. Many desires that clinicians and the folk would say are irresistible turn out to be resistible after all.

Even in extreme cases of phobia or addiction we can usually imagine some reason such that if the agent had had that reason for not acting as he did, he would not have so acted. But it does not follow that in these cases the desires on which the agent acted were resistible by him at the time of action. Suppose, for example, 
that Fred has agoraphobia and that his fear is so strong that he has not ventured out of his house in ten years, despite our many attempts to persuade him to do so. We decide finally that we just have not been presenting Fred with the right reasons and we threaten to burn his house to the ground if he does not open his door today. When it becomes evident that the threat will not work, we start throwing flaming brands through his windows. Fred, panic stricken, tears open his front door and runs screaming into the night, having finally been presented with what he takes to be a good and sufficient reason for leaving his home.

(Mele 1990: 456)

An odd feature of most counterfactual accounts of irresistibility is that they test whether you have the ability to resist a certain desire in the actual situation by looking at the goings on in quite 'distant' counterfactual situations. These situations are quite different in a host of ways, including the person's cognitions, attention, emotions, physiology, and so on. Why should whether I have the ability to resist in the here and now be assessed by looking at situations so far removed? Mele brings this point home by asking us to consider the case of a woman:

[W] ho, under ordinary circumstances, cannot even budge a 300 pound weight, but who, upon finding her child pinned under a 400 pound timber manages, due to a sudden burst of adrenalin, to raise the timber from his body. Surely, it would be misleading to say that she can lift 400 pounds.

(Mele 1990: 456)

It seems we need to relativize irresistibility to a context. The woman can't lift 300 pounds in ordinary contexts but she can when her child is threatened and she is in a highadrenaline state. Fred's agoraphobic fears are irresistible in most ordinary contexts, though they are resistible in certain extreme contexts—such as his house being on fire-where his thoughts, emotions, and physiology are quite different. How, then, should we define this notion of context?

If we specify the context as the entirety of one's psychology (and perhaps physiology) then all desires that one fails to resist will likely turn out to be irresistible. If I fail to resist scratching a very mild mosquito bite, if you hold all my thoughts, motivations, physiology, etc., fixed, then presumably I will do the same thing in all counterfactual scenarios, since my thoughts, motivations, and physiology, etc., are presumably the basis for what I do. So what is needed is a refined account in which, in testing the relevant counterfactuals, some aspects of a person's context are allowed to vary but other aspects are held fixed (for example, that the person is not experiencing a sudden burst of adrenaline should presumably be held fixed). Supplying the needed account in a way that handles a wide range of cases while avoiding counterexamples will surely be challenging.

\section{Time Slice Failure Versus Cumulative Failure}

Thus far we have been considering the issue of irresistibility of desires from a time slice perspective. The agent has a certain desire at a certain time and we are asking whether that particular desire can be resisted.

It is possible that this perspective misses a crucial part of the issue. In many conditions, such as addictions, that are (putatively) associated with irresistible desires, the 
person confronts not just a single desire but rather a sequence of hundreds and thousands of them over the course of weeks and months. This opens up another way to think about irresistibility, one in which the focus is on failures in resisting over long stretches of time rather than failures in resisting in a single instance. ${ }^{4}$

Suppose the mechanisms of willpower are highly reliable but have a small but nonzero error rate-on rare occasions a person who undertakes willpower performs the requisite self-control operations incorrectly and willpower lapses. This supposition seems reasonable because exercising willpower is a complex, multifaceted endeavor. A person might need to do things such as remind herself of prior resolutions, redirect attention away from the tempting stimulus, vividly imagine negative future consequences, and the like. Doing these sorts of things requires the coordinated interaction of multiple psychological processes-memory, attention, imagination, emotion, etc. It is plausible that when multiple complex processes need to interact in a coordinated way, there is room for things to sometimes go awry.

If we combine the claim that temptation-directed desires are encountered extremely frequently and willpower is reliable but nonetheless has a small probability of error, we get-simply as a matter of mathematics-the conclusion that, given enough time, there will be inevitable failures of willpower. The basis for failure isn't a capacity limit along the lines of the Baumeister and colleagues' muscle model. That model, recall, identifies a specific time-limited condition - having one's ability for willpower depleted by prior exertion - that generates a very high probability of failure. In the 'fallibility' model under consideration, the probability of failure of willpower at any given time slice remains miniscule. It is, rather, the cumulative nature of the problem - the piling up over time of probabilities that are themselves tiny-that generates the inevitability of giving in.

It is standard to explain the (involuntary) failure of willpower either in terms of desires that are too strong or self-control capacities that are too weak, or both. It is an interesting feature of the 'fallibility' model that it doesn't postulate either of these kinds of defects. First, if we look at each desire that the person confronts individually, that is, each member of the larger sequence of ongoing desires, none is in any obvious sense too strong and certainly none seems so strong as to be irresistible. One striking piece of evidence for this claim is that the person will have typically faced desires of roughly the same strength countless other times and will have successfully resisted them. How can a desire that is irresistible, or in some interesting sense 'too strong,' be so reliably defeated?

Second, the self-control capacities of the person don't appear to be too weak or somehow limited. After all, the person is supposed to be like anyone else in her selfcontrol abilities. Other than the universal characteristic that the exercise of willpower is fallible and has a small probability of error, no specific defect in self-control capacities was ever postulated. Nonetheless, the model shows how, although desire is not too strong and self-control is not too weak, and although the person sincerely stands firmly against her temptation-directed desires, she will inevitably eventually give in.

\section{Conclusion}

Influential theories say reflective self-control is central for freedom and moral responsibility, and the ability to exercise willpower is part of the set of capacities that make reflective self-control possible. Conversely, irresistible desires, and other conditions that produce failures of willpower, constrain one's freedom and are widely recognized as excusing moral responsibility. Given these interconnections, further investigation into 
willpower-philosophical and empirical—promises to illuminate freedom and moral responsibility as well.

\section{Notes}

1 This is a crude way of putting the principle, and it is wrong as stated (see Mele [2003] for a detailed discussion). But the ways it goes wrong are not so pertinent to the present discussion.

2 Sripada (2014) provides an extensive discussion.

3 See the Additional Readings section.

4 I develop the model sketched in the next few paragraphs in greater detail in Sripada (2013) and in Sripada (in preparation) "Addiction, Fallibility, and Responsbility."

\section{Bibliography}

Baumeister, R.E., Bratslavsky, E., Muraven, M., and Tice, D.M. (1998) "Ego Depletion: Is the Active Self a Limited Resource?" Journal of Personality and Social Psychology 74: 1252-65.

Beedie, C.J. and Lane, A.M. (2012) "The Role of Glucose in Self-Control Another Look at the Evidence and an Alternative Conceptualization," Personality and Social Psychology Review 16: 143-53.

Carter, E.C. and McCullough, M.E. (2014) "Publication Bias and the Limited Strength Model of SelfControl: Has The Evidence for Ego Depletion Been Overestimated?" Frontiers in Psychology 5: 823.

Connor, T.D. (2013) "Self-Control, Willpower and the Problem of Diminished Motivation," Philosophical Studies 168: 783-96.

Fischer, J.M. (2012) "Semicompatibilism and Its Rivals," The Journal of Ethics 16: 117-43.

Fischer, J.M. and Ravizza, M. (1998) Responsibility and Control: A Theory of Moral Responsibility. New York: Cambridge University Press.

Frankfurt, H. (1971) "Freedom of the Will and the Concept of a Person," The Journal of Philosophy 68: 5-20.

Gailliot, M.T. and Baumeister, R.F. (2007) "The Physiology of Willpower: Linking Blood Glucose to Self-Control," Personality and Social Psychology Review 11: 303-27.

Gailliot, M.T., Baumeister, R.F., DeWall, C.N., Maner, J.K., Plant, E.A., Tice, D.M., Brewer, L.E., and Schmeichel, B.J. (2007) "Self-Control Relies on Glucose as a Limited Energy Source: Willpower is More Than a Metaphor," Journal of Personality and Social Psychology 92: 325-36.

Gert, B. and Duggan, T.J. (1979) "Free Will as the Ability to Will," Noûs 13: 197-217.

Hagger, M.S. and Chatzisarantis, N.L.D. (2016) "A Multilab Preregistered Replication of the Ego-Depletion Effect," Perspectives on Psychological Science 11(4): 546-73.

Hagger, M.S., Wood, C., Stiff, C., and Chatzisarantis, N.L. (2010) "Ego Depletion and the Strength Model of Self-Control: A Meta-Analysis," Psychological Bulletin 136: 495-525.

Holton, R. (2004) "Rational Resolve," The Philosophical Review 113: 507-35.

Inzlicht, M. and Schmeichel, B.J. (2012) "What Is Ego Depletion? Toward a Mechanistic Revision of the Resource Model of Self-Control," Perspectives on Psychological Science 7: 450-63.

Inzlicht, M., Schmeichel, B.J., and Macrae, C.N. (2014) "Why Self-Control Seems (But May Not Be) Limited," Trends in Cognitive Sciences 18: 127-33.

Kennett, J. and Smith, M. (1996) "Frog and Toad Lose Control," Analysis 56: 63-73.

Kennett, J. and Smith, M. (1997) "Synchronic Self-Control Is Always Non-Actional," Analysis 57: 123-31.

Kool, W. and Botvinick, M. (2014) "A Labor/Leisure Tradeoff in Cognitive Control," Journal of Experimental Psychology: General 143: 131-41.

Kurzban, R. (2010) “Does the Brain Consume Additional Glucose During Self-Control Tasks?" Evolutionary Psychology: An International Journal of Evolutionary Approaches to Psychology and Behavior 8: 244-59.

Kurzban, R., Duckworth, A., Kable, J.W., and Myers, J. (2013) "An Opportunity Cost Model of Subjective Effort and Task Performance," The Behavioral and Brain Sciences 36: 661-79.

Levy, N. (ed.) (2013) Addiction and Self-Control: Perspectives from Philosophy, Psychology, and Neuroscience. New York: Oxford University Press.

Mele, A. (1987) Irrationality: An Essay on Akrasia, Self-Deception, and Self-Control. New York: Oxford University Press.

Mele, A. (1990) "Irresistible Desires," Noûs 24: 455-72.

Mele, A. (1997) "Underestimating Self-control: Kennett and Smith on Frog and Toad," Analysis 57: $119-23$. 


\section{WILLPOWER, FREEDOM, AND RESPONSIBILITY}

Mele, A. (1998) "Synchronic Self-Control Revisited: Frog and Toad Shape Up," Analysis 58: 305-10.

Mele, A. (2003) Motivation and Agency. New York: Oxford University Press.

Mele, A.R. (2013) "Self-Control, Motivational Strength, and Exposure Therapy," Philosophical Studies 170: $359-75$.

Morse, S.J. (1994) "Culpability and Control," Pennsylvania Law Review 142: 1587-660.

Morse, S.J. (2000) "Hooked on Hype: Addiction and Responsibility," Law and Philosophy 19: 3-49.

Morse, S.J. (2002) "Uncontrollable Urges and Irrational People," Virginia Law Review 88: 1025-78.

Muraven, M. and Baumeister, R.F. (2000) "Self-regulation and Depletion of Limited Resources," Psychological Bulletin 126: 247-52.

Pickard, H. (2015) "Psychopathology and the Ability to Do Otherwise," Philosophy and Phenomenological Research 90: 135-63.

Scanlon, T. (1998) What We Owe Each Other. Cambridge: Harvard University Press.

Sripada, C. (2013) "The Second Hit in Addiction," in W. Sinnott-Armstrong (ed.), Moral Psychology: Free Will and Moral Responsibility, Vol. 4. Cambridge: MIT Press.

Sripada, C. (2014) "How is Willpower Possible? The Puzzle of Synchronic Self-Control and the Divided Mind," Noûs 48: 41-74.

Wallace, R.J. (1998) Responsibility and the Moral Sentiments. Harvard: Harvard University Press.

Watson, G. (1975) "Free Agency," The Journal of Philosophy 72: 205-20.

Wolf, S. (1993) Freedom Within Reason. New York: Oxford University Press.

Zhu, J. (2005) "Explaining Synchronic Self-Control," The Southern Journal of Philosophy XLIIl: 475-92.

\section{Further Reading}

There is a lively ongoing debate about the puzzle of synchronic self-control. See Mele (1987, 1997, 1998, 2013), Kennett and Smith (1996, 1997), Zhu (2005), Sripada (2012), and Connor (2013).

In addition to Frankfurt, Watson, and Fischer and Ravizza, other authors also argue that freedom is intimately connected with reflective self-control or guidance of action by reason. See, for example, Gert and Duggan (1979), Wolf (1993), and Wallace (1998).

There is a large body of evidence that performance on self-control tasks decreases with prior prolonged exertion of self-control. See Hagger et al. (2010) for an extensive meta-analysis. Recently, some theorists have raised doubts about the strength of this evidence. See, for example, Carter and McCullough (2014). In addition, Hagger and Chatzisarantis (2016) reports on a preregistered study involving 23 labs and over 2,000 participants in which self-control depletion was not observed. In addition to the models offered by Baumeister et al. (1998) and Kurzban et al. (2013), alternative explanations of the fatiguing of willpower (or apparent fatiguing) are put forward in Inzlicht and Schmeichel (2012), Inzlicht et al. (2014), and Kool and Botvinick (2014).

The topic of irresistible desires is discussed in philosophy in Mele (1990) and Pickard (2015), with the latter adding a clinical point of view. Morse discusses irresistible desires from the perspective of legal theory $(1994,2000,2002)$. There is a large literature in philosophy and the behavioral sciences about the irresistibility of desires in substance addiction. The essays collected in Levy (2013) provide a very helpful overview of positions.

\section{Related Topics}

Addiction

Self-Control and Akrasia 


\section{0 \\ ADDICTION \\ Hanna Pickard}

The Addict is a central character in the contemporary free will debate. Classic compatibilism holds that freedom consists in the absence of more or less common external constraints on actions, such as threats or coercion by others, the use of physical force or restrictions, paralysis or disability, and the lack of choices and opportunities. Incompatibilism contends that freedom of action is not the same as freedom of will. Absence of external constraints does not guarantee that we have free will, understood as a distinctive (if difficult to analyze) power to do otherwise: freedom requires that we be able to choose, for ourselves, whether to act in a certain way or not, so that we ourselves and nothing else determine what we do and decide our futures. There is a dramatic standoff. From the incompatibilist perspective, classic compatibilism gives us a severely limited account of the nature of freedom. From the classic compatibilist perspective, the free will trumpeted by incompatibilism may be little more than a chimera. At this point in the debate, enter The Addict. In response to the stand-off, contemporary compatibilism concedes to incompatibilism that the absence of external constraints is not enough for freedom of will as opposed to freedom of action. There must also be an absence of internal constraints, namely, the compulsion characteristic of mental disorder in general, and of addiction in particular. Free will, as opposed to free action, is what those of us who are not addicts purportedly have, and what The Addict purportedly lacks. It is a form of freedom worth wanting: addiction is a devastating condition that destroys lives. And it is a form of freedom compatible with determinism: whether or not determinism is true, we are able to choose what we do in a way that The Addict cannot.

Writing over a century ago, William James described the figure of The Addict thus:

The craving for a drink in real dipsomaniacs, or for opium or chloral in those subjugated, is of a strength of which normal persons can form no conception. "Were a keg of rum in one corner of a room and were a cannon constantly discharging balls between me and it, I could not refrain from passing before that cannon in order to get the rum"; "If a bottle of brandy stood at one hand and the pit of hell yawned at the other, and I were convinced that I should be pushed in as sure as I took one glass, I could not refrain": such statements abound in dipsomaniacs' mouths.

(James 1890: 543)

According to James, The Addict is literally powerless over the desire to use drugs: "subjugated" by "cravings" of such "strength" that they cannot "refrain" from acting on 
them no matter the circumstances and costs, including cannon balls and hell. More recently, The Addict has been described by contemporary philosophers as someone who "inevitably succumbs" to a desire to use drugs "too powerful ... to withstand" resulting in the person potentially being "helplessly violated by [their] own desires" (Frankfurt 2003 [1971]: 329); as "susceptible" to "compulsions that usually nullify any semblance of voluntary choice" (Charland 2002: 41); and as required to go "where the addiction leads [them], because the addiction holds the leash" (Elliott 2002: 48). The Addict's desire for drugs is irresistible. As they cannot but take drugs, they lack the freedom of will that those of us who are not prey to such compulsions have.

However, the difficulty in resting content with the picture painted by contemporary compatibilism is that the character of The Addict is just that: a dramatic character. The Addict bears little resemblance to real-world addicts (cf. Levy 2006; Pickard 2012). Addiction is indeed a terrible problem that has harrowing consequences. But addicts are not subject to irresistible desires. If their will is indeed unfree, it is far less clear why this is and in what way it is true than the free will debate tends to presume.

In what follows, I first detail the evidence for the claim that addictive desires are not irresistible. I then briefly consider how this evidence specifically bears on reasonsresponsive and hierarchical theories of free will, before turning to consider the connection between addiction and autonomy. Finally, I suggest that, in so far as addicts lack freedom, this may reside, as classic compatibilism suggests, fundamentally in external rather than internal constraints. Namely, conditions of psycho-social adversity, poverty, and disadvantage that cause suffering and limit choices and opportunities.

\section{The Evidence Against the Irresistibility of Addictive Desire}

Broadly speaking, popular culture and current medical orthodoxy concur with the philosophical depiction of The Addict as subject to irresistible desires. Addiction is widely viewed as a chronic, relapsing neurobiological disease characterized by compulsive use of drugs despite negative consequences (cf. WHO 2004; NIDA 2009). 'Drugs' include not only illegal drugs but also alcohol as well as pharmaceutical drugs that are open to abuse. 'Negative consequences' include the neglect of other pleasures and interests; the inability to fulfil important social and occupational roles and responsibilities; ruined relationships; the loss of social standing and community; cognitive impairment and mental health problems; physical disability and disease; and, lastly, death (cf. WHO 1992; APA 2013).

Proponents of this view of addiction often seek support from our increasing neurobiological knowledge of the acute and chronic effects of drugs on the brain (Koob and Le Moal 1997; Koob and Volkow 2010). For example, Louis Charland suggests that drug-seeking and drug-taking behavior is "a direct physiological consequence of dramatic neuroadaptations produced in the reward pathways of the brain" (Charland 2002: 40; my emphasis). There is indeed no question that long-term heavy use of drugs directly affects levels of synaptic dopamine as opposed to affecting them only indirectly via the normal neural processes sub-serving learning and reward. This can explain why cues associated with drugs trigger a desire for them which over-estimates their anticipated reward and hence is unusually strong in its motivational strength (Montague et al. 2004; Redish et al. 2008; Schultz 2011). Over time, wanting drugs may even come apart from liking them: cues may trigger cravings and strongly motivate drug-seeking and drug-taking, even though consumption no longer offers much pleasure or genuine reward (for a review see Berridge and Robinson 2011; cf. Holton and Berridge 2013). 
However, despite the importance of neurobiological knowledge for our understanding of addiction, it does not establish that addiction is a neurobiological disease of compulsion (cf. Satel and Lilienfeld 2013). One issue is why the effects of drugs on the brain should be considered as pathological or constitutive of a dysfunction or disorder (Stephens and Graham 2009; Levy 2013a). But an additional and independent issue is why they evidence compulsion or irresistibility of desire. Presumably all human action is underpinned by neurobiological mechanisms; the question with respect to addiction is whether there is good reason to believe that the effects of drugs on the brain directly cause behavior that by-passes the human capacity for choice and control in its entirety, in contrast to other forms of behavior. Although our increasing knowledge certainly explains how cues associated with drugs trigger desires that are unusually strong in motivational strength and which fail to track level of hedonic reward, it does not suggest that such desires are impossible to resist. Hard to resist, undoubtedly. But irresistible?

In response, it might be suggested that evidence for irresistibility lies open to view in the behavior of addicts. For instance, Al Mele writes:

The basic compatibilist idea is (roughly) that when mentally healthy people act intentionally in the absence of compulsion [...] they act freely, and an action's being deterministically caused does not suffice for its being compelled ... people who act freely are exercising a rational capacity of such a kind that, had their situation been different in any one of a variety of important ways, they would have responded to the difference with a different suitable action [.. .] For example, although I spent the day working, I would have spent the day relaxing if someone had bet me $\$ 500$ that I would not relax all day [. . . ] Offer a compulsive hand-washer $\$ 500$ not to wash his hands all day and see what happens.

(Mele 2006: 188, 189)

A similar line of thought can be offered with respect to addiction: offer an addict $\$ 500$ not to use drugs all day and see what happens. Presuming they would nonetheless use drugs, there is evidence of irresistibility.

In fact, this 'experiment' has been conducted. Contingency management (CM) is a form of treatment that offers addicts rewards in return for clean urine samples, produced three times per week. The pilot study offered $\$ 100$ per week, but it was soon discovered that comparable outcomes could be achieved by much smaller rewards, such as modest monetary incentives, small prizes, vouchers, and lucky dips. CM treatment significantly improves abstinence and treatment-compliance compared to standard forms of treatment such as counselling and cognitive-behavioral therapy (for a review, see Petry et al. 2011). For many addicts, the reward structure is sufficient to motivate abstinence. Contra Mele's argument as extrapolated, the offer of $\$ 500$ for a single drug-free day would seem likely to incentivize abstinence for all but the very wealthiest addicts for whom the money was insignificant (of whom there are few, see below). CM treatment shows that, in many cases, if we shift the circumstances in which addicts find themselves so that abstinence brings an immediate and certain (if small) reward, addicts respond by shifting their behavior.

$\mathrm{CM}$ treatment is not the only source of evidence that addicts respond to incentives. Anecdotal and first-person reports abound of addicts who are diagnosed as dependent (and so suffer withdrawal) going 'cold turkey' (cf. Heyman 2009, 2013a). Large-scale 


\section{ADDICTION}

epidemiological studies demonstrate that the majority of addicts 'mature out' without clinical intervention in their late twenties and early thirties, as the responsibilities and opportunities of adulthood, such as parenthood and employment, increase (for a review of these findings see Heyman 2009; cf. Peele 1985; Foddy and Savulescu 2006; Pickard 2012). Rates of use are cost-sensitive: indeed, some addicts choose to undergo withdrawal in order to decrease tolerance, thereby reducing the cost of future use (Ainslie 2000). Experimental studies suggest that when given a forced choice between small sums of money and drugs, addicts will often choose money (Hart et al. 2000; Hart 2013). Only one-third of heroin addicts who participated in one of the famous 'Swiss trials' offering heroin on prescription chose to continue heroin maintenance at follow-up; the rest said 'No' (contra an addict famously interviewed by Louis Charland, see below for further discussion) and declined the offer of daily, safe, free heroin (Perneger et al. 1998; cf. Foddy and Savulescu 2006). Finally, animal research on addiction has convincingly demonstrated that, although the majority of cocaine-addicted rats will escalate self-administration if offered no alternative goods, they will forgo cocaine and choose alternative goods, such as saccharin or same-sex snuggling, if available (Ahmed 2010; Zernig et al. 2013; see below for further discussion).

If addictive desires were irresistible, then it should be rare if not indeed impossible for addicts to respond to incentives and forgo drugs. Yet it is not only possible but common. The most obvious explanation is that addicts choose to abstain when they are sufficiently motivated to do so: they are not subject to internal compulsion and 'helplessly violated' by their desires.

Philosophers sometimes suggest that such evidence does not in fact establish that addicts have significant choice and control over drug use. The reason offered is that the capacity to respond to incentives must be relativized to a motivational and epistemic context (cf. Mele 1990). Otherwise, as Neil Levy puts it, "We get the absurdity that, say, agoraphobics are not compelled to remain indoors, since, given the appropriate incentives [e.g. the house is on fire], they would leave" (2011a: 271). Applying this lesson to addiction, the suggestion is that the fact that addicts refrain from use in particular circumstances (e.g., when undergoing CM treatment, or when they secure a good job or become a parent) does not show that they have control outside of these circumstances; all it shows is that they have control in these circumstances (cf. Levy 2011a). Control must always be relativized to circumstances.

Extreme circumstances can indeed affect people's capacities. For example, in order to save a child from death, a parent may have the capacity to move a crushing weight even though in standard conditions they lack the requisite physical strength. But this point should not bar us from holding that, in less extreme circumstances, behavioral change following motivational change provides strong evidence of a general capacity for behavioral control. Consider, for instance, a man who 'sees red' and routinely resorts to physical violence in drunken disputes-except when in view of a policeman. On such occasions, he is highly motivated not to hit, which he would otherwise do, out of fear of being detained and charged with common assault. Does his restraint in this context show only that he can control his aggression when in view of a policeman, but not necessarily otherwise? Arguably, this is not the natural understanding of this man's behavior. Rather, the natural understanding is that his restraint shows that he has a general capacity to control his aggression, but that he only exercises it when he wants to. There is a basic, commonsense distinction between what a person can do but won't (because the person doesn't want to) and what a person wants to do but can't (because the person 
lacks the capacity). We must recognize extremes, but relativizing control too strongly to motivational and epistemic circumstances threatens the cogency of this distinction (cf. Pickard 2012).

With respect to addiction, the incentives that appear to motivate abstinence are not extreme but rather modest and common: to return to James' example, it does not take cannon balls to stop an alcoholic from running across the room to the punch bowl. These incentives thus provide strong evidence that addicts have the general capacity to control their use in a broad range of ordinary circumstances. Strikingly, this point can be found even in Griffith Edwards and Milton Gross's seminal discussion of the disease model of alcohol dependence. They write that "it is unclear, however, whether the experience [of alcoholism] is truly one of losing control rather than one of deciding not to exercise control" (Edwards and Gross 1976: 1060; note that the point can be made less contentiously, by withholding judgement as to whether addicts decide not to exercise control and emphasizing instead the fact that they don't exercise control). Of course, the attribution of a general capacity is consistent with the possibility that there may be occasions where, due to any variety of constraints, it cannot be exercised. The point is rather that our understanding of addiction ought to respect the strength of the evidence that addicts do not appear to be compelled to use. They respond to incentives and as a result evidence the ability to make choices and exercise control over their drug consumption.

One question that remains is what to make of the testimony of addicts who say they 'can't' control their drug use, such as the 'dipsomaniacs' purportedly quoted by James. A famous recent example is an addict named Cynthia interviewed by Louis Charland who claims: "If you're addicted to heroin, then by definition you can't say 'No' to the stuff" (Charland 2002: 37). There are a number of important considerations here. First, what people say is in general affected by what the upshot of their saying it will be. There is variation between addicts with respect to the extent to which they report an inability to control their use (Heyman 2009) and also with respect to what the same addict may report to different people at different times (Davies 1992). The explanation of such variance likely depends in part on how social expectations and anticipated responses affect how addicts frame self-reports. For example, in contexts where addicts may fear blame, a report of powerlessness may offer an excuse; while in contexts, such as self-help groups, where personal agency and responsibility is emphasized, a report of powerlessness may risk ostracization. Second, there are looping effects: the wide-spread availability and acceptance of a particular theory of human experience and behavior, such as addiction, can affect how people subject to those experiences and that behavior understand themselves (Hacking 1995, 2000). Third, 'can't' can have multiple meanings (cf. Sinnott-Armstrong and Pickard 2013). When addicts say they can't resist, they may not be claiming that it is literally impossible for them to resist but rather that abstinence is very difficult, and that the costs of forgoing drugs are high, and the benefits of using drugs are many (see below for further discussion). For all these reasons, the testimony of addicts, like other forms of self-report, is a complicated form of evidence for use in theorizing. However, it is extremely important for other reasons, namely, that it helps us to understand what it is like to live with addiction, at least for the particular addict telling the story. This is essential for individually-tailored clinical care, as well as a potential source of wider social understanding, compassion, and empathy (for articles that weave together philosophical considerations with first-person stories, see Flanagan [2011, 2013]). 


\section{Contemporary Compatibilism and Addiction}

If addicts respond to incentives and so evidence choice and control over their drug consumption, where does that leave The Addict of contemporary compatibilism?

Consider, first, John Martin Fischer and Mark Ravizza's reasons-responsive account. Fischer and Ravizza argue that we have guidance control over our actions when they proceed from a mechanism that is both regularly receptive to reasons and at least sometimes reactive to reasons (Fischer and Ravizza 1998; note that the mechanism must also be 'one's own,' e.g., not subject to intervention by evil neuroscientists). Receptivity involves recognizing reasons and forming beliefs about how they count for or against actions. Reactivity requires that one's actual mechanism will sometimes issue in different actions when one is presented with different scenarios offering different reasons. Guidance control is designed to be compatible with determinism as it is evaluated counterfactually but without presupposing that, given the actual scenario, there is an alternative possible action that is genuinely open to the agent. Fischer and Ravizza contend that irresistible urges in general and addiction in particular are not reasonsresponsive and so do not evidence guidance control $(1998: 35,48)$ : the rest of us are supposed to have what addicts and other people who suffer from compulsion lack. But responsiveness to incentives is a form of responsiveness to reasons (e.g., the fact that an addict will get a CM treatment reward if they don't use drugs is a reason not to use drugs). Although The Addict may lack guidance control, addicts don't.

Consider, next, Harry Frankfurt's hierarchical theory. Frankfurt claims that we have free will when our first-order desires that move us to act are the desires that we want to have: in other words, when our second-order volitions (to use Frankfurt's term) mesh with our effective first-order desires. (Frankfurt 2003 [1971]). He famously illustrates this idea by comparing three sorts of addict: wanton addicts, willing addicts, and unwilling addicts.

According to Frankfurt, these three addicts are similar in two respects. First, they may all experience conflict between a first-order desire to use drugs and a first-order desire not to use drugs. Second, because they are addicts and the desire to use drugs is irresistible, it wins out. However, he holds there is yet an important difference between them. Wanton addicts have no second-order volitions whatsoever as to which first-order desire wins out: they are passive spectators of the battle between their desires, and so, to that extent, lack free will by default. Willing addicts, in contrast, embrace the first-order desire which wins out: they want for the desire to use drugs to move them to action. Given that it does, Frankfurt holds that they have free will—even if their will is not in another sense free, as the desire for drugs is irresistible. Finally, unwilling addicts want for their desire to use drugs not to be effective. Yet, because it is irresistible, it is. They are therefore alienated from the desire that moves them to action. For that reason, Frankfurt holds that they lack the free will that willing addicts (and the rest of us) possess. For they do not endorse or identify with the desire they act on.

However, Frankfurt's assumption that addictive desires are irresistible is not idle. For, without it, the difference between the willing and the unwilling addict seems less a difference in freedom, than a difference in self-identity, self-integrity, and selfcontentment.

To see this, suppose that, in line with the evidence detailed above, we reject Frankfurt's assumption and hold instead that addictive desires are not irresistible. There is no question that addicts sometimes (although not always) have conflicting first-order desires. 
They may both want and not want to use drugs at the very same time, and they may oscillate between a desire to use drugs and a desire not to use them over time (for further discussion see below). But if we allow that they are nonetheless responsive to incentives and have choice and control over their drug consumption, then when the willing addict decisively (to use Frankfurt's term) wants to act on the desire to use drugs at the time of choice, they will; and when the unwilling addict decisively wants not to act on the desire to use drugs at the time of choice, they won't. In other words, the wills of both addicts would appear to be equally free.

We are all of us, of course, familiar with the experience of having a first-order desire that we do not want to have. For example, some people may wish they did not have a desire for junk food, say, or for promiscuous sex, or for aggression and violence. In the willing addict's case, the desire they don't want to have is the desire not to take the drug. In the unwilling addict's case, it is the desire to take the drug. The more of our first-order desires we feel alienated from-in the sense of wishing we did not have them-the more we can feel our self-integrity and self-contentment to be under strain. But it is only if we act on these first-order desires against our second-order volitions despite not wanting to (in some significant way or degree) that our freedom would seem to be compromised. In other words, lack of mesh between first-order and second-order states is not in itself sufficient for lack of freedom.

Indeed, Frankfurt himself seems at places to recognize this point. When explaining why the willing addict possesses a freedom that the unwilling addict lacks, he says: "I am inclined to understand [the willing addict's] situation as involving the overdetermination of his first-order desire to take the drug. This desire is his effective desire because he is physiologically addicted. But it is his effective desire also because he wants it to be [. . . ] it is therefore not only because of his addiction that his desire for the drug is effective" (2003 [1971]: 335, 336, my italics). In other words, the willing addict has a freedom that the unwilling addicts lacks not only because their second-order volition endorses the first-order desire that happens to be effective, but because their second-order volition contributes to its efficacy. They not only want the will they have, but will that they have it. Compare: "it is in securing the conformity of [their] will to [their] second-order volitions, then, that a person exercises freedom of the will (2003 [1971]: 331, my italics).”

Addicts can differ profoundly in the extent to which they embrace a self-identity as an addict and feel at ease with their addictive choices. But that in itself does not suffice to track a difference with respect to whether or not they have free will. Frankfurt's unwilling addict intuitively counts as unfree because Frankfurt assumes their desire for drugs is irresistible and so they act despite their second-order volition; and his willing addict intuitively counts as free because, when we probe deeper, there is a hidden suggestion that their desire for drugs is in fact responsive to their second-order volition (and hence, and contra Frankfurt's initial hypothesis, their addictive desires are not wholly irresistible). In other words, lack of mesh between first-order desires and second-order volitions may affect self-identity, self-integrity, and self-contentment, but only lack of efficacy affects freedom.

Hence, on neither reasons-responsive nor hierarchical theories do addicts ultimately lack free will, for they respond to incentives and so evidence choice and control. Of course, contemporary compatibilists have also constructed hypothetical examples of non-pathological agents, such as imagined victims of evil brain-manipulating neuroscientists, who purportedly lack the power to do otherwise (however that notion is 
ultimately analyzed) and so, too, a form of freedom that the rest of us take ourselves to possess (for critical discussion see Alvarez 2009 and Steward 2009). But, once it is acknowledged that The Addict is nothing like actual addicts, the standard supposed realworld example of action in absence of free will, to which contemporary compatibilists typically appeal, is lost (cf. Pickard 2015).

Nonetheless, the idea that there is some sort of link between rationality and the self and freedom, and which is compromised in addiction, is clearly intuitive. Addiction is characterized, as noted above, by desires that oscillate over time, as well as ambivalence, regret, and deep shame (Flanagan 2013). Addicts are typically not at peace with themselves. Responding to this consideration, Neil Levy has argued that, although addicts respond to incentives and so are free to choose to use or not to use at a time, their autonomy (in one sense of that multi-faceted idea) is yet impaired when their pattern of choices is considered over time (Levy 2006).

Levy draws on George Ainslie's influential theory of hyperbolic temporal discounting to explain this idea (Ainslie 2001). We are all of us inclined to discount the value of future rewards compared with present rewards. This can be considered rational to the extent that, broadly speaking and adjusting for the relative expected value of the rewards, the present reward is certain while the future reward is uncertain. But, in addition, we typically discount future rewards not simply exponentially, but hyperbolically. This means that, as a reward nears in time, its expected value increases sharply, shifting in response to availability (as opposed e.g., to shifting due to re-assessment of intrinsic worth) (Ainslie 2001; cf. Heyman 2009). Addicts discount the future even more hyperbolically than non-addicts (Bickel and Marsch 2001; Bickel et al. 2014). So, with the drug within immediate reach, its value skyrockets. But, when it is not within immediate reach, its value is much reduced. This creates 'judgement shifts' (Holton 2004; see also Levy 2011b) whereby preferences or all-things-considered judgements as to what is best to do fluctuate in response to availability of drug rewards, creating an inability to extend one's will consistently over time. For, when discounting is hyperbolic, one cannot straightforwardly count on the fact that, if one (for good reason) resolves to abstain from drugs from now onwards, one won't in fact change one's mind in the future, when drugs (let us suppose) are again within immediate reach. Hence, according to Levy, addicts are not unified but fragmented in their selves, because they cannot effectively extend their will over time. Although addicts respond to incentives and so are free to choose to use or not to use at any one time, their autonomy is yet impaired according to Levy, because (compared to people who are not addicted) their choices are inconsistent over time (Levy 2006; see also Levy 2011b).

Levy's depiction of addicts is empirically informed and pinpoints a genuine way in which they are less autonomous compared to people who are more able to diachronically extend their will. All of us are prone to hyperbolic discounting and judgement shifts to a degree. On Levy's view, addicts do not lack free will due to the internal constraint of compulsion, but rather have less autonomy (again, in one sense of that multi-faceted idea) due to an impairment in their diachronically extended agency. Such autonomy is intuitively worth wanting. It would also appear to be fully consistent with determinism. Levy has therefore pinpointed something to which contemporary compatibilism can appeal which is connected to ideas of rationality and freedom and the self, and which people, including addicts, can enact more or less effectively. But, as Levy himself recognizes, his account does not offer a sharp divide between addicts and the rest of us. Equally, autonomy, as he describes it, can be compromised even though a person has 
choice and control over their actions at the time and so would appear to retain the power to do otherwise (again, however that is ultimately analyzed).

\section{External Constraints: Poverty, Mental Health, and Limited Choices and Opportunities}

Let us briefly take stock. The Addict is a dramatic character in the free will debate, far removed from the reality of addiction. Unlike The Addict, addicts are not subject to irresistible desires: they respond to incentives and have choice and control over their actions. This means they do not straightforwardly offer contemporary compatibilism a way of articulating a form of free will worth wanting. But, as Levy suggests, addicts may yet be impaired with respect to their capacity to act consistently as a unified agent over time; correspondingly, they may experience deep regret and shame. They may be less autonomous than people who are more able to effectively extend their will diachronically and thereby experience a more unified sense of self.

If this is correct, the question is why addicts suffer this impairment. What is the source of the reduced autonomy characteristic of addiction?

The Addict is usually described without mention of contextual factors, but realworld addiction is associated with lower socio-economic status and mental health problems, especially concurrent diagnoses of mood, anxiety, and personality disorders (Compton et al. 2007; Heyman 2009). There are of course exceptions, but on the whole addicts come from underprivileged backgrounds of poor opportunity and have a range of problems in addition to their addiction, which cause terrible suffering and limit choices.

Lower socio-economic status affects cognitive and emotional development (Hackman et al. 2010). Poverty and disadvantage increase stress and negative emotions, which may in turn lead to short-sighted decision making, by limiting attention and favoring habitual behaviors, at the expense of longer-term goal-directed decision-making processes (Haushofer and Fehr 2014). Such temporal myopia may not only further entrench poverty but equally further entrench other habits which pay off in the short term but cost in the long term, such as drug use.

It is well known that, quite generally, drugs offer means to fulfilling multiple ends, including: (1) improved social interaction; (2) facilitated mating and sexual behavior; (3) improved cognitive performance and counteracting fatigue; (4) facilitated recovery and coping with psychological stress; (5) self-medication for mental problems; (6) sensory curiosity-expanded experiential horizons; and, finally (and in ways most self-evidently) (7) euphoria, hedonia, and high (Muller and Schumann 2011). Especially with respect to items 4 and 5 of this list, the 'self-medication' hypothesis has long been a staple of clinical understanding of addiction (Khantzian 1985, 1997). It is common knowledge that drugs offer relief from psychological distress, including stress and negative emotions (core symptoms of mood, anxiety, and personality disorders): we 'reach for the bottle' or 'drown our sorrows' when in need. For addicts with mental health problems who live in impoverished circumstances, drugs may provide a habitual and, in the short term, effective way of managing the severe psychological distress and negative emotions such circumstances involve. Put crudely, drugs offer a way of coping with pain and misery, when choices are limited and opportunities for genuine improvement in socio-economic status and overall wellbeing in the future are few (cf. Pickard 2012). They pay off in the short term, even though they may also contribute to the long-term 
entrenchment of some of the problems that cause the psychological distress they are then used to relieve.

Strikingly, animal research on addiction supports this explanation. Caged, isolated rats will escalate self-administration of drugs, forgoing food and water, sometimes even to the point of death (Bozarth and Wise 1985; Fitch and Roberts 1993; Dworkin et al. 1995). But, in the 1970s, Bruce Alexander conducted a now famous experiment called "Rat Park" (Alexander et al. 1978, 1985; for some fun, see the comic strip at: http:// www.stuartmcmillen.com/comics_en/rat-park/). Alexander took morphine-addicted rats out of their cages, and placed them in a spacious, comfortable, naturalistic setting, where rats of both sexes were able to co-habit, nest and reproduce. Rats were offered a choice between morphine-laced water and plain water. On the whole, they chose to forgo the morphine and drink plain water, even when they experienced withdrawal symptoms, and even when the morphine-laced water was sweetened to significantly appeal to the rat palate. Recent studies complement Alexander's findings. The majority of self-administering rats that are offered an alternative good, such as saccharin or samesex snuggling, will forgo drugs and choose the other reward instead (Ahmed 2010; Zernig et al. 2013). The basic upshot of animal research on addiction is that environmental enrichments in most experimental choice settings protect against addiction (Vandaele et al. 2016; for discussion in relation to human addiction, see Pickard and Ahmed [forthcoming]; for some complementary findings from research on human addiction, see Heyman et al. [2014]). Offer rats alternative rewards to drugs, and they take them.

The medically orthodox view of addiction as a chronic, relapsing neurobiological disease characterized by compulsive use of drugs despite negative consequences has genuine explanatory power. Even if addicts rarely use drugs in the face of cannon balls and hell, they do use drugs despite terrible damage to their lives. Compulsion can explain why they persist in using in face of negative consequences: they cannot stop themselves. Hence the rejection of compulsion and the acknowledgement that addicts respond to incentives brings with it an explanatory burden. Why, if addicts could choose otherwise, do they persist in using (for discussion see Pickard 2016; Pickard and Ahmed, forthcoming)?

Situating addiction within a realistic socio-economic and mental health context is part of the answer to this question. As Gene Heyman puts it:

it is possible that the drug is the best choice when the frame of reference is restricted to the current values of the immediately available options but the worst choice when the frame of reference expands to include future costs.

(Heyman 2013b)

On the whole, drugs bring short-term benefits to people who struggle with lower socio-economic status and mental health problems. Moreover, the costs of use are often long-term rather than immediate, and any future benefits that might accrue from forgoing drugs in the present are both delayed and uncertain. Consider, in this respect, the rewards offered in CM treatment in return for clean urine samples. It is striking that modest monetary incentives, small prizes, vouchers, and lucky dips can motivate abstinence, while the large costs of long-term drug use on their own don't. But, although small, CM rewards are both immediately available and reliably delivered (for further discussion of delay and positive versus negative reinforcement in relation to addiction, see Levy [2013b]). They offer, in other words, a bird in the hand, as opposed to two very flighty birds in the bush. 
In summary, addicts do not lack free will at a time, but their autonomy may be impaired because they struggle to extend their will effectively over time. They are prone to temporal myopia, which is not only characteristic of people who come from underprivileged backgrounds of poor opportunity with additional mental health problems and limited choices, but also intelligible in light of such circumstances. Addicts struggle with many of the worst of life's miseries from which drugs offer temporary escape, with few if any alternative goods on offer. When it comes to addiction, classic compatibilism hits the mark: loss of freedom, in the form of reduced autonomy, resides fundamentally in external constraints. Addicts are oppressed less by inner compulsion than by environmental conditions of psycho-social adversity, poverty, and disadvantage that cause suffering and limit choices, now and in the foreseeable future. For this reason, when addicts make choices that cause harm to themselves and others, we might hold that it is appropriate at least in some cases to excuse them from blame-there are, after all, mitigating circumstances (cf. Pickard 2012, 2015).

\section{Acknowledgments}

I would like to thank Neil Levy and Ian Phillips for very helpful comments on an earlier version of this chapter.

\section{References}

Ahmed, S.H. (2010) "Validation Crisis in Animal Models of Drug Addiction: Beyond Non-Disordered Drug Use Toward Drug Addiction," Neuroscience Biobehavioral Review 35: 172-84.

Alexander, B.K., Coambs, R.B., and Hadaway, P.F. (1978) "The Effect of Housing and Gender On Morphine Self-Administration in Rats," Psychopharmacology 58: 175-9.

Alexander, B.K., Peele, S., Hadaway, P.F., Morse, S.J., Brodsky, A., and Beyerstein, B.L. (1985) "Adult, Infant, and Animal Addiction," in S. Peele (ed.), The Meaning of Addiction, Lexington: Lexington Books, pp. 77-96.

Alvarez, M. (2009) "Actions, Thought-Experiments and the 'Principle of Alternate Possibilities," Australasian Journal of Philosophy 87: 61-81.

Ainslie, G. (2000) “A Research-Based Theory of Addictive Motivation," Law and Philosophy 19: 77-115.

Ainslie, G. (2001) Breakdown of Will. New York: Cambridge University.

American Psychiatric Association (APA) (2013) Diagnostic and Statistical Manual of Mental Disorders, 5th edn. Washington, DC: American Psychiatric Association.

Berridge, K. and Robinson, T. (2011) "Drug Addiction as Incentive Sensitization," in J. Poland and G. Graham (eds), Addiction and Responsibility. Cambridge: MIT Press, pp. 21-53.

Bickel, W.K. and Marsch, L.A. (2001) "Toward a Behavioral Economic Understanding of Drug Dependence: Delay Discounting Processes," Addiction 96: 73-86.

Bickel, W.K., Koffarnus, M.N., Moody, L., and Wilson, A.G. (2014) "The Behavioral- and Neuro-Economic Process of Temporal Discounting: A Candidate Behavioral Marker of Addiction," Neuropharmacology 76: 518-27.

Bozarth, M.A., and Wise, R.A. (1985) "Toxicity Associated with Long-Term Intravenous Heroin and Cocaine Self-Administration in the Rat," JAMA 254: 81-3.

Charland, L. (2002) "Cynthia's Dilemma: Consenting to Heroin Prescription," American Journal of Bioethics 2: 37-47.

Compton, W.M., Thomas, Y.F., Stinson, F.S., and Grant, B.F. (2007) "Prevalence, Correlates, Disability, Comorbidity of DSM-IV Drug Abuse and Dependence in the United States: Results from the National Epidemiologic Survey On Alcohol and Related Conditions," Archives of General Psychiatry 64: 566-76.

Davies, J.B. (1992) The Myth of Addiction. Amsterdam: Harwood Academic Publishers.

Dworkin, S.I., Mirkis, S., and Smith, J.E. (1995) "Response-Dependent Versus Response-Independent Presentation of Cocaine: Differences in the Lethal Effects of the Drug," Psychopharmacology (Berl) $117: 262-6$. 


\section{ADDICTION}

Edwards, G. and Gross, M.M. (1976) “Alcohol Dependence: Provisional Description of a Clinical Syndrome," British Medical Journal 1(6017): 1058-61.

Elliott, C. (2002) "Who Holds the Leash?" American Journal of Bioethics 2: 48.

Fischer, J.M. and Ravizza, M. (1998) Responsibility and Control: A Theory of Moral Responsibility. Cambridge: Cambridge University Press.

Fitch, T.E. and Roberts, D.C. (1993) "The Effects of Dose and Access Restrictions On the Periodicity of Cocaine Self-Administration in the Rat," Drug Alcohol and Dependence 33: 119-28.

Flanagan, O. (2011) "What is it Like to be an Addict?" in J. Poland and G. Graham (eds), Addiction and Responsibility. Cambridge: MIT Press, pp. 269-92.

Flanagan O. (2013) "The Shame of Addiction," Frontiers in Psychiatry 5: 120. doi: 10.3389/fpsyt.2013.00120.

Foddy, B. and Savulescu, J. (2006) "Addiction and Autonomy: Can Addicted People Consent to the Prescription of Their Drug of Addiction?" Bioethics 20: 1-15.

Frankfurt, H. (2003 [1971]) "Freedom of the Will and the Concept of a Person," in G. Watson (ed.), Free Will. Oxford: Oxford University Press, pp. 322-36.

Hacking, I. (1995) Rewriting the Soul: Multiple Personality and the Science of Memory. New Jersey: Princeton University Press.

Hacking, I. (2000) The Social Construction of What. Cambridge: Harvard University Press.

Hackman, D.A., Farah, M.J., and Meaney, M.J. (2010) "Socioeconomic Status and the Brain: Mechanistic Insights from Human and Animal Research," Nature Reviews Neuroscience 11: 651-9.

Hart, C.L., Haney, M., Foltin, R.W., and Fischman, M.W. (2000) "Alternative Reinforcers Differentially Modify Cocaine Self-Administration by Humans," Behavioural Pharmacology 11: 87-91.

Hart, C. (2013) High Price. New York: Harper Collins Publishing.

Haushofer, J. and Fehr, E. (2014) "On the Psychology of Poverty," Science 344: 862-7.

Heyman, G. (2009) Addiction: A Disorder of Choice. Cambridge: Harvard University Press.

Heyman, G. (2013a) Quitting Drugs: Quantitative and Qualitative Features. Annual Review of Clinical Psychology 9: 29-59.

Heyman, G. (2013b) Addiction and Choice: Theory and New Data. Frontiers in Psychiatry 4: 31. doi: $10.3389 /$ fpsyt.2013.00031.

Heyman, G., Dunn, B.J., and Mignone, J. (2014) "Disentangling the Correlates of Drug Use in a Clinic and Community Sample: A Regression Analysis of the Associations Between Drug Use, Years-Of-School, Impulsivity, IQ, Working Memory, and Psychiatric Symptoms," Frontiers in Psychiatry 5: 70. doi: 10.3389/ fpsyt.2014.00070.

Holton, R. (2004) "Rational Resolve," The Philosophical Review 113: 507-35.

Holton, R. and Berridge, K. (2013) "Addiction Between Choice and Compulsion," in N. Levy (ed.), Addiction and Self-Control: Perspectives from Philosophy, Psychology, and Neuroscience. New York: Oxford University Press, pp. 239-68.

James, W. (1890) Principles of Psychology. New York: Henry Holt and Company.

Khantzian, E.J. (1985) "The Self-Medication Hypothesis of Addictive Disorders: Focus On Heroin and Cocaine Dependence," American Journal of Psychiatry 142: 1259-64.

Khantzian, E.J. (1997) "The Self-Medication Hypothesis of Substance Use Disorders: A Reconsideration and Recent Application," Harvard Review of Psychiatry 4: 231-44.

Koob, G.F. and Le Moal, M. (1997) "Drug Abuse: Hedonic Homeostatic Dysregulation," Science 278: $52-58$

Koob, G.F. and Volkow, N.D. (2010) "Neurocircuitry of Addiction," Neuropsychopharmacology 35: 217-38.

Levy, N. (2006) "Autonomy and Addiction," Canadian Journal of Philosophy 36: 427-47.

Levy, N. (2011a) "Addiction and Compulsion," in T. O'Connor and C. Sandis (eds), A Companion to the Philosophy of Action. Oxford: Blackwell, pp. 267-73.

Levy, N. (2011b) "Addiction, Responsibility, and Ego Depletion," in J. Poland and G. Graham (eds), Addiction and Responsibility. Cambridge: MIT Press, pp. 89-111.

Levy, N. (2013a) "Addiction is Not a Brain Disease (and it Matters)," Frontiers in Psychiatry 4: 24. doi: $10.3389 /$ fpsyt.2013.00024.

Levy, N. (2013b). "Punishing the Addict: Reflections on Gene Heyman," in T. A. Nadelhoffer (ed.), The Future of Punishment. New York: Oxford University Press, pp. 233-45.

Mele, A. (1990) "Irresistible Desires," Noûs 24: 455-72.

Mele, A. (2006) "Free Will: Theories, Analysis, and Data," in S. Pockett, W. Banks, and S. Gallagher (eds), Does Consciousness Cause Behavior? Cambridge: MIT Press, pp. 187-205. 
Montague, P.R., Hyman, S.E., and Cohen, J.D. (2004) "Computational Roles for Dopamine in Behavioral Control," Nature 431: 760-7.

Muller, C.P. and Schumann, G. (2011) "Drugs as Instruments: A New Framework for Non-Addictive Psychoactive Drug Use," Behavioural and Brain Sciences 34: 293-310.

National Institute on Drug Abuse (NIDA) (2009) Principles of Drug Addiction Treatment: A Research-Based Guide. Bethesda: National Institute on Drug Abuse.

Peele, S. (1985) The Meaning of Addiction. Lexington: Lexington Books.

Perneger, T.V., Giner, F., Del Rio, M., and Mino, A. (1998) "A Randomised Trial of Heroin Maintenance Programme for Addicts Who Fail in Conventional Drug Treatment," British Medical Journal 317: 13-18.

Petry, N.M., Alessi, S.M., and Rash, C.J. (2011) "Contingency Management Treatment of Drug and Alcohol Use Disorders," in J. Poland and G. Graham (eds), Addiction and Responsibility. Cambridge: MIT Press, pp. 225-45.

Pickard, H. (2012) "The Purpose in Chronic Addiction," American Journal of Bioethics Neuroscience 3: 30-9.

Pickard, H. (2015) "Psychopathology and the Ability to do Otherwise," Philosophy and Phenomenological Research 90: 135-63.

Pickard, H. (2016) "Denial in Addiction," Mind and Language 31: 277-99.

Pickard, H. and Ahmed, S. (forthcoming) "How Do You Know You Have a Drug Problem? The Role of Knowledge of Negative Consequences in Explaining Drug Choice in Humans and Rats," in N. Heather and G. Segal (eds), Addiction and Choice. Oxford: Oxford University Press.

Redish, A.D., Jensen, S., and Johnson, A. (2008) "A Unified Framework for Addiction: Vulnerabilities in the Decision Process," Behavioural Brain Science 31: 415-37.

Satel, S. and Lilienfeld, S.O. (2013) "Addiction and the Brain-Disease Fallacy," Frontiers in Psychiatry 4: 141. doi: $10.3389 /$ fpsyt.2013.00141.

Schultz, W. (2011) "Potential Vulnerabilities of Neuronal Reward, Risk, and Decision Mechanisms to Addictive Drugs," Neuron 69: 603-17.

Sinnott-Armstrong, W., and Pickard, H. (2013) "What is Addiction?" in K.W.M. Fulford, M. Davies, R.T. Gipps, G. Graham, J. Sadler, G. Strangellini, and T. Thornton (eds), The Oxford Handbook of Philosophy of Psychiatry, Oxford: Oxford University Press, pp. 851-64.

Stephens, G.L. and Graham, G. (2009) "An Addictive Lesson: A Case Study in Psychiatry as Cognitive Neuroscience," in M. R. Broome and L. Bortolotti (eds), Psychiatry as Cognitive Neuroscience. Oxford: Oxford University Press, pp. 203-20.

Steward, H. (2009) "Fairness, Agency, and the Flicker of Freedom," Noûs 43: 64-93.

Vandaele, Y., Cantin, L., Serre, F., Vouillac, C., and Ahmed, S.H. (2016) "Choosing Under the Influence: A Drug-Specific Mechanism by Which the Setting Controls Drug Choices in Rats," Neuropsychopharmacology 4: 646-57.

World Health Organisation (WHO) (1992) ICD-10 Classifications of Mental and Behavioural Disorder: Clinical Descriptions and Diagnostic Guidelines. Geneva: World Health Organisation.

World Health Organization (WHO) (2004) Neuroscience of Psychoactive Substance Use and Dependence. Geneva: World Health Organization.

Zernig, G., Kummer, K.K., and Prast, J.M. (2013) "Dyadic Social Interaction as an Alternative Reward to Cocaine," Frontiers in Psychiatry 4: 100. doi: 10.3389/fpsyt.2013.00100.

\section{Further Reading}

Charland, L. (2002) "Cynthia's Dilemma: Consenting to Heroin Prescription," American Journal of Bioethics 2: 37-47. (An empirically-sensitive but strong statement of the view that addicts have no choice or control over consumption.)

Foddy, B. and Savulescu, J. (2006) "Addiction and Autonomy: Can Addicted People Consent to the Prescription of Their Drug of Addiction?" Bioethics 20: 1-15. (A robust reply to Charland's paper "Cynthia's dilemma".)

Frankfurt, H. (2003 [1971]) "Freedom of the Will and the Concept of a Person," in G. Watson (ed.), Free Will. Oxford: Oxford University Press, pp. 322-36. (The classic discussion of The Addict in the free will literature.)

Heyman, G. (2009) Addiction: A Disorder of Choice. Cambridge: Harvard University Press. (A comprehensive analysis of the data indicating that addicts are responsive to incentives-also includes an interesting discussion of aspects of the history of drug consumption.) 


\section{ADDICTION}

Holton, R. and Berridge, K. (2013) “Addiction Between Choice and Compulsion," in N. Levy (ed.), Addiction and Self-Control: Perspectives from Philosophy, Psychology, and Neuroscience. New York: Oxford University Press, pp. 239-68. (An empirically-informed article that does what it says-offers an account of addiction that balances choice and compulsion.)

Levy, N. (2006) "Autonomy and Addiction," Canadian Journal of Philosophy 36: 427-47. (A readable but nuanced discussion of the temporal dynamics of decision-making in addiction.)

Pickard, H. and Ahmed, S. (forthcoming) "How Do You Know You Have a Drug Problem? The Role of Knowledge of Negative Consequences in Explaining Drug Choice in Humans and Rats," in N. Heather and G. Segal (eds), Addiction and Choice. Oxford: Oxford University Press. (Contains an accessible discussion of some of the more striking puzzles to arise from the history of research on animal models of addiction.)

\section{Related Topics}

Semicompatibilism

Identificationist Views

Reasons-Responsive Views

Classical Compatibilism

Willpower, Freedom, and Responsibility

Self-Control and Akrasia 


\section{1 \\ FOLK INTUITIONS \\ Adam Feltz}

Experimental philosophy is a relatively new approach to philosophy that uses some methods of behavioral science to help illuminate some philosophical issues (Feltz 2009; Knobe et al. 2012; Cova and Kitano 2014). ${ }^{1}$ One prominent area of experimental philosophy involves exploring 'folk intuitions' about the 'compatibility question' (Kane 1996; Sommers 2010). ${ }^{2}$ The compatibility question asks 'Is free will and moral responsibility compatible with determinism?' Compatibilists give an affirmative answer whereas incompatibilists give a negative answer. A widely accepted philosophical answer remains elusive and perhaps is not likely forthcoming (Feltz and Cokely 2012). However, one commonly held assumption is that folk intuitions are important evidence for the correct answer (Nahmias et al. 2004, 2005, 2006b; Sommers 2010). A descriptive understanding of folk intuitions does not necessarily solve any theoretical or practical issues. However, a descriptive understanding can put constraints on theories (Gigerenzer 2008). At a minimum, a theory or conceptual analysis of freedom and moral responsibility that is contrary to folk intuitions has an obligation to explain why those intuitions are mistaken - a burden that theories or analyses that are consistent with folk intuitions do not shoulder (Nahmias et al. 2006b). Philosophical theories that postulate conditions for freedom and moral responsibility that are uninformed by the way humans actually are is likely to result in 'philosophical fictions' (Mele 2001). In this spirit, this chapter reviews folk intuitions about the compatibility question from two different approaches. The first section reviews direct assessments of the compatibility question and the second section reviews indirect assessments of the compatibility question.

\section{Directly Assessing the Compatibility Question}

Direct assessments of the compatibility question directly probe people's intuitions about determinism's relation to freedom and moral responsibility. To do this, experimental philosophers typically provide some scenario describing determinism (Nahmias et al. 2005). A description of determinism is used because determinism is a nuanced philosophical concept not likely reflected in everyday thought. Scenarios can transparently capture the central, relevant aspects of determinism. For example, Nichols and Knobe (2007) gave participants the following scenario:

\section{High Affect}

Imagine a universe (Universe A) in which everything that happens is completely caused by whatever happened before it. This is true from the very 
beginning of the universe, so what happened in the beginning of the universe caused what happened next, and so on right up until the present. For example, one day John decided to have French Fries at lunch. Like everything else, this decision was completely caused by what happened before it. So, if everything in this universe was exactly the same up until John made his decision, then it had to happen that John would decide to have French Fries.

In Universe A, a man named Bill has become attracted to his secretary, and he decides that the only way to be with her is to kill his wife and three children. He knows that it is impossible to escape from his house in the event of a fire. Before he leaves on a business trip, he sets up a device in his basement that burns down the house and kills his family.

Nichols and Knobe (2007)

Participants were asked: "Is Bill fully morally responsible for killing his wife?" Seventytwo percent of participants responded "yes" to this direct assessment of compatibility (see also Nichols 2011).

Other theorists have found similar results. For example, Nahmias et al. (2005, 2006b) also gave participants scenarios describing determinism while asking about morally good (e.g., returning a lost necklace), morally neutral (e.g., jogging), or morally bad (e.g., stealing a necklace) actions. In all of their studies, most of the participants (66 to 88 percent) thought that the person was free and morally responsible for acting (Nahmias et al. 2006b). This general effect has been replicated using different descriptions of determinism, different actions, and in different cultures (Feltz et al. 2009, 2012; Sarkissian et al. 2010; Cova et al. 2012; Feltz and Millan 2015).

While it might be tempting to think that folk intuitions support compatibilism, there is a host of factors that can influence people's intuitions. One prominent factor is whether actions are described concretely or abstractly. Concretely described actions provide information about a particular person's action (e.g., paragraph two of High Affect). In the abstract condition, participants are not given concrete, descriptive information about the action (e.g., paragraph two of High Affect is omitted). Rather, in the abstract condition participants are asked if a person could be fully morally responsible in Universe A. In one study, 86 percent of participants did not think that one could be fully morally responsible in Universe A (Nichols and Knobe 2007). The abstract/ concrete difference has been replicated a number of times, using different materials, and cross-culturally (Nahmias et al. 2006a; De Brigard et al. 2009; Nahmias and Murray 2010; Sarkissian et al. 2010; Cova et al. 2012).

There are a number of possible explanations for the concrete/abstract difference. Some accounts focus on explaining the seemingly inconsistent responses as somehow part of people's core concept of free will and moral responsibility. Other accounts hold that some intuitions are distorted or otherwise biased and as a result can on occasion be mistakes. The most prominent account that holds that some of these intuitions are mistakes is the affective performance error model (Nichols and Knobe 2007). According to this model, if people have strong (negative) emotional reactions, they are more likely to have compatibilist intuitions. For example, in High Affect, stalking and raping a stranger is an action that is likely to elicit a strong negative emotional reaction. In the abstract case, there is likely to be little affect generated by simply asking if one could be free and morally responsible in Universe A. To test this hypothesis, Nichols and 
Knobe (2007) created a low-affect scenario that concretely described a man cheating on his taxes. Twenty-three percent of participants responded that the man in the low affect case is fully morally responsible for cheating on his taxes. According to Nichols and Knobe, these results suggest that people's emotional reactions prevent the correct application of their otherwise incompatibilist theory of moral responsibility.

There is tenuous evidence that affect plays a large role in people's intuitions relevant to direct assessments of the compatibility question. Other experiments that used a slightly different methodology did not find the difference between the high and low affect cases (Feltz et al. 2009). Moreover, those with affective deficiencies still had compatibilist responses to High Affect (Cova et al. 2012). A meta-analysis of studies measuring the effect of affect found that while the effect of affect is real, the effect is very small (about 1 percent of the total variance) (Feltz and Cova 2014). This suggests that even if affect can influence some people's judgments, affect is not a very important factor for many people.

Another account relies on the possibility that the abstract and the concrete conditions lead to different understandings of determinism. Nahmias and Murray (2010) stress that determinism should be distinguished from 'bypassing.' Bypassing occurs when one's mental states do not play a role in the production of an action. One can think free will and moral responsibility to be compatible with determinism while thinking that they are incompatible with bypassing. Determinism does not entail that an agent's mental states are bypassed or irrelevant to the production of the action. This distinction could explain why participants judge people not to be morally responsible for their actions in the abstract condition. However, in the concrete condition, it is explicitly stated that the person acts the way he does on the basis of his desires (e.g., he wants to be with his secretary) and beliefs (e.g., he knows that it is impossible to escape from his house in the event of a fire), which would lead participants to understand that people in Universe A are not 'bypassed.' Empirical evidence supports this hypothesis, suggesting that participants are indeed more likely to consider that person's mental states are bypassed in the abstract condition than in the concrete condition (Murray and Nahmias 2014; but see De Brigard and Brady [2013] and Rose and Nichols [2013] for a challenge to the bypassing account).

A third account focuses on the fact that a norm is broken in the concrete but not abstract conditions. According to the Norm Broken, Agent Responsible hypothesis, people are natural incompatibilists (Mandelbaum and Ripley 2012). This natural tendency accounts for participants' answers in the abstract condition. However, people also have the unconscious belief that whenever a norm is broken, an agent is responsible for breaking the norm. In the concrete condition where a norm is broken, this unconscious belief counters our natural tendency to judge free will and moral responsibility to be incompatible with determinism.

Finally, psychological distance could account for the abstract/concrete difference. People tend to have more compatibilist intuitions to the extent that a person is described as being 'psychologically close' spatially or temporally (Roskies and Nichols 2008; Weigel 2011). Perceived psychological distance may influence how one construes the events and results in different sets of processes being triggered. If an event is psychologically distant, people tend to construe the events abstractly. When the events are psychologically close, people construe the events concretely. Similarly, concretely described actions may be construed as more psychologically close than abstractly described actions thereby engaging a different set of psychological processes. Because 
different psychological processes generate intuitions about abstract and concrete actions, none of the intuitions need to be psychologically or conceptually erroneous even if both intuitions cannot be metaphysically true (Sinnott-Armstrong 2008; Weigel 2011). ${ }^{3}$

While all of these studies have dissenting minorities, little effort has been devoted to predicting who have those intuitions. One individual difference that has been consistently related to compatibilist intuitions is the global personality trait extraversion. Extraversion is a member of the Big Five Personality traits and is represented in many contemporary personality inventories (John and Srivastava 1999). An extravert tends to be a "communicative, sociable, energetic person who thrives on social contact and who does not regulate tightly his/her emotional reactions" (Akert and Panter 1988: 966). Extraversion is also correlated with unique socially minded judgment processes, scenario interpretations, and memory retrieval processes (Rusting and Larsen 1997; Lucas and Fujita, 2000; Zelenski and Larsen 2002; Chamorro-Premuzic et al. 2006). A number of studies have found a consistent connection between compatibilist intuitions and extraversion (as measured by a standard personality instrument, for example, the Ten Item Personality Inventory [Gosling et al. 2003]). This relation has been found in standard scenarios such as High Affect (Feltz and Cokely 2008, 2009; Feltz et al. 2012; Feltz 2013; Feltz and Millan 2015), in different cultures (Cokely and Feltz 2009), and even in verified free will experts (Schulz et al. 2011).

The concrete/abstract difference is puzzling because it appears that the same person can have both compatibilist and incompatibilist intuitions (but see Nelkin 2006; Sinnott-Armstrong 2008). An individual differences approach suggests otherwise. Some work indicates that there is remarkable stability in people's intuitions concerning the compatibility question (Feltz et al. 2009). Additionally, the consistent relation of extraversion with compatibilist intuitions suggests that there are stable, predictable differences in people's intuitions. So instead of widespread inconsistent intuitions, only a small number of people may have inconsistent intuitions. To illustrate, take the affective performance error model. The small overall effect of affect may simply reflect the relatively small number of people who are influenced by affect (e.g., the extremely extraverted) (A. Feltz and E.T. Cokely, unpublished data). These results generally caution against inferring any process-level causal mechanism without controlling for individual differences. To do otherwise is to risk describing causal processes that nobody, or very few people, actually have (Cronbach 1957; Feltz and Cokely 2013).

\section{Indirect Assessments of the Compatibility Question}

Some have argued that directly assessing the compatibility question leaves central philosophical elements of the free will debate untouched. Sommers (2010) notes it would be obviously question begging if incompatibilists started with the intuition that the answer to the compatibility question is 'no.' Rather, philosophers of free will typically argue for an answer to the compatibility question. Attempting to answer the compatibility question by directly assessing folk intuitions about freedom and moral responsibility in deterministic worlds thereby misses the important philosophical mark. Hence, there is call for indirect assessments that explore premises in arguments for an answer to the compatibility question.

One indirect assessment of the compatibility question involves folk conceptions or experiences of the ability to do otherwise. Some work suggests that the majority of people (62 percent) describe an account of the ability to do otherwise that is consistent 
with compatibilism ('I could have chosen to do otherwise only if something had been different') and only the minority responded in a way consistent with libertarianism ('I could have chosen to do otherwise even if everything else at the moment of choice had been exactly the same') (Nahmias et al. 2004: 174).

Subsequent work suggests that participants have libertarian conceptions of the ability to do otherwise. For example, when imagining approaching a fork in the path while sledding, participants were asked to rate their agreement with the following sentence: "When deciding which way the sled will go, it feels like I can either go to the left or go to the right." Most participants agreed with the statement. Then participants were 'trained' on determinism - they were given a description of determinism and were required to answer a comprehension question about determinism. After correctly answering the comprehension question, participants were asked whether their response to the original ability question was consistent with determinism. Participants' indicated that their experience of the ability to do otherwise was inconsistent with the description of determinism. This general pattern was replicated in two subsequent experiments and was similar for either imagined or real choices (Deery et al. 2013) and is also found in young children (Nichols 2004).

A second indirect assessment involves Frankfurt-style cases. Frankfurt-style cases have served an important role by providing some evidence that genuinely open alternative possibilities are not necessary for moral responsibility (Frankfurt 1971). Woolfolk et al. (2006) found that a person acting in Frankfurt-like situations was judged to be morally responsible for bad actions if the person identified with the action. Other studies more closely follow Frankfurt-style cases and found that many people think that in some circumstances, a person can be morally responsible even if the person could not have done or prevented anything else than what the person in fact does or does not prevent (Miller and Feltz 2011; Cova 2014).

A final line of research involves manipulation arguments. Those who wish to give an incompatibilist answer to the compatibility question often deploy manipulation arguments. For example, Pereboom (2001) uses a four-case argument to show that some prominent compatibilists' conditions for freedom and moral responsibility (e.g., having one's psychology causally integrated in the right way with the production of the action) are not sufficient for moral responsibility if determinism is true. The first case in the series is one that involves a person whose every decision is directly manipulated by neuroscientists. The second scenario involves neuroscientists programming a person to make all the decisions he does. The third scenario involves a person indoctrinated by his culture to make all the decisions he does. The fourth scenario involves a typical deterministic scenario. Pereboom claims that we should have the intuition that the person is not morally responsible in the first, total manipulation case even if causal integrationist conditions are satisfied. Since there is no relevant difference between the first and the subsequent three cases, one should judge the determined person is not free. That would force an incompatibilist conclusion to the compatibility question.

When given all four scenarios, many people appreciate the difference between a locally manipulated person and a person operating in a deterministic universe. In fact, there is a linear relation of increasing free will and moral responsibility judgments as a function of the 'manipulation' becoming more and more remote (Feltz 2013). This pattern was the same regardless if the manipulation was done intentionally (i.e., by a neuroscientist) or non-intentionally (i.e., by a brain tumor). However, the intentionality of the manipulator also appeared to play in a role in folk intuitions. Overall, many more 
people thought that one is more free and morally responsible when the manipulation was non-intentional compared to when the manipulation was intentional. In fact, the only case where participants judged that a person was not free or morally responsible was when the manipulation was intentional and direct. In all the other scenarios, participants' mean responses indicated that the person was free and morally responsible. This finding suggests that people tend to think that a person can be free and morally responsible across a number of manipulation-like situations. ${ }^{4}$

When one is manipulated, some may think that one is not acting from one's true, deep-seated character and values (Sripada 2012). These are the kinds of mental states that compatibilists think allow freedom and moral responsibility. If a person's mental states (that reflect one's deep self) are not integrated in the right way with the production of the action, then that person is not free. Hence, those who think that the manipulated person acts from the 'deep self' without hindrance or damage are likely to think that a person is free and morally responsible even if manipulated. However, those who think there is some kind of damage or hindrance to the deep self are likely to judge that the person was not free or morally responsible. This pattern of results are just what the compatibilist would predict (McKenna 2008).

\section{Conclusion}

At a minimum, everyday intuitions about the compatibility question are philosophically important. Folk intuitions have been incorporated into mainstream philosophical theorizing or these intuitions have been argued to be not relevant for some philosophical purposes (see for example, Horvarth 2010; Bjornsson and Persson 2013; Gorin 2013). Perhaps surprisingly, intuitions about these abstract, philosophical issues are also likely to be practically important. To illustrate, intuitions about the compatibility question are related to some personality traits (e.g., extraversion). Personality traits are also related to a number of real-world outcomes including health, professional satisfaction, and happiness (Revelle et al. 2011; Cokely et al. 2012). It stands to reason, then, that intuitions about the compatibility question also have real world implications. For example, people appear to have different notions of freedom and moral responsibility. If we attempt to alter some of those people's beliefs, then they may have experiences that are not congruent with their enduring values resulting in lower overall wellbeing. For society, the diversity of beliefs about freedom and moral responsibility may also be good. It seems reasonable that we want to hold some people morally responsible (regardless whether they actually are morally responsible), and some people with strong notions of freedom and moral responsibility will do that. But tempering these strong notions with weaker notions may allow for compassion (Pereboom 2001). Hence, in addition to philosophically important implications, future research will likely reveal that intuitions about the compatibility question are also practically important.

\section{Notes}

1 'Intuition' is a term of art in philosophy (Feltz and Bishop 2010). Here, an intuition is just a response to the types of scenarios described in this paper.

2 Other research has focused on measuring people's beliefs about their own freedom, moral responsibility, the nature of the world, and consequences of those beliefs (Viney et al. 1982, 1984, 1988; Stroessner and Green 1990; Haynes et al. 2003; Vohs and Schooler 2008; Paulhus and Carey 2011; Carey and Paulhus 2013; Nadelhoffer et al. 2014). 


\section{ADAM FELTZ}

3 Evidence about folk intuitions can be put to a number of different philosophical uses including helping illuminate metaphysical truths, conceptual truths, or normative truths (Stich 2010; Feltz and Cokely 2012).

4 Extraversion was related to judgments for those given only the determinism scenario. Emotional stability predicted stronger free will judgments for those given all four scenarios. So, individual differences are likely important for indirect assessments as well.

\section{References}

Akert, R.M. and Panter, A.T. (1988) "Extraversion and the Ability to Decode Nonverbal-Communication," Personality and Individual Differences 9: 965-72.

Bjornsson, G. and Persson, K. (2013) “A Unified Empirical Account of Responsibility Judgments," Philosophy and Phenomenological Research 87: 611-39.

Carey, J.M. and Paulhus, D.L. (2013) "Worldview Implications of Believing in Free Will and/or Determinism: Politics, Morality, and Punitiveness," Journal of Personality 81: 130-41.

Chamorro-Premuzic, T., Furnham, A., and Ackerman, P. L. (2006) "Ability and Personality Correlates of General Knowledge," Personality and Individual Differences 41: 419-29.

Cokely, E.T. and Feltz, A. (2009) "Adaptive Variation in Judgment and Philosophical Intuition Reply," Consciousness and Cognition 18: 356-8.

Cokely, E.T., Galesic, M., Schulz, E., Ghazal, S., and Garcia-Retamero, R. (2012) "Measuring Risk Literacy: The Berlin Numeracy Test," Judgment and Decision Making 7: 25-47.

Cova, F. (2014) "Frankfurt-Style Cases User Manual: Why Frankfurt-Style Enabling Cases Do Not Necessitate Tech Support," Ethical Theory and Moral Practice 17: 505-21.

Cova, F., Bertoux, M., Bourgeois-Gironde, S., and Dubois, B. (2012) "Judgments About Moral Responsibility and Determinism in Patients with Behavioural Variant of Frontotemporal Dementia: Still Compatibilists," Consciousness and Cognition 21: 851-64.

Cova, F. and Kitano, Y. (2014) "Experimental Philosophy and the Compatibility of Free Will and Determinism: A Survey," Annals of the Japan Association for the Philosophy of Science 22: 17-37.

Cronbach, L.J. (1957) "The Two Disciplines of Scientific Psychology," American Psychologist 12: 671-84.

De Brigard, F. and Brady, W. (2013) "The Effect of What We Think May Happen On Our Judgments of Responsibility," Review of Philosophy and Psychology 4: 259-69.

De Brigard, F., Mandelbaum, E., and Ripley, D. (2009) "Responsibility and the Brain Sciences," Ethical Theory and Moral Practice 12: 511-24.

Deery, O., Bedke, M., and Nichols, S. (2013) "Phenomenal Abilities: Incompatibilism and the Experience of Agency," in D. Shoemaker (ed.), Oxford Studies in Agency and Responsibility. Oxford: Oxford University Press, pp. 126-50.

Feltz, A. (2009) "Experimental Philosophy," Analyse and Kritik 31: 201-19.

Feltz, A. (2013) "Pereboom and Premises: Asking The Right Questions in the Experimental Philosophy of Free Will," Consciousness and Cognitio 22: 53-63.

Feltz, A. and Bishop, M. (2010) "The Proper Role of Intuitions in Epistemology," in M. Milkowski and K. Talmont-Kaminiski (eds), Beyond Description: Naturalism and Normativity. London: College Publications, pp. 101-22.

Feltz, A. and Cokely, E.T. (2008) "The Fragmented Folk: More Evidence of Stable Individual Differences in Moral Judgments and Folk Intuitions," in B.C. Love, K. McRae and V.M. Sloutsky (eds), Proceedings of the 30th Annual Conference of the Cognitive Science Society. Austin: Cognitive Science Society, pp. 1771-6.

Feltz, A. and Cokely, E.T. (2009) "Do Judgments About Freedom and Responsibility Depend On Who You Are? Personality Differences in Intuitions About Compatibilism and Incompatibilism," Consciousness and Cognition 18: 342-50.

Feltz, A. and Cokely, E.T. (2012) "The Philosophical Personality Argument," Philosophical Studies 161: 227-46.

Feltz, A. and Cokely, E.T. (2013) "Predicting Philosophical Disagreement," Philosophy Compass 8: 978-89.

Feltz, A. and Cova, F. (2014) "Moral Responsibility and Free Will: A Meta-Analysis," Consciousness and Cognition 30: 234-46.

Feltz, A. and Millan, M. (2015) "An Error Theory for Compatibilist Intuitions," Philosophical Psychology 28: 529-55.

Feltz, A., Cokely, E.T., and Nadelhoffer, T. (2009) "Natural Compatibilism versus Natural Incompatibilism: Back to the Drawing Board," Mind and Language 24: 1-23.

Feltz, A., Perez, A., and Harris, M. (2012) "Free Will, Causes, and Decisions Individual Differences in Written Reports," Journal of Consciousness Studies 19: 166-89. 


\section{FOLK INTUITIONS}

Frankfurt, H. (1971) "Freedom of the Will and the Concept of a Person," The Journal of Philosophy 68: 5-20.

Gigerenzer, G. (2008) "Moral Intuition = Fast and Frugal Heuristic?" in W. Sinnott-Armstrong (ed.), Moral Psychology, Volume 2: The Cognitive Science of Morality: Intuition and Diversity. Cambridge: MIT Press.

Gorin, M. (2013) "What Makes an Intuition a Compatibilist Intuition? A Response to Sripada," Philosophia 41: $1205-15$.

Gosling, S.D., Rentfrow, P.J., and Swann, W.B. (2003) "A Very Brief Measure of the Big-Five Personality Domains," Journal of Research in Personality 37: 504-28.

Haynes, S. D., Rojas, D., and Viney, W. (2003) "Free Will, Determinism, and Punishment," Psychological Reports 93: 1013-21.

Horvarth, J. (2010) "How (not) to react to experimental philosophy," Philosophical Psychology 23: 448-80.

John, O.P. and Srivastava, S. (1999) "The Big-Five Trait Taxonomy History, Measurement, and Theoretical Perspectives," in L.A. Pervin and O.P. John (eds), Handbook of Personality: Theory and Research, 2nd edn. New York: Guildford Press, pp. 102-38.

Kane, R. (1996) The Significance of Free Will. New York: Oxford University Press.

Knobe, J., Buckwalter, W., Nichols, S., Robbins, P., Sarkissian, H., and Sommers, T. (2012) "Experimental Philosophy," Annual Review of Psychology 63: 81-99.

Lucas, R.E. and Fujita, F. (2000) "Factors Influencing the Relation Between Extraversion and Pleasant Affect," Journal of Personality and Social Psychology 79: 1039-56.

Mandelbaum, D. and Ripley, D. (2012) "Explaining the Abstract/Concrete Paradoxes in Moral Psychology: The NBAR Hypothesis," Review of Philosophy and Psychology 3: 351-68.

McKenna, M. (2008) “A Hard-Line Reply to Pereboom's Four-Case Manipulation Argument," Philosophy and Phenomenological Research 77: 142-59.

Mele, A. (2001) "Acting Intentionally: Probing Folk Intuitions," in B. F. Malle, L. J. Moses and D. A. Baldwin (eds), Intentions and Intentionality. Cambridge: MIT Press, pp. 27-43.

Miller, J.S. and Feltz, A. (2011) "Frankfurt and the Folk: An Experimental Investigation of Frankfurt-Style Cases," Consciousness and Cognition 20: 401-14.

Murray, D., and Nahmias, E. (2014) "Explaining Away Incompatibilist Intuitions," Philosophy and Phenomenological Research 88: 434-67.

Nadelhoffer, T., Shepard, J., Nahmias, E., Sripada, C., and Ross, L.T. (2014) "The Free Will Inventory: Measuring Beliefs About Agency and Responsibility," Consciousness and Cognition 25: 27-41.

Nahmias, E., Coates, D.J. and Kvaran, T. (2006a) "Free Will, Moral Responsibility, and Mechanism: Experiments on Folk Intuitions," Philosophy and the Empirical 31: 214-42.

Nahmias, E., Morris, S., Nadelhoffer, T., and Turner, J. (2004) "The Phenomenology of Free Will," Journal of Consciousness Studies 11: 162-79.

Nahmias, E., Morris, S., Nadelhoffer, T., and Turner, J. (2005) "Surveying Freedom: Folk Intuitions About Free Will and Moral Responsibility," Philosophical Psychology 18: 561-84.

Nahmias, E., Morris, S., Nadelhoffer, T., and Turner, J. (2006b) "Is Incompatibilism Intuitive?" Philosophy and Phenomenological Research 73: 28-53.

Nahmias, E. and Murray, D. (2010) "Experimental Philosophy on Free Will: An Error Theory for Incompatibilst Intuitions," in J.A. Aguilar, A. Buckareff and K. Frankish (eds), New Waves in Philosophy of Action. New York: Palgrave Macmillan, pp. 189-215.

Nelkin, D.K. (2006) "Do We Have a Coherent Set of Intuitions About Moral Responsibility?" Philosophy and the Empirical 31: 243-59.

Nichols, S. (2004) "The Folk Psychology of Free Will: Fits and Starts," Mind and Language 19: 473-502.

Nichols, S. (2011) "Experimental Philosophy and the Problem of Free Will," Science 331: 1401-3.

Nichols, S. and Knobe, J. (2007) "Moral Responsibility and Determinism: The Cognitive Science of Folk Intuitions," Noûs 41: 663-85.

Paulhus, D.L. and Carey, J.M. (2011) "The FAD-Plus: Measuring Lay Beliefs Regarding Free Will and Related Constructs," Journal of Personality Assessment 93: 96-104.

Pereboom, D. (2001) Living Without Free Will. Cambridge: Cambridge University Press.

Revelle, W., Wilt, J., and Condon, D. (2011) "Individual Differences and Differential Psychology: A Brief History and Prospect," in T. Chamorro-Premuzic, S. Von Stumm and A. Furnham (eds), The WileyBlackwell Handbook of Individual Differences. Malden: Blackwell, pp. 3-38.

Rose, D. and Nichols, S. (2013) "The Lesson of Bypassing," Review of Philosophy and Psychology 4: 599-619.

Roskies, A. and Nichols, S. (2008) "Bringing Moral Responsibility Down to Earth," Journal of Philosophy 105: 228-47. 
Rusting, C.L. and Larsen, R.J. (1997) "Extraversion, Neuroticism, and Susceptibility to Positive and Negative Affect: A Test of Two Theoretical Models," Personality and Individual Differences 22: 607-12.

Sarkissian, H., Chatterjee, A., De Brigard, F., Knobe, J., Nichols, S., and Sirker, S. (2010) "Is Belief in Free Will a Cultural Universal?" Mind and Language 25: 346-58.

Schulz, E., Cokely, E.T., and Feltz, A. (2011) "Persistent Bias in Expert Judgments About Free Will and Moral Responsibility: A Test of the Expertise Defense," Consciousness and Cognition 20: 1722-31.

Sinnott-Armstrong, W. (2008) "Abstract + Concrete = Paradox?" in J. Knobe and S. Nichols (eds), Experimental Philosophy. Oxford: Oxford University Press, pp. 209-30.

Sommers, T. (2010) "Experimental Philosophy and Free Will," Philosophy Compass 5: 192-212.

Sripada, C. (2012) "What Makes a Manipulated Agent Unfree?" Philosophy and Phenomenological Research 85: 563-93.

Stich, S. (2010) "Experimental Philosophy and the Bankruptcy of 'The Great Tradition.”' Paper presented at the Experimental Philosophy Workshop, Wroclow, Poland.

Stroessner, S.J. and Green, C.W. (1990) "Effects of Belief in Free Will or Determinism on Attitudes toward Punishment and Locus of Control," Journal of Social Psychology 130: 789-99.

Viney, W., Mcintyre, R., and Viney, D.W. (1984) "Validity of a Scale Designed to Measure Beliefs in Free Will and Determinism," Psychological Reports 54: 867-72.

Viney, W., Parkermartin, P., and Dotten, S.D.H. (1988) "Beliefs in Free Will and Determinism and Lack of Relation to Punishment Rationale and Magnitude," Journal of General Psychology 115: 15-23.

Viney, W., Waldman, D.A., and Barchilon, J. (1982) "Attitudes toward Punishment in Relation to Beliefs in Free Will and Determinism," Human Relations 35: 939-49.

Vohs, K.D. and Schooler, J.W. (2008) "The Value of Believing in Free Will - Encouraging A Belief in Determinism Increases Cheating," Psychological Science 19: 49-54.

Weigel, C. (2011) "Distance, Anger, Freedom: An Account of the Role of Abstraction in Compatibilist and Incompatibilist Intuitions," Philosophical Psychology 24: 803-23.

Woolfolk, R.L., Doris, J.M., and Darley, J.M. (2006) "Identification, Situational Constraint, and Social Cognition: Studies in the Attribution of Moral Responsibility," Cognition 100: 283-301.

Zelenski, J.M. and Larsen, R.J. (2002) "Predicting the Future: How Affect-Related Personality Traits Influence Likelihood Judgments of Future Events," Personality and Social Psychology Bulletin 28: 1000-10.

\section{Further Reading}

Feltz, A. and Cokely, E.T. (2009) "Do Judgments About Freedom and Responsibility Depend On Who You Are? Personality Differences in Intuitions About Compatibilism and Incompatibilism," Consciousness and Cognition 18: 342-50. (A good place to start understanding how personality predicts intuitions about freedom and moral responsibility.)

John, O.P. and Srivastava, S. (1999) "The Big-Five Trait Taxonomy History, Measurement, and Theoretical Perspectives," in L.A. Pervin and O.P. John (eds), Handbook of Personality: Theory and Research, 2nd edn. New York: Guildford Press, pp. 102-38. (Gives a general introduction into personality.)

Nadelhoffer, T., Shepard, J., Nahmias, E., Sripada, C., and Ross, L.T. (2014) "The Free Will Inventory: Measuring Beliefs About Agency and Responsibility," Consciousness and Cognition 25: 27-41. (A good introduction and review of people's beliefs about how much freedom they have.)

Nahmias, E., Morris, S., Nadelhoffer, T., and Turner, J. (2004) “The Phenomenology of Free Will," Journal of Consciousness Studies 11: 162-79. (The paper that arguably started the empirical exploration of philosophical intuitions about freedom and moral responsibility.)

Sommers, T. (2012) Relative Justice: Cultural Diversity, Free Will, and Moral Responsibility. Princeton: Princeton University Press. (Gives a sustained argument concerning some implications of the diversity of free will intuitions.)

\section{Related Topics}

Classical Compatibilism

Skeptical Views about Free Will

Neuroscientific Threats to Free Will

Born Free? Children's Intuitions about Choice 


\section{2 \\ BORN FREE? CHILDREN'S INTUITIONS ABOUT CHOICE}

\section{Adam Bear and Paul Bloom}

Certain intuitions about human agency are universal and foundational. There are clashing views over whether free will exists, or whether determinism is compatible with moral responsibility - but nobody doubts that some of our actions are the product of choice and others are accidents. We draw upon this distinction when we assess whether somebody is guilty of a wrongdoing, deserves praise for an accomplishment, or is acting rationally. Our concept of choice figures in more banal aspects of our life as well, as when we reason about our own behaviors. It is hard to imagine what life would be like being unable to tell if our own actions were done on purpose or by accident-unable to appreciate the difference, say, between calling the person you wanted to speak to versus dialing a wrong number.

We explore here the development of this understanding, focusing specifically on the question of whether our understanding of choice is rooted in a first-person experience of agency, or whether it is product of a folk theory of mental life. To explore this, we first review studies that explore children's concepts of choice in other individuals, and then we discuss research that tests children's ability to introspect on their own subjective experience, distinguishing between actions that are chosen versus those that are not. Based on our review, we tentatively conclude that the foundations of our understanding emerge from, or at least are substantially influenced by, a developing folk theory. Phenomenological experience plays less of a role than many would believe.

\section{Children's Intuitions About the Choice of Others}

Young children have some understanding of choice. Nichols (2004) presented children aged 3 to 7 with a number of simple scenarios and asked them about whether an agent or object made a choice or could have done otherwise in these various situations. For example, children were shown a box, which the experimenter slid open. In one condition, the experimenter touched the bottom of the box and asked the child, "After the lid was open, did I have to touch the bottom, or could I have done something else instead?" In the other condition, a ball was dropped to the bottom of the box when the lid was slid open, and the child was asked whether the ball had to touch the bottom, or whether it could have done something else instead. The children answered just as adults 
would, indicating that the agent could have decided not to touch the bottom of the box, but that the ball had to touch the bottom of the box.

Children also understand that choice is limited by physical constraints. In a study by Kushnir et al. (2009), 4-year-old participants were read stories about an agent who desired something that is either physically possible or physically impossible. In one scenario, the actor Mary wanted to either step off a stool and go to the ground or step off the stool and "float in the air and never come down." The children agreed that Mary could go to the ground, but said that she could not float in the air. In another study, children were asked to draw on a piece of paper either a dot or a line. In the condition in which they were asked to draw a line, the experimenter held the children's hand and prevented them from drawing the line, forcing them to draw a dot instead. Children in this condition correctly stated that they could not have drawn a line instead of a dot, whereas those in the unconstrained condition in which they were simply asked to draw a dot correctly agreed that they could have drawn a line instead. Hence, children seem to have a basic understanding of how the laws of physics limit choice for both objects and agents.

Further studies find a subtler appreciation. If 4 -year-olds are told that a certain drawing makes a puppet unhappy, they tend to deny that they could have made that drawing. Likewise, if they are told that everyone else before them has drawn a line, children tend to deny that they could have drawn something else (Chernyak et al. 2010).

These findings are intriguing. On the one hand, they suggest that children have a subtle understanding of how morality and convention constrain choice. On the other hand, these answers are not the same as those that adults would give, suggesting a real developmental difference. That is, adults say that one can commit immoral or unconventional acts, although, usually, one shouldn't. So why do young children say otherwise?

One interpretation of these results is linguistic. All of the studies above test children's intuitions by asking them questions with the English modal auxiliaries 'can' and 'could.' The problem here is that these linguistic constructions can be used to indicate that some action is not physically possible (e.g., 'you can't fly'), but also that some action 'should not' be done (e.g., 'you can't hit your sister'). And so when children respond to certain questions by saying that one can't do a certain thing, they might be construing the question as being about morality, not possibility. This would suggest that they might have a fully mature understanding of choice, appreciating that one can choose to do immoral and unconventional acts, but that they differ from adults in their interpretation of questions.

In support of this account, children do seem to understand how these various constraints differ from each other. Kalish (1998) presented 3- to 4-year-old children with stories describing physical and social violations. For example, one physical violation involved a boy wanting to become a fish, and a social violation involved a boy wanting to play in the snow with no clothes on. Although these children tended to say that an agent could not perform either type of violation, they gave different types of justifications for why they thought that this was the case. For physical violations, the children correctly made reference to physical limitations that made these actions impossible. In contrast, for social violations, the children gave 'reason' justifications, referencing the violation of social rules and the likely negative consequences that would result from these transgressions. These results suggest that, even though children say that agents 'cannot' perform certain actions that violate social norms, they may, in fact, actually 
understand that these behaviors are in some sense possible to perform, but just unwise or immoral. In other words, children may use the modal language of 'can' and 'cannot' slightly differently from the way adults use it, but nevertheless understand at a conceptual level the differences between physical and social violations.

At the same time, though, other findings by Phillips and Bloom (J. Phillips and P. Bloom "Do Children Believe That Immoral Acts Are Magical?" under review) suggest that children really do have a different understanding of choice than adults. In one study, 4- to 7-year-olds and adults were told about impossible acts, such as a boy throwing his hat into the air and the hat transforming into a candy bar; immoral acts, such as a boy stealing a candy bar; and ordinary acts, such as a boy waiting to get home to eat his favorite snack. The question that the subjects were asked didn't involve 'can' or 'could'-it was whether the acts were 'possible' or 'impossible.'

Adults, not surprisingly, said that the physically impossible scenarios were 'impossible' but that the immoral acts were 'possible.' The youngest children tested, however, made no distinction between the two; they were both impossible. (They agreed, however, that the ordinary acts were possible, showing that they understood the question.) A second study asked children and adults for their judgments as to which acts were 'magical.' The finding replicated; once again, the younger children did not distinguish immoral acts from physically impossible acts—-both were described as being magical.

These results support the conclusion that young children really do represent immoral choices as impossible. This finding is particularly striking given that children are likely to have not only witnessed but probably actually performed many of the immoral actions they judged to be impossible (e.g., taking another child's toy, lying to one's parent, being mean to another child).

In summary, young children have a relatively sophisticated understanding of other individual's choices. Not only do they make important distinctions between agents' and objects' capacity to do otherwise, but they appreciate that people's choices are constrained by physical law, and can distinguish between different kinds of constrained and unconstrained actions. At the same time, though, there are interesting developmental differences-children seem to have difficulty appreciating that immoral actions are possible choices, even though they have observed such actions and have engaged in them themselves.

\section{Children's Intuitions About Their Own Choices}

Imagine that as you are walking down the street, someone bumps into you, knocking you over. The woman who did this immediately apologizes; she wasn't looking where she was going, and hadn't meant to collide into you. How can you know if she is telling the truth? To know for sure, you would have to somehow look into her mind at the time of the incident and examine whether, when she hit you, she had a certain kind of conscious experience of agency. Though this experience is hard to pin down, we know that we have it all the time in our day-to-day lives when we choose to move our limbs, type on a keyboard, or engage in conversation with someone. And, when it is missing in cases in which it would normally be present - for example, when our knee moves unexpectedly—we can be sure that we did not intend to do this thing. ${ }^{1}$

This experience of intentionality plays a crucial role in how we, as adults, conceptualize our own choices. But how does it figure in to children's understanding of their mentally guided action? In the theory of mind literature more broadly, researchers have 
debated this issue for a long time. One camp holds that children's understanding of intention (among other mental states) is primarily theory driven and that the child's own experiences play only a subsidiary role in developing a concept of choice (Gopnik and Wellman 1992; Saxe 2005). Others contend that first-person experience of one's own mind is the main source by which children reason about other minds (Goldman 1989; Harris 1992).

In order to help settle this debate in the context of children's understanding of intention and choice, we need to examine the extent to which children incorporate their first-person experience of intentionality into their third-person theory-of-mind judgments. But it is first worth noting that, in other related domains, children have demonstrated marked failures to introspect on and make careful discriminations in their phenomenology. In one classic study, children are presented with a candy box and asked what's in it; they usually say "candy." Then they are shown that it contains pencils. Interestingly, they then claim that they believed that the box had pencils in it all along (Perner et al. 1987; Gopnik and Astington 1988), suggesting that they are not accessing a previous experience of having believed that there was candy in the box just moments before. Other research finds that children do not seem to comprehend that they are thinking most of the time that they are awake, and they often fail to recall what they were thinking about in the recent past, even when the answer is straightforward (Flavell et al. 1995). These findings not only suggest that a third-person folk theory of mind develops prior to first-person introspection, but may even suggest that young children understand their own minds via a third-person theory (see Carruthers 2009).

What about the specific case of children's phenomenology of intentionality? In the earliest study on this topic, Shultz et al. (1980) asked 3- to 7-year-olds to perform a number of tasks that were intentional or unintentional. For instance, children had to select a shiny penny on a table that also had a dull penny on it. In the 'intentional' version, the children picked it up normally. In the 'accidental' version, the children wore distorting glasses that made the shiny penny look as if it were in the location of the dull penny, leading them to pick up the dull penny by mistake. The children were then asked if they meant to perform the action. They did just as well as when they were asked to make judgments about another person's actions, suggesting that, at this age, firstperson phenomenology did not provide any advantage over third-person observation for this simple task that required distinguishing intentional and unintentional action.

Of course, phenomenology may not have been helpful in this case simply because judging intentionality was easy enough to do without the help of conscious experience. However, in a clever follow-up, Shultz et al. (1980) tested how children would fare in making these judgments in cases in which phenomenology plays a more central role. For example, in one case, children were asked to either intentionally move their leg or intentionally try not to move their leg as the experimenter induced a femoral (kneejerk) reflex in them, which they could not prevent from causing their knee to move. Afterwards, children were asked whether they moved their leg on purpose. Surprisingly, the 3- to 4-year-olds were no more likely to answer 'no' when they tried to prevent their leg from moving than when they moved their leg intentionally. Similarly, Lang and Perner (2002) induced a knee-jerk reflex in 3- to 5-year-old American children and found that two-thirds of these children incorrectly judged that they 'meant to' move their leg when, in fact, this movement was clearly elicited by the experimenter. Thus, children at this age seem to struggle to incorporate their experience of intentionality (or lack thereof) into their concept of choice. 
In another set of studies, Montgomery and Lightner (2004) measured 3- to 4-yearolds' ability to distinguish intentional from involuntary movements by asking them whether they 'tried to' draw various pictures. In some cases, drawing was self-guided by the child, while in other cases, an experimenter moved the children's arm as their eyes were closed and drew something completely unexpected. Even when children were asked a forced-choice question about which of the two drawings they tried to draw, they were no more likely to pick the self-initiated drawing than the one that was both passively guided by the experimenter and whose contents were surprising. In conjunction with the knee-jerk findings described above, these results provide compelling evidence that phenomenology does not fully figure in to young children's concept of intention. ${ }^{2}$

It may be the case that young children just, by default, think that most or all of what they do is intentional until they develop a more sophisticated concept of intention that takes their phenomenology into account. It may also be the case that children are actively confusing intention and the related concept of desire. Specifically, they may erroneously think that whenever a desired outcome is achieved, that outcome must have been intended.

This is not a bad heuristic - most of the time, desires and intentions coincide. If you are thirsty and want some water, and you find yourself drinking water, it's an excellent bet that you intended to drink water. But desire and intention are different in a number of respects. You might desire something and yet not form an intention to act upon that desire-one might desire to kiss someone, say, but not intend to kiss that person. And sometimes intentions fail to achieve desires. Consider a baseball player who sees a fastball coming towards home plate and forms an intention to hit the ball and swings his bat-but misses and strikes out. Obviously, the player did not desire this bad outcome even though he intended to swing his bat.

Schult (2002) examined this latter kind of disconnect between intention and desire in 3-to 5-year-olds. Children played a game in which, in several trials, they had to aim and throw a beanbag at one of three buckets. There was a prize in only one randomly selected bucket, and the children did not know ahead of time which of the buckets had the prize. At the beginning of each trial, the children were asked to announce which bucket they would try to hit, and once the beanbag landed in one of the buckets, the experimenter then revealed whether or not the bucket that was hit contained a prize. As a result, there were four possible kinds of trials: the children could (1) hit their intended target, which contained a prize; (2) hit their intended target, which did not contain a prize; (3) hit a non-intended target, which contained a prize; or (4) hit a non-intended target, which did not contain a prize. If children think that achieving a desired outcome implies that they intended that outcome, as Schult (2002) predicted, then they should make systematic errors in situation (3). This is precisely what was found for the 3-year-olds: even though the children in this condition had declared, just moments before, the bucket that they were aiming for and trying to hit, they nevertheless later claimed that they were aiming for a different bucket if it contained a prize.

This task bears certain similarities to the candy-box task discussed earlier, in which children claim to have believed that there were pencils in the candy box all along even though they had actually at first believed that the box contained candy (Perner et al. 1987; Gopnik and Astington 1988). But in this candy task, it is difficult to assess whether children's judgments reflect something interesting about how they represent 
beliefs over time or whether the effects are simply due to lapses in memory. In contrast, memory is unlikely to play an important role in the beanbag task. Whereas young children in this task frequently mistook their intentions if their missed throw happened to yield a prize, they did not, for the most part, answer incorrectly in cases in which they missed their intended target and did not get a prize, suggesting that it is really something about achieving a desired outcome that leads to errors in attributing intention.

We have now reviewed a number of studies suggesting that children do not successfully incorporate a phenomenology of intentionality into their third-person intentionality judgments. But there is a further question left unanswered concerning the nature of children's phenomenology itself. Do children simply have trouble integrating this experience into their intentionality judgments, or is their experience itself different from that of adults?

Little work has explored this question, although one study might be relevant. Metcalfe et al. (2010) had 8- to 10-year-olds and adults play a computer game in which Xs and Os fell from the top of a screen. Participants were tasked with moving the cursor to touch the Xs while avoiding contact with the Os, and these shapes would disappear as soon as they were touched. On some iterations of the game, however, 'magic' was introduced into the game, which made the Xs disappear even when the cursor was close but not directly touching these shapes. In other words, participants gained an undeserved advantage in the game whenever magic was in play. After every 15-second block of this game, participants were asked how 'in control' they felt when playing the game. Whereas adults decreased their ratings of control considerably when magic was introduced into the game, the children did not acknowledge any apparent loss of control. While it's hard to draw a strong conclusion from children's failure to notice a manipulation, it might be that this developmental difference exists becausein line with Schult's (2002) findings - even older children might be more prone to experience a desired result (in this case, making the Xs disappear) as if they intentionally produced it even when they did not.

In our lab, we have begun to explore questions about children's introspective access to their phenomenology. In a set of 40 trials, five circles are presented on a screen in random positions. Five- to 7-year-old participants are asked to choose one of these circles in their head as quickly as they can, and then after either half a second, a second, two seconds, or three seconds, one of these circles, which the computer selects randomly, turns red. The children are first asked whether they had time to make a choice before one of the circles turned red and then, if they say yes, whether the circle that turned red was the one that they chose in their head. If the children are accurately reporting what was taking place in their mind, they should answer 'yes' on approximately 20 percent of the trials in which they indicate that they had time to make a guess before one of the circles turned red since there is a one in five probability that a given circle that was chosen will turn red. In contrast, if they are misrepresenting their mental activities, children may deviate from these chance levels. For example, if they are confusing the circle they actually chose with a desire they have to choose the circle that turns red-as the beanbag study (Schult 2002) might suggest-we should expect the children to be statistically above chance levels at saying they chose the red circle.

Indeed, this is what we find. In particular, there is a strong age effect, with 5-year-olds claiming that they chose the red circle almost all of the time, 6-year-olds saying 'yes' less than the 5-year-olds do but still well above chance, and 7-year-olds answering closest to chance levels. 


\section{Conclusion}

In this chapter, we have explored two facets of children's developing understanding of choice and intention. We have seen that even from a young age, children appear to have a quite sophisticated ability to distinguish constrained from unconstrained actions and delineate various kinds of constraint. But we have seen as well that children differ from adults in certain deep ways, including, perhaps, having a more constrained notion of choice, in which immoral or unconventional choices cannot be done-they are impossible, they are magic. We have seen as well that children struggle to perform seemingly easy tasks that require them to introspect on their phenomenology in order to judge whether they tried to perform some behavior.

In light of these two pieces of evidence, it may be that the adult concept of choice is not primarily derived from first-person experience, but is instead the product of a third-person theory, and it is only later in development that consciousness begins to influence these folk judgments. Nevertheless, much more work is needed to clarify this relationship between phenomenology and third-person theorizing-perhaps explaining how the former becomes integrated into the latter and why an experience of choice is important to our survival at all.

\section{Notes}

1 Two qualifications: first, there are situations in which we ascribe an intention or choice to some action even if there is no accompanying phenomenology. This typically applies to more global kinds of intentions (e.g., intentionally attending college). See Pacherie (2008) for an extended discussion of the different kinds of intention and their relationship to phenomenology. And second, there are some philosophers who are skeptical to varying degrees about the existence of any sort of phenomenology. We are not, but this issue takes us far outside the scope of this chapter; the discussion here is unchanged if one replaces phrases such as 'the experience of making a choice' with 'access to a certain sorts of past mental event.'

2 It is worth noting that young children's struggles to distinguish intentional and involuntary action are not unique to first-person cases. For example, when shown movies of actions that were either intentional or unintentional, 4-year-olds were inclined to judge the unintentional actions as intentional (Smith 1978). Children's failures in these third-person cases may be the result of the first-person failures of introspection that we have discussed, or they may reflect more theoretical failures in understanding the folk concept of intention (see Rosset and Rottman [2014] for extended discussion).

\section{References}

Carruthers, P. (2009) "How We Know Our Own Minds: The Relationship Between Mindreading and Metacognition," Behavioral and Brain Sciences 32: 121-38.

Chernyak, N., Kushnir, T., and Wellman, H.M. (2010) "Developing Notions of Free Will: Preschoolers' Understanding of How Intangible Constraints Bind Their Freedom of Choice," in R. Camtrabone and S. Ohlsson (eds), Proceedings of the 32nd Annual Meeting of the Cognitive Science Society, pp. 2601-6.

Flavell, J.H., Green, F.L., Flavell, E.R., and Harris, P.L. (1995) "Young Children's Knowledge About Thinking," Monographs of the Society for Research in Child Development 60: i, iii, v-vi, 1-113.

Goldman, A.I. (1989) "Interpretation Psychologized," Mind and Language 4: 161-85.

Gopnik, A. and Astington, J.W. (1988) "Children's Understanding of Representational Change and its Relation to the Understanding of False Belief and the Appearance-Reality Distinction," Child Development 59: 26-37.

Gopnik, A. and Wellman, H.M. (1992) "Why the Child's Theory of Mind Really Is a Theory," Mind and Language 7: 145-71.

Harris, P.L. (1992) "From Simulation to Folk Psychology: The Case for Development," Mind and Language 7: 120-44. 
Kalish, C. (1998) "Reasons and Causes: Children's Understanding of Conformity to Social Rules and Physical Laws," Child Development 69: 706-720.

Kushnir, T., Wellman, H. M., and Chernyak, N. (2009) "Preschoolers' Understanding of Freedom of Choice," in N. Taatgen and H. van Rijn (eds), Proceedings of the 31st Annual Meeting of the Cognitive Science Society, pp. 87-92.

Lang, B. and Perner, J. (2002) "Understanding of Intention and False Belief and the Development of Self-Control," British Journal of Developmental Psychology 20: 67-76.

Metcalfe, J., Eich, T.S., and Castel, A.D. (2010) "Metacognition of Agency Across the Lifespan," Cognition 116: 267-82.

Montgomery, D.E. and Lightner, M. (2004) "Children's Developing Understanding of Differences Between Their Own Intentional Action and Passive Movement," British Journal of Developmental Psychology 22: 417-38.

Nichols, S. (2004) "The Folk Psychology of Free Will: Fits and Starts," Mind and Language 19: 473-502.

Pacherie, E. (2008) "The Phenomenology of Action: A Conceptual Framework," Cognition 107: 179-217.

Perner, J., Leekam, S.R., and Wimmer, H. (1987) "Three-Year-Olds' Difficulty with False Belief: The Case for a Conceptual Deficit," British Journal of Developmental Psychology 5: 125-37.

Rosset, E., and Rottman, J. (2014) "The Big 'Whoops!' In the Study of Intentional Behavior: An Appeal for a New Framework in Understanding Human Actions," Journal of Cognition and Culture 14: 27-39.

Saxe, R. (2005) "Against Simulation: The Argument from Error," Trends in Cognitive Sciences 9: 174-9.

Schult, C.A. (2002) "Children's Understanding of the Distinction between Intentions and Desires," Child Development 73: 1727-47.

Shultz, T.R., Wells, D., and Sarda, M. (1980) "Development of the Ability to Distinguish Intended Actions from Mistakes, Reflexes, and Passive Movements," British Journal of Social and Clinical Psychology 19: 301-10.

Smith, M.C. (1978) "Cognizing the Behavior Stream: The Recognition of Intentional Action," Child Development 49: 736-43.

\section{Further Reading}

Cavazzana, A., Begliomini, C., and Bisiacchi, P.S. (2014) "Intentional Binding Effect in Children: Insights from a New Paradigm," Frontiers in Human Neuroscience 8: 651. dx.doi.org/10.3389/fnhum.2014.00651. (Studies suggesting that the strength of 'intentional binding' - whereby the temporal experience of an action and its consequences get shifted toward each other in time-increases over development.)

Chernyak, N., Kushnir, T., Sullivan, K.M., and Wang, Q. (2013) "A Comparison of American and Nepalese Children's Concepts of Freedom of Choice and Social Constraint," Cognitive Science 37: 1343-55. (A cross-cultural exploration of children's judgments of choice.)

Wegner, D.M. (2002) The Illusion of Conscious Will. Cambridge: MIT Press. (An extensively developed adult theory of the experience of agency, similar to the one we discuss for children.)

\section{Related Topics}

Situationism, Social Psychology, and Free Will

Folk Intuitions 


\section{Section V}

\section{FREE WILL AND THEOLOGY}

It has been claimed that "the concept of free will has its origin in Christian thought" (Vierkant et al. 2013: 1). While the initial papers in Section III give us reason to think that this claim isn't true, philosophical reflection on free will certainly has a close affinity with Christian theology. Concerns about the nature and existence of free will, on the one hand, and about the credibility of theistic belief and commitment on the other have long preoccupied philosophers, particularly (though not exclusively) those within the Christian tradition. Furthermore, there is no denying that the history of philosophical inquiry into these two sets of issues has been dynamic and, at least to a significant degree, interconnected.

This interconnection is also true with regard to contemporary philosophical reflection. For much of the twentieth century, theistic philosophy of religion was seen as marginalized by much of the discipline, especially by those working within the Anglo-American philosophical tradition. Since roughly the mid-1970s, however, things have changed dramatically. While there is reason to think that theism is still a significant minority position within philosophy, philosophy of religion plays a larger and more respected role than it used to. To oversimplify what is a rather complex history, Alvin Plantinga's work on the logical problem of evil can be seen as indicative of, and perhaps a catalyst for, a major shift. Plantinga presented a defense, as opposed to a theodicy, in response to the logical problem of evil. At the heart of Plantinga's defense is an appeal to the possible existence and value of free will (as understood by libertarians) as a justifying reason for God's permission of evil. The bare possibility of libertarian free will, Plantinga has argued, can be used to establish the broadly logical compatibility of God and evil. While some scholars think that Plantinga's defense is not ultimately successful, it is fairly common to claim his work as decisive in responding to the logical problem of evil, opening again the door for the rationality of religious belief. Consider, for instance, these words from William Rowe, himself an atheist:

Some philosophers have contended that the existence of evil is logically inconsistent with the existence of the theistic God. No one, I think, has succeeded in establishing such an extravagant claim. Indeed, granted incompatibilism, there is a fairly compelling argument for the view that the existence of evil is logically consistent with the existence of the theistic God.

(Rowe 2009: 253, note 1) 
The past four decades have seen an explosion of interest in the relationship between philosophical debates about the nature of free will and related theological disputes. (This increase has been most prominently developed within a Christian theological framework, but the increase is also visible within Jewish and Islamic frameworks, and even - though to a lesser degree-within eastern religious traditions.)

Attention to the logical problem of evil has, in many ways, now been usurped by the burgeoning literature on the evidential problem of evil and the problem of divine hiddenness. But replies to these problems on behalf of theistic belief also typically make essential appeals to the value and nature of free will. Furthermore, considerations of free will have played an important role in philosophical reflection on a number of other central topics in theology and the philosophy of religion, including the divine attributes, theories of eschatology, the nature of divine action, and the contours of divine providence. It is worth noting that, although libertarianism appears to be a minority view in the discipline of philosophy writ large, philosophers working in these areas of expansion (on topics at the intersection of free will and theology) tend disproportionately toward libertarianism. (For more on this, see Speak and Timpe 2016.) One important, although certainly not the only, explanation for the libertarian shift within this domain of inquiry is likely to involve the extraordinarily robust conceptions of responsibility that have typically accompanied theistic worldviews-conceptions of responsibility, for example, that might be needed to justify eternal damnation in hell. Here one thinks of Strawson's definition of 'true moral responsibility' as

responsibility of such a kind that, if we have it, then it makes sense, at least, to suppose that it could be just to punish some of us with (eternal) torment in hell and reward others with (eternal) bliss in heaven.

(Strawson 1994: 9)

The papers in this section reflect the above brief historical survey. (They also reflect the Christian-centric nature of current philosophy of religion mentioned earlier.) The section begins with a chapter on the relationship between free will and the problemor, more accurately, problems - of evil. Historically, the treatment of the problem of evil is particularly challenging for those who endorse theological determinism. As with the discussions of compatibilism more broadly, in these issues the compatibility or lack thereof of freedom with certain kinds of necessitation is central. Even if one rejects theological determinism, traditional forms of Western monotheism have also asserted God's providential control of creation. How that doctrine relates to free will depends not only on how strong the doctrine of providence is but also on the understanding of creaturely free will at work. Although the kind of necessitation involved in divine knowledge need not commit one to theological determinism, the factive nature of divine omniscience that traditionally goes by the name theological fatalism also raises a potential threat to free will. The concern of theological fatalism is an instance of a larger argumentative pattern that David Hunt calls an 'incompatibility argument': an argument showing that a certain fact about God or about God's attributes is incompatible with a particular view of free will. Though other incompatibility arguments are not explicitly considered here, one can find them focused on other divine attributes besides omniscience.

The next two papers in the section relate to theological accounts of human nature. The first of these explores the connections between human freedom and human nature; 
more specifically, it explores whether libertarianism regarding free will or substance dualism regarding human persons requires the other, and what role belief in teleological explanation plays in motivating both. The second explores the historically rich intersection of human freedom and theological reflection on grace. The final chapter in this section focuses not on human freedom but on divine free will. Here one encounters not only the importance of how we construe the nature of divine freedom, but also another form of incompatibility argument-one that seeks to pit one divine attribute against another. How does God's perfect freedom relate to his moral perfection and his omnipotence?

K.T.

\section{References}

Rowe, W. (2009) "The Problem of Evil and Some Varieties of Atheism," in K. Timpe (ed.), Arguing About Religion. New York: Routledge, pp. 246-54.

Speak, D. and Timpe, K. (2016) "Introduction," in K. Timpe and D. Speak (eds), Free Will and Theism: Connections, Contingencies, and Concerns. Oxford: Oxford University Press, pp. 1-26.

Strawson, G. (1994). "The Impossibility of Moral Responsibility," Philosophical Studies 75: 5-24.

Vierkant, T., Kiverstein, J., and Clark, A. (2013) "Decomposing the Will: Meeting the Zombie Challenge," in A. Clark, J. Kiverstein, and T. Vierkant (eds), Decomposing the Will. Oxford: Oxford University Press, pp. 1-30. 
$\because$ Taylor \& Francis Taylor \& Francis Group http://taylorandfrancis.com 


\section{3 \\ FREE WILL AND THE PROBLEM OF EVIL \\ Daniel Speak}

Two platitudes animate this chapter. The first is that the problem of evil is a central preoccupation of philosophers, and especially of philosophers of religion. The second is that any serious effort to address the problem of evil invites quite fundamental reflection upon the nature and value of free will. Less platitudinously, the recent debate over the problem of evil has done almost as much to stoke interest in and consideration of the contours of human agency as have any of the intrinsically intriguing elements of the contemporary free will discussion. The problem of evil, for good or ill, is a driving force in the free will debate.

My goal in this chapter is to provide some explanation for this fact and introduce a few of the delicate issues regarding free will that are continuing to emerge from debate over the problem of evil. Of special interest, as the unfolding story will explain shortly, is the fact that theistic responses to the problem of evil have provoked substantial interest in the viability of libertarianism about free will. I will conclude, therefore-although all too briefly-by considering the controversial possibility of a viable compatibilist response to the problem of evil.

\section{Mackie and Free Will}

Though something properly considered the problem of evil has been faced by philosophers and theologians for millennia, the contemporary issues can reasonably be seen to have taken shape around the middle of the last century. In fact, it isn't completely arbitrary to identify the publication in 1955 of J.L. Mackie's influential paper "Evil and Omnipotence" as the first volley in the contemporary debate. In it, Mackie argued that the set of propositions endorsed by traditional theists cannot all reasonably be thought to be true together. He purported, in short, to detect something like a formal inconsistency in theistic belief with respect to the facts of evil. Setting aside, for now, the dramatic conclusion of Mackie's argument (namely, that the theist essentially contradicts herself), his paper sparked a deeply influential discussion and gave important initial shape to the issues that all parties to it have more or less respected ever since. This is to say that Mackie's approach largely set the argumentative terms for the ongoing debate. In particular, Mackie's paper formalized the idea that the contemporary debate over the problem of evil was largely to be a polemical one.

What I mean is that prior to Mackie, the problem was less a matter of the plausibility of atheism and more an explanatory challenge internal to theism. In Leibniz's Theodicy, 
for example, and even in Hume's Dialogues Concerning Natural Religion (I claim), the existence of evil is treated largely as a call to theistic philosophers and theologians to close an explanatory gap by providing an account of God's reasons for causing or permitting it. I do not mean to suggest that no atheistically inclined thinkers prior to Mackie had thought of evil as something like compelling evidence for the claim that God does not exist. Surely many of them (including Hume) did. My point is rather that Mackie's article in some sense formalized the contemporary idea that evil is a problem principally because it can provide a philosophical fulcrum for explicit arguments against the claim that God exists. From Mackie onward, to raise the problem of evil is first and foremost to raise an objection to the rationality of theistic belief.

Another crucial contribution of Mackie's article was that it put questions of human agency front and center by challenging the intuitive claim that God can be given moral cover for allowing the world's horrors by virtue of creating human beings with free will. Mackie was, of course, well aware of the long tradition among theists of appealing to human free will in this context. Nevertheless, in perhaps the most widely treated section of Mackie's paper, he argues that this appeal does not really help with the problem. He characterizes the appeal to free will, in fact, as one among a wider set of "fallacious solutions" to the problem as he raises it. The explanation of the fallaciousness is, in my view, a bit quick and heavy-handed but there is no question that something substantive can be found beneath the complaint here. In particular, Mackie makes two related points about the appeal to free will that have functioned as the throwing down of a philosophical gauntlet.

Famously, and as what can appear to be a throw-away line, Mackie begins his attack on a free will response to his problem in this way: "I think that this solution is unsatisfactory primarily because of the incoherence of the notion of freedom of the will: but I cannot discuss this topic adequately here, although some of my criticisms will touch upon it" (1955: 209). Now, you might think that a philosopher who takes himself to have grounds for thinking that the view he is targeting is incoherent might give quite serious and sustained attention to revealing the inconsistency. Instead we are left to work out the putative inconsistency for ourselves. He does leave us some clues, however. Piecing them together, it seems that Mackie takes something like libertarianism about free will to entail irresolvable difficulties. According to libertarianism, recall, free will is incompatible with thoroughgoing determinism. That is, the libertarian insists that although (normal adult) human beings do enjoy free will, they would not enjoy it if determinism were true. The libertarian is, therefore, committed to the view that determinism is false. The incoherence of this view appears to emerge from the fact that the undetermined nature of the supposedly free actions would be inconsistent with control. To be undetermined, Mackie seems to think, is to be random. But random events are under no one's control. So libertarianism is committed to an inconsistency by virtue of insisting that freely willed actions are indeterministically controlled by the agent; indeterministic control being something like an oxymoron. It isn't hard to get into the spirit of this kind of concern by putting on our Humean hats-and keep in mind that Mackie, like many of the Anglo-American philosophers of his day, was sporting his Humean hat quite proudly. Furthermore, we should recognize that this kind of reasoning continues to animate various aspects of the current debate in the form of more carefully worked out versions of luck and randomness objections to libertarianism (See van Inwagen 2000 and Mele 2006. For replies, see Griffith 2005, Vargas 2012, and Speak 2011). 
Mackie's second claim about the fallaciousness of the free will response to his problem is slightly more developed. Here he contends that a being with God's knowledge and power would be able to bring into existence a world in which human beings genuinely enjoy free will and yet also use this freedom only to do what is good and right. Why think this, you ask? Good question. It is because it is obvious that there is nothing logically problematic about a world containing free beings who always choose to act rightly. "If there is no logical impossibility in a man's freely choosing the good on one, or on several, occasions, there cannot be a logical impossibility in his freely choosing the good on every occasion" (1955: 209). And we can suppose that if there is no logical impossibility in one free person always choosing well, then there is no logical impossibility in a whole world of people doing so as well. But the only limitations on God could be logical ones; and, thus, God must be thought to be able to do whatever is logically possible. By this kind of reasoning (that I have made a bit more explicit, I think, than Mackie himself did), we get the big conclusion that God could have created a world with free beings who always act well.

God was not, then, faced with a choice between making innocent automata and making beings who, in acting freely, would sometimes go wrong: there was open to him the obviously better possibility of making beings who would act freely but always go right. Clearly, his failure to avail himself of this possibility is inconsistent with his being both omnipotent and wholly good.

(1955: 209)

Tempting as it is to begin assessing Mackie's claims, let's postpone this for now, because it will be worth our time to turn first to some of the wider philosophical repercussions of his article, especially as they relate to matters of free will. In important respects, the crucial work on the problem of evil by John Hick and Alvin Plantinga, much of it explicitly aimed at responding to Mackie, laid the groundwork for what might rightly be considered the theistic obsession with libertarianism during the last half of the twentieth century and the first few decades of the twenty-first.

\section{Hick, Free Will, and Theodicy}

In his influential monograph Evil and the God of Love, published initially in 1966, John Hick proposed what he called "A Theodicy for Today." Taking his leave from the dominant Augustinian impulses that had driven theistic approaches to the problem of evil for more than a millennium, Hick purported to find in Irenaeus the seeds of a distinctively contemporary response. What characterizes Augustinian theodicy, according to Hick, is an emphasis on something like an historical fall of human beings from grace by way of a bad use of free will. In some respect, the Augustinian is committed to the view that the world's evils are principally, or at least substantially, a consequence of human fallenness, understood fairly traditionally in terms of the Judeo-Christian account of the errors of the first human beings. The need for an updated theodicy, from Hick's point of view, was largely a function of the fact that the Augustinian anthropology seemed to be running pretty obviously up against the story of human emergence and evolution being told by the best science. It was becoming increasingly implausible to suppose that human beings had some initial set of ancestors who began their lives with the kind of developed rationality and understanding that the biblical account attributes 
to Adam and Eve. Without this plausibility, however, the Augustinian response to the problem of evil would appear to be in serious trouble. By contrast, Hick's Irenaean approach emphasized instead an anthropology compatible with the modern scientific story of human beings as products of a long slow process of evolution. In particular, Hick claimed to find in Irenaeus' thought at least the hint of a picture of God's plans for humanity beginning with immature and undeveloped creatures who are brought collectively to maturity over time. Hick took this hint and developed what he called a "soul-making" theodicy according to which the principle reason that God permits the world's evils is that they are necessary features of an environment conducive to the kind of moral and spiritual development that God is attempting to cultivate in human beings (and perhaps more widely in creation). The idea is, then, that just as the moral development of individuals seems to require various kinds of resistance and challenge, so also does the wider moral progress of humanity taken as a whole. Furthermore, since the developmental process that evil makes possible is so extraordinarily valuable, God is justified in permitting the admittedly sad conditions in which we find ourselves.

With this shockingly terse picture of Hick's theodicy before us, two points need to be developed-one about the nature of 'theodicy' and another about the role of free will in Hick's account. First, about theodicy. What did Hick take himself to be doing in offering his "Theodicy for Today?" It seems that he intended to show that, despite the existence of evil in all of its actual forms, it is nevertheless rational to believe that God (understood more or less in the standard way) exists because it is plausible that God has a morally sufficient reason for permitting these evils. In fact, this gives us a glimpse into the project of theodicy more generally. In contemporary philosophy of religion, a theodicy is taken to be an effort to show how it is reasonable to believe that the evils of the world are justly permitted by a maximally good and powerful being. We will contrast this with the project of 'defense' shortly.

And now about the role of free will in Hick's theodicy. At the heart of Hick's soul-making account is a deep commitment to libertarian free will. This commitment arises from an attractive axiological idea. Making this explicit, Hick admits that

[t]he value-judgment that is implicitly being invoked here is that one who has attained to goodness by meeting and eventually mastering temptations, and thus by rightly making responsible choices in concrete situations, is good in a richer and more valuable sense than would be one created ab initio in a state of either innocence or virtue.

So the personal and collective development that Hick's theodicy prizes requires the real possibility of moral failure. And it is for this reason that it "is not taking place . . by a natural and inevitable evolution, but through a hazardous adventure in individual freedom" (1978: 256).

Hick was quite well aware of Mackie's argument for the incoherence of theism and of his complaints about the viability of an appeal to free will in response to it. Nevertheless, Hick explicitly built a libertarian conception of free will into his soul-making theodicy. In an interesting way, Hick conceded a central point to Mackie but went on to develop a nuanced reply. Recall that Mackie had insisted that God should have been able to bring about a world in which human beings were free but in which they always 
made good choices. Somewhat surprisingly, Hick grants this point. What he denies is the conclusion that Mackie draws from it; namely, that maximally powerful absolute goodness would have availed itself of this option. This is because Hick allows that the compatibilist brand of free will that Mackie has in mind (roughly, one according to which an action is free as long as it flows from the agent's own will, never mind how the agent came to have that will) can perhaps give us much of what we want with respect to our moral actions toward one another-but we want even more than this. Or, better, it is plausible to suppose that God would want more than this for us. This is because God would want our responses to divine love and direction also to be without contrivance. Thus, Hick asks in response to Mackie, "[i]s it logically possible for God so to make men that they will freely respond to Himself in love and trust and faith?" (1978: 258). And it is to this question that he is prepared to answer no. Hick's considered view seems to be, then, that both the highest form of interpersonal morality and authentic relationship between creature and creator require that creatures enjoy a libertarian brand of free will. Admittedly, Hick does little to defend the plausibility of the claim that human beings actually enjoy such freedom, conceding, even, that "it may be that it cannot be independently established by philosophical analysis" (1978: 277). The best Hick does in supporting his controversial account of free will, on my view, he does by pointing to C.A. Campbell's On Selfhood and Godhood (1957) as "[t]he fullest and most adequate exposition and defence" of the conception he takes himself to be deploying (1978: 276). Be this as it may, Hick's theodicy substantially stands or falls with the case (both metaphysical and axiological) for libertarian free will (for more recent efforts at positive theodicy that also depend substantially on a libertarian account of free will, see Swinburne [1998] and Stump [2010]).

\section{Plantinga, Free Will, and Defense}

Not long after Hick's book had made its first waves, Alvin Plantinga's groundbreaking The Nature of Necessity was published (1974). As a seminal contribution to the metaphysics of modality, its influence has reached long beyond the philosophy of religion. However, Plantinga took the opportunity in the later chapters of this book to apply his insights regarding modality to some live issues in the philosophy of religion. In particular, in chapter IX, he formulated what has become the canonical version of the most influential response to the challenge for theistic belief posed by Mackie's argument. His extraordinarily influential "Free Will Defense" put libertarianism on center stage. Many of the complex details of Plantinga's argument aren't needed for our purposes here. What will be worth emphasizing, however, is the nature of defense as Plantinga conceived of it and the crucial role of a libertarian conception of free will in his overall argument.

Plantinga insisted that the theist need not offer a theodicy in response to an argument from evil for atheism. A theodicy is, after all, a serious philosophical enterprise, since it involves defending at least to the level of plausibility some morally sufficient reason God has to permit all of the world's evils. Plantinga, however, took notice of the fact that offering a theodicy is more than is demanded of the theist in response to an argument such as Mackie's. Mackie had argued that the central theistic propositions (that God exists, is omnipotent and omnibenevolent, and that evil exists) form an inconsistent set. It is not possible, Mackie claimed, for all of them to be true at the same time. As a result, Plantinga insisted, it would be enough for the rationality of theistic belief if the theist could show that Mackie's argument had not succeeded. It would be 
enough, that is, if the theist could show the mere (broadly logical or metaphysical) possibility of all of the theistic propositions being true together. This is what Plantinga meant by a defense-an effort to show not what God's good reasons for allowing evils are plausibly supposed to be but rather (and only) that there is no formal inconsistency among the propositions endorsed by the theist. To affect his defense, Plantinga aims to show that there is a proposition the theist might accept (describing a state of affairs that is broadly logically possible) that, when combined with the standard theistic beliefs, entails that evil exists. If he can succeed in this project, then he will have shown that, strictly speaking, the set of standard theistic beliefs is not, contrary to Mackie's claims, inconsistent with the existence of evil.

The proposition that Plantinga uses to make his defense work is something like this:

(P) human free will is extremely valuable and God was not able to insure a world containing human free will (and all the goods contingent upon it) without also allowing a world containing evil.

Notice that, given the goals of a defense, Plantinga does not need to show that $(\mathrm{P})$ is true. He doesn't need to show even that it is plausibly thought true. All he needs to show is that it is possibly true. For if $(\mathrm{P})$ is so much as possibly true, then Mackie's claim that that there is a formal inconsistency among the propositions that the traditional theist accepts is flatly false.

To demonstrate that $(\mathrm{P})$ is possibly true, Plantinga invokes a libertarian conception of free will. Now, take note of the fact that $(\mathrm{P})$ has both a divine value component and a divine power component. With respect to the first, the defense requires that it is at least possible that God places an extremely high value on libertarian free will and/or the goods contingent upon it. With respect to the second, the defense requires that it is at least possible that not even an omnipotent being can insure a world containing beings with libertarian free will and no evil. To be fair, Plantinga does little with regard to the value point beyond appealing to the intuitive idea that free will is necessary for deep reciprocal love and robust moral responsibility. Again, however, perhaps nothing more is needed, since the argument requires only that it is possible that $(\mathrm{P})$ is true. The real challenge, Plantinga seemed to think, was with the divine power component. After all, Mackie had suggested in his argument that there is no logical incoherence in the concept of a world containing libertarian free creatures who always use their freedom to do what is good. Importantly, Plantinga does not challenge this claim. Instead, Plantinga challenges an implicit assumption of Mackie's reasoning here: namely, the assumption that an omnipotent being can bring about any logically possible world (an arguably false assumption that Plantinga calls "Leibniz Lapse"). Assuming libertarianism-and some auxiliary propositions that would seem to have just as good a claim on being possibly true-Plantinga argues that God may not have been able to guarantee a world without evil because it may be that actualizing a world containing robustly free creatures will have to be an essentially cooperative enterprise between God and these free creatures. As libertarian free creatures, God cannot simply make them act well, since that would undermine their freedom. And while such creatures might have chosen freely only to act well - there being a possible world in which they do nothing wrong - there might nevertheless have been nothing God could have done, consistent with their free will, to insure that they would act well. In a nutshell, Plantinga's claim is that, granting libertarianism, even an omnipotent being may not be able to actualize just any possible 
world it wants. The conclusion would seem to be that the theist can defend herself against Mackie's attack by way of an appeal to libertarian free will.

\section{Compatibilism and Defense}

The unfolding philosophical dialectic I have very briefly described, beginning with Mackie and running through Hick and Plantinga, may explain what might otherwise be a puzzling sociological fact regarding contemporary philosophers. According to a recent respectable survey of professional philosophers, those inclined toward theism are also strikingly more inclined toward libertarianism than are their non-theistic counterparts (http://philpapers.org/surveys/results.pl; accessed 28 June 2016). Given the role that the invocation of libertarianism has played in the most influential responses to the polemical versions of the problem of evil through the last third of the twentieth century (and beyond), the survey results should be substantially less surprising. In fact, a deflationary or debunking interpretation of this phenomenon may be tempting. Put somewhat indelicately, it is possible to interpret this data in such a way as to cast doubt on the epistemic or broadly philosophical sincerity of theists with respect to questions of human free will. Perhaps, that is, we should worry that theistic libertarians have reached their conclusions about free will only to give themselves apologetic cover with respect to the problem of evil (Vargas 2016). I will set aside consideration of this kind of argument here, noting only that a parallel judgment might be rendered with respect to the corresponding sociological result that philosophers inclined toward atheism decisively favor compatibilism over libertarianism.

Granting that theistic attraction to libertarianism is philosophically legitimate, we can still wonder if there is as tight a connection as has traditionally been supposed between incompatibilism and any marginally satisfying theistic response to the problem of evil. We might ask, for example, if a compelling theodicy will have to appeal to libertarianism. For reasons of space (and also by virtue of the popularity of the view that the theist does not need a theodicy), I will ignore this question but try to address the closely related question regarding defense. More precisely, we can consider whether there can be a compelling compatibilist free will defense.

Since the initial appearance of Plantinga's formal defense, a number of philosophers have attempted to argue that a similar defense could be launched without invoking libertarianism (Bishop 1993; Howesepian 2007). However, Jason Turner has recently made a particularly clear and illuminating case for the claim that there can indeed be a compatibilist free will defense (2013). Considering Turner's argument will give me a chance not only to highlight some important issues that lie at the heart of the contemporary free will debate but will also allow me to make what I take to be an important and heretofore unnoticed point about the nature of defense.

Let's begin with the intuitive idea animating resistance to the possibility of a compatibilist free will defense. As Turner notes, it appears to be something like this. If we suppose that free will is compatible with thoroughgoing determination, then it will seem that an omnipotent and omniscient being will be able to establish the initial conditions of a world in such a way as to insure (by way of determinism) that creatures always act rightly while also meeting compatibilist conditions for freedom and responsibility. In other words, God should be able to bring about the very world that Mackie insisted God should bring about - namely, one in which human beings are free but never do anything wrong or bad (call this a 'Mackie world'). Here Turner concedes that many accounts of 
compatibilism will indeed have the consequence that God should be able to get a Mackie world. He takes particular notice of this consequence for Harry Frankfurt's famous account of compatibilist free agency developed in terms of proper fit within an agent's motivational structure between higher and lower order desires. This point can surely be extended to apply to related influential mesh accounts of free agency (Watson 2004). The same point can be made, I boldly assert without evidence here, with respect to the reasons-responsiveness accounts of responsible agency developed by John Martin Fischer and Mark Ravizza (1998), among others (Vargas 2013). Given determinism and divine power, there seems no reason to think that God should have had any special problem getting agents who never do anything wrong but who are also free and/or responsible by the light of each of these important compatibilist accounts. Turner's strategy is to develop a broadly compatibilist account of free will that does not appear to allow God to insure a Mackie world, thereby demonstrating that it is possible to offer a defense in response to Mackie's argument that does not depend upon libertarianism.

To appreciate Turner's strategy, it helps to take note of the susceptibility of compatibilist accounts of free will to manipulation counterarguments (Mele 2006, 184-95). In a manipulation counterargument, the critic of compatibilism constructs a case wherein some powerful (and generally nefarious) manipulator is able to control another agent, perhaps by tinkering directly with her neurology or perhaps, less proximally, by tinkering with her early zygote, so as to bring it about that the agent does precisely as the manipulator wants at some later time. The proponent of a manipulation argument thus attempts to illicit the intuition that the agent does not perform the manipulated action freely or responsibly, even though the agent meets the contested compatibilist conditions for freedom (having a proper fit between higher and lower order desires, for example, or acting from a properly reasons-responsive mechanism, etc.). Finally, the proponent insists that there is no relevant difference between the action performed by the manipulated agent and any action performed by a determined agent. Thus, the manipulation arguer concludes, free agency is not compatible with determinism.

The compatibilist, of course, has a number of different open lines of reply. For Turner's purposes, the most important of these is the historical maneuver. According to historical compatibilists, it matters how an agent came to have the mental states constituting (or substantially underwriting) her action. Here Turner suggests that the historical compatibilist might accept that there is an important difference between manipulated and determined agents. The manipulated agent's action depends on the manipulator's choice whereas the merely determined agent's action does not. Plausibly, Turner claims, the compatibilist can insist that having one's action depend on the choice of another agent is what undercuts freedom. In other words, the compatibilist might accept:

Independence. If S's arranging matters in way w would result in T's being causally determined to $\mathrm{A}$, and if $\mathrm{S}$ knows this and arranges matters in way $\mathrm{w}$ in order to get $\mathrm{T}$ to $\mathrm{A}$, then $\mathrm{T}$ does not freely $\mathrm{A}$.

(Turner 2013: 130)

What this form of independent compatibilism emphasizes, then, is that it is the dependence of the manipulated agent on the manipulator (and not the determinism simpliciter) that functions to undermine free agency.

Now for the independent compatibilist free will defense. If free will is compatible with determinism but not with dependence, then God can create a world with free 
and determined creatures; but God has to be careful here. For, if God creates the initial conditions of a deterministic world in such a way as to bring it about that future agents behave in a certain way, then those future agents will not be free-because the independence principle will have been violated. So creating a deterministic world with free creatures would seem to require either that God not know about the ways that the initial conditions will result in future creaturely action or that God not arrange those conditions in order to get creatures to act in a certain way. Either way, however, there is room for the epistemic possibility that, because of God's efforts to respect the independence principle, some evil will have to "slip in through the cracks" (2013: 131).

My considered judgment is that there is nothing transparently incoherent in the account of independent compatibilism that Turner has sketched. Furthermore, I will concede that a successful free will defense (of a certain sort) against Mackie's initial argument can be launched from the foundation of independent compatibilism. In essence, then, I am conceding that there can in fact be a compatibilist free will defense. And this is a point not to be brushed by too quickly. For, again, it has widely been thought that libertarianism will have to be invoked by any successful free will defense. I will now violate my own admonition and brush by this point far too quickly. For with this (admittedly substantial) concession made to Turner, I would like to defend the importance of libertarianism for the free will defense nevertheless.

To do this, allow me to draw a distinction between a divested and an invested defense. In a defense, as we have seen, the defender proffers a set of propositions the theist could accept that, taken together with the standard theistic propositions, entail that evil exists. And by doing so, the defender demonstrates that Mackie was wrong in insisting that there is a contradiction in theistic belief. But when we say that 'the theist' could accept the propositions constituting the defense, do we have any particular theist in mind? Presumably not. Plantinga's original defense was aimed at showing merely that some theist or other could accept all of the propositions of standard theism without being involved in inconsistency; and Plantinga took this to be enough to show that Mackie's argument had failed. In an important sense I agree. However, as many have noticed, Plantinga himself was not much attached to a number of the propositions constituting his formal defense. After all, his defense depends on at least two modal claims that we can suppose he has had not the slightest temptation to accept in de-modalized terms. He accepts that it is possible that every creaturely essence suffers from transworld depravity; he also accepts that it is possible that all natural evil is the result of demonic free will. But Plantinga was never inclined to think that everyone is transworld depraved or that all natural evil is the result of demonic free will. Indeed, we can surmise that he has always, in fact, been inclined to think it flatly false that everyone is transworld depraved and that natural evil is caused by demons. It is for this reason that I would like to characterize Plantinga's argument as a divested defense. He is not invested in all of the propositions constituting his defense.

By contrast, an invested defense is constituted by propositions the defender is not inclined to believe are false. Is there some reason to want an invested defense when a divested defense has already succeeded? I think so. The reason is that a divested defense, such as Plantinga's, has shown only (but of course this is still a lot!) that some theist or other is involved in no formal inconsistency. This will be enough to show that theism simpliciter is not inconsistent. But what about the theism of a particular defender? What about, for example, Plantinga's theism? Here it is much less clear that a divested defense does all that we would like it to do. We might put this by saying that Plantinga's divested 
defense shows only that a theist who accepts some propositions that are true for all Plantinga knows but which Plantinga himself is inclined to think are false is involved in no formal inconsistency. Can that constitute a defense of Plantinga's theism? Not clearly. What it could be reasonable for Plantinga to want is a defense not of theism simpliciter but of his own theistic beliefs in the face of a Mackie-style argument. I claim that this would require constructing an invested defense - a defense that proceeds from propositions the defender himself (in our imagined case here, Plantinga) is not inclined to think are false.

With this distinction sketched (and somewhat motivated) I can now express my view regarding Turner's independent compatibilist free will defense. My view is this. It can function as a divested defense, much as Plantinga's did. However, I suspect that it will not be able to function as an invested defense for any theist. And this is because nearly everyone (and especially nearly every theist) should be inclined to think that independent compatibilism is false.

Now, a great deal could be said about the implausibility of independent compatibilism; but the following will have to suffice here. It is extraordinarily hard to escape the feeling that the independence principle is ad hoc and motivated only by a concern to parry the manipulation arguments. This is, by the way, no formal complaint about Turner's employment of the principle. Turner is clearly attempting to develop a defense of the sort Plantinga originally formulated—what I am calling a divested defense. So, strictly speaking, there can be no more complaint about the implausibility or ad hoc nature of the independence principle than there can be of the thesis of universal transworld depravity. Still, my larger point is that, like the thesis of universal transworld depravity, the independence principle is unlikely to be able to feature in an invested defense. In the spirit of suspicionsfor that is all that space will allow me here-I further suspect that no form of compatibilism will be able to serve in an invested defense, either because it is transparently implausible as an account of human free will or because (like Frankfurt's account, which I am not claiming is implausible) it will not be able to meet the dialectical demands of defense.

\section{Conclusion}

I have been too hasty at a number of points throughout this brief chapter. I will defend my hastiness by returning to the larger goals I enunciated at the beginning. The problem of evil has animated a great deal of debate about the nature of free will. My main aim has been to contextualize and explain this phenomenon. In particular, I have tried to highlight the way that the problem of evil has made the libertarian conception of free will especially attractive to theistically inclined philosophers. Will this attraction continue? I suspect that it will. For even if a divested compatibilist free will defense can succeed, the theist is likely to seek an invested defense, if not a full-blown theodicy; and compatibilist-friendly versions of these responses to the problem of evil are not particularly promising (though for more optimism than I am able to muster about the prospects for a response without free will of any sort, see Pereboom 2016).

\section{References}

Bishop, J. (1993) "Compatibilism and the Free Will Defense," Australasian Journal of Philosophy 71: 104-20. Campbell, C.A. (1957) On Selfhood and Godhood. London: Allen and Unwin.

Fischer, J. and Ravizza, M. (1998) Responsibility and Control: A Theory of Moral Responsibility. New York: Cambridge University Press. 
Griffith, M. (2005) "Does Free Will Remain a Mystery? A Response to van Inwagen," Philosophical Studies 124: 261-9.

Hick, J. (1978) Evil and the God of Love, 2nd edn. San Francisco: Harper and Row.

Howesepian, A. (2007) "Compatibilism, Evil, and the Free-Will Defense," Sophia 46: 217-36.

Mackie, J.L. (1955) "Evil and Omnipotence," Mind 64: 200-12.

Mele, A. (2006) Free Will and Luck. New York: Oxford University Press.

Pereboom, D. (2016) "Libertarianism and Theological Determinism," in K. Timpe and D. Speak (eds), Free Will and Theism: Connections, Contingencies, and Concerns. New York: Oxford University Press, pp. 112-31.

Plantinga, A. (1974) The Nature of Necessity. Oxford: Clarendon.

Speak, D. (2011) "Libertarianism, Luck, and Gift," The Modern Schoolmen 88: 29-49.

Stump, E. (2010) Wandering in Darkness. New York: Oxford University Press.

Swinburne, R. (1998) Providence and the Problem of Evil. New York: Oxford University Press.

Turner, J. (2013) "Compatibilism and the Free Will Defense," Faith and Philosophy 30: 125-37.

van Inwagen, P. (2000) "Free Will Remains a Mystery," Philosophical Perspectives 14: 1-19.

Vargas, M. (2012) "Why the Luck Problem Isn't," Philosophical Issues 22: 491-536.

Vargas, M. (2013) Building Better Beings: A Theory of Moral Responsibility. New York: Oxford University Press.

Vargas, M. (2016) "The Runeberg Problem: Theism, Libertarianism, and Motivated Reasoning," in K. Timpe and D. Speak (eds), Free Will and Theism: Connections, Contingencies, and Concerns. New York: Oxford University Press, pp. 27-47.

Watson, G. (2004) Agency and Answerability. New York: Oxford University Press.

\section{Further Reading}

Adams, M. (2000) Horrendous Evils and the Goodness of God. Ithaca: Cornell University Press. (In addition to being a foremost authority on Medieval philosophy, Adams is also a philosopher of religion of the first order. In this book, she challenges the consensus view that Plantinga's free will defense is demonstratively successful and issues her influential minority report regarding what she takes to be the irrelevance of libertarian free will.)

Plantinga, A. (1977) God, Freedom, and Evil. Grand Rapids: Eerdmans Publishing. (This is an extraordinarily clear and accessible re-presentation of a number of the more influential arguments from the author's tour de force, The Nature of Necessity. Of special importance here is the development of the free will defense in response to J.L. Mackie's challenge.)

Speak, D. (2014) The Problem of Evil. Cambridge: Polity Press. (This is an accessible treatment of the main contours of the contemporary problem of evil as it is being addressed by analytic philosophers of religion. Reflection on the nature and value of free will appears throughout.)

Timpe, K. and Speak, D. (eds) (2016) Free Will and Theism: Connections, Contingencies, and Concerns. New York: Oxford University Press. (This collection brings together new work from leading thinkers regarding the relationship between theorizing about free will and theorizing about the existence and nature of God. The problem of evil plays a crucial role for a number of contributors, but special attention might be given to the essays by Derk Pereboom, Timothy O'Connor, and Laura Ekstrom.)

van Inwagen, P. (2006) The Problem of Evil. New York, Oxford University Press. (This monograph is based on the author's influential Gifford Lectures. Here, a premier figure in the field [who has made numerous and seminal contributions both in the debate regarding human free will and in broader discussions of the philosophy of religion] outlines his distinctive perspective on the core question.)

\section{Related Topics}

Identificationist Views

Reasons-Responsiveness Views

Classical Compatibilism

Event-Causal Libertarianism

Agent Causation

Manipulation Arguments

Determinism 


\section{4 \\ FREE WILL AND \\ THEOLOGICAL FATALISM \\ David P. Hunt}

\section{Omniscience and Agency}

Omniscience, like the other classic divine attributes, generates puzzles that have perplexed philosophers and theologians for centuries. Among the most perplexing are those that arise when the knowledge in question concerns the future. What would it be like to be an omniscient agent who already knows everything that will happen? Knowledge, like power, should enhance agency, but there are reasons to think that foreknowledge might be an exception. If the future is already known, one can hardly use that knowledge to bring about a different future (since that would falsify the foreknowledge on which the action was based); nor does it seem possible to use one's foreknowledge to bring about the very future one foreknows (since that would generate an explanatory circle). Once God foresees the Holocaust, for instance, it's arguably too late (in the explanatory order) to do anything about it. It is very hard, then, to see how foreknowledge could benefit God (Hasker 1989: 57-63). Perhaps it's still important to attribute foreknowledge to God, even if he can't use it, because its lack would constitute a defect in the divine perfection. Unfortunately, the mere possession of foreknowledge seems enough to cause trouble for God. If one cannot decide to do something while already knowing that one will do it, then-since divine omniscience must encompass God's own future actions-it would appear that the Supreme Agent is maximally impotent (Kapitan 1991). This is a theologically worrisome result, to say the least. (For one response, see Hunt 1993.)

Considerations such as these raise a prima facie problem of fatalism for God. But the puzzle that has attracted the most attention concerns the implications of divine foreknowledge, not for God's own agency, but for the agency of others. A classic statement of the problem can be found in Augustine:

How is it that these two propositions are not contradictory and inconsistent: (1) God has foreknowledge of everything in the future; and (2) We sin by the will, not by necessity? For ... if God foreknows that someone is going to sin, then it is necessary that he sin. But if it is necessary, the will has no choice about whether to $\sin . .$. [So:] either we draw the heretical conclusion that God does not foreknow everything in the future; or . . . we must admit that sin happens by necessity and not by will. 
This is explicitly an incompatibility argument: it is designed to show that a certain assumption about God is incompatible with a certain assumption about free will, so that one of them must be rejected. The same is true of the most important twentieth-century reformulation of the argument, that of Nelson Pike, who announces at the beginning of his classic essay that "there is a selection from among the various doctrines and principles clustering about the notions of knowledge, omniscience, and God which, when brought together, demand the conclusion that if God exists, no human action is voluntary" (Pike 1965: 27). Developing and evaluating that argument will be the business of this chapter. It's a complex business, since the argument has received an extraordinary amount of attention during the last 50 years.

\section{The Argument}

Suppose that Jill, upon returning home from work, decides of her own free will to sit down and peruse the mail she has just collected from her mailbox. Let $\mathrm{T}$ be the specific time (say, 5:49 p.m. on May 18, 2016) at which she acts on this decision. Then

\section{(A) Jill sits at $\mathrm{T}$ freely.}

Given divine foreknowledge, God knew before Jill was even born that she would sit at T. Let $T_{0}$ be an arbitrary time prior to Jill's birth. So

(B) God knows at $\mathrm{T}_{0}$ that Jill will sit at $\mathrm{T}$.

The problem, as Augustine recognized, is that there is a powerful argument for the conclusion that (A) and (B) are incompatible. Since (A) and (B) are not formally inconsistent, the alleged inconsistency has to be brought out with the aid of some auxiliary premises. This is clear in the quotation from Augustine, where we see the incompatibility of foreknowledge and freedom established via their connections with necessity: what is foreknown by God is necessary; what is done freely isn't necessary; therefore, divine foreknowledge and human freedom are incompatible. Let's follow Augustine's lead, starting with (A).

There are a number of conditions that must be satisfied for Jill's action at $\mathrm{T}$ to be done freely, but only one is relevant to bringing out the incompatibility of divine foreknowledge and human freedom. This is that Jill could have done otherwise than sit at T, if only by refraining from sitting. So

(1) If Jill sits at $\mathrm{T}$ freely, then Jill could have refrained from sitting at $\mathrm{T}$.

This 'alternatives condition' on free will may seem evident in its own right, but it also derives support from a neighboring condition on moral responsibility, the Principle of Alternate Possibilities (PAP), according to which a person is morally responsible for an action only if the person could have done otherwise. Because the sense in which Jill is presumed to sit freely in (A) is the sense required for moral responsibility, (1) would seem to be true if PAP is true.

If Jill could have refrained from sitting at $T$, her sitting at $T$ cannot have been the necessary consequence of conditions over which she had no control. If her legs suddenly buckled at $T$, just as she passed by a seat, she could not have refrained from sitting at $\mathrm{T}$-unless they buckled because she failed to take her anti-leg-buckling pills that 
morning. But suppose the conditions necessitating Jill's sitting at $\mathrm{T}$ were in place before she was even born. Then it would seem that Jill could not possibly have exercised control over those conditions. When Jill came into existence, it was already too late for her to do anything about the conditions entailing that she will sit at $\mathrm{T}$; consequently, it has always been too late for her to refrain from sitting at $\mathrm{T}$.

These prior conditions, if they obtain, constitute facts about the past; but not just any facts about the past that entail Jill's sitting at $T$ will do the job. The following all entail that Jill will sit at $\mathrm{T}$ and (assuming that Jill does indeed sit at $\mathrm{T}$ ) are in some sense 'facts about the past:'

(a) The mail that Jill would read at $\mathrm{T}$ was deposited in her mailbox at 11:28 that morning.

(b) On May 17, 2016, Jill's neighbor Frank correctly predicted that she would sit down to read her mail at $T$.

(c) Napoleon scratched his ear at 5:49 p.m. on May 18, 1816, exactly 200 years before Jill will sit down to read her mail.

(d) It was true at $T_{0}$ that Jill will sit at $T$.

But these are not the sorts of facts about the past that have any tendency to make us think that Jill could not have refrained from sitting at $T$. The problem is that these facts are not strictly about the past; (d), perhaps, is not genuinely about the past at all, since the fact in question seems simply to be (relative to $T_{0}$ ) that Jill will sit at $T$. Such facts have come to be called 'soft facts' about the past. 'Hard facts' are those that are genuinely and strictly about the past, and hard facts figure in the next auxiliary premise:

(2) If Jill could have refrained from sitting at $\mathrm{T}$, then at the time she was born there were no hard facts about the past entailing that she would sit at $\mathrm{T}$.

This is, of course, just a necessary, not a sufficient, condition for Jill to have been able to refrain. We'll return to the distinction between hard and soft facts later.

With (1) and (2) in place, we're in a position to draw an important inference from (A), Jill's sitting freely at T, namely,

$\left(A^{*}\right)$ At the time Jill was born there were no hard facts about the past entailing that she would sit at $\mathrm{T}$.

In Augustine's terms, if Jill sits at $\mathrm{T}$ freely, Jill does not sit at $\mathrm{T}$ 'by necessity,' in that her sitting at T isn't locked into place before she is even born; relative to the time of her birth, at least, her sitting at $\mathrm{T}$ is still contingent.

Now let's approach the incompatibility from the other end. What conditions must be satisfied for God to know that Jill will sit at T? This question is hard enough to answer when the knower is human, and it can only be harder yet when the knower is God. But if knowledge is at least true belief (whatever further conditions it must satisfy), we can avoid the most controversial issue surrounding the analysis of knowledge. Even God, presumably, can't know something if he doesn't even believe it. So

(3) If God knows at $T_{0}$ that Jill will sit at $T$, then God believes at $T_{0}$ that Jill will sit at $\mathrm{T}$. 
Divine belief may be radically different from human belief, but the belief in (3) surely involves, at a minimum, some state of the divine mind at $T_{0}$ in virtue of which God can be said to accept or endorse the proposition that Jill will sit at $T$.

God not only isn't wrong about anything (and so is inerrant), but he can't be wrong about anything (making him infallible). This means that God's holding this belief entails that Jill will sit at $T$. Moreover, the fact that the divine mind realized at $T_{0}$ a belief with this content rather than some other content seems, at the time Jill was born, to be genuinely and strictly about the past- that is, it seems to be a hard fact about the past. So

(4) If God believes at $T_{0}$ that Jill will sit at $T$, then at the time Jill was born there was a hard fact about the past entailing that she would sit at $\mathrm{T}$.

This hard fact about the past, which is now beyond Jill's (or anyone's) control, is an instance of the 'necessity of the past,' conveyed in such maxims as 'what's done is done.' This is not logical necessity, since there are logically possible worlds with a different past. (In a world in which Jill doesn't even exist, God certainly doesn't believe at $T_{0}$ that Jill will sit at T!) But it is arguably stronger than natural or causal necessity. Aristotle notes that "this alone is lacking even to God, to make undone things that have once been done" (Aristotle 1980: 139), and Aquinas comments: "As such it is more impossible than the raising of the dead to life, which implies no contradiction, and is called impossible only according to natural power" (Aquinas 1969 [1271]: 199). Because what is necessary when past might have been non-necessary or accidental when future, the medievals called this accidental necessity.

Given, then, that (B) God knows at $T_{0}$ that Jill will sit at $\mathrm{T}$, it follows from (3) and (4) that

$\left(\mathrm{B}^{*}\right)$ At the time Jill was born there was a hard fact about the past entailing that she would sit at $\mathrm{T}$.

We might say that the accidental necessity of this hard fact about the past 'transfers' to Jill's future action. In Augustine's terms, if God foreknows at $T_{0}$ that Jill will sit at T, then Jill does sit at $\mathrm{T}$ 'by necessity,' in that her sitting at $\mathrm{T}$ is locked into place before she is even born; her sitting at $\mathrm{T}$ is, from the first moment of her existence, no longer contingent.

$\left(A^{*}\right)$ and $\left(B^{*}\right)$ are explicitly contradictory. This means that the assumption from which they've been shown to follow-that (A) and (B) are both true-must be rejected. Jill's sitting freely at $\mathrm{T}$ is incompatible with God's foreknowing that she will sit at $\mathrm{T}$. Since the argument does not turn on anything peculiar to Jill, or the action of sitting, or the time $\mathrm{T}$ at which she sits, it follows that divine foreknowledge is incompatible with human freedom.

This argument for 'theological fatalism' poses a more serious challenge to human freedom than does 'logical' or 'future-truth fatalism,' in which God's knowing at $T_{0}$ that Jill will sit at $\mathrm{T}$ is replaced with a purely logical or semantic premise like

(d) It was true at $T_{0}$ that Jill will sit at $T$,

since (d) (as noted earlier) does not seem to be a hard fact about the past (Widerker 1989). Still, none of its premises has escaped criticism. We'll look first at the inference from $(A)$ to $\left(A^{*}\right)$ and then at the inference from $(B)$ to $\left(B^{*}\right)$. 


\section{Challenging the Contingency of Human Freedom}

PAP, a 'freedom version' of which undergirds premise (1) of the argument, "has generally seemed so overwhelmingly plausible that some philosophers have even characterized it as an a priori truth" (Frankfurt 1969: 829). It has nevertheless been the subject of an influential critique by Harry Frankfurt. Frankfurt's rejection of PAP rests on a counterexample involving an agent, Jones, and a "counterfactual intervener," Black, who has the power to cause Jones to perform a certain action (say, deciding to kill Smith) if Jones doesn't do it on his own. Frankfurt maintained that, if Jones does act on his own in this scenario, he could be held morally responsible for his action, even though the presence of the counterfactual intervener meant that he couldn't do otherwise. If Frankfurt is right, $\mathrm{PAP}$ is false, and the reasons why $\mathrm{PAP}$ is false are equally reasons why its freedom version is false. This invalidates the main reason for accepting (1).

An important vulnerability of Frankfurt's original counterexample, on which many critics have fastened, is that even if the counterfactual intervener succeeds in stripping Jones of any alternatives to deciding to kill Smith, Jones retains a plethora of other alternatives, some of which are arguably relevant to his moral responsibility for deciding to kill Smith (Fischer 1994: Chapter 7). The debate over the persistence and significance of these "flickers of freedom" is ongoing. But a scenario in which Black's counterfactual intervener is replaced by an omniprescient deity is immune to this problem. Infallible foreknowledge eliminates all Jill's alternatives, and it does so without jeopardizing the judgment that she is free in the sense required for moral responsibility. In divine foreknowledge cases, as in Frankfurt's original case, the conditions which eliminated the person's alternatives "played no role at all in leading him to act as he did," so that in their absence "[h]e would have acted the same" (Frankfurt 1969: 836, 837). This is why we continue to hold the agent morally responsible in Frankfurt-cases, even if we think his alternatives have been stripped, and it's why we should continue to regard the agent as free in the face of divine foreknowledge (Hunt 2003). This is the moral that Augustine himself seems to have drawn (Hunt 1999). Divine foreknowledge doesn't cause or compel what it knows (Augustine 1993 [395]: 78). Even if the agent can't refrain from doing what God foreknew he would do, that isn't sufficient reason to regard him as unfree, given that "[a] man does not therefore sin because God foreknew that he would sin" (Augustine 1950 [426]: 157, 158).

Denying PAP is pretty costly, however, since it plays a critical role in our moral reasoning and it isn't obvious how to replace it. Perhaps the most promising direction to look for a replacement is sourcehood (Fischer 1999; Pereboom 2000; Timpe 2007; Shabo 2010). But there is another point at which the inference to $\left(A^{*}\right)$ can be blocked. There are, notoriously, different ways of understanding the 'could have' that links (1) and (2). We are typically satisfied that someone could have done something the person did not in fact do if we have reason to think that, had the person decided to do it, nothing would have prevented the person from acting on that decision-for example, that Jill would have succeeded in feeding the dog, or calling her mother, or simply standing lost in thought at $\mathrm{T}$, if she had decided to do any of these things instead of sitting down to read her mail. Call this the 'conditional analysis' of 'could have.' This analysis might be satisfied, however, even if Jill's doing otherwise (and deciding to do otherwise) were ruled out by factors that were in place before she was even born. On causal determinism, for example, the conjunction of the natural laws and the state of the universe at $T_{0}$ constitutes just such a factor. But it's consistent with causal determinism that, were Jill 
to decide otherwise, she would do otherwise. 'Compatibilists' hold that, in such a case, we should say that Jill could have refrained from sitting at $\mathrm{T}$, even though there were conditions in place before she was born entailing that she would sit at T (Ayer 1954). Compatibilists will therefore deny (2), while 'incompatibilists' will accept it. This is a major parting of the ways, addressed elsewhere in this volume at some length, so no more will be said about it here.

\section{Challenging the Necessity of Foreknown Actions}

The greater the metaphysical distance between God and human beings, the more room there is to speculate that divine knowledge might be so different from human knowledge that it doesn't involve beliefs at all. William Alston (1986) and Linda Zagzebski (1991: 85-96) have both presented models of divine omniscience, inspired by Aquinas, on which God does not have beliefs. These models rest on concepts of metaphysical simplicity and cognitive perfection that are not easy to grasp, but they do force one to confront the question whether (3) is as secure as it seems to be. Still, one might think that God's knowing at $\mathrm{T}_{0}$ that Jill will sit at $\mathrm{T}$ must correspond to some state of the divine mind, whether or not 'belief' is an apt term for this state, and this state might be enough to provide a hard fact about the past, at the time Jill was born, entailing that she will sit at T (Hasker 1988). If so, the argument that divine foreknowledge is incompatible with human freedom is back in business.

Most who object to the necessity of foreknown actions have focused their attention on (4) rather than (3). A radical critique might challenge the very idea of accidental necessity as a modality characteristic of the past; but this extreme position runs counter to deep intuitions about the necessity of the past. The principal assault has come from those who accept the necessity of the past but argue, following William Ockham (1983 [1322-4]), that God's having believed at $\mathrm{T}_{0}$ that Jill will sit at $\mathrm{T}$ is really a soft fact about the past.

The prima facie problem with this 'Ockhamist' approach is that someone's having held a particular belief yesterday looks like a paradigmatic hard fact about the past. The content of the belief, including whether the belief is about tomorrow, seems irrelevant to the hardness/softness question. This is certainly true in the case of human belief. If I believed yesterday that candidate X will prevail in tomorrow's election, the fact that I held that belief yesterday seems as hard as any fact about the past; nothing that might happen now or in the future could make it not a fact. It's not clear why things should be any different when the forebeliever is God. John Martin Fischer puts the problem this way:

the only way in which God's belief at [ $\left.\mathrm{T}_{0}\right]$ about [Jill] at [T] could be a soft fact about the past [prior to T] would be if one and the same state of the mind of the person who was God at [ $\mathrm{T}_{0}$ ] would count as one belief if [Jill sat at T] but a different belief (or not a belief at all) if [Jill did not sit at T].

(Fischer 1983: 76)

It's hard to see how this "incompatibilist constraint," as Fischer terms it, could be satisfied.

There are various ways that Ockhamists have attempted to overcome this prima facie difficulty with their position. One is to formulate an independently plausible 
account of the distinction between hard and soft facts, on which God's past beliefs about the contingent future come out as soft facts about the past (Adams 1967). These accounts all include a soft fact's entailing something about the future, but no simple entailment condition succeeds (e.g., that Jill ate escargot yesterday is surely a hard fact about the past, but it entails a fact about the future: that she won't eat escargot tomorrow for the first time). So more complex accounts have been formulated (Freddoso 1983; Hoffman and Rosenkrantz 1984; Kvanvig 1986: 102-9), but these have failed to carry the day. One reason is that they seem designed to ensure that God's forebeliefs will be soft, thereby begging the question; another is that they're so laden with qualifiers, in an effort to avoid counterexample, that they collapse under their own baroque complexity (Zagzebski 1991: 74).

Alvin Plantinga has appealed to what might be called paradigm entailments as a way around this problem. He insists that he is "not adopting an 'entailment' criterion, according to which a fact about the past is a hard fact about the past if and only if it entails no proposition about the future." But he does suggest that some propositions about the future-and it's clear that Jill will sit at $T$ is the kind of proposition he has in mind - are such that no proposition entailing it could be "a hard fact about the past, because no such proposition is strictly about the past" (Plantinga 1986: 248). If Plantinga is right about this, then

\section{(e) God believed at $\mathrm{T}_{0}$ that Jill will sit at $\mathrm{T}$}

is not a hard fact about the past, as required by (4), since it entails that Jill will sit at T. But this proves too much: not only would (e) not satisfy the condition "at the time Jill was born there was a hard fact about the past entailing that she would sit at T," but nothing would - the condition is self-contradictory. One consequence is that Plantinga's reason for affirming the compatibility of human freedom and divine foreknowledge is equally a reason for affirming the compatibility of human freedom and causal determinism, since the latter is the thesis that the laws of nature and the state of the world at any given instant jointly entail the state of the world at any subsequent instant (van Inwagen 1983: 65), and thus entail Jill's sitting at T. Few philosophers concerned to defeat theological fatalism would find this a welcome result.

So something more than entailment, even paradigm entailment, appears to be necessary. One candidate is that soft facts about the past are explained by the future and 'counterfactually dependent' on the future (if the future were different, the soft fact would be different). That's exactly how matters stand with God's belief at $T_{0}$ that Jill will sit at $\mathrm{T}$ : God believes at $\mathrm{T}_{0}$ that Jill will sit at $\mathrm{T}$ because Jill will sit at $\mathrm{T}$; were Jill not to sit at $\mathrm{T}$, the fact about what God believed at $\mathrm{T}_{0}$ would be different. If explanatory and counterfactual dependence on the future are enough to make a fact soft, then God's believing at $\mathrm{T}_{0}$ that Jill will sit at $\mathrm{T}$ was, at the time Jill was born, a soft fact about the past (Craig 1987: 69-74). It's not clear, however, that this is enough to reinstate Jill's freedom. If a time traveler from 2293 knocked on my door yesterday, this event, which is explanatorily and counterfactually dependent on the future, seems now to be a fixed part of the past-just as fixed as my non-time-traveling neighbor's knocking on my door yesterday; as such, the future can't now unfold in a way that contradicts it. But then we're back to God's past beliefs limiting Jill's future possibilities.

Finally, there is an approach that might be called 'skeptical compatibilism,' since it holds that we can know that God's past beliefs about the contingent future are soft 
facts about the past, and therefore compatible with human freedom, without knowing how this can be so. Assume that God exists in all possible worlds and is omniscient in all possible worlds. Then the following two propositions are logically equivalent, because any world in which the one is true is a world in which the other is true:

(d) It was true at $\mathrm{T}_{0}$ that Jill will sit at $\mathrm{T}$.

(e) God believed at $\mathrm{T}_{0}$ that Jill will sit at $\mathrm{T}$.

But if (d) is a soft fact about the past-and (d) is a soft fact if anything is a soft factthen so is (e) (Plantinga 1986: 250). Alternatively, if (d) is consistent with Jill's sitting freely at $\mathrm{T}$-and most participants in the debate over theological fatalism agree that the argument for logical fatalism based on (d) is fallacious-(e) must also be consistent with Jill's freedom (Warfield 1997). In either case, theological fatalism is false. One problem with this strategy is that it can be run in the other direction: since (e) is a hard fact about the past (and God's past cognitive states do seem just as hard as my past cognitive states), and (e) is inconsistent with Jill's freedom (for reasons brought out in the argument for theological fatalism), the same is true of (d) - since it's logically equivalent to (e). Skeptical compatibilism arguably begs the question (Hunt 2002).

Of all the argument's premises, (4) has received the most attention, but none of the main Ockhamist critiques that have been developed thus far is problem-free.

\section{Accepting the Argument}

Suppose that none of the argument's four premises is expendable. Then (A) and (B) are incompatible and it becomes necessary to reject one or the other (or both). To respond to the argument by rejecting $(\mathrm{A})$ is to deny that anyone ever acts freely. This can of course be done on other grounds: because one thinks that free will is conceptually incoherent (Strawson 1994), or ruled out by empirical facts about the world (Pereboom 2001), or inconsistent with theological doctrines such as divine sovereignty or predestination (John Calvin, on at least one standard interpretation). Someone who rejects (A) because of the argument is a theological fatalist. It is noteworthy that the argument for theological fatalism, impressive as it is, has led virtually no one to become a theological fatalist.

A more common response to the argument is to deny its assumption about divine foreknowledge. There are multiple grounds for rejecting (B). An obvious ground is atheism. But the threat of theological fatalism does not provide a compelling reason to be an atheist, since there are three notable ways to deny (B) while remaining within the theistic camp.

The first way is to deny the existence of future-contingent truths such as Jill will sit at $T$. The idea is that, if Jill's sitting at $T$ is indeed a contingent matter, then it turns out at $\mathrm{T}$ that Jill sits at $\mathrm{T}$, and it's only then, at $\mathrm{T}$, that it becomes true that Jill sits at $\mathrm{T}$; at earlier times, such as $\mathrm{T}_{0}$, it is not yet true that Jill will sit at $\mathrm{T}$ (Prior 1967: 113-36). This seems to have been Aristotle's response to the 'future-truth' argument for logical fatalism (Aristotle 1963: 50-3). But if it isn't true at $\mathrm{T}_{0}$ that Jill will sit at T, God certainly won't foreknow at $\mathrm{T}_{0}$ that Jill will sit at $\mathrm{T}$. So-called 'open theists,' who deny exhaustive 
foreknowledge, have found this position especially attractive, since it preserves divine omniscience (Rhoda et al. 2006). (There are fewer truths for God to know, but he nevertheless knows all of them.) A purely philosophical (as opposed to theological) reason for rejecting future-contingent truth comes from presentism, which maintains that only the present is real. Now a proposition is true by 'corresponding to' or 'supervening on' reality. Whatever supervenience or correspondence come to here, they are a relation of one sort or another to reality. But if the future is not real, it does not qualify as a relatum in this relation, and hence there are no truths about it. A prima facie problem with this presentist argument against future-contingent truths, as it stands, is that it is equally an argument against truths about the past (Sanson and Caplan 2010). Since the existence of truths about the past is non-negotiable, presentists need to explain how their theory can accommodate them (Zimmerman 2010). It's an open question whether a viable presentist account of truths about the past won't work for future-contingent truths as well.

A second way is to accept the existence of future-contingent truths but deny that God knows them. One explanation of why God might not know these truths is that he refrains from knowing them to make room for human freedom (Willard 1998: 244-53). More typical of this approach, however, is the view that no one (including God) can know them, because they are logically or metaphysically unknowable. This looks like a straightforward denial of divine omniscience, understood as God's knowing all truths. Defenders can concede this point, insisting that it was a mistake to include omniscience in God's cognitive perfection in the first place, or they can produce a new account of omniscience. The most prominent defenders, such as Richard Swinburne (2006: 22-6), William Hasker (1989), and Peter van Inwagen (2008), take the latter route. Hasker, for example, offers this definition of divine omniscience: "It is impossible that God should at any time believe what is false, or fail to know any true proposition such that his knowing that proposition at that time is logically possible" (1989: 187). Critics, however, have challenged the very idea of 'logically unknowable truths' and disputed the theological acceptability of the new concepts of omniscience (Craig 2002).

Finally, one might accept both the existence of future-contingent truths and God's knowledge of them, but deny that he knows them as future, since God does not exist in time. On this view, famously associated with Boethius (2000 [524]), (B) is false; what is true instead is

(B') God (timelessly) knows that Jill will sit at T,

and (B') does not supply a fact about the past that can lock in Jill's sitting at T before she is even born, as the argument requires. The Boethian move raises at least a couple of questions, however. One is whether this view of God is coherent. Though it is the classical view, it has come in for increasing criticism in recent years (Davis 1983). The other question is whether a timeless deity generates a fatalistic threat of its own. It might seem that what is fixed in eternity is no less accidentally necessary, and so no less threatening to human freedom, than what is fixed in the past (Zagzebski 1991: 60-3). If that's right, the argument can be easily modified to show that (A) is incompatible with (B'). But intuitions are a fragile guide here, and Boethius's own intuitions are that eternity is more like the present than it is like the past. More worrisome, perhaps, is the possibility of God's causing tokens of his eternal knowledge to exist in 
time-for example, a stone inscribed with the sentence 'Jill will sit down to read her mail at 5:49 p.m. on May 18, 2016' which God (timelessly) causes to exist prior to Jill's birth. Such "freedom-denying prophetic objects," as van Inwagen (2008) calls them, are arguably just as incompatible with Jill's freely sitting at T as is God's believing at $\mathrm{T}_{0}$ that she will sit at $\mathrm{T}$.

Of these three grounds for rejecting (B), perhaps the most notable trend during the last 10 to 20 years is the growing popularity of the first, which denies future-contingent truth. This development has gone hand-in-hand with the rise of open theism.

\section{Final Word}

The philosophical energy that has been expended on responding to this argument is remarkable. Theists, of course, have a theological interest in breaking the argument (or finding ways to accommodate it). But the argument is fascinating quite apart from any antecedent commitment to divine foreknowledge or to human freedom. Suppose that Jill's sitting at $\mathrm{T}$ is a paradigmatic instance of free agency; if ever there was an instance of free agency, this is it. Now add one more condition: before Jill was born, God foreknew that Jill would sit at T. How could that additional condition, just by itself, have as a consequence that Jill's sitting at T isn't an instance of free agency after all? Yet here's an argument showing that it does have this consequence. That's a real puzzler, and engaging with it requires rethinking some of the most fundamental issues in philosophy, from truth and time to freedom and necessity (Hunt 1998). This makes it a classic philosophical problem.

\section{References}

Adams, M.M. (1967) “Is the Existence of God a 'Hard' Fact?" The Philosophical Review 76: 492-503.

Alston, W. (1986) "Does God Have Beliefs?" Religious Studies 22: 287-306.

Aquinas (1969 [1271]) Summa Theologiae, Vol. 2, "The Mind and Power of God," trans. T. Gilby, O.P. (ed.). Garden City: Image Books.

Aristotle (1963) Categories and De Interpretatione, trans. J.L. Ackrill. Oxford: Clarendon.

Aristotle (1980) The Nicomachean Ethics, trans. and intro. D. Ross, J. L. Ackrill, and J.O. Urmson. Oxford: Oxford University Press.

Augustine (1950 [413-26/27]) The City of God, trans. M. Dods, intro. T. Merton (but bk. V trans. J.J. Smith). New York: Random House.

Augustine (1993 [387/88-95]) On Free Choice of the Will, trans. T. Williams. Indianapolis and Cambridge: Hackett.

Ayer, A.J. (1954) "Freedom and Necessity," in A.J. Ayer, Philosophical Essays. London: Macmillan.

Boethius (2000 [524]) The Consolation of Philosophy, trans. and intro. P.G. Walsh. New York: Oxford University Press.

Craig, W.L. (1987) The Only Wise God. Grand Rapids: Baker Book House.

Craig, W.L. (2002) "What Does God Know?" in D. Huffman and E. Johnson (eds), God Under Fire: Modern Scholarship Reinvents God. Grand Rapids: Zondervan, pp. 137-56.

Davis, S. (1983) Logic and the Nature of God. Grand Rapids: Eerdmans.

Fischer, J.M. (1983) "Freedom and Foreknowledge," The Philosophical Review 92: 67-79.

Fischer, J.M. (1994) The Metaphysics of Free Will. Cambridge: Blackwell.

Fischer, J.M. (1999) "Recent Work on Moral Responsibility," Ethics 110: 93-139.

Freddoso, A. (1983) "Accidental Necessity and Logical Determinism," Journal of Philosophy 80: 257-78.

Frankfurt, H. (1969) "Alternate Possibilities and Moral Responsibility,” Journal of Philosophy 66: 829-39.

Hasker, W. (1988) "Yes, God Has Beliefs!” Religious Studies 24: 385-94.

Hasker, W. (1989) God, Time, and Knowledge. Ithaca and London: Cornell University Press.

Hoffman, J. and Rosenkrantz, G. (1984) "Hard and Soft Facts," The Philosophical Review 93: 419-34. 


\section{DAVID P. HUNT}

Hunt, D. (1993) "Divine Providence and Simple Foreknowledge," Faith and Philosophy 10: 396-416.

Hunt, D. (1998) "What Is the Problem of Theological Fatalism?" International Philosophical Quarterly 38: $17-30$.

Hunt, D. (1999) "On Augustine's Way Out," Faith and Philosophy 16: 1-26.

Hunt, D. (2002) "The Compatibility of Divine Determinism and Human Freedom: A Modest Proposal," Faith and Philosophy 19: 485-502.

Hunt, D. (2003) "Freedom, Foreknowledge, and Frankfurt," in D. Widerker and M. McKenna (eds), Moral Responsibility and Alternative Possibilities: Essays on the Importance of Alternative Possibilities. Burlington: Ashgate Publishing Co., pp. 159-83.

Kapitan, T. (1991) "Agency and Omniscience," Religious Studies 27: 105-20.

Kvanvig, J. (1986) The Possibility of an All-Knowing God. New York: St. Martin's Press.

Ockham, W. (1983 [1322-4]) Predestination, Foreknowledge, and Future Contingents, 2nd edn, trans. M.M. Adams and N. Kretzmann. Indianapolis: Hackett.

Pereboom, D. (2000) "Alternative Possibilities and Causal Histories," Philosophical Perspectives 14: $119-37$.

Pereboom, D. (2001) Living without Free Will. Cambridge: Cambridge University Press.

Pike, N. (1965) "Divine Omniscience and Voluntary Action," The Philosophical Review 74: 27-46.

Plantinga, A. (1986) “On Ockham's Way Out," Faith and Philosophy 3: 235-69.

Prior, A. (1967) Past, Present, and Future. Oxford: Clarendon Press.

Rhoda, A., Boyd, G., and Belt, T. (2006) "Open Theism, Omniscience, and the Nature of the Future," Faith and Philosophy 23: 432-59.

Sanson, D. and Caplan, B. (2010) "The Way Things Were," Philosophy and Phenomenological Research 81: 24-39.

Shabo, S. (2010) "Uncompromising Source Incompatibilism," Philosophy and Phenomenological Research 80: 349-83.

Strawson, G. (1994) “The Impossibility of Moral Responsibility," Philosophical Studies 75: 5-24.

Swinburne, R. (2006) Providence and the Problem of Evil. Oxford: Oxford University Press.

Timpe, K. (2007) "Source Incompatibilism and Its Alternatives," American Philosophical Quarterly 44: 143-55.

van Inwagen, P. (1983) An Essay on Free Will. New York: Oxford University Press.

van Inwagen, P. (2008) "What Does an Omniscient Being Know about the Future?" in J. Kvanvig (ed.), Oxford Studies in Philosophy of Religion, Vol. 1. Oxford: Oxford University Press, pp. 216-30.

Warfield, T. (1997) "Divine Foreknowledge and Human Freedom Are Compatible," Noûs 31: 80-6.

Widerker, D. (1989) "Two Forms of Fatalism," in J.M. Fischer (ed. and intro.), God, Foreknowledge, and Freedom. Stanford: Stanford University Press, pp. 97-110.

Willard, D. (1998) The Divine Conspiracy. New York: Harper Collins.

Zagzebski, L. (1991) The Dilemma of Freedom and Foreknowledge. New York: Oxford University Press.

Zimmerman, D. (2010) "The A-Theory of Time, Presentism, and Open Theism," in M. Stewart (ed.), Science and Religion in Dialogue, Vol. 2. Hoboken: Wiley-Blackwell.

\section{Further Reading}

Beilby, J.K. and Eddy, P.R. (eds) (2001) Divine Foreknowledge: Four Views. Downers Grove: InterVarsity Press. (A relatively accessible presentation in which G. Boyd defends Open Theism, W. L. Craig draws on Ockham and Molina, D. Hunt argues for 'simple foreknowledge,' and P. Helm takes a broadly Calvinist position.)

Fischer, J.M. (ed.) (1989) God, Foreknowledge, and Freedom. Stanford: Stanford University Press. (An anthology that collects some of the most important essays from the early period of the contemporary debate, beginning with Nelson Pike's classic1965 article.)

Fischer, J.M. and Todd, P. (eds) (2015) Freedom, Fatalism, and Foreknowledge. Oxford: Oxford University Press. (This collection shows how the debate has continued and also refocused in recent years.)

Hasker, W. (1989) God, Time, and Knowledge. Ithaca: Cornell University Press. (An influential treatment of the foreknowledge problem and related issues, which anticipates the current popularity of Open Theism.)

Zagzebski, L. (1991) The Dilemma of Freedom and Foreknowledge. Oxford: Oxford University Press. (The single best monograph on the problem to date, in my view.) 


\section{Related Topics}

Classical Compatibilism

Skeptical Views about Free Will

The Consequence Argument

Frankfurt-Style Examples

Logical Fatalism

Leeway vs. Sourcehood Conceptions of Free Will

Aristotle

Augustine of Hippo

Free Will and Theological Determinism

Free Will and Providence

Divine Free Will 


\section{5 \\ FREE WILL AND THEOLOGICAL DETERMINISM \\ Leigh Vicens}

\section{Introduction}

In his Dictionary of the Bible, Reformed theologian Benjamin Warfield wrote:

There is nothing that is, and nothing that comes to pass, that [God] has not first decreed and then brought to pass by His creation or providence ... . Nothing comes to pass, whether in the sphere of necessary or free causation, whether good or bad ... save as the outworking in fact of what had lain in the Divine mind as purpose from all eternity, and is now only unfolding into actuality as the fulfillment of His all-determining will.

(Warfield 1909)

While Warfield was attempting to define the term predestination, I take the above passage to offer a good characterization of theological determinism - the view, in brief, that God determines every event that occurs in the history of creation. There have been many expressions of this basic conviction in Jewish, Christian, and Muslim theology, and various arguments offered in support of it, from biblical texts that suggest it (cf. Feinberg 2001: 679-82) to considerations of divine perfection that imply it (Helm 1993: 44-54). Some theists even accept determinism first on empirical or philosophical grounds, and then go on to reason that if all events are determined, they must ultimately be so by the Creator of all (cf. McCann 2005: 145). This article will focus, not on reasons for accepting theological determinism, but on how those who do accept this view have conceived of the nature and extent of human freedom. As we will see, much turns on how theological determinists spell out (or do not spell out) what it means for God to determine events, as well as what other metaphysical assumptions they make about the compatibility of such determinism and free will. Below, I will discuss four possible (though perhaps not collectively exhaustive) positions that theological determinists have held on the issue of human freedom. The first are 'standard' compatibilists about determinism and human freedom; the second think that human freedom is incompatible with natural determinism, but compatible with theological determinism; and the third are 'standard' incompatibilists about determinism and 
human freedom, and so conclude that we are not free. The second group may be subdivided further, into those who take theological determinism to be causal, though different from natural determinism in some respect, and those who think that the way the Creator determines events has nothing in common with the way created causes do, so that causal language cannot be used unequivocally of God and creation. This latter group takes theological determinism to be compatible with a libertarian account of human freedom.

\section{'Standard' Compatibilism}

John Calvin seems to have espoused a form of classic compatibilism regarding free will and determinism in his Institutes of the Christian Religion. There can be no doubt that Calvin was a theological determinist. Near the beginning of the work, he lays out his strong doctrine of divine providence. After noting that it has been the "common persuasion of all ages" to attribute some events to chance—-such as one's being killed by a falling tree, or surviving a storm at sea-he writes:

But whoever has been taught from the mouth of Christ, that the hairs of his head are all numbered, will seek further for a cause, and conclude that all events are governed by the secret counsel of God. And respecting things inanimate, it must be admitted, that, though they are all naturally endued with their peculiar properties, yet they exert not their power, any further than they are directed by the present hand of God. They are, therefore, no other than instruments into which God infuses as much efficacy as he pleases, bending and turning them into actions, according to his will.

(Calvin 1813: I.XVI.II)

While Calvin uses much figurative language to speak of God's governance of creationfor example, "it belongs no less to his hands than to his eyes" (1813: I.XVI.IV)_ passages such as the above suggest that he indeed thinks of God as the primary cause of all events in the world, and of creatures as secondary ("inferior" - cf. 1813: I.XVI.IX) causes.

As adamant as Calvin is that God must be understood to be the determiner of all events, equally is he adamant that such divine determination does not remove the possibility of creaturely freedom. At various points, he suggests that when considering the issue of free will, we should simply set aside considerations of divine providence, which are opaque to us. For instance, in speaking of humans before the Fall, Calvin writes, "In this integrity man was endued with free will, by which, if he had chosen, he might have obtained eternal life. For here it would be unreasonable to introduce the question respecting the secret predestination of God" (1813: I.XV.VIII). However, reading further, one finds Calvin suggesting a compatibilist conception of free will, since his reason for setting aside considerations of God's "secret predestination" is that "we are not discussing what might possibly have happened or not, but what was the real nature of man" (1813: I.XV.VIII). Even when speaking of humans in their fallen state, in which we are "not possessed of free will for good works" but "capable of doing nothing but sin" (1813: II.II.VI), Calvin admits, "man will be said to possess free will in this sense ... [that] he does evil voluntarily, and not by constraint" (1813: II.II.VII). While he is reluctant to use the word "free" in describing humans after the Fall—since he is wary of encouraging 
Pelagianism (1813: II.II.VIII)—Calvin is clear that we are morally responsible for our actions, and liable to judgment, even lacking the ability to do otherwise. But how can we be held accountable for actions that are unavoidable? Calvin's answer seems to be two-fold: first, our inability to do anything but evil "arises not from creation, but from the corruption of nature ... It originated in the revolt of the first man from his Maker" of which "all men are justly accounted guilty"; and second, even now we sin voluntarily, not against our wills (1813: II.V.I). In other words, Calvin seems to agree with Hobbes, that man is free to the extent that "he finds no stop, in doing what he has the will, desire, or inclination" to do (1651: Ch. XXI). This, I take it, is the classic compatibilist position.

One contemporary theological determinist who is even more explicit that divine determination should be thought of in causal terms, along the lines of natural determinism, is Paul Helm. In defending his view, which he calls "theistic compatibilism," Helm states that "the truth of [non-theistic, or natural] compatibilism is assumed" and goes on to argue that "if non-theistic determinism is compatible with freedom then ... theistic creation [i.e. determinism] is as well" (1988: 146). In other words, Helm suggests that the compatibility of theological determinism and human freedom is "precisely parallel" to the compatibility of natural determinism and human freedom (1988: 147). In his discussion of theistic compatibilism, Helm responds to Anthony Flew's objection that there is a disanalogy between natural and divine determination of our actions, since in the former case (assuming no God) "human movings are supposed to be ... the latest outcomes of ultimately impersonal causes" such that "there is and can be no one else to blame," whereas in the latter case, "responsibility must at the very least be shared with, if not shifted wholly onto" God (quoted in Helm 1988: 148). In response, Helm suggests that if, given natural determinism, "it is fair to be blamed for what one has been caused ... to do, when what one has done was voluntary or intentional," then the same must be true, given theological determinism (1988: 158). Thus, Helm suggests his own commitment to a classic compatibilist account of free will, according to which one is free and responsible for her actions even if she is deterministically caused-by personal or impersonal forces- to act as she does, so long as what she does is something she intended or willed.

Some contemporary theological determinists have accepted Calvin's basic position, that free will is compatible with causal determinism, but have proposed more sophisticated necessary conditions for free will that do not fall prey to problems with classic compatibilism. (cf. Bernard Berofsky's "Classical Compatibilism," Chapter 4, this volume, for a discussion of the difficulties facing this view.) Lynn Rudder Baker, for instance, notes, "some kinds of causes (e.g., coercion, physical manipulation) block exercise of a compatibilist free will" (Baker 2003: 460); and so she builds into her account of freedom conditions that are meant to exclude such causes. Her account, similar to Harry Frankfurt's hierarchical view, is as follows: "Person S has compatibilist free will for a choice or action if:

(i) S wills $X$,

(ii) $S$ wants to will $X$,

(iii) $S$ wills $X$ because she wants to will $X$, and

(iv) S would still have willed X even if she (herself) had known the provenance of her wanting to will X."

(Baker 2003: 467) 
Baker notes that her account is compatibilist in the sense that "a person S's having free will with respect to an action (or choice) A is compatible with A's being caused ultimately by factors outside of S's control" (Baker 2003: 460). She makes no distinction, with respect to the question of an agent's freedom, whether the agent's action is caused "by God or by natural events" (Baker 2003: 461). Thus Baker's account, like Helm's, would seem to stand (or fall) by the claim that free will is compatible with causal determinism of any sort, natural or theological.

\section{Theological-But-Not-Natural Compatibilism}

While Helm and Baker hold that both natural and theological determinism are compatible with human freedom, other theological determinists distinguish between the two forms of determinism, and maintain that only the latter is compatible with free will. This, at least, is how Thomas Flint interprets a number of theologians writing in the tradition of Thomas Aquinas, such as Reginald Garrigou-Lagrange and Theodore Kondoleon. Flint notes that such modern Thomists "have generally been reluctant to allow that the circumstances in which a free action is performed could be determinative of that action." And yet, he says, "the core Thomist contention is that every contingent event and proposition, including those involving free agents, is completely determined by God" (Flint 1988: 165). In quoting these thinkers at length, Flint makes clear that they understand God's determination of human action to be of a causal sort. GarrigouLagrange, for instance, stresses, "there is no determination without a determining cause, and the supreme determining cause is God, otherwise He would be determined by another. But this is nothing else than the principle of causality" (quoted in Flint 1988: 163). How then, do such Thomists reconcile the claim that a free choice cannot be determined by the circumstances in which it takes place with the insistence that God determines our free choices? Flint suggests that Garrigou-Lagrange and Kondoleon maintain that divine concurrent activity is not part of the circumstances in which an agent acts, since such activity is simultaneous with the action (Flint 1988: 167). This distinguishes theological determinism from natural determinism, since when a chain of natural events determines an agent's action, those events presumably occur before the action does.

More recently, Hugh McCann has offered a similar way of differentiating divine from natural causation. McCann suggests that when one natural event causes another, a "causal nexus" may be located and the "causal distance" measured between the cause and its effect. When God causes an event, though, there is no such nexus, no such distance between God and His effect, since God does not first take some action (e.g., issuing a command) that is then the event-cause of the resulting effect. Rather, "the first manifestation of God's creative will regarding our decisions and actions is ... nothing short of the acts themselves." Likewise, McCann says, God does not first create us, and then cause us to will and do things; rather, "God creates us in our willings, so that all that we are and do emanates directly from him" (McCann 2005: 145, 146).

If these characterizations of God's causation (as simultaneous with rather than prior to its effects, a form of agent- rather than event-causation, etc.) are accurate, then there are indeed grounds for differentiating divine from natural determination. The question, then, is whether these grounds are sufficient for concluding that theological determinism is compatible with human freedom, assuming natural determinism is not. While I suggested above that Helm's and Baker's accounts of free will stand or fall by the claim 
that any sort of causal determinism may be compatible with human freedom, the accounts now before us stand or fall by the contention that it is not deterministic causation as such that precludes free will, but some feature particular to natural deterministic causation, such as that natural causes occur before their effects. However, while one of the most influential arguments for the incompatibility of causal determinism and human freedom - the Consequence Argument-relies on the premise that, in a deterministic world, the ultimate causes of our actions are events of the distant past, the reason why this is considered a problem is simply that such causes lie outside of our control. So if the Consequence Argument establishes the incompatibility of free will and natural determinism, a parallel argument appealing to the fact that God's will, taken as a determining cause, likewise lies outside of our control should establish the incompatibility of free will and theological determinism (Vicens 2012). To put the point differently, it seems that those who hold that God's determination of our actions is both causal, and compatible with human freedom, ought to be 'standard' compatibilists about determinism and free will, rather than theological-but-not-natural compatibilists, since the differentiating features of natural determining causes pose no additional threat to free will, once one accepts that God's determining causation is compatible with human freedom.

\section{Non-Causal Determinism and Libertarian Freedom}

While some Thomistic thinkers seem to conceive of God's determination of events in the world along causal lines (though distinct in specifiable ways from natural causation), others adamantly deny that God should be considered a cause at all, at least in any univocal sense as creatures are. Herbert McCabe, for instance, maintains that "God makes no difference to the universe" and cannot be appealed to in explanations of why events happen (McCabe 1987: 6), that God does not "interact" with creatures (McCabe 1987: 14), and that when we act freely, we are not caused to act by anything or anyone other than ourselves (McCabe 1987: 12). This is not to say, however, that events occur outside of God's active willing and causing them, but rather that God is not an "existent among others" or, like created causes, a power that operates from the "outside" or even "alongside" that which it effects (McCabe 1987: 14). Other Thomists, such as Austin Farrer, appeal to Aquinas' doctrine of analogy to explain (or rather, to avoid explaining) in what sense God can be thought of as cause or agent:

According to this doctrine, we believe that God's way of acting is the infinitely higher analogue of our own way, but we cannot conceive it otherwise than in terms of our own. God's agency must actually be such as to work omnipotently on, in, or through creaturely agencies without either forcing them or competing with them. But as soon as we try to conceive it in action, we degrade it to the creaturely level and place it in the field of interacting causalities. The result can only be (if we take it literally) monstrosity and confusion.

(Farrer 1967: 62)

In the same vein, Michael Hoonhout applauds Aquinas for intentionally discussing the doctrine of divine providence twice in his Summa Theologiae-first in the context of "the essence of God" and then in the context of "the nature of creation" (Hoonhout 2002: 4, 5) - in recognition of "two radically different orders of intelligibility" and the "uniqueness of the Creator-created relation" (2002: 6). He writes: 
Double affirmations which seemingly contradict each other are to be expected if the integrity of each term is distinguished and respected. For there can be no real contradiction when the terms are of entirely different orders of intelligibility; attributes proper to one are improper to the other because 'God' and 'world' are not in some common genus, called 'reality as we know it.'

(Hoonhout 2002: 7)

I take the seemingly contradictory "double affirmations" to which Hoonhout refers to be these: that God determines everything that occurs in the world, and that humans have a non-deterministic form of freedom. One finds a number of writers who seem clearly committed to theological determinism when considering the 'order' of the Creator, speaking of the possibility of libertarian human freedom in the context of the 'order' of creation. Kathryn Tanner, for instance, writes that since

God does not bring about the human agent's choice by intervening in the created order as some sort of supernatural cause, so as to make up the difference between created conditions and the human being's choice and to supply that otherwise missing factor or impetus that takes away the indifference of the human will,

(Tanner 1994: 125)

one can "still affirm a very strong libertarian version of the human being's freedom" (Tanner 1994: 126). In response to the objection that the sort of universal divine causation that she has in mind means that humans are unable to do otherwise than God wills (and so, that they do not have libertarian freedom), Tanner asks:

What ... does the inability of a human agent to do otherwise than God wills mean ...? A theologian who holds to our picture of God as creator might claim that this is an inability like that whereby I say that insofar as I am choosing to do something I cannot choose not to choose ... All it means is that I cannot choose and not choose to do the same thing at the same time.

(Tanner 1994: 128)

Since such an inability is no threat to free will as libertarians construe it, Tanner concludes that neither is her conception of divine omni-causation.

It is hard to know how to assess the claims of the theologians just described, who maintain, on the one hand, that God determines everything that occurs in the world, and on the other, that humans may have libertarian freedom. The argument that these two statements are not contradictory depends on the claim that divine causation is utterly unique-nothing like natural causation—such that God's deterministically causing our actions does not preclude our being their ultimate source in the strong sense that libertarians have in mind. Yet, some of the things these thinkers say about divine causation, in attempt to show its utter uniqueness, seem also to be true of natural causation. Consider, for instance, McCabe's contention that God's power does not operate "outside" or "alongside" that which it effects, or Farrer's assertion that God's agency works through creaturely agencies "without either forcing them or competing with them." A 'standard' compatibilist would surely say the same about natural determining causes. Suppose, for instance, that my love of my sister is determined by some 
complex nexus of genes, upbringing, and environmental factors, such that when I hear her insulted, I cannot but feel offended and react in her defense. The proximal causes of my reactive behavior are not some external forces pushing or pulling me against my will, or somehow competing with me for causal power. They are, rather, the convictions and commitments that are central to my identity. Indeed, even when discussing the distal causes of my reactive behavior (the genetic and environmental factors that gave rise to my convictions and commitments) one can echo McCabe's language about the "creative causal power of God": it is this complex of causes "that makes me me" (McCabe 1987: 13). But of course, a 'standard' libertarian will deny that this is enough to underwrite my freedom and moral responsibility for what I do.

Perhaps, though, McCabe and others do not mean to say that it is these features of divine causation - the fact that it does not operate 'outside' or 'alongside' of us, etc.that make it unique. Perhaps divine causation is unique in some way that, given its uniqueness, is entirely unspecifiable. The Thomistic appeal to the doctrine of analogy seems to suggest as much. But then, if the way God causes events is really nothing at all like the way natural causes do, such that there is no univocal core to our language of divine and natural causation, it may be inappropriate to categorize this view as theological determinism at all, since the term 'determinism' would seem to have something to do with our 'creaturely' concepts of, for instance, conditional necessity. In considering the objection that his categorization of Farrer and Tanner as theological determinists reflects "a failure to qualify appropriately the analogy of action in its theological use," Thomas Tracy writes that in speaking of God determining events:

We need to make use here of only the most abstract and formal notion of agency: that God intentionally brings about certain states of affairs. The worry about determinism is triggered by the claim that this divine 'bringing about' is sufficient for its effect when that effect is a free act. However mysterious the nature of God's activity and however inadequate our analogies for it, if we affirm its universal sufficiency, we logically cannot affirm that creatures are free in the full incompatibilist sense.

(Tracy 1994: 96, footnote 20)

In other words, if God's causation of some event can truly be said to be sufficient for that event's occurrence, then God's causation of all events does imply determinism of the sort that is incompatible with libertarian freedom. However, those who I have categorized as theological determinists may simply deny that God's determination of an event is sufficient for that event's occurrence, or they may maintain that the meaning of 'sufficiency' here and in the case of natural determining causes is not itself univocal. If that is the case, then Tracy seems right to conclude that "talk of sufficiency and necessity is rendered utterly opaque. At this point, analogical usage appears to collapse into equivocation" (Tracy 1994: 96, footnote 20) and we are left without any idea of what theological 'determinism' actually means.

\section{Hard Determinism}

So far I have discussed theological determinists who, in different ways, attempt to show that their view of divine providence is compatible with human freedom. One final position that theological determinists may take is the 'standard' incompatibilist one, 
maintaining that determinism of any sort is incompatible with free will, and that therefore we are not free. Derk Pereboom has recently expounded this 'hard' theological determinist position. Pereboom admits that the view is incompatible with desert in the basic sense of deserving praise or blame just because one has performed an action "given sensitivity to its moral status, and not by virtue of consequentialist or contractualist considerations" (Pereboom 2011: 265, 266); yet he argues that the hard determinist position is compatible with judgments of value (e.g., that behavior is good or bad), as well as the reactive attitudes and practices which are central to traditional theism, and which might seem to presuppose basic desert (Pereboom 2011: 266, 267). For instance, one might worry that the attitudes of guilt and repentance, which are both "essential to good interpersonal relationships for agents prone to wrongdoing," and also "required for the moral improvement ... and sense of integrity" of such agents, are threatened by hard determinism (Pereboom 2011: 268). However, Pereboom contends that even without a sense of basic desert, we may come to recognize that "we have slighted what we take to be of value, disregarded principles we sincerely think we should live by, and failed to be the sorts of people we think we should be" (quoting Hilary Bok in Pereboom 2011:268); and we may "resolve not to perform an action of this kind again, and perhaps seek out help to make this change" (Pereboom 2011: 268, 269). So, the core features of guilt and repentance may be preserved. Likewise, Pereboom argues that the core features of forgiveness, gratitude, and love-also central to theistic belief and practice-are compatible with the hard deterministic view. For, even without free will, we can be willing "to cease to regard past immoral behavior as a reason to weaken or dissolve" relationships with others (forgiveness); we can be thankful "toward someone who has acted beneficially" and joyful "as a response to what someone has done" (gratitude); and we can, in relationship with another, wish "well for the other," take on "the aims and desires of the other" and desire to be together (love) (Pereboom 2011: 269, 270).

Some critics of Pereboom's view have argued, however, that shearing such reactive attitudes of the belief that one is in control of one's own actions would leave a person with no real sense of moral agency in relation to God. Timothy O'Connor, for instance, suggests that on Pereboom's account, a person's "repentant" confession could only take something like the following form:

Yes, God, I agree, that what you have made of me thus far is flawed in respects $\mathrm{X}, \mathrm{Y}$, and Z .... I'm on board with changing those things straightaway. I'll do my part, if that is what you have foreordained me to do. If not, not. You're calling the shots ... Since I am confessing, I confess this all leaves me a bit confused. I'm not making excuses, exactly (although I am blameless). These features really do stink, and they ought to change. Here's hoping they do.

(O'Connor 2016: 138)

O'Connor suggests that such "repentance" is nothing like what traditional theists have in mind when they confess their sins to God, since it does not, and cannot, involve the sincere commitment to change one's ways.

Even supposing that hard determinism is somehow compatible with such reactive attitudes and practices central to theistic traditions, it is another question whether the denial of free will and moral responsibility in the basic-desert sense is itself compatible with the teachings of these religions. It may be that some theological concepts often associated with free will and basic desert, such as sin, punishment, blessing, and curse, 


\section{LEIGH VICENS}

can be given a hard deterministic gloss. One might argue, for instance, that the "wages of sin" - often interpreted by Christians as retributive punishment for disobedience to God-are better understood as the natural consequences thereof. Still, it is unclear what sense a hard determinist can make of the many New Testament passages that explicitly proclaim the freedom found in Christ (e.g., Galatians 5:1, 2 Corinthians 3:17). And a hard (Christian) determinist would also need to offer some interpretation of "God's righteous judgment" (cf. Romans 2), and give some account of how a just God could allow those who are not deserving of praise or blame to "receive recompense" for the good and evil they have done (2 Corinthians 5:10). Suffice to say, there is exegetical work to be done for the hard theological determinist who is a faithful reader of Scripture.

\section{References}

Baker, L.R. (2003) "Why Christians Should Not Be Libertarians: An Augustinian Challenge," Faith and Philosophy 20: 460-78.

Calvin, J. (1813) Institutes of the Christian Religion, Vol. I. Sixth American Edition. Trans. J. Allen. Philadelphia: Presbyterian Board of Publication, available from http://www.gutenberg.org/files/45001/45001-h/45001-h. html (accessed 24 June 2016).

Farrer, A. (1967) Faith and Speculation. London: A. and C. Black.

Feinberg, J. (2001) No One Like Him. Wheaton: Crossway Books.

Flint, T. (1998) "Two Accounts of Providence," in T. Morris (ed.), Divine and Human Action: Essays in the Metaphysics of Theism. Ithaca: Cornell University Press, pp. 147-81.

Helm, P. (1988) Eternal God: A Study of God without Time. Oxford: Oxford University Press.

Helm, P. (1993) The Providence of God. Downers Grove: InterVarsity Press.

Hobbes, T. (1651) Leviathan. Adelaide: University of Adelaide, available from http://ebooks.adelaide.edu. au/h/hobbes/thomas/h68l/index.html (accessed 24 June 2016).

Hoonhout, M. (2002) "Grounding Providence in the Theology of the Creator: The Exemplarity of Thomas Aquinas," The Heythrop Journal 43: 1-19.

McCabe, H. (1987) God Matters. New York: Continuum.

McCann, H. (2005) "The Author of Sin?" Faith and Philosophy 22: 144-59.

O'Connor, T. (2016) "Against Theological Determinism," in K. Timpe and D. Speak (eds), Free Will and Theism: Connections, Contingencies, and Concerns. Oxford: Oxford University Press, pp. 132-41.

Pereboom, D. (2011) "Theological Determinism and Divine Providence," in K. Perszyk (ed.), Molinism: The Contemporary Debate. Oxford: Oxford University Press, pp. 262-80.

Tanner, K. (1994) "Human Freedom, Human Sin, and God the Creator," in T. Tracy (ed.), The God Who Acts: Philosophical and Theological Explorations. University Park: Pennsylvania State University Press, pp. 111-35.

Tracy, T. (1994) "Divine Action, Created Causes, and Human Freedom," in T. Tracy (ed.), The God Who Acts: Philosophical and Theological Explorations. University Park: Pennsylvania State University Press, pp. $77-102$.

Vicens, L. (2012) "Divine Determinism, Human Freedom, and the Consequence Argument," International Journal for Philosophy of Religion 71: 145-55.

Warfield, B. (1909). "Predestination," in J. Hastings (ed.), A Dictionary of the Bible, Vol. 4. New York: Charles Scribner's Sons, available from: http://www.monergism.com/thethreshold/sdg/warfield/warfield_ predestination.html (accessed 24 June 2016).

\section{Further Reading}

Burrell, D. (2008) “Creator/Creatures Relation: 'The Distinction' v. 'Onto-Theology,” Faith and Philosophy 25: 177-89. (Burrell rejects univocal language for divine and human causation.)

Hasker, W. (2008) "On Behalf of the Pagans and Idolaters: A Response to Burrell," Faith and Philosophy 25: 197-212. (Hasker raises critical questions about Burrell's view, mentioned above.)

Pereboom, D. (2016) "Libertarianism and Theological Determinism," in K. Timpe and D. Speak (eds), Free Will and Theism: Connections, Contingencies, and Concerns. Oxford: Oxford University Press, pp. 112-31. (Pereboom defines and defends the hard theological determinist position.) 
Talbott, T. (2008) "Why Christians Should Not Be Determinists: Reflections on the Origin of Original Sin," Faith and Philosophy 25: 300-17. (Talbott argues that Christians who accept the goodness of God and sinfulness of humanity should reject theological determinism, even if they also reject libertarian human freedom.)

Vicens, L. (2014) "Theological Determinism," Internet Encyclopedia of Philosophy, available from: http:// www.iep.utm.edu/theo-det/ (accessed 24 June 2016). (Vicens considers arguments for theological determinism, as well as implications regarding human freedom and the problem of evil.)

\section{Related Topics}

Classical Compatibilism

Skeptical Views about Free Will

The Consequence Argument

Thomas Aquinas

Thomas Hobbes and John Bramhall

Free Will and Providence

Determinism 


\section{6 \\ FREE WILL AND \\ SUBSTANCE DUALISM \\ Stewart Goetz}

\section{Introduction}

Substance dualism (dualism, for short) is the view that a human being is a soul (mind)body composite. For the sake of simplicity and clarity, I will assume that the soul is the person. In the words of C. S. Lewis, "A soul is that which can say I am" (Lewis 2004: 409). Libertarianism is the position that a person is free, at least on some occasions, to make ultimate and irreducible undetermined choices for reasons (purposes).

What is the relationship between dualism and libertarianism? Is the truth of one necessary and/or sufficient for the truth of the other? Are the two conceptually related such that the concept of one implies the concept of the other? As of now, I am unaware of any widely accepted argument that supports an affirmative answer to either of these questions. Nevertheless, it is noteworthy that dualists are very often also libertarians. A very short list of dualist-libertarians among contemporary and not so contemporary philosophers includes C. A. Campbell, William Hasker, J. P. Moreland, Alvin Plantinga, Thomas Reid, Richard Swinburne, Charles Taliaferro, and Dean Zimmerman. In what follows, I provide overviews of dualism and libertarianism and maintain that beliefs in them go hand in hand because each is basic in nature in the sense that it is not inferred from other beliefs but grounded in a non-observational, direct awareness of the self. I end by pointing out that those who reject libertarianism do so at least in part because they reject ultimate and irreducible purposeful (teleological) explanations of actions. And those who reject such explanations are typically naturalists. Perhaps if one were to reject naturalism, one would be far more receptive, first, to the reality of ultimate and irreducible purposeful explanations and then, second, to the reality of both libertarian freedom (because a choice is ultimately explained in terms of an irreducible purpose) and the soul (because a soul is that thing that chooses for ultimate and irreducible purposes).

\section{Dualism}

Robert Kane is a libertarian who does not think very highly of a belief in dualism. He explicates the epistemic relationship between libertarianism and dualism as follows:

One crude reaction [to the suggestion that we are not independent sources of active motions of our physical bodies and] ... in defense of our psyches (or ourselves as independent sources of activity) is to insist that we are not in 
the natural world at all. The self behind the window is outside the natural world altogether, looking in on it. This reaction is, of course, mind-body dualism of the Cartesian kind. I do not wish to defend such a view here, for I believe, along with most contemporary philosophers, that it is too crude a reaction to the dialectic of selfhood, and creates more puzzles than it solves ... But I think it is important to understand why dualism is a natural reaction at a certain stage in the dialectic of selfhood. It is an attempt to salvage the self or psyche as an independent source of activity by placing it beyond the subversive influences of the 'world' or 'not-self.'

(Kane 1996: 94)

According to Kane, a belief in dualism is reactive in the sense that people introduce the soul on the grounds that its existence is necessary to explain the reality of libertarian freedom in which they believe. However, there is good reason to think Kane is mistaken. According to the experimental cognitive scientist, Jesse Bering, human beings are believers in dualism from the get-go (Bering 2006). Similarly, the psychologist Nicholas Humphrey recognizes the human inclination to believe in dualism, and he cites others who deem this belief common:

Thus, development psychologist Paul Bloom aptly describes human beings as "natural-born dualists." Anthropologist Alfred Gell writes: "It seems that ordinary human beings are 'natural dualists,' inclined more or less from day one, to believe in some kind of 'ghost in the machine' ... " Neuropsychologist Paul Broks writes: "The separateness of body and mind is a primordial intuition ... Human beings are natural born soul makers, adept at extracting unobservable minds from the behaviour of observable bodies, including their own."

(Humphrey 2011: 195)

In short, the idea of the soul, whether or not it is of a ghostlike entity, has always been as universal as the air we breathe. For example, historically, a belief in the soul is found among the Greeks, Jews, Hindus (the atman), native North Americans, North Eurasians, and the Japanese (Bremmer 1983). And the contemporary action theorist, Alfred Mele, who is agnostic about our possession of libertarian free will, writes the following about participants in his studies that are designed to elicit convictions about the nature of human freedom: "I am confident that most of the participants in my studies believe in nonphysical souls" (Mele 2014: 227). If Bering, Bloom, Bremmer, et al. are right, it is not implausible to maintain that a belief in dualism is typically basic and not espoused in virtue of an intellectual effort to salvage the self as a source of activity that is not completely determined by goings-on in the physical world. Given a basic belief in dualism, it is Kane and many other contemporary philosophers who are the reactionaries insofar as they argue against dualism.

A basic belief, while not explained in terms of other beliefs, is not inexplicable. What, besides another belief, might explain belief in the soul? Roderick Chisholm contrasts the perception of external objects with awareness of the self. With the former, we know that:

Whatever our perspective upon the perceived object may be, there will always be certain parts of the perceived object that we do perceive and certain other 
parts of the perceived object that we do not perceive. Moreover, and this is the important point about external perception, if we know that we are perceiving a certain physical thing, then we are also capable of knowing that we are perceiving something that is just a proper part of that thing. But the situation is different when we perceive ourselves to be thinking.

I may perceive myself to be thinking and know that I am doing so and yet be unable to know whether I am perceiving any proper part of anything that I am perceiving. It may be, for all anyone knows, that whenever I perceive myself to be thinking, I do perceive some part of myself. This would be the case, for example, if I could not perceive myself to be thinking without perceiving some part of my body, and if, moreover, I were identical with my body or with that part of my body. But it is not true that, whenever I perceive myself to be thinking, I thereby perceive what I can know to be a part of myself.

(Chisholm 1994: 100)

In terms of epistemic strength, we can think of Chisholm as delineating a weaker position about self-awareness: whenever I am aware of myself, I am not aware of myself having any substantive parts. In light of my failure to be aware of any such parts, I come to have the basic belief that I am a soul, where a soul is an entity that is, among other things, simple in the sense that it does not have any substantive parts.

According to Chisholm, for all I know I might have substantive parts. But I also might not. Thus, it is possible that the explanation of my failure to be aware of myself having substantive parts is that I am aware of my not having any such parts. Awareness on my part of myself not having substantive parts is a stronger epistemic position and would explanatorily ground my having the belief that I am a simple soul. Descartes can plausibly be read as expressing this stronger view in the following comments:

[I]n the first place ... there is a great difference between mind and body, inasmuch as body is by nature always divisible, and the mind is entirely indivisible. For, as a matter of fact, when I consider the mind, that is to say, myself inasmuch as I am only a thinking thing, I cannot distinguish in myself any parts, but apprehend myself to be clearly one and entire; and although the whole mind seems to be united to the whole body, yet if a foot, or an arm, or some other part, is separated from my body, I am aware that nothing has been taken away from my mind. And the faculties of willing, feeling, conceiving, etc. cannot be properly speaking said to be its parts, for it is one and the same mind which employs itself in willing and in feeling and understanding.

(Descartes 1967, I: 196)

Descartes claims that he apprehends himself to be clearly one and entire and, as a result, understands that he is without parts and, thereby, indivisible. He points out that this indivisibility does not preclude his having a multiplicity of properties (faculties such as willing, feeling, conceiving, etc.). But a multiplicity (complexity) at the level of properties is not the same as being made up of substantial parts.

Descartes' claim about the contents of self-awareness, if correct, would explain why a belief in the soul is basic and not reactive in nature. It would also help answer the concern of some that it is difficult, if not impossible, to provide a positive characterization 
of the soul. According to this objection, all one learns about the soul from dualists is that it is not this and not that: it is not complex, it is not in space, it is not extended, it is not physical, etc. But this criticism is unfounded. A soul is first and foremost that simple thing that has the capacity to think, the capacities to experience pleasure and pain, the capacities to believe and desire, and the power to choose, etc.

At this point, a critic of dualism might respond that a soul is typically described as a thing that is not in space. Thus, we can give no positive characterization of its location. While it is true that Descartes seems to have held that the soul is not located in space, many other dualists believe that the soul is located in space. Indeed, up until the time of Descartes, the accepted view was that the soul is located in the space where it seems to be located, which is in the space occupied by its physical body. After all, each of us feels pains in our feet, hands, head, etc., often simultaneously. Hence, dualists such as Augustine and Aquinas held that the soul is located in its entirety at each point in space that it feels like it occupies (see Goetz and Taliaferro 2011: Chapters 2 and 3).

\section{Libertarianism}

Descartes says (in the block quote in the previous section) that he has the faculties of willing and conceiving. If we equate willing with choosing and conceiving with thinking and invoke the distinction between being an agent and being a patient, then we can consider the activity of choosing to think about something. For example, because I agreed to write this chapter, I had alternatives from which to choose. I might have fulfilled my desire to watch the World Cup quarterfinal game between Germany and France as opposed to thinking about dualism and libertarianism. As a matter of fact, I chose to think about the topics of this chapter. What explained this choice? Intuitively, I made this choice for a purpose, which was that I prepare myself for writing this chapter. Of great importance here is the fact that a purposeful explanation is ultimately and irreducibly teleological in nature.

To choose for a purpose is freely to perform a mental action for a purpose. However, sometimes I deterministically intend and proceed to act for a reason without choosing to act. I do not need to choose because I have a reason to act in one way and no reason to act in any other way. Hence, I deterministically go ahead and intend to act for the reason that I have. Thus, choice requires a plurality of reasons to act in incompatible ways. Absent this plurality, I simply go ahead by default and deterministically intend to act (and, barring the unexpected, so act) (Mele 1992: Chapter 12). It is plausible to think of this kind of situation as involving noncausal, teleological determinism, where this determinism is internal to an agent because it is a function of his or her reasongiving structure.

So the idea of purposeful action is a genus of which there are species. Some purposeful actions are free actions in the form of choices while others are determined purposeful actions. The belief that we perform purposeful actions (act for purposes) is most plausibly regarded as basic in nature. We are directly aware of ourselves acting for purposes. Hence, it might come as a surprise to someone being initiated into the contemporary philosophical study of action and freedom that most participants in the discussion talk solely or for the most part in terms of the causes of actions (including choices). One of the most well-known arguments for the causalist position is given by Donald Davidson (Davidson 1980: 9, 11, 32, 87). He questions whether "because" in "She did X because" can be plausibly understood without invoking the notion of causation. According to 
him, the sense of "because" in "She chose to do such-and-such because ... " cannot be noncausal in nature in light of the distinction between having a reason and choosing to act with it and having a reason and choosing to act because of it. One may justify a choice to act by citing a reason one has even if, in choosing, one did not choose because of it, but one cannot explain a choice by citing a reason unless one chose because of it. Davidson argues that if the sense of "because" is not causal, then we are left without an analysis of "because" in "She chose to do such-and-such because ...," where we go on to name a reason. Reasons explanations must, therefore, be causal explanations.

Because Davidson believes that a reason explains a choice only if it consists of what he calls a pro-attitude (a desire plus a belief), his argument for the view that the sense of "because" in reasons explanations must be causal in nature implies the following about the explanatory role of desires and beliefs: Whenever an agent chooses to act for a reason, she has desires and beliefs prior to and/or simultaneously with her choosing. It is the having by her (an event) of these propositional attitudes that causally explains her choice. It is either the eventful coming to have such propositional attitudes or the eventful persistence in having these attitudes that serves as the cause of the agent's choice.

At this point, an example might prove helpful. Consider an example of Carl Ginet's in which agent $S$ urgently needs her glasses, which she has left in R's room where $\mathrm{R}$ is now sleeping. S has a desire to wake R, because she would then have R's company, but also a desire not to wake R, because she knows that R needs the sleep (Ginet 1990: 145, 146). S chooses to enter R's room in order to get her glasses, knowing as she does so that her action will satisfy her desire to wake R. Could it nevertheless be true that $\mathrm{S}$ did choose to enter the room for the purpose that she wake R? It seems right to say that $\mathrm{S}$ did not choose to enter the room for the purpose that she wake $\mathrm{R}$ if she was so disposed that had it turned out that her entering the room did not wake R, S would not have felt that her plan had failed to be completely realized, and that she must then either wake $\mathrm{R}$ in some other way or choose to abandon part of her plan. And S's not being committed to waking $\mathrm{R}$ is quite compatible with S's expecting and desiring to wake $\mathrm{R}$.

$\mathrm{S}$ has two reasons to enter R's room, namely, a desire to wake $\mathrm{R}$ and a desire to get her glasses, and beliefs about how to fulfill these desires. $S$ has two reasons that justify her entering R's room. According to Davidson, if S chooses to enter R's room because of one of the reasons but not the other, this can only be because one of the reasons caused her to choose in this way. The reason that causes S's choice explains that choice.

Contrary to what Davidson argues, the distinction between justifying a choice and explaining a choice can be preserved when "because" is understood teleologically. In the case of S, what understanding "because" teleologically implies is that S chose to enter R's room in order to achieve the purpose that she get her glasses but not in order to achieve the purpose that she wake $\mathrm{R}$. There is a fact of the matter here that $\mathrm{S}$ chose for one of the reasons and not the other. Teleological explanation of a choice makes reference to a future goal of an agent (in S's case, that she get her glasses) with respect to which she sees her chosen action as a means. What Davidson would wrongly have us believe is that this reference to a future end must always be converted into a reference to a prior and/or simultaneous eventful cause, if we are to have an adequate explanation of an agent's choice.

What, then, about a belief in libertarianism, which is the idea that some of our purposeful actions are undetermined choices? Is a belief in it, like the beliefs in the soul and purposeful explanations of our actions, basic? Not surprisingly, there are weaker and 
stronger epistemological positions regarding libertarianism that mirror the weaker and stronger epistemological positions concerning the soul's existence. To illustrate the weaker position concerning libertarianism, consider the following comments by the nonlibertarian Daniel Dennett. According to him, we as agents fail to be aware of the causes of our choices (Dennett 1984: 77). He points out that it is erroneous to believe that our choices have no causes and are undetermined. Such a belief fails to take into account the fact that mental events are surface or macro features of the world that are likely effects of undetectable micro causes. It is because a choice "bubbles up to consciousness from we know not where" (Dennett 1984: 78), and we are unaware of any causes of it at the surface level, that we think it is uncaused simpliciter. According to Dennett:

Whatever else we are, we are information-processing systems, and all informationprocessing systems rely on amplifiers of a sort. Relatively small causes are made to yield relatively large effects ... Vast amounts of information arrive on the coattails of negligible amounts of energy, and then, thanks to amplification powers of systems of switches, the information begins to do some work, ... leading eventually to an action whose pedigree of efficient . . . causation is so hopelessly inscrutable as to be invisible. We see the dramatic effects leaving; we don't see the causes entering; we are tempted by the hypothesis that there are no causes.

(Dennett 1984: 76, 77)

As with the weaker epistemic position concerning the soul, one might hold that a belief in libertarianism is basic because of a failure to be aware of any causes of our choices. And as with the weaker epistemic position concerning the soul, one might explain this failure to be aware of any causes of choices in terms of awareness that there are no causes. Thus, the stronger epistemic position in support of libertarianism holds that we are aware of our choices being undetermined because we are aware of them not having any causes. And we are aware of them not having any causes because awareness of a choice is awareness of an event of an agent that is essentially uncaused (Goetz 2008).

The plausibility of this stronger epistemic position rests in part on views about the nature of a choice. Philosophers such as Dennett believe that a choice is a higher level conscious event whose causes are lost in the lower level workings of the brain. His view presupposes a prior rejection of the soul as the agent making the choice. However, if a choice is an event in a substantially simple soul, it is a lower level occurrence, and the idea that its causal history, or the lack thereof, is beyond the agent's conscious awareness loses its plausibility.

The view that choices are uncaused mental events is known as noncausal libertarianism. It has been unpopular not only among determinists (including compatibilists) but also among libertarians known as agent causationists who have insisted upon the need for causation in explaining freedom of choice. According to agent causationists, causation is a genus of which there are two species, agent and event causation. With agent causation, when an agent makes a choice an event that is either the choice or a part of it is caused by the agent, but there is no additional event involving the agent that causally produces the choice or the relevant event-part of it. Moreover, the agent who causes the choice or the relevant event-part is not caused to cause that action/event. 
Timothy O'Connor is a contemporary agent causationist who dismisses noncausal libertarianism on the grounds that there must be something to link the reason for which an agent chooses with that choice.

Were we . . simply [to] claim that the [choice] was uncaused [and made for a reason], then noting the fact that the agent had a reason that motivated acting in that way would not suffice to explain it (as Davidson has famously argued). For in that case, any number of actions may have been equally likely to occur, and the agent would not have exercised any sort of control over which of these was actually performed.

(O’Connor 1995: 191)

O'Connor believes that the link between a reason to choose and the choice made for that reason must be agent-causal in nature. An agent's exercise of active or agent-causal power "provides a necessary link between reason and [choice], without which the reason could not in any significant way explain the [choice]" (O'Connor 2000: 88). According to O'Connor, a choice is defined as a complex state of affairs consisting of an agent's bearing a causal relation to a causally simple mental event that is the comingto-be of an intention to act (O'Connor 1995: 198, endnote 15). A reason will explain a choice only if the noncausal teleological connection between it and the coming-to-be of the intention to act is coupled with the agent's agent-causing of the coming-to-be of the intention, where this agent-causal activity must itself be uncaused or have no sufficient causal condition (O'Connor 1995: 186, 187; 1996: 146). Thus, in the case of agent $\mathrm{S}$, she entered R's room because of her desire to get her glasses and with her desire to wake $\mathrm{R}$ because she agent-caused the coming-to-be of the intention to enter R's room, where the content of that intention includes reference to the desire (reason) to get her glasses which the action of entering the room will satisfy.

Does O'Connor's agent-causal libertarianism have a leg up on noncausal libertarianism? Not at all. To see why, what one needs to ask is "What explains S's agent-causing of the coming-to-be of the intention to enter R's room?" (Rice 2011). Presumably, the answer is that it is teleologically explained by the same reason for entering R's room that teleologically explains S's choosing to enter that room, which is that she get her glasses. Thus, all that O'Connor's agent causationist account does is relocate the ultimate and primitive teleological connection, which on the noncausal libertarian view is between the choice and the reason for which it is made, to the relationship between agent's exercising of agent-causal power, which O'Connor claims is essentially uncaused (O'Connor 2000: 81, footnote 25; 2002: 349) and the reason for which it is made. Therefore, agent causation is explanatorily superfluous.

\section{Conclusion}

In discussing how to account for libertarian freedom, I have stressed the centrality of teleological explanations of choices. Perhaps the issue that ultimately divides libertarians and non-libertarians is not a disagreement about the nature of freedom but the respective acceptance and rejection of ultimate and irreducible teleological explanations of human choices. To develop this idea just a bit, consider the following thoughts about libertarian freedom by the non-libertarian Derk Pereboom (Pereboom 2014: 65-70). He believes that the most plausible species of libertarianism must include agent 
causation. Let us concede this point for the sake of discussion. He makes clear that if there are exercises of agent-causal power, then it is only reasonable to think that those exercises of power causally produce events in the brains of human beings that diverge from the events that would occur in those brains in accordance with natural physical laws alone. The problem, he says, is there is no evidence that such events occur.

But is there really no evidence that such events occur? The relevant events presumably include those in Pereboom's own brain which lead to the movements of his fingers that depress the keys of his computer when he authors papers and books. Is it really plausible to maintain that on these occasions the movements of his fingers and the brain events that causally produce them are ultimately completely explicable in terms of non-teleological, law-governed physical events? Neil Levy (2014) describes cases of what he terms "global automatism" in which subjects engage in complex and seemingly teleological behavior, while supposedly not being conscious of what they are doing. For example, Levy describes a case of a man, Kenneth Parks, who walked to his car, drove 23 kilometers to his in-law's home, strangled his father-in-law into unconsciousness and repeatedly stabbed his mother-in-law, who later died. Parks subsequently drove to a police station, where he notified police of what he thought he might have done and first noticed severed tendons in his severely injured arms. He pleaded not guilty and was acquitted on the grounds that his behavior was caused by a serious sleep disorder. Levy also describes a case of sleep emailing in which a subject was caused by a sleep disorder to type an intelligible email, without being conscious of what she was doing.

If subjects can be unconsciously and blindly caused to perform these seemingly purposeful behaviors, might it be plausible to maintain that all of our behavior, even the writing of a book, is ultimately explicable in terms of purposeless causes? Not in the least. Borrowing from Levy, one can plausibly hold that subjects originally engage in conscious, purposeful activity that programs their brains with 'action scripts,' which are sets of motor representations that can subsequently be non-consciously causally activated to produce forms of behavior that could only have had their causal origins in conscious purposefully held intentions and choices. Thus, there can be instances of global automatism only because there is conscious purposeful activity at the outset, and there is no good reason to accept the idea of universal global automatism from the get-go. If Pereboom believes it is reasonable to espouse the notion of universal global automatism ab initio, then it is easy to understand why he also believes there is no evidence for the occurrence of brain events that diverge from those that would occur in accordance with natural physical laws alone.

In the end, perhaps questions about the nature of freedom, while important, are really secondary in nature. Perhaps the primary issue dividing libertarians and non-libertarians is whether there is explanatory space for ultimate and irreducible teleological explanations. Stated in different terms, perhaps the primary issue dividing the two groups concerns the truth or falsity of naturalism, where naturalism is the view that all that goes on is in principle completely explicable in purposeless, causal terms (Goetz and Taliaferro 2008; Schlosser 2011). Perhaps, if one rejects naturalism, there is much less reason to react negatively toward dualism, where the soul is that thing which acts purposefully, whether nondeterministically or deterministically. While a belief in a dualism of kinds of explanations, teleological and causal, is not the explanation for a belief in a dualism of soul and body, it meshes conceptually very well with it. 


\section{References}

Bering, J. (2006) "The Folk Psychology of Souls," Behavioral and Brain Sciences 29: 453-62.

Bremmer, J. (1983) The Early Greek Concept of the Soul. Princeton: Princeton University Press.

Chisholm, R. (1994) "On the Observability of the Self," in Q. Cassam (ed.), Self-Knowledge, Oxford: Oxford University Press, pp. 94-108.

Davidson, D. (1980) Essays on Actions and Events. Oxford: Clarendon Press.

Dennett, D. (1984) Elbow Room: The Varieties of Free Will Worth Wanting. Cambridge: MIT Press.

Descartes, R. (1967) The Philosophical Works of Descartes, Vol. I, E.S. Haldane and G.R.T. Ross (eds). Cambridge: Cambridge University Press.

Ginet, C. (1990) On Action. Cambridge: Cambridge University Press.

Goetz, S. (2008) Freedom, Teleology, and Evil. London: Continuum.

Goetz, S. and Taliaferro, C. (2008) Naturalism. Grand Rapids: Eerdmans.

Goetz, S. and Taliaferro, C. (2011) A Brief History of the Soul. Oxford: Wiley-Blackwell.

Humphrey, N. (2011) Soul Dust. Princeton: Princeton University Press.

Kane, R. (1996) The Significance of Free Will. Oxford: Oxford University Press.

Levy, N. (2014) Consciousness and Moral Responsibility. Oxford: Oxford University Press.

Lewis, C.S. (2004) The Collected Letters of C. S. Lewis: Books, Broadcasts, and the War,1931-1949, Vol. II, W. Hooper (ed.). New York: HarperSanFrancisco.

Mele, A.R. (1992) Springs of Action: Understanding Intentional Behavior. Oxford: Oxford University Press.

Mele, A.R. (2014) "Reply to Nadelhoffer and Vargas," in W. Sinnott-Armstrong (ed.), Moral Psychology: Free Will and Moral Responsibility, Vol. 4. Cambridge: MIT Press.

O'Connor, T. (1995) "Agent Causation," in T. O'Connor (ed.), Agents, Causes, and Events: Essays on Indeterminism and Free Will. Oxford: Oxford University Press, pp. 173-200.

O'Connor, T. (1996) "Why Agent Causation?" Philosophical Topics 24: 143-58.

O'Connor, T. (2000) Persons and Causes: The Metaphysics of Free Will. Oxford: Oxford University Press.

O'Connor, T. (2002) "Libertarian Views: Dualist and Agent-Causal Theories," in R. Kane (ed.), The Oxford Handbook of Free Will, Oxford: Oxford University Press, pp. 337-55.

Pereboom, D. (2014) Free Will, Agency, and Meaning in Life. Oxford: Oxford University Press.

Rice, R.L.H. (2011) "Agent Causation and Acting for Reasons," American Philosophical Quarterly 48: 333-45.

Schlosser, M.E. (2011) "Agency, Ownership, and the Standard Theory," in J.H. Aguilar, A.A. Buckareff, and K. Frankish (eds), New Waves in Philosophy of Action. New York: Palgrave Macmillan, pp. 13-31.

\section{Further Reading}

Goetz, S. (2008) Freedom, Teleology, and Evil. London: Bloomsbury. (Goetz argues for a teleological understanding of free will, libertarianism, and substance dualism.)

Mawson, T. J. (2011) Free Will: A Guide for the Perplexed. London: Bloomsbury. (An overview of the breadth of issues involved with free will, including its relationship to the soul.)

O'Connor, T. (1995) Agents, Causes, and Events: Essays on Indeterminism and Free Will. New York: Oxford University Press. (A leading teleological account of agent-causal libertarian freedom.)

Pereboom, D. (2001) Living without Free Will. Cambridge: Cambridge University Press. (An argument against the existence of free will, in part, based on the kinds of beings we have reason to believe humans are.)

Timpe, K. (2013) Free Will: Sourcehood and Its Alternatives, 2nd edn. London: Bloomsbury. (A libertarian account of free will that is compatible with both dualism and other views of human nature.)

\section{Related Topics}

Event-Causal Libertarianism

Agent Causation

René Descartes

Thomas Hobbes and John Bramhall

Neuroscientific Threats to Free Will 


\section{7 \\ FREE WILL AND GRACE \\ Timothy Pawl}

Discussions of the relationship between free will and grace are traditionally located within a larger dialectic about the interrelations between grace, freedom, God's knowledge, predestination, divine sovereignty, and God's providential control over creation. That larger discussion has many moving parts. In the Catholic intellectual tradition, these parts and their interrelations were debated in many places, most forcefully and prolongedly in the de Auxiliis controversy. As the Catholic Encyclopedia says, "after twenty years of discussion public and private, and eighty-five conferences in the presence of the popes, the question was not solved." This chapter does not aim to succeed where those hundreds of learned philosophers and theologians failed. Rather, its goal is to present one aspect of those debates - a difficulty concerning the interrelations of grace and free will — and show some of the common traditional and contemporary views on the issue.

I begin by presenting an argument that concludes in a contradiction. The premises of that argument have strong support from the Christian intellectual tradition. After presenting the support for the premises, I will explore some ways in which thinkers have responded to this problem. In this chapter, I will focus exclusively on Christian teachings, since the conception of grace at the center of the discussion is a Christian conception.

The main concern about the interrelations of free will and grace can be put briefly as follows. According to the traditional Christian teaching, at least in the West, where the councils of bishops I go on to cite met, grace is required as a necessary condition for any fallen human to do just about anything that is good or pleasing to God. And God does not owe this grace to anyone, but rather it is a gratuitous gift (hence we call it 'grace' and not, say, 'merit'). But, at the same time, one can be responsible for lacking grace, and for not doing that which one cannot do without the grace one has not received. A difficulty arises here: if it is not in my control to acquire grace, or to do anything good by means of which I can acquire grace without first having grace, how can I be responsible for lacking grace, or for any omission of an act that I do not perform and lack the requisite grace to perform? The remainder of this chapter considers this question.

\section{The Problem Presented}

1. If whether or not something occurs is outside the control of an agent, then that agent is not morally responsible for its not occurring.

2. It is outside the control of every post-fall, human agent that she come to faith, or perform other salutary actions. 
3. No post-fall, human agent is morally responsible for her not coming to faith, or for her not performing other salutary actions (Modus Ponens, 1, 2).

4. However, at least some post-fall, human agents are morally responsible for their not coming to faith, or for their not performing salutary actions.

5. Contradiction! (Conjunction 3,4).

Since Steps 3 and 5 are derivations from Premises 1, 2, and 4, I will focus the following discussion on the support available from the Christian tradition for 1, 2, and 4. After providing support for those claims in this section, I go on to provide some responses to this argument in the following section.

Premise 1 is a near neighbor to the commonly accepted principle 'ought implies can.' If one thinks, as seems intuitively true, that one can be blamed for something only if she ought to have done it, then, together with ought implies can (and hypothetical syllogism, then contraposition), we can derive the truth of the aspect of Premise 1 relevant to this argument: if someone cannot do something, then she is not blameworthy for not doing it.

We find Premise 1 accepted by very many people in the free will and moral responsibility literature. For instance, Thomas Nagel (1993: 58), in literature unrelated to the problem of grace and free will, writes "Prior to reflection it is intuitively plausible that people cannot be morally assessed for what is not their fault, or for what is due to factors beyond their control." Derk Pereboom provides the "core incompatibilist claim about origination" as follows:

(O) If an agent is morally responsible for her deciding to perform an action, then the production of this decision must be something over which the agent has control, and an agent is not morally responsible for the decision if it is produced by a source over which she has no control.

(Pereboom 2001: 47)

It is the last conjunct of that core claim that expresses something very close to Premise 1. Pereboom writes elsewhere (Pereboom 2001: 48) "by incompatibilist intuitions, an agent is not responsible for decisions determined by factors beyond his control." For more authors expressing that control is required for moral evaluation, see K. E. Boxer (2013: Chapter 1), Randolph Clarke (2006: 17), and Michael McKenna (2012: 12).

In the literature on grace and free will, we find Premise 1, or something similar, affirmed by many of the discussants. Scott Ragland writes, "if faith is not free-if it is not up to us whether or not we have faith - then those who fail to have faith are not morally responsible for this failure" (Ragland 2006: 346). Eleonore Stump affirms that for an agent to be free and morally responsible for an act "she herself needs to be in control of her action; her act has to be produced by her own intellect and will" (Stump 2001: 126). Kevin Timpe writes as follows:

An agent can only be morally responsible for an event that she has some control over. Let us call this the control condition for moral responsibility: an agent $S$ is morally responsible for an event $e$ only if $S$ has (or at some point had) control over the occurrence of $e$. 
In addition, Timpe states, "control over an event is required for moral responsibility" (2007: 298). Keith Wyma writes "If God lays a demand, an 'ought,' upon us, he must supply the 'can,' the ability to carry out what's required" (2004: 267) and again, more colorfully, "if she had no control over getting drunk, can she be blamed for her subsequent blacked-out drunken brawl with a deacon? Seemingly not" (2004: 272).

Moreover, we find paragons in Christian intellectual tradition affirming it. As Kantzer Komline (2014: n. 89) notes in her excellent article on Cyprian's influence on Augustine's understanding of grace and free will, Justin Martyr writes in his First Apology, section 43:

Unless the human race has the power by free choice to avoid evil and to choose good, there is no responsibility for actions of whatever kind they be.

(Justin Martyr 1997: 52)

Athenagoras, a second-century philosopher and convert to Christianity writes, when discussing the punishment of the fallen angels, "for you would not honor the virtuous and punish evildoers if vice and virtue were not within their free choice" (1956: 62).

Jesus himself says things that Christian thinkers read as supporting Premise 1. In the Gospel of John, Jesus says:

Remember the word I have said to you, "Servants are not greater than their master." If they [anyone] persecuted me they will persecute you; if they kept my word, they will keep yours also. But they will do all these things to you on account of my name, because they do not know him who sent me. If I had not come and spoken to them, they would not have sin, but now they have no excuse for their sin.

(John, 15:20-22, NRSV; emphasis mine)

What does it mean when Jesus says that if he had not come and spoken to the people, that they would not have sin, but that now they have no excuse for their sin? Aquinas (following St. Augustine), understands the passage as follows:

[I]f Christ had not come and had not spoken to them, they could not have believed. And no one is charged with a sin for not doing what he can't do at all.

(Aquinas 1980: Chapter 15, Article 5, Paragraph 2046, p. 416, emphasis added)

Here we find Aquinas stating that if one can't do something, then he is not charged with a sin for not doing it. This claim is a paraphrase of Premise 1 of the above argument. Elsewhere he writes, "It is therefore evident that a good or evil action deserves praise or blame, in so far as it is in the power of the will" (Aquinas 1981 ST. I-II q.21 a.3 resp). Moreover, Aquinas writes:

It must be stated that no one is bound to what is above his powers except in the manner in which it is possible for him. However, believing is above man's natural power. Hence it [the act of believing] arises from a gift of God ... A man, therefore, is bound to believe insofar as he is helped by God to believe.

(Aquinas 1983: Quod 2, q.2 a.1 resp) 
Here Aquinas claims that no one is bound to do what is above his powers. But then, if we are only blameworthy for not doing what we are bound to do, then no one is blameworthy for not doing what is beyond his power. The latter half of the quotation will be important when we turn to replies to this argument.

Concerning Premise 2, that it is outside of the control of every post-fall, human agent that she come to faith, or do other salutary actions, this claim is part of the traditional Christian doctrine of grace. The traditional doctrine of grace was developed in response to debates concerning whether a person, from her own power alone, and without divine assistance, could live an upright, sinless life. That question was forcefully answered in the negative: one cannot live uprightly without special divine graces. Similarly, one cannot earn or merit the gift of faith. To think otherwise is to affirm what has been called the Pelagian heresy, after Pelagius, a contemporary of St. Augustine. For some work on Pelagianism and its relation to the orthodox doctrine, primarily espoused by St. Augustine of Hippo, see Bonner (1992, 1993), Rackett (2002), and Augustine (2004).

The next question naturally arises: if one can neither live a perfectly sinless life nor earn one's salvation without grace, what can a person do without such grace? Can a person want to act uprightly of her own power, without special divine aid in the form of grace? Or is even the wanting to do good itself a good thing that one cannot do without the aid of divine grace? To affirm that a person, after the Fall, could form the desire to come to faith or perform a salutary act, that is, an act meritorious for salvation, without the aid of divine grace is to affirm what has come to be known as SemiPelagianism, a view which was condemned, at least in the West, at the Second Council of Orange in 529, the teachings of which are mainly quotations and paraphrases from the works of St. Augustine. As the Catholic Encyclopedia (Weber 1911) states: "The acts of the council, which were signed by the bishops, the pretorian prefect Liberius and seven other distinguished laymen, were forwarded to Rome and approved by Boniface II on 25 January, 531. They consequently enjoy œecumenical authority.” This council is also held as important for some confessional protestant groups, especially the Reformed. In the Canons of the Second Council of Orange, we find expressed the following:

Canon 1. If anyone denies that it is the whole man, that is, both body and soul, that was "changed for the worse" through the offense of Adam's sin, but believes that the freedom of the soul remains unimpaired ... he is deceived by the error of Pelagius and contradicts the scripture...

Canon 4. If anyone maintains that God awaits our will to be cleansed from sin, but does not confess that even our will to be cleansed comes to us through the infusion and working of the Holy Spirit, he resists the Holy Spirit ...

Canon 6. If anyone says that God has mercy upon us when, apart from his grace, we believe, will, desire, strive, labor, pray, watch, study, seek, ask, or knock, but does not confess that it is by the infusion and inspiration of the Holy Spirit within us that we have the faith, the will, or the strength to do all these things as we ought; or if anyone makes the assistance of grace depend on the humility or obedience of man and does not agree that it is a gift of grace itself that we are obedient and humble, he contradicts the Apostle...

(Leith 1982: 38-9) 
An earlier council at Carthage (418) claimed that it is a gift of grace that humans are able both to desire to do and actually able to do what they know they ought to do (Pohle 1917: 25). And the same council claims that the knowledge of what to do, and the love of doing what one ought to do also are gifts from God (Pohle 1917: 28).

Aquinas and others agree with this view, claiming that humans cannot will or do good acts apart from a unique grace given by God. Aquinas, at least in his later works, following Augustine, somewhat tempers this response by claiming that there are some good things that a human can do without a unique grace, such as planting a vineyard (Summa theologiae, I-II q.109, a.5, resp.). For some good work on the progression of Aquinas's thought on free will and grace, see Lawler (1971). Fr. Joseph Pohle, a manual theologian working in the early part of the twentieth century, writes in his dogmatic treatise on the Catholic doctrine of grace, that it is a certain proposition that "Fallen man, whether pagan or sinner, is able to perform some naturally good works without the aid of grace" (1917: 55).

The type of grace under discussion in this chapter has been called 'actual grace' by theologians, as opposed to 'habitual grace.' Habitual grace is also known as 'sanctifying grace,' which is the grace whereby a person is brought into salvific union with God. It is that which places the person into a supernatural state by providing the gifts of the theological virtues: faith, hope, and love. Pohle defines actual grace as:

[A]n unmerited, supernatural, internal divine help, based on the merits of Jesus Christ, which renders man pleasing in the sight of God, enabling him to perform salutary acts; or, somewhat more succinctly, as a supernatural help bestowed for the performance of salutary acts, in consideration of the merits of Jesus Christ.

(Pohle 1917: 15)

In short, on the traditional Christian view, the human free will is weakened due to sin. Not only are humans unable to perform salutary acts on their own power, apart from divine grace, we cannot even have the will or desire to perform salutary acts apart from the special grace given by God. Moreover, such grace is a free gift from God, unmerited and unmeritable on our own, gratuitously given by God.

Step 3 is justified by derivation from Premises 1 and 2. Thus, provided that the justification for 1 and 2 is sufficient, Step 3 is justified as well.

Concerning Premise 4, the traditional Christian view is that one can be responsible for the omissions of one's actions. For instance, in the parable of the sheep and goats, Christ commands the metaphorical goats to depart from him into everlasting hellfire, saying:

"You that are accursed, depart from me into the eternal fire prepared for the devil and his angels; for I was hungry and you gave me no food, I was thirsty and you gave me nothing to drink, I was a stranger and you did not welcome me, naked and you did not give me clothing, sick and in prison and you did not visit me." Then they also will answer, "Lord, when was it that we saw you hungry or thirsty or a stranger or naked or sick or in prison, and did not take care of you?" Then he will answer them, "Truly I tell you, just as you did not do it to one of the least of these, you did not do it to me."

(Matthew 25:41-45, NRSV) 
Here the explanation for their moral condemnation is their omission to do something, for instance, feed the hungry. But that very action is one they could neither perform nor will to perform without grace from God, which God is free either to give or not to give.

Step 5 concludes to a contradiction, and so must be false. As such, since the argument is valid, at least one of the premises must be false, or there must be a hidden equivocation in the argument.

Here, then, is the problem. Grace is required for me to do anything, or just about anything, salutary, morally praiseworthy, or good. And that grace is not something I can attain for myself, or earn, or merit. Yet I can be morally responsible for my omissions, as when I omit to render unto God the adoration due to him. You can rightly hold me morally responsible and blame me for things that I didn't do but should have. How can this be, though, if my being able to do the thing in question - indeed, even my ability to will to do the thing in question-is something over which I do not have control? I cannot do the thing without outside, gratuitously given, unmeritable help; I cannot will to do the thing without outside gratuitously given, unmeritable help; I cannot will to will to do the thing without outside gratuitously given, unmeritable help, etc. If control is a necessary condition for freedom and moral responsibility, and I lack that requisite control over some of my actions or inactions, then I can be neither free nor responsible for those actions or inactions.

In what follows, I will present some common replies to this quandary.

\section{The Solutions Presented}

One response to this argument is to deny the truth of the first premise. Ragland (2006: 347) notes that Harry Frankfurt (1986), Gary Watson (1999), and Lynne Rudder Baker (2003) each have a way, as compatibilists, of denying the truth of this first premise. Ragland writes:

These thinkers ... claim that the causal origins of an action are irrelevant to the question of whether it is free, so it is possible for us to be morally responsible for our actions even if they are causally determined by another agent.

(Ragland 2006: 347)

Control, for them, is not a necessary condition for moral evaluation.

A second response is to deny the second premise. One way to do this is to deny the traditional doctrine of grace. Perhaps it is naturally under our control, without a special gift of grace, to desire the gift of faith, or to do salutary acts. Or perhaps it is in our control to come to faith, not insofar as we can do it on our own, but insofar as the grace required is not gratuitous, but rather owed. This is the view of James Gould (2008), who claims that while, on the traditional view, "grace is undeserved, supererogatory and free," in fact, he claims, "an offer of saving grace is deserved, obligatory, and must be distributed equally. ... Being offered salvation is a human right and offering it a divine duty" (2008: 261, 262). On this view:

God does not owe us efficacious grace, grace that actually saves by causing us to repent and believe. But God does owe us sufficient grace, grace that-by enlightening our minds and freeing our wills—-makes us fully able to respond to 
the offer of salvation. Actual salvation requires our cooperation, and God's assistance must leave us free to accept or reject God's love.

(Gould 2008: 265)

Here we see that, on Gould's view, since all humans receive the grace to be fully able to respond to the offer of salvation, it is false that it is outside of every post-fall human's control to come to faith. Each human, on this view, has the grace required-since God is obliged to give it - to come to cooperate with God's work of salvation. And so it is in the post-fall human's control whether to come to faith, or whether to do salutary acts.

A view that is similar in results but different insofar as it does not deny the traditional doctrine of grace is suggested by Ragland $(2006: 360,361)$. He draws a common distinction between prevenient grace and cooperating grace (though he focuses on "convincing grace," which is, in the traditional way of carving the distinction, a species of cooperating grace). Pohle draws the distinction well when he says:

The vital acts of the soul are either spontaneous impulses or free acts of the will. Grace may precede free-will or coöperate with it. If it precedes the free determination of the will it is called prevenient; if it accompanies (or coincides with) that determination and merely coöperates with the will, it is called coöperative grace.

(Pohle 1917: 32)

Prevenient grace is elsewhere called 'operative' grace or 'antecedent' grace, as in, antecedent to the act of the will. Prevenient grace is grace one receives and is affected by without the will's consent. Ragland claims of prevenient grace:

On this view, God not only offers, but gives grace to all people. This grace gives them the ability—absent from fallen human nature by itself—-to trust Christ. Whether people choose to exercise this ability to have saving faith is a matter of libertarian freedom in the fullest sense-a matter of deliberate choice.

(Ragland 2006: 360, emphasis in original)

Ragland's view, then, is similar to Gould's insofar as it denies Premise 2, since it is not outside the control of the agent to come to faith, given God's gratuitous gift of prevenient grace. This account differs from Gould's insofar as Ragland's account does not require grace to be owed to any fallen human. Both accounts agree, though, that no fallen human earns the divine help required to control whether one accepts the offer of grace. That special divine help, the prevenient grace, is given by God, unearned by humans, and such that it provides the post-fall human with the means by which to control whether she cooperates with grace to accept the gift of faith.

Ragland's sort of view is a common Catholic view, too. The Council of Trent teaches that humans (it does not explicitly say 'all') receive unearned, prevenient grace whereby they can cooperate with God in their salvation. Pohle draws the common distinction between efficacious and sufficient grace.

By efficacious grace (gratia efficax) we understand that divine assistance which with infallible certainty includes the free salutary act ... Merely sufficient grace (gratia mere sufficiens) is that divine assistance whereby God communicates to 
the human will full power to perform a salutary act (posse) but not the action itself (agere).

(Pohle 1917: 41)

A person with merely sufficient grace, then, is someone who has the full power to act as she ought to receive the gift of faith, but has not so acted. As Pohle notes:

[T] here is no real but a purely logical distinction between efficacious and merely sufficient grace. If we look to the final result, however, we find that this differs according as the will either freely coöperates with grace or refuses its coöperation. If the will coöperates, grace becomes truly efficacious; if the will resists, grace remains "merely sufficient." In other words, merely sufficient grace confers full power to act, but is rendered ineffective by the resistance of the will.

(Pohle 1917: 42, 43)

One who receives the prevenient merely sufficient grace can make that grace become efficacious. Recall, though, that efficacious grace is not a new type of grace; it is suffcient grace that the human has cooperated with in the act of coming to faith. The question, then, becomes, 'To whom does God give sufficient grace?' For if God gives it to all humans, then no human is in a position, due only to a lack of grace, such that it is outside her control whether she can come to faith, or perform a salutary action. As Pohle notes, and is at pains to prove, "God gives all men [i.e., humans] sufficient graces" (1917: 167-186). But then given this view of the saturation of prevenient grace, Premise 2 of the argument is false; that is, it is false that it is outside of the control of every post-fall, human agent that she come to faith, or do other salutary actions. For more on the distinction between efficacious and sufficient grace, presented in a way perhaps inconsistent with Fr. Pohle's position outlined here, see Reginald GarrigouLagrange (1998: pt. 3, Chapter 1). Also see Heidi Russell's (2010) recent and helpful article on the issue.

Here we might draw a distinction between something's being outside of one's control without aid, and something's being outside of one's control with aid. Considered without the gratuitous aid given by God, it is outside of a human's control to come to faith. But considered in the actual situation she is in, with the aid she has been given, it is in her control to come to faith. The proponent of these three views under discussion here, Gould's, Ragland's, and Pohle's views, claims that the relevant criterion for control is the person's control over coming to faith all things considered, including divine aid. And on such a criterion and reading of Premise 2, Premise 2 is false.

Do any of these three views, as briefly stated, run afoul of the Anti-Pelagian Constraint? If so, I do not see how. No human does or even wills anything good or salutary without some prior grace changing the human so as to be able to do it. No postfallen human performs a salutary act without grace, or even desires to perform such an act, without the prevenient grace given by God. Many might be surprised about this judgment, but I think that is due to a misunderstanding of what Pelagianism requires. For a good discussion of why seven different views that may be charged with Pelagianism in fact are not Pelagian, see Richard Cross (2005).

Eleonore Stump (2001, 2005: Chapter 13, 2007) provides another way to deny Premise 2. On her view, post-fallen humans have the requisite control over coming to faith, not insofar as they have the power to assent to the free gift of faith, but rather because 
they have the power to cease resisting. According to Stump, the human will has three positions with respect to something willable: it can will for it, it can will against it, and it can be neutral, or 'quiescent' with respect to it. You desire that your car will be there when you leave the building; you desire against its being vandalized; and you have no desire one way or the other about whether the fifth car down the row from your own is red or not. Before the infusion of grace, Stump says, the sinner has two alternate possibilities open to her-quiescence and rejection (2005: 402). Neither rejecting grace, nor being in a quiescent state, which itself is not an act of the will, but the lack of an act of the will for either acceptance or rejection of the option in question, is a good action. And so neither rejection nor quiescence is something that requires grace on the part of the post-fall person. Once a person becomes quiescent, God infuses the grace required for faith into that person. It is ultimately up to the person whether she is quiescent or rejects the offer of God's grace. But since it is up to the person in question - since it is under her control-Premise 2 is false. Her coming to faith is under her control, not insofar as she can cause her coming to faith, but insofar as she can of her own power refrain from doing something, such that, were she to so refrain, God would bring her to faith.

Stump cites some evidence from the work of Aquinas to the effect that he may have held such a view (2005: 403). He writes in his Summa contra gentiles:

Although one may neither merit in advance nor call forth divine grace by a movement of his free choice, he is able to prevent himself from receiving this grace ... And since this ability to impede or not to impede the reception of divine grace is within the scope of free choice, not undeservedly is responsibility for the fault imputed to him who offers an impediment to the reception of grace. In fact, as far as $\mathrm{He}$ is concerned, God is ready to give grace to all; "indeed He wills all men to be saved, and to come to the knowledge of the truth," as is said in 1 Timothy (2:4). But those alone are deprived of grace who offer an obstacle within themselves to grace; just as, while the sun is shining on the world, the man who keeps his eyes closed is held responsible for his fault, if as a result some evil follows, even though he could not see unless he were provided in advance with light from the sun.

(Aquinas 1991: SCG III 159)

Here we see that, according to Aquinas, the person has it in her control to either impede (an action) or not impede (inaction) the reception of grace. Were she not to hinder, God would give her grace. And so, she has control over whether she receives grace or not. Thus, on this view, Premise 2 is false.

There has been some discussion about whether a post-fall person has sufficient control over her coming to quiescence in order for it to be under her control, but not the result of some act she intentionally performs prior to the infusion of grace. As Ragland (2006) concludes: "Even though quiescence is contingent or undetermined, it does not result from an active choice by the agent, and so is not under her control." Kevin Timpe has offered a detailed account on which quiescence can be under the control of the agent insofar as it is an omission, not an "active choice" as Ragland requires (2007, 2015: Chapter 4). To see other discussions of Stump's view, see Ian DeWeese-Boyd (2006), James Gibson (2014), Lynne Rudder Baker (2006), Simon Kittle (2015), and Stan Tyvoll (2004). Michael Rota (2015) makes use of the concept of quiescence in his work concerning foreknowledge and free will. 
Finally, one might deny the fourth premise. One way to do so would be to deny that there is any moral responsibility, as Bruce Waller (2011) has done. On such a view, Premise 4 is false.

In a less extreme response to the argument, one might claim that no one is responsible for not believing if she has not received the grace required to do so. Those who have received the requisite grace and disbelieve do so under their own control and are blameworthy for it; those who have not received the requisite grace are not blameworthy for their lack of faith. We find Aquinas saying things of this sort, when he writes, as I quoted him above, "A man, therefore, is bound to believe insofar as he is helped by God to believe" (Aquinas 1983: Quod 2, q.2 a.1 resp.). Likewise we find him dividing those who do not believe the articles of the faith into two categories, those who have never heard and are not responsible for their not hearing, and those who have heard, or are responsible for their not hearing (ST II-II q.10 a.1 resp.). The first disbelieve by way of "pure negation" and are not blameworthy for their lack of belief in the articles of the faith. Even with this distinction between those who are blameworthy for their disbelief and those who disbelieve by way of pure negation, we do not get justification for affirming the falsity of Premise 4. Premise 4 requires only that at least one person is responsible for lacking faith, or for not doing a salutary action. This seems difficult to deny.

\section{Conclusion}

To conclude, the traditional Christian conception of grace seems at odds with a conception of free will or moral responsibility that requires some sort of control over one's own actions. For the Christian conception of grace claims that grace is required for every salutary act, and yet one can be accountable for not performing some salutary acts. In response, some compatibilists can deny the truth of the first premise, the control condition for moral responsibility. Those who value the control condition, including most or all libertarians, on the other hand, most often deny the second premise. There are two standard ways to do this. First, they can claim that all people receive the grace required to respond to the offer of faith and to perform salutary actions freely and deliberately, in which case it is within everyone's power (posterior to the initial prevenient gracing) to accept or reject the gift of faith. Second, they can claim that even prior to the reception of any grace, there is something under a person's control—say, being quiescent with respect to the offer of grace-whereby she controls whether or not she receives the gift of grace. Finally, a third option in response to this problem is to claim that people who do not receive the grace to believe or to perform salutary actions simply are not personally responsible for their unbelief or lack of such actions, in any case.

Perhaps the strongest response is a proof by cases. Distinguish between the two readings of Premise 2 mentioned above: it could mean that it is outside one's control without any divine aid to come to faith, or it could mean it is outside one's control even with divine aid to come to faith. If understood in the first sense, one can either deny Premise 2, or one can deny Premise 4. The quiescent response denies the relevant disambiguation of Premise 2, since, even without divine aid, there is something under a person's control, being quiescent, that gives her control over whether she comes to faith. Or, if one thinks the quiescence response fails, she may grant Premise 2, but insist that, on pain of equivocation, Premise 4 need be modified, too, to say that some people are responsible for not coming to faith without divine aid. And this, the objector continues, is false; as we have seen Aquinas claim earlier, and as seems intuitively right in this case, a man is 
bound to believe insofar as he is helped by God to believe. Were he not helped at all, he would not be bound at all. And if not bound at all, not blameworthy. Finally, on the other side of the initial proof by cases, one might read Premise 2 as meaning that it is outside one's control to come to faith with divine aid. Here Gould and Ragland would respond by denying this disambiguation of Premise 2, insofar as the divine aid makes coming to faith under the power of the agent in question. As such, this potential strongest response would conclude, in either viable understanding of Premise 2, at least one premise of the argument is false, and so the problem presented is unsound.

\section{Acknowledgments}

I thank Matthews Grant, Michael Rota, Mark Spencer, and Kevin Timpe for comments on previous drafts of this chapter. In a number of places in this chapter I draw on Pawl (2005).

\section{Bibliography}

Aquinas, T. (1980) Commentary on the Gospel of John, trans. F. Larcher. Albany: Magi Books.

Aquinas, T. (1981) The Summa Theologica of St. Thomas Aquinas, trans. Fathers of the English Dominican Province. Allen: Christian Classics.

Aquinas, T. (1983) Quodlibetal Questions 1 and 2, 1st edn, S. Edwards (ed.). Toronto: Pontifical Institute of Mediaeval Studies.

Aquinas, T. (1991) Summa Contra Gentiles: Book Three: Providence: Part II, trans. V. Bourke. Notre Dame: University of Notre Dame Press.

Athenagoras (1956) Embassy for the Christians, The Resurrection of the Dead, trans. J.H. Crehan SJ. New York: Paulist Press.

Augustine, St. (2004) St. Augustin Anti-Pelagian Writings: Nicene and Post-Nicene Fathers of the Christian Church Part 5, P. Schaff (ed.). Whitefish: Kessinger Publishing, LLC.

Baker, L.R. (2003) "Why Christians Should Not Be Libertarians," Faith and Philosophy 20: 460-78.

Baker, L.R. (2006) "Moral Responsibility Without Libertarianism," Noûs 40: 307-30.

Basinger, D. and Basinger, R. (eds) (1986) Predestination and Free Will: Four Views of Divine Sovereignty and Human Freedom. Downers Grove: InterVarsity Press.

Bonner, G. (1992) "Pelagianism and Augustine," Augustinian Studies 23: 33-51.

Bonner, G. (1993) "Augustine and Pelagianism," Augustinian Studies 24: 27-47.

Boxer, K.E. (2013) Rethinking Responsibility, 1st edn. Oxford: Oxford University Press.

Clarke, R. (2006) Libertarian Accounts of Free Will. New York: Oxford University Press.

Cross, R. (2005) "Anti-Pelagianism and the Resistibility of Grace," Faith and Philosophy 22: 199-210.

DeWeese-Boyd, I. (2006) "Grace and Freedom," Faith and Philosophy 23: 80-92.

Frankfurt, H. (1986) "Three Concepts of Free Action: II," in Moral Responsibility, J.M. Fischer (ed.). Ithaca: Cornell University Press, pp. 113-23.

Garrigou-Lagrange, R. (1998) Predestination: The Meaning of Predestination in Scripture and the Church. Reprint edition. Charlotte: TAN Books.

Geisler, N.L. (2010) Chosen but Free: A Balanced View of God's Sovereignty and Free Will, 3rd edn. Minneapolis: Bethany House Publishers.

Gibson, J.A. (2014) "Anselm on Freedom and Grace," Oxford Studies in Philosophy of Religion 5: 88-121.

Gould, J.B. (2008) "The Grace We Are Owed," Faith and Philosophy 25: 261-75.

Justin Martyr (1997) St. Justin Martyr: The First and Second Apologies, trans. L. William Barnard. New York: Paulist Press.

Kittle, S. (2015) "Grace and Free Will: Quiescence and Control," Journal of Analytic Theology 3: 89-108.

Komline, H.K. (2014) "Grace, Free Will, and the Lord's Prayer: Cyprian's Importance for the 'Augustinian' Doctrine of Grace," Augustinian Studies 45: 247-79.

Lawler, M.G. (1971) "Grace and Free Will in Justification: A Textual Study in Aquinas," The Thomist 35: 601-30.

Leith, J.H. (1982) Creeds of the Churches: A Reader in Christian Doctrine, from the Bible to the Present. Atlanta: John Knox Press. 


\section{TIMOTHY PAWL}

McKenna, M. (2012) Conversation and Responsibility, 1st edn. New York: Oxford University Press.

Nagel, T. (1993) "Moral Luck," in D. Statman (ed.), Moral Luck. Albany: State University of New York Press, pp. 57-72.

Pawl, T. (2005) "Aquinas on Blameworthiness and the Virtue of Faith," Journal of Postgraduates in Wuhan University 21: 21-6.

Pereboom, D. (2001) Living without Free Will. Cambridge: Cambridge University Press.

Pohle, J. (1917) Grace, Actual and Habitual: A Dogmatic Treatise, trans. A. Preuss. London: B. Herder.

Rackett, M.R. (2002) "What's Wrong with Pelagianism?" Augustinian Studies 33: 223-37.

Ragland, C.P. (2006) "The Trouble with Quiescence: Stump on Grace and Freedom," Philosophia Christi 8: 343-62.

Rogers, K. (2008) Anselm on Freedom, 1st edn. Oxford and New York: Oxford University Press.

Rota, M. (2015) "Synchronic Contingency and the Problem of Freedom and Foreknowledge in Advance," Faith and Philosophy 32: 81-96.

Russell, H. (2010) "Efficacious and Sufficient Grace," Philosophy and Theology 22: 353-72.

Stump, E. (2001) “Augustine on Free Will,” in E. Stump and N. Kretzman (eds), Cambridge Companion to Augustine. New York: Cambridge University Press, pp. 124-7.

Stump, E. (2005) Aquinas. London: Routledge.

Stump, E. (2007) "Justifying Faith, Free Will, and the Atonement," in R. Velkley (ed.), Freedom and the Human Person. Washington, DC: Catholic University of America Press, pp. 90-105.

Timpe, K. (2007) “Grace and Controlling What We Do Not Cause," Faith and Philosophy 24: 284-99.

Timpe, K. (2015) Free Will in Philosophical Theology. London: Bloomsbury Academic.

Tyvoll, S. (2004) "An Anselmian-Quiescence Approach to the Problem of Grace and Merit," Budhi: A Journal of Ideas and Culture 7: 35-58.

Waller, B.N. (2011) Against Moral Responsibility. Cambridge: MIT Press.

Watson, G. (1999) "Soft Libertarianism and Hard Compatibilism," The Journal of Ethics 3: 353-68.

Weber, N. (1911) "Councils of Orange," in The Catholic Encyclopedia. New York: Robert Appleton Company. Wyma, K.D. (2004) "Innocent Sinfulness, Guilty Sin: Original Sin and Divine Justice," in P. van Inwagen (ed.), Christian Faith and the Problem of Evil. Cambridge: Wm. B. Eerdmans Publishing, Co., pp. 263-76.

\section{Further Reading}

Basinger, D. and Basinger, R. (eds) (1986) Predestination and Free Will: Four Views of Divine Sovereignty and Human Freedom. Downers Grove: InterVarsity Press. (This is a good discussion of multiple views on the relation between free will and God's providence. It includes discussion of the relation between grace and free will from different theological positions.)

Garrigou-Lagrange, R. (1998) Predestination: The Meaning of Predestination in Scripture and the Church. Reprint edition. Charlotte: TAN Books. (This is a reprint of a classic work. Fr Garrigou Lagrange is one of the great, perhaps the greatest, exponents of a school of Thomistic thought sometimes called Neo-Scholastic Thomism or Neo-Thomism. In this work he presents a careful Thomistic view of providence and free will, including a discussion of grace and freedom.)

Pohle, J. (1917) Grace, Actual and Habitual: A Dogmatic Treatise, trans. A. Preuss. London: B. Herder. (This is a long and careful book on grace, which has a good discussion of grace and freedom. This work has the added benefit of including many texts from previous thinkers on the points of contention.)

Rogers, K. (2008) Anselm on Freedom, Oxford: Oxford University Press. (Chapter 7 of this book focuses on Anselm's views concerning grace and freedom.)

\section{Related Topics}

The Consequence Argument

Augustine of Hippo

Thomas Aquinas

Free will and Theological Fatalism

Free will and Theological Determinism

The Relationship between Moral Responsibility and Freedom

Blame 


\section{8 \\ FREE WILL AND PROVIDENCE \\ Ken Perszyk}

To believe in divine providence is to believe that God is in control, using his power and knowledge to direct the world to the supremely good end(s) for which it was created. There are many different accounts of how God runs the world, and of his relationship with his creatures. A strong account of providence, endorsed by many throughout the history of Christianity, entails the thesis that everything that happens is specifically intended or permitted by God. God did not create the world and then take a handsoff approach. He not only continually sustains the world in existence, but he concurs with creatures in every one of their activities (acting in them or on the effects of their activities). God's sovereignty is complete, that is, it covers or ranges over every detail. $\mathrm{He}$ also has complete and certain knowledge (foreknowledge) of everything that happens, and this knowledge must in part be a function of his sovereignty if he is genuinely in control, that is, if he really plans or provides for all things, and not (merely) reacts to what happens. God's providence is not restricted to having general strategies or contingency plans. He takes no risks in creation, and so nothing that happens can take him by surprise.

To believe in human free will is to believe that we have control over at least some of our actions or choices. Our free actions, and those for which we are morally responsible, must in some sense be 'up to us,' which is usually cashed out in one or both of the following senses: (i) we have alternative possibilities available —at a minimum, the possibility of (freely) refraining from doing the action (hereafter, the 'AP-condition' on free will); and (ii) the source of the action is in us, not in something outside us and/or over which we have no control (hereafter, the 'sourcehood condition' on free will; see the chapter on leeway versus sourcehood conceptions). Christians, Jews, and Muslims are particularly keen to maintain our free will (and moral responsibility). Among other things, it seems required for the highest forms of loving personal relationship with God. For instance, for the Christian, God's sovereignty and our freedom (moral responsibility) appear to be affirmed together in some of the same Scriptural passages-for example, Acts 2:23 and Luke 22:22.

There is at least a tension between the belief in divine providence and the belief that we are sometimes free. It seems that the stronger one's account of providence is, the harder it is to preserve our freedom. If God has the complete sovereignty over creation that the tradition attributes to him, how could anything really be 'up to us' - when we act, how could we have any genuine options available, and how could we be the (ultimate) 
source of the action? And conversely, if creatures are really free-have genuine options available and are the (ultimate) source of their actions- how could God have 'complete' sovereignty over everything that happens? The tension, if not inconsistency, between maintaining both divine sovereignty and human freedom has been felt throughout the history of Christianity-from the Pelagian Controversy in the early fifth century and subsequent Semi-Pelagian Controversy, to the dispute between Luther and Erasmus in the early sixteenth century, the battle between the Dominicans (led by Bañez) and the Jesuits (led by Molina) in the late sixteenth and early seventeenth centuries, the Quinquarticular (Five Points) Controversy between Calvinists and Arminians in the early seventeenth century, and the eighteenth century dispute between the early Methodists Whitefield and Wesley. Though the context of these debates is different today, the underlying issues are similar and remain largely unresolved.

Different answers have been given as to whether or how maintaining a strong account of divine providence is logically compatible with maintaining our freedom. The answer one gives will turn in large part on one's view about the nature of free will, which demonstrates important inter-connections between theological doctrines and work in the metaphysics of free will. I will focus on three accounts of divine providence (along with their views on human freedom) that have occupied center stage in recent times: Calvinism (sometimes called 'Thomism' or 'Augustinianism'), Molinism, and Open Theism.

\section{Calvinism}

'Calvinism' is used here as a convenient label for a family of views that maintain a doctrine of theological determinism, which is or entails the thesis that God's willing or decreeing something is necessary and sufficient for its occurrence. (See also the chapter on free will and theological determinism.) Many or most Calvinists do not want to say that God intends or (directly) causes evil, but merely permits it —or if he intends or causes the existence of the act, he merely permits the defect in the act. For our purposes, 'Calvinism' should not be tied to the particular package of theological views associated with John Calvin (1509-1564). (The same applies, mutatis mutandis, to the labels 'Thomism' or 'Augustinianism.') Calvinists fully endorse the strong account of providence sketched above. God's complete control does not entail that God is the only agent (cause), contra occasionalism, though some (e.g., Yandell 1999: 339), will doubt this. God accomplishes his purposes directly or indirectly through genuine secondary causes. One way or other, he determines everything that happens, including our choices or actions.

But then could we be, or are we, ever free? "Yes," say Calvinists. There have been few theological hard determinists - that is, those who think free will is incompatible with theological determinism, theological determinism is true, and so we are never freealthough Pereboom (2011) is a recent example. Some Calvinists say that theological determinism is true and we're free, but don't ask them how-they rest content with an appeal to mystery. Other Calvinists have given explanations for how we could be free under theological determinism. Some (e.g., Helm 1993; Couenhoven 2013) are compatibilists. They appear to say that free will is compatible with determinism-causal or theological-where causal determinism is understood as the thesis that the past and laws of nature entail a unique future, and theological determinism is understood as the thesis that God's decrees entail a unique future. God might determine some of our free 
actions via causal determinism; others may follow directly from his decrees. Few of these compatibilist Calvinists, however, appear to give us much in the way of a detailed positive account of free will. (Couenhoven [2013] is an exception, although he is largely engaged in Augustine scholarship.)

Perhaps their best hope is to endorse a hierarchical 'mesh' theory of the sort proposed by Frankfurt (1971). According to such a theory, the sort of free will required for moral responsibility is a function of having the right 'mesh' or connection between various elements (choices and desires or preferences) or levels of an agent's mental or psychological economy. The details of Frankfurt's account are not important here. Its key feature is that it is an 'internalist,' not 'externalist,' theory, to use a distinction drawn by Mele (1995) and Fischer and Ravizza (1998: 252); what is important is that it is a 'nonhistorical,' not an 'historical,' account. Whether one acts of her own free will (or is morally responsible for what she does) is solely a matter of facts internal to her psychology; the (causal) history of the source or springs of her action is irrelevant:

It seems to me that if someone does something because he wants to do it, and if he has no reservations about that desire but is wholeheartedly behind it, then - so far as his moral responsibility for doing it is concerned - it really does not matter how he got that way ... As long as they are unequivocally attributable to him as his desires and his attitudes, it makes no difference ... how he came to have them ... It is what we are, rather than the history of our development, that counts.

(Frankfurt 2002: 27)

I think it is easier to defend compatibilism, especially about theological determinism, if the history of the springs of our actions doesn't matter. If that's right, compatibilist Calvinists have a vested interest in the intramural debate between contemporary compatibilists over whether free will (moral responsibility) is essentially an historical concept. They should be cheering for an externalist/non-historical victory.

Other 'Calvinists' (including in more recent times Kondoleon [1983] and McCann $[1995,2005])$ are not straightforward compatibilists, as this term is usually understood today. They are incompatibilists about free will and (ordinary) causal determinism, but they allow God to determine (cause) our free acts. As a result, these Calvinists are also critical of standard libertarians. The latter's mistake, the former think, is to assume that to determine our volitions or actions, God would have to act upon us and from outside of us, perhaps using the mechanism of event causation via deterministic laws of nature, which they too think would undermine our freedom. But as one such Calvinist puts it, God "does not make us act; he makes us acting, so that the freedom that goes with genuine action can still be present" (McCann 2005: 146). This is supposed to be a libertarian-friendly account insofar as it denies the compatibility of (causal) determinism and our free will, or (more generally) denies the causation or determination of our free acts by 'external' factors or conditions (over which we have no control). But this position denies 'strong libertarianism,' which is libertarianism-minimally, the thesis that free will is incompatible with (causal) determinism, some of our actions are free, and so determinism is false- together with the thesis that a person freely does something at a time only if the total activity of all other causes, including God, at that time is compatible with the person's refraining from doing it (Flint 1998: 84-94, 2009: 266-69; Freddoso 1988: 24-8). 
Aside from the charge that Calvinists of any of the kinds mentioned above cannot preserve the 'relevant' (i.e., libertarian) reading of the AP-condition on free will, assuming this condition is required, (strong) libertarians will also think that Calvinists cannot preserve the sourcehood-condition. Regardless of the form it takes, Molinists and Open Theists will say that the Calvinist account of God's providence and relation to us violates the standard libertarian requirement of an absence of determination by causes (factors, conditions, etc.) over which we have no control. For this it does not matter whether the determinants of our actions are outside or inside of us. The Calvinist God would simply be too controlling or manipulative. We would not be the genuine source of our free acts; God, not us, would have 'ultimate responsibility' for our actions. And it (allegedly) gets worse. Molinists and Open Theists routinely claim that Calvinism would make it even harder, if not impossible, to get God off the hook for the horrors of the world.

\section{Molinism}

Molinism is named after Luis de Molina (1535-1600). Molinists endorse both a strong account of providence and strong libertarianism. They think the two are logically compatible, and in fact together entail, the thesis that God has middle knowledge. Middle knowledge is so-called because it comes in-between God's 'natural' and 'free' knowledge, what Aquinas calls God's "simple knowledge" and "knowledge of vision." By his natural knowledge, God knows everything that must be, and in knowing this, he knows everything that is possible. These truths are necessary-they are true 'no matter what'-and so not under his control. By his free knowledge, he knows everything that will be but need not be. These truths are contingent-they are as a matter of fact true, but could have been false-and under his control. What is unique to Molinism is that it also affirms that by his middle knowledge, he knows everything that would be if things were a certain way. To be more precise, God has middle knowledge only if there are true counterfactuals of creaturely freedom (hereafter CCFs) that are contingent but not under his control. CCFs are conditional propositions stating how any creature God might create would freely behave in any set of circumstances in which that creature was created and left free. Some CCFs are in fact 'fulfilled,' that is, have true antecedents, so the term 'counterfactuals of freedom' may not be the best. CCFs are not the sole objects of middle knowledge (e.g., if there is genuine indeterminism in nature, the objects of middle knowledge also include conditional propositions stating what would result from any possible combination of natural, as opposed to free, indeterministic secondary causes), but they have been the nearly-exclusive focus of attention in the contemporary literature.

The following, in brief, is how Molinists reconcile strong providence and strong libertarianism. God's creative decisions are guided by his middle knowledge of CCFs. Since he has no control over their truth-values, it is not up to him which worlds or sets of worlds containing free creatures are open to ('feasible for') him to create. Unlike for Calvinists, not every logically possible world is open to God to create. But which of the worlds open to him is or will be actual is completely up to him. Since he knows by his middle knowledge what each creature he might create would do in any possible situation in which that creature were placed and left free, he knows what he has to do to get the world from within the set open to him that he wants. He might not be able to get what he would most prefer if he were calling all the shots as under Calvinism (there seems to be a trade-off here: think about the problem of evil). But by deciding which 
comprehensive creative act to perform, that is, by selecting the 'right' antecedents of CCFs - the 'right' combination of creatures to create and circumstances in which they are placed-it is completely up to God which world open to him is actual. Middle knowledge thus allows one to explain how God can exercise complete and specific sovereignty over creation even if it contains creatures that are free in the way strong libertarians insist. And so, God's providential plan for the world is guaranteed to succeed even if creatures are free to do otherwise in the circumstances in which they choose or act.

Middle knowledge also allows one to explain in at least a nuts-and-bolts sense how it is that God can have complete and certain foreknowledge of our free actions. God's foreknowledge of our free actions follows from his middle knowledge of CCFs together with his knowledge of his complete creative act —of his knowledge of which (sets of) antecedents of CCFs he decides to actualize. After all, modus ponens is valid! God's foreknowledge of our actions doesn't (allegedly) rob us of freedom, for while we cannot do otherwise in the sense that it cannot be the case both that God believes we will do something and we don't do it, there is still a relevant sense in which we can do otherwise than God has always foreknown (assuming for the sake of argument that God is in time and has beliefs at times). We have 'counterfactual power' or control over God's past beliefs: we have the power to act in such a way that, had we not so acted, a true CCF about us would have been false, and God would not have believed what he in fact believed.

Middle knowledge has tremendous explanatory power. (For a less enthusiastic assessment, see Fischer [2011].) It has been used, for example, to reconcile predestination and human freedom. Predestination is that part or aspect of divine providence that concerns salvation. In one account utilizing middle knowledge, God's predestination of the elect is wholly gratuitous, that is, not based on or because of their foreseen merits or good works, though it 'comes after' his middle knowledge of how they would (favorably) respond to his grace. By having middle knowledge and knowledge of his own decrees, God can be assured that the elect will respond favorably to and persevere in his grace, even though they are also free not to so respond and persevere. Middle knowledge has also been used (Craig 1989) to account for the reprobation of the non-elect (or at least the unevangelized, assuming Christian exclusivism), although Molinism does not by itself entail the thesis that anyone will be lost forever. Molinism, and Calvinism for that matter, fit particularly well with a doctrine of universalism - the thesis that everyone will (eventually) be saved—although few seem to have seized the opportunity to combine them.

Molinism has been the subject of intense controversy, historically and in more recent times. The contemporary debate has focused primarily on two broad sets of issues. The first is more theoretical. Is the thesis of middle knowledge logically coherent, that is, free of contradiction? A number of objections indirectly challenge the Molinist account of providence by directly attacking the coherence of the thesis of middle knowledge that underlies it. There are at least four lines of anti-Molinist objection here: (i) there are or can be no true CCFs; (ii) even if there are or were any true CCFs, they aren't or can't be true prior to God's creative decisions; (iii) even if any are or were true prior to God's creative decrees, God cannot know them prior to any of those decrees; and (iv) CCFs are or would be under God's control. If any of these lines of objection are right, middle knowledge cannot be the right explanatory mechanism for reconciling a strong account of providence and human freedom as it is understood by (strong) libertarians. Molinists, not surprisingly, think these objections fail. 
I don't have the space to get into the details of these anti-Molinist objections and the standard Molinist replies to them. (For more details, see Perszyk [2013], which is particularly accessible to those who are new to the Molinism Wars.) But let me provide a glimpse of one sort of anti-Molinist argument that involves some big issues in contemporary discussions of the metaphysics of free will.

Frankfurt (1969) spawned a cottage industry in the literature over whether the AP-condition is required, which he denied. Molinism entails the AP-condition or something like it. The reason is that Molinism requires the idea that we have 'counterfactual power' over some true CCFs about us - at least those with true antecedentsand this in turn requires the AP-condition. For to say that I have counterfactual power over a true CCF about me is just to say that there is something I can do in the circumstances in which I act (as specified in the antecedent of the CCF), viz., I am able to do or refrain from doing the action specified in the consequent, such that were I to do it (or refrain from doing it, as the case may be), the true CCF about me would be false (since everyone agrees that a counterfactual with a true antecedent and false consequent is false). So, if I couldn't do otherwise in the circumstances, a Consequence-type Argument for the incompatibility of Molinism with our freedom would be decisive. If I could have (freely) refrained from doing the action in question, but the truth of the CCF together with its antecedent entail that I do not refrain, then I must have or had counterfactual power over the CCF (or its antecedent), given that Molinists would deny that we have any causal power over CCFs or their antecedents. So, we have counterfactual power over true CCFs about us if and only if we can do other than what the consequents say we will do. QED. Several anti-Molinist arguments (from a libertarian perspective) target this so-called counterfactual power Molinists say we have. They in effect try to turn the Consequence Argument for the incompatibility of our free will and (causal) determinism against Molinists: since we have no choice about the truth of CCFs about us, and we also have no choice about whether God actualized their antecedents, we have no choice about the actions specified in their consequents, and so we're never free. (For further discussion of this and, more generally, the relationship between Molinism and the Consequence Argument against compatibilism, see Perszyk [2003], Hasker [2011], and Cohen [2015].)

The second broad set of issues facing Molinism is more practical/theological. Even if the thesis of middle knowledge is or were logically coherent, would it really be a benefit overall for a satisfying account of providence? A number of objections more directly challenge the Molinist account of providence by arguing that endorsing the thesis of middle knowledge either does not have the benefits Molinists claim, or-if it is conceded that Molinism has some benefits-it is a detriment overall for a satisfying account of providence. For example, Hasker (2004: 101f, 114) thinks it makes the problem of evil substantially worse than on the Open Theist view. It's not hard to see why he thinks this: if God knew what Hitler would do if he created him, left him free, and placed him in the very circumstances that thereby guaranteed the Holocaust, could God be the supremely good and perfectly loving agent?

Calvinists typically argue that middle knowledge would give God too little control. Molinists are thus guilty of false advertising. Their account of providence does not preserve God's complete sovereignty, for how could there be contingent truths that an all-powerful being would simply have to put up with? The typical Molinist response is that this objection fails because it assumes that God must be able to do what is logically impossible, but what is logically impossible cannot be done by anyone. Given (strong) 
libertarianism, it is simply logically impossible for anyone other than me to cause my free actions. This dispute highlights what is at the source of the Calvinist's disagreement with Molinists, viz., the latter's (strong) libertarianism. This, the former think, should be rejected. It inappropriately sets us up in competition with God, playing a 'zero-sum game' where our gain is God's loss, and vice versa (Burrell 1993: Chapter 7; McCann 1995). In their applications of middle knowledge to a range of issues involving providence, Molinists are fond of ascribing 'counterfactual power' over the past to us-for example, in reconciling God's foreknowledge and our free will. Calvinists might also try to turn this against Molinists. Why not let God cause CCFs to be true, and insist that this doesn't rob us of our freedom because we are able to do otherwise than the consequents of the CCFs say we will because we have (mere) 'counterfactual power' over God's causing those CCFs to be true? If this works, Molinism is in big trouble: it collapses into Calvinism! (While [Flint 2009: 278] is optimistic that this important challenge can be met, he concedes that Molinists have not yet done so.) An anti-Molinist might also complain that the Molinist God would—-barring amazing luck with respect to CCFs_have insufficient and certainly less than complete control insofar as (given libertarianism) the antecedents of CCFs will typically include or depend on (prior) creaturely free actions or their results, and God can only bring them about if free creatures themselves cause or bring them about.

Open Theists (to whom I return in more detail below), on the other hand, think that middle knowledge would give God too much control, robbing him of his ability to create free creatures or relate to them in appropriate ways. The culprit in this case is the strong account of providence Molinists and Calvinists share, which Open Theists think should be rejected. There are a number of ways one might press the objection that Molinism gives God too much control, making him a "manipulator than which none greater can be conceived" (Hasker 1990: 123, 124). Here's one way.

Manipulation Arguments have received lots of press lately. Manipulation Arguments were first used in recent debates in the free will literature as arguments for the incompatibility of free will and (causal) determinism. More recently, Manipulation Arguments have been used by externalist/historical compatibilists against their internalist/nonhistorical compatibilist colleagues. One might construct various Manipulation Arguments against Molinism. This would be related to an attempt to turn a Consequence-type Argument against Molinism, but would perhaps focus more explicitly on the sourcehoodcondition for free will. The general structure of an anti-Molinist Manipulation Argument would be something like this: (i) Agents in a (causally) deterministic world do not act freely; (ii) there is no relevant difference between a causally deterministic world and a Molinist God-governed world; therefore, (iii) agents in a Molinist God-governed world do not act freely. One way to flesh out this basic argument might be to produce an anti-Molinist variant of Pereboom's (2001) Four Case Manipulation Argument against compatibilism. The strategy would be to begin with a case of covert manipulation of an agent, perhaps by the direct stimulation of her brain, which causes all of her actions, where 'everyone'—or at least any self-respecting card-carrying libertarian-will agree that the agent in question does not perform actions freely. Then one would construct further manipulation cases, tweaking the form the manipulation takes and arguing that there is no relevant difference between each case and the one that comes before it. Finally, we get a case of an otherwise normal agent in a Molinist God-governed world, and the claim will be that there is no relevant difference between this and the more ordinary cases of freedom-cancelling manipulation, including perhaps-for the sake of 
libertarians - the case of ordinary causal determinism. The claim will be that in all these cases, the lack of freedom is best explained by the fact that the source of the agent's actions is traced back to conditions that were beyond her control. In the case involving CCFs, whether or not God is ultimately the source of the truth of CCFs about us, they are true (under Molinism) prior to our existence and would (still) have been true even if we had never been born, in which case it doesn't seem right to say we ever had or have any power, causal or counterfactual, over them. Given that we also had or have no power of either sort over whether God actualized the antecedents of CCFshow could we, if God used CCFs and actualized the relevant antecedents in creating the world long before we were born?-it follows that we have no power of either sort over our actions, and so (under Molinism) we aren't free. The ultimate source of our actions doesn't reside in us. We have in effect returned to a Consequence-type Argument against Molinism or, if there is no appeal whatsoever to the AP-condition, we have an anti-Molinist variant of the so-called Direct Argument.

Molinists, of course, can be expected to deny the second premise of the basic Manipulation Argument against them, and so deny the relevant premise of an anti-Molinist Four Case Manipulation Argument. They will also insist that they can endorse the Consequence Argument and Direct Argument for the incompatibility of (causal) determinism and our freedom. I leave it to readers to decide who has the upper hand here. If, or when, Molinists are forced to say that we can have causal power or control over the logically deductive consequences of states of affairs not under our causal control, critics of Molinism might well be excused if they think this in effect is just the definition of standard compatibilism with respect to free will and determinism. If that's right, Molinists are really compatibilists masquerading as champions of (strong) libertarianism.

\section{Open Theism}

Open Theism is a newcomer on the philosophical theology scene, only appearing as an explicit and clearly articulated alternative to Calvinism and Molinism in the past 20 to 25 years. Like Molinism, Open Theists are committed to (strong) libertarianism, but they reject the strong account of providence endorsed by Molinists and Calvinists. Instead, God governs the world primarily by having general strategies and probably a host of contingency plans which are, overall, ordered for the good of creation but whose detailed consequences he neither intended nor foresaw prior to adopting them.

Unlike Molinists and like Calvinists, Open Theists deny God's middle knowledge; but also, and unlike Calvinists, they deny God's foreknowledge of our free actions, though they insist that God is still omniscient. Either there are truths about what we will freely do, but they cannot be known by anyone, or there are no such truths to be known, and all propositions about our future free actions are false or neither true nor false. Either way, God still knows everything it is possible to know. At any time, God knows everything that has happened and is happening, but he does not know everything that will happen. He might know in advance what free creatures will/would probably do, but he cannot know what they will do or would do in different possible circumstances. And so God cannot, unlike under Molinism, make creative decisions on the basis of knowing these things. The future is open, causally or metaphysically, and open with respect to what God knows about it.

Open Theists still maintain that God is omnipotent. He can, and does at times, intervene unilaterally in the world, but normally he does not appear to interfere with or 
override our freedom. Open Theists think that the strong account of providence endorsed by Calvinists and Molinists places too much emphasis on God's power. Instead, they think love is the more/most important divine attribute. God could have kept all the power to himself, but out of his boundless love he willingly limits the exercise of his power by giving us our own control, limited though it is due to our physical and other circumstances. Open Theists think that focusing on God's love, not power, is a powerful corrective to what they see as the overly-Hellenistic conception of God and account of providence endorsed by Calvinists and Molinists. This means that Open Theists think God's relation to the world and creatures is dynamic and genuinely interactive. God lets himself be conditioned by free creatures and does various things in part because of or in response to what we do. That's precisely what genuine personal relationships of the highest or best kind involve! God is ontologically independent of creation, as required by the traditional doctrine of creation ex nihilo; but he depends, relationally, on what free creatures do. This is another way of saying, contra Aquinas, that there is a 'real relation' between God and his creatures. God is thus a genuine risk-taker in creation, opening himself up to the real possibility of failure and disappointment, at least in terms of the specific way(s) his purposes are achieved or in the case of individual creatures. But Opennists are quick to add that God is also infinitely resourceful and competent, and so they insist that we can rest assured that his overall or ultimate plan for creation will succeed.

There are clear virtues in the Open Theist's position, perhaps especially their emphasis on God's love. Other alleged benefits are less clear, for example, the idea that it makes the problem of evil easier in comparison with Calvinists and Molinists. Perhaps the biggest issue, aside from some thinking that libertarian theories (whether or not of the 'strong' type) are overly problematic, is the risk-taking that Open Theists admit delivers a (much) weaker account of providence than Calvinists and Molinists offer. Open Theists still think they offer a satisfying account of providence, but do they? The Opennist God may not be "the bookie than which none greater can be conceived" (Flint 1990: 114), but is risk-taking - whether or not it would be reckless-becoming of the Creator ex nihilo of all else that exists, and does it, for example, really make the problem of evil any easier? Readers should decide this for themselves.

\section{References}

Burrell, D. (1993) Freedom and Creation in Three Traditions. Notre Dame: University of Notre Dame Press.

Cohen, Y. (2015) "Molinists Still Cannot Endorse the Consequence Argument," International Journal for Philosophy of Religion 77: 231-46.

Couenhoven, J. (2013) Stricken by Sin, Cured by Christ: Agency, Necessity, and Culpability in Augustinian Theology. Oxford: Oxford University Press.

Craig, W.L. (1989) '“No Other Name:' A Middle Knowledge Perspective on the Exclusivity of Salvation Through Christ," Faith and Philosophy 6: 172-88.

Fischer, J.M. (2011) "Putting Molinism in its Place," in K. Perszyk (ed.), Molinism: The Contemporary Debate. Oxford: Oxford University Press, pp. 208-26.

Fischer, J.M. and Ravizza, M. (1998) Responsibility and Control: A Theory of Moral Responsibility. Cambridge: Cambridge University Press.

Flint, T. (1990) "Hasker's God, Time, and Knowledge," Philosophical Studies 60: 103-15.

Flint, T. (1998) Divine Providence: The Molinist Account. Ithaca: Cornell University Press.

Flint, T. (2009) "Divine Providence," in T. Flint and M. Rea (eds), The Oxford Handbook of Philosophical Theology. Oxford: Oxford University Press, pp. 262-85.

Frankfurt, H. (1969) "Alternate Possibilities and Moral Responsibility," Journal of Philosophy 66: 829-39.

Frankfurt, H. (1971) "Freedom of the Will and the Concept of a Person," Journal of Philosophy 68: 5-20. 
Frankfurt, H. (2002) "Reply to John Martin Fischer," in S. Buss and L. Overton (eds), Contours of Agency: Essays on Themes from Harry Frankfurt. Cambridge: MIT Press, pp. 27-32.

Freddoso, A. J. (1988) "Introduction," in trans. A.J. Freddoso and L. de Molina, On Divine Foreknowledge (Part IV of the Concordia). Ithaca: Cornell University Press, pp. 1-81.

Hasker, W. (1990) "Response to Thomas Flint," Philosophical Studies 60: 117-26.

Hasker, W. (2004) Providence, Evil and the Openness of God. London: Routledge.

Hasker, W. (2011) "Trenton Merricks on Some Anti-Molinist Arguments," in K. Perszyk (ed.), Molinism: The Contemporary Debate. Oxford: Oxford University Press, pp. 73-7.

Helm, P. (1993) The Providence of God. Grand Rapids: InterVarsity Press.

Kondoleon, T. (1983) "The Free Will Defense: New and Old," The Thomist 47: 1-41.

McCann, H.J. (1995) "Divine Sovereignty and the Freedom of the Will," Faith and Philosophy 12: 582-98.

McCann, H.J. (2005) "The Author of Sin?" Faith and Philosophy 22: 144-59.

Mele, A. (1995) Autonomous Agents: From Self-Control to Autonomy. New York: Oxford University Press.

Pereboom, D. (2001) Living without Free Will. Cambridge: Cambridge University Press.

Pereboom, D. (2011) "Theological Determinism and Divine Providence," in K. Perszyk (ed.), Molinism: The Contemporary Debate. Oxford: Oxford University Press, pp. 262-80.

Perszyk, K. (2003) "Molinism and the Consequence Argument: A Challenge," Faith and Philosophy 20: $131-51$

Perszyk, K. (2013) "Recent Work on Molinism," Philosophy Compass 8: 755-70.

Yandell, K. (1999) Philosophy of Religion: A Contemporary Introduction. London: Routledge.

\section{Further Reading}

Cobb, J.B. and Griffin, D.R. (1976) Process Theology: An Introductory Exposition. Philadelphia: Westminster Press. (An early classic exposition of the main tenets of process theism, which offers an account of providence that differs in some key respects from Open Theism.)

Kvanvig, J. (2011) Destiny and Deliberation: Essays in Philosophical Theology. Oxford: Oxford University Press. (A critique of Open Theism and Molinism, advocating 'Philosophical Arminianism' as the best way to combine strong providence and libertarianism.)

McKenna, M. (2009) "Compatibilism: State of the Art," in E. Zalta (ed.), The Stanford Encyclopedia of Philosophy, available from: http://plato.stanford.edu/entries/compatibilism/supplement (accessed 29 June 2016). (A survey of the main recent compatibilist accounts of free will/moral responsibility, including hierarchical 'mesh' theories.)

Pinnock, C., Rice, R., Sanders, J., Hasker, W., and Basinger, D. (1994) The Openness of God: A Biblical Challenge to the Traditional Understanding of God. Downers Grove: InterVarsity Press. (A classic early statement and defense of Open Theism by some of its main proponents.)

\section{Related Topics}

Identificationist Views

The Consequence Argument

Manipulation Arguments

Frankfurt-Style Examples

Leeway vs. Sourcehood Conceptions of Free Will

Augustine of Hippo

Thomas Aquinas

Free Will and the Problem of Evil

Free Will and Theological Fatalism

Free Will and Theological Determinism

Divine Free Will 


\section{9 \\ DIVINE FREE WILL \\ T. J. Mawson}

\section{Introduction}

One need only skim the other contributions to this volume to realize that philosophers are by no means agreed about whether or not we have free will or about what it is (or would be) if we do (or did) have it. Nor are philosophers by any means agreed about whether or not there is a God, or even about how best to conceive of the God, the existence of which they then disagree about. So it is unsurprising that what I shall have to say on the topic of divine free will is going to be controversial. However, within the classical theistic tradition at least, there is a consensus (that's what makes it a tradition) that God, presuming He exists at all, should be understood as being essentially omnipotent, omniscient, perfectly good, and perfectly free. I shall be narrowing my focus to the philosophical puzzles surrounding how, within the constraints imposed by this tradition, these properties are best understood as relating to one another.

Most would agree that free will, at least to the extent that it is going to be efficacious, requires, or perhaps simply is, the power to bring about what one wishes to bring about. If so, God's being perfectly free requires Him not to be in any way constrained in bringing about what He wishes. Two things, I suggest, constrain the freedom of human agents such as ourselves-our lack of power and our lack of knowledge. Sometimes we just aren't powerful enough to do what we'd ideally wish to do and we have to settle for second best (or worse) and sometimes we don't know quite what it is we're doing as we do it, and thus, we inadvertently end up doing second best (or worse). God is by definition omnipotent, so He could never be less than perfectly free in what He chose to do as a result of not having enough power to do anything closer to what He ideally wished to do. And God is by definition omniscient, so He could never be less than perfectly free in what $\mathrm{He}$ chose to do as a result of not knowing exactly what it was He was doing as $\mathrm{He}$ was doing it. The classical theistic view then is that there are none of the limitations on God's freedom that there are on ours and it is in virtue of this that He is perfectly free.

\section{Two Questions}

Two questions may now be raised.

First: 'Does God have the ability to do bad things?'

Contemporary discussion of this question was initiated by Pike (1969). The arguments to the effect that the problem it poses is an insuperable one for theists were later 
well summed up by Morriston (2001). (Other useful contemporary discussions of the issue are Lehe 1986; Wielenberg 2000; Funkhouser 2006; Senor 2006.)

In response to the question 'Does God have the ability to do a bad thing?', we might initially be tempted to answer 'Yes,' for we certainly have this power, so surely God should have it too.

The second question: 'Must God create the best of all possible worlds?'

In response to this, we might initially be tempted to answer 'Yes' too, for if God is by definition perfectly good, that seems to suggest that He'll have to do-and thus create- the best.

The traditional theistic response to each of these two questions however has been to urge us to resist temptation; the answer to each of these two questions, theistic tradition has taught, is in fact 'No.' I shall be arguing that the negative answer is, in both cases, right.

In answering this second question as I do, I disagree with Leibniz, who taught that God must create the one uniquely best world; if there had, per impossibile, been no such, He would have created nothing at all (Leibniz 1710/1985). Although then the issue goes back at least three hundred years, contemporary discussion of it was really kicked off by Rowe (2004), who argues that there failing to be a best possible world entails the impossibility of there being a morally unsurpassable being (for a morally unsurpassable being would have to create the best), and, as God is best defined as morally unsurpassable, there cannot be a God. This argument has been much discussed. Although it was in effect anticipated by Adams (1987), it has received detailed replies from, for example, Almeida (2008), Leftow (2005a, 2005b, 2007), and O'Connor (2008); and detailed and ongoing treatment in the works of Kraay (2006, 2007, 2008, 2009, 2011a, 2011b). Other notable discussions may be found in Howard-Snyder and Howard-Snyder (1994, 1996), Brown and Nagasawa (2005), Wainwright (2005), and Langtry (2008). Rowe's position has defenders, for example, Wielenberg (2004) and Steinberg $(2005,2007)$.

In a nutshell, my argument for answering these questions with a 'No' will be as follows.

With respect to the first question: when we properly understand the nature of perfect power, knowledge, and goodness, we can see that God cannot have the ability to do bad things - indeed, He cannot have the ability to do anything that is less than what perfect goodness requires. That doesn't though make Him less powerful than us (who do have this ability), because the ability to do less than is perfect would be a liability, rather than a power, for Him (even though—somewhat confusingly—it is a power for us). God's being unable to be less than perfectly good doesn't adversely affect His freedom eitherthat He cannot choose to do things which He has the power to avoid doing and which He realizes He has every reason to avoid doing (including then His not simply having no desire to do these things, but an unalloyed desire to avoid doing them) doesn't make Him less free than us either. After all, none of us are able to choose to do such things. Answering the first question negatively in this fashion then preserves God's power and freedom, although it might seem to make it harder to answer the second question negatively. Given that God is of necessity perfectly good, won't He have to-powerfully and freely, perhaps, but have to nonetheless — create the best world that He can, whichHis being omnipotent - means the best of all possible worlds? No again, I shall argue, in that God's doing what perfect goodness requires of Him doesn't oblige Him to engage in what one might call the 'maximization of value' - that is, creating the so-called 'best of all possible worlds.' Failure to produce a good states of affairs if the absence of it won't 
leave any actual person worse off is not a failure to live up to the standards of perfect goodness. Thus God is not constrained by His perfect goodness to create the best of all possible worlds as it's traditionally conceived even if there is such (as there probably isn't). Well, that's it in a nutshell. Now for some more detail.

\section{Some Background: Goodness, and God's and Our Differing Relations to It}

While the nature of goodness is at least as controversial a topic in philosophy as are the natures of free will and God, I must assume some things about it if I'm ever to get started properly on the topic of this chapter. Allow me then to assume the following.

Goodness is an objective property of some actions, states of affairs, and people. An action's being good is an objective reason for one to perform it and one action's being better than another incompatible action is a reason for one to perform the better action, rather than the worse. Goodness is a matter of behaving as one ought in one's relations with morally weighty individuals - people, most notably, but also, plausibly, some higher animals - and perfect goodness is a matter of one's doing the best thing that one can for such 'creatures,' as I shall call them, whenever there is a best and doing one of the best things that one can whenever two or more are equally good and none better. Now for some words about our relation to goodness, so understood, and God's.

None of us are ever perfectly good towards one another. And this in itself does not make us blameworthy. One fails to be perfectly good blamelessly, for example, when one tries but fails to do the best or joint best that one believes one can for someone, failing either due to lack of power or lack of knowledge (as long as one does not by so failing thereby also fail to do that which one ought to do and one's failure is itself the result of one's negligence). And often one fails to be perfectly good blamelessly when one doesn't even try to do the best or joint best that one can for someone, as long as one tries to meet one's obligations towards them (and again as long as any failure to do so cannot be put down to one's own negligence). If one is morally obliged to do something for someone in a particular situation, then one should do that thing for anyone in the same situation. When one does something good for someone that goes beyond what one is obliged to do for them, it is not true that one should do the same thing for anyone in their situation. In the case of a supererogatory act, one cannot do it from a disinterested sense of duty; but one can do it for the sake of the person for whom one's doing it. In virtue of this 'directedness' towards the good of the particular people for whom one is performing them, it does not seem unnatural therefore to call acts of supererogation acts of love. The traditional theistic understanding of God is that $\mathrm{He}$ is perfectly loving. God's perfect goodness then is His perfectly fulfilling His duties towards His creatures and, furthermore, whenever there is a logically possible best or joint best thing for Him to do for them, His doing that too. We then have the freedom to refrain from good acts that are not morally required of us, acts of supererogation, and yet still, often if not always, avoid blame. God, in virtue of His necessary perfect goodness, doesn't have this sort of freedom and yet the claim is that He is nevertheless perfectly free. As well as failing to be perfectly good blamelessly, sometimes we fail blameworthily; sometimes we do something which not simply fails to be the best or joint best that we could do for someone, but something which we ought not to have done at all. We then have the freedom to refrain from doing our duty. Again, God, in 
virtue of His necessary perfect goodness, doesn't have this sort of freedom and again the claim is that He is nevertheless perfectly free.

\section{Why God's not being Able to be Less than Perfect Does Not Restrict His Freedom}

The claim is then that these differences between our situation and God's in no way restrict God's power or freedom. Why they might seem to do so arises, I shall argue, from the fact that similar restrictions on us would reduce our power and freedom.

We humans fail to be perfectly loving for four reasons: we reasonably conclude that we don't have enough time/resources; we're unreasonable; we're ignorant; and/or we're selfish.

When we fail to go beyond our duty with regard to someone, this could be because we correctly judge ourselves to have fulfilled our duty and reasonably enough wish to spend what we judge to be our finite time and resources elsewhere. I could buy my colleague a birthday present, but I choose not to do so, spending the money instead on something for myself. When we so direct ourselves, it would be odd to call our actions 'selfish,' for selfishness carries with it the implication of blameworthiness and, in that in such cases we will have fulfilled our obligations, we will not blameworthy. Perhaps we might best call such failures to be perfectly good 'reasonably self-interested' or 'expedient' failures to do supererogatory actions.

What then of the second sort of case, when we fail to be perfectly good not merely by failing to do the most good that we could do for others but by doing less than we ought to do for them? That, I suggest, must be due to one or a mixture of the following three reasons. Firstly, it might be because we know what we ought to do, but are acted on by factors beyond our control, for example, overwhelming desires, and in this respect are thus unreasonable. Perhaps I know that I ought not to steal my pupils' essays, but my kleptomania knows no bounds and means that I am unable to restrain myself from adding them to my hoard. To this extent, I am less than perfectly free. (I may nevertheless be blameworthy for stealing, if I did not and am not taking the steps that I ought to take to deal with my kleptomania.) Second, it might be because we are ignorant-we just don't know what we should do. Perhaps I state to a pupil who is distraught at his difficulties in understanding formal logic my belief that for every $x$, if $x$ is a cloud, then $x$ has a silver lining. I say this in the hope that it will comfort him, but it has the opposite effect. (Again I may nevertheless be blameworthy if I have been negligent in the way that I got into or remain in this state of ignorance about what sort of things are comforting things to say, for example, in not attending the courses that the College formally asked me to attend after noting the high rate of depression amongst those of my pupils to whom I teach logic.) Third, we might be selfish. We could do our duty; we know we should; but we freely choose to do something else instead, something which we calculate will serve us better. I know that I really should stay in my room to give the tutorial that I have scheduled, but I realize that I'd enjoy the SCR wine-tasting that's been scheduled for the same time rather more and I decide that I'm going to prioritise my own enjoyment over my duties. This sort of action deserves the name 'selfish' because it is the blameworthy following of one's self-interest at the expense of another. It is not simply that by attending the wine-tasting I am acting expediently within the parameters imposed by my obligations, I am knowingly violating those parameters in order to further my own interests. 
If the mere fact that it would be good for somebody if we did something for them disabled us from being able to refrain from doing it for them, then we would never be able to get any of our time or resources for ourselves. It is thus a power for us to be able to refrain from doing the best that we can for people. And the same goes for the ability not simply to fail to do the best that we can for people but to do what we know we ought not to do. Whatever normative theory one adopts, thought experiments can always be constructed that yield at the level of intuition a conflict between what it is most reasonable for a finite agent to do and what they should do, a fortiori what it would be supererogatory for them to do. Where prudence and duty conflict, it can be overall reasonable to be prudent rather than dutiful; a fortiori where prudence and supererogation conflict.

In that sometimes it is overall most reasonable for us to fail to be supererogatorily good and indeed to fail even to do our duty, so the capacity to be less than perfect both in the sense of knowingly failing to do the best one could for someone and in the sense of knowingly failing to do what one ought to do for them are genuine powers for us; they are abilities that it is good for us to have. Thus we, finite humans, have more power and thus freedom (freedom to exercise that power) if our knowing that a thing that we want to do is less than the best thing we could do does not in itself prevent us from doing it; and we have more power and freedom if our knowing that a thing that we want to do is something that we are under an obligation not to do does not in itself prevent us from doing it. In the context of considering divine free will, the crucial question is obviously this: 'Could these abilities be powers rather than liabilities for God?' And the answer, I suggest, is 'No.'

The ability, knowingly and without any weakness of will, to do less than duty requires is only plausibly a power, an ability which it is good to have, when one is in a situation where one reasonably desires an outcome that one reasonably believes one cannot achieve without deviating from what duty requires. God's omnipotence assures Him of being able to get whatever it is He desires without deviating from what duty requires. And His omniscience, that He knows this. What about the ability to refrain from doing the best or joint best that one can for someone? Again, this is only plausibly a power when one is in a situation where it is reasonable for one to think that one has finite resources available to one and thus that it is expedient to conserve them for other uses. And again, God could never be in such a situation. So, to ask the question whether God has the ability to perform an action that is less than moral perfection demands is to ask whether He has the ability to perform an action which of necessity there is good reason for Him not to perform relative to some other (it is less than moral perfection demands and remember we are assuming that one action being better than another incompatible action is objectively a reason to perform the first action) and which — being omnipotent- $\mathrm{He}$ need not perform in order to bring about any other state of affairs He might wish to bring about. In other words, it is to ask whether He has the ability to perform a completely unreasonable action-not only is there no reason to do it, but every reason is lining up against doing it. To answer the question of whether God might, nevertheless, be able to do it 'No' is then obviously not in any way to retreat from a claim that God is all powerful; such an ability would always be a liability; it could never be a power. We might be tempted to ask, 'But wouldn't He be more powerful/free were He to have the power/freedom to do such unreasonable actions?' But the answer to such a question would be 'No'; again, such a power is an impossibility; it is not logically possible for anyone to choose to do an action that he or she knows he or she has no reason whatsoever to do and every reason to avoid doing (including, remember, the reason of having 
an unalloyed and strong desire to avoiding doing it). The 'ability' to choose to do such actions is a logical impossibility, so nobody is or could be made more or less powerful or free by the having of it. For God (though not, I have argued, for us) every action short of that demanded by moral perfection falls into this category.

The claim so far then is that it is in virtue of our not being omnipotent and omniscient, that it is good for us-a power-that we can choose to do other than what perfect goodness demands. We can choose in our relationships with other creatures to do things that we know aren't the best that we could do for them and we can even choose to do things that we know aren't simply not the best that we could do for one another, but are things we shouldn't do to one another. In virtue of His being omnipotent and omniscient, it is good for God-an absence of a liability - that He cannot do either of these sorts of thing: He cannot choose to do anything other than what perfect goodness demands, whatever is perfectly loving towards us, His imperfect creatures.

\section{God, Alternate Possibilities, and Creating the Best}

One might think that there's a difficulty raised for divine free will by the conception of freedom whereby for genuine freedom it has to be possible for an agent to do otherwise than he or she actually does when we commit ourselves in the way that we have to claiming of God that, due to His omnipotence and omniscience, He is of necessity perfectly good. For, as we have seen, His necessarily being perfectly good entails that He not have been able to do otherwise than whatever perfect goodness demands. He remains, I have argued, despite this, perfectly powerful nonetheless, for His being unable to deviate from whatever perfect goodness demands is an expression of power (the ability to deviate would be a liability for Him). But how, one might argue, can He remain free at all, let alone perfectly free, when $\mathrm{He}$ is not able to deviate and freedom requires alternate possibilities? The answer is a simple one. God has alternate possibilities allowed for by the demand of perfect goodness: the demand of perfect goodness is disjunctive.

We see the same sort of disjunctive structure in the case of the everyday urgings that goodness gives us and the demands that duty makes on us. Suppose it would be good or possibly even my duty to give a certain amount of money to charity. I might still find myself asking, 'Shall I give to charity x or y?' And I might find myself asking this even if I'm in no relevant way ignorant of what each charity would do with my money; I might be certain that each would produce good with it but quite different-incommensurablegood. The right analysis of this sort of situation is sometimes that the urging of goodness to supererogation or the demand of morality to do one's duty is disjunctive. Perhaps in this case it tells me simply to give this money to one charity or the other and leaves it at that. And the same thing applies to the demand of perfect goodness. God thus satisfies the principle of alternate possibilities. So, what's the problem?

A problem may seem to arise if one considers cases where there is a uniquely best thing for God to do for His creatures, for when there is a uniquely best thing for Him to do for His creatures, this is what God must do. Even then, one might suggest, there will still be alternative ways of God's doing this best thing, so He will still satisfy the principle of alternate possibilities, but it must be conceded that in such a case He does not retain the ability to choose between options of differing value-where there is a best or joint best for His creatures, His necessary moral perfection ensures He will do this best or one of these joint bests. Such a scenario may then be said to be a manifestation of at 
least some 'shrinkage' in God's options. But the important point to make is that in such a situation, God will not have been forced so to shrink His options; any shrinkage in God's options could only result from a well-informed choice that He had made 'earlier' so to shrink them. I say 'earlier' with some caution as, if God is outside time, this wouldn't be a temporal 'earlier.' Pushing such concerns aside, we may say this.

Prior to the creation of any universe, God's perfect goodness-requiring of Him that He do the best (or one of the joint best) things for His creatures whenever there is one-dictated nothing at all as to what He must or mustn't do for the simple reason that there were no creatures. In particular, it is worth stressing that He was not forced by the standard of perfection to 'look through,' as it were, every logically possible world and, should He have found when looking at them that one had more value in it than any other, create that one rather than any other-create 'the best of all possible worlds.' I myself think that there is no best of all possible worlds in this sense: some values are incommensurable and some values are capable of being extended without limit, that is, for every logically possible world with a certain amount of that value, there's another with a bit more. However, my point here is that even supposing that there is a uniquely best of all possible worlds, God was not required by the standard of perfection to create it. That is because the standard of perfection does not require of Him that He be what we might call a 'value maximizer'; failure to create a better universe, rather than a worse, is not, as such, a falling short of the standard of perfection; only if some actual creature is made worse off than he or she would otherwise have been by one's doing so is such a failure a falling short of the standard and, as just pointed out, prior to His creating, there were no creatures to set such constraints on Him. At this stage then, every metaphysical possibility was equally open to Him. Nobody else has ever so fully satisfied the principle of alternate possibilities as God did then.

God could have created nothing at all. Or He could have created a type of universe that would have resulted in no shrinkage at all in the options then available to Him in His subsequent interaction with it. That is because He could have created a universe with no morally weighty creatures in it. For example, He might have created a universe consisting simply of a single hydrogen atom; hydrogen atoms aren't things towards which He could have duties or for which there is a best thing or are joint best things that He could then do for them. The first shrinkage comes in only once He has created a universe with morally weighty creatures in it, for, from then on, His perfect goodness entails, at the least, that He do whatever it is that it is His duty to do for such creatures. It is worth pointing out that some such universes are ones in which He would not be necessitated by His perfect goodness to go beyond His duty for them; these would be universes where the morally weighty creatures were ones for whom there was no best (or joint best). Perhaps ours is such a universe? If it isn't, because we or some of us are in fact creatures for whom there is a best (or joint best), that itself will be the result of His informed choice to shrink his options yet further; He will have knowingly either created us such that we are essentially creatures for whom there is a best or joint best or have further interacted with some of us, so as to make those particular creatures with whom He has interacted such that there is, accidentally, now a best or joint best for them. Perhaps humans are such that there is a best for all of us; if so, then God must give that to us all. Conversely, perhaps there is no general truth about humans per se in virtue of which there is a best for all of us, but He has made some of us such.

Bearing in mind once more the caveat about using temporal terms to talk about God, it is then true to say that earlier choices by God can shrink His options for later choices, 


\section{T. J. MAWSON}

but none of these choices were forced on Him (the first, to create or not to create, could be said to have been 'forced' on Him by logic, I suppose, but that would be quite a forced sense of 'forced') and so we may say that God-despite, through omnipotence, omniscience, and perfect goodness, being unable to choose to be less than perfect goodness demands - had an infinite number of alternate possibilities open to Him in creation and any shrinkage in His options thereafter will only have been as a result of how these earlier choices were made by a God who was omniscient about the shrinkage that would be consequential on His making those choices and was the ultimate author of all his actions or, as tradition puts it, the prime mover.

\section{Acknowledgments}

I would like to thank Kevin Timpe and everyone involved with this volume for their help in improving my thinking and writing for it.

\section{References}

Adams, R.M. (1987) "Must God Create the Best?" in R.M. Adams, The Virtue of Faith and Other Essays in Philosophical Theology. New York: Oxford University Press, pp. 51-64.

Almeida, M. (2008) The Metaphysics of Perfect Beings. New York: Routledge.

Brown, C. and Nagasawa, Y. (2005) "The Best of All Possible Worlds," Synthese 143: 309-20.

Funkhouser, E. (2006) "On Privileging God's Moral Goodness," Faith and Philosophy 23: 409-22.

Howard-Snyder, D. and Howard-Snyder, F. (1994) "How an Unsurpassable Being Can Create a Surpassable World," Faith and Philosophy 11: 260-8.

Howard-Snyder, D. and Howard-Snyder, F. (1996) “The Real Problem of No Best World," Faith and Philosophy 13: 422-5.

Kraay, K. (2006) "The Problem of No Best World," in C. Taliaferro and P. Draper (eds), A Companion to Philosophy of Religion, 2nd edition. Oxford: Blackwell, pp. 491-9.

Kraay, K. (2007) "God and the Hypothesis of No Prime Worlds," International Journal for Philosophy of Religion 59: 49-68.

Kraay, K. (2008) “Divine Unsurpassability,” Philosophia 35: 293-300.

Kraay, K. (2009) "Creation, Actualization and God's Choice Among Possible Worlds," Philosophy Compass 3: 854-72.

Kraay, K. (2011a) "Can God Choose a World at Random?" in Y. Nagasawa and E.J. Wielenberg (eds), New Waves in Philosophy of Religion. Basingstoke: Palgrave Macmillan.

Kraay, K. (2011b) "Incommensurability, Incomparability, and God's Choice of a World," International Journal for Philosophy of Religion 69: 91-102.

Langtry, B. (2008) God, the Best, and Evil. Oxford: Oxford University Press.

Leftow, B. (2005a) "No Best World: Moral Luck," Religious Studies 41: 165-81.

Leftow, B. (2005b) "No Best World: Creaturely Freedom," Religious Studies 41: 269-85.

Leftow, B. (2007) "Rowe, Aquinas and God's Freedom," Philosophical Books 48: 195-206.

Lehe, R. (1986) "God's Perfection and Freedom," Faith and Philosophy 3: 319-23.

Leibniz, G. (1710/1985) Theodicy. LaSalle: Open Court.

Morriston, W. (2001) "Omnipotence and Necessary Moral Perfection: Are They Compatible?" Religious Studies 37: 143-60.

O'Connor, T. (2008) Theism and Ultimate Explanation: The Necessary Shape of Contingency. Oxford: Blackwell. Pike, N. (1969) “Omnipotence and God's Ability to Sin," American Philosophical Quarterly 6: 208-16.

Rowe, W. (2004) Can God Be Free? Oxford: Oxford University Press.

Senor, T. (2006) "God's Goodness Needs No Privilege: A Reply to Funkhouser," Faith and Philosophy 23: $423-31$.

Steinberg, J. (2005) "Why an Unsurpassable Being Cannot Create a Surpassable World," Religious Studies 41: 323-33.

Steinberg, J. (2007) "Leibniz, Creation and the Best of All Possible Worlds," International Journal for Philosophy of Religion 62: 123-33. 


\section{DIVINE FREE WILL}

Wainwright, W. J. (2005) "Rowe on God's Freedom and God's Grace," Philo 8: 12-22.

Wielenberg, E. (2000) "Omnipotence Again," Faith and Philosophy 17: 26-47.

Wielenberg, E. (2004) “A Morally Unsurpassable God Must Create the Best," Religious Studies 40: 43-62.

\section{Further Reading}

Everything that is given in the references section is worth reading. As mentioned in the main text, Wes Morriston summed up the case against Theism arising from the first question in his 2001 "Omnipotence and necessary moral perfection: are they compatible?" Religious Studies 37: 143-60. I recommend that. Hoping I may be forgiven for putting forward some of my own work for your consideration, I mention that I replied to Morriston with a piece in that same journal and then a fuller reply, also in that journal. I'd recommend that fuller reply: Mawson, T.J. (2005) "Freedom, Human and Divine," Religious Studies 41: 55-69. I also treat the issue in Mawson, T.J. (2005) Belief in God. Oxford: Oxford University Press, which contains a discussion of the issue of whether or not God should be thought of as having to create the best of all possible worlds. In that, I take inspiration from the work of Bob Adams cited, which too I would recommend: Adams, R.M. (1987) "Must God Create the Best?" in R.M. Adams, The Virtue of Faith and Other Essays in Philosophical Theology. New York: Oxford University Press, pp. 51-64.

\section{Related Topics}

Dispositional Compatibilism

Agent Causation

Leeway vs. Sourcehood Conceptions of Free Will

Free will and Theological Determinism

Free will and Providence 
$\because$ Taylor \& Francis Taylor \& Francis Group http://taylorandfrancis.com 


\section{Section VI}

\section{SPECIAL TOPICS}

One of the major frustrations confronting those who engage in the free will debate is its stubborn refusal to behave itself. All philosophical questions are about others, in ways that entail that answers to one affect answers to others. In fact, that kind of holism is a fact of intellectual life across all disciplines. "In principle, our botany constrains our astronomy, if only we could think of ways to make them connect", as Fodor writes. But the free will debate seems an extreme case, inasmuch as claims about it are not merely constrained by work in multiple fields, but actually seem to lie across many fields at once.

Free will is often characterized as a topic falling within the remit of metaphysics. That certainly seems appropriate, insofar as it is concerned centrally with issues to do with the nature of causation. But it is sometimes considered the province of moral philosophers, due to its close connection with autonomy, moral responsibility, and blame. Philosophers of religion can lay claim to it as well, both for historical reasons and because free will remains central to the topic of theodicy and to the human relation to God. Philosophers of mind sometimes claim it as their own, since decision-making and reasoning are so central to freedom of the will. The main topics in moral psychology intersect closely with it: self-deception is prima facie a threat to free will, and weakness of the will is even more closely intertwined. Recently, scientists have got into the act: the top spot in the Google Scholar rankings by citation for the tag 'free will' is occupied by John-Dylan Haynes, a neuroscientist.

If this refusal to behave itself makes the topic of free will so frustrating (by ensuring that none of us can feel confident in their expertise across the full range of topics that are central to it), it is also what makes it so exciting. There is always more to learn about free will, other angles to bring to bear to it, other ways in which disciplines may productively engage on its terrain. The chapters in this section illustrate how exciting this kind of territory can be, as well as how productive it is to traverse this terrain.

Chapters cover some of the topics just mentioned (although the topics themselves are badly behaved: you will find discussion of weakness of the will, say, in other sections of the handbook). There are arguments that agents are morally responsible only for their weak-willed actions (Rosen; Zimmerman); on many views, the truth of this claim would entail that only such actions are free. Meanwhile, other authors have argued that weakwilled actions are not free at all. Akrasia must therefore be a central concern for any handbook on free will. Free will is also a topic in the philosophy of mind, and some of the chapters make its concerns central. Mental causation seems a necessary condition 
of free choice, but some philosophers are eliminativist about such causation. A satisfactory account of mental causation seems therefore to be a necessary condition of any account of free will. Other questions that are within the purview of philosophers of mind also matter: the nature of deliberation, and the pathologies of the mind to which we are subject, such as mental illness, are also essential to understanding human freedom. Finally, philosophers have sometimes appealed to the phenomenology of agency in arguing for free will. But it is only recently that there has been careful and systematic work on phenomenology of agency; grappling with it is essential to assessing its evidential value.

For the past century, the free will debate has centrally been concerned with whether causal determinism undermines freedom. But the concept of determinism is deceptively complicated, and falls within the purview of physics and its philosophy. Hence the need for a chapter on physics. But free will is also very much a practical problem: its vindication or elimination affects our conception of ourselves as human beings and may require us to rethink our practices of blaming one another, and indeed our criminal justice system. Hence the need for systematic explorations of the nature of blame and of free will's relation to the law.

Philosophy is notorious for the low proportion of women in the field, relative to other humanities and even to many of the sciences. Yet some of the most exciting developments in philosophy have been in the area of feminist philosophy, both as a distinctive area in its own right and as an approach (perhaps better, a set of approaches) to other issues. A number of feminist philosophers have made important contributions on the topic of free will (broadly understood), yet too many specialists in the area remain unaware of them. We hope that the chapter in this volume highlighting some of this work will play a role in reversing this neglect.

The free will debate is unruly, always opening up new fronts and finding new connections to old topics. The chapter on free will and time travel represents yet another way in which it can branch out in unexpected ways. We could not hope to cover every topic that might be seen as falling within the entire free will debate-sometimes it seems co-extensive with all of philosophy and much of the cognitive sciences, too-but we hope to have presented almost every major topic. Perhaps the handbook will contribute to sparking off the next wave of extensions and rethinkings of this ever-shifting, ever fascinating, question.

N.L. 


\section{0 \\ SELF-CONTROL AND AKRASIA}

\section{Christine Tappolet}

Imagine you are Ulysses. You know that the songs of the Sirens are extremely beautiful as well as dangerously seductive, yielding to the temptation to join the Sirens being likely to prove fatal. Suppose that by contrast to the original story, you fail to get tied to the mast-you fail to bind yourself, to use Jon Elster's expression (1977). Is it possible that in spite of your better judgment, you jump overboard to follow the Sirens? Suppose that it is freely and intentionally that you jump into the sea. You act freely in the sense that nothing forces you to act the way you do-it is not because you are pushed overboard by a gust of wind or compelled by a compulsive urge that you jump. And your action is intentional-for instance, you do not jump because you trip over a loose rope or because you are so confused as to think that jumping into the sea is the best way to escape the Sirens. Can it really be the case that at the same time as you jump, you really judge that you have decisive reasons not to join the Sirens, or that all things considered, it would be better-decisively better, in this instance-not to do so?

If so, such actions, which have been called "akratic" (from akrasia, which means lack of mastery in Greek) but also "incontinent" (from the Latin incontinentia) and "weakwilled," can be characterized roughly as actions performed in spite of the agent's better judgment. A question that has been at the center of recent philosophical debates is whether such actions are possible. This debate can be traced back to Socrates, Plato, and Aristotle. Initially conceived of as a problem belonging to ethics, the question addressed being whether and, if so, how an agent could yield to temptation in spite of his knowing that this was bad, the recent debate concerns our general understanding of how actions are related to practical judgment. Even though everyone in the debate would agree that akratic actions appear to be a commonly recognized phenomenon, it is only in the wake of Donald Davidson's influential paper, "How is Weakness of the Will Possible?" (Davidson 1970), that philosophers have come to accept the possibility of akratic actions. As we shall see, the question remains controversial.

The question of the possibility of akratic actions obviously depends on how such actions are characterized, and it is no surprise that very different conceptions of akratic actions have been proposed. One difficulty in understanding recent debates is that, as I indicated, many terms have been used to refer to akratic actions, but moreover quite different phenomena have been distinguished. For example, Richard Holton $(1999,2009)$ proposes to distinguish between akrasia and weakness of will, where the former relates to acting in spite of one's better judgment, and the latter is defined in 
terms of irrational reconsideration of the agent's resolution. So it is important to clarify whether the disagreement is about how to describe what is supposed to be one and the same phenomenon, or whether the discussion is about a number of different and possibly only loosely related phenomena.

In spite of the important variety of available accounts, what is commonly assumed is that akrasia is opposed to self-control, akratic actions often being thought to instantiate a paradigmatic self-control failure. Weakness of will understood as irrational resolution reconsideration also counts as a paradigmatic self-control failure. As such, that both akrasia and weakness of will are considered to be opposed to self-control is not a problem. Akrasia and weakness of will could well constitute two kinds of self-control failures, along with addiction and compulsion. The question that is raised, however, is that of the nature of self-control. Is self-control one unified phenomenon, or are there several distinct phenomena? Moreover, a puzzle arises here. If we suppose that akrasia is opposed to self-control, the question is how akratic actions could be free and intentional. After all, it would seem that it is only if an action manifests self-control that it can count as free.

My plan is to explore the relation between akrasia and self-control. The first section presents what I shall call the standard conception, according to which akrasia and self-control are contraries, and introduces the puzzle that this conception raises. The second section turns to the arguments for and against the possibility of free and intentional akratic actions. The third section questions the claim that akratic actions are necessarily opposed to actions manifesting self-control.

\section{The Standard Conception}

The contemporary debate around akrasia is largely based on Aristotle's seminal account. According to Aristotle, enkrateia and akrasia, along with virtue and vice, are character traits (Nicomachean Ethics, VII). Enkrateia, which literally means mastery and is often translated by "continence," but also by "self-control," is not as praiseworthy as virtue. This is so because in contrast to the virtuous agent, the enkratic agent experiences passions such as anger or exaggerated appetites for pleasure, which are contrary to reason. What characterizes the enkratic agent is that he manages to resist these temptations. As a result, the enkratic agent generally does what a virtuous agent would in similar circumstances. Similarly, akrasia, which literally means lack of mastery, is not as blameworthy as vice. The akratic agent not only experiences the same wayward passions as the enkratic agent, but he also yields to these passions. In contrast to the vicious agent, however, the akratic agent has knowledge of the right action. Interestingly, the knowledge attributed to the akratic agent is not unqualified. The akratic agent has knowledge, but he is not exercising or using it, like someone who is asleep, mad, or drunk (Nicomachean Ethics, VII: 1147a10-24; see Kraut 2008; Müller 2015).

By failing to attribute full-blown knowledge of the akratic agent, Aristotle appears to deny the possibility of "clear-eyed akrasia" (Charlton 1988: Chapter 3). Aristotle thus comes close to the Socratic thesis, according to which it is not possible to act against one's knowledge of the right, a thesis that Aristotle in fact criticizes as going against the appearances. More specifically, Socrates is said to have denied the possibility of voluntary action performed in spite of knowing that what is done is bad or less than the best: "no one [. . .] acts against what he believes best - people act so only by reason of ignorance" (Nicomachean Ethics, VII: 1145b25-30). A similar denial can be 
found in Plato: "No one who either knows or believes that there is another possible course of action better than the one he is following, will ever continue on his present course" (Protagoras 358b-c).

Even though only a few contemporary thinkers would be tempted by the claim that there is no akrasia in any sense similar to what Socrates had in mind, the basic opposition between akrasia and self-control is widely accepted (see Davidson 1970; Levy 2011). Here is for instance how Alfred Mele states this view:

I will follow Aristotle in understanding self-control and akrasia as two sides of the same coin. [.. .] Self-controlled individuals are agents who have significant motivation to conduct themselves as they judge best and a robust capacity to do what it takes so to conduct themselves in the face of (actual or anticipated) motivation [...]. Akratic individuals, conversely, suffer from a deficiency in one or both of these connections.

(Mele 2002: 531; see also 1992, 1995)

These claims concern akrasia as an attribute of agents. Contemporary discussions have rather focused on types of actions. Mele specifies what he calls "strict incontinent actions" in the following way:

An action $\mathrm{A}$ is a strict incontinent action if and only if it is performed intentionally and freely and, at the time at which it is performed, its agent consciously holds a judgment to the effect that there is good and sufficient reason for his not performing an $\mathrm{A}$ at that time.

(Mele 1992: 7, 2012; see also Davidson 1970: 22)

According to this definition, strict akratic actions are freely and intentionally performed in spite of the agent's better judgment, where the better judgment is characterized in terms of good and sufficient reasons - what appear to be decisive reasons-and where the conflict is specified as being synchronic instead of involving a diachronic change of mind.

Mele argues that such actions are perfectly possible. However, if we assume that free akratic actions are possible, and if we assume that akrasia is opposed to self-control, it follows that actions manifesting lack of self-control can be free. This might seem not much of a problem, but on reflection the idea that freedom and self-control can come apart is puzzling. As many would agree, free agency requires self-control. Intuitively, an agent is free only if she is in control of what she does. Robert Kane, for one, starts his contribution to Four Views of Free Will as follows: "The problem of free will has arisen in history whenever people have been led to suspect that their actions might be determined or necessitated by factors unknown to them and beyond their control" (Kane 2007: 5). Someone who is under the control of another agent is as unfree as a marionette pulled by strings. Similarly, it appears that an agent is only free if she is in control of what she thinks and desires. If what an agent wants is controlled by someone else, as when the person is under hypnosis, the agent is just as unfree as the marionette in the hands of the puppeteer. So, self-control clearly appears necessary to free agency.

One way to come to see that there is a puzzle is to focus on the notion of free agency. As Gary Watson underlined in his influential article "Free Will and Free Action," the notion of free agency involves two different features that both need to be captured, 
self-determination (or autonomy) and the availability of alternative possibilities (Watson 1987: 145). Now even if self-control and autonomy, understood as the capacity to govern oneself, might well be different concepts, they appear closely connected. It is unclear how one could govern oneself without also controlling oneself. Indeed, selfcontrol is often thought to be essential to autonomy. Here is how Marina Oshana formulates this assumption: "Autonomous persons are beings in actual control of their own choices, actions, and goals. [. . .] Implicit in the idea of actual control over one's life is the idea of self-control" (Oshana 2006: 3).

Now, the problem is that if free agency requires self-control, then it would seem that free agency excludes lack of self-control. Put differently, in so far as an action is free, it cannot be one that manifests lack of self-control. But this makes for a problem if one accepts that there are strict akratic actions. This puzzle can be expressed in the form of a paradox:

1) Self-control excludes akrasia.

2) Akratic actions can be free.

3) Free agency requires self-control.

There are at least as many ways to solve this puzzle as there are propositions. You can question whether self-control excludes akrasia, whether akratic actions can be free, and whether free agency requires self-control. I shall assume that given a reasonable understanding of free agency and self-control, free agency requires self-control. Instead, I want to focus on the two other propositions making up the paradox, starting with the second one.

Before I do so, let me note that a similar paradox involves the notion of autonomy. In a nutshell, the problem is that it seems plausible that autonomy requires self-control, and yet there is reason to think that actions that are characterized by a lack of selfcontrol, such as akratic actions, can be autonomous, given that they can be free. The question that is raised is whether akratic actions can be autonomous (Mele 1995: 194, fn. 11, 2002).

Also, let me also pause to mark the distance between contemporary discussions and Aristotle's conception. Put simply, no such paradox arises for Aristotle. First, Aristotle was thinking in terms of voluntariness and not in terms of the modern notion of free agency. Even so, a similar puzzle could be spelled out by tying voluntariness to selfcontrol. But second, and more importantly, neither our puzzle nor its ancient equivalent would have been a problem for Aristotle. This is so because Aristotle presumably would have just as many qualms about the possibility of strict akrasia as he has about voluntary actions that conflict with full-blown knowledge.

\section{The Possibility of Strict Akrasia}

In a striking passage, Sarah Broadie claims "we all know that [incontinence] often happens; thus we know that it can happen" (1991: 266). As I said, she is far from alone in accepting the possibility of free akratic actions, a majority of contemporary philosophers being in agreement on this point (Bratman 1979; Audi 1979; Broadie 1991; Smith 1994; McIntyre 1990, 2006; Holton 1999, 2009; Arpaly 2000; Kennett 2001; Searle 2001; Stroud 2003, 2008; Henden 2004; Dodd 2009). Compared with how akrasia has been conceived in the history of philosophy since Socrates, there thus has been a 
radical shift (but see Hare 1952; Davidson 1970; Watson 1977; Buss 1997; Tenenbaum 1999, 2003, 2007; Levy 2011, for the view that strict akrasia is impossible). So, what are the arguments for and against the possibility of strict akrasia?

On the face of it, free and intentional action performed in spite of the judgment that one has decisive reasons not to perform that action, where that judgment is contemporaneous to the action, seems perfectly possible. First, there is no blatant contradiction in the definition of strict akratic actions. Indeed, it seems easy enough to imagine cases satisfying the definition. Is it not possible that Ulysses jumps into the sea to join the Sirens even though exactly at the same time, he judges that he has decisive reasons not to do so? Or if you find this example far-fetched, is it not possible that Sarah judges that she has decisive reasons not to have a third chocolate mousse while, freely and intentionally, she nonetheless goes for it? Such possibilities are hard to deny. Finally, a further reason to accept the possibility of strict akratic actions comes from the fact that we consider agents to be responsible for their akratic actions. This suggests that we consider the actions to be free, for it is plausible to assume that actions for which we hold someone morally responsible are free actions. It would appear unfair to consider someone to be responsible for an action caused by an irresistible urge, for instance. At most, we could consider that person to be responsible for not having developed the required self-control capacities, but this is a distinct failure.

Of course, appearances might be misleading. Maybe these descriptions are inaccurate. How could it be excluded that Ulysses in a sense knows that joining the Sirens is too risky, but that there is something wrong with that cognition (Tenenbaum 2007)? Or else, Ulysses might have undergone a possibly irrational change of mind, the songs of the Sirens causing him to revise his evaluation of the situation (Ainslie 1975, 1992; Elster 1979; Jackson 1984)? Ulysses might even have resolved not to yield to the seduction of the Sirens, but again, their songs make him revise his resolution (Holton 1999; Dodd 2009). Similarly, how could it be excluded that Sarah does not actually judge but merely believe in a dispositional sense that she should not have this chocolate mousse (Levy 2011)? Maybe Sarah only judges that she should reduce her calorie intake overall, where this goal is so vague as to be compatible with judging you should ingest any particular dessert (Tenenbaum and Raffman 2012; Andreou 2014). (For yet other possibilities, such as hypocrisy, confusion, mention of a purely conventional norm, etc., see Hare 1992.)

But then, maybe not. It could well be that these alternative descriptions correspond to possible variations of our two cases, but that at the time they fail to accurately describe Ulysses and Sarah. So it might seem that what we have is a mere clash of intuitions, where little can be done to move forward. Yet, I believe that this conclusion misrepresents the dialectic. What has to be underlined is that strict akrasia appears perfectly possible, and so what is needed to deny its possibility is sufficient reason to believe that appearances are misleading. Giving such a reason is exactly what philosophers from Socrates onwards have attempted to do. They lined up a number of arguments to show that strict akrasia is not possible. Let us look at the main arguments. As far as I can see, four of them can be distinguished.

The first argument against the possibility of strict akrasia appeals to an attractive conception of intentional action, according to which intentional action is done in the light of some imagined good (Aristotle Nicomachean Ethics, I; Aquinas Summa Theologica, 1st Part of the 2nd Part, question 1; Anscombe 1957; Davidson 1970). Obviously, this conception and the ensuing argument could just as well be expressed in 
terms of decisive reasons. On this conception, an agent who intentionally acts sets a positive value on some end, and given his belief that an action of the kind he can perform will realize the valued end, he acts. More precisely, an action will count as intentional only if the agent judges that it is best for him to perform that action (Davidson 1970: 23). If we further suppose that an action needs to be intentional for it to be free, it follows that actions that conflict with what the agent judges best cannot be free. Thus, in so far as akratic actions are not in the guise of the good, they cannot be free.

In response, it can be denied that intentional actions have to be done in the guise of the good (Stocker 1979; Velleman 1992). For instance, as David Velleman underlines, Satan seems an example of an agent who intentionally pursues the bad (Velleman 1992: 18). Be that as it may, it is not necessary to deny that intentional action is performed in the guise of the good in order to make room for strict akrasia. The assumption in the above argument that should come under scrutiny is that acting in the light of the good requires making a judgment. To make this assumption is to overlook a number of plausible alternatives. The mere fact that an action is caused by a desire might be sufficient for the considering that the action is done in the light of the good. Indeed, desires have been considered to be perceptions of the good (Stampe 1987; Oddie 2005; Tenenbaum 2007). Another possibility is to suggest that acting on the basis of emotions can, at least in certain conditions, be seen as acting in the light of the good (Jones 2003; Tappolet 2003, 2016).

A related argument has been offered by Sarah Buss (1997). The argument turns on role of preferences in intentional actions. It is based on the plausible idea that someone who acts a certain way while she would prefer to act otherwise does not act freely and intentionally. Thus, it seems impossible to force an agent to do something intentionally when she prefers not to do it. At best, it is possible to modify her preferences by using threats. In Buss's own words:

"[. . . ] since no one can be compelled to set a particular goal for herself as long as she prefers to pursue a different goal instead, no one can be compelled to intend to do one thing as long as she prefers to do another."

If we further assume that to prefer doing something amounts to judging that it would be better, all things considered, to do this thing, or else to judge that one has more reasons to do it, it follows that the agent who acts against her better judgment does not act freely and intentionally.

The question, obviously, is whether it is justified to take the relation between preferences and better judgments to be this close. The question of what kind of mental states preferences are is controversial (Hausman 2012). In any case, there is surely room for the view that preferences and better judgments can come apart. Preferences might be understood in purely behavioral terms, for instance. Even if we take the preferences at stake to be psychological states, however, there is room for the claim that only appropriate preferences are correlated to better judgments. On this account, to judge that something is better than something else, all things considered, would be to judge that it would be fitting or appropriate, in the relevant sense, to prefer the former to the latter (for such accounts, see Brentano 1889; Scanlon 1998, inter alia).

The third argument I would like to consider is also closely connected to the conception of intentional action as being done in the guise of the good. It is based on 
considerations bearing on the nature of the judgments that are involved in akratic actions. The intuition that is invoked is that such judgments, whatever their exact content, are not theoretical, but practical. Such judgments do not merely describe what is the case concerning our practical reasons, but tell us what to do, and motivate us accordingly. On this theory, there is a necessary or internal tie between better judgments, on the one hand, and motivation and action, on the other.

Richard Hare (1952), a proponent of a radical version of internalism with respect to moral judgments, claimed that to account for the action-guidingness of moral judgments, one has to adopt noncognitivism and suppose that such judgments involve imperatives, which we address to ourselves. When you assent to the judgment that you ought to tell the truth, you order yourself to do so. And given this, Hare thought it would follow that you will indeed tell the truth, if you are free to do so. Thus, it would be impossible for an agent to freely fail to do something while judging that she ought to do this. If the agent fails to act according to such a judgment, it must be because she was physically or psychologically unable to do so. Or else, the agent in fact did not really make the judgment in question. Hare's views, and more particularly his noncognitivism about moral judgments, are highly problematic. However, it is not necessary to embrace noncognitivism in order to defend internalism about practical judgments. One can simply claim that there is an internal relation between better judgments, whatever their exact nature, on the one hand, and motivation and action, on the other. Thus, one can hold with Davidson that if an agent judges that an action $\mathrm{x}$ is better than another action $\mathrm{y}$, she will be more motivated to do $\mathrm{x}$ than to do $\mathrm{y}$, and if she is free to do $\mathrm{x}$, she will do $\mathrm{x}$, if she does either $\mathrm{x}$ or $\mathrm{y}$ (Davidson 1970: 23) As we have seen, the akratic agent judges that what she does not do is better. According to the principle we are considering, if the agent makes such a judgment and is free to act accordingly, she will act accordingly, if she acts at all. If not, then she was not free to do so.

What should we think of this principle? We can agree that it is necessary to establish a distinction between theoretical judgments, which simply aim at describing reality, and practical judgments, which are in some way internally connected to motivation and action. However, as has been underlined by Sarah Stroud (2003), the distinction between these two kinds of judgments can be maintained without ruling out strict akrasia. Following Michael Smith (1994), it is possible to develop a weaker form of internalism with respect to moral, and more generally, with respect to practical judgments. Smith proposes that if an agent judges that she has to perform an action, either she will be motivated to act accordingly, or else she suffers from practical irrationality. In so far as this weaker principle establishes a tight connection between practical judgments and motivation or action, it preserves the distinction between practical and theoretical judgments. But of course, this new principle is perfectly compatible with the possibility of strict akratic actions. What it entails is simply that such actions are practically irrational, something which is hardly controversial. Even those who claim that it is sometimes more rational to act against one's better judgment agree that some irrationality is involved (Audi 1990; McIntyre 1990; Arpaly 2000; Brunero 2013).

The last argument against the possibility of strict akratic actions I shall discuss directly questions the claim that akratic can be free. According to Gary Watson (1977), it is not possible to distinguish between akratic and compulsive actions in terms of freedom: neither of them could have acted otherwise. Watson asks what explains that the agent fails to resist the temptation. He discusses two explanations, both of which he considers to be unsatisfactory. According to the first explanation, the agent does not 
resist the temptation because he chooses not to resist. Watson claims that we cannot assume this, for "to choose not to implement this choice would be to change [the] original judgment" (1977: 55). Thus, what we would have is a case of recklessness, not a case of akrasia. The second explanation is that the effort to resist the temptation is culpably insufficient. If we suppose that the action is free, we have to assume that the agent could have made a sufficient effort. Hence, the question is why the agent did not make this effort. Again, one cannot say that the agent did not make the relevant effort because he thought the effort was not worth it, for that would indicate that the agent had changed his mind. Moreover, one cannot say that the agent was mistaken about the effort required, for this would be a different fault from that of akrasia.

The intuition driving Watson's argument is that choice, and hence, free action, follows better judgment. This is a conception of action which ties together free agency and autonomy, and sees free action as flowing from the agent's evaluative capacities. What free action requires is controversial, but the force of the conception Watson is proposing should not be underestimated. Before putting aside Watson's argument, we would need a plausible alternative to the account of free agency he proposes. The fact is that there a number of alternatives. According to one such alternative, free agency is explained in terms of the exercise of a rational capacity. The difference between the weak agent and the compulsive agent is that the latter has, but fails to exercise, the rational capacity to bring her desires into line with her better judgment, while the latter lacks this capacity (see Smith 2003). In any case, what has to be underlined is that there are accounts according to which choice and free action need not follow from judgments regarding the good or regarding reasons.

Let us take a step back. There appear to be no conclusive arguments against the possibility of strict akratic actions. In fact, what transpires from the discussion is that the objections to that possibility rely on a number of quite theoretical and controversial claims regarding human agency. Given the initial plausibility of the possibility of strict akrasia, it is far from clear that they should convince us. In any case, it would seem that to solve the puzzle we started with we need to reconsider the standard conception, according to which akrasia and self-control are opposite.

\section{Akrasia and Self-Control}

As I said, the claim that akratic actions cannot by definition be actions that manifest self-control is standardly accepted. But on reflection, this is far from obvious. By all accounts the notion of self-control is a relational one. The basic notion is that of the self being in control of something else-her actions, her thoughts, her feelings, or more generally and also somewhat more mysteriously, of her own self. By contrast, the concept of actions freely and intentionally performed against the agent's better judgment does not, as such, involve the idea of the self. What needs to be added to arrive at the idea of a self-control failure is the further thought that better judgments represent the self. In Aristotelian terms, if the self is the faculty of reason, acting against the verdict of reason, acting against this verdict constitutes a self-control failure. According to Aristotle, "reason more than anything else is man." (Nicomachean Ethics, 1178a; also see Plato, Republic, 588b-592b; Watson 1975). The question is whether we should accept this conception of agency.

A first problem to consider, however, is that it is plausible to distinguish different notions of self-control. In an often quoted passage, John L. Austin offers a counter-example to 
the view that acting against one's better judgment necessarily comes with loss of self-control.

Plato, I suppose, and after him Aristotle, fastened this confusion upon us [...]. I am very partial to ice cream, and a bombe is served divided into segments corresponding one to one with the persons at High Table: I am tempted to help myself to two segments and do so, thus succumbing to temptation and even conceivably (but why necessarily?) going against my principles. But do I lose control of myself? Do I raven, do I snatch the morsel from the dish and wolf them down, impervious to the consternation of my colleagues? Not a bit of it. We often succumb to temptation with calm and even with finesse.

(Austin 1970: 198 fn. 1)

A plausible move to account for such examples is to distinguish between different capacities. Thus, Jeannette Kennett (2013) proposes to distinguish between intentional self-control and normative self-control (see also Kennett 2001; Mele 2002; Schroeter 2004; Henden 2008). Accordingly, the agent helping himself to two bombe segments can be said to have intentional control over his action, in the sense that his action manifests his capacity to bring his action in line with his intention. However, this action would fail to manifest normative self-control, understood as the capacity to bring one's actions into line with one's self.

A second type of cases cannot be dealt with in this way. Consider the often discussed example of Huckleberry Finn (Bennett 1974). As the case is construed by Alison McIntyre, Huck fails to turn Jim in to the slave hunters in spite of his judgment that all things considered, he ought to do so. Now it seems plausible to say that Huck's decision not to turn Jim in is morally more admirable, which makes it a case of so-called "inverse akrasia" (Arpaly and Schroeder 1999). But what matters here is that Huck's decision appears both more rational and, in particular, more responsive to reasons compared to the decision to act on his better judgment (Audi 1990; McIntyre 1990; Arpaly 2000; Jones 2003; Tappolet 2003; Brunero 2013). In particular, it is more reasons-responsive because his better judgment allegedly neglects important considerations, such as Jim's being his friend, Jim's desire for freedom, etc. Now, it seems that it is Huck's emotionshis feeling of friendship and his sympathy for Jim-that lead him to disregard his doubtful moral principles. Huck's emotions thus appear to enable him to be properly reasons-responsive, and more so than if he had acted on his better judgment (Jones 2003; Tappolet 2003, 2016).

If this is on the right lines, what we have here is an action freely and intentionally performed against the agent's better judgment that nonetheless manifests the capacity to bring one's action into line with the agent's self. We would have an akratic action that also manifests normative self-control. This is so, at least, if we assume that normative self-control requires reasons-responsiveness (Kennett 2001; Henden 2008). The claim is that normative self-control, which constitutes us as autonomous, self-governed agents, is the capacity to govern oneself according to one's reasons. The assumption that normative self-control requires reasons-responsiveness rests on a conception of the self that would need to be examined. But its initial plausibility makes it reasonable to suggest that akrasia need not be opposed to normative self-control. 


\section{CHRISTINE TAPPOLET}

\section{Conclusion}

Let us look back at the puzzle we started with. The problem was that if we assume that free agency requires self-control, so that free actions are actions that manifest selfcontrol, the possibility of strict akratic actions is ruled out. As we have seen, the three following claims are inconsistent:

1) Self-control excludes akrasia.

2) Akratic actions can be free.

3) Free agency requires self-control.

I have argued that the solution to the paradox is to reject the first proposition. Not only can there be actions performed against the agent's better judgment which manifest intentional self-control, but there can be actions performed against the agent's better judgment which manifest normative self-control, the very form of self-control which has commonly been thought to be opposed to akrasia. In a nutshell, pace Aristotle, akrasia does not exclude enkrateia.

\section{Acknowledgments}

I would like thank John Brunero, Laetitia Monteils-Laeng, Mauro Rossi and Sarah Stroud for useful comments on various stages of this material. Also, I am grateful to Samuel Dishaw for useful research assistance. Part of the third section is drawn from Tappolet (2013).

\section{References}

Ainslie, G. (1975) "Specious Reward: A Behavioral Theory of Impulsiveness and Impulse Control," Psychological Bulletin 82: 463-96.

Ainslie, G. (1992) Picoeconomics: The Interaction of Successive Motivational States Within the Person. Cambridge: Cambridge University Press.

Andreou, C. (2014) "Temptation, Resolutions, and Regret," Inquiry 57: 275-92.

Anscombe, G.E.M. (1957) Intention. Oxford: Basil Blackwell.

Aquinas, T. (1964-1973) Summa Theologica, trans. by T. Gilby, T. Suttor, J.P. Reid, W.D. Hughes, W.J. Hill, T.R. Heath, and C. Ernst. London: Eyre and Spottiswoode and New York: McGraw-Hill.

Aristotle (1915) Nicomachean Ethics, trans. W. D. Ross, The Works of Aristotle, vol. 9. Oxford: Clarendon Press.

Arpaly, N. (2000) “On Acting Rationally Against One’s Best Judgment," Ethics 110: 488-513.

Arpaly, N. and Schroeder, T. (1999) "Praise, Blame and the Whole Self," Philosophical Studies 93: 161-88.

Audi, R. (1979) "Weakness of Will and Practical Judgment," Noûs 13: 173-96.

Audi, R. (1990) "Weakness of Will and Rational Action," Australasian Journal of Philosophy 68: 270-81.

Austin, J.L. (1970) Philosophical Papers. Oxford: Oxford University Press.

Bennett, J. (1974) "The Conscience of Huckleberry Finn," Philosophy 49: 123-34.

Bratman, M. (1979) "Practical Reasoning and Weakness of the Will," Noûs 13: 153-71.

Brentano, F. (1889) The Origin of Our Knowledge of Right and Wrong. London: Routledge and Kegan Paul.

Broadie, S. (1991) Ethics with Aristotle. Oxford: Oxford University Press.

Brunero, J. (2013) "Rational Akrasia," Organon F 20: 546-66.

Buss, S. (1997) "Weakness of Will," Pacific Philosophical Quarterly 78: 13-44.

Charlton, W. (1988) Weakness of Will. Oxford: Basil Blackwell.

Davidson, D. (1970) "How Is Weakness of the Will Possible?" in J. Feinberg (ed.), Moral Concepts. Oxford: Oxford University Press, pp. 21-42.

Dodd, D. (2009) "Weakness of Will as Intention-Violation," European Journal of Philosophy 17: 45-59. 
Elster, J. (1977) "Ulysses and the Sirens: A Theory of Imperfect Rationality," Social Science Information Social Science Information 16: 469-526.

Elster, J. (1979) Ulysses and the Sirens: Studies in Rationality and Irrationality. Cambridge: Cambridge University Press.

Hare, R.M. (1952) The Language of Morals. Oxford: Clarendon Press.

Hare, R.M. (1992) "Weakness of the Will," in L.C. Becker and C.B. Becker (eds), Encyclopedia of Ethics. New York: Garland, pp. 1304-7.

Hausman, D.M. (2012) Preference, Value, Choice, and Welfare. Cambridge: Cambridge University Press.

Henden, E. (2004) "Intentions, All-Out Evaluations and Weakness of the Will," Erkenntnis 61: 53-74.

Henden, E. (2008) "What is Self-Control?" Philosophical Psychology 21: 69-90.

Holton, R. (1999) "Intention and Weakness of Will," Journal of Philosophy 96: 241-62.

Holton, R. (2009) Willing, Wanting, Waiting. Oxford: Oxford University Press.

Jackson, F. (1984) "Weakness of Will," Mind 93: 1-18.

Jones, K. (2003) "Emotion, Weakness of Will, and the Normative Conception of Agency," in A. Hatzimoysis (ed.), Philosophy and the Emotions. Cambridge: Cambridge University Press, pp. 181-200.

Kane, R. (2007) "Libertarianism," in J.M. Fischer (ed.), Four Views on Free Will. Oxford: Blackwell, pp. 5-43.

Kennett, J. (2001) Agency and Responsibility: A Common-Sense Moral Psychology. Oxford: Oxford University Press.

Kennett, J. (2013) "Just Say No?" in N. Levy (ed.), Addiction and Self-Control: Perspectives from Philosophy, Psychology, and Neuroscience. Oxford: Oxford University Press, pp. 144-64.

Kraut, R. (2008) "Aristotle's Ethics," in Stanford Encyclopedia of Philosophy, available from: http://plato. stanford.edu/entries/aristotle-ethics/ (accessed 29 June 2016).

Levy, N. (2011) "Resisting 'Weakness of the Will," Philosophy and Phenomenological Research 82: 134-55.

McIntyre, A. (1990) "Is Akratic Action Always Irrational?" in O.J. Flanagan and A. Rorty (eds), Identity, Character, and Morality: Essays in Moral Psychology. Cambridge: MIT Press, pp. 379-400.

McIntyre, A. (2006) "What is Wrong with Weakness of Will?" Journal of Philosophy 103: 284-311.

Mele, A.R. (1992) Irrationality: An Essay on Akrasia, Self-Deception, and Self-Control. Oxford: Oxford University Press.

Mele, A.R. (1995) Autonomous Agents: From Self-Control to Autonomy. Oxford: Oxford University Press.

Mele, A.R. (2002) "Autonomy and Akrasia," Philosophical Explorations 5: 207-16.

Mele, A.R. (2012) Backsliding: Understanding Weakness of Will. Oxford: Oxford University Press.

Müller, J. (2015) “Aristotle on Actions from Lack of Control," Philosophers' Imprint 15: 1-35.

Oddie, G. (2005) Value, Reality, and Desire. Oxford: Clarendon Press.

Oshana, M. (2006) Personal Autonomy in Society. Aldershot/Burlington: Ashgate.

Plato (1993) Republic, trans. R. Waterfield. Oxford: Oxford University Press.

Scanlon, T. (1998) What We Owe to Each Other. Harvard: Belknap Press of Harvard University Press.

Schroeter, F. (2004) "Endorsement and Autonomous Agency," Philosophy and Phenomenological Research 69: 633-59.

Searle, J.R. (2001) Rationality in Action. Cambridge: MIT Press.

Smith, M. (1994) The Moral Problem. Oxford: Blackwell.

Smith, M. (2003) "Rational Capacities," in S. Stroud and C. Tappolet (eds), Weakness of Will and Varities of Practical Irrationality. Oxford: Clarendon Press, pp. 17-38.

Stampe, D. W. (1987) "The Authority of Desire," The Philosophical Review 96: 335-81.

Stocker, M. (1979) "Desiring the Bad: An Essay in Moral Psychology," Journal of Philosophy 76: 738-53.

Stroud, S. (2003) "Weakness of Will and Practical Judgement," in S. Stroud and C. Tappolet (eds), Weakness of Will and Practical Irrationality. Oxford: Clarendon Press, pp. 121-46.

Stroud, S. (2008) "Weakness of Will," in E. Zalta (ed.), Stanford Encyclopedia of Philosophy, available from: http://plato.stanford.edu/entries/weakness-will/ (accessed 29 June 2016).

Tappolet, C. (2003) "Emotions and the intelligibility of akratic action," in S. Stroud and C. Tappolet (eds), Weakness of Will and Practical Irrationality, Oxford: Clarendon Press, pp. 97-120.

Tappolet, C. (2013), "Weakness of Will," in H. LaFollette (ed.), International Encyclopedia of Ethics, Hoboken: Wiley-Blackwell, pp. 5412-21.

Tappolet, C. (2016) Emotions, Values, and Agency. Oxford: Oxford University Press.

Tenenbaum, S. (1999) "The Judgment of a Weak Will," Philosophy and Phenomenological Research 59: 875-911.

Tenenbaum, S. (2003) “Accidie, Evaluation, and Motivatlon," in C. Tappolet and S. Stroud (eds), Weakness of Will and Practical Irrationality, Oxford: Clarendon Press, p. 147. 


\section{CHRISTINE TAPPOLET}

Tenenbaum, S. (2007) Appearances of the Good: An Essay on the Nature of Practical Reason. Cambridge: Cambridge University Press.

Tenenbaum, S. and Raffman, D. (2012) "Vague Projects and the Puzzle of the Self-Torturer," Ethics 123: $86-112$.

Velleman, J.D. (1992) "The Guise of the Good," Noûs 26: 3-26.

Watson, G. (1975) "Free Agency," Journal of Philosophy 72: 205-20.

Watson, G. (1977) "Skepticism About Weakness of Will," The Philosophical Review 86: 316-39.

Watson, G. (1987) "Free Action and Free Will," Mind 96: 154-72.

\section{Further Reading}

Aristotle (1915) Nicomachean Ethics, trans. W. D. Ross, The Works of Aristotle, Vol. 9. Oxford: Clarendon Press. (The locus classicus for the debates about akrasia and self-control.)

Davidson, D. (1970) "How Is Weakness of the Will Possible?" in J. Feinberg (ed.), Moral Concepts. Oxford: Oxford University Press, pp. 21-42. (Davidson's paper has put the question of the possibility of akrasia into the center-stage of contemporary debates and has set the agenda for much of the discussions.)

Holton, R. (2009) Willing, Wanting, Waiting. Oxford: Oxford University Press. (Holton's very readable book proposes a new, empirically inspired account of weakness of will, as distinct from akrasia.)

McIntyre, A. (1990) "Is Akratic Action Always Irrational?" in O.J. Flanagan and A. Rorty (eds), Identity, Character, and Morality: Essays in Moral Psychology. Cambridge: MIT Press, pp. 379-400. (By arguing that akratic action might be rational, McIntyre raises a question that has since then been central in the debates.)

Mele, A.R. (1992) Irrationality: An Essay on Akrasia, Self-Deception, and Self-Control. Oxford: Oxford University Press. (This useful defense of the claim that akrasia is possible constitutes an excellent starting point for a reader new to the debate.)

\section{Related Topics}

Reasons-Responsive Views

Aristotle

Thomas Aquinas

Addiction

Deliberation

The Relationship between Moral Responsibility and Freedom

Free Will and the Phenomenology of Agency 


\section{1 \\ FREE WILL AND
CRIMINAL LAW \\ Erin Kelly}

\section{Introduction}

If someone has been treated fairly, we can infer something important about her position with respect to other people in her society: her legitimate claims have been acknowledged and balanced appropriately with theirs. Whatever exactly a person's legitimate claims might be, fairness requires that they take the rights and interests of everyone into consideration. In this chapter, I sketch the tension that arises when we attempt to reconcile the interest each person has in avoiding criminal sanctions with the claims each person has for the protection of their basic rights against criminal violation by other people. The criminal law's resolution of this tension points to its criteria of 'free will'criteria that are more about morality or justice than metaphysics. I submit that in criminal law, the concept of 'free will' is best understood as expressing the judgment that the accused offender had a reasonable opportunity to avoid criminal sanctions. In turn, 'reasonable opportunity' is determined by reference to considerations such as the defendant's liberty interests, her subjective limitations, and the rights of other people not to be harmed by her. This notion of reasonable opportunity expresses criminal law's operative conception of institutional fairness: the fairness that obtains when the principles of criminal justice, which comprise general standards, have adequately taken all ethically relevant factors into consideration.

Turning critically to criminal law theory, I argue that standard criminal law conceptions of free will create serious problems for any effort to explain or to justify our current doctrine and practices on the basis of a retributive theory of punishment. In short, retributive justice grounds punishment in blameworthiness and desert, yet the criminal law's criteria of free will call for the punishment of actors who may be neither blameworthy nor deserving of punishment. An authentically retributivist criminal law would have to be much more demanding than ours is about what counts as free will. If we are to salvage the prospects for justifying anything resembling contemporary AngloAmerican criminal law doctrine, we must look away from retributive theory. This is true even were we to set aside the excesses of overpunishment, excesses that are rampant in the United States and which would be rejected by any reasonable retributive theory. Apart from excessive sentences for many crimes, including violent crimes, as well as the questionable practice of incarcerating people convicted of a range of nonviolent and even trivial offenses, the criteria of legal guilt and punishment are not well calibrated to 
judgments of blameworthiness and desert. This does not necessarily mean that less blameworthy and less deserving criminal offenders should be thought to have lacked a reasonable opportunity to have avoided their offenses. But it does prompt us to understand the basis for their punishment, when it can be justified, in nonretributive terms. This should have significant consequences both for how we regard criminal offenders and how we ought to understand the 'expressive function' of punishment.

\section{Agency and Liability in Criminal Law}

I begin by describing operative criteria of liability to criminal sanctions, which I have suggested can be understood to represent the criminal law's interpretation of 'free will.'

Liability to criminal sanctions almost always requires a voluntary act (actus reus) and a culpable state of mind (mens rea). A voluntary act involves a doing by an agent. The Model Penal Code (MPC) — a highly influential effort by academics and judges working under the auspices of the American Law Institute to provide a systematic criminal code-characterizes a voluntary act by reference to bodily movements that are "the product of the effort or determination of the actor, either conscious or habitual," in contrast to non-voluntary acts such as convulsions, movements during sleep, and conduct resulting from hypnotic suggestion. A famous teaching example is provided by Martin v. State (1944), in which the court found that an intoxicated man who had been carried to a highway by police was not guilty of "being drunk on a public highway," since he did not voluntarily appear there. His appearance on the highway was not the product of his effort or determination. Of course, an act can be voluntary without being intentional with respect to its harmful outcome, as is the case in reckless and negligent behavior that results in injury. Acts are voluntary if they require some effort or determination on the part of the agent, even if the agent lacks knowledge of the moral quality of the act because he is (legally) insane, lacks control over the impulse that prompted the act, or lacks awareness of its possible consequences (as in negligent behavior). Insanity and other excuses, such as mistake or duress, apply inside the broad domain of voluntary action. They do not negate the actus reus of a criminal offense.

Whether a voluntary act (or omission) was committed is treated as an 'objective' or observable matter of fact. While there is a sense in which voluntariness goes to mental state, it is understood as something that can be inferred from the observable qualities of action. A person who is not in the grip of a seizure, sleepwalking, hypnotized, or physically forced by another person to behave as she does, is acting voluntarily. By contrast with the 'objective' elements of an offense, the mens rea element must be proved on the basis of evidence that the defendant 'subjectively' possessed a certain mental state at the time the crime was committed. A mens rea element typically specifies the agent's level of intention or awareness in acting. In most cases, evidence must be presented to show that the defendant had a certain intention, some particular knowledge, or that she was reckless. Regarding mistakes of fact, many states have adopted the Model Penal Code's proposals. The MPC $\$ 2.04$ holds that if the defendant labors under a mistaken factual belief that negates the required mental state element, he cannot be found guilty of that offense, even when the mistake is not reasonable.

Because different crimes are defined by reference to different mental states, among other factors, a defendant's incapacity to form a certain kind of intention might establish his innocence of the particular offense charged. For example, assault with intent to commit murder requires that the defendant act with an intention to cause the 
victim's death. It thus presupposes that the defendant had the capacity to foresee and intend that consequence. The ability to form an intention to attack another is insuffcient. In People v. Ireland (1969), a California appeals court reversed a felony-murder conviction on the ground that the jury should have been instructed to consider whether the defendant, who had been suffering under emotional pressure and had consumed prescribed medications and alcohol, was capable of 'malice aforethought' at the time he shot and killed his wife. The lower court had instructed the jury to find the defendant guilty of second degree felony-murder if it found that the homicide was the direct causal result of an assault with a dangerous weapon. The court of appeals ruled that this was a mistake and that the jury should have been instructed to consider the defendant's ability, at the time, to form the intent to kill.

In the absence of excusing factors, such as diminished capacity or insanity, the law often allows mens rea to be established on the basis of a presumption. This means that the mens rea element of the crime can be inferred on the basis of some other facts. For example, if some item is found together with the defendant in his car, the defendant can be presumed to possess the item, that is, to have knowledge of its possession. The U.S. Supreme Court has held that a presumption is constitutionally acceptable when its truth is "more likely than not" and provided that the jury is instructed that it may choose to accept or reject it. (County Court v. Allen [1979]) The role of presumptions means that mens rea might be established on the basis of circumstantial evidence. Sometimes the mens rea for a specific intent crime is proved by reliance on the general presumption that a person intends the natural and probable consequences of his acts. The Court holds that this presumption is permissible provided that it is not introduced as a mandatory presumption that shifts to the defendant a burden of persuasion on the intent element of the offense (Sandstrom v. Montana [1979]; Francis v. Frankin [1985]). Thus, the prosecution is permitted to argue that a defendant who aims a gun at someone and shoots at close range can be presumed to intend to kill the victim. Presumptions also operate to establish recklessness. According to the MPC, a reckless person "consciously disregards a substantial and unjustifiable risk." A judgment of recklessness is typically made on the basis of an inference from observed behavior.

Reliance on presumptions to establish mens rea threatens to erode the purportedly subjective character of the relevant mental state, because it means that the mental state of a particular defendant can be established on the basis of a conclusion about the typical mental state of most defendants in circumstances similar to the defendant's circumstances. In this way, the scope of a particular person's liability is a function of what it is reasonable to expect of most people. Moreover, in other cases, no evidence of subjective mental state, whether direct or indirect, is required. For example, in cases of criminal negligence, the mens rea is established by direct appeal to a reasonable person standard. The Model Penal Code $\$ 2.02$ (d.) defines a negligent actor as someone who "should be aware of a substantial and unjustifiable risk that the material element exists or will result from his conduct." A defendant can be held to have acted with criminal negligence if a reasonable person in the defendant's circumstances would have been aware of the risk involved and refrained from so acting. Although this criterion leaves open the question of what counts as the defendant's circumstances, and whether those circumstances might include psychological abnormalities or diminished mental capacities, courts have been reluctant to consider psychological characteristics to belong to the defendant's circumstances. By contrast, physical limitations and injuries do count among the circumstances that bear on which expectations count as reasonable. Blindness or 
serious physical injury might well undermine a judgment of criminal negligence when those physical limitations bear on the defendant's ability to perceive and avoid a risk that persons of ordinary physical ability would perceive. Courts have not treated a defendant's psychological limitations in an analogous way. They have resisted individualizing the negligence standard to fit an individual defendant's psychological limitations. Low intelligence, temperament, and mental illness have not been included as factors that can be used to limit a defendant's liability for criminal negligence. ${ }^{1}$

In State v Patterson (2011), a Connecticut appellate court upheld a conviction of criminally negligent homicide although the defendant had an IQ of 61 which, according to the court, places her within the bottom one-half of 1 percent of the population. The defendant withheld water from a two-year-old boy in order to prevent him from wetting his bed and after four days the boy died of dehydration. The defense argued that the defendant was not capable of perceiving the risk to the boy, but the court ruled that, "[e]ven if ... the defendant was incapable of perceiving the risk of death ... we cannot consider the defendant's diminished mental capacity in the context of criminally negligent homicide because we employ an objective standard." The court is claiming that the defendant's inability to perceive the risk of death was irrelevant to her guilt because a reasonable person would have perceived the risk; in judging whether negligent homicide has been committed, the law holds all defendants to the same standard of reasonable conduct.

While in negligence cases mens rea is established by direct reference to a reasonable person standard, strict liability crimes require no proof of mens rea at all. Statutory rape, at least in some states, and also some prevalent narcotics and firearms statutes, do not require that the prosecution prove that the defendant acted with negligence, much less recklessness, knowledge, or purpose. The accused is guilty of rape if the victim was under the age specified by statute (e.g., 16), even if the accused had good reason to believe that the victim was older.

In short, the criminal law maintains that when it can be established that an offender satisfies the act and mental state requirements of an offense, and has no justification or excuse for the behavior in question, the offender is liable to criminal sanctions. These broad criteria set the legal standard of avoidability: they define the sense in which a person could have complied with the law and with morality. Or, to put the point another way, the law holds that it was possible for that person to have avoided his crime, and reasonable to have required it of him. The law regards his will and action as relevantly free. As indicated, particularly with respect to crimes that hinge on negligence, but even with respect to crimes requiring certain forms of intentionality, the conception of "reasonable opportunity to avoid" that is built into the twin requirements of mens rea and actus reus is thin. Some and perhaps many actors who are accurately deemed offenders will have not had a realistic chance to avoid committing the offense under the circumstances in which they committed it.

At the outset I claimed that the law's conception of reasonable opportunity to avoid criminal sanctions is a function of how it treats a defendant's liberty interests, subjective limitations, and the rights of other people not to be harmed. I have begun to examine the role of an individual's subjective limitations in determining fair treatment of her. This is important for assessing the retributive view, since a person's subjective limitations would seem relevant to morally reasonable judgments of blameworthiness and desert. The court's limited sensitivity to these considerations thus raises doubts about the retributivist theory of punishment, if that theory is meant to rationalize anything like current criminal law doctrine. I will now push this point further. 


\section{Excuses in Criminal Law}

Even granted that the requirements of mens rea and actus reus set only a thin requirement of reasonable opportunity to avoid, one may ask whether the requirement is made thicker through the recognition of excuses that defeat liability notwithstanding proof that the defendant committed the crime charged. A survey of the nature of legal excuses confirms the reluctance of courts to individualize criteria of criminal liability to a defendant's psychological capacities and limitations. In considering how excuses function in criminal law, I will be especially concerned with law's regard for a defendant's moral capacity: her capacity to recognize and to be guided by moral reasons. Legally recognized justifications and excuses typically rely on a reasonable person standard in a way that does not permit as relevant a consideration of a defendant's moral incapacity or diminished moral capacity.

For example, the application of an objective standard of reasonable conduct is found in the court's understanding of the scope of the 'provocation' defense. Provocation is a defense that reduces a charge of murder to the lesser offense of manslaughter. The Model Penal Code defines two principle components to the defense. First, the defendant must have acted under the influence of extreme emotional disturbance and, second, there must have been a "reasonable explanation or excuse" for the emotional disturbance.

People v. Cassasa (1980) is a murder case in which the defendant tried and failed to use the provocation defense. The defense argued that Cassasa acted under the influence of extreme emotional disturbance because he was obsessed with the victim, in whom he had a romantic interest. After she broke off their relationship he was "devastated," and began behaving bizarrely. He broke into the apartment below hers in order to eavesdrop on her. He also broke into her apartment when she was not there and lay in her bed armed with a knife. On his final visit to her apartment, he stabbed her to death when she refused his offer of a gift. The trial court found Cassasa guilty of second-degree murder. The court of appeals affirmed his conviction. The appeals court found that the defendant had acted under the influence of extreme emotional disturbance, but that the defendant's emotional reaction at the time of the commission of the crime was "so peculiar to him" that it could not be considered reasonable so as to reduce the conviction to manslaughter. Since a reasonable person would not have been provoked by the circumstances that in fact provoked the defendant, Cassasa's emotional disturbance did not mitigate the charge against him from murder to manslaughter. Interestingly, the court also argued that Cassasa's disturbed state was not the product of external factors but was rather "a stress he created within himself, dealing mostly with a fantasy, a refusal to accept the reality of the situation." In other words, the court suggests that Cassasa at some level chose to feel disturbed rather than face reality. In this way, the court emphasizes its finding that the cause of the stress was inside the agent rather than in the agent's situation, removing it from the set of emotional disturbances for which there could be a reasonable explanation or excuse. But the court also seems to imply that Cassasa's emotional disturbance was under his control and that, in that sense, he could have acted otherwise. Perhaps the court was, in this case, uncomfortable with the legal criteria for responsibility and in search of a metaphysical rationale, since whether or not the disturbance was under his control seems irrelevant to the legal notion of provocation. The defense of provocation fails when it is demonstrated that a reasonable person would not have been provoked by the circumstances that provoked the defendant, whether or not the defendant could have avoided the provocation. 
Duress as a legal defense resembles the defense of provocation. The Model Penal Code $\$ 2.09$ defines duress by reference to what "a person of reasonable firmness in [the defendant's] situation would have been unable to resist." The courts have found that a person's size, strength, and physical health can be accounted for as aspects of the actor's situation, but not matters of temperament or mental health, with the exception of "battered women's syndrome." Some courts have ruled that battered women's syndrome is irrelevant to the "purely objective" reasonableness standard, while others have found that a history of domestic abuse is relevant to whether the defendant "reasonably believed that her life was in danger" for the purposes of determining whether she acted under duress (Dando v. Yukins [2006]). While courts are divided on the relevance of battered women's syndrome to duress as a defense to crimes other than homicide, they are now mostly in agreement that battered women's syndrome can support a defendant's self-defense argument that she reasonably perceived a threat of imminent danger from her abuser when she killed him (Rogers v. State [1993]). Juries are instructed to consider not whether a reasonable person per se would have formed the belief that her life was in danger, but whether a reasonable person who has endured domestic abuse would have.

Courts are divided on age and intellectual disability. In State v. Heinemann (2007), the court rejected a 16-year-old defendant's duress defense, claiming that although her immaturity made her more vulnerable to duress, her defense was precluded in view of, "[t]he legislature's determination to treat sixteen year olds as adults for purposes of [eligibility for trial in juvenile court]." In United States v. Johnson (2005), the court considered the relevance of intellectual disability to a duress defense and claimed,

Unlike... non-mental physical disabilities, mental deficiency or retardation is difficult to identify, more difficult to quantify, and more easily feigned. For these reasons and others, it was the common law rule going back to at least 1616, and still is, that an adult suffering from a mental deficiency is nevertheless held to a reasonable person standard.

By contrast, in Commonwealth v. DeMarco (2002), the court found that "the fact that a defendant suffers from 'a gross and verifiable' mental disability ... is a relevant consideration" to the question whether an objective person of reasonable firmness would have been able to resist the threat.

The reasoning I have highlighted in discussing provocation and duress is representative of legal reasoning about excuses in general. The backbone of legal excuses are circumstances that would render expectations of a reasonable person's compliance with law unreasonable, and the circumstances that constitute an unreasonable obstacle to law-abidingness for a reasonable person are mostly limited to factors other than temperament, personality, or mental health. Relevant constraints on free will are understood situationally in a way that is not individualized to subjective moral capacity. With few exceptions, the criminal law sets and holds everyone to the same set of expectations, expectations that it deems reasonable despite the fact that it is harder and perhaps much harder for some people to meet those expectations. But since the difficulty some people have complying with the law might well be relevant to whether or how much we should blame them, we should avoid inferring moral blameworthiness from criminal guilt. 


\section{The Insanity Defense}

The narrow room allotted by law for evaluations of subjective capacity implies that a person has 'free will' even though that person may be subjectively incapable of taking moral reasons seriously. The exception to this is 'insanity:' the utter breakdown of rational thought and understanding. The criminal law of almost every state permits insanity as a complete defense against criminal charges. A successful insanity defense thus results in acquittal, although, in practice, acquittals of this sort are rare because the legal definition of insanity is highly restrictive.

The majority of states follow the so-called M'Naghten formulation, which requires the defendant to establish that

at the time of the committing of the act, [he] was laboring under such a defect of reason, from disease of the mind, as not to know the nature and quality of the act he was doing; or, if he did know it, that he did not know he was doing what was wrong.

M'Naghten's Case (1843)

This formulation fixes on a defendant's cognitive impairments, which must be so severe that the defendant either had no idea what he was doing, or that it was wrong. Mentally ill defendants whose impairments are motivational or volitional do not benefit from this definition of insanity and are subject to normal prosecution.

By contrast with the M'Naghten formulation, the drafters of the Model Penal Code favored a broader conception of insanity. The MPC $\$ 4.01$ maintains that,

A person is not responsible for criminal conduct if at the time of such conduct as a result of mental disease or defect he lacks substantial capacity either to appreciate the criminality (wrongfulness) of his conduct or to conform his conduct to the requirements of law.

Thus, the MPC definition allows, while the M'Naghten definition does not, that motivational impairments, potentially encompassing sociopathy, could support an insanity acquittal. The MPC Commentaries $\$ 4.01$ emphasize this difference:

One shortcoming of the [M'Naghten] criterion is that it authorizes a finding of responsibility in a case in which the actor is not seriously deluded concerning his conduct or its consequences, but in which the actor's appreciation of the wrongfulness of his conduct is a largely detached or abstract awareness that does not penetrate to the affective level. Insofar as a formulation centering on 'knowledge' does not readily lend itself to application to emotional abnormalities, the M'Naghten test appears less than optimal as a standard of responsibility in cases involving affective disorder.

In the 1960s and 1970s, some courts embraced versions of this broader conception, but the trend since the 1980s has been to narrow the definition — a trend fueled in part by the jury's acquittal by reason of insanity of President Reagan's would-be assassin John Hinckley, which in turn prompted Congress to legislate a narrow definition of insanity applicable to defendants accused of federal crimes. 
In practice, the difference between these formulations may be inconsequential. It is estimated that "no more than [0].25 percent of terminated felony prosecutions" involve insanity acquittals, and both experimental and historical studies indicate very little difference in the willingness of juries to acquit on the basis of insanity on any of the formulations of its criteria (Kadish et al. 2012: 961, 982). Politics aside, the MPC formulation raises difficult evidentiary issues, as the court emphasizes in United States $v$. Lyons (1984) when it rejects the 'volitional prong' of the MPC formulation. The court asserted that, "a majority of psychiatrists now believe that they do not possess sufficient accurate scientific bases for measuring a person's capacity for self-control or for calibrating the impairment of that capacity ...." The court concludes, "[W]e see no prudent course for the law to follow but to treat all criminal impulses-including those not resisted-as resistible." In other words, prudence dictates that volitional impairments are not excusing.

On either formulation, but especially the M'Naghten formulation, the legal category of insanity is much narrower than the medical category of mental illness. Mental illness spans a wide range of abnormalities, including many impairments that are severe yet fall short on either the cognitive or the volitional prong of the MPC definition. Mentally ill individuals might be seriously disturbed, confused, or irrational while retaining some understanding of the moral difference between right and wrong and some capacity to control their own behavior. Importantly, they might lack anything close to normal responsiveness to moral concerns without being insane. This is true of many people who commit terrible crimes.

In moral terms, notions of responsibility and accountability are typically understood to presuppose rational and moral competence, in particular, as I have suggested, the capacity to understand and to be guided by - that is, to care about-moral reasons. Sensitivity to moral reasons is critical to the relevance of at least two primary functions of morality. First of all, it is critical to the action-guiding function of morality. Morality is directed to those who can grasp and apply its principles and who are, at least in ordinary circumstances, motivated to do so. This supposes a moral subject's rational capacity for understanding and deliberation as well as her moral concern for the needs and interests of other people. A subject with these competencies can and often does act for moral reasons.

Like morality, the law also aspires to direct behavior. Yet the criminal law's reliance on sanctions to secure compliance permits it to maintain an action-guiding function without presuming that its subjects are morally motivated. The law's directives are relevant even to people who care little about the moral interests of other people, provided they possess some rational ability to protect their own interest in avoiding criminal sanctions. Thus, restricting the insanity defense to cases of cognitive (vs. volitional) dysfunction is consistent with understanding the law as a set of action-guiding norms. But a result of this definition of insanity is the possible conviction of individuals whose capacity to be motivated by moral reasons is diminished, even very significantly.

A second function of morality concerns how to evaluate people in view of their actions. Here, the question is whether a person is a suitable subject for familiar aspects of moral evaluation, including blame. A familiar position is that only a person who is capable of being guided by moral reasons is a suitable subject of our 'reactive attitudes' and other blaming responses, including punishment. This moral condition has enjoyed some legal recognition. In Morissette v. United States (1952), the court asserts, "Historically, our substantive criminal law is based on a theory of punishing the vicious will. 
It postulates a free agent confronted with a choice between doing right and wrong, and choosing freely to do wrong" (quoting Pound 1927). Indeed, blaming responses typically reflect not only our understanding of a wrongdoer's moral qualities, but also our sense of her capacity to modify her behavior in view of the requirements of morality. A wrongdoer's moral capacity to have made a better choice is important. In particular, an agent's capacity to be sensitive to the needs and interests of other people when she has failed to act well is a familiar condition for the appropriateness of blame. The point of blame is partly to indicate that a person has rejected reasons she had-reasons that were reasons for her to have acted differently — and that her capacity to have done better makes our dissatisfaction with her appropriate.

Focusing the legal definition of insanity on a person's cognitive impairments risks refusing the insanity defense to persons who are motivationally impaired enough to compromise their moral blameworthiness. While they may be deemed guilty of their crimes, it might be the case that it is inappropriate or misguided to blame them morally for their wrongdoing. When a person's capacity to appreciate morality is compromised, this casts doubt on a relevant counterfactual. A morally capable wrongdoer is somebody who was capable of acting for moral reasons that she failed to take seriously but could have. I have suggested that when we have good reason to doubt a person's capacity, or full capacity, for moral responsiveness, this may have consequences for our moral attitudes and behavior toward her. Although we may be frustrated or disappointed by her behavior, our considered response lacks the moralistic edge characteristic of blame. It seems morally inappropriate to blame someone for acting badly when that person was not capable of understanding and being moved by the requirements of morality. Because her action does not represent her rejection of a morally better course of action that was available to her, it seems misguided or even pointless to admonish her in moral terms for her choice.

Skepticism about moral capacity is especially likely to come up in the arena of criminal justice. A retributive rationale for criminal punishment purports to gain its foothold in a person's moral blameworthiness for a particular instance of wrongdoing. But the relevant judgment of the offender's capacity to have acted better can be hard confidently to make, especially when that person is mentally ill. There might be good precautionary reasons to tailor the insanity defense narrowly. Permitting mental illness, more broadly, to excuse would pose a serious problem, since many violent criminals are disturbed and we need to protect ourselves from them. A consequence of tailoring the insanity defense narrowly, however, is that we use the criminal justice system to incapacitate some wrongdoers who are not blameworthy for their wrongdoing. This poses a serious problem for the retributive theory of punishment.

\section{Moral Blameworthiness and Criminal Sentencing}

A retributivist might attempt to rescue the view by emphasizing that the phase of a criminal trial in which guilt is determined is separate from the sentencing phase. It might be argued that appraisals of blameworthiness are properly made only in the sentencing phase. While it might be true that guilt does not imply blameworthiness, considerations that may be introduced at sentencing provide a broader basis upon which to render and calibrate a judgment of blameworthiness, or so the retributivist might argue.

The Supreme Court has expressed concern about the moral competence of defendants in a limited range of cases involving the harshest sentences and, in particular, 
regarding the death penalty. It is worth examining those cases with an eye to whether they indicate, more broadly, that the court thinks the severity of punishment should be influenced by an assessment of the offender's moral competence. In Atkins v. Virginia (2002), the U.S. Supreme Court accepted that intellectually disabled individuals have diminished capacities to understand and process information, to communicate, to abstract from mistakes and learn from experience, to engage in logical reasoning, to control impulses, and to understand other people's reactions to their behavior. The Court found these impairments relevant to the permissibility of the death penalty, on several grounds. First, it held that intellectually disabled individuals who have committed murder are less culpable than the average murderer, and hence, do not deserve the death penalty, which is reserved for maximally culpable killings. Second, the Court reasoned that the cognitive impairments from which intellectually disabled people suffer make them less responsive to sanctions, and hence, undermine attempts to threaten them with the death penalty in order to deter them from committing capital offenses. Finally, the Court concluded that these defendants' impairments render them more apt to be wrongfully convicted: intellectually disabled defendants are susceptible to wrongful conviction through false confessions and a diminished ability to assist their lawyers, and they face diminished prospects for mitigation in sentencing since "their demeanor may create an unwarranted impression of lack of remorse for their crimes."

The courts have also expressed concern about the rational and moral capacity of juveniles, applying to juveniles concerns voiced about the intellectually disabled in death penalty cases. In Roper v. Simmons (2005), the U.S. Supreme Court held that it is unconstitutional to apply the death penalty to juveniles. The court argued that immaturity diminishes culpability, as does the susceptibility of juveniles to peer pressure, and that neither retribution nor deterrence provide adequate justification for imposing the death penalty on juveniles. ${ }^{3}$ In Ford v. Wainwright (1986), the Court prohibited the execution of the insane, invoking what the Justices took to be a national consensus "that such an execution simply offends humanity ...." As a matter of federal constitutional law, insanity thus operates as a mitigating factor in punishment when it comes to the death penalty.

These considerations the court invoked raise general concerns about the justifiability of punishing the young or intellectually disabled, yet the court's acknowledgement of these concerns only in relation to the death penalty is used to limit their reach (Gottschalk 2015: 172-6). The court emphasizes that the death penalty is a unique and rare form of punishment, implying that considerations that limit its application might not upset the justification of other punishments, including many cases of life without parole (LWOP), namely, 'the other death penalty,' death in prison. Of course we might wonder why, if diminished responsibility is unsettling when we consider the harshest penalty, it should not also be unsettling to us when we consider other sentences, some of which are also extremely harsh. Worries about the moral accountability of the mentally ill and juveniles are especially pressing for retributive accounts, according to which punishment should be applied in proportion to desert.

In fact, regarding juveniles the Court has extended its reasoning somewhat. In Miller v. Alabama (2012), the court claimed that adolescence is "marked by rashness, proclivity for risk, and inability to assess consequences," and that these factors should be treated as mitigating factors when it comes to sentencing juveniles to life without parole. The court concluded that mandatory life sentences for juveniles constitute cruel and unusual 
punishment in violation of the Eighth Amendment. Similar reasoning in Jackson v. Hobbs (2011), suggest that criminal liability should track both moral culpability and 'capacity for change' as well as developed skills in reasoning about costs and benefits that give the threat of legal sanctions possible deterrent effect. But again, the fact that LWOP is rarely imposed on juveniles in the U.S. (and in other countries) figures centrally in the court's reasoning and is treated as a basis for limiting the reach of these decisions.

Apart from the court's reluctance to impose the very harshest punitive measures on the intellectually disabled or juveniles, individualized attention to moral capacity is mostly at odds with how the law governs sentencing. While mitigating considerations can indeed be introduced into the sentencing phase after guilt has been established, typically mental illness short of the stringent legal notion of 'insanity' does not mitigate sentences, and neither does youth. As a result, U.S. jails and prisons have a large population of inmates who are mentally ill, intellectually disabled, and immature. A 2005 study conducted by the U.S. Government's Bureau of Justice Statistics found that over half of all prison and jail inmates suffer from a serious mental illness (http:// www.bjs.gov/content/pub/pdf/mhppji.pdf). Juvenile cases are commonly referred to adult criminal court, particularly (but not always) for serious crimes. A 'direct file' statute passed in the state of Florida, for example, permits prosecutors wide discretion to refer juveniles to adult court, including any 16- or 17-year old who is accused of a felony, violent or not. In three states-Pennsylvania, Wisconsin, and Nevadachildren as young as 10 years old can be tried as adults for murder. As discussed above, although the Supreme Court has decided that a mandatory sentence of life without parole cannot be imposed on juveniles, 37 states still allow it as a sentencing option, leaving room for judges to impose a life sentence, at their discretion. Many states have responded by resentencing juveniles to what are de facto life sentences. Studies show that, in general, juveniles in criminal court do not normally receive lighter sentences than their adult counterparts, and there is some evidence indicating that they are actually treated more punitively. ${ }^{4}$

The criminal law is of two minds. As we have seen, when it comes to the harshest penalties, the law is somewhat sensitive to questions of moral capacity. It places some limits on the punishment of the intellectually disabled, juveniles, and the mentally ill. Conversely, expressing concern about public safety, the courts permit juveniles to be tried as adults, and even the severely mentally ill and disabled can be convicted and punished harshly for criminal behavior. In United States v. Lyons (1984), a case I mentioned earlier, a majority of the court explicitly argued that as a society we cannot afford to consider the potential moral relevance of most mental incapacities. In particular, the court asserts that is not practical to consider a person's diminished capacity for self-control, because, "[t]he line between an irresistible impulse and an impulse not resisted is probably no sharper than between twilight and dusk" (quoting American Psychiatric Association 1982). This suggests a broad skepticism about the relevance of assessments of moral incapacity to criminal justice. Furthermore, in Penry v. Lynaugh (1989) the court notes that introducing a defendant's intellectual disability as a mitigating factor may be a double-edged sword that enhances the likelihood that the jury will treat it instead as an aggravating factor of future dangerousness. Whether or not moral blameworthiness is relevant, in theory, to how we ought to treat criminal wrongdoers, the court is wary of attempts to bring it to bear on criminal sentencing. 


\section{ERIN KELLY}

\section{Legal Culpability vs. Moral Blameworthiness}

I have argued that in view of the law's resistance to the relevance of moral capacity to criminal liability, a popular rationale for criminal sanctions cannot reasonably be maintained. The misfit between criminal liability and moral competence entails that criminal sanctions cannot be justified as expressions of moral blame. This causes a problem for the retributive ideal as well as, more broadly, for accounts of the 'expressive meaning' of punishment, if that meaning involves moral blame in the ordinary sense. If there are legally liable defendants who are not morally blameworthy enough to deserve the punishment they get, expressive views cannot justify punishing them. Criminal culpability does not entail moral blameworthiness. Despite the fact that legal culpability is popularly identified as a form of moral blame, legal guilt must be distinguished from moral blameworthiness. If the imposition of criminal sanctions on people with diminished moral capacity can be justified, it should be in terms that do not depend on blameworthiness and desert.

\section{Acknowledgements}

I am grateful to John Goldberg, Evan Linn, Neil Levy, members of the UCLA Philosophy Department, especially Seana Shiffrin, and participants in a Criminal Law Theory Workshop at the University of Michigan Law School (2015) for helpful comments on an earlier draft. I thank the Harvard Law School for hosting me as visiting scholar (2014 to 2015) and Alex Whiting for his illuminating class on criminal law.

\section{Notes}

1 An exception is State v. Everhart (1977) in which the court reversed an involuntary homicide conviction of a girl with an IQ of 72. The girl had given birth in her bedroom and inadvertently smothered to death the baby she believed was already dead.

2 The court cites Bonnie (1983). See also United States v. Johnson (2005).

3 See also Thompson v. Oklahoma (1988), where the Court affirms the diminished culpability of offenders under the age of 16 .

4 For a helpful review of the empirical literature on the 'juvenile penalty,' see Jordan (2014).

\section{References}

American Law Institute Model Penal Code (1962) Philadelphia: The American Law Institute.

American Psychiatric Association (1982) Statement on the Insanity Defense, 11. Washington DC: American Psychiatric Association.

Atkins v. Virginia (2002) 536 U.S. 304.

Bonnie, R.J. (1983) "The Moral Basis of the Insanity Defense," American Bar Association Journal 69: 194-7.

Commonwealth v. DeMarco (2002) 570 Pa. 263, 273.

County Court v. Allen (1979) 442 U.S. 140.

Dando v. Yukins (2006) 461 F. 3d 791, 801, 6th Cir.

Ford v. Wainwright (1986) 477 U.S. 399.

Francis v. Frankin (1985) 105 U.S. 165.

Gottschalk, M. (2015) Caught: The Prison State and the Lockdown of American Politics. Princeton: Princeton University Press.

Jackson v. Hobbs (2011) 132 S.Ct. 548.

Jordan, K.L. (2014) "Juvenile Status and Criminal Sentencing: Does it Matter in the Adult System?" Youth Violence and Juvenile Justice 12: 315-31. 
Kadish, S.H., Schulhofer, S.J., Steiker, C.S., and Barkow, R.E. (eds) (2012) Criminal Law and its Processes: Cases and Materials, 9th edn. New York: Wolters Kluwer Law and Business.

Martin v. State (1944) 31 Ala. App. 334, 17 So. $2 d 427$.

Miller v. Alabama (2012) 132 S.Ct. 2455.

M'Naghten's Case (1843) House of Lords 10 Cl. \& F. 200, 8 Eng. Rep. 718.

Morissette v. United States (1952) 342 U.S. 246, 250 n.4.

Penry v. Lynaugh (1989) 492 U.S. 302.

People v. Cassasa (1980) 49 N.Y.2d 668, 404 N.E.2d 1310.

People v. Ireland (1969) 70 Cal.2d 522.

Pound, R. (1927) Introduction to F. Sayre, Cases on Criminal Law. Rochester: Lawyer's Co-Operative Publishing Company.

Rogers v. State (1993) Fla. Dist. Ct. App. 616 So. 2d 1098, 1100.

Roper v. Simmons (2005) 543 U.S. 551.

Sandstrom v. Montana (1979) 442 U.S. 510.

State v. Everhart (1977) 291 N. C. 700, 231 S. E. 2 d 604.

State v. Heinemann (2007) Conn. 920 A.2d 278.

State v Patterson (2011) 131 Conn. App. 65.

Thompson v. Oklahoma (1988) 487 U.S. 813, 835.

United States v. Johnson (2005) 416 F.3d 464, 6th Cir.

United States v. Lyons (1984) 731 F.2d 243, 249, 5th Cir.

\section{Further Reading}

Green, T.A. (2014) Freedom and Criminal Responsibility in American Legal Thought. New York: Cambridge University Press. (Historical survey of the relevance of the free will debate to legal theory and notions of criminal responsibility.)

Hart, H.L.A. (2008) Punishment and Responsibility: Essays in the Philosophy of Law, 2nd edn. Oxford: Oxford University Press. (Highly influential set of papers, including papers on the philosophy of punishment, mens rea, excuses, and criminal responsibility.)

Kadish, S.H., Schulhofer, S.J., Steiker, C.S., and Barkow, R.E. (eds) (2012) Criminal Law and its Processes: Cases and Materials, 9th edn. New York: Wolters Kluwer Law and Business. (First-rate textbook of cases and commentary, with extensive references to further reading.)

Katz, L., Moore, M.S., and Morse, S.J. (2007) Foundations of Criminal Law. New York: Foundation Press. (Collection of seminal papers on the theory of criminal law, with attention to act and mental state requirements, excusing conditions, and mental abnormality.)

\section{Related Topics}

Revisionism

Skeptical Views about Free Will

Self-control and Akrasia

Blame

The Relationship between Moral Responsibility and Freedom

Marginal Agents and Responsibility Pluralism

Determinism 


\section{2 \\ DELIBERATION \\ E. J. Coffman}

When you're deliberating about what to do, must you believe of each contemplated course of action that you're free to pursue it? And does acting freely require that you first deliberate about what to do? If there's a single sense of 'deliberate' on which we should answer both questions affirmatively, then there is an interesting doxastic requirement on free action: you act freely only if you've believed of more than one course of action that you're free to pursue it.

Because space is limited and other chapters contain discussions bearing on the relationship between deliberation and free action (see 'Related Topics'), I'll focus on the relationship between deliberation and 'freedom-involving' beliefs. I distinguish between two pertinent senses of 'deliberation,' and two corresponding interpretations of the claim that you deliberate among multiple courses of action only if you believe of each that you're free to pursue it (in a slogan: deliberation requires 'freedominvolving' beliefs). Next, I discuss two salient attempted counterexamples to the claim that deliberation requires 'freedom-involving' beliefs. While one interpretation of this claim should be rejected in light of the examples, I argue that the other interpretation-specifically, the thesis that you try to choose among multiple contemplated courses of action only if you believe of each that you're free to pursue it - can be defended from the aforementioned examples. Having defended the indicated thesis from the putative counterexamples, I then present the recent literature's main argument for said thesis. Finally, I explain and assess three main kinds of objections to that main argument.

\section{Two Senses of 'Deliberation'}

Some contributors to the recent literature on the relationship between deliberation and 'freedom-involving' beliefs use 'deliberation' to denote the process of trying to decide which one of multiple contemplated courses of action to pursue. For example, van Inwagen (1983: 154; cf. Taylor 1980; Searle 2001) says that "[t]o deliberate is to try to decide between ... various incompatible courses of action." So understood, deliberation is a type of mental activity central to the life of any normal human agent. It's plausible to say with van Inwagen (1983) that a person "who [never tried to decide among multiple contemplated courses of action] would either move about in random jerks and scuttles, or would withdraw into catatonia" (1983: 157), and that deliberation (so understood) is a type of "behavior that [one] would have to be literally mad to give up" (1983: 160). 


\section{DELIBERATION}

Other contributors to the literature use 'deliberation' to denote the process of trying to figure out which one of multiple contemplated courses of action should be pursued. For example, Fischer (2005: 324; cf. Bok 1998; Pereboom 2008) says that "the process of deliberation ... involves identifying and weighing reasons with an eye to figuring out what we have sufficient reason to do." So understood, while the ability to deliberate distinguishes normal human agents from other kinds of agents (Nelkin 2011), a normal human agent might fail to regularly exercise this relatively 'high order' ability due to limited time, energy, attention, and so on. Unlike one's regularly failing to try to choose among multiple contemplated courses of action, one's regularly failing to try to figure out which course of action one should pursue would not warrant institutionalization. While the second, more 'reflective' kind of deliberation may well be distinctive of normal human agents, it is arguably less central to their lives than is the first, less 'reflective' kind.

As I've already intimated, the two senses of 'deliberation' distinguished above are logically independent. On the one hand, you might try to choose among multiple contemplated courses of action without trying to figure out which course of action you should pursue. Maybe you're a young child who lacks the conceptual wherewithal to try to figure out what you should do, but who can nevertheless try to decide among multiple contemplated courses of action — say, requesting pizza or instead spaghetti for dinner (cf. Mele 2003: 78). Alternatively, perhaps you're a suitably cognitively sophisticated adult facing a choice between two competing courses of action, A and B. Yet, due to lack of time (or energy, ... .), you might fail to engage in the 'higher order' activity of evaluating entertained considerations for/against $\mathrm{A}$ and $\mathrm{B}$ in an effort to figure out which one you should pursue, moving straight to the 'ground floor' activity of (merely) entertaining considerations for/against $\mathrm{A}$ and $\mathrm{B}$ in an effort to decide which one to pursue.

The reverse holds as well: trying to figure out what you should do doesn't suffice for your trying to decide what to do. Of course, processes of these types often overlap. You might try to figure out which one of multiple contemplated courses of action you should pursue in a larger effort to decide which one to pursue (cf. Mele 2003: 87; Streumer 2010: 249). But such processes needn't overlap (Kapitan 1986). Recall from the last paragraph the possibility that you (merely) entertain considerations for/against courses of action $\mathrm{A}$ and $\mathrm{B}$, in an effort to decide which one to pursue, without also evaluating those considerations in an effort to figure out which of $A$ and $B$ you should pursue. Suppose that you self-consciously choose to pursue A, without first trying to figure out whether you should pursue A (perhaps you have an especially strong desire to pursue A). Since you know that you've already chosen A over B, you're no longer trying to choose between A and B. Still, despite having chosen to pursue A, you might subsequently try to figure out which of $\mathrm{A}$ and $\mathrm{B}$ is better supported by the considerations you entertained before choosing $\mathrm{A}$, in hopes of discovering that those considerations really do favor $\mathrm{A}$ over B.

The two pertinent senses of 'deliberation' yield two different readings of the claim that you deliberate among multiple contemplated courses of action only if you believe of each that you're free to pursue it:

Belief in Freedom Requirement 1 (BFR-1). If you're trying to choose among multiple contemplated courses of action, then you believe (at least dispositionally) about each one that you're free to pursue it. 


\section{E. J. COFFMAN}

Belief in Freedom Requirement 2 (BFR-2). If you're trying to figure out which one of multiple contemplated courses of action you should pursue, then you believe (at least dispositionally) about each one that you're free to pursue it.

Failure to distinguish between our two senses of 'deliberation' puts one at risk of failing to distinguish between BFR-1 and BFR-2, which, in turn, puts one at risk of talking past theorists whose work one aims to engage (Coffman and Warfield 2005; Nelkin 2011). One example of such 'failure to engage' (among many that could be offered) must suffice. The following discussion will foreshadow some of §II's findings.

According to van Inwagen (1983: 154), "one cannot deliberate about whether to perform a certain act unless one believes it is possible for one to perform it." Context makes clear that van Inwagen is here endorsing BFR-1, rather than BFR-2. In one of the earliest published replies to van Inwagen's discussion of doxastic requirements on deliberation, Waller (1985) presents the following alleged counterexample to van Inwagen's view:

I believe that my ultimate choice [about how to bet at a horse racing track] is completely and uniquely determined (by my learning history, my past patterns of reinforcement, the current influences on me): my bet will be the causal result of those determining factors, and I could not choose other than I shall choose. Will I now find it impossible to deliberate about a number of options, since I believe that only one is really possible? Certainly not. For I must still carry out the ... deliberation process in order to arrive at my betting choice ... I recognize that my deliberation process-involving my beliefs, memories, hopes, changing knowledge of odds and jockeys and weather conditions-is an essential part of my choosing among various horses.

(Waller 1985: 49)

By 'deliberation process,' Waller seems to have in mind his trying to figure out which bet he should place. But that's not the same kind of activity that van Inwagen focused on-namely, trying to decide which one of multiple contemplated courses of action to pursue. While I'm inclined to agree that something along the lines of Waller's example can justify rejecting BFR-2 (cf. Fischer 2005: 325ff.), such a case fails to engage BFR-1. This is an important shortcoming, for a wide range of historical and contemporary philosophers spanning key divides over the nature and existence of freedom would not only accept that something in BFR-1's general vicinity must be correct but also concede that BFR-1 itself is at least initially plausible (cf. van Inwagen 1983; Kapitan 1986; Nelkin 2004).

However, BFR-1's initial plausibility notwithstanding, many contemporary action theorists reject it on the basis of allegedly clear counterexamples. Let us consider some of the key cases such theorists wield against BFR-1.

\section{Two Attempted Counterexamples to BFR-1}

In this section, I'll describe and assess what I regard as the two most promising attempted counterexamples to BFR-1, which together well represent a wide range of putative counterexamples to BFR-1 found in the recent literature. I'll argue that while one of these cases casts considerable doubt on BFR-2, neither is a clear counterexample to BFR-1. 
The Deliberating Determinist (cf. Waller 1985; Kapitan 1986; Pettit 1989; Clarke 1992; Nelkin 2004; Pereboom 2008).

Let 'determinism' denote the thesis that there is at any instant exactly one physically possible future (van Inwagen 1983). BFR-1 entails that anyone who believes determinism to be true and tries to choose among multiple contemplated courses of action holds explicitly inconsistent beliefs. Surely, though, there could be a determinist who deliberates (in the relevant sense) without explicitly contradicting herself.

Reply: The objector must be thinking that BFR-1 entails that you deliberate (in the relevant sense) only if you believe that determinism is false. Perhaps the objector thinks this because $s /$ he fallaciously infers it from BFR-1 plus the further claim (on which BFR-1 is neutral) that you are in fact free to pursue each of multiple courses of action only if determinism is false. In any case, the objector is mistaken: BFR-1 allows for the existence of a determinist who tries to choose among multiple courses of action without explicitly contradicting herself. Perhaps this determinist hasn't yet considered the question whether freedom to pursue each of multiple courses of action is compatible with determinism; or perhaps she has considered this question, and either answered it affirmatively or suspended judgment. Although some prominent proponents of BFR-1 have also endorsed the different claim that deliberating (in the relevant sense) requires that one disbelieve determinism (cf. Taylor 1980; Searle 2001), such a claim is neither entailed by BFR-1 nor plausible on its face (cf. Coffman and Warfield 2005).

Anticipated rejoinder: BFR-1 entails that any deliberating incompatibilist determinist holds beliefs that are at least implicitly inconsistent. Surely, though, there could be an incompatibilist determinist who deliberates without implicitly contradicting herself.

Reply: The second premise of this argument amounts to little more than a bald assertion that the initially plausible BFR-1 is in fact false. The argument thus provides little reason to doubt BFR-1.

Anticipated rejoinder:

We can imagine an incompatibilist determinist who continues to deliberate between $\mathrm{O} 1$ and $\mathrm{O} 2$ despite admitting that in his sense one of these options is impossible. He may say that he does not know which is the impossible option and that he is happy about deliberating because it raises the probability that the option he eventually chooses-the only possible one, as it happens-will satisfy his desires ... The determinist in our example can readily deny both that he believes that it is possible that $\mathrm{O} 1$ and that he believes that it is possible that $\mathrm{O} 2 \ldots$

(Pettit 1989: 43)

Reply: The objector highlights an interesting possibility. There could be an incompatibilist determinist who (a) rationally deliberates (in the relevant sense) without basing his deliberative activity on any beliefs about his freedom to pursue each contemplated course of action; and (b) sincerely makes each of the following claims: (i) only one of his contemplated courses of action is such that he's free to pursue it; (ii) he doesn't know which course of action is the one he's free to pursue; and (iii) he doesn't believe about any contemplated course of action that he's free to pursue it.

Of course, this possibility impugns BFR-1 only if BFR-1 rules it out. But BFR-1 allows for this possibility. To see this, note first that BFR-1 does not entail that rational deliberative activity must be based on the required 'freedom-involving' beliefs. In other 


\section{E. J. COFFMAN}

words, BFR-1 allows that one could deliberate-indeed, deliberate rationally — without basing one's deliberative activity on the mandated 'freedom-involving' beliefs. Second, BFR-1 requires only that a deliberator dispositionally believe about each contemplated course of action that she's free to pursue it. Accordingly, BFR-1 allows that there could be a deliberator who doesn't occurrently believe that she's free to pursue each of her contemplated courses of action, but instead occurrently (and perhaps truly) believes that she's free to pursue only one of those courses of action. And finally, BFR-1 allows that such a deliberator could hold a reasonable (though mistaken) 'higher-order' belief to the effect that she doesn't believe about any of her contemplated courses of action that she's free to pursue it. Consistent with BFR-1, we've now generated all the materials we need to allow for the objector's envisaged possibility. That possibility therefore casts little doubt on BFR-1.

\section{The Frankfurtized Voter}

Nelkin (2004) describes the following intriguing case, which stems from a famous example due to Frankfurt (1969):

[Y] ou know that a brilliant scientist has the ability to fiddle with your brain in a way that causes you to act as she wishes you to. You know that she wants you to vote for Gore over Bush in the upcoming presidential race, and that if you do not decide to vote as she wishes, she will cause you to vote that way. So, for instance, you know that if you were to prepare to vote for Bush or otherwise fail to decide to vote for Gore, the brilliant scientist would cause you to vote for Gore.

(Nelkin 2004: 107)

According to Nelkin,

[Y] ou could still evaluate the reasons for voting for each candidate and decide to vote for Gore on the basis of those reasons. In this case, . . . you know that conditions exist which are sufficient for your voting for Gore, while you nevertheless deliberate and decide to vote for him. Further, ... you do not believe you could forgo the action upon which you decide.

(2004: 107, 108)

Nelkin deems this case a counterexample to BFR-1.

Reply: Nelkin's example illustrates the following possibility. Without ever believing that you're free to pursue each of your contemplated courses of action (for example, voting for Bush and voting for Gore), you could nevertheless 'evaluate the reasons' for/against each course of action; eventually judge that one in particular is uniquely well supported by your reasons; and — at least partly on the basis of that evaluative judgment-decide to pursue the course of action that (you judge) your reasons best support.

But BFR-1 allows for this possibility. Again, what Nelkin's example illustrates is that one could-absent pertinent 'freedom-involving' beliefs-figure out which of one's contemplated courses of action one should pursue, and then choose to pursue that course of action at least partly on the basis of one's evaluative judgment. Highlighting this possibility impugns BFR-2, which I'll now set aside for the remainder of our 
discussion. However, as our earlier discussion of two kinds of deliberation makes clear, one could successfully try to figure out which of one's contemplated courses of action one should pursue, and then choose accordingly, without ever having to try to choose between those courses of action. Since BFR-1's antecedent concerns only the phenomenon of trying to choose between multiple contemplated courses of action, BFR-1 is consistent with the fact that one could successfully try to figure out what one should do, and then choose accordingly, without holding pertinent 'freedom-involving' beliefs. Contrary to what Nelkin suggests, then, her case does not impugn BFR-1 (cf. Coffman and Warfield 2005).

\section{The Main Argument for BFR-1}

Having defended BFR-1 from the two most promising attempted counterexamples to it, I turn now to the main argument for BFR-1. The argument in question is abductive and stems from the following kind of case, one early and influential version of which was presented by van Inwagen (1983: 154; the case below is modelled closely on a more recent example from van Inwagen [2009]):

Sam is in a room with a single (currently closed) door that provides the only way out of the room. As Sam is trying to choose between leaving the room and staying there, he hears a click that may have been the sound of the door's being locked. Sam is now in a state of uncertainty as to whether the door is locked.

(van Inwagen 2009: 268)

Claim: If Sam were to now resume trying to decide whether to leave the room, this activity would be somehow odd in a way that it was not before Sam became uncertain as to whether the door is locked. This claim—which, so far as I can tell, would be endorsed by every theorist who has discussed such a case in print (for a representative sampling, see van Inwagen 1983: 154; Waller 1985: 49; Kapitan 1986: 247; Clarke 1992: 104; Fischer 2005: 326; Pereboom 2008: 296, 297; Nelkin 2011: 130)—constitutes one of the most important data for theories of doxastic requirements on deliberation of the relevant kind (= trying to choose among multiple contemplated courses of action).

BFR-1 well explains the fact that it would be odd for Sam to resume trying to decide whether to leave the room while remaining uncertain as to whether the door is locked. According to BFR-1, if Sam were to resume trying to decide whether to leave the room, he would believe (at least dispositionally) that he's free to leave the room. Believing that he's free to leave the room would commit Sam to believing a further proposition on which (by hypothesis) he would be suspending judgment (in light of the relevant auditory evidence)—namely, [The door is unlocked]. Hence, BFR-1 implies that if Sam were to resume trying to decide whether to leave the room while remaining uncertain as to whether the door is locked, he would be in the awkward position of suspending judgment on a proposition to whose truth he's committed by certain of his beliefs. In this way, BFR-1 well explains why it would be odd for Sam to resume trying to decide whether to leave the room while remaining uncertain as to whether the door is locked. Absent is another promising explanation of the fact that it would be odd for Sam to resume trying to decide whether to leave the room while remaining uncertain as to whether the door is locked, that fact constitutes a strong reason to believe BFR-1. 


\section{Objections to the Argument for BFR-1}

Each of the main objections to the above argument for BFR-1 identifies an alternative doxastic requirement on (the relevant kind of) deliberation, and argues that the alternative requirement explains the indicated datum at least as well as BFR-1 does. In this section, I'll explain and assess the three most prominent objections of this sort.

The 'No Belief in Inability' Condition (cf. Waller 1985; Pettit 1989; Clarke 1992; Bok 1998; Pereboom 2008).

Consider this alternative to BFR-1:

You try to choose among multiple contemplated courses of action only if you don't believe about any of those courses of action that you're not free to pursue it.

This 'negative' doxastic requirement is both initially plausible and yields an alternative (to BFR-1's) explanation as to why it would be odd for Sam to resume trying to decide whether to leave the room while remaining uncertain as to whether the door is locked.

Reply: First, the proposed 'negative' condition seems too strong, for it seems possible that one try to choose among multiple contemplated courses of action despite believing about some of them that one can't pursue them (cf. Coffman and Warfield 2005). Perhaps the most realistic case along these lines involves a deliberator who believes occurrently about each of his contemplated courses of action that he can pursue it, but due to (say) an as yet undiagnosed inferiority complex believes dispositionally about some of those courses of action that he can't pursue them. Second (and more importantly), since Sam in fact satisfies the indicated 'negative' condition - that is, Sam doesn't (in his present uncertain state) believe about any of his contemplated courses of action that he can't pursue it (van Inwagen 2009) - the proposed condition does not in fact explain the relevant datum (Nelkin 2011).

The 'Belief in Epistemic Possibility' Condition (cf. Dennett 1984; Kapitan 1986; Fischer 2005; Pereboom 2008).

Here's another alternative to BFR-1:

You try to choose among multiple contemplated courses of action only if you believe about each course of action that your pursuing it is (for you) epistemically possible- that is, you believe about each course of action that you may pursue it (where 'may' here expresses an epistemic, rather than a metaphysical, modality).

Unlike the 'No Belief in Inability' condition (but like BFR-1), this is a 'positive openness' requirement on deliberation that is both initially plausible and yields an alternative (to BFR-1's) explanation of the relevant datum.

Reply: First, the proposed requirement seems too strong. At least two different kinds of cases bring out this problem. For starters (and as our earlier discussion of different kinds of deliberation suggests), it seems that there could be relatively immature or unsophisticated agents who lack the concept of epistemic possibility yet nevertheless sometimes try to choose between multiple contemplated courses of action-for example, requesting pizza or spaghetti for dinner (cf. Coffman and Warfield 2005). But even if engaging in deliberation (of the relevant sort) requires having the concept of epistemic 
possibility, there are still persuasive counterexamples to the proposed requirement. Consider the following case due to Nelkin (2011; cf. Clarke 1992):

[Y] ou are engaged in a long-anticipated activity ... You receive a call from a friend who desperately needs to talk to someone about the sudden and unexpected death of a family member. In the past, you have always deliberated about what to do in situations of this sort and have always resolved things in favor of talking to your friend . . . Based on these considerations . . . you know you will decide the same way today. However, you haven't yet deliberated and decided to do so yet. But you can and do.

Nelkin (2011: 126, 127)

Despite knowing that you're going to talk to your friend, you still have to make an effort to choose between (a) pursuing this course of action and (b) omitting it (in favor of continuing in your current, long-anticipated activity). Further, this case can be understood so that, by reflecting on your epistemic situation, you recognize that you know that you're going to talk to your friend; and you infer from this 'second-order' knowledge that omitting talking to your friend is not (for you) epistemically possible. Amplified in this way, the case becomes a counterexample to the proposed requirement (cf. Coffman 2010).

So the proposed alternative to BFR-1 is arguably too strong. However, there's a second and even more powerful defense of the argument for BFR-1 against the proposed alternative. For it turns out that the requirement in question suffers from the same explanatory impotency as the 'No Belief in Inability' condition. Since we can easily interpret Sam's case in such a way that he satisfies the proposed requirement-that is, in such a way that Sam believes (in his present uncertain state) that he may leave the room, but also that he may stay - the indicated requirement does not in fact explain the pertinent datum (cf. Kapitan 1986).

The 'Belief in Deliberative Efficacy' Condition(s) (cf. Kapitan 1986; Bok 1998; Pereboom 2008; Nelkin 2011).

Consider one last alternative to BFR-1:

You try to choose among multiple contemplated courses of action only if you believe about each course of action that you would pursue it (to completion) were you to choose to pursue it.

Unlike the first two alternatives to BFR-1, this is an initially plausible 'positive openness' requirement on deliberation that really does yield an explanation of the relevant datum. For if this proposal is true, then in deliberating about whether to leave the room, Sam would come to believe that he would leave the room were he to so choose, which belief would commit him to disbelieving a proposition on which (by hypothesis) he is simultaneously and properly suspending judgment-namely, [The door is locked].

Reply: The proposal as stated is too strong, and all the most obvious revisions yield a requirement that either is too strong or fails to explain the relevant datum. To begin, it seems that one could try to choose between courses of action A and B while not believing of either that one would pursue it (to completion) were one to so choose, due to (say) the occurrent self-knowledge that one occasionally fails through weakness of will to execute one's intentions (cf. Pereboom 2008). In light of this kind of counterexample 


\section{E. J. COFFMAN}

to the initial proposal, one might try revising the consequent in any of three ways (cf. Pereboom 2008):

- Might: ... you believe about each course of action that you might pursue it (to completion) were you to so choose.

- Normal: ... you believe about each course of action that, under normal conditions, you would pursue it (to completion) were you to so choose.

- Probable: ... you believe about each course of action that you probably would pursue it (to completion) were you to so choose.

Unfortunately, none of these possible revisions yields an explanation of the relevant datum that's as plausible as BFR-1. For each of Might and Normal, the resulting requirement doesn't explain the datum, since neither of the pertinent 'conditional' beliefs would commit Sam to denying that the door is locked. And for each of Normal and Probable, even if each of the resulting requirements can be interpreted so as to imply that in deliberating, Sam would form a belief that committed him to denying that the door is locked (which is not completely obvious), each envisaged requirement is arguably too strong. For it seems that there could be a relatively immature or unsophisticated agent (a young child, for example) who tries to choose among multiple contemplated courses of action while lacking both the concept of normal conditions as well as the pertinent probability concept.

Finally, this kind of problem also plagues the following somewhat different 'Belief in Deliberative Efficacy' condition recently suggested by Nelkin (2011):

You try to choose among multiple contemplated courses of action only if you believe about your effort to choose that it will explain why you pursue whichever contemplated course of action you ultimately pursue rather than any of the others.

(Nelkin 2011: 142)

Even if this requirement can explain the key datum arising from reflection on the 'Sam' case (which is not completely obvious), it is arguably too strong: it's implausible that simply trying to choose among multiple courses of action requires you to form a belief about that very effort, and also implausible that simply making such an effort requires believing that there will be a contrastive explanation of your pursuing whichever contemplated course of action you ultimately pursue.

BFR-1 is initially plausible and can be defended from the most promising attempted counterexamples. Moreover, the main argument for BFR-1 can be defended from the most prominent objections. Hence, if free action requires prior deliberation of the relevant sort - an issue addressed in other chapters - the interesting doxastic requirement on free action mentioned at the outset of this chapter may well hold.

\section{References}

Bok, H. (1998) Freedom and Responsibility. Princeton: Princeton University Press.

Clarke, R. (1992) "Deliberation and Beliefs about One's Abilities," Pacific Philosophical Quarterly 73: 101-13. Coffman, E.J. (2010) "Omniprescience and Tough Choices," Oxford Studies in Philosophy of Religion 3: 41-54.

Coffman, E.J. and Warfield, T. (2005) "Deliberation and Metaphysical Freedom," Midwest Studies in Philosophy 29: 25-44. 


\section{DELIBERATION}

Dennett, D. (1984) Elbow Room: The Varieties of Free Will Worth Wanting. Cambridge: MIT Press.

Fischer, J. (2005) "Free Will and Moral Responsibility," in D. Copp (ed.), The Oxford Handbook of Ethical Theory. Oxford: Oxford University Press, pp. 321-54.

Frankfurt, H. (1969) "Alternate Possibilities and Moral Responsibility," The Journal of Philosophy 66: 829-39.

Kapitan, T. (1986) "Deliberation and the Presumption of Open Alternatives," Philosophical Quarterly 36: 230-51.

Mele, A. (2003) Motivation and Agency. Oxford: Oxford University Press.

Nelkin, D. (2004) "The Sense of Freedom," in J. Campbell, M. O'Rourke, and D. Shier (eds), Freedom and Determinism. Cambridge: MIT Press, pp. 105-34.

Nelkin, D. (2011) Making Sense of Freedom and Responsibility. Oxford: Oxford University Press.

Pereboom, D. (2008) "A Compatibilist Account of the Beliefs Required for Rational Deliberation," The Journal of Ethics 12: 287-306.

Pettit, P. (1989) "Determinism with Deliberation," Analysis 49: 42-4.

Searle, J. (2001) Rationality in Action. Cambridge: MIT Press.

Streumer, B. (2010) "Practical Reasoning," in T. O'Connor and C. Sandis (eds.), A Companion to the Philosophy of Action. Malden: Blackwell, pp. 244-51.

Taylor, R. (1980) Action and Purpose. Atlantic Highlands: Humanities Press.

van Inwagen, P. (1983) An Essay on Free Will. Oxford: Oxford University Press.

van Inwagen, P. (2009) Metaphysics. Boulder: Westview.

Waller, B. (1985) “Deliberating about the Inevitable," Analysis 45: 48-52.

\section{Further Reading}

Henden, E. (2010) “Deliberation Incompatibilism," Dialectica 64: 313-33. (Important recent defense of theses related to BFR-1 and BFR-2.)

Levy, N. (2006) "Determinist Deliberations," Dialectica 60: 453-9. (Important recent criticisms of theses related to BFR-1 and BFR-2.)

Pettit, P. (2010) "Deliberation and Decision," in T. O'Connor and C. Sandis (eds), A Companion to the Philosophy of Action. Malden: Blackwell, pp. 252-8. (Helpful discussion of deliberation and its significance in the philosophy of action more generally.)

\section{Related Topics}

Skeptical Views about Free Will

Frankfurt-Style Examples

Logical Fatalism

Aristotle

Thomas Hobbes and John Bramhall

Immanuel Kant

Thomas Reid

Free Will and Theological Fatalism

Divine Free Will

Self-Control and Akrasia

Free Will and the Phenomenology of Agency

Determinism 


\section{3 \\ BLAME \\ Dana Kay Nelkin}

\section{Varieties of Blame and Free Will}

One of the most important sets of phenomena thought to be at stake in the debate over whether we have free will are our practices of holding each other, and ourselves, responsible. Of these, our practice of blaming often takes center stage, and justifiably so. If we do not have free will, would we be justified in blaming anyone? Many have taken the answer to be 'no,' and for this very reason, the question of whether we are free agents has been especially pressing. But there are many who disagree with this answer, and to adjudicate the debate over whether blame is indeed at stake in the free will debate, we need to begin by getting clearer on the nature of blame itself.

Now there are some uses of the word 'blame' and applications of the associated concept of blame that are clearly not relevant to the free will debate. For example, there is what is sometimes called 'causal blame,' as when someone blames high wind for a power outage. The high wind is not even an agent, and so not a candidate for the kind of blame thought to have any relevance to the free will debate. But even in cases involving the blame of agents, and even in cases involving moral blame of agents, it is possible to distinguish different senses of blame. For example, following Gary Watson, we can distinguish between two notions of responsibility, and two corresponding notions of blame. Blame in the 'attributability' sense is attributing a moral fault of some sort to a person that is exhibited in a faulty action, such as cruelty or heartlessness, and blame in the 'accountability' sense is holding someone to account for a wrong done (Watson 1996/2004). It seems that merely blaming in the attributability sense is not the same thing as blaming in the sense of holding someone accountable. Although there is controversy over whether being blameworthy in the sense of appropriately having such a moral fault attributed to one is sufficient for being blameworthy in the sense of appropriately being held accountable, it seems possible for both parties to this disagreement to agree that whether or not the sufficiency claim is true, it is a substantive claim, and also that the corresponding kinds of blame are distinct. In what follows, I will assume unless noted that we can clearly distinguish between these two kinds of blame, and I will focus here on blame in the accountability sense. The reason for doing so is that the question about whether we have free will arises most obviously when it comes to this sort of blame. It is natural to think that someone could lack free will for any number of reasons (physical determinism, mental illness, coercion), but nevertheless be appropriately judged to manifest cruelty or heartlessness in acting in a certain way. A moral fault is attributed, but one is not thereby rightly held accountable. Without prejudging the question of whether blame of the accountability kind is ultimately appropriate in 
the absence of free will, we can see that it is at least more tempting at the outset to think that being held accountable requires free agency than that being judged to have exhibited a moral failing does. Even many of those who argue for the justifiability of accountability blame in the absence of free will take themselves to bear the burden of explaining why it might have seemed otherwise.

\section{Accounts of (Accountability) Blame}

What exactly is blame in the accountability sense? There is a vibrant debate about the nature of blame, and a rich variety of proposals. Since, as we have seen, there are different concepts of blame, and different phenomena that go by the label 'blame' in some cases, it is less than obvious that a particular proposal is really intended as an account of accountability blame in particular. And some notable proposals are explicitly described as 'revisionist,' adding to the challenge of identifying those proposals that are genuine competitors for the best account of accountability blame. I will here canvass several accounts that have been taken to be promising candidates.

On one sort of view, often attributed to consequentialists such as J.J.C. Smart (1961), blaming is a kind of informal sanctioning or punishing (see Feinberg 1970). To blame is to scold or impose some sort of harsh treatment in response to a wronging. But this cannot capture the essence of blame, since it seems possible to blame the dead and even to blame the living without expressing oneself in any way. It also seems possible to blame without intending harm to the target of one's blame, as when one blames a loved one for, say, forgetting to keep a promise; and since intending harm is essential to punishment, blame cannot simply be a form of punishment. But there may yet be other important connections between blame and sanction, even if blame is not itself a sanction. For example, blame might presuppose the judgment that a person is deserving of sanction without thereby involving any intention to sanction or even any judgment that it would be good if it were to occur (see Nelkin 2013a for further discussion). Or blame might be thought to predispose one to treat others in generally adverse ways, or to serve in some way "the ends of retributive and compensatory justice" (Watson 1996/2004: 279-80). An influential view of punishment is that it expresses blame, or blaming attitudes such as resentment and indignation, without being the same thing as blame, which itself requires no expression.

With this in mind, it is natural to consider the proposal that blaming is a matter of making judgments of some kind that need not be expressed. There are several variations of this kind of account. First, one might take the relevant judgments to be ones attributing ill will as expressed in the action or omission for which an agent is blamed. But as we have already seen, it appears possible to make such a judgment without holding someone accountable. Alternatively, one might take the relevant judgment to be that the agent in question is blameworthy. This suggestion faces at least two challenges, however. The first is a worry about explanatory circularity. Given the surface language, it seems that blameworthiness ought to be understood in terms of blame and not vice versa. (This issue about priority of explanation is taken up in the next section.) The second worry is that it seems coherent to say sincerely: "I judge him to be blameworthy, but I do not blame him." This suggests that judging blameworthy is not sufficient for blame, even if some sort of judgment may be necessary for it. (For an interesting analysis of this kind of utterance using speech act theory, see Beardsley 1970.) While these challenges do not rule out the possibility of identifying another judgment with a 
different content that is both necessary and sufficient for blame, a more common reaction by those who take there to be something appealing in the judgment view has been to add further conditions to ones involving judgment, arguing that judgment alone is too 'cold' to count as blaming in the relevant sense.

George Sher, for example, argues that what it is to blame someone is to have "affective and behavioral dispositions" that "can be traced to the combination of a belief that that person has acted badly or has a bad character and a desire that this not be the case" (Sher 2006: 114). While adding the conative element of desire answers some of the criticisms of the judgment views, it, too, has been criticized for not capturing the essence of blame. For example, Angela Smith has argued that one could blame someone without having such a desire (her example is the group of Republicans who blamed President Clinton for his affair with Monica Lewinsky without at all desiring that it was not the case). Nor is such a belief and desire sufficient for the motivational and behavioral dispositions that even Sher seems to think essentially connected to blame (Smith 2013: 35-7).

T.M. Scanlon offers an account of blame having the following two components: a judgment that an agent is blameworthy for an action (where to make such a judgment is to judge "that the action shows that something about the agent's attitudes toward others impairs the relations that others can have with him or her"), and taking one's own relationship with the agent to be impaired in just the way the judgment takes to be appropriate (Scanlon 2008: 128, 129). If we understand "taking the relationship to be impaired" to be a judgment without any implications for behavior, then we could see this as a pure judgment view. But even if it is fundamentally a judgment, it is reasonable to think that one couldn't make a judgment with this particular content without one's relationship being in some way actually modified or impaired by one's dispositions to spend less time with the other or share fewer confidences, for example.

Scanlon's account has been criticized along a number of dimensions in ways that bring out some of the main fault lines in the debate about blame. As with one version of the judgment view described earlier, we can start by asking whether understanding blame in terms of the blameworthy is to reverse the proper order of explanation. Further, there seem to be counterexamples to both the necessity and to the sufficiency of the conditions proposed for blame. For example, one might blame one's child without taking one's relationship to be impaired. And one might take one's relationship to be impaired, say, in a case of friendship, such as when a friend has to choose between fulfilling obligations to different friends, while not blaming the person for making the choice she does. It is important to note that Scanlon acknowledges that his account might strike some as revisionary (2008: 122), and if it is, then purported counterexamples to our current concept of blame would not be devastating objections. In that case, though, the debate would shift to the question of whether revision is called for. (It is instructive here to compare Scanlon's account to Pereboom's explicitly forward-looking account of blame and blameworthiness, according to which we can be justified in keeping some but not all of our responsibility practices, if we are not free agents [Pereboom 2013, 2014]. This view is clearly revisionary, and does not purport to compete with many accounts of accountability blame.)

It is also worth noting that, as Pereboom (2014) observes and Scanlon himself accepts about his own view, both Scanlon's and Sher's accounts could be recognized as legitimate forms of blame even by free will skeptics. This is not by itself a reason to reject the accounts, but even if it turns out to be correct that free will is not required for 
justified accountability blame, it would be desirable for such an account at least to explain how we might have initially thought that free will is implicated. As they stand, neither account offers such an explanation. Of course, one might deny that Sher and Scanlon are trying to capture blame in the accountability sense in the first place. If that were true, however, then at least some important participants in the debate would simply have been talking past each other from the start.

Finally, and importantly, Scanlon's account has also been criticized for failing to capture the 'sting' of blame. And one natural way of trying to repair this purported deficiency is by requiring something missing from both of these accounts: an emotional condition.

In his widely influential "Freedom and Resentment," Peter Strawson (1963) argued that we ought to see resentment, indignation, guilt, and forgiveness, among other so-called "reactive attitudes," as taking center stage in discussions of freedom and responsibility. Many have thought that taking these attitudes is essential to blaming. For example, R. Jay Wallace writes that "to blame a person is to be subject to one of [the] reactive emotions because of what the person has done" (Wallace 1994: 75). While such emotions are certainly associated with many instances of blame, we might ask whether they are necessary. Can one blame someone even if one lacks these emotions? Consider blame outside of the context of personal relationships. Sher, for example, suggests that we might blame strangers or people who committed misdeeds in the distant past without feeling any emotions at all (Sher 2006, 2013). Because a defender of the reactive attitudes account of blame might insist that these are not genuine cases of blame, a full evaluation would be aided by more investigation into what else might be added to (or replace) judgment of some sort to capture what is distinctive about blame.

Another strategy is to adopt an insight of the reactive-attitudes account without explicating blame in terms of the attitudes at all. Strawson, for one, takes the reactive attitudes to embody moral demands. But one might agree that reactive attitudes can embody demands, but reject the idea that they are strictly necessary in order to make demands. It is the making of demands itself that is fundamental to blame, on this view. But it is not clear exactly what the contents of the demands are that are supposed to be central to blaming. It does not make sense to demand that you not do the thing you did earlier since you can't go back in time. You can, of course, demand that someone not do the same sort of thing in the future. But that is something we could do with anyone, not only those who have already acted badly, so it is not clear that this is yet blame. On some views, the demands in question are demands that others justify their actions (e.g., Smith 2008). Making such demands may be a part of our reaction to being wronged much of the time, but again it seems neither necessary nor sufficient for blame. For one thing, suppose that the target of the demand manages to justify the action in question. Then we should not blame him, and it seems perfectly coherent to have suspended judgment about blameworthiness and all else until we have given him a chance to meet this demand. So it seems that there might be circumstances in which we reasonably make such a demand, but we do not (yet) blame. Similarly, we might decide that the action is unjustifiable and blame the target without making this sort of demand either externally or internally. None of this is to say that demands are unrelated to what makes someone blameworthy, since the flouting of legitimate demands may be part of what makes someone blameworthy, for example; it is just to cast doubt on the idea that what it is to blame must be partly constituted by the making of demands. 
Another suggestion for how to replace the reactive attitudes as a necessary condition for blame is to include instead as a condition of blame, in addition to a judgment of a certain sort, the registering a moral protest in the modification of one's judgments, intentions, and expectations toward another. Smith, for one, suggests that what is appealing about the reactive attitudes accounts is that reactive attitudes come close to capturing this idea (Smith 2013: 28-9). (Talbert also suggests that protest is a function of blame, but, in contrast to Smith, he takes blame to be the expression of the negative reactive attitudes or a judgment of their appropriateness [Talbert 2012: 90]).

Drawing partly on Hieronymi (2004), Smith (2013) understands protest to be a kind of registering and challenging of a claim implicit in the wrong action, namely a claim that such an action is acceptable, and a seeking of some sort of moral acknowledgment from the wrongdoer or the community. While this is a rich account, it is not yet clear that what we have is blame in the accountability sense. Could we protest a cruel and contemptuous action in this sense while explicitly refusing to hold the agent accountable for it? Perhaps someone suffering from mental illness could have an excuse for his action that renders him not blameworthy, even though we might rightly register and challenge a claim implicit in his action. Now, not all of the authors who have recently proposed views of this sort explicitly describe their task as providing an account of blame in the accountability sense. It might be that there are simply multiple concepts of blame with overlapping extensions and an account that features protest at its center is one important one. Protest is indeed of great moral importance in human life, but it remains to be seen whether an account that puts it at center stage can capture blame in the accountability sense.

Faced with serious challenges to each view described to this point, one might adopt a hybrid view in which blame is seen to require a conjunction of conditions from accounts we have already seen. This might help if we were convinced that, say, protest, was necessary but not sufficient, but it would need to be combined with other conditions not already rejected for being unnecessary themselves. Another kind of hybrid view would be to see blame as requiring one of a disjunction of conditions. But here we might ask what makes the set of disparate conditions all ones that can constitute blame, and without an answer, the view would be unappealing. Further, it would not help in rounding out accounts whose conditions seem necessary, but insufficient.

There are other kinds of accounts that can explain what is attractive in a variety of accounts we have already canvassed without reducing to either a conjunction or a disjunction of them. For example, Michael McKenna $(2012,2013)$ sees blame fundamentally as a move in a moral conversation (see Watson 1987/2004 for discussion of blame as essentially communicative). On his view, the paradigms of blame are instances of expression and essentially communicative (in this way sharing some features of those accounts that feature demand or protest), while instances of unexpressed blame are non-paradigmatic and can be understood in derivative terms. According to McKenna, blame cannot be understood independently of the conversational moves that come before and after. Since there are many ways of expressing the same thing, and since there are many different expressions that would be felicitous in response to an opening of a conversation, this view can accommodate the idea that a number of responses to wrongdoing count as blame, without requiring that any particular kind of response is necessary. For example, on McKenna's view, taking up a reactive attitude like indignation is unnecessary. Blame on this view is a response to ill will as expressed in action in the first stage of the conversation, and can convey anger, 
shunning, and alienation as expressions of morally reactive attitudes (McKenna 2013: 132). This view has the advantage of being able to accommodate insights from a number of the previous accounts. McKenna offers examples of what can count (e.g., the failure to issue a regular invitation to lunch where this has a negative meaning for the one blamed, the expression of indignation), but we might also ask whether we can identify conditions for what can count as blame, or whether there are general constraints on the content of the conversational move, and, if so, what exactly they are. We might also ask how to account for unexpressed blame. McKenna urges us to adopt an interesting methodological assumption that provides a response to both sorts of questions. He rejects the very project of finding necessary and sufficient conditions for blame, opting to focus on what he sees as the prototypical cases of blame, which he takes to be expressed. Other more peripheral cases might then be accounted for in terms of similarity or other relations to the prototypical ones. It is possible that this is the best that we can do. But how satisfying this is might ultimately depend on how we see the relationship between blame and blameworthiness, an issue we will take up in the next section, as well as how we see the relationship between blameworthiness and punishment.

Another approach that joins the prototype approach in being interestingly different from the others we have examined is to see blame in functionalist terms. Victoria McGeer explicitly takes this kind of approach, seeing blame as defined by the input of wrongdoing and various behavioral outputs, which themselves aim at regulating behavior and preventing further norm violations (McGeer 2013: 172). As it happens, the reactive attitudes often (but not always) play this role. This sort of view also has the advantage of explaining the centrality of the reactive attitudes in discussions of blame without taking them to be necessary or sufficient. But there is some reason to doubt that our concept of blame is at bottom a functional one, and that blame is whatever plays a particular functional role. Suppose we were to discover that what we were calling 'blame' turned out to be quite ineffective in regulating moral behavior (and many current theories of education and parenting purport to rest on such discoveries). In that case, we would not be likely to say that we had not blamed in the past, for example. Yet even if this approach to the concept of blame and its nature does not work in the end, there is much that can be fruitfully discussed about the functions it serves (see, for example, Watson 1996/2004: 280; Talbert 2012).

Given the apparent counterexamples and objections to all of the specific proposals of necessary and sufficient conditions for blame, and given the concern that a prototype approach might not be fully satisfying, we are left with the following choices. First, we can try to explain why the apparent counterexamples are merely apparent, and defend particular views against objections. Second, we can await a new view, perhaps one that combines the insights of some of these (including the prototype approach) in the right way via either conjunction or disjunction. Third, we can recognize that blame is itself a phenomenon that can be instantiated, and, importantly, expressed, in a variety of ways in different contexts. This is not to treat blame as a functional concept with different realizations, but as a category that admits of different kinds of instantiations (as it is possible for both oaks and magnolias to be trees). To blame is to hold a wrong against someone, and this requires taking a certain stance toward the wrongdoer. In turn, this requires making certain negative judgments and also being disposed in certain ways. (For example, on my view, holding a wrong against another person is partly to be prepared to hold the wrongdoer to the obligations 
incurred by having performed the wrongdoing (Nelkin 2013b)). Taking such a stance can be manifested in a variety of ways depending on the context. Each of these three strategies might be fruitfully pursued.

\section{Blame and Blameworthiness}

What is the relationship between blame and blameworthiness? Start with the following thesis: if someone is blameworthy for performing an action, then it is, in a relevant sense, appropriate to blame her for it, and vice versa. So far, this seems to be a simple claim about what 'blameworthiness' means. And it seems uncontroversial to say that blameworthiness is defined in terms of blame. And equally uncontroversially, it would seem that the property of being blameworthy for an action is just the property of its being appropriate, in the sense that one is worthy of it, to blame. At the same time, inspired by Peter Strawson's influential "Freedom and Resentment," there has been much recent debate surrounding the question whether we should understand blameworthiness to be an essentially response-dependent property or not. One way to see how debate arises, consistent with agreement that to be blameworthy is to be worthy of a particular kind of response is as follows: we can ask whether being blameworthy is grounded in some further properties, and, if so, whether these properties are themselves response-dependent or not.

To see even better how controversy arises, note that writers often substitute for 'blame' what they take to be constitutive of blame in the thesis connecting blame and blameworthiness. For example, as we have seen, some take blame to be the taking up of the reactive attitudes, such as resentment or indignation toward another. Staying with this example, and substituting 'taking the reactive attitudes' for 'blame,' we now have the following substantive thesis: A person is blameworthy for performing an action if and only if it is appropriate to respond to A's action with the reactive attitudes. And now we can ask whether it is the appropriateness of taking the attitudes that explains why A is blameworthy, or, rather, whether A's blameworthiness explains the appropriateness of the attitudes. Some have observed that the debate on this point has certain parallels with recent discussions of other evaluative and ethical concepts and properties such as 'the funny' and 'the good' (Ramirez 2012; Todd forthcoming). Are the emotional responses more fundamental in explaining the property of 'the funny' or 'the good,' or are the emotional responses answerable to responseindependent properties?

On some response-dependent views about evaluative concepts such as 'the funny' or 'the fearsome,' such concepts are not to be understood in response-independent terms (see, for example, D'Arms and Jacobson 2003). For example, the fearsome is not to be understood in terms of being dangerous, nor is the funny to be understood in terms of incongruity, though these properties might be referred to in 'rules of thumb;' otherwise, giving a response-dependent account of the concepts would be 'superfluous.' And this naturally suggests that the funny and the fearsome are not response-independent properties. Should we think of blameworthiness in a similar way? To answer affirmatively would be to say that the conditions that make us blameworthy are simply ones like its being appropriate to respond to us with resentment and related attitudes. (On one reading of Strawson [1963] that emphasizes his claim that there is no justification of our moral responsibility practices outside of those practices themselves, Strawson is himself a proponent of this kind of view.) There are 
objections to this sort of approach, however. For example, such an account must explain why we seem to be able to give quite detailed response-independent conditions as excusing of blameworthiness, to take just one example, and this has not been done. (Interestingly, D'Arms and Jacobson explicitly contrast resentment with emotions like fear, which they take to be more apt for the response-dependent account of their target properties.)

On a second kind of account, being blameworthy is grounded simply in the appropriateness of the relevant blaming responses, but there are response-independent conditions that are co-extensive with being blameworthy and that are related in some way to blameworthiness other than by a relationship of grounding. (See Wallace 1994; and on a reading of Strawson [1963] that emphasizes his own identification of excuses and exemptions in response-independent terms, Strawson can be seen to be a proponent of this kind of view.) This kind of account faces its own challenges. First, it might be asked whether offering the response-dependent account is in some way superfluous, as D'Arms and Jacobson suggest is the case if indeed we have response-independent conditions available. Second, the account must explain what the relation of blameworthiness to the response-independent conditions is, if it is not being grounded in them. A variant of this view is McKenna's (2012) proposal that there is a mutual grounding of blameworthiness and appropriate blaming responses; but this view faces the objection that grounding is an asymmetrical relationship. (See Fine 2001 and deRosset 2013 for recent discussion of grounding and explanation.)

On a third sort of view, the property of being blameworthy is response-dependent in the sense that being blameworthy is a matter of a certain kind of response being appropriate, while it is also the case that being blameworthy is grounded in wholly responseindependent conditions, which could include the target agent acting with control or acting with free will, for example. This sort of view accounts for the very salient fact suggested by the surface language of both blameworthiness and responsibility that what it is to be blameworthy is for certain responses to be appropriate. But at the same time it accommodates in the most natural way the existence and intensity of the very debate over whether free will is required for blameworthiness in its recognition that there are response-independent conditions that ground blameworthiness, or in virtue of which an agent is blameworthy (see Brink and Nelkin 2013; Nelkin 2011). This view is not without its challenges, however. Proponents should ultimately explain why possessing the relevant response-independent conditions (whether control, or free agency, or the freedom to do otherwise, and/or something else) makes one worthy of blame for wrongdoing. And a full answer to this question will ultimately have to be given in conjunction with an answer to the question of the last section: what exactly is it to blame in the accountability sense?

Further, the question will have to be answered in conjunction with a further question concerning the relationship between blame and blameworthiness: How should we understand 'worthy' in 'blameworthy?' In some discussions, 'worthy' is treated as equivalent to 'appropriate candidate for' and in others as 'deserving of.' (For the latter, see Pereboom [2013, 2014], who offers an account of the kind of responsibility related to free will as essentially one of 'basic desert' of blame or praise.) 'Desert' itself has a variety of uses, but on one notable one, what one deserves is measured on a scale of size of harms and benefits. If this were the correct notion of 'worthy' in the accountability sense of blameworthiness, then a further constraint on an acceptable account of the nature of accountability blame would be that it is a kind of harm. 


\section{Blame and Forgiveness}

Forgiveness is often understood to consist in the foreswearing of blame on the part of one who is wronged. So it is not surprising that just as there are many accounts of blame, there are many accounts of forgiveness. According to a very influential account, often (but misleadingly) attributed to Butler, forgiveness is the foreswearing of resentment in particular. In contrast, according to a debt-release model of forgiveness, forgiving is a matter of ceasing to hold the wrongdoer to obligations incurred as the result of the wrongdoing. The former fits well with the reactive attitudes account of blame, the latter with the account of blame as holding an offense against another person in a way that includes the holding to obligations. Because of the tight connection between blame and forgiveness, it makes sense to develop an account of each in light of the other.

At the same time, there is an interesting asymmetry between the two phenomena. Forgiveness seems to be something that only those who are wronged have the standing to do, whereas blame seems to be something anyone can do (whether they ought to or not). Suppose Avery gratuitously reveals a confidence of Pedro's. Pedro's friend might blame Avery and feel indignation, but only Pedro himself is in a position to forgive Avery. It seems it is not Pedro's friend's place to do so, and, as a result, he simply cannot forgive Avery. As we will see in the final section, there are questions about who has the standing to justifiably blame, as there are questions about who has the standing to forgive. But the standing to forgive seems to be constrained in particular to those who have been wronged (or perhaps to those who have in some way been authorized to forgive on their behalf), whereas the standing to blame is not similarly constrained. There may be a thirdparty analogue of forgiveness, available to all. But this is an under-explored question.

\section{Praise and Blame}

There is much more focus on blame than on praise in the literature, and at least one explanation for this fact might be that, as Watson (1996/2004) suggests, blame tends to be a "more serious affair," with more being at stake. Another might be that discussion of responsibility in the law focuses on blame rather than praise, and given the parallels between legal and moral responsibility, the emphasis is placed on blame rather than praise in the moral literature.

Nevertheless, even if only in passing, praise and blame are very often mentioned in the same breath, and are naturally taken to be opposites. But even this apparently obvious claim is questioned with surprising frequency in discussions of blame. For example, Coates and Tognazzini (2013), following Brandt (1958), suggest that the idea of private blame makes sense in a way that private praise does not. Scanlon (2013: 95) finds a very different reason for thinking the two are not opposite, suggesting that praise is a purely evaluative notion whereas blame requires more. As against the former suggestion, we might concede that private praise is perhaps less frequent than private blame, and that obstacles to overt praise tend to be easier to overcome than obstacles to overt blame. But private praise is not incoherent; a coach might privately praise an athlete, thinking that doing so outwardly would undermine the athlete's motivation to prove herself, for example. As against the latter suggestion, once we have distinguished between different kinds of blame - attributability and accountability - we can see that there is a kind of praise that is merely evaluative, and a kind that is not. But we can say something similar about blame. 
Other sorts of grounds for asymmetry seem to pose more of a challenge to seeing the two phenomena as opposites. For example, if blame requires the attribution of wrongdoing on the part of a responsible agent, then we can ask what the opposite attribution is in the case of praise. An attribution of an action that fulfills moral requirements for which one meets the conditions of responsibility? Perhaps this is correct, but because we do not think praise is justified by all permissible action done by responsible agents, and we often praise supererogatory action, it seems that the conditions of blameworthiness and praiseworthiness themselves might come apart in ways that undermine the idea that they are opposites, and so the idea that blame and praise are opposites. As has been pointed out, 'holding accountable' itself doesn't obviously seem apt when it comes to praiseworthy actions in the way it does when it comes to blameworthy ones. Such worries are not decisive, however, and point to further development of accounts of the conditions that ground both praiseworthiness and blameworthiness. Recent exploration of common factors that appear to ground degrees of both praiseworthiness and blameworthiness, such as difficulty in performing the action in question, have the potential for a contributing role here (Coates and Swenson 2013; Nelkin 2016).

\section{The Scope of Blame}

Without getting into the details of the debate about what the conditions are for blameworthiness, we can ask a more general question about the scope of accountability blame that has implications for the relationship between blame and freedom. The question is what kinds of things are people blameworthy, and so, appropriately blamed, for. Actions? Omissions? Character? Wrongdoing? Motives? Recently, there has been renewed interest in the particular question of whether people can only be blameworthy for instances of wrongdoing, or whether, instead, people can be blameworthy for performing permissible actions albeit with ill will or bad motives. One sort of case that has been thought to support the latter view is due to Julia Driver: one permissibly refuses to give a kidney to one's brother, but one can nevertheless be blameworthy for doing so (Driver 1992; see also McKenna 2012). On this view, it is the meaning with which an action is done (or omitted), where meaning is determined by motives and attitudes, and not the deontic status of an action, that ultimately underlies blameworthiness. This has potential implications for the free will debate because action seems like the paradigm instance of something free; what motive one has does not (initially anyway) seem like the kind of thing that is the object of free choice. This assumption itself might fruitfully be questioned, as can the assumption that motives do not themselves partly determine the rightness or wrongness of an action or omission. (The role of intentions and reasons in determining permissibility is itself a subject of intense debate.) Those who take blameworthiness to be restricted to violations of moral obligation can also respond to cases such as Driver's described above by disagreeing that the agent in question has done nothing wrong if indeed blameworthy. Further, given that we have distinguished between different kinds of blame, it is open to those who restrict accountability blameworthiness to wrongdoing to say that such a restriction does not preclude attributability blameworthiness for having bad character or bad motives.

\section{The Norms of Blame}

Finally, just because someone is blameworthy, and so in an important sense it is appropriate to blame her, it does not follow that any particular person ought to blame her. 
Consider an instructive analogy. Just because a joke is funny (on whatever account of 'funniness' you like), it does not follow that any ought to laugh at it. Suppose your friend tells a very funny joke about a mutual friend of yours who is present. It might be a genuinely funny joke, but because you know that your laughing would hurt your mutual friend, it would be wrong of you, all things considered, to laugh. Similarly, a person might be blameworthy, and thus, there is a sense in which blame would be an appropriate response. But there might be factors that make it the case that particular people-or even everyone- ought to refrain from blaming. For example, many take it that hypocrisy overrides any reason to blame someone when you yourself are guilty of the same offense. If this is right, then it appears that blame, like forgiveness, is related to requirements of standing. But there is a difference that goes beyond even the difference noted earlier: a hypocrite might blame even if she does not have the standing to do so appropriately, whereas it seems that a third party cannot forgive at all (whether rightly or wrongly). Still, when it comes to blaming, and possibly also when it comes to forgiving, whether and, if so, how one ought to blame will depend on more than whether the target of one's blame is blameworthy. Other factors that might support whether all things considered one ought to blame include complicity and 'meddling' (Tognazzini and Coates 2014), the kind of relationship between the relevant parties (Scanlon 2008), the severity of the offense (Smith 2007), and whether one is judgmental or compassionate (Kelly 2013; Watson 2013). Thus, even if we could settle the question of what the conditions are in virtue of which a person is blameworthy, and we could settle whether they include free agency, there could still be much interesting work to do in identifying the norms or ethics of blame itself.

\section{Acknowledgments}

Many thanks to David Brink, Neil Levy, and Sam Rickless for very helpful comments and discussion.

\section{References}

Beardsley, E. (1970) "Moral Disapproval and Moral Indignation," Philosophy and Phenomenological Research 31: 161-76.

Brandt, R. (1958) "Blameworthiness and Obligation," in A.I. Melden (ed.), Essays in Moral Philosophy. Seattle: Washington, pp. 3-39.

Brink, D.O. and Nelkin, D.K. (2013) "Fairness and the Architecture of Moral Responsibility," Oxford Studies in Agency and Responsibility 1: 284-313.

Coates, D.J. and Swenson, P. (2013) "Reasons-Responsiveness and Degrees of Responsibility," Philosophical Studies 165: 629-45.

Coates, D. J. and Tognazzini, N.A. (2013) "The Contours of Blame," in D.J. Coates and N.A. Tognazzini (eds), Blame: Its Nature and Norms. Oxford: Oxford University Press, pp. 3-26.

D’Arms, J. and Jacobson, D. (2003) "The Significance of Recalcitrant Emotion (Or Anti-Quasijudgmentalism)," Royal Institute of Philosophy Supplement 52: 127-45.

deRosset, L. (2013) "Grounding Explanations," Philosopher's Imprint 13: 1-26.

Driver, J. (1992) "The Suberogatory," Australasian Journal of Philosophy 70: 286-95.

Feinberg, J. (1970) Doing and Deserving: Essays in the Theory of Responsibility. Princeton: Princeton University Press.

Fine, K. (2001) “The Question of Realism,” Philosopher's Imprint 1: 1-30.

Hieronymi, P. (2004) "The Force and Fairness of Blame," Philosophical Perspectives 18: 115-48.

Kelly, E. (2013) "What is an Excuse?" in D.J. Coates and N.A. Tognazzini (eds), Blame: Its Nature and Norms. Oxford: Oxford University Press, pp. 244-62.

McGeer, V. (2013) "Civilizing Blame," in D.J. Coates and N.A. Tognazzini (eds), Blame: Its Nature and Norms. Oxford: Oxford University Press, pp. 162-88. 
McKenna, M. (2012) Responsibility and Conversation. New York: Oxford University Press.

McKenna, M. (2013) "Directed Blame and Conversation," in D.J. Coates and N.A. Tognazzini (eds), Blame: Its Nature and Norms, Oxford: Oxford University Press, pp. 119-40.

Nelkin, D.K. (2011) Making Sense of Freedom and Responsibility. Oxford: Oxford University Press.

Nelkin, D.K. (2013a) "Desert, Fairness, and Resentment," Philosophical Explorations 16: 117-32.

Nelkin, D.K. (2013b) "Freedom and Forgiveness," in I. Haji and J. Caouette (eds), Free Will and Moral Responsibility. Newcastle Upon Tyne: Cambridge Scholars Press, pp. 165-88.

Nelkin, D.K. (2016) "Difficulty and Degrees of Moral Praiseworthiness and Blameworthiness," Noûs 50: 356-78.

Pereboom, D. (2013) "Free Will Skepticism, Blame, and Obligation," in D.J. Coates and N.A. Tognazzini (eds), Blame: Its Nature and Norms. Oxford: Oxford University Press, pp. 189-206.

Pereboom, D. (2014) Free Will Skepticism, Agency, and Meaning in Life. Oxford: Oxford University Press.

Ramirez, E.J. (2012) A Sensible Sentimentalism: The Role of the Emotions in Evaluative Concepts and Reactive Attitudes. Berkeley: University of California, San Diego dissertation.

Scanlon, T.M. (2008) Moral Dimensions: Permissibility, Meaning, Blame. Cambridge: Harvard University Press.

Scanlon, T.M. (2013) "Interpreting Blame," in D.J. Coates and N.A. Tognazzini (eds), Blame: Its Nature and Norms. Oxford: Oxford University Press, pp. 84-99.

Sher, G. (2006) In Praise of Blame. Oxford: Oxford University Press.

Sher, G. (2013) "Wrongdoing and Relationships: The Problem of the Stranger," in D.J. Coates and N.A. Tognazzini (eds), Blame: Its Nature and Norms. Oxford: Oxford University Press, pp. 49-65.

Smart, J.J.C. (1961) "Free-Will, Praise, and Blame," Mind 70: 290-306.

Smith, A. (2007) "On Being Responsible and Holding Responsible," Journal of Ethics 2: 465-84.

Smith, A. (2008) "Control, Responsibility, and Moral Assessment," Philosophical Studies 138: 367-92.

Smith, A. (2013) "Moral Blame and Moral Protest," in D.J. Coates and N.A. Tognazzini (eds), Blame: Its Nature and Norms. Oxford: Oxford University Press, pp. 27-47.

Strawson, P.F. (1963) "Freedom and Resentment," Proceedings of the British Academy 48: 1-25.

Talbert, M. (2012) "Moral Competence, Moral Blame, and Protest," Journal of Ethics 16: 89-109.

Todd, P. (forthcoming) "Strawson, Moral Responsibility, and the 'Order of Explanation': An Intervention," Ethics.

Tognazzini, N.A. and Coates, D. J. (2014), "Blame," E.N. Zalta (ed.), The Stanford Encyclopedia of Philosophy (Summer 2014 Edition), available from: http://plato.stanford.edu/archives/sum2014/entries/blame/ (accessed 29 June 2016).

Wallace, R.J. (1994) Responsibility and the Moral Sentiments. Cambridge: Harvard University Press.

Watson, G. (1987/2004) "Responsibility and the Limits of Evil: Variations on a Strawsonian Theme," in F. Schoeman (ed.), Responsibility, Character, and the Emotions: Essays in Moral Psychology. Cambridge: Cambridge University Press, pp. 256-86, reprinted in G. Watson, Agency and Answerability. Oxford: Oxford University Press.

Watson, G. (1996/2004) "Two Faces of Responsibility," reprinted in G. Watson, Agency and Answerability. Oxford: Oxford University Press.

Watson, G. (2013) "Standing in Judgment," in D.J. Coates and N.A. Tognazzini (eds), Blame: Its Nature and Norms. Oxford: Oxford University Press, pp. 282-302.

\section{Further Reading}

Coates, D.J. and Tognazzini, N.A. (eds) (2013) Blame: Its Nature and Norms. Oxford: Oxford University Press. (An excellent cutting-edge collection of essays on all aspects of the topic, several of which are cited above.) McKenna, M. and Russell, P. (eds) (2008) Free Will and Reactive Attitudes: Perspectives on P.F. Strawson's "Freedom and Resentment." Burlington: Ashgate Publishing. (Contains a number of interesting articles focused particularly on Strawson's seminal article calling attention to the relationship between freedom and the blaming attitudes.)

\section{Related Topics}

Free Will and Moral Sentiments: Strawsonian Views

Revisionism

The Relationship between Moral Responsibility and Freedom 


\section{4 \\ THE RELATIONSHIP BETWEEN MORAL RESPONSIBILITY AND FREEDOM}

Benjamin Rossi and Ted A. Warfield

Our focus is on the relationship between moral responsibility (hereafter 'responsibility') and freedom (sometimes called 'free will'). We open with remarks about the general conceptual relationship between responsibility and freedom. We then explore, as a case study, a prominent account of responsibility with special focus on what this accounts says or implies, if anything, about freedom. We close with discussion of the relation between responsibility and freedom if it turns out that there are multiple notions of responsibility.

\section{General Relationship}

Both freedom and responsibility are contested notions. There are many different theories or accounts of responsibility and many different theories or accounts of freedom. The different accounts seem to be in competition with one another. Whether such competition is real or illusory, however, is itself a contested matter. Perhaps there is one legitimate notion of responsibility with many different proposed accounts of it. Or perhaps there are multiple legitimate notions of responsibility. The same is true of the apparently competing accounts of freedom.

Given this state of play concerning accounts of responsibility and accounts of freedom, it might seem hopeless to attempt to theorize about the general relationship between responsibility and freedom. One might think that there is no hope for reaching conclusions about the relationship between two concepts about which there is so much disagreement. Such an immediate conclusion, however, would be overly pessimistic. Compare this situation to the state of play concerning the relationship between knowledge and truth. There are many different competing theories of knowledge and many different competing theories of truth. There is also controversy over whether the different accounts of each notion are genuinely in competition with one other or whether there are multiple legitimate notions of either or both. These controversies do not prevent there from being widespread agreement about the following general conceptual relation between knowledge and truth: knowledge entails truth (knowing that 
$\mathrm{P}$ entails that $\mathrm{P})$. Perhaps some similarly important conclusion about the relation between responsibility and freedom can be established despite the noted disagreements about each notion individually. We are pessimistic about a definitive conclusion about the relation between responsibility and freedom emerging as it does in the case of the relation between knowledge and truth. The possibility, however, is an open possibility worth some exploration.

Two possibilities worth consideration are (a) that responsibility entails freedom (that one is responsible for X only if one is free with respect to X) and (b) that freedom entails responsibility (that one is free with respect to $\mathrm{X}$ only if one is responsible for $\mathrm{X}$ ). We take no stand about the range of ' $\mathrm{X}$ ' in the above schema, proceeding informally for ease of exposition. After the following paragraph containing one point about the suggestion that freedom entails responsibility, we focus our attention on the suggestion that responsibility entails freedom. Of the two suggestions noted above we think this is both the more plausible and more interesting possibility.

Much could be said about the suggestion that freedom implies responsibility but the view faces a challenge that we find at least initially plausible. Some free actions seem to be morally empty. For example, at 2:00 PM in an ordinary office setting, Lauren freely changes into more comfortable shoes. Nothing of any moral consequence is involved. If this is correct, then being free with respect to $\mathrm{X}$ does not entail being responsible for $\mathrm{X}$. Perhaps the suggestion that freedom implies responsibility should be understood as the suggestion that freedom with respect to $\mathrm{X}$ implies responsibility for $\mathrm{X}$ for any $\mathrm{X}$ of moral significance. We set aside this interesting possibility to focus more fully on the suggestion that responsibility entails freedom.

Why might one think that responsibility for $\mathrm{X}$ requires freedom with respect to $\mathrm{X}$ ? As an example, why think that Michael's being responsible for the broken glass implies that he freely broke the glass? An initial defense of this claim would likely focus on the intuitive force of a defense of Michael from the charge of responsibility that cited factors that sufficed for his not having freely broken the glass. 'Michael was forced to break the glass' and 'Michael accidentally dropped the glass' are two examples of possible defenses of this sort. One citing either defense in rejecting Michael's responsibility for breaking the glass probably has the following in mind: the cited defense rules out Michael's having freely broken the glass and claims that his lack of responsibility follows. The idea is presumably that if absence of responsibility is best explained in such situations by lack of freedom then responsibility implies freedom.

This idea requires further scrutiny. Even if in some cases a lack of freedom significantly explains the absence of responsibility, it does not follow that responsibility requires freedom. It might be, for example, that the way that freedom is undercut in a particular case (rather than simply the absence of freedom itself) is what explains the absence of responsibility in that case. This would block the general conclusion that freedom is necessary for responsibility. Although it seems quite plausible that if Michael is forced to break the glass then he is not free and therefore not responsible, this may have more to do with his having been forced (this is the way he is not free) than simply with his not having been free. Other factors that would plausibly undermine Michael's freedom would not so plausibly block his responsibility. We briefly discuss two such factors below. Both issues to be discussed are themselves quite controversial. We introduce the issues to illustrate challenges one must face if defending the claim that responsibility requires freedom. We do not here take a stand on the debate about either sub-issue. 
First, if Michael breaks the glass but does not freely do so he may well still be responsible if he is in a situation that in many ways parallels standard Frankfurt cases (see this volume, Chapter 15). Michael breaks the glass, and intentionally so, because he wants to do so and no significant outside pressure or force makes him do this. Unbeknownst to Michael, a Frankfurt-style (inactive) counterfactual intervener stood ready to intervene in such a way that inevitably Michael would choose to break the glass and then break the glass. The counterfactual intervener did not, however, intervene. Michael breaks the glass, as one says, on his own. Many think that in such a case, it is quite plausible that Michael is responsible for breaking the glass (he did so because he wanted to, no significant external pressure, etc.). It is at least arguable, however, that the presence of the Frankfurt intervener in the overall situations suffices for Michael's not having freely broken the glass. This is especially plausible if one thinks that freedom requires alternative possibilities and that a suitably constructed Frankfurt scenario precludes alternative possibilities. As noted above, these assumptions are contentious (see Warfield [2007] for extensive discussion of the relation between freedom and responsibility in the context of Frankfurt cases).

Second, one might think that Michael is responsible, though not free, for breaking the glass if he breaks the glass because of features of his longstanding well-formed character. A variant on this suggestion adds additionally that the longstanding well-formed character also be a virtuous character. The main idea behind this suggestion is that habitual character-driven behavior may well be behavior for which one is responsible even if the behavior in question is not free because it is driven by a strong character. The idea behind the variant proposal is that in the case of virtuous actions ascriptions of responsibility are true even if an agent's freedom is undermined by the force of virtuous and strong character (for roots of the former sort of proposal, see Dennett 1984, and for one discussion of the latter type of proposal, see Nelkin 2011). Why would one think that actions 'driven by' (that is, 'necessitated in the context by') character are not free? The first pass suggestion is that such necessitation precludes the existence of alternative possibilities required by freedom. We emphasize that the view that freedom requires alternative possibilities does not presuppose any particular type of theory of freedom. The view is consistent with both compatibilist and incompatibilist positions on freedom (for discussion, see van Inwagen 2008). Why think that such character driven acts are acts for which the agent in question is responsible? The likely defense parallels that in the Frankfurt-style possibility explained above (he does so intentionally, because he wants to do so, and in the absence of outside pressures) and adds that an act that is character driven in this way is plausibly an expression of important facts about the agent in question's (metaphorical) identity. Again, such positions are controversial and we are not attempting to settle or even enter the debate here.

So far, we discussed what might be called substantive attempts to defend the claim that responsibility requires freedom. We close this section with a rather different approach one might take to this issue. This approach can be called a 'stipulative' approach to the issue. Robert Kane, though providing no citations, has noted that "[m]any philosophers actually define free will as the kind of freedom (whatever it may be) that is necessary [for] ... moral responsibility" and Kane calls such a stipulation "useful" for various purposes (Kane 2005: 80). If such a stipulation is introduced, it might seem that the question of the whether responsibility requires freedom is trivialized. If free will is just any notion of freedom necessary for responsibility, then it might seem that responsibility does indeed require freedom and that the issue of the relation between freedom and responsibility is settled quickly via stipulation. 
This, however, is not the case. After all, if there is no "kind of freedom" necessary for responsibility then the attempt to define free will in this way either fails or leads to the conclusion that there is no such thing as "free will" so defined. No mere stipulation can avoid these possibilities. We reject Kane's claim that such a stipulation is useful and think it is clearly a mistake to attempt to settle via stipulation the issue of the relation between responsibility and freedom. The earlier discussion in this section strongly suggests that the issue is a matter of substantive debate. A stipulation that one side of this debate is correct will not make that debate go away.

\section{Case Study}

We now consider, as a case study, one specific well-known account of responsibility: R. Jay Wallace's compatibilist account. We focus on Wallace's remarks in Responsibility and the Moral Sentiments (1994) as the main statement of his view and explore what the view implies about the relation between responsibility and freedom. We do not extensively critically assess the theory of responsibility itself. Our purpose is to show and explore some of the complexities that arise concerning the relationship between responsibility and freedom on this well worked-out theory of responsibility.

Wallace's account of responsibility foregrounds the role of Strawsonian reactive attitudes like guilt, indignation, and resentment. On Wallace's view, these attitudes are grounded in beliefs that the expectations-and in particular, the moral obligations- to which we hold persons have not been met. To hold someone responsible, on this view, is essentially to be subject to such attitudes and to express them in the form of sanctions. By the same token, to judge that someone is responsible is to judge that they or their actions are the appropriate object of such attitudes. Furthermore, the norms that govern the appropriateness of reactive attitudes are themselves moral norms. Hence, for Wallace, a person is morally responsible for an action if and only if it is fair to hold her responsible for that action. As a consequence of this approach, Wallace is concerned throughout with identifying principles of fairness that can explain and justify commonsense patterns of responsibility ascriptions.

Wallace distinguishes between two sorts of responsibility ascriptions. The first is moral accountability: a morally accountable agent is the sort of agent whose violation of moral obligations one accepts would render reactive emotions appropriate. The second is moral blameworthiness: a blameworthy agent is a morally accountable agent who is appropriately blamed for violating moral obligations we accept in a specific instance. Wallace identifies two conditions corresponding to these ascriptions that govern their appropriateness: an accountability condition ('A' condition) and a blameworthiness condition ('B' condition). On Wallace's view, an agent is morally accountable only if she possesses the power to grasp and apply moral reasons and the power to control or regulate her behavior in the light of such reasons. Wallace calls these powers the "powers of reflective self-control" (Wallace 1994: 157). An agent who is not morally accountable is, in Wallace's terminology, exempted from moral responsibility. An agent is appropriately blamed only if, in addition to possessing these powers, she intentionally violates a moral obligation to which we hold her. An agent is not blameworthy for $\Phi$-ing (despite being morally accountable for $\Phi$-ing) when she is excused.

As we have seen, Wallace's conception of responsibility is grounded in the practice of holding others responsible through the expression of reactive attitudes, and the conditions for fairly holding an agent responsible for some action are just that the agent is 
both accountable and blameworthy in acting. The main point of relevance to our case study can now be stated: nothing falls out of this general conception of moral responsibility about the relationship between moral responsibility and freedom or the nature of whatever freedom we may enjoy. Indeed, one of the primary burdens of Wallace's book is to substantively argue that neither accountability nor blameworthiness require incompatibilist freedom. In so doing, Wallace addresses the line of argument according to which what unifies standard excusing and exempting circumstances for moral responsibility is that they demonstrate that the agent could not have done otherwise. Since according to incompatibilists, determinism is incompatible with robust access to alternative possibilities, all agents would be either exempted or excused from moral responsibility if determinism were true. Wallace blocks this 'generalization' strategy by invoking his $\mathrm{A}$ - and B-conditions to explain exemptions and excuses. The satisfaction of the A- and B-conditions is not at all threatened by the truth of determinism, according to Wallace (although for critical discussion, see Haji 2002: 209). In the rest of the section, we will discuss Wallace's conditions and their relationship to freedom in more detail.

On Wallace's view, freedom is not required for moral responsibility: it is neither a necessary condition for being a responsible agent, nor a requirement for being appropriately blamed for some specific action (Wallace 1994: 3). Wallace's conception of freedom is what he calls "strong freedom of the will," by which he means "the kind of freedom [that] involves, roughly speaking, the availability of a range of alternative possibilities, holding fixed the laws of nature and the facts about the past" (1994: 230). He assumes that freedom so construed is incompatible with the truth of determinism, and argues that it is not necessary for responsibility. First, the crucial necessary condition for being a responsible agent involves the possession of certain general capacities-namely, powers to recognize and respond to moral reasons—and merely possessing these capacities does not require that an agent be able to do otherwise holding fixed the laws of nature and the past. Although Wallace does not give a detailed account of the relevant powers, nor of what it is to possess them, we might imagine an account along the lines of John Martin Fischer's "reasons-responsive mechanism” view (Fischer 2006). On this view, an agent possesses reasons-responsive powers just in case in a wide range of circumstances in which the agent's reasons were different than in the actual sequence, the agent would recognize these reasons and in at least some of these circumstances would respond appropriately. In other words, the possession of general powers might be cashed out in terms of a series of counterfactuals relating different sets of reasons for action (in Wallace's case, moral reasons) to different responses. As an account of the conditions for responsibility, this account does not require 'strong' freedom of will. It requires that the agent has the ability to do otherwise only given an alternative or counterfactual past in which the agent had different reasons than she, in fact, has, and it does not require that the agent has the ability to do otherwise than what she did in a specific instance. In addition, Wallace does not think that the powers of reflective self-control need to be acquired in any particular way in order to be responsibility-grounding.

Furthermore, Wallace's view is significantly less demanding than other compatibilist accounts of responsibility in not requiring that an agent's action either issued from the exercise of the relevant moral capacities in the actual sequence or could have issued from these capacities in alternative sequences at the time of action (for such a view, see Wolf 1990). Wallace's account does not require that for an agent to be responsible for $\Phi$-ing, she must have either exercised or had the ability to exercise 
reflective self-control in $\Phi$-ing or deciding to $\Phi$. Wallace's argument for this claim once again relies on our intuitions about moral exemptions. Agents are exempted from responsibility, Wallace argues, not because they lack the specific ability or opportunity to exercise their powers of reflective self-control at the time of action, but because they lacked the general capacities for reflective self-control. The specific ability requirement, if accepted, could motivate a stronger freedom condition: suppose that an agent $S$ had decisive moral reason not to $\Phi$ at $t$ and she $\Phi$-ed at $t$. If her moral responsibility for $\Phi$-ing requires that she was able to appropriately respond to her moral reasons at $t$, then it requires that she was able not to $\Phi$ at $t$. But this ability to do otherwise than what she did could entail an ability to access an alternative possibility holding fixed the past and the laws. Thus, by arguing against the requirement for a specific ability to exercise the moral powers, Wallace blocks one motivation for an incompatibilist freedom requirement.

If freedom of the will is not necessary as an 'A-condition' of responsibility, neither is it necessary as a 'B-condition' on Wallace's view. To be blameworthy for a specific action, Wallace claims, an agent needs only to have intentionally, or by choice, violated a moral obligation we accept. But agents can meet this condition without being free to do otherwise: to intentionally $\Phi$, it is not necessary that one was able not to $\Phi$. All that is required for blameworthiness is the capacity for agential choice, the exercise of that capacity, and a non-deviant causal connection between choice and action.

As we have seen, Wallace's claim that freedom of the will is not required for responsibility is motivated by his denial of the 'generalization strategy'. If non-freedom-requiring agential features can best explain why some agents are either exempted or excused from responsibility, the argument goes, then it is safe to conclude that non-freedom-requiring conditions are all that is needed for responsibility. This conclusion may be too hasty. Wallace's account of the excusing and exempting conditions, if correct, does not seem to establish the necessity and sufficiency of the relevant agential powers for responsibility. At best, it establishes only that these conditions are necessary. For this reason, it does not follow from Wallace's argument that 'strong' freedom of the will is not necessary for responsibility. Because his A- and B-conditions are merely necessary conditions for responsibility, there is logical space for, say, a libertarian account according to which Wallace's A-condition plus freedom of the will are jointly necessary and sufficient for moral accountability, or that Wallace's A-condition plus his B-condition plus freedom of the will are jointly necessary and sufficient for blameworthiness.

This is an instance of a more general point about the debate about freedom and responsibility: dialectically, those who deny that responsibility requires freedom need to argue that the conditions they offer on responsibility are sufficient, and not merely necessary, for moral responsibility. Without this, their account is simply silent on whether responsibility also requires freedom. Of course, to defend the additional claim that responsibility does require freedom requires an argument. And Wallace's point is that given his 'normative' account of responsibility, we do not have a source of intuitions relating freedom and responsibility that is independent of intuitions about excusing and exempting conditions that might give the freedom requirement purchase. Wallace takes this to raise a significant barrier for one wanting to defend the view that responsibility does require freedom.

It should be clear that nothing in Wallace's account rules out the possibility that agents sometimes or always have 'strong' freedom of the will, even supposing that free will is incompatible with determinism. His account does entail, however, that having 
free will is never itself sufficient for responsibility even if, as we suggested in the last section, we restrict the "freedom with respect to X entails responsibility for X" thesis to any $\mathrm{X}$ of moral significance. On his view, a hypothetical agent who acts freely even in the 'strong' sense but lacks the power to respond to moral reasons is not a responsible agent-not even the sort of agent whom it makes sense to hold responsible. Furthermore, a hypothetical agent who acts freely and with the power to respond to moral reasons but who acts unintentionally is excused from blame, despite the fact that she could have done otherwise.

Wallace's account of responsibility, then, is strictly committed to the claim that 'strong' freedom of the will is neither necessary nor sufficient for responsibility. However, his argumentative strategy leaves logical space for the necessity of freedom for responsibility. Moreover, nothing falls out of his theory about whether human agents sometimes or always enjoy strong freedom. The case study of Wallace illustrates some of the complexities of determining the relationship between responsibility and freedom within a particular theory.

\section{Moral Responsibility Equivocity}

Recent writers on responsibility have come to recognize a position noted in our opening section that we will call 'moral responsibility equivocity:' the claim that there are multiple 'senses' or 'conceptions' of responsibility. This raises the following possibility: if responsibility is an equivocal notion, then each sense of responsibility may exhibit a different relationship to freedom.

Gary Watson was one of the first writers to offer a sustained discussion of the different 'faces' of moral responsibility, and many others have employed his initial distinctions with significant modifications. We cannot do justice to all of the subtleties of these discussions here, so what follows is merely a broad outline of the conceptual terrain. Broadly speaking, moral responsibility has been distinguished into two kinds: attributability and accountability. For an agent to be morally responsible in the attributability sense for some action $\Phi$ is for the agent to be open to certain sorts of appraisals on account of $\Phi$. These appraisals are commonly called, after Watson, aretaic, and they are concerned with the agent's character (Shoemaker 2011), adopted ends and values (Fischer and Tognazzini 2011), or reason-based evaluative judgments (Smith 2008). The general idea is that an action is attributable to an agent when it is reflective of, because it flows from, the agent's practical identity: her commitments, values, cares, and the like. Aretaic appraisals evaluate those aspects of an agent's practical identity in terms of norms or standards of excellence in the relevant practical domains. Causal responsibility for an action is not sufficient for attributability-responsibility, since some actions may not reflect an agent's practical commitments-for example, involuntary actions. The aretaic appraisals that attributability-ascriptions license are normatively 'deeper' than appraisals of, for example, an agent's beauty because they concern aspects of her 'self' that determine the sorts of relationship we can have with her. So, for example, when I recognize that a certain action performed by an agent reflects the reasons the agent took to justify the action, my recognition of these reasons (and their divergence from the actual justifying reasons there are in that situation) may give me serious pause about whether or not to deal with the agent in various ways in the future. Finally, such appraisals might include moral predicates such as 'cruel,' 'malicious,' or 'selfish;' but they may also include non-moral predicates such as 'shoddy,' 'lazy,' and the like. 
In this sense, attributability-responsibility is a wider notion than, but includes, a kind of moral responsibility.

For an agent to be morally responsible in the accountability sense for $\Phi$ is for her to be a sensible target of moralized reactive attitudes on account of $\Phi$. When an agent is morally responsible for $\Phi$-ing in this sense, responding to the agent in certain ways—for example, by having and/or expressing indignation, resentment, anger-would be appropriate in principle. Attributability and accountability ascriptions can come apart for at least two sorts of reason. First, an agent's being attributability-responsible for an action or attitude does not entail that she is accountable for the action or attitude if there are no substantive moral duties, liabilities, etc., that govern the attitudes or conduct in question. Watson offers an illuminating example:

If someone betrays her ideals by choosing a dull but secure occupation in favor of a riskier but potentially more enriching one, or endangers something of deep importance to her life for trivial ends ... then she has acted badly—cowardly, self-indulgently, at least unwisely. But ... [u]nless we think that she is responsible to us or to others to live the best life she can—and that is a moral question-we do not think she is accountable here.

(Watson 1996: 231)

Watson's point is that a person's betrayal of her personal ideals may or may not count as a violation of an interpersonal moral norm, depending upon our operative moral theory. If it does not, then the agent is not a sensible target of the reactive attitudes in virtue of her betrayal: she is not accountable.

In the second sort of case, an action $\Phi$ may be attributable to an agent but she is not accountable for it because the appropriateness of the accountability ascription depends upon the agent possessing or exercising some powers or capacities that she lacks in the circumstances of her $\Phi$-ing. Here writers often focus on the case of psychopaths, as in David Shoemaker's discussion of moral responsibility:

[I]s [the psychopath] accountability-responsible? I do not believe so. To be accountability responsible is just to be susceptible for being the appropriate target of sanctions ... communicating relationship-defining demands. But the key moral relationship-defining demand - that you be sensitive to my interests-is simply lost on the psychopath ... The kind of moral address involved in holding someone accountable is thus pointless with respect to the psychopath.

(Shoemaker 2011: 629)

The point is that while the psychopath may be subject to various aretaic appraisals to the extent that his actions reflect his evaluative commitments and reason-grounded evaluative judgments, he may not be a sensible target of the reactive attitudes given his inability to respond appropriately to specifically moral reasons. A psychopath may be rightly appraised as cruel, cowardly, or self-indulgent-and we may be disposed to alter our relationship to him in various ways on the basis of these predications-even when he cannot respond to moral reasons.

There is, in addition, a third distinctive component of moral responsibility that we will call culpability. As with accountability, this notion also implicates the reactive attitudes. However, culpability goes beyond accountability in this sense: while 
accountability is concerned with whether an agent, in $\Phi$-ing, is a sensible target of the moralized reactive attitudes, culpability is concerned with whether we are justified, in the circumstances, in targeting the agent with any of the reactive attitudes or the various sanctions that express these attitudes on account of her $\Phi$-ing. An example might help illustrate the point.

Suppose Jones comes upon a car accident; the driver is unconscious. Being a member of the 'TV' generation, Jones expects the car to explode at any moment, and so he rushed to the driver and drags him clear of the wreck. The result: the driver is paralyzed for life (whereas he would not have been if Jones had left him where he was), and the car does not explode. Now, did Jones do wrong?

(Zimmerman 1988: 41)

Now, one possible reading of this case is that what Jones did was morally wrong, since believing that what you are doing is the right thing does not make it so, but that he ought to be excused from culpability because of his beliefs. To put the point in terms of our distinctions between senses of responsibility, Jones is accountability-responsible for his actions and their consequences just because he is the sort of agent that it makes sense to target with the reactive attitudes-unlike, for example, a dog, a psychopath, or a temporarily insane person. In addition, what Jones did falls within the domain of conduct governed by interpersonal moral duties. But because he is excused in virtue of his (let us suppose) false but justified beliefs, he does not deserve to be the target of the reactive attitudes. He is not, in other words, culpable for what he did. Further evidence of this distinction comes from cases like that of Robert Harris, a severely abused child turned adult murderer. Gary Watson argues convincingly that such cases demonstrate the sensitivity of our reactive attitudes to factors like abusive childhoods. One way to understand such cases is in terms of the distinction between accountability and culpability. While killers like Harris exercise the capacities that make them sensible targets for the reactive attitudes, their formative circumstances render them at least less culpable for their actions (for discussion of further possible distinctions within the general notion of culpability, see Fischer and Tognazzini 2011).

We have then, perhaps, three distinct and independent notions of responsibility. The important point for our discussion is that each distinctive conception of responsibility may have different conditions of successful ascription, including conditions pertaining to freedom. For example, Watson argues that because culpability-ascriptions-as distinct from attributability or accountability ascriptions-license the "imposition of demands on people" - demands that are often adverse and unwelcome-it is "unfair to impose sanctions upon people unless they have a reasonable opportunity to avoid incurring them" (Watson 1996: 237). This leads him to postulate a requirement on responsibility that the agent had a reasonable opportunity to have done otherwise. It is unfair, Watson argues, to target agents with the reactive attitudes or related sanctions if they couldn't have avoided performing the morally objectionable act. One might argue that avoidability requires the ability to do otherwise, and further argue that such an ability is incompatible with determinism. One could hold all of this while still believing that accountability and attributability ascriptions do not require avoidability, and that such ascriptions are independent of any notion of freedom. Perhaps all that is required for successful attributability- and accountability-ascriptions is the possession and/or 
exercise of various agential capacities under the circumstances of action, and not the ability to do otherwise at the time of action or that the action can be causally traced to some antecedent free choice.

Another possibility here, however, is that the three allegedly distinct notions we have identified are not wholly independent. It is plausible, for example, that these notions of responsibility are not logically unconnected: in particular, we think it likely that culpability-responsibility entails both accountability-responsibility and attributability-responsibility (although for an opposing view, see Scanlon 1998: Chapter 6). After all, how can an agent be an appropriate target of reactive attitudes in virtue of $\Phi$-ing unless her $\Phi$-ing reflected the agent's practical identity and her powers to respond to moral reasons and fell within a domain of conduct governed by interpersonal moral norms?

One agreeing with the above observation might push for further connections between these notions of responsibility and freedom. For example, a theorist who requires Wallace's "strong" freedom for mere attributability-responsibility may be committed to such a freedom condition for all three forms of moral responsibility. Peter Vallentyne appears to be one such theorist, at least with respect to attributability-responsibility for morally bad outcomes. Vallentyne argues that attributability-responsibility requires that the outcome must be suitably causally related to at least one of the agent's choices (Vallentyne 2008: 62). In addition, his conception of causal relation is that the choice increases the objective chance that the outcome will occur. On Vallentyne's understanding of this conception, if a choice was determined by prior events, then the agent is not responsible for any outcome in virtue of that choice. Hence, his chance-increasing conception of the causal condition of attributability-responsibility entails a freedom requirement on both accountability-responsibility and culpability given that attributabilityresponsibility is necessary for both.

The previous two paragraphs illustrate at least the following three points. First, we see that that moral responsibility equivocity raises the possibility that various distinct notions of responsibility relate differently to freedom. Second, we see that (arguable) formal relations between various notions of responsibility may imply that even distinct notions of responsibility stand in the same relationship to freedom. Third, we see that within debates about whether responsibility is an equivocal notion, further debates about the relation between various notions of responsibility and freedom remain complex.

\section{References}

Dennett, D. (1984) Elbow Room: Varieties of Free Will Worth Wanting. Cambridge: MIT Press.

Fischer, J.M. (2006) My Way: Essays on Moral Responsibility. New York: Oxford University Press.

Fischer, J.M. and Tognazzini, N. (2011) "The Physiognomy of Responsibility," Philosophy and Phenomenological Research 82: 381-417.

Haji, I. (2002) "Compatibilist Views of Freedom and Responsibility," in R. Kane (ed.), The Oxford Handbook of Free Will. New York: Oxford University Press.

Kane, R. (2005) A Contemporary Introduction to Free Will. New York: Oxford University Press.

Nelkin, D.K. (2011) Making Sense of Freedom and Responsibility. New York: Oxford University Press.

Scanlon, T.M. (1998) What We Owe to Each Other. Cambridge: Harvard University Press.

Shoemaker, D. (2011) "Attributability, Answerability, and Accountability: Toward a Wider Theory of Moral Responsibility," Ethics 121: 602-32.

Smith, A. (2008) "Control, Responsibility, and Moral Assessment," Philosophical Studies 138: 367-92.

Vallentyne, P. (2008) "Brute Luck and Responsibility," Politics, Philosophy and Economics 7: 57-80. 
van Inwagen, P. (2008) "How to Think about the Problem of Free Will," Journal of Ethics 12: 327-41.

Wallace, R.J. (1994) Responsibility and the Moral Sentiments. Cambridge: Harvard University Press.

Warfield, T. (2007) "Metaphysical Compatibilism's Appropriation of Frankfurt," Oxford Studies in Metaphysics 3: 283-95.

Watson, G. (1996) "Two Faces of Responsibility," Philosophical Topics 24: 227-48.

Wolf, S. (1990) Freedom Within Reason. New York: Oxford University Press.

Zimmerman, M. (1988) An Essay on Moral Responsibility. Totowa: Rowman \& Littlefield.

\section{Further Reading}

Clarke, R., McKenna, M., and Smith, A. (eds) (2015) The Nature of Moral Responsibility: New Essays. Oxford: Oxford University Press. (Collection of new professional-level essays on various topics concerning moral responsibility.)

Talbert, M. (2016) Moral Responsibility: An Introduction. Malden: Polity Press. (Compact survey of moral responsibility and related topics suitable for students and those new to the field.)

Vargas, M. (2013) Building Better Beings: A Theory of Moral Responsibility. Oxford: Oxford University Press. (Important contribution to discussion of moral responsibility and its relation to free will.)

\section{Related Topics}

Reasons-Responsive Views

Free Will and Moral Sentiments: Strawsonian Views

Frankfurt-Style Examples

Blame

Marginal Agents and Responsibility Pluralism 


\section{5}

\section{A FEMINIST APPROACH TO MORAL RESPONSIBILITY}

\section{Marina Oshana}

\section{Introduction}

The task of this chapter is to make headway toward a feminist, or feminist friendly, account of moral responsibility. One might question why a feminist account would be needed or useful. After all, there are a number of accounts of responsibility currently on offer, and I will spend some time rehearsing these. However, I believe a feminist account would go deeper than current accounts in key respects. To anticipate, a feminist account would approach questions about moral responsibility, and responsibility more generally, from a vantage point that broadens the foci of responsibility beyond concerns about the free will of the actor or concerns about the psychological control condition for responsible agency, as is customarily the case. A feminist account would be more attentive to the socio-relational circumstances that shape the aretaic profilethe character and the values - of a potential responsible party. A feminist account would be less inclined to emphasize the deployment of principles of rationality in moral reasoning. A feminist would question the effectiveness and the propriety of a perspective of impartiality at various stages: in assessing desert, attributing fault, and in demanding an account from the responsible party. All told, a feminist account of responsibility would most likely be holistic in its treatment of the responsible subject, and relational in its treatment of the conditions for accountability and answerability. These conditions rest at the heart of our concept of responsibility and at the heart of our responsibility practices.

In the first section of this chapter, I will offer preliminary answers to two familiar questions. They are, "What does it take it be a responsible agent?" and "What is involved in holding a person responsible?" The answers I offer draw on work I have done on the topic as well as from accounts that have become classic in the contemporary literature. Section two will mine work that has been done in feminist social epistemology for insights into what these accounts of knowledge acquisition and epistemic responsibility can suggest about moral responsibility. In section three, I will suggest some lessons we might draw from feminist jurisprudence. 


\section{Classic Accounts of Responsibility}

\section{Control and Epistemic Competence}

What does it take it be a responsible agent? To answer, notice that legal and moral contexts treat ascriptions of responsibility essentially as attributions; as designations of a particular legal or moral status. The designation relies on assumptions about what it is to be a responsible agent, and will appeal to some theory about what it means to attribute an act, choice, trait of character, quality of will, virtue or vice to someone such that she bears responsibility for it. One assumption is that the actor is an agent. An agent is someone capable of deliberation and intentional action, and is capable of instituting standards of conduct for herself. A second assumption is that behavior for which the agent is responsible must be behavior formed by or due somehow to the agent rather than induced in the agent. Specifically, one who is a responsible agent must exercise (some type of) authority over what she is to do, and she must (in some sense) direct her behavior. The task is to specify what type of authority and what sense of direction is required, but the point of these two assumptions is just that, when an attribution of responsibility is made, the actor has exhibited control.

Adapting a distinction originally advanced by John Martin Fischer and Mark Ravizza (1998), I will stipulate that an agent is thought to possess legislative control when her mental states, her actions, and her traits of character and such originate in intentional choice and when they are authentic to the agent; that is, expressive of her values, interests, and defining commitments. Evidence of executive control appears in the type of mechanism, such as practical reflection, from which the person's action arises; it appears in the causal history leading up to the action performed; and it is evident in the 'non-alien' (for want of a better term) quality of the mechanism that drives action. ${ }^{1}$ The former speaks to control over what to do; the latter, over control in so doing.

There is some debate about what constitutes an alien mechanism. Frankfurtians hold that a mechanism will be alien to the actor when it is one which the actor rejects as her will or spring to action. My view is that a mechanism is alien (and enervates executive control) when it is sufficient to override the will of the person, whether she desires it or not. Key to executive control is a history in which phenomena such as coercion, manipulation, and intimidation as well as assorted deviant environmental and psychological phenomena play no guiding role in the agent's action (or, if they play a role, this role is overdetermined by the will of the agent). Equally precluded are internal conditions that might debilitate the resolve of the actor. One who is susceptible to psychosis or phobias, or who is the target of intimidation or of the devious tactics of others, may be a responsible agent but one whom we excuse from responsibility on those occasions when it is apparent that elements alien to the actor in the sense defined above functioned as the principal mechanisms driving the agent's behavior.

Assumptions about the epistemic abilities of the agent are made as well when an attribution of responsibility is made. We assume the agent is epistemically competent. Epistemic competence guarantees, among other things, (i) that the responsible party is aware of herself as an agent; (ii) that she is aware of herself as someone with a distinguishing identity; and (iii) that she is familiar with the moral standards to which she and those with whom she interacts are held. The responsible actor grasps, even if she refuses to abide by, the normative import of her conduct. 
The requirements of control and of competence I have described so far are all, arguably, of a non-metaphysically demanding sort. I say 'arguably' because some philosophers charge that these conditions demand the fulfillment of the principle of alternate possibilities, viz., a person is responsible for what she has done only if she was free at the time to do otherwise, where freedom to do otherwise allegedly necessitates the falsity of causal determinism. However, a large number of philosophers emphasize that the control needed for responsible agency is control of a compatibilist variety. ${ }^{2}$ The most influential of these accounts have been P.F. Strawson's (1962) expressivist account and Harry Frankfurt's (1988) neo-Humean, psychologistic account of free agency. These have, very roughly, informed two trajectories for exploring the phenomenon of responsibility in ways that depend little on metaphysical presuppositions about the truth or falsity of causal determinism. Accounts of the Frankfurtian mold allow that responsibility is consistent with the possibility of a causally determined world, even if robust alternatives for action in the form of metaphysical freedom to do otherwise are not. What such accounts seek, instead, is positive evidence that choice and action are 'authentic;' authenticity is signaled by the actor's identification with or lack of repudiation of her reasons for action. Authenticity is standardly verified by the absence of psychological, physical, and environmental impedimenta (neurosis, psychic dissonance, wantonness). Many broadly Frankfurtian accounts focus critically on the suggestion of a 'real-self' and on the concerns that define the actor and that serve as the foundation of her actions as decisive of responsible agency (Watson 1975; Wolf 1987). Broadly Strawsonian accounts look to the responsiveness capabilities of putative agents (Wallace 1994). Philosophers who locate elements of both in their work include Gary Watson (1996) and Angela Smith (2005, 2012).

\section{Attributability and Character}

Once the conditions of control have been set, further refinements are expected. One suggestion is that responsibility is primarily a form of attribution. Gary Watson has pressed this view, arguing that the "notion of responsibility central to ethical life and ethical appraisal" is concerned with conduct that reveals a person's evaluative allegiances (1996: 229). A person can be held responsible if her behavior can be attributed to "those principles and ends which [the agent]—in a cool and non-self-deceptive moment-articulates as definitive of the good, fulfilling, and defensible life" (1975: 105, 106). To be attributed with responsibility is to be recognized as an agent "in the strong sense" - that is, as an individual with a moral capacity to "adopt certain ends among others" as one's own and thus "to declare what one stands for" (1996: 233). In this manner, the agent "is in an important sense answerable for what she does" (1996: 229).

To simplify, to be attributable-responsible is to have judgments made about one's moral character based on the evaluative attitudes that frame one's conduct. By itself, a judgment of attributability fails to provide all that we require of an account of responsibility. Attribution of an evaluative profile does not amount to an attribution of fault, blame, or liability, although attributability-responsibility typically serves as a first step toward justified blame (and praise). Watson agrees: the other face of responsibility, viz., the accountability face, appears when sanctions are fairly applied. While some philosophers contend that attributability implies answerability for those attitudes that are 'rationally related' to the actor's character and will (Smith 2005), their view is that a judgment of attributability need not be accompanied by the expectation that an explanation of the act in question is forthcoming. ${ }^{3}$ 


\section{Accountability ${ }^{4}$}

I think answerability does carry such an expectation. This is because I regard answerability as tantamount to accountability, and because I regard accountability, which carries this expectation, as key to ascriptions of responsibility. To respond to the second question I posed at the start, holding accountable is what we are doing when we hold a person responsible. When we claim a person to be morally responsible, we are declaring that the person should explain her intentions (or at least her beliefs) about her behavior in a way that makes contact with the morally (or more generally normative) dimensions of the action. Holding persons accountable is a social exercise of ascribing and of taking on responsibility. Where a person is accountable-morally, legally, or practically-it is assumed that the person can offer an explanation of her intentions or beliefs about her behavior at issue. Accountability is a capability of the responsible agent; to be responsible a person must be capable of a type of interlocution. It is typically assumed, as well, that the person ought to offer an explanation of her intentions or beliefs about her behavior. An account ought to be forthcoming because expectations about the interlocutionary and normative competencies of the agent have been antecedently verified. It has been determined that the agent is attentive (or can be attentive) to reasons in support of or in opposition to the activity for which responsibility is alleged. These reasons are interpersonally salient, and we see that the agent recognizes them as such. Ideally, they are reasons that the accountable agent as well as others in the moral community are disposed to take as directives for action. That she recognizes them as interpersonally salient is apparent in the agent's ability, if not her inclination, to converse with persons other than herself about the normative merit of her actions. Someone who is insensible to common moral feeling or whose moral sensitivity is highly erratic lacks immersion in the common experience accountability requires.

What preempts responsibility in a direct way, then, is not causal determinism but a failure of moral sensitivity exemplified by a failure of responsiveness. Receptivity and responsiveness give substance to the control and epistemic competence conditions sketched above. Now, it may turn out that metaphysical phenomena beyond the reach of the actor decide whether a person meets or fails to meet the epistemic and control conditions. In the end, metaphysical phenomena might preempt responsibility. My point is the simple one that questions of accountability arise due to questions about the capabilities of the actor to notice what is of moral consequence and to be able to provide a response in light of what is of moral consequence. These questions do not (as a rule) arise because we fear that some metaphysical constraint has been violated. We do want to know that occurrences ordinarily taken to undercut responsibility (such as coercion, deception, non-culpable ignorance, and psychosis) occupy no principal role in the origin of a person's decision and action. But typically, we are not looking for evidence that will corroborate or refute the metaphysical thesis of causal determinism, and our interest typically is not to explore the metaphysical character of a person's capacity or lack of capacity for accountability.

\section{Feminist Epistemology and Responsible Agency}

The analysis of responsibility sketched above lends itself to feminist interpretation and refinement. A feminist account would take the ability (and, hopefully, the inclination) to attend to the salience of interpersonal norms of conduct and to display an 
appropriate level of dialogical engagement pertaining to these norms as an expression of the idea that responsibility is a phenomenon that can only be assessed contextually against publically shared suppositions about our relationships with others.

The obvious place to begin for casting a broadly feminist light upon questions of responsibility is care-based feminist ethics. The tradition originated in the work of eighteenthand nineteenth-century feminists such as Mary Wollstonecraft, John Stuart Mill, and Charlotte Perkins Gilman. These scholars, to quote Rosemarie Tong and Nancy Williams:

...challenged the ontological presupposition that the more separate the self is from others, the more fully-developed that self is. They also questioned the presupposition that the more universal, abstract, impartial, and rational knowledge is, the more closely it mirrors reality. In place of these presuppositions, decidedly present in most traditional ethics, they instead suggested the ontological assumption that the more connected the self is to others, the better the self is. They also offered the epistemological presupposition that the more particular, concrete, partial, and emotional knowledge is, the more likely it represents the way in which people actually experience the world.

(Tong and Williams 2014)

In what follows, I will focus on how the ethics of care has altered philosophical discourse in the area of moral epistemology. The epistemological presuppositions noted by Tong and Williams bear upon the feminist approach to responsibility I am proposing. Among the questions we need to answer are questions about the content of knowledge required for responsible agency: If a person is to be held accountable, what must the person know or be capable of knowing? What is it that a person should be aware of if the person is to have moral and practical knowledge? There are, in addition, questions to be asked about knowledge acquisition: What are the right, or best, ways of acquiring moral knowledge of a sort requisite to being responsible and to holding responsible? Finally, there are questions to be asked about the epistemic environment: What must conditions on the ground be like in order to develop the faculties for being responsible?

Headway on the first and second questions can be achieved by heeding a remark made by Maggie Little. Little observes that "The attentiveness necessary to good moral judgment is best ensured ... when we care, not simply about impersonal moral ideals such as justice, but about people themselves" (1995: 123). Moreover, Little contends, "possession of certain desires and emotions turns out to be a necessary condition of discerning moral properties" (1995: 125). Indeed:

Affect ... is crucial to moral knowledge, and in two independent ways. First, given our human epistemic limitations, caring for recognizably moral ends is crucial to being attentive to the morally salient details of the situations we face. This is an important point in its own right. For even if the ideal epistemic stance turns out to be a dispassionate one, we will not make the (oddly common) fallacy of taking features of the ideal as direct guides to what we should strive for. (Sometimes getting better means cultivating precisely those features not found in the ideal.) Second, possessing appropriate affect turns out to be a necessary precondition for seeing the moral landscape. This need not render morality some poor second cousin to science, for affect may be revealing of truth.

(Little 1995: 133) 
Little's position is that affect is constitutive of one's ability to properly perceive the moral landscape; affect does not merely smooth the function of an extant ability. Here we have a sense of what a feminist ethic of care would say in response to the questions of what a responsible agent must know, and about how such knowledge is obtained. A responsible agent must attend in a heightened way to the beings upon whom her actions and choices have effect. Absent affective perception, Little worries that we allow into the moral fold "creatures who fully apprehend the moral landscape-who gaze intelligibly at the moral order, in all its glory-and yet never respond as merited" (1995: 128). Little is right that we not allow outright amoralists into the fold, but surely her point is the stronger one that we must expect of morally competent, and usually compassionate, beings such as ourselves a great deal more. Her point is that it is not enough that we deliberate well, or that we grasp moral principles and ideals. We cannot know what morality requires of us (especially what it requires of us as accountable persons) absent proper affective understanding. A feminist approach would call attention to valuable epistemic devices such as emotional response (Little mentions "care, concern, love, but also anger, revulsion, indignation;" 1995: 118), all of which serve as forms of perception that enable us to better understand and to more completely apprehend details of the moral terrain. These devices do not obscure what is morally relevant but make what is morally relevant apparent. A feminist approach would ask us to rethink the conditions for epistemic competence-for what count as the morally salient elements of a situation and for what receptivity and responsiveness to these include.

Admittedly, engaged and particularized listening from a stance of caring is far more demanding an epistemic practice than that to which we have grown accustomed, and that we take as adequate for the purpose of assessments of responsibility. If Little's take on moral epistemology is correct-I find it intriguing - then knowing what is required of us as moral and responsible beings forces us to a level of thoughtfulness and sensitivity that we may find uncomfortably intrusive. Cultivating epistemic competence would mean cultivating empathic perception. Within the practice of holding accountable, we would be asked to attend more closely to the subjective narrative of actor and perhaps to adapt our expectations for what constitutes a satisfactory account-one that would generate forgiveness, restore moral order, exculpate the actor, and so forth-to the particular dimensions of the relationship. No one-size-fits-all set of criteria for satisfaction of the accountability expectation and for moral assessment more generally would be at our disposal. If this generous stance is a recommendation from feminist ethics worth absorbing into our responsibility practices, we may wish to extend it no further than to members of our intimate social circle. Fair play, however, may oblige otherwise. ${ }^{6}$

One might object that we need not cast any of this as a feminist analysis of moral knowledge. We could describe Little's arguments as insights into a broader problem of epistemic disparity and treat a revised analysis of the conditions of responsible agency as a way of blunting the force of this disparity. This invites the third question, about the epistemic environment, posed above. As Miranda Fricker has argued (2006, 2007), socially privileged people are often regarded as having greater moral authority given their dominance in public life. Others (minorities, women, workers, etc.) have 'credibility deficits,' the result of which is that the former are believed, incorrectly, to have a better grasp of the morally salient features of a situation. We would do well to bear in mind that our own perceptual position regarding moral matters is not authoritative by default. 
So perhaps assessing the conditions of responsible agency would oblige us to be more alert to what Fricker calls power imbalances in the economies of identity-power and of credibility. The conditions for moral accountability we have considered rely on background assumptions about the credibility and testimonial trustworthiness of the accountable party. These assumptions are often framed in light of unconscious prejudices or schemas, shared quasi-perceptual representations of individuals or groups of people and of the characteristics associated with them. Many of these schemas are affiliated with morally and socially significant dimensions of life, which are essential to the social identity of the subject. Testimonial injustice results when a person's epistemic credibility is linked to a prejudice that "tracks the subject through different dimensions of social activity" (Fricker 2007: 27). The primary harm of testimonial injustice is that subjects are degraded in their capacity as knowers, as givers of knowledge, and, at root, as distinctively human $(2007: 44,54)$. Notably, the subject of the injustice suffers a loss of credibility as a responsible agent.?

Rethinking responsible agency along feminist or more broadly socially relational lines means that we need to take pains to ensure that any judgments we make about the credibility of a potentially responsible party be sensitized to prejudicial imbalances of the sort that make testimonial injustice probable. In addition, it means heeding the fact that one of the chief constituents of responsible agency is the capacity for self-understanding or self-knowledge, and as we know—or ought to know-self-knowledge is socially mediated. It counsels careful attention to the fact that attributions of responsibility and interlocutionary practices of expectation, account, and response transpire within a climate in which "some social groups are unable to dissent from distorted understandings of their social experiences" (Fricker 2006: 96). At its worst, epistemic injustice poisons the entire landscape for moral epistemic development and for our understanding of what is involved in assessments of responsible agency. It constitutes a social injustice "that undermines the subject in his capacity as an interpreter of his own social experience, in his capacity, that is, for social self-knowledge" (2006: 108). In addition to disabling the cognitive powers and moral agency of the subject of injustice, such injustices place us all "at risk of failing to develop the complex cognitive and moral virtues of fair-mindedness, impartiality, and the ability to sort relevant evidence from irrelevant evidence when making credibility assessments" (Marsh 2011: 287).

\section{Feminist Juridical Notion of Responsibility as a Function of Duties and of Rights}

Let us turn to the insight an account of responsible agency might glean from work done in feminist legal theory on the nature of rights and responsibilities. We are responsible for our decisions and actions, but so many of these link us to various others in countless ways, some of which are inescapably moral. Martha Minow and Mary Shanley argue for a theory of relational rights and responsibilities that would better capture "relationships of moral connection" than would a classically liberal theory of rights that highlights individual freedoms (Minow and Shanley 1996: 19).

There is certainly much to value in a rights based approach to law and to moral responsibility. A rights based approach ideally works to protect diverse individuals from social discrimination, and promises to safeguard fundamental liberties. I do not wish to deny this value. A feminist account of responsibility could accept such an account, suitably amended. For instance, Minow and Shanley reject a contractualist picture of 
social rights and responsibilities, arguing that it is empirically misguided to restrict the idea of the responsible subject to "that of a self-possessing individual linked to others only by agreement" (Minow and Shanley 1996: 12). Rather:

A conception of relational rights and responsibilities ... would view rights as claims grounded in and arising from human relationships of varying degrees of intimacy ... The issues for resolution thus are not simply the rights of adults who entered a contract, nor of community standards about contracts in such circumstances, but the moral and psychological dimensions of persons whose claims arise out of actual and potential relationships.

(Minow and Shanley 1996: 23, 24)

A feminist account of responsibility would be congenial to treating rights and liberties as goods embedded in particular relations. Just as family law must come to regard "people simultaneously as individuals and as persons deeply involved in relationships of interdependency and mutual responsibility" (1996: 6), so too must an adequate account of moral responsibility. For example, an adequate account of moral responsibility would have to attend to what it means to be a responsible agent within the familial and marital context. What moral norms must that responsible agent be familiar with? What freedom or authority must that agent wield? What kinds of reasons can we expect that agent to take up as justificatory and motivational? What asymmetries of power (some warranted, others not) are found in relations of this particular sort?

\section{Conclusion}

In conclusion, I have suggested that a feminist approach to responsibility would be relational and not disproportionately individualistic. Attribution and accountability are socially mediated practices. A feminist account of the freedoms required for responsible agency would not rest content with the old liberal saws of 'freedom to do otherwise' and freedom from interference or with freedom to act in a way that expresses one's defining evaluative commitments. Rather, the freedom sought will be freedom contextualized to the complex social relationships that define our lives. Perhaps the language of rights would play a diminished role in such an account. For the most part, a feminist account of responsible agency would look outside the box.

\section{Notes}

1 Fischer and Ravizza (1998) contrast regulative control which requires the ability freely to do X or Y, and thus calls for alternative possibilities, and guidance control, which is the ability freely to instigate action by taking ownership of the action. The latter is compatible with causal determinism. I develop the distinction between legislative and executive control in Oshana (2004).

3 Not all non-metaphysical accounts are explicitly compatibilist. Strawson is arguably neutral between compatibilism and incompatibilism.

3 For Smith, accountability is an enhanced species of answerability: Answerability for $\Phi$ turns on the fact that $\Phi$ is connected to the actor's core evaluative judgments, for these convey reasons the actor takes to justify her actions. To be accountable, Smith argues, signals the further and distinct idea that the actor is open to sanction and is, perhaps, susceptible to being called to account publically for her behavior because the actor has flouted a relationship-defining demand, or because a claim to good will has been overlooked. Smith (2012) and David Shoemaker (2011) debate whether these represent facets of one account of responsibility or are distinct types of responsibility. 
4 Borrowed from Oshana (2010: Chapter 4).

5 Space precludes a satisfyingly thorough exploration of these questions. For further discussion, see Oshana (forthcoming).

6 I am not suggesting Little would agree. Little allows that the requisite level of attentiveness and the scope of details to which one does (and should?) attend largely "reflects one's interests, desires, in brief, what one cares about" (1995: 122). The level of caring attention I rightly direct to the moral features of my child's circumstances will be greater-one would hope — than that I direct to the circumstances of a stranger.

7 Gerald Marsh (2011) argues this.

\section{References}

Fischer, J.M. and Ravizza, M. (1998) Responsibility and Control. Cambridge: Cambridge University Press.

Frankfurt, H. (1988) "Alternate Possibilities and Moral Responsibility," in H. Frankfurt, The Importance of What We Care About. Cambridge: Cambridge University Press, pp. 1-10.

Fricker, M. (2006) "Powerlessness and Social Interpretation," Episteme: A Journal of Social Epistemology 3: $96-108$.

Fricker, M. (2007) Epistemic Injustice: Power and the Ethics of Knowing. Oxford: Oxford University Press.

Little, M.O. (1995) "Seeing and Caring: The Role of Affect in Feminist Moral Epistemology," Hypatia 10: $117-37$.

Marsh, G. (2011) "Trust, Testimony, and Prejudice in the Credibility Economy," Hypatia 26: 280-93.

Minow, M. and Shanley, M. (1996) "Relational Rights and Responsibilities: Revisioning the Family in Liberal Political Theory and Law," Hypatia 11: 4-29.

Oshana, M. (2004) "Moral Accountability," Philosophical Topics 32: 255-74.

Oshana, M. (2010) The Importance of How We See Ourselves: Self-Understanding and Responsible Agency. Lanham: Rowman and Littlefield.

Oshana, M. (forthcoming) "What might a social theory of responsibility look like?" in K. Hutchinson, C. Mackenzie, and M. Oshana (eds), The Social Dimensions of Moral Responsibility.

Shoemaker, D. (2011) "Attributability, Answerability, and Accountability: Toward a Wider Theory of Moral Responsibility,” Ethics 121: 602-32.

Smith, A. (2005) "Responsibility for Attitudes: Activity and Passivity in Mental Life," Ethics 115: 236-71.

Smith, A. (2012) "Attributability, Answerability, and Accountability: In Defense of a Unified Account," Ethics 122: 575-89.

Strawson, P.F. (1962) "Freedom and Resentment," Proceedings of the British Academy 48: 1-25.

Tong, R. and Williams, N. (2014) "Feminist Ethics," The Stanford Encyclopedia of Philosophy (Fall 2014 Edition), E.N. Zalta (ed.), available from: http://plato.stanford.edu/archives/fall2014/entries/feminismethics/ (accessed 24 June 2016).

Wallace, R.J. (1994) Responsibility and the Moral Sentiments. Harvard: Harvard University Press.

Watson, G. (1975) "Free Agency," Journal of Philosophy 72: 205-20.

Watson, G. (1996) "Two Faces of Responsibility," Philosophical Topics 24: 227-48.

Wolf, S. (1987) "Sanity and the Metaphysics of Responsibility," in F. Schoeman (ed.), Responsibility, Character and the Emotions. New York: Cambridge University Press, pp. 46-62.

\section{Further Reading}

Anderson, E. (1995) "Feminist Epistemology: An Interpretation and Defense," Hypatia 10: 50-84. (An influential paper explaining feminist epistemology as the domain of social epistemology concerned with the impact "of socially constructed conceptions and norms of gender and gender-specific interests and experiences on the production of knowledge" [1995: 54].)

Antony, L. and Witt, C. (eds) (1993) A Mind of One's Own: Feminist Essays on Reason and Objectivity. Boulder: Westview. (The seminal collection of papers addressing the role that objectivity and rationality have traditionally played in philosophical thought and practice.)

Grasswick, H. (2012) "Knowing Moral Agents," in S.L. Crasnow and A.M. Superson (eds), Out from the Shadows: Analytical Feminist Contributions to Traditional Philosophy. Oxford: Oxford University Press, pp. 307-38. (A noteworthy treatment of the socially interactive dimensions of knowledge acquisition in the context of moral inquiry. Grasswick argues that moral knowledge does not consist in just a grasp of 


\section{MARINA OSHANA}

moral principles but involves the "cultivation of perceptual skill" and is dependent on facts about our embeddedness in communities, our use of language, and our shared values and practices.)

Jones, K. (2012) "Emotional Rationality as Practical Rationality," in S.L. Crasnow and A.M. Superson (eds), Out from the Shadows: Analytical Feminist Contributions to Traditional Philosophy. Oxford: Oxford University Press, pp. 333-52. (An insightful and innovative argument for the role emotions play in solving the problem of how to frame practical deliberations and properly utilize "reason giving considerations" salient to one's situation.)

Walker, M.U. (2007) Moral Understandings: A Feminist Study in Ethics, 2nd edn. New York: Oxford University Press. (A widely cited, critical study of the ineluctable force that socially constructed relationships of status, political power, and history have upon moral theory, moral knowledge, and our practices of moral responsibility.)

\section{Related Topics}

Semicompatibilism

Identification Views

Reasons-Responsive Views

The Relationship between Moral Responsibility and Freedom 


\section{6 \\ FREE WILL AND THE PHENOMENOLOGY OF AGENCY \\ Tim Bayne}

\section{Introduction}

For most of the twentieth Century, questions concerning free will were approached from the perspective of metaphysics and the philosophy of language, and the conscious aspects of free agency—what it's like to experience oneself as a free agent-received cursory attention at best. Things have changed over the last decade or so, and there is now a lively and rapidly growing literature devoted to questions that lie at the interface between the phenomenology of agency and accounts of free will.

Four sets of questions dominate this debate. The first set of questions are analytical in focus. What exactly is the phenomenology of agency? Does it have representational content? If so, what is its content? The second set of questions concern etiological matters. What gives rise to the phenomenology of agency? What role might the phenomenology of agency play in accounting for folk conceptions of free will? The third set of questions are epistemic. What role might the phenomenology of agency play in justifying claims about the existence of free will? And the fourth set of questions are concerned with constitutive matters. Might the phenomenology of agency be necessary for free will in some way?

\section{Analytical Questions}

Our everyday perspective on agency involves both beliefs and experiences (Bayne and Pacherie 2007). Not only do I believe that I am the agent responsible for the production of these sentences, I also experience myself as the agent responsible for their production. Although questions concerning the nature of folk psychological beliefs regarding agency are not irrelevant here, our present focus is on agentive experience.

The literature on agentive experience contains references to many kinds of conscious states, including (among many others) 'the experience of deliberation,' 'the experience of decision-making,' 'the experience of intentionality,' 'the experience of mental causation,' 'the sense of control,' 'the sense of effort,' the experience of choice,' and, of course, the 'experience of freedom' (Wakefield and Dreyfus 1991; Bayne 2008; Horgan et al. 2003; Nahmias et al. 2004; Pacherie 2008). Just how these various terms are 
related to each other is something of a vexed question. What is clear, however, is that at the heart of the relationship between free will and the phenomenology of agency is the phenomenology (or experience) of freedom.

We can begin by distinguishing a background phenomenology of freedom from a focal phenomenology of freedom. The background phenomenology of freedom is arguably a fairly ubiquitous, albeit recessive, component of one's everyday conscious experience. It involves the sense that one is an agent with the capacity to exert a significant amount of control over one's mental and physical environment. One can enjoy experiences of this kind even when one is not acting. Although it is not without interest, the literature on the phenomenology of free will has paid relatively little attention to the background phenomenology of freedom, and has instead concentrated on focal experiences of freedom. Such experiences arise in contexts of deliberation and decision-making, and-to a first approximation-are characterized by the sense that one is now 'making up one's mind'- that one has the power to settle matters that are currently open.

Why think that our awareness of freedom is really experiential as opposed to taking the form of a purely cognitive state such as a judgment? The answer is provided by considering a free will sceptic — that is, someone who believes that they do not meet the conditions required for the possession of free will (whatever they might be). It seems perfectly conceivable that such a person might nonetheless experience themselves as exercising free will.

Not only does this consideration motivate the idea that there is a phenomenology of freedom, it also motivates the idea that the phenomenology of freedom has representational content. (Indeed, it also motivates the idea that the phenomenology of freedom is at least somewhat independent of belief.) Experiences of freedom are not 'raw feels' that are merely caused by or correlated with (putatively) free actions, but are instead states that represent certain actions as free. In much the way that visual experiences represent objects in one's environment as instantiating various properties (e.g., being in motion), so too experiences of freedom represent one's actions as instantiating various properties. And just as the contents of visual experience can be at odds with the contents of explicit judgment, so too the contents of agentive experiences can be at odds with the contents of explicit judgment. Although non-representational conceptions of the phenomenology of freedom are possible-for example, one could think of such states as simply the conscious aspects of the exercise of free will-I will assume the representationalist account in what follows. (From the representationalist perspective one should refer to experiences as of free will, but in the interests of readability I will drop the qualifier.)

How might we capture the representational content of experiences of freedom? For present purposes, we can identify a state's experiential content with its veridicality conditions: that is, what the world must be like in order for the experience to be veridical. Thus, a central project for those interested in the analysis of experiences of freedom is to give an account of its veridicality conditions.

Now, one might assume that in order to be legitimately described as an experience of freedom, an account of an experience's veridicality conditions must refer to all of the necessary conditions on freedom. For example, if free will requires the absence of a certain kind of luck, then an experience of free will would need to represent the absence of that kind of luck. If correct, this assumption would raise acute questions about the very possibility of experiences of freedom, for it is far from obvious that all of the necessary conditions on free will can be experientially represented. However, there is reason to think that this assumption can be resisted. An alternative view allows that an 
experience of freedom might be legitimately so-called even if a characterization of its content doesn't refer to all of the necessary features of freedom. Consider, for example, our labels for perceptual experiences. We have no hesitation in referring to an experience as an 'experience (as) of an apple,' even though some of the properties that are necessary for being an apple — such as having a particular genetic structure — cannot be experientially represented. Similarly, one might argue that it is possible to have an experience of freedom even though some of the properties that are necessary for freedom cannot be experientially represented. In short, the relationship between the content of experiences of freedom and the nature of free will itself might be somewhat opaque, and one might not be able to recover the latter from an analysis of the former.

With these points in hand, let us turn to two core debates about the content of experiences of freedom. One of these debates concerns libertarianism, the other concerns the self. I begin with libertarianism.

I suggested earlier that the phenomenology of freedom can be understood as the sense that it is 'up to one' which of various possible states of affairs are actualized-that one has the power to settle matters that are currently open. A central question concerns how this notion of openness should be understood. Some theorists claim that it should be understood in libertarian terms. According to this view, the phenomenology of freedom would not be veridical should determinism turn out to be true. This idea can be found in the work of William of Ockham, and in our own era has been defended by Carl Ginet (1990), Keith Lehrer (1960), Timothy O'Connor (1995), Galen Strawson (2004) and John Searle (1984). As Searle has put it, "we sense the possibility of alternative courses of action built into these experiences ... that we could be doing something else right here and now, that is, all other conditions remaining the same" (1984: 95).

Although popular, the libertarian analysis of the phenomenology of freedom has not gone unchallenged, and many theorists deny that human beings have experiences with libertarian content. Although such theorists can sometimes be read as denying that there is a phenomenology of freedom, it is perhaps more accurate to take them to recognize that there is a phenomenology of freedom while denying that it has libertarian content.

One question raised by the foregoing is whether libertarianism could be experientially encoded. The question is not an idle one, for there are constraints on the kinds of properties that can be experientially represented. It is possible to believe that the Taj Mahal was completed in 1653 , but it does not appear to be possible for such a fact to be experientially represented. Similarly, one might argue that although libertarianism can be the object of belief, it cannot be the object of experience. An experience as of libertarian freedom would need to represent (if only implicitly) that determinism is false, and it is far from clear how that might be possible. As Richard Holton has put it, "What is it to experience one's action as not causally determined, or oneself as an uncaused cause? I have no idea how that could be the content of an experience" (2009: 416). Intuitively, claims about the falsity (or truth, for that matter) of determinism are no more amenable to experiential representation than claims about the date on which the Taj Mahal was completed.

Philosophers haven't agreed about the veridicality conditions of experiences of freedom, but what do the folk think? (There are a couple of reasons for wanting an account of what view the folk take of the phenomenology of freedom. For one thing, one might think that folk views of the matter are likely to be less subject to 'theoretical contamination.' Further, folk accounts of the phenomenology of freedom may ground—and 
thus explain-folk conceptions of freedom.) Although studies of folk views of free will have tended to focus on what the folk believe about free will (e.g., Monroe and Malle 2010), there has been some work on the folk phenomenology of freedom-or, perhaps more accurately, on what the folk believe about the phenomenology of freedom. This line of research was initiated by Eddy Nahmias and colleagues (2004), who asked participants to imagine (or recall) an experience of making a difficult choice, and then asked whether that experience was best described in compatibilist terms ("I could have chosen to do otherwise even if everything at the moment of choice had been exactly the same"), incompatibilist terms ("I could have chosen to do otherwise only if something had been different-for instance, different considerations had come to mind as I deliberated or I had experienced different desires at the time"), or whether it resisted both compatibilist and incompatibilist descriptions. Nahmias and colleagues found that 62 percent of their subjects preferred the compatibilist description as compared to 35 percent who preferred the libertarian description.

Oisín Deery and colleagues (2013) have criticized this study on the grounds that asking subjects about difficult decisions may have primed them to ignore the intended incompatibilist meaning of "could have done otherwise" and parse the phrase in commitment-expressive terms. In an attempt to avoid this problem, Deery and colleagues told subjects that they (that is, the experimenters) would donate 50 cents to one of two charities, a foundation that protects the tree Castanae Dentata or a foundation that protects the tree Ulmus Dentata, depending on how the subjects chose. Subjects were instructed to decide between the two charities, and were then asked to indicate their level of agreement (on a 7-point scale) with the following statement:

When deciding which option to choose, it feels like I can either choose to donate to the endangered tree Castanae Dentata or choose to donate to the endangered tree Ulmus Dentata.

Subjects were then trained on the notion of determinism (described by the experimenters as 'causal completeness'), and asked to indicate their level of agreement with the following statement:

Even though it felt like I could either choose to donate to Castanae Dentata or choose to donate to Ulmus Dentata, if causal completeness is true, then I couldn't really have chosen differently than I did.

Deery et al. (2013) found that 31 of their 37 students gave a response of 5 or above on the 7 -point scale, a response that the author took to be indicative of libertarian phenomenology.

What should we make of this study? Although it suggests that people can be led to describe their experiences of freedom in incompatibilist terms, it is far from clear that we should conclude that the folk really have incompatibilist phenomenology; indeed, it is not even clear whether we should conclude that the folk believe themselves to have incompatibilist phenomenology. One of the lessons of recent work in experimental philosophy is that folk responses to questionnaires are highly sensitive to the way in which questions are framed (Nichols and Knobe 2007). One possibility is that by first training subjects on the notion of causal completeness and then asking whether their phenomenology of freedom in any way conflicted with that notion Deery and 
colleagues may have inadvertently primed their subjects to report incompatibilist phenomenology.

Perhaps future research will elucidate folk conceptions of the phenomenology of freedom, but at this stage matters are anything but clear. One possibility is that some of the folk (believe themselves to) have libertarian phenomenology whereas other folk (believe themselves to) have compatibilist phenomenology. This proposal gains some support from the finding that there are significant individual differences in folk conceptions of free will (Feltz and Cokely 2009). Another possibility-floated by Nahmias et al. (2004) — is that certain kinds of actions may be associated with libertarian experiences whereas other kinds of actions may be associated with compatibilist experiences. Perhaps the only thing that can be said with any certainty at this point is that questions about the content of folk experiences of freedom are open ones.

If the veridicality conditions of experiences of freedom are not libertarian in nature, then what are they? Describing the phenomenology of freedom as 'compatibilist' doesn't really provide a positive characterization of its content. Close inspection of the literature reveals that the compatibilist approach can be developed in a variety of ways. According to some, the feeling of freedom "simply discloses that we were able to act in accord with our strongest desire at the time, and that we could indeed have acted otherwise if a different motive had prevailed at the time" (Grünbaum 1952). Other compatibilists argue for a rather bolder-and, in my view, significantly more plausibleconception of the phenomenology of freedom. For example, Richard Holton claims that in choosing we experience ourselves as settling issues that are psychologically open for us-" "our experience tells us that our choice is not determined by our beliefs and desires, or by any other psychological states . . . to which we have access" (2006: 15) _ but he is at pains to emphasize that this sense of psychological openness is in no way at odds with determinism, for an action could be determined by physical causes without being determined by psychological causes.

Let me turn now to questions about the way in which the self might figure in the phenomenology of freedom. The idea that the phenomenology of freedom is selfinvolving in important ways is a common theme in the literature, although different authors focus on different facets of this theme. Terry Horgan has emphasized the experience of the self-as-initiator. How, he asks, should one characterize the "actional phenomenal dimension" of the act of raising one's hand and clenching one's fingers?

You experience your arm, hand, and fingers as being moved by you yourselfrather than experiencing their motion either as fortuitously moving just as you want them to move, or passively experiencing them as being caused by your own mental states.

(2015: 2; see also Horgan and Timmons 2011; Horgan et al. 2003)

Martine Nida-Rümelin has noted that the self seems to be present not only in bodily action but also in the control of attention and mental action.

A person may direct her attention upon the specific color of the sky. In doing so she will in some cases experience herself as causing the upholding of that attention during the whole period in which the attention is directed upon that specific colour. 
And Galen Strawson suggests that there is a "radical, absolute, buck-stopping up-tome-ness in choice and action," a sense that is "indissociable from the ordinary, sane, and sober adult human sense of self" (2004: 380, 394; see also Strawson 1986/2010: 83).

These claims run counter to what we might regard as a deflationary-and perhaps traditional-view, according to which the self features in the phenomenology of agency only insofar as it functions as the 'location' of those mental events (or states) that are experienced as the primary causes of one's actions. On this view, I experience myself as raising my arm only insofar as I am aware of the beliefs and desires that are responsible for this action as my beliefs and desires. Horgan, Nida-Rümelin and Strawson appear to reject this 'place-holder' conception of the phenomenology of the self in favor of an account according to which it is oneself rather than one's mental states or events which is experienced as the cause of one's actions.

But if the self is indeed experienced as a genuine cause of one's actions does it follow that we have returned to some form of libertarianism, albeit a libertarianism of an agentcausal rather than event-causal variety? Although some of the quotations given above certainly invite such a view-consider Strawson's reference to a "radical, absolute, buck-stopping up-to-me-ness in choice and action"-I am inclined to side with those who claim that the self is represented in agentive experience in a manner that has no bearing on the debate between compatibilists and incompatibilists (Horgan 2015; Pereboom 2015). One can experience oneself as the initiator of an action without experiencing oneself as lying outside the realm of ordinary event causation.

Although questions concerning the content of the phenomenology of freedom have dominated the debate, they are not the only questions that an analysis of the phenomenology of freedom must address. Another set of questions concerns the distribution of such experiences: when we do enjoy the phenomenology of freedom? (Although distribution questions apply to both background and focal forms of the phenomenology of freedom, discussion has centered on the latter.) Do experiences of freedom occur only when one attends to one's own agency, or do such experiences characterize deliberation and decision-making even when one's own agency isn't the focus of one's attention? Are experiences of freedom restricted to occasions in which one is confronted by a momentous moral decision and where the considerations on each side are equally counter-balanced (as some accounts of free will might suggest), or are they a ubiquitous feature of everyday waking life, albeit one that we may be inclined to overlook (perhaps because of their ubiquity)? These questions are contested in much the way that parallel questions about the distribution of free will itself are contested; indeed, it is possible that questions about the distribution of free will are contested precisely because questions about the distribution of experiences of free will are contested.

\section{Genetic Questions}

Let me turn from questions concerning the analysis of the phenomenology of freedom to questions about its genesis. What are the psychological and neural mechanisms responsible for the phenomenology of freedom? Is the phenomenology of freedom an aspect of experience enjoyed by all neurotypical human beings, or is it heavily dependent on particular forms of cultural scaffolding? Do experiences of freedom emerge early in development-perhaps with the acquisition of the capacity for intentional agency? or do they arise only later, perhaps only as and when the child internalizes the norms associated with the reactive attitudes? 
Although there is a large and rapidly growing literature on the psychology and neuroscience of agentive experience in general, little of it has any direct relevance to these questions, and detailed accounts of the genesis of the phenomenology of freedom have yet to be developed. Perhaps the most influential body of experimental work that bears on the phenomenology of freedom is that conducted by Benjamin Libet (Libet et al. 1983; Libet 1985). In these experiments, subjects are told to perform some simple motor action (such as flex their wrist) at a moment of their choosing within a specified period of time (say, 20 seconds), and that this action should be performed 'spontaneously.' At the same time, they are instructed to monitor their agentive experiences, and to identify the time at which they were first aware of the 'decision,' 'urge' or 'intention'-Libet used these terms interchangeably - to act. Subjects do this by watching a clock face with a dial that rotates rapidly (once every $2560 \mathrm{~ms}$ ). Libet referred to the judgment of the time of their 'decision' ('urge,' 'intention') to act as the 'W judgment.' While subjects were both acting and monitoring their urges (intentions, decisions) to act, Libet used an electroencephalogram (EEG) to measure their neural activity. These measurements revealed preparatory brain activity — what Libet called a type II readiness potential (RP) — prior to the action. The critical question in which Libet was interested concerned the temporal relationship between the RP on the one hand and the subjects' W judgments on the other hand.

The EEG revealed that the RP preceded the subjects' actions by about $550 \mathrm{~ms}$. However, on average subjects reported that they felt that they had decided to move only 200 ms prior to the action (dating that point to the onset of muscle activity initiating the movement). In other words, there appeared to be a gap of about $350 \mathrm{~ms}$ between the RP and the point at which subjects claimed to be aware of their decision (urge, intention) to act. Libet argued that the gap of 150 ms between the agent's conscious decision and the onset of the action allowed for a kind of free will in the form of conscious veto, but many theorists have seen in Libet's results the death-knell of free will. For example, William Banks and Susan Pocket (2007) describe Libet's experiments as providing "the first direct neurophysiological evidence in support of [the idea that perceived freedom of action is an illusion]" (2007: 658).

This conclusion might be challenged on many grounds (see, for example, Bayne 2011; Mele 2009), but here I am interested in the Libet paradigm only insofar as it raises questions about the phenomenology of freedom. One question concerns whether the kinds of actions elicited in these experiments- 'Libet actions' - are genuine examples of free will. Although Libet took himself to have studied an "incontrovertible and ideal example" of a free act (Libet et al. 1983: 640), not everyone shares his view. Adina Roskies, for example, claims that Libet actions are at best "degenerate" examples of free will, and suggests that we ought to focus on actions that are grounded in our reasons and motivations if we are interested in "how awareness and action are related insofar as they bear on freedom and responsibility" (Roskies 2011: 19). In addressing this issue, one might consider whether Libet actions involve the phenomenology of freedom, for if they do then there is at least a prima facie case for regarding them as genuine examples of free will despite their lack of integration with the agent's reasons and motivations.

A second question concerns the content of the phenomenology of freedom as it occurs in Libet actions. On one reconstruction of his argument, Libet is assuming that the experience of agency represents itself as initiating the relevant bodily action. It is this assumption, which is supposedly at odds with the neuroscientific findings, for the 
claim is that the bodily action is initiated by the readiness potential, which occurs some 350 milliseconds prior to the experience of agency. Leaving to one side the question of whether the readiness potentially really does function as the point of origin of the relevant action, we might ask whether experiences of agency represent themselves as initiating actions. It is far from clear that they do. One experiences oneself as initiating the action, but it is highly doubtful whether one experiences one's own experiences of agency as initiating one's actions (Bayne 2006; Horgan 2010).

In addition to questions about the genesis of the phenomenology of freedom, one might also ask about the role that the phenomenology of freedom plays in grounding folk beliefs about free will. Just as many of our folk beliefs about the physical world can be explained by appeal to perceptual experience, so too one might suggest that many of our folk beliefs about free will can be explained by appealing to agentive experience. Perhaps, as Galen Strawson claims, "The true centre of our commitment to belief in freedom lies ... in our experience of our own agency" (1986/2010: 80). Call this the empiricist account of (belief in the existence of) free will.

The most straightforward version of the empiricist approach takes the folk conception of free will to be simply read off from agentive experience. Should it turn out that (significant numbers of) the folk have a libertarian conception of free will, then one might explain why this is the case by appealing to the fact that (significant numbers of) the folk have libertarian experiences of freedom. However, there are also less straightforward versions of the empiricist approach. For example, one might appeal to the Spinozan idea that we are simply unaware of the causes of our behavior, and infer on that basis that our actions are uncaused. As Nichols (2012) has pointed out, this proposal stands in need of supplementation, for we don't typically regard an event as uncaused simply because we fail to experience its cause. How might it be patched up? Nichols makes the plausible suggestion that the folk assume that any causes of their actions would need to be introspectively available. Given that many of our actions don't appear to have introspectively discernable sufficient psychological causes, the folk conclude that such actions don't have fully sufficient causes.

Some version of the empiricist account of belief in libertarian free will is very appealing, but it is not the only approach on the market. For example, one might argue that the appeal of libertarianism is due to a certain picture of what real moral responsibility requires (Nichols 2004). The idea, roughly, is that the folk assume both that we enjoy deep moral responsibility for many of our actions and that deep moral responsibility requires libertarian free will, and on that basis of these assumptions draw the inference that we possess libertarian free will.

Of course, the foregoing presupposes that the folk have a libertarian conception of free will, and that assumption is contested (Nahmias et al. 2005, 2006; Turner and Nahmias 2006). Although there is some cross-cultural research on folk conceptions of free will (Sarkissian et al. 2010), the vast majority of quantitative data we have concerns the views of Western undergraduates, and such views might not be representative of folk views in general. My own view is that it is highly plausible that at least some of the folk within contemporary Western society have at least some degree of commitment to libertarianism. But it is worth noting that the empiricist approach might still be of interest even with respect to folk views of free will that are compatibilist in character, for here too we can ask whether the commitment to a certain version of compatibilist free will might be grounded in the phenomenology of freedom. 


\section{Epistemic Questions}

What role might experiences of freedom play in debates about the existence of free will? Although some libertarians have explicitly rejected the suggestion that introspection provides evidence for their view (van Inwagen 1983; see Guillon 2014 for discussion), a number of libertarians have appealed to agentive experience in order to justify their position. Libertarianism, they claim, is pro tanto justified in virtue of the fact that we experience ourselves as exercising libertarian free will (Campbell 1951; Lehrer 1960; O'Connor 1995).

Engaging with this argument in detail goes beyond the scope of this chapter, but it is possible to identify some of the general issues that it raises. First, unlike a number of other arguments that have been offered for libertarianism, the argument from experience does justice to the fact that libertarianism is at best a contingent truth and not something that one would expect to follow from purely a priori considerations. Second, the argument is on firm ground insofar as experiential content is typically regarded as a legitimate source of evidence. Having an experience with the content that $\mathrm{P}$ is usually regarded as a source of warrant for believing that $\mathrm{P}$ is the case. Just as it is reasonable to regard visual experiences (as) of one's hand as moving as providing one with pro tanto justification for the claim that one's hand is moving, so too it would seem reasonable to regard the experience (as) of oneself as acting freely as providing oneself-and indeed others, perhaps-with evidence that one is acting freely.

But although prima facie plausible, the argument from agentive experience faces serious objections. Some objections attempt to undercut the evidential force of agentive experience. One kind of undercutting objection appeals to the existence of introspective disputes about the phenomenology of freedom. Even if a subject does experience herself as having libertarian freedom, the mere fact that libertarian construals of the phenomenology of freedom are contested arguably undermines the justification that would otherwise be provided by her experience. Another undercutting objection appeals to the possibility that the phenomenology of freedom is cognitive penetrated, and that experiences as of libertarian free will (for example) are grounded in a prior commitment to the existence of libertarian free will. If the phenomenology of freedom were subject to top-down expectations in this way then there would be an important respect in which the argument from experience would be undercut: although individuals who were unaware that their experiences of freedom were dependent on their expectations might be justified in taking themselves to have libertarian free will, those privy to the relevant facts would not be so justified. I know of no evidence that the phenomenology of freedom is dependent on expectation in this way, but there is some evidence that certain aspects of agentive experience can be modulated by expectation (Desantis et al. 2011).

But perhaps the strongest objections to the argument from experience are rebutting objections. Rather than attempting to undermine the evidential force of appeals to agentive experience as undercutting objections do, rebutting objections claim that the pro tanto evidence provided by agentive experience is outweighed by competing considerations. There is an extensive body of research in cognitive science detailing a myriad of ways in which our actions and decisions are influenced by factors of which we are not conscious, and the Spinozan idea that our actions have causes of which we are not aware is more compelling now than it has ever been. If the processes responsible for the phenomenology of freedom are oblivious to some of these factors, then the experiences 
generated by those processes might erroneously represent one's decisions as 'open' when in fact they are 'settled.' In summary, even if the phenomenology of agency has libertarian content, attempts to justify libertarianism by appealing to such content are unlikely to succeed.

\section{Constitutive Questions}

Let me conclude this chapter by considering a question that is one of the most interesting but least explored questions in this neighborhood: is there a constitutive relationship between free will and the phenomenology of freedom? It is, I assume, possible to experience oneself as a free agent without actually being a free agent, but is it possible to be a free agent without experiencing oneself as free?

A number of authors have advanced accounts of free will according to which the answer to this question is 'no.' For example, Carl Ginet claimed that a free action must possess what he called the "actish" phenomenal quality (Ginet 1990, 1997). Although it is not entirely clear what Ginet meant by "the actish phenomenal quality," he seems to have taken agentive experience of some kind to be a constitutive feature of free will. A more thorough examination of this issue can be found in Galen Strawson's book Freedom and Belief. In that work, Strawson defends the claim that the experience of freedom is a constitutive condition on its possession. His central argument for this view involves an appeal to creatures which are stipulated to have all of the cognitive capacities necessary for free will, but lack any experience of themselves as ultimately responsible for what they do. Strawson claims that such creatures couldn't possess genuine free, and hence that the experience of oneself as free is a constitutive feature of free will.

I have a certain amount of sympathy for Strawson's claim, but many will remain unmoved by it. In his review of Strawson's book, Thomas Nagel expressed skepticism on precisely this point, asking why it wouldn't be possible for a person to act freely while laboring under the illusion that they had no freedom? At this point what is needed is an account of why the experience of freedom might be a constitutive feature of free will itself. Unfortunately, Strawson provides no such account, and confesses that he is himself puzzled as to why freedom might require the experience thereof (Strawson 1986/2010: Appendix A).

There are two sorts of answers one might give as to why the experience of freedom is required for free will. One account centers on the epistemic properties of the phenomenology of freedom. Roughly speaking, the idea is that in order to be truly free, an agent must possess non-inferential knowledge of its own freedom, and that in turn requires that it experience itself as free. Another account centers on the role that the phenomenology of freedom might play in allowing an individual to control his or her actions. In order to have the kind of control over one's agency that true freedom requires - the thought runs - the existence of this control must itself be experientially manifest to the agent. Neither of these two proposals has received much attention in the literature, and it would be premature to speculate on what sustained examination of them might reveal. My own hunch is that neither proposal is able to provide any support for the claim that the phenomenology of freedom is metaphysically necessary for free will, but that one or other of these proposals might provide some support for the claim that the actions of creatures like us can be free only insofar as they are experienced as free. 


\section{Bibliography}

Banks, W.P. and Pockett, S. (2007) "Benjamin Libet's work on the neuroscience of free will," in M. Velmans and S. Schneider (eds), The Blackwell Companion to Consciousness. Oxford: Blackwell, pp. 657-70.

Bayne, T. (2006) "Phenomenology and the Feeling of Doing: Wegner On the Conscious Will," in S. Pockett, W.P. Banks, and S. Gallagher (eds), Does Consciousness Cause Behavior? Cambridge: MIT Press, pp. 169-86.

Bayne, T. (2008) "The Phenomenology of Agency," Philosophy Compass 3: 1-21.

Bayne, T. (2011) "Libet and the Case for Free Will Skepticism," in R. Swinburne (ed.), Free Will and Modern Science. Oxford: Oxford University Press, pp. 25-46.

Bayne, T. and Pacherie, E. (2007) "Narrators and Comparators: The Architecture of Agentive SelfAwareness," Synthese 159: 475-91.

Campbell, C.A. (1951) "Is Freewill a Pseudo-Problem?" Mind 60: 441-65.

Deery, O., Bedke, M., and Nichols, S. (2013) "Phenomenal Abilities: Incompatibilism and the Experience of Agency," in D. Shoemaker (ed.), Oxford Studies in Agency and Responsibility. Oxford: Oxford University Press, pp. 126-50.

Desantis, A., Roussel, C., and Wasxak, F. (2011) "On the Influence of Causal Beliefs On the Feeling of Agency," Consciousness and Cognition 20: 1211-20.

Feltz, A. and Cokely, E. (2009) "Do Judgments About Freedom and Responsibility Depend On Who You Are? Personality Differences in Intuitions About Compatibilism and Incompatibilism," Consciousness and Cognition 18: 342-50.

Ginet, C. (1990) On Action. Cambridge: Cambridge University Press.

Ginet, C. (1997) "Freedom, Responsibility and Agency," The Journal of Ethics 1: 85-98.

Grünbaum, A. (1952) "Causality and the Science of Human Behavior," American Scientist 40: 665-76.

Guillon, J.B. (2014) "Van Inwagen on Introspected Freedom," Philosophical Studies 168: 645-63.

Holton, R. (2003) "How is Strength of Will Possible?" in S. Stround and C. Tappolet (eds), Weakness of Will and Practical Irrationality. Oxford: Clarendon, pp. 39-67.

Holton, R. (2006) "The Act of Choice," Philosophers' Imprint 6: 1-15.

Holton, R. (2009) "Determinism, Self-Efficacy, and the Phenomenology of Free Will," Inquiry 52: 412-28.

Horgan, T. (2010) "The Phenomenology of Agency and the Libet Results," in W. Sinnott-Armstrong and L. Nadel (eds), Conscious Will and Responsibility: A Tribute to Benjamin Libet. New York: Oxford University Press, pp. 159-172.

Horgan, T. (2015) "Injecting the Phenomenology of Agency into the Free Will Debate," in D. Shoemaker (ed.), Oxford Studies in Agency and Responsibility. Oxford: Oxford University Press, pp 34-61.

Horgan, T. and Timmons, M. (2011) "Introspection and the Phenomenology of Free Will: Problems and Prospects," Journal of Consciousness Studies 18: 180-205.

Horgan, T., Tienson, J., and Graham, G. (2003) "The Phenomenology of First-Person Agency," in S. Walter and H.D. Heckmann (eds), Physicalism and Mental Causation: The Metaphysics of Mind and Action. Exeter: Imprint Academic, pp. 323-40.

Lehrer, K. (1960) “Can We Know That We Have Free Will by Introspection?” The Journal of Philosophy 57: $145-57$.

Libet, B. (1985) "Unconscious Cerebral Initiative and the Role of Conscious Will in Voluntary Action," Behavioral and Brain Sciences 8: 529-66.

Libet, B., Gleason, C.A., Wright, E.W., and Pearl, D. (1983) "Time of Unconscious Intention to Act in Relation to Onset of Cerebral Activity (Readiness-Potential)," Brain 106: 623-42.

Mele, A. (2009) Effective Intentions: The Power of Conscious Will. New York: Oxford University Press.

Monroe, A.E. and Malle, B. (2010) "From Uncaused Will to Conscious Choice: The Need to Study, Not Speculate About, People's Folk Concept of Free Will," Review of Philosophy and Psychology 9: 211-24.

Nahmias, E., Morris, S., Nadelhoffer, T., and Turner, J. (2004) "The Phenomenology of Free Will," Journal of Consciousness Studies 11: 162-79.

Nahmias, E., Morris, S., Nadelhoffer, T., and Turner, J. (2005) "Surveying Freedom: Folk Intuitions about Free Will and Moral Responsibility," Philosophical Psychology 18: 561-84.

Nahmias, E., Morris, S., Nadelhoffer, T., and Turner, J. (2006) "Is Incompatibilism Intuitive?" Philosophy and Phenomenological Research 73: 28-53.

Nichols, S. (2004) "The Folk Psychology of Free Will: Fits and Starts," Mind and Language 19: 473-502.

Nichols, S. (2012) "The Indeterminist Intuition: Sources and Status," The Monist 95: 290-307.

Nichols, S. and Knobe, J. (2007) "Moral Responsibility and Determinism: The Cognitive Science of Folk Intuitions," Noûs 41: 663-85. 
Nida-Rümelin, M. (2007) "Doings and Subject Causation,” Erkenntnis 67: 255-72.

O'Connor, T. (1995) "Agent Causation,” in T. O'Connor (ed.), Agents, Causes and Events: Essays on Indeterminism and Free Will. New York: Oxford University Press, pp. 173-200.

Pacherie, E. (2008) “The Phenomenology of Agency: A Conceptual Framework," Cognition 107: 179-217.

Pereboom, D. (2015) "The Phenomenology of Agency and Deterministic Agent-Causation,” in H. Pedersen and M. Altman (eds), Horizons of Authenticity in Phenomenology, Existentialism, and Moral Psychology: Essays in Honor of Charles Guignon. New York: Springer, pp. 277-94.

Roskies, A. (2011) “Why Libet's Studies Don't Pose a Threat to Free Will,” in W. Sinnott-Armstrong and L. Nadel (eds), Conscious Will and Responsibility. New York: Oxford University Press, pp. 11-22.

Sarkissian, H., Chatterjee, A., de Brigard, F., Knobe, J., Nichols, S., and Sirker, S. (2010) "Is Belief in Free Will a Cultural Universal?" Mind and Language 25: 346-58.

Searle, J. (1984) Minds, Brains and Science. Cambridge: Harvard University Press.

Strawson, G. (1986/2010) Freedom and Belief, 2nd edn. Oxford: Oxford University Press.

Strawson, G. (2004) "Free Agents," Philosophical Topics 32: 371-403.

Turner, J. and Nahmias, E. (2006) "Are the Folk Agent-Causationists?” Mind and Language 21: 597-609.

van Inwagen, P. (1983) An Essay on Free Will. Oxford: Clarendon Press.

Wakefield, J. and Dreyfus, H. (1991) "Intentionality and the Phenomenology of Action," in E. LePore and R. van Gulick (eds), John Searle and His Critics. Oxford: Blackwell, pp. 259-70.

\section{Further Reading}

Horgan, T. (2010) "The Phenomenology of Agency and the Libet Results," in W. Sinnott-Armstrong and L. Nadel (eds), Conscious Will and Responsibility: A Tribute to Benjamin Libet. New York: Oxford University Press, pp. 159-172. (Criticizes influential interpretations of the Libet results from the perspective of an analysis of the phenomenology of free will.)

Horgan, T., Tienson, J., and Graham, G. (2003) “The Phenomenology of First-Person Agency,” in S. Walter and H.D. Heckmann (eds), Physicalism and Mental Causation: The Metaphysics of Mind and Action. Exeter: Imprint Academic, pp. 323-40. (The paper that has arguably done the most to spark the recent interest in the phenomenology of agency.)

Mylopoulos, M. and Lau, H. (2014) "Naturalizing Free Will: Paths and Pitfalls," in A. Mele (ed.), Surrounding Free Will: Philosophy, Psychology, Neuroscience. Oxford University Press, pp. 123-44. (Argues that there is no reason to assign any significant weight to phenomenology in evaluating theories of free will.)

Nahmias, E., Morris, S., Nadelhoffer, T., and Turner, J. (2004) “The Phenomenology of Free Will," Journal of Consciousness Studies 11: 162-79. (An important paper that sets out some of the central debates surrounding the phenomenology of free will.)

\section{Related Topics}

Neuroscientific Threats to Free Will

Empirical Perspectives on Consciousness and its Relationship to Free Will and Moral Responsibility

Folk Intuitions

Mental Causation 


\section{7 \\ MENTAL CAUSATION \\ Rebekah L. H. Rice}

\section{Introduction}

When I want to comfort my young child, my limbs move so as to pick him up. When the actor hears his cue, he enters the stage. When you feel thirsty, you reach for the glass of water. These are common, everyday episodes. And we generally find it quite natural to say more. My desire to comfort my child doesn't merely correlate with (or precede, as the case may be) my lifting my child. Rather, I lift him because I wish to comfort him. And the 'because' is naturally read causally in this context, so that it is correct to say that my desire to comfort him is part of a causal nexus that issues in my limbs moving as they do.

What's more, some philosophers have argued that it is in virtue of being causal that mental items, such as beliefs, desires, intentions, and the like, explain or rationalize the actions we perform (Davidson 1963/2001). After all, such mental items seem particularly well-suited to serve as reasons for action (Kim 1998). As Davidson puts it, "A reason rationalizes an action only if it leads us to see something the agent saw, or thought he saw, in his action" (Davidson 1963/2001). And since humans don't generally act wantonly, but for reasons, an account of human action according to which an agent's mental states or events both cause and make understandable her action renders a picture of the human person that squares nicely with the view we have of ourselves as rational participants in the world.

Something like a Davidsonian view about the nature of action and action explanation remains the received view in action theory today. But, as one might expect, the view has its detractors and several alternative theories are available. Some of these agree that action requires a causal account, though they disagree about what does the causing (e.g., O'Connor 2002; Clarke 2003; Steward 2012) while others deny that we ought to think about action in causal terms at all (Ginet 1990; McCann 1998; Sehon 2005). Regardless of the view one selects, it is generally agreed that any account of action and action explanation must account for the very intuitive idea that what I want, or what I believe, or what I intend explains what I do. And a Davidsonian-style view offers a straightforward account: The reason (i.e., mental state) that causes my action is the reason (mental state) that explains it.

Now, it may be that some of our actions are voluntary and others are not. Whether an act is voluntary turns, according to some thinkers, on its being caused in some specified way-typically, that its coming about is the result of a causal process that is indeterministic (i.e., probabilistic/statistical) (Kane 1996). For others, it depends on the action's issuing from powers of the agent herself (O'Connor 2002; Clarke 2003; Steward 2012). And for still others, it comes down to a question about the source of the 
action (Timpe 2008). And there are, of course, those who think the relevant consideration concerns not the nature of the causation at all, but some other factor-for example, that the agent has certain higher-order desires pertaining to her first-order ones (Frankfurt 1969). Other chapters in this volume attend to such matters in detail. What is of interest for our present purposes is that all such views take for granted that the behaviors that count as voluntary are those that properly count as actions. And if actions are those behaviors which at least seem to issue from mental states, then lurking in the background of all such discussions is a question about how and whether the mental is causally efficacious in the way we are apt to suppose.

\section{The Mental and the Physical}

Our present discussion owes much to one that took place in the seventeenth century between René Descartes and his critics. Descartes characterized human persons as entities composed of both an immaterial substance - a mind - and a material substance, or a body. The mind, on Descartes' view, is that in which the various mental states or properties reside, whether they be thoughts, desires, beliefs, sensations, perceptions, feelings, and is itself the subject of experience. Importantly, for Descartes, the mind and the body causally interact so that it is your being thirsty that causes you to reach for your water glass and it is the tissue damage caused by my accidentally placing my hand on the hot grill that then produces a sensation of pain in me. For Descartes, there is both mental-to-physical causation (as when a person acts for a reason) and physical-to-mental causation (as in the case where tissue damage produces pain), as well as, we can imagine, mental-to-mental causation (as when my seeing a shadowy figure approaching me produces fear in me).

Descartes' commitment to causal interaction between the mental and the physical gave rise to the now famous 'mind-body problem.' It began with a simple question posed by one of Descartes' critics, Princess Elisabeth of Bohemia, who asks Descartes to tell her "how the soul of a human being (it being only a thinking substance) can determine the bodily spirits, in order to bring about voluntary actions" (Shapiro 2007: 62). What Elisabeth seems to be pointing to is the inadequacy of the sort of mechanistic view of causation that (it would have been thought at the time) appears to account fairly well for physical-to-physical causation to account for mental-to-physical causation. And she wonders whether Descartes can offer an alternative given that he countenances mindbody causal interaction. As it turns out, Descartes cannot, and the mind-body problem has come to plague the sort of dualism Descartes defended ever since.

Now, just what 'problem' the mind-body problem exposes for substance dualism remains a topic of dispute among philosophers. In particular, philosophers disagree about whether it reveals a deep incoherence in the very notion of mind-body causal interaction. But there's no question that substance dualism has fallen out of favor in philosophical circles. Indeed, most philosophers today hold some version of physicalism, the view that human persons are physical entities not composed (even in part) of an immaterial soul. While the mind-body problem has undoubtedly played some role in this, the arguments for physicalism are typically mounted on empirical grounds, or, in any case, the view is generally advanced as a contingent thesis about what entities like you and me happen to be like. But with the move to physicalism, the challenge of mental causation has not disappeared. In fact, the physicalist faces her own set of challenges here. It is to these that I now turn. 


\section{Threats to Mental Causation}

The loss of mental causation is far from inconsequential. As Jerry Fodor has famously, and rather theatrically, put it:

If it isn't literally true that my wanting is causally responsible for my reaching, and my itching is causally responsible for my scratching, and my believing is causally responsible for my saying ... if none of that is literally true, then practically everything I believe about anything is false and it's the end of the world.

(Fodor 1990: 156)

Let's return to the case where my desire to comfort my child causes me to move my body so as to lift him. If physicalism is true, then this scenario does not imply mind-body interaction since there is no mind - that is, no mental substance. But beliefs and their ilk are something. They are, perhaps, properties of the physical organism which is the person, or perhaps slightly more innocuously, they are events occurring in that organism, or states of the physical organism. How exactly such mental events relate to other physical events of the same organism-particularly those with which they appear to correlate-is an important question (an answer would constitute a theory of the mental). But insofar as the physicalist wants to tell the familiar story about thirst causing waterglass-reachings and headaches causing aspirin-takings, she must grant (or so it would seem at first blush) that mental states have causal efficacy-that they are capable of bringing about further physical states. However, problems arise when we discover that other assumptions and doctrines that demand our respect appear to present obstacles to mental causation.

\section{Anomalous Monism}

One such doctrine concerns what Davidson has called the "nomological character of causality." A widely accepted way of linking laws and causation is this: causally connected events must instantiate, or be subsumed under, a law. If heating a liquid causes the molecules to speed up, there must be a general law connecting events of the first type and events of the second type. That is, there must be a law stating that the heating of a liquid is generally followed by an increase in the speed of the molecules. For Davidson, laws capable of supporting the causal relation must be "strict" laws. According to the standard understanding, strict laws are (i) exceptionless; (ii) not hedged by a ceteris paribus clause; and (iii) part of a closed and comprehensive system of laws over a certain domain. On Davidson's view, there are strict laws only in fundamental physics. Indeed, according to his mental anomalism, there are no strict laws about mental phenomena. (Davidson 1970, 1973, 1974_all appear in Davidson 2001). That's because any given mental intentional state (Davidson restricts his anomalous monism to intentional states-beliefs, desires, etc.) is actually a physical state or event which falls under a mental kind. In Davidson's words, "every mental event that is causally related to a physical event is a physical event" (Davidson 2001: 224). Now, a given state's falling under a mental kind does not preclude its also falling under a physical kind. And this is where we see the feature of the view that qualifies it as monism: all intentional states are actually physical states. So, while there are no psychophysical 
strict laws, there are strict laws at the level of the physics. In "Actions, Reasons, and Causes" he says:

The laws whose existence is required if reasons are causes of actions do not, we may be sure, deal in the concepts in which rationalizations must deal. If the causes of a class of events (actions) fall in a certain class (reasons) and there is a law to back each singular causal statement, it does not follow that there is any law connecting events classified as reasons with events classified as actions-the classifications may even be neurological, chemical, or physical.

(Davidson 2001: 17)

Davidson's suggestion is that the correct place to look for the laws that underpin rational causation is not at the psychological level, but instead at the biological/physical (or perhaps ultimately, the microphysical) level. The result is that an attitude (e.g., belief or desire) never causes behavior because it is a token of some attitude type. Rather, it causes behavior because it is (also) a token of a physical type.

While Davidson takes himself to have preserved mental causation, critics have noted that Davidson's anomalous monism gives rise to epiphenomenalism-the view that the mental is causally inefficacious (McLaughlin 1989; Kim 2006). In Davidson's case, the mental events do not cause anything in virtue of being mental. Rather, their causal efficacy is entirely owing to their falling under a physical kind. The upshot is that there appears to be no mental causation per se.

\section{The Exclusion Argument}

A second doctrine concerns the causal closure of the physical domain ('closure principle,' for short).

Closure Principle. If a physical event has a cause at time t, it has a sufficient physical cause at $\mathrm{t}$.

In searching for causes of physical events, we never need venture beyond the realm of the physical. As Kim puts it, "the physical domain is causally, and hence explanatorily, self-sufficient and self-contained" (Kim 2006: 195). Suppose, as our familiar story about action implies, that a mental event, $m$, causes a physical event, $p$. (Note that the causal arrow is here at a diagonal, rather than straight from left to right, to indicate what is often referred to as 'downward causation,' meaning that the causation moves from the higher, mental level to the lower, physical level. The levels will become important when we talk about the physicalist's commitment to the dependence of the mental on the physical a bit later.)

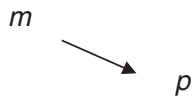

The closure principle claims that there must also be a physical cause of $p-$ an event, $p^{*}$. 


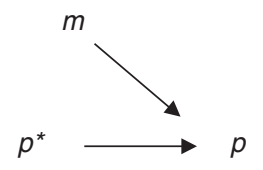

This gives rise to the following dilemma (fashioned after Kim's formulation in 2006: 196), where ' $=$ ' means 'is identical to:'

1. Either $m=p^{*}$ or $p$ has two distinct causes, $m$ and $p^{*}$ (i.e., $p$ is causally overdetermined).

2. If $m=p^{*}$, then there is no mental causation (since what we supposed to be mentalto-physical causation is actually physical-to-physical causation).

3. If $p$ has two distinct causes, $m$ and $p^{*}$, then there is widespread overdetermination (since every instance of mental-to-physical causation will be overdetermined).

4. So, either there is no mental causation, or $p$ is overdetermined.

Embracing the first horn of the dilemma renders mental states epiphenomenal, or causally inert and undercuts the familiar account of action with which we began. As regards the second horn, genuine cases of overdetermination occur when two independent causal chains converge at a single effect as when a house fire is caused by a short circuit and a lightning strike simultaneously, or when two bullets hit a person at the same time, either of which would have been sufficient to kill him. We can allow for some causal overdetermination, but some philosophers have thought it becomes problematic if we suppose it to be widespread (Kim 2005). Others disagree (Bennett 2003, 2008; Sider 2003), but we'll come back to this in the next section. In any case, if every case of mental-to-physical causation involves (at least) two sufficient causes, then every case in which I act will be a case of overdetermination. Now multiply this by all actions performed by persons at any time in history and the overdetermination will be very widespread indeed!

Impalement by the second horn is actually worse than just stated. For by the closure principle, $p^{*}$ is itself sufficient to produce $p$. It would have brought about $p$ even if $m$ had not occurred. And according to Kim, this significantly weakens the status of $m$ as a cause of $p$. Indeed, Kim offers the following principle of causal exclusion:

Exclusion Principle: No event can have two or more sufficient causes, all occurring at the same time, unless it is a genuine case of overdetermination.

To vindicate $m$ as a genuine cause of $p, m$ should be able to bring about $p$ without there being a synchronous $p^{*}$. But on any version of physicalism, every mental event has a physical causal partner (or correlate) that would have brought about the effect, even if $m$ had not.

Kim takes the lesson of the exclusion argument to be that insofar as we wish to preserve mental causation, we must reduce $m$ to $p^{*}$. The familiar story about agency can be maintained with the proviso that it is not my belief/desire pair or intention, but the respective state's physical substrate (or realizer, if you prefer) which causes the bodily movement that constitutes my action. Actions therefore involve physical causal sequences through and through. Now, one can do this in a number of ways. Perhaps, for example, a belief's functional role is reducible to causal processes in the subject's brain. Or perhaps, minimally, every token $m$ is identical with some token $p$, or else $m$ types are 
identical with $p$ types. The upshot of these moves is to deny that the mental is something over and above the physical. And, accordingly, there is no distinctively mental causation, at least of the sort we'd originally imagined.

\section{Replies to the Exclusion Argument}

There is a vast and ever-growing body of literature pertaining to the exclusion argument and proposed replies to it. While there is no way to do it justice here, in what follows I will sketch some of the key moves, particularly as they've played out over the past two decades.

While Kim offers the closure principle as a commitment of all physicalists (indeed, the argument's force is undoubtedly owing to the fact that, overwhelmingly, nonreductive physicalists—at whom the argument takes aim-accept it), one kind of reply to the exclusion argument is to deny the closure principle. Lynne Rudder Baker (1993), for example, does so on the grounds that there are circumstances in which we ought to prioritize commonsense explanations over metaphysical principles. She says:

My suggestion is to take as our philosophical starting-point, not a metaphysical doctrine about the nature of causation or of reality, but a range of explanations that have been found worthy of acceptance ... Construing explanations as answers to "why" questions, with perhaps some constraints on what counts as an adequate answer, my proposal is to begin with explanations that earn their keep, rather than with the metaphysics, which seems to me a freeloader that just interferes with real work.

(Baker 1993: 92, 93)

Notice that Baker does not provide reason for thinking that the closure principle is false other than that it conflicts with certain explanations we're apt to offer. But, as happens time and time again, philosophical inquiry can reveal that what we're inclined to say - and certainly what we do say as a matter of ordinary discourse — on a broad range of topics can turn out to be strictly-speaking false (or just plain old false). But even more importantly, a denial of the closure principle will lead to property dualism at which point a version of the old mind-body problem resurfaces. Interestingly, contrary to Cartesian approaches, some contemporary dualists are formulating theories that are themselves friendly to the closure principle (e.g., Chalmers 1996). Regardless of these developments, however, the problem of mental causation, as we're construing it, is a distinctive problem for the physicalist. And even if she does not reduce mental states to physical states, the physicalist posits that beyond merely correlating, the mental and the physical are intimately related in the sense that the former is dependent on the latter.

One way to unpack this dependence is in terms of supervenience. There are many versions of supervenience on offer, but for our purposes it will do to express the idea in terms of the well-known maxim, 'no mental difference without a physical difference.' In other words, if $x$ and $y$ are in every way alike physically, then they are in every way alike mentally. Importantly, the sort of dependence envisaged here is asymmetric (the mental is dependent on the physical, but the physical is not so dependent on the mental). It is in part because of this dependence relation that the exclusion argument gets off the ground. For physicalists of all stripes seem committed to there being a subvenient 
physical base for every mental state. And it is the causal candidacy of the item (or process) occupying the subvenient base that threatens the causal role of the mental.

Some philosophers maintain the irreducibility of the mental while nevertheless characterizing their causal contribution in a way that weds that contribution very tightly to the corresponding physical causal story. For example, on Shoemaker's nonreductive view, mental properties are not identical to physical properties, but are realized by physical properties (Shoemaker 2001, 2007). One way to characterize Shoemaker's notion of realization is this: "Q $Q$ is a realizer of $P$ just in case $P$ 's causal powers are a subset of Q's" (Kim 2010: 105). If mental causal powers are a subset of physical causal powers, it would seem that mental causal powers just are physical causal powers. What's more, Shoemaker claims that events are individuated on the basis of their causal powers and this has led some to reply that Shoemaker's view bears a striking resemblance to type physicalism (according to which mental properties are physical properties) and, far from preserving a distinct causal role for irreducible mental items, Shoemaker's strategy is a reductionist one (Kim 2010; Ney 2010).

While nonreductive physicalists deny the identity of the mental and the physical, they nevertheless see the two as enjoying a tight relationship such that the mental and physical are not exactly distinct (in the sense of being wholly independent), either. This consideration may itself suggest a third response to the Exclusion Argument. Recall that the exclusion principle rules out two or more sufficient causes of a single effect $e$ except for cases in which $e$ is overdetermined. The sorts of overdetermination cases we considered-a house fire being simultaneously brought about by both a short circuit and a lightning strike—are instances of "strong overdetermination" (Bennett 2003). But, it is argued, there is a disanalogy between these cases of overdetermination and the case in which $m$ and $p^{*}$ overdetermine $p$. Because of the tight relationship between $m$ and $p^{*}$, their overdetermining $p$ is neither surprising nor coincidental, and not problematic in any other way.

In the case where the house fire is genuinely overdetermined by the short circuit and the lightning strike, the following two conditionals are true:

A. If the short circuit had occurred without the lightning strike, the house fire would still have occurred.

B. If the lightning strike had occurred without the short circuit, the house fire would still have occurred.

Because A and B are true, the house fire is overdetermined (in the strong sense). But now consider the case where $m$ and $p^{*}$ are each sufficient causes of $p$. The relevant counterfactuals are:

C. If $m$ had occurred without $p^{*}, p$ would still have occurred.

D. If $p^{*}$ had occurred without $m, p$ would still have occurred.

One way to understand Bennett's proposal is to focus on D and note that because of the relationship between $p^{*}$ and $m, \mathrm{D}$ is false. Of course, in the actual world $p^{*}$ occurs with $m$. But this is a contingent fact (as the multiple realizability of the mental suggests). There are worlds in which $p^{*}$ occurs without $m$. The question is whether $p^{*}$ would bring about $p$ in such worlds. Bennett says "although there are worlds in which [ $\left.p^{*}\right]$ occurs without $m$, they are different enough from the actual world that we have little or no 
reason to think that $[p]$ would occur there" (Bennett 2003: 487). To use Bennett's example, a world in which my neural activity occurs in a petri dish is not a world in which we would expect it to cause, say, my moving my left foot. So while $p^{*}$ is a suffcient cause of $p$ (closure principle), $p^{*}$ 's causing of $p$ is not entirely without contribution from $m$ since the conditions necessary for $p^{*}$ 's causing $p$ are precisely the conditions which underpin the relationship between $p^{*}$ and $m$. In a world in which $p^{*}$ occurs without $m$, these conditions do not hold and $p^{*}$ would not, or in any case, might not, cause p. All of this suggests, Bennett thinks, that $\mathrm{D}$ is false. And because $\mathrm{D}$ is false, the mental/physical case does not turn out to be a case of strong overdetermination. It may still involve overdetermination of some kind — a 'weak' variety—but such overdetermination is innocuous and can be accepted without pain of positing widespread overdetermination of a problematic sort.

The move here is unquestionably an interesting, and arguably viable, one. But it's important to note that, as Bennett herself acknowledges (Bennett 2003: 490, 491), the distinction between problematic and unproblematic overdetermination may undermine the claim that each of $m$ and $p^{*}$ are causally sufficient for $p$. In particular, it's not clear that Bennett's line of argumentation can be applied to $\mathrm{C}$ in such a way as to render $m$ causally sufficient for $p$ and thereby defend genuine mental causation.

Finally, some philosophers have noted that the exclusion argument presupposes a 'thick' conception of causation according to which causation is production or generation. On this view, causes are 'oomphy.' But other 'thinner' conceptions of causation are available (e.g., regularity or counterfactual accounts). Kim certainly appreciates that "causation as generation, or effective production and determination, is in many ways a stronger relation than mere counterfactual dependence." But he insists that "it is causation in this [first] sense that is fundamentally involved in the problem of mental causation" (Kim 2005: 18). Now, it is only when causes are thought to contribute something (in the sense of energy transfer or flow, say) that a supposed contribution on the part of an irreducible mental state constitutes a violation of the closure principle, since such an occurrence would imply that the physical cause is not sufficient and the physical causal story is thereby incomplete.

This paves the way for a fourth reply to the exclusion argument. Perhaps the causal role of the mental can be redescribed in a way that does not involve production or generation, but something weaker. In doing so, $m$ will no longer compete with $p^{*}$ as a sufficient cause of $p$ and exclusion will be averted (Van Gulick 1993; Loewer 2002; Sider 2003). Let's consider a recent version of this strategy. Christian List and Peter Menzies have argued that if we understand causation as "difference-making" (a conception shared by multiple accounts of causation, including counterfactual, interventionist and contrastive accounts), Kim's formulation of the exclusion principle turns out to be false (List and Menzies 2009).

The argument is this. As is now familiar enough, given the closure and exclusion principles, $p^{*}$ rules out $m$ as a cause of $p$. But, List and Menzies point out, although $m$ supervenes on $p^{*}$, it might instead have supervened on some other neural structure, say, $p^{* *}$. By analogy, consider the case of a pigeon that is trained to peck always and only at red objects (Yablo 1992). Every time the pigeon is presented with red objects, it pecks at them. Now let's suppose that the pigeon is presented with an object that is crimson and, unsurprisingly, it pecks at it. Which of the following caused the pigeon to peck at the crimson object: the fact that the object is red or the fact that it is crimson? According to List and Menzies, by the exclusion principle, we would need to say that because being crimson is causally sufficient for being pecked at (and notice, too, that being red 
supervenes on being crimson), the redness of the object is not a cause of the pecking. However, this seems wrong. So, perhaps our original assessment-that the causal sufficiency of $p^{*}$ rules out $m$ as a cause-was wrong as well. Indeed, List and Menzies find it an unpalatable result that $p^{*}$ is credited as being causal (thereby excluding $m$ ), when it is $m$-and not $p^{*}$ - that makes the difference for $p$.

Now, on List and Menzies' view, "making a difference" is given a counterfactual analysis. And while the details of the view are nuanced and deserving of careful evaluation, there are a couple of things to be said about the general move they're making, particularly as regards its viability as a reply to the exclusion argument. First, it's not clear that difference-making can simply replace production or generation in characterizing the contribution of the mental. If theories like difference-making and other counterfactual analyses have as their explanatory target typical causal attributions whereas production accounts aim at a description of how causation in fact happens in the world (as Ney suggests in, for example, 2012), then moving to a difference-making account to avoid exclusion amounts to changing the subject. Consider the way in which List and Menzies argue that difference-making is indeed a causal notion. They list four reasons for this conclusion: (1) difference-making "is often used as the central motivating idea behind various theories of causation;" (2) the epistemology of causation is "closely tied to establishing properties as difference-makers for other properties;" (3) causal relevance or difference-making "plays a central role in theories of causal explanation;" and (4) the difference-making account on offer "stands in stark contrast to the opacity of the notion of productive or generative causation” (List and Menzies 2009: 485). This set of reasons is revealing. It suggests that the target of the difference-making view is to track causal attributions. After all, difference-making as a motivation for causal accounts, its relevance to epistemological considerations and explanation all point to difference-making as an approach to tracking such attributions. Whether the difference-making view achieves clarity that the production view lacks, as (4) suggests, is a topic for another occasion. But if our interest in mental causation is to figure out, as Ney puts it, "whether irreducible mental states have what it takes to participate in genuine causal relations" (2012: 242), then it may be that we cannot dispense of causation in the thick sense.

Second, recall that our central motivation for defending mental causation-the reason we care about mental causation in the first place-is that we wish to preserve agency. Agents are difference-makers, no doubt, but it's far from obvious that differencemaking alone-in the List/Menzies sense-will suffice to underpin a view of ourselves as actors in the world; being, as we are, the sorts of things capable of bringing about results in a natural environment and as creatures capable, if you will, of influencing, even producing portions of the world. In recent years, philosophers have shown an increased interest in understanding the nature of the causation involved in mental causation and, correspondingly, in action. There is no doubt that this will give rise to a rich and illuminating discussion moving forward.

\section{Bibliography}

Baker, L.R. (1993) "Metaphysics and Mental Causation," in J. Heil and A.R. Mele (eds), Mental Causation. New York and Oxford: Oxford University Press, pp. 75-96.

Bennett, K. (2003) "Why the Exclusion Problem Seems Intractable, and How, Just Maybe, to Tract It," Nô̂s 37: 471-97.

Bennett, K. (2008) "Exclusion Again," in J. Hohwy and Jesper Kallestrup (eds), Being Reduced: New Essays on Reduction, Explanation, and Causation. Oxford and New York: Oxford University Press, pp. 280-306. 
Chalmers, D. (1996) The Conscious Mind. New York and Oxford: Oxford University Press.

Clarke, R. (2003) Libertarian Accounts of Free Will. Oxford and New York: Oxford University Press.

Davidson, D. (1963/2001) Essays on Actions and Events. Oxford and New York: Oxford University Press.

D'Oro, G. (ed.) (2013) Reasons and Causes: Causalism and Non-Causalism in the Philosophy of Action. Basingstoke: Palgrave Macmillan.

Fodor, J. (1990) "Making Mind Matter More" in J. Fodor, A Theory of Content and Other Essays. Cambridge: MIT Press, pp. 137-59.

Frankfurt, H. (1969) "Alternate Possibilities and Moral Responsibility," Journal of Philosophy 66: 829-39.

Ginet, C. (1990) On Action. Cambridge and New York: Cambridge University Press.

Kane, R. (1996) The Significance of Free Will. Oxford and New York: Oxford University Press.

Kim, J. (1993) "Can Supervenience and 'Non-Strict Laws' Save Anomalous Monism?" in J. Heil and A. Mele (eds), Mental Causation. Oxford: Oxford University Press, pp. 19-26.

Kim, J. (1998) "Reasons and the First-Person" in J.A.M. Bransen and S.E. Cuypers (eds), Human Action, Deliberation and Causation. Dordrecht: Kluwer Academic Publishers, pp. 67-87.

Kim, J. (2005) Physicalism, or Something Near Enough. Princeton: Princeton University Press.

Kim, J. (2006) Philosophy of Mind, 2nd edn. Cambridge: Westview Press.

Kim, J. (2010) "Thoughts on Sydney Shoemaker's Physical Realization," Philosophical Studies 148: 101-12.

List, C. and Menzies, P. (2009) "Non-Reductive Physicalism and the Limits of the Exclusion Principle," Journal of Philosophy 106: 475-502.

Loewer, B. (2002) "Comments on Jaegwon Kim's Mind and the Physical World," Philosophy and Phenomenological Research 65: 655-62.

McCann, H. (1998) The Works of Agency: On Human Action, Will, and Freedom. Ithaca: Cornell University Press.

McLaughlin, B.P. (1989) "Type Epiphenomenalism, Type Dualism, and the Causal Priority of the Physical," Philosophical Perspectives 3: 109-35.

McLaughlin, B.P. (1993) "On Davidson's Response to the Charge of Epiphenomenalism" in J. Heil and A.R. Mele (eds), Mental Causation. Oxford: Oxford University Press, pp. 27-40.

Ney, A. (2010) "Convergence on the Problem of Mental Causation: Shoemaker's Strategy for (Nonreductive?) Physicalists," Philosophical Issues 20: 438-45.

Ney, A. (2012) "The Causal Contribution of Mental Events" in S. Gozzano and C. Hill (eds), New Perspectives on Type Identity: The Mental and the Physical. Cambridge: Cambridge University Press, pp. 230-50.

O'Connor, T. (2002) Persons and Causes: The Metaphysics of Free Will. Oxford: Oxford University Press.

Sehon, S. (2005) Teleological Realism: Mind, Agency, and Explanation. Cambridge: MIT Press.

Shapiro, L. (2007) The Correspondence between Princess Elisabeth of Bohemia and René Descartes. Chicago: University of Chicago Press.

Shoemaker, S. (2001) "Realization and Mental Causation" in C. Gillett and B. Loewer (eds), Physicalism and Its Discontents. Cambridge: Cambridge University Press, pp. 74-98.

Shoemaker, S. (2007) Physical Realization. Oxford: Oxford University Press.

Sider, T. (2003) "What's So Bad About Overdetermination?" Philosophy and Phenomenological Research 67: 719-26.

Steward, H. (2012) A Metaphysics for Freedom. Oxford and New York: Oxford University Press.

Timpe, K. (2008) Sourcehood and its Alternatives, 2nd edn. London: Continuum.

Van Gulick, R. (1993) "Who's in Charge Here? And Who's Doing all the Work?" in J. Heil and A. Mele (eds), Mental Causation. New York and Oxford: Oxford University Press, pp. 233-56.

Yablo, S. (1992) "Mental Causation," The Philosophical Review 101: 245-80.

\section{Further Reading}

Bennett, K. (2003) "Why the Exclusion Problem Seems Intractable, and How, Just Maybe, to Tract It," Noûs 37: 471-97. (Offers a response to the exclusion argument by arguing that the overdetermination involved in cases of mental causation is not of a problematic sort.)

Davidson, D. (2001) Essays on Actions and Events. Oxford: Oxford University Press. (A collection of this key figure's seminal essays on events and the nature of agency.)

Heil, J. and A. Mele (eds) (1993) Mental Causation. Oxford and New York: Oxford University Press. (A collection of articles representing some key work on the topic of mental causation.) 


\section{MENTAL CAUSATION}

Kim, J. (2005) Physicalism, or Something Near Enough. Princeton: Princeton University Press. (A sustained argument for a nuanced reduction of the mental to the physical.)

Gillett, C and Loewer, B. (eds) (2001) Physicalism and Its Discontents. Cambridge: Cambridge University Press. (A collection of articles representing the various positions with respect to physicalism.)

\section{Related Topics}

Event-Causal Libertarianism

Agent Causation

Non-Causal Libertarianism

Frankfurt-Style Examples

Leeway vs. Sourcehood Conceptions of Free Will

René Descartes 


\section{8}

\section{MARGINAL AGENTS AND RESPONSIBILITY PLURALISM}

David Shoemaker

James Fallon is a highly-regarded neuroscientist, someone who has contributed important work on Parkinson's disease, Alzheimer's disease, schizophrenia, and addiction. But he describes his own interpersonal interactions as follows:

If you knew me, you'd probably say, "Oh, he's a fun guy"—or maybe, "He’s a big-mouth and a blowhard narcissist"-but I also think you'd say, "All in all, he's interesting, and smart, and okay." But here's the thing-the closer to me you are, the worse it gets. Even though I have a number of very good friends, they have all ultimately told me over the past two years when I asked themand they were consistent even though they hadn't talked to each other-that I do things that are quite irresponsible. It's not like I say, Go get into trouble. I say, Jump in the water with me.

(Ohikuare 2014)

As an example, Fallon cites a time when he manipulated his brother into joining him on a wildly dangerous trip to the Kitum Caves, in Nairobi, where they had a significant chance of catching Ebola. Once his brother knew the danger they were actually in and how his brother had manipulated him into going — as he had manipulated him many times in the past—he became outraged and never fully trusted him again.

Given this and many other tales, Fallon's self-description as a narcissistic jerk rings true. He also seems morally responsible for lying to and tormenting his brother. However, in 2005, Fallon accidentally discovered that he has the "brain of a psychopath," possessing a series of genetic alleles known as warrior genes that put him at high risk for aggression and violence and produce deficiencies in fear, emotional responses, and empathy that dispose him to risk-taking behavior. ${ }^{1}$ In light of this information, does he still seem morally responsible for his deeds?

Becoming aware of such facts tends to produce in us a kind of unease, I think, but it is not the unease of uncertainty; rather, it is the unease of ambivalence. While Fallon may now strike many of us as not (or at least less) responsible in some ways, he may still seem - to the same respondents - to be responsible in some other ways. But to the extent 
that most theorists believe moral responsibility to be monistic-that is, believe that there is only type of responsibility that either does or doesn't apply to all agents-how might we make sense of such ambivalence?

Psychopaths are just one among many types of marginal agents, agents at the borders of our moral responsibility communities who often produce in us this kind of ambivalence about their status. Others include those with clinical depression, high-functioning autism, mild intellectual disabilities, and moderate dementia, as well as those with traumatic or morally deprived upbringings. As it turns out, these real-life agents-agents many of us either are or may become - and our ambivalent responses to them can teach us quite a bit about the nature of moral responsibility. In this essay, I will explain why the panoply of marginal cases puts serious pressure on a monistic view of responsibility by focusing on three such cases: psychopathy, autism, and dementia.

\section{The Variety of Responses to Marginal Agents}

Any plausible theory of moral responsibility will have to account for-or at least explain away-our responsibility responses, the wide range of attitudes and practices often construed as instances of holding someone responsible. But what are the relevant responses? In what follows, I will focus primarily just on our emotional responses and leave aside the wide range of practices built on top of them (although I will return to this issue later). ${ }^{2}$ Now the first payoff of taking marginal agency seriously is that our ambivalence in these cases reveals a wider range of responsibility responses than theorists usually consider. For example, in the case of Fallon we may think, "Well, anger or resentment of him feels rather pointless- he just can't appreciate what his dangerous stunt was like for his brother, after all. Nevertheless, his brother's reluctance to trust him anymore seems perfectly legitimate, as Fallon really is an untrustworthy, manipulative, narcissistic jerk, so disdaining or feeling contempt for him still seems appropriate."

Consider next the self-report of a 13-year-old boy with autism, Naoki Higashida:

When I see I've made a mistake, my mind shuts down. I cry, I scream, I make a huge fuss, and I just can't think straight about anything anymore ... Finally, finally, I'll calm down and come back to myself. Then I see no sign of the tsunami attack—only the wreckage I've made. And when I see that, I hate myself. I just hate myself.

(Quoted from Higashida 2013)

Higashida is clearly holding himself responsible in a variety of ways, including regret and self-hatred, and for different things, including his mistakes and his overreactions to them. Yet we are likely to be ambivalent to him, admiring him for his concern to avoid mistakes, proud of his good decisions and perhaps disapproving, alongside his own regret for, his bad ones, but we also likely see the degree of his regret as way overboard, and his self-hatred - and any hatred we may feel for him in light of his overreactions-as completely inappropriate. Finally, consider the self-report of someone in the midst of Alzheimer's dementia:

[P]eople do not have time to explain to me over and over again, things that I don't understand ... They cannot depend on me to remember the simplest of 
instructions ... The trust relationship between husband and wife, father and son, grandfather and grandchild is breaking. Not because we do not love each other as much as in the past, in fact now it is even more. It is strained to the point of breaking by the symptoms of Alzheimer's disease.

(Quoted in Snyder 2006: 272, 273)

Here again, our responses—especially the responses of those in caregiving relationshipsto someone in this state would tend toward ambivalence. These are agents for whom resentment, indignation, and moral disapproval no longer feel appropriate, but if their inner lives are anything like this person's, the appropriateness of some other responses may well be left intact, for example, admiration or esteem for their bravery and fortitude, or even disdain or contempt for their persisting meanness.

In these three marginal cases alone, we notice a wide variety of responsibility responses to which we are susceptible: admiration, esteem, disdain, contempt, hatred, regret, pride, disapproval, approval, anger, resentment, indignation, and gratitude. And there are many other responsibility responses that may arise in different contexts: abhorrence, revulsion, shame, awe, elevation, veneration, disappointment, irritation, frustration, appreciation, approbation, guilt, hurt feelings, warm feelings, and gratification. ${ }^{3}$ All of these may be, at one time or another, deployed to others or ourselves, and often several overlapping responses feel appropriate. We tend to think that others and ourselves are, ordinarily, fully eligible for any of these responses. But in the marginal cases, we tend to think that such agents are eligible for only some of them. Our feelings pull us in multiple directions.

According to monistic theorists of responsibility, there is just one type of responsibility, and so to the extent that the above are indeed responsibility responses, responsible agents are either eligible or ineligible for the entirety of these responses (depending on what they have done, the attitudes they express, or the way they are), full stop. ${ }^{4}$ Pluralistic views, by contrast, maintain that there is more than one type of responsibility. One could thus be responsible on one type but not another. For the few responsibility pluralists there are, these different types are associated with different subsets of our responsibility responses (see, for example, Watson 1996, 2011; Shoemaker 2011, 2014, 2015; McKenna 2012). Consequently, were an agent responsible on one type but not another, that agent would be eligible for some of our responsibility responses but not others. And these would count as different types of responsibility in virtue of the fact that the different subsets are responses to the expression of very different sorts of agential capacities.

While I will discuss some specific pluralistic theories in the following sections, it will be helpful to illustrate the basic idea with a simple model. Some of our responsibility responses - for example, admiration and disdain-look to be responses to good or bad expressions of agential character. Others-for example, resentment or gratitude-look to be responses to expressions of disregard or regard (the degree to which one takes seriously the interests of others, say). But people of poor character may sometimes take people's interests seriously, and people of good character sometimes may not. Indeed, the different objects of our different responses (where these are appropriate) seem to require very different agential capacities. The first depends on one's being able to have and express character traits, which more or less consist in different kinds of emotional or evaluative dispositions. The second, it is usually thought, depends on one's having a certain kind of normative competence (i.e., being able to recognize relevant moral reasons) and being able to exercise a certain kind of control over one's actions 
(or attitudes). Consequently, were an agent capable of only the first, for example, then the pluralist could say that she was responsible only in the character-sense but not in the regard-sense, and so say that only a certain subset of responsibility responses would be appropriate for her.

Let us turn, then, to explore three specific marginal cases. The aim is to show that pluralistic theories do better than monistic theories in accounting for our ambivalent responses to them. I will conclude by exploring ways for the monist to fight back.

\section{Psychopathy}

Monistic verdicts on the moral responsibility of psychopaths have been split. The majority of philosophical theorists deny that psychopaths are responsible agents, or at least urge that their responsibility is severely diminished, while a healthy minority takes the opposite stance. Theorists on both sides mostly agree on the empirical facts about psychopaths, and, in particular, on the nature of their deficits. What they disagree about is whether those deficits are responsibility-undermining. And even those theorists who believe psychopaths' deficits are responsibility-undermining disagree over which deficits do the undermining and why. I will first survey and discuss skepticism about psychopathic responsibility before turning to those who affirm such responsibility.

Psychopaths have well-documented impairments in their capacities for fear, emotion, and empathy. There are roughly two traditions in the literature defending psychopathy exemptions from responsibility: cognitive and non-cognitive. The cognitivist tradition focuses on how psychopaths' deficits yield general impairments in grasping and/or applying moral reasons. ${ }^{5}$ Normally, various facts about how your interests will be affected by my actions count as (prima facie) reasons for me. I generally take seriously the fact that it will cause you pain as a reason not to step on your foot. For psychopaths, however, facts about others' interests tend not to appear to them to be reasons. The fact that it will cause you pain just does not appear to them to be a reason not to step on it. But interestingly, facts about their own interests tend not to appear to them to be (prudential) reasons either. Many of them flit from job to job, or from project to project, with no clear ends-that is, pursuits they deem worth pursuing-in sight. As a result, their fortunes often fluctuate wildly, depending on how long their attention rests on any one pursuit. They also tend not to see why they should avoid certain actions that will land them in prison, even though they profess to dislike it (Cleckley 1976). And their prudential and moral reasoning deficits are often taken to be a function of their empathic deficits, their inability to fully understand what matters from someone's perspective, including their own (e.g., Deigh 1995; Glannon 1997; Darwall 1998; and discussed in Maibom 2008).

Those from the noncognitivist tradition of exemptions, however, tend to emphasize psychopaths' motivational impairments in avoiding actions they otherwise know-in some sense- to be wrong. This presumed lack of moral motivation is often taken to stem from their emotional deficits, as this purportedly indicates that they lack the capacity to care about others — or the demands of morality generally — and so are unmoved to avoid actions they may still, in some sense, recognize to be wrong (see, e.g., Fingarette 1967; Murphy 1972; Shoemaker 2007). But it might also stem from what some have taken to be their general lack of impulse control: they are sometimes thought to be powerless against the force of their desires, regardless of any judgments they might make, or they may simply lack various inhibitory mechanisms altogether (see, e.g., Blair 1997). 
A lesser-traveled, but perhaps more plausible, route is to ground psychopaths' lack of responsibility in an impairment that cuts across the cognitive/non-cognitive divide, namely, an impairment of moral sense (see Pritchard 1974; Russell 2004; McKenna 2012: 80-2). On this construal, the psychopath's particular deficiencies of feeling and reason place him, in effect, outside of our form of life, rendering him unable to deal with us in anything like the ordinary interpersonal terms of engagement. Imagine someone who utterly lacks a sense of humor, but who nevertheless studies us and figures out when to make the right laughing noises. Even though he may lack no information about what constitutes a joke and the kind of laughter that appropriately accompanies different kinds, he still doesn't have a full understanding of humor, and he is also never genuinely amused (Pritchard 1974: 639, 640). A moral sense, like a sense of humor, requires both robust understanding and a range of attitudinal dispositions. Psychopaths, on this construal, lack responsibility because they lack a moral sense.

Those who disagree with this general verdict point to different capacities psychopaths share with the rest of us that are sufficient to preserve responsibility despite their other impairments. These theorists tend to downplay the importance of psychopaths' so-called impairments of moral understanding, doing so in two different ways. Heidi Maibom (2008) argues, for instance, that empathy is not necessary for moral understanding, that such understanding may derive instead from a variety of sources, for example, religious belief or Kantian universalization. To the extent that there is no impairment blocking psychopaths' arrival at moral understanding via these alternative routes, they should not be let off the hook for responsibility, despite being impaired in empathy.

The other way of urging psychopathic responsibility comes from a tradition according to which one's responsibility for $A$ is a matter of $A$ being attributable to one in such a way that one could, in principle, answer for A by citing one's judgments about A's worth (see Scanlon 1998; Smith 2005, 2012; Talbert 2008). Note that this requires only the capacity for making judgments about the worth of reasons generally. So one could be responsible for judging some category of reasons as worthless even if one were blind to their normative force. To the extent that psychopaths judge our interests to be worthless, they are responsible, on this construal, for ignoring or undermining them. After all, if a psychopath judges that my pain doesn't count as a reason for him not to step on my foot, it will surely feel as if some negative responsibility response is warranted, for that's just nasty behavior!

The dialectic is at a stalemate. But there are compelling insights on both sides. What, then, is to be done? When these theorists render verdicts on psychopathic responsibility, they are applying an antecedent, monistic theory of responsibility to them. Such an approach, however, fails to take seriously our ambivalence toward them. Gary Watson articulates the 'trouble with psychopaths' thus:

Those who ... deliberately and callously harm, defraud, and manipulate others, as psychopaths frequently do, seem appropriately subject to blame ... And yet psychopathy ... precisely involves an incapacity to recognize the interests of others as making any valid claims on them ... The difficulty is that what appears to explain a good bit of the conduct for which we naturally want to blame these individuals is the very incapacity that disqualifies them as moral agents. 
Watson's solution is not to reject one or the other sources of this presumed tension, but to account for both within a pluralistic theory-one on which our earlier example was modeled-according to which there are two 'faces,' or types, of responsibility (see Watson 1996). Psychopaths are responsible and blameable on what he calls the attributability face, given that their actions express a fault in their character-they enjoy hurting others! - whereas they are not responsible or blameable on the accountability face, as "they lack the capacity for moral reciprocity or mutual recognition that is necessary for intelligibly holding someone accountable to basic moral demands and expectations" (Watson 2011: 308). Consequently, some of our responsibility responses-those targeting faults of character (e.g., disdain or contempt) - may still be appropriate toward psychopaths, even if others-those targeting adherence to demands for reciprocity or mutual recognition (e.g., resentment or indignation)—are not.

Such an approach seems preferable to the monistic approach insofar as it accounts for both our ambivalence and the insights of the monistic theorists. After all, judging that someone's interests are worthless and then acting on a desire to trample them is just what cruelty is, and cruelty surely warrants contempt. But to the extent that such a person is incapable of empathy, or is lacking in moral sense generally (and so is indeed blind to the class of moral reasons against trampling one's interests), it does seem pointless, and inappropriate, to express one's resentment to him, as such a response does seem to involve an expression of a moral demand he is just incapable of understanding.

\section{Autism}

Very few responsibility theorists have written about autism, which is most fundamentally characterized as a disorder of social communication. What little conversation there has been, however, is fascinating and important. It was initiated by Jeanette Kennett, who contrasted those who have high-functioning autism with psychopaths (Kennett 2002). Her main point was that, were empathic impairments sufficient for exempting psychopaths from moral agency (and, let us assume, responsibility), then those with high-functioning autism ought to be exempt as well, given their similar empathic impairments. ${ }^{6}$ Nevertheless, she claims, those with high-functioning autism can be excellent moral agents, well-meaning and wishing to do the right thing (Kennett 2002: 351), despite their impairments in simulating the mental states of others. Consequently, empathy cannot be the ground or essence of moral agency it has been thought to be. Rather, she argues, it must instead be moral concern-a kind of caring about (reverence for) moral reasons - which psychopaths lack and those with high-functioning autism have. As empathy is only one means for figuring out moral reasons, those who lack it may still find, as those with high-functioning autism have, alternative means for doing so, given that they are motivated to be moral, and Kennett suggests that their abilities (and obvious moral agency) consequently tend to favor a Kantian, rather than Humean, picture of moral agency.

In response, Victoria McGeer (2008) wonders whether those with autism really have moral concern. Instead, there is much evidence suggesting that they have an overriding "need to abide by whatever rules they have been taught without sharing our understanding of the ends those rules are meant to serve" (McGeer 2008: 240). If one were born into a world in which one had severe difficulty knowing what others were thinking, feeling, or wanting, or how one ought to respond to those things, one would likely try "to keep everything the same" in order to reduce "some of the terrible fear" (Jolliffe 
et al. 1992: 16; quoted in McGeer 2008: 240). So too it may be that those Kennett takes to have "reverence for reason" actually just cling to whatever social norms they can divine, regardless of their basis. This would mean that when their behavior conforms to morality, it would reflect less a moral concern than a prudential one.

In addition, it seems that, given their significant impairments in empathy, at least some of our responsibility responses to them would be pointless. After all, when I express my anger, say, to you for stepping on my foot, I am, most fundamentally, demanding that you at least acknowledge what you did to me. Genuine guilt, apology, and reconciliation seem impossible without it. But acknowledgment requires some fairly sophisticated capacities, for to do so, one must be able to take up the perspective of the injured party, not only to understand what things were like from her perspective (and with her values), but also to feel what things were like for her (see Shoemaker [2015] for discussion). Most of us engage in this perspective-taking all the time without much noticing it, but this is an activity those with high-functioning autism are generally unable to engage in (or are quite impaired at), and so acknowledgment-demanding anger, say, would be pointless for them.

What this thought brings out is the basis for a lingering ambivalence to those with high-functioning autism in light of the insights of both Kennett and McGeer. While it may indeed be pointless or inappropriate to hold those with autism to account in a variety of blaming ways, there still seems something right as well in the thought that they are quite different from psychopaths, despite having empathic deficits in common. So what does the difference consist in? We get a clue from Kennett's way of describing some people with autism, namely, as "well-meaning," and as "wishing . . . to do the right thing" (Kennett 2002: 351). What McGeer and I are suggesting is that they lack, or have a diminished, capacity for grasping moral reasons, given their lack of or deficient empathy. But this impairment is perfectly compatible with being a well-meaning person, the type of person disposed to want to do right by others, even if she cannot determine what that is. And we may well have a variety of (appropriate) positive responses to such persons, including admiration and esteem. Further, as the quote from Higashida earlier suggests, we may feel, along with those with autism, disapproval or pride for their judgments that we would think ought to correlate with a certain tempered degree of regret or pride on their own part, also independently of their ability to regard others in certain ways. But disapproval or pride and admiration or esteem are all, in their own way, responsibility responses. So a pluralistic approach may well explain our ambivalence to marginal autistic agents in a more satisfying way than a monistic theory, implying that they are capable of some types of responsibility (a la Kennett) but not others (a la McGeer).

\section{Dementia}

Finally, consider the case of Alzheimer's dementia and moral responsibility, a previously unexplored topic. ${ }^{7}$ In its major form, it is diagnosed in light of serious memory impairments in tandem with one of six other cognitive impairments: language function (aphasia), the ability to activate or execute intact motor capacities (apraxia), complex attention, impaired social cognition, or a disturbance in planning, organizing, sequencing, or abstracting abilities (executive functioning) (American Psychiatric Association 2013: Code 331.9). In the middle stages of the disease, there is a point at which the kind of ambivalence I have been discussing often creeps in, evidenced in reports by 
caregivers and family members, but resonant, I am sure, with many of us who now have loved ones with the disease (for suggestions along these lines, see, e.g., Siegler et al. 1994; Monfort 1995; Hansebo and Kihlgren 2002). The basic, familiar, thought is that, while a certain subset of responsibility responses starts to feel quite inappropriate at this point, another subset may still feel fitting. In particular, acknowledgment-demanding responses (such as anger) start to feel pointless, as may critical or disapproving responses, yet admiration, esteem, and even disdain may still have a place.

For example, consider one's moderately demented grandfather, who, upon your arrival, gets up to bring you a piece of chocolate (with considerable pain), then stares out the window for several minutes, forgetting your presence, perhaps unaware of who you are. Expressions of gratitude feel pointless at that point, given his lack of conscious connection with the chocolate-giving agent. Nevertheless, he is kind, and admirable thereby. Indeed, such an assessment can be made with more confidence to the extent that this is the sort of thing he always used to do, that is, we would say he is still kind. There seems to be some remnant of his character that makes appropriate our admiration, even though he is now lacking the other sorts of cognitive capacities that would render various other responsibility responses appropriate. ${ }^{8}$

A monistic theory of responsibility will once again have difficulty accounting for such ambivalence in our responses, whereas a pluralistic theory of responsibility can easily do so. If different subsets of our responses take as their objects different agential features and capacities, then those with moderate dementia may simply be responsible on some types of responsibility but not others. For example, while their abilities to regard others or make good judgments about reasons have been significantly impaired by impairments to both memory and executive functioning, certain things may still matter to them sufficiently to count as character traits they occasionally express in their attitudes and actions. ${ }^{9}$ Thus might a pluralistic theory explain why some responses (admiration or even disdain) remain appropriate for them whereas others (anger, gratitude, moral disapproval, for example) are not.

\section{Monistic Replies}

My aim thus far has been to show how our ambivalence to several cases of marginal agency puts serious pressure on monistic theories of responsibility. I have done so by demonstrating how easily a pluralistic theory of responsibility can account for this ambivalence, suggesting that monistic theories have, prima facie, much more difficulty doing so. Perhaps, though, monists have a plausible way of dealing with this ambivalence after all. In this final section, I will briefly evaluate two possible monistic strategies for doing so.

The first strategy would be to insist that not all of the responses I have discussed are genuine (moral) responsibility responses. Leading examples of this approach claim instead that the only genuine responsibility responses are those exclusively to wrongings or violations of obligations (see, e.g., Wallace 1994; Darwall 2006). Consequently, our ambivalence is not a responsibility ambivalence; rather, our genuine responsibility responses are still unified in being (all together) suspended or not to certain agents, even though there may be other (non-responsibility) responses to different agential features that are not in sync with these. Perhaps these other responses are merely character appraisals, not responsibility assessments, for instance. ${ }^{10}$ In all three of the marginal cases I have discussed, then, perhaps all of the genuine responsibility responses (anger 
and its ilk) are all appropriately switched off, and that's all we need to know to see that these agents are not responsible, period.

This view tends-implausibly-to exclude positive responses from the realm of 'the genuine' responsibility responses. But even if they are included, this monistic theorist would still say that 'genuine' responsibility is restricted to those responses that are inexorably attached to blaming (or praising) treatment of others, for example, anger and its ilk along with (only) gratitude or commendation on the positive side. Resentment and indignation, for instance, have struck many theorists as necessarily associated with at least the motivational impulse to dole out harsh treatment, sanctions, or punishment (for just three, see Watson 2004: 275-9; McKenna 2012: Chapters 6 and 7; and Pereboom 2014: Chapter 6; for a counter-view, see Scanlon 2008: Chapter 4).

Nonetheless, while it may be true that our general treatment of people to whom we have these emotional responses may be of a distinctively different sort than our treatment (if any) of people solely in light of, say, their bad characters, that is not yet to say that our initial responses - the attitudes we have in light of our perceptions of various agential features-have any such distinguishing marks. Indeed, none of our responses necessarily involve treatments at all; rather, what treatments there are, are built on top of these responses, and they are certainly not required of them. This is obviously true in cases of admiration or disapproval, both of which I may feel about you privately or from afar. But it is also true for what many have thought are the paradigm 'treatment-associated' responses, namely, anger and its ilk. These are typically thought to have that inexorable connection to the kinds of blaming sanctions and punishments that ostensibly ground viewing them in a very different way from the other responses I have identified. But there is nothing about anger (or resentment, or indignation) per se that has an inexorable connection to sanctions. Anger may be fully discharged via my shaking voice, or my oh-soquiet shutting of the door, or my refusal to greet you with my ordinary good cheer (for this last example, see Scanlon [2008: 144]). In none of these cases, though, is there any necessary connection to harming, censuring, or sanctioning you. These latter sorts of treatments are sometimes built on top of anger and its ilk, to be sure, but often they are not, especially in familiar interpersonal morality. Instead, such angry responses are more plausibly described as responses to (negative) expressions of practical agency, but if so, there is simply no treatment-basis on which one could justifiably exclude some subset of the responses I have identified as part of the responsibility roster. And it is hard to think of another reason to do so. Such exclusion instead seems a kind of moralistic emotional chauvinism.

A second strategy for the monist to account for our general ambivalence toward cases of marginal agency is to insist that, while all of the responses I have identified are indeed responsibility responses, there remains just one type of all-things-considered responsibility verdict in any case, one that is perhaps a weighted function of expressions of all the different agential features the different responsibility responses target. ${ }^{11}$ This response distinguishes between a monistic theory of responsibility and an all-or-nothing theory of responsibility, and embraces only the former. In other words, the only type of responsibility might, as many think, come in degrees, so rather than people being responsible or not, full stop, they would be more or less responsible on the only type, depending on the range and expression of their various targeted agential features. To illustrate by drawing from our initial model, perhaps one's degree of responsibility is a function of the extent to which one's actions or attitudes express one's character and one's regard. So, for example, perhaps psychopaths, given that they have and express robust character traits but are somewhat impaired with respect to regard, are less 
responsible for their actions and attitudes than neuro-typical humans, but are nevertheless more responsible than those with moderate dementia, who may lack regard altogether and have less robust character traits.

This strategy is much closer to the spirit of pluralism, and, indeed, the filled-out view may be essentially identical to pluralism, just with a different label. If so, I am fine with it, as long we note just how radically different this view would be from the standard view of responsibility, which typically takes seriously only one subset of our responses to only one subset of agential features (as in the first response above). Nevertheless, there remains something to be said for emphasizing the plurality of agential features rather than keeping them under a monistic rubric, which is that if we take responsibility to be a single, monistic (albeit scalar) function of the expressions of distinct agential capacities, we run roughshod over the possibility of familiar fine-grained assessments of responsibility. Suppose, again drawing from our simple model, that one agent lacked the ability to express some features of her character but nevertheless was fully able to regard others, whereas a second agent had full characterological capacities but lacked the capacity to regard others in the demanded ways. Each then, on this monistic alternative, would have one-half responsibility. But this coarse-grained assessment would gloss their very different sources of reduced responsibility, which are their very different incapacities. Indeed, knowing that someone was only one-half responsible for her actions or attitudes would not yet give me any indication of which sorts of responses would be appropriate for her. On the pluralistic alternative, however, if someone were, say, incapacitated for regard, while being fully capacitated for expressions of character-as, say, seems true of psychopaths — she could be fully eligible for disdain, but not anger, whereas someone impaired in character but capable of regard ${ }^{12}$ could be eligible for anger but not disdain. Adopting talk of different types of responsibility better accounts for the fine-grained nature of our responses to those (partially) responsible members in our moral midst.

\section{Conclusion}

I have argued that ambivalence to the real-life marginal agents among us puts serious pressure on monistic theories of responsibility, theories maintaining that there is only one type of responsibility that (typically) obtains all-or-nothing. A better explanation of our ambivalence comes from a pluralistic approach to responsibility, according to which marginal agents are responsible on some types but not responsible on others. Such theories do greater justice to our rich and complicated interpersonal human exchanges.

\section{Acknowledgments}

I am grateful to Neil Levy for helpful discussion of an earlier draft of this chapter.

\section{Notes}

1 See the most recent information about it here: http://www.register-herald.com/cnhi_network/extremelyviolent-crimes-tied-to-gene-in-study-of-criminals/article_d473d933-e5e3-519c-8997-f9573f9a5416. html (accessed 29 June 2016).

2 This will be quite a controversial move for those who believe that our responsibility responses are inexorably linked to certain institutions and practices, which typically involve the doling out of 


\section{DAVID SHOEMAKER}

sanctions, punishments, and rewards. On one (sociological) story, it may be thought that we feel the emotions we do precisely because they were structured by these practices. That we can sometimes feel the emotions separately from the practices doesn't yet show that there isn't some kind of constitutive link between them. On another (evolutionary) story, it is widely agreed that the negative emotional responsibility responses we have (e.g., anger, resentment, indignation) evolved to facilitate in-group cooperation, as they effectively motivate sanctioning behavior even in the face of poor cost-benefit tradeoffs. My response is that the fact that there may be such sociological or evolutionary explanations for our having the responses we have may play no, or may play no more than a limited, role in determining whether they are currently fitting responses to have. Consider, by analogy, amusement. There is surely a fascinating sociological or evolutionary story to tell that explains why we have the amusement mechanism we have, probably having to do with group bonding or the social pressures of coming to live in larger groups (see, for example, http://www.technologyreview.com/view/421480/the-evolutionaryorigin-of-laughter/). But that story is just irrelevant to whether amusement is fitting now, for example, to whether some joke or state of affairs merits one's amusement. To figure out the right story about what merits such a response will be difficult, of course, and evolutionary or sociological stories may help, but they will only be part of the story. We also need to appeal to various normative standards that have developed around the response independently of those explanations. The same goes, I believe, for our responsibility responses. For example, the fact that anger played a certain motivational role in sanctioning free riding may be irrelevant to whether my anger in response to someone's condescending attitude toward me is merited. I defend the distinct treatment of our emotional responsibility responses and our responsibility practices in greater detail in Shoemaker (2015). My thanks to Neil Levy for discussion on this point.

3 Of course, some of these responses are not exclusively responsibility responses; we may experience (fitting) hatred, awe, warm feelings, or gratification to animals or mere states of affairs. What I have in mind, then, are agential triggers of these emotional responses, that is, when they are responses to some expression (either an action or an attitude) of agents' qualities of will. Only creatures capable of having the relevant sorts of qualities of will are therefore capable of responsibility and these fitting deployments of the responsibility responses. See Shoemaker $(2013,2015)$ for greater explanation and defense.

4 Some monists might say that responsible agents are either eligible or ineligible for the entirety of merely a central range of responsibility responses, namely, those that ground various sanctioning or rewarding institutions and practices (and that might be the only ones relevant to worries about free will). I respond to an objection like this in the final section of the chapter.

5 Leading theorists of this tradition include Wallace (1994: 177, 178), Fields (1996), Fine and Kennett (2004), Levy (2007), and Haji (2010). In Fischer and Ravizza's nuanced account (1998: 76-8), some psychopaths are likely impaired in this way, whereas others may not be.

6 One might deny that 'moral agency' amounts to 'eligibility for moral responsibility,' and I suspect that Kennett herself would resist a conflation of the two. Perhaps moral agents are appropriate targets of moral appraisals (as good and bad in certain respects) but not the appropriate targets of genuine responsibility responses. I lack space to explore the issue here (although I do say something about it in Shoemaker [2015]). For now, I will say that the position about autistic responsibility articulated in the text is one that it could be reasonable to advance, given Kennett's views on autistic moral agency. Call the position, then, Kennettian.

7 Annette Dufner (2013) discusses dementia and criminal, but not moral, responsibility. I first discussed the issue in Shoemaker (2014).

8 There is another sort of phenomenon familiar to caregivers and loved ones of those with dementia, and it typically occurs during the early stages of Alzheimer's disease, when agents may fluctuate between full-fledged responsibility (of all types) and mitigated responsibility (of all or some types). At one point in time, then, they may have all the requisite functioning responsibility capacities; at others, they may not. Such cases are interesting in their own right, but I am obviously concerned with cases not of fluctuation but of fragmentation, wherein agents are, at the same point in time, seemingly capable of some types of responsibility but not others. This is the phenomenon illustrated by the chocolates example just given in the text.

9 On the possibility of those with moderate dementia still valuing, see Jaworska (1999).

10 Both Julia Driver and Jeanette Kennett suggest such a stance in their recently presented work.

11 This is a strategy suggested informally to me by Christian Coons.

12 I argued in Shoemaker (2009) that this group might include those with mild intellectual disabilities. 


\section{References}

American Psychiatric Association (2013) Diagnostic and Statistical Manual of Mental Disorders, Fifth Edition, DSM-5. Washington, DC: American Psychiatric Association.

Blair, J. (1997) "A Cognitive Developmental Approach to Morality: Investigating the Psychopath," in S. Baron-Cohen (ed.), The Maladapted Mind: Classic Readings in Evolutionary Psychopathology. Hove: Psychology Press, pp. 85-113.

Cleckley, H. (1976) The Mask of Sanity, 5th edn. St. Louis: C.V. Mosley.

Darwall, S. (1998) "Empathy, Sympathy, Care," Philosophical Studies 89: 261-82.

Darwall, S. 2006. The Second-Person Standpoint. Cambridge: Harvard University Press.

Deigh, J. (1995) "Empathy and Universalizability," Ethics 105: 743-63.

Dufner, A. (2013) "Should the Late Stage Demented Be Punished for Past Crimes?" Criminal Law and Philosophy 7: 137-50.

Fields, L. (1996) "Psychopathy, Other-Regarding Moral Beliefs, and Responsibility," Philosophy, Psychiatry, and Psychology 3: 261-77.

Fine, C. and Kennett, J. (2004) "Mental Impairment, Moral Understanding, and Criminal Responsibility: Psychopathy and the Purposes of Punishment," International Journal of Law and Psychiatry 27: 425-43.

Fingarette, H. (1967) On Responsibility. New York: Basic.

Fischer, J. and Ravizza, M. (1998) Responsibility and Control. Cambridge: Cambridge University Press.

Glannon, W. (1997) "Psychopathy and Responsibility," Journal of Applied Philosophy 14: 263-75.

Haji, I. (2010) "Psychopathy, Ethical Perception, and Moral Culpability," Neuroethics 3: 135-50.

Hansebo, G. and Kihlgren, M. (2002) "Carers' Interactions with Patients Suffering from Severe Dementia: A Difficult Balance to Facilitate Mutual Togetherness," Journal of Clinical Nursing 11: 225-36.

Higashida, N. (2013) The Reason I Jump: The Inner Voice of a Thirteen-Year-Old Boy with Autism, Trans. K.A. Yoshida and D. Mitchell. New York: Random House.

Jaworska, A. (1999) "Respecting the Margins of Agency: Alzheimer's Patients and the Capacity to Value," Philosophy and Public Affairs 28: 105-38.

Jolliffe, T., Lansdown, R., and Robinson, C. (1992) "Autism: A Personal Account," Communication 26: $12-19$.

Kennett, J. (2002) “Autism, Empathy, and Moral Agency," Philosophical Quarterly 52: 340-57.

Levy, N. (2007) "The Responsibility of the Psychopath Revisited," Philosophy, Psychology, and Psychiatry 14: $129-38$.

Maibom, H. (2008) "The Mad, the Bad, and the Psychopath," Neuroethics 1: 167-84.

McGeer, V. (2008) "Varieties of Moral Agency: Lessons from Autism (and Psychopathy)," in W. SinnottArmstrong (ed.), Moral Psychology, Volume 3, The Neuroscience of Morality: Emotion, Brain Disorders, and Development. Cambridge and London: MIT Press, pp. 227-57.

McKenna, M. (2012) Conversation and Responsibility. New York: Oxford University Press.

Monfort, J.C. (1995) "The Difficult Elderly Patient: Curable Hostile Depression or Personality Disorder?" International Psychogeriatrics 7: 95-111.

Murphy, J. (1972) "Moral Death: A Kantian Essay on Psychopathy," Ethics 82: 284-98.

Ohikuare, J. (2014) "Life as a Nonviolent Psychopath," The Atlantic, January 21. Available from: http:// www.theatlantic.com/health/archive/2014/01/life-as-a-nonviolent-psychopath/282271/ (accessed 29 June 2016)

Pereboom, D. (2014) Free Will, Agency, and Meaning in Life. Oxford: Oxford University Press.

Pritchard, M.S. (1974) "Responsibility, Understanding, and Psychopathology," The Monist 58: 630-45.

Russell, P. (2004) "Responsibility and the Condition of Moral Sense," Philosophical Topics 32: 287-305.

Scanlon, T.M. (1998) What We Owe to Each Other. Cambridge: The Belknap Press of Harvard University Press.

Scanlon, T.M. (2008) Moral Dimensions. Cambridge: Belknap Press of Harvard University Press.

Shoemaker, D. (2007) "Moral Address, Moral Responsibility, and the Boundaries of the Moral Community," Ethics 118: 70-108.

Shoemaker, D. (2009) "Responsibility and Disability," Metaphilosophy 40: 438-61.

Shoemaker, D. (2011) "Attributability, Answerability, and Accountability: Toward a Wider Theory of Moral Responsibility," Ethics 121: 602-32.

Shoemaker, D. (2013) "Qualities of Will," Social Philosophy and Policy 30: 95-120.

Shoemaker, D. (2014) "Remnants of Character," in J. D'Arms and D. Jacobson (eds), Moral Psychology and Human Agency. Oxford: Oxford University Press, pp. 84-107. 


\section{DAVID SHOEMAKER}

Shoemaker, D. (2015) Responsibility from the Margins. Oxford: Oxford University Press.

Siegler, I.C., Dawson, D.V., and Welsh, K.A. (1994) "Caregiver Ratings of Personality Change in Alzheimer's Disease Patients: A Replication," Psychology and Aging 9: 464-6.

Smith, A. (2005) "Responsibility for Attitudes: Activity and Passivity in Mental Life," Ethics 115: 236-71.

Smith, A. (2012) "Attributability, Answerability, and Accountability: In Defense of a Unified Account," Ethics 122: 575-89.

Snyder, L. (2006) "Personhood and Interpersonal Communication in Dementia," in J.C. Hughes, S.J. Louw, and S.R. Sabat (eds), Dementia: Mind, Meaning, and the Person. Oxford: Oxford University Press, pp. 259-76.

Talbert, M. (2008) "Blame and Responsiveness to Moral Reasons: Are Psychopaths Blameworthy?" Pacific Philosophical Quarterly 89: 516-35.

Wallace, R.J. (1994) Responsibility and the Moral Sentiments. Cambridge: Harvard University Press.

Watson, G. (1996) "Two Faces of Responsibility," Philosophical Topics 24: 227-48.

Watson, G. (2004) Agency and Answerability. Oxford: Oxford University Press.

Watson, G. (2011) "The Trouble with Psychopaths," in R.J. Wallace, R. Kumar, and S. Freeman (eds), Reasons and Recognition: Essays on the Philosophy of T.M. Scanlon. Oxford: Oxford University Press, pp. 307-31.

\section{Further Reading}

Blair, R., Jones, L., Clark, F., and Smith, M. (1995) "Is the Psychopath 'Morally Insane'?" Personality and Individual Differences 19: 741-52. (Further development and discussion of Blair's groundbreaking work on psychopaths.)

Blair, R.J.R. (1996) "Brief Report: Morality in the Autistic Child," Journal of Autism and Developmental Disorders 26: 571-9. (Blair applies some of what he learned from psychopaths and developmental impairments to children with autism.)

Kozuch, B. and McKenna, M. (2016) "Free Will, Moral Responsibility, and Mental Illness," in D. Moseley and G. Gala (eds), Philosophy and Psychiatry: Problems, Intersections and New Perspectives. New York: Routledge, pp. 89-113. (Cutting-edge discussion of the extent to which mental illness does-and does not-undermine moral responsibility.)

Stout, M. (2005) The Sociopath Next Door. New York: Broadway Books. (Accessible and informative book about the types of psychopaths that live amongst us, as well as their various impairments.)

Talbert, M. (2012) “Accountability, Aliens, and Psychopaths: A Reply to Shoemaker," Ethics 122: 562-74. (Talbert's ongoing defense of the responsibility of psychopaths.)

\section{Related Topics}

Free Will and Moral Sentiments: Strawsonian Views

Born Free? Children's Intuitions about Choice

Free Will and the Law

Blame 


\section{9 \\ DETERMINISM \\ Charlotte Werndl}

A system is deterministic just in case the state of the system at one time fixes the state of the system at all future times. A system is indeterministic just in case it is not deterministic. The question whether systems (or models or the world) are deterministic or indeterministic has concerned philosophers and scientists from the very beginning of philosophical and scientific thinking and still concerns them today. This article focuses on three recent discussions on determinism in the philosophy of science. First, determinism and predictability will be discussed (Section 2). Then, second, the chapter turns to the topic of determinism, indeterminism, observational equivalence, and randomness (Section 3). Finally, third, there will be a discussion about deterministic probabilities (Section 4). The chapter will end with a conclusion (Section 5).

\section{Determinism and Predictability}

It has often been believed that determinism and predictability go together in the sense that deterministic systems are always predictable. Determinism is an ontological thesis. Predictability — that the future states of a system can be predicted - is an epistemological thesis. An illustration of mixing together determinism and predictability is the following famous quote by Laplace:

We may regard the present state of the universe as the effect of its past and the cause of its future. An intellect which at a certain moment would know all forces that set nature in motion, and all positions of all items of which nature is composed, if this intellect were also vast enough to submit these data to analysis, it would embrace in a single formula the movements of the greatest bodies of the universe and those of the tiniest atom; for such an intellect nothing would be uncertain and the future just like the past would be present before its eyes.

(Laplace 1951: 4)

Here the first sentence is about the ontological thesis of determinism and the remainder of the quote concerns the epistemological notion of predictability.

For Laplace's intellect who knows the precise initial states of all items of which nature is composed as well as all forces that set nature in motion, determinism and predictability indeed go together: because of determinism, initial states uniquely determine the future. Since the intellect knows both the laws of nature and the initial states in all 
their details, the intellect can also predict the future. However, the situation is fundamentally different for beings like us, who cannot know the initial states in all their details because there is always some measurement inaccuracy. In that case determinism and predictability do not go together and turn out to be very different notions.

In particular, in recent decades, chaos theory has highlighted that deterministic systems can be unpredictable in various different ways. Chaos theory is a field of study in mathematics that is part of dynamical systems theory and was developed in the second half of the twentieth century. As a mathematical theory it has applications in several disciplines including physics, meteorology, climate science, engineering, biology and economics.

Chaos theory studies the behavior of systems that are deterministic but at the same time show complicated behavior and are random and hence also unpredictable. Furthermore, chaos theorists and philosophers have often claimed that chaotic systems are special in the sense that they are unpredictable in a way other deterministic systems are not (cf. Stone 1989; Smith 1998; Werndl 2009b).

Let us now have a closer look in which sense deterministic systems can be unpredictable and what the unpredictability associated with chaotic dynamical systems amounts to. For illustration purposes, it will be good to have a very simple example at hand. Consider a model of the evolution of the daily amount of precipitation over time where the possible amount of daily precipitation is in the range $[0 \mathrm{~mm}, 10 \mathrm{~mm}]$ and the amount of precipitation $x_{t+1}$ at day $t+1$ is obtained from the amount of precipitation $x_{t}$ at day $t$ by the following equation:

$$
x_{t+1}=\left\{\begin{array}{cc}
2 x_{t} & 0 \leq x_{t} \leq 5 \\
2\left(10-x_{t}\right) & 5<x_{t}<10
\end{array}\right.
$$

In chaos theory this map is called the tent map and it is shown in Figure 59.1. Note that, clearly, the dynamics of the tent map is deterministic.

Let me now turn to a first concept of unpredictability for deterministic systems, called asymptotic unpredictability. As mentioned above, when measuring initial states such as the initial temperature, there will always be a certain inaccuracy. Thus a measurement corresponds to an extended bundle of initial conditions that represents the possible initial states compatible with the measurement. A system is said to be asymptotically

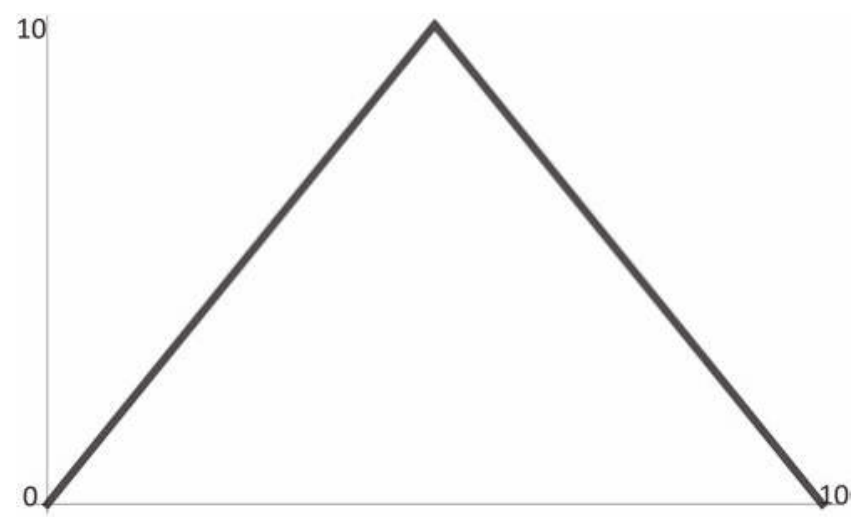

Figure 59.1 The tent map. 
unpredictable when any extended bundle of initial conditions, no matter how small, eventually over time spreads out more than a specific diameter representing the prediction accuracy of interest. Such a system is unpredictable in the sense that for any measurements of the initial states (regardless how fine), it will not be possible to predict the system with the desired prediction accuracy for all points of time in the future (cf. Werndl 2009b). The tent map is asymptotically unpredictable. Figure 59.2 illustrates this by showing how a relatively small bundle of initial states spreads out over the entire range of possible values after just four time steps. Hence the evolution of the daily amount of precipitation is not predictable for all times.

When presented with notions such as asymptotic predictability, it becomes clear how systems that evolve according to deterministic laws can still be unpredictable: if the system is deterministic, it can still be that one cannot predict the state of system sufficiently far in the future because very close initial states eventually lead to entirely different outcomes. In discussions about asymptotic unpredictability, sometimes the further claim has been made that this is the unpredictability unique to chaotic systems (e.g., Stone 1989: 127). However, it is easy to see that this cannot be true. For instance, a system where the possible states are in $(0, \infty)$ and the evolution is given by $x_{t+1}=c x_{t}$ for $c>1$ shows asymptotical unpredictability, but this system is not chaotic because it is not random or complicated in any sense (cf. Smith 1998; Werndl 2009b).

Werndl (2009b) has argued that approximate probabilistic irrelevance is the kind of unpredictability that is unique to chaos. Unlike asymptotic unpredictability, approximate probabilistic irrelevance is a probabilistic concept of unpredictability. According to this concept, any measurement (i.e., knowledge of the initial states that the system may currently be in) is irrelevant for practical purposes for predicting outcomes sufficiently far in the future, that is, makes it neither more nor less likely that the outcome is in any region of phase space of interest. This means that not only is it impossible to predict with certainty in which region the system will end up in in the sufficiently distant future, but that also for practical purposes knowledge of the currently possible initial states neither lowers, nor heightens, the probability that the system will end up in a certain region of phase space in the sufficiently distant future.

As illustrated in Figure 59.2, the tent map is subject to this kind of unpredictability: The prior or default probability distribution of the tent map is the uniform distribution over the possible amounts of precipitation, i.e., the interval $[0 \mathrm{~mm}, 10 \mathrm{~mm}]$. Suppose, for instance, that the knowledge of the amount of precipitation today is represented by the uniform distribution over $[0 \mathrm{~mm}, 10 / 8 \mathrm{~mm}]$. Further, suppose one would like to know how likely it is that the amount of precipitation will be in some range, for example, $[70 / 8 \mathrm{~mm}, 10 \mathrm{~mm}]$ (i.e., in the set $B$ ) in the future. Then, if the prediction lead time is sufficiently long, for example, four days, all one can say is that the probability of the amount of precipitation being in $[70 / 8 \mathrm{~mm}, 10 \mathrm{~mm}]$ is $1 / 8$ as given by the prior or default probability distribution. That is, knowledge that the system is currently in $[0 \mathrm{~mm}, 10 / 8 \mathrm{~mm}]$ will be entirely irrelevant for

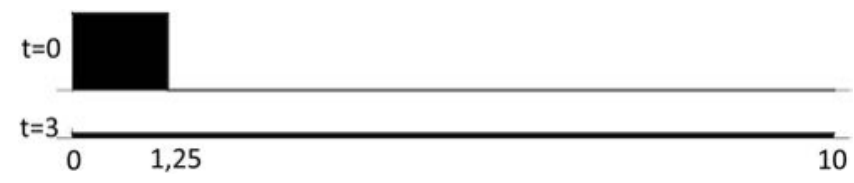

Figure 59.2 A bundle of initial states spreads out over the entire interval for the tent map. 
predicting whether the amount of precipitation will be in $[70 / 8 \mathrm{~mm}, 10 \mathrm{~mm}]$ after four time steps. Approximate probabilistic irrelevance shows us another way in which deterministic systems can be unpredictable. Werndl (2009b) has argued that this kind of unpredictability is also unique to chaotic systems, that is, that only chaotic systems and no other deterministic systems show. Approximate unpredictability is a strong form of unpredictability and its discussion raises the question whether deterministic systems can be random and have properties similar to those of indeterministic processes, to which we now turn.

\section{Determinism, Indeterminism and Randomness}

Consider again our example of the model of the evolution of the daily amount of precipitation, where $[0 \mathrm{~mm}, 10 \mathrm{~mm}]$ is the range of possible amounts of precipitation, the dynamics is given by equation (1) and the probability of a certain outcome is measured by the uniform probability measure over $[0 \mathrm{~mm}, 10 \mathrm{~mm}]$. Note that, as already emphasized, we can never measure states with infinite precision. Thus possible measurements correspond to a coarse-graining of the space of possible states. Figure 59.3 (top) shows a measurement with only two possible outcomes, while Figure 59.3 (bottom) shows a much finer measurement with eight possible outcomes. So when a deterministic system is observed, all we see is a sequence of observed outcomes. Suppose that our model of the evolution of the daily amount of precipitation is found to be in good agreement with the observations. Can we then be certain that the dynamics underlying the evolution of the daily amount of precipitation is deterministic? Or could there be observational equivalence between deterministic and indeterministic models and could it be that the evolution of the daily amount of precipitation is governed by an indeterministic process?

To make progress on these questions, it needs to be made clear what an indeterministic model and process is and what observational equivalence amounts to. The focus here will be on stochastic models and processes. Consider the example where a coin is tossed every day, which corresponds to a two-valued Bernoulli model. A stochastic model such as a two-valued Bernoulli model consists of a set of possible outcomes (e.g., 'heads' or 'tails') and $Z_{t}$ denotes the outcome of the process at time $t$ (e.g., whether the coin landed 'heads' or 'tails' at day $t)$. The probability distributions $P\left(Z_{t}=e\right)$ give one the probability that the outcome of the process is $e$ at time $t$ (e.g., that the probability of tossing 'heads' today is $1 / 2)$; conditional probability distributions $P\left(Z_{t}=e\right.$ given that $Z_{r}=d$ ) give one the probability that the outcome is in $e$ at $t$ given that it was $d$ at $r$ (e.g. that the probability of tossing 'heads' today is $1 / 2$ given that I tossed 'heads' yesterday).

Now a deterministic model such as the model of the evolution of the daily amount of precipitation and a stochastic model such as the sequence of coin tosses are said to be observationally equivalent just in case the stochastic model and the deterministic model relative to the coarse-graining corresponding to the possible measurements give the same predictions (cf. Werndl 2009a). More specifically, the predictions obtained from the stochastic

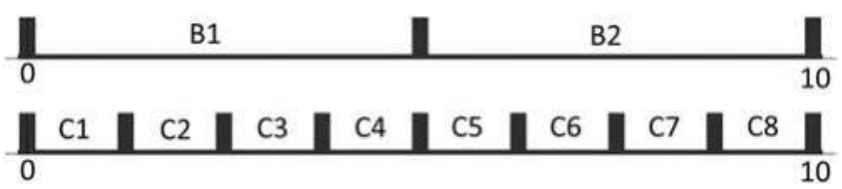

Figure 59.3 A measurement with two (top) and with eight (bottom) outcomes. 
model are the probability distributions over the sequence of outcomes. Concerning the deterministic model, recall that a probability measure is defined over all possible states. Consequently, the predictions derived from the deterministic model relative to a certain coarse-graining (representing the possible measurements) are the probability distributions over the sequences of observations of the deterministic system. Hence what is meant by the phrase that the deterministic model and the stochastic model give the same predictions is that the possible observed values of the stochastic system and deterministic system are the same, and that the probability distributions over the sequences of observations of the deterministic model and the sequences of outcomes of the stochastic model are the same.

There are a host of results showing that deterministic models are often observationally equivalent to stochastic models (Werndl 2009a, 2011, 2013a). An example for this is our deterministic model of the evolution of the daily precipitation: relative to the observational accuracy shown in Figure 59.3 (top), it is observationally equivalent to a twostate Bernoulli model such as our example of the sequence of coin tosses (outcome B1 corresponds to 'heads' and outcome 'B2' to 'tails'). Relative to the observational accuracy shown in Figure 59.3 (bottom), the deterministic model of the tent map is observationally equivalent to a Markov model. For Markov models the next outcome only depends on the previous outcome and no other outcomes (and Markov models are among the most widely used stochastic models in science).

In the case where a deterministic model relative to a certain measurement accuracy and a stochastic model are observationally equivalent, the question arises: which model is preferable? There would be underdetermination if the data equally supported the deterministic and the stochastic model. Suppes (1993) and Suppes and de Barros (1996) argue there is underdetermination in these cases.

Werndl (2013a, 2013b) points out that one needs to distinguish between the currently possible observations (given the current technology etc.), and the observations that are possible in principle (assuming that there are no limits, in principle, on observational accuracy). She argues that relative to observations that are possible in principle it will always be clear whether the deterministic or stochastic model is preferable (cf. also Wüthrich 2011). However, she argues that matters are less clear relative to the currently possible observations. Here underdetermination could arise, but, in her view, underdetermination can still be avoided for the most commonly discussed examples of a choice between deterministic models of Newtonian theory and stochastic models. Her argument makes use of the idea of indirect evidence, which is best introduced with an example. The theory of natural selection is only about processes happening out there in nature. So data about artificial breeding cannot be derived from the theory of natural selection. Still, with evolutionary theory as a bridge, data about artificial breeding can (and are often taken to) provide indirect evidence for the theory of natural selection.

Laudan and Leplin (1991) emphasize that indirect evidence can block the conclusion of underdetermination. For instance, suppose that there is a hypothesis $\mathrm{H}$ that does not follow from evolutionary theory but that (together with auxiliary hypotheses) gives rise to the same predictions as the theory of natural selection. Then the theory of natural selection is preferable relative to evidence and there is no underdetermination between $\mathrm{H}$ and the theory of natural selection because only the theory of natural selection is additionally supported by indirect evidence from artificial breeding. Similarly, Werndl (2013a) argues, the deterministic models from Newtonian mechanics are supported by indirect evidence from similar Newtonian models but the stochastic models are not, and thus, the former are preferable. This argument can also be illustrated with 
our example of the evolution of the daily precipitation: suppose that the tent map was derivable from a general well-confirmed theory of the climate but the stochastic model is not derivable from any more general theory. Then the deterministic model would receive indirect evidence from other similar models of the climate theory and would hence be preferable to the stochastic model.

Stochastic processes such as Bernoulli processes and Markov processes are random. The results of observational equivalence show that deterministic models can be observationally equivalent to Bernoulli models or Markov models. Hence these results show that deterministic models can show randomness properties similar or equal to those stochastic processes. Indeed, a major task of the mathematical field of ergodic theory was to investigate to what extent randomness properties of stochastic models can also be found in deterministic models, and the investigations showed that many randomness properties carry over to deterministic models (Ornstein and Weiss 1991). To provide a concrete example: recall the discussion of approximate probabilistic irrelevance as a kind of unpredictability in the previous section. Eagle (2005: 775) defines randomness as a strong form of unpredictability: an event is random just in case the probability of the event conditional on evidence equals the prior probability of the event. This idea is at the heart of approximate probabilistic irrelevance. Consequently, this concept of unpredictability can be regarded as a certain kind of randomness, and this randomness can also be found in deterministic systems such as the tent map. Let me finally turn to the third main topic of this article: the question of deterministic probabilities.

\section{Probability and Determinism}

Philosophers have often questioned whether ontic probabilities (i.e., probabilities that are real features of the world) can exist given deterministic laws. The method of arbitrary functions, which has been developed and advocated, amongst others, by Hopf, Poincare, Reichenbach and von Kries, promises to show that determinism and probabilities are compatible (it is important to note that this method is only meant to apply to certain cases and not to all situations where there are ontic probabilities).

The method of arbitrary functions is best introduced with an example (cf. Strevens, 2011). Consider a simple wheel of fortune that is painted in equal numbers of very small equal-sized white, light grey, and dark grey sections. The wheel is given a certain initial velocity, and when it comes to rest, a fixed pointer tells one the outcome (white or light grey or dark grey). We immediately tend to think that the probability of the outcome 'white,' 'light grey,' and 'dark grey' is $1 / 3$, despite the fact that the dynamics of the wheel is deterministic (or, if quantum effects crop up, the dynamics is at least approximately deterministic, and all that will be said carries over to this case).

A more detailed analysis of the wheel of fortune can substantiate this judgment. First of all, we have to look at the dynamics of the wheel, that is, how initial velocities give rise to certain outcomes. As shown in Figure 59.4, what is distinctive is what Strevens (2003) calls a microconstant dynamics, that is, given small ranges of initial velocities, the proportion of initial velocities leading to the outcomes 'white,' 'light grey,' and 'dark grey' is $1 / 3$, respectively. Second, we have to look at how the wheel of fortune is prepared in a certain initial velocity. We can model the preparation of the system by a probability distribution $\mathrm{p}$ over the initial velocities.

Usually our knowledge about this initial probability distribution is very limited. Furthermore, different ways of spinning a wheel by different persons, etc. can be expected 


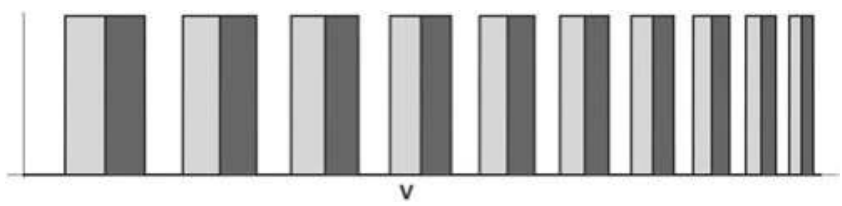

Figure 59.4 Conversion of initial velocities into white, light grey and dark grey outcomes.

to correspond to different initial probability distributions. However, all this does not matter if the plausible assumption holds that all the possible probability densities $\mathrm{p}$ that we might employ do not fluctuate drastically on a very small region (Strevens [2003] calls probability densities with this property "macro-periodic"). Given a microconstant dynamics and a macro-periodic probability density, the probabilities for the outcomes 'white,' 'light grey,' and 'dark grey' will all be approximately $1 / 3$. This is illustrated by Figure 59.5, which shows two very different initial probabilities that both lead to probability $1 / 3$ for the outcomes 'white,' 'light grey,' and 'dark grey.'

In conclusion: even though the wheel of fortune is governed by deterministic equations, there are still ontic probabilities and these are explained by a microconstant dynamics and a class of possible probability distributions that are macro-periodic. Evidently, the method of arbitrary functions is of particular relevance when there is a class of possible initial densities. The prime example to which the method was applied by Hopf, Poincare, van Kries and Reichenbach, etc. are games of chance. Next to this, it has also been suggested that it can make sense of deterministic probabilities in statistical mechanics, ecology and the social sciences (Strevens 2003; Abrams 2012; Werndl 2013b).

From a philosophical point of view, a crucial question is how to interpret the probabilities of the method of arbitrary functions. And how to interpret these probabilities will depend on how one interprets the initial probability distribution. Thus let us ask: how should the initial probability distributions be interpreted? For lack of space, we can only discuss here three proposals (another proposal can be found in Rosenthal [2010, 2012]).

Abrams' (2012) answer to this question is based on the frequencies obtained by actual inputs. More specifically, he argues that the correct input probability distribution is the microconstant probability measure that minimizes differences between probabilities and the frequencies obtained by the actual inputs. Yet it is unclear why there

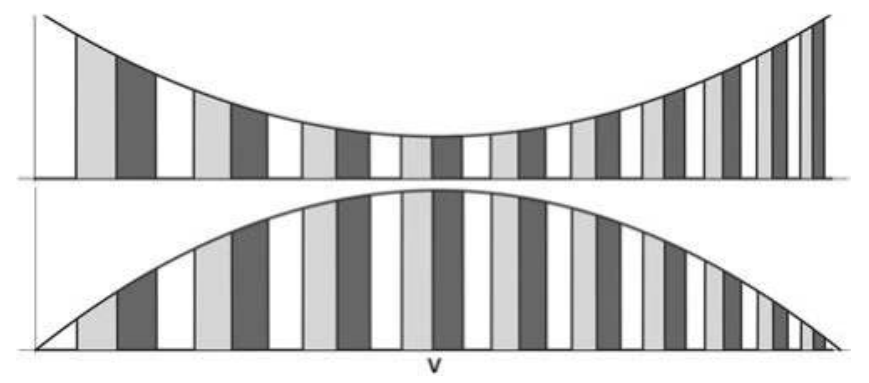

Figure 59.5 Conversion of initial velocities for densities into white, light grey and dark grey outcomes. 
is a need for such a minimization procedure (and it is also not clear why the measure has to be strictly microconstant). Furthermore, as Abrams' account is based on actual frequencies, it inherits many problems of finite frequentism (Rosenthal 2010, 2012; Myrvold 2012, forthcoming). For instance, there are cases where the first 50 tosses of a coin are highly unusual in the sense that they suggest that the coin is biased while it is not (which would become clear if further coin tosses were made). Abrams' account cannot make sense of such judgments since it is based on actual frequencies.

Strevens (2011) claims that for nearly all long series of trials of the system the initial conditions constitute a set that is macroperiodically distributed. He emphasizes that the initial distributions should just provide a summary of the actual occurrences of initial states and should have nothing to do with probabilities. He regards it as crucial that the initial distributions are not interpreted as probabilities because what is needed is an interpretation of the probabilities of the method of arbitrary functions that arises from non-probabilistic facts. Note that Strevens has to appeal to the condition that nearly all long series of trials produce macroperiodically distributed sets to avoid obvious objections (such as that we need an account why in an experimental situation that differs only in unimportant details, the same probabilities will arise).

Strevens' proposal is original and worthwhile, but there are also some problems. One problem can be illustrated with the example of the initial velocities of the wheel of fortune. When the wheel is spun repeatedly in the same context, one will find that the frequency distribution of the initial velocities approximates a certain density distribution. Because of this, scientists postulate that there is a probability distribution that describes the probability of preparing the wheel in a certain initial velocity. This probability distribution is useful from a predictive perspective in the sense that it usually gives correct predictions about the frequencies of initial velocities produced in the future in the same context. Yet since for Strevens there is nothing more than the actual occurrences of the initial velocities, he cannot make sense of such a predictive power. Another problem looms in the 'nearly-all' condition. Strevens makes this condition more precise by claiming that the actual distributions are macro-periodic in nearly all relevantly close possible worlds, where 'nearly-all' is measured in terms of the Lebesgue measure, which measures 'ways of altering the world.' Yet it remains unclear why one can formally assign a measure to 'ways of altering the world' and, even if one can do this, why the Lebesgue measure is the correct measure to use (cf. Rosenthal 2010, 2012).

In my opinion, a more promising possibility is to interpret initial distributions as probability distributions that are physical quantities characterizing the particular situation at hand (as has been suggested by Szabò 2007; see also Sober 2010). In more detail, the concept of ontic probabilities can be reduced to ordinary physical quantities (as a consequence, the precise meaning of the probabilities will depend on the context of application). Hence, the probabilities of the method of arbitrary functions are simply physical quantities that characterize particular physical situations at hand.

It has been argued above that the method of arbitrary functions can provide an explanation of how probabilities arise out of determinism. Given this, let me now address the prominent worry that deterministic probabilities lead to a violation of the Principal Principle - a principle that establishes a connection between chances and credences (e.g., Schaffer 2007). According to the Principal Principle, the credence of a rational agent in the occurrence of an event $E$ should equal the chance of $E$ as long as the agent has no inadmissible knowledge about the truth of $E$. More precisely: for all events $E$, all $P$ and all $K$ 


$$
c r_{c}(E \mid P \& K)=p
$$

where ' $c r_{t}$ ' stands for the agent's credence at time $t, P$ is the proposition stating that the chance that $E$ occurs is $p$ and $K$ is an arbitrary admissible proposition. Now the crucial question is how an 'admissible proposition' is defined. Lewis (1986) famously suggested that laws of nature as well as historical information about the exact state of a system up to time $t$ always count as admissible. Hence, given deterministic laws, the credences in equation (2) would be either 0 and 1 and the existence of nontrivial probabilities would lead to a violation of the Principal Principle. Because a violation of the Principal Principle is regarded as unacceptable, a common conclusion drawn from is that there are no deterministic probabilities.

This conclusion is too quick, and there are alternative and better ways to characterize an admissible proposition. In particular, Frigg and Hoefer (2015: 553) propose the following definition: a proposition $K$ is admissible with respect to event $E$ and chance setup $S$ iff " $K$ contains only the sort of information whose impact on reasonable credence about $E$, if any, comes entirely by way of impact on credence about the chances of those outcomes" (see also Glynn 2010). Given this alternative definition, as desired, the Principal Principle (2) comes out as true.

\section{Conclusion}

The questions of determinism and indeterminism have concerned philosophers and scientists from the very beginning of philosophical and scientific thinking. This article illustrates that this topic is still very much a relevant one: as philosophy and science change and progress, there is always more that can be discovered and learnt about determinism and indeterminism. This article has focused on three recent discussions on determinism in the philosophy of science. First, determinism and predictability was discussed. It was emphasized that determinism and prediction are very different notions, and it was shown how the recent mathematical field of chaos theory has shed light on the various ways in which deterministic systems can be unpredictable. The second topic of the chapter was determinism, indeterminism, observational equivalence and randomness. Here results were presented that show that deterministic and indeterministic models can be observationally equivalent and the question was discussed how to choose between deterministic and indeterministic models. Further, it was argued that certain randomness properties of indeterministic systems carry over to deterministic systems. Finally, the third topic the article focused on was deterministic probabilities. Here it was argued that the method of arbitrary function is promising for understanding how deterministic probabilities can arise and that deterministic probabilities are not in violation of the Principal Principle.

\section{Bibliography}

Abrams, M. (2012) "Mechanistic Probability," Synthese 187: 343-75.

Berlanger, C. (2013) "On Two Mathematical Definitions of Observational Equivalence: Manifest Isomorphism and Epsilon-Congruence Reconsidered," Studies in History and Philosophy of Science Part B 44: 69-76.

Eagle, A. (2005) "Randomness is Unpredictability," The British Journal for the Philosophy of Science 56: 749-90. 


\section{CHARLOTTE WERNDL}

Earman, J. (1986) A Primer on Determinism. Berlin and New York: Springer.

Frigg, R. and Hoefer, C. (2015) "The Best Human System for Statistical Mechanics," Erkenntnis 80(3): 551-74.

Glynn, L. (2010) "Deterministic Chance," The British Journal for the Philosophy of Science 61: 51-80.

Laplace, P.S. (1951) A Philosophical Essay on Probabilities. New York: Dover Publications.

Laudan, L. and Leplin, J. (1991) "Empirical Equivalence and Underdetermination," Journal of Philosophy 88: 269-85.

Lewis, D. (1986) Philosophical Papers. Oxford: Oxford University Press.

Myrvold, W. (2012) "Deterministic Laws and Epistemic Chances," in Y. Ben-Menahem and M. Hemmo (eds), Probability in Physics. New York: Springer, pp. 73-85.

Myrvold, W. (forthcoming) "Probabilities in Statistical Mechanics," in C. Hitchcock and A. Hajek Oxford (eds), Handbook of Probability and Philosophy. Oxford: Oxford University Press.

Ornstein, D. and Weiss, B. (1991) "Statistical Properties of Chaotic Systems," Bulletin of the American Mathematical Society 24: 11-116.

Rosenthal, J. (2010) "The Natural-Range Conception of Probability," in G. Ernst and A. Hüttemann (eds), Time, Chance and Reduction, Philosophical Aspects of Statistical Mechanics. Cambridge: Cambridge University Press, pp. 71-91.

Rosenthal, J. (2012) "Probabilities as Ratios of Ranges in Initial State Spaces," Journal of Logic, Language and Information 21: 217-36.

Schaffer, J. (2007) "Deterministic Chance," The British Journal for the Philosophy of Science 58(2): 113-40.

Smith, P. (1998) Explaining Chaos. Cambridge: Cambridge University Press.

Sober, E. (2010) "Evolutionary Theory and the Reality of Macro Probabilities," in E. Eells and J. Fetzner (eds), Probability in Science. Heidelberg: Springer, pp. 133-62.

Stone, M. A. (1989) "Chaos, Prediction and Laplacian Determinism," American Philosophical Quarterly 26: $123-31$.

Strevens, M. (2003) Bigger Than Chaos. Cambridge: Harvard University Press.

Strevens, M. (2011) "Probability out of Determinism," in C. Beisbart and S. Hartmann (eds), Probabilities in Physics. Oxford: Oxford University Press, pp. 339-64.

Suppes, P. (1993) "The Transcendental Character of Determinism," Midwest Studies in Philosophy 18: 242-57.

Suppes, P. and de Barros, A. (1996) "Photons, Billiards and Chaos," in P. Weingartner and G. Schurz (eds), Law and Prediction in the Light of Chaos Research. Berlin: Springer, pp. 189-201.

Szabò, L.E. (2007) “Objective Probability-Like Things With and Without Indeterminism," Studies in History and Philosophy of Modern Physics 38: 626-34.

Werndl, C. (2009a) "Are Deterministic Descriptions and Indeterministic Descriptions Observationally Equivalent?" Studies in History and Philosophy of Modern Physics 40: 232-42.

Werndl, C. (2009b) "What are the New Implications of Chaos for Unpredictability?" The British Journal for the Philosophy of Science 60: 195-220.

Werndl, C. (2010) "The Simple Behaviour of Complex Systems Explained? Review of 'Bigger Than Chaos, Understanding Complexity Through Probability' (Michael Strevens)," The British Journal for the Philosophy of Science 61: 875-82.

Werndl, C. (2011) "On the Observational Equivalence of Continuous-Time Deterministic and Indeterministic Descriptions," European Journal for the Philosophy of Science 1: 193-225.

Werndl, C. (2013a) "On Choosing Between Deterministic and Indeterministic Models: Underdetermination and Indirect Evidence," Synthese 190: 2243-65.

Werndl, C. (2013b) "Justifying Typicality Measures of Boltzmannian Statistical Mechanics and Dynamical System," Studies in History and Philosophy of Modern Physics 44: 470-9.

Winnie, J. (1998) "Deterministic Chaos and the Nature of Chance," in J. Erman and J. Norton (eds), The Cosmos of Science: Essays of Exploration. Pittsburgh: Pittsburgh University Press, pp. 299-324.

Wüthrich, C. (2011) "Can the world be shown to be indeterministic after all?" in C. Beisbart and S. Hartmann (eds), Probabilities in Physics. Oxford: Oxford University Press, pp. 365-89.

\section{Further Reading}

Belnap, N., Perloff, M. and Xu, M (2001). Facing the Future. Agents and Choices in Our Indeterminist World. New York: Oxford University Press. (Discusses theories of human action that assume that actions are made by agents in an indeterministic world.) 


\section{DETERMINISM}

Glynn, L. (2010) "Deterministic Chance," The British Journal for the Philosophy of Science 61: 51-80. (Gives general arguments as to how probabilities can arise in a deterministic world.)

Hoefer, C. (2015) “Causal Determinism,” E. Zalta (ed.), The Stanford Encyclopedia of Philosophy (Spring 2010 Edition), available from: http://plato.stanford.edu/archives/spr2010/entries/determinism-causal/ (accessed 22 June 2016). (An overview article about philosophical work on determinism.)

Earman, J. (1986) A Primer on Determinism. Berlin and New York: Springer. (An introduction to determinism from the viewpoint of philosophy of science and philosophy of physics.)

Strevens, M. (2003) Bigger than Chaos. Cambridge: Harvard University Press. (Provides an accessible introduction to the method of arbitrary functions and into how probabilities arise out of determinism.)

\section{Related Topics}

Classical Compatibilism

The Consequence Argument

Free Will and Time Travel 


\section{0 \\ FREE WILL AND TIME TRAVEL \\ Neal A. Tognazzini}

When thinking about potential threats to free will, people tend to think big. If there is an essentially omniscient and everlasting God, for example, then what God believed millions of years ago about the future entails every true proposition about what we're up to now, and since it's not up to any of us what God believed millions of years ago, what we're up to now isn't up to any of us, either (Pike 1965). Alternatively, if causal determinism is true, then the laws that govern our world, together with facts about how the world was millions of years ago, entail every true proposition about what we're up to now, and since it's not up to any of us what the laws are like or what the world was like millions of years ago, what we're up to now isn't up to any of us, either (van Inwagen 1983). Finally — and I mention one last example here because we'll return to it latereven if there is no God, presumably there were, millions of years ago, true future-tensed statements about what we would be up to millions of years later, and those true futuretensed statements entail(ed) all the present-tense propositions about what we're up to now. Again, since it's not up to us what was true millions of years ago, what we're up to now isn't up to us, either (Taylor 1963).

These three threats to free will - the threat from logical determinism, causal determinism, and God's foreknowledge-are all global threats, because they are general theses about the nature of reality whose alleged consequences would be disastrous for every creature whatsoever. But there are local threats to free will that are worth considering, too, puzzles about relatively well-circumscribed portions of reality that appear to threaten this or that person's free will. In this chapter, I intend to explore one of these more modest threats, one that arises from endorsing the possibility of time travel to the past.

Most discussions of free will and time travel occur in contexts where what's at issue is whether time travel is metaphysically possible. In those contexts, the worry is that if it were possible for someone to travel to the past, then contradictions could be true. For example, the time traveler would be able to kill his grandfather (because he would train for the occasion, he would have a gun, he would know where to find his grandfather, etc.), and also would not be able to kill his grandfather (because if he were to kill his grandfather, then he himself wouldn't exist to travel back in time in the first place). There seems to be general agreement, at least in the last 40 years, that these sorts of worries do not show that time travel to the past is metaphysically impossible (Lewis 1976; Wasserman forthcoming). I agree, but I am not concerned with whether time 
travel is metaphysically possible. Instead, I plan to take for granted that it is, and then ask what it would mean for the free will of the time traveler. It's a common thought that time travelers to the past would somehow be constrained to do only those things that they in fact did do, that they wouldn't be free to do anything that didn't already happen. That is, it's a common thought that we should be incompatibilists about free will and time travel to the past. (Note that this is a different sense of the term 'incompatibilist' than is typical in debates about free will and, say, determinism.) But is this common thought right?

In what follows, I'll suggest that the answer to this question is complicated. On the traditional way of thinking about free will, I think the incompatibilist about time travel and free will wins the day. However, I'll also consider a residual worry with the incompatibilist conclusion, one that contains the seeds of a new-and, I think, more promising - way of thinking about free will, about what it is for an action to be up to someone.

\section{Models of Time Travel}

To begin, let's distinguish between three different models for travelling to the past: the single timeline model, the branching timeline model, and the hypertime model. We'll be concerned with the single timeline model, but I'll briefly describe the others for the sake of contrast. To understand the models, I find it useful to assume that spacetime is a four-dimensional block, which contains every spatiotemporal thing that has ever, does now, or will ever exist. (I say that I find this assumption useful, but let me hasten to add that it is dispensable [Keller and Nelson 2001; van Inwagen 2010].) You and I are in the block, but so are Abraham Lincoln and the people whose birth year is 2115. Now suppose that Harry is born in 2100, enters a time machine in the year 2120 and travels back 100 years to 2020, shakes his grandfather's hand, and then goes back to the future, arriving one minute after he left.

On the single timeline model, if you imagine scanning the four-dimensional spacetime block from left to right, starting at the year 2019, here's what you would see (you'll have to suppress a couple of spatial dimensions in your mind's eye): in the year 2020, a 20-year-old Harry appears, with his time machine, seemingly out of nowhere. He exits his time machine, finds his grandfather, and shakes his hand. Then he re-enters the time machine and disappears. Harry's grandfather then grows up, gets married, and has children (one of whom is Harry's mother), and then little baby Harry himself is born in 2100 , grows into a time travel enthusiast who finally enters a time machine in the year 2120, and then disappears with his time machine. After a minute passes (you're still scanning the block left-to-right), Harry and his time machine reappear (both are more than a minute older), Harry exits, and he goes about his life. On this model, Harry does not cause anything to happen in the past that didn't (already) happen in the past. It may sound odd, but as Harry departs, we can truly say of him that he is about to experience an event that has already taken place. (Does that mean that the event is both future and past? Yes and no. If we're talking about external time, the event Harry is about to experience is only past. But if we're talking about Harry's personal time [the ordering of his life experiences from younger to older], then the event is only future [see Lewis 1976].)

The branching timeline model, on the other hand, promises to open up the possibility that what the time traveler does on his journey into the past is different than what 
happened 'the first time around.' (On the single timeline model, there is only one 'time around.') To picture things on the branching timeline model, we can again imagine a four-dimensional block universe, except now it has a branching structure. There is a single trunk from the beginning of time until the year 2020, but at 2020 the trunk sports a branch, so that the four-dimensional block universe at that point looks like a ' $y$ ' that has been laid on its side. The trunk, as it continues past the sprouted branch, contains the 'first time around,' where Harry's grandfather lives out his life sans handshake. But the sprouted branch contains the 'second time around,' where Harry arrives in his time machine and shakes his grandfather's hand. (I'll ignore the very good question of whether this story really counts as time travel.)

Finally, consider the hypertime model (Goddu 2003; van Inwagen 2010; Hudson 2014). The idea here is that in addition to the sequence of moments within the fourdimensional spacetime block itself, there is also a sequence of hypermoments (moments in a second dimension of time) through which the very shape of the spacetime block might morph and change. Picture it this way: you are outside of the spacetime block (with a God's-eye perspective on all of spatiotemporal reality—past, present, and future) and you have a reel-to-reel video camera. As hypertime passes (for you, who are outside of the spatiotemporal block), you are capturing what the block looks like from hypermoment to hypermoment. (Each hypermoment is represented by a frame on your filmstrip.) If the spacetime block hypernever changes its shape, then you are filming a rather boring movie-just like staring at a loaf of bread that never rots (so, perhaps like staring at a Twinkie). But once we have the idea of hypertime, we can use it to imagine a shapeshifting block. Truths about what is (simply) past are always about what the leftward sections of the spacetime block contains, but truths about what is hyperpast are about what the filled-up frames on your filmstrip represent the spacetime block as (hyper)having contained at those frames. To imagine time travel on this model, all we have to do is to imagine that what the spacetime block contains at one hypermoment is different from what it contains at the next hypermoment. At the first hypermoment, the block contains a grandfather who never got to meet his grandson. But at the next hypermoment, the spacetime block contains not only the 20-year-old Harry who is spooling up his time machine in the year 2120, but also a slightly older Harry who is shaking hands with his grandfather in the year 2020. (The contents of the 2020 slice of the spacetime block have changed from what they hyperwere.)

The particular (local) incompatibilist argument I'll consider arises most naturally (or, perhaps, only) on the single timeline model of time travel. I've sketched the others only for the sake of contrast, so that the reader doesn't automatically begin thinking in terms of the Back to the Future movie franchise, with its fading photographs and changing of the past. The worry for free will that arises in the context of single timeline time travel arises in part because of the natural thought that we can't change the past.

\section{A Worrisome Time Travel Story}

To home in on the worry I have in mind, let's talk about another Harry, this one from Harry Potter and the Prisoner of Azkaban (Rowling 1999). Here's the background you need: Harry is a wizard who knows how to cast a spell to ward off dark creatures called Dementors (the spell is called a Patronus), and he has a friend named Hermione who has a device called a timeturner, which looks like a charm necklace but which allows its 
wearer(s) to travel through time. And here's how our story goes (told from the perspective of Harry's personal time): at $t_{1}$ Harry's life is threatened by several Dementors, but at $t_{2}$ he is saved because someone lurking in the shadows casts a Patronus spell at the Dementors. Hours later, at $t_{3}$, he and Hermione use a timeturner to travel back to $t_{1}$, where Harry sees himself (his younger self) threatened by the Dementors. At $t_{2}$, Harry casts a Patronus spell at the Dementors, thus saving his own life. Just before $t_{3}$, Harry and Hermione use the timeturner to travel back to the future, and they arrive just in time to see themselves (their younger selves) disappearing at $t_{3}$ to begin their adventures in the past.

This is a single timeline story of time travel to the past. Harry saves his own life at $t_{2}$, and because he does, it is true at $t_{3}$ that he saved his own life, even though the younger version of him at $t_{3}$ (the one about to head back in time) doesn't realize that this is what happened (he knows someone saved his life, but he doesn't know it was/will be him). As the story unfolds in the book, the realization that the person in the shadows was (is) himself is liberating. As Harry puts it (Rowling 1999: 412), "I knew I could do it [i.e. cast the Patronus spell] this time because I'd already done it!" In other words, since he knew that he would save himself (talking from his perspective before casting the spell, but with the knowledge that he had lived long enough to travel back in time), he knew that he was able to save himself. This realization is, in fact, what enabled him (perhaps it's what allowed him to summon the necessary concentration). But by the same token, we might wonder whether saving his own life was a free action of his-whether, given the peculiar circumstances, it really was up to him whether he cast the Patronus. After all, had he failed to cast the Patronus, he wouldn't have survived the Dementor attack, and hence wouldn't exist to even be faced with the choice of whether to save himself.

Lest we think that this sort of worry only arises for agents who are in the midst of a time-travelling adventure, it's worth pointing out that there is another question that arises from the story as we have told it, namely: was Harry's action of travelling back in time at $t_{3}$ a free action? At $t_{3}$, (younger) Harry has not yet experienced the thrill of traveling through time. But the fact that he will soon arrive in the past and save his own life leads to uncomfortable questions about his freedom just the same. After all, had he failed to travel back in time, nobody would have been in the shadows ready to save him from the Dementor attack (we can stipulate that Hermione, even if she were to have traveled to the past alone, wouldn't have been able to cast a strong enough Patronus), and so he wouldn't exist to even be faced with the choice of whether to go back in time. The puzzle to be considered in what follows isn't only about the free will of time travelers while they are time traveling; rather, it's about free will, given the possibility of time travel.

On the traditional model of thinking about free will, whether an action is up to someone (i.e., whether it is free) is a matter of whether the person is both able to perform the action and also able to refrain from performing it (van Inwagen 1983). Adopting that model for the moment, our questions about Harry become:

$$
\begin{aligned}
& \text { Q1: At } t_{2} \text {, is (older) Harry able to refrain from casting the Patronus? } \\
& \text { Q2: At } t_{3} \text {, is (younger) Harry able to refrain from going back in time? }
\end{aligned}
$$

It seems to me that these questions will have the same answer, so for ease of exposition I will focus only on Q2. 


\section{Time Travel and Fatalism}

In the previous section, I sketched the argument for the conclusion that Harry isn't able to refrain from travelling back in time at $t_{3}$. But the sketch I gave relied on some unstated premises that are best brought into the open. So consider how we might regiment the argument:

1. (Older) Harry casts the Patronus at $t_{2}$.

2. Necessarily, (older) Harry casts the Patronus at $t_{2}$ only if he travels back in time at $t_{3}$ (where $t_{2}$ is externally past, relative to $t_{3}$ ).

3. So, if Harry hadn't traveled back in time at $t_{3}$, then some fact about the past would have been false.

4. If, in order for $S$ to do $A$, some fact about the past would have to be false, then $\mathrm{S}$ isn't able to do A.

5. Therefore, Harry isn't able to refrain from travelling back in time at $t_{3}$.

The crucial ingredient of this argument is premise (4), which captures the idea that the past is fixed - that is, the past is not something that anyone is able to do anything about anymore. (No use crying over spilled milk, and all that.) This premise-we might call it The Principle of the Fixity of the Past (FP) — plays a crucial role in the global incompatibilist arguments we canvassed at the beginning of this chapter, so it shouldn't be surprising that it shows up in this context too. It's precisely because God's beliefs are in the past that they seem to cause trouble for free will, and it's precisely because the thesis of causal determinism implies that our actions are entailed by the past and the laws (which also seemed fixed) that it seems to cause trouble for free will. (Note that I'm using the word 'entail' in a broadened sense throughout this chapter: something of one ontological category entails something of a different ontological category, in this sense, if it's not metaphysically possible for the first thing to obtain [or exist, or happen, or be true, etc.] without the second thing obtaining [or existing, or happening, or being true, etc.].) Likewise, what's causing trouble for Harry here is that there are facts about the past that seem to entail what he does. And things are even worse for Harry, because the fact that he's a time traveler means that he has two pasts- the external past and his personal past - and both contain events that entail his actions at future times (times in the external future and times in his personal future).

So how can a compatibilist about time travel and free will respond? David Lewis is perhaps the Platonic Ideal of a compatibilist, and what he would say is that this argument is "a bit of fatalist trickery" (Lewis 1976). His remarks explaining that verdict are worth quoting in full:

Fatalists - the best of them-are philosophers who take facts we count as irrelevant in saying what someone can do, disguise them somehow as facts of a different sort that we count as relevant, and thereby argue that we can do less than we think ... I am not going to vote Republican next fall. The fatalist argues that, strange to say, I not only won't but can't; for my voting Republican is not compossible with the fact that it was true already [in the past] that I was not going to vote Republican ... My rejoinder is that this is a fact, sure enough; however, it is an irrelevant fact about the future masquerading as a relevant fact about the past, and so should be left out of account in saying what, in any ordinary sense, 
I can do. We are unlikely to be fooled by the fatalist's methods of disguise in this case, or other ordinary cases. But in cases of time travel, precognition, or the like, we're on less familiar ground, so it may take less of a disguise to fool us. Also, new methods of disguise are available, thanks to the device of personal time.

(Lewis 1976: 151)

The fatalist is someone who worries that since future-tensed propositions about our actions were true millions of years ago, and since the past truth of those propositions entails the present truth about what we are up to now, we don't have free will with respect to anything that we ever do. What Lewis is saying in the above quotation, however, is that some facts that appear to be about the past aren't really about the past; they are simply masquerading. In particular, all of the facts that the fatalist points to-facts about which future-tensed propositions were true millions of years ago-are not genuinely about the past. Since they aren't, Lewis says that we shouldn't take them into consideration when trying to determine what I'm able to do in the here and now.

Another way of saying this is to say that since those facts aren't genuinely about the past, they aren't covered by The Principle of the Fixity of the Past. More carefully stated, (FP) only applies to facts that are genuinely about the past, and not every fact that was true in the past is really about the past. In the language of Ockhamism (Pike 1965; Fischer 1989), there's a distinction to be drawn between soft and hard facts-facts that are temporally relational (soft) versus facts that are temporally intrinsic (hard) and it's only the hard facts that are plausibly thought to be fixed. So (FP) should really be more carefully stated as the Principle of the Fixity of the Hard Past:

(FHP) If, in order for S to do A, some hard fact about the past would have to be false, then $\mathrm{S}$ is not able to do $\mathrm{A}$.

But now if this principle appears as premise (4) in the above argument, then the argument turns out to be invalid. The 'past fact' that entails that Harry travels back in time at $t_{3}-$ namely, the fact that (older) Harry casts a Patronus at $t_{2}$-is a temporally relational (soft) fact, since whether it obtains depends crucially on what happens in the future. In particular, whether Harry casts the Patronus at $t_{2}$ depends on whether he goes back in time at $t_{3}$. So, although it is a fact that obtains at $t_{2}$, it's not wholly about $t_{2}$, and hence isn't one of the facts that we need to hold fixed when deciding what Harry is able to do at $t_{3}$.

All this is a way of saying: if Ockhamism seems like a good solution to the problem of logical fatalism - and to many people, it does-then it's also a good solution to the puzzle about time travel and free will. In cases of time travel, past and future go all topsy-turvy, but if we carefully separate personal past from external past, and soft past from hard past, then we should be able to sort things out properly, and we'll end up compatibilists. What's tricky is just that some of the time traveler's personal past lies in the external future (and so need not be held fixed, even though it's past in some sense), and some of the time traveler's personal future lies in the external past (and so may be a soft fact that need not be held fixed, even though it's in the external past).

\section{Incompatibilism Revived}

Pointing out that sometimes facts about the future masquerade as facts about the past is helpful in responding to fatalism, and it's also helpful in giving a first response to the 
incompatibilist worry about time travel. But there seems to be something else that's worrisome about time travel, even once we do our best to avoid being fooled by fatalist trickery. We can bring out this additional worry by comparing the following two questions:

1. Suppose it was true a million years ago that I will have a cup of coffee tomorrow morning. If I'm nevertheless able to refrain, then it must be possible for me to refrain. What would the world be like if I were to refrain?

2. Suppose that (older Harry) did cast the Patronus at $t_{2}$. If Harry is nevertheless able to refrain from going back in time at $t_{3}$, then it must be possible for him to refrain. What would the world be like if he were to refrain?

The first question seems like it has a relatively straightforward answer: if I were to refrain from having that cup of coffee, then something that was in fact true would be false. That thought is perhaps initially worrying, but once we make the distinction between hard and soft facts, the worry dissolves. If I were to refrain from having that cup of coffee, only some soft fact about the past would be false.

But the answer to the second question, while equally straightforward, seems much more worrisome. If Harry were to refrain from going back in time at $t_{3}$, then he would have died at an earlier time, and hence wouldn't have existed at $t_{3}$. But if he hadn't existed at $t_{3}$, then he wouldn't have been around to do anything at $t_{3}$, and hence wouldn't have been around to refrain from going back in time at $t_{3}$. Since Harry's very existence at $t_{3}$ seems to rely on something he is about to do in his personal future, this situation seems more puzzling than the one above. But what exactly is the problem?

To see what it is, consider the following two principles, neither of which seems to rely on the thought that the past is fixed, but both of which seem to generate the incompatibilist worry nonetheless (Vihvelin 1996; Spencer 2013).

(KV) S is able to do A only if, had S tried to do A, S would or at least might have succeeded.

(JS) $\mathrm{S}$ is able to refrain from doing A only if, had $\mathrm{S}$ not done $\mathrm{A}, \mathrm{S}$ would have done something else instead.

Both principles specify necessary conditions on someone's being able to do something, and in each case the necessary condition is that certain counterfactuals should come out true. According to $(\mathrm{KV})$, roughly, in order for $\mathrm{S}$ to be able to do $\mathrm{A}$, there must be some relatively nearby world in which $\mathrm{S}$ tries to do $\mathrm{A}$ and succeeds. The thought here is that if S doesn't do A but nevertheless could have, then a world in which $\mathrm{S}$ does A must have been accessible to her. And although the notion of accessibility is admittedly obscure, it seems clear enough that if she wouldn't succeed in doing A, even if she had tried, then she lacks access to a world in which she does A-that is, she wasn't able to do A.

But you might worry about putting too much weight on the notion of trying (Vranas 2010), in which case principle (JS) can do the same work. Imagine we're in a world in which $\mathrm{S}$ does $\mathrm{A}$, and we're wondering whether $\mathrm{S}$ was able to do otherwise. The thought behind principle (JS) is that it's not enough to find nearby worlds in which it's false that $\mathrm{S}$ does $\mathrm{A}$, because there are two ways that it can be false that $\mathrm{S}$ does $\mathrm{A}$. First, and most 
naturally, S might do something else. But another way it could turn out false that $\mathrm{S}$ does A is if S doesn't exist, and so isn't around to do anything at all. What principle (JS) says is that those worlds without $S$ don't count when it comes to determining whether $S$ was able to do otherwise. If there isn't an accessible world where $S$ is doing something other than $\mathrm{A}$, then $\mathrm{S}$ isn't able to do anything other than $\mathrm{A}$.

Focusing on principle (JS), let's now return to Harry. In fact, Harry traveled back in time at $t_{3}$, but if he hadn't, what would he have been doing instead? It's seems like we have to say that there's nothing he would have been doing instead, because the nearby worlds in which he doesn't go back in time at $t_{3}$ are worlds in which younger Harry dies at $t_{2}$ and hence are worlds in which there is no older Harry at $t_{3}$ at all. But what this means is that if principle (JS) is true, then Harry is not able to refrain from traveling back in time at $t_{3}$. In the form of an argument:

1. Harry is able to refrain from traveling back in time at $t_{3}$ only if, had Harry not traveled back in time at $t_{3}$, he would have done something else instead.

2. But if Harry had not traveled back in time at $t_{3}$, then he would not have existed at $t_{3}$ (and so wouldn't have been doing something else).

3. It's possible that Harry doesn't travel back in time at $t_{3}$ (since it's possible that Harry never existed at all). (On why this premise is needed, see Spencer 2013.)

4. So, it's not the case that, had Harry not traveled back in time at $t_{3}$, then he would have done something else instead.

5. Therefore, Harry is not able to refrain from traveling back in time at $t_{3}$.

If this argument relies on any sort of fatalist trickery, it's at least not obvious what the trick is. Instead, what it seems to rely on is a rather plausible principle that specifies a necessary condition on someone's being able to refrain from doing something, along with a couple of other plausible counterfactuals. Of course, it's controversial how to evaluate counterfactuals like those that appear in the premises of this argument (Lewis 1973), but there doesn't seem to be anything special about these.

So, Lewis is right that we don't ordinarily hold soft facts fixed when deciding what someone is able to do. Nevertheless, claims about what people are able to do seem to require the truth of some rather mundane counterfactuals, and those counterfactuals come out false in time travel scenarios. The incompatibilist challenge can be revived even once it is liberated of its fatalist attire.

\section{A Residual Worry}

One bothersome aspect of the incompatibilist conclusion is that it seems to commit us to the existence of "strange shackles" on the time traveler. That's Ted Sider's phrase, and he continues: "once the inability of the time traveler to kill her former self is admitted, one wonders what prevents her from doing so" (Sider 2002: 122). Surely we don't have to suppose that there is some "guardian of logic" (2002: 132) that disables the time traveler from doing things we would ordinarily say non-timetravelers could do.

One way we might respond to this worry is to point out that the arguments that have been given for the conclusion that time travelers are able to kill their grandfathers all fail (Wasserman forthcoming). Another way would be to say that the notion of freedom is, after all, a modal notion, so it shouldn't be at all surprising if it turns out that truths 
about what would happen if things were different render an agent unfree, even if there seems to be no mechanism by which his lack of freedom is secured (but see Byerly 2014).

But I actually think that there is a way of refining the "strange shackles" objection to give it more force. And the way in which we refine it will, in fact, lead us to an alternative model of what it is for an action to be up to an agent- that is, to a model of free will that is different from the model according to which free will is a matter of being both able to perform an action and able to refrain. On this new model, compatibilism about time travel and free will can (perhaps) be resurrected.

\section{Entailment vs. Sourcehood}

The big incompatibilist worries mentioned at the outset all share a structure: in each case, there is something that's not up to anyone but that seems to be the source of what everyone does. But the worries as I outlined them above invoked the notion of entailment, and we might wonder whether entailment is a legitimate and worrying sense of sourcehood. That is, I've presupposed that when $p$ entails $q$, there's nothing wrong with saying that $p$ is the source of $q$. But is that right?

To see why we might doubt it, consider again the distinction between hard and soft facts. The response to the logical fatalist, and to the argument for time travel incompatibilism that we considered at first, is that the facts at issue are actually only soft facts about the past, and thus that the Principle of the Fixity of the Past, once properly understood as applying only to hard facts about the past, doesn't show us that they are fixed. More work would need to be done in order to show that those facts aren't fixed, of course, but here's one observation that takes us some distance toward that conclusion: those past facts about what I will go on to do are true, if they are true at all, at least partly in virtue of what I do in the future. In other words, those past facts aren't the source of what I do. If anything, the explanatory relationship is the other way around.

What this observation shows us, if it's right, is that some fact about the past might entail what I do without being the source of what I do. (Similar considerations will be at play in the debate about causal determinism and free will if we are inclined to adopt a Humean view of the laws of nature [Beebee and Mele 2002].) So, it doesn't follow from the fact that my actions are entailed by some fact about the past that the fact about the past isn't at least partly up to me. Although I don't have the space here to argue for the point, I'm inclined to think that what's central to a proper understanding of free will aren't facts about whether an agent is able to do otherwise, but rather facts about whether the allegedly free actions occur in virtue of relevant facts about me and my mental states. What's worrisome about the thesis of causal determinism (if we don't go Humean about the laws) is that if it is true, my actions seem to occur in virtue of stuff that isn't me. And that's precisely why God's foreknowledge has seemed less worrisome to many, because his beliefs_ - even if he held them millions of years ago — are what they are at least partly in virtue of what I do in the future (Todd 2013; Tognazzini 2015).

But now return to the "strange shackles" worry. I submit that the motivation behind this worry is the thought that although the time travel story might show us that a fact about the past (namely, Harry's casting the Patronus at $t_{2}$ ) entails that Harry will travel back in time at $t_{3}$, nothing about the time travel story seems to suggest that there's anything beyond Harry himself that is the source of Harry's decision to travel back in time at $t_{3}$. The reason that literal shackles can disable us isn't simply the fact that our being in them entails that we won't perform certain actions. Rather, it's that our not 
performing those actions is explained by the fact that we are in shackles, together with the fact that the shackles are something outside of our own agency (cf. Frankfurt 1969). So if you find it bizarre that Harry could somehow be rendered unfree merely by the fact that his future self did something in the past which entails that he'll perform a certain action in the present, then perhaps what's worrying you is that it's Harry's actions themselves that are doing the entailing, and surely Harry can't be 'shackled' by something that he himself does. (Well, I suppose that Ulysses does tie himself to the mast. But the point is that shackles are worrisome for free will only when they aren't self-imposed and nevertheless do explanatory work.)

So, what I'd like to suggest in closing is that the "strange shackles" objection, once properly understood, actually points us toward a different conception of free will, one according to which what matters is not whether an agent is able to do otherwise, but whether the action occurs in virtue of some relevant facts about the agent and his mental states. It's puzzling to conclude that Harry lacks free will, precisely because it looks like he is involved in everything that allegedly constrains him. And how could he be his own shackles? If truths about abilities are governed by principles such as (JS), and questions about free will are questions about abilities, then Harry can be shackled by actions that lie in his personal future. To revive compatibilism, we could always try to find some way to reject (JS). But what I'm suggesting is that maybe a better way to go is to reject the link between free will and the ability to do otherwise. Perhaps my actions can be up to me even though I'm not able to refrain from performing them. Unfortunately, though, I don't have space to do any more than simply leave that as a suggestion.

\section{Acknowledgments}

For conversations that have shaped my thinking about these issues, thanks very much to John Martin Fischer, Kelly McCormick, Joshua Spencer, Patrick Todd, Ryan Wasserman, and the students in my 2014 freshman seminar (Metaphysics for Muggles) at The College of William \& Mary.

\section{References}

Beebee, H. and Mele, A. (2002) "Humean Compatibilism," Mind 111: 201-23.

Byerly, T.R. (2014) The Mechanics of Divine Foreknowledge and Providence. New York: Bloomsbury.

Fischer, J.M. (ed) (1989) God, Foreknowledge, and Freedom. Palo Alto: Stanford University Press.

Frankfurt, H. (1969) "Alternate Possibilities and Moral Responsibility," The Journal of Philosophy 66: 829-39.

Goddu, G.C. (2003) "Time Travel and Changing the Past (Or How to Kill Yourself and Live to Tell the Tale)," Ratio 16: 16-32.

Hudson, H. (2014) Hypertime and the Fall. Oxford: Oxford University Press.

Keller, S. and Nelson, M. (2001) "Presentists Should Believe in Time-Travel," The Australasian Journal of Philosophy 79: 333-45.

Lewis, D. (1973) Counterfactuals. Oxford: Blackwell.

Lewis, D. (1976) "The Paradoxes of Time Travel," American Philosophical Quarterly 13: 145-52.

Pike, N. (1965) "Divine Omniscience and Voluntary Action," The Philosophical Review 74: 27-46.

Rowling, J.K. (1999) Harry Potter and the Prisoner of Azkaban. New York: Scholastic.

Sider, T. (2002) "Time Travel, Coincidences, and Counterfactuals," Philosophical Studies 110: 115-38.

Spencer, J. (2013) "What Time Travelers Cannot Not Do (But Are Responsible for Anyway)," Philosophical Studies 166: 149-62.

Taylor, R. (1963) "Fatalism," The Philosophical Review 71: 56-66.

Todd, P. (2013) "Soft Facts and Ontological Dependence," Philosophical Studies 164: 829-44. 
Tognazzini, N. (2015) “Grounding the Luck Objection," The Australasian Journal of Philosophy 93: 127-38. van Inwagen, P. (1983) An Essay on Free Will. Oxford: Clarendon Press.

van Inwagen, P. (2010) "Changing the Past," Oxford Studies in Metaphysics 5: 3-40.

Vihvelin, K. (1996) "What Time Travelers Cannot Do," Philosophical Studies 81: 315-30.

Vranas, P. (2010) "What Time Travelers May Be Able to Do," Philosophical Studies 150: 115-21.

Wasserman, R. (forthcoming) The Paradoxes of Time Travel. Oxford: Oxford University Press.

\section{Further Reading}

Arntzenius, F. (2006) "Time Travel: Double Your Fun,” Philosophy Compass 1: 599-616. (An entertaining and accessible introduction to time travel and some of its worries.)

Carroll, J. (2010) "Context, Conditionals, Fatalism, Time Travel, and Freedom," in J. Campbell, M. O'Rourke, and H. Silverstein (eds), Time and Identity. Cambridge: MIT Press, pp. 79-93. (This essay, and those by Kiourti and Vranas below, are contributions to the discussion of Kadri Vihvelin's thought-provoking article (see above).)

Fischer, J.M. and Todd, P. (eds) (2015) Freedom, Foreknowledge, and Fatalism. New York: Oxford University Press. (A state-of-the-art introduction to, and a collection of essays about, the issues of foreknowledge and fatalism.)

Kiourti, I. (2008) "Killing Baby Suzy," Philosophical Studies 139: 343-52.

Vranas, P. (2009) "Can I Kill My Younger Self? Time Travel and the Retrosuicide Paradox," Pacific Philosophical Quarterly 90: 520-34.

\section{Related Topics}

Classical Compatibilism

Logical Fatalism

Free Will and Theological Fatalism 


\section{INDEX}

A Dissertation on the Passions 323

A Free Will - Origins of the Notion in Ancient Thought 227

'A Theodicy for Today' 491

A Treatise of Human Nature 323, 324, 325, 327, 329

Abhinavagupta 399

abnormality 97, 98, 99

Abrams, M. 675-6

absence causation 32-3

absent good 320

absolute modality 359-60

abstractly described actions $469,470,471$

accidental necessity 503, 505

accountability: and blameworthiness 600-606, 607,

608-9; and criminal law 584, 586; feminist

approaches 625, 626, 627-9, 630; and moral

responsibility 106, 615-16, 617, 618, 619-21; and

Reid 334, 336, 338; and responsibility pluralism 661

Action Challenge 332, 333-6

'action scripts' 529

actional synchronic self-control 444-5

'Actions, Reasons, and Causes' 648

'actish phenomenal quality' 642

active determinism 395-6

active power $56,79,276-7,332,333,334-5,336-7$,

$338-41$

active willing $87,88,89,90,92,516$

actual causal processes $12,28,31$

actual grace 535

'actual sequences' $8,12,184-5,186-8,214,220,222$, 223

actual threats 423

actualization of behaviour-states $333,334,335-6,338$

addiction 405-6, 454-5; animal research 457, 463; and compatibilism 454, 455, 456, 459-62, 464; and

contingency management treatment 456, 457, 459,

463; disease model of alcohol dependence 458; and external constraints 454, 462-4; Frankfurt-Style examples 459-60; hyperbolic temporal discounting theory 461; incentives to abstain 456-8, 461,

462,463 ; irresistibility of addictive desire 455-8,
459-60, 462; 'maturing out' of 457; and neuroscience 455-6; and reasons-responsive theories 459, 460; and temporal myopia 462, 464; and willpower 450-1; willing/unwilling addicts 459-60

Aeschylus 230-1

'affections' of the will 276, 278-80

affective passions $325-6$

agent causation 2, 72-3; and Anselm 259-60; and

Aquinas 270, 271; and blameworthiness 600; and

Bramhall/Hobbes debate 303, 304; and causal power

$74,75,76,78-9,82,83$; and classical compatibilism

47; and coincidence 82-3; compatibilism and

incompatibilism 76; and determinism 73, 75, 76,

$77-8,82$; and deviant causal chains 81 ; disappearing agent objection $77,78,83$; and dispositional compatibilism 55, 59; and event-causal libertarianism 63, 64-5, 67, 69, 72, 77; and exceptionality 76, 81-2; and Frankfurt-Style examples 182; and God 74, 76, 78; and Hume 324-5, 326-7; and immanent causation 74; implausibility/impossibility objections $81-3$; and indeterminism 73, 77; irreducible substance causation 73, 75; and Kant 128, 353; and Leibniz 293, 294-7, 299-300, 301; and libertarianism 76, 77; and luck 77, 78, 205-6; and Manipulation Arguments 168-9, 172; metaphysics and epistemology 78-9; mind and body 74-5; motivations 76-9; and naturalism 75, 76, 82; and non-causal libertarianism $87,91,92$; objections to 77, 79-83; realism about causation 73-4; reasons and reasons-explanations $75-6,80-1$; and reasons-responsive theories 29; and reduction 78; and Reid 332, 333-4, 336, 337-8, 341; and responsible agency $72,77,79-80,83$; and skepticism 125-6, 127, 128-9; and substance dualism 525-8; sufficiency objections $80-1$; and timing of actions 80 agent-based reasons-responsive theories 31, 32, 33, 34 agent-reasons 337 
Ainslie, G. 461

akrasia 565-8; and 'incontinence' 565, 567, 568; and intentional actions 569-71; and self-control 566-8, 569, 572-4; strict akrasia 568-72; and weakness of will 565-6

Alanen, L. K. 288

Alexander of Aphrodisias 234

Alexander, B. 463

alien mechanisms 624

Allison, H. 349

Alston, W. 505

alternate possibilities 358-60, 362, 558-60; see also PAP

'Alternate Possibilities and Moral Responsibility' 179 'alternatives condition' 501

Alvarez, M. 182

Alzheimer's disease 657-8, 662-3

ambivalence 103, 656-7, 658, 660, 661, 662-4, 665

Ambrose 249, 253

American Law Institute 578

American Psychiatric Association 587

Ammonius 267

An Enquiry Concerning Human Understanding 324, 329-30

An Enquiry Concerning the Principles of Morals 323

An Essay Concerning Human Understanding 147, 323

An Essay on Free Will 152, 196, 201

Analects 376

animal principles of action 337

anomalous monism 348-9, 647-8

Anselm 258-62, 278, 290

'anything goes' relativism 143

apparent threats 423

approximate probabilistic irrelevance $671-2,674$

aptitudinal suitability 282

Aquinas, T. 278-9; and Aristotle 232-3; and

Condemnation 275; and contingency 265, 267-70; and determinism 265, 268-70; and divine causality 264, 265, 268-70, 271; and Duns Scotus 278-9; and foreknowledge of God 264, 266-8; and grace 533-4, 535, 539, 540; and happiness 280; and human nature 265-6, 271-2; and Molinism 546; and sin 264, 266, 272-4; and stoicism 245; and temporal fatalism 265, 266-8; theological and anthropological problems 264-6; and theological determinism 515, 516, 518; and theological fatalism 503, 505; voluntarism and intellectualism 270-2

Árdal, P. S. 325

'Are We Free to Break the Laws' 216

aretaic character profiles $618,619,623$

Aristotle: and akrasia 565, 566, 568, 573, 574; and causal determinism 233, 234, 236; and Chinese perspectives 375,378 ; concept and conceptions of will 225, 227-30, 233-4; and Duns Scotus 276-7; and human nature 272; and indeterminism 233, 234; and logical fatalism 191-2; and moral responsibility 236, 241; and prohairesis 229-30,
231-2, 233, 375; and rational/non-rational desires 227-8, 229, 230, 231, 233-4; reasons-responsive theories 29; and retributive attitudes 243-4; and temporal fatalism 267; virtue and vice 231-2, 234; and volition 227, 229-31; and voluntary action 227, 229, 231-2, 234, 358; and 'wishes' 230-3

Arminianism 308-9, 310-11, 544

Arpaly, N. 21, 22, 438

Assumption of Exhaustiveness 126

Assumption of Monism 138, 139

asymptotic unpredictability 670-1

Athenagoras 533

Atkins v. Virginia (2002) 586

attributability: and blameworthiness 608-9; and consciousness 438-9, 442; feminist approaches 625, 629, 630; and moral responsibility 105-6, 618-19, 620-1; and responsibility pluralism 660, 661

Augustine: and bondage to sin 251, 253-4, 256; and Christ 251, 253-4; and compatibilism 46, 247, 248, 251, 252-3, 255; and conceptions of free will 227, 247-9; and determinism 248, 252-3; development of views 249-52; and God 248, 250, 251-2, 253-5; and grace 534; and involuntary sin 254, 255, 256; and libertarianism 247-8, 249-50, 252; and moral responsibility 248, 254-6; and original $\sin 247,248$, 249-50, 252-3, 254; and predestination 247, 248, 250, 252; and problem of evil 491-2; and theological fatalism 501, 502

Aurobindo, S. 400

Austin, J. L. 41, 572-3

autism 657, 661-2

avoidability transfer principles 161

Ayer, A. J. 41, 214-15, 216

Back to the Future 682

background phenomenology 634, 638

Bailey, A. 160

Baker, L. R. 514, 515-16, 536, 650

Balanced Discourses 384

Bañez, D. 264

Banks, W. 639

bare-bones concept (of identificationism) 21-2, 23-5

Bargh, J. 416

Barlee, W. 311

'basic desert' 2, 77, 78, 111-12, 115, 121-2, 130-2, 519-20, 607

Bateson, M. 436-7

'Bathroom' experiment 410, 412, 413

Baumeister, R. 417, 447, 451

Beaman, A. 418

'Belief in Deliberative Efficacy' condition 597-8

'Belief in Epistemic Possibility' condition 596-7

Bennett, K. 651-2

Bering, J. 523

Bernoulli models 672, 673, 674

Berofsky, B. 48, 215

Beta 161 
beta decay 92

Beyond Good and Evil 365, 367, 368, 371

BFR-1 (Belief in Freedom Requirement 1) 591, 592-8

BFR-2 (Belief in Freedom Requirement 2) 592

Bhagavad Gītā 392

Bhattacharya, K. C. 401

Bird, G. 349

bivalence 148, 191, 192, 196, 197-8, 201, 238, 391

Blackwelder, J. 410

blameworthiness: and accountability 600-606, 607, 608-9; accounts of 601-6; and agent causation 600; and criminal law 577-8, 580, 582, 584-8; and divine free will 556; and forgiveness 608 ; functionalist views 605; and grace 533-4, 535-6, 540, 541; and judgment 601-2, 603-4; and moral responsibility 606-7, 608-9, 615-16; and nonstandard views 142, 143-4; norms of blame 609-10; praise and blame 608-9; and reactive attitudes 603-5, 606, 608; reasons-responsive theories 33-4, 35; relationship with 'blame' 606-7; response-dependent/independent conditions 606-7; and revisionism 110-11, 112, 601, 602; scope of blame 609; and skepticism 131; varieties of blame 600-601

Bloom, P. 479, 523

Bobzien, S. 233

Boethius 266-7, 508

bondage to evil/sin 251, 253-4, 256

Bonner, G. 248

Book of Teachings 391

Bradley, F. H. 41, 46

Bramhall, J. 303-11

branching timeline model 681-2

Brandt, R. 608

Brasil-Neto, J. 425

Bratman, M. 20-1

Bremmer, J. 523

Brink, D. 34, 36

broad identificationism 16-17, 18-19, 23-5

broadening strategy 417

Broadie, S. 568

Broks, P. 523

Buddhism 375, 379, 381, 390-1, 394-5, 397, 402

'bundles of perceptions' 323-4, 326-7

Buss, S. 570

'bypassing' 470

C\&D (clear and distinct) perceptions 285-9, 290

Calvin, J./Calvinism 308-11, 513-14, 544-6, 548, 549, 551

Campbell, C. A. 41, 493

Campbell, J. 148, 214, 217

Cann, A. 410

capital punishment 354,586

care-based ethics 627-8

Carneades 242

Carruthers, P. 438
Cartesian approaches 74-5, 650-1

Caruso, G. 121, 431, 439

Casebeer, W. 418

Categorical Imperative 33

causal determinism: and Aquinas 268-70; and

Aristotle 233, 234, 236; and control condition 434;

and event-causal libertarianism 62-4; feminist

approach 625, 626; and grace 536; and Hume

327-9; and Locke 316; and Manipulation

Arguments 169, 173, 174; and providence 544-5, 548, 549; and semicompatibilism 5-7, 8-13; and skepticism 121, 122, 125, 126, 131-2; and

sourcehood 221; and Stoicism 236-7, 238-9, 241; and theological determinism 514, 515, 516; and theological fatalism 504-5, 506; and time travel $680,684,688$

causal indeterminism 8, 9-10, 63, 65-7, 68, 69

'causal indifferentism' 325

causal necessity 48, 63, 400, 503

causal power 1 ; and agent causation $74,75,76,78-9$, 82, 83; and dispositional compatibilism 56, 57, 59; and divine causality 269; and Kant 351; and mental causation 651; and providence 548, 550; and skepticism 127-8; and substance dualism 528-9; and theological determinism 518

CCFs (counterfactuals of creaturely freedom) 546-7, 548-50

Cetanā 394-5

Chakrabarty, A. 226

Chalmers, D. 213

Chan 379

'chancy lucky' 126, 127

chaos theory 670-1

Charland, L. 455, 458

children's intuitions on choice 477-83

Chinese perspectives 374-5; Buddhism 375, 379, 381; and causality 384-5; Confucius/Confucianism 375, 376, 377-9, 380, 381, 383, 384-5, 386; Daoism 375, 379, 381, 382, 383, 386; and determinism 374, 380-1, 384; and 'fate' 380-1, 384, 385, 386; and 'heart-mind' 376-8, 385, 386; and 'human nature' 378-9, 385, 386; and Kant 374-5; and 'self-so' 381-4, 385; and spontaneity 378-9, 381-2, 383, 385

Chisholm, R. 41, 47, 74, 77, 82, 83, 129, 523-4

Christ 251, 253-4, 273, 533, 535

Chrysippus 7, 234, 237, 238, 239, 240, 241, 242

Cicero 229-30, 238, 249

City of God 251, 252

Clarke, R. 47, 66, 73-4, 75, 80, 81, 125, 128, 215

Clarke, S. 333

classical compatibilism 1, 2; and addiction 454, 455, 464; and agent-causation 47; and Consequence

Argument 154; and counterfactual power 43-5, 46, 49; and determinism 41, 43, 44-7, 48, 49; dispositional analysis of free will 41-3; and Frankfurt-Style examples 41, 42; and 
identificationism 15-16, 17, 18, 19, 23; and incompatibilism 41, 46-8; and indeterminism 47; and libertarianism 47-8; and liberty of indifference and luck 46-7; and luck 48; and moral responsibility 41, 43, 47-8, 49; and self-determinism 45-6, 47; and semicompatibilism 5-6, 10; and Strawsonian theories 96, 97; theory of necessity 48-9

classical incompatibilism 151, 153, 157-8, 159

closure principle 648-50, 652

CM (contingency management) treatment 456, 457, 459,463

Coates, D. J. 608

'co-fated' events 236, 238, 241

coincidence $82-3,128-9$

commandeering thought 368-9

commonsense compatibilism 54

Commonwealth v. DeMarco (2002) 582

compatibilism 1, 2; and addiction 454, 455, 456, 459-62, 464; and agent causation 76; and Aristotle 233; and Augustine 247, 248, 251, 252-3, 255; classical see classical compatibilism; and Consequence Argument 151, 154; dispositional see dispositional compatibilism; and event-causal libertarianism 63, 64, 66, 68; and folk intuitions 468-73; and Frankfurt-Style examples 179, 180; and grace 536, 540; and Hegel 356, 360, 361-2; independent compatibilism 496-8; and Kant 343, 346, 347-9, 351; and leeway-based approaches 215-17 , 222-3; and Leibniz 293, 295, 297, 299, 301; leeway compatibilism 30, 33-4, 43, 215-18; and Locke 316; and 'logical problem of evil' 486, 489, 495-8; and luck 204, 205, 207, 211; and major arguments 147-8; and mental causation 348-9; and moral responsibility $614,615,616-17$; and neuroscience 428; and Nietzsche 366, 368; and nonstandard views 136-7, 138-9, 140-2, 143-4; and phenomenology of agency 636-7, 640; and providence 544-5, 548, 549, 550; and reasonsresponsive theories $28-30,31,32,33-4,36,37$; semicompatibilism see semicompatibilism; and skepticism 121, 124, 126, 127, 129-30; source compatibilism 30, 31, 32, 33-4, 36, 221; and sourcehood 220-1, 222-3; and Stoicism 236, 237, 245; and Stoics 225-6; and Strawsonian theories 96-7, 99, 101, 102, 106; and theological determinism 512, 513-16, 517-18

compossibilism 169, 172, 173

concession strategies 413, 416

concretely described actions 469, 470, 471

concupiscibile 273

Condemnation (of 1277) 275-6

conditional analysis 43-5, 60, 216, 504

conditionalism 216-17

confabulations 405, 435-6, 441

Confessions 253, 254, 255

Confucius/Confucianism 375, 376, 377-9, 380, 381, 383, 384-6 connotational revision 115-16, 117

conscious awareness 417, 439, 527

conscious intention 123-4, 427

consciousness: and confabulations 435-6, 441;

'consciousness thesis' 437, 438, 439-40; empirical perspectives 434-42; and implicit attitudes/biases 436, 438, 440-2; and Indian philosophies 395, 398-9; and moral responsibility 435, 437-40, 441-2; and Nietzsche 364, 371; and neuroscience 428, 430-1; and 'overlearned' actions 439-40; and substance dualism 527, 529

'consciousness thesis' 437, 438, 439-40

Consequence Argument 148, 151-2; basic argument 159-60; and Beta 161; and compatibilism 151, 154; conditional version of 161 ; and determinism 151 , $152,153-4,155,156,157-8,159,161$; and dispositional compatibilism 55; extension versions of 158-60, 161; grounding propositions 152, 158; Humean approach 154-5, 160; and incompatibilism 151, 152, 153, 157-8, 159, 161; and Kant 351; and logical fatalism 191, 192, 193, 194-5, 201; and luck 206; meta-issues 161; modal transfer principles 152; $\mathrm{N}$-operator argument 155-6; and no-choice transfer rules 152-3, 154, 155-6, 158, 161; and providence 548, 550; and reasons-responsive theories 30, 36; and semicompatibilism 6-7, 12; and theological determinism 516; transfer versions of 152-8, 161 consequentialism 111-12, 139, 243, 519, 601 constitutive luck 127, 148, 167, 174, 177

contextualism 139, 141, 154

contingency 265, 267-70, 275-8, 293-4, 298, 301, 305-6

'contingent being' 269

contingent propositions 157, 192, 197-9, 306

contractualism 139, 141-2, 519, 629-30

control condition 434, 439-40

Conversation with Burman 289

cooperating grace 537

Copp, D. 218

core bundle of free will 58-9, 60

Council of Trent 537

Counterexample Step (Four-case Argument) 167-9, 175

counterfactual intervention $8,11,31-3,147,180,504$, 614,652

counterfactual power 43-5, 46, 49, 215, 547-9

counterfactual properties 56-7

'crazy ethics' 136

creature consciousness 437, 440

'credibility deficits' 628

Crick, F. 429

criminal law: agency and liability in 578-80; and blameworthiness $577-8,580,582,584-8$; duress defense 582; excuses in 581-2; insanity defense 583-5; and juveniles 586-7; and mental capacity 579-80, 582, 583-5, 586, 587; and morality 584-8; provocation defense 581,582 ; and retributive justice $577-8,580,585-6,588$ 
criticism and counterevidence strategy 416-17

Critique of Judgment 352

Critique of Pure Reason 343, 345, 346

culpability 104, 306, 586-8, 619-21

currently possible observations 673

D'Arms, J. 607

Daoism 375, 379, 381, 382, 383, 386

Darley, J. 418

Davidson, D. 81, 330, 348-9, 526, 565, 571, 645, 647-8

Daybreak 364

de Barros, A. 673

De Interpretatione 191-2

de Molina, L. 546

Deery, O. 636-7

deflationism 348, 349-50

Dehaene, S. 427, 428

deliberation 590: and Aristotle 229, 231-2, 233, 234;

'Belief in Deliberative Efficacy' condition 597-8;

'Belief in Epistemic Possibility' condition 596-7;

'Belief in Freedom Requirement 1' 591, 592-8;

'Belief in Freedom Requirement 2' 592; Chinese perspectives 377; and classical compatibilism 46-7; and determinism 593-4; and dispositional compatibilism 53, 55-6, 58-9; and doxastic requirements 590, 592, 595-6, 598; and eventcausal libertarianism 65, 68-9; Frankfurt-Style examples 594-5; and 'freedom-involving' beliefs 590, 593-5; and Kant 352; and Leibniz 293-4, 296-7, 298; and Locke 316, 319-20, 321-2; and logical fatalism 192; 'No Belief in Inability' condition 596, 597; and neuroscience 425, 428, 430; senses of 590-2; and situationism 416, 417; and stoicism 236, 238-40; and willpower 445

dementia 657-8, 662-3

Dennett, D. 65, 527

denotational revision $115-16,117$

Descartes, R.: and agent causation 75; clear and distinct perceptions 285-9, 290; defining 'freedom' 286-90; and determinism 286-91; and God 284-6, 289, 290-1; and importance of freedom 284-6; and intellect/intellectualism 285-9; and laws of nature 290-1; and mental causation 646; moral/absolute distinction 287-8, 290; and substance dualism $524-5$

determinism 1, 2, 669; and agent causation 73, 75, 76, $77-8,82$; and approximate probabilistic irrelevance 671-2, 674; and Aquinas 265, 268-70; and asymptotic unpredictability 670-1; and Augustine 248, 252-3; causal see causal determinism; and chaos theory 670-1; Chinese perspectives 374, 380-1, 384; and classical compatibilism 41, 43, 44-7, 48, 49; and Consequence Argument 151, 152, $153-4,155,156,157-8,159,161$; and control condition 434; and deliberation 593-4; and Descartes 286-91; and dispositional compatibilism
53-6, 60; and Duns Scotus 275, 276-7, 278, 281-2; and folk intuitions 468-70, 471-2; and FrankfurtStyle examples 179, 181-2, 184; hard see hard determinism; and Hegel 356, 357, 359, 360-2; and Hobbes 303, 306-8; and Hume 326, 327-30; Indian philosophies 391, 392, 393, 395-6, 400-402; and Kant 343, 345-6, 347-51, 353; and karma 390, 393-4, 399-402; and leeway-based approaches 215-17; and Leibniz 293, 294, 298-301; and Locke 315-16; and 'logical problem of evil' 486, 490, 495-7; and luck 204-5; and major arguments 148; and Manipulation Arguments 166-7, 168-70, 171-2, 173-5, 176-7; method of arbitrary functions 674-6, 677; and moral responsibility 616, 617-18, 620; and neuroscience 428-9; and Nietzsche 364, 367-8; and non-causal libertarianism 86-7, 88-91, 92, 94; and observational equivalence $672-3,674$, 677; and phenomenology of agency 635-6, 637; and predictability 669-72; and Principal Principle 676-7; and probability 674-7; and providence 544-5, 548, 549, 550; and randomness 672-4; and reasons-responsive theories 29-30, 34, 36; self-determinism 45-6, 47, 63, 250, 275, 289, 294, $365,376,568$; and situationism 412; and stochastic models 672-3, 674; and Stoicism 240-3; and Strawsonian theories 96-8, 102-3, 350; and substance dualism 525-7, 529; theological see theological determinism

deviant causal processes 28, 81, 361

diachronic self-control 444

Dialectical School 192

Dialogues Concerning Natural Religion 490

Dictionary of the Bible 512

'difference-making' 652-3

Dihle, A. 227

Dijksterhuis, A. 416

'Dime in the Phone Booth' experiment 409-10, 412,415

Diodoran principles 191, 192, 195, 201-2

Diodorus 192, 201

Direct Argument 550

disappearing agent objection 77, 78, 83, 128, 205

'disease model' of alcohol dependence 458

disjunction 18-19, 23-4, 304-5, 398, 558, 604-5

dispositional compatibilism 1, 52-3, 58-9; and agent causation 55, 59; and causal powers 56, 57, 59; and classical compatibilism 41-3, 48; and Conditional Analysis 60; and core bundle of free will 58-9, 60; and counterfactual properties 56-7; and determinism 53-6, 59, 60; dispositions and abilities 56-8, 59, 60; and incompatibilism 54-6, 59; and libertarianism 54-5, 59; and moral responsibility $52,53,54$; objections to 59-60; and semicompatibilism 54

divided mind 445

divine causality 264, 265, 268-70, 271, 307-11, 517-18 
divine free will 553-60

'doctrine of necessity' 328-9

Dong Zhongshu 379, 384

Doris, J. 407, 410-11

'double affirmations' 517

Double, R. 143

doxastic requirements 590, 592, 595-6, 598

Dretske, F. 75

Driver, J. 609

Duggan, T. 34

Duns Scotus 270, 275-6; and 'affections' of the will 276, 278-80; and Aristotle 276-7; and Condemnation 275-6; and contingency 275-6, 277-8; and determinism 275, 276-7, 278, 281-2; and happiness/unhappiness 280-1, 282; and intellect/intellectualism 275-6, 278-9, 280, 281-2; and rational power $276-8,279-80,281-2$; and scope of will's freedom 280-1

duress defense 582

Eagle, A. 674

Edwards, G. 458

EEG (electroencephalogram) 123, 639

Effective Intentions 426-7

efficient causality 75, 79, 81, 233, 294, 296, 299, 332, $333,337-41,360,361$

efficient-causal exclusivity $337-8$

Ekstrom, L. 65-6, 72

eliminativism 49, 115, 117, 429-30, 564

Elster, J. 565

embarrassment 410, 412, 413, 414, 415, 417, 418

Emerson, R. W. 394

empathic deficits 659, 662

empirical causality 347, 349

end-states 337

enkratic independence 370, 371, 372

Ensurance Formulation (of Luck Argument) 206-7

entailment 155-6, 506, 688-9

Epictetus 227, 237, 240-1, 244, 245

epiphenomenalism 430-1, 648

epistemic competence 624, 626-9

epistemic condition 434

epistemology 78-9, 268, 284, 394, 396, 397, 527, $626-9,669$

Essay Concerning Human Understanding 313, 314-15, 316, 317, 318, 319-20, 321, 322

Eudemian 232

evaluative independence 371,372

event-causal libertarianism 2, 62; and agent causation 63, 64-5, 67, 69, 72, 77; and Bramhall/Hobbes debate 303, 304-5; and causal determinism 62-4; and causal indeterminism 65-7, 68, 69; and compatibilism 63, 64, 66, 68; and Frankfurt-Style examples 66; and incompatibilism 63, 67, 68; and Kant 350-4; and Leibniz 293, 299; and luck 68, 69, 205-6; and modest libertarianism 65; and non-causal libertarianism 89-91; objections to
68-9; and preferences 65-6; and self-determinism

63; and skepticism 127-8

'Evil and Omnipotence' 489

Evil and the God of Love 491

exceptionality $76,81-2$

Exclusion Argument 648-53

executive control 624

experimental philosophy 144

Explanation Step (Four-case Argument) 173-5, 177

explanatory factors 180, 183, 184, 185, 188

Explanatory Formulation (of Luck Argument) 208-9

explicability of the world 356, 357, 358, 360

extraversion 471

extreme forces 408

extrinsic properties 57

faith $261-2,268,370,531-2,534-5,536-41$

'fallibility' model of willpower 451

Fallon, J. 656

Farrer, A. 516, 517

'fate' (ming) 380-1, 384, 385, 386

feminist approaches 564, 623-30

Fichte, J. G. 358

Finch, A. 148, 160, 199

first-order desires 37, 168, 173, 184, 220-1, 445-6, 459-60, 646

Fischer, J. M.: and addiction 459; and agent causation 297; and Chines perspectives 383; and consciousness 440; and Consequence Argument 161; and deliberation 591; and feminist approaches 624; and Frankfurt-Style examples 182, 183, 186-7, 188; and identificationism 19; and leeway-based conceptions 214, 215, 217, 218; and moral responsibility 616 ; and providence 545 ; and reasonsresponsive theories 30, 31-2, 34-6, 130, 188,

412-14, 446, 496; and semicompatibilism 136, 215, 221; and sourcehood 221-2; and theological fatalism 505

'five-phases' 384-5

Flew, A. 514

'flickers of freedom' 7, 181, 504

Flint, T. 515

'flow' model 18

fMRI (functional magnetic resonance imaging) 123

focal phenomenology 634,638

Fodor, J. 647

folk conceptions/intuitions 109-10, 112-16, 468-73, 633, 635-7

Ford v. Wainwright (1986) 586

foreknowledge of God: and Aquinas 264, 266-8; and Bramhall/Hobbes debate 307; Indian philosophies 397; and providence 547, 549, 550; and semicompatibilism 5, 6, 8, 12; and theological fatalism 500-502, 503, 504, 505-8, 509; and time travel $680,684,688$

forgiveness 519, 608, 610

Four Views of Free Will 567 
Four-case Argument 13, 167-75, 176-7, 472, 549, 550

Frankfurt, H./Frankfurt-Style examples: actual sequences 184-5, 186-8; and addiction 459-60; and agent causation 182; alternative views of freedom 184-8; and causation concepts 183-4; and Chinese perspectives 383; and classical compatibilism 41, 42; and compatibilism 179, 180; and deliberation 594-5; and determinism 179, 181-2, 184; and event-causal libertarianism 66; explanatory factors $180,183,184,185,188$; and feminist approaches 624,625 ; and folk intuitions 472; and grace 536; and identificationism 15, 16, 17-18, 20-1, 22-3; and incompatibilism 179, 180, 181-2; and indeterminism 181-2, 184; inevitability factors 180 , 183, 185; and 'logical problem of evil' 496; main replies and new examples 181-3; and major arguments 147, 148; and Manipulation Arguments 173; and moral responsibility 179, 182, 186-8, 614; and non-causal libertarianism 86; original examples 179-80; and Principle of Alternate Possibilities 179-85, 188; and providence 545, 548; and reasons-responsive theories 30-3, 34, 37, 185; and Reid 334; RELEVANCE principle 185-8; retreat from counterexample strategy 183-4; robust alternatives 181-2, 183; and semicompatibilism 7-8, 11-12; and skepticism 129-30; and sourcehood 220-2; SUPERVENIENCE principle 186-8; and theological determinism 514; and theological fatalism 504; and willpower 445-6

Franklin, C. 148

Frede, D. 227

Frede, M. 227

'Free Will and Free Action' 567

'Free Will Defense' 493

'Free Will in Aristotle?' 227

Freedom and Belief 642

'Freedom and Resentment' 96, 131, 142, 243, 350, 603, 606

'freedom-involving' beliefs 590, 593-5

Fricker, M. 628-9

Frigg, R. 677

full-blooded action/agency 22, 78

future-directedness 199

Gandhi, M. K. 394

Gauthier, R.-A. 227, 228, 233

Gay Science 367

Gell, A. 523

Genealogy of Morality 364

Generalization Argument (Four-case Argument) 172-3, 175, 176

Generalization Step (Four-case Argument) 170-2, 177

Gert, B. 34

Gilman, C. P. 627

Ginet, C. 32, 87, 160, 526, 642

global automatism 529

Glover, J. 138
God: and agent causation 74, 76, 78; and alternate possibilities 558-60; and Anselm 258-62; and Augustine 248, 250, 251-2, 253-5; and Bramhall/ Hobbes debate 306-7, 308-11; and classical compatibilism 49; and Descartes 284-6, 289, 290-1; and divine causality 264, 265, 268-70, 271, 307-11, 517-18; and divine free will 553-60; foreknowledge of see foreknowledge of God; goodness of 280, 284, $285,310,554-6,558-60$; and grace 531, 533, 535-41; and hard determinism 122; and human nature 273; and Indian philosophies 390, 392, 394, 397, 399-400; and Kant 350; and Leibniz 294-5, 297, 299-300; and 'logical problem of evil' 485, 486, 490-3, 494, 495-7; and 'middle knowledge' 291, 546-9, 550; omnipotence of 237, 248, 284-5, $308,310,384,390,487,491,493-4,550,553,554$, 557-8, 560; omniscience of 12, 192, 308, 384, 390, 394, 400, 486, 495, 500-501, 505, 507, 508, 550, $553,557,558,560,680$; and providence 268,291 , 486, 512, 513, 516, 518, 543-51; and Rollback Formulation of Luck Argument 207-8; and semicompatibilism 5, 6, 8, 12; 'shrinkage' of options 559-60; sovereignty of 543-4, 547, 548; and Stoicism 236, 237-8, 239, 240-1, 244-5; and theological determinism 512-13, 514, 515-18, 519-20; and theological fatalism 500-509

Gongbo Liao 380

Gould, J. 536-7, 538, 541

grace: and Anselm 261; and Aquinas 265-6, 272-4; and Augustine 247-53, 255-6; Christian conception of 531, 540-1; and faith 531-2, 534-5, 536-41; and God 531, 533, 535-41; Indian philosophies 393, 394, 400; and moral responsibility 531-3, 536, 540; and Pelagianism 534, 538; and praiseworthiness/blameworthiness 533-4, 535-6, 540, 541; and $\sin 533,534-5,539$

Graham, A. C. 382

gratitude 132, 390, 519, 663, 664

Gross, M. 458

grounding propositions 152,158

guidance control 215, 221, 383, 459

guilt 132, 413, 417, 519; see also criminal law

Guo Xiang 379

habitual grace 535

Haji, I. 159, 182

Hallett, M. 431

Hanna, R. 350

happiness/unhappiness 280-1, 282

happy hard determinism 139

hard determinism: 'happy' 139; and Hegel 356, 362; and nonstandard views 136-7, 138-9, 140-1, 143-4; and providence 544; and skepticism 121, 122-3, 126; and theological determinism 518-20 hard facts 199-200, 502-3, 505-7, 685-6, 688 hard incompatibilism 115, 365, 366, 372

Hare, R. 571 
Harman, G. 407, 410-11

Harré, R. 79

Harris, R. 620

Harry Potter and the Prisoner of Azkaban 682-3, 684, 685, 686, 687, 688-9

Hasker, W. 508, 548

'heart-mind' (xin) 376-8, 385, 386

'Heaven's Mandate' 380, 381

Hegel, G. W. F.: and alternate possibilities 358-60, 362; challenges to possibility of free will 357-61; and determinism 356, 357, 359, 360-2; and incompatibilism 356, 357, 359, 360, 361-3; and indeterminism 359, 360, 362; and necessity 356-7, 358-60, 361

Helm, P. 514, 515-16

Heyman, G. 463

Hick, J. 491-3, 495

'hierarchy of desire' 15, 20

Hieronymi, P. 604

Higashida, N. 657, 662

High Affect scenario 468-70

higher level conscious events 527

higher-order desires 37, 184, 445-6, 646

Hinckley, J. 583

Hitchcock, C. 209

Hobart, R. E. 47

Hobbes, T.: Bramhall debate 303-11; and Calvinism 308-10, 311; and classical compatibilism 41, 42, 44, 45, 46, 49; and determinism 303, 306-8; and event-causation 303, 304-5; and God 306-7, 308-11; and Hegel 357, 358; metaphysical view of freedom 313; and negative liberty 377

Hodgson, D. 67

Hoefer, C. 299, 677

Holbach, P. 121

Holton, R. 565-6, 635, 637

Honderich, T. 121, 122-3, 138, 142-3, 431

Hoonhout, M. 516-17

Horgan, T. 637-8

'How is Weakness of the Will Possible?' 565

'How to Think About the Problem of Free Will' 213

'Huckleberry Finn' 438, 573

Hudson, H. 348, 349, 350

'human nature' (xing) 378-9, 385, 386

Human, All Too Human 364

Hume, D.: and affective passions 325-6; and agent causation 324-5, 326-7; and bundles of perceptions 323-4, 326-7; and classical compatibilism 41, 42, 43, 44, 47, 48-9; and Consequence Argument 154-5, 160; and determinism 326, 327-30; and event-causal libertarianism 128, 351; and evil 490; and moral responsibility 96; and naturalism 323; and nature of free will 225; and necessitation 323, 327-8, 329; and non-causal libertarianism 86-7, 92, 93, 94; and spontaneity 326, 329; and volition 323-4, 325-6, 327, 328-9, 330

Humphrey, N. 523
Hunt, D. 486

hyperbolic temporal discounting theory 461 hypertime model 682

idealism 74-5; see also transcendental idealism identificationism 2, 15; and ability to act otherwise 15-19; bare-bones concept 21-2, 23-5; broad identificationism 16-17, 18-19, 23-5; and classical compatibilism 15-16, 17, 18, 19, 23; competing accounts of 19-21; Frankfurt-Style examples 16, 17-18, 20; and 'hierarchy of desire' 15, 20; and moral responsibility 17-19, 22-4; and motivation 15-16, 17-18, 19-21, 23-4; narrow identificationism 17-18, 19, 22-5; robust concept of 17, 19, 21-2, 23-5; and volition 20, 21, 22; and weak-willed actors/actions 17, 19, 21-2, 23-4; willing/unwilling addicts $17,18-19,22-4$

illusionism 3, 143

immanent causation 74

immaturity 97, 98

implicit attitudes/biases 436, 438, 440-2

inactive free consciousness 395-6

incompatibilism 1-2; and addiction 454; and agent causation 76; and Augustine 247-8; and classical compatibilism 41, 46-8; and Consequence Argument 151, 152, 153, 157-8, 159, 161; and deliberation 593; and dispositional compatibilism 54-6, 59; and event-causal libertarianism 63, 67, 68; and folk intuitions 470, 471-2; and FrankfurtStyle examples 179, 180, 181-2; and grace 532; and Hegel 356, 357, 359, 360, 361-3; and Kant 343, 346, 348, 349; and leeway-based approaches 217-18; and libertarianism 213; and luck 203-4, 205-6, 207, 209, 210; and major arguments 147-8; and Manipulation Arguments 166-7, 173-4, 177; and moral responsibility 614, 616, 617; and Nietzsche 365, 366, 372; and nonstandard views $137,138,142,144$; and phenomenology of agency 636-7; and providence 545; and reasons-responsive theories 28-30, 32, 34, 36-7; and scepticism 122, 126; and semicompatibilism 5-6, 9, 10-13; and sourcehood 219-20; and Strawsonian theories 96, 98, 102; and theological determinism 512-13, 518-9; and theological fatalism 486, 501, 502, 503, 505-6; and time travel 681, 682, 684, 685-7, 688; source incompatibilism 10-11, 12, 13, 46, 173-4, 219, 287, 361-3; source incompatibilism 11, 12, 46, $219,248,287,361-3$

incompossibilism 169, 173-4, 175, 177

'incontinence' 229, 230, 565, 567, 568

independent compatibilism 496-8

indeterminism 2, 669; and agent causation 73, 77; and Aristotle 233, 234; causal 8, 9-10, 63, 65-7, 68; and classical compatibilism 47; and Duns Scotus 277, 282; and Frankfurt-Style examples 181-2, 184; and Hegel 359, 360, 362; and luck 203-7, 208, 209-11; and major 


\section{INDEX}

arguments 148; and Manipulation Arguments 168, 171-2, 174; and mental causation 645; and neuroscience 428; and randomness 672; and reasons-responsive theories 29-30; and semicompatibilism 8, 9, 10,11; and skepticism 123, 124-5, 126, 128-9; and Strawsonian theories 99

Indian philosophies: Buddhism 390-1, 394-5, 397, 402; Cetanā 394-5; and determinism 391, 392, 393, 395-6, 400-402; and God 390, 392, 394, 397, 399-400; İsā Upanişad 389-91, 402; Jainism 393-4; Kashmir Shaivism 398-9; Mahābhārata 391-2; Mīmāmsā 396; Nyāya School 397-8, 401-2; Sāmkhya Dualism 395-6; Subject as Freedom 401; Swami Vivekananda 400-401; Vedānta systems 399-400; and volition 389-90, 394, 396-7, 402; Yogavāsiștha 393

indirect evidence 673-4

inevitability factors $180,183,185$

infallible determination 298

'inferentially promiscuous' beliefs 440

Infinite Adam example 157

Ingham, M. B. 281

initial velocities 674-6

initiation 8-9

insanity defense 583-5

Institutes of the Christian Religion 513

intellect/intellectualism: and Aquinas 266, 268, 270-2, 273; and Aristotle 229, 232; and Augustine 248, 249-51; and Descartes 285-9; and Duns Scotus 275-6, 278-9, 280, 281-2; and Leibniz 293, 294, $297-8,300,301$

intentional action/intentionality: and agent causation 75; and akrasia 569-71; and children's intuitions on choice 479-82; and criminal law 580; feminist approaches 624; and Hume 324, 326; and identificationism 16; and neuroscience 425-6, 431-2; and non-causal libertarianism 89, 92; and situationalism 408, 412

internal sourcehood 11, 12-13

intrinsic properties 57

involuntary $\sin 254,255,256$

irascibile 273

Irenaeus 491-2

irreducible substance causation 73,75

irresistibility testing 449-50

İśā Upanişad 389-91, 402

Isidore of Seville 249

Jackson v. Hobbs (2011) 587

Jackson, T. 311

Jacobs, J. 75

Jacobson, D. 607

Jainism 393-4

James, W. 454-5, 458

Jo, H.-G. 427

Johnson, D. 156, 195, 201, 210 judgment shift 448-9

‘justificatory asymmetry' 354

Justin Martyr 533

Kahn, C. 228

Kalish, C. 478

Kane, R. 9, 10, 47, 66-7, 127, 172, 214, 219, 362-3, 431, 522-3, 567, 614-15

Kant, I.: and agent-causal libertarianism 128; and Chinese perspectives 374-5; and compatibilism 343, 346, 347-9, 351; and deflationism 348, 349-50; and determinism 343, 345-6, 347-51, 353; and event-causal libertarianism 350-4; and God 350; and incompatibilism 343, 346, 348, 349; and libertarianism 343, 347-8, 349, 350-4; and moral agency 101, 102, 104; and moral responsibility 347, 354; and noumena 343, 344, 345-7, 348, 349, 350, 351-2, 354; and Pereboom 350; and reasonsresponsive theories $29,33,35$; and transcendental freedom 346-8, 349, 350, 353-4; and transcendental idealism 343-6, 350

Kapitan, T. 192

karma 390, 393-4, 399-402

Kashmir Shaivism 398-9

Kennett, J. 573, 661, 662

Kim, J. 648, 649, 650, 652

King, M. 438

King, P. 279

Kirwan, C. 247

Klein, M. 138

Knobe, J. 468-70

Komline, K. 533

Kondoleon, T. 515, 545

Kushnir, T. 478

'Lady in Distress' experiment 410, 413, 414-15, 416

Lang, B. 480

Laozi 381-2, 383

Laplace, P. S. 669

Laplacian determinism 374

Latané, B. 410, 418

Laudan, L. 673

Law of Non-Contradiction 198

lawful sufficiency 184

Lawler, M. G. 535

'lazy argument' 236-7, 238-9

Lectura 279

leeway-based approaches 148, 214-18, 222-3; and compatibilism 215-17, 222-3; and conceptions of free will 213-14; and determinism 215-17; and incompatibilism 217-18; leeway compatibilism 30, 33-4, 43, 215-18; leeway conceptions 148, 191, 192-3, 201; leeway freedom 30, 31, 34, 36; Luck and Mind Arguments 218, 222; and moral responsibility 214, 215, 218; and semicompatibilism 215

legislative control 624

Lehrer, K. 43, 155 
Leibniz, G.: and agent causation 293, 294-7, 299-300, 301; and compatibilism 293, 295, 297, 299, 301; and contingency 293, 294, 298, 301; and determinism 293, 294, 298-301; and God 294-5, 297, 299-300; and intelligence 293, 294, 297-8, 300, 301; and spontaneity 293, 294-7, 298, 301; and theodicy 489-90; three conditions for freedom 293-4

Leiter, B. 123, 372

Lenman, J. 141

Leplin, J. 673

Levy, N. 121, 126-7, 140, 167, 208, 457, 461, 462, 463,529

Lewis, C. S. 522

Lewis, D. 154, 155, 216, 351, 398, 677, 684-5, 687

Liberius 534

libertarianism 2; and agent causation 76, 77; and Augustine 247-8, 249-50, 252; and classical compatibilism 47-8; and Descartes 289; and dispositional compatibilism 54-5, 59; event-causal see event-causal libertarianism; and folk intuitions 472; and Hegel 356, 360, 362; and incompatibilism 213; and Indian philosophies 392, 393; and Kant $343,347-8,349,350-4$; and 'logical problem of evil' 485, 486, 489, 490, 493-5, 496, 497, 498; and luck 204-6, 209, 210-11; and Manipulation Arguments 167, 172; non-causal see non-causal libertarianism; and nonstandard views 137, 138, $139,142,143-4$; and phenomenology of agency $635-7,638,640-2$; and providence 545-7, 548-50, 551; and reasons-responsive theories 30; and revisionism 113-15; and skepticism 125, 127-9; and sourcehood 219; and Strawsonian theories 96-7, 98-9, 103; and substance dualism 522-3, 525-9; and theological determinism 513, 516-18

liberty of indifference 46-7

Libet, B. 121, 123, 124, 423-4, 425, 639-40

Lightner, M. 481

List, C. 652-3

Little, M. 627-8

Living Without Free Will 168

Locke, J.: and classical compatibilism 41, 42, 43-4, 46, 47; and compatibilism 316; conceptions of freedom 313-15, 316-17, 321, 322; and deliberation 316, 319-20, 321-2; and determinism 315-16; and Frankfurt-Style examples 7; and major arguments 147; man in a locked room scenario $7,44,147$, 314-15, 334-5; and suspension 319-22; and volition 313-15, 318-19, 321; and weakness of will 317-19

logical fatalism 148, 191, 192-6; and bivalence 191, 192, 196, 197-8, 201; and Consequence Argument 191, 192, 193, 194-5, 201; contingent propositions 192, 197-9; and Diodoran principles 191, 192, 195, 201-2; and hard facts 199-200; history of 191-2; and leeway theorists 191, 192-3, 201; N-operator argument 194-5; and Ockhamism 192,
199-201; and Principle of Fixity of the Past 195-6, 199-200, 201; responses to 196-201; and soft facts 199-200; and sourcehood 191; and theological fatalism 192; and true-at-a-time propositions 195, 196, 197, 201

'logical problem of evil' 284-5: and compatibilism 486, 489, 495-8; and defense 493-8; and determinism 486, 490, 495-7; and God 485, 486, 490-3, 494, 495-7; and Hick 491-3, 495; and libertarianism 485, 486, 489, 490, 493-5, 496, 497, 498; and Mackie 489-91, 492, 494-5, 496, 497, 498; and Plantinga 485, 493-5, 497-8; and theodicy 485, 489-90, 491-3, 495, 498

Lombard, P. 279

looping effects 458

Low Affect scenario 470

Lowe, E. J. 73, 75-6, 81

luck 148, 203-6; and agent causation 77, 78; and classical compatibilism 48; and compatibilism 204, 205, 207, 211; and Consequence Argument 206; constitutive luck 127, 148, 167, 174, 177; and determinism 204-5; and dispositional compatibilism 52; Ensurance Formulation of Luck Argument 206-7; and event-causal libertarianism 68, 69; Explanatory Formulation of Luck Argument 208-9; and incompatibilism 203-4, 205-6, 207, 209, 210; and indeterminism 203-7, 208, 209-11; and leeway-based approaches 218, 222; and libertarianism 204-6, 209, 210-11; and Mind Argument 206, 209-11; and moral responsibility 203, 204-5, 209, 211; Rollback Formulation of Luck Argument 207-8; and skepticism 126-7

LWOP (life without parole) 586, 587

McCabe, H. 516, 517

McCann, H. 515, 545

McFadyen, A. 248

McFarland, I. 248-9

McGeer, V. 605, 661-2

MacIntyre, A. 227

McIntyre, A. 573

McKay, T. 156, 195, 201, 210

McKenna, M. 30, 104-5, 182, 216, 219, 604-5, 607

Mackie, J. L. 489-91, 492-3, 494-5, 496, 497, 498

Madhva 399, 400

'magical' acts 479, 482, 483

Magna Moralia 232

Mahābhārata 391-2

Mahāyāna Buddhism 395

Maibom, H. 660

Mandelbaum, E. 441

Manifest Activity 339-40

man-in-a-locked-room scenario 7, 44, 147, 314-15, 334-5

Manipulation Arguments 148, 166-7; and agent causation 168-9, 172; and causal determination 169, 173, 174; and compossibilism 169, 172, 173; and 
constitutive luck 167, 174, 177; Counterexample Step 167-9, 175; and determinism 166-7, 168-70, 171-2, 173-5, 176-7; Explanation Step 173-5, 177; and Four-case Argument 167-75, 176-7; Generalization Argument 172-3, 175, 176; Generalization Step 170-2, 177; and incompatibilism 166-7, 173-4, 177; and incompossibilism 169, 173-4, 175, 177; and indeterminism 168, 171-2, 174; and libertarianism 167, 172; and metaphysics 166-7, 168-9, 171-2, 174-5, 177; and moral responsibility 166, 168, 169, 170, 171, 175, 176; and No-difference Defense 170-3, 174, 176; nondiagnostic 175-7; and providence 549, 550; structure of 167; Zygote Argument 175-6

Marcus Aurelius 244-5

marginal agents 105, 657-9

Markosian, N. 299

Markov models 673, 674

Martin v. State (1944) 578

Masicampo, E. J. 417

Master Argument 192

materialism 22, 75

Maximus the Confessor 228

māyā 399

mechanism-based reasons-responsive theories 31-2, 33,34

Meditations on First Philosophy 284, 289, 290, 291

Meerbote, R. 348, 349, 350

Mele, A. 48, 65, 124, 130, 171-2, 175-6, 426-7, $449-50,456,523,545,567$

Mencius 376-7, 378-9, 380, 383, 384

mental causation 563, 645-6; and 'differencemaking' 652-3; and anomalous monism 647-8; and causal power 651 ; and closure principle 648-50, 652; and compatibilism 348-9; and Exclusion Argument 648-53; Indian philosophies 397; and Nietzsche 364; and physical causation 646-9, 650-2; threats to 647-50; and voluntary actions 645-6

mental fatigue 447

Menzies, P. 652-3

mesh theories 37, 184-5, 545

metanormative relativism 143

Metaphysical Foundations of Natural Science 351-2

Metcalfe, J. 482

method of arbitrary functions 674-6, 677

MFT (minimal free will thesis) 158

Mickelson, K. 148, 167

microconstant dynamics 674-5

'middle knowledge' 291, 546-9, 550

Milgram, S. 410

Mill, J. S. 41, 42-3, 44, 627

Miller v. Alabama (2012) 586

Milton, J. 309

Mīmāmsā 396

Mind Argument 206, 209-11, 218, 222

'mind-body problem' 646, 650
Minow, M. 629-30

M'Naghten formulation 583, 584

modal strategy 413-14

modal transfer principles 152

modest libertarianism 65

modular epiphenomenalism 430-1

Mohammedan fatalism 367

Molinism 546-50, 551

Molyneux, W. 317-18

'momentary determinacy' 379

monism 138, 139, 348-9, 647-8, 657, 658, 659, 660-1, $662-5$

Montgomery, D. E. 481

Moore, G. E. 41, 45, 216

'moral account' 105

'moral address' 105

moral agency 101, 102, 104, 338, 376, 378, 438, 519, 629, 661

'moral contribution' 105

moral responsibility: and accountability 106, 615-16, 617, 618, 619-21; and Aristotle 236, 241; and attributability 105-6, 618-19, 620-1; and Augustine 248, 254-6; 'basic desert' 2, 77, 78, 111-12, 115, 121-2, 130-2, 519-20, 607; and blameworthiness 606-7, 608-9, 615-16; Chinese perspectives 375 , 376-8; and classical compatibilism 41, 43, 47-8, 49; and compatibilism 614, 615, 616-17; and criminal law 584-8; and culpability 619-20; and determinism 616, 617-18, 620; diagnostic accounts of 109-10, 113-15, 118; and dispositional compatibilism 52, 53, 54; and empirical perspectives on consciousness 435, 437-40, 441-2; and eternal damnation 486; and event-causal libertarianism 68; feminist approaches 623-30; folk concepts/intuitions 109-10, 112-16, 468, 469-70, 471-3; and Frankfurt-Style examples 179, 182, 186-8, 614; and grace 531-3, 536, 540; and identificationism 17-19, 22-4; and incompatibilism 614, 616, 617; and Kant 347, 354; and leeway-based approaches 214, 215, 218; and Locke 315, 318; and luck 203, 204-5, 209, 211; and major arguments 147; and Manipulation Arguments 166, 168, 169, 170, 171, 175, 176; and marginal agents 105, 657-9; 'moral responsibility equivocity' 618-21; and non-causal libertarianism 86; and nonstandard views 136-8, 139, 140-2, 143, 144; prescriptive accounts of 109-13, 118; and providence 543; and reactive attitudes 615, 619-21; and reasons-responsive theories $27,28,30-1,33$, 616; relationship with freedom 612-21; and responsibility pluralism 656-65; and revisionism 109-12, 113-15, 116, 117-18; and semicompatibilism 5-11, 13; and situationism 408, 410, 411-15, 416, 418; and skepticism 121-2, 123, 125-6, 127, 129, 130-1; and sourcehood 221-2; and Stoicism 237, 238, 240-3, 244; Strawsonian theories 96-7, 98, 101-4, 105, 106; and theological 
fatalism 501, 504; Wallace case study 615-18; and willpower 444, 445-7, 451-2

'Moral Skeptics' 96

Morissette v. United States (1952) 584

Morriston, W. 554

Morse, S. 448-9

motivational impairments 583, 659

motivational system 37,446

Motive Challenge 332, 336-8

Moyal, G. J. D. 288

Mozi 377

MPC (Model Penal Code) 578, 579, 581, 582, 583, 584

MRR (Moderate Reasons-Responsiveness) 35, 36

Murray, D. 470

'muscle model' of willpower 447, 451

Nadelhoffer, T. 121

Nagel, T. 174, 532, 642

Nahmias, E. 124, 429, 430, 469, 470, 636, 637

narrow identificationism 17-18, 19, 22-5

narrow-profile emotional responses 132

natural determinism $512,513,514,515-16$

natural selection 673

naturalism: and agent causation 75, 76, 82; and Hume 323, 325, 328; and neuroscience 428-9; and nonstandard views 142-3; and revisionism 110, 112-13, 114, 117; and Strawsonian theories 97, 99-100, 102, 106, 107; and substance dualism 522, 529

'necessary being' 269

necessitation 157, 271, 294, 298, 306, 323, 327-8, $329,486,614$

negative liberty 377

Nelkin, D. K. 18, 33, 34, 35, 36, 143-4, 183, 594-5, 597, 598

neuroscience: and addiction 455-6; and confabulations 405; and determinism/indeterminism 428-9; and empirical perspectives on consciousness 434; and human agency 429-30; Libet-style studies 423-4, 425, 426-7, 428; and modular epiphenomenalism 430-1; and naturalism 428-9; and readiness potential 424, 427, 428; and skepticism 121, 123-4, 129, 130; threats to free will 405, 423-32; and transcranial magnetic stimulation 425; and volition 430, 431; Wegner-style studies 424-5, 426

Newsome, W. T. 429

Newton's first law 93-4

Newtonian models 673

Ney, A. 653

Nichols, S. 116, 132-3, 468-70, 477, 640

Nicomachean Ethics 231, 232, 234

Nida-Rümelin, M. 637-8

Nielsen, K. M. 225

Nietzsche, F.: and commandeering thought 368-9; and compatibilism 366, 368; conceptions of free will 364-5; and determinism 364, 367-8; and evaluative independence 371,372 ; and incompatibilism 365, 366, 372; and skepticism 123; 'strong' and 'weak' will 368, 369-70; and ultimate free will 365-7, 368, 372; and ultimately originated action 365-6, 370

'No Belief in Inability' condition 596, 597

no past objection rule 157, 160

'no real choice' 53

'no reasonable choice' 53

no-choice transfer rules 152-3, 154, 155-6, 158, 161

No-difference Defense 170-3, 174, 176

non-actional synchronic self-control 444

non-causal determinism 516-18

non-causal libertarianism 2, 86-9, 91-4; and active willing $87,88,89,90,92$; and agent causation 87, 91, 92; and 'deciding' 87-8, 90, 91-2; and determinism 86-7, 88-91, 92, 94; and event-causal libertarianism 89-91; and motivation 90, 93; and substance dualism 526, 527-8; and volition 86-7, 89-90, 91-4

'non-chancy lucky' 126, 127

non-deviant causal processes 28

non-moral agency 338

nonstandard views 2-3, 136-7; and compatibilism 136-7, 138-9, 140-2, 143-4; contextualism 139, 141; and contractualism 141-2; and 'free will problem' $136,137-8,140,141-2,144$; and hard determinism 136-7, 138-9, 140-1, 143-4; and illusionism 143; and incompatibilism 137, 138, 142, 144; and libertarianism 137, 138, 139, 142, 143-4; mapping of 138-44; and moral responsibility 136-8, 139, 140-2, 143, 144; and praiseworthiness/

blameworthiness 142, 143-4; and reactivenaturalism 142-3; and semicompatibilism 136; and 'standard views' 136-7; and utilitarianism 139-41, 142,144

non-violence 393-4

$\mathrm{N}$-operator argument 155-6, 194-5

'Norm Broken, Agent Responsible' hypothesis 470 noumena 343, 344, 345-7, 348, 349, 350, 351-2, 354

Nowell-Smith, P. H. 49

Nozick, R. 42, 358

Nyāya School 397-8, 401-2

Nyāyalìlāvatī 398

O’Connor, T. 73, 75, 81, 83, 128, 519, 528

O'Keefe, T. 225

'Obedience to Authority' experiment 410, 412

'objective attitude' 97-9, 100, 103, 106

'objective worth' of achievements 10 observational equivalence 672-3, 674, 677

Ockhamism 192, 199-201, 505-7, 685

Of the Conduct of the Understanding 313

On Free Choice of the Will 247, 250

On Selfhood and Godhood 493

On the Fall of the Devil 276, 278 
open theism 507, 509, 546, 548-9, 550-1

opportunity cost model 447-8

'Optimists' 96-7, 106

Ordinatio 279, 280

Origen 249

Original Adam example 157

original $\sin 247,248,249-50,252-3,254,272-3,390$

Oscillating Adam example 157, 159

Oshana, M. 568

'ought implies can' principle 183, 218, 354, 532

overdetermination $7,329,460,649,651-2$

'overlearned' actions 439-40

PAP (Principle of Alternate Possibilities) 43, 147-8, 179-85, 188, 241-2, 259, 501, 504, 558-9, 625

Paradise Lost 309

Parks, K. 529

Passion and Value in Hume's Treatise 325

Passions of the Soul 289

passive power 56

Pelagianism 534, 538, 544

Penry v. Lynaugh (1989) 587

People v. Cassasa (1980) 581

People v. Ireland (1969) 579

Pereboom, D.: and agent causation 77, 78, 82-3; and blameworthiness 602; and classical compatibilism 47; Four-case Argument 13, 167-75, 472, 549, 550; and Frankfurt-Style examples 182; and grace 532; and Kant 350; and luck 205-6; and nonstandard views 140; and providence 544; and revisionism 115; and semicompatibilism 11, 12-13; and skepticism 121, 127-30; and sourcehood 219; and substance dualism 528-9; and theological determinism 519

Perihermeneias 269

Perner, J. 480

Perry, J. 154, 156

'person-situation debate' 407

'Pessimists' 96-7, 98-9, 101, 106

Pettit, P. 593

PFGP (Principle of the Fixity of the Given Past) 160 phenomenal consciousness 435

'phenomenal soul' 352

phenomenology of agency: analytical questions 633-8; background phenomenology 634, 638; and compatibilism/incompatibilism 636-7, 640; constitutive questions 642; and determinism 635-6, 637; epistemic questions 641-2; focal phenomenology 634, 638; folk conceptions 633, 635-7; genetic question 638-40; and libertarianism $635-7,638,640-2$

Phillips, J. 479

physical causation $76,88,333,646-9,650-2$

physical violations 478

Pierce, T. 311

Pike, N. 501, 553-4

Plantinga, A. 485, 493-5, 497-8, 506
Plato 237, 565, 567, 573

Pockett, S. 427, 639

Pohle, Fr. J. 535, 537-8

'positive openness' requirements 596, 597

possible in principle observations 673

Potter, K. 401-2

'practical identity' of agents 618,621

praiseworthiness: and grace 533-4, 535-6, 540, 541; and nonstandard views $142,143-4$; reasonsresponsive theories 33-4, 35; revisionism 110-11, 112; and skepticism 131

predestination $247,248,250,252,507,512,513$, 531,547

predictability/unpredictability 396, 428, 669-72, 674,677

preemption scenarios 184

prejudicial imbalances 629

presentism 508

prevenient grace 537,538

Price, R. 41

Priestley, J. 121

prime movers $65,67,560$

Principal Principle 676-7

Principle of Bivalence 238

principle of philosophical conservatism 115

Principle of the Fixity of the Past 195-6, 199-200, 201, 684, 685

Principle of the Fixity of the Present 195

Principle of the Inescapability of the Laws 160

Principles of Philosophy 287, 289, 291

Prior, A. N. 192

'prior-sign' examples 181-2

probability 83, 129, 184, 209, 210, 451, 482, 598, 671-7

prohairesis 229-30, 231-2, 233, 375

providence $268,291,486,512,513,516,518,543-51$

provocation defense 581,582

Pruss, A. 157

psychopathy 656-7, 659-61

Purdy, S. C. 427

purposeful action $525-7$

quality of will 97, 105-6, 438, 624

quantum mechanics 124-5, 128-9, 137

Questions on the Metaphysics 276, 280

quiescence 539,540

Ragland, S. 532, 537, 538, 539, 541

Rāmānuja 399, 400

randomness 672-4

'Rat Park' experiment 463

rational power $273,276-8,279-80,281-2$

rational self-control 101, 102, 103-4, 313

'rational spontaneity' 297

rational/non-rational desires 227-8, 229, 230, 231, 233-4

'rationally speaking random' 125,126 
Ravizza, M.: and addiction 459; and agent causation 297; and consciousness 440; and Consequence Argument 161; and feminist approach 624; and Frankfurt-Style examples 188; and identificationism 19; and providence 545; and reasons-responsive theories 30, 31-2, 34-6, 412-14, 446, 496; and skepticism 130; and sourcehood 221

Rea, M. 199

reactive attitudes 2; and blameworthiness 603-5, 606, 608; and criminal law 584; and moral responsibility 615, 619-21; and skepticism 122, 131-2; and stoicism 237, 243-4; and Strawsonian theories 97-101, 102-5, 106-7; and theological determinism 519

reactive-naturalism $142-3$

'Reality of the Future' 401

Reason View 33

reasons-reactivity 35-6, 414, 446, 459

reasons-receptivity 35-6, 414, 446, 459

reasons-responsive theories 2, 27-8; and absence causation 32-3; actual causal processes 28, 31; and addiction 459, 460; agent-based 31, 32, 33, 34; and akrasia 573; and Aristotle 231; and compatibilism 28-30, 31, 32, 33-4, 36, 37; and Consequence Argument 30, 36; and determinism/indeterminism 29-30, 34, 36; deviant/non-deviant causal processes 28; Frankfurt-Style examples 30-3, 34, 37, 185; and incompatibilism 28-30, 32, 34, 36-7; and libertarianism 30; mechanism-based 31-2, 33, 34; and mesh theories 37; Moderate ReasonsResponsiveness 35, 36; and moral responsibility 27, 28, 30-1, 33, 616; praiseworthiness/

blameworthiness 33-4, 35; reasons-reactivity and receptivity 35-6, 414, 446, 459; and situationism 412-15; spectrum of responsiveness 28, 33-7; and Strawsonian theories 101, 104-5; and willpower 446

Reath, A. 349

ref lective equilibrium 10

regulative control 215, 221

Reid, T.: Action Challenge 332, 333-6; and active power 332, 333, 334-5, 336-7, 338-41; actualization of behaviour-states 333, 334, 335-6, 338; and agent causation 76, 79, 332, 333-4, 336, 337-8, 341; and classical compatibilism 41; and efficient causality 332, 333, 337-41; Motive Challenge 332, 336-8; Volition Challenge 332, 339-41

RELEVANCE principle 185-8

repentance 132,519

replacementism 117

Replies to [the Manichean] Simplicianum 250-1

Reportatio 279, 280

representational content 435, 438, 633, 634

Responsibility and the Moral Sentiments 615, 616

Responsibility from the Margins 105 responsibility pluralism: and ambivalence 656-7, 658, $660,661,662-4,665$; and autism 657, 661-2; and dementia 657-8, 662-3; and marginal agents 657-9; and monism 657, 658, 659, 660-1, 662, 663-5; and moral responsibility 656-65; and psychopathy 656-7, 659-61; and responsibility responses 657, $658-9,660,661,662-4$

responsibility responses $657,658-9,660,661,662-4$ responsible agency: and agent causation 72, 77, 79-80, 83; and Augustine 250; feminist approaches 623, 625, 626-9, 630; and moral responsibility 102, 106; and situationism 418; and willpower 445-6

retributive justice $49,103-4,115,123,237,243,354$, $390,400,520,577-8,580,585-6,588$

revision strategy 414-15

revisionism 2, 109-10, 117-18; 'basic desert' moral responsibility 111-12, 115; and blameworthiness 601, 602; connotational revision 115-16, 117; denotational revision 115-16, 117; diagnostic accounts of moral responsibility 109-10, 113-15, 118; and eliminativism 115, 117; and libertarianism 113-15; and moral responsibility 109-12, 113-15, 116, 117-18; motivational challenge 110, 115-17; and naturalism 110, 112-13, 114, 117; and nonstandard views 140; praiseworthiness and blameworthiness 110-11, 112; prescriptive accounts of moral responsibility 109-13, 118; and principle of philosophical conservatism 115

Rist, J. 248

robust alternatives 181-2, 183, 625

robust concept (of identificationism) 17, 19, 21-2, 23-5

Rocca, D. 286

Rodin, J. 410

Rollback Formulation (of Luck Argument) 207-8

Roper v. Simmons (2005) 586

Rosenthal, D. 430, 431

Roskies, A. 428, 639

Ross, W.D. 227

Rowe, W. 339, 485, 554

RP (readiness potential) 424, 427, 428, 639

Russell, P. 48, 138, 143

Ryle, G. 230

salvation 251-2, 260, 261-2, 534, 536-7, 547

Sāmkhya Dualism 395-6

Samuels, S. 418

Sartorio, C. 30, 32, 147, 157, 222-3

Scanlon, T. 141, 602-3, 608

Schlick, M. 49

Schrödinger's cat 397

Schroeder, T. 21, 22

Schult, C. A. 481, 482

Schurger, A. 427, 428

Second Council of Orange 534

second-order desires 129, 168, 173, 220-1, 417

second-order volition 20, 220, 459-60 
Seidman, J. 21, 22

self-conception 356,360

self-control: and akrasia 566-8, 569, 572-4; and

Manipulation Arguments 176; and moral

responsibility 615, 616-17; Strawsonian theories

101, 102-4; and willpower 444-5, 447-8, 451

self-creation 138,174

self-determinism 45-7, 63, 250, 275, 289, 294, 365, 376,568

'Self-Forming Willings' 362

selfishness 556

self-knowledge 371, 438, 597, 629

'self-so' (ziran) 381-4, 385

semantic agnosticism 116-17

semicompatibilism 2; and causal determinism 5-7,

8-13; and classical compatibilism 5-6, 10; and

Consequence Argument 6-7, 12; and dispositional

compatibilism 54; and foreknowledge of God 5, 6,

8, 12; and Frankfurt-Style examples 7-8, 11-12; and incompatibilism 5-6, 9, 10-13; and indeterminism $8,9,10,11$; and initiation 8-9; and leeway-based approaches 215; and moral responsibility 5-11, 13; and nonstandard views 136; and source incompatibilism 10-11, 12, 13; and sourcehood 9-11, 12-13, 221

Seneca 237

Sentences 279, 280

Shanley, M. 629-30

SHARKS example 185-6, 187

Shepherd, J. 426

Sher, G. 602-3

Shoemaker, D. 21, 105-6

Shoemaker, S. 651

Shultz, T. R. 480

Sider, T. 687

sin: and Anselm 258, 260-1; and Aquinas 264, 266, 272-4; and Augustine 247-50, 252-3, 254-6; and Bramhall/Hobbes debate 308-11; and grace 533, 534-5, 539; 'wages of sin' 520

single timeline model 681, 682, 683

Sitt, J. D. 427, 428

situationism: and character 411-12; and determinism 412; and moral responsibility 408, 410, 411-15, 416, 418; in philosophy 410-11; in psychology 407-10; and reasons-responsive theories 412-15; strong and extreme forces 408 ; 'surprising dispositions' 408-10, 412-13, 415-16, 417, 418; and trait rarity 407-8, 411; and unconscious processing 415-17; and virtue 410-11

skepticism 2, 121-2; and agent causation 125-6, 127, 128-9; and causal determinism 121, 122, 125, 126, 131-2; and compatibilism 121, 124, 126, 127, 129-30; and event-causal libertarianism 127-8; and hard determinism 121, 122-3, 126; and indeterminism 123, 124-5, 126, 128-9; and libertarianism 125, 127-9; living without free will 130-3; and luck 126-7; and moral responsibility
$121-2,123,125-6,127,129,130-1$; and neuroscience 121, 123-4, 129, 130; personal relationships and emotion $131-3$; and praiseworthiness/blameworthiness 131; and reactive attitudes 122, 131-2; and Strawsonian theories 97, 99-101, 102, 103, 106, 131-2

Skinner, B. F. 121

Smart, J. J. C. 140, 601

Smilansky, S. 126, 139, 140, 143

Smith, Adam 96

Smith, Angela 21, 25, 103, 438, 602, 604

Smith, M. 571

social violations 478-9

Socrates $244,565,566$

'soft determinism' 216

soft facts 199-200, 502, 505-7, 685-8

Some Thoughts Concerning Education 313

Sommers, T. 121, 143, 471

Soon, C. S. 424

soul 42, 229-30, 232, 233-4, 272-3, 294-5, 297, 352, $371,393-4,492,524-5,526-7,529,646$

source compatibilism 30, 31, 32, 33-4, 36, 221

source freedom $30,31,34$

source incompatibilism 10-11, 12, 13, 46, 173-4, 219, 248, 287, 361-3

sourcehood 148, 218-23; and compatibilism 220-1, 222-3; and conceptions of free will 214; FrankfurtStyle examples 220-2; and incompatibilism 219-20; and libertarianism 219; and logical fatalism 191; and moral responsibility $221-2$; and providence 543-4, 545, 546, 549-50; and semicompatibilism 9-11, 12-13, 221; and theological fatalism 504; and time travel 688

spectrum of responsiveness 28, 33-7

Spinoza, B. 121, 122, 133, 287

spontaneity: and Anselm 258-9, 260; Chinese perspectives $378-9,381-2,383,385$; and compatibilism 46, 53; and Hume 326, 329; and Leibniz 293, 294-7, 298, 301; and non-causal libertarianism 87, 88-9, 90, 92; and neuroscience 424, 427; and phenomenology of agency 639

SQUEAKY BUTTON example 185-6, 187, 188 standard compatibilism 512, 513-16, 517-18, 550 standard incompatibilism 512-13, 518-9

state consciousness 437, 440, 441

State v. Heinemann (2007) 582

State v. Patterson (2011) 580

Steward, H. 74, 76, 82, 83, 182

Stich, S. 440

'stipulative' approach 614-15

stochastic models 672-3, 674

Stoicism: and causal determinism 236-7, 238-9, 241; and Chinese perspectives 377; and 'co-fated' events 236, 238, 241; and compatibilism 225-6, 236, 237, 245; and conceptions of free will 227; and God 236, 237-8, 239, 240-1, 244-5; and human action 239-40; and 'lazy argument' 236-7, 238-9; and 
moral responsibility 237, 238, 240-3, 244; and Principle of Alternate Possibilities 241-2; retribution and reactive attitudes 243-4; and virtue 241-3, 244, 245, 251; and voluntary action 229

'strange shackles' objection 687-9

Strawson, G. 121, 124-6, 174, 357, 358, 486, 638, 640, 642

Strawson, P. F./Strawsonian theories 2; and blameworthiness 603, 606-7; and classical compatibilism 41, 96, 97; and compatibilism 96-7, 99, 101, 102, 106; and determinism 96-8, 102-3, 350; excuses and exemptions 97-8; and feminist approaches 625; and incompatibilism 96, 98, 102; and libertarianism 96-7, 98-9, 103; and moral responsibility 96-7, 98, 101-4, 105, 106, 615; and naturalism 97, 99-100, 102, 106, 107; and nonstandard views 142-3; and 'objective attitude' 97-9, 100, 103, 106; and quality of will 97, 105-6; and rational self-control 101, 102, 103-4; and reactive attitudes 97-101, 102-5, 106-7; and reasons-responsive theories 101, 104-5; and skepticism 97, 99-101, 102, 103, 106, 131-2; and Stoicism 243

streams of consciousness 352, 353

Strevens, M. 674, 675

strict akrasia 568-72

strong enough incompatibilism 158

strong forces 408

Stroud, S. 571

Stump, E. 247, 248, 532, 538-9

substance dualism 522-9

Summa contra gentiles 539

Summa Theologiae 266, 516

'supercompatibilists' 204

supervenience 186-8, 508, 650-1, 652-3

Suppes, P. 673

'surprising dispositions' 408-10, 412-13, 415-16, 417, 418

Swinburne, R. 508

synchronic self-control 444-5

Tanner, K. 517

Tao Qian 381

Taylor, R. 167

teleological determinism 525-6

Tempier, S. 275, 276

temporal fatalism 265, 266-8

temporal myopia 462, 464

tent map 670-1

Tertullian 249

The Concept of Mind 230

The Nature of Necessity 493

The Subject as Freedom 401

The Theory of Will in Classical Antiquity 227

theodicy 252, 485, 489-90, 491-3, 495, 498, 563

Theodicy 294, 298, 489-90 theological determinism 486, 512-13; and causal determinism 514, 515, 516; and hard determinism 518-20; and libertarianism 513, 516-18; natural determinism 512, 513, 514, 515-16; and non-causal determinism 516-18; and providence 544-5; standard compatibilism 512, 513-16, 517-18; standard incompatibilism 512-13, 518-9

theological fatalism: challenging the contingency of human freedom 504; and divine foreknowledge 500-502, 503, 504, 505-8, 509; Frankfurt-Style examples 504; hard and soft facts 502, 503, 505-7; and incompatibilism 486, 501, 502, 503, 505-6; and Ockhamism 505-7; omniscience and agency 500-501, 505, 508; and Principle of Alternate Possibilities 501, 504

theory of necessity 48-9

Thomas Reid on Freedom and Morality 339

Three Rival Versions of Moral Enquiry 227

Timaeus 237

time travel 564, 680-1; and causal determinism 680, 684, 688; and Consequence Argument 153-4, 155, 158, 160; and entailment 688-9; and fatalism 684-5, 687; and foreknowledge of God 680, 684, 688; and incompatibilism 681, 682, 684, 685-7, 688; models of 681-2; soft and hard facts 685-8; and sourcehood 688; 'strange shackles' objection 687-9; and theological fatalism 506

Timpe, K. 75, 148, 219, 532-3, 539

TMS (transcranial magnetic stimulation) 425

Todd, P. 197, 200

Tognazzini, N. A. 219, 221, 608

Tong, R. 627

Tononi, G. 440

trait rarity 407-8, 411

transcendental freedom 346-8, 349, 350, 353-4

transcendental idealism 343-6, 350

'transeunt causation' 74

Treatise of Human Nature 128

'treatment-associated' responses 664

tripartite theory of responsibility 105-6

'true wants' 2, 15, 16-17, 23, 253

true-at-a-time propositions 195, 196, 197, 201

Turner, J. 495-6, 497, 498

Twelve Monkeys 153-4

Twilight of the Idols 364, 371

Twisse, W. 311

Two Treatises of Government 313

ultimate free will 365-7, 368, 372

ultimate responsibility 10, 125, 365-6, 546

'ultimate sourcehood' 9, 10

ultimately originated action 365-6, 370

unavoidability transfer principles 161

unconscious processing 415-17

underdetermination 673

United States v. Johnson (2005) 582

United States v. Lyons (1984) 584, 587 
unwilling/willing addicts $17,18-19,22-4,459-60$

utilitarianism 49, 139-41, 142, 143, 144

Utpaladeva 399

Vallentyne, P. 621

valuational system 446

van Inwagen, P.: and conceptions of free will 213; and Consequence Argument 6, 148, 151, 152, 153, 155, 158-60, 161, 193, 194, 351; and deliberation 590, 592; and leeway conceptions 215, 216; and logical fatalism 193, 194, 196, 201; and luck 206, 207-8, 210; and theological fatalism 508-9

Vargas, M. 109, 111-13, 114, 115, 116-17, 140, 213, 204, 414-15

Vedānta systems 399-400

Vedas 389-91, 396

Velleman, D. 20, 22, 25, 78, 570

veridicality conditions 634-7, 637

vice $231-2$, 234, 236, 239, 241, 243-4, 250, 318, 533, 566,624

Vicens, L. 157

Victim Premise 170, 172

Vihvelin, K. 33, 217

Vilhauer, B. 121, 143

virtue: and akrasia 566; and Aquinas 272, 273; and Aristotle 231-2, 234; and Augustine 251-2; Chinese perspectives 376-7, 378; Indian philosophies 391, 394; and Locke 317, 318; and situationism 410-11; and Stoicism 241-3, 244, 245, 251

Visuddhimagga 395

Vivekananda 400-401

Vohs, K. 417

volition: and agent causation 72; and Aristotle 227, 229-31; and Descartes 289, 290; and dispositional compatibilism 58, 60; and Duns Scotus 277-8; and Hume 323-4, 325-6, 327, 328-9, 330; and identificationism 20, 21, 22; Indian philosophies 389-90, 394, 396-7, 402; and Locke 313-15, 318-19, 321; and neuroscience 430, 431; and non-causal libertarianism 86-7, 89-90, 91-4; and Reid 332, 339-41; second-order 20, 220, 459-60

voluntary action: and akrasia 566, 568; and Aristotle 227, 229, 231-2, 234, 358; and criminal law 578; and Locke 313-14; and mental causation 645-6

'wages of sin' 520

Wallace, R. J. 101, 102, 104, 130, 603, 615-18, 621

Waller, B. 121, 132, 540, 592

Walter, S. 431

Wang Chong 384

wanton addicts 459

Warfield, B. 512

Warfield, T. 160
Watkins, E. 350-1

Watson, G.: and akrasia 567-8, 571-2; and blameworthiness 600, 608; and feminist approach 625; and grace 536; and identificationism 20, 21; and mesh theories 37; and moral responsibility 618-19, 620; and psychopathy 660-1; and sourcehood 220; Strawsonian theories 102-3; and willpower 446, 448

weak incompatibilism 158

weakness of will 563; and akrasia 565-6; and Aristotle 230; and deliberation 597; and divine free will 557; and identificationism 17, 19, 21-2, 23-4; and Locke 317-19; and Nietzsche 368, 369-70; reasonsresponsive theories 37

Wegner, D. 121, 123, 424-5, 426

Werndl, C. 671-2, 673

Western philosophical tradition 225

Wetzel, J. 248

Wheatley, T. 424-5, 426

wide-profile emotional responses 132-3

Widerker, D. 161, 183, 218

Wilde, O. 444

William of Ockham 192, 505, 635

Williams, N. 627

willing/unwilling addicts $17,18-19,22-4$, 459-60

willpower 444-5; and addiction 450-1; failures of 446-7, 450-1; 'fallibility' model 451; and FrankfurtStyle examples 445-6; irresistibility testing 449-50; and judgment shift 448-9; limitations on 447-8; and moral responsibility 444, 445-7, 451-2; 'muscle model' 447, 451; opportunity cost model 447-8; and self-control 444-5, 447-8, 451; successful 445-6; and synchronic self-control 444-5; time slice versus cumulative failure 450-1

'wishes' 230-3

Wittgenstein, L. 329, 350

Wolf, S. 33, 35, 143-4, 248

Wollstonecraft, M. 627

Wood, A. 360

Woolfolk, R. L. 472

Wyma, K. 533

Xunzi 377, 383

Yaffe, G. 339-40

Yogavāsiștha 393

Zagzebski, L. 505

Zai Wo 378

Zeno of Citium 237, 239

Zhang, J. 157, 160

Zhu Xi 377-8, 385

Zhuangzi 379, 381-2, 383

Zimmerman, M. 620

Ziporyn, B. 379

Zygote Argument 175-6 